\title{
ANNUAL PEAK DISCHARGES AND STAGES FOR GAGING STATIONS IN GEORGIA THROUGH SEPTEMBER 1990
}

\section{By Glen W. Hess and Timothy C. Stamey}

U.S. GEOLOGICAL SURVEY

Open-File Report 92-113

Prepared in cooperation with the

GEORGIA DEPARTMENT OF TRANSPORTATION HIGHWAY DIVISION 


\section{U.S. DEPARTMENT OF THE INTERIOR \\ BRUCE BABBITT, Secretary}

\section{U.S. GEOLOGICAL SURVEY}

Dallas L. Peck, Director

For additional information write to:

District Chief

U.S. Geological Survey 3039 Amwiler Road, Suite 130

Peachtree Business Center

Atlanta, GA 30360-2824
Copies of this report can be purchased from:

U.S. Geological Survey

Books and Open-File Reports Section

Federal Center

Box 25425

Denver, CO 80225 


\title{
CONTENTS
}

\author{
Abstract 1 \\ Introduction 1 \\ Annual peak discharges and stage data for streamflow-gaging stations in Georgia 2 \\ Summary 2 \\ Selected references 8 \\ Glossary 10
}

\section{ILLUSTRATIONS}

Figures 1.-5. Maps showing regional boundary and location of gaging stations in:

1. Northwest Georgia 3

2. Northeast Georgia 4

3. Southwest Georgia 5

4. Southeast Georgia 6

5. Atlanta Metropolitan area 7

\section{TABLES}

Table 1. Alphabetical list of streamflow-gaging stations 11

2. Annual peak discharges and stage data for streamflow-gaging stations in Georgia, through September $1990 \quad 22$ 


\section{CONVERSION FACTORS, VERTICAL DATUM, AND ACRONYMS}

Multiply

By

To obtain

\section{Length}

foot (ft)

0.3048

meter

mile (mi)

1.609

kilometer

\section{Elow}

cubic foot per second $\left(\mathrm{ft}^{3} / \mathrm{s}\right)$

0.02832

cubic meter per second

Area

square mile (mi²)

2.590

square kilometer

\section{VERTICAL DATUM}

Sea Level--In this report, "sea level" refers to the National Geodetic Vertical Datum of 1929 (NGVD of 1929)--a geodetic datum derived from a general adjustment of the first-order level nets of both the United States and Canada, formerly called Sea Level Datum of 1929.

\section{ACRONYMS}

USGS

GDOT

U.S. Geological Survey

Georgia Department of Transportation 


\title{
ANNUAL PEAK DISCHARGES AND STAGES
}

\author{
FOR GAGING STATIONS IN GEORGIA
}

THROUGH SEPTEMBER 1990

By

\author{
Glen W. Hess and Timothy C. Stamey
}

\begin{abstract}
A knowledge of annual peak discharges and stages can provide a better understanding of the hydrologic and hydraulic characteristics of flooding at a particular stream site. Annual peak-discharge and stage data are needed for flood-frequency analyses of streamflow commonly used in the design of hydraulic structures in a flood plain, flood-plain management, and other uses by urban planners and engineers. Annual peak discharges and stages through September 30,1990, and historical flood data from as early as 1796, were compiled for 493 gaging stations in Georgia having 5 or more years of record. These data include other information on station location, description, drainage area, type of gage(s), description of the stage-discharge relation, and historical data.
\end{abstract}

\section{INTRODUCTION}

Knowledge of annual peak discharges and stage information can provide a better understanding of the hydrologic and hydraulic characteristics at a particular stream site. Annual peak-discharge data and stage are used in flood-frequency studies. Knowledge of the magnitude and frequency of floods is essential for the design of hydraulic structures, such as bridges, culverts, embankments, dams, and levees in a flood plain; flood-plain management; and other uses, such as flood warning, flood forecasting, and reservoir design. Flood-plain management includes flood-plain zoning, land-use regulations, and establishing flood boundaries and floodinsurance rates.

This report presents annual peak discharges and stages and randomly collected historic peaks dating as far back as $\mathbf{1 7 9 6}$ for $\mathbf{4 9 3}$ gaging stations in Georgia having five or more years of record. These discharge data can be used to determine the magnitude and frequency of floods at a particular stream site. The value of gaging station statistics lies in the transferability of flood information from gaged sites to ungaged sites using regionalization techniques, which was used to prepare a companion report entitled, "Techniques for Estimating Magnitude and Frequency of Floods in Rural Basins in Georgia" (Stamey and Hess, 1992). Reports presenting the results of previous flood studies conducted in the State are listed in the "Selected References" of this report. 
This report was prepared as part of an ongoing cooperative program of water-resources investigations between the U.S. Geological Survey (USGS) and the Georgia Department of Transportation (GDOT), Highway Division, and is based on data collected and published by the USGS for many years. These data were collected as part of various cooperative programs between the USGS and other Federal, State, and local agencies. The principal cooperating agencies that helped fund the collection of annual peak-discharge and stage data, and other streamflow data in Georgia, are

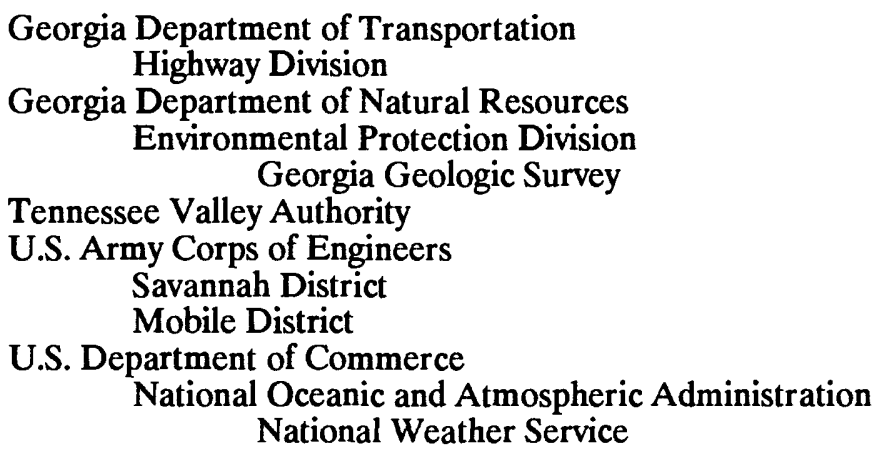

The authors also wish to thank the Georgia Power Company for assisting in the data-collection program.

\section{ANNUAL PEAK DISCHARGES AND STAGE DATA FOR STREAMFLOW-GAGING STATIONS IN GEORGIA}

Data were collected primarily by the USGS in cooperation with various Federal, State, and local agencies. Annual peak discharge and stage data for 493 gaging stations having 5 or more years of record are presented in this report. A network of continuous-record streamflow stations was established between the late 1800 's to 1950 to define the flow characteristics of large streams (drainage areas more than $500 \mathrm{mi}^{2}$ ). Many crest-stage gages were installed in the early 1950's to determine annual flood-peak stages on medium-size streams (drainage areas 20 to $500 \mathrm{mi}^{2}$ ) in the selected areas of insufficient geographic coverage in the State. A flood-frequency program on small streams (drainage areas less than $20 \mathrm{mi}^{2}$ ) began in 1964 when more than 100 flood hydrograph and rainfall gages were installed. Data were collected at these sites for 10 or more years. Additional small stream gages were included in the program in 1976 and 1984 to insure a better geographical coverage of annual peak data.

The streamflow-gaging stations included in this report are shown in figures 1-5, and are listed alphabetically in table 1 [at the back of this report], along with map numbers (from figures 1-5), figure number, station numbers, and page numbers where data are located. The annual peak-discharge and stage data, station location, drainage area, type of gage(s), description of the stage-discharge relation, available randomly collected historical data, and other pertinent remarks are given in table 2 [at the back of this report].

\section{SUMMARY}

Annual peak discharges and stages through September 30, 1990, and historical peaks as early as 1796 were compiled for 493 streamflow-gaging stations in Georgia having 5 or more years of record. Thee data are presented in this report along with information on the location, drainage area, type of gage(s), stage-discharge relation, available randomly collected historical data, and other pertinent remarks. These data can help planners and managers to better understand the hydrologic and hydraulic characteristics at a particular stream site, and are necessary for determining magnitude and frequency of floods. The annual peak discharges in this report were used to determine the frequency of floods in Georgia, described in a companion report entitled, "Techniques for Estimating Magnitude and Frequency of Floods in Rural Basins in Georgia". 

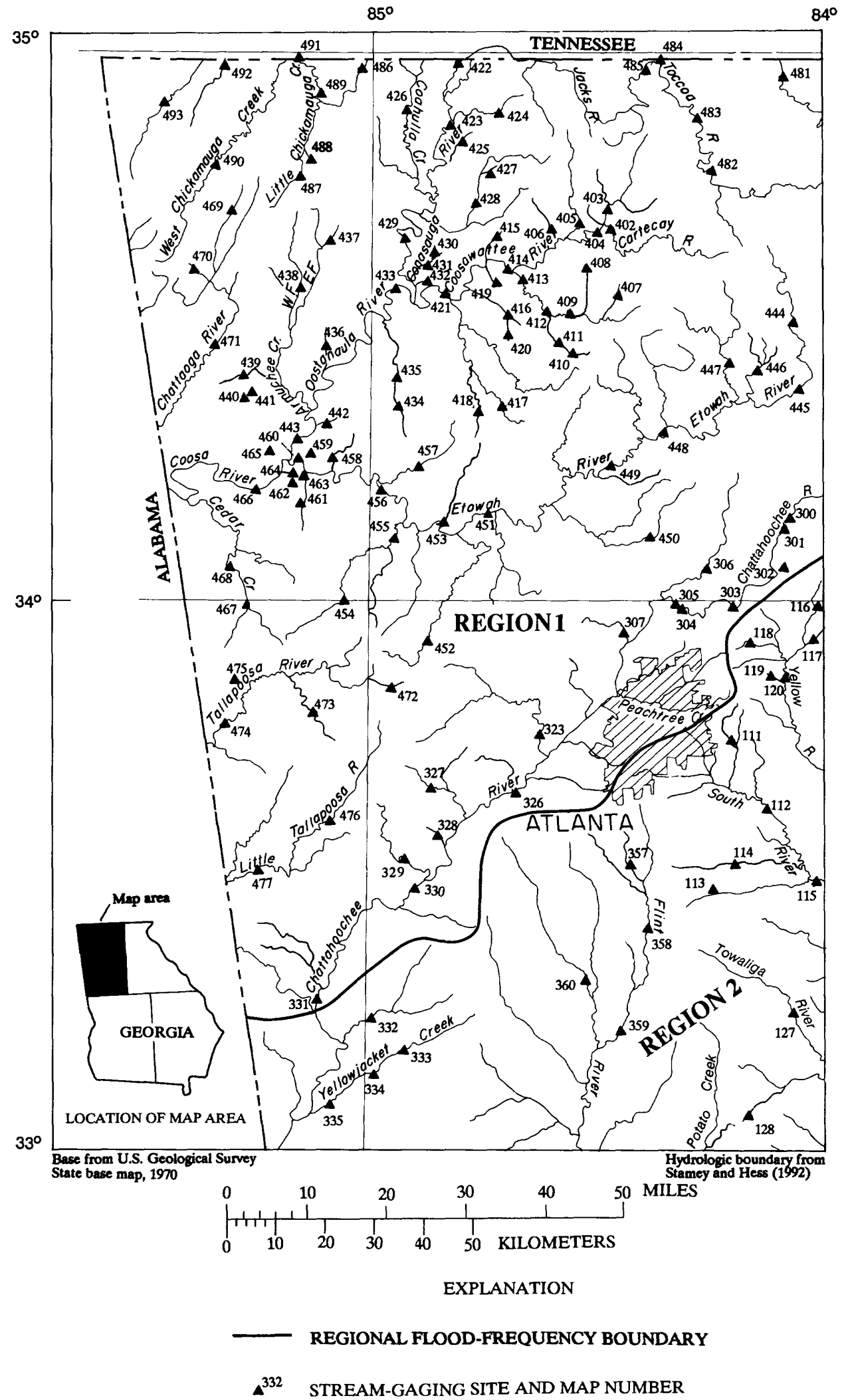

Figure 1.--Regional boundary and gaging stations in northwestern Georgia. 


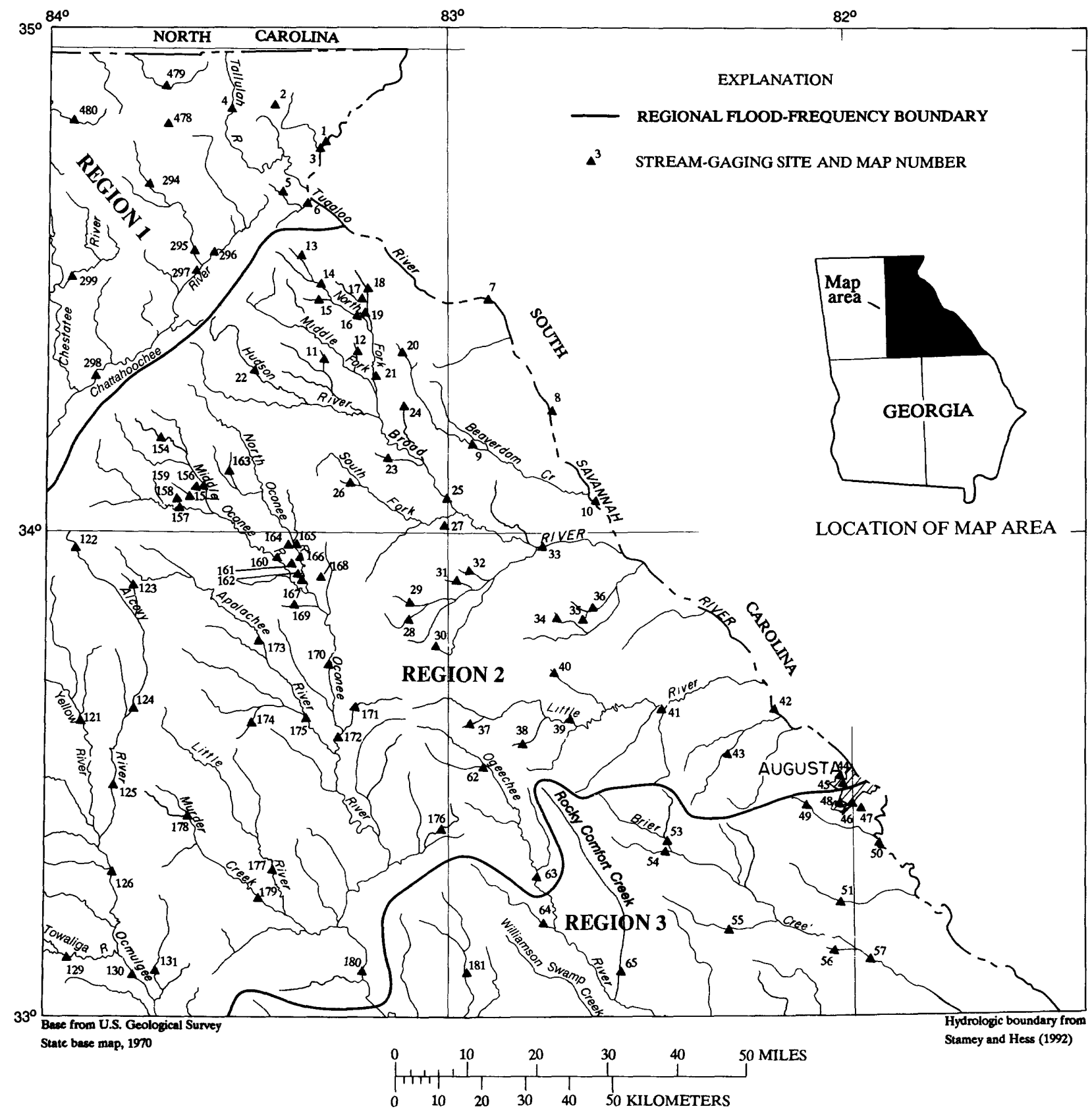

Figure 2.--Regional boundary and gaging stations in northeastern Georgia. 


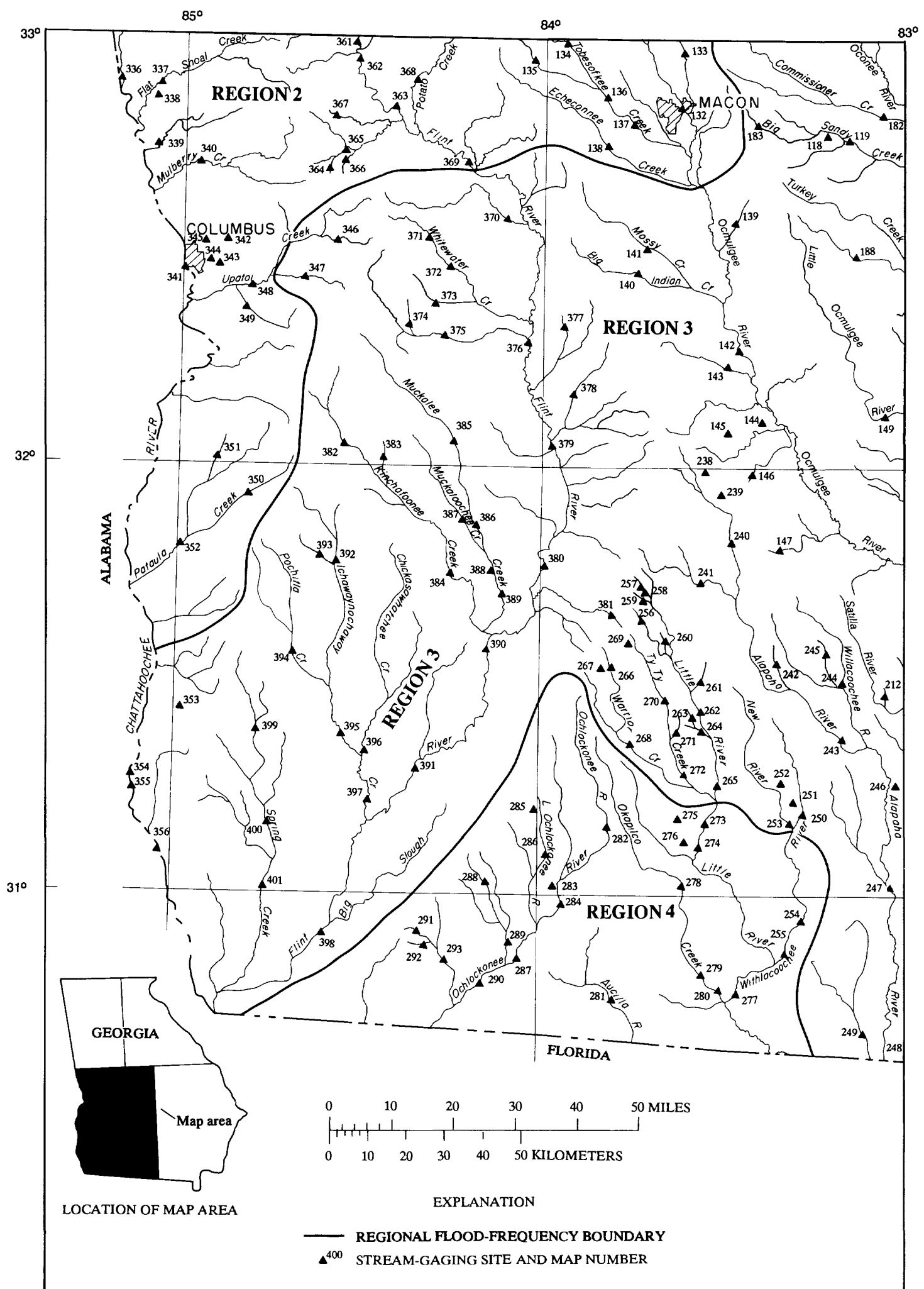

Base from U.S. Geological Survey State base map, 1970

Figure 3.--Regional boundary and gaging stations in southwestern Georgia. 


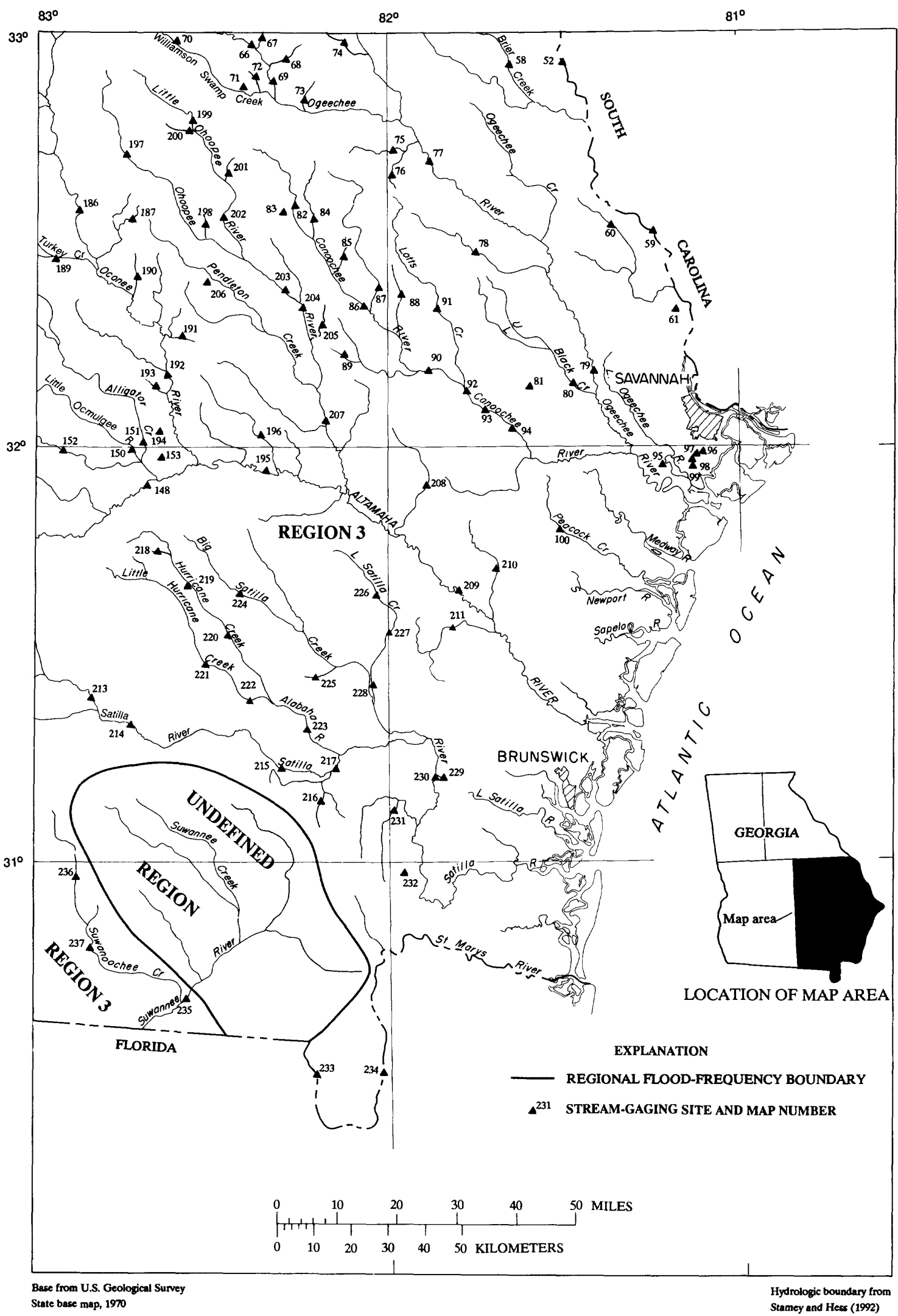

Figure 4.--Regional boundary and gaging stations in southeastern Georgia. 


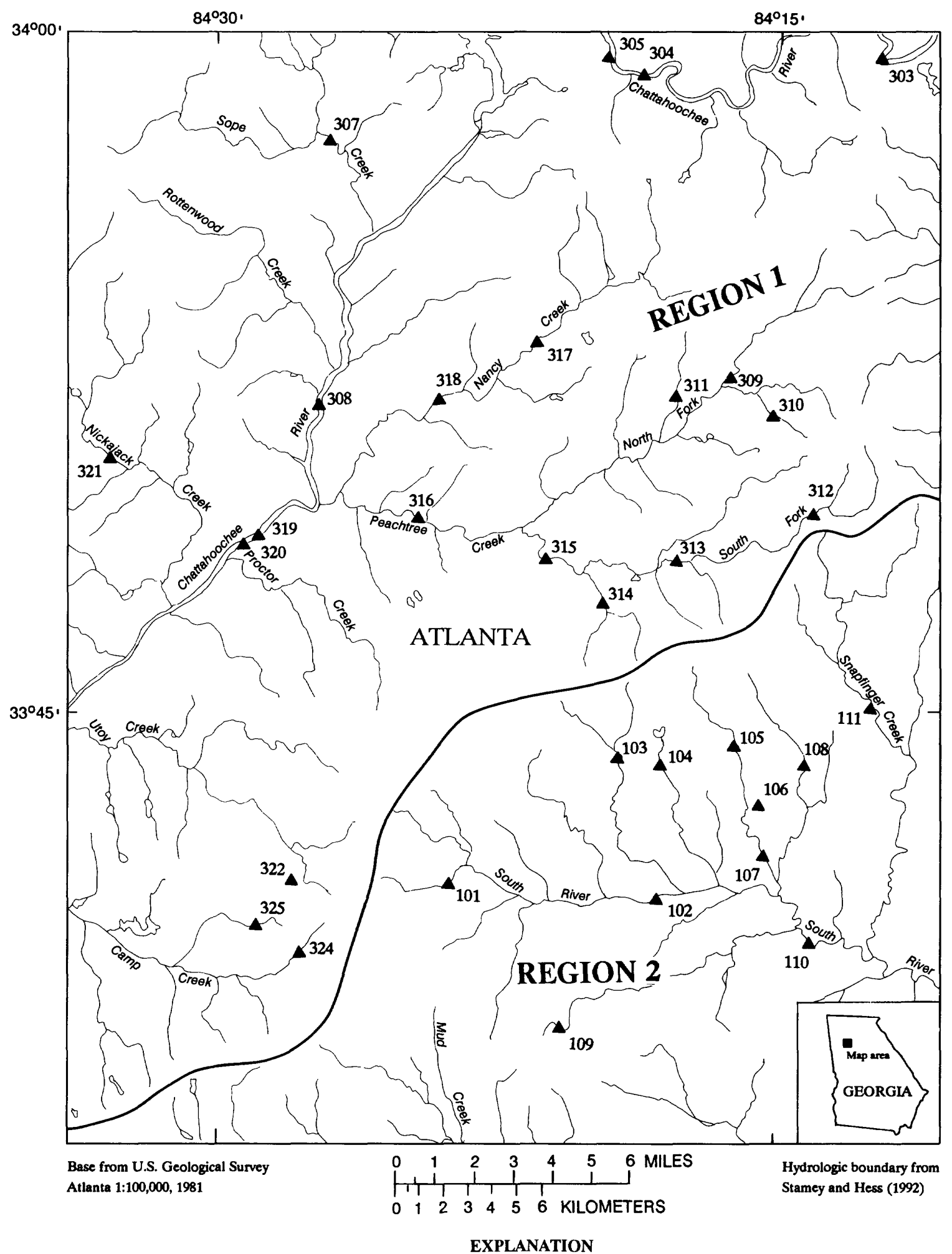

REGIONAL FLOOD-FREQUENCY BOUNDARY
109 STREAM-GAGING SITE AND MAP NUMBER

Figure 5. --Regional boundary and gaging stations in the Atlanta Metropolitan area. 


\section{SELECTED REFERENCES}

Barnes, H.H., Jr., and Golden, H.G., 1966, Magnitude and frequency of floods in the United States, Part 2B, South Atlantic slope and eastern Gulf of Mexico basins, Ogeechee River to Pearl River: U.S. Geological Survey Water-Supply Paper 1674, 409 p.

Bunch, C.M., and Price, McGlone, 1962, Floods in Georgia magnitude and frequency: U.S. Geological Survey Open-File Report, Atlanta, Georgia, 152 p.

Carter, R.W., 1951, Floods in Georgia, magnitude and frequency: U.S. Geological Survey Circular 100, 127 p.

Federal Investigative Board, 1977, Report of failure of Kelly Barnes Dam, Toccoa, Georgia: U.S. Army Corps of Engineers, National Weather Service, Soil Conservation Service, and U.S. Geological Survey, 37 p.

Golden, H.G., 1977, Preliminary flood-frequency relations for urban streams in Metropolitan Atlanta, Georgia: U.S. Geological Survey Open-File Report 77-57, 16 p.

Golden, H.G., and Hess, G.W., 1991, Georgia floods and droughts in National Water Summary 1988-89-Hydrologic events and floods and droughts: U.S. Geological Survey Water-Supply Paper 2375, p. 239246.

Golden, H.G., and Price, McGlone, 1976, Flood-frequency analysis for small natural streams in Georgia: U.S. Geological Survey Open-File Report 76-511, 75 p.

Hess, G.W., and Price, M., 1989, Comparison of methods for estimating flood magnitudes for selected frequencies on small natural streams in Georgia: U.S. Geological Survey Water Resources Bulletin, v. $25,18 \mathrm{p}$.

Hess, G.W., and Stamey, T.C., 1992, Floods on selected streams in the vicinity of Augusta, Georgia, October 1213, 1990: U.S. Geological Survey Open-File Report 92-37, 11 p.

Inman, E.J., 1983, Flood-frequency relations for urban streams in metropolitan Atlanta, Georgia: U.S. Geological Survey Water-Resources Investigations Report 83-4203, 38 p.

-..-- 1986, Simulation of flood hydrographs for Georgia streams: U.S. Geological Survey Water-Resources Investigations Report 86-4004, 41 p.

---- 1988, Flood-frequency relations for urban streams in Georgia: U.S. Geological Survey Water-Resources Investigations Report 88-4085, 36 p.

Pearman, J.L., Stamey, T.C., Hess, G.W., and Nelson, G.H. Jr., 1991, Floods of February and March 1990 in Alabama, Georgia and Florida: U.S. Geological Survey Water-Resources Investigations Report 91$4089,44 \mathrm{p}$.

Price, McGlone, 1979, Floods in Georgia, magnitude and frequency: U.S. Geological Survey Water-Resources Investigations Report 78-137, 269 p.

Price, McGlone, and Hess, G.W., 1986, Verification of regression equations for estimating flood magnitudes for selected frequencies on small natural streams in Georgia: U.S. Geological Survey Water-Resources Investigations Report 86-4337, 39 p.

-.-- 1987, Flood-flood characteristics of Nancy Creek at Georgia Highway 400 extension, near Atlanta, Georgia: U.S. Geological Survey Open-File Report 87-386, 25 p. 


\section{SELECTED REFERENCES--Continued}

Sanders, C.L., Jr., Kubik, H.E., Hoke, J.T., Jr., and Kirby, W.H., 1990, Flood frequency of the Savannah River at Augusta, Georgia: U.S. Geological Survey Water-Resources Investigations Report 90-4024, 87 p.

Sanders, C.L., Jr., and Sauer, V.B., 1979, Kelly Barnes Dam flood of November 6, 1977 near Toccoa, Georgia: U.S. Geological Survey Hydrologic-Investigations Atlas HA-613.

Speer, P.R., and Gamble, C.R., 1964a, Magnitude and frequency of floods in the United States, Part 2A, South Atlantic slope basins, James River to Savannah River: U.S. Geological Survey Water-Supply Paper $1676,329 \mathrm{p}$.

-.-- 1964b, Magnitude and frequency of floods in the United States, Cumberland and Tennessee River basins: U.S. Geological Survey Water-Supply Paper 1676, part 3B, 340 p.

Stamey, T.C., 1990, Update of flood-flow characteristics of Nancy Creek at Georgia Highway 400 Extension, near Atlanta, Georgia: U.S. Geological Survey Open-File Report 90-166, 21 p.

Stamey, T.C. and Hess, G.W., Techniques for estimating magnitude and frequency of floods in rural basins in Georgia: U.S. Geological Survey Water-Resources Investigations Report 93-4016, 76 p.

U.S. Geological Survey, 1961-64, Surface-water records of Georgia, water years 1961-64: Atlanta, Ga., U.S. Geological Survey Water Data Reports (published annually).

-.-- 1965-68, Water-resources data for Georgia, 1965-68, part 1.--surface-water records: Atlanta, Ga., U.S. Geological Survey Water Data Reports (published annually).

-.-- 1969-74, Water-resources data for Georgia, water years 1969-74: Atlanta, Ga., U.S. Geological Survey Water-Data Reports (published annually).

---- 1975-80, Water-resources data for Georgia, water years 1975-80: Atlanta, Ga., U.S. Geological Survey Water-Data Reports GA-75-1 to GA-80-1 (published annually).

-.-- 1981-90, Water-resources data for Georgia, water years 1981-90: Atlanta, Ga., U.S. Geological Survey Water-Data Reports GA-81-1 to GA-90-1 (published annually). 


\section{GLOSSARY}

Some of the technical terms used in this report are defined for convenience and clarification.

Area-velocity study - A procedure for computing discharge on the basis of area and velocity characteristics of a stream obtained from curren-meter measurements.

Bankfull stage - The water surface of a stream that overtops natural or artifical banks of the main channel above which flow occurs in the overbank areas of the flood plain.

Computed inflow hydrograph - A method of computing inflow hydrograph based upon the basic flood-routing formula of inflow equals outflow, plus the change in storage of a reservoir.

Continuous-record station - A gaging station where a consistent record of stage is obtained within a specified time interval between readings.

Contracted-opening measurement - A procedure for computing peak discharge using the hydraulic characteristics of the open-channel width contractions.

Crest-stage gage - A device for recording the elevation of the flood crest (peak) of a stream.

Culvert computation - A procedure for computing peak discharge using the hydraulic characteristics of culverts and water-surface profile.

Current meter - An instrument used to measure the velocity of water.

Drainage area - The drainage area of a stream at a specified location is that area measured in a horizontal plane which is enclosed by a drainage divide.

Flood/hydrograph rainfall station - A gaging station that records the elevation of the flood peak and rainfall.

Flow-over dam measurement - A procedure for computing discharge over dams, weirs, and embankments using the water-surface elevation and geometry of the particular structure.

Historical data - Data about major floods which occurred either before or after the period of systematic data collection.

Indirect measurement - A procedure for computing peak discharge on the basis of hydraulic equations which relate the discharge to the water-surface profile, the geometry of the channel and the hydraulic structures.

Slope-area mesurement - A procedure for computing peak discharge on the basis of a uniform flow equation involving channel characteristics, water-surface profiles, and a channel-roughness coefficient.

Slope-conveyance study - A procedure for computing discharge on the basis of a uniform flow equation involving channel characteristics and water-surface profiles.

Stage-discharge relation - At the gaging station, the relation of discharge to stage, and sometimes other variables, such as rate of change in stage, fall in a reach between gages and gate openings.

Water-stage recorder - A device which records the water-surface with a specified time interval between readings.

Water-year - The 12-month period beginning October 1 and ending on September 30 of any given year, and designated by the calendar year in which the water year ends. 
Map Figure Station number number number
Page

Station name

number

\begin{tabular}{|c|c|c|c|c|}
\hline 00381 & 3 & 02350520 & Abrams Creek Tributary near Doles, Ga. & 215 \\
\hline 00223 & 4 & 02227290 & Alabaha River near Blackshear, Ga. & 132 \\
\hline 00247 & 3 & 02316390 & Alapaha River at Lakeland, Ga. & 144 \\
\hline 00240 & 3 & 02315700 & Alapaha River at Rebecca, Ga. & 141 \\
\hline 00248 & 3 & 02317500 & Alapaha River at Statenville, Ga. & 145 \\
\hline 00243 & 3 & 02316000 & Alapaha River near Alapaha, Ga. & 142 \\
\hline 00238 & 3 & 02315650 & Alapaha River Tributary no. 2, near Pitts, Ga. & 140 \\
\hline 00239 & 3 & 02315670 & Alapaha River Tributary no. 3, near Rochelle, Ga. & 140 \\
\hline 00246 & 3 & 02316260 & Alapaha River Tributary no. 4, near Willacoochee, Ga. & 144 \\
\hline 00124 & 2 & 02208450 & Alcovy River above Covington, Ga. & 80 \\
\hline 00125 & 2 & 02209000 & Alcovy River below Covington, Ga. & 81 \\
\hline 00122 & 2 & 02208050 & Alcovy River near Lawrenceville, Ga. & 80 \\
\hline 00154 & 2 & 02217000 & Allen Creek at Talmo, Ga. & 97 \\
\hline 00151 & 4 & 02216100 & Alligator Creek near Alamo, Ga. & 96 \\
\hline 00209 & 4 & 02226000 & Altamaha River at Doctortown, Ga. & 125 \\
\hline 00195 & 4 & 02225000 & Altamaha River near Baxley, Ga. & 118 \\
\hline 00447 & 1 & 02390000 & Amicalola Creek near Dawsonville, Ga. & 250 \\
\hline 00035 & 2 & 02192400 & Anderson Mill Creek near Danburg, Ga. & 41 \\
\hline 00036 & 2 & 02192420 & Anderson Mill Creek Tributary near Danburg, Ga. & 40 \\
\hline 00173 & 2 & 02219000 & Apalachee River near Bostwick, Ga. & 107 \\
\hline 00175 & 2 & 02219500 & Apalachee River near Buckhead, Ga. & 108 \\
\hline 00264 & 3 & 02317820 & Arnold Creek near Tifton, Ga. & 152 \\
\hline 00263 & 3 & 02317810 & Arnold Creek Tributary near Tifton, Ga. & 152 \\
\hline 00002 & 2 & 02177100 & Ashley Creek near Clayton, Ga. & 23 \\
\hline 00281 & 3 & 02326200 & Aucilla River near Boston, Ga. & 160 \\
\hline 00437 & 1 & 02387800 & Bailey Creek near Villanow, Ga. & 245 \\
\hline 00409 & 1 & 02381900 & Ball Creek near Talking Rock, Ga. & 231 \\
\hline 00147 & 3 & 02215280 & Ball Creek Tributary near Rochelle, Ga. & 93 \\
\hline 00288 & 3 & 02327550 & Barnetts Creek near Meigs, Ga. & 164 \\
\hline 00289 & 3 & 02327700 & Barnetts Creek near Thomasville, Ga. & 164 \\
\hline 00431 & 1 & 02387200 & Beamer Creek near Spring Place, Ga. & 242 \\
\hline 00015 & 2 & 02189600 & Bear Creek near Mize, Ga. & 29 \\
\hline 00208 & 4 & 02225850 & Beards Creek near Glennville, Ga. & 124 \\
\hline 00205 & 4 & 02225330 & Beaver Creek near Cobbtown, Ga. & 123 \\
\hline 00009 & 2 & 02188500 & Beaverdam Creek at Dewy Rose, Ga. & 26 \\
\hline 00123 & 2 & 02208200 & Beaverdam Creek Tributary at Bold Springs, Ga. & 80 \\
\hline 00338 & 3 & 02340260 & Big Branch near West Point, Ga. & 191 \\
\hline 00306 & 1 & 02335700 & Big Creek near Alpharetta, Ga. & 174 \\
\hline 00216 & 4 & 02226580 & Big Creek near Hoboken, Ga. & 129 \\
\hline 00067 & 4 & 02200900 & Big Creek near Louisville, Ga. & 56 \\
\hline 00140 & 3 & 02214500 & Big Indian Creek at Perry, Ga. & 90 \\
\hline 00185 & 3 & 02223360 & Big Sandy Creek near Irwinton, Ga. & 113 \\
\hline 00183 & 3 & 02223300 & Big Sandy Creek near Jeffersonville, Ga. & 113 \\
\hline 00184 & 3 & 02223349 & Big Sandy Creek Tributary near Irwinton, Ga. & 113 \\
\hline 00224 & 4 & 02227400 & Big Satilla Creek near Alma, Ga. & 132 \\
\hline 00128 & 1 & 02211459 & Big Towaliga Creek near Barnesville, Ga. & 82 \\
\hline 00080 & 4 & 02202600 & Black Creek near Blitchton, Ga. & 62 \\
\hline
\end{tabular}


Table 1.--Alphabetical list of streamflow-gaging stations--Continued

Map Figure Station

number number number

Station name

Page

number

\begin{tabular}{|c|c|c|c|c|}
\hline 00351 & 3 & 02343219 & Bluff Springs Branch near Lumpkin, Ga. & 198 \\
\hline 00072 & 4 & 02201160 & Boggy Gut Creek near Wadley, Ga. & 58 \\
\hline 00058 & 4 & 02198000 & Brier Creek at Millhaven, Ga. & 51 \\
\hline 00478 & 2 & 03544947 & Brier Creek near Hiawassee, Ga. & 267 \\
\hline 00053 & 2 & 02197520 & Brier Creek near Thomson, Ga. & 49 \\
\hline 00057 & 2 & 02197830 & Brier Creek near Waynesboro, Ga. & 51 \\
\hline 00025 & 2 & 02191300 & Broad River above Carlton, Ga. & 34 \\
\hline 00033 & 2 & 02192000 & Broad River near Bell, Ga. & 39 \\
\hline 00161 & 2 & 02217505 & Brooklyn Creek at Athens, Ga. & 101 \\
\hline 00162 & 2 & 02217506 & Brooklyn Creek Tributary at Athens, Ga. & 101 \\
\hline 00028 & 2 & 02191890 & Brooks Creek near Lexington, Ga. & 36 \\
\hline 00055 & 2 & 02197600 & Brushy Creek near Wrens, Ga. & 50 \\
\hline 00375 & 3 & 02349350 & Buck Creek near Ellaville, Ga. & 211 \\
\hline 00374 & 3 & 02349330 & Buck Creek Tributary near Tazewell, Ga. & 211 \\
\hline 00074 & 4 & 02201350 & Buckhead Creek near Waynesboro, Ga. & 59 \\
\hline 00181 & 2 & 02223082 & Buffalo Creek near Linton, Ga. & 112 \\
\hline 00231 & 4 & 02228050 & Buffalo Creek at Hickox, Ga. & 136 \\
\hline 00030 & 2 & 02191930 & Buffalo Creek near Lexington, Ga. & 37 \\
\hline 00156 & 2 & 02217250 & Buffalo Creek Tributary near Jefferson, Ga. & 98 \\
\hline 00275 & 3 & 02318015 & Bull Creek near Norman Park, Ga. & 157 \\
\hline 00344 & 3 & 02341546 & Bull Creek Tributary at Columbus, Ga. & 194 \\
\hline 00276 & 3 & 02318020 & Bull Creek Tributary near Ellenton, Ga. & 158 \\
\hline 00049 & 2 & 02196820 & Butler Creek at Fort Gordon, Ga. & 46 \\
\hline 00324 & 5 & 02337081 & Camp Creek at College Park, Ga. & 183 \\
\hline 00357 & 1 & 02344300 & Camp Creek near Fayetteville, Ga. & 202 \\
\hline 00090 & 4 & 02203000 & Canoochee River near Claxton, Ga. & 66 \\
\hline 00092 & 4 & 02203280 & Canoochee River near Daisy, Ga. & 67 \\
\hline 00093 & 4 & 02203500 & Canoochee River near Groveland, Ga. & 67 \\
\hline 00086 & 4 & 02202865 & Canoochee River near Metter, Ga. & 64 \\
\hline 00094 & 4 & 02203505 & Canoochee River near Pembroke, Ga. & 68 \\
\hline 00082 & 4 & 02202800 & Canoochee Creek near Swainsboro, Ga. & 63 \\
\hline 00402 & 1 & 02379500 & Cartecay River near Ellijay, Ga. & 228 \\
\hline 00467 & 1 & 02397410 & Cedar Creek at Cedartown, Ga. & 262 \\
\hline 00468 & 1 & 02397500 & Cedar Creek near Cedartown, Ga. & 262 \\
\hline 00145 & 3 & 02215230 & Cedar Creek near Pineview, Ga. & 92 \\
\hline 00373 & 3 & 02349030 & Cedar Creek near Rupert, Ga. & 210 \\
\hline 00168 & 2 & 02217990 & Cedar Creek Tributary near Whitehall, Ga. & 104 \\
\hline 00304 & 5 & 02335450 & Chattahoochee River above Roswell, Ga. & 173 \\
\hline 00356 & 3 & 02344000 & Chattahoochee River at Alaga, Ala. & 201 \\
\hline 00308 & 5 & 02336000 & Chattahoochee River at Atlanta, Ga. & 175 \\
\hline 00300 & 1 & 02334430 & Chattahoochee River at Buford Dam near Buford, Ga. & 170 \\
\hline 00354 & 3 & 02343500 & Chattahoochee River at Columbia, Ala. & 199 \\
\hline 00341 & 3 & 02341500 & Chattahoochee River at Columbus, Ga. & 193 \\
\hline 00331 & 1 & 02338500 & Chattahoochee River at Franklin, Ga. & 187 \\
\hline
\end{tabular}


Table 1.--Alphabetical list of streamflow-gaging stations--Continued

Map Figure Station

number number number

Station name

Page

number

\begin{tabular}{|c|c|c|c|c|}
\hline 00294 & 1 & 02330450 & Chattahoochee River at Helen,Ga. & 167 \\
\hline 00320 & 5 & 02336500 & Chattahoochee River at Oakdale, Ga. & 181 \\
\hline 00336 & 3 & 02339500 & Chattahoochee River at West Point, Ga. & 190 \\
\hline 00319 & 5 & 02336490 & Chattahoochee River at State Highway 280, near Atlanta, Ga. & 181 \\
\hline 00301 & 1 & 02334500 & Chattahoochee River near Buford, Ga. & 170 \\
\hline 00355 & 3 & 02343801 & Chattahoochee River near Columbia, Ala. & 200 \\
\hline 00297 & 2 & 02331600 & Chattahoochee River near Cornelia, Ga. & 168 \\
\hline 00326 & 1 & 02337170 & Chattahoochee River near Fairburn, Ga. & 184 \\
\hline 00298 & 2 & 02333000 & Chattahoochee River near Gainesville, Ga. & 169 \\
\hline 00295 & 2 & 02331000 & Chattahoochee River near Leaf, Ga. & 167 \\
\hline 00303 & 5 & 02335000 & Chattahoochee River near Norcross, Ga. & 172 \\
\hline 00305 & 5 & 02335500 & Chattahoochee River near Roswell, Ga. & 173 \\
\hline 00330 & 1 & 02338000 & Chattahoochee River near Whitesburg, Ga. & 187 \\
\hline 00492 & 1 & 03568500 & Chattanooga Creek near Flintstone, Ga. & 276 \\
\hline 00471 & 1 & 02398000 & Chattooga River at Summerville, Ga. & 264 \\
\hline 00001 & 2 & 02177000 & Chattooga River near Clayton, Ga. & 22 \\
\hline 00003 & 2 & 02178000 & Chattooga River near Tallulah Falls, Ga. & 23 \\
\hline 00299 & 2 & 02333500 & Chestatee River near Dahlonega, Ga. & 169 \\
\hline 00396 & 3 & 02354500 & Chickasawhatchee Creek at Elmodel, Ga. & 224 \\
\hline 00383 & 3 & 02350685 & Choctahatchee Creek Tributary near Plains, Ga. & 216 \\
\hline 00426 & 1 & 02385000 & Coahulla Creek near Varnell, Ga. & 239 \\
\hline 00196 & 4 & 02225100 & Cobb Creek near Lyons, Ga. & 119 \\
\hline 00108 & 5 & 02203870 & Cobbs Creek near Atlanta, Ga. & 73 \\
\hline 00367 & 3 & 02346217 & Coleoatchee Creek near Manchester, Ga. & 207 \\
\hline 00182 & 3 & 02223200 & Commissioner Creek at Toomsboro, Ga. & 112 \\
\hline 00429 & 1 & 02387000 & Conasauga River at Tilton, Ga. & 241 \\
\hline 00423 & 1 & 02384500 & Conasauga River near Eton, Ga. & 237 \\
\hline 00422 & 1 & 02384000 & Conasauga River near Tennga, Ga. & 237 \\
\hline 00109 & 5 & 02203884 & Conley Creek near Forest Park, Ga. & 74 \\
\hline 00466 & 1 & 02397000 & Coosa River near Rome, Ga. & 261 \\
\hline 00414 & 1 & 02382500 & Coosawattee River at Carters, Ga. & 233 \\
\hline 00404 & 1 & 02380500 & Coosawattee River near Ellijay, Ga. & 229 \\
\hline 00421 & 1 & 02383500 & Coosawattee River near Pine Chapel, Ga. & 236 \\
\hline 00201 & 4 & 02225240 & Crooked Creek near Kite, Ga. & 121 \\
\hline 00225 & 4 & 02227422 & Crooked Creek Tributary near Bristol, Ga. & 133 \\
\hline 00191 & 4 & 02224400 & Cypress Creek near Tarrytown, Ga. & 116 \\
\hline 00089 & 4 & 02202950 & Cypress Flat Creek Tributary near Collins, Ga. & 66 \\
\hline 00259 & 3 & 02317775 & Daniels Creek near Ashburn, Ga. & 150 \\
\hline 00432 & 1 & 02387300 & Dead Mans Branch near Resaca, Ga. & 242 \\
\hline 00241 & 3 & 02315900 & Deep Creek near Ashburn, Ga. & 141 \\
\hline 00458 & 1 & 02395500 & Dikes Creek near Rome, Ga. & 257 \\
\hline 00210 & 4 & 02226030 & Doctors Creek near Ludowici, Ga. & 126 \\
\hline 00327 & 1 & 02337400 & Dog River near Douglasville, Ga. & 185 \\
\hline 00104 & 5 & 02203830 & Dolittle Creek near Atlanta, Ga. & 72 \\
\hline 00020 & 2 & 02190800 & Double Branch at Bowersville, Ga. & 32 \\
\hline
\end{tabular}


Table 1.--Alphabetical list of streamflow-gaging stations--Continued

\begin{tabular}{|c|c|c|c|c|}
\hline $\begin{array}{c}\text { Map } \\
\text { number }\end{array}$ & $\begin{array}{c}\text { Figure } \\
\text { number }\end{array}$ & $\begin{array}{l}\text { Station } \\
\text { number }\end{array}$ & Station name & $\begin{array}{c}\text { Page } \\
\text { number }\end{array}$ \\
\hline
\end{tabular}

\begin{tabular}{|c|c|c|c|c|}
\hline 00026 & 2 & 02191600 & Double Branch near Danielsville, Ga. & 35 \\
\hline 00442 & 1 & 02388400 & Dozier Creek near Shannon, Ga. & 247 \\
\hline 00416 & 1 & 02382800 & Dry Creek at Oakman, Ga. & 234 \\
\hline 00469 & 1 & 02397750 & Duck Creek above Lafayette, Ga. & 263 \\
\hline 00060 & 4 & 02198532 & Ebenezer Creek Tributary near Kildare, Ga. & 52 \\
\hline 00138 & 3 & 02214000 & Echeconnee Creek near Macon, Ga. & 89 \\
\hline 00403 & 1 & 02380000 & Ellijay River at Ellijay, Ga. & 228 \\
\hline 00451 & 1 & 02394000 & Etowah River above Cartersville, Ga. & 254 \\
\hline 00449 & 1 & 02392000 & Etowah River at Canton, Ga. & 252 \\
\hline 00460 & 1 & 02396000 & Etowah River at Rome, Ga. & 258 \\
\hline 00448 & 1 & 02391000 & Etowah River near Ball Ground, Ga. & 251 \\
\hline 00453 & 1 & 02394670 & Etowah River near Cartersville, Ga. & 255 \\
\hline 00444 & 1 & 02388900 & Etowah River near Dahlonega, Ga. & 249 \\
\hline 00445 & 1 & 02389000 & Etowah River near Dawsonville, Ga. & 249 \\
\hline 00456 & 1 & 02395000 & Etowah River near Kingston, Ga. & 256 \\
\hline 00459 & 1 & 02395990 & Etowah River Tributary at Rome, Ga. & 257 \\
\hline 00454 & 1 & 02394820 & Euharlee Creek at Rockmart, Ga. & 255 \\
\hline 00131 & 2 & 02212600 & Falling Creek near Julliette, Ga. & 84 \\
\hline 00407 & 1 & 02381600 & Fausett Creek near Talking Rock, Ga. & 230 \\
\hline 00087 & 4 & 02202900 & Fifteenmile Creek near Metter, Ga. & 65 \\
\hline 00485 & 1 & 03560000 & Fightingtown Creek at McCaysville, Ga. & 273 \\
\hline 00406 & 1 & 02381300 & Fir Creek near Ellijay, Ga. & 230 \\
\hline 00342 & 3 & 02341542 & Flat Rock Creek at Columbus, Ga. & 194 \\
\hline 00337 & 3 & 02340250 & Flat Shoal Creek near West Point, Ga. & 191 \\
\hline 00390 & 3 & 02352500 & Flint River at Albany, Ga. & 220 \\
\hline 00398 & 3 & 02356000 & Flint River at Bainbridge, Ga. & 225 \\
\hline 00376 & 3 & 02349500 & Flint River at Montezuma, Ga. & 212 \\
\hline 00391 & 3 & 02353000 & Flint River at Newton, Ga. & 221 \\
\hline 00380 & 3 & 02350500 & Flint River at Oakfield, Ga. & 214 \\
\hline 00369 & 3 & 02347500 & Flint River near Culloden, Ga. & 208 \\
\hline 00359 & 1 & 02344500 & Flint River near Griffin, Ga. & 203 \\
\hline 00358 & 1 & 02344350 & Flint River near Lovejoy, Ga. & 202 \\
\hline 00361 & 3 & 02345000 & Flint River near Molena, Ga. & 204 \\
\hline 00363 & 3 & 02346180 & Flint River near Thomaston, Ga. & 205 \\
\hline 00379 & 3 & 02350000 & Flint River near Vienna, Ga. & 214 \\
\hline 00362 & 3 & 02345500 & Flint River near Woodbury, Ga. & 204 \\
\hline 00146 & 3 & 02215245 & Folsom Creek Tributary near Rochelle, Ga. & 93 \\
\hline 00027 & 2 & 02191750 & Fork Creek at Carlton, Ga. & 36 \\
\hline 00120 & 1 & 02207000 & Garner Creek near Snellville, Ga. & 79 \\
\hline 00095 & 4 & 02203540 & Grove River Tributary near Savannah, Ga. & 68 \\
\hline 00149 & 3 & 02215800 & Gum Swamp Creek near Chauncey, Ga. & 95 \\
\hline 00038 & 2 & 02193400 & Harden Creek near Sharon, Ga. & 41 \\
\hline 00097 & 4 & 02203542 & Harmon Canal near Savannah, Ga. & 69 \\
\hline 00096 & 4 & 02203541 & Harmon Canal Tributary at Savannah, Ga. & 68 \\
\hline 00470 & 1 & 02397830 & Harrisburg Creek near Hawkins, Ga. & 263 \\
\hline
\end{tabular}




\begin{tabular}{|c|c|c|c|c|}
\hline 00441 & 1 & 02388320 & Heath Creek near Armuchee, Ga. & 247 \\
\hline 00440 & 1 & 02388300 & Heath Creek near Rome, Ga. & 246 \\
\hline 00455 & 1 & 02394950 & Hills Creek near Taylorsville, Ga. & 256 \\
\hline 00479 & 2 & 03545000 & Hiwassee River at Presley, Ga. & 268 \\
\hline 00034 & 2 & 02192300 & Hog Fork Fishing Creek Tributary near Tignall, Ga. & 40 \\
\hline 00428 & 1 & 02385800 & Holly Creek near Chatsworth, Ga. & 240 \\
\hline 00377 & 3 & 02349695 & Horsehead Creek near Montezuma, Ga. & 213 \\
\hline 00465 & 1 & 02396680 & Horseleg Creek at Rome, Ga. & 260 \\
\hline 00022 & 2 & 02191200 & Hudson River at Homer, Ga. & 33 \\
\hline 00083 & 4 & 02202810 & Hughes Prong to Canoochee Creek near Swainsboro, Ga. & 63 \\
\hline 00200 & 4 & 02225210 & Hurricane Branch near Wrightsville, Ga. & 121 \\
\hline 00219 & 4 & 02226900 & Hurricane Creek near Hazlehurst, Ga. & 130 \\
\hline 00220 & 4 & 02227000 & Hurricane Creek near Alma, Ga. & 130 \\
\hline 00328 & 1 & 02337448 & Hurricane Creek Tributary near Fairplay, Ga. & 185 \\
\hline 00395 & 3 & 02353500 & Ichawaynochaway Creek at Milford, Ga. & 223 \\
\hline 00392 & 3 & 02353100 & Ichawaynochaway Creek near Graves, Ga. & 221 \\
\hline 00397 & 3 & 02355000 & Ichawaynochaway Creek near Newton, Ga. & 224 \\
\hline 00187 & 4 & 02223700 & Indian Branch Tributary near Scott, Ga. & 115 \\
\hline 00011 & 2 & 02189020 & Indian Creek near Carnesville, Ga. & 28 \\
\hline 00242 & 3 & 02315980 & Jacks Creek near Ocilla, Ga. & 142 \\
\hline 00346 & 3 & 02341600 & Juniper Creek near Geneva, Ga. & 195 \\
\hline 00366 & 3 & 02346210 & Kimbrough Creek near Talbotton, Ga. & 206 \\
\hline 00382 & 3 & 02350600 & Kinchafoonee Creek at Peston, Ga. & 215 \\
\hline 00384 & 3 & 02350900 & Kinchafoonee Creek near Dawson, Ga. & 216 \\
\hline 00043 & 2 & 02195150 & Kiokee Creek at Appling, Ga. & 44 \\
\hline 00365 & 3 & 02346195 & Lazer Creek near Talbotton, Ga. & 206 \\
\hline 00260 & 3 & 02317780 & Lime Sink Creek near Sycamore, Ga. & 150 \\
\hline 00345 & 3 & 02341548 & Lindsey Creek Tributary at Columbus, Ga. & 195 \\
\hline 00360 & 1 & 02344700 & Line Creek near Senoia, Ga. & 203 \\
\hline 00054 & 2 & 02197550 & Little Brier Creek near Thomson, Ga. & 49 \\
\hline 00245 & 3 & 02316220 & Little Brushy Creek near Ocilla, Ga. & 143 \\
\hline 00487 & 1 & 03566685 & Little Chickamauga Creek near Ringgold, Ga. & 274 \\
\hline 00488 & 1 & 03566687 & Little Chickamauga Creek Tributary near Ringgold, Ga. & 274 \\
\hline 00114 & 1 & 02204300 & Little Cotton Indian Creek near Stockbridge, Ga. & 76 \\
\hline 00271 & 3 & 02317905 & Little Creek near Omega, Ga. & 155 \\
\hline 00269 & 3 & 02317890 & Little Creek near Sylvester, Ga. & 154 \\
\hline 00212 & 3 & 02226190 & Little Creek near Willacoochee, Ga. & 127 \\
\hline 00163 & 2 & 02217660 & Little Curry Creek near Jefferson, Ga. & 101 \\
\hline 00222 & 4 & 02227200 & Little Hurricane Creek below Alma, Ga. & 131 \\
\hline 00221 & 4 & 02227100 & Little Hurricane Creek near Alma, Ga. & 131 \\
\hline 00393 & 3 & 02353200 & Little Ichawaynochaway Creek near Shelllman, Ga. & 222 \\
\hline 00032 & 2 & 02191970 & Little Macks Creek near Lexington, Ga. & 38 \\
\hline 00286 & 3 & 02327415 & Little Ochlockonee River near Moultrie, Ga. & 163 \\
\hline 00150 & 4 & 02216000 & Little Ocmulgee River at Towns, Ga. & 95 \\
\hline 00064 & 2 & 02200100 & Little Ogeechee River at Hamburg, Ga. & 54 \\
\hline
\end{tabular}


Table 1.--Alphabetical list of streamflow-gaging stations--Continued

Map Figure Station number number number

\begin{tabular}{|c|c|c|c|c|}
\hline 00202 & 4 & 02225250 & Little Ohoopee River near Swainsboro, Ga. & 121 \\
\hline 00199 & 4 & 02225200 & Little Ohoopee River near Wrightsville, Ga. & 120 \\
\hline 00005 & 2 & 02181800 & Little Panther Creek near Tallulah Falls, Ga. & 24 \\
\hline 00274 & 3 & 02318000 & Little River near Adel, Ga. & 157 \\
\hline 00256 & 3 & 02317760 & Little River near Ashburn, Ga. & 148 \\
\hline 00473 & 1 & 02411800 & Little River near Buchanan, Ga. & 265 \\
\hline 00177 & 2 & 02220900 & Little River near Eatonton, Ga. & 109 \\
\hline 00265 & 3 & 02317830 & Little River near Lenox, Ga. & 153 \\
\hline 00041 & 2 & 02194000 & Little River near Lincolnton, Ga. & 43 \\
\hline 00450 & 1 & 02392500 & Little River near Roswell, Ga. & 253 \\
\hline 00273 & 3 & 02317980 & Little River near Sparks, Ga. & 156 \\
\hline 00249 & 3 & 02317600 & Little River near Statenville, Ga. & 145 \\
\hline 00262 & 3 & 02317800 & Little River near Tifton,Ga. & 151 \\
\hline 00039 & 2 & 02193500 & Little River near Washington, Ga. & 42 \\
\hline 00226 & 4 & 02227430 & Little Satilla Creek at Odum, Ga. & 133 \\
\hline 00227 & 4 & 02227470 & Little Satilla Creek near Jesup, Ga. & 134 \\
\hline 00228 & 4 & 02227500 & Little Satilla River near Offerman, Ga. & 134 \\
\hline 00476 & 1 & 02413000 & Little Tallapoosa River at Carrollton, Ga. & 266 \\
\hline 00477 & 1 & 02413200 & Little Tallapoosa River near Bowden, Ga. & 267 \\
\hline 00135 & 3 & 02213400 & Little Tobesofkee Creek near Forsyth, Ga. & 87 \\
\hline 00061 & 4 & 02198740 & Lockner Creek Tributary near Rincon, Ga. & 53 \\
\hline 00493 & 1 & 03568933 & Lookout Creek near New England, Ga. & 277 \\
\hline 00091 & 4 & 02203150 & Lotts Creek Tributary near Statesboro, Ga. & 67 \\
\hline 00031 & 2 & 02191960 & Macks Creek near Lexington, Ga. & 38 \\
\hline 00475 & 1 & 02411902 & Mann Creek Tributary near Tallapoosa,Ga. & 266 \\
\hline 00051 & 2 & 02197190 & McBean Creek near McBean, Ga. & 48 \\
\hline 00472 & 1 & 02411735 & McClendon Creek Tributary near Dallas, Ga. & 264 \\
\hline 00190 & 4 & 02224200 & Mercer Creek near Soperton, Ga. & 116 \\
\hline 00155 & 2 & 02217200 & Middle Oconee River near Jefferson, Ga. & 98 \\
\hline 00160 & 2 & 02217500 & Middle Oconee River near Athens, Ga. & 100 \\
\hline 00174 & 2 & $\mathbf{0 2 2 1 9 3 0 0}$ & Mile Branch near Madison, Ga. & 107 \\
\hline 00343 & 3 & 02341544 & Mill Branch at Columbus, Ga. & 194 \\
\hline 00424 & 1 & 02384540 & Mill Creek near Crandall, Ga. & 238 \\
\hline 00081 & 4 & 02202605 & Mill Creek near Pembroke, Ga. & 62 \\
\hline 00078 & 4 & 02202300 & Mill Creek near Statesboro, Ga. & 61 \\
\hline 00261 & 3 & 02317795 & Mill Creek near Tifton, Ga. & 151 \\
\hline 00024 & 2 & 02191280 & Mill Shoal Creek near Royston, Ga. & 34 \\
\hline 00141 & 3 & 02214820 & Mossy Creek near Perry, Ga. & 90 \\
\hline 00339 & 3 & 02340500 & Mountain Oak Creek near Hamilton, Ga. & 192 \\
\hline 00405 & 1 & 02381100 & Mountaintown Creek Tributary near Ellijay, Ga. & 229 \\
\hline 00388 & 3 & 02351890 & Muckalee Creek at State Highway 195 near Leesburg, Ga. & 218 \\
\hline 00385 & 3 & 02351500 & Muckalee Creek near Americus, Ga. & 217 \\
\hline 00389 & 3 & 02351900 & Muckalee Creek near Leesburg, Ga. & 219 \\
\hline 00386 & 3 & 02351700 & Muckalee Creek near Smithville, Ga. & 217 \\
\hline 00387 & 3 & 02351800 & Muckaloochee Creek at Smithville, Ga. & 218 \\
\hline
\end{tabular}


Table 1.--Alphabetical list of streamflow-gaging stations--Continued

Map Figure Station

number number number

Station name

Page

number

\begin{tabular}{|c|c|c|c|c|}
\hline 00340 & 3 & 02341220 & Mulberry Creek near Mulberry Grove, Ga. & 192 \\
\hline 00157 & 2 & 02217380 & Mulberry River near Winder, Ga. & 99 \\
\hline 00158 & 2 & 02217400 & Mulberry River Tributary near Winder, Ga. & 99 \\
\hline 00159 & 2 & 02217450 & Mulberry River Tributary no. 2, near Jefferson, Ga. & 100 \\
\hline 00198 & 4 & 02225180 & Mulepen Creek near Adrian, Ga. & 120 \\
\hline 00179 & 2 & 02221525 & Murder Creek below Eatonton, Ga. & 110 \\
\hline 00178 & 2 & 02221000 & Murder Creek near Monticello, Ga. & 109 \\
\hline 00071 & 4 & 02201110 & Nails Creek near Bartow, Ga. & \\
\hline 00317 & 5 & 02336360 & Nancy Creek at Rickenbacker Way at Atlanta, Ga. & 180 \\
\hline 00318 & 5 & 02336380 & Nancy Creek at Randall Mill Road at Atlanta, Ga. & 180 \\
\hline 00332 & 1 & 02338660 & New River near Corinth, Ga. & 188 \\
\hline 00253 & 3 & 02317734 & New River near Nashville, Ga. & 147 \\
\hline 00252 & 3 & 02317730 & New River Tributary near Nashville, Ga. & 147 \\
\hline 00257 & 3 & 02317765 & Newell Branch near Worth, Ga. & 149 \\
\hline 00258 & 3 & 02317770 & Newell Branch near Ashburn, Ga. & 149 \\
\hline 00321 & 5 & 02336610 & Nickajack Creek near Mableton, Ga. & 182 \\
\hline 00013 & 2 & 02189050 & North Fork Broad River above Toccoa, Ga. & 28 \\
\hline 00021 & 2 & 02191000 & North Fork Broad River near Carnesville, Ga. & 32 \\
\hline 00016 & 2 & 02190000 & North Fork Broad River near Lavonia, Ga. & \\
\hline 00014 & 2 & 02189500 & North Fork Broad River near Toccoa, Ga. & \\
\hline 00325 & 5 & 02337100 & North Fork Camp Creek at Atlanta, Ga. & 184 \\
\hline 00309 & 5 & 02336080 & North Fork Peachtree Creek near Chamblee, Ga. & 176 \\
\hline 00311 & 5 & 02336102 & North Fork Peachtree Creek Tributary near Atlanta, Ga. & 177 \\
\hline 00310 & 5 & 02336090 & North Fork Peachtree Creek Tributary near Chamblee, Ga. & 176 \\
\hline 00166 & 2 & 02217900 & North Oconee River at Athens, Ga. & 103 \\
\hline 00165 & 2 & 02217750 & North Oconee River Tributary at Athens, Ga. & 102 \\
\hline 00233 & 4 & 02228500 & North Prong St Mary’s River at Moniac, Ga. & 137 \\
\hline 00480 & 2 & 03550500 & Nottely River near Blairsville, Ga. & 269 \\
\hline 00481 & 1 & 03553500 & Nottely River near Ivylog, Ga. & 264 \\
\hline 00047 & 2 & 02196730 & Oates Creek at Old Savannah Road at Augusta, Ga. & 45 \\
\hline 00046 & 2 & 02196725 & Oates Creek at White Road at Augusta, Ga. & 45 \\
\hline 00349 & 3 & 02341900 & Ochillee Creek near Cusseta, Ga. & 197 \\
\hline 00282 & 3 & 02327200 & Ochlockonee River at Moultrie, Ga. & 161 \\
\hline 00290 & 3 & 02327810 & Ochlockonee River near Cairo, Ga. & 165 \\
\hline 00284 & 3 & 02327355 & Ochlockonee River near Coolidge, Ga. & 162 \\
\hline 00287 & 3 & 02327500 & Ochlockonee River near Thomasville, Ga. & 163 \\
\hline 00283 & 3 & 02327350 & Ochlockonee River Tributary near Coolidge, Ga. & 161 \\
\hline 00142 & 3 & 02215000 & Ocmulgee River at Hawkinsville, Ga. & 91 \\
\hline 00130 & 2 & 02212500 & Ocmulgee River at Juliette, Ga. & 83 \\
\hline 00148 & 4 & 02215500 & Ocmulgee River at Lumber City, Ga. & 94 \\
\hline 00132 & 3 & 02213000 & Ocmulgee River at Macon, Ga. & 85 \\
\hline 00126 & 2 & 02210500 & Ocmulgee River near Jackson, Ga. & 81 \\
\hline 00144 & 3 & 02215220 & Ocmulgee River Tributary near Abbeville, Ga. & 92 \\
\hline 00484 & 1 & 03559500 & Ocoee River at Copperhill, Tenn. & 272 \\
\hline 00186 & 4 & 02223500 & Oconee River at Dublin, Ga. & 114 \\
\hline
\end{tabular}




\begin{tabular}{|c|c|c|c|c|}
\hline 00180 & 2 & 02223000 & Oconee River at Milledgeville, Ga. & 111 \\
\hline 00172 & 2 & 02218500 & Oconee River near Greensboro, Ga. & 106 \\
\hline 00192 & 4 & 02224500 & Oconee River near Mount Vernon, Ga. & 117 \\
\hline 00170 & 2 & 02218300 & Oconee River near Penfield, Ga. & 105 \\
\hline 00194 & 4 & 02224800 & Oconee River Tributary no. 2 , near Glenwood, Ga. & 118 \\
\hline 00063 & 2 & 02200000 & Ogeechee River at Jewell, Ga. & 54 \\
\hline 00077 & 4 & 02202000 & Ogeechee River at Scarboro, Ga. & 60 \\
\hline 00079 & 4 & 02202500 & Ogeechee River near Eden, Ga. & 61 \\
\hline 00066 & 4 & 02200500 & Ogeechee River near Louisville, Ga. & 55 \\
\hline 00069 & 4 & 02200950 & Ogeechee River near Wadley, Ga. & 57 \\
\hline 00204 & 4 & 02225320 & Ohoopee River near Aline, Ga. & 122 \\
\hline 00203 & 4 & 02225300 & Ohoopee River near Oak Park, Ga. & 122 \\
\hline 00207 & 4 & 02225500 & Ohoopee River near Reidsville, Ga. & 124 \\
\hline 00197 & 4 & 02225150 & Ohoopee River near Wrightsville, Ga. & 119 \\
\hline 00280 & 3 & 02318725 & Okapilco Creek at Quitman, Ga. & 160 \\
\hline 00278 & 3 & 02318600 & Okapilco Creek near Berlin, Ga. & 159 \\
\hline 00279 & 3 & 02318700 & Okapilco Creek near Quitman, Ga. & 159 \\
\hline 00433 & 1 & 02387500 & Oostanaula River at Resaca, Ga. & 243 \\
\hline 00443 & 1 & 02388500 & Oostanaula River near Rome, Ga. & 248 \\
\hline 00435 & 1 & 02387570 & Oothkalooga Creek at Adairsville, Ga. & 244 \\
\hline 00434 & 1 & 02387560 & Oothkalooga Creek Tributary at Adairsville, Ga. & 244 \\
\hline 00394 & 3 & 02353400 & Pachitla Creek near Edison, Ga. & 222 \\
\hline 00006 & 2 & 02182000 & Panther Creek near Toccoa, Ga. & 25 \\
\hline 00352 & 3 & 02343225 & Pataula Creek near Georgetown, Ga. & 198 \\
\hline 00350 & 3 & 02343200 & Pataula Creek near Lumpkin, Ga. & 197 \\
\hline 00113 & 1 & 02204285 & Pates Creek near Flippen, Ga. & 75 \\
\hline 00370 & 3 & 02348300 & Patsiliga Creek near Reynolds, Ga. & 209 \\
\hline 00316 & 5 & 02336300 & Peachtree Creek at Atlanta, Ga. & 179 \\
\hline 00100 & 4 & 02203559 & Peacock Creek at McIntosh, Ga. & 70 \\
\hline 00211 & 4 & 02226100 & Penholoway Creek near Jesup, Ga. & 126 \\
\hline 00193 & 4 & 02224650 & Peterson Creek at Glenwood, Ga. & 117 \\
\hline 00117 & 1 & 02205500 & Pew Creek near Lawrenceville, Ga. & 77 \\
\hline 00347 & 3 & 02341723 & Pine Knot Creek near Juniper, Ga. & 196 \\
\hline 00417 & 1 & 02382900 & Pine Log Creek near Rydal, Ga. & 234 \\
\hline 00425 & 1 & 02384600 & Pinhook Creek near Eton, Ga. & 238 \\
\hline 00430 & 1 & 02387100 & Polecat Creek near Spring Place, Ga. & 241 \\
\hline 00291 & 3 & 02327860 & Popple Branch near Whigham, Ga. & 165 \\
\hline 00169 & 2 & 02218100 & Porters Creek at Watkinsville, Ga. & 104 \\
\hline 00368 & 3 & 02346500 & Potato Creek near Thomaston, Ga. & 207 \\
\hline 00452 & 1 & 02394400 & Pumpkinvine Creek below Dallas, Ga. & 254 \\
\hline 00045 & 2 & 02196605 & Raes Creek Tributary no. 1 , at Augusta,Ga. & 44 \\
\hline 00044 & 2 & 02196570 & Raes Creek Tributary no. 2, at Augusta, Ga. & 44 \\
\hline 00419 & 1 & 02383200 & Redbud Creek near Ranger, Ga. & 235 \\
\hline 00420 & 1 & 02383220 & Redbud Creek Tributary near Ranger, Ga. & 236 \\
\hline 00085 & 4 & 02202850 & Reedy Branch near Metter, Ga. & 64 \\
\hline
\end{tabular}


Table 1.--Alphabetical list of streamflow-gaging stations--Continued

Map Figure Station

Page

number number number

Station name

number

\begin{tabular}{|c|c|c|c|c|}
\hline 00084 & 4 & 02202820 & Reedy Creek near Twin City, Ga. & 64 \\
\hline 00206 & 4 & 02225350 & Reedy Creek Tributary near Soperton, Ga. & 123 \\
\hline 00075 & 4 & 02201800 & Richardson Creek near Millen, Ga. & 59 \\
\hline 00427 & 1 & 02385700 & Rock Creek near Chatsworth, Ga. & 239 \\
\hline 00418 & 1 & 02383000 & Rock Creek near Fairmount, Ga. & 235 \\
\hline 00065 & 2 & 02200400 & Rocky Comfort Creek near Grange, Ga. & 55 \\
\hline 00436 & 1 & 02387700 & Rocky Creek at Curryville, Ga. & 244 \\
\hline 00188 & 3 & 02224000 & Rocky Creek near Dudley, Ga. & 115 \\
\hline 00040 & 2 & 02193600 & Rocky Creek near Washington, Ga. & 42 \\
\hline 00048 & 2 & 02196760 & Rocky Creek Tributary at Augusta, Ga. & 45 \\
\hline 00285 & 3 & 02327400 & Sallys Branch Tributary near Sale City, Ga. & 162 \\
\hline 00230 & 4 & 02228000 & Satilla River at Atkinson, Ga. & 135 \\
\hline 00213 & 4 & 02226200 & Satilla River near Douglas, Ga. & 127 \\
\hline 00217 & 4 & 02226582 & Satilla River near Hoboken, Ga. & 129 \\
\hline 00214 & 4 & 02226300 & Satilla River near Pearson, Ga. & 128 \\
\hline 00215 & 4 & 02226500 & Satilla River near Waycross, Ga. & 128 \\
\hline 00229 & 4 & 02227990 & Satilla River Tributary no. 2, at Atkinson, Ga. & 135 \\
\hline 00232 & 4 & 02228055 & Satilla River Tributary no. 3, near Winokur, Ga. & 136 \\
\hline 00139 & 3 & 02214280 & Savage Creek near Bullard, Ga. & 89 \\
\hline 00050 & 2 & 02197000 & Savannah River at Augusta, Ga. & 46 \\
\hline 00010 & 2 & 02189000 & Savannah River near Calhoun Falls, S.C. & 27 \\
\hline 00042 & 2 & 02195000 & Savannah River near Clarks Hill, S.C. & 43 \\
\hline 00059 & 4 & 02198500 & Savannah River near Clyo, Ga. & 52 \\
\hline 00008 & 2 & 02187500 & Savannah River near Iva, S.C. & 26 \\
\hline 00052 & 4 & 02197500 & Savannah River near Millhaven, Ga. & 48 \\
\hline 00410 & 1 & 02381950 & Scarecorn Creek above Hinton, $\mathrm{Ga}$. & 231 \\
\hline 00411 & 1 & 02382000 & Scarecorn Creek at Hinton, Ga. & 232 \\
\hline 00364 & 3 & 02346193 & Scott Creek near Talbotton, Ga. & 205 \\
\hline 00023 & 2 & 02191270 & Scull Shoal Creek near Danielsville, Ga. & 33 \\
\hline 00076 & 4 & 02201830 & Sculls Creek near Millen, Ga. & 60 \\
\hline 00073 & 4 & 02201250 & Seals Creek Tributary near Midville, Ga. & 58 \\
\hline 00118 & 1 & 02206000 & Shetley Creek near Norcross, Ga. & 78 \\
\hline 00105 & 5 & 02203835 & Shoal Creek at Atlanta, Ga. & 72 \\
\hline 00107 & 5 & 02203850 & Shoal Creek near Atlanta, Ga. & 73 \\
\hline 00446 & 1 & 02389300 & Shoal Creek near Dawsonville, Ga. & 250 \\
\hline 00106 & 5 & 02203845 & Shoal Creek Tributary near Atlanta, Ga. & 72 \\
\hline 00461 & 1 & 02396290 & Silver Creek Tributary no. 1 , near Rome, Ga. & 258 \\
\hline 00462 & 1 & 02396510 & Silver Creek Tributary no. 2, at Lindale Road near Rome, Ga. & 259 \\
\hline 00463 & 1 & 02396515 & Silver Creek Tributary no. 2, at U.S. 27 \& 411 near Rome, Ga. & 259 \\
\hline 00464 & 1 & 02396550 & Silver Creek Tributary no. 3, at Rome, Ga. & 259 \\
\hline 00329 & 1 & 02337500 & Snake Creek near Whitesburg, Ga. & 186 \\
\hline 00111 & 5 & 02203950 & Snapfinger Creek near Decatur, Ga. & 75 \\
\hline 00307 & 5 & 02335870 & Sope Creek near Marietta, Ga. & 174 \\
\hline 00296 & 2 & 02331500 & Soque River near Demorest, Ga. & 168 \\
\hline 00489 & 1 & 03566700 & South Chickamauga Creek at Ringgold, Ga. & 275 \\
\hline
\end{tabular}


Table 1.--Alphabetical list of streamflow-gaging stations--Continued

Map Figure Station number number number

Station name

Page

number

\begin{tabular}{|c|c|c|c|c|}
\hline 00491 & 1 & 03567500 & South Chickamauga Creek near Chickamauga, Tn. & 276 \\
\hline 00062 & 2 & 02199700 & South Fork Ogeechee River near Crawfordville, Ga. & 53 \\
\hline 00315 & 5 & 02336250 & South Fork Peachtree Creek at Atlanta, Ga. & 179 \\
\hline 00312 & 5 & 02336150 & South Fork Peachtree Creek at Clarkston, Ga. & 177 \\
\hline 00313 & 5 & 02336180 & South Fork Peachtree Creek near Decatur, Ga. & 178 \\
\hline 00314 & 5 & 02336238 & South Fork Peachtree Creek Tributary near Atlanta, Ga. & 178 \\
\hline 00102 & 5 & 02203800 & South River at Atlanta, Ga. & 71 \\
\hline 00101 & 5 & 02203600 & South River at East Point, Ga. & 70 \\
\hline 00110 & 5 & 02203900 & South River near Atlanta, Ga. & 74 \\
\hline 00112 & 1 & 02204070 & South River near Lithonia, Ga. & 75 \\
\hline 00115 & 1 & 02204500 & South River near McDonough, Ga. & 76 \\
\hline 00322 & 5 & 02336700 & South Utoy Creek Tributary at East Point, Ga. & 182 \\
\hline 00400 & 3 & 02356640 & Spring Creek at Colquitt, Ga. & 226 \\
\hline 00399 & 3 & 02356100 & Spring Creek near Arlington, Ga. & 226 \\
\hline 00401 & 3 & 02357000 & Spring Creek near Iron City, Ga. & 227 \\
\hline 00068 & 4 & 02200930 & Spring Creek near Louisville, Ga. & 56 \\
\hline 00234 & 4 & 02231100 & St Marys River near St. George, Ga. & 137 \\
\hline 00037 & 2 & 02193300 & Stephens Creek near Crawfordville, Ga. & 41 \\
\hline 00012 & 2 & 02189030 & Stephens Creek Tributary at Carnesville, Ga. & 28 \\
\hline 00439 & 1 & 02388200 & Storey Mill Creek near Summerville, Ga. & 246 \\
\hline 00103 & 5 & 02203820 & Sugar Creek near Atlanta, Ga. & 71 \\
\hline 00415 & 1 & 02382600 & Sugar Creek near Chatsworth, Ga. & 234 \\
\hline 00486 & 1 & 03566660 & Sugar Creek near Ringgold, Ga. & 273 \\
\hline 00302 & 1 & 02334885 & Suwanee Creek near Suwanee, Ga. & 171 \\
\hline 00235 & 4 & 02314500 & Suwannee River at Fargo, Ga. & 138 \\
\hline 00236 & 4 & 02314600 & Suwannoochee Creek at Dupont, Ga. & 139 \\
\hline 00237 & 4 & 02314700 & Suwannoochee Creek near Thelma, Ga. & 139 \\
\hline 00323 & 1 & 02337000 & Sweetwater Creek near Austell, Ga. & 183 \\
\hline 00413 & 1 & 02382300 & Talking Rock Creek near Carters, Ga. & 233 \\
\hline 00412 & 1 & 02382200 & Talking Rock Creek near Hinton, Ga. & 232 \\
\hline 00474 & 1 & 02411900 & Tallapoosa River at Tallapoosa, Ga. & 265 \\
\hline 00004 & 2 & 02178400 & Tallulah River near Clayton, Ga. & 24 \\
\hline 00167 & 2 & 02217905 & Tanyard Creek at Athens, Ga. & 103 \\
\hline 00353 & 3 & 02343267 & Temple Creek near Blakely, Ga. & 199 \\
\hline 00088 & 4 & 02202910 & Ten Mile Creek Tributary at Pulaski, Ga. & 65 \\
\hline 00153 & 4 & 02216610 & Tillman Mill Creek near Lumber City, Ga. & 97 \\
\hline 00293 & 3 & 02328000 & Tired Creek near Cairo, Ga. & 166 \\
\hline 00136 & 3 & 02213470 & Tobesofkee Creek above Macon, Ga. & 87 \\
\hline 00134 & 3 & 02213350 & Tobesofkee Creek below Forsyth, Ga. & 86 \\
\hline 00137 & 3 & 02213500 & Tobesofkee Creek near Macon, Ga. & 88 \\
\hline 00483 & 1 & 03559000 & Toccoa River near Blue Ridge, Ga. & 271 \\
\hline 00482 & 1 & 03558000 & Toccoa River near Dial, Ga. & 270 \\
\hline 00017 & 2 & 02190100 & Toms Creek near Eastonollee, Ga. & 30 \\
\hline 00019 & 2 & 02190500 & Toms Creek near Martin, Ga. & 31 \\
\hline 00018 & 2 & 02190200 & Toms Creek Tributary near Avalon, Ga. & 31 \\
\hline
\end{tabular}


Table 1.--Alphabetical list of streamflow-gaging stations--Continued

Map Figure Station

number number number

Station name

\begin{tabular}{|c|c|c|c|c|}
\hline 00129 & 2 & 02211500 & Towaliga River near Forsyth, Ga. & 83 \\
\hline 00127 & 1 & 02211300 & Towaliga River near Jackson, Ga. & 82 \\
\hline 00171 & 2 & 02218450 & Town Creek near Greensboro, $\mathbf{G a}$. & 105 \\
\hline 00408 & 1 & 02381700 & Town Creek Tributary near Ellijay, Ga. & 231 \\
\hline 00164 & 2 & 02217730 & Tributary to North Oconee River at Athens, Ga. & 102 \\
\hline 00029 & 2 & 02191910 & Trouble Creek at Lexington, Ga. & 37 \\
\hline 00143 & 3 & 02215100 & Tucsawhatchee Creek near Hawkinsville, Ga. & 92 \\
\hline 00007 & 2 & 02184000 & Tugaloo River near Hartwell, Ga. & 25 \\
\hline 00378 & 3 & 02349900 & Turkey Creek at Byromville,Ga. & 213 \\
\hline 00189 & 4 & 02224100 & Turkey Creek near Dublin, Ga. & 116 \\
\hline 00152 & 4 & 02216180 & Turnpike Creek near McRae, Ga. & 96 \\
\hline 00457 & 1 & 02395120 & Two Run Creek near Kingston, Ga. & 257 \\
\hline 00270 & 3 & 02317900 & Ty Ty Creek at Ty Ty, Ga. & 155 \\
\hline 00272 & 3 & 02317910 & Ty Ty Creek Tributary at Crosland, Ga. & 156 \\
\hline 00348 & 3 & 02341800 & Upatoi Creek near Columbus, Ga. & 196 \\
\hline 00056 & 2 & 02197810 & Walnut Branch near Waynesboro, Ga. & 50 \\
\hline 00133 & 3 & 02213050 & Walnut Creek near Gray, Ga. & 86 \\
\hline 00268 & 3 & 02317870 & Warrior Creek near Sumner, Ga. & 154 \\
\hline 00266 & 3 & 02317840 & Warrior Creek near Sylvester, Ga. & 153 \\
\hline 00267 & 3 & 02317845 & Warrior Creek Tributary near Sylvester, Ga. & 153 \\
\hline 00438 & 1 & 02388000 & West Armuchee Creek near Sublingan, Ga. & 245 \\
\hline 00490 & 1 & 03567200 & West Chickamauga Creek near Kensington, Ga. & 275 \\
\hline 00218 & 4 & 02226700 & Whitehead Creek near Denton, Ga. & 129 \\
\hline 00372 & 3 & 02349000 & Whitewater Creek below Rambullette Creek near Butler, Ga. & 210 \\
\hline 00371 & 3 & 02348485 & Whitewater Creek near Butler, Ga. & 209 \\
\hline 00176 & 2 & 02220550 & Whitten Creek near Sparta, Ga. & 108 \\
\hline 00116 & 1 & 02205000 & Wildcat Creek near Lawrenceville, Ga. & 77 \\
\hline 00244 & 3 & 02316200 & Willacoochee River near Ocilla, Ga. & 143 \\
\hline 00070 & 4 & 02201000 & Williamson Swamp Creek at Davisboro, Ga. & 57 \\
\hline 00098 & 4 & 02203543 & Wilshire Canal near Savannah, Ga. & 69 \\
\hline 00099 & 4 & 02203544 & Wilshire Canal Tributary near Savannah, Ga. & 69 \\
\hline 00254 & 3 & 02317748 & Withlacoochee River near Bemiss, Ga. & 148 \\
\hline 00250 & 3 & 02317700 & Withlacoochee River near Nashville, Ga. & 146 \\
\hline 00277 & 3 & 02318500 & Withlacoochee River near Quitman, Ga. & 158 \\
\hline 00255 & 3 & 02317755 & Withlacoochee River near Valdosta, Ga. & 148 \\
\hline 00251 & 3 & 02317710 & Withlacoochee River Tributary near Nashville, Ga. & 146 \\
\hline 00292 & 3 & 02327900 & Wolf Creek near Whigham, Ga. & 166 \\
\hline 00121 & 2 & 02207500 & Yellow River near Covington, Ga. & 79 \\
\hline 00119 & 1 & 02206500 & Yellow River near Snellville, Ga. & 78 \\
\hline 00333 & 1 & 02338775 & Yellowjacket Creek at Hogansville, Ga. & 188 \\
\hline 00334 & 1 & 02338840 & Yellowjacket Creek below Hogansville, Ga. & 189 \\
\hline 00335 & 1 & 02339000 & Yellowjacket Creek near LaGrange, Ga. & 189 \\
\hline
\end{tabular}


Table 2.--Annual peak discharges and stage data for streamflow-gaging stations in Georgia, through September 1990

An underscore line in the water-year column indicates discontinuous record; a line in the gage-height column indicates a change in datum and means that the gage heights above and below the line are not comparable; a line in the date and discharge columns indicates a change in gage location; and a continuous line from the date column through the discharge column indicates a change in gage locations and datum.

[a, peak stage occurred on a different day, b, peak stage below base of gage (discharge is less than published discharge, unless gage height is shown); c, historic peak; -, data not available; $\mathrm{mi}$, mile; $\mathrm{ft}^{3} / \mathrm{s}$, cubic feet per second; $\mathrm{mi}^{2}$, square miles; NOTE: Sea level is used instead of National Geodetic Vertical Datum of 1929]

\section{SAVANNAH RIVER BASIN}

\section{CHATTOOGA RIVER NEAR CLAYTON, GEORGIA}

LOCATION.--Lat $34^{\circ} 48^{\prime} 50^{\prime \prime}$, long $83^{\circ} 18^{\prime} 22^{\prime \prime}$, Oconee County, S.C., on left bank $150 \mathrm{ft}$ downstream from bridge on U.S. Highway 76 , 2.8 mi upstream from Stekoa Creek, 7 mi southeast of Clayton, 9 mi downstream from Warwoman Creek, and 9 mi upstream from confluence with Tallulah River.

DRAINAGE AREA.-207 $\mathrm{mi}^{2}$.

GAGE.--Water-stage recorder. Datum of gage is $1,165.6 \mathrm{ft}$ above sea level (levels from the Georgia Department of Transportation). May 1907 to June 1908 , nonrecording gage at site $400 \mathrm{ft}$ upstream at different datum.

STAGE-DISCHARGE RELATION.-Defined by current-meter measurements below $4,700 \mathrm{ft}^{3} / \mathrm{s}$, and extended above on basis of slope-area measurements at 15,700 and $29,000 \mathrm{ft}^{3} / \mathrm{s}$.

REMARKS.--Peak records for 1907-08 are too short to determine annual peaks. Stage records for 1915, 1928, and 1929 from Georgia Power Company. Discharge records for 1917-27 estimated on basis of records for U.S. Geological Survey gage on Chattooga River near Tallulah Falls, Ga. (02178000); drainage area, $256 \mathrm{mi}^{2}$.

\begin{tabular}{|c|c|c|c|c|c|c|c|c|c|c|c|}
\hline $\begin{array}{l}\text { Water } \\
\text { year }\end{array}$ & Date & $\begin{array}{c}\text { Discharge } \\
\left(\mathrm{ft}^{3} / \mathrm{s}\right)\end{array}$ & $\begin{array}{c}\text { Gage } \\
\text { height } \\
\text { (ft) }\end{array}$ & $\begin{array}{c}\text { Water } \\
\text { year }\end{array}$ & Date & $\begin{array}{c}\text { Discharge } \\
\left(\mathrm{ft}^{3} / \mathrm{s}\right)\end{array}$ & $\begin{array}{c}\text { Gage } \\
\text { height } \\
\text { (ft) }\end{array}$ & $\begin{array}{l}\text { Water } \\
\text { year }\end{array}$ & Date & $\begin{array}{c}\text { Discharge } \\
\left(\mathrm{ft}^{3} / \mathrm{s}\right)\end{array}$ & $\begin{array}{c}\text { Gage } \\
\text { height } \\
\text { (ft) }\end{array}$ \\
\hline$\underline{1915}$ & Oct. 15 & 12,600 & $8.25 \mathrm{c}$ & 1948 & July 12 & 12,400 & 8.11 & 1970 & Nov. 02 & 3,480 & 4.15 \\
\hline$\overline{1917}$ & Mar. 24 & 14,000 & - & 1949 & June 16 & 13,900 & 8.66 & 1971 & Feb. 22 & 3,290 & 3.91 \\
\hline 1918 & Jan. 28 & 5,900 & - & 1950 & Mar. 13 & 4,740 & 4.73 & 1972 & Dec. 07 & 7,440 & 6.06 \\
\hline 1919 & Dec. 22 & 16,000 & - & 1951 & Dec. 07 & 5,220 & 5.02 & 1973 & May 28 & 19,600 & 10.74 \\
\hline 1920 & Dec. 09 & 8,200 & - & 1952 & Mar. 11 & 13,400 & 8.50 & 1974 & Dec. 26 & 6,400 & 5.58 \\
\hline 1921 & Feb. 10 & 4,100 & - & 1953 & Feb. 21 & 6,020 & 5.40 & 1975 & Sept.24 & 6,340 & 5.55 \\
\hline 1922 & Jan. 21 & 6,200 & .. & 1954 & Jan. 22 & 6,230 & 5.50 & 1976 & May 15 & 18,500 & 10.37 \\
\hline 1923 & Dec. 17 & 5,300 & - & 1955 & Feb. 06 & 5,820 & 5.30 & 1977 & Mar. 13 & 13,000 & 8.25 \\
\hline 1924 & Sept.20 & 9,200 & - & 1956 & Apr. 16 & 5,820 & 5.30 & 1978 & Jan. 26 & 7,850 & 6.24 \\
\hline 1925 & Dec. 08 & 3,900 & - & 1957 & Apr. 05 & 5,820 & 5.34 & 1979 & Mar. 04 & 14,800 & 9.03 \\
\hline 1926 & Jan. 18 & 6,200 & - & 1958 & Nov. 19 & 5,620 & 5.20 & 1980 & Nov. 02 & 10,900 & 7.52 \\
\hline 1927 & Dec. 26 & 3,600 & - & 1959 & May 31 & 5,620 & 5.17 & 1981 & May 27 & 4,120 & 4.41 \\
\hline 1928 & Aug. 15 & 20,100 & $10.90 \mathrm{c}$ & 1960 & Oct. 09 & 6,440 & 5.60 & 1982 & Feb. 03 & 5,000 & 4.89 \\
\hline 1929 & Sept.26 & 11,400 & $7.70 \mathrm{c}$ & 1961 & Feb. 25 & 7,310 & 6.00 & 1983 & Feb. 02 & 7,910 & 6.27 \\
\hline$\overline{1940}$ & Aug. 30 & 29,000 & 13.80 & 1962 & Dec. 12 & 9,660 & 7.01 & 1984 & Feb. 13 & 4,810 & 4.79 \\
\hline 1941 & July 07 & 7,530 & 6.10 & 1963 & Mar. 06 & 5,420 & 5.10 & 1985 & Aug. 17 & 4,740 & 4.75 \\
\hline 1942 & Feb. 17 & 6,870 & 5.75 & 1964 & Sept.29 & 9,880 & 7.08 & 1986 & Nov. 05 & 4,850 & 4.81 \\
\hline 1943 & Dec. 29 & 6,870 & 5.80 & 1965 & Oct. 04 & 27,200 & 13.20 & 1987 & Nov. 26 & 10,400 & 7.34 \\
\hline 1944 & Mar. 19 & 3,840 & 4.25 & 1966 & Feb. 13 & 13,400 & 8.50 & 1988 & Jan. 20 & 4,920 & 4.85 \\
\hline 1945 & Apr. 17 & 2,930 & 3.70 & 1967 & June 04 & 15,400 & 9.27 & 1989 & July 04 & 5,200 & 5.00 \\
\hline 1946 & Feb. 10 & 6,650 & 5.70 & 1968 & Mar. 12 & 5,620 & 5.25 & 1990 & Feb. 16 & 11,000 & 7.59 \\
\hline 1947 & Jan. 20 & 6,440 & 5.57 & 1969 & June 15 & 14,700 & 9.00 & & & & \\
\hline
\end{tabular}




\section{SAVANNAH RIVER BASIN}

\section{ASHLEY CREEK NEAR CLAYTON, GEORGIA}

LOCATION.--Lat $34^{\circ} 52^{\prime} 40^{\prime \prime}$, long $83^{\circ} 26^{\prime} 18^{\prime \prime}$, Rabun County, at culvert on State Highway 2, 1.2 mi west of Clayton city limits.

DRAINAGE AREA.-0.99 $\mathrm{mi}^{2}$.

GAGE.--Flood-stage/rainfall recorder. Datum of gage is about 1,966 ft above sea level (from topographic map).

STAGE-DISCHARGE RELATION.--Defined by current-meter measurements below $2.6 \mathrm{tt}^{3} / \mathrm{s}$, and extended above on basis of culvert computations.

REMARKS.--Some peaks may be affected by a recreational pond upstream.

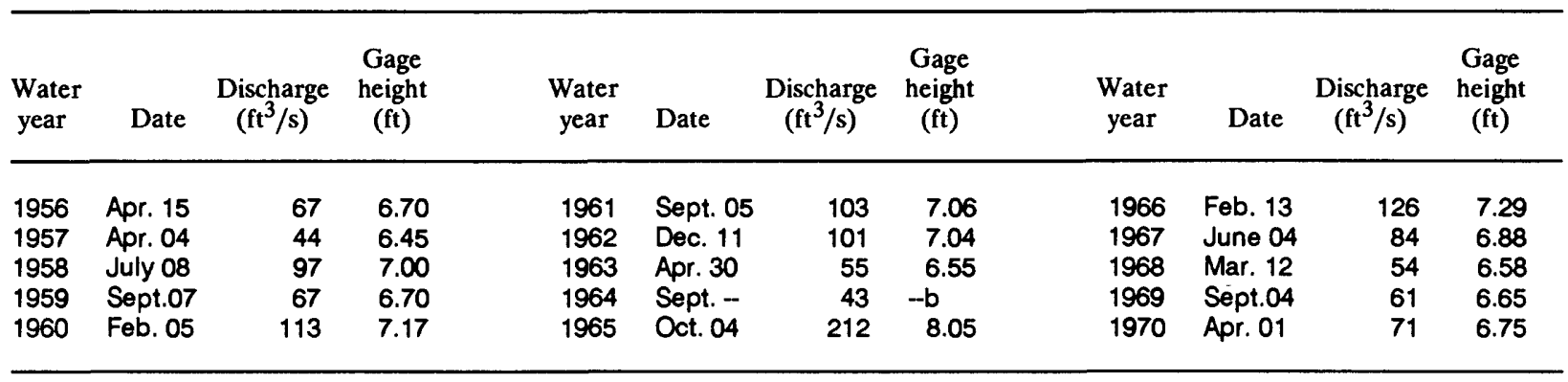

\section{CHATTOOGA RIVER NEAR TALLULAH FALLS, GEORGIA}

LOCATION.--Lat $34^{\circ} 47^{\prime} 31^{\prime \prime}$, long $83^{\circ} 19^{\prime} 22^{\prime \prime}$, Rabun County, on right bank $300 \mathrm{ft}$ upstream from Camp Creek, 5.5 mi upstream from confluence with Tallulah River, and 8 mi east of Tallulah Falls.

DRAINAGE AREA.--256 $\mathrm{mi}^{2}$.

GAGE.--Nonrecording prior to Aug. 18, 1917; water-stage recorder thereafter. Datum of gage is about $960 \mathrm{ft}$ above sea level (from U.S. Army Corps of Engineers river profile).

STAGE-DISCHARGE RELATION.--Defined by current-meter measurements below $5,800 \mathrm{ft}^{3} / \mathrm{s}$, and extended above on basis of computation of peak flows passing station near Clayton.

\begin{tabular}{|c|c|c|c|c|c|c|c|c|c|c|c|}
\hline $\begin{array}{l}\text { Water } \\
\text { year }\end{array}$ & Date & $\begin{array}{c}\text { Discharge } \\
\left(\mathrm{ft}^{3} / \mathrm{s}\right)\end{array}$ & $\begin{array}{c}\text { Gage } \\
\text { height } \\
\text { (ft) }\end{array}$ & $\begin{array}{l}\text { Water } \\
\text { year }\end{array}$ & Date & $\begin{array}{c}\text { Discharge } \\
\left(\mathrm{ft}^{3} / \mathrm{s}\right)\end{array}$ & $\begin{array}{c}\text { Gage } \\
\text { height } \\
\text { (ft) }\end{array}$ & $\begin{array}{l}\text { Water } \\
\text { year }\end{array}$ & Date & $\begin{array}{c}\text { Discharge } \\
\left(\mathrm{ft}^{3} / \mathrm{s}\right)\end{array}$ & $\begin{array}{c}\text { Gage } \\
\text { height } \\
\text { (ft) }\end{array}$ \\
\hline $\begin{array}{l}1917 \\
1918 \\
1919 \\
1920 \\
1921\end{array}$ & $\begin{array}{l}\text { Mar. } 24 \\
\text { Jan. } 28 \\
\text { Dec. } 22 \\
\text { Dec. } 09 \\
\text { Feb. } 10\end{array}$ & $\begin{array}{r}17,600 \\
7,410 \\
19,600 \\
10,200 \\
5,100\end{array}$ & $\begin{array}{r}14.00 \\
8.00 \\
15.00 \\
9.90 \\
6.30\end{array}$ & $\begin{array}{l}1922 \\
1923 \\
1924 \\
1925\end{array}$ & $\begin{array}{l}\text { Jan. } 21 \\
\text { Dec. } 17 \\
\text { Sept. } 20 \\
\text { Dec. } 08\end{array}$ & $\begin{array}{r}7,690 \\
6,610 \\
11,500 \\
4,840\end{array}$ & $\begin{array}{r}8.20 \\
7.43 \\
10.68 \\
6.10\end{array}$ & $\begin{array}{l}1926 \\
1927 \\
1928 \\
1929\end{array}$ & $\begin{array}{l}\text { Jan. } 18 \\
\text { Dec. } 26 \\
\text { Aug. } 15 \\
\text { Sept. } 26\end{array}$ & $\begin{array}{r}7,760 \\
4,470 \\
22,400 \\
14,200\end{array}$ & $\begin{array}{r}8.25 \\
5.78 \\
16.40 \\
12.30\end{array}$ \\
\hline
\end{tabular}


LOCATION.--Lat $34^{\circ} 53^{\prime} 25^{\prime \prime}$, long $83^{\circ} 31^{\prime} 50^{\prime \prime}$, Rabun County, on right bank $100 \mathrm{ft}$ downstream from county highway bridge, $120 \mathrm{ft}$ downstream from Persimmon Creek, 8 mi upstream from Burton Dam, and 10.3 mi west of Clayton.

DRAINAGE AREA.--56.5 $\mathrm{mi}^{2}$.

GAGE.-Water-stage recorder. Datum of gage is $1,868.93 \mathrm{ft}$ above sea level (levels by Georgia Department of Transportation). STAGE-DISCHARGE RELATION.--Defined by current-meter measurements below $5,600 \mathrm{tt}^{3} / \mathrm{s}$, and extended above on basis of contracted-area and slope-area estimates at $7,500 \mathrm{ft}^{3} / \mathrm{s}$. Bankfull stage and discharge, $6 \mathrm{ft}$ and 2,100 $\mathrm{ft}^{3} / \mathrm{s}$.

REMARKS.--Peak discharges for 1965-66 and 1973-74 are estimated. Flood of May 28, 1973 was highest since 1940 based on information of nearby stations.

\begin{tabular}{|c|c|c|c|c|c|c|c|c|c|c|c|}
\hline $\begin{array}{l}\text { Water } \\
\text { year }\end{array}$ & Date & $\begin{array}{c}\text { Discharge } \\
\left(\mathrm{ft}^{3} / \mathrm{s}\right) \\
.\end{array}$ & $\begin{array}{c}\text { Gage } \\
\text { height } \\
\text { (ft) }\end{array}$ & $\begin{array}{l}\text { Water } \\
\text { year }\end{array}$ & Date & $\begin{array}{c}\text { Discharge } \\
\left(\mathrm{ft}^{3} / \mathrm{s}\right)\end{array}$ & $\begin{array}{c}\text { Gage } \\
\text { height } \\
\text { (ft) }\end{array}$ & $\begin{array}{l}\text { Water } \\
\text { year }\end{array}$ & Date & $\begin{array}{c}\text { Discharge } \\
\left(\mathrm{ft}^{3} / \mathrm{s}\right)\end{array}$ & $\begin{array}{c}\text { Gage } \\
\text { height } \\
\text { (ft) }\end{array}$ \\
\hline $\begin{array}{l}1965 \\
1966 \\
1967 \\
1968 \\
1969 \\
1970 \\
1971 \\
1972 \\
1973\end{array}$ & $\begin{array}{l}\text { Oct. } 04 \\
\text { Feb. } 13 \\
\text { Aug. } 23 \\
\text { Mar. } 12 \\
\text { June } 15 \\
\text { Dec. } 30 \\
\text { Feb. } 22 \\
\text { Dec. } 07 \\
\text { May } 28\end{array}$ & $\begin{array}{r}7,440 \\
5,140 \\
2,800 \\
3,100 \\
2,470 \\
2,010 \\
976 \\
2,160 \\
8,500\end{array}$ & $\begin{array}{r}11.12 \\
9.17 \\
6.84 \\
7.18 \\
6.48 \\
5.93 \\
4.41 \\
6.11 \\
12.00\end{array}$ & $\begin{array}{l}1974 \\
1975 \\
1976 \\
1977 \\
1978 \\
1979 \\
1980 \\
1981 \\
1982\end{array}$ & $\begin{array}{l}\text { Dec. } 26 \\
\text { Mar. } 13 \\
\text { May } 15 \\
\text { Mar. } 30 \\
\text { Nov. } 05 \\
\text { Mar. } 04 \\
\text { Mar. } 21 \\
\text { May } 27 \\
\text { Feb. } 03\end{array}$ & $\begin{array}{l}4,660 \\
2,410 \\
6,530 \\
3,580 \\
4,090 \\
6,240 \\
2,880 \\
1,600 \\
1,960\end{array}$ & $\begin{array}{r}8.74 \\
6.47 \\
10.36 \\
7.68 \\
8.24 \\
10.12 \\
6.93 \\
5.35 \\
5.88\end{array}$ & $\begin{array}{l}1983 \\
1984 \\
1985 \\
1986 \\
1987 \\
1988 \\
1989 \\
1990\end{array}$ & $\begin{array}{l}\text { Feb. } 02 \\
\text { Feb. } 14 \\
\text { Aug. } 17 \\
\text { May } 27 \\
\text { Nov. } 26 \\
\text { Jan. } 20 \\
\text { June } 20 \\
\text { Feb. } 16\end{array}$ & $\begin{array}{r}3,260 \\
2,000 \\
1,010 \\
980 \\
3,510 \\
2,110 \\
3,500 \\
4,900\end{array}$ & $\begin{array}{l}7.41 \\
5.96 \\
4.47 \\
4.42 \\
7.69 \\
6.08 \\
7.68 \\
9.00\end{array}$ \\
\hline
\end{tabular}

\section{LITTLE PANTHER CREEK NEAR TALLULAH FALLS, GEORGIA}

LOCATION.--Lat $34^{\circ} 42^{\prime} 48^{\prime \prime}$, long $83^{\circ} 24^{\prime} 07^{\prime \prime}$, Habersham County, at culvert on U.S. Highway $441,1.3$ mi southwest of Tallulah Falls. DRAINAGE AREA.--2.5 $\mathrm{mi}^{2}$.

GAGE.--Crest-stage gage prior to Jan. 12, 1967; flood-stage/rainfall recorder thereafter. Datum of gage is about $1,530 \mathrm{ft}$ above sea level (from topographic map).

STAGE-DISCHARGE RELATION.--Defined by current-meter measurements below $60 \mathrm{ft}^{3} / \mathrm{s}$, and extended above on basis of culvert computations.

REMARKS.--Flood of June 16, 1949, was highest since 1927 based on information at nearby stations.

\begin{tabular}{|c|c|c|c|c|c|c|c|c|c|c|c|}
\hline $\begin{array}{l}\text { Water } \\
\text { year }\end{array}$ & Date & $\begin{array}{c}\text { Discharge } \\
\left(\mathrm{ft}^{3} / \mathrm{s}\right)\end{array}$ & $\begin{array}{c}\text { Gage } \\
\text { height } \\
\text { (ft) }\end{array}$ & $\begin{array}{l}\text { Water } \\
\text { year }\end{array}$ & Date & $\begin{array}{c}\text { Discharge } \\
\left(\mathrm{ft}^{3} / \mathrm{s}\right)\end{array}$ & $\begin{array}{c}\text { Gage } \\
\text { height } \\
\text { (ft) }\end{array}$ & $\begin{array}{l}\text { Water } \\
\text { year }\end{array}$ & Date & $\begin{array}{c}\text { Discharge } \\
\left(\mathrm{ft}^{3} / \mathrm{s}\right)\end{array}$ & $\begin{array}{c}\text { Gage } \\
\text { height } \\
\text { (ft) }\end{array}$ \\
\hline $\begin{array}{l}1949 \\
1956 \\
1957 \\
1958 \\
1959 \\
1960 \\
1961\end{array}$ & $\begin{array}{l}\text { June } 16 \\
\text { Apr. } 14 \\
\text { Apr. } 05 \\
\text { Nov. } 19 \\
\text { May } 31 \\
\text { Apr. } 12 \\
\text { Feb. } 25\end{array}$ & $\begin{array}{r}710 \\
78.0 \\
48.0 \\
61.0 \\
92.0 \\
48.0 \\
124\end{array}$ & $\begin{array}{c}11.10 \mathrm{c} \\
8.20 \\
7.90 \\
8.05 \\
8.30 \\
7.90 \\
8.50\end{array}$ & $\begin{array}{l}1962 \\
1963 \\
1964 \\
1965 \\
1966 \\
1967 \\
1968\end{array}$ & $\begin{array}{l}\text { Dec. } 11 \\
\text { Mar. } 12 \\
\text { Jan. } 24 \\
\text { Oct. } 04 \\
\text { Feb. } 13 \\
\text { June } 04 \\
\text { Mar. } 12\end{array}$ & $\begin{array}{l}183 \\
585 \\
194 \\
138 \\
258 \\
319 \\
78.0\end{array}$ & $\begin{array}{r}8.85 \\
10.64 \\
8.91 \\
8.59 \\
9.24 \\
9.54 \\
8.20\end{array}$ & $\begin{array}{l}1969 \\
1970 \\
1971 \\
1972 \\
1973 \\
\frac{1974}{1976}\end{array}$ & $\begin{array}{l}\text { June } 10 \\
\text { Mar. -- } \\
\text { Mar. } 03 \\
\text { May } 14 \\
\text { May } 27 \\
\text { Dec. } 31 \\
\text { May } 29\end{array}$ & $\begin{array}{r}183 \\
30.0 \\
57.0 \\
176 \\
678 \\
43.0 \\
300\end{array}$ & $\begin{array}{c}8.86 \\
--b \\
8.01 \\
8.81 \\
11.01 \\
7.84 \\
9.45 c\end{array}$ \\
\hline
\end{tabular}


LOCATION.--Lat $34^{\circ} 40^{\prime} 40^{\prime \prime}$, long $83^{\circ} 20^{\prime} 43^{\prime \prime}$, Stephens County, on left bank at Yonah Dam Settlement, 0.2 mi upstream from mouth, and 7 mi north of TOccoa.

DRAINAGE AREA.--32.5 $\mathrm{mi}^{2}$.

GAGE.--Water-stage recorder prior to 1972; crest-stage gage thereafter. Datum of gage is $673.53 \mathrm{ft}$ above sea level (levels by Georgia Power Company).

STAGE-DISCHARGE RELATION.--Defined by current-meter measurements below $800 \mathrm{tt}^{3} / \mathrm{s}$, and extended above on basis of slope-area measurements at $2,500,5,500$, and $15,000 \mathrm{tt}^{3} / \mathrm{s}$. Bankfull stage and discharge, $10 \mathrm{ft}$ and $3,350 \mathrm{ft}^{3} / \mathrm{s}$.

REMARKS.--Gage-height record prior to 1943 furnished by Georgia Power Company.

\begin{tabular}{|c|c|c|c|c|c|c|c|c|c|c|c|}
\hline $\begin{array}{l}\text { Water } \\
\text { year }\end{array}$ & Date & $\begin{array}{c}\text { Discharge } \\
\left(\mathrm{ft}^{3} / \mathrm{s}\right)\end{array}$ & $\begin{array}{c}\text { Gage } \\
\text { height } \\
\text { (ft) }\end{array}$ & $\begin{array}{l}\text { Water } \\
\text { year }\end{array}$ & Date & $\begin{array}{c}\text { Discharge } \\
\left(\mathrm{ft}^{3} / \mathrm{s}\right)\end{array}$ & $\begin{array}{c}\text { Gage } \\
\text { height } \\
\text { (ft) }\end{array}$ & $\begin{array}{l}\text { Water } \\
\text { year }\end{array}$ & Date & $\begin{array}{c}\text { Discharge } \\
\left(\mathrm{ft}^{3} / \mathrm{s}\right)\end{array}$ & $\begin{array}{c}\text { Gage } \\
\text { height } \\
\text { (ft) }\end{array}$ \\
\hline $\begin{array}{l}1927 \\
1928 \\
1929 \\
1930 \\
1931 \\
1932 \\
1933 \\
1934 \\
1935 \\
1936 \\
1937 \\
1938 \\
1939 \\
1940 \\
1941 \\
1942 \\
1943\end{array}$ & $\begin{array}{l}\text { Feb. } 23 \\
\text { Aug. } 15 \\
\text { Sept. } 25 \\
\text { Mar. } 08 \\
\text { Nov. } 16 \\
\text { Dec. } 14 \\
\text { Oct. } 16 \\
\text { June } 06 \\
\text { Oct. } 06 \\
\text { Sept.29 } \\
\text { Dec. } 31 \\
\text { Oct. } 18 \\
\text { Aug. } 17 \\
\text { Aug. } 13 \\
\text { July } 07 \\
\text { Feb. } 16 \\
\text { Apr. } 19\end{array}$ & $\begin{array}{r}1,050 \\
3,500 \\
3,500 \\
650 \\
385 \\
1,710 \\
2,290 \\
3,420 \\
2,780 \\
13,500 \\
1,470 \\
2,150 \\
7,750 \\
4,540 \\
2,360 \\
3,910 \\
2,180\end{array}$ & $\begin{array}{r}4.70 \\
8.40 \\
8.40 \\
3.80 \\
3.10 \\
5.90 \\
6.80 \\
8.30 \\
7.50 \\
17.00 \\
5.50 \\
6.60 \\
12.70 \\
9.60 \\
6.90 \\
8.90 \\
6.80\end{array}$ & $\begin{array}{l}1944 \\
1945 \\
1946 \\
1947 \\
1948 \\
1949 \\
1950 \\
1951 \\
1952 \\
1953 \\
1954 \\
1955 \\
1956 \\
1957 \\
1958 \\
1959 \\
1960\end{array}$ & $\begin{array}{l}\text { Mar. } 19 \\
\text { Sept. } 16 \\
\text { Jan. } 06 \\
\text { Jan. } 20 \\
\text { July } 11 \\
\text { June } 16 \\
\text { June } 08 \\
\text { Oct. } 20 \\
\text { Mar. } 11 \\
\text { July } 22 \\
\text { Jan. } 22 \\
\text { Feb. } 06 \\
\text { Apr. } 15 \\
\text { Apr. } 04 \\
\text { Nov. } 19 \\
\text { May } 31 \\
\text { Feb. } 05\end{array}$ & $\begin{array}{r}2,430 \\
814 \\
5,440 \\
1,660 \\
2,430 \\
15,100 \\
1,020 \\
810 \\
3,500 \\
3,740 \\
2,570 \\
2,010 \\
1,150 \\
810 \\
592 \\
1,530 \\
1,000\end{array}$ & $\begin{array}{r}7.20 \\
4.18 \\
11.30 \\
5.90 \\
7.00 \\
18.00 \\
4.67 \\
4.18 \\
8.40 \\
8.78 \\
7.20 \\
6.40 \\
4.85 \\
4.20 \\
3.65 \\
5.60 \\
4.60\end{array}$ & $\begin{array}{l}1961 \\
1962 \\
1963 \\
1964 \\
1965 \\
1966 \\
1967 \\
1968 \\
1969 \\
1970 \\
1971 \\
1972 \\
1973 \\
1974 \\
1975 \\
1976 \\
1978\end{array}$ & $\begin{array}{l}\text { Feb. } 25 \\
\text { Dec. } 12 \\
\text { Mar. } 12 \\
\text { Jan. } 25 \\
\text { Oct. } 04 \\
\text { Feb. } 13 \\
\text { June } 04 \\
\text { Mar. } 12 \\
\text { Feb. } 02 \\
\text { Nov. } 02 \\
\text { July } 31 \\
\text { May } 14 \\
\text { May } 28 \\
\text { July } 07 \\
\text { Mar. } 13 \\
\text { May } 29 \\
\text { Nov. } 05\end{array}$ & $\begin{array}{r}2,220 \\
2,110 \\
5,680 \\
2,480 \\
4,260 \\
3,660 \\
5,030 \\
860 \\
2,640 \\
290 \\
574 \\
1,990 \\
6,460 \\
975 \\
12,200 \\
4,000 \\
5,300\end{array}$ & $\begin{array}{r}6.70 \\
6.54 \\
11.64 \\
7.15 \\
9.79 \\
8.95 \\
10.79 \\
4.32 \\
7.49 \\
2.83 \\
3.62 \\
6.36 \\
12.46 \\
4.55 \\
16.73 \\
9.42 \\
11.16\end{array}$ \\
\hline
\end{tabular}

\section{TUGALOO RIVER NEAR HARTWELL, GEORGIA}

LOCATION.--Lat $34^{\circ} 29^{\prime} 06^{\prime \prime}$, long $82^{\circ} 54^{\prime} 33^{\prime \prime}$, Hart County, on right bank 0.75 mi upstream from Beaverdam Creek, 5 mi upstream from confluence with Seneca River, and 10 mi north of Hartwell.

DRAINAGE AREA.--909 $\mathrm{mi}^{2}$.

GAGE.--Water-stage recorder. Datum of gage is about $570 \mathrm{ft}$ above sea level (by barometer). April 1925 to September 1927 at datum about $1 \mathrm{ft}$ higher.

STAGE-DISCHARGE RELATION.--Defined by current-meter measurements below $28,000 \mathrm{ft}^{3} / \mathrm{s}$.

REMARKS.--The peak discharges have minor regulations from powerplants above station and from Lake Burton and Mathis

Reservoir on the Tallulah River. Lake Burton (maximum flood-control storage, 106,000 acre-ft) completed in 1926, and Mathis Reservoir (maximum flood-control storage, 23,000 acre-ft) completed in 1914, regulate the flow from $150 \mathrm{mi}^{2}$ of Tallulah River basin. Station inundated by Hartwell Reservoir since October 1959.

\begin{tabular}{|c|c|c|c|c|c|c|c|c|c|c|c|}
\hline $\begin{array}{l}\text { Water } \\
\text { year }\end{array}$ & Date & $\begin{array}{c}\text { Discharge } \\
\left(\mathrm{ft}^{3} / \mathrm{s}\right)\end{array}$ & $\begin{array}{l}\text { Gage } \\
\text { height } \\
\text { (ft) }\end{array}$ & $\begin{array}{l}\text { Water } \\
\text { year }\end{array}$ & Date & $\begin{array}{c}\text { Discharge } \\
\left(\mathrm{ft}^{3} / \mathrm{s}\right)\end{array}$ & $\begin{array}{c}\text { Gage } \\
\text { height } \\
\text { (ft) }\end{array}$ & $\begin{array}{l}\text { Water } \\
\text { year }\end{array}$ & Date & $\begin{array}{c}\text { Discharge } \\
\left(\mathrm{ft}^{3} / \mathrm{s}\right)\end{array}$ & $\begin{array}{c}\text { Gage } \\
\text { height } \\
\text { (ft) }\end{array}$ \\
\hline $\begin{array}{l}1926 \\
1927 \\
1940 \\
1941 \\
1942 \\
1943 \\
1944 \\
1945\end{array}$ & $\begin{array}{l}\text { Jan. } 18 \\
\text { Dec. } 29 \\
\text { Aug. } 31 \\
\text { July } 07 \\
\text { Feb. } 17 \\
\text { Dec. } 29 \\
\text { Mar. } 20 \\
\text { Feb. } 23\end{array}$ & $\begin{array}{r}18,200 \\
9,140 \\
28,600 \\
13,200 \\
20,500 \\
17,400 \\
18,800 \\
8,600\end{array}$ & $\begin{array}{r}8.76 \\
6.67 \\
10.80 \\
7.80 \\
9.40 \\
8.70 \\
8.96 \\
6.55\end{array}$ & $\begin{array}{l}1946 \\
1947 \\
1948 \\
1949 \\
1950 \\
1951 \\
1952 \\
1953\end{array}$ & $\begin{array}{l}\text { Jan. } 07 \\
\text { Jan. } 20 \\
\text { July } 13 \\
\text { June } 17 \\
\text { Sept.09 } \\
\text { Oct. } 20 \\
\text { Mar. } 11 \\
\text { Feb. } 21\end{array}$ & $\begin{array}{l}25,400 \\
15,200 \\
18,800 \\
27,800 \\
12,800 \\
15,300 \\
25,100 \\
15,300\end{array}$ & $\begin{array}{r}10.30 \\
8.25 \\
8.98 \\
10.40 \\
7.61 \\
8.22 \\
10.00 \\
8.25\end{array}$ & $\begin{array}{l}1954 \\
1955 \\
1956 \\
1957 \\
1958 \\
1959 \\
1960\end{array}$ & $\begin{array}{l}\text { Jan. } 16 \\
\text { Feb. } 07 \\
\text { Apr. } 16 \\
\text { Apr. } 05 \\
\text { Nov. } 19 \\
\text { June } 01 \\
\text { Feb. } 06\end{array}$ & $\begin{array}{l}19,200 \\
18,200 \\
12,800 \\
16,700 \\
10,300 \\
12,800 \\
12,400\end{array}$ & $\begin{array}{l}8.98 \\
8.67 \\
7.64 \\
8.50 \\
6.90 \\
7.60 \\
7.60\end{array}$ \\
\hline
\end{tabular}


LOCATION.-Lat $34^{\circ} 15^{\prime} 20^{\prime \prime}$, long $82^{\circ} 44^{\prime} 42^{\prime \prime}$, Anderson County, on left bank at downstream side of bridge on State Highway 184 , $0.5 \mathrm{mi}$ upstream from Littie Generostee Creek, $5.8 \mathrm{mi}$ southwest of Iva, and at mile 296.5.

DRAINAGE AREA,--2,231 $\mathrm{mi}^{2}$.

GAGE.--Recording. Datum of gage is $432.26 \mathrm{ft}$ above sea level (levels by U.S. Army Corps of Engineers).

STAGE-DISCHARGE RELATION.--Defined by current-meter measurements.

REMARKS.--Peak discharges regulated by storage in Hartwell Reservoir (maximum flood-control storage, 1,708,600 acre-ft) subsequent to 1959. Minor regulation from Lake Burton and Mathis Reservoir. (See station 0218400.)

\begin{tabular}{|c|c|c|c|c|c|c|c|c|c|c|c|}
\hline $\begin{array}{l}\text { Water } \\
\text { year }\end{array}$ & Date & $\begin{array}{c}\text { Discharge } \\
\left(\mathrm{ft}^{3} / \mathrm{s}\right)\end{array}$ & $\begin{array}{c}\text { Gage } \\
\text { height } \\
\text { (ft) }\end{array}$ & $\begin{array}{l}\text { Water } \\
\text { year }\end{array}$ & Date & $\begin{array}{c}\text { Discharge } \\
\left(\mathrm{ft}^{3} / \mathrm{s}\right)\end{array}$ & $\begin{array}{c}\text { Gage } \\
\text { height } \\
\text { (ft) }\end{array}$ & $\begin{array}{l}\text { Water } \\
\text { year }\end{array}$ & Date & $\begin{array}{l}\text { Discharge } \\
\left(\mathrm{ft}^{3} / \mathrm{s}\right)\end{array}$ & $\begin{array}{c}\text { Gage } \\
\text { height } \\
\text { (ft) }\end{array}$ \\
\hline $\begin{array}{l}1950 \\
1951 \\
1952 \\
1953 \\
1954 \\
1955 \\
1956 \\
1957 \\
1958 \\
1959 \\
1960\end{array}$ & $\begin{array}{l}\text { Oct. } 08 \\
\text { Oct. } 21 \\
\text { Mar. } 12 \\
\text { Feb. } 22 \\
\text { Jan. } 16 \\
\text { Feb. } 07 \\
\text { Apr. } 16 \\
\text { Apr. } 06 \\
\text { Nov. } 19 \\
\text { Apr. } 13 \\
\text { Apr. } 06\end{array}$ & $\begin{array}{l}27,500 \\
27,200 \\
54,400 \\
36,800 \\
44,200 \\
34,000 \\
31,200 \\
34,800 \\
32,000 \\
22,000 \\
12,300\end{array}$ & \begin{tabular}{r}
\multicolumn{1}{c}{} \\
8.98 \\
12.74 \\
10.44 \\
11.28 \\
10.04 \\
9.65 \\
10.08 \\
9.67 \\
8.22 \\
6.16
\end{tabular} & $\begin{array}{l}1961 \\
1962 \\
1963 \\
1964 \\
1965 \\
1966 \\
1967 \\
1968 \\
1969 \\
1970 \\
1971\end{array}$ & $\begin{array}{l}\text { Mar. } 07 \\
\text { Dec. } 18 \\
\text { Apr. } 30 \\
\text { Apr. } 08 \\
\text { Oct. } 05 \\
\text { Mar. } 04 \\
\text { June } 06 \\
\text { Jan. } 12 \\
\text { May } 02 \\
\text { July } 29 \\
\text { Mar. } 03\end{array}$ & $\begin{array}{l}10,400 \\
21,200 \\
21,400 \\
44,300 \\
29,500 \\
35,000 \\
30,800 \\
29,000 \\
28,100 \\
28,600 \\
31,300\end{array}$ & $\begin{array}{r}5.79 \\
7.89 \\
7.86 \\
11.25 \\
8.87 \\
9.79 \\
8.88 \\
8.58 \\
8.44 \\
8.51 \\
8.96\end{array}$ & $\begin{array}{l}1972 \\
1973 \\
1974 \\
1975 \\
1976 \\
1977 \\
1978 \\
1979 \\
1980 \\
1981\end{array}$ & $\begin{array}{l}\text { Jan. } 07 \\
\text { Dec. } 15 \\
\text { Aug. } 09 \\
\text { Mar. } 13 \\
\text { Mar. } 31 \\
\text { Mar. } 30 \\
\text { Jan. } 25 \\
\text { Apr. } 13 \\
\text { Mar. } 28 \\
\text { July } 24\end{array}$ & $\begin{array}{l}31,000 \\
32,000 \\
28,100 \\
33,700 \\
29,600 \\
28,800 \\
31,300 \\
33,300 \\
30,500 \\
27,800\end{array}$ & $\begin{array}{l}8.43 \\
8.57 \\
8.01 \\
8.82 \\
8.23 \\
8.12 \\
8.47 \\
8.73 \\
8.36 \\
7.99\end{array}$ \\
\hline
\end{tabular}

02188500 BEAVERDAM CREEK AT DEWY ROSE, GEORGIA

(Formerly published as "South Beaverdam Creek at Dewy Rose, Georgia")

LOCATION.--Lat $34^{\circ} 10^{\prime} 52^{\prime \prime}$, long $82^{\circ} 56^{\prime} 38^{\prime \prime}$, Elbert County, on left bank $50 \mathrm{ft}$ upstream from highway bridge, 1 mi northeast of Dewy Rose, and 3 mi upstream from confluence with North Beaverdam Creek. DRAINAGE AREA.--35.8 $\mathrm{mi}^{2}$.

GAGE.--Water-stage recorder. Datum of gage is $581.07 \mathrm{ft}$ above sea level, supplementary adjustment of 1936 (from U.S. Coast and Geodetic Survey benchmark). Prior to Nov. 20,1952, nonrecording gage at same site and datum.

STAGE-DISCHARGE RELATION.--Defined by current-meter measurements below $2,300 \mathrm{ft}^{3} / \mathrm{s}$, and extended above on basis of slope-area measurements at $6,570 \mathrm{ft}^{3} / \mathrm{s}$. Bankfull and stage discharge, $12 \mathrm{ft}$ and $2,900 \mathrm{ft}^{3} / \mathrm{s}$.

HISTORICAL DATA.--Flood-stage of Aug. 25, 1852 and Aug. 25, 1908, based on information furnished by local resident. Flood-peak of Aug. 15, 1928, determined from floodmark. Flood of June 4, 1967, was highest since 1908 based on information furnished by local resident.

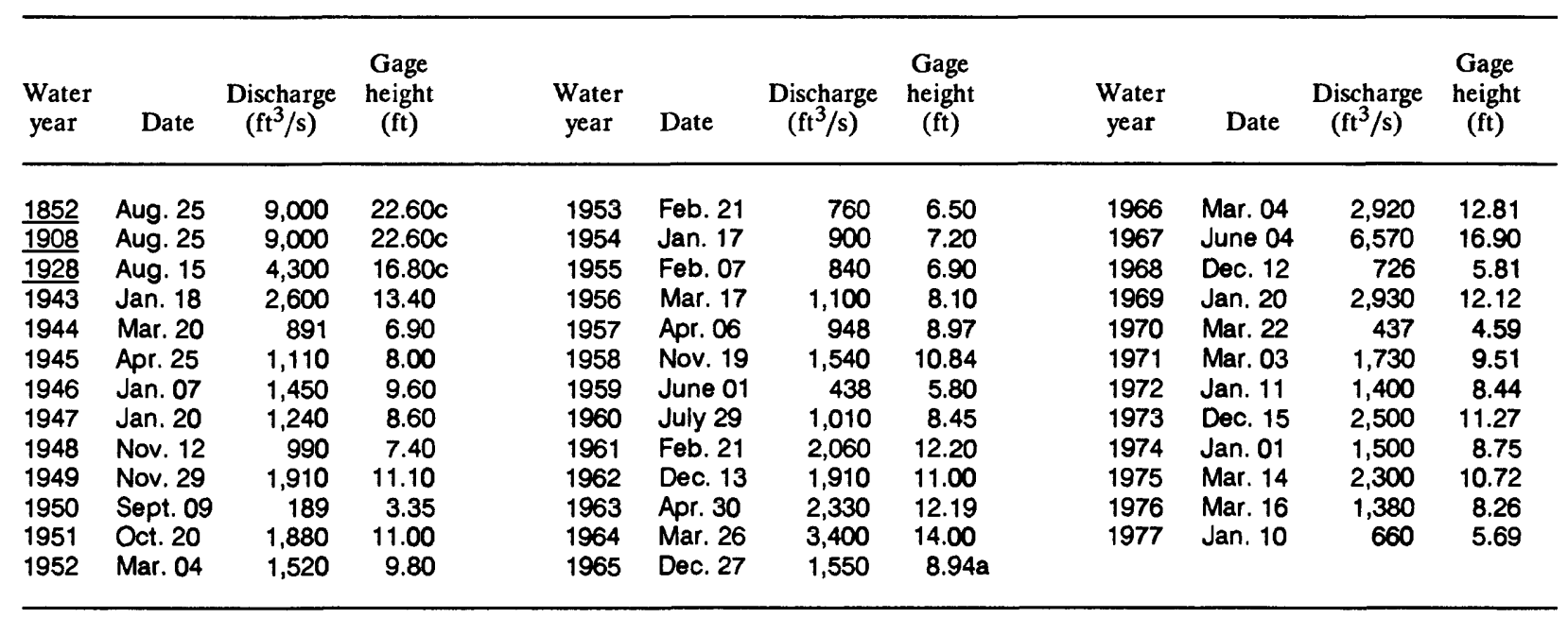




\section{SAVANNAH RIVER BASIN}

\section{SAVANNAH RIVER NEAR CALHOUN FALLS, SOUTH CAROLINA}

LOCATION.--Lat $34^{\circ} 04^{\prime} 15^{\prime \prime}$, long $82^{\circ} 38^{\prime} 30^{\prime \prime}$, Abbeville County, on left bank $150 \mathrm{ft}$ upstream from bridge on State Highway $72,1.0$ mi downstream from Seaboard Coast Line Railroad bridge, 1.5 mi downstream from Rocky River, 3.0 southwest of Calhoun Falls, and at mile 279.7.

DRAINAGE AREA.--2,876 $\mathrm{mi}^{2}$. At site used prior to Mar. 13, 1930

$, 2,712 \mathrm{mi}^{2}$.

GAGE.--Nonrecording gage prior to Mar. 13, 1930; recording Mar. 13, 1930 to July 30, 1932; nonrecording July 31,1932 to Mar. 31 , 1938; recording thereafter. Datum of gage is $363.53 \mathrm{ft}$ above sea level. At site $1 \mathrm{mi}$ upstream at datum $5.5 \mathrm{ft}$ higher prior to July 1, 1928. At or near present site at datum $2 \mathrm{ft}$ higher from July 1, 1928 to Mar. 12, 1930.

STAGE-DISCHARGE RELATION.--Defined by current-meter measurements below $14,000 \mathrm{ft}^{3} / \mathrm{s}$ at former site. Peak discharges for 1904-1927 are from rating table based on discharge measurements made 1896-1903. Defined by current-meter measurements below $50,000 \mathrm{ft}^{3} / \mathrm{s}$, and extended above on basis of area-velocity studies and logarithmic plotting at present site.

REMARKS.--Peak discharges regulated by storage in Hartwell Reservoir (maximum flood-control storage, 1,708,600 acre-ft) subsequent to 1959. Minor regulation from Lake Burton and Mathis Reservoir. (See station 0218400.) Gage height, Jan. 1, 1904 to Mar. 12, 1930, and from July 31, 1932 to Mar. 31, 1938, from graphs based on gage readings by the U.S. Weather Bureau. Records for Mar. 13, 1930, to July 30, 1932, furnished by Commonwealth and Southern Corporation in connection with a Federal Power Commission license.

\begin{tabular}{|c|c|c|c|c|c|c|c|c|c|c|c|}
\hline $\begin{array}{l}\text { Water } \\
\text { year }\end{array}$ & Date & $\begin{array}{c}\text { Discharge } \\
\left(\mathrm{ft}^{3} / \mathrm{s}\right)\end{array}$ & $\begin{array}{c}\text { Gage } \\
\text { height } \\
\text { (ft) }\end{array}$ & $\begin{array}{l}\text { Water } \\
\text { year }\end{array}$ & Date & $\begin{array}{c}\text { Discharge } \\
\left(\mathrm{ft}^{3} / \mathrm{s}\right)\end{array}$ & $\begin{array}{c}\text { Gage } \\
\text { height } \\
\text { (ft) }\end{array}$ & $\begin{array}{l}\text { Water } \\
\text { year }\end{array}$ & Date & $\begin{array}{c}\text { Discharge } \\
\left(\mathrm{ft}^{3} / \mathrm{s}\right)\end{array}$ & $\begin{array}{c}\text { Gage } \\
\text { height } \\
(\mathrm{ft})\end{array}$ \\
\hline$\underline{1897}$ & Apr. 05 & 57,400 & $15.30 \mathrm{c}$ & 1926 & Jan. 19 & 28,300 & 8.60 & 1953 & Feb. 22 & 38,400 & 6.94 \\
\hline 1900 & Feb. 14 & 76,500 & 19.70 & $\underline{1927}$ & Dec. 29 & $\underline{27,800}$ & $\underline{8.50}$ & 1954 & Jan. 17 & 44,600 & 7.44 \\
\hline 1901 & Sept.18 & 66,500 & 17.40 & 1928 & Aug. 17 & 130,000 & 11.90 & 1955 & Feb. 07 & 40,200 & 6.89 \\
\hline 1902 & Feb. 28 & 76,100 & 19.60 & 1929 & Sept.27 & 85,400 & 8.70 & 1956 & Sept.26 & 40,200 & 7.02 \\
\hline 1903 & June 07 & 57,800 & 15.40 & 1930 & Oct. 02 & 105,000 & $\underline{10.10}$ & 1957 & Apr. 06 & 38,100 & 6.79 \\
\hline 1904 & Aug. 09 & 33,900 & 9.90 & 1931 & Apr. 23 & 15,800 & 4.22 & 1958 & Nov. 19 & 38,100 & 6.76 \\
\hline 1905 & July 02 & 47,400 & 13.00 & 1932 & Dec. 04 & 41,400 & 7.10 & 1959 & June 02 & 32,800 & 6.41 \\
\hline 1906 & Mar. 20 & 42,200 & 11.80 & 1933 & Oct. 17 & 97,600 & 11.60 & 1960 & Feb. 13 & 19,600 & 5.03 \\
\hline 1907 & Oct. 04 & 33,900 & 9.90 & 1934 & June 05 & 39,400 & 7.00 & 1961 & Mar. 08 & 17,400 & 4.79 \\
\hline 1908 & Aug. 25 & 114,000 & 28.20 & 1935 & Jan. 10 & 29,400 & 6.00 & 1962 & Dec. 19 & 26,000 & 5.62 \\
\hline 1909 & June 04 & 43,900 & 12.20 & 1936 & Apr. 07 & 96,200 & 11.50 & 1963 & Apr. 30 & 30,900 & 6.12 \\
\hline 1910 & Mar. 01 & 45,200 & 12.50 & 1937 & Oct. 01 & 63,000 & 9.00 & 1964 & Apr. 08 & 60,000 & 8.08 \\
\hline 1911 & Jan. 04 & 23,500 & 7.50 & 1938 & Oct. 20 & 53,100 & 8.20 & 1965 & Oct. 06 & 44,800 & 6.91 \\
\hline 1912 & Mar. 16 & 75,700 & 19.50 & 1939 & Aug. 19 & 49,600 & 7.88 & 1966 & Mar. 04 & 52,500 & 7.50 \\
\hline 1913 & Mar. 15 & 48,300 & 13.20 & 1940 & Aug. 13 & 96,500 & 11.52 & 1967 & June 05 & 39,900 & 6.76 \\
\hline 1914 & Dec. 30 & 22,200 & 7.20 & 1941 & July 07 & 36,300 & 6.70 & 1968 & Jan. 10 & 33,200 & 6.17 \\
\hline 1915 & July 01 & 38,300 & 10.90 & 1942 & Feb. 18 & 47,200 & 7.73 & 1969 & Jan. 20 & 43,400 & 7.04 \\
\hline 1916 & Dec. 30 & 44,800 & 12.40 & 1943 & Jan. 18 & 53,100 & 8.21 & 1970 & July 29 & 32,000 & 5.89 \\
\hline 1917 & Mar. 25 & 40,000 & 11.30 & 1944 & Mar. 20 & 49,500 & 7.91 & 1971 & Mar. 04 & 45,600 & 6.97 \\
\hline 1918 & Aug. 03 & 26,100 & 8.10 & 1945 & Apr. 25 & 33,300 & 6.40 & 1972 & Jan. 10 & 35,700 & 6.20 \\
\hline 1919 & Dec. 23 & 59,100 & 15.70 & 1946 & Jan. 08 & 68,400 & 9.41 & 1973 & Dec. 16 & 43,400 & 6.80 \\
\hline 1920 & Dec. 10 & 63,100 & 16.60 & 1947 & Jan. 20 & 44,800 & 7.47 & 1974 & Apr. 05 & 31,400 & 5.84 \\
\hline 1921 & Feb. 09 & 51,800 & 14.00 & 1948 & Mar. 07 & 29,800 & 6.11 & 1975 & Mar. 14 & 47,100 & 7.32 \\
\hline 1922 & Mar. 11 & 34,800 & 10.10 & 1949 & Nov. 29 & 61,800 & 8.94 & 1976 & Mar. 16 & 39,400 & 6.72 \\
\hline 1923 & Dec. 19 & 35,700 & 10.30 & 1950 & Oct. 08 & 29,400 & 5.98 & 1977 & Mar. 30 & 35,200 & 6.35 \\
\hline 1924 & Sept.21 & 40,000 & 11.30 & 1951 & Oct. 21 & 28,800 & 5.98 & 1978 & Jan. 26 & 45,000 & 7.16 \\
\hline 1925 & Jan. 19 & 31,700 & 9.40 & 1952 & Mar. 24 & 58,000 & 8.65 & & & & \\
\hline
\end{tabular}


LOCATION.--Lat $34^{\circ} 21^{\prime} 19^{\prime \prime}$, long $83^{\circ} 17^{\prime} 16^{\prime \prime}$, Franklin County, at culvert on State Highway 59, 3.2 mi west of Carnesville.

DRAINAGE AREA.-7.63 $\mathrm{mi}^{2}$.

GAGE.--Flood-stage/rainfall recorder. Datum of gage is about $635 \mathrm{ft}$ above sea level (from topographic map).

STAGE-DISCHARGE RELATION.--Defined by current-meter measurements below $700 \mathrm{ft}^{3} / \mathrm{s}$, and extended above on basis of areavelocity determinations. Bankfull stage and discharge, $7 \mathrm{ft}$ and $850 \mathrm{ft}^{3} / \mathrm{s}$.

REMARKS.--Flood of May 29, 1976 was highest since 1961, based on comparison with nearby stations.

\begin{tabular}{|c|c|c|c|c|c|c|c|c|c|c|c|}
\hline $\begin{array}{l}\text { Water } \\
\text { year }\end{array}$ & Date & $\begin{array}{c}\text { Discharge } \\
\left(\mathrm{ft}^{3} / \mathrm{s}\right)\end{array}$ & $\begin{array}{c}\text { Gage } \\
\text { height } \\
\text { (ft) }\end{array}$ & $\begin{array}{l}\text { Water } \\
\text { year }\end{array}$ & Date & $\begin{array}{c}\text { Discharge } \\
\left(\mathrm{ft}^{3} / \mathrm{s}\right)\end{array}$ & $\begin{array}{c}\text { Gage } \\
\text { height } \\
\text { (ft) }\end{array}$ & $\begin{array}{l}\text { Water } \\
\text { year }\end{array}$ & Date & $\begin{array}{c}\text { Discharge } \\
\left(\mathrm{ft}^{3} / \mathrm{s}\right)\end{array}$ & $\begin{array}{c}\text { Gage } \\
\text { height } \\
\text { (ft) }\end{array}$ \\
\hline $\begin{array}{l}1964 \\
1965 \\
1966 \\
1967 \\
1968\end{array}$ & $\begin{array}{l}\text { Mar. } 25 \\
\text { Mar. } 25 \\
\text { Mar. } 04 \\
\text { June } 04 \\
\text { June } 08\end{array}$ & $\begin{array}{r}920 \\
495 \\
1,160 \\
774 \\
444\end{array}$ & $\begin{array}{l}7.35 \\
4.58 \\
8.16 \\
6.56 \\
4.16\end{array}$ & $\begin{array}{l}1969 \\
1970 \\
1971 \\
1972\end{array}$ & $\begin{array}{l}\text { Apr. } 18 \\
\text { Aug. } 10 \\
\text { Aug. } 04 \\
\text { Jan. } 10\end{array}$ & $\begin{array}{r}1,080 \\
279 \\
900 \\
699\end{array}$ & $\begin{array}{l}7.95 \\
2.59 \\
7.25 \\
6.06\end{array}$ & $\begin{array}{l}1973 \\
1974 \\
1975 \\
1976\end{array}$ & $\begin{array}{l}\text { Mar. } 16 \\
\text { Dec. } 31 \\
\text { Mar. } 13 \\
\text { May } 29\end{array}$ & $\begin{array}{r}912 \\
803 \\
795 \\
3,150\end{array}$ & $\begin{array}{l}7.31 \\
6.75 \\
6.70 \\
9.94\end{array}$ \\
\hline
\end{tabular}

\section{STEPHENS CREEK TRIBUTARY AT CARNESVILLE, GEORGIA}

LOCATION.--Lat $34^{\circ} 21^{\prime} 51^{\prime \prime}$, long $83^{\circ} 13^{\prime} 16^{\prime \prime}$, Franklin County, at culvert on State Highway 145, 0.9 mi southeast of Carnesville. DRAINAGE AREA. $-0.39 \mathrm{mi}^{2}$.

GAGE.--Flood-stage/rainfall recorder. Datum of gage is about $680 \mathrm{ft}$ above sea level (from topographic map).

STAGE-DISCHARGE RELATION.--Defined by current-meter measurements below $8 \mathrm{ft}^{3} / \mathrm{s}$, and extended above on basis of culvert computations. Bankfull stage and discharge, $4 \mathrm{ft}$ and $145 \mathrm{ft}^{3} / \mathrm{s}$.

\begin{tabular}{|c|c|c|c|c|c|c|c|c|c|c|c|}
\hline $\begin{array}{l}\text { Water } \\
\text { year }\end{array}$ & Date & $\begin{array}{c}\text { Discharge } \\
\left(\mathrm{ft}^{3} / \mathrm{s}\right)\end{array}$ & $\begin{array}{c}\text { Gage } \\
\text { height } \\
\text { (ft) }\end{array}$ & $\begin{array}{l}\text { Water } \\
\text { year }\end{array}$ & Date & $\begin{array}{c}\text { Discharge } \\
\left(\mathrm{ft}^{3} / \mathrm{s}\right)\end{array}$ & $\begin{array}{c}\text { Gage } \\
\text { height } \\
\text { (ft) }\end{array}$ & $\begin{array}{l}\text { Water } \\
\text { year }\end{array}$ & Date & $\begin{array}{c}\text { Discharge } \\
\left(\mathrm{ft}^{3} / \mathrm{s}\right)\end{array}$ & $\begin{array}{c}\text { Gage } \\
\text { height } \\
\text { (ft) }\end{array}$ \\
\hline $\begin{array}{l}1964 \\
1965 \\
1966 \\
1967 \\
1966\end{array}$ & $\begin{array}{l}\text { Mar. } 25 \\
\text { Mar. -- } \\
\text { Mar. } 04 \\
\text { June } 04 \\
\text { June } 11\end{array}$ & $\begin{array}{r}138 \\
54.0 \\
173 \\
150 \\
66.0\end{array}$ & $\begin{array}{c}3.87 \\
--b \\
4.37 \\
4.05 \\
2.77\end{array}$ & $\begin{array}{l}1969 \\
1970 \\
1971 \\
1972\end{array}$ & $\begin{array}{l}\text { Apr. } 18 \\
\text { Sept. } 04 \\
\text { July } 25 \\
\text { Jan. } 10\end{array}$ & $\begin{array}{l}181 \\
60.0 \\
64.0 \\
64.0\end{array}$ & $\begin{array}{l}4.50 \\
2.67 \\
2.73 \\
2.73\end{array}$ & $\begin{array}{l}1973 \\
1974 \\
1975 \\
1976\end{array}$ & $\begin{array}{l}\text { May } 12 \\
\text { Dec. } 31 \\
\text { Mar. } 13 \\
\text { Mar. } 29\end{array}$ & $\begin{array}{l}152 \\
134 \\
134 \\
150\end{array}$ & $\begin{array}{l}4.07 \\
3.81 \\
3.81 \\
5.04\end{array}$ \\
\hline
\end{tabular}

\section{NORTH FORK BROAD RIVER ABOVE TOCCOA, GEORGIA (North Fork Broad River Subwatershed No. 1)}

LOCATION.-Lat $34^{\circ} 34^{\prime} 25^{\prime \prime}$, long $83^{\circ} 22^{\prime} 00^{\prime \prime}$, Stephens County, in pool of flood-detention reservoir on left side of downstream headwall of culvert under county road (abandoned railroad embankment), $1.5 \mathrm{mi}$ west of Toccoa, and $2.2 \mathrm{mi}$ upstream from Denmans Creek.

DRAINAGE AREA.--3.66 $\mathrm{mi}^{2}$

GAGE.-Water-stage recorder. Datum of gage is $894.34 \mathrm{ft}$ above sea level (levels by U.S. Soil Conservation Service). REMARKS.--Peak discharges listed are computed inflow values (average for 15-minute interval).

\begin{tabular}{|c|c|c|c|c|c|c|c|c|c|c|c|}
\hline $\begin{array}{l}\text { Water } \\
\text { year }\end{array}$ & Date & $\begin{array}{c}\text { Discharge } \\
\left(\mathrm{ft}^{3} / \mathrm{s}\right)\end{array}$ & $\begin{array}{c}\text { Gage } \\
\text { height } \\
\text { (ft) }\end{array}$ & $\begin{array}{l}\text { Water } \\
\text { year }\end{array}$ & Date & $\begin{array}{c}\text { Discharge } \\
\left(\mathrm{ft}^{3} / \mathrm{s}\right)\end{array}$ & $\begin{array}{c}\text { Gage } \\
\text { height } \\
\text { (ft) }\end{array}$ & $\begin{array}{l}\text { Water } \\
\text { year }\end{array}$ & Date & $\begin{array}{c}\text { Discharge } \\
\left(\mathrm{ft}^{3} / \mathrm{s}\right)\end{array}$ & $\begin{array}{c}\text { Gage } \\
\text { height } \\
\text { (ft) }\end{array}$ \\
\hline 1959 & Sept.07 & 186 & - & 1962 & Dec. 12 & 295 & - & 1965 & Oct. 04 & 85 & - \\
\hline 1960 & Feb. 05 & 174 & - & 1963 & Mar. 06 & 839 & $\cdots$ & 1966 & Feb. 13 & 577 & - \\
\hline 1961 & Feb. 25 & 571 & - & 1964 & Jan. 25 & 610 & - & 1969 & Aug. 22 & 308 & $-c$ \\
\hline
\end{tabular}




\section{SAVANNAH RIVER BASIN}

\section{NORTH FORK BROAD RIVER NEAR TOCCOA, GEORGIA}

LOCATION.-Lat $34^{\circ} 30^{\prime} 49^{\prime \prime}$, long $83^{\circ} 19^{\prime} 19^{\prime \prime}$, Stephens County, on right bank 50 ft upstream from relocated bridge on State Highway 106, 1 mi downstream from Carnes Creek, and 5 mi south of Toccoa. DRAINAGE AREA.- $-18.3 \mathrm{mi}^{2}$.

GAGE.--Water-stage recorder. Datum of gage is $750.41 \mathrm{ft}$ above sea level (levels by U.S. Soil Conservation Service). Prior to July 14, 1960, at site $50 \mathrm{ft}$ downstream at same datum.

STAGE-DISCHARGE RELATION.-Defined by current-meter measurements below $1,100 \mathrm{ft}^{3} / \mathrm{s}$, and extended above on the basis of straight-line extension.

REMARKS.-Storm runoff affected for short periods by five flood-detention reservoirs (combined capacity, 1,560 acre-ft).

\begin{tabular}{|c|c|c|c|c|c|c|c|c|c|c|c|}
\hline $\begin{array}{l}\text { Water } \\
\text { year }\end{array}$ & Date & $\begin{array}{c}\text { Discharge } \\
\left(\mathrm{ft}^{3} / \mathrm{s}\right)\end{array}$ & $\begin{array}{c}\text { Gage } \\
\text { height } \\
\text { (ft) }\end{array}$ & $\begin{array}{l}\text { Water } \\
\text { year }\end{array}$ & Date & $\begin{array}{c}\text { Discharge } \\
\left(\mathrm{ft}^{3} / \mathrm{s}\right)\end{array}$ & $\begin{array}{c}\text { Gage } \\
\text { height } \\
\text { (ft) }\end{array}$ & $\begin{array}{l}\text { Water } \\
\text { year }\end{array}$ & Date & $\begin{array}{c}\text { Discharge } \\
\left(\mathrm{ft}^{3} / \mathrm{s}\right)\end{array}$ & $\begin{array}{l}\text { Gage } \\
\text { height } \\
\text { (ft) }\end{array}$ \\
\hline $\begin{array}{l}1955 \\
1956 \\
1957 \\
1958 \\
1959\end{array}$ & $\begin{array}{l}\text { Feb. } 06 \\
\text { Apr. } 16 \\
\text { Apr. } 05 \\
\text { Feb. } 26 \\
\text { Sept. } 07\end{array}$ & $\begin{array}{r}1,060 \\
830 \\
640 \\
570 \\
730\end{array}$ & $\begin{array}{l}8.33 \\
7.50 \\
6.42 \\
5.90 \\
6.14\end{array}$ & $\begin{array}{l}1960 \\
1961 \\
1962 \\
1963 \\
1964\end{array}$ & $\begin{array}{l}\text { Feb. } 05 \\
\text { Feb. } 25 \\
\text { Dec. } 12 \\
\text { Mar. } 06 \\
\text { Jan. } 25\end{array}$ & $\begin{array}{l}\frac{643}{1450} \\
1030 \\
2000 \\
1540\end{array}$ & $\begin{array}{r}5.70 \\
9.00 \\
7.30 \\
10.30 \\
8.51\end{array}$ & $\begin{array}{l}1965 \\
1966 \\
1967 \\
1968 \\
1969\end{array}$ & $\begin{array}{l}\text { Oct. } 05 \\
\text { Mar. } 04 \\
\text { June } 04 \\
\text { Mar. } 12 \\
\text { Jan. } 20\end{array}$ & $\begin{array}{r}655 \\
1,770 \\
998 \\
1,210 \\
1,140\end{array}$ & $\begin{array}{l}4.46 \\
8.93 \\
5.83 \\
5.87 \\
6.30\end{array}$ \\
\hline
\end{tabular}

\section{BEAR CREEK (NORTH FORK BROAD RIVER NEAR SUBWATERSHED NO. 6) NEAR MIZE, GEORGIA}

LOCATION.--Lat $34^{\circ} 29^{\prime} 07^{\prime \prime}$, long $83^{\circ} 18^{\prime} 38^{\prime \prime}$, Stephens County, at edge of pool $255 \mathrm{ft}$ upstream from left end of earthfill dam on

Bear Creek, 1 mi upstream from mouth, and 2 mi east of Mize.

DRAINAGE AREA.--3.62 $\mathrm{mi}^{2}$.

GAGE.-Water-stage recorder. Datum of gage is $\mathbf{7 4 3 . 1 3} \mathrm{ft}$ above sea level (levels by U.S. Soil Conservation Service).

REMARKS.--Peak discharges listed are computed inflow values (average for 15-minute interval).

\begin{tabular}{|c|c|c|c|c|c|c|c|c|c|c|c|}
\hline $\begin{array}{l}\text { Water } \\
\text { year }\end{array}$ & Date & $\begin{array}{c}\text { Discharge } \\
\left(\mathrm{ft}^{3} / \mathrm{s}\right)\end{array}$ & $\begin{array}{c}\text { Gage } \\
\text { height } \\
\text { (ft) }\end{array}$ & $\begin{array}{l}\text { Water } \\
\text { year }\end{array}$ & Date & $\begin{array}{c}\text { Discharge } \\
\left(\mathrm{ft}^{3} / \mathrm{s}\right)\end{array}$ & $\begin{array}{c}\text { Gage } \\
\text { height } \\
\text { (ft) }\end{array}$ & $\begin{array}{l}\text { Water } \\
\text { year }\end{array}$ & Date & $\begin{array}{c}\text { Discharge } \\
\left(\mathrm{ft}^{3} / \mathrm{s}\right)\end{array}$ & $\begin{array}{c}\text { Gage } \\
\text { height } \\
\text { (ft) }\end{array}$ \\
\hline $\begin{array}{l}1957 \\
1958 \\
1959 \\
1960 \\
1961\end{array}$ & $\begin{array}{l}\text { Apr. } 05 \\
\text { July } 14 \\
\text { May } 31 \\
\text { Feb. } 05 \\
\text { Feb. } 21\end{array}$ & $\begin{array}{l}287 \\
316 \\
396 \\
249 \\
644\end{array}$ & $\begin{array}{l}- \\
- \\
- \\
-\end{array}$ & $\begin{array}{l}1962 \\
1963 \\
1964 \\
1965\end{array}$ & $\begin{array}{l}\text { Dec. } 12 \\
\text { Mar. } 05 \\
\text { Mar. } 25 \\
\text { Mar. } 17\end{array}$ & $\begin{array}{r}457 \\
1,000 \\
658 \\
121\end{array}$ & $\begin{array}{l}- \\
- \\
-\end{array}$ & $\begin{array}{l}1966 \\
1967 \\
1968 \\
1969\end{array}$ & $\begin{array}{l}\text { Mar. } 04 \\
\text { June } 04 \\
\text { Dec. } 11 \\
\text { Aug. } 22\end{array}$ & $\begin{array}{r}728 \\
267 \\
150 \\
1,780\end{array}$ & $\begin{array}{l}- \\
- \\
- \\
-\end{array}$ \\
\hline
\end{tabular}




\section{SAVANNAH RIVER BASIN}

\section{NORTH FORK BROAD RIVER NEAR LAVONIA, GEORGIA}

LOCATION.--Lat $34^{\circ} 27^{\prime} 10^{\prime \prime}$, long $83^{\circ} 14^{\prime} 23^{\prime \prime}$, Franklin County, on right bank $50 \mathrm{ft}$ above bridge on county road, 2.1 mi upstream from Toms Creek and $7.8 \mathrm{mi}$ west of Lavonia.

DRAINAGE AREA. $-42.0 \mathrm{mi}^{2}$.

GAGE.--Water-stage recorder. Datum of gage is $680.36 \mathrm{ft}$ above sea level (levels by U.S. Soil Conservation Service).

STAGE-DISCHARGE RELATION.--Defined by current-meter measurements below $1,750 \mathrm{ft}^{3} / \mathrm{s}$, and extended above on the basis of straight-line extension.

REMARKS.-Storm runoff affected by eight small flood-detention reservoirs (combined capacity, 4,420 acre-ft).

HISTORICAL DATA.-Flood stages of 1933 and 1950 based on information provided by local resident.

\begin{tabular}{|c|c|c|c|c|c|c|c|c|c|c|c|}
\hline $\begin{array}{l}\text { Water } \\
\text { year }\end{array}$ & Date & $\begin{array}{c}\text { Discharge } \\
\left(\mathrm{ft}^{3} / \mathrm{s}\right)\end{array}$ & $\begin{array}{c}\text { Gage } \\
\text { height } \\
\text { (ft) }\end{array}$ & $\begin{array}{c}\text { Water } \\
\text { year }\end{array}$ & Date & $\begin{array}{c}\text { Discharge } \\
\left(\mathrm{ft}^{3} / \mathrm{s}\right)\end{array}$ & $\begin{array}{c}\text { Gage } \\
\text { height } \\
\text { (ft) }\end{array}$ & $\begin{array}{l}\text { Water } \\
\text { year }\end{array}$ & Date & $\begin{array}{c}\text { Discharge } \\
\left(\mathrm{ft}^{3} / \mathrm{s}\right)\end{array}$ & $\begin{array}{c}\text { Gage } \\
\text { height } \\
\text { (ft) }\end{array}$ \\
\hline 1933 & Apr. -- & - & $17.50 \mathrm{c}$ & 1959 & May 31 & 1,060 & 11.00 & 1965 & Mar. 26 & 800 & 8.56 \\
\hline 1950 & July 00 & - & $15.50 c$ & 1960 & Feb. 05 & 1,010 & 9.64 & 1966 & Mar. 04 & 1,920 & 11.25 \\
\hline 1956 & Apr. 16 & 1,060 & 11.00 & 1962 & Dec. 12 & 1,920 & 11.80 & 1968 & Mar. 12 & 935 & 8.85 \\
\hline 1957 & Apr. 05 & 950 & 10.73 & 1963 & Mar. 06 & 2,240 & 12.70 & 1969 & Aug. 22 & 2,220 & 12.31 \\
\hline 1958 & Apr. 15 & 570 & 9.37 & 1964 & Mar. 26 & 1,710 & 11.40 & & & & \\
\hline
\end{tabular}

\section{TOMS CREEK (NORTH FORK BROAD RIVER SUBWATERSHED NO. 11) NEAR EASTANOLLEE, GEORGIA}

LOCATION.--Lat $34^{\circ} 29^{\prime} 01^{\prime \prime}$, long $83^{\circ} 14^{\prime} 02^{\prime \prime}$, Stephens County, on edge of pool, about $750 \mathrm{ft}$ upstream from left end of earthfill dam, 2 mi south of Eastanollee, and 4 mi upstream from mouth.

DRAINAGE AREA.--3.79 $\mathrm{mi}^{2}$.

GAGE.-Water-stage recorder. Datum of gage is $730.60 \mathrm{ft}$ above sea level (levels by U.S. Soil Conservation Service).

REMARKS.--Peak discharges listed are computed inflow values (average for 15-minute interval).

\begin{tabular}{|c|c|c|c|c|c|c|c|c|c|c|c|}
\hline $\begin{array}{l}\text { Water } \\
\text { year }\end{array}$ & Date & $\begin{array}{c}\text { Discharge } \\
\left(\mathrm{ft}^{3} / \mathrm{s}\right)\end{array}$ & $\begin{array}{c}\text { Gage } \\
\text { height } \\
(\mathrm{ft})\end{array}$ & $\begin{array}{l}\text { Water } \\
\text { year }\end{array}$ & Date & $\begin{array}{c}\text { Discharge } \\
\left(\mathrm{ft}^{3} / \mathrm{s}\right)\end{array}$ & $\begin{array}{c}\text { Gage } \\
\text { height } \\
\text { (ft) }\end{array}$ & $\begin{array}{c}\text { Water } \\
\text { year }\end{array}$ & Date & $\begin{array}{c}\text { Discharge } \\
\left(\mathrm{ft}^{3} / \mathrm{s}\right)\end{array}$ & $\begin{array}{c}\text { Gage } \\
\text { height } \\
\text { (ft) }\end{array}$ \\
\hline 1957 & Apr. 05 & 335 & -- & 1962 & Dec. 12 & 521 & - & 1966 & Mar. 04 & 679 & - \\
\hline 1958 & Aug. 24 & 360 & -. & 1963 & Mar. 06 & 1,020 & - & 1967 & June 04 & 664 & - \\
\hline 1959 & Apr. 12 & 376 & - & 1964 & Mar. 25 & 718 & -- & 1968 & Mar. 12 & 235 & -- \\
\hline 1960 & Feb. 05 & 209 & -- & 1965 & July 28 & 379 & -- & 1969 & Aug. 22 & 2,270 & - \\
\hline 1961 & Feb. 25 & 565 & - & & & & & & & & \\
\hline
\end{tabular}


LOCATION.--Lat $34^{\circ} 29^{\prime} 35^{\prime \prime}$, long $83^{\circ} 13^{\prime} 23^{\prime \prime}$, Stephens County, at upstream edge of crown in earthfill dam on unnamed tributary to Toms Creek, $0.8 \mathrm{mi}$ upstream from mouth, and $1.6 \mathrm{mi}$ southwest of Avalon.

DRAINAGE AREA. $-1.20 \mathrm{mi}^{2}$.

GAGE.--Water-stage recorder. Datum of gage is $735.33 \mathrm{ft}$ above sea level (levels by U.S. Soil Conservation Service).

REMARKS.--Peak discharges listed are computed inflow values (average for 15 -minute interval).

\begin{tabular}{|c|c|c|c|c|c|c|c|c|c|c|c|}
\hline $\begin{array}{l}\text { Water } \\
\text { year }\end{array}$ & Date & $\begin{array}{c}\text { Discharge } \\
\left(\mathrm{ft}^{3} / \mathrm{s}\right)\end{array}$ & $\begin{array}{c}\text { Gage } \\
\text { height } \\
\text { (ft) }\end{array}$ & $\begin{array}{l}\text { Water } \\
\text { year }\end{array}$ & Date & $\begin{array}{c}\text { Discharge } \\
\left(\mathrm{ft}^{3} / \mathrm{s}\right)\end{array}$ & $\begin{array}{c}\text { Gage } \\
\text { height } \\
\text { (ft) }\end{array}$ & $\begin{array}{l}\text { Water } \\
\text { year }\end{array}$ & Date & $\begin{array}{c}\text { Discharge } \\
\left(\mathrm{ft}^{3} / \mathrm{s}\right)\end{array}$ & $\begin{array}{c}\text { Gage } \\
\text { heigh } \\
\text { (ft) }\end{array}$ \\
\hline $\begin{array}{l}1955 \\
1956 \\
1957 \\
1958 \\
1959\end{array}$ & $\begin{array}{l}\text { Feb. } 06 \\
\text { July } 05 \\
\text { July } 24 \\
\text { Aug. } 24 \\
\text { July } 18\end{array}$ & $\begin{array}{l}128 \\
628 \\
166 \\
350 \\
432\end{array}$ & $\begin{array}{l}-- \\
- \\
- \\
- \\
-\end{array}$ & $\begin{array}{l}1960 \\
1961 \\
1962 \\
1963 \\
1964\end{array}$ & $\begin{array}{l}\text { Mar. } 30 \\
\text { Feb. } 21 \\
\text { Dec. } 12 \\
\text { Mar. } 05 \\
\text { Mar. } 25\end{array}$ & $\begin{array}{l}274 \\
319 \\
352 \\
726 \\
439\end{array}$ & $\begin{array}{l}-. \\
-. \\
-- \\
-.\end{array}$ & $\begin{array}{l}1965 \\
1967 \\
1968 \\
1969\end{array}$ & $\begin{array}{l}\text { July } 14 \\
\text { June } 04 \\
\text { June } 11 \\
\text { Aug. } 22\end{array}$ & $\begin{array}{l}341 \\
485 \\
117 \\
541\end{array}$ & $\begin{array}{l}- \\
- \\
- \\
-\end{array}$ \\
\hline
\end{tabular}

\section{TOMS CREEK NEAR MARTIN, GEORGIA}

LOCATION.--Lat $34^{\circ} 27^{\prime} 47^{\prime \prime}$, long $83^{\circ} 13^{\prime} 19^{\prime \prime}$, Stephens County, on left bank $30 \mathrm{ft}$ downstream from county road bridge, $1.2 \mathrm{mi}$ upstream from mouth, and 3 mi southwest of Martin.

DRAINAGE AREA.--10.3 $\mathrm{mi}^{2}$.

GAGE.--Water-stage recorder. Datum of gage is $681.66 \mathrm{ft}$ above sea level (levels by U.S. Soil Conservation Service).

STAGE-DISCHARGE RELATION.--Defined by current-meter measurements below $750 \mathrm{ft}^{3} / \mathrm{s}$, and extended above on basis of areavelocity study

REMARKS.--Storm runoff at gage affected by four flood-detention reservoirs (combined capacity, 1,600 acre-ft).

\begin{tabular}{|c|c|c|c|c|c|c|c|c|c|c|c|}
\hline $\begin{array}{l}\text { Water } \\
\text { year }\end{array}$ & Date & $\begin{array}{c}\text { Discharge } \\
\left(\mathrm{ft}^{3} / \mathrm{s}\right)\end{array}$ & $\begin{array}{c}\text { Gage } \\
\text { height } \\
\text { (ft) }\end{array}$ & $\begin{array}{l}\text { Water } \\
\text { year }\end{array}$ & Date & $\begin{array}{c}\text { Discharge } \\
\left(\mathrm{ft}^{3} / \mathrm{s}\right)\end{array}$ & $\begin{array}{c}\text { Gage } \\
\text { height } \\
\text { (ft) }\end{array}$ & $\begin{array}{l}\text { Water } \\
\text { year }\end{array}$ & Date & $\begin{array}{c}\text { Discharge } \\
\left(\mathrm{ft}^{3} / \mathrm{s}\right)\end{array}$ & $\begin{array}{c}\text { Gage } \\
\text { height } \\
\text { (ft) }\end{array}$ \\
\hline $\begin{array}{l}1955 \\
1956 \\
1957 \\
1958 \\
1959\end{array}$ & $\begin{array}{l}\text { Feb. } 06 \\
\text { Mar. } 16 \\
\text { Apr. } 05 \\
\text { Aug. } 24 \\
\text { May } 31\end{array}$ & $\begin{array}{l}700 \\
726 \\
304 \\
278 \\
484\end{array}$ & $\begin{array}{l}8.40 \\
8.41 \\
7.88 \\
8.03 \\
6.92\end{array}$ & $\begin{array}{l}1960 \\
1961 \\
1962 \\
1963 \\
1964\end{array}$ & $\begin{array}{l}\text { Mar. } 30 \\
\text { Feb. } 21 \\
\text { Dec. } 12 \\
\text { Mar. } 06 \\
\text { Mar. } 25\end{array}$ & $\begin{array}{r}544 \\
880 \\
830 \\
1,300 \\
810\end{array}$ & $\begin{array}{l}7.42 \\
8.80 \\
8.15 \\
9.40 \\
7.84\end{array}$ & $\begin{array}{l}1965 \\
1966 \\
1967 \\
1968 \\
1969\end{array}$ & $\begin{array}{l}\text { July } 28 \\
\text { Mar. } 04 \\
\text { June } 04 \\
\text { Dec. } 11 \\
\text { Aug. } 22\end{array}$ & $\begin{array}{r}563 \\
795 \\
750 \\
347 \\
1,540\end{array}$ & $\begin{array}{r}6.33 \\
7.74 \\
7.56 \\
5.17 \\
10.10\end{array}$ \\
\hline
\end{tabular}




\section{SAVANNAH RIVER BASIN}

\section{DOUBLE BRANCH AT BOWERSVLLE, GEORGIA}

LOCATION.--Lat $34^{\circ} 22^{\prime} 51^{\prime \prime}$, long $83^{\circ} 05^{\prime} 28^{\prime \prime}$, Hart County, at culvert on State Highway 17 at Bowersville.

DRAINAGE AREA.--0.50 $\mathrm{mi}^{2}$.

GAGE.--Crest-stage gage prior to Sept. 23, 1965; flood-stage recorder Sept. 23, 1965 to Nov. 15, 1967; flood-stage/rainfall recorder thereafter. Datum of gage is about $790 \mathrm{ft}$ above sea level (from topographic map).

STAGE-DISCHARGE RELATION.--Defined by culvert computations.

\begin{tabular}{|c|c|c|c|c|c|c|c|c|c|c|c|}
\hline $\begin{array}{l}\text { Water } \\
\text { year }\end{array}$ & Date & $\begin{array}{c}\text { Discharge } \\
\left(\mathrm{ft}^{3} / \mathrm{s}\right)\end{array}$ & $\begin{array}{c}\text { Gage } \\
\text { height } \\
\text { (ft) }\end{array}$ & $\begin{array}{l}\text { Water } \\
\text { year }\end{array}$ & Date & $\begin{array}{c}\text { Discharge } \\
\left(\mathrm{ft}^{3} / \mathrm{s}\right)\end{array}$ & $\begin{array}{c}\text { Gage } \\
\text { height } \\
\text { (ft) }\end{array}$ & $\begin{array}{l}\text { Water } \\
\text { year }\end{array}$ & Date & $\begin{array}{c}\text { Discharge } \\
\left(\mathrm{ft}^{3} / \mathrm{s}\right)\end{array}$ & $\begin{array}{c}\text { Gage } \\
\text { height } \\
\text { (ft) }\end{array}$ \\
\hline 1960 & July 28 & 278 & 4.78 & 1966 & Mar. 04 & 190 & 3.86 & 1971 & June 27 & 115 & 3.04 \\
\hline 1961 & Feb. 21 & 243 & 4.42 & 1967 & June 04 & 396 & 5.94 & 1972 & Jan. 13 & 81 & 2.64 \\
\hline 1962 & Dec. 12 & 230 & 4.27 & 1968 & Dec. 11 & 106 & 2.94 & 1973 & May 27 & 336 & 5.34 \\
\hline 1963 & Apr. 30 & 273 & 4.73 & 1969 & Apr. 18 & 449 & 6.47 & 1974 & Dec. 31 & 115 & 3.04 \\
\hline 1964 & Apr. 06 & 275 & 4.76 & 1970 & July 00 & 48 & $--b$ & 1975 & Mar. 13 & 126 & 3.17 \\
\hline 1965 & Mar. -- & 78 & $--b$ & & & & & & & & \\
\hline
\end{tabular}

\section{NORTH FORK BROAD RIVER NEAR CARNESVILLE, GEORGIA}

LOCATION.-Lat $34^{\circ} 19^{\prime} 25^{\prime \prime}$, long $83^{\circ} 11^{\prime} 10^{\prime \prime}$, Franklin County, at bridge on State Highway 51, 1 mi downstream from Unawatti Creek, 3 mi upstream from confluence with Middle Fork Broad River, and 4.5 mi southeast of Carnesville. DRAINAGE AREA. $-119 \mathrm{mi}^{2}$.

GAGE.-Water-stage recorder. Datum of gage is $600.33 \mathrm{ft}$ above sea level, supplementary adjustment of 1936 (from U.S. Coast and Geodetic Survey benchmark). October 1, 1942 to Dec. 31, 1944, wire-weight gage. April 29, 1954 to Sept. 27, 1963, water-stage recorder, and Sept. 28. 1963 to Dec. 17, 1964, water-stage recorder at site $125 \mathrm{ft}$ upstream at same datum.

STAGE-DISCHARGE RELATION.--Defined by current-meter measurements below $5,000 \mathrm{ft}^{3} / \mathrm{s}$, and extended above on basis on slope-area measurements at $11,400 \mathrm{ft}^{3} / \mathrm{s}$.

REMARKS.--Storm runoff affected for short periods since 1955 by small flood-detention reservoirs above gage (combined capacity, 9,520 acre-ft).

\begin{tabular}{|c|c|c|c|c|c|c|c|c|c|c|c|}
\hline $\begin{array}{l}\text { Water } \\
\text { year }\end{array}$ & Date & $\begin{array}{c}\text { Discharge } \\
\left(\mathrm{ft}^{3} / \mathrm{s}\right)\end{array}$ & $\begin{array}{c}\text { Gage } \\
\text { height } \\
\text { (ft) }\end{array}$ & $\begin{array}{l}\text { Water } \\
\text { year }\end{array}$ & Date & $\begin{array}{c}\text { Discharge } \\
\left(\mathrm{ft}^{3} / \mathrm{s}\right)\end{array}$ & $\begin{array}{l}\text { Gage } \\
\text { height } \\
\text { (ft) }\end{array}$ & $\begin{array}{c}\text { Water } \\
\text { year }\end{array}$ & Date & $\begin{array}{c}\text { Discharge } \\
\left(\mathrm{ft}^{3} / \mathbf{s}\right)\end{array}$ & $\begin{array}{c}\text { Gage } \\
\text { height } \\
\text { (ft) }\end{array}$ \\
\hline 1943 & Jan. 18 & 3,400 & 7.60 & 1959 & June 01 & 1,330 & 5.20 & 1965 & Mar. 26 & 2,200 & 6.55 \\
\hline 1944 & Mar. 29 & 2,670 & 6.80 & 1960 & Feb. 05 & 2,670 & 6.81 & 1966 & Mar. 04 & 6,250 & 10.68 \\
\hline$\underline{1951}$ & Oct. 20 & 5,000 & $9.47 \mathrm{c}$ & 1961 & Feb. 21 & 11,400 & 14.60 & 1967 & June 04 & 8,060 & 12.20 \\
\hline$\overline{1955}$ & Feb. 07 & 1,800 & 5.70 & 1962 & Dec. 12 & 6,230 & 10.30 & 1968 & Jan. 10 & 2,240 & 6.55 \\
\hline 1956 & Mar. 16 & 2,760 & 6.90 & 1963 & Mar. 06 & 9,100 & 13.00 & $\underline{1969}$ & Apr. 18 & 5,500 & 10.00 \\
\hline 1957 & Apr. 05 & 2,060 & 5.95 & 1964 & $\overline{\text { Mar. 26 }}$ & $\overline{7,930}$ & 12.08 & $\overline{1976}$ & May 29 & 11,800 & $14.80 \mathrm{c}$ \\
\hline 1958 & Nov. 19 & 1,950 & 5.85 & & & & & & & & \\
\hline
\end{tabular}




\section{HUDSON RIVER AT HOMER, GEORGIA}

LOCATION.--Lat $34^{\circ} 20^{\prime} 15^{\prime \prime}$, long $83^{\circ} 29^{\prime} 17^{\prime \prime}$, Banks County, on downstream side of center pier of bridge on State Highway 15 at Homer, $3.6 \mathrm{mi}$ upstream from Webb Creek, and $10.8 \mathrm{mi}$ upstream from Grove Creek.

DRAINAGE AREA. $-60.9 \mathrm{mi}^{2}$.

GAGE.-Water-stage recorder. Datum of gage is $694.61 \mathrm{ft}$ above sea level (from U.S. Geological Survey benchmark). July 10,1950 to June 19, 1959, crest-stage gage at site $60 \mathrm{ft}$ downstream at same datum.

STAGE-DISCHARGE RELATION.--Defined by current-meter measurements below $5,100 \mathrm{ft}^{3} / \mathrm{s}$, and extended above on the basis of straight-line extension. Bankfull stage and discharge, $6 \mathrm{ft}, 550 \mathrm{ft}^{3} / \mathrm{s}$.

REMARKS.--Peak discharge for 1953 is estimated.

\begin{tabular}{|c|c|c|c|c|c|c|c|c|c|c|c|}
\hline $\begin{array}{l}\text { Water } \\
\text { year }\end{array}$ & Date & $\begin{array}{c}\text { Discharge } \\
\left(\mathrm{ft}^{3} / \mathrm{s}\right)\end{array}$ & $\begin{array}{c}\text { Gage } \\
\text { height } \\
\text { (ft) }\end{array}$ & $\begin{array}{l}\text { Water } \\
\text { year }\end{array}$ & Date & $\begin{array}{c}\text { Discharge } \\
\left(\mathrm{ft}^{3} / \mathrm{s}\right)\end{array}$ & $\begin{array}{c}\text { Gage } \\
\text { height } \\
\text { (ft) }\end{array}$ & $\begin{array}{l}\text { Water } \\
\text { year }\end{array}$ & Date & $\begin{array}{c}\text { Discharge } \\
\left(\mathrm{ft}^{3} / \mathrm{s}\right)\end{array}$ & $\begin{array}{c}\text { Gage } \\
\text { height } \\
\text { (ft) }\end{array}$ \\
\hline 1951 & Oct. 20 & 2,270 & 10.41 & 1961 & Feb. 21 & 3,750 & 12.20 & 1971 & Mar. 03 & 938 & 7.64 \\
\hline 1952 & Mar. 04 & 5,660 & 13.76 & 1962 & Dec. 12 & 3,350 & 11.90 & 1972 & May 14 & 2,330 & 10.34 \\
\hline 1953 & Feb. 21 & 1,250 & - & 1963 & Mar. 06 & 4,080 & 12.50 & 1973 & Mar. 17 & 1,750 & 9.44 \\
\hline 1954 & Jan. 16 & 2,830 & 11.04 & 1964 & Mar. 26 & 4,530 & 12.86 & 1974 & Jan. 01 & 2,980 & 11.27 \\
\hline 1955 & Feb. 07 & 2,050 & 9.89 & 1965 & Mar. 25 & 1,180 & 8.15 & 1975 & Mar. 14 & 2,250 & 10.23 \\
\hline 1956 & Mar. 16 & 1,420 & 8.93 & 1966 & Mar. 04 & 3,950 & 12.38 & 1976 & May 29 & 7,050 & 14.73 \\
\hline 1957 & Apr. 05 & 1,290 & 8.60 & 1967 & Jan. 08 & 1,920 & 9.66 & 1977 & Mar. 30 & 4,280 & 12.48 \\
\hline 1958 & Apr. 15 & 792 & 6.87 & 1968 & Mar. 13 & 1,250 & 8.47 & 1978 & Nov. 06 & 3,070 & 11.27 \\
\hline 1959 & May 31 & $\underline{1,120}$ & 8.06 & 1969 & Aug. 22 & 5,580 & 13.70 & 1979 & Apr. 13 & 4,920 & 13.10 \\
\hline 1960 & July 28 & 1,140 & 8.12 & 1970 & Mar. 22 & 686 & 6.78 & & & & \\
\hline
\end{tabular}

\section{SCULL SHOAL CREEK NEAR DANIELSVILLE, GEORGIA}

LOCATION.--Lat $34^{\circ} 09^{\prime} 30^{\prime \prime}$, long 8309'51", Madison County, at State Highway 191, 4 mi northeast of Danielsville.

DRAINAGE AREA. $-8.75 \mathrm{mi}^{2}$.

GAGE.--Crest-stage gage prior to Nov. 15, 1969; flood-stage recorder Nov. 15, 1967 to Apr. 2, 1968; Flood-stage/rainfall recorder thereafter. Datum of gage is about $610 \mathrm{ft}$ above sea level (from topographic map).

STAGE-DISCHARGE RELATION.--Defined by current-meter measurements below $700 \mathrm{ft}^{3} / \mathrm{s}$, and extended above on basis of contracted-opening measurement at 4,380 ft $3 / \mathrm{s}$. Bankfull stage and discharge, $8 \mathrm{ft}$, and $500 \mathrm{ft}^{3} / \mathrm{s}$.

REMARKS.--Flood of June 4, 1967 was highest since 1961 based on comparison with nearby stations.

\begin{tabular}{lrcccccccccr}
\hline $\begin{array}{l}\text { Water } \\
\text { year }\end{array}$ & Date & $\begin{array}{c}\text { Discharge } \\
\left(\mathrm{ft}^{3} / \mathrm{s}\right)\end{array}$ & $\begin{array}{c}\text { Gage } \\
\text { height } \\
(\mathrm{ft})\end{array}$ & $\begin{array}{c}\text { Water } \\
\text { year }\end{array}$ & Date & $\begin{array}{c}\text { Discharge } \\
\left(\mathrm{ft}^{3} / \mathrm{s}\right)\end{array}$ & $\begin{array}{c}\text { Gage } \\
\text { height } \\
(\mathrm{ft})\end{array}$ & $\begin{array}{c}\text { Water } \\
\text { year }\end{array}$ & $\begin{array}{c}\text { Gage } \\
\text { Date }\end{array}$ & $\begin{array}{c}\text { Discharge } \\
\left(\mathrm{ft}^{3} / \mathrm{s}\right)\end{array}$ & $\begin{array}{c}\text { height } \\
(\mathrm{ft})\end{array}$ \\
\hline 1964 & May 06 & 708 & 8.77 & 1968 & Dec. 12 & 333 & 7.32 & 1972 & Jan. 10 & 460 & 7.92 \\
1965 & June 12 & 551 & 8.27 & 1969 & Jan. 20 & 792 & 8.98 & 1973 & Mar. 31 & 1,670 & 10.70 \\
1966 & Mar. 04 & 1,200 & 9.89 & 1970 & Mar. 20 & 131 & 5.52 & 1974 & Dec. 31 & 220 & 6.54 \\
1967 & June 04 & 4,380 & 13.10 & 1971 & Mar. 03 & 956 & 9.39 & 1975 & Mar. 14 & 848 & 9.12 \\
\hline
\end{tabular}




\title{
SAVANNAH RIVER BASIN
}

\section{MILL SHOAL CREEK NEAR ROYSTON, GEORGIA}

LOCATION.--Lat $34^{\circ} 16^{\prime} 13^{\prime \prime}$, long $83^{\circ} 06^{\prime} 08^{\prime \prime}$, Hart County, at culvert on State Highway 17, 1.2 mi southeast of Royston. DRAINAGE AREA.--0.32 $\mathrm{mi}^{2}$.

GAGE.--Flood-stage/rainfall recorder prior to Sept. 30, 1975. Crest-stage gage thereafter. Datum of gage is about $770 \mathrm{ft}$ above sea level (from topographic map).

STAGE-DISCHARGE RELATION.--Defined by culvert computations.

\begin{tabular}{|c|c|c|c|c|c|c|c|c|c|c|c|}
\hline $\begin{array}{l}\text { Water } \\
\text { year }\end{array}$ & Date & $\begin{array}{c}\text { Discharge } \\
\left(\mathrm{ft}^{3} / \mathrm{s}\right)\end{array}$ & $\begin{array}{c}\text { Gage } \\
\text { height } \\
\text { (ft) }\end{array}$ & $\begin{array}{l}\text { Water } \\
\text { year }\end{array}$ & Date & $\begin{array}{c}\text { Discharge } \\
\left(\mathrm{ft}^{3} / \mathrm{s}\right)\end{array}$ & $\begin{array}{c}\text { Gage } \\
\text { height } \\
\text { (ft) }\end{array}$ & $\begin{array}{l}\text { Water } \\
\text { year }\end{array}$ & Date & $\begin{array}{l}\text { Discharge } \\
\left(\mathrm{ft}^{3} / \mathrm{s}\right)\end{array}$ & $\begin{array}{c}\text { Gage } \\
\text { height } \\
\text { (ft) }\end{array}$ \\
\hline 1964 & Mar, 25 & 169 & 4.99 & 1972 & Jan. 10 & 57 & 2.98 & 1980 & May 21 & 133 & 4.39 \\
\hline 1965 & Mar. 17 & 97 & 3.78 & 1973 & Mar. 16 & 174 & 5.05 & 1981 & Sept.08 & 154 & 4.74 \\
\hline 1966 & Mar. 04 & 118 & 4.13 & 1974 & Jan. 21 & 137 & 4.45 & 1982 & Jan. 04 & 232 & 5.96 \\
\hline 1967 & June 04 & 211 & 5.66 & 1975 & Mar. 14 & 152 & 4.70 & 1983 & Apr. 09 & 44 & 2.68 \\
\hline 1968 & Dec. 11 & 24 & 2.16 & 1976 & May 29 & 106 & 3.93 & 1984 & Dec. 03 & 139 & 4.48 \\
\hline 1969 & Apr. 15 & 150 & 4.66 & 1977 & Aug. 18 & 45 & 2.69 & 1985 & June 30 & 160 & 4.83 \\
\hline 1970 & Mar. -- & 15 & $--b$ & 1978 & Nov. 05 & 159 & 4.81 & 1986 & Mar. -- & 15.0 & $-b$ \\
\hline 1971 & July 05 & 108 & 3.96 & 1979 & July 21 & 133 & 4.38 & 1987 & Jan. 19 & 51.0 & 2.86 \\
\hline
\end{tabular}

\author{
02191300 BROAD RIVER ABOVE CARLTON, GEORGIA \\ (Prior to January 1, 1918, published as "Broad River near Carlton, Georgia")
}

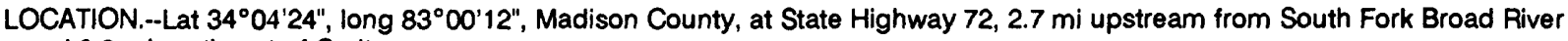
and 2.8 mi northeast of Carlton.

DRAINAGE AREA.-760 $\mathrm{mi}^{2}$. At former site, $762 \mathrm{mi}^{2}$. Peak discharges at both sites are considered equivalent.

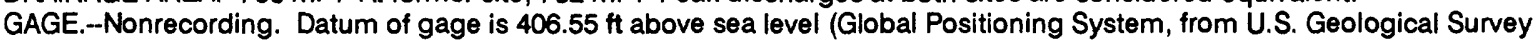
benchmark). Prior to Jan. 1, 1918, at Seaboard Coast Line Railway bridge about 0.75 mi downstream at datum $5.67 \mathrm{ft}$ lower. STAGE-DISCHARGE RELATION.--Defined by current-meter measurements below $8,300 \mathrm{ft}^{3} / \mathrm{s}$, and extended above to $70,000 \mathrm{f}^{3} / \mathrm{s}$, by logarithmic plotting at former site. Peak discharges 1913-18 are from rating table based on mesurements made 1898-1912. Defined by current-meter measurements below $20,000 \mathrm{ft}^{3} / \mathrm{s}$ at present site. Peaks $1918-49$ are from rating table based on discharge measurements made after 1950. Bankfull stage and discharge, $15 \mathrm{ft}$ and $8,000 \mathrm{ft}^{3} / \mathrm{s}$.

REMARKS.-Stage record since Jan. 1, 1913, furnished by National Weather Service (formerly U.S. Weather Bureau). The flood stage of 1908 is the highest since 1888 , based on information at nearby streams.

\begin{tabular}{|c|c|c|c|c|c|c|c|c|c|c|c|}
\hline $\begin{array}{l}\text { Water } \\
\text { year }\end{array}$ & Date & $\begin{array}{c}\text { Discharge } \\
\left(\mathrm{ft}^{3} / \mathrm{s}\right)\end{array}$ & $\begin{array}{c}\text { Gage } \\
\text { height } \\
\text { (ft) }\end{array}$ & $\begin{array}{l}\text { Water } \\
\text { year }\end{array}$ & Date & $\begin{array}{c}\text { Discharge } \\
\left(\mathrm{ft}^{3} / \mathrm{s}\right)\end{array}$ & $\begin{array}{c}\text { Gage } \\
\text { height } \\
\text { (ft) }\end{array}$ & $\begin{array}{l}\text { Water } \\
\text { year }\end{array}$ & Date & $\begin{array}{c}\text { Discharge } \\
\left(\mathrm{ft}^{3} / \mathrm{s}\right)\end{array}$ & $\begin{array}{c}\text { Gage } \\
\text { height } \\
\text { (ft) }\end{array}$ \\
\hline 1898 & Sept.02 & 26,600 & 20.00 & 1930 & Oct. 02 & 28,800 & 27.90 & 1961 & Feb. 22 & 24,500 & 26.00 \\
\hline 1899 & Feb. 27 & 19,500 & 15.80 & 1931 & Nov. 17 & 3,800 & 10.00 & 1962 & Dec. 13 & 14,100 & 20.20 \\
\hline 1900 & Feb. 13 & 31,600 & 22.70 & 1932 & Dec. 04 & 11,400 & 18.20 & 1963 & May 01 & 17,700 & 22.40 \\
\hline 1901 & Sept.18 & 17,800 & 14.80 & 1933 & Dec. 13 & 8,800 & 16.00 & 1964 & Mar. 27 & 22,900 & 25.20 \\
\hline 1902 & Feb. 28 & 43,200 & 28.20 & 1934 & June 03 & 8,300 & 15.50 & 1965 & Mar. 25 & 10,600 & 17.50 \\
\hline 1903 & Mar. 24 & 29,700 & 21.70 & 1935 & Oct. 11 & 8,800 & 16.00 & 1966 & Mar. 05 & 15,600 & 21.20 \\
\hline 1904 & Aug. 09 & 10,400 & 10.40 & 1936 & Apr. 07 & 29,000 & 28.00 & 1967 & June 05 & 19,000 & 23.10 \\
\hline 1905 & Feb. 21 & 8,220 & 9.00 & 1937 & Jan. 03 & 16,000 & 21.40 & 1968 & Jan. 11 & 7,640 & 14.80 \\
\hline 1906 & Jan. 23 & 24,900 & 19.00 & 1938 & Oct. 19 & 22,500 & 25.00 & 1969 & Jan. 21 & 16,000 & 21.40 \\
\hline 1907 & Apr. 24 & 6,200 & 7.60 & 1939 & Aug. 18 & 21,000 & 24.20 & 1970 & Mar. 22 & 6,840 & 13.80 \\
\hline 1908 & Aug. 25 & 70,000 & 39.00 & 1940 & Aug. 13 & 17,000 & 22.00 & 1971 & Mar. 03 & 18,000 & 22.50 \\
\hline 1909 & June 04 & 14,100 & 12.70 & 1941 & July 07 & 10,000 & 17.00 & 1972 & Jan. 11 & 15,600 & 21.20 \\
\hline 1910 & Aug. 31 & 20,500 & 16.40 & 1942 & Mar. 21 & 13,400 & 19.70 & 1973 & Mar. 17 & 16,000 & 21.40 \\
\hline 1911 & Apr. 08 & 5,640 & 8.50 & 1943 & Jan. 18 & 19,000 & 23.10 & 1974 & Jan. 02 & 5,800 & 12.50 \\
\hline 1912 & Mar. 15 & 42,800 & 28.00 & 1944 & Mar. 20 & 10,000 & 17.00 & 1975 & Mar. 13 & 15,600 & 21.20 \\
\hline
\end{tabular}




\begin{tabular}{|c|c|c|c|c|c|c|c|c|c|c|c|}
\hline $\begin{array}{l}\text { Water } \\
\text { year }\end{array}$ & Date & $\begin{array}{c}\text { Discharge } \\
\left(\mathrm{ft}^{3} / \mathrm{s}\right)\end{array}$ & $\begin{array}{c}\text { Gage } \\
\text { height } \\
\text { (ft) }\end{array}$ & $\begin{array}{l}\text { Water } \\
\text { year }\end{array}$ & Date & $\begin{array}{c}\text { Discharge } \\
\left(\mathrm{ft}^{3} / \mathrm{s}\right)\end{array}$ & $\begin{array}{c}\text { Gage } \\
\text { height } \\
\text { (ft) }\end{array}$ & $\begin{array}{l}\text { Water } \\
\text { year }\end{array}$ & Date & $\begin{array}{c}\text { Discharge } \\
\left(\mathrm{ft}^{3} / \mathrm{s}\right)\end{array}$ & $\begin{array}{c}\text { Gage } \\
\text { height } \\
\text { (ft) }\end{array}$ \\
\hline 1913 & Mar. 15 & 30,300 & 22.00 & 1945 & Mar. 25 & 11,100 & 17.90 & 1976 & May 30 & 26,000 & 26.80 \\
\hline 1914 & Dec. 29 & 11,000 & 10.80 & 1946 & Jan. 07 & 16,200 & 21.50 & 1977 & Mar. 31 & 11,700 & 18.35 \\
\hline 1915 & Oct. 15 & 20,000 & 16.10 & 1947 & $\operatorname{Jan} .20$ & 12,400 & 19.00 & 1978 & Nov. 06 & 27,500 & 27.25 \\
\hline 1916 & Dec. 18 & 23,900 & 18.40 & 1948 & Mar. 07 & 7,800 & 15.00 & 1979 & Apr. 13 & 19,700 & 23.50 \\
\hline 1917 & Mar. 27 & $\underline{15,200}$ & 13.30 & 1949 & Nov. 29 & 21,600 & 24.50 & 1980 & Mar. 29 & 12,600 & 19.10 \\
\hline 1918 & $\overline{\text { Aug. } 03}$ & $\overline{5,400}$ & $\overline{12.00}$ & 1950 & Sept.09 & 3,400 & 9.50 & 1981 & Feb. 11 & 6,900 & 13.72 \\
\hline 1920 & Dec. 10 & 29,500 & 28.20 & 1951 & Oct. 20 & 17,000 & 22.00 & 1982 & Jan. 04 & 19,500 & 23.40 \\
\hline 1921 & Feb. 10 & 20,100 & 23.70 & 1952 & Mar. 12 & 15,300 & 21.00 & 1983 & Apr. 09 & 8,200 & 14.73 \\
\hline 1922 & Feb. 15 & 11,000 & 17.80 & 1953 & Feb. 22 & 8,800 & 16.00 & 1984 & Dec. 06 & 14,000 & - \\
\hline 1923 & May 30 & 12,500 & 19.10 & 1954 & Jan. 17 & 9,160 & 16.30 & 1985 & Feb. 06 & 10,000 & - \\
\hline 1924 & Dec. 05 & 5,480 & 12.10 & 1955 & Feb. 07 & 9,880 & 16.90 & 1986 & Nov. 30 & 4,000 & 10.23 \\
\hline 1925 & Jan. 18 & 10,100 & 17.10 & 1956 & Mar. 17 & 8,800 & 16.00 & 1987 & Mar. 01 & 13,100 & 19.45 \\
\hline 1926 & Jan. 18 & 7,160 & 14.20 & 1957 & Apr. 06 & 8,300 & 15.50 & 1988 & Jan. 21 & 6,190 & 12.55 \\
\hline 1927 & Mar. 09 & 2,680 & 8.60 & 1958 & Nov. 19 & 8,100 & 15.30 & 1989 & July 17 & 7,220 & 13.63 \\
\hline 1928 & Aug. 16 & 24,500 & 26.00 & 1959 & May 27 & 7,400 & 14.50 & 1990 & Oct. 01 & 28,300 & 27.50 \\
\hline 1929 & Mar. 05 & 22,900 & 25.20 & 1960 & Jan. 31 & 8,400 & 15.60 & & & & \\
\hline
\end{tabular}

\section{DOUBLE BRANCH NEAR DANIELSVILLE, GEORGIA}

LOCATION.--Lat $34^{\circ} 06^{\prime} 06^{\prime \prime}$, long $83^{\circ} 14^{\prime} 11^{\prime \prime}$, Madison County, at culvert on U.S. Highway $29,1.8$ mi south of Danielsville.

DRAINAGE AREA, $-4.77 \mathrm{mi}^{2}$.

GAGE.--Flood-stage/rainfall recorder. Datum of gage is about $630 \mathrm{ft}$ above sea level (from topographic map).

STAGE-DISCHARGE RELATION.--Defined by current-meter measurements below $500 \mathrm{ft}^{3} / \mathrm{s}$, and extended above on basis of culvert computations. Bankfull stage and discharge, $6.0 \mathrm{ft}$ and $520 \mathrm{ft}^{3} / \mathrm{s}$.

REMARKS.--Flood of June 4, 1967 was highest since 1961 based on comparison with nearby stations.

\begin{tabular}{|c|c|c|c|c|c|c|c|c|c|c|c|}
\hline $\begin{array}{l}\text { Water } \\
\text { year }\end{array}$ & Date & $\begin{array}{c}\text { Discharge } \\
\left(\mathrm{ft}^{3} / \mathrm{s}\right)\end{array}$ & $\begin{array}{c}\text { Gage } \\
\text { height } \\
\text { (ft) }\end{array}$ & $\begin{array}{l}\text { Water } \\
\text { year }\end{array}$ & Date & $\begin{array}{c}\text { Discharge } \\
\left(\mathrm{ft}^{3} / \mathrm{s}\right)\end{array}$ & $\begin{array}{c}\text { Gage } \\
\text { height } \\
\text { (ft) }\end{array}$ & $\begin{array}{l}\text { Water } \\
\text { year }\end{array}$ & Date & $\begin{array}{c}\text { Discharge } \\
\left(\mathrm{ft}^{3} / \mathrm{s}\right)\end{array}$ & $\begin{array}{c}\text { Gage } \\
\text { height } \\
\text { (ft) }\end{array}$ \\
\hline 1964 & July 18 & 1,110 & 7.83 & 1969 & Jan. 20 & 442 & 5.58 & 1973 & Mar. 31 & 854 & 7.18 \\
\hline 1965 & Oct. 04 & 400 & 5.30 & 1970 & Mar. 20 & 102 & 2.55 & 1974 & Dec. 31 & 168 & 3.68 \\
\hline 1966 & May 27 & 1,150 & 7.93 & 1971 & Mar. 03 & 528 & 6.04 & 1975 & Mar. 13 & 496 & 5.88 \\
\hline 1967 & June 04 & 3,200 & 10.68 & 1972 & Jan. 10 & 295 & 4.60 & 1976 & May 29 & 442 & 5.48 \\
\hline 1968 & Dec. 11 & 274 & 4.44 & & & & & & & & \\
\hline
\end{tabular}


LOCATION.--Lat $34^{\circ} 02^{\prime} 55^{\prime \prime}$, long $83^{\circ} 01^{\prime} 16^{\prime \prime}$, Madison County, at State Highway 72 , at Carlton.

DRAINAGE AREA.--16 $\mathrm{mi}^{2}$, with $13.8 \mathrm{mi}^{2}$ contributing to flow.

GAGE.--Crest-stage gage prior to Nov. 16, 1967; flood-stage recorder Nov. 16, 1967 to Apr. 2, 1968; flood-stage/rainfall recorder thereafter. Datum of gage is $\mathbf{4 6 6 . 5 3} \mathrm{ft}$ above sea level (from Georgia Department of Transportation).

STAGE-DISCHARGE RELATION.-Defined by current-meter measurements below $1,900 \mathrm{ft}^{3} / \mathrm{s}$. Bankfull stage and discharge, $6.0 \mathrm{ft}$ and $910 \mathrm{ft}^{3} / \mathrm{s}$.

REMARKS.--2.2 $\mathrm{mi}^{2}$ almost completely controlled by small dam in headwaters.

\begin{tabular}{|c|c|c|c|c|c|c|c|c|c|c|c|}
\hline $\begin{array}{l}\text { Water } \\
\text { year }\end{array}$ & Date & $\begin{array}{c}\text { Discharge } \\
\left(\mathrm{ft}^{3} / \mathrm{s}\right)\end{array}$ & $\begin{array}{c}\text { Gage } \\
\text { height } \\
\text { (ft) }\end{array}$ & $\begin{array}{l}\text { Water } \\
\text { year }\end{array}$ & Date & $\begin{array}{c}\text { Discharge } \\
\left(\mathrm{ft}^{3} / \mathrm{s}\right)\end{array}$ & $\begin{array}{c}\text { Gage } \\
\text { height } \\
\text { (ft) }\end{array}$ & $\begin{array}{l}\text { Water } \\
\text { year }\end{array}$ & Date & $\begin{array}{c}\text { Discharge } \\
\left(\mathrm{ft}^{3} / \mathrm{s}\right)\end{array}$ & $\begin{array}{c}\text { Gage } \\
\text { height } \\
\text { (ft) }\end{array}$ \\
\hline 1964 & May 06 & 1,240 & 6.97 & 1968 & Jan. 10 & 493 & 4.03 & 1972 & Jan. 10 & 511 & 4.13 \\
\hline 1965 & Oct. 04 & 519 & 4.17 & 1969 & Jan. 20 & 1,080 & 6.50 & 1973 & May 28 & 1,410 & 7.43 \\
\hline 1966 & Mar. 04 & 1,150 & 6.72 & 1970 & Mar. 20 & 429 & 3.63 & 1974 & Apr. 04 & 480 & 3.95 \\
\hline 1967 & June 04 & 1,920 & 8.53 & 1971 & Mar. 03 & 1,210 & 6.88 & 1975 & Mar. 13 & 842 & 5.73 \\
\hline
\end{tabular}

\section{BROOKS CREEK NEAR LEXINGTON, GEORGIA}

LOCATION.-Lat $33^{\circ} 50^{\prime} 30^{\prime \prime}$, long $83^{\circ} 05^{\prime 22}$ ", Oglethorpe County, at State Highway 22, 2.2 mi south of Lexington.

DRAINAGE AREA.-12.3 $\mathrm{mi}^{2}$.

GAGE.--Crest-stage gage prior to Nov. 16, 1967; flood-stage recorder Nov. 16, 1967 to Apr. 3, 1968; flood-stage/rainfall recorder thereafter. Datum of gage is about $533 \mathrm{ft}$ above sea level (from topographic map).

STAGE-DISCHARGE RELATION.-Defined by current-meter measurements below $740 \mathrm{ft}^{3} / \mathrm{s}$, and extended above on basis of contracted-opening measurement at 2,500 $\mathrm{tt}^{3} / \mathrm{s}$. Bankfull stage and discharge, $8.5 \mathrm{ft}$ and $590 \mathrm{ft}^{3} / \mathrm{s}$.

HISTORICAL DATA.--Flood peaks for the floods of 1948, 1959, and 1961 provided by the Georgia Department of Transportation.

\begin{tabular}{|c|c|c|c|c|c|c|c|c|c|c|c|}
\hline $\begin{array}{l}\text { Water } \\
\text { year }\end{array}$ & Date & $\begin{array}{c}\text { Discharge } \\
\left(\mathrm{ft}^{3} / \mathrm{s}\right)\end{array}$ & $\begin{array}{c}\text { Gage } \\
\text { height } \\
\text { (ft) }\end{array}$ & $\begin{array}{l}\text { Water } \\
\text { year }\end{array}$ & Date & $\begin{array}{c}\text { Discharge } \\
\left(\mathrm{ft}^{3} / \mathrm{s}\right)\end{array}$ & $\begin{array}{c}\text { Gage } \\
\text { height } \\
\text { (ft) }\end{array}$ & $\begin{array}{l}\text { Water } \\
\text { year }\end{array}$ & Date & $\begin{array}{c}\text { Discharge } \\
\left(\mathrm{ft}^{3} / \mathrm{s}\right)\end{array}$ & $\begin{array}{c}\text { Gage } \\
\text { height } \\
\text { (ft) }\end{array}$ \\
\hline 1948 & Feb. 09 & 2,100 & $11.50 c$ & 1967 & May 22 & 211 & 6.80 & 1972 & Jan. 11 & 546 & 8.39 \\
\hline$\underline{1959}$ & Oct. -- & 1,300 & $10.20 c$ & 1968 & Jan. 11 & 490 & 8.25 & 1973 & Apr. 01 & 871 & 9.14 \\
\hline 1961 & Feb. 25 & 2,800 & $12.50 \mathrm{c}$ & 1969 & Jan. 20 & 1,180 & 9.85 & 1974 & Apr. 04 & 711 & 8.78 \\
\hline 1964 & Mar. 25 & 2,370 & 11.90 & 1970 & Mar. 19 & 244 & 7.09 & $\underline{1975}$ & Apr. 02 & 566 & 8.44 \\
\hline 1965 & Oct. 04 & 1,160 & 9.81 & 1971 & Aug. 19 & 2,710 & 12.39 & 1978 & Nov. 05 & 1,880 & $11.20 c$ \\
\hline 1966 & Oct. 01 & 1,820 & 11.11 & & & & & & & & \\
\hline
\end{tabular}




\section{SAVANNAH RIVER BASIN}

\section{TROUBLE CREEK AT LEXINGTON, GEORGIA}

LOCATION.-Lat $33^{\circ} 52^{\prime} 24^{\prime \prime}$, long 83 $03^{\prime} 00^{\prime \prime}$, Oglethorpe County, at culvert on State Highway 77, 0.6 mi northeast of Lexington. DRAINAGE AREA.--2.70 $\mathrm{mi}^{2}$.

GAGE.-Crest-stage gage prior to Sept. 23, 1965; flood-stage recorder thereafter. Datum of gage is about $600 \mathrm{ft}$ above sea level (from topographic map).

STAGE-DISCHARGE RELATION.--Defined by current-meter measurements below $32 \mathrm{tt}^{3} / \mathrm{s}$, and extended above on basis of culvert computations.

\begin{tabular}{|c|c|c|c|c|c|c|c|c|c|c|c|}
\hline $\begin{array}{l}\text { Water } \\
\text { year }\end{array}$ & Date & $\begin{array}{c}\text { Discharge } \\
\left(\mathrm{ft}^{3} / \mathrm{s}\right)\end{array}$ & $\begin{array}{c}\text { Gage } \\
\text { height } \\
\text { (ft) }\end{array}$ & $\begin{array}{l}\text { Water } \\
\text { year }\end{array}$ & Date & $\begin{array}{c}\text { Discharge } \\
\left(\mathrm{ft}^{3} / \mathrm{s}\right)\end{array}$ & $\begin{array}{c}\text { Gage } \\
\text { height } \\
\text { (ft) }\end{array}$ & $\begin{array}{l}\text { Water } \\
\text { year }\end{array}$ & Date & $\begin{array}{c}\text { Discharge } \\
\left(\mathrm{ft}^{3} / \mathrm{s}\right)\end{array}$ & $\begin{array}{c}\text { Gage } \\
\text { height } \\
\text { (ft) }\end{array}$ \\
\hline 1959 & May 31 & 110 & 5.04 & 1965 & Oct. 04 & 164 & 5.80 & 1971 & Mar. 03 & 569 & 10.12 \\
\hline 1960 & Jan. 31 & 54 & 3.95 & 1966 & Oct. 01 & 221 & 6.51 & 1972 & June 20 & 94 & 4.76 \\
\hline 1961 & Mar. 31 & 63 & 4.16 & 1967 & June 22 & 103 & 4.91 & 1973 & Mar. 31 & 215 & 6.44 \\
\hline 1962 & Feb. 22 & 184 & 6.05 & 1968 & July 09 & 133 & 5.38 & 1974 & Apr. 04 & 189 & 6.11 \\
\hline 1963 & Apr. 30 & 60 & 4.10 & 1969 & Apr. 18 & 226 & 6.58 & $\underline{1975}$ & Apr. 02 & 170 & 5.88 \\
\hline 1964 & Apr. 06 & 231 & 6.64 & 1970 & Mar. 19 & 64 & 4.18 & $\overline{1978}$ & Nov. 05 & 352 & $8.02 c$ \\
\hline
\end{tabular}

\section{BUFFALO CREEK NEAR LEXINGTON, GEORGIA}

LOCATION.--Lat $33^{\circ} 46^{\prime} 40^{\prime \prime}$, long $83^{\circ} 03^{\prime} 01^{\prime \prime}$, Oglethorpe County, at culvert on State Highway 22,7 mi southeast of Lexington. DRAINAGE AREA. $-5.60 \mathrm{mi}^{2}$.

GAGE.--Flood-stage/rainfall recorder prior to Sept. 30, 1975. Crest-stage gage thereafter. Datum of gage is about $518 \mathrm{ft}$ above sea level (from topographic map).

STAGE-DISCHARGE RELATION.--Defined by current-meter measurements below $450 \mathrm{ft}^{3} / \mathrm{s}$, and extended above on basis of culvert computations. Bankfull stage and discharge, $6 \mathrm{ft}$ and $620 \mathrm{ft}^{3} / \mathrm{s}$.

\begin{tabular}{|c|c|c|c|c|c|c|c|c|c|c|c|}
\hline $\begin{array}{l}\text { Water } \\
\text { year }\end{array}$ & Date & $\begin{array}{c}\text { Discharge } \\
\left(\mathrm{ft}^{3} / \mathrm{s}\right)\end{array}$ & $\begin{array}{c}\text { Gage } \\
\text { height } \\
\text { (ft) }\end{array}$ & $\begin{array}{l}\text { Water } \\
\text { year }\end{array}$ & Date & $\begin{array}{c}\text { Discharge } \\
\left(\mathrm{ft}^{3} / \mathbf{s}\right)\end{array}$ & $\begin{array}{c}\text { Gage } \\
\text { height } \\
\text { (ft) }\end{array}$ & $\begin{array}{l}\text { Water } \\
\text { year }\end{array}$ & Date & $\begin{array}{c}\text { Discharge } \\
\left(\mathrm{ft}^{3} / \mathrm{s}\right)\end{array}$ & $\begin{array}{c}\text { Gage } \\
\text { height } \\
\text { (ft) }\end{array}$ \\
\hline 1964 & Mar. 25 & 572 & 5.83 & 1973 & Apr. 07 & 393 & 5.09 & 1982 & Apr. 26 & 1,650 & 9.47 \\
\hline 1965 & Dec. 25 & 485 & 5.48 & 1974 & Apr. 04 & 460 & 5.38 & 1983 & Apr. 09 & 1,460 & 8.82 \\
\hline 1966 & Apr. 26 & 522 & 5.63 & 1975 & Apr. 02 & 588 & 5.89 & 1984 & Jan. 11 & 262 & 4.27 \\
\hline 1967 & Mar. 10 & 824 & 6.68 & 1976 & May 29 & 845 & 6.75 & 1985 & Feb. 06 & 199 & 3.66 \\
\hline 1968 & Jan. 11 & 248 & 4.15 & 1977 & Mar. 22 & 296 & 4.54 & 1986 & Jan. 19 & $6,6.0$ & 1.85 \\
\hline 1969 & Apr. 18 & 1,210 & 7.83 & 1978 & Jan. 25 & 674 & 6.18 & 1987 & Mar. 31 & 189 & 3.54 \\
\hline 1970 & Mar. 20 & 387 & 5.06 & 1979 & Feb. 26 & 560 & 5.78 & 1988 & Feb. 04 & 204 & 3.71 \\
\hline 1971 & Mar. 03 & 1,210 & 7.84 & 1980 & Mar. 28 & 367 & 4.96 & 1989 & Apr. 15 & 330 & 4.53 \\
\hline 1972 & Jan. 10 & 397 & 5.11 & 1981 & Feb. 11 & 328 & 4.75 & 1990 & Oct. 01 & 832 & 6.76 \\
\hline
\end{tabular}




\section{SAVANNAH RIVER BASIN}

\section{MACKS CREEK NEAR LEXINGTON, GEORGIA}

LOCATION.--Lat $33^{\circ} 55^{\prime} 24^{\prime \prime}$ long 82 $58^{\prime} 30^{\prime \prime}$, Oglethorpe County, at culvert on State Highway 77, 8 mi northeast of Lexington. DRAINAGE AREA.-3.45 $\mathrm{mi}^{2}$.

GAGE.--Crest-stage gage prior to Sept. 23, 1965; flood-stage recorder thereafter. Datum of gage is about $519 \mathrm{ft}$ above sea level (from topographic map).

STAGE-DISCHARGE RELATION.--Defined by current-meter measurements below $90 \mathrm{ft}^{3} / \mathrm{s}$, and extended above on basis of culvert computations. Bankfull stage and discharge, $5.5 \mathrm{ft}$ and $295 \mathrm{ft}^{3} / \mathrm{s}$.

REMARKS.--Flood of Nov. 5, 1977 was highest since 1948 based on comparison with nearby stations.

\begin{tabular}{|c|c|c|c|c|c|c|c|c|c|c|c|}
\hline $\begin{array}{l}\text { Water } \\
\text { year }\end{array}$ & Date & $\begin{array}{c}\text { Discharge } \\
\left(\mathrm{ft}^{3} / \mathrm{s}\right)\end{array}$ & $\begin{array}{l}\text { Gage } \\
\text { height } \\
\text { (ft) }\end{array}$ & $\begin{array}{l}\text { Water } \\
\text { year }\end{array}$ & Date & $\begin{array}{c}\text { Discharge } \\
\left(\mathrm{ft}^{3} / \mathrm{s}\right)\end{array}$ & $\begin{array}{l}\text { Gage } \\
\text { height } \\
\text { (ft) }\end{array}$ & $\begin{array}{l}\text { Water } \\
\text { year }\end{array}$ & Date & $\begin{array}{c}\text { Discharge } \\
\left(\mathrm{ft}^{3} / \mathrm{s}\right)\end{array}$ & $\begin{array}{c}\text { Gage } \\
\text { height } \\
\text { (ft) }\end{array}$ \\
\hline 1959 & May 31 & 120 & 3.52 & 1965 & Oct. 04 & 167 & 4.32 & 1971 & Mar. 03 & 732 & 8.70 \\
\hline 1960 & Jan. 31 & 195 & 4.85 & 1966 & Oct. 01 & 164 & 4.26 & 1972 & Aug. 11 & 86 & 2.91 \\
\hline 1961 & Mar. 31 & 253 & 5.20 & 1967 & June 27 & 197 & 4.76 & 1973 & Apr. 01 & 232 & 5.05 \\
\hline 1962 & Feb. 22 & 300 & 5.49 & 1968 & June 08 & 188 & 4.66 & 1974 & Apr. 04 & 81 & 2.78 \\
\hline 1963 & June 17 & 378 & 6.09 & 1969 & Jan. 19 & 280 & 5.39 & $\underline{1975}$ & Mar. 13 & 137 & 3.81 \\
\hline 1964 & Apr. 06 & 430 & 6.40 & 1970 & Mar. 19 & 48 & 1.94 & $\overline{1978}$ & Nov. 05 & 1370 & $13.16 \mathrm{c}$ \\
\hline
\end{tabular}

\section{LITTLE MACKS CREEK NEAR LEXINGTON, GEORGIA \\ (formerly published as "Macks Creek Tributary No. 2 near Lexington, Georgia"}

LOCATION.--Lat 3356 '09", long 82 57'41", Oglethorpe County, on right bank, $10 \mathrm{ft}$ upstream from end of culvert wingwall on State Highway $77,11.3$ mi northeast of junction with U.S. Highway 78 , in Lexington.

DRAINAGE AREA.--1.73 $\mathrm{mi}^{2}$.

GAGE.--Crest-stage gage prior to Sept. 29, 1965; flood-stage/rainfall recorder Sept. 24, 1965 to July 1, 1970; water-stage/rainfall recorder July 1, 1970 to Oct. 1, 1974; water-stage recorder thereafter. Datum of gage is $503 \mathrm{ft}$ above sea level (from topographic map).

STAGE-DISCHARGE RELATION.--Defined by current-meter measurements below $15 \mathrm{ft}^{3} / \mathrm{s}$, and extended above on basis of culvert computations. Bankfull stage and discharge, $10 \mathrm{ft}$ and $3,350 \mathrm{tt}^{3} / \mathrm{s}$.

REMARKS.--Flood of Nov. 5, 1977 was highest since 1948 based on comparison with nearby stations. Peak discharge for 1968 is estimated.

\begin{tabular}{|c|c|c|c|c|c|c|c|c|c|c|c|}
\hline $\begin{array}{l}\text { Water } \\
\text { year }\end{array}$ & Date & $\begin{array}{c}\text { Discharge } \\
\left(\mathrm{ft}^{3} / \mathrm{s}\right)\end{array}$ & $\begin{array}{c}\text { Gage } \\
\text { height } \\
\text { (ft) }\end{array}$ & $\begin{array}{l}\text { Water } \\
\text { year }\end{array}$ & Date & $\begin{array}{c}\text { Discharge } \\
\left(\mathrm{ft}^{3} / \mathrm{s}\right)\end{array}$ & $\begin{array}{c}\text { Gage } \\
\text { height } \\
\text { (ft) }\end{array}$ & $\begin{array}{l}\text { Water } \\
\text { year }\end{array}$ & Date & $\begin{array}{c}\text { Discharge } \\
\left(\mathrm{ft}^{3} / \mathrm{s}\right)\end{array}$ & $\begin{array}{c}\text { Gage } \\
\text { height } \\
\text { (ft) }\end{array}$ \\
\hline 1959 & Sept. 07 & 341 & 5.61 & 1968 & June 08 & 70 & - & 1977 & Mar. 21 & 65 & 3.01 \\
\hline 1960 & Jan. 31 & 128 & 3.22 & 1969 & Jan. 19 & 198 & 4.12 & 1978 & Nov. 05 & 853 & 10.49 \\
\hline 1961 & Apr. 27 & 145 & 3.44 & 1970 & Mar. 19 & 44 & 1.90 & 1979 & Apr. 13 & 320 & 6.11 \\
\hline 1962 & Feb. 22 & 288 & 5.10 & 1971 & Mar. 03 & 494 & 7.05 & 1980 & Mar. 28 & 127 & 3.93 \\
\hline 1963 & June 17 & 200 & 4.11 & 1972 & Aug. 11 & 71 & 2.39 & 1981 & Feb. 10 & 51 & 2.77 \\
\hline 1964 & Apr. 06 & 360 & 5.78 & 1973 & Apr. 01 & 294 & 5.16 & 1982 & Feb. 16 & 70 & 3.10 \\
\hline 1965 & Oct. 04 & 290 & 5.13 & 1974 & Apr. 04 & 112 & 3.00 & 1983 & Apr. 08 & 320 & 6.11 \\
\hline 1966 & Oct. 01 & 212 & 4.28 & 1975 & Mar. 13 & 106 & 3.62 & 1984 & Dec. 06 & 333 & 6.23 \\
\hline 1967 & June 26 & 388 & 6.04 & 1976 & Mar. 16 & 372 & 6.75 & 1985 & Feb. 05 & 98 & 3.44 \\
\hline
\end{tabular}




\section{SAVANNAH RIVER BASIN \\ 02192000 BROAD RIVER NEAR BELL, GEORGIA}

LOCATION.-Lat $33^{\circ} 58^{\prime} 27^{\prime \prime}$, long $82^{\circ} 46^{\prime} 12^{\prime \prime}$, Elbert County, at downstream side of main channel pier of bridge on State Highway $17,0.5 \mathrm{mi}$ downstream from Long Creek, $1 \mathrm{mi}$ south of Bells Crossroads, and $12 \mathrm{mi}$ southeast of Elberton.

DRAINAGE AREA.-1,430 $\mathrm{mi}^{2}$, approximately.

GAGE.--Water-stage recorder. Datum of gage is $357.16 \mathrm{ft}$ above sea level, supplementary adjustment of 1936 (from Georgia Department of Transportation). Prior to October 1928, nonrecording gage at railroad bridge about 1 mi downstream at datum $1.12 \mathrm{ft}$ lower. October 1928 to July 1932, and August 1937 to January 1939, nonrecording gage at present site and datum.

STAGE-DISCHARGE RELATION.--Defined by current-meter measurements below $50,000 \mathrm{ft}^{3} / \mathrm{s}$, and extended above on basis of slope-conveyance studies. Bankfull stage and discharge, $18 \mathrm{ft}$ and $14,500 \mathrm{ft}^{3} / \mathrm{s}$.

HISTORICAL DATA.-Flood of Oct. 2, 1929, thought to be highest since 1888 based on records at station on Broad River at Carlton (02191300).

REMARKS.--Stage records for 1927-28 from Alabama Power Co., for 1929-30 from Allied Engineers, Inc., and for 1931-32 from Commonwealth and Southern Corp.

\begin{tabular}{|c|c|c|c|c|c|c|c|c|c|c|c|}
\hline $\begin{array}{l}\text { Water } \\
\text { year }\end{array}$ & Date & $\begin{array}{c}\text { Discharge } \\
\left(\mathrm{ft}^{3} / \mathrm{s}\right)\end{array}$ & $\begin{array}{c}\text { Gage } \\
\text { height } \\
\text { (ft) }\end{array}$ & $\begin{array}{l}\text { Water } \\
\text { year }\end{array}$ & Date & $\begin{array}{c}\text { Discharge } \\
\left(\mathrm{ft}^{3} / \mathrm{s}\right)\end{array}$ & $\begin{array}{c}\text { Gage } \\
\text { height } \\
\text { (ft) }\end{array}$ & $\begin{array}{l}\text { Water } \\
\text { year }\end{array}$ & Date & $\begin{array}{c}\text { Discharge } \\
\left(\mathrm{ft}^{3} / \mathrm{s}\right)\end{array}$ & $\begin{array}{c}\text { Gage } \\
\text { height } \\
\text { (ft) }\end{array}$ \\
\hline 1927 & Dec. 29 & 9,830 & 13.50 & 1952 & Mar. 05 & 27,700 & 24.30 & 1972 & Jan. 12 & 26,600 & 23.87 \\
\hline 1928 & Aug. 16 & $\underline{44,900}$ & $\underline{28.10}$ & 1953 & Feb. 23 & 12,500 & 16.50 & 1973 & Dec. 22 & 27,200 & 24.12 \\
\hline$\overline{1929}$ & Mar. 06 & $\overline{43,500}$ & 29.50 & 1954 & Jan. 18 & 14,700 & 18.00 & 1974 & Jan. 03 & 18,300 & 20.22 \\
\hline 1930 & Oct. 02 & 79,400 & 34.80 & 1955 & Feb. 08 & 14,700 & 18.00 & 1975 & Mar. 15 & 37,100 & 26.71 \\
\hline 1931 & Nov. 17 & 7,140 & 12.00 & 1956 & Mar. 18 & 17,400 & 19.70 & 1976 & Mar. 17 & 30,800 & 25.36 \\
\hline 1932 & June 16 & 14,800 & 18.20 & 1957 & Apr. 07 & 11,900 & 16.10 & 1977 & Apr. 01 & 13,900 & 17.48 \\
\hline$\overline{1938}$ & July 26 & 25,100 & 24.10 & 1958 & Apr. 17 & 15,200 & 18.30 & 1978 & Nov. 07 & 42,900 & 28.60 \\
\hline 1939 & Aug. 19 & 20,300 & 21.40 & 1959 & June 02 & 16,800 & 19.30 & 1979 & Apr. 14 & 30,900 & 25.39 \\
\hline 1940 & Aug. 14 & 28,400 & 25.10 & 1960 & Feb. 01 & 17,900 & 20.00 & 1980 & Mar. 30 & 21,900 & 22.10 \\
\hline 1941 & July 17 & 14,600 & 17.80 & 1961 & Feb. 23 & 24,300 & 23.00 & 1981 & Feb. 12 & 14,300 & 17.73 \\
\hline 1942 & Mar. 22 & 29,100 & 25.40 & 1962 & Dec. 14 & 20,600 & 21.40 & 1982 & Feb. 04 & 25,300 & 23.43 \\
\hline 1943 & Jan. 19 & 33,300 & 27.20 & 1963 & May 01 & 30,000 & 25.10 & 1983 & Apr. 09 & 26,400 & 23.87 \\
\hline 1944 & Mar. 21 & 20,000 & 21.00 & 1964 & Mar. 27 & 34,600 & 26.52 & 1984 & Dec. 07 & 22,500 & 22.17 \\
\hline 1945 & Apr. 26 & 24,500 & 23.30 & 1965 & Oct. 06 & 19,800 & 21.00 & 1985 & Feb. 07 & 14,600 & 17.86 \\
\hline 1946 & Jan. 08 & 27,800 & 24.80 & 1966 & Mar. 05 & 29,100 & 24.78 & 1986 & Dec. 01 & 8,560 & 13.31 \\
\hline 1947 & Jan. 21 & 26,900 & 24.40 & 1967 & June 05 & 36,500 & 27.06 & 1987 & Mar. 02 & 23,200 & 22.49 \\
\hline 1948 & Feb. 10 & 19,900 & 21.30 & 1968 & Jan. 11 & 16,600 & 19.16 & 1988 & Jan. 21 & 9,250 & 13.99 \\
\hline 1949 & Nov. 29 & 47,400 & 30.30 & 1969 & Jan. 21 & 31,400 & 25.55 & 1989 & July 17 & 12,600 & 16.54 \\
\hline 1950 & Mar. 14 & 4,420 & 9.18 & 1970 & Mar. 23 & 15,000 & 18.16 & 1990 & Oct. 02 & 56,100 & 30.98 \\
\hline 1951 & Oct. 22 & 22,900 & 22.80 & 1971 & Mar. 04 & 37,900 & 27.42 & & & & \\
\hline
\end{tabular}


LOCATION.--Lat $33^{\circ} 49^{\prime} 05^{\prime \prime}$, long $82^{\circ} 45^{\prime} 21^{\prime \prime}$, Wilkes County, at culvert on State Highway $17,4.2$ mi south of Tignall. DRAINAGE AREA.--0.097 $\mathrm{mi}^{2}$.

GAGE.--Crest-stage gage prior to Jan. 11, 1967; flood-stage/rainfall recorder for Jan. 11, 1967 to Sept. 30, 1975; crest-stage gage thereafter. Datum of gage is about $530 \mathrm{ft}$ above sea level (from topographic map).

STAGE-DISCHARGE RELATION.--Defined by culvert computations.

REMARKS.--Peak discharges for $1960-63$ are estimated.

\begin{tabular}{|c|c|c|c|c|c|c|c|c|c|c|c|}
\hline $\begin{array}{l}\text { Water } \\
\text { year }\end{array}$ & Date & $\begin{array}{c}\text { Discharge } \\
\left(\mathrm{ft}^{3} / \mathrm{s}\right)\end{array}$ & $\begin{array}{c}\text { Gage } \\
\text { height } \\
\text { (ft) }\end{array}$ & $\begin{array}{l}\text { Water } \\
\text { year }\end{array}$ & Date & $\begin{array}{c}\text { Discharge } \\
\left(\mathrm{ft}^{3} / \mathrm{s}\right)\end{array}$ & $\begin{array}{c}\text { Gage } \\
\text { height } \\
\text { (ft) }\end{array}$ & $\begin{array}{l}\text { Water } \\
\text { year }\end{array}$ & Date & $\begin{array}{c}\text { Discharge } \\
\left(\mathrm{ft}^{3} / \mathrm{s}\right)\end{array}$ & $\begin{array}{c}\text { Gage } \\
\text { height } \\
\text { (ft) }\end{array}$ \\
\hline 1959 & May 31 & $\$ 2.0$ & 7.55 & 1969 & Apr. 18 & 85.0 & 8.66 & 1979 & Feb. 24 & 19.0 & 6.27 \\
\hline 1960 & Jan. 31 & 25.0 & - & 1970 & Mar. 20 & 8.0 & 5.71 & 1980 & Mar. 28 & 20.0 & 6.28 \\
\hline 1961 & Mar. -- & 30.0 & - & 1971 & Sept.01 & 116 & 9.41 & 1981 & Feb. 11 & 11.0 & 5.87 \\
\hline 1962 & Feb. 22 & 30.0 & -- & 1972 & June 28 & 48.0 & 7.43 & 1982 & Sept. 01 & 66.0 & 8.11 \\
\hline 1963 & June 17 & 30.0 & - & 1973 & June 28 & 51.0 & 7.57 & 1983 & Mar. 06 & 68.0 & 8.16 \\
\hline 1964 & Apr. 06 & 46.0 & 7.33 & 1974 & Jan. 29 & 29.0 & 6.74 & 1984 & July 14 & 98.0 & 8.97 \\
\hline 1965 & Dec. 25 & 50.0 & 7.50 & 1975 & Apr. 02 & 111 & 9.28 & 1985 & July 14 & 44.0 & 7.31 \\
\hline 1966 & Mar. 04 & 59.0 & 7.87 & 1976 & May 15 & 36.0 & 6.97 & 1986 & May 28 & 64.0 & 8.04 \\
\hline 1967 & Mar. 10 & 36.0 & 6.96 & 1977 & Mar. 13 & 46.0 & 7.36 & $\underline{1987}$ & Aug. 07 & 17.0 & 6.17 \\
\hline 1968 & June 08 & 47.0 & 7.41 & 1978 & May 08 & 85.0 & 8.66 & $\overline{1990}$ & Oct. 01 & 90.0 & $8.85 \mathrm{c}$ \\
\hline
\end{tabular}

\section{ANDERSON MILL CREEK NEAR DANBURG, GEORGIA}

LOCATION.--Lat $33^{\circ} 48^{\prime} 55^{\prime \prime}$, long $82^{\circ} 41^{\prime} 35^{\prime \prime}$, Wilkes County, at culvert on State Highway $44,4.2$ mi southwest of Danburg. DRAINAGE AREA.--5.49 $\mathrm{mi}^{2}$.

GAGE.--Flood-stage/rainfall recorder. Datum of gage is about $440 \mathrm{ft}$ above sea level (from topographic map).

STAGE-DISCHARGE RELATION.--Defined by current-meter measurements below $440 \mathrm{ft}^{3} / \mathrm{s}$, and extended above, on basis of culvert computations.

\begin{tabular}{|c|c|c|c|c|c|c|c|c|c|c|c|}
\hline $\begin{array}{l}\text { Water } \\
\text { year }\end{array}$ & Date & $\begin{array}{c}\text { Discharge } \\
\left(\mathrm{ft}^{3} / \mathrm{s}\right)\end{array}$ & $\begin{array}{c}\text { Gage } \\
\text { height } \\
\text { (ft) }\end{array}$ & $\begin{array}{l}\text { Water } \\
\text { year }\end{array}$ & Date & $\begin{array}{c}\text { Discharge } \\
\left(\mathrm{ft}^{3} / \mathrm{s}\right)\end{array}$ & $\begin{array}{c}\text { Gage } \\
\text { height } \\
\text { (ft) }\end{array}$ & $\begin{array}{l}\text { Water } \\
\text { year }\end{array}$ & Date & $\begin{array}{c}\text { Discharge } \\
\left(\mathrm{ft}^{3} / \mathrm{s}\right)\end{array}$ & $\begin{array}{c}\text { Gage } \\
\text { height } \\
\text { (ft) }\end{array}$ \\
\hline 1964 & Apr. 06 & 744 & 6.72 & 1968 & June 08 & 301 & 4.07 & 1972 & June 28 & 668 & 6.32 \\
\hline 1965 & Dec. 25 & 786 & 6.93 & 1969 & Apr. 18 & 1,110 & 8.46 & 1973 & Feb. 02 & 832 & 7.16 \\
\hline 1966 & Mar. 04 & 726 & 6.63 & 1970 & Mar. 19 & 211 & 3.28 & 1974 & Jan. 30 & 185 & 2.90 \\
\hline 1967 & Mar. 10 & 218 & 3.46 & 1971 & Sept. 01 & 942 & 7.71 & 1975 & Apr. 02 & 818 & 7.09 \\
\hline
\end{tabular}


LOCATION.--Lat $33^{\circ} 49^{\prime} 42^{\prime \prime}$, long $82^{\circ} 41^{\prime} 13^{\prime \prime}$, Wilkes County, at culvert on State Highway 44, 3.5 mi southwest of Danburg. DRAINAGE AREA.-0.92 $\mathrm{mi}^{2}$.

GAGE.-Flood-stage recorder. Datum of gage is about $460 \mathrm{ft}$ above sea level (from topographic map).

STAGE-DISCHARGE RELATION.--Defined by culvert computations.

\begin{tabular}{|c|c|c|c|c|c|c|c|c|c|c|c|}
\hline $\begin{array}{l}\text { Water } \\
\text { year }\end{array}$ & Date & $\begin{array}{c}\text { Discharge } \\
\left(\mathrm{ft}^{3} / \mathrm{s}\right)\end{array}$ & $\begin{array}{c}\text { Gage } \\
\text { height } \\
\text { (ft) }\end{array}$ & $\begin{array}{l}\text { Water } \\
\text { year }\end{array}$ & Date & $\begin{array}{c}\text { Discharge } \\
\left(\mathrm{ft}^{3} / \mathrm{s}\right)\end{array}$ & $\begin{array}{c}\text { Gage } \\
\text { height } \\
\text { (ft) }\end{array}$ & $\begin{array}{l}\text { Water } \\
\text { year }\end{array}$ & Date & $\begin{array}{c}\text { Discharge } \\
\left(\mathrm{ft}^{3} / \mathrm{s}\right)\end{array}$ & $\begin{array}{c}\text { Gage } \\
\text { height } \\
\text { (ft) }\end{array}$ \\
\hline 1964 & Mar. 25 & 180 & 5.14 & 1968 & Apr. 05 & 36 & 2.87 & 1972 & June 28 & 210 & 5.51 \\
\hline 1965 & Dec. 25 & 194 & 5.31 & 1969 & Apr. 18 & 373 & 7.30 & 1973 & Feb. 02 & 268 & 6.20 \\
\hline 1966 & Mar. 04 & 158 & 4.86 & 1970 & Mar. 19 & 28 & 2.72 & 1974 & Jan. 30 & 82 & 3.74 \\
\hline 1967 & Mar. 10 & 52 & 3.17 & 1971 & Mar. 03 & 237 & 5.85 & 1975 & Apr. 02 & 333 & 6.90 \\
\hline
\end{tabular}

\section{STEPHENS CREEK NEAR CRAWFORDVILLE, GEORGIA}

LOCATION.--Lat $33^{\circ} 36^{\prime} 05^{\prime \prime}$, long $82^{\circ} 55^{\prime} 28^{\prime \prime}$, Taliaferro County, at culvert on State Highway $22,3.5$ mi northwest of Crawfordville. DRAINAGE AREA, $-6.30 \mathrm{mi}^{2}$.

GAGE.--Flood-stage/rainfall recorder. Datum of gage is about $450 \mathrm{ft}$ above sea level (from topographic map).

STAGE-DISCHARGE RELATION.--Defined by current-meter measurements below $250 \mathrm{ft}^{3} / \mathrm{s}$, and extended above on basis of culvert computations.

\begin{tabular}{|c|c|c|c|c|c|c|c|c|c|c|c|}
\hline $\begin{array}{l}\text { Water } \\
\text { year }\end{array}$ & Date & $\begin{array}{c}\text { Discharge } \\
\left(\mathrm{ft}^{3} / \mathrm{s}\right)\end{array}$ & $\begin{array}{c}\text { Gage } \\
\text { height } \\
\text { (ft) }\end{array}$ & $\begin{array}{l}\text { Water } \\
\text { year }\end{array}$ & Date & $\begin{array}{c}\text { Discharge } \\
\left(\mathrm{ft}^{3} / \mathrm{s}\right)\end{array}$ & $\begin{array}{c}\text { Gage } \\
\text { height } \\
\text { (ft) }\end{array}$ & $\begin{array}{c}\text { Water } \\
\text { year }\end{array}$ & Date & $\begin{array}{c}\text { Discharge } \\
\left(\mathrm{ft}^{3} / \mathrm{s}\right)\end{array}$ & $\begin{array}{c}\text { Gage } \\
\text { height } \\
\text { (ft) }\end{array}$ \\
\hline$\underline{1961}$ & Feb. 27 & 500 & $6.20 c$ & 1968 & Jan. 10 & 440 & 6.00 & 1972 & Jan. 11 & 444 & 6.02 \\
\hline 1964 & Mar. 25 & 1,210 & 8.17 & 1969 & Apr. 18 & 2,270 & 9.62 & 1973 & Apr. 07 & 727 & 7.13 \\
\hline 1965 & Dec. 25 & 1,870 & 9.12 & 1970 & Mar. 21 & 911 & 7.58 & 1974 & Apr. 04 & 708 & 7.08 \\
\hline 1966 & May 22 & 1,110 & 7.98 & 1971 & Mar. 02 & 787 & 7.28 & 1975 & Apr. 02 & 708 & 7.08 \\
\hline 1967 & Mar. 10 & 460 & 6.08 & & & & & & & & \\
\hline
\end{tabular}

\section{HARDEN CREEK NEAR SHARON, GEORGIA}

LOCATION.--Lat $33^{\circ} 33^{\prime} 10^{\prime \prime}$, long $82^{\circ} 50^{\prime} 15^{\prime \prime}$, Taliaferro County, at culvert on State Highway 47, 2.5 mi west of Sharon. DRAINAGE AREA.--3.98 $\mathrm{mi}^{2}$.

GAGE.--Flood-stage/rainfall recorder. Datum of gage is about $490 \mathrm{ft}$ above sea level (from topographic map).

STAGE-DISCHARGE RELATION.--Defined by current-meter measurements below $130 \mathrm{ft}^{3} / \mathrm{s}$, and extended above on basis of culvert computations.

\begin{tabular}{|c|c|c|c|c|c|c|c|c|c|c|c|}
\hline $\begin{array}{l}\text { Water } \\
\text { year }\end{array}$ & Date & $\begin{array}{c}\text { Discharge } \\
\left(\mathrm{ft}^{3} / \mathrm{s}\right)\end{array}$ & $\begin{array}{c}\text { Gage } \\
\text { height } \\
\text { (ft) }\end{array}$ & $\begin{array}{l}\text { Water } \\
\text { year }\end{array}$ & Date & $\begin{array}{c}\text { Discharge } \\
\left(\mathrm{ft}^{3} / \mathrm{s}\right)\end{array}$ & $\begin{array}{c}\text { Gage } \\
\text { height } \\
\text { (ft) }\end{array}$ & $\begin{array}{l}\text { Water } \\
\text { year }\end{array}$ & Date & $\begin{array}{c}\text { Discharge } \\
\left(\mathrm{ft}^{3} / \mathrm{s}\right)\end{array}$ & $\begin{array}{c}\text { Gage } \\
\text { height } \\
\text { (ft) }\end{array}$ \\
\hline 1964 & Apr. 06 & 1,060 & 6.22 & 1968 & Jan. 10 & 222 & 3.44 & 1972 & Jan. 10 & 286 & 4.03 \\
\hline 1965 & Dec. 26 & 710 & 5.73 & 1969 & Aug. 03 & 787 & 5.87 & 1973 & Feb. 01 & 819 & 5.92 \\
\hline 1966 & June 10 & 352 & 4.48 & 1970 & Mar. 21 & 597 & 5.48 & 1974 & Apr. 04 & 232 & 3.54 \\
\hline 1967 & Mar. 10 & 472 & 5.09 & 1971 & Mar. 02 & 438 & 4.94 & 1975 & Apr. 02 & 525 & 5.30 \\
\hline
\end{tabular}




\section{SAVANNAH RIVER BASIN \\ 02193500 LITTLE RIVER NEAR WASHINGTON, GEORGIA}

LOCATION.--Lat $33^{\circ} 36^{\prime} 40^{\prime \prime}$, long $82^{\circ} 44^{\prime} 40^{\prime \prime}$, Wilkes County, near left bank on downstream side of highway bridge pier, $700 \mathrm{ft}$ downstream from Reedy Creek, $4 \mathrm{mi}$ downstream from Georgia Railroad bridge, $6 \mathrm{mi}$ upstream from Williams Creek, and $9 \mathrm{mi}$ south of Washington.

DRAINAGE AREA.--291 $\mathrm{mi}^{2}$.

GAGE.-Water-stage recorder from Sept. 21, 1949 to June 23, 1971; May 16, 1989 to present at same site, different datum.

Datum of gage is $353.88 \mathrm{ft}$ above sea level (levels by Global Positioning System).

STAGE-DISCHARGE RELATION.--Defined by current-meter measurements below $14,700 \mathrm{ft}^{3} / \mathrm{s}$. Bankfull stage and discharge, $18 \mathrm{ft}$ and $6,400 \mathrm{ft}^{3} / \mathrm{s}$.

\begin{tabular}{|c|c|c|c|c|c|c|c|c|c|c|c|}
\hline $\begin{array}{l}\text { Water } \\
\text { year }\end{array}$ & Date & $\begin{array}{c}\text { Discharge } \\
\left(\mathrm{ft}^{3} / \mathrm{s}\right)\end{array}$ & $\begin{array}{c}\text { Gage } \\
\text { height } \\
\text { (ft) }\end{array}$ & $\begin{array}{l}\text { Water } \\
\text { year }\end{array}$ & Date & $\begin{array}{c}\text { Discharge } \\
\left(\mathrm{ft}^{3} / \mathrm{s}\right)\end{array}$ & $\begin{array}{c}\text { Gage } \\
\text { height } \\
\text { (ft) }\end{array}$ & $\begin{array}{l}\text { Water } \\
\text { year }\end{array}$ & Date & $\begin{array}{c}\text { Discharge } \\
\left(\mathrm{ft}^{3} / \mathrm{s}\right)\end{array}$ & $\begin{array}{c}\text { Gage } \\
\text { height } \\
\text { (ft) }\end{array}$ \\
\hline 1950 & Oct. 08 & 3,790 & 17.60 & 1958 & Apr. 17 & 9,220 & 24.40 & 1966 & Mar. 05 & 7,440 & 22.82 \\
\hline 1951 & Oct. 22 & 2,160 & 13.40 & 1959 & June 03 & 3,140 & 16.20 & 1967 & Mar. 11 & 4,390 & 18.58 \\
\hline 1952 & Mar. 04 & 13,100 & 27.60 & 1960 & Jan. 31 & 7,910 & 22.90 & 1968 & Jan. 11 & 4,950 & 19.37 \\
\hline 1953 & May 01 & 9,880 & 24.80 & 1961 & Feb. 25 & 9,110 & 24.10 & 1969 & Apr. 19 & 10,300 & 25.71 \\
\hline 1954 & Feb. 21 & 1,300 & 10.00 & 1962 & Feb. 23 & 8,500 & 23.60 & 1970 & Mar. 22 & 7,360 & 22.67 \\
\hline 1955 & Feb. 08 & 2,280 & 13.80 & 1963 & $\operatorname{Jan} .21$ & 6,710 & 21.53 & $\underline{1971}$ & Mar. 03 & 15,500 & $\underline{27.93}$ \\
\hline 1956 & Apr. 12 & 5,680 & 20.30 & 1964 & May 03 & 13,400 & 27.84 & $\overline{1990}$ & Oct. 01 & 13,000 & $\overline{27.62}$ \\
\hline 1957 & Mar. 26 & 3,480 & 17.00 & 1965 & Dec. 27 & 13,100 & 27.56 & & & & \\
\hline
\end{tabular}

\section{ROCKY CREEK NEAR WASHINGTON, GEORGIA}

LOCATION.--Lat $33^{\circ} 42^{\prime} 55^{\prime \prime}$, long $82^{\circ} 44^{\prime} 42^{\prime \prime}$, Wilkes County, at culvert on State Highway $47,1.5$ mi south of Washington. DRAINAGE AREA.--1.14 $\mathrm{mi}^{2}$.

GAGE.--Flood-stage/rainfall recorder. Datum of gage is about $550 \mathrm{ft}$ above sea level (from topographic map).

STAGE-DISCHARGE RELATION.--Defined by current-meter measurements below $25 \mathrm{ft}^{3} / \mathrm{s}$, and extended above on basis of culvert computations.

\begin{tabular}{lccccccccccc}
\hline $\begin{array}{l}\text { Water } \\
\text { year }\end{array}$ & Date & $\begin{array}{c}\text { Discharge } \\
\left(\mathrm{ft}^{3} / \mathrm{s}\right)\end{array}$ & $\begin{array}{c}\text { Gage } \\
\text { height } \\
(\mathrm{ft})\end{array}$ & $\begin{array}{c}\text { Water } \\
\text { year }\end{array}$ & Date & $\begin{array}{c}\text { Discharge } \\
\left(\mathrm{ft}^{3} / \mathrm{s}\right)\end{array}$ & $\begin{array}{c}\text { Gage } \\
\text { height } \\
(\mathrm{ft})\end{array}$ & $\begin{array}{c}\text { Water } \\
\text { year }\end{array}$ & $\begin{array}{c}\text { Gage } \\
\text { Date }\end{array}$ & $\begin{array}{c}\text { Discharge } \\
\left(\mathrm{ft}^{3} / \mathrm{s}\right)\end{array}$ & $\begin{array}{c}\text { height } \\
\left(\mathrm{ft}^{3}\right)\end{array}$ \\
\hline & & & & & & & & & & & \\
1964 & Mar. 25 & 303 & 5.01 & 1968 & July 10 & 164 & 3.43 & 1972 & Aug. 11 & 299 & 4.97 \\
1965 & Dec. 25 & 515 & 6.96 & 1969 & Apr. 18 & 673 & 8.28 & 1973 & Feb. 02 & 436 & 6.30 \\
1966 & Mar. 04 & 458 & 6.48 & 1970 & Mar. 19 & 200 & 3.88 & 1974 & Jan. 30 & 249 & 4.46 \\
1967 & July 01 & 478 & 6.65 & 1971 & Sept.01 & 448 & 6.40 & 1975 & Apr. 02 & 419 & 6.16 \\
\hline
\end{tabular}




\section{LITTLE RIVER NEAR LINCOLNTON, GEORGIA}

LOCATION.--Lat $33^{\circ} 38^{\prime} 40^{\prime \prime}$, long $82^{\circ} 28^{\prime} 40^{\prime \prime}$, Lincoln County, on downstream side of Raysville Bridge on State Highway $43,0.5$ mi downstream from Big Creek, $2.5 \mathrm{mi}$ south of Amity, and $10 \mathrm{mi}$ south of Lincolnton.

DRAINAGE AREA.--574 $\mathrm{mi}^{2}$.

GAGE.--Nonrecording. Datum of gage is $271.7 \mathrm{ft}$ above sea level (unadjusted) (from U.S. Geological Survey benchmark).

STAGE-DISCHARGE RELATION.--Defined by current-meter measurements below $17,000 \mathrm{ft}^{3} / \mathrm{s}$, and extended above on basis of slope-conveyance studies at a discharge of $54,000 \mathrm{ft}^{3} / \mathrm{s}$. Bankfull stage and discharge, $15 \mathrm{ft}$ and $6,200 \mathrm{ft}^{3} / \mathrm{s}$.

HISTORICAL DATA.--Flood-stage of Sept. 28, 1929, based on information furnished by local resident. This is thought to be highest flood since 1908, based on information at nearby stations.

REMARKS.--This station inundated by J. Strom Thurmond Reservoir (formerly Clarks Hill Reservoir)

\begin{tabular}{lccccccccccc}
\hline $\begin{array}{l}\text { Water } \\
\text { year }\end{array}$ & Date & $\begin{array}{c}\text { Discharge } \\
\left(\mathrm{ft}^{3} / \mathrm{s}\right)\end{array}$ & $\begin{array}{c}\text { Gage } \\
\text { height } \\
(\mathrm{ft})\end{array}$ & $\begin{array}{c}\text { Water } \\
\text { year }\end{array}$ & Date & $\begin{array}{c}\text { Discharge } \\
\left(\mathrm{ft}^{3} / \mathrm{s}\right)\end{array}$ & $\begin{array}{c}\text { Gage } \\
\text { height } \\
(\mathrm{ft})\end{array}$ & $\begin{array}{c}\text { Water } \\
\text { year }\end{array}$ & $\begin{array}{c}\text { Gage } \\
\text { Date }\end{array}$ & $\begin{array}{c}\text { Discharge } \\
\left(\mathrm{ft}^{3} / \mathrm{s}\right)\end{array}$ & $\begin{array}{c}\text { height } \\
(\mathrm{ft})\end{array}$ \\
\hline $\mathbf{1 9 2 9}$ & Sept.28 & 54,000 & $44.30 \mathrm{c}$ & 1946 & Dec. 25 & 4,920 & 12.20 & 1949 & Nov. 29 & 12,400 & 23.00 \\
1943 & Jan. 19 & 9,580 & 20.00 & 1947 & Mar. 08 & 9,920 & 20.40 & 1950 & Oct. 08 & 9,100 & 19.40 \\
1944 & Mar. 23 & 16,900 & 26.40 & 1948 & Feb. 10 & 9,750 & 20.20 & 1951 & Feb. 08 & 2,090 & 6.40 \\
1945 & Apr. 25 & 5,040 & 12.40 & & & & & & & & \\
\hline
\end{tabular}

\section{SAVANNAH RIVER NEAR CLARKS HILL, SOUTH CAROLINA}

LOCATION.--Lat $33^{\circ} 38^{\prime} 40^{\prime \prime}$, long $82^{\circ} 12^{\prime} 05^{\prime \prime}$, McCormick County, on right bank 1.2 mi downstream from J. Strom Thurmond Reservoir dam (formerly Clarks Hill Reservoir dam), 2.4 mi southwest of Clarks Hill, 2.5 mi upstream from Kiokee Creek and at mile 236.5.

DRAINAGE AREA.--6,150 $\mathrm{mi}^{2}$.

GAGE.-Water-stage recorder. Datum of gage is $182.69 \mathrm{ft}$ above sea level (levels by U.S. Army Corps of Engineers).

STAGE-DISCHARGE RELATION.--Defined by current-meter measurements. Bankfull and discharge, $17 \mathrm{ft}$ and $66,000 \mathrm{ft}^{3} / \mathrm{s}$.

REMARKS.--Peak discharges regulated by storage in Hartwell Reservoir (maximum flood-control storage, 1,708,600 acre-ft) since 1959, and J. Strom Thurmond Reservoir (maximum flood-control storage, 1,730,000 acre-ft) since 1951. Minor regulation from Lake Burton and Mathis Reservoir. (See station 02184000.)

\begin{tabular}{|c|c|c|c|c|c|c|c|c|c|c|c|}
\hline $\begin{array}{l}\text { Water } \\
\text { year }\end{array}$ & Date & $\begin{array}{c}\text { Discharge } \\
\left(\mathrm{ft}^{3} / \mathrm{s}\right)\end{array}$ & $\begin{array}{c}\text { Gage } \\
\text { height } \\
\text { (ft) }\end{array}$ & $\begin{array}{l}\text { Water } \\
\text { year }\end{array}$ & Date & $\begin{array}{c}\text { Discharge } \\
\left(\mathrm{ft}^{3} / \mathrm{s}\right)\end{array}$ & $\begin{array}{c}\text { Gage } \\
\text { height } \\
\text { (ft) }\end{array}$ & $\begin{array}{l}\text { Water } \\
\text { year }\end{array}$ & Date & $\begin{array}{c}\text { Discharge } \\
\left(\mathrm{ft}^{3} / \mathrm{s}\right)\end{array}$ & $\begin{array}{c}\text { Gage } \\
\text { height } \\
\text { (ft) }\end{array}$ \\
\hline 1940 & Aug. 14 & 196,000 & 29.34 & 1945 & Apr. 26 & 61,200 & 15.72 & 1950 & Oct. 09 & 36,800 & 11.61 \\
\hline 1941 & July 08 & 54,900 & 14.12 & 1946 & Jan. 08 & 110,000 & 22.11 & 1951 & Oct. 22 & 48,700 & 14.54 \\
\hline 1942 & Mar. 23 & 99,300 & 20.77 & 1947 & Jan. 21 & 87,000 & 19.99 & 1952 & Mar. 07 & 35,400 & $11.56 \mathrm{a}$ \\
\hline 1943 & Jan. 20 & 111,000 & 22.16 & 1948 & Feb. 10 & 63,600 & 16.61 & 1953 & May 07 & 30,000 & 10.52 \\
\hline 1944 & Mar. 21 & 111,000 & 22.31 & 1949 & Nov. 30 & 154,000 & 26.35 & 1954 & Mar. 30 & 30,000 & 10.67 \\
\hline
\end{tabular}




\section{SAVANNAH RIVER BASIN}

\section{KIOKEE CREEK AT APPLING, GEORGIA}

LOCATION.--Lat $33^{\circ} 32^{\prime} 33^{\prime \prime}$, long $82^{\circ} 18^{\prime} 56^{\prime \prime}$, Columbia County, at bridge on U.S. Highway $221,3.4$ miles north of Interstate 20 , exit 61, at Appling.

DRAINAGE AREA. $-43.9 \mathrm{mi}^{2}$.

GAGE.-Crest-stage gage. Datum of gage is about $225 \mathrm{ft}$ above sea level (from topographic map).

STAGE-DISCHARGE RELATION.--Defined by current-meter measurements below $1,230 \mathrm{ft}^{3} / \mathrm{s}$, and extended above on basis of straight-line extension. Bankfull stage and discharge, $7 \mathrm{ft}$ and $100 \mathrm{ft}^{3} / \mathrm{s}$.

\begin{tabular}{|c|c|c|c|c|c|c|c|c|c|c|c|}
\hline $\begin{array}{l}\text { Water } \\
\text { year }\end{array}$ & Date & $\begin{array}{c}\text { Discharge } \\
\left(\mathrm{ft}^{3} / \mathrm{s}\right)\end{array}$ & $\begin{array}{c}\text { Gage } \\
\text { height } \\
\text { (ft) }\end{array}$ & $\begin{array}{l}\text { Water } \\
\text { year }\end{array}$ & Date & $\begin{array}{c}\text { Discharge } \\
\left(\mathrm{ft}^{3} / \mathrm{s}\right)\end{array}$ & $\begin{array}{c}\text { Gage } \\
\text { height } \\
\text { (ft) }\end{array}$ & $\begin{array}{l}\text { Water } \\
\text { year }\end{array}$ & Date & $\begin{array}{l}\text { Discharge } \\
\left(\mathrm{ft}^{3} / \mathrm{s}\right)\end{array}$ & $\begin{array}{c}\text { Gage } \\
\text { height } \\
\text { (ft) }\end{array}$ \\
\hline 1984 & May 04 & 1,770 & 10.18 & 1987 & Jan. 19 & 1,310 & 9.76 & 1989 & Sept.22 & 1,170 & 9.65 \\
\hline 1985 & Feb. 06 & 1,900 & 10.27 & 1988 & Mar. -- & 730 & $-\mathrm{b}$ & 1990 & Jan. -- & 730 & $-b$ \\
\hline 1986 & Oct. 22 & 1,650 & 10.08 & & & & & & & & \\
\hline
\end{tabular}

\section{RAES CREEK TRIBUTARY NO. 2, AT AUGUSTA, GEORGIA}

LOCATION.--Lat 33³0'19", long 82 02'34", Richmond County, at culvert on Skinner Mill Road at junction with Boy Scout Road, at Augusta.

DRAINAGE AREA.--0.66 $\mathrm{mi}^{2}$

GAGE.--Flood-stage/rainfall recorder prior to 1986. Crest-stage gage, 1986-88.

STAGE-DISCHARGE RELATION.--Defined by current-meter measurements below $10 \mathrm{ft}^{3} / \mathrm{s}$, and extended above on the basis of culvert computations.

REMARKS.--Flow is affected by urbanization. Peak discharges for 1983, 1986, and 1988 undetermined owing to debris in culvert.

\begin{tabular}{|c|c|c|c|c|c|c|c|c|c|c|c|}
\hline $\begin{array}{l}\text { Water } \\
\text { year }\end{array}$ & Date & $\begin{array}{c}\text { Discharge } \\
\left(\mathrm{ft}^{3} / \mathrm{s}\right)\end{array}$ & $\begin{array}{c}\text { Gage } \\
\text { height } \\
\text { (ft) }\end{array}$ & $\begin{array}{l}\text { Water } \\
\text { year }\end{array}$ & Date & $\begin{array}{c}\text { Discharge } \\
\left(\mathrm{ft}^{3} / \mathrm{s}\right)\end{array}$ & $\begin{array}{c}\text { Gage } \\
\text { height } \\
\text { (ft) }\end{array}$ & $\begin{array}{l}\text { Water } \\
\text { year }\end{array}$ & Date & $\begin{array}{c}\text { Discharge } \\
\left(\mathrm{ft}^{3} / \mathrm{s}\right)\end{array}$ & $\begin{array}{c}\text { Gage } \\
\text { height } \\
\text { (ft) }\end{array}$ \\
\hline $\begin{array}{l}1979 \\
1980 \\
1981 \\
1982\end{array}$ & $\begin{array}{l}\text { July } 20 \\
\text { Mar. } 17 \\
\text { Aug. } 12 \\
\text { May. } 30\end{array}$ & $\begin{array}{l}126 \\
119 \\
121 \\
159\end{array}$ & $\begin{array}{l}5.96 \\
5.77 \\
5.83 \\
6.80\end{array}$ & $\begin{array}{l}1983 \\
1984 \\
1985\end{array}$ & $\begin{array}{l}\text { Sept. } 13 \\
\text { May. } 03 \\
\text { July } 14\end{array}$ & $\begin{array}{r}-. \\
177 \\
79.0\end{array}$ & $\begin{array}{l}8.27 \\
7.26 \\
4.62\end{array}$ & $\begin{array}{l}1986 \\
1987 \\
1988\end{array}$ & $\begin{array}{l}\text { Aug. } 28 \\
\text { Aug. } 01 \\
\text { May. } 24\end{array}$ & $\begin{array}{r}-. \\
112 \\
-.\end{array}$ & $\begin{array}{l}9.98 \\
5.77 \\
7.65\end{array}$ \\
\hline
\end{tabular}

\section{RAES CREEK TRIBUTARY NO. 1, AT AUGUSTA, GEORGIA}

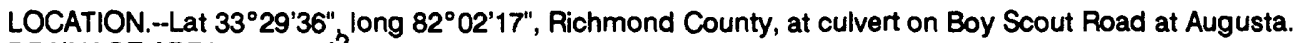

DRAINAGE AREA.--1.67 $\mathrm{mi}^{2}$.

GAGE.--Flood-stage/ rainfall recorder prior to 1986. Crest-stage gage 1986 thereafter. Datum of gage is $194.90 \mathrm{ft}$ above sea level (from U.S. Army Corps of Engineers benchmark).

STAGE-DISCHARGE RELATION.--Defined by current-meter measurement below $103 \mathrm{ft}^{3} / \mathrm{s}$ and extended above on the basis of culvert computations.

REMARKS.--Flow is affected by urbanization. Peak discharges for 1986 and 1988 undetermined owing to debris in culvert.

\begin{tabular}{|c|c|c|c|c|c|c|c|c|c|c|c|}
\hline $\begin{array}{l}\text { Water } \\
\text { year }\end{array}$ & Date & $\begin{array}{c}\text { Discharge } \\
\left(\mathrm{ft}^{3} / \mathrm{s}\right)\end{array}$ & $\begin{array}{c}\text { Gage } \\
\text { height } \\
\text { (ft) }\end{array}$ & $\begin{array}{l}\text { Water } \\
\text { year }\end{array}$ & Date & $\begin{array}{c}\text { Discharge } \\
\left(\mathrm{ft}^{3} / \mathrm{s}\right)\end{array}$ & $\begin{array}{c}\text { Gage } \\
\text { height } \\
\text { (ft) }\end{array}$ & $\begin{array}{l}\text { Water } \\
\text { year }\end{array}$ & Date & $\begin{array}{c}\text { Discharge } \\
\left(\mathrm{ft}^{3} / \mathrm{s}\right)\end{array}$ & $\begin{array}{c}\text { Gage } \\
\text { height } \\
\text { (ft) }\end{array}$ \\
\hline $\begin{array}{l}1979 \\
1980 \\
1981 \\
1982\end{array}$ & $\begin{array}{l}\text { May. } 31 \\
\text { Oct. } 04 \\
\text { Aug. } 12 \\
\text { May. } 24\end{array}$ & $\begin{array}{r}986 \\
765 \\
655 \\
1,240\end{array}$ & $\begin{array}{l}7.34 \\
7.06 \\
6.90 \\
7.61\end{array}$ & $\begin{array}{l}1983 \\
1984 \\
1985 \\
1986\end{array}$ & $\begin{array}{l}\text { Sept. } 13 \\
\text { July } 01 \\
\text { July } 14 \\
\text { July } 24\end{array}$ & $\begin{array}{r}1,250 \\
795 \\
900 \\
-\end{array}$ & $\begin{array}{l}7.62 \\
7.10 \\
7.25 \\
8.37\end{array}$ & $\begin{array}{l}1987 \\
1988 \\
1989\end{array}$ & $\begin{array}{l}\text { Aug. } 01 \\
\text { Apr. } 23 \\
\text { July } 12\end{array}$ & $\begin{array}{l}1,170 \\
1,640 \\
1,640\end{array}$ & $\begin{array}{l}7.68 \\
8.08 \\
8.08\end{array}$ \\
\hline
\end{tabular}




\section{SAVANNAH RIVER BASIN}

\section{OATES CREEK AT WHITE ROAD AT AUGUSTA, GEORGIA}

LOCATION.--Lat $33^{\circ} 27^{\prime} 19^{\prime \prime}$, long $82^{\circ} 00^{\prime} 23^{\prime \prime}$, Richmond County, at culvert on White Road.

DRAINAGE AREA.- $-1.44 \mathrm{mi}^{2}$.

GAGE.--Flood-stage/rainfall recorder prior to 1986. Crest-stage gage 1986-89. Datum of gage is $140.84 \mathrm{ft}$ above sea level (from

U.S. Army Corps of Engineers benchmark).

STAGE-DISCHARGE RELATION.--Defined by current-meter measurement below $25 \mathrm{ft}^{3} / \mathrm{s}$ and extended above on the basis of culvert computations.

REMARKS.--Flow is affected by urbanization. Peak discharge for 1983 undetermined owing to debris in culvert.

\begin{tabular}{|c|c|c|c|c|c|c|c|c|c|c|c|}
\hline $\begin{array}{l}\text { Water } \\
\text { year }\end{array}$ & Date & $\begin{array}{c}\text { Discharge } \\
\left(\mathrm{ft}^{3} / \mathrm{s}\right)\end{array}$ & $\begin{array}{c}\text { Gage } \\
\text { height } \\
\text { (ft) }\end{array}$ & $\begin{array}{l}\text { Water } \\
\text { year }\end{array}$ & Date & $\begin{array}{c}\text { Discharge } \\
\left(\mathrm{ft}^{3} / \mathrm{s}\right)\end{array}$ & $\begin{array}{c}\text { Gage } \\
\text { height } \\
\text { (ft) }\end{array}$ & $\begin{array}{l}\text { Water } \\
\text { year }\end{array}$ & Date & $\begin{array}{c}\text { Discharge } \\
\left(\mathrm{ft}^{3} / \mathbf{s}\right)\end{array}$ & $\begin{array}{c}\text { Gage } \\
\text { height } \\
\text { (ft) }\end{array}$ \\
\hline $\begin{array}{l}1979 \\
1980 \\
1981 \\
1982\end{array}$ & $\begin{array}{l}\text { July } 21 \\
\text { Oct. } 04 \\
\text { Aug. } 12 \\
\text { Aug. } 18\end{array}$ & $\begin{array}{l}130 \\
115 \\
156 \\
132\end{array}$ & $\begin{array}{l}4.42 \\
4.18 \\
4.85 \\
4.45\end{array}$ & $\begin{array}{l}1983 \\
1984 \\
1985 \\
1986\end{array}$ & $\begin{array}{l}\text { Nov. } 30 \\
\text { May. } 04 \\
\text { Feb. } 02 \\
\text { Aug. } 06\end{array}$ & $\begin{array}{r}154 \\
75.0 \\
201\end{array}$ & $\begin{array}{l}5.88 \\
4.81 \\
3.57 \\
5.59\end{array}$ & $\begin{array}{l}1987 \\
1988 \\
1989\end{array}$ & $\begin{array}{l}\text { Aug. } 01 \\
\text { May. } 24 \\
\text { Oct. } 03\end{array}$ & $\begin{array}{l}102 \\
158 \\
201\end{array}$ & $\begin{array}{l}4.04 \\
4.94 \\
5.59\end{array}$ \\
\hline
\end{tabular}

\section{OATES CREEK AT OLD SAVANNAH ROAD AT AUGUSTA, GEORGIA}

LOCATION.--Lat $33^{\circ} 26^{\prime} 39^{\prime \prime}$, long $81^{\circ} 59^{\prime} 19^{\prime \prime}$, Richmond County, at culvert on Old Savannah Road at Augusta.

DRAINAGE AREA. $-4.06 \mathrm{mi}^{2}$.

GAGE.--Flood-stage/rainfall recorder.

STAGE-DISCHARGE RELATION.--Defined by current-meter measurement below $248 \mathrm{ft} / \mathrm{s}$ and extended above on the basis of culvert computations.

REMARKS.--Flow is affected by urbanization.

\begin{tabular}{|c|c|c|c|c|c|c|c|c|c|c|c|}
\hline $\begin{array}{l}\text { Water } \\
\text { year }\end{array}$ & Date & $\begin{array}{c}\text { Discharge } \\
\left(\mathrm{ft}^{3} / \mathbf{s}\right)\end{array}$ & $\begin{array}{c}\text { Gage } \\
\text { height } \\
\text { (ft) }\end{array}$ & $\begin{array}{l}\text { Water } \\
\text { year }\end{array}$ & Date & $\begin{array}{c}\text { Discharge } \\
\left(\mathrm{ft}^{3} / \mathrm{s}\right)\end{array}$ & $\begin{array}{c}\text { Gage } \\
\text { height } \\
\text { (ft) }\end{array}$ & $\begin{array}{l}\text { Water } \\
\text { year }\end{array}$ & Date & $\begin{array}{c}\text { Discharge } \\
\left(\mathrm{ft}^{3} / \mathbf{s}\right)\end{array}$ & $\begin{array}{c}\text { Gage } \\
\text { height } \\
\text { (ft) }\end{array}$ \\
\hline $\begin{array}{l}1979 \\
1980 \\
1981\end{array}$ & $\begin{array}{l}\text { July } 22 \\
\text { Mar. } 12 \\
\text { Aug. } 12\end{array}$ & $\begin{array}{l}204 \\
250 \\
252\end{array}$ & $\begin{array}{l}5.84 \\
6.52 \\
6.55\end{array}$ & $\begin{array}{l}1982 \\
1983\end{array}$ & $\begin{array}{l}\text { May. } 30 \\
\text { Sept. } 13\end{array}$ & $\begin{array}{l}239 \\
339\end{array}$ & $\begin{array}{l}6.51 \\
7.57\end{array}$ & $\begin{array}{l}1984 \\
1985\end{array}$ & $\begin{array}{l}\text { May. } 04 \\
\text { Feb. } 05\end{array}$ & $\begin{array}{l}328 \\
201\end{array}$ & $\begin{array}{l}7.45 \\
6.04\end{array}$ \\
\hline
\end{tabular}

\section{ROCKY CREEK TRIBUTARY AT AUGUSTA, GEORGIA}

LOCATION.--Lat $33^{\circ} 27^{\prime} 07^{\prime \prime}$, long $82^{\circ} 02^{\prime} 57^{\prime \prime}$, Richmond County, at culvert on U.S. Highways 78 and 278 at Augusta.

DRAINAGE AREA. $-1.56 \mathrm{mi}^{2}$.

GAGE.--Flood-stage/rainfall recorder prior to 1986. Crest-stage gage thereafter. Datum of gage is $182.30 \mathrm{ft}$ above sea level (from

U.S. Army Corps of Engineers benchmark).

STAGE-DISCHARGE RELATION.--Defined by current-meter measurement below $8 \mathrm{ft}^{3} / \mathrm{s}$ and extended above on the basis of culvert computations.

REMARKS.--Flow is affected by urbanization.

\begin{tabular}{|c|c|c|c|c|c|c|c|c|c|c|c|}
\hline $\begin{array}{l}\text { Water } \\
\text { year }\end{array}$ & Date & $\begin{array}{c}\text { Discharge } \\
\left(\mathrm{ft}^{3} / \mathrm{s}\right)\end{array}$ & $\begin{array}{c}\text { Gage } \\
\text { height } \\
\text { (ft) }\end{array}$ & $\begin{array}{l}\text { Water } \\
\text { year }\end{array}$ & Date & $\begin{array}{c}\text { Discharge } \\
\left(\mathrm{ft}^{3} / \mathrm{s}\right)\end{array}$ & $\begin{array}{c}\text { Gage } \\
\text { height } \\
\text { (ft) }\end{array}$ & $\begin{array}{l}\text { Water } \\
\text { year }\end{array}$ & Date & $\begin{array}{c}\text { Discharge } \\
\left(\mathrm{ft}^{3} / \mathrm{s}\right)\end{array}$ & $\begin{array}{c}\text { Gage } \\
\text { height } \\
\text { (ft) }\end{array}$ \\
\hline $\begin{array}{l}1979 \\
1980 \\
1981 \\
1982\end{array}$ & $\begin{array}{l}\text { July } 20 \\
\text { Oct. } 04 \\
\text { Aug. } 10 \\
\text { May. } 30\end{array}$ & $\begin{array}{l}251 \\
274 \\
274 \\
365\end{array}$ & $\begin{array}{l}4.15 \\
4.32 \\
4.32 \\
5.07\end{array}$ & $\begin{array}{l}1983 \\
1984 \\
1985 \\
1986\end{array}$ & $\begin{array}{l}\text { Sept. } 13 \\
\text { May. } 03 \\
\text { June } 29 \\
\text { Aug. } 06\end{array}$ & $\begin{array}{l}356 \\
372 \\
148 \\
510\end{array}$ & $\begin{array}{l}4.99 \\
5.12 \\
3.37 \\
6.25\end{array}$ & $\begin{array}{l}1987 \\
1988 \\
1989\end{array}$ & $\begin{array}{l}\text { Aug. } 01 \\
\text { Apr. } 23 \\
\text { Oct. } 03\end{array}$ & $\begin{array}{l}424 \\
345 \\
519\end{array}$ & $\begin{array}{l}5.68 \\
5.13 \\
6.31\end{array}$ \\
\hline
\end{tabular}




\section{SAVANNAH RIVER BASIN}

\section{BUTLER CREEK AT FORT GORDON, GEORGIA}

LOCATION.--Lat $33^{\circ} 26^{\prime} 35^{\prime \prime}$, long $82^{\circ} 07^{\prime} 45^{\prime \prime}$, Richmond County, on upstream side of abandoned bridge, $600 \mathrm{ft}$ upstream from U.S. Highways 78 and 278 at Fort Gordon.

DRAINAGE AREA.--7.5 $\mathrm{mi}^{2}$

GAGE.-Water-stage recorder. Datum of gage is $270.58 \mathrm{ft}$ above sea level (from U.S. Army Corps of Engineers benchmark).

STAGE-DISCHARGE RELATION.--Defined by current-meter measurement below $290 \mathrm{ft}^{3} / \mathrm{s}$ and extended above on the basis of straight-line extension.

REMARKS.--Flow is affected by urbanization.

HISTORICAL DATA.--Flood stage of September 1929 furnished by the Georgia Department of Transportation.

\begin{tabular}{|c|c|c|c|c|c|c|c|c|c|c|c|}
\hline $\begin{array}{l}\text { Water } \\
\text { year }\end{array}$ & Date & $\begin{array}{c}\text { Discharge } \\
\left(\mathrm{ft}^{3} / \mathrm{s}\right)\end{array}$ & $\begin{array}{c}\text { Gage } \\
\text { height } \\
\text { (ft) }\end{array}$ & $\begin{array}{l}\text { Water } \\
\text { year }\end{array}$ & Date & $\begin{array}{c}\text { Discharge } \\
\left(\mathrm{ft}^{3} / \mathrm{s}\right)\end{array}$ & $\begin{array}{c}\text { Gage } \\
\text { height } \\
\text { (ft) }\end{array}$ & $\begin{array}{l}\text { Water } \\
\text { year }\end{array}$ & Date & $\begin{array}{c}\text { Discharge } \\
\left(\mathrm{ft}^{3} / \mathrm{s}\right)\end{array}$ & $\begin{array}{c}\text { Gage } \\
\text { height } \\
\text { (ft) }\end{array}$ \\
\hline $\begin{array}{l}\frac{1929}{1969} \\
1970 \\
1971 \\
1972 \\
1973 \\
1974 \\
1975\end{array}$ & $\begin{array}{l}\text { Sept. -- } \\
\text { Apr. 15 } \\
\text { Mar. } 30 \\
\text { Mar. } 03 \\
\text { June } 20 \\
\text { Apr. } 07 \\
\text { Apr. } 05 \\
\text { Apr. } 03\end{array}$ & $\begin{array}{r}2,300 \\
389 \\
213 \\
500 \\
180 \\
369 \\
142 \\
346\end{array}$ & $\begin{array}{c}12.40 c \\
6.10 \\
4.43 \\
7.00 \\
4.06 \\
5.93 \\
3.60 \\
5.73\end{array}$ & $\begin{array}{l}1976 \\
1977 \\
1978 \\
1979 \\
1980 \\
1981 \\
1982 \\
1983\end{array}$ & $\begin{array}{l}\text { July } 07 \\
\text { Mar. } 21 \\
\text { Jan. } 26 \\
\text { July } 19 \\
\text { Mar. } 13 \\
\text { Aug. } 10 \\
\text { Dec. } 31 \\
\text { Apr. } 08\end{array}$ & $\begin{array}{l}294 \\
315 \\
298 \\
412 \\
341 \\
445 \\
265 \\
366\end{array}$ & $\begin{array}{l}5.24 \\
5.44 \\
5.28 \\
6.30 \\
5.68 \\
6.57 \\
4.95 \\
5.90\end{array}$ & $\begin{array}{l}1984 \\
1985 \\
1986 \\
1987 \\
1986 \\
1989 \\
1990\end{array}$ & $\begin{array}{l}\text { Mar. } 25 \\
\text { Feb. } 05 \\
\text { Nov. } 22 \\
\text { Jan. } 19 \\
\text { Feb. } 04 \\
\text { July } 20 \\
\text { June } 09\end{array}$ & $\begin{array}{l}459 \\
204 \\
259 \\
250 \\
150 \\
148 \\
133\end{array}$ & $\begin{array}{l}6.68 \\
4.42 \\
5.03 \\
4.94 \\
3.31 \\
3.68 \\
3.46\end{array}$ \\
\hline
\end{tabular}

\section{SAVANNAH RIVER AT AUGUSTA, GEORGIA}

LOCATION.--Lat $33^{\circ} 22^{\prime 2} 25^{\prime \prime}$ long $81^{\circ} 56^{\prime} 35^{\prime \prime}$, Richmond County, Ga.-Aiken County, S.C., at New Savannah Bluff Lock and Dam, 0.2 mi upstream from Butler Creek, 12 mi downstream from Augusta, and at mile 187.4.

DRAINAGE AREA.--7,508 $\mathrm{mi}^{2}$, including that at Butler Creek; $7,240 \mathrm{mi}^{2}$ at former site.

GAGE.--Water-stage recorder. Datum of gage is $96.58 \mathrm{ft}$ above sea level (from U.S. Army Corps of Engineers benchmark). September 3, 1875 to Sept. 30, 1932; nonrecording or recording gage at Fifth Street Bridge at datum $102.06 \mathrm{ft}$ above sea level (levels by Southeastern Engineering Co.). October 1, 1932 to Sept. 30, 1936, recording gage at Thirteenth Street Bridge at datum $104.56 \mathrm{ft}$ above sea level (levels by U.S. Army Corps of Engineers). October 1, 1936 to Nov. 10, 1948, recording gage at site 0.2 mi downstream from preesnt site at present datum. At present site since Nov. 10, 1948. Peak discharges at all sites are considered equivalent.

STAGE-DISCHARGE RELATION.--Defined for period prior to levee construction (completed in 1914) by current-meter measurements below $127,000 \mathrm{ft}^{3} / \mathrm{s}$ and by slope-conveyance study at $360,000 \mathrm{ft}^{3} / \mathrm{s}$. Defined for subsequent period by current-meter measurements below $300,000 \mathrm{ft}^{3} / \mathrm{s}$ and by computation of flow over Stevens Creek Dam to $350,000 \mathrm{ft}^{3} / \mathrm{s}$. Bankfull stage and discharge, $21 \mathrm{ft}$ and $36,000 \mathrm{ft}^{3} / \mathrm{s}$. At site used prior to Oct. 1, 1936, bankfull stage and discharge, $32 \mathrm{ft}$ and approximately $110,000 \mathrm{ft}^{3} / \mathrm{s}$.

HISTORICAL DATA.--The crest of great floods during the period 1796 to 1875 were marked by local residents and noted in the local newspaper. Flood of January 17, 1796, reached a stage of about $40 \mathrm{ft}$ (at site and datum of Fifth Street gage), marked by local residents; discharge approximately $360,000 \mathrm{ft} / \mathrm{s}$, by slope-conveyance study. Little information exists and the data are considered approximate. Data furnished by the U.S. Army Corps of Engineers.

REMARKS.--Peaks for periods of nonrecording gage are from graphs based on gage readings by the U.S. Weather Bureau (now National Weather Service) and the city of Augusta. Gage heights for June 11, 1927 to July 31, 1932, furnished by Savannah River Electric Co. Subsequent to Sept. 30, 1938, gage heights collected in cooperation with the U.S. Army Corps of Engineers. Peak discharges since December 1951 affected by storage in J. Strom Thurmond Lake (formerly Clarks Hill Lake) (maximum flood-control storage, 1,730,000 acre-ft) since Feb. 1961 by Hartwell Lake (maximum flood-control storage, 1,708,000 acre-ft, and since Oct. 1984, by Richard B. Russell Reservoir (maximum flood-control storage, 126,800 acre-ft). Minor regulation from Lake Burton and Mathis Reservoir. (See station 02184000.)

\begin{tabular}{|c|c|c|c|c|c|c|c|c|c|c|c|}
\hline $\begin{array}{l}\text { Water } \\
\text { year }\end{array}$ & Date & $\begin{array}{c}\text { Discharge } \\
\left(\mathrm{ft}^{3} / \mathrm{s}\right)\end{array}$ & $\begin{array}{c}\text { Gage } \\
\text { height } \\
\text { (ft) }\end{array}$ & $\begin{array}{l}\text { Water } \\
\text { year }\end{array}$ & Date & $\begin{array}{c}\text { Discharge } \\
\left(\mathrm{ft}^{3} / \mathrm{s}\right)\end{array}$ & $\begin{array}{c}\text { Gage } \\
\text { height } \\
\text { (ft) }\end{array}$ & $\begin{array}{l}\text { Water } \\
\text { year }\end{array}$ & Date & $\begin{array}{c}\text { Discharge } \\
\left(\mathrm{ft}^{3} / \mathrm{s}\right)\end{array}$ & $\begin{array}{c}\text { Gage } \\
\text { height } \\
\text { (ft) }\end{array}$ \\
\hline$\underline{1796}$ & Jan. 17 & 360,000 & 40.00 & 1911 & Apr. 14 & 32,800 & 19.10 & 1951 & Oct. 22 & 46,300 & 22.32 \\
\hline 1840 & May 28 & 270,000 & 37.80 & 1912 & Mar. 17 & 234,000 & 36.80 & 1952 & Mar. 06 & 39,300 & 21.53 \\
\hline 1852 & Aug. 29 & 250,000 & 37.40 & 1913 & Mar. 16 & 156,000 & 35.10 & 1953 & May 08 & 35,200 & 20.80 \\
\hline$\overline{1864}$ & Jan. 01 & 185,000 & 34.90 & 1914 & Dec. 31 & 48,000 & 24.30 & 1954 & Mar. 30 & 25,500 & 17.39 \\
\hline
\end{tabular}


SAVANNAH RIVER BASIN

02197000 SAVANNAH RIVER AT AUGUSTA, GEORGIA-Continued

\begin{tabular}{|c|c|c|c|c|c|c|c|c|c|c|c|}
\hline $\begin{array}{l}\text { Water } \\
\text { year }\end{array}$ & Date & $\begin{array}{c}\text { Discharge } \\
\left(\mathrm{ft}^{3} / \mathrm{s}\right)\end{array}$ & $\begin{array}{c}\text { Gage } \\
\text { height } \\
\text { (ft) }\end{array}$ & $\begin{array}{l}\text { Water } \\
\text { year }\end{array}$ & Date & $\begin{array}{c}\text { Discharge } \\
\left(\mathrm{ft}^{3} / \mathrm{s}\right)\end{array}$ & $\begin{array}{c}\text { Gage } \\
\text { height } \\
\text { (ft) }\end{array}$ & $\begin{array}{l}\text { Water } \\
\text { year }\end{array}$ & Date & $\begin{array}{c}\text { Discharge } \\
\left(\mathrm{ft}^{3} / \mathrm{s}\right)\end{array}$ & $\begin{array}{c}\text { Gage } \\
\text { height } \\
\text { (ft) }\end{array}$ \\
\hline$\underline{1865}$ & Jan. 11 & 240,000 & 36.90 & 1915 & Jan. 20 & 61,000 & 28.20 & 1955 & Apr. 15 & 23,900 & 16.77 \\
\hline 1876 & Dec. 30 & 86,400 & 28.60 & 1916 & Feb. 03 & 82,400 & 31.00 & 1956 & Apr. 12 & 18,600 & 14.70 \\
\hline 1877 & Apr. 14 & 119,000 & 31.40 & 1917 & Mar. 06 & 68,000 & 29.20 & 1957 & May 07 & 18,000 & 14.08 \\
\hline 1878 & Nov. 23 & 51,500 & 23.50 & 1918 & Jan. 30 & 45,500 & 25.50 & 1958 & Apr. 18 & 66,300 & 22.91 \\
\hline 1879 & Aug. 03 & 44,000 & 22.00 & 1919 & Dec. 24 & 128,000 & 35.00 & 1959 & June 08 & 28,500 & 18.65 \\
\hline 1880 & Dec. 16 & 102,000 & 30.10 & 1920 & Dec. 11 & 133,000 & 35.40 & 1960 & Feb. 14 & 34,900 & 20.58 \\
\hline 1881 & Mar. 18 & 130,000 & 32.20 & 1921 & Feb. 11 & 129,000 & 35.10 & 1961 & Apr. 02 & 34,800 & 20.56 \\
\hline 1882 & Sept.12 & 93,300 & 29.30 & 1922 & Feb. 16 & 92,000 & 32.00 & 1962 & Jan. 09 & 32,500 & 20.09 \\
\hline 1883 & Jan. 22 & 111,000 & 30.80 & 1923 & Feb. 28 & 59,700 & 28.00 & 1963 & Mar. 23 & 31,300 & 19.52 \\
\hline 1884 & Apr. 16 & 81,000 & 28.00 & 1924 & Sept.22 & 59,700 & 28.00 & 1964 & Apr. 09 & 87,100 & 24.16 \\
\hline 1885 & Jan. 26 & 77,000 & 27.50 & 1925 & Jan. 20 & 150,000 & 36.50 & 1965 & Dec. 27 & 34,600 & 20.62 \\
\hline 1886 & May 21 & 135,000 & 32.50 & 1926 & Jan. 20 & 55,300 & 27.30 & 1966 & Mar. 06 & 39,300 & 21.50 \\
\hline 1887 & July 31 & 173,000 & 34.50 & 1927 & Dec. 30 & 39,000 & 24.00 & 1967 & Aug. 25 & 26,500 & 18.10 \\
\hline 1888 & Sept.11 & 303,000 & 38.70 & 1928 & Aug. 17 & 226,000 & 40.40 & 1968 & Jan. 12 & 35,900 & 20.94 \\
\hline 1889 & Feb. 19 & 149,000 & 33.30 & 1929 & Sept.27 & 343,000 & 46.30 & 1969 & Apr. 21 & 45,600 & 22.24 \\
\hline 1890 & Feb. 27 & 48,500 & 22.90 & 1930 & Oct. 02 & 350,000 & 45.10 & 1970 & Apr. 01 & 25,200 & 17.68 \\
\hline 1891 & Mar. 10 & 197,000 & 35.50 & 1931 & Nov. 17 & 26,100 & 19.90 & 1971 & Mar. 05 & 63,900 & 23.30 \\
\hline 1892 & Jan. 20 & 140,000 & 32.80 & 1932 & Jan. 09 & 93,800 & 30.40 & 1972 & Jan. 20 & 33,700 & 20.36 \\
\hline 1893 & Feb. 14 & 60,000 & 25.00 & 1933 & Oct. 18 & 92,600 & 30.30 & 1973 & Apr. 08 & 40,200 & 21.63 \\
\hline 1894 & Aug. 07 & 54,000 & 24.00 & 1934 & Mar. 05 & 73,200 & 28.50 & 1974 & Feb. 23 & 32,900 & 20.13 \\
\hline 1895 & Jan. 11 & 106,000 & 30.40 & 1935 & Mar. 15 & 63,700 & 27.40 & 1975 & Mar. 25 & 45,600 & 22.24 \\
\hline 1896 & July 10 & 107,000 & 30.50 & 1936 & Apr. 08 & 258,000 & 41.20 & 1976 & June 05 & 33,300 & 20.27 \\
\hline 1897 & Apr. 06 & 93,300 & 29.30 & 1937 & Jan. 04 & 91,400 & 30.10 & 1977 & Apr. 07 & 34,200 & 20.50 \\
\hline 1898 & Sept.02 & 117,000 & 31.30 & 1938 & Oct. 21 & $\underline{91,400}$ & $\underline{30.10}$ & 1978 & Jan. 26 & 43,100 & 21.98 \\
\hline 1899 & Feb. 08 & 113,000 & 31.00 & 1939 & Mar. 02 & 90,900 & 24.10 & 1979 & Feb. 27 & 37,300 & 21.13 \\
\hline 1900 & Feb. 15 & 138,000 & 32.70 & 1940 & Aug. 15 & 239,000 & 29.40 & 1980 & Mar. 31 & 47,200 & 22.33 \\
\hline 1901 & Apr. 04 & 124,000 & 31.80 & 1941 & July 08 & 53,300 & 22.89 & 1981 & Feb. 12 & 17,700 & 14.70 \\
\hline 1902 & Mar. 01 & 175,000 & 34.60 & 1942 & Mar. 23 & 105,000 & 24.56 & 1982 & Jan. 02 & 30,700 & 19.39 \\
\hline 1903 & Feb. 09 & 147,000 & 33.20 & 1943 & Jan. 20 & 117,000 & 25.10 & 1983 & Apr. 10 & 66,100 & 23.21 \\
\hline 1904 & Aug. 10 & 63,000 & 25.50 & 1944 & Mar. 22 & 128,000 & 25.53 & 1984 & Mar. 05 & 34,000 & 20.35 \\
\hline 1905 & Feb. 14 & 64,800 & 25.80 & 1945 & Apr. 27 & 64,000 & 23.16 & 1985 & Feb. 07 & 25,700 & 17.89 \\
\hline 1906 & Jan. 05 & 96,600 & 29.60 & 1946 & Jan. 09 & 97,200 & 24.43 & 1986 & Oct. 03 & 21,000 & 15.74 \\
\hline 1907 & Oct. 05 & 52,000 & 23.60 & 1947 & Jan. 22 & 86,000 & 23.97 & 1987 & Mar. 06 & 29,200 & 18.98 \\
\hline 1908 & Aug. 27 & 307,000 & 38.80 & 1948 & Feb. 10 & $\underline{83,200}$ & 23.90 & 1988 & Feb. 05 & 13,600 & 10.61 \\
\hline 1909 & June 05 & 87,300 & 28.70 & 1949 & Nov. 30 & 154,000 & 26.61 & 1989 & Sept.22 & 20,200 & 15.33 \\
\hline 1910 & Mar. 02 & 69,800 & 26.40 & 1950 & Oct. 09 & 32,500 & 20.10 & 1990 & Feb. 27 & 35,300 & 20.69 \\
\hline
\end{tabular}




\section{SAVANNAH RIVER BASIN}

\section{MCBEAN CREEK NEAR MCBEAN, GEORGIA}

LOCATION.--Lat $33^{\circ} 14^{\prime} 12^{\prime \prime}$ long $82^{\circ} 02^{\prime} 38^{\prime \prime}$, Richmond County, at State Highway 21, 5.5 mi west of McBean.

DRAINAGE AREA.--41.4 $\mathrm{mi}^{2}$.

GAGE.--Crest-stage gage. Datum of gage is about $170 \mathrm{ft}$ above sea level (from topographic map).

STAGE-DISCHARGE RELATION.--Defined by discharge measurement below $2,700 \mathrm{ft}^{3} / \mathrm{s}$. Bankfull stage and discharge, $5 \mathrm{ft}$ and $800 \mathrm{ft}^{3} / \mathrm{s}$.

REMARKS.--Peak discharges for 1965-66, and 1971 are estimated.

\begin{tabular}{|c|c|c|c|c|c|c|c|c|c|c|c|}
\hline $\begin{array}{l}\text { Water } \\
\text { year }\end{array}$ & Date & $\begin{array}{c}\text { Discharge } \\
\left(\mathrm{ft}^{3} / \mathrm{s}\right)\end{array}$ & $\begin{array}{c}\text { Gage } \\
\text { height } \\
\text { (ft) }\end{array}$ & $\begin{array}{l}\text { Water } \\
\text { year }\end{array}$ & Date & $\begin{array}{c}\text { Discharge } \\
\left(\mathrm{ft}^{3} / \mathrm{s}\right)\end{array}$ & $\begin{array}{c}\text { Gage } \\
\text { height } \\
\text { (ft) }\end{array}$ & $\begin{array}{l}\text { Water } \\
\text { year }\end{array}$ & Date & $\begin{array}{c}\text { Discharge } \\
\left(\mathrm{ft}^{3} / \mathrm{s}\right)\end{array}$ & $\begin{array}{c}\text { Gage } \\
\text { height } \\
\text { (ft) }\end{array}$ \\
\hline $\begin{array}{l}1963 \\
1964 \\
1965 \\
1966 \\
1967 \\
1968 \\
1969 \\
1970 \\
1971 \\
1972\end{array}$ & $\begin{array}{l}\text { June } 18 \\
\text { May. } 03 \\
\text { Oct. } 16 \\
\text { Apr. } 04 \\
\text { Mar. } 11 \\
\text { Apr. -- } \\
\text { Jan. } 19 \\
\text { Mar. } 31 \\
\text { Mar. } 03 \\
\text { Jan. } 10\end{array}$ & $\begin{array}{l}278 \\
335 \\
520 \\
410 \\
290 \\
200 \\
331 \\
341 \\
450 \\
280\end{array}$ & $\begin{array}{c}4.33 \\
4.75 \\
5.62 \\
5.12 \\
4.42 \\
--b \\
4.72 \\
4.79 \\
5.30 \\
4.33\end{array}$ & $\begin{array}{l}1973 \\
1974 \\
1975 \\
1976 \\
1977 \\
1978 \\
1979 \\
1980 \\
1981\end{array}$ & $\begin{array}{l}\text { Apr. } 07 \\
\text { Feb. } 15 \\
\text { Apr. } 03 \\
\text { Mar. } 16 \\
\text { Mar. } 13 \\
\text { Jan. } 26 \\
\text { May. } 31 \\
\text { Mar. } 12 \\
\text { Feb. } 11\end{array}$ & $\begin{array}{l}262 \\
251 \\
266 \\
245 \\
249 \\
288 \\
268 \\
286 \\
257\end{array}$ & $\begin{array}{l}4.21 \\
4.12 \\
4.24 \\
4.08 \\
4.11 \\
4.41 \\
4.25 \\
4.39 \\
4.17\end{array}$ & $\begin{array}{l}1982 \\
1983 \\
1984 \\
1985 \\
1986 \\
1987 \\
1988 \\
1989 \\
1990\end{array}$ & $\begin{array}{l}\text { Jan. } 01 \\
\text { Feb. } 14 \\
\text { July } 31 \\
\text { Feb. } 06 \\
\text { Nov. } 22 \\
\text { Mar. } 01 \\
\text { Sept.09 } \\
\text { Sept.22 } \\
\text { Feb. -- }\end{array}$ & $\begin{array}{l}225 \\
262 \\
264 \\
274 \\
295 \\
301 \\
216 \\
272 \\
180\end{array}$ & $\begin{array}{l}3.92 \\
4.21 \\
4.22 \\
4.30 \\
4.46 \\
4.51 \\
3.84 \\
4.26 \\
--b\end{array}$ \\
\hline
\end{tabular}

\section{SAVANNAH RIVER NEAR MILLHAVEN, GEORGIA}

LOCATION.--Lat $32^{\circ} 56^{\prime} 20^{\prime \prime}$, long $81^{\circ} 30^{\prime} 10^{\prime \prime}$, Screven County, on downstream side of left pier of drawspan of bridge on U.S. Highway 301, 2 mi downstream from Rocky Creek, 9 mi east of Millhaven and at mile 118.7.

DRAINAGE AREA.--8,650 $\mathrm{mi}^{2}$, approximately.

GAGE.-Water-stage recorder. Datum of gage is $52.42 \mathrm{ft}$ above sea level (levels by U.S. Army Corps of Engineers).

STAGE-DISCHARGE RELATION.--Defined by current-meter measurement below $141,000 \mathrm{ft}^{3} / \mathrm{s}$, and extended above by logarithmic plotting. Bankfull stage and discharge, $15 \mathrm{ft}$ and $20,000 \mathrm{ft}^{3} / \mathrm{s}$.

HISTORICAL DATA.--Flood-stage of October 1929, from information furnished by U.S. Army Corps of Engineers. This peak was the highest since 1796 based on other stations on the Savannah River.

REMARKS.--Peak discharges are affected by storage in Lake Burton, Mathis Reservoir, Hartwell, and J. Strom Thurmond (formerly Clarks Hill Lake). See station 02197000 for dates of regulations and maximum flood-control storage capacities.

\begin{tabular}{|c|c|c|c|c|c|c|c|c|c|c|c|}
\hline $\begin{array}{l}\text { Water } \\
\text { year }\end{array}$ & Date & $\begin{array}{c}\text { Discharge } \\
\left(\mathrm{ft}^{3} / \mathrm{s}\right)\end{array}$ & $\begin{array}{c}\text { Gage } \\
\text { height } \\
\text { (ft) }\end{array}$ & $\begin{array}{l}\text { Water } \\
\text { year }\end{array}$ & Date & $\begin{array}{c}\text { Discharge } \\
\left(\mathrm{ft}^{3} / \mathrm{s}\right)\end{array}$ & $\begin{array}{c}\text { Gage } \\
\text { height } \\
\text { (ft) }\end{array}$ & $\begin{array}{l}\text { Water } \\
\text { year }\end{array}$ & Date & $\begin{array}{c}\text { Discharge } \\
\left(\mathrm{ft}^{3} / \mathrm{s}\right)\end{array}$ & $\begin{array}{c}\text { Gage } \\
\text { height } \\
\text { (ft) }\end{array}$ \\
\hline $\begin{array}{l}\frac{1925}{1928} \\
1929 \\
1930 \\
1936 \\
1940 \\
1941 \\
1942 \\
1943 \\
1944 \\
1945 \\
1946 \\
1947 \\
1948 \\
1949\end{array}$ & $\begin{array}{l}\text { Jan. } 23 \\
\text { Aug. } 27 \\
\text { Mar. } 10 \\
\text { Oct. } 05 \\
\text { Apr. } 09 \\
\text { Aug. } 18 \\
\text { July } 13 \\
\text { Mar. } 26 \\
\text { Jan. } 23 \\
\text { Mar. } 26 \\
\text { May. } 01 \\
\text { Jan. } 12 \\
\text { Jan. } 25 \\
\text { Feb. } 14 \\
\text { Dec. } 03\end{array}$ & $\begin{array}{r}110,000 \\
98,000 \\
116,000 \\
220,000 \\
170,000 \\
141,000 \\
38,400 \\
73,000 \\
80,900 \\
89,300 \\
42,900 \\
68,600 \\
67,500 \\
61,000 \\
108,000\end{array}$ & $\begin{array}{l}25.10 c \\
24.10 \\
25.60 \\
30.80 \\
28.61 c \\
27.00 \\
18.20 \\
22.00 \\
22.60 \\
23.40 \\
18.80 \\
21.60 \\
21.53 \\
21.10 \\
24.91\end{array}$ & $\begin{array}{l}1950 \\
1951 \\
1952 \\
1953 \\
1954 \\
1955 \\
1956 \\
1957 \\
1958 \\
1959 \\
1960 \\
1961 \\
1962 \\
1963 \\
1964\end{array}$ & $\begin{array}{l}\text { Oct. } 14 \\
\text { Oct. } 27 \\
\text { Mar. } 29 \\
\text { May. } 12 \\
\text { Apr. } 06 \\
\text { Apr. } 18 \\
\text { Mar. } 19 \\
\text { May. } 11 \\
\text { Apr. } 22 \\
\text { June } 13 \\
\text { Feb. } 17 \\
\text { Apr. } 24 \\
\text { Jan. } 15 \\
\text { Mar. } 27 \\
\text { Apr. } 15\end{array}$ & $\begin{array}{l}18,500 \\
25,700 \\
38,500 \\
31,800 \\
17,600 \\
15,000 \\
13,700 \\
13,900 \\
41,400 \\
27,400 \\
37,100 \\
32,400 \\
27,400 \\
29,200 \\
71,700\end{array}$ & $\begin{array}{l}14.87 \\
16.53 \\
18.26 \\
17.52 \\
14.40 \\
13.21 \\
11.95 \\
12.27 \\
18.94 \\
16.59 \\
18.28 \\
17.60 \\
16.75 \\
17.22 \\
22.10\end{array}$ & $\begin{array}{l}1965 \\
1966 \\
1967 \\
1968 \\
1969 \\
1970 \\
1983 \\
1984 \\
1985 \\
1986 \\
1987 \\
1988 \\
1989 \\
1990\end{array}$ & $\begin{array}{l}\text { Apr. } 04 \\
\text { Mar. } 09 \\
\text { June } 17 \\
\text { Jan. } 16 \\
\text { Apr. } 25 \\
\text { Apr. } 04 \\
\text { Apr. } 15 \\
\text { May. } 12 \\
\text { Feb. } 10 \\
\text { Nov. } 25 \\
\text { Mar. } 10 \\
\text { Oct. } 02 \\
\text { Mar. } 26 \\
\text { Mar. } 02\end{array}$ & $\begin{array}{l}32,800 \\
37,100 \\
22,000 \\
26,800 \\
37,200 \\
18,200 \\
58,000 \\
33,900 \\
19,700 \\
15,200 \\
27,600 \\
11,900 \\
19,800 \\
36,000\end{array}$ & $\begin{array}{l}17.66 \\
18.05 \\
15.47 \\
16.64 \\
18.31 \\
14.14 \\
- \\
17.83 \\
14.69 \\
12.71 \\
16.79 \\
10.80 \\
14.73 \\
18.14\end{array}$ \\
\hline
\end{tabular}




\section{SAVANNAH RIVER BASIN}

\section{BRIER CREEK NEAR THOMSON, GEORGIA}

LOCATION.--Lat $33^{\circ} 22^{\prime} 06^{\prime \prime}$, long $82^{\circ} 28^{\prime} 06^{\prime \prime}$, McDuffie County, on downstream side of bridge on State Highway 17, $0.2 \mathrm{mi}$ upstream from Sweetwater Creek, and $6.9 \mathrm{mi}$ south of Thomson.

DRAINAGE AREA. $-55 \mathrm{mi}^{2}$, approximately.

GAGE.--Water-stage recorder. Datum of gage is about $330 \mathrm{ft}$ above sea level (from topographic map).

STAGE-DISCHARGE RELATION.--Defined by current-meter measurement below $4,300 \mathrm{ft}^{3} / \mathrm{s}$, and extended above based on straight-line extension. Bankfull stage and discharge, $12 \mathrm{ft}$ and $1,600 \mathrm{ft}^{3} / \mathrm{s}$.

REMARKS.--High-water mark of flood of Feb. 24, 1961 from Georgia Department of Transportation was highest since 1929 based on comparison with nearby stations.

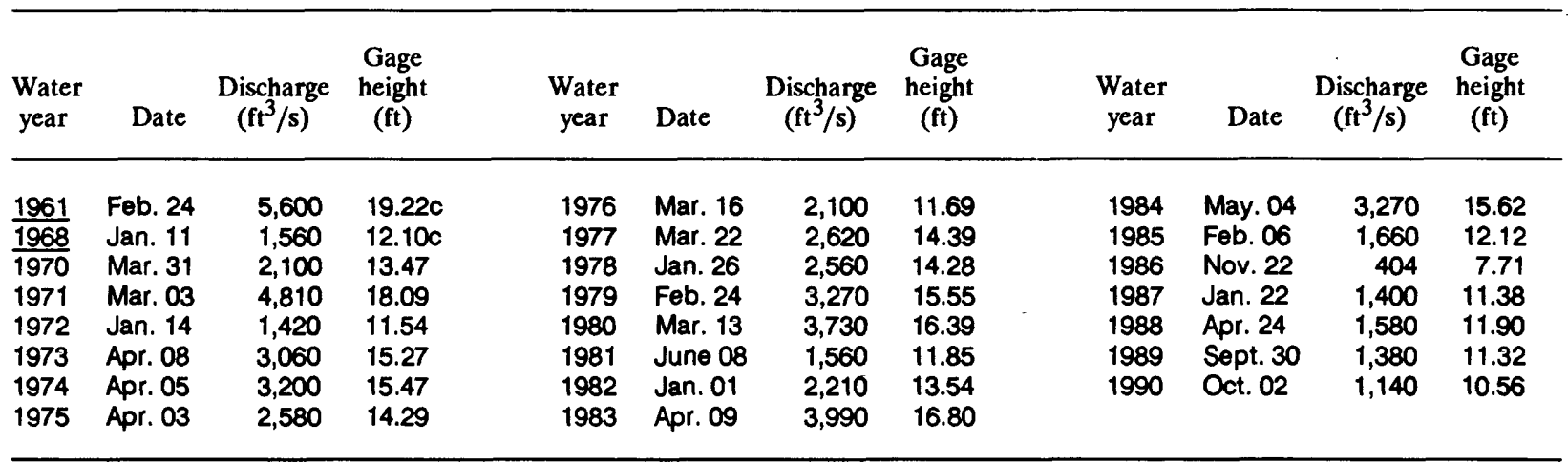

\section{LITTLE BRIER CREEK NEAR THOMSON, GEORGIA}

LOCATION.--Lat $33^{\circ} 20^{\prime} 24^{\prime \prime}$, long $82^{\circ} 27^{\prime} 29^{\prime \prime}$, McDuffie County, on left bank at downstream side of bridge on State Highway 17 , one-half mile above mouth and 9 miles south of Thomson.

DRAINAGE AREA.--24 mi², approximately.

GAGE.--Water-stage recorder. Datum of gage is $313.95 \mathrm{ft}$ above sea level, supplementary adjustment of 1936 (from Georgia Department of Transportation). Prior to June 23,1960, crest-stage gage at same site and datum.

STAGE-DISCHARGE RELATION.--Defined by current-meter measurement below $800 \mathrm{tt}^{3} / \mathrm{s}$, and extended above on the basis of straight-line extension.

REMARKS.--The peak discharges may or may not be affected by backwater. Peak discharges for 1964, 1965, and 1967 are estimated.

\begin{tabular}{|c|c|c|c|c|c|c|c|c|c|c|c|}
\hline $\begin{array}{l}\text { Water } \\
\text { year }\end{array}$ & Date & $\begin{array}{c}\text { Discharge } \\
\left(\mathrm{ft}^{3} / \mathrm{s}\right)\end{array}$ & $\begin{array}{c}\text { Gage } \\
\text { height } \\
\text { (ft) }\end{array}$ & $\begin{array}{l}\text { Water } \\
\text { year }\end{array}$ & Date & $\begin{array}{c}\text { Discharge } \\
\left(\mathrm{ft}^{3} / \mathrm{s}\right)\end{array}$ & $\begin{array}{l}\text { Gage } \\
\text { height } \\
\text { (ft) }\end{array}$ & $\begin{array}{l}\text { Water } \\
\text { year }\end{array}$ & Date & $\begin{array}{c}\text { Discharge } \\
\left(\mathrm{ft}^{3} / \mathrm{s}\right)\end{array}$ & $\begin{array}{c}\text { Gage } \\
\text { height } \\
\text { (ft) }\end{array}$ \\
\hline $\begin{array}{l}1952 \\
1953 \\
1954 \\
1955 \\
1956 \\
1957\end{array}$ & $\begin{array}{l}\text { Mar. } 04 \\
\text { Sept. } 27 \\
\text { Jan. } 16 \\
\text { Apr. -- } \\
\text { Mar. } 16 \\
\text { June } 00\end{array}$ & $\begin{array}{l}960 \\
495 \\
210 \\
550 \\
445 \\
272\end{array}$ & $\begin{array}{l}8.53 \\
7.77 \\
7.02 \\
7.85 \\
7.65 \\
7.22\end{array}$ & $\begin{array}{l}1958 \\
1959 \\
1960 \\
1961 \\
1962\end{array}$ & $\begin{array}{l}\text { Apr. } 16 \\
\text { May. -- } \\
\text { Jan. } 31 \\
\text { Feb. } 25 \\
\text { Jan. } 06\end{array}$ & $\begin{array}{r}820 \\
470 \\
796 \\
1,300 \\
676\end{array}$ & $\begin{array}{l}8.34 \\
7.66 \\
8.26 \\
8.94 \\
8.06\end{array}$ & $\begin{array}{l}1963 \\
1964 \\
1965 \\
1966 \\
1967\end{array}$ & $\begin{array}{l}\text { Mar. } 13 \\
\text { May. } 03 \\
\text { Dec. } 26 \\
\text { Mar. } 04 \\
\text { Mar. } 11\end{array}$ & $\begin{array}{r}496 \\
1,800 \\
1,100 \\
602 \\
700\end{array}$ & $\begin{array}{l}7.76 \\
9.68 \\
8.56 \\
7.78 \\
9.14\end{array}$ \\
\hline
\end{tabular}


LOCATION.--Lat $33^{\circ} 10^{\prime} 37^{\prime \prime}$, long $82^{\circ} 18^{\prime} 21^{\prime \prime}$, Jefferson County, at right bank on downstream side on State Highway $80,5 \mathrm{mi}$ southwest of Wrens, and 5.5 mi upstream from Little Brushy Creek.

DRAINAGE AREA.--28 $\mathrm{mi}^{2}$.

GAGE.--Water-stage recorder. Datum of gage is $282.56 \mathrm{ft}$ above sea level (levels from Georgia Department of Transportation).

STAGE-DISCHARGE RELATION.--Defined by current-meter measurement below $4,230 \mathrm{ft}^{3} / \mathrm{s}$.

\begin{tabular}{|c|c|c|c|c|c|c|c|c|c|c|c|}
\hline $\begin{array}{l}\text { Water } \\
\text { year }\end{array}$ & Date & $\begin{array}{c}\text { Discharge } \\
\left(\mathrm{ft}^{3} / \mathrm{s}\right)\end{array}$ & $\begin{array}{c}\text { Gage } \\
\text { height } \\
\text { (ft) }\end{array}$ & $\begin{array}{l}\text { Water } \\
\text { year }\end{array}$ & Date & $\begin{array}{c}\text { Discharge } \\
\left(\mathrm{ft}^{3} / \mathrm{s}\right)\end{array}$ & $\begin{array}{c}\text { Gage } \\
\text { height } \\
\text { (ft) }\end{array}$ & $\begin{array}{l}\text { Water } \\
\text { year }\end{array}$ & Date & $\begin{array}{c}\text { Discharge } \\
\left(\mathrm{ft}^{3} / \mathrm{s}\right)\end{array}$ & $\begin{array}{c}\text { Gage } \\
\text { height } \\
\text { (ft) }\end{array}$ \\
\hline $\begin{array}{l}1959 \\
1960 \\
1961 \\
1962 \\
1963 \\
1964 \\
1965 \\
1966 \\
1967 \\
1968 \\
1969\end{array}$ & $\begin{array}{l}\text { Mar. } 06 \\
\text { Mar. } 30 \\
\text { July } 19 \\
\text { Feb. } 22 \\
\text { Jan. } 21 \\
\text { Aug. } 12 \\
\text { Mar. } 25 \\
\text { Mar. } 04 \\
\text { Mar. } 11 \\
\text { July } 12 \\
\text { June } 30\end{array}$ & $\begin{array}{l}425 \\
752 \\
728 \\
592 \\
292 \\
658 \\
324 \\
800 \\
206 \\
276 \\
148\end{array}$ & $\begin{array}{l}5.73 \\
7.28 \\
7.25 \\
6.55 \\
4.95 \\
6.90 \\
5.13 \\
7.44 \\
5.11 \\
5.66 \\
4.43\end{array}$ & $\begin{array}{l}1970 \\
1971 \\
1972 \\
1973 \\
1974 \\
1975 \\
1976 \\
1977 \\
1978 \\
1979 \\
1980\end{array}$ & $\begin{array}{l}\text { Mar. } 31 \\
\text { Mar. } 03 \\
\text { Jan. } 14 \\
\text { Apr. } 07 \\
\text { Feb. } 07 \\
\text { Feb. } 19 \\
\text { Mar. } 17 \\
\text { Mar. } 22 \\
\text { Jan. } 26 \\
\text { July } 22 \\
\text { Mar. } 13\end{array}$ & $\begin{array}{r}425 \\
1,200 \\
318 \\
608 \\
316 \\
355 \\
229 \\
356 \\
532 \\
276 \\
905\end{array}$ & $\begin{array}{l}6.42 \\
8.03 \\
5.09 \\
6.87 \\
5.15 \\
5.38 \\
5.24 \\
6.33 \\
6.55 \\
5.43 \\
7.05\end{array}$ & $\begin{array}{l}1981 \\
1982 \\
1983 \\
1984 \\
1985 \\
1986 \\
1987 \\
1988 \\
1989 \\
1990\end{array}$ & $\begin{array}{l}\text { Feb. } 11 \\
\text { Feb. } 04 \\
\text { Feb. } 14 \\
\text { Mar. } 25 \\
\text { Feb. } 06 \\
\text { Nov. } 22 \\
\text { Jan. } 19 \\
\text { Sept. } 09 \\
\text { Apr. } 10 \\
\text { Feb. } 17\end{array}$ & $\begin{array}{r}195 \\
244 \\
375 \\
414 \\
356 \\
334 \\
660 \\
95.0 \\
154 \\
136\end{array}$ & $\begin{array}{l}4.59 \\
5.02 \\
5.58 \\
5.72 \\
5.90 \\
5.73 \\
7.28 \\
3.61 \\
4.43 \\
4.26\end{array}$ \\
\hline
\end{tabular}

\section{WALNUT BRANCH NEAR WAYNESBORO, GEORGIA}

LOCATION.--Lat $33^{\circ} 08^{\prime} 11^{\prime \prime}$, long $82^{\circ} 02^{\prime} 10^{\prime \prime}$, Burke County, at highway bridge on U.S. Highway 25 , about 7.1 mi south of BurkeRichmond County line, and 3.7 mi north of Waynesboro.

DRAINAGE AREA.--11.9 $\mathrm{mi}^{2}$

GAGE.--Flood-stage/rainfall recorder.

STAGE-DISCHARGE RELATION.--Defined by current-meter measurement below $198 \mathrm{tt}^{3} / \mathrm{s}$, and extended above on basis of straight-line extension. Bankfull stage and discharge, $6 \mathrm{ft}$ and $85 \mathrm{ft}^{3} / \mathrm{s}$.

\begin{tabular}{|c|c|c|c|c|c|c|c|c|c|c|c|}
\hline $\begin{array}{l}\text { Water } \\
\text { year }\end{array}$ & Date & $\begin{array}{c}\text { Discharge } \\
\left(\mathrm{ft}^{3} / \mathrm{s}\right)\end{array}$ & $\begin{array}{c}\text { Gage } \\
\text { height } \\
(\mathrm{ft})\end{array}$ & $\begin{array}{l}\text { Water } \\
\text { year }\end{array}$ & Date & $\begin{array}{c}\text { Discharge } \\
\left(\mathrm{ft}^{3} / \mathrm{s}\right)\end{array}$ & $\begin{array}{c}\text { Gage } \\
\text { height } \\
\text { (ft) }\end{array}$ & $\begin{array}{l}\text { Water } \\
\text { year }\end{array}$ & Date & $\begin{array}{c}\text { Discharge } \\
\left(\mathrm{ft}^{3} / \mathrm{s}\right)\end{array}$ & $\begin{array}{c}\text { Gage } \\
\text { height } \\
\text { (ft) }\end{array}$ \\
\hline $\begin{array}{l}1965 \\
1966 \\
1967 \\
1968\end{array}$ & $\begin{array}{l}\text { Dec. } 26 \\
\text { Mar. } 04 \\
\text { Mar. } 11 \\
\text { Jan. } 10\end{array}$ & $\begin{array}{r}241 \\
598 \\
160 \\
65.0\end{array}$ & $\begin{array}{l}7.58 \\
8.89 \\
7.09 \\
6.08\end{array}$ & $\begin{array}{l}1969 \\
1970 \\
1971\end{array}$ & $\begin{array}{l}\text { May. } 19 \\
\text { Mar. } 31 \\
\text { Mar. } 04\end{array}$ & $\begin{array}{l}156 \\
257 \\
206\end{array}$ & $\begin{array}{l}7.08 \\
7.66 \\
7.39\end{array}$ & $\begin{array}{l}1972 \\
1973 \\
1974\end{array}$ & $\begin{array}{l}\text { Jan. } 14 \\
\text { Feb. } 02 \\
\text { Feb. } 07\end{array}$ & $\begin{array}{l}328 \\
301 \\
228\end{array}$ & $\begin{array}{l}8.01 \\
7.88 \\
7.51\end{array}$ \\
\hline
\end{tabular}


LOCATION.--Lat $33^{\circ} 07^{\prime} 05^{\prime \prime}$, long $81^{\circ} 57^{\prime} 50^{\prime \prime}$, Burke County, on left bank on downstream end of pier of bridge on State Highway 56 , 3.8 mi northeast of Waynesboro.

DRAINAGE AREA.--473 $\mathrm{mi}^{2}$.

GAGE.--Water-stage recorder. Datum of gage is $173.78 \mathrm{ft}$ above sea level (from U.S. Coast and Geodetic Survey benchmark).

From Nov. 9, 1949 to June 4, 1953, crest-stage gage at site $150 \mathrm{ft}$ downstream and at datum $0.40 \mathrm{ft}$ higher. All gage readings have been adjusted to present datum.

STAGE-DISCHARGE RELATION.--Defined by current-meter measurement below $14,200 \mathrm{ft}^{3} / \mathrm{s}$. above on the basis of slopeconveyance studies at 41,000 and $48,000 \mathrm{ft}^{3} / \mathrm{s}$. Bankfull stage and discharge, $8 \mathrm{ft}$ and $2,500 \mathrm{ft}^{3} / \mathrm{s}$.

REMARKS.--Flood-stages of Oct. 1, 1929 and Apr. 9, 1936 based on information provided by local residents. The 1929 flood was probably the greatest since Millhaven Plantation was settled in 1796 . Peak discharges for 1929 and 1936 are estimated.

\begin{tabular}{|c|c|c|c|c|c|c|c|c|c|c|c|}
\hline $\begin{array}{l}\text { Water } \\
\text { year }\end{array}$ & Date & $\begin{array}{c}\text { Discharge } \\
\left(\mathrm{ft}^{3} / \mathrm{s}\right)\end{array}$ & $\begin{array}{c}\text { Gage } \\
\text { height } \\
\text { (ft) }\end{array}$ & $\begin{array}{l}\text { Water } \\
\text { year }\end{array}$ & Date & $\begin{array}{c}\text { Discharge } \\
\left(\mathrm{ft}^{3} / \mathrm{s}\right)\end{array}$ & $\begin{array}{c}\text { Gage } \\
\text { height } \\
\text { (ft) }\end{array}$ & $\begin{array}{l}\text { Water } \\
\text { year }\end{array}$ & Date & $\begin{array}{c}\text { Discharge } \\
\left(\mathrm{ft}^{3} / \mathrm{s}\right)\end{array}$ & $\begin{array}{c}\text { Gage } \\
\text { height } \\
\text { (ft) }\end{array}$ \\
\hline $\begin{array}{l}\frac{1930}{1936} \\
1952 \\
1953 \\
1970 \\
1971 \\
1972 \\
1973 \\
1974\end{array}$ & $\begin{array}{l}\text { Oct. 01 } \\
\text { Apr. 09 } \\
\text { Mar. 09 } \\
\text { May 09 } \\
\text { Apr. 03 } \\
\text { Mar. 05 } \\
\text { Jan. } 15 \\
\text { Apr. } 10 \\
\text { Apr. 08 }\end{array}$ & $\begin{array}{r}48,000 \\
41,000 \\
5,400 \\
4,700 \\
3,770 \\
10,800 \\
3,600 \\
4,450 \\
3,610\end{array}$ & $\begin{array}{c}23.00 c \\
21.60 c \\
10.00 \\
9.60 \\
9.15 \\
12.28 \\
8.92 \\
9.44 \\
8.93\end{array}$ & $\begin{array}{l}1975 \\
1976 \\
1977 \\
1978 \\
1979 \\
1980 \\
1981 \\
1982\end{array}$ & $\begin{array}{l}\text { Apr. } 06 \\
\text { Mar. } 20 \\
\text { Mar. } 24 \\
\text { Jan. } 28 \\
\text { Feb. } 27 \\
\text { Mar. } 15 \\
\text { Feb. } 15 \\
\text { Jan. } 04\end{array}$ & $\begin{array}{l}3,850 \\
2,360 \\
4,230 \\
5,200 \\
5,230 \\
6,320 \\
2,520 \\
3,600\end{array}$ & $\begin{array}{r}9.06 \\
7.96 \\
9.31 \\
9.88 \\
9.90 \\
10.46 \\
8.18 \\
8.92\end{array}$ & $\begin{array}{l}1983 \\
1984 \\
1985 \\
1986 \\
1987 \\
1988 \\
1989 \\
1990\end{array}$ & $\begin{array}{l}\text { Apr. } 11 \\
\text { May. } 07 \\
\text { Feb. } 09 \\
\text { Nov. } 26 \\
\text { Jan. } 22 \\
\text { Apr. } 27 \\
\text { Apr. } 14 \\
\text { Oct. } 05\end{array}$ & $\begin{array}{l}3,740 \\
3,400 \\
4,170 \\
1,730 \\
3,800 \\
1,770 \\
1,870 \\
1,930\end{array}$ & $\begin{array}{l}9.09 \\
8.85 \\
9.35 \\
7.43 \\
9.13 \\
7.47 \\
7.80 \\
7.85\end{array}$ \\
\hline
\end{tabular}

\section{BRIER CREEK AT MILLHAVEN, GEORGIA}

LOCATION.--Lat $32^{\circ} 56^{\prime} 00^{\prime \prime}$, long $81^{\circ} 39^{\prime} 05^{\prime \prime}$, Screven County, near right bank on downstream side of pier of highway bridge at Millhaven, 8.5 mi upstream from Beaver Dam Creek.

DRAINAGE AREA.--646 $\mathrm{mi}^{2}$.

GAGE.--Water-stage recorder. Datum of gage is $95.88 \mathrm{ft}$ above sea level, supplementary adjustment of 1936 (from U.S. Coast and Geodetic Survey benchmark). Prior to June 7,1950 , nonrecording gage at site $200 \mathrm{ft}$ downstream at same datum. June 7 , 1950 to Apr. 30, 1951, nonrecording gage at present site and datum.

STAGE-DISCHARGE RELATION.--Defined by current-meter measurement below $20,000 \mathrm{ft}^{3} / \mathrm{s}$, and extended above on basis of slope-conveyance studies. Bankfull stage and discharge, $8 \mathrm{ft}$ and $2,000 \mathrm{ft}^{3} / \mathrm{s}$.

HISTORICAL DATA.--Flood stage of January 1925, October 1929, and April 1936 based on information provided by Georgia Department of Transportation. The 1929 flood was probably the greatest since Millhaven Plantation was settled in 1796. REMARKS.--Peak discharge for 1950 is estimated.

\begin{tabular}{|c|c|c|c|c|c|c|c|c|c|c|c|}
\hline $\begin{array}{l}\text { Water } \\
\text { year }\end{array}$ & Date & $\begin{array}{c}\text { Discharge } \\
\left(\mathrm{ft}^{3} / \mathrm{s}\right)\end{array}$ & $\begin{array}{c}\text { Gage } \\
\text { height } \\
\text { (ft) }\end{array}$ & $\begin{array}{l}\text { Water } \\
\text { year }\end{array}$ & Date & $\begin{array}{c}\text { Discharge } \\
\left(\mathrm{ft}^{3} / \mathrm{s}\right)\end{array}$ & $\begin{array}{c}\text { Gage } \\
\text { height } \\
\text { (ft) }\end{array}$ & $\begin{array}{l}\text { Water } \\
\text { year }\end{array}$ & Date & $\begin{array}{c}\text { Discharge } \\
\left(\mathrm{ft}^{3} / \mathrm{s}\right)\end{array}$ & $\begin{array}{c}\text { Gage } \\
\text { height } \\
\text { (ft) }\end{array}$ \\
\hline 1925 & Jan. 23 & 43,000 & $22.10 \mathrm{c}$ & 1954 & Dec. 20 & 1,560 & 7.40 & 1973 & Apr. 12 & 4,130 & 10.93 \\
\hline 1930 & Oct. 01 & 64,000 & $25.10 \mathrm{C}$ & 1955 & Apr. 20 & 3,220 & 10.00 & 1974 & Apr. 10 & 3,140 & 9.82 \\
\hline$\overline{1936}$ & Apr. 09 & 43,000 & $22.10 \mathrm{c}$ & 1956 & Mar. 22 & 2,900 & 9.60 & 1975 & Apr. 08 & 3,450 & 10.18 \\
\hline$\overline{1938}$ & Apr. 13 & 3,110 & 10.00 & 1957 & Apr. 01 & 1,140 & 6.40 & 1976 & Mar. 22 & 2,290 & 8.54 \\
\hline 1939 & Mar. 03 & 5,900 & 12.20 & 1958 & Apr. 21 & 4,440 & 11.20 & 1977 & Mar. 26 & 3,990 & 10.72 \\
\hline 1940 & Aug. 16 & 25,400 & 17.40 & 1959 & Mar. 12 & 2,340 & 8.80 & 1978 & Jan. 30 & 4,710 & 11.44 \\
\hline 1941 & July 22 & 2,720 & 9.40 & 1960 & Apr. 06 & 9,300 & 13.60 & 1979 & Mar. 01 & 4,950 & 11.68 \\
\hline 1942 & Mar. 26 & 4,100 & 10.90 & 1961 & Apr. 17 & 7,240 & 12.60 & 1980 & Mar. 17 & 5,930 & 12.17 \\
\hline 1943 & Mar. 26 & 4,100 & 10.90 & 1962 & Feb. 27 & 3,500 & 10.30 & 1981 & Feb. 17 & 2,050 & 8.31 \\
\hline 1944 & Mar. 28 & 6,360 & 12.40 & 1963 & Jan. 26 & 3,700 & 10.50 & 1982 & Jan. 06 & 3,450 & 10.19 \\
\hline 1945 & Mar. 03 & 997 & 6.00 & 1964 & May. 07 & 9,000 & 13.50 & 1983 & Apr. 14 & 3,550 & 10.30 \\
\hline 1946 & Jan. 01 & 2,040 & 8.30 & 1965 & Dec. 31 & 6,360 & 12.40 & 1984 & May. 09 & 2,870 & 9.45 \\
\hline 1947 & Mar. 13 & 3,800 & 10.60 & 1966 & Mar. 06 & 6,420 & 12.43 & 1985 & Feb. 11 & 3,620 & 10.37 \\
\hline 1948 & Sept. 11 & 4,900 & 11.60 & 1967 & Mar. 16 & 4,490 & 11.24 & 1986 & Dec. 13 & 1,970 & 8.00 \\
\hline 1949 & Dec. 03 & 4,700 & 11.30 & 1968 & Jan. 17 & 1,910 & 8.08 & 1987 & Jan. 24 & 4,410 & 11.15 \\
\hline 1950 & Mar. 16 & 1,200 & - & 1969 & Apr. 22 & 1,360 & 6.97 & 1988 & Apr. 30 & 1,520 & 7.24 \\
\hline 1951 & Mar. 21 & 1,060 & 6.30 & 1970 & Apr. 05 & 3,700 & 10.50 & 1989 & Apr. 16 & 2,140 & 8.34 \\
\hline 1952 & Mar. 09 & 4,200 & 11.00 & 1971 & Mar. 07 & 9,720 & 14.34 & 1990 & Dec. 15 & 1,890 & 8.00 \\
\hline 1953 & May. 09 & 3,140 & 9.90 & 1972 & Jan. 17 & 3,780 & 10.58 & & & & \\
\hline
\end{tabular}




\section{SAVANNAH RIVER BASIN}

\section{SAVANNAH RIVER NEAR CLYO, GEORGIA}

LOCATION.-Lat $32^{\circ} 31^{\prime} 30^{\prime \prime}$, long $81^{\circ} 15^{\prime} 45^{\prime \prime}$, Effingham County, on downstream side of center pier of drawspan of bridge on Seaboard Coast Line Railroad, $3.0 \mathrm{mi}$ north of Clyo, and at mile 60.9 .

DRAINAGE AREA.- $-9,850 \mathrm{mi}^{2}$

GAGE.-Water-stage recorder. Datum of gage is $13.39 \mathrm{ft}$ above sea level. Prior to Jan. 31,1933, nonrecording gage at same site and at datum $4.00 \mathrm{ft}$ higher. Jan 31, 1933 to June 12, 1945, nonrecording gage at same site and datum. Al gage readings have been adjusted to present datum.

STAGE-DISCHARGE RELATION.--Defined by current-meter measurement below $130,000 \mathrm{ft}^{3} / \mathrm{s}$, and extended by logarithmic plotting. Bankfull stage and discharge, $11 \mathrm{ft}$ and $15,000 \mathrm{ft}^{3} / \mathrm{s}$.

HISTORICAL DATA.--Flood stage of October 1929, from information furnished by U.S. Army Corps of Engineers, was the highest since 1796 based on comparison with nearby stations on the Savannah River.

REMARKS.--Peak discharge prior to June 13, 1945, are from graphs based on gage readings. Gage heights prior to 1930 furnished by U.S. Army Corps of Engineers and those for 1930-37 furnished by National Weather Service. Peak discharges are affected by storage in Lake Burton, Mathis Reservoirs, Hartwell and J. Strom Thurmond Lakes (formerly Clarks Hill Lake). (See station 02197000 for dates of regulation and maximum flood-control storage capacities.)

\begin{tabular}{|c|c|c|c|c|c|c|c|c|c|c|c|}
\hline $\begin{array}{l}\text { Water } \\
\text { year }\end{array}$ & Date & $\begin{array}{c}\text { Discharge } \\
\left(\mathrm{ft}^{3} / \mathrm{s}\right)\end{array}$ & $\begin{array}{l}\text { Gage } \\
\text { height } \\
\text { (ft) }\end{array}$ & $\begin{array}{c}\text { Water } \\
\text { year }\end{array}$ & Date & $\begin{array}{c}\text { Discharge } \\
\left(\mathrm{ft}^{3} / \mathrm{s}\right)\end{array}$ & $\begin{array}{c}\text { Gage } \\
\text { height } \\
\text { (ft) }\end{array}$ & $\begin{array}{l}\text { Water } \\
\text { year }\end{array}$ & Date & $\begin{array}{c}\text { Discharge } \\
\left(\mathrm{ft}^{3} / \mathrm{s}\right)\end{array}$ & $\begin{array}{c}\text { Gage } \\
\text { height } \\
\text { (ft) }\end{array}$ \\
\hline 1925 & Jan. 24 & 134,000 & 23.90 & 1947 & Jan. 28 & 63,200 & 19.40 & 1969 & Apr. 29 & 39,700 & 16.74 \\
\hline 1926 & Jan. 28 & 31,400 & 15.40 & 1948 & Feb. 17 & 71,000 & 19.66 & 1970 & Apr. 07 & 21,000 & 13.31 \\
\hline 1927 & Mar. 06 & 20,600 & 13.40 & 1949 & Dec. 06 & 104,000 & 22.17 & 1971 & Mar. 06 & 54,500 & 18.11 \\
\hline 1928 & Aug. 23 & 106,000 & 22.30 & 1950 & Oct. 19 & 16,000 & 12.21 & 1972 & Jan. 26 & 36,400 & 16.30 \\
\hline 1929 & Mar. 11 & 128,000 & 23.60 & 1951 & Nov. 01 & 22,600 & 13.38 & 1973 & Apr. 15 & 44,500 & 17.29 \\
\hline 1930 & Oct. 06 & 270,000 & 29.70 & 1952 & Apr. 02 & 41,300 & 16.90 & 1974 & Mar. 01 & 33,000 & 15.78 \\
\hline 1931 & Nov. 28 & 18,200 & 12.77 & 1953 & May. 17 & 35,800 & 15.80 & 1975 & Mar. 24 & 50,600 & 17.83 \\
\hline 1932 & Jan. 15 & 59,600 & 19.18 & 1954 & Apr. 12 & 18,800 & 12.49 & 1976 & June 14 & 33,500 & 15.87 \\
\hline 1933 & Jan. 04 & 59,600 & 19.20 & 1955 & Apr. 23 & 15,500 & 11.35 & 1977 & Dec. 22 & 33,400 & 15.85 \\
\hline 1934 & June 15 & 43,800 & 17.20 & 1956 & Mar. 22 & 14,100 & 10.47 & 1978 & Feb. 03 & 38,700 & 16.81 \\
\hline 1935 & Mar. 22 & 29,100 & 15.20 & 1957 & May. 15 & 15,000 & 11.15 & 1979 & Apr. 27 & 36,600 & 16.34 \\
\hline 1937 & Jan. 11 & 65,800 & 19.40 & 1959 & June 18 & 26,000 & 14.36 & 1981 & Feb. 16 & 13,600 & 10.38 \\
\hline 1938 & Apr. 16 & 48,400 & 17.80 & 1960 & Feb. 19 & 40,900 & 17.35 & 1982 & Jan. 11 & 19,500 & 12.89 \\
\hline 1939 & Mar. 08 & 70,100 & 20.40 & 1961 & Apr. 25 & 34,900 & 16.20 & 1983 & Apr. 17 & 58,600 & 18.40 \\
\hline 1940 & Aug. 22 & 128,000 & 23.60 & 1962 & Jan. 19 & 28,200 & $14.98 \mathrm{a}$ & 1984 & May. 14 & 37,700 & 16.48 \\
\hline 1941 & July 17 & 36,500 & 16.30 & 1963 & Mar. 31 & 29,200 & 15.27 & 1985 & Feb. 15 & 19,500 & 12.89 \\
\hline 1942 & Mar. 29 & 73,000 & 20.00 & 1964 & Apr. 18 & 83,800 & 20.22 & 1986 & Nov. 28 & 15,800 & 11.50 \\
\hline 1943 & Jan. 27 & 73,000 & 20.00 & 1965 & Apr. 06 & 38,000 & 16.52 & 1987 & Mar. 13 & 29,700 & 15.57 \\
\hline 1944 & Mar. 29 & 95,200 & 21.60 & 1966 & Mar. 11 & 42,800 & 17.10 & 1988 & Oct. 04 & 11,400 & 8.93 \\
\hline 1945 & May. 05 & 34,400 & 16.00 & 1967 & June 22 & 22,500 & 13.67 & 1989 & Sept.26 & 14,200 & 10.54 \\
\hline 1946 & Jan. 16 & 64,400 & 19.50 & 1968 & Jan. 21 & 28,000 & 14.84 & 1990 & Mar. 05 & 39,400 & 16.70 \\
\hline
\end{tabular}

\section{EBENEZER CREEK TRIBUTARY NEAR KILDARE, GEORGIA}

LOCATION.-Lat $32^{\circ} 33^{\prime} 04^{\prime \prime}$, long $81^{\circ} 22^{\prime} 15^{\prime \prime}$, Effingham County, at culvert on Clyo Road near Kildare.

DRAINAGE AREA.-- $1.02 \mathrm{mi}^{2}$.

GAGE.-Flood-stage/rainfall recorder.

STAGE-DISCHARGE RELATION.--Defined by current-meter measurements below $20 \mathrm{ft}^{3} / \mathrm{s}$, and extended above on basis of culvert computations.

\begin{tabular}{|c|c|c|c|c|c|c|c|c|c|c|c|}
\hline $\begin{array}{l}\text { Water } \\
\text { year }\end{array}$ & Date & $\begin{array}{c}\text { Discharge } \\
\left(\mathrm{ft}^{3} / \mathrm{s}\right)\end{array}$ & $\begin{array}{c}\text { Gage } \\
\text { height } \\
\text { (ft) }\end{array}$ & $\begin{array}{l}\text { Water } \\
\text { year }\end{array}$ & Date & $\begin{array}{c}\text { Discharge } \\
\left(\mathrm{ft}^{3} / \mathrm{s}\right)\end{array}$ & $\begin{array}{c}\text { Gage } \\
\text { height } \\
\text { (ft) }\end{array}$ & $\begin{array}{l}\text { Water } \\
\text { year }\end{array}$ & Date & $\begin{array}{c}\text { Discharge } \\
\left(\mathrm{ft}^{3} / \mathrm{s}\right)\end{array}$ & $\begin{array}{c}\text { Gage } \\
\text { height } \\
\text { (ft) }\end{array}$ \\
\hline $\begin{array}{l}1979 \\
1980 \\
1981\end{array}$ & $\begin{array}{l}\text { Sept.04 } \\
\text { Mar. } 13 \\
\text { June } 11\end{array}$ & $\begin{array}{l}31.0 \\
18.0 \\
60.0\end{array}$ & $\begin{array}{l}1.10 \\
0.86 \\
1.58\end{array}$ & $\begin{array}{l}1982 \\
1983 \\
1984\end{array}$ & $\begin{array}{l}\text { Feb. } 12 \\
\text { Mar. } 06 \\
\text { May. } 03\end{array}$ & $\begin{array}{l}24.0 \\
32.0 \\
29.0\end{array}$ & $\begin{array}{l}0.99 \\
1.11 \\
1.07\end{array}$ & $\begin{array}{l}1985 \\
1986\end{array}$ & $\begin{array}{l}\text { Aug. } 08 \\
\text { Nov. } 22\end{array}$ & $\begin{array}{l}13.0 \\
65.0\end{array}$ & $\begin{array}{l}0.71 \\
1.66\end{array}$ \\
\hline
\end{tabular}




\section{SAVANNAH RIVER BASIN}

\section{LOCKNER CREEK TRIBUTARY NEAR RINCON, GEORGIA}

LOCATION.--Lat $32^{\circ} 20^{\prime} 54^{\prime \prime}$, long $81^{\circ} 11^{\prime} 11^{\prime \prime}$, Effingham County, at culvert on unpaved road, 0.4 mile west of intersection with Old Augusta Road near Rincon. DRAINAGE AREA.-1.59 $\mathrm{mi}^{2}$.

GAGE.-Flood-stage/rainfall recorder.

STAGE-DISCHARGE RELATION.--Defined by current-meter measurements below $60 \mathrm{tt}^{3} / \mathrm{s}$, and extended above on basis of culvert computations.

\begin{tabular}{|c|c|c|c|c|c|c|c|c|c|c|c|}
\hline $\begin{array}{l}\text { Water } \\
\text { year }\end{array}$ & Date & $\begin{array}{c}\text { Discharge } \\
\left(\mathrm{ft}^{3} / \mathrm{s}\right)\end{array}$ & $\begin{array}{c}\text { Gage } \\
\text { height } \\
\text { (ft) }\end{array}$ & $\begin{array}{l}\text { Water } \\
\text { year }\end{array}$ & Date & $\begin{array}{c}\text { Discharge } \\
\left(\mathrm{ft}^{3} / \mathrm{s}\right)\end{array}$ & $\begin{array}{c}\text { Gage } \\
\text { height } \\
\text { (ft) }\end{array}$ & $\begin{array}{l}\text { Water } \\
\text { year }\end{array}$ & Date & $\begin{array}{l}\text { Discharge } \\
\left(\mathrm{ft}^{3} / \mathbf{s}\right)\end{array}$ & $\begin{array}{c}\text { Gage } \\
\text { height } \\
\text { (ft) }\end{array}$ \\
\hline $\begin{array}{l}1979 \\
1980 \\
1981\end{array}$ & $\begin{array}{l}\text { Sept.04 } \\
\text { Mar. } 13 \\
\text { Aug. } 19\end{array}$ & $\begin{array}{r}107 \\
41.0 \\
27.0\end{array}$ & $\begin{array}{l}8.23 \\
3.14 \\
2.36\end{array}$ & $\begin{array}{l}1982 \\
1983\end{array}$ & $\begin{array}{l}\text { July } 09 \\
\text { Mar. } 17\end{array}$ & $\begin{array}{l}57.0 \\
51.0\end{array}$ & $\begin{array}{l}4.06 \\
3.77\end{array}$ & $\begin{array}{l}1984 \\
1985\end{array}$ & $\begin{array}{l}\text { Mar. } 06 \\
\text { Aug. } 30\end{array}$ & $\begin{array}{r}48.0 \\
108\end{array}$ & $\begin{array}{l}3.58 \\
8.31\end{array}$ \\
\hline
\end{tabular}

\section{OGEECHEE RIVER BASIN}

02199700 SOUTH FORK OGEECHEE RIVER NEAR CRAWFORDVILLE, GEORGIA

LOCATION.--Lat $33^{\circ} 31^{\prime} 00^{\prime \prime}$, long $82^{\circ} 54^{\prime} 22^{\prime \prime}$, Taliaferro County, at State Highway 22,3 miles south of Crawfordville. DRAINAGE AREA. $-31.3 \mathrm{mi}^{2}$.

GAGE.--Crest-stage gage. Datum of gage is $340.97 \mathrm{ft}$ above sea level (from Georgia Department of Transportation).

STAGE-DISCHARGE RELATION.--Defined by current-meter measurement below $1,600 \mathrm{ft}^{3} / \mathrm{s}$ and extended above on the basis of straight-line extension.

REMARKS.--The flood stage of 1948 provided by Georgia Department of Transportation and the discharge is an estimate. Peaks below $9.0 \mathrm{ft}$ may be affected by backwater.

\begin{tabular}{|c|c|c|c|c|c|c|c|c|c|c|c|}
\hline $\begin{array}{l}\text { Water } \\
\text { year }\end{array}$ & Date & $\begin{array}{c}\text { Discharge } \\
\left(\mathrm{ft}^{3} / \mathrm{s}\right)\end{array}$ & $\begin{array}{l}\text { Gage } \\
\text { height } \\
\text { (ft) }\end{array}$ & $\begin{array}{l}\text { Water } \\
\text { year }\end{array}$ & Date & $\begin{array}{c}\text { Discharge } \\
\left(\mathrm{ft}^{3} / \mathrm{s}\right)\end{array}$ & $\begin{array}{c}\text { Gage } \\
\text { height } \\
\text { (ft) }\end{array}$ & $\begin{array}{l}\text { Water } \\
\text { year }\end{array}$ & Date & $\begin{array}{c}\text { Discharge } \\
\left(\mathrm{ft}^{3} / \mathrm{s}\right)\end{array}$ & $\begin{array}{c}\text { Gage } \\
\text { height } \\
\text { (ft) }\end{array}$ \\
\hline $\begin{array}{l}\frac{1949}{1951} \\
1952 \\
1953 \\
1954 \\
1955 \\
1956\end{array}$ & $\begin{array}{l}\text { Dec. } 01 \\
\text { Dec. } 09 \\
\text { Mar. } 03 \\
\text { May. } 01 \\
\text { Dec. } 14 \\
\text { Feb. } 07 \\
\text { Mar. } 16\end{array}$ & $\begin{array}{r}3,700 \\
698 \\
2,260 \\
2,380 \\
390 \\
762 \\
1,260\end{array}$ & $\begin{array}{c}17.13 c \\
7.75 \\
13.40 \\
13.72 \\
6.00 \\
8.06 \\
10.23\end{array}$ & $\begin{array}{l}1957 \\
1958 \\
1959 \\
1960 \\
1961 \\
1962 \\
1963\end{array}$ & $\begin{array}{l}\text { Dec. } 25 \\
\text { Feb. } 06 \\
\text { Feb. -- } \\
\text { Jan. } 30 \\
\text { Feb. } 25 \\
\text { Feb. } 22 \\
\text { June } 28\end{array}$ & $\begin{array}{r}984 \\
1,150 \\
675 \\
1,590 \\
2,580 \\
1,470 \\
1,320\end{array}$ & $\begin{array}{r}9.09 \\
9.84 \\
7.71 \\
11.29 \\
14.25 \\
10.87 \\
10.44\end{array}$ & $\begin{array}{l}1964 \\
1965 \\
1966 \\
1967 \\
1968 \\
1969\end{array}$ & $\begin{array}{l}\text { May. } 02 \\
\text { Dec. } 26 \\
\text { Mar. } 04 \\
\text { Mar. } 10 \\
\text { Jan. } 21 \\
\text { May. } 19\end{array}$ & $\begin{array}{l}2,190 \\
2,220 \\
1,550 \\
1,750 \\
1,110 \\
1,620\end{array}$ & $\begin{array}{r}13.22 \\
13.30 \\
11.17 \\
11.82 \\
9.63 \\
11.40\end{array}$ \\
\hline
\end{tabular}




\section{OGEECHEE RIVER BASIN}

\section{OGEECHEE RIVER AT JEWELL, GEORGIA}

LOCATION.--Lat $33^{\circ} 17^{\prime} 48^{\prime \prime}$, long $82^{\circ} 46^{\prime} 40^{\prime \prime}$, Hancock-Warren County line, 0.5 mi downstream from Long Creek, 5 mi downstream from Georgia Railroad bridge, on Georgia Highway 16 at Jewell.

DRAINAGE AREA.--242 $\mathrm{mi}^{2}$.

GAGE.--Crest-stage gage after November 29, 1983; nonrecording gage at site $500 \mathrm{ft}$ upstream at different datum from Sept. 13, 1943 to March 24, 1944. All gage readings have been adjusted to present datum. Datum of gage is $331.28 \mathrm{ft}$ above sea level (from Georgia Department of Transportation).

STAGE-DISCHARGE RELATION.--Defined by current-meter measurements below $8,500 \mathrm{ft}^{3} / \mathrm{s}$ and extended above on the basis of slope-conveyance studies. Bankfull stage and discharge, $10 \mathrm{ft}$ and $2,000 \mathrm{ft}^{3} / \mathrm{s}$.

REMARKS.--Flood stages of 1888, 1928, 1929, and 1961 provided by Georgia Department of Transportation. Flood of 1888 was probably highest since 1840 based on comparison with nearby stations. Flood stage of 1971 flood from floodmarks.

\begin{tabular}{|c|c|c|c|c|c|c|c|c|c|c|c|}
\hline $\begin{array}{l}\text { Water } \\
\text { year }\end{array}$ & Date & $\begin{array}{c}\text { Discharge } \\
\left(\mathrm{ft}^{3} / \mathrm{s}\right)\end{array}$ & $\begin{array}{c}\text { Gage } \\
\text { height } \\
\text { (ft) }\end{array}$ & $\begin{array}{l}\text { Water } \\
\text { year }\end{array}$ & Date & $\begin{array}{c}\text { Discharge } \\
\left(\mathrm{ft}^{3} / \mathrm{s}\right)\end{array}$ & $\begin{array}{c}\text { Gage } \\
\text { height } \\
\text { (ft) }\end{array}$ & $\begin{array}{l}\text { Water } \\
\text { year }\end{array}$ & Date & $\begin{array}{c}\text { Discharge } \\
\left(\mathrm{ft}^{3} / \mathrm{s}\right)\end{array}$ & $\begin{array}{c}\text { Gage } \\
\text { height } \\
\text { (ft) }\end{array}$ \\
\hline 1888 & Dec. -- & 27,000 & $34.12 \mathrm{c}$ & 1971 & Mar. 02 & 6,200 & $19.15 \mathrm{c}$ & 1987 & $\operatorname{Jan} .20$ & 3,100 & 12.85 \\
\hline$\overline{1928}$ & Aug. 16 & 15,000 & $25.82 \mathrm{C}$ & 1984 & May 04 & 4,580 & 15.99 & 1988 & Apr. 12 & 2,460 & 11.32 \\
\hline 1929 & Sept.28 & 22,500 & $30.12 \mathrm{c}$ & 1985 & Feb. 06 & 5,670 & 18.25 & 1989 & Oct. 04 & 2,620 & 11.73 \\
\hline$\overline{1944}$ & $\frac{\text { Mar. 24 }}{\text { Feb. } 25}$ & $\frac{9,650}{18,500}$ & $\begin{array}{l}22.92 \\
27.52 \mathrm{c}\end{array}$ & 1986 & Feb. - & 1,400 & $--b$ & 1990 & Oct. 01 & 7,800 & 22.16 \\
\hline
\end{tabular}

\section{LITTLE OGEECHEE RIVER AT HAMBURG, GEORGIA}

LOCATION.--Lat 33 $12^{\prime} 25^{\prime \prime}$, long $82^{\circ} 46^{\prime} 38^{\prime \prime}$, Washington County, at State Highway 248, at Hamburg.

DRAINAGE AREA. $-55 \mathrm{mi}^{2}$.

GAGE.--Crest-stage gage. Datum of gage is about $335 \mathrm{ft}$ above sea level (from topographic map).

STAGE-DISCHARGE RELATION.--Defined by current-meter measurements below $460 \mathrm{ft}^{3} / \mathrm{s}$, and extended above on basis of computation of flow over dam.

REMARKS.--Storage by small milldam may affect lower peak discharges.

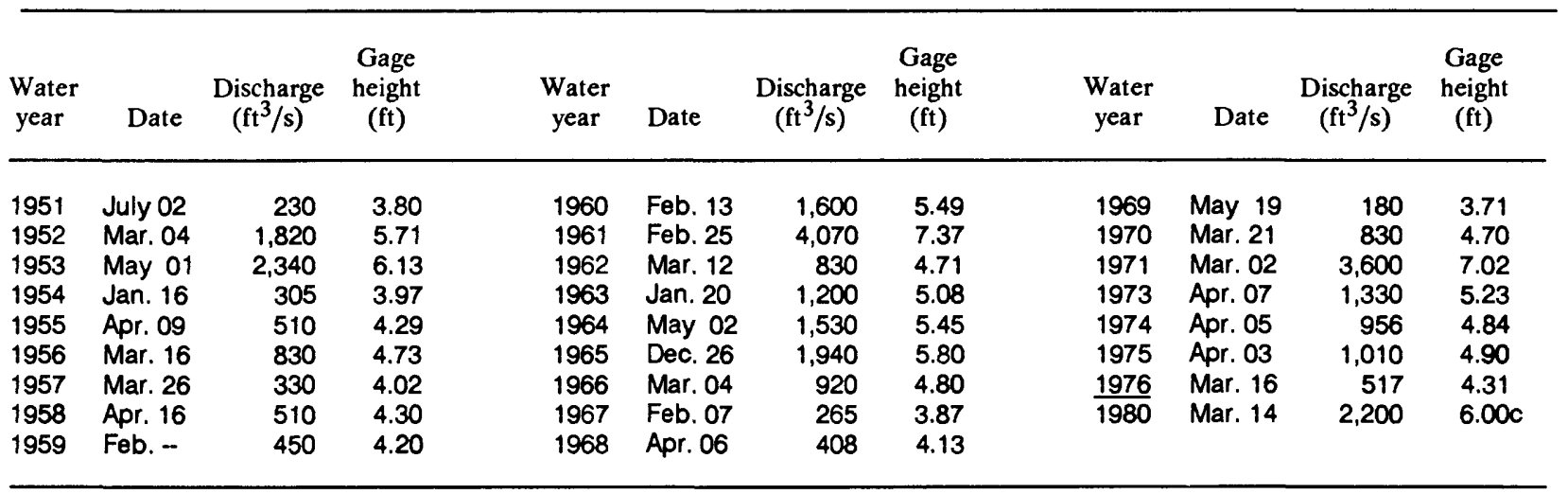


LOCATION.--Lat 3306'09", long $82^{\circ} 34^{\prime} 02^{\prime \prime}$, Jefferson County, at bridge on State Highway 88, 1.5 mi northeast of Grange. DRAINAGE AREA. $-188 \mathrm{mi}^{2}$.

GAGE.--Crest-stage gage. Datum of gage is $250.10 \mathrm{tt}$ above sea level (from U.S. Geological Survey benchmark). STAGE-DISCHARGE RELATION.--Defined by current-meter measurements below $4,000 \mathrm{tt}^{3} / \mathrm{s}$.

\begin{tabular}{|c|c|c|c|c|c|c|c|c|c|c|c|}
\hline $\begin{array}{l}\text { Water } \\
\text { year }\end{array}$ & Date & $\begin{array}{c}\text { Discharge } \\
\left(\mathrm{ft}^{3} / \mathrm{s}\right)\end{array}$ & $\begin{array}{c}\text { Gage } \\
\text { height } \\
(\mathrm{ft})\end{array}$ & $\begin{array}{c}\text { Water } \\
\text { year }\end{array}$ & Date & $\begin{array}{c}\text { Discharge } \\
\left(\mathrm{ft}^{3} / \mathrm{s}\right)\end{array}$ & $\begin{array}{c}\text { Gage } \\
\text { height } \\
(\mathrm{ft})\end{array}$ & $\begin{array}{l}\text { Water } \\
\text { year }\end{array}$ & Date & $\begin{array}{c}\text { Discharge } \\
\left(\mathrm{ft}^{3} / \mathrm{s}\right)\end{array}$ & $\begin{array}{c}\text { Gage } \\
\text { height } \\
\text { (ft) }\end{array}$ \\
\hline $\begin{array}{l}1979 \\
1980 \\
1981 \\
1982\end{array}$ & $\begin{array}{l}\text { Feb. } 28 \\
\text { Mar. } 14 \\
\text { Feb. } 11 \\
\text { Jan. } 02\end{array}$ & $\begin{array}{l}3,610 \\
4,020 \\
1,650 \\
1,840\end{array}$ & $\begin{array}{l}14.41 \\
14.82 \\
11.76 \\
12.06\end{array}$ & $\begin{array}{l}1983 \\
1984 \\
1985 \\
1986\end{array}$ & $\begin{array}{l}\text { Apr. } 11 \\
\text { May } 05 \\
\text { Feb. } 06 \\
\text { Apr. } 23\end{array}$ & $\begin{array}{r}2,280 \\
1,760 \\
584 \\
680\end{array}$ & $\begin{array}{r}12.80 \\
11.93 \\
9.03 \\
9.60\end{array}$ & $\begin{array}{l}1987 \\
1988 \\
1989 \\
1990\end{array}$ & $\begin{array}{l}\text { Jan. } 20 \\
\text { Apr. } 19 \\
\text { Apr. } 11 \\
\text { Oct. } 02\end{array}$ & $\begin{array}{r}1,660 \\
770 \\
1,190 \\
1,550\end{array}$ & $\begin{array}{r}11.76 \\
9.86 \\
10.91 \\
11.60\end{array}$ \\
\hline
\end{tabular}

\section{OGEECHEE RIVER NEAR LOUISVILLE, GEORGIA}

LOCATION.--Lat $32^{\circ} 58^{\prime} 03^{\prime \prime}$, long $82^{\circ} 23^{\prime} 26^{\prime \prime}$, Jefferson County, at U.S. Highway 1,1 mi downstream from Louisville and Wadley Railroad bridge, 2 mi south of Louisville, 2 mi downstream from Rocky Comfort Creek, and 2 mi upstream from Big Creek. DRAINAGE AREA.--800 $\mathrm{mi}^{2}$.

GAGE.--Nonrecording prior to Aug. 30, 1941; recording Aug. 30, 1941 to Dec. 31, 1949; crest-stage gage thereafter. Datum of gage is $199.24 \mathrm{ft}$ above sea level (levels by U.S. Army Corps of Engineers), supplementary adjustment 1936.

STAGE-DISCHARGE RELATION.--Defined by current-meter measurements below $17,000 \mathrm{ft}^{3} / \mathrm{s}$, and extended above on basis of slope-conveyance study. Bankful stage and discharge, $11 \mathrm{ft}$ and $2,000 \mathrm{ft}^{3} / \mathrm{s}$..

HISTORICAL DATA.-Flood stage of October 1929 based on information from Central of Georgia Railway Company, and was the highest flood known since 1840 based on comparison with nearby stations. The local newspaper, published since 1871 , referred to the October 1929 flood as the "highest in history".

REMARKS.--Peak discharges for 1951 and 1971 are estimated.

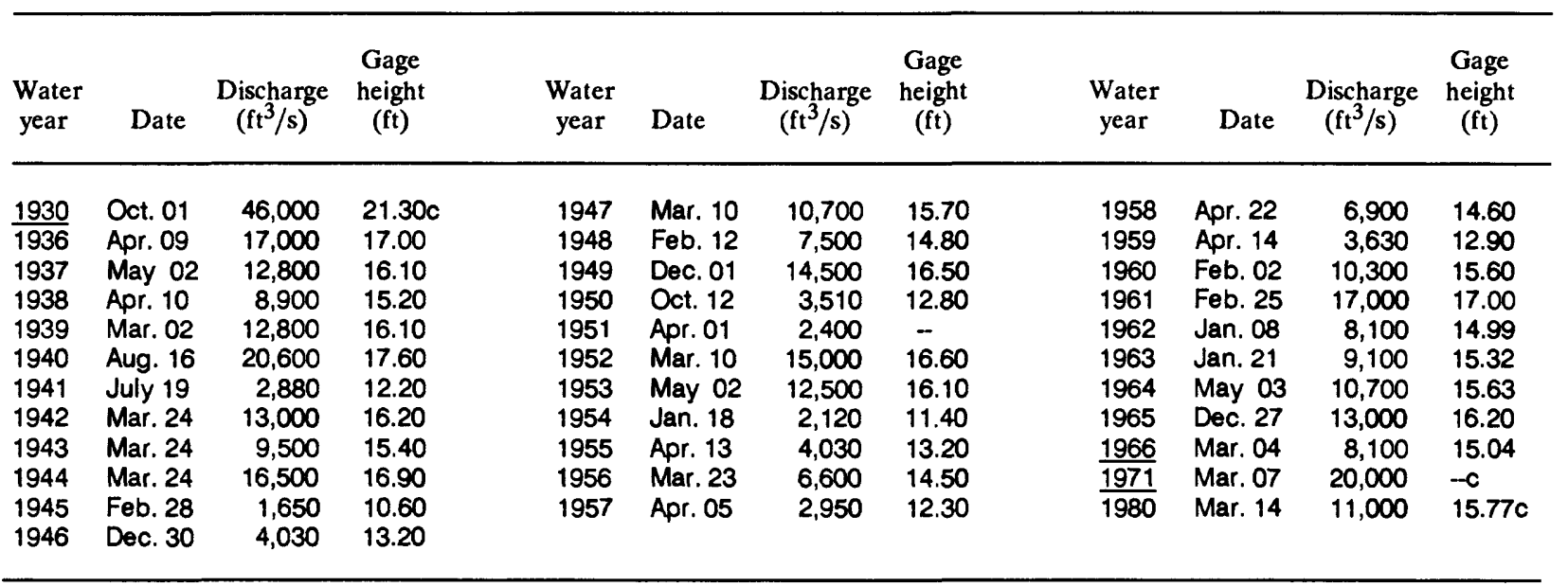




\section{OGEECHEE RIVER BASIN}

\section{BIG CREEK NEAR LOUISVILLE, GEORGIA}

LOCATION.--Lat $32^{\circ} 59^{\prime} 00^{\prime \prime}$, long $82^{\circ} 21^{\prime} 23^{\prime \prime}$, Jefferson County, at State Highway 17, about 3.2 mi southeast of Louisville. DRAINAGE AREA. $-95.8 \mathrm{mi}^{2}$.

GAGE.--Crest-stage gage. Datum of gage is $210.2 \mathrm{ft}$ above sea level (from Georgia Department of Transportation).

STAGE-DISCHARGE RELATION.--Defined by current-meter measurements below $2,160 \mathrm{ft}^{3} / \mathrm{s}$. Bankful stage and discharge, $5 \mathrm{ft}$ and $640 \mathrm{ft}^{3} / \mathrm{s}$.

\begin{tabular}{|c|c|c|c|c|c|c|c|c|c|c|c|}
\hline $\begin{array}{l}\text { Water } \\
\text { year }\end{array}$ & Date & $\begin{array}{c}\text { Discharge } \\
\left(\mathrm{ft}^{3} / \mathrm{s}\right)\end{array}$ & $\begin{array}{c}\text { Gage } \\
\text { height } \\
\text { (ft) }\end{array}$ & $\begin{array}{l}\text { Water } \\
\text { year }\end{array}$ & Date & $\begin{array}{c}\text { Discharge } \\
\left(\mathrm{ft}^{3} / \mathrm{s}\right)\end{array}$ & $\begin{array}{c}\text { Gage } \\
\text { height } \\
\text { (ft) }\end{array}$ & $\begin{array}{l}\text { Water } \\
\text { year }\end{array}$ & Date & $\begin{array}{c}\text { Discharge } \\
\left(\mathrm{ft}^{3} / \mathrm{s}\right)\end{array}$ & $\begin{array}{l}\text { Gage } \\
\text { height } \\
\text { (ft) }\end{array}$ \\
\hline $\begin{array}{l}1951 \\
1952 \\
1953 \\
1954 \\
1955 \\
1956 \\
1957 \\
1958 \\
1959\end{array}$ & $\begin{array}{l}\text { July } 00 \\
\text { Mar. } 03 \\
\text { May } 02 \\
\text { May } 13 \\
\text { Apr. } 14 \\
\text { Mar. } 16 \\
\text { Dec. } 23 \\
\text { July } 07 \\
\text { May } 31\end{array}$ & $\begin{array}{l}328 \\
472 \\
448 \\
261 \\
690 \\
548 \\
370 \\
548 \\
318\end{array}$ & $\begin{array}{l}4.00 \\
4.63 \\
4.53 \\
3.66 \\
5.18 \\
4.96 \\
4.19 \\
4.93 \\
4.09\end{array}$ & $\begin{array}{l}1960 \\
1961 \\
1962 \\
1963 \\
1964 \\
1965 \\
1966 \\
1967 \\
1968\end{array}$ & $\begin{array}{l}\text { Apr. } 04 \\
\text { Apr. } 16 \\
\text { Mar. } 12 \\
\text { Oct. } 05 \\
\text { May } 03 \\
\text { July } 30 \\
\text { Mar. } 04 \\
\text { May } 23 \\
\text { Jan. } 04\end{array}$ & $\begin{array}{r}735 \\
812 \\
705 \\
508 \\
1,370 \\
1,590 \\
1,550 \\
1,560 \\
170\end{array}$ & $\begin{array}{l}5.27 \\
5.42 \\
5.21 \\
4.76 \\
5.92 \\
6.09 \\
6.06 \\
6.07 \\
3.11\end{array}$ & $\begin{array}{l}1969 \\
1970 \\
1971 \\
1972 \\
1973 \\
1974 \\
1975 \\
\frac{1976}{1980}\end{array}$ & $\begin{array}{l}\text { Aug. } 23 \\
\text { Mar. } 30 \\
\text { Mar. } 03 \\
\text { Jan. } 11 \\
\text { Apr. } 08 \\
\text { Feb. } 17 \\
\text { Apr. } 15 \\
\text { Mar. } 16 \\
\text { Mar. } 14\end{array}$ & $\begin{array}{r}336 \\
860 \\
2,160 \\
902 \\
990 \\
642 \\
1,010 \\
472 \\
1,680\end{array}$ & $\begin{array}{l}4.18 \\
5.47 \\
6.42 \\
5.44 \\
5.55 \\
5.02 \\
5.58 \\
4.66 \\
6.16 c\end{array}$ \\
\hline
\end{tabular}

02200930 SPRING CREEK NEAR LOUISVILLE, GEORGIA

(Formerly published as "Ogeechee River Tributary near Louisville, Georgia")

LOCATION.--Lat $32^{\circ} 55^{\prime} 20^{\prime \prime}$, long $82^{\circ} 18^{\prime} 49^{\prime \prime}$, Jefferson County, at culvert on State Highway 17, 8.5 mi southeast of Louisville. DRAINAGE AREA.-14.2 $\mathrm{mi}^{2}$.

GAGE.--Flood-stage recorder pirior to Dec. 30, 1969; flood-stage/rainfall recorder Dec. 30, 1969 to Sept. 30, 1975; crest-stage gage thereafter. Datum of gage is about $210 \mathrm{ft}$ above sea level (from topographic map).

STAGE-DISCHARGE RELATION.--Defined by current-meter measurements below $136 \mathrm{ft}^{3} / \mathrm{s}$, and extended above on basis of culvert computations.

REMARKS.--Flood of 1980 was highest since 1961 , based on comparison with nearby stations.

\begin{tabular}{|c|c|c|c|c|c|c|c|c|c|c|c|}
\hline $\begin{array}{l}\text { Water } \\
\text { year }\end{array}$ & Date & $\begin{array}{c}\text { Discharge } \\
\left(\mathrm{ft}^{3} / \mathrm{s}\right)\end{array}$ & $\begin{array}{c}\text { Gage } \\
\text { height } \\
\text { (ft) }\end{array}$ & $\begin{array}{l}\text { Water } \\
\text { year }\end{array}$ & Date & $\begin{array}{c}\text { Discharge } \\
\left(\mathrm{ft}^{3} / \mathrm{s}\right)\end{array}$ & $\begin{array}{c}\text { Gage } \\
\text { height } \\
\text { (ft) }\end{array}$ & $\begin{array}{l}\text { Water } \\
\text { year }\end{array}$ & Date & $\begin{array}{c}\text { Discharge } \\
\left(\mathrm{ft}^{3} / \mathrm{s}\right)\end{array}$ & $\begin{array}{c}\text { Gage } \\
\text { height } \\
\text { (ft) }\end{array}$ \\
\hline $\begin{array}{l}1965 \\
1966 \\
1967 \\
1968 \\
1969 \\
1970 \\
1971 \\
1972 \\
1973\end{array}$ & $\begin{array}{l}\text { Feb. } 17 \\
\text { Mar. } 04 \\
\text { May } 22 \\
\text { May } 00 \\
\text { May } 15 \\
\text { Mar. } 31 \\
\text { May } 13 \\
\text { Jan. } 14 \\
\text { Feb. } 02\end{array}$ & $\begin{array}{r}273 \\
870 \\
120 \\
90.0 \\
198 \\
264 \\
142 \\
472 \\
280\end{array}$ & $\begin{array}{c}4.42 \\
6.70 \\
2.78 \\
--b \\
3.78 \\
4.35 \\
3.10 \\
5.55 \\
4.48\end{array}$ & $\begin{array}{l}1974 \\
1975 \\
1976 \\
1977 \\
1978 \\
1979 \\
1980 \\
1981 \\
1982\end{array}$ & $\begin{array}{l}\text { Jan. } 29 \\
\text { Apr. } 14 \\
\text { July } 20 \\
\text { Mar. } 21 \\
\text { Jan. } 26 \\
\text { Apr. } 25 \\
\text { Mar. } 13 \\
\text { May } 00 \\
\text { Jan. } 01\end{array}$ & $\begin{array}{r}155 \\
190 \\
198 \\
308 \\
386 \\
342 \\
1,130 \\
90.0 \\
122\end{array}$ & $\begin{array}{l}3.28 \\
3.70 \\
3.78 \\
4.68 \\
5.13 \\
4.90 \\
7.35 \\
- \\
2.82\end{array}$ & $\begin{array}{l}1983 \\
1984 \\
1985 \\
1986 \\
1987 \\
1988 \\
1989 \\
1990\end{array}$ & $\begin{array}{l}\text { Mar. } 06 \\
\text { Mar. } 25 \\
\text { Mar. - } \\
\text { Nov. } 22 \\
\text { Feb. } 27 \\
\text { Apr. } 19 \\
\text { Apr. }-\overline{0} \\
\text { Oct. } 02\end{array}$ & $\begin{array}{r}910 \\
258 \\
90.0 \\
171 \\
398 \\
103 \\
92.0 \\
182\end{array}$ & $\begin{array}{c}6.70 \\
4.31 \\
-b \\
3.86 \\
5.59 \\
3.00 \\
--b \\
3.80\end{array}$ \\
\hline
\end{tabular}


LOCATION.--Lat $32^{\circ} 52^{\prime} 11^{\prime \prime}$, long $82^{\circ} 19^{\prime} 11^{\prime \prime}$, Jefferson County, at bridge on State Highway 78, 4.5 mi east of Wadley.

DRAINAGE AREA.-990 $\mathrm{mi}^{2}$, approximately.

GAGE.--Crest-stage gage. Datum of gage is about $180 \mathrm{ft}$ (from topographic map).

STAGE-DISCHARGE RELATION.--Defined by current-meter measurements below $25,000 \mathrm{ft}^{3} / \mathrm{s}$.

REMARKS.-Flood stage of 1961 provided by Georgia Department of Transportation.

\begin{tabular}{|c|c|c|c|c|c|c|c|c|c|c|c|}
\hline $\begin{array}{l}\text { Water } \\
\text { year }\end{array}$ & Date & $\begin{array}{c}\text { Discharge } \\
\left(\mathrm{ft}^{3} / \mathrm{s}\right)\end{array}$ & $\begin{array}{c}\text { Gage } \\
\text { height } \\
\text { (ft) }\end{array}$ & $\begin{array}{l}\text { Water } \\
\text { year }\end{array}$ & Date & $\begin{array}{c}\text { Discharge } \\
\left(\mathrm{ft}^{3} / \mathrm{s}\right)\end{array}$ & $\begin{array}{c}\text { Gage } \\
\text { height } \\
\text { (ft) }\end{array}$ & $\begin{array}{l}\text { Water } \\
\text { year }\end{array}$ & Date & $\begin{array}{c}\text { Discharge } \\
\left(\mathrm{ft}^{3} / \mathrm{s}\right)\end{array}$ & $\begin{array}{c}\text { Gage } \\
\text { height } \\
\text { (ft) }\end{array}$ \\
\hline $\begin{array}{l}1961 \\
1970 \\
1971 \\
1972 \\
1973 \\
1974 \\
1975\end{array}$ & $\begin{array}{l}\text { Feb. } 25 \\
\text { Apr. } 03 \\
\text { Mar. } 07 \\
\text { Jan. } 18 \\
\text { Apr. } 10 \\
\text { Apr. } 12 \\
\text { Apr. } 14\end{array}$ & $\begin{array}{r}13,800 \\
7,280 \\
24,200 \\
8,660 \\
8,180 \\
5,460 \\
9,230\end{array}$ & $\begin{array}{l}13.70 c \\
11.70 \\
16.25 \\
12.22 \\
12.06 \\
11.88 \\
12.41\end{array}$ & $\begin{array}{l}1976 \\
1977 \\
1978 \\
1979 \\
1980 \\
1981\end{array}$ & $\begin{array}{l}\text { Mar. } 19 \\
\text { Mar. } 26 \\
\text { Jan. } 26 \\
\text { Mar. } 01 \\
\text { Mar. } 15 \\
\text { Feb. } 13\end{array}$ & $\begin{array}{r}7,540 \\
7,500 \\
10,800 \\
13,800 \\
12,800 \\
7,110\end{array}$ & $\begin{array}{l}11.81 \\
11.79 \\
12.93 \\
13.69 \\
13.46 \\
11.63\end{array}$ & $\begin{array}{l}1982 \\
1983 \\
1984 \\
1985 \\
1986 \\
1987\end{array}$ & $\begin{array}{l}\text { Jan. } 04 \\
\text { Apr. } 11 \\
\overline{\text { Feb. }} 09 \\
\overline{\text { Jan. } 20}\end{array}$ & $\begin{array}{l}6,380 \\
9,890 \\
4,200 \\
9,530 \\
4,200 \\
7,520\end{array}$ & $\begin{array}{l}11.31 \\
12.63 \\
-b \\
12.51 \\
-b \\
11.80\end{array}$ \\
\hline
\end{tabular}

\section{WILLIAMSON SWAMP CREEK AT DAVISBORO, GEORGIA}

LOCATION.--Lat $32^{\circ} 58^{\prime} 32^{\prime \prime}$ long $82^{\circ} 36^{\prime} 36^{\prime \prime}$, Washington County, at bridge on State Highway 231 at Davisboro.

DRAINAGE AREA.--109 $\mathrm{mi}^{2}$.

GAGE.-Water-stage recorder; from Aug. 16, 1978 to May 8, 1980. Crest-stage gage at same site and datum. Datum of gage is $263.00 \mathrm{ft}$ from high water mark (from Georgia Department of Transportation).

STAGE-DISCHARGE RELATION.--Defined by current-meter measurements below $3,300 \mathrm{ft}^{3} / \mathrm{s}$, and extended above on the basis of straight-line extension.

REMARKS.--Flood stage of 1929, 1966, and 1977 are based on information provided by local residents. Peak discharges for 1929 , 1966, and 1977 are estimates.

\begin{tabular}{|c|c|c|c|c|c|c|c|c|c|c|c|}
\hline $\begin{array}{l}\text { Water } \\
\text { year }\end{array}$ & Date & $\begin{array}{c}\text { Discharge } \\
\left(\mathrm{ft}^{3} / \mathrm{s}\right)\end{array}$ & $\begin{array}{c}\text { Gage } \\
\text { height } \\
\text { (ft) }\end{array}$ & $\begin{array}{l}\text { Water } \\
\text { year }\end{array}$ & Date & $\begin{array}{c}\text { Discharge } \\
\left(\mathrm{ft}^{3} / \mathrm{s}\right)\end{array}$ & $\begin{array}{c}\text { Gage } \\
\text { height } \\
\text { (ft) }\end{array}$ & $\begin{array}{l}\text { Water } \\
\text { year }\end{array}$ & Date & $\begin{array}{c}\text { Discharge } \\
\left(\mathrm{ft}^{3} / \mathrm{s}\right)\end{array}$ & $\begin{array}{c}\text { Gage } \\
\text { height } \\
\text { (ft) }\end{array}$ \\
\hline $\begin{array}{l}\frac{1929}{\frac{1966}{1977}} \\
\frac{1979}{1980}\end{array}$ & $\begin{array}{l}\text { Sept.29 } \\
\text { Mar. } 04 \\
\text { Mar. } 21 \\
\text { Feb. } 25 \\
\text { Mar. } 13\end{array}$ & $\begin{array}{r}14,000 \\
5,000 \\
4,600 \\
2,300 \\
3,430\end{array}$ & $\begin{array}{c}15.00 c \\
11.80 c \\
11.60 c \\
9.94 \\
11.13\end{array}$ & $\begin{array}{l}1981 \\
1982 \\
1983 \\
1984 \\
1985\end{array}$ & $\begin{array}{l}\text { Feb. } 12 \\
\text { Feb. } 04 \\
\text { Feb. } 15 \\
\text { Feb. } 28 \\
\text { Feb. } 06\end{array}$ & $\begin{array}{r}698 \\
1,540 \\
1,290 \\
935 \\
726\end{array}$ & $\begin{array}{l}7.75 \\
9.02 \\
8.91 \\
8.20 \\
7.86\end{array}$ & $\begin{array}{l}1986 \\
1987 \\
1988 \\
1989 \\
1990\end{array}$ & $\begin{array}{l}\text { Nov. } 23 \\
\text { Jan. } 19 \\
\text { Apr. } 27 \\
\text { Mar. } 24 \\
\text { Oct. } 02\end{array}$ & $\begin{array}{r}2,270 \\
2,730 \\
228 \\
414 \\
977\end{array}$ & $\begin{array}{r}9.92 \\
10.43 \\
5.52 \\
6.64 \\
8.27\end{array}$ \\
\hline
\end{tabular}


LOCATION.--Lat $32^{\circ} 52^{\prime} 25^{\prime \prime}$, long $82^{\circ} 26^{\prime} 34^{\prime \prime}$, Jefferson County, at culvert on U.S. Highway 319, 1.8 mi east of Bartow. DRAINAGE AREA.--8.36 $\mathrm{mi}^{2}$.

GAGE.--Flood-stage/rainfall recorder. Datum of gage is about $236 \mathrm{ft}$ above sea level (from topographic map).

STAGE-DISCHARGE RELATION.--Defined by current-meter measurements below $567 \mathrm{ft}^{3} / \mathrm{s}$, and extended above on basis of culvert computations.

\begin{tabular}{|c|c|c|c|c|c|c|c|c|c|c|c|}
\hline $\begin{array}{l}\text { Water } \\
\text { year }\end{array}$ & Date & $\begin{array}{c}\text { Discharge } \\
\left(\mathrm{ft}^{3} / \mathrm{s}\right)\end{array}$ & $\begin{array}{c}\text { Gage } \\
\text { height } \\
\text { (ft) }\end{array}$ & $\begin{array}{l}\text { Water } \\
\text { year }\end{array}$ & Date & $\begin{array}{c}\text { Discharge } \\
\left(\mathrm{ft}^{3} / \mathrm{s}\right)\end{array}$ & $\begin{array}{c}\text { Gage } \\
\text { height } \\
\text { (ft) }\end{array}$ & $\begin{array}{l}\text { Water } \\
\text { year }\end{array}$ & Date & $\begin{array}{c}\text { Discharge } \\
\left(\mathrm{ft}^{3} / \mathrm{s}\right)\end{array}$ & $\begin{array}{c}\text { Gage } \\
\text { height } \\
(\mathrm{ft})\end{array}$ \\
\hline $\begin{array}{l}1965 \\
1966 \\
1967 \\
1968\end{array}$ & $\begin{array}{l}\text { Dec. } 26 \\
\text { Mar. } 04 \\
\text { Aug. } 21 \\
\text { Jan. } 10\end{array}$ & $\begin{array}{r}242 \\
625 \\
102 \\
97\end{array}$ & $\begin{array}{l}2.76 \\
3.91 \\
1.91 \\
1.86\end{array}$ & $\begin{array}{l}1969 \\
1970 \\
1971\end{array}$ & $\begin{array}{l}\text { Aug. } 23 \\
\text { Mar. } 31 \\
\text { July } 01\end{array}$ & $\begin{array}{l}242 \\
252 \\
350\end{array}$ & $\begin{array}{l}2.76 \\
2.81 \\
3.26\end{array}$ & $\begin{array}{l}1972 \\
1973 \\
1974\end{array}$ & $\begin{array}{l}\text { Jan. } 14 \\
\text { Feb. } 02 \\
\text { Feb. } 07\end{array}$ & $\begin{array}{l}654 \\
565 \\
355\end{array}$ & $\begin{array}{l}4.21 \\
4.41 \\
3.67\end{array}$ \\
\hline
\end{tabular}

\section{BOGGY GUT CREEK NEAR WADLEY, GEORGIA}

LOCATION.--Lat $32^{\circ} 53^{\prime} 42^{\prime \prime}$, long $82^{\circ} 24^{\prime} 02^{\prime \prime}$, Jefferson County, at culvert on U.S. Highway 1,2 mi south of Wadley. DRAINAGE AREA.--7.05 $\mathrm{mi}^{2}$.

GAGE.--Flood-stage/rainfall recorder. Datum of gage is about $200 \mathrm{ft}$ above sea level (from topographic map).

STAGE-DISCHARGE RELATION.--Defined by current-meter measurements below $200 \mathrm{ft}^{3} / \mathrm{s}$, and extended above on basis of culvert computations.

\begin{tabular}{|c|c|c|c|c|c|c|c|c|c|c|c|}
\hline $\begin{array}{l}\text { Water } \\
\text { year }\end{array}$ & Date & $\begin{array}{c}\text { Discharge } \\
\left(\mathrm{ft}^{3} / \mathrm{s}\right)\end{array}$ & $\begin{array}{c}\text { Gage } \\
\text { height } \\
\text { (ft) }\end{array}$ & $\begin{array}{l}\text { Water } \\
\text { year }\end{array}$ & Date & $\begin{array}{c}\text { Discharge } \\
\left(\mathrm{ft}^{3} / \mathrm{s}\right)\end{array}$ & $\begin{array}{c}\text { Gage } \\
\text { height } \\
\text { (ft) }\end{array}$ & $\begin{array}{l}\text { Water } \\
\text { year }\end{array}$ & Date & $\begin{array}{c}\text { Discharge } \\
\left(\mathrm{ft}^{3} / \mathrm{s}\right)\end{array}$ & $\begin{array}{c}\text { Gage } \\
\text { height } \\
\text { (ft) }\end{array}$ \\
\hline $\begin{array}{l}1965 \\
1966 \\
1967 \\
1968\end{array}$ & $\begin{array}{l}\text { Dec. } 26 \\
\text { Mar. } 04 \\
\text { Feb. } 07 \\
\text { Jan. } 10\end{array}$ & $\begin{array}{r}394 \\
1,130 \\
143 \\
47\end{array}$ & $\begin{array}{l}5.17 \\
7.66 \\
4.02 \\
3.11\end{array}$ & $\begin{array}{l}1969 \\
1970 \\
1971\end{array}$ & $\begin{array}{l}\text { May } 15 \\
\text { Aug. } 08 \\
\text { Apr. } 24\end{array}$ & $\begin{array}{r}202 \\
1,800 \\
347\end{array}$ & $\begin{array}{r}4.36 \\
10.04 \\
4.91\end{array}$ & $\begin{array}{l}1972 \\
1973 \\
1974\end{array}$ & $\begin{array}{l}\text { Jan. } 13 \\
\text { Feb. } 02 \\
\text { Apr. } 09\end{array}$ & $\begin{array}{l}773 \\
905 \\
478\end{array}$ & $\begin{array}{l}6.56 \\
7.00 \\
5.51\end{array}$ \\
\hline
\end{tabular}

02201250 SEALS CREEK TRIBUTARY NEAR MIDVILLE, GEORGIA

(Formerly published as "Ogeechee River Tributary No. 2 Near Midville, Georgia")

LOCATION.--Lat $32^{\circ} 51^{\prime} 04^{\prime \prime}$, long $82^{\circ} 13^{\prime} 58^{\prime \prime}$, Burke County, at culvert on State Highway $305,2.2$ mi north of Midville.

DRAINAGE AREA, --0.99 $\mathrm{mi}^{2}$.

GAGE.--Flood-stage/rainfall recorder. Datum of gage is about $230 \mathrm{ft}$ above sea level (from topographic map).

STAGE-DISCHARGE RELATION.--Defined by current-meter measurements below $43 \mathrm{tt}^{3} / \mathrm{s}$, and extended above on basis of culvert computations.

\begin{tabular}{|c|c|c|c|c|c|c|c|c|c|c|c|}
\hline $\begin{array}{l}\text { Water } \\
\text { year }\end{array}$ & Date & $\begin{array}{c}\text { Discharge } \\
\left(\mathrm{ft}^{3} / \mathrm{s}\right)\end{array}$ & $\begin{array}{c}\text { Gage } \\
\text { height } \\
\text { (ft) }\end{array}$ & $\begin{array}{l}\text { Water } \\
\text { year }\end{array}$ & Date & $\begin{array}{c}\text { Discharge } \\
\left(\mathrm{ft}^{3} / \mathrm{s}\right)\end{array}$ & $\begin{array}{c}\text { Gage } \\
\text { height } \\
\text { (ft) }\end{array}$ & $\begin{array}{l}\text { Water } \\
\text { year }\end{array}$ & Date & $\begin{array}{c}\text { Discharge } \\
\left(\mathrm{ft}^{3} / \mathrm{s}\right)\end{array}$ & $\begin{array}{c}\text { Gage } \\
\text { height } \\
\text { (ft) }\end{array}$ \\
\hline 1964 & July 31 & 82.0 & 2.44 & 1968 & May. --b & 32.0 & -- & 1972 & Jan. 14 & 42.0 & 1.74 \\
\hline 1965 & Feb. 17 & 28.0 & 1.45 & 1969 & May. 18 & 56.0 & 1.99 & 1973 & Feb. 02 & 62.0 & 2.09 \\
\hline 1966 & Mar. 04 & 52.0 & 1.92 & 1970 & Aug. 08 & 65.0 & 2.15 & 1974 & Nov. - & 32.0 & $-\mathrm{b}$ \\
\hline 1967 & Feb. 07 & 32.0 & $--b$ & 1971 & Jan. --b & 32.0 & - & & & & \\
\hline
\end{tabular}




\section{OGEECHEE RIVER BASIN}

\section{BUCKHEAD CREEK NEAR WAYNESBORO, GEORGIA}

LOCATION.--Lat $32^{\circ} 58^{\prime} 21^{\prime \prime}$ l long $82^{\circ} 07^{\prime} 15^{\prime \prime}$, Burke County, at State Highway 56, 10 mi southwest of Waynesboro.

DRAINAGE AREA.--64 $\mathrm{mi}^{2}$.

GAGE.--Crest-stage gage. Datum of gage is $198.58 \mathrm{ft}$ above sea level (from U.S. Geological Survey benchmark).

STAGE-DISCHARGE RELATION.--Defined by current-meter measurements below $3,000 \mathrm{ft}^{3} / \mathrm{s}$, and extended above on basis of slope-conveyance studies. Bankfull state and discharge, $6 \mathrm{ft}$ and $800 \mathrm{ft}^{3} / \mathrm{s}$.

REMARKS.--Flood stage of 1929 provided by Georgia Department of Transportation. Peak discharge for 1929 flood is estimated.

\begin{tabular}{|c|c|c|c|c|c|c|c|c|c|c|c|}
\hline $\begin{array}{l}\text { Water } \\
\text { year }\end{array}$ & Date & $\begin{array}{c}\text { Discharge } \\
\left(\mathrm{ft}^{3} / \mathrm{s}\right)\end{array}$ & $\begin{array}{c}\text { Gage } \\
\text { height } \\
\text { (ft) }\end{array}$ & $\begin{array}{c}\text { Water } \\
\text { year }\end{array}$ & Date & $\begin{array}{c}\text { Discharge } \\
\left(\mathrm{ft}^{3} / \mathrm{s}\right)\end{array}$ & $\begin{array}{c}\text { Gage } \\
\text { height } \\
\text { (ft) }\end{array}$ & $\begin{array}{l}\text { Water } \\
\text { year }\end{array}$ & Date & $\begin{array}{c}\text { Discharge } \\
\left(\mathrm{ft}^{3} / \mathrm{s}\right)\end{array}$ & $\begin{array}{c}\text { Gage } \\
\text { height } \\
\text { (ft) }\end{array}$ \\
\hline $\begin{array}{l}1929 \\
1963 \\
1964 \\
1965 \\
1966 \\
1967 \\
1968 \\
1969\end{array}$ & $\begin{array}{l}\text { July } 00 \\
\text { Jan. } 22 \\
\text { Mar. } 08 \\
\text { Feb. } 18 \\
\text { Mar. } 05 \\
\text { Feb. } 08 \\
\text { Dec. } 28 \\
\text { May } 19\end{array}$ & $\begin{array}{r}9,000 \\
880 \\
1,140 \\
1,140 \\
3,550 \\
424 \\
292 \\
728\end{array}$ & $\begin{array}{c}11.60 c \\
6.18 \\
6.52 \\
6.49 \\
8.20 \\
5.01 \\
4.68 \\
5.68\end{array}$ & $\begin{array}{l}1970 \\
1971 \\
1972 \\
1973 \\
1974 \\
1975 \\
1976\end{array}$ & $\begin{array}{l}\text { Mar. } 31 \\
\text { Mar. } 15 \\
\text { Jan. } 14 \\
\text { Feb. } 03 \\
\text { Feb. } 17 \\
\text { Feb. } 20 \\
\text { Mar. } 16\end{array}$ & $\begin{array}{r}1,550 \\
595 \\
2,040 \\
1,490 \\
897 \\
1,250 \\
496\end{array}$ & $\begin{array}{l}6.61 \\
5.43 \\
6.97 \\
6.56 \\
5.94 \\
6.35 \\
5.19\end{array}$ & $\begin{array}{l}1977 \\
1978 \\
1979 \\
1980 \\
1981 \\
1982 \\
1983\end{array}$ & $\begin{array}{l}\text { Mar. } 21 \\
\text { Jan. } 26 \\
\text { Feb. } 27 \\
\text { Mar. } 13 \\
\text { Apr. } 01 \\
\text { Jan. } 02 \\
\text { Mar. } 07\end{array}$ & $\begin{array}{r}1,040 \\
2,010 \\
1,870 \\
2,980 \\
508 \\
605 \\
2,950\end{array}$ & $\begin{array}{l}6.12 \\
6.95 \\
6.81 \\
7.62 \\
5.22 \\
5.05 \\
7.60\end{array}$ \\
\hline
\end{tabular}

\section{RICHARDSON CREEK NEAR MILLEN, GEORGIA}

LOCATION.--Lat $32^{\circ} 43^{\prime} 23^{\prime \prime}$, long $81^{\circ} 58^{\prime} 35^{\prime \prime}$, Jenkins County, at State Highway 67,6 mi southwest of Millen.

DRAINAGE AREA. $-43 \mathrm{mi}^{2}$, approximately.

GAGE.--Crest-stage gage. Datum of gage is about $140 \mathrm{ft}$ above sea level (from topographic map).

STAGE-DISCHARGE RELATION.--Defined by current-meter measurements below $1,800 \mathrm{ft}^{3} / \mathrm{s}$, and extended above on the basis of straight-line extension. Bankfull stage and discharge, $4 \mathrm{ft}$ and $400 \mathrm{ft}^{3} / \mathrm{s}$.

\begin{tabular}{|c|c|c|c|c|c|c|c|c|c|c|c|}
\hline $\begin{array}{l}\text { Water } \\
\text { year }\end{array}$ & Date & $\begin{array}{c}\text { Discharge } \\
\left(\mathrm{ft}^{3} / \mathrm{s}\right)\end{array}$ & $\begin{array}{c}\text { Gage } \\
\text { height } \\
\text { (ft) }\end{array}$ & $\begin{array}{l}\text { Water } \\
\text { year }\end{array}$ & Date & $\begin{array}{c}\text { Discharge } \\
\left(\mathrm{ft}^{3} / \mathrm{s}\right)\end{array}$ & $\begin{array}{c}\text { Gage } \\
\text { height } \\
(\mathrm{ft})\end{array}$ & $\begin{array}{c}\text { Water } \\
\text { year }\end{array}$ & Date & $\begin{array}{c}\text { Discharge } \\
\left(\mathrm{ft}^{3} / \mathrm{s}\right)\end{array}$ & $\begin{array}{c}\text { Gage } \\
\text { height } \\
\text { (ft) }\end{array}$ \\
\hline $\begin{array}{l}1963 \\
1964 \\
1965 \\
1966 \\
1967 \\
1968 \\
1969\end{array}$ & $\begin{array}{l}\text { Oct. } 05 \\
\text { Sept.01 } \\
\text { Feb. } 18 \\
\text { Mar. } 05 \\
\text { Jan. } 03 \\
\text { Aug. } 01 \\
\text { May } 19\end{array}$ & $\begin{array}{r}1,880 \\
1,480 \\
1,070 \\
678 \\
694 \\
276 \\
490\end{array}$ & $\begin{array}{l}5.69 \\
5.45 \\
5.01 \\
4.51 \\
4.53 \\
3.62 \\
4.16\end{array}$ & $\begin{array}{l}1970 \\
1971 \\
1972 \\
1973 \\
1974 \\
1975 \\
1976\end{array}$ & $\begin{array}{l}\text { Apr. } 01 \\
\text { Aug. } 16 \\
\text { Dec. } 03 \\
\text { Feb. } 03 \\
\text { Feb. } 09 \\
\text { July } 15 \\
\text { July } 20\end{array}$ & $\begin{array}{r}655 \\
605 \\
346 \\
505 \\
294 \\
1,410 \\
342\end{array}$ & $\begin{array}{l}4.47 \\
4.39 \\
3.84 \\
4.19 \\
3.68 \\
5.34 \\
3.83\end{array}$ & $\begin{array}{l}1977 \\
1978 \\
1979 \\
1980 \\
1981 \\
1982 \\
1983\end{array}$ & $\begin{array}{l}\text { Oct. } 09 \\
\text { Jan. } 26 \\
\text { Feb. } 26 \\
\text { Mar. } 13 \\
\text { Apr. } 01 \\
\text { Apr. } 26 \\
\text { Feb. } 14\end{array}$ & $\begin{array}{r}480 \\
998 \\
1,120 \\
2,400 \\
195 \\
249 \\
610\end{array}$ & $\begin{array}{l}4.14 \\
4.91 \\
5.05 \\
6.04 \\
3.32 \\
3.53 \\
4.41\end{array}$ \\
\hline
\end{tabular}




\section{OGEECHEE RIVER BASIN}

02201830 SCULLS CREEK NEAR MILLEN, GEORGIA

(Formerly published as "Hooker Branch Tributary near Millen, Georgia"

LOCATION.--Lat $32^{\circ} 39^{\prime} 34^{\prime \prime}$, long $81^{\circ} 59^{\prime} 29^{\prime \prime}$, Jenkins County, at culvert on State Highway 121, 11 mi southwest of Millen. DRAINAGE AREA.-4.38 $\mathrm{mi}^{2}$

GAGE.--Flood-stage/rainfall recorder. Datum of gage is about $180 \mathrm{ft}$ above sea level (from topographic map).

STAGE-DISCHARGE RELATION.--Defined by current-meter measurements below $150 \mathrm{ft}^{3} / \mathrm{s}$, and extended above on basis of culvert computations.

\begin{tabular}{|c|c|c|c|c|c|c|c|c|c|c|c|}
\hline $\begin{array}{l}\text { Water } \\
\text { year }\end{array}$ & Date & $\begin{array}{c}\text { Discharge } \\
\left(\mathrm{ft}^{3} / \mathrm{s}\right)\end{array}$ & $\begin{array}{c}\text { Gage } \\
\text { height } \\
\text { (ft) }\end{array}$ & $\begin{array}{l}\text { Water } \\
\text { year }\end{array}$ & Date & $\begin{array}{c}\text { Discharge } \\
\left(\mathrm{ft}^{3} / \mathrm{s}\right)\end{array}$ & $\begin{array}{c}\text { Gage } \\
\text { height } \\
\text { (ft) }\end{array}$ & $\begin{array}{l}\text { Water } \\
\text { year }\end{array}$ & Date & $\begin{array}{c}\text { Discharge } \\
\left(\mathrm{ft}^{3} / \mathrm{s}\right)\end{array}$ & $\begin{array}{c}\text { Gage } \\
\text { height } \\
\text { (ft) }\end{array}$ \\
\hline $\begin{array}{l}1965 \\
1966 \\
1967 \\
1968\end{array}$ & $\begin{array}{l}\text { Feb. } 17 \\
\text { May } 25 \\
\text { July } 08 \\
\text { Aug. } 09\end{array}$ & $\begin{array}{l}156 \\
278 \\
239 \\
138\end{array}$ & $\begin{array}{l}3.16 \\
3.73 \\
3.56 \\
3.06\end{array}$ & $\begin{array}{l}1969 \\
1970 \\
1971 \\
1972\end{array}$ & $\begin{array}{l}\text { May } 15 \\
\text { Mar. } 22 \\
\text { June } 17 \\
\text { Dec. } 03\end{array}$ & $\begin{array}{r}164 \\
144 \\
228 \\
94\end{array}$ & $\begin{array}{l}3.21 \\
3.11 \\
3.51 \\
2.86\end{array}$ & $\begin{array}{l}1973 \\
1974 \\
1975\end{array}$ & $\begin{array}{l}\text { June } 20 \\
\text { Feb. } 07 \\
\text { July } 15\end{array}$ & $\begin{array}{r}184 \\
94 \\
195\end{array}$ & $\begin{array}{l}3.31 \\
2.91 \\
3.36\end{array}$ \\
\hline
\end{tabular}

\section{OGEECHEE RIVER AT SCARBORO, GEORGIA}

LOCATION.--Lat $32^{\circ} 42^{\prime} 38^{\prime \prime}$, long $81^{\circ} 52^{\prime} 46^{\prime \prime}$, Jenkins County, at abandoned highway bridge at Scarboro, and 7.5 mi southeast of Millen.

DRAINAGE AREA.--1,940 $\mathrm{mi}^{2}$.

GAGE.--Nonrecording prior to Dec. 18, 1941; recording Dec. 18, 1941 to June 30, 1971; crest-stage gage thereafter. Datum of gage is $111.81 \mathrm{ft}$ above sea level (levels from U.S. Army Corps of Engineers), supplementary adjustment of 1936.

STAGE-DISCHARGE RELATION.--Defined by current-meter measurements below $25,000 \mathrm{ft}^{3} / \mathrm{s}$, and extended above on basis of conveyance studies. Bankfull stage and discharge, $6.5 \mathrm{ft}$ and $2,000 \mathrm{ft}^{3} / \mathrm{s}$.

HISTORICAL DATA.--Flood stages of January 1925 and October 1929, from information furnished by Mr. T.F. Yarbrough, agent for Central of Georgia Railroad Company during the period 1912-1942. The October 1929 flood was the great flood of memory dating back to about 1840 , based on information from the oldest residents of the area.

REMARKS.--Peak discharge for 1925, 1930, 1954, and 1983 are estimated.

\begin{tabular}{|c|c|c|c|c|c|c|c|c|c|c|c|}
\hline $\begin{array}{l}\text { Water } \\
\text { year }\end{array}$ & Date & $\begin{array}{c}\text { Discharge } \\
\left(\mathrm{ft}^{3} / \mathrm{s}\right)\end{array}$ & $\begin{array}{l}\text { Gage } \\
\text { height } \\
\text { (ft) }\end{array}$ & $\begin{array}{l}\text { Water } \\
\text { year }\end{array}$ & Date & $\begin{array}{c}\text { Discharge } \\
\left(\mathrm{ft}^{3} / \mathrm{s}\right)\end{array}$ & $\begin{array}{c}\text { Gage } \\
\text { height } \\
\text { (ft) }\end{array}$ & $\begin{array}{l}\text { Water } \\
\text { year }\end{array}$ & Date & $\begin{array}{c}\text { Discharge } \\
\left(\mathrm{ft}^{3} / \mathrm{s}\right)\end{array}$ & $\begin{array}{c}\text { Gage } \\
\text { height } \\
\text { (ft) }\end{array}$ \\
\hline$\frac{1925}{1930}$ & $\begin{array}{l}\text { Jan. -- } \\
\text { Oct. -- }\end{array}$ & $\begin{array}{l}56,000 \\
75,000\end{array}$ & $\begin{array}{l}15.90 c \\
17.00 c\end{array}$ & $\begin{array}{l}1954 \\
1955\end{array}$ & $\begin{array}{l}\text { Oct. } 02 \\
\text { Apr. } 19\end{array}$ & $\begin{array}{l}3,600 \\
6.110\end{array}$ & -8.97 & $\begin{array}{l}1973 \\
1974\end{array}$ & Feb. 05 & $\begin{array}{r}16,600 \\
9000\end{array}$ & 10.74 \\
\hline$\frac{1500}{1937}$ & May 06 & 12,900 & 10.71 & 1956 & Mar. 24 & 7,310 & 9.34 & 1975 & Feb. 25 & 16,200 & 10.67 \\
\hline 1938 & Apr. 14 & 11,600 & 10.38 & 1957 & Apr. 06 & 3,220 & 7.74 & 1976 & Mar. 24 & 7,720 & 9.18 \\
\hline 1939 & Mar. 05 & 20,600 & 12.12 & 1958 & Apr. 23 & 7,800 & 9.48 & 1977 & Mar. 26 & 11,500 & 9.96 \\
\hline 1940 & Aug. 17 & 24,600 & 12.80 & 1959 & Mar. 11 & 6,690 & 9.14 & 1978 & Jan. 28 & 17,300 & 10.85 \\
\hline 1941 & July 24 & 6,320 & 8.90 & 1960 & Apr. 07 & 19,400 & 11.90 & 1979 & Mar. 02 & 18,000 & 10.96 \\
\hline 1942 & Mar. 28 & 14,000 & 10.90 & 1961 & Apr. 18 & 17,700 & 11.60 & 1980 & Mar. 15 & 27,900 & 12.44 \\
\hline 1943 & Mar. 28 & 11,900 & 10.50 & 1962 & Mar. 15 & 12,900 & 10.70 & 1981 & Feb. 20 & 6,600 & 8.90 \\
\hline 1944 & Mar. 27 & 24,600 & 12.80 & 1963 & Jan. 27 & 11,900 & 10.51 & 1982 & Jan. 07 & 8,320 & 9.33 \\
\hline 1945 & Feb. 26 & 3,030 & 7.64 & 1964 & Apr. 13 & 13,400 & 10.79 & 1983 & Apr. 14 & 10,000 & - \\
\hline 1946 & Jan. 20 & 6,540 & 9.08 & 1965 & Jan. 02 & 14,000 & 10.93 & 1984 & Mar. 08 & 6,560 & 8.89 \\
\hline 1947 & Mar. 11 & 9,450 & 9.95 & 1966 & Mar. 07 & 25,400 & 12.11 & 1985 & Feb. 13 & 8,600 & 9.40 \\
\hline 1948 & Apr. 04 & 15,500 & 11.20 & 1967 & Mar. 20 & 6,080 & 8.57 & 1986 & Dec. 17 & 8,200 & 9.30 \\
\hline 1949 & Dec. 05 & 15,500 & 11.20 & 1968 & Jan. 20 & 4,450 & 8.05 & 1987 & Jan. 25 & 16,500 & 10.71 \\
\hline 1950 & Mar. 19 & 2,430 & 7.26 & 1969 & May 22 & 8,100 & 9.02 & 1988 & Apr. 30 & 2,700 & 7.13 \\
\hline 1951 & Apr. 03 & 3,740 & 8.00 & 1970 & Apr. 03 & 12,300 & 10.10 & 1989 & Apr. 19 & 5,030 & 8.39 \\
\hline 1952 & Mar. 11 & 11,000 & 10.32 & 1971 & Mar. 08 & 25,700 & 12.13 & 1990 & Oct. 09 & 5,620 & 8.62 \\
\hline 1953 & May 09 & 14,400 & 11.00 & 1972 & Jan. 18 & 15,000 & 10.50 & & & & \\
\hline
\end{tabular}




\section{OGEECHEE RIVER BASIN}

\section{MILL CREEK NEAR STATESBORO, GEORGIA}

LOCATION.-Lat $32^{\circ} 28^{\prime} 28^{\prime \prime}$, long $81^{\circ} 45^{\prime} 17^{\prime \prime}$, Bulloch County, at State Highway 73, 2.2 mi northeast of Statesboro.

DRAINAGE AREA.--39 $\mathrm{mi}^{2}$, approximately.

GAGE.--Crest-stage gage. Datum of gage is about $140 \mathrm{ft}$ above sea level (from topographic map).

STAGE-DISCHARGE RELATION.--Defined by current-meter measurements below $800 \mathrm{ft}^{3} / \mathrm{s}$, and above on the basis of straight-line extension. Bankfull stage and discharge, $4 \mathrm{ft}$ and $400 \mathrm{ft}^{3} / \mathrm{s}$.

\begin{tabular}{|c|c|c|c|c|c|c|c|c|c|c|c|}
\hline $\begin{array}{l}\text { Water } \\
\text { year }\end{array}$ & Date & $\begin{array}{c}\text { Discharge } \\
\left(\mathrm{ft}^{3} / \mathrm{s}\right)\end{array}$ & $\begin{array}{c}\text { Gage } \\
\text { height } \\
\text { (ft) }\end{array}$ & $\begin{array}{l}\text { Water } \\
\text { year }\end{array}$ & Date & $\begin{array}{c}\text { Discharge } \\
\left(\mathrm{ft}^{3} / \mathrm{s}\right)\end{array}$ & $\begin{array}{c}\text { Gage } \\
\text { height } \\
\text { (ft) }\end{array}$ & $\begin{array}{l}\text { Water } \\
\text { year }\end{array}$ & Date & $\begin{array}{c}\text { Discharge } \\
\left(\mathrm{ft}^{3} / \mathrm{s}\right)\end{array}$ & $\begin{array}{c}\text { Gage } \\
\text { height } \\
\text { (ft) }\end{array}$ \\
\hline $\begin{array}{l}1963 \\
1964 \\
1965 \\
1966\end{array}$ & $\begin{array}{l}\text { June } 26 \\
\text { Sept.01 } \\
\text { Feb. } 18 \\
\text { Mar. } 05\end{array}$ & $\begin{array}{l}790 \\
970 \\
880 \\
844\end{array}$ & $\begin{array}{l}4.56 \\
4.81 \\
4.66 \\
4.66\end{array}$ & $\begin{array}{l}1967 \\
1968 \\
1969 \\
1970\end{array}$ & $\begin{array}{l}\text { Jan. } 03 \\
\text { Aug. -- } \\
\text { May } 20 \\
\text { Mar. } 31\end{array}$ & $\begin{array}{r}417 \\
100 \\
934 \\
1,000\end{array}$ & $\begin{array}{l}4.07 \\
-b \\
4.76 \\
4.86\end{array}$ & $\begin{array}{l}1971 \\
1972 \\
1973 \\
1974\end{array}$ & $\begin{array}{l}\text { June } 19 \\
\text { Feb. } 03 \\
\text { Apr. } 02 \\
\text { Feb. } 17\end{array}$ & $\begin{array}{l}562 \\
576 \\
835 \\
375\end{array}$ & $\begin{array}{l}4.31 \\
4.33 \\
4.52 \\
3.87\end{array}$ \\
\hline
\end{tabular}

\section{OGEECHEE CREEK NEAR EDEN, GEORGIA}

LOCATION.--Lat 32 $11^{\prime} 29^{\prime \prime}$, long $81^{\circ} 24^{\prime} 58^{\prime \prime}$, Effingham County, on right bank $600 \mathrm{ft}$ downstream from Jenks bridge on U.S. Highways 25, 80, and 280, and State Highway 26, 2 mi upstream from Seaboard Coast Line Railroad bridge, 3 mi upstream from Black Creek, and 2 mi west of Eden.

DRAINAGE AREA.--2,650 $\mathrm{mi}^{2}$, approximately.

GAGE.-Water-stage recorder. Datum of gage is $19.64 \mathrm{ft}$ above sea level (levels from U.S. Army Corps of Engineers), supplementary adjustment of 1936. Prior to Oct. 1, 1939, nonrecording gage at site $600 \mathrm{ft}$ upstream at same datum.

STAGE-DISCHARGE RELATION.--Defined by current-meter measurements below $25,000 \mathrm{ft}^{3} / \mathrm{s}$, and estimated above, based on conveyance studies. Bankfull stage and discharge, $9 \mathrm{ft}$ and $5,200 \mathrm{ft}^{3} / \mathrm{s}$. Above a gage height of $17.4 \mathrm{ft}$, the stage-discharge relation is indefinite as part of the Ogeechee River flow crosses the divide into the Little Ogeechee River.

HISTORICAL DATA.--Flood stage of 1898 from information furnished by the Georgia Department of Transportation. Flood stages of January 1925, August 1928, March 1929, October 1929, and March 1936, from information furnished by the Central of Georgia Railway Company and the U.S. Army Corps of Engineers. The flood of October 1929 was the highest known since at least 1840 from information provided by the Central of Georgia Railway Company.

REMARKS.-Peaks discharges for 1925 and 1930 are estimated.

\begin{tabular}{|c|c|c|c|c|c|c|c|c|c|c|c|}
\hline $\begin{array}{l}\text { Water } \\
\text { year }\end{array}$ & Date & $\begin{array}{c}\text { Discharge } \\
\left(\mathrm{ft}^{3} / \mathrm{s}\right)\end{array}$ & $\begin{array}{c}\text { Gage } \\
\text { height } \\
\text { (ft) }\end{array}$ & $\begin{array}{c}\text { Water } \\
\text { year }\end{array}$ & Date & $\begin{array}{c}\text { Discharge } \\
\left(\mathrm{ft}^{3} / \mathrm{s}\right)\end{array}$ & $\begin{array}{c}\text { Gage } \\
\text { height } \\
\text { (ft) }\end{array}$ & $\begin{array}{c}\text { Water } \\
\text { year }\end{array}$ & Date & $\begin{array}{c}\text { Discharge } \\
\left(\mathrm{ft}^{3} / \mathrm{s}\right)\end{array}$ & $\begin{array}{c}\text { Gage } \\
\text { height } \\
\text { (ft) }\end{array}$ \\
\hline $\begin{array}{l}\frac{1898}{1925} \\
\frac{1928}{1929} \\
\frac{1930}{1936} \\
1937 \\
1938 \\
1939 \\
1940 \\
1941 \\
1942 \\
1943 \\
1944 \\
1945 \\
1946 \\
1947 \\
1948 \\
1949 \\
1950\end{array}$ & $\begin{array}{l}\text { June } 00 \\
\text { Jan. -- } \\
\text { Aug. -- } \\
\text { Mar. -- } \\
\text { Oct. -- } \\
\text { Mar. 14 } \\
\text { May } 11 \\
\text { Apr. } 19 \\
\text { Mar. 09 } \\
\text { Aug. } 23 \\
\text { July } 30 \\
\text { Apr. } 01 \\
\text { Apr. } 01 \\
\text { Mar. } 31 \\
\text { Mar. } 04 \\
\text { Jan. } 26 \\
\text { Mar. } 19 \\
\text { Apr. } 03 \\
\text { Dec. } 10 \\
\text { Sept.10 }\end{array}$ & $\begin{array}{r}36,000 \\
70,000 \\
17,800 \\
25,000 \\
78,000 \\
30,000 \\
11,400 \\
10,800 \\
23,700 \\
20,200 \\
5,700 \\
13,100 \\
10,700 \\
26,300 \\
3,980 \\
7,620 \\
14,200 \\
20,900 \\
17,800 \\
3,800\end{array}$ & $\begin{array}{c}15.90 \mathrm{c} \\
19.50 \mathrm{c} \\
12.80 \mathrm{c} \\
14.30 \mathrm{c} \\
20.00 \mathrm{c} \\
15.20 \mathrm{c} \\
11.55 \\
11.52 \\
14.20 \\
13.80 \\
9.30 \\
12.20 \\
11.50 \\
14.70 \\
8.14 \\
10.30 \\
12.10 \\
13.30 \\
12.80 \\
8.10\end{array}$ & $\begin{array}{l}1951 \\
1952 \\
1953 \\
1954 \\
1955 \\
1956 \\
1957 \\
1958 \\
1959 \\
1960 \\
1961 \\
1962 \\
1963 \\
1964 \\
1965 \\
1966 \\
1967 \\
1968 \\
1969 \\
1970\end{array}$ & $\begin{array}{l}\text { Apr. } 03 \\
\text { Mar. } 16 \\
\text { May } 14 \\
\text { Jan. } 01 \\
\text { Apr. } 24 \\
\text { Mar. } 30 \\
\text { Apr. } 13 \\
\text { Mar. } 14 \\
\text { Mar. } 09 \\
\text { Apr. } 10 \\
\text { Apr. } 22 \\
\text { Mar. } 19 \\
\text { Feb. } 01 \\
\text { Apr. } 18 \\
\text { Feb. } 23 \\
\text { Mar. } 11 \\
\text { Jan. } 17 \\
\text { Jan. } 27 \\
\text { Sept.05 } \\
\text { Apr. } 07\end{array}$ & $\begin{array}{r}5,000 \\
12,000 \\
15,600 \\
5,180 \\
6,100 \\
6,700 \\
3,920 \\
9,200 \\
7,850 \\
24,000 \\
21,200 \\
13,700 \\
11,600 \\
14,600 \\
17,800 \\
25,200 \\
6,720 \\
4,010 \\
8,520 \\
13,600\end{array}$ & $\begin{array}{r}8.90 \\
11.60 \\
12.40 \\
9.00 \\
9.50 \\
9.80 \\
8.20 \\
10.60 \\
10.40 \\
14.00 \\
13.40 \\
12.12 \\
11.53 \\
11.86 \\
12.41 \\
14.05 \\
9.71 \\
8.22 \\
10.34 \\
11.71\end{array}$ & $\begin{array}{l}1971 \\
1972 \\
1973 \\
1974 \\
1975 \\
1976 \\
1977 \\
1978 \\
1979 \\
1980 \\
1981 \\
1982 \\
1983 \\
1984 \\
1985 \\
1986 \\
1987 \\
1988 \\
1989 \\
1990\end{array}$ & $\begin{array}{l}\text { Mar. } 13 \\
\text { Jan. } 22 \\
\text { Feb. } 10 \\
\text { Feb. } 25 \\
\text { Feb. } 28 \\
\text { Mar. } 29 \\
\text { Mar. } 30 \\
\text { Feb. } 02 \\
\text { Mar. } 06 \\
\text { Mar. } 19 \\
\text { Feb. } 27 \\
\text { Jan. } 14 \\
\text { Apr. } 20 \\
\text { Mar. } 09 \\
\text { Feb. } 19 \\
\text { Dec. } 20 \\
\text { Jan. } 28 \\
\text { Apr. } 29 \\
\text { Apr. } 25 \\
\text { Jan. } 10\end{array}$ & $\begin{array}{r}23,000 \\
15,400 \\
16,500 \\
10,300 \\
17,100 \\
7,230 \\
12,800 \\
17,200 \\
18,000 \\
28,800 \\
5,420 \\
8,760 \\
12,100 \\
10,900 \\
7,160 \\
10,800 \\
19,300 \\
3,330 \\
5,670 \\
9,430\end{array}$ & $\begin{array}{r}13.61 \\
12.08 \\
12.30 \\
10.87 \\
12.42 \\
9.91 \\
11.49 \\
12.45 \\
12.59 \\
14.77 \\
9.11 \\
10.42 \\
11.33 \\
11.02 \\
10.02 \\
11.01 \\
12.87 \\
7.84 \\
9.40 \\
10.94\end{array}$ \\
\hline
\end{tabular}




\section{OGEECHEE RIVER BASIN}

02202600 BLACK CREEK NEAR BLICHTON, GEORGIA

LOCATION.--Lat $32^{\circ} 10^{\prime} 04^{\prime \prime}$, long $81^{\circ} 29^{\prime} 18^{\prime \prime}$, Bryan County, at bridge on U.S. Highway 280 (State Highway 30 ), 4.2 mi upstream from Mill Creek, and $5.8 \mathrm{mi}$ southwest of Blichton.

DRAINAGE AREA.--232 $\mathrm{mi}^{2}$.

GAGE.--Water-stage recorder. Datum of gage is about $30 \mathrm{ft}$ above sea level (from topographic map).

STAGE-DISCHARGE RELATION.--Defined by current-meter measurement below $4,600 \mathrm{ft}^{3} / \mathrm{s}$.

\begin{tabular}{|c|c|c|c|c|c|c|c|c|c|c|c|}
\hline $\begin{array}{l}\text { Water } \\
\text { year }\end{array}$ & Date & $\begin{array}{c}\text { Discharge } \\
\left(\mathrm{ft}^{3} / \mathrm{s}\right)\end{array}$ & $\begin{array}{c}\text { Gage } \\
\text { height } \\
\text { (ft) }\end{array}$ & $\begin{array}{l}\text { Water } \\
\text { year }\end{array}$ & Date & $\begin{array}{c}\text { Discharge } \\
\left(\mathrm{ft}^{3} / \mathrm{s}\right)\end{array}$ & $\begin{array}{c}\text { Gage } \\
\text { height } \\
\text { (ft) }\end{array}$ & $\begin{array}{l}\text { Water } \\
\text { year }\end{array}$ & Date & $\begin{array}{c}\text { Discharge } \\
\left(\mathrm{ft}^{3} / \mathrm{s}\right)\end{array}$ & $\begin{array}{c}\text { Gage } \\
\text { height } \\
(\mathrm{ft})\end{array}$ \\
\hline $\begin{array}{l}1980 \\
1981 \\
1982 \\
1983\end{array}$ & $\begin{array}{l}\text { Mar. } 15 \\
\text { Apr. } 06 \\
\text { Feb. } 17 \\
\text { Feb. } 17\end{array}$ & $\begin{array}{r}1,590 \\
290 \\
968 \\
2,260\end{array}$ & $\begin{array}{r}9.98 \\
6.75 \\
8.93 \\
10.51\end{array}$ & $\begin{array}{l}1984 \\
1985 \\
1986 \\
1987\end{array}$ & $\begin{array}{l}\text { Mar. 08 } \\
\text { Sept. 03 } \\
\text { Mar. } 17 \\
\text { Jan. } 24\end{array}$ & $\begin{array}{r}4,540 \\
808 \\
1,020 \\
3,340\end{array}$ & $\begin{array}{r}12.32 \\
8.59 \\
8.84 \\
11.52\end{array}$ & $\begin{array}{l}1988 \\
1989 \\
1990\end{array}$ & $\begin{array}{l}\text { Sept.20 } \\
\text { Sept. } 24 \\
\text { Jan. } 09\end{array}$ & $\begin{array}{l}1,090 \\
2,600 \\
5,620\end{array}$ & $\begin{array}{r}8.98 \\
10.92 \\
12.91\end{array}$ \\
\hline
\end{tabular}

\section{MILL CREEK NEAR PEMBROKE, GEORGIA}

LOCATION.--Lat $32^{\circ} 09^{\prime} 39^{\prime \prime}$, long $81^{\circ} 36^{\prime} 15^{\prime \prime}$, Bryan County, at culvert on State Highway 119 , near Pembroke.

DRAINAGE AREA.--5.39 $\mathrm{mi}^{2}$.

GAGE.--Flood-stage/rainfall recorder prior to Sept. 9, 1986. Crest-stage gage thereafter

STAGE-DISCHARGE RELATION.--Defined by current-meter measurements below $113 \mathrm{tt}^{3} / \mathrm{s}$, and extended above on basis of culvert computations.

\begin{tabular}{|c|c|c|c|c|c|c|c|c|c|c|c|}
\hline $\begin{array}{l}\text { Water } \\
\text { year }\end{array}$ & Date & $\begin{array}{c}\text { Discharge } \\
\left(\mathrm{ft}^{3} / \mathrm{s}\right)\end{array}$ & $\begin{array}{c}\text { Gage } \\
\text { height } \\
\text { (ft) }\end{array}$ & $\begin{array}{l}\text { Water } \\
\text { year }\end{array}$ & Date & $\begin{array}{c}\text { Discharge } \\
\left(\mathrm{ft}^{3} / \mathrm{s}\right)\end{array}$ & $\begin{array}{c}\text { Gage } \\
\text { height } \\
\text { (ft) }\end{array}$ & $\begin{array}{l}\text { Water } \\
\text { year }\end{array}$ & Date & $\begin{array}{c}\text { Discharge } \\
\left(\mathrm{ft}^{3} / \mathrm{s}\right)\end{array}$ & $\begin{array}{c}\text { Gage } \\
\text { height } \\
\text { (ft) }\end{array}$ \\
\hline $\begin{array}{l}1979 \\
1980 \\
1981 \\
1982\end{array}$ & $\begin{array}{l}\text { Sept. } 04 \\
\text { Mar. } 13 \\
\text { June } 12 \\
\text { July } 12\end{array}$ & $\begin{array}{r}178 \\
158 \\
95 \\
104\end{array}$ & $\begin{array}{l}3.48 \\
2.79 \\
2.09 \\
2.19\end{array}$ & $\begin{array}{l}1983 \\
1984 \\
1985 \\
1986\end{array}$ & $\begin{array}{l}\text { Mar. } 17 \\
\text { Jan. } 27 \\
\text { Aug. } 31 \\
\text { Feb. } 11\end{array}$ & $\begin{array}{r}129 \\
154 \\
24 \\
187\end{array}$ & $\begin{array}{l}2.44 \\
2.70 \\
1.17 \\
4.16\end{array}$ & $\begin{array}{l}1987 \\
1988 \\
1989 \\
1990\end{array}$ & $\begin{array}{l}\text { Jan. } 01 \\
\text { Aug. } 30 \\
\text { Sept. } 21 \\
\text { Dec. } 08\end{array}$ & $\begin{array}{l}160 \\
161 \\
136 \\
141\end{array}$ & $\begin{array}{l}2.85 \\
2.89 \\
2.51 \\
2.50\end{array}$ \\
\hline
\end{tabular}




\section{OGEECHEE RIVER BASIN}

\section{CANOOCHEE CREEK NEAR SWAINSBORO, GEORGIA}

LOCATION.--Lat $32^{\circ} 36^{\prime} 19^{\prime \prime}$, long $82^{\circ} 15^{\prime} 21^{\prime \prime}$, Emanuel County, at U.S. Highway $80,4.8$ mi east of Swainsboro.

DRAINAGE AREA.--46 $\mathrm{mi}^{2}$, approximately (revised).

GAGE.--Crest-stage gage. Datum of gage is about $210 \mathrm{ft}$ above sea level (from topographic map).

STAGE-DISCHARGE RELATION.--Defined by current-meter measurements below $1,400 \mathrm{ft}^{3} / \mathrm{s}$, and extended above on basis of slope-conveyance studies.

REMARKS.--Flood stage of October 1929 from information furnished by the Georgia Department of Transportation. Peak discharge for 1929 is estimated.

\begin{tabular}{|c|c|c|c|c|c|c|c|c|c|c|c|}
\hline $\begin{array}{l}\text { Water } \\
\text { year }\end{array}$ & Date & $\begin{array}{c}\text { Discharge } \\
\left(\mathrm{ft}^{3} / \mathrm{s}\right)\end{array}$ & $\begin{array}{c}\text { Gage } \\
\text { height } \\
\text { (ft) }\end{array}$ & $\begin{array}{l}\text { Water } \\
\text { year }\end{array}$ & Date & $\begin{array}{c}\text { Discharge } \\
\left(\mathrm{ft}^{3} / \mathrm{s}\right)\end{array}$ & $\begin{array}{c}\text { Gage } \\
\text { height } \\
\text { (ft) }\end{array}$ & $\begin{array}{l}\text { Water } \\
\text { year }\end{array}$ & Date & $\begin{array}{c}\text { Discharge } \\
\left(\mathrm{ft}^{3} / \mathrm{s}\right)\end{array}$ & $\begin{array}{c}\text { Gage } \\
\text { height } \\
\text { (ft) }\end{array}$ \\
\hline $\begin{array}{l}\frac{1929}{1951} \\
1952 \\
1953 \\
1954 \\
1955 \\
1956 \\
1957 \\
1958 \\
1959\end{array}$ & $\begin{array}{l}\text { Sept. } 0 \\
\text { Apr. } 01 \\
\text { Feb. } 20 \\
\text { Sept.27 } \\
\text { Jan. } 01 \\
\text { Apr. } 15 \\
\text { Feb. } 06 \\
\text { June } 00 \\
\text { Oct. } 04 \\
\text { Mar. } 08\end{array}$ & $\begin{array}{r}2,820 \\
368 \\
570 \\
1,360 \\
385 \\
780 \\
350 \\
472 \\
540 \\
680\end{array}$ & $\begin{array}{l}9.40 c \\
4.66 \\
5.39 \\
6.94 \\
4.70 \\
5.93 \\
4.58 \\
5.05 \\
5.30 \\
5.71\end{array}$ & $\begin{array}{l}1960 \\
1961 \\
1962 \\
1963 \\
1964 \\
1965 \\
1966 \\
1967 \\
1968\end{array}$ & $\begin{array}{l}\text { Apr. } 05 \\
\text { Apr. } 16 \\
\text { Mar. } 12 \\
\text { Oct. } 07 \\
\text { Feb. } 18 \\
\text { Feb. } 18 \\
\text { Mar. } 05 \\
\text { Jan. } 03 \\
\text { Dec. -- }\end{array}$ & $\begin{array}{r}1,440 \\
1,020 \\
680 \\
1,220 \\
760 \\
1,250 \\
940 \\
600 \\
235\end{array}$ & $\begin{array}{l}7.04 \\
6.43 \\
5.70 \\
6.77 \\
5.88 \\
6.82 \\
6.28 \\
5.50 \\
\text {--b }\end{array}$ & $\begin{array}{l}1969 \\
1970 \\
1971 \\
1972 \\
1973 \\
1974 \\
1975 \\
1976 \\
1980\end{array}$ & $\begin{array}{l}\text { Sept.01 } \\
\text { Mar. } 31 \\
\text { Mar. } 26 \\
\text { Jan. } 12 \\
\text { Feb. } 03 \\
\text { Feb. } 17 \\
\text { July } 30 \\
\text { Mar. } 16 \\
\text { Mar. } 13\end{array}$ & $\begin{array}{r}1,220 \\
990 \\
1,040 \\
644 \\
1,260 \\
376 \\
938 \\
330 \\
2,000\end{array}$ & $\begin{array}{l}6.77 \\
6.39 \\
6.48 \\
5.61 \\
7.13 \\
4.67 \\
6.47 \\
4.48 \\
7.94 c\end{array}$ \\
\hline
\end{tabular}

02202810 HUGHES PRONG TO CANOOCHEE CREEK NEAR SWAINSBORO, GEORGIA

(Formerly published as "Rock Creek near Swainsboro, Georgia")

LOCATION.--Lat $32^{\circ} 37^{\prime} 29^{\prime \prime}$, long $82^{\circ} 19^{\prime} 04^{\prime \prime}$, Emanuel County, at culvert on State Highway 56, 2 mi north of Swainsboro.

DRAINAGE AREA. $-5.05 \mathrm{mi}^{2}$.

GAGE.--Flood-stage/rainfall recorder. Datum of gage is about $249 \mathrm{ft}$ above sea level (from topographic map).

STAGE-DISCHARGE RELATION.--Defined by current-meter measurements below $190 \mathrm{ft}^{3} / \mathrm{s}$, and extended above on basis of culvert computations.

REMARKS.--Flood stage of October 1929 from information furnished by the Georgia Department of Transportation.

\begin{tabular}{|c|c|c|c|c|c|c|c|c|c|c|c|}
\hline $\begin{array}{l}\text { Water } \\
\text { year }\end{array}$ & Date & $\begin{array}{c}\text { Discharge } \\
\left(\mathrm{ft}^{3} / \mathrm{s}\right)\end{array}$ & $\begin{array}{c}\text { Gage } \\
\text { height } \\
\text { (ft) }\end{array}$ & $\begin{array}{l}\text { Water } \\
\text { year }\end{array}$ & Date & $\begin{array}{c}\text { Discharge } \\
\left(\mathrm{ft}^{3} / \mathrm{s}\right)\end{array}$ & $\begin{array}{c}\text { Gage } \\
\text { height } \\
\text { (ft) }\end{array}$ & $\begin{array}{l}\text { Water } \\
\text { year }\end{array}$ & Date & $\begin{array}{c}\text { Discharge } \\
\left(\mathrm{ft}^{3} / \mathrm{s}\right)\end{array}$ & $\begin{array}{l}\text { Gage } \\
\text { height } \\
\text { (ft) }\end{array}$ \\
\hline $\begin{array}{l}\frac{1930}{1965} \\
1966 \\
1967 \\
1968\end{array}$ & $\begin{array}{l}\text { Oct. } 03 \\
\text { Feb. } 17 \\
\text { Mar. } 03 \\
\text { Jan. } 01 \\
\text { Jan. -- }\end{array}$ & $\begin{array}{r}1,000 \\
188 \\
153 \\
182 \\
26.0\end{array}$ & $\begin{array}{l}5.60 \mathrm{c} \\
3.25 \\
3.07 \\
3.22 \\
--b\end{array}$ & $\begin{array}{l}1969 \\
1970 \\
1971 \\
1972\end{array}$ & $\begin{array}{l}\text { May } 19 \\
\text { Mar. } 22 \\
\text { Mar. } 03 \\
\text { Dec. } 03\end{array}$ & $\begin{array}{l}92.0 \\
182 \\
178 \\
168\end{array}$ & $\begin{array}{l}2.72 \\
3.22 \\
3.20 \\
3.15\end{array}$ & $\begin{array}{l}1973 \\
1974 \\
1975 \\
1980\end{array}$ & $\begin{array}{l}\text { Feb. } 02 \\
\text { Feb. } 16 \\
\text { July } 15 \\
\text { Mar. } 18\end{array}$ & $\begin{array}{r}207 \\
89.0 \\
170 \\
380\end{array}$ & $\begin{array}{l}3.35 \\
2.70 \\
3.16 \\
4.00 c\end{array}$ \\
\hline
\end{tabular}




\section{OGEECHEE RIVER BASIN}

\section{REEDY CREEK NEAR TWIN CITY, GEORGIA}

LOCATION.-Lat $32^{\circ} 35^{\prime} 40^{\prime \prime}$, long $82^{\circ} 12^{\prime} 23^{\prime \prime}$, Emanuel County, at culvert on U.S. Highway $80,2.5$ mi west of Twin City. DRAINAGE AREA.--9.36 $\mathrm{mi}^{2}$ (revised).

GAGE.-Water-stage/rainfall recorder. Piror to Nov. 17, 1967, flood-stage recorder; Nov. 17, 1967 to Sept. 9, 1970, floodstage/rainfall recorder. Datum of gage is about $220 \mathrm{ft}$ above sea level (from topographic map).

STAGE-DISCHARGE RELATION.--Defined by current-meter measurements below $220 \mathrm{ft}^{3} / \mathrm{s}$, and extended above on basis of culvert computations.

REMARKS.--Flood stage of 1929 based on information from the Georgia Department of Transportation. Discharge for 1974 is estimated from nearby stations.

\begin{tabular}{|c|c|c|c|c|c|c|c|c|c|c|c|}
\hline $\begin{array}{l}\text { Water } \\
\text { year }\end{array}$ & Date & $\begin{array}{c}\text { Discharge } \\
\left(\mathrm{ft}^{3} / \mathrm{s}\right)\end{array}$ & $\begin{array}{c}\text { Gage } \\
\text { height } \\
\text { (ft) }\end{array}$ & $\begin{array}{l}\text { Water } \\
\text { year }\end{array}$ & Date & $\begin{array}{c}\text { Discharge } \\
\left(\mathrm{ft}^{3} / \mathrm{s}\right)\end{array}$ & $\begin{array}{c}\text { Gage } \\
\text { height } \\
\text { (ft) }\end{array}$ & $\begin{array}{l}\text { Water } \\
\text { year }\end{array}$ & Date & $\begin{array}{c}\text { Discharge } \\
\left(\mathrm{ft}^{3} / \mathrm{s}\right)\end{array}$ & $\begin{array}{c}\text { Gage } \\
\text { height } \\
\text { (ft) }\end{array}$ \\
\hline$\underline{1930}$ & Oct. 03 & 1,830 & $7.70 c$ & 1968 & July 10 & 47.0 & 1.72 & 1972 & Dec. 03 & 180 & 2.75 \\
\hline$\overline{1965}$ & Feb. 17 & 315 & 3.39 & 1969 & Sept. 19 & 228 & 2.99 & 1973 & Feb. 02 & 194 & 3.12 \\
\hline 1966 & Mar. 03 & 270 & 3.19 & 1970 & Mar. 21 & 388 & 3.69 & $\underline{1974}$ & Feb. 16 & 166 & 2.98 \\
\hline 1967 & Jan. 02 & 281 & 3.24 & 1971 & Mar. 03 & 341 & 3.50 & $\overline{1980}$ & Mar. 13 & 1,180 & $5.79 c$ \\
\hline
\end{tabular}

\section{REEDY BRANCH NEAR METTER, GEORGIA}

LOCATION.--Lat $32^{\circ} 28^{\prime} 43^{\prime \prime}$, long $82^{\circ} 07^{\prime} 45^{\prime \prime}$, Candler County, at culvert on State Highway $23,7.5$ mi northwest of Metter. DRAINAGE AREA. $-3.41 \mathrm{mi}^{2}$.

GAGE.-Flood-stage/rainfall recorder. Datum of gage is about $210 \mathrm{ft}$ above sea level (from topographic map).

STAGE-DISCHARGE RELATION.--Defined by current-meter measurements below $170 \mathrm{ft}^{3} / \mathrm{s}$, and extended above on basis of culvert computations.

\begin{tabular}{|c|c|c|c|c|c|c|c|c|c|c|c|}
\hline $\begin{array}{l}\text { Water } \\
\text { year }\end{array}$ & Date & $\begin{array}{c}\text { Discharge } \\
\left(\mathrm{ft}^{3} / \mathrm{s}\right)\end{array}$ & $\begin{array}{c}\text { Gage } \\
\text { height } \\
\text { (ft) }\end{array}$ & $\begin{array}{l}\text { Water } \\
\text { year }\end{array}$ & Date & $\begin{array}{c}\text { Discharge } \\
\left(\mathrm{ft}^{3} / \mathrm{s}\right)\end{array}$ & $\begin{array}{c}\text { Gage } \\
\text { height } \\
\text { (ft) }\end{array}$ & $\begin{array}{l}\text { Water } \\
\text { year }\end{array}$ & Date & $\begin{array}{c}\text { Discharge } \\
\left(\mathrm{ft}^{3} / \mathrm{s}\right)\end{array}$ & $\begin{array}{c}\text { Gage } \\
\text { height } \\
\text { (ft) }\end{array}$ \\
\hline $\begin{array}{l}1965 \\
1966 \\
1967 \\
1968\end{array}$ & $\begin{array}{l}\text { Feb. } 17 \\
\text { May } 25 \\
\text { Aug. } 11 \\
\text { Jan. - }\end{array}$ & $\begin{array}{r}132 \\
278 \\
185 \\
25.0\end{array}$ & $\begin{array}{l}5.89 \\
6.74 \\
6.22 \\
--b\end{array}$ & $\begin{array}{l}1969 \\
1970 \\
1971 \\
1972\end{array}$ & $\begin{array}{l}\text { June } 04 \\
\text { Aug. } 24 \\
\text { Mar. } 03 \\
\text { Feb. } 01\end{array}$ & $\begin{array}{l}188 \\
242 \\
134 \\
127\end{array}$ & $\begin{array}{l}6.24 \\
6.54 \\
5.94 \\
5.00\end{array}$ & $\begin{array}{l}1973 \\
1974 \\
1980\end{array}$ & $\begin{array}{l}\text { June } 22 \\
\text { Feb. } 08 \\
\text { Mar. } 13\end{array}$ & $\begin{array}{l}257 \\
179 \\
208\end{array}$ & $\begin{array}{l}6.69 \\
6.19 \\
6.35 c\end{array}$ \\
\hline
\end{tabular}

\section{CANOOCHEE RIVER NEAR METTER, GEORGIA}

LOCATION.--Lat $32^{\circ} 21^{\prime} 20^{\prime \prime}$ long $82^{\circ} 05^{\prime} 25^{\prime \prime}$, Candler County, at bridge on State Highways 121 and 23,5 mi south of Metter. DRAINAGE AREA.--202 $\mathrm{mi}^{2}$.

GAGE.--Crest-stage gage. Datum of gage is about $202 \mathrm{ft}$ above sea level (from topographic map).

STAGE-DISCHARGE RELATION.--Defined by current-meter measurements below $3,100 \mathrm{ft}^{3} / \mathrm{s}$, and extended above on basis of straight-line extension.

\begin{tabular}{|c|c|c|c|c|c|c|c|c|c|c|c|}
\hline $\begin{array}{l}\text { Water } \\
\text { year }\end{array}$ & Date & $\begin{array}{c}\text { Discharge } \\
\left(\mathrm{ft}^{3} / \mathrm{s}\right)\end{array}$ & $\begin{array}{c}\text { Gage } \\
\text { height } \\
\text { (ft) }\end{array}$ & $\begin{array}{c}\text { Water } \\
\text { year }\end{array}$ & Date & $\begin{array}{c}\text { Discharge } \\
\left(\mathrm{ft}^{3} / \mathrm{s}\right)\end{array}$ & $\begin{array}{c}\text { Gage } \\
\text { height } \\
\text { (ft) }\end{array}$ & $\begin{array}{l}\text { Water } \\
\text { year }\end{array}$ & Date & $\begin{array}{c}\text { Discharge } \\
\left(\mathrm{ft}^{3} / \mathrm{s}\right)\end{array}$ & $\begin{array}{c}\text { Gage } \\
\text { height } \\
\text { (ft) }\end{array}$ \\
\hline 1970 & Apr. 01 & 2,400 & 10.43 & 1976 & June 22 & 930 & 8.90 & 1982 & June 05 & 1,310 & 9.39 \\
\hline 1971 & Mar. 26 & 2,880 & 10.75 & 1977 & Oct. 20 & 1,760 & 9.76 & 1983 & Feb. 16 & 2,440 & 10.46 \\
\hline 1972 & Feb. 03 & 1,970 & 10.07 & 1978 & Jan. 26 & 3,420 & 11.06 & 1984 & Mar. 07 & 1,380 & 9.48 \\
\hline 1973 & Feb. 04 & 2,040 & 10.14 & 1979 & Feb. 27 & 3,900 & 11.30 & 1985 & Feb. - & 900 & $--b$ \\
\hline 1974 & Feb. 17 & 1,490 & 9.59 & 1980 & Mar. 15 & 4,220 & 11.46 & 1986 & Dec. 14 & 3,740 & 11.22 \\
\hline 1975 & May 03 & 2,380 & 10.42 & 1981 & Feb. 19 & 600 & 8.15 & & & & \\
\hline
\end{tabular}




\section{OGEECHEE RIVER BASIN}

02202900 FIFTEEN MILE CREEK NEAR METTER, GEORGIA

LOCATION.--Lat $32^{\circ} 23^{\prime} 33^{\prime \prime}$, long $82^{\circ} 00^{\prime} 55^{\prime \prime}$, Candler County, at State Highway 46, 2.5 mi east of Metter.

DRAINAGE AREA. - $147 \mathrm{mi}^{2}$.

GAGE.-Crest-stage gage. Datum of gage is about $150 \mathrm{ft}$ above sea level (from topographic map).

STAGE-DISCHARGE RELATION.--Defined by current-meter measurements below $6,600 \mathrm{ft}^{3} / \mathrm{s}$. Bankfull stage and discharge, $5.0 \mathrm{ft}$ and $920 \mathrm{ft}^{3} / \mathrm{s}$.

REMARKS.--Flood stage of May 1966 is highest since 1948, based on comparison with nearby stations.

\begin{tabular}{|c|c|c|c|c|c|c|c|c|c|c|c|}
\hline $\begin{array}{l}\text { Water } \\
\text { year }\end{array}$ & Date & $\begin{array}{c}\text { Discharge } \\
\left(\mathrm{ft}^{3} / \mathrm{s}\right)\end{array}$ & $\begin{array}{c}\text { Gage } \\
\text { height } \\
\text { (ft) }\end{array}$ & $\begin{array}{c}\text { Water } \\
\text { year }\end{array}$ & Date & $\begin{array}{c}\text { Discharge } \\
\left(\mathrm{ft}^{3} / \mathrm{s}\right)\end{array}$ & $\begin{array}{c}\text { Gage } \\
\text { height } \\
\text { (ft) }\end{array}$ & $\begin{array}{c}\text { Water } \\
\text { year }\end{array}$ & Date & $\begin{array}{c}\text { Discharge } \\
\left(\mathrm{ft}^{3} / \mathrm{s}\right)\end{array}$ & $\begin{array}{c}\text { Gage } \\
\text { height } \\
\text { (ft) }\end{array}$ \\
\hline 1963 & Oct. 07 & 1,680 & 6.07 & 1970 & Mar. 31 & 1,660 & 6.08 & 1977 & Mar. 04 & 1,090 & 5.28 \\
\hline 1964 & Feb. 21 & 2,120 & 6.50 & 1971 & Mar. 26 & 2,270 & 6.62 & 1978 & Jan. 26 & 2,120 & 6.50 \\
\hline 1965 & Feb. 18 & 2,010 & 6.35 & 1972 & Feb. 03 & 1,440 & 5.82 & 1979 & Feb. 25 & 1,920 & 6.32 \\
\hline 1966 & May 25 & 6,400 & 8.96 & 1973 & Apr. 02 & 1,400 & 5.76 & 1980 & Mar. 15 & 2,890 & 7.06 \\
\hline 1967 & Jan. 03 & 1,170 & 5.41 & 1974 & Feb. 17 & 1,310 & 5.63 & 1981 & Apr. 03 & 527 & 4.02 \\
\hline 1968 & May 00 & 492 & $-b$ & 1975 & July 16 & 3,300 & 7.33 & 1982 & Apr. 28 & 741 & 4.59 \\
\hline 1969 & May 20 & 2,200 & 6.57 & 1976 & June 21 & 769 & 4.66 & 1983 & Feb. 19 & 1,620 & 6.04 \\
\hline
\end{tabular}

\section{TEN MILE CREEK TRIBUTARY AT PULAKSI, GEORGIA}

LOCATION.--Lat $32^{\circ} 23^{\prime} 18^{\prime \prime}$, long $81^{\circ} 58^{\prime} 17^{\prime \prime}$, Candler County, at culvert on State Highway 46, 0.8 mi west of Pulaski.

DRAINAGE AREA.--1.14 $\mathrm{mi}^{2}$.

GAGE.--Flood-stage/rainfall recorder prior to 1975. Crest-stage gage thereafter. Datum of gage is about $200 \mathrm{ft}$ above sea level (from topographic map).

STAGE-DISCHARGE RELATION.--Defined by current-meter measurements below $60 \mathrm{ft}^{3} / \mathrm{s}$, and extended above on basis of culvert computations.

REMARKS.--Flood stage of May 1966 is highest since 1948, based on comparison with nearby stations.

\begin{tabular}{|c|c|c|c|c|c|c|c|c|c|c|c|}
\hline $\begin{array}{l}\text { Water } \\
\text { year }\end{array}$ & Date & $\begin{array}{c}\text { Discharge } \\
\left(\mathrm{ft}^{3} / \mathrm{s}\right)\end{array}$ & $\begin{array}{c}\text { Gage } \\
\text { height } \\
\text { (ft) }\end{array}$ & $\begin{array}{l}\text { Water } \\
\text { year }\end{array}$ & Date & $\begin{array}{c}\text { Discharge } \\
\left(\mathrm{ft}^{3} / \mathrm{s}\right)\end{array}$ & $\begin{array}{c}\text { Gage } \\
\text { height } \\
\text { (ft) }\end{array}$ & $\begin{array}{l}\text { Water } \\
\text { year }\end{array}$ & Date & $\begin{array}{c}\text { Discharge } \\
\left(\mathrm{ft}^{3} / \mathrm{s}\right)\end{array}$ & $\begin{array}{c}\text { Gage } \\
\text { height } \\
\text { (ft) }\end{array}$ \\
\hline 1965 & Mar. 23 & 147 & 4.54 & 1973 & Apr. 07 & 84 & 3.72 & 1981 & Apr. 02 & 47 & 3.21 \\
\hline 1966 & May 25 & 599 & 7.67 & 1974 & Feb. 16 & 39 & 3.09 & 1982 & June 04 & 131 & 4.23 \\
\hline 1967 & Aug. 30 & 275 & 5.42 & 1975 & Feb. 14 & 88 & 3.77 & 1983 & Feb. 14 & 68 & 3.52 \\
\hline 1968 & May 00 & 18.0 & $-b$ & 1976 & June 21 & 241 & 5.16 & 1984 & May 03 & 189 & 4.74 \\
\hline 1969 & Sept. 02 & 281 & 5.47 & 1977 & Mar. 04 & 107 & 3.99 & 1985 & Feb. - & 18 & $--b$ \\
\hline 1970 & Mar. 22 & 41 & 3.12 & 1978 & Jan. 25 & 120 & 4.12 & 1986 & Dec. 13 & 277 & 5.44 \\
\hline 1971 & Apr. 23 & 61 & 3.42 & 1979 & Sept.26 & 66 & 3.48 & 1987 & Mar. 01 & 116 & 4.08 \\
\hline 1972 & Dec. 10 & 56 & 3.35 & 1980 & Mar. 13 & 61 & 3.42 & & & & \\
\hline
\end{tabular}




\section{OGEECHEE RIVER BASIN}

\section{CYPRESS FLAT CREEK TRIBUTARY NEAR COLLINS, GEORGIA}

LOCATION.--Lat $32^{\circ} 13^{\prime} 09^{\prime \prime}$, long $82^{\circ} 07^{\prime} 14^{\prime \prime}$, Tattnall County, at culvert on State Highways 23, 212, and 57,3 mi north of Collins. DRAINAGE AREA.--1.39 $\mathrm{mi}^{2}$.

GAGE.--Flood-stage/rainfall recorder. Datum of gage is about $200 \mathrm{ft}$ above sea level (from topographic map).

STAGE-DISCHARGE RELATION.--Defined by current-meter measurements below $90 \mathrm{tt}^{3} / \mathrm{s}$, and extended above on basis of culvert computations.

\begin{tabular}{|c|c|c|c|c|c|c|c|c|c|c|c|}
\hline $\begin{array}{l}\text { Water } \\
\text { year }\end{array}$ & Date & $\begin{array}{c}\text { Discharge } \\
\left(\mathrm{ft}^{3} / \mathrm{s}\right)\end{array}$ & $\begin{array}{c}\text { Gage } \\
\text { height } \\
\text { (ft) }\end{array}$ & $\begin{array}{l}\text { Water } \\
\text { year }\end{array}$ & Date & $\begin{array}{c}\text { Discharge } \\
\left(\mathrm{ft}^{3} / \mathrm{s}\right)\end{array}$ & $\begin{array}{c}\text { Gage } \\
\text { height } \\
\text { (ft) }\end{array}$ & $\begin{array}{l}\text { Water } \\
\text { year }\end{array}$ & Date & $\begin{array}{c}\text { Discharge } \\
\left(\mathrm{ft}^{3} / \mathrm{s}\right)\end{array}$ & $\begin{array}{c}\text { Gage } \\
\text { height } \\
\text { (ft) }\end{array}$ \\
\hline 1965 & Oct. 04 & 308 & 3.92 & 1969 & May 19 & 105 & 2.06 & 1973 & June 08 & 120 & 2.31 \\
\hline 1966 & Mar. 03 & 201 & 2.99 & 1970 & Mar, 22 & 101 & 2.01 & 1974 & Feb. 07 & 73 & 1.91 \\
\hline 1967 & Aug. 30 & 283 & 3.71 & 1971 & Sept. 19 & 61 & 1.51 & $\overline{1980}$ & Mar. 13 & 143 & $2.49 \mathrm{c}$ \\
\hline 1968 & May 00 & 24 & $--b$ & 1972 & Dec, 03 & 102 & 2.15 & & & & \\
\hline
\end{tabular}

\section{CANOOCHEE RIVER NEAR CLAXTON, GEORGIA}

LOCATION.--Lat $32^{\circ} 11^{\prime} 05^{\prime \prime}$, long $81^{\circ} 53^{\prime} 20^{\prime \prime}$, Evans County, on right bank $400 \mathrm{ft}$ upstream from bridge on State Highway $73,2 \mathrm{mi}$ northeast of Claxton, and 10 mi upstream from Lotts Creek.

DRAINAGE AREA.--555 $\mathrm{mi}^{2}$.

GAGE.--Water-stage recorder. Datum of gage is $80.5 \mathrm{ft}$ above sea level (levels from Georgia Department of Transportation). Prior to Oct. 20,1949, nonrecording gage at same site and datum.

STAGE-DISCHARGE RELATION.--Defined by current-meter measurements below $11,600 \mathrm{ft}^{3} / \mathrm{s}$, and extended above on basis of straight-line extension. Bankfull stage and discharge, $9 \mathrm{ft}$ and $1,500 \mathrm{ft}^{3} / \mathrm{s}$.

REMARKS.--Flood stage of January 1925 and October 1929, based on information furnished by Georgia Department of Transportation. Flood stage of 1925 is highest since 1840, based on comparison with nearby stations. Peak discharges for 1925 and 1930 are estimated.

\begin{tabular}{|c|c|c|c|c|c|c|c|c|c|c|c|}
\hline $\begin{array}{l}\text { Water } \\
\text { year }\end{array}$ & Date & $\begin{array}{c}\text { Discharge } \\
\left(\mathrm{ft}^{3} / \mathrm{s}\right)\end{array}$ & $\begin{array}{c}\text { Gage } \\
\text { height } \\
\text { (ft) }\end{array}$ & $\begin{array}{l}\text { Water } \\
\text { year }\end{array}$ & Date & $\begin{array}{c}\text { Discharge } \\
\left(\mathrm{ft}^{3} / \mathrm{s}\right)\end{array}$ & $\begin{array}{c}\text { Gage } \\
\text { height } \\
\text { (ft) }\end{array}$ & $\begin{array}{l}\text { Water } \\
\text { year }\end{array}$ & Date & $\begin{array}{c}\text { Discharge } \\
\left(\mathrm{ft}^{3} / \mathrm{s}\right)\end{array}$ & $\begin{array}{c}\text { Gage } \\
\text { height } \\
\text { (ft) }\end{array}$ \\
\hline 1925 & Jan. -- & 20,500 & $17.80 c$ & 1955 & Sept.17 & 2,620 & 11.00 & 1973 & Apr. 03 & 4,590 & 12.71 \\
\hline$\overline{1930}$ & Oct. -- & 20,000 & $17.60 \mathrm{c}$ & 1956 & May 07 & 2,830 & 11.30 & 1974 & Feb. 18 & 3,160 & 11.63 \\
\hline$\overline{1938}$ & Apr. 13 & 2,580 & 10.50 & 1957 & May 27 & 2,760 & 11.20 & 1975 & Apr. 17 & 5,270 & 13.09 \\
\hline 1939 & Feb. 28 & 11,600 & 13.80 & 1958 & Mar. 11 & 3,500 & 12.00 & 1976 & June 23 & 3,100 & 11.57 \\
\hline 1940 & Aug. 17 & 7,690 & 12.90 & 1959 & Mar. 08 & 5,700 & 13.20 & 1977 & Mar. 15 & 4,310 & 12.54 \\
\hline 1941 & July 21 & 5,200 & 12.20 & 1960 & Apr. 07 & 6,400 & 13.50 & 1978 & Jan. 27 & 5,670 & 13.42 \\
\hline 1942 & Mar. 09 & 2,820 & 10.80 & 1961 & Apr. 19 & 4,800 & 12.90 & 1979 & Feb. 28 & 6,170 & 13.53 \\
\hline 1943 & Mar. 25 & 2,560 & 10.50 & 1962 & Mar. 16 & 3,010 & 11.50 & 1980 & Mar. 17 & 5,960 & 13.68 \\
\hline 1944 & Mar. 25 & 9,350 & 13.30 & 1963 & June 28 & 2,520 & 10.90 & 1981 & Apr. 04 & 1,760 & 9.78 \\
\hline 1945 & Oct. 25 & 1,880 & 9.50 & 1964 & Jan. 14 & 5,300 & 13.00 & 1982 & Feb. 15 & 2,730 & 11.17 \\
\hline 1946 & Jan. 22 & 2,190 & 10.00 & 1965 & Feb. 19 & 6,800 & 13.83 & 1983 & Feb. 18 & 4,310 & 12.54 \\
\hline 1947 & Apr. 20 & 3,470 & 11.40 & 1966 & May 26 & 12,600 & 16.58 & 1984 & May 05 & 4,870 & 12.88 \\
\hline 1948 & Apr. 02 & 12,100 & 13.90 & 1967 & Jan. 06 & 3,410 & 11.86 & 1985 & Sept.01 & 1,850 & 9.97 \\
\hline 1949 & Dec. 10 & 4,160 & 11.80 & 1968 & Jan. 15 & 396 & 3.65 & 1986 & Feb. 13 & 5,080 & 13.00 \\
\hline 1950 & Sept.09 & 1,710 & 8.90 & 1969 & May 21 & 9,000 & 15.01 & 1987 & Jan. 24 & 5,360 & 13.15 \\
\hline 1951 & Apr. 01 & 2,840 & 10.90 & 1970 & Mar. 24 & 5,000 & 12.95 & 1988 & May 01 & 1,700 & 9.61 \\
\hline 1952 & Mar. 29 & 2,130 & 9.90 & 1971 & Mar. 06 & 5,490 & 13.40 & 1989 & Apr. 15 & 2,350 & 10.74 \\
\hline 1953 & Sept. 28 & 8,500 & 13.70 & 1972 & Feb. 05 & 5,430 & 13.17 & 1990 & Jan. 09 & 7,720 & 14.35 \\
\hline 1954 & Oct. 06 & 2,940 & 11.50 & & & & & & & & \\
\hline
\end{tabular}




\section{OGEECHEE RIVER BASIN}

\section{LOTTS CREEK TRIBUTARY NEAR STATESBORO, GEORGIA}

LOCATION.--Lat $32^{\circ} 20^{\prime} 53^{\prime \prime}$, long $81^{\circ} 52^{\prime} 06^{\prime \prime}$, Bulloch County, at culvert on U.S. Highways 25 and 301,8 mi southwest of Statesboro. DRAINAGE AREA.--2.37 $\mathrm{mi}^{2}$.

GAGE.--Flood-stage/rainfall recorder recorder. Datum of gage is about $130 \mathrm{ft}$ above sea level (from topographic map).

STAGE-DISCHARGE RELATION.--Defined by current-meter measurements below $150 \mathrm{ft}^{3} / \mathrm{s}$, and extended above on basis of culvert computations.

REMARKS.--Flood stage of May 1966 is highest since 1948, based on comparison with nearby stations.

\begin{tabular}{|c|c|c|c|c|c|c|c|c|c|c|c|}
\hline $\begin{array}{l}\text { Water } \\
\text { year }\end{array}$ & Date & $\begin{array}{c}\text { Discharge } \\
\left(\mathrm{ft}^{3} / \mathrm{s}\right)\end{array}$ & $\begin{array}{c}\text { Gage } \\
\text { height } \\
\text { (ft) }\end{array}$ & $\begin{array}{l}\text { Water } \\
\text { year }\end{array}$ & Date & $\begin{array}{c}\text { Discharge } \\
\left(\mathrm{ft}^{3} / \mathrm{s}\right)\end{array}$ & $\begin{array}{c}\text { Gage } \\
\text { height } \\
\text { (ft) }\end{array}$ & $\begin{array}{l}\text { Water } \\
\text { year }\end{array}$ & Date & $\begin{array}{c}\text { Discharge } \\
\left(\mathrm{ft}^{3} / \mathrm{s}\right)\end{array}$ & $\begin{array}{c}\text { Gage } \\
\text { height } \\
\text { (ft) }\end{array}$ \\
\hline 1965 & Oct. 04 & 384 & 4.17 & 1969 & Sept.02 & 301 & 3.77 & 1972 & Dec. 20 & 112 & 3.01 \\
\hline 1966 & May 25 & 908 & 5.57 & 1970 & Mar. 22 & 90 & 2.87 & 1973 & Mar. 09 & 120 & 3.11 \\
\hline 1967 & Aug. 26 & 37 & 2.32 & 1971 & July 31 & 164 & 3.27 & 1974 & Aug. 14 & 208 & 3.45 \\
\hline 1968 & Feb. -- & 21 & $-\mathrm{b}$ & & & & & & & & \\
\hline
\end{tabular}

\section{CANOOCHEE RIVER NEAR DAISY, GEORGIA}

LOCATION.--Lat $32^{\circ} 08^{\prime} 54^{\prime \prime}$, long $81^{\circ} 46^{\prime} 56^{\prime \prime}$, Evans-Bullock County line, at bridge on U.S. Highway 280 and State Highway 30,3 mi east of Daisy.

DRAINAGE AREA.--833 $\mathrm{mi}^{2}$

GAGE.--Crest-stage gage. Datum of gage is about $60 \mathrm{ft}$ above sea level (from topographic map).

STAGE-DISCHARGE RELATION.--Defined by current-meter measurement below $7,100 \mathrm{ft}^{3} / \mathrm{s}$, and extended above on basis of straight-line extension.

\begin{tabular}{|c|c|c|c|c|c|c|c|c|c|c|c|}
\hline $\begin{array}{l}\text { Water } \\
\text { year }\end{array}$ & Date & $\begin{array}{c}\text { Discharge } \\
\left(\mathrm{ft}^{3} / \mathrm{s}\right)\end{array}$ & $\begin{array}{c}\text { Gage } \\
\text { height } \\
\text { (ft) }\end{array}$ & $\begin{array}{l}\text { Water } \\
\text { year }\end{array}$ & Date & $\begin{array}{c}\text { Discharge } \\
\left(\mathrm{ft}^{3} / \mathrm{s}\right)\end{array}$ & $\begin{array}{c}\text { Gage } \\
\text { height } \\
\text { (ft) }\end{array}$ & $\begin{array}{l}\text { Water } \\
\text { year }\end{array}$ & Date & $\begin{array}{c}\text { Discharge } \\
\left(\mathrm{ft}^{3} / \mathrm{s}\right)\end{array}$ & $\begin{array}{l}\text { Gage } \\
\text { height } \\
\text { (ft) }\end{array}$ \\
\hline 1970 & Mar. 26 & 7,640 & 13.58 & 1976 & June 24 & 4,820 & 11.62 & 1982 & Feb. 16 & 3,990 & 10.70 \\
\hline 1971 & Mar. 08 & 7,910 & 13.73 & 1977 & Mar. 16 & 5,690 & 12.35 & 1983 & Feb. 19 & 6,450 & 12.89 \\
\hline 1972 & Feb. 06 & 7,950 & 13.75 & 1978 & Jan. 28 & 7,320 & 13.40 & 1984 & Mar. 08 & 7,090 & 13.27 \\
\hline 1973 & Apr. 05 & 7,070 & 13.26 & 1979 & Mar. 01 & 7,070 & 13.26 & 1985 & Sept.02 & 2,460 & 8.41 \\
\hline 1974 & Feb. 19 & 4,660 & 11.46 & 1980 & Mar. 17 & 7,610 & 13.56 & 1986 & Nov. 24 & 10,600 & 15.10 \\
\hline 1975 & Apr. 16 & 7,630 & 13.57 & 1981 & Apr. 06 & 2,350 & 8.43 & & & & \\
\hline
\end{tabular}

\section{CANOOCHEE RIVER NEAR GROVELAND, GEORGIA}

LOCATION.--Lat 32 $05^{\prime} 55^{\prime \prime}$, long $81^{\circ} 43^{\prime} 43^{\prime \prime}$, Bryan County, on upstream side of Moodys Bridge, 3.3 mi south of Groveland, and 6 mi downstream from Lotts Creek.

DRAINAGE AREA.--921 $\mathrm{mi}^{2}$, approximately.

GAGE.--Nonrecording gage. Datum of gage is about $45 \mathrm{ft}$ above sea level (from topographic map).

STAGE-DISCHARGE RELATION.--Defined by current-meter measurement below $4,200 \mathrm{ft}^{3} / \mathrm{s}$.

\begin{tabular}{|c|c|c|c|c|c|c|c|c|c|c|c|}
\hline $\begin{array}{l}\text { Water } \\
\text { year }\end{array}$ & Date & $\begin{array}{c}\text { Discharge } \\
\left(\mathrm{ft}^{3} / \mathrm{s}\right)\end{array}$ & $\begin{array}{c}\text { Gage } \\
\text { height } \\
\text { (ft) }\end{array}$ & $\begin{array}{l}\text { Water } \\
\text { year }\end{array}$ & Date & $\begin{array}{c}\text { Discharge } \\
\left(\mathrm{ft}^{3} / \mathrm{s}\right)\end{array}$ & $\begin{array}{c}\text { Gage } \\
\text { height } \\
\text { (ft) }\end{array}$ & $\begin{array}{l}\text { Water } \\
\text { year }\end{array}$ & Date & $\begin{array}{c}\text { Discharge } \\
\left(\mathrm{ft}^{3} / \mathrm{s}\right)\end{array}$ & $\begin{array}{c}\text { Gage } \\
\text { height } \\
\text { (ft) }\end{array}$ \\
\hline 1903 & Sept.17 & 6,500 & 18.20 & 1905 & Feb. 18 & 4,080 & 14.80 & 1907 & July 05 & 4,750 & 16.60 \\
\hline 1904 & Feb. 13 & 4,300 & 15.40 & 1906 & June 17 & 5,500 & 17.20 & & & & \\
\hline
\end{tabular}




\section{OGEECHEE RIVER BASIN}

\section{CANOOCHEE RIVER NEAR PEMBROKE, GEORGIA}

LOCATION.--Lat $32^{\circ} 03^{\prime} 30^{\prime \prime}$, long $81^{\circ} 39^{\prime} 06^{\prime \prime}$, Bryan County, $100 \mathrm{ft}$ downstream of bridge on State Highway 119 , about 6 mi south of Pembroke.

DRAINAGE AREA.-959 $\mathrm{mi}^{2}$

GAGE.--Crest-state gage. Datum of gage is $34.50 \mathrm{ft}$ above sea level (from Georgia Department of Transportation).

STAGE-DISCHARGE RELATION.-Defined by current-meter measurement below $9,900 \mathrm{ft}^{3} / \mathrm{s}$, and above based on slope-

conveyance studies.

REMARKS.--Flood stage of September 1929, based on information furnished by Georgia Department of Transportation, is highest since 1840 based on comparison with nearby stations. Peak discharge for 1929 is estimated.

\begin{tabular}{|c|c|c|c|c|c|c|c|c|c|c|c|}
\hline $\begin{array}{l}\text { Water } \\
\text { year }\end{array}$ & Date & $\begin{array}{c}\text { Discharge } \\
\left(\mathrm{ft}^{3} / \mathrm{s}\right)\end{array}$ & $\begin{array}{c}\text { Gage } \\
\text { height } \\
\text { (ft) }\end{array}$ & $\begin{array}{l}\text { Water } \\
\text { year }\end{array}$ & Date & $\begin{array}{c}\text { Discharge } \\
\left(\mathrm{ft}^{3} / \mathrm{s}\right)\end{array}$ & $\begin{array}{c}\text { Gage } \\
\text { height } \\
\text { (ft) }\end{array}$ & $\begin{array}{l}\text { Water } \\
\text { year }\end{array}$ & Date & $\begin{array}{c}\text { Discharge } \\
\left(\mathrm{ft}^{3} / \mathrm{s}\right)\end{array}$ & $\begin{array}{c}\text { Gage } \\
\text { height } \\
\text { (ft) }\end{array}$ \\
\hline 1929 & Sept.29 & 32,000 & $25.00 c$ & 1952 & Apr. 01 & 2,800 & 16.13 & 1956 & Apr. 17 & 2,500 & 15.84 \\
\hline$\overline{1950}$ & Sept.09 & 3,350 & 16.50 & 1953 & Sept.29 & 9,900 & 19.00 & 1958 & Apr. 08 & 5,000 & 17.43 \\
\hline 1951 & Apr. 02 & 3,800 & 16.81 & 1954 & Jan. 01 & 3,100 & 16.33 & $\overline{1963}$ & Jan. 20 & 3,200 & $16.44 c$ \\
\hline
\end{tabular}

\section{GROVE RIVER TRIBUTARY NEAR SAVANNAH, GEORGIA}

LOCATION.--Lat 31 ${ }^{\circ} 58^{\prime} 28^{\prime \prime}$, long $81^{\circ} 13^{\prime} 10^{\prime \prime}$, Chatham County, at culvert on Grove Point Road, near Savannah.

DRAINAGE AREA.- $-0.74 \mathrm{mi}^{2}$.

GAGE.--Flood-stage/rainfall recorder.

STAGE-DISCHARGE RELATION.-Defined by current-meter measurement below $45 \mathrm{tt}^{3} / \mathrm{s}$, and extended above on basis of culvert computations.

REMARKS.-Flow is affected by urbanization.

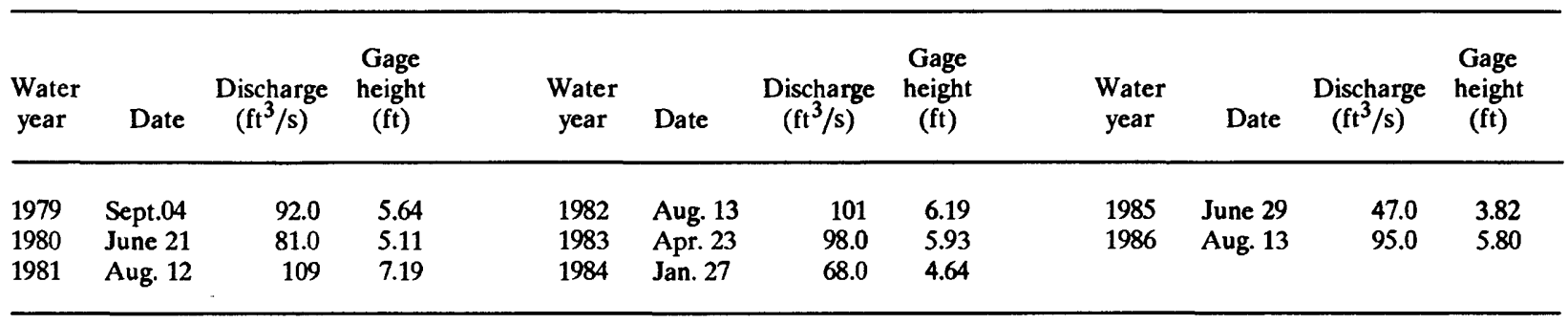

\section{HARMON CANAL TRIBUTARY AT SAVANNAH, GEORGIA}

LOCATION.--Lat $32^{\circ} 00^{\prime} 02^{\prime \prime}$, long 81 $06^{\prime} 49^{\prime \prime}$, Chatham County, at culvert on Hodgson Memorial Drive (Edgewater Road), at Savannah. DRAINAGE AREA. $-0.24 \mathrm{mi}^{2}$

GAGE.--Flood-stage/rainfall recorder.

STAGE-DISCHARGE RELATION.-Defined by current-meter measurement below $45 \mathrm{ft}^{3} / \mathrm{s}$, and extended above on basis of culvert computations.

REMARKS.--Flow is affected by urbanization.

\begin{tabular}{lccccccccccc}
\hline $\begin{array}{l}\text { Water } \\
\text { year }\end{array}$ & Date & $\begin{array}{c}\text { Discharge } \\
\left(\mathrm{ft}^{3} / \mathrm{s}\right)\end{array}$ & $\begin{array}{c}\text { Gage } \\
\text { height } \\
(\mathrm{ft})\end{array}$ & $\begin{array}{c}\text { Water } \\
\text { year }\end{array}$ & Date & $\begin{array}{c}\text { Discharge } \\
\left(\mathrm{ft}^{3} / \mathrm{s}\right)\end{array}$ & $\begin{array}{c}\text { Gage } \\
\text { height } \\
(\mathrm{ft})\end{array}$ & $\begin{array}{c}\text { Water } \\
\text { year }\end{array}$ & $\begin{array}{c}\text { Gage } \\
\text { Date }\end{array}$ & $\begin{array}{c}\text { Discharge } \\
\left(\mathrm{ft}^{3} / \mathrm{s}\right)\end{array}$ & $\begin{array}{c}\text { height } \\
(\mathrm{ft})\end{array}$ \\
\hline 1979 & July 07 & 70.0 & 5.99 & 1982 & July 11 & 73.0 & 6.32 & 1985 & July 29 & 75.0 & 6.73 \\
1980 & Sept. 06 & 70.0 & 6.00 & 1983 & Sept. 01 & 78.0 & 7.03 & 1986 & Aug. 12 & 66.0 & 5.59 \\
1981 & Aug. 12 & 78.0 & 6.98 & 1984 & Aug. 19 & 74.0 & 6.54 & & & & \\
\hline
\end{tabular}




\section{OGEECHEE RIVER BASIN}

\section{HARMON CANAL NEAR SAVANNAH, GEORGIA}

LOCATION.--Lat $32^{\circ} 00^{\prime} 00^{\prime \prime}$, long $81^{\circ} 07^{\prime} 45^{\prime \prime}$, Chatham County, at culvert on Perimeter Road, within the limits of Hunter Army

Airfield, near Savannah.

DRAINAGE AREA.-1.27 $\mathrm{mi}^{2}$.

GAGE.--Flood-stage/rainfall recorder.

STAGE-DISCHARGE RELATION.--Defined by current-meter measurement below $127 \mathrm{tt}^{3} / \mathrm{s}$, and extended above on basis of culvert computations.

REMARKS.--Flow is affected by urbanization.

\begin{tabular}{|c|c|c|c|c|c|c|c|c|c|c|c|}
\hline $\begin{array}{l}\text { Water } \\
\text { year }\end{array}$ & Date & $\begin{array}{c}\text { Discharge } \\
\left(\mathrm{ft}^{3} / \mathrm{s}\right)\end{array}$ & $\begin{array}{c}\text { Gage } \\
\text { height } \\
\text { (ft) }\end{array}$ & $\begin{array}{l}\text { Water } \\
\text { year }\end{array}$ & Date & $\begin{array}{c}\text { Discharge } \\
\left(\mathrm{ft}^{3} / \mathrm{s}\right)\end{array}$ & $\begin{array}{l}\text { Gage } \\
\text { height } \\
\text { (ft) }\end{array}$ & $\begin{array}{l}\text { Water } \\
\text { year }\end{array}$ & Date & $\begin{array}{c}\text { Discharge } \\
\left(\mathrm{ft}^{3} / \mathrm{s}\right)\end{array}$ & $\begin{array}{l}\text { Gage } \\
\text { height } \\
\text { (ft) }\end{array}$ \\
\hline 1979 & Sept. 04 & 267 & 6.48 & 1982 & Apr. 25 & 179 & 4.76 & 1985 & July 29 & 264 & 6.42 \\
\hline 1980 & Mar. 12 & 208 & 5.30 & 1983 & Sept. 01 & 273 & 6.60 & 1986 & July 26 & 189 & 4.93 \\
\hline 1981 & Aug. 12 & 270 & 6.55 & 1984 & Aug. 20 & 216 & 5.45 & & & & \\
\hline
\end{tabular}

02203543 WILSHIRE CANAL NEAR SAVANNAH, GEORGIA

LOCATION.--Lat 31 $59^{\prime} 27^{\prime \prime}$, long $81^{\circ} 08^{\prime} 15^{\prime \prime}$, Chatham County, at culvert on Tibet Avenue near Savannah.

DRAINAGE AREA.--0.95 $\mathrm{mi}^{2}$.

GAGE.--Flood-stage/rainfall recorder prior to Sept. 9, 1986. Crest-stage gage thereafter.

STAGE-DISCHARGE RELATION.--Defined by current-meter measurement below $64 \mathrm{ft}^{3} / \mathrm{s}$, and extended above on basis of culvert computations.

REMARKS.--Flow is affected by urbanization.

\begin{tabular}{|c|c|c|c|c|c|c|c|c|c|c|c|}
\hline $\begin{array}{l}\text { Water } \\
\text { year }\end{array}$ & Date & $\begin{array}{c}\text { Discharge } \\
\left(\mathrm{ft}^{3} / \mathrm{s}\right)\end{array}$ & $\begin{array}{c}\text { Gage } \\
\text { height } \\
\text { (ft) }\end{array}$ & $\begin{array}{l}\text { Water } \\
\text { year }\end{array}$ & Date & $\begin{array}{c}\text { Discharge } \\
\left(\mathrm{ft}^{3} / \mathrm{s}\right)\end{array}$ & $\begin{array}{c}\text { Gage } \\
\text { height } \\
\text { (ft) }\end{array}$ & $\begin{array}{l}\text { Water } \\
\text { year }\end{array}$ & Date & $\begin{array}{c}\text { Discharge } \\
\left(\mathrm{ft}^{3} / \mathrm{s}\right)\end{array}$ & $\begin{array}{c}\text { Gage } \\
\text { height } \\
\text { (ft) }\end{array}$ \\
\hline 1979 & Sept.04 & 221 & 7.95 & 1983 & Sept.01 & 246 & 8.89 & 1987 & Sept.06 & 241 & 8.70 \\
\hline 1980 & June 21 & 204 & 7.21 & 1984 & Aug. 20 & 211 & 7.48 & 1988 & Aug. 30 & 172 & 6.31 \\
\hline 1981 & Aug. 12 & 235 & 8.49 & 1985 & Aug. 02 & 223 & 8.03 & 1989 & June 30 & 185 & 6.61 \\
\hline 1982 & May 30 & 197 & 6.91 & 1986 & Mar. 13 & 134 & 5.57 & 1990 & Aug. 02 & 162 & 6.11 \\
\hline
\end{tabular}

02203544 WILSHIRE CANAL TRIBUTARY NEAR SAVANNAH, GEORGIA

LOCATION.--Lat $31^{\circ} 58^{\prime} 25^{\prime \prime}$, long $81^{\circ} 08^{\prime} 20^{\prime \prime}$, Chatham County, at culvert on Windsor Road near Savannah.

DRAINAGE AREA.--0.18 $\mathrm{mi}^{2}$.

GAGE.--Flood-stage/rainfall recorder prior to Sept. 11, 1986. Crest-stage gage thereafter.

STAGE-DISCHARGE RELATION.--Defined by current-meter measurement below $40 \mathrm{ft}^{3} / \mathrm{s}$, and extended above on basis of culvert computations.

REMARKS.--Flow is affected by urbanization.

\begin{tabular}{|c|c|c|c|c|c|c|c|c|c|c|c|}
\hline $\begin{array}{l}\text { Water } \\
\text { year }\end{array}$ & Date & $\begin{array}{c}\text { Discharge } \\
\left(\mathrm{ft}^{3} / \mathrm{s}\right)\end{array}$ & $\begin{array}{c}\text { Gage } \\
\text { height } \\
\text { (ft) }\end{array}$ & $\begin{array}{l}\text { Water } \\
\text { year }\end{array}$ & Date & $\begin{array}{c}\text { Discharge } \\
\left(\mathrm{ft}^{3} / \mathrm{s}\right)\end{array}$ & $\begin{array}{c}\text { Gage } \\
\text { height } \\
\text { (ft) }\end{array}$ & $\begin{array}{l}\text { Water } \\
\text { year }\end{array}$ & Date & $\begin{array}{c}\text { Discharge } \\
\left(\mathrm{ft}^{3} / \mathrm{s}\right)\end{array}$ & $\begin{array}{c}\text { Gage } \\
\text { heigh } \\
\text { (ft) }\end{array}$ \\
\hline 1979 & Sept.04 & 78.0 & 3.82 & 1983 & June 22 & 82.0 & 4.39 & 1987 & Sept.06 & 82.0 & 4.30 \\
\hline 1980 & Aug. 09 & 69.0 & 3.14 & 1984 & Aug. 20 & 75.0 & 3.57 & 1988 & Aug. 11 & 75.0 & 3.53 \\
\hline 1981 & Aug. 12 & 73.0 & 3.43 & 1985 & Aug. 02 & 76.0 & 3.69 & 1989 & July 23 & 68.0 & 3.08 \\
\hline 1982 & May 30 & 76.0 & 3.66 & 1986 & Mar. 13 & 46.0 & 2.39 & 1990 & Oct. 18 & 61.0 & 2.89 \\
\hline
\end{tabular}




\section{NORTH NEWPORT RIVER BASIN \\ 02203559 PEACOCK CREEK AT MCINTOSH, GEORGIA}

LOCATION.--Lat $31^{\circ} 48^{\prime} 49^{\prime \prime}$, long $81^{\circ} 31^{\prime} 13^{\prime \prime}$, Liberty County, at culvert on county road, 0.4 mi southwest of U.S. Highway 82 , and $0.9 \mathrm{mi}$ south of Mclntosh.

DRAINAGE AREA.--33 $\mathrm{mi}^{2}$.

GAGE.-Water-stage recorder. Datum of gage is $0.40 \mathrm{ft}$ above sea level (levels by Georgia Department of Transportation).

STAGE-DISCHARGE RELATION.--Defined by current-meter measurement below $460 \mathrm{tt}^{3} / \mathrm{s}$, and above on the basis of slopeconveyance studies.

\begin{tabular}{|c|c|c|c|c|c|c|c|c|c|c|c|}
\hline $\begin{array}{l}\text { Water } \\
\text { year }\end{array}$ & Date & $\begin{array}{c}\text { Discharge } \\
\left(\mathrm{ft}^{3} / \mathrm{s}\right)\end{array}$ & $\begin{array}{l}\text { Gage } \\
\text { height } \\
\text { (ft) }\end{array}$ & $\begin{array}{l}\text { Water } \\
\text { year }\end{array}$ & Date & $\begin{array}{c}\text { Discharge } \\
\left(\mathrm{ft}^{3} / \mathrm{s}\right)\end{array}$ & $\begin{array}{c}\text { Gage } \\
\text { height } \\
\text { (ft) }\end{array}$ & $\begin{array}{l}\text { Water } \\
\text { year }\end{array}$ & Date & $\begin{array}{c}\text { Discharge } \\
\left(\mathrm{ft}^{3} / \mathrm{s}\right)\end{array}$ & $\begin{array}{c}\text { Gage } \\
\text { height } \\
\text { (ft) }\end{array}$ \\
\hline 1967 & Jan. 05 & 250 & 8.75 & 1971 & Aug. 18 & 600 & 10.50 & 1975 & Apr. 16 & 472 & 9.83 \\
\hline 1968 & June 09 & 120 & 8.23 & 1972 & June 21 & 800 & 10.90 & 1976 & June 05 & 269 & 9.22 \\
\hline 1969 & Sept. 01 & 1,050 & 11.33 & 1973 & Sept. 28 & 370 & 9.84 & 1977 & Oct. 18 & 456 & 9.79 \\
\hline 1970 & May 31 & 588 & 10.47 & 1974 & Aug. 11 & 197 & 8.31 & & & & \\
\hline
\end{tabular}

\section{ALTAMAHA RIVER BASIN \\ 02203600 SOUTH RIVER AT EAST POINT, GEORGIA}

LOCATION.--Lat $33^{\circ} 40^{\prime} 50^{\prime \prime}$, long $84^{\circ} 25^{\prime} 15^{\prime \prime}$, Fulton County, at culvert on Harland Drive, at East Point.

DRAINAGE AREA.-1.49 $\mathrm{mi}^{2}$.

GAGE.--Crest-stage gage. Prior to October 1, 1969, water-stage recorder at same site and datum. Datum of gage is about $890 \mathrm{ft}$ above sea level (from topographic map).

STAGE-DISCHARGE RELATION.--Defined by current-meter measurement below $360 \mathrm{ft}^{3} / \mathrm{s}$, and extended above on basis of culvert computations..

REMARKS.--Flood peaks are affected by increasing amounts of urbanization.

\begin{tabular}{|c|c|c|c|c|c|c|c|c|c|c|c|}
\hline $\begin{array}{l}\text { Water } \\
\text { year }\end{array}$ & Date & $\begin{array}{c}\text { Discharge } \\
\left(\mathrm{ft}^{3} / \mathrm{s}\right)\end{array}$ & $\begin{array}{c}\text { Gage } \\
\text { height } \\
\text { (ft) }\end{array}$ & $\begin{array}{c}\text { Water } \\
\text { year }\end{array}$ & Date & $\begin{array}{c}\text { Discharge } \\
\left(\mathrm{ft}^{3} / \mathrm{s}\right)\end{array}$ & $\begin{array}{c}\text { Gage } \\
\text { height } \\
\text { (ft) }\end{array}$ & $\begin{array}{c}\text { Water } \\
\text { year }\end{array}$ & Date & $\begin{array}{c}\text { Discharge } \\
\left(\mathrm{ft}^{3} / \mathrm{s}\right)\end{array}$ & $\begin{array}{c}\text { Gage } \\
\text { height } \\
\text { (ft) }\end{array}$ \\
\hline 1964 & Aug. 05 & 820 & 10.00 & 1969 & May 16 & 804 & 9.85 & 1975 & Sept.00 & 750 & 9.43 \\
\hline 1965 & June 07 & 493 & 7.40 & 1970 & Mar. 19 & 565 & 8.00 & 1976 & Mar. 16 & 543 & 7.82 \\
\hline 1966 & Aug. 06 & 806 & 9.90 & 1971 & Aug. 02 & 565 & 8.00 & 1977 & Aug. 21 & 571 & 8.05 \\
\hline 1967 & Mar. 10 & 792 & 9.80 & 1972 & Jan. 10 & 565 & 8.00 & 1978 & Nov. 05 & 854 & 10.23 \\
\hline 1968 & Dec. 19 & 650 & 8.72 & 1973 & Feb. 01 & 620 & 8.44 & & & & \\
\hline
\end{tabular}




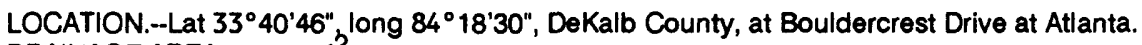

DRAINAGE AREA.--41.5 $\mathrm{mi}^{2}$.

GAGE.--Crest-stage gage. Datum of gage is $758.70 \mathrm{ft}$ above sea level (levels by U.S. Army Corps of Engineers).

STAGE-DISCHARGE RELATION.--Defined by current-meter measurement below $4,500 \mathrm{ft}^{3} / \mathrm{s}$, and above based on straight-line extension. Bankfull stage and discharge, $7 \mathrm{ft}$ and $2,300 \mathrm{ft}^{3} / \mathrm{s}$.

HISTORICAL DATA.--The flood of Feb. 25, 1961 is thought to be the highest since at least 1946, based on comparison with nearby stations.

REMARKS.--Flood peaks are affected by increasing amounts of urbanization. Peak discharges for 1958-59 are estimated.

\begin{tabular}{|c|c|c|c|c|c|c|c|c|c|c|c|}
\hline $\begin{array}{l}\text { Water } \\
\text { year }\end{array}$ & Date & $\begin{array}{c}\text { Discharge } \\
\left(\mathrm{ft}^{3} / \mathrm{s}\right)\end{array}$ & $\begin{array}{c}\text { Gage } \\
\text { height } \\
\text { (ft) }\end{array}$ & $\begin{array}{l}\text { Water } \\
\text { year }\end{array}$ & Date & $\begin{array}{c}\text { Discharge } \\
\left(\mathrm{ft}^{3} / \mathrm{s}\right)\end{array}$ & $\begin{array}{c}\text { Gage } \\
\text { height } \\
\text { (ft) }\end{array}$ & $\begin{array}{l}\text { Water } \\
\text { year }\end{array}$ & Date & $\begin{array}{c}\text { Discharge } \\
\left(\mathrm{ft}^{3} / \mathrm{s}\right)\end{array}$ & $\begin{array}{c}\text { Gage } \\
\text { height } \\
\text { (ft) }\end{array}$ \\
\hline 1951 & Feb. 21 & 1,810 & 6.15 & 1964 & Apr. 06 & 4,950 & 9.27 & 1977 & Aug. 21 & 2,400 & 5.90 \\
\hline 1952 & Dec. 21 & 2,460 & 7.21 & 1965 & Dec. 26 & 2,200 & 5.45 & 1978 & Nov. 05 & 5,120 & 9.41 \\
\hline 1953 & July 16 & 2,380 & 7.12 & 1966 & Feb. 13 & 4,300 & 8.98 & 1979 & Apr. 13 & 5,040 & 9.36 \\
\hline 1954 & Jan. 22 & 1,390 & 4.96 & 1967 & Aug. 23 & 3,700 & 8.29 & 1980 & May 23 & 6,200 & 10.13 \\
\hline 1955 & Feb. 06 & 1,640 & 5.70 & 1968 & Mar. 12 & 3,500 & 8.05 & 1981 & Feb. 11 & 3,180 & 7.55 \\
\hline 1956 & Mar. 16 & 2,900 & 7.66 & 1969 & Apr. 18 & 4,650 & 9.12 & 1982 & Feb. 03 & 3,770 & 8.27 \\
\hline 1957 & Apr. 05 & 2,800 & 7.64 & 1970 & Sept.00 & 1,400 & $--b$ & 1983 & Apr. 08 & 5,030 & 9.35 \\
\hline 1958 & Feb. 06 & 1,670 & - & 1971 & Mar. 03 & 3,860 & 8.54 & 1984 & July 31 & 2,230 & 5.82 \\
\hline 1959 & May 31 & 1,400 & - & 1972 & Jan. 10 & 2,900 & 6.53 & 1985 & Mar. -- & 2,000 & $--b$ \\
\hline 1960 & Jan. 30 & 5,700 & 9.79 & 1973 & Feb. 01 & 5,130 & 9.42 & 1986 & Mar. -- & 2,000 & $-\mathrm{b}$ \\
\hline 1961 & Feb. 25 & 8,000 & 11.09 & 1974 & Dec. 31 & 4,460 & 8.97 & $\underline{1987}$ & Jan. 19 & 2,320 & 6.04 \\
\hline 1962 & Feb. 22 & 3,200 & 7.43 & 1975 & Apr. 02 & 2,800 & 6.31 & $\overline{1990}$ & Mar. 17 & 7,020 & $10.61 \mathrm{c}$ \\
\hline 1963 & Apr. 30 & 4,220 & 8.77 & 1976 & Mar. 16 & 9,560 & 11.88 & & & & \\
\hline
\end{tabular}

\section{SUGAR CREEK NEAR ATLANTA, GEORGIA}

LOCATION.--Lat $33^{\circ} 41^{\prime} 41^{\prime \prime}$, long 84 $18^{\prime} 15^{\prime \prime}$, DeKalb County, at culvert on Clifton Church Road, near Atlanta.

DRAINAGE AREA.--8.67 $\mathrm{mi}^{2}$.

GAGE.--Crest-stage gage. Datum of gage is $763.97 \mathrm{ft}$ above sea level (levels by U.S. Army Corps of Engineers).

STAGE-DISCHARGE RELATION.--Defined by current-meter measurement below $1,200 \mathrm{ft}^{3} / \mathrm{s}$, and extended above on basis of culvert computations.

REMARKS.--Flow is affected by urbanization. Flood peak for 1961 flood from floodmarks.

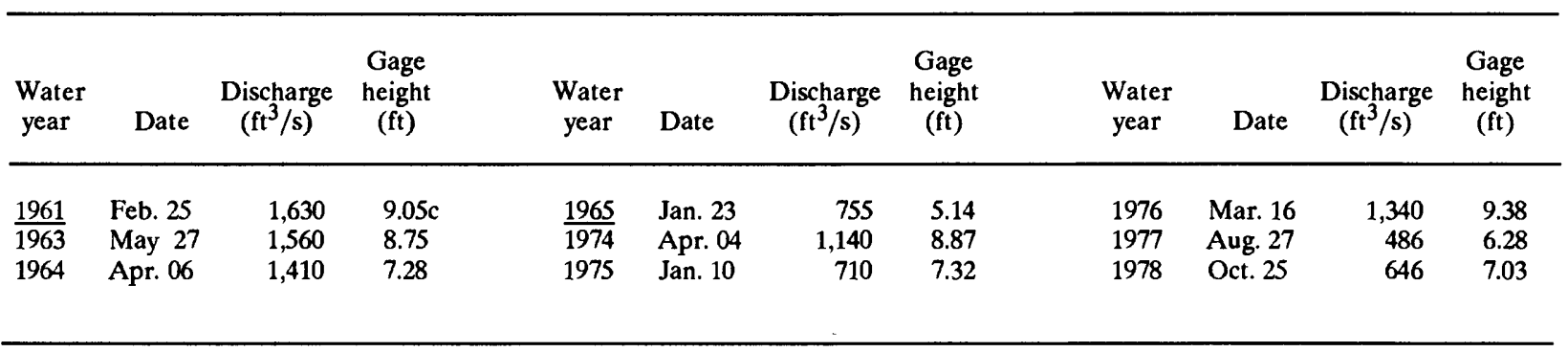




\section{ALTAMAHA RIVER BASIN}

\section{DOLITTLE CREEK NEAR ATLANTA, GEORGIA}

LOCATION.--Lat $33^{\circ} 42^{\prime} 30^{\prime \prime}$, long $84^{\circ} 17^{\prime} 45^{\prime \prime}$, DeKalb County, at culvert on Whites Mill Road, 3.2 mi east of Atlanta. DRAINAGE AREA.--3.88 $\mathrm{mi}^{2}$.

GAGE.--Crest-stage gage. Datum of gage is $801.35 \mathrm{ft}$ above sea level (levels by U.S. Army Corps of Engineers). STAGE-DISCHARGE RELATION.--Defined by culvert computations.

REMARKS.--Flood peaks are affected by increasing amounts of urbanization. Peak discharges for 1964-65 are estimated. Flood peak for 1961 flood from floodmarks.

\begin{tabular}{|c|c|c|c|c|c|c|c|c|c|c|c|}
\hline $\begin{array}{l}\text { Water } \\
\text { year }\end{array}$ & Date & $\begin{array}{c}\text { Discharge } \\
\left(\mathrm{ft}^{3} / \mathrm{s}\right)\end{array}$ & $\begin{array}{c}\text { Gage } \\
\text { height } \\
\text { (ft) }\end{array}$ & $\begin{array}{l}\text { Water } \\
\text { year }\end{array}$ & Date & $\begin{array}{c}\text { Discharge } \\
\left(\mathrm{ft}^{3} / \mathrm{s}\right)\end{array}$ & $\begin{array}{c}\text { Gage } \\
\text { height } \\
\text { (ft) }\end{array}$ & $\begin{array}{l}\text { Water } \\
\text { year }\end{array}$ & Date & $\begin{array}{c}\text { Discharge } \\
\left(\mathrm{ft}^{3} / \mathrm{s}\right)\end{array}$ & $\begin{array}{c}\text { Gage } \\
\text { height } \\
\text { (ft) }\end{array}$ \\
\hline$\frac{1961}{1963}$ & $\begin{array}{l}\text { Feb. } 25 \\
\text { May } 27\end{array}$ & $\begin{array}{l}1,100 \\
1,400\end{array}$ & $\begin{array}{c}8.88 \mathrm{c} \\
10.30\end{array}$ & $\begin{array}{l}1964 \\
1965\end{array}$ & $\begin{array}{l}\text { May } 02 \\
\text { Dec. } 04\end{array}$ & $\begin{array}{l}560 \\
550\end{array}$ & & 1966 & Feb. 13 & 720 & 5.28 \\
\hline
\end{tabular}

\section{SHOAL CREEK AT ATLANTA, GEORGIA}

LOCATION.--Lat $33^{\circ} 44^{\prime} 48^{\prime \prime}$, long $84^{\circ} 16^{\prime} 50^{\prime \prime}$, DeKalb County, at culvert on Line Street, near Atlanta.

DRAINAGE AREA.--3.43 $\mathrm{mi}^{2}$.

GAGE.--Flood-stage/rainfall recorder prior to Oct. 2, 1980. Crest-stage gage thereafter.

STAGE-DISCHARGE RELATION.--Defined by current-meter measurement below $215 \mathrm{ft} / \mathrm{s}$, and extended above on basis of culvert computations.

REMARKS.--Flow is affected by urbanization. Flood of May 1980 is thought to be the highest since 1963 based on records at nearby stations.

\begin{tabular}{|c|c|c|c|c|c|c|c|c|c|c|c|}
\hline $\begin{array}{l}\text { Water } \\
\text { year }\end{array}$ & Date & $\begin{array}{c}\text { Discharge } \\
\left(\mathrm{ft}^{3} / \mathrm{s}\right)\end{array}$ & $\begin{array}{c}\text { Gage } \\
\text { height } \\
\text { (ft) }\end{array}$ & $\begin{array}{c}\text { Water } \\
\text { year }\end{array}$ & Date & $\begin{array}{c}\text { Discharge } \\
\left(\mathrm{ft}^{3} / \mathrm{s}\right)\end{array}$ & $\begin{array}{c}\text { Gage } \\
\text { height } \\
\text { (ft) }\end{array}$ & $\begin{array}{l}\text { Water } \\
\text { year }\end{array}$ & Date & $\begin{array}{c}\text { Discharge } \\
\left(\mathrm{ft}^{3} / \mathrm{s}\right)\end{array}$ & $\begin{array}{c}\text { Gage } \\
\text { height } \\
\text { (ft) }\end{array}$ \\
\hline 1973 & June 05 & 1,010 & 7.24 & 1979 & Sept. 01 & 778 & 5.42 & 1985 & May 02 & 425 & 3.10 \\
\hline 1974 & Apr. 04 & 778 & 5.42 & 1980 & May 23 & 2,140 & 9.29 & 1986 & Dec. 01 & 638 & 4.42 \\
\hline 1975 & June 10 & 699 & 4.84 & 1981 & Oct. -- & 536 & $-b$ & 1987 & June 03 & 689 & 4.79 \\
\hline 1976 & Mar. 16 & 854 & 6.03 & 1982 & Sept. 02 & 648 & 4.49 & 1988 & Jan. 20 & 640 & 4.43 \\
\hline 1977 & Mar. 21 & 325 & 2.55 & 1983 & Mar. 05 & 1,390 & 7.99 & 1989 & June 20 & 719 & 5.09 \\
\hline 1978 & May 08 & 570 & 3.73 & 1984 & Feb. 27 & 812 & 5.75 & 1990 & Feb. 09 & 966 & 6.91 \\
\hline
\end{tabular}

\section{SHOAL CREEK TRIBUTARY NEAR ATLANTA, GEORGIA}

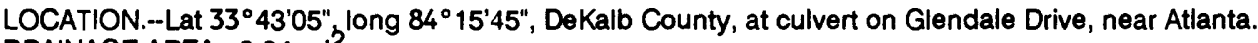

DRAINAGE AREA.--0.84 $\mathrm{mi}^{2}$.

GAGE.--Flood-stage/rainfall recorder prior to June 23, 1978. Crest-stage gage after March 25, 1980.

STAGE-DISCHARGE RELATION.--Defined by current-meter measurement below $17 \mathrm{tt}^{3} / \mathrm{s}$, and extended above on basis of culvert computations.

REMARKS.--Flow is affected by urbanization.

\begin{tabular}{|c|c|c|c|c|c|c|c|c|c|c|c|}
\hline $\begin{array}{l}\text { Water } \\
\text { year }\end{array}$ & Date & $\begin{array}{c}\text { Discharge } \\
\left(\mathrm{ft}^{3} / \mathrm{s}\right)\end{array}$ & $\begin{array}{c}\text { Gage } \\
\text { height } \\
\text { (ft) }\end{array}$ & $\begin{array}{l}\text { Water } \\
\text { year }\end{array}$ & Date & $\begin{array}{c}\text { Discharge } \\
\left(\mathrm{ft}^{3} / \mathrm{s}\right)\end{array}$ & $\begin{array}{c}\text { Gage } \\
\text { height } \\
\text { (ft) }\end{array}$ & $\begin{array}{l}\text { Water } \\
\text { year }\end{array}$ & Date & $\begin{array}{c}\text { Discharge } \\
\left(\mathrm{ft}^{3} / \mathrm{s}\right)\end{array}$ & $\begin{array}{c}\text { Gage } \\
\text { height } \\
\text { (ft) }\end{array}$ \\
\hline 1963 & May 27 & 720 & 6.80 & 1977 & May 26 & 176 & 3.02 & 1985 & July 17 & 366 & 4.45 \\
\hline 1964 & Jan. 24 & 330 & 4.12 & 1978 & May 08 & 446 & 4.88 & 1986 & Oct. 01 & 358 & 4.39 \\
\hline 1965 & Dec. 26 & 460 & 5.04 & 1980 & May 23 & 358 & 4.39 & 1987 & Aug. 04 & 287 & 3.86 \\
\hline 1973 & July 31 & 464 & 5.13 & 1981 & Sept.01 & 335 & 4.23 & 1988 & Feb. -- & 150 & $--b$ \\
\hline 1974 & Dec. 26 & 402 & 4.55 & 1982 & Mar. 15 & 427 & 4.88 & 1989 & June 20 & 560 & 5.75 \\
\hline 1975 & June 10 & 600 & 5.70 & 1983 & Mar. 05 & 751 & 6.92 & 1990 & Jan. 20 & 397 & 4.67 \\
\hline 1976 & May 28 & 516 & 5.27 & 1984 & July 02 & 222 & 3.35 & & & & \\
\hline
\end{tabular}




\section{ALTAMAHA RIVER BASIN}

\section{SHOAL CREEK NEAR ATLANTA, GEORGIA}

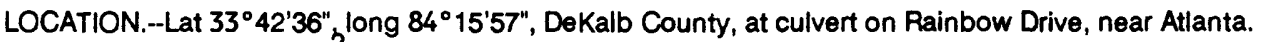

DRAINAGE AREA. $-7.50 \mathrm{mi}^{2}$.

GAGE.--Flood-stage/rainfall recorder. Datum of gage is 789.05 above sea level (levels by U.S. Army Corps of

Engineers).

STAGE-DISCHARGE RELATION.--Defined by current-meter measurement below $252 \mathrm{ft}^{3} / \mathrm{s}$, and extended above on basis

of culvert computations.

REMARKS.--Flow is affected by urbanization.

\begin{tabular}{|c|c|c|c|c|c|c|c|c|c|c|c|}
\hline $\begin{array}{l}\text { Water } \\
\text { year }\end{array}$ & Date & $\begin{array}{c}\text { Discharge } \\
\left(\mathrm{ft}^{3} / \mathrm{s}\right)\end{array}$ & $\begin{array}{c}\text { Gage } \\
\text { height } \\
\text { (ft) }\end{array}$ & $\begin{array}{l}\text { Water } \\
\text { year }\end{array}$ & Date & $\begin{array}{c}\text { Discharge } \\
\left(\mathrm{ft}^{3} / \mathrm{s}\right)\end{array}$ & $\begin{array}{c}\text { Gage } \\
\text { height } \\
\text { (ft) }\end{array}$ & $\begin{array}{l}\text { Water } \\
\text { year }\end{array}$ & Date & $\begin{array}{c}\text { Discharge } \\
\left(\mathrm{ft}^{3} / \mathrm{s}\right)\end{array}$ & $\begin{array}{c}\text { Gage } \\
\text { height } \\
\text { (ft) }\end{array}$ \\
\hline 1963 & May 27 & 2,670 & 10.10 & 1974 & Apr. 04 & 1,280 & 5.52 & 1977 & Mar. 21 & 532 & 3.82 \\
\hline 1964 & Mar. 25 & 1,180 & 6.15 & 1975 & June 10 & 1,340 & 5.80 & 1978 & Aug. 11 & 1,160 & 5.06 \\
\hline 1965 & June 11 & 1,000 & 4.97 & 1976 & M?ar. 16 & 1,580 & 6.72 & 1979 & Sept.01 & 1,350 & 5.84 \\
\hline
\end{tabular}

\section{COBBS CREEK NEAR ATLANTA, GEORGIA}

LOCATION.--Lat 33 $43^{\prime} 44^{\prime \prime}$, long $84^{\circ} 14^{\prime} 17^{\prime \prime}$, DeKalb County, at culvert on Snapfinger Road, near Atlanta.

DRAINAGE AREA.--3.68 $\mathrm{mi}^{2}$.

GAGE.-Flood-stage/rainfall recorder. Datum of gage is $\mathbf{8 4 1 . 6 0}$ above sea level (levels by U.S. Army Corps of Engineers).

STAGE-DISCHARGE RELATION.--Defined by current-meter measurement below $50 \mathrm{ft}^{3} / \mathrm{s}$, and extended above on basis of culvert computations.

REMARKS.--Flow is affected by urbanization. Peak discharge for 1964 is estimated.

\begin{tabular}{|c|c|c|c|c|c|c|c|c|c|c|c|}
\hline $\begin{array}{l}\text { Water } \\
\text { year }\end{array}$ & Date & $\begin{array}{c}\text { Discharge } \\
\left(\mathrm{ft}^{3} / \mathrm{s}\right)\end{array}$ & $\begin{array}{c}\text { Gage } \\
\text { height } \\
\text { (ft) }\end{array}$ & $\begin{array}{l}\text { Water } \\
\text { year }\end{array}$ & Date & $\begin{array}{c}\text { Discharge } \\
\left(\mathrm{ft}^{3} / \mathrm{s}\right)\end{array}$ & $\begin{array}{c}\text { Gage } \\
\text { height } \\
\text { (ft) }\end{array}$ & $\begin{array}{l}\text { Water } \\
\text { year }\end{array}$ & Date & $\begin{array}{c}\text { Discharge } \\
\left(\mathrm{ft}^{3} / \mathrm{s}\right)\end{array}$ & $\begin{array}{c}\text { Gage } \\
\text { height } \\
\text { (ft) }\end{array}$ \\
\hline 1963 & May 27 & 3,400 & 11.40 & $\underline{1967}$ & Nov. 10 & 950 & 4.56 & 1977 & Mar. 21 & 268 & 3.39 \\
\hline 1964 & Mar. 25 & 750 & - & $\overline{1974}$ & Apr. 04 & 707 & 4.99 & 1978 & May 08 & 590 & 4.60 \\
\hline 1965 & Dec. 26 & 880 & 4.24 & 1975 & Aug. 27 & 764 & 5.18 & 1979 & Sept.01 & 725 & 5.03 \\
\hline 1966 & Feb. 13 & 1,120 & 5.12 & 1976 & Mar. 16 & 947 & 5.79 & 1980 & May 23 & 1,060 & 6.25 \\
\hline
\end{tabular}




\section{ALTAMAHA RIVER BASIN}

\section{CONLEY CREEK NEAR FOREST PARK, GEORGIA}

LOCATION.--Lat $33^{\circ} 38^{\prime} 08^{\prime \prime}$, long $84^{\circ} 20^{\prime} 37^{\prime \prime}$, Clayton County, at culvert on culvert on Rock Cut Road near Forest Park.

DRAINAGE AREA.--1.88 $\mathrm{mi}^{2}$.

GAGE.--Flood-stage/rainfall recorder prior to July 5, 1978. Crest-stage gage after March 25, 1980. Datum of gage is $844.80 \mathrm{ft}$ above sea level (levels by U.S. Army Corps of Engineers).

STAGE-DISCHARGE RELATION.--Defined by current-meter measurement below $42 \mathrm{ft} / \mathrm{s}$, and extended above on basis of culvert computations.

REMARKS.--Flow is affected by urbanization. Peak discharge for 1983 undetermined owing to debris in culvert.

\begin{tabular}{|c|c|c|c|c|c|c|c|c|c|c|c|}
\hline $\begin{array}{l}\text { Water } \\
\text { year }\end{array}$ & Date & $\begin{array}{c}\text { Discharge } \\
\left(\mathrm{ft}^{3} / \mathrm{s}\right)\end{array}$ & $\begin{array}{c}\text { Gage } \\
\text { height } \\
\text { (ft) }\end{array}$ & $\begin{array}{l}\text { Water } \\
\text { year }\end{array}$ & Date & $\begin{array}{c}\text { Discharge } \\
\left(\mathrm{ft}^{3} / \mathrm{s}\right)\end{array}$ & $\begin{array}{l}\text { Gage } \\
\text { height } \\
\text { (ft) }\end{array}$ & $\begin{array}{l}\text { Water } \\
\text { year }\end{array}$ & Date & $\begin{array}{c}\text { Discharge } \\
\left(\mathrm{ft}^{3} / \mathrm{s}\right)\end{array}$ & $\begin{array}{c}\text { Gage } \\
\text { height } \\
\text { (ft) }\end{array}$ \\
\hline 1966 & May 27 & 560 & 6.03 & 1978 & Nov. 05 & 1,230 & 9.72 & 1985 & July 17 & 447 & 4.64 \\
\hline 1967 & Nov. 10 & 670 & 6.30 & $\overline{1980}$ & June 24 & 1,010 & 7.71 & 1986 & Oct. 01 & 379 & 4.19 \\
\hline 1968 & Mar. 12 & 480 & 5.42 & 1981 & Mar. 30 & 379 & 4.19 & 1987 & June 11 & 404 & 4.36 \\
\hline$\overline{1974}$ & July 26 & 855 & 7.38 & 1982 & Mar. 15 & 497 & 4.94 & 1988 & Apr. 23 & 493 & 4.92 \\
\hline 1975 & Jan. 10 & 656 & 6.28 & 1983 & Mar. 05 & - & 10.30 & 1989 & June 20 & 543 & 5.21 \\
\hline 1976 & July 27 & 836 & 7.27 & 1984 & May 03 & 654 & 5.85 & 1990 & Jan. 20 & 1,010 & 7.70 \\
\hline 1977 & Aug. 26 & 417 & 4.66 & & & & & & & & \\
\hline
\end{tabular}

\section{SOUTH RIVER NEAR ATLANTA, GEORGIA}

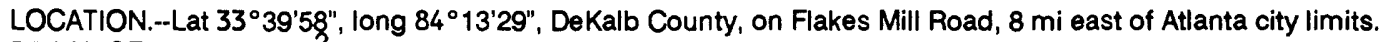

DRAINAGE AREA.--99 $\mathrm{mi}^{2}$, approximately.

GAGE.--Crest-stage gage prior to Aug. 23, 1979; water-stage recorder from August 23, 1979 to Sept. 30, 1983; crest-stage gage thereafter. Datum of gage is $717.75 \mathrm{ft}$ above sea level (levels from DeKalb County benchmark).

STAGE-DISCHARGE RELATION.--Defined by current-meter measurement below $12,000 \mathrm{ft}^{3} / \mathrm{s}$. Bankful stage and discharge, $8 \mathrm{ft}$ and $2,500 \mathrm{ft}^{3} / \mathrm{s}$.

REMARKS.--The flood of Feb. 25, 1961, is thought to be the highest since at least 1946, based on information at nearby stations.

Flood peaks are affected by urbanization.

\begin{tabular}{|c|c|c|c|c|c|c|c|c|c|c|c|}
\hline $\begin{array}{l}\text { Water } \\
\text { year }\end{array}$ & Date & $\begin{array}{c}\text { Discharge } \\
\left(\mathrm{ft}^{3} / \mathrm{s}\right)\end{array}$ & $\begin{array}{c}\text { Gage } \\
\text { height } \\
\text { (ft) }\end{array}$ & $\begin{array}{l}\text { Water } \\
\text { year }\end{array}$ & Date & $\begin{array}{c}\text { Discharge } \\
\left(\mathrm{ft}^{3} / \mathrm{s}\right)\end{array}$ & $\begin{array}{c}\text { Gage } \\
\text { height } \\
\text { (ft) }\end{array}$ & $\begin{array}{l}\text { Water } \\
\text { year }\end{array}$ & Date & $\begin{array}{c}\text { Discharge } \\
\left(\mathrm{ft}^{3} / \mathrm{s}\right)\end{array}$ & $\begin{array}{c}\text { Gage } \\
\text { height } \\
\text { (ft) }\end{array}$ \\
\hline 1951 & Feb. 21 & 2,990 & 8.66 & 1965 & Dec. 26 & 2,960 & 8.70 & 1978 & Jan. 25 & 4,960 & 11.66 \\
\hline 1952 & Dec. 21 & 4,460 & 10.75 & 1966 & Feb. 13 & 7,200 & 14.87 & 1979 & Apr. 13 & 8,820 & 17.17 \\
\hline 1953 & Apr. 30 & 2,920 & 8.62 & 1967 & Aug. 23 & 3,990 & 10.27 & 1980 & Mar. 08 & 6,700 & 14.41 \\
\hline 1954 & Jan. 22 & 2,360 & 7.78 & 1968 & Mar. 12 & 5,820 & 12.88 & 1981 & Feb. 11 & 4,940 & 11.49 \\
\hline 1955 & Feb. 06 & 3,410 & 9.30 & 1969 & Apr. 18 & 6,320 & 13.55 & 1982 & Feb. 03 & 5,260 & 11.94 \\
\hline 1956 & Mar. 16 & 6,930 & 13.71 & 1970 & Apr. 18 & 2,150 & $--b$ & 1983 & Mar. 06 & 7,020 & 14.72 \\
\hline 1957 & Apr. 05 & 3,760 & 9.80 & 1971 & Mar. 03 & 5,730 & 12.76 & 1984 & Dec. 06 & 3,250 & 8.82 \\
\hline 1958 & Feb. 06 & 2,990 & 8.72 & 1972 & Jan. 10 & 4,220 & 10.60 & 1985 & July 29 & 2,060 & 7.29 \\
\hline 1959 & May 31 & 2,500 & 8.02 & 1973 & Feb. 01 & 6,520 & 13.89 & 1986 & Nov. 30 & 2,400 & 7.75 \\
\hline 1960 & Apr. 04 & 4,460 & 10.76 & 1974 & Dec. 31 & 6,020 & 13.17 & 1987 & Jan. 19 & 3,450 & 9.11 \\
\hline 1961 & Feb. 25 & 12,500 & 21.30 & 1975 & Apr. 02 & 3,450 & 9.77 & 1988 & Jan. 21 & 6,190 & 12.55 \\
\hline 1962 & Feb. 22 & 5,620 & 12.65 & 1976 & Mar. 16 & 11,000 & 19.89 & 1989 & June 21 & 4,960 & 11.41 \\
\hline 1963 & Apr. 30 & 6,810 & 14.34 & 1977 & Jan. 09 & 3,180 & 9.04 & 1990 & Mar. 17 & 9,400 & 18.25 \\
\hline 1964 & Apr. 06 & 7,720 & 15.58 & & & & & & & & \\
\hline
\end{tabular}




\section{ALTAMAHA RIVER BASIN}

\section{SNAPFINGER CREEK NEAR DECATUR, GEORGIA}

LOCATION.--Lat $33^{\circ} 45^{\prime} 48^{\prime \prime}$, long $84^{\circ} 13^{\prime} 13^{\prime \prime}$, DeKalb County, at Redan Road, 3.6 mi east of Decatur.

DRAINAGE AREA. $-13.2 \mathrm{mi}^{2}$.

GAGE.-Crest-stage gage. Datum of gage is $846.81 \mathrm{ft}$ above sea level (levels by U.S. Army Corps of Engineers).

STAGE-DISCHARGE RELATION.--Defined by current-meter measurement below $3,300 \mathrm{ft}^{3} / \mathrm{s}$, and above on the basis of straight-line extension.

REMARKS.--Flood peaks are affected by increasing amounts of urbanization. Flood peak of 1961 from floodmarks. The flood of May 27, 1963 is thought to be the highest since 1946, based on information from nearby stations.

\begin{tabular}{|c|c|c|c|c|c|c|c|c|c|c|c|}
\hline $\begin{array}{l}\text { Water } \\
\text { year }\end{array}$ & Date & $\begin{array}{c}\text { Discharge } \\
\left(\mathrm{ft}^{3} / \mathrm{s}\right)\end{array}$ & $\begin{array}{c}\text { Gage } \\
\text { height } \\
\text { (ft) }\end{array}$ & $\begin{array}{l}\text { Water } \\
\text { year }\end{array}$ & Date & $\begin{array}{c}\text { Discharge } \\
\left(\mathrm{ft}^{3} / \mathrm{s}\right)\end{array}$ & $\begin{array}{c}\text { Gage } \\
\text { height } \\
\text { (ft) }\end{array}$ & $\begin{array}{l}\text { Water } \\
\text { year }\end{array}$ & Date & $\begin{array}{c}\text { Discharge } \\
\left(\mathrm{ft}^{3} / \mathrm{s}\right)\end{array}$ & $\begin{array}{c}\text { Gage } \\
\text { height } \\
\text { (ft) }\end{array}$ \\
\hline $\begin{array}{l}\frac{1961}{1963} \\
1964 \\
1965\end{array}$ & $\begin{array}{l}\text { Feb. } 25 \\
\text { May } 27 \\
\text { Mar. } 25 \\
\text { Dec. } 26\end{array}$ & $\begin{array}{r}2,100 \\
3,800 \\
2,200 \\
820\end{array}$ & $\begin{array}{c}11.20 c \\
14.18 \\
11.40 \\
7.60\end{array}$ & $\begin{array}{l}1966 \\
1967 \\
1968 \\
1969\end{array}$ & $\begin{array}{l}\text { Feb. } 13 \\
\text { Nov. } 10 \\
\text { Mar. } 12 \\
\text { Apr. } 18\end{array}$ & $\begin{array}{r}2,350 \\
960 \\
1,880 \\
2,300\end{array}$ & $\begin{array}{r}11.70 \\
8.30 \\
10.75 \\
11.50\end{array}$ & $\frac{\frac{1970}{1973}}{1990}$ & $\begin{array}{l}\text { Mar. } 19 \\
\text { June } 06 \\
\text { Mar. } 17\end{array}$ & $\begin{array}{l}2,560 \\
3,800 \\
1,680\end{array}$ & $\begin{array}{l}12.10 \\
14.20 c \\
10.32 c\end{array}$ \\
\hline
\end{tabular}

\section{SOUTH RIVER NEAR LITHONIA, GEORGIA}

LOCATION.--Lat $33^{\circ} 37^{\prime} 47^{\prime \prime}$, long $84^{\circ} 07^{\prime} 43^{\prime \prime}$, DeKalb-Rockdale County line, at bridge on Klondike Road, 1.1 mile south of State Highway 212, $5.8 \mathrm{mi}$ southwest of Lithonia.

DRAINAGE AREA.-- $182 \mathrm{mi}^{2}$

GAGE.--Water-stage recorder. Datum of gage is $660.90 \mathrm{ft}$ above sea level (levels from DeKalb County benchmark).

STAGE-DISCHARGE RELATION.--Defined by current-meter measurement below $8,130 \mathrm{ft}^{3} / \mathrm{s}$, and extended above based on straight-line extension.

REMARKS.--Flood peaks are affected by urbanization. Peak discharge for Febuary 1961 flood is an estimate. The flood stage of April 1963 is based on information provided by the Georgia Department of Transportation.

\begin{tabular}{|c|c|c|c|c|c|c|c|c|c|c|c|}
\hline $\begin{array}{l}\text { Water } \\
\text { year }\end{array}$ & Date & $\begin{array}{c}\text { Discharge } \\
\left(\mathrm{ft}^{3} / \mathrm{s}\right)\end{array}$ & $\begin{array}{c}\text { Gage } \\
\text { height } \\
\text { (ft) }\end{array}$ & $\begin{array}{l}\text { Water } \\
\text { year }\end{array}$ & Date & $\begin{array}{c}\text { Discharge } \\
\left(\mathrm{ft}^{3} / \mathrm{s}\right)\end{array}$ & $\begin{array}{c}\text { Gage } \\
\text { height } \\
\text { (ft) }\end{array}$ & $\begin{array}{l}\text { Water } \\
\text { year }\end{array}$ & Date & $\begin{array}{c}\text { Discharge } \\
\left(\mathrm{ft}^{3} / \mathrm{s}\right)\end{array}$ & $\begin{array}{c}\text { Gage } \\
\text { height } \\
\text { (ft) }\end{array}$ \\
\hline$\frac{\frac{1961}{1963}}{1984}$ & $\begin{array}{l}\text { Feb. } 25 \\
\text { Apr. } 30 \\
\text { Dec. } 06\end{array}$ & $\begin{array}{r}17,000 \\
9,630 \\
5,230\end{array}$ & $\begin{array}{r}-- \\
11.80 \\
9.55\end{array}$ & $\begin{array}{l}1985 \\
1986 \\
1987\end{array}$ & $\begin{array}{l}\text { Feb. } 06 \\
\text { Nov. } 30 \\
\text { Jan. } 19\end{array}$ & $\begin{array}{l}3,910 \\
4,140 \\
5,650\end{array}$ & $\begin{array}{l}8.69 \\
8.94 \\
9.83\end{array}$ & $\begin{array}{l}1988 \\
1989 \\
1990\end{array}$ & $\begin{array}{l}\text { Feb. } 04 \\
\text { June } 21 \\
\text { Mar. } 17\end{array}$ & $\begin{array}{r}4,260 \\
6,360 \\
12,500\end{array}$ & $\begin{array}{r}9.01 \\
10.22 \\
13.03\end{array}$ \\
\hline
\end{tabular}

\section{PATES CREEK NEAR FLIPPEN, GEORGIA}

LOCATION.--Lat $33^{\circ} 29^{\prime} 34^{\prime \prime}$, long $84^{\circ} 14^{\prime} 44^{\prime \prime}$, Henry County, on left upstream headwall of culvert on Buster Lewis Road, 3.6 mi west of Flippen.

DRAINAGE AREA. $-11.9 \mathrm{mi}^{2}$

GAGE.-Water-stage recorder. Datum of gage is about $720 \mathrm{ft}$ above sea level (from topographic map).

STAGE-DISCHARGE RELATION.--Defined by current-meter measurement below $510 \mathrm{ft}^{3} / \mathrm{s}$, and extended above on the basis of culvert computations.

\begin{tabular}{|c|c|c|c|c|c|c|c|c|c|c|c|}
\hline $\begin{array}{l}\text { Water } \\
\text { year }\end{array}$ & Date & $\begin{array}{c}\text { Discharge } \\
\left(\mathrm{ft}^{3} / \mathrm{s}\right)\end{array}$ & $\begin{array}{c}\text { Gage } \\
\text { height } \\
\text { (ft) }\end{array}$ & $\begin{array}{l}\text { Water } \\
\text { year }\end{array}$ & Date & $\begin{array}{c}\text { Discharge } \\
\left(\mathrm{ft}^{3} / \mathrm{s}\right)\end{array}$ & $\begin{array}{c}\text { Gage } \\
\text { height } \\
\text { (ft) }\end{array}$ & $\begin{array}{l}\text { Water } \\
\text { year }\end{array}$ & Date & $\begin{array}{c}\text { Discharge } \\
\left(\mathrm{ft}^{3} / \mathrm{s}\right)\end{array}$ & $\begin{array}{c}\text { Gage } \\
\text { height } \\
\text { (ft) }\end{array}$ \\
\hline $\begin{array}{l}1978 \\
1979 \\
1980\end{array}$ & $\begin{array}{l}\text { Nov. } 05 \\
\text { Apr. } 13 \\
\text { May } 20\end{array}$ & $\begin{array}{l}816 \\
511 \\
699\end{array}$ & $\begin{array}{l}9.40 \\
6.17 \\
8.23\end{array}$ & $\begin{array}{l}1981 \\
1982 \\
1983\end{array}$ & $\begin{array}{l}\text { Feb. } 11 \\
\text { Feb. } 03 \\
\text { Mar. } 06\end{array}$ & $\begin{array}{l}589 \\
457 \\
680\end{array}$ & $\begin{array}{l}6.99 \\
5.55 \\
7.44\end{array}$ & $\frac{1984}{1990}$ & $\begin{array}{l}\text { Feb. } 13 \\
\text { Mar. } 17\end{array}$ & $\begin{array}{l}623 \\
837\end{array}$ & $\begin{array}{l}6.93 \\
8.82 c\end{array}$ \\
\hline
\end{tabular}




\section{ALTAMAHA RIVER BASIN}

\section{LITTLE COTTON INDIAN CREEK NEAR STOCKBRIDGE, GEORGIA}

LOCATION.--Lat $33^{\circ} 31^{\prime} 26^{\prime \prime}$, long $84^{\circ} 11^{\prime} 41^{\prime \prime}$, Henry County, at State Highway 42, 2.5 mi southeast of Stockbridge.

DRAINAGE AREA.--50 $\mathrm{mi}^{2}$, approximately.

GAGE.--Crest-stage gage. Datum of gage is $681.60 \mathrm{ft}$ above sea level.

STAGE-DISCHARGE RELATION.--Defined by current-meter measurement below $3,400 \mathrm{ft}^{3} / \mathrm{s}$. Stage-discharge record affected by backwater from ponds built downstream after 1964. Peak discharge for 1964 is estimated.

\begin{tabular}{|c|c|c|c|c|c|c|c|c|c|c|c|}
\hline $\begin{array}{l}\text { Water } \\
\text { year }\end{array}$ & Date & $\begin{array}{c}\text { Discharge } \\
\left(\mathrm{ft}^{3} / \mathrm{s}\right)\end{array}$ & $\begin{array}{c}\text { Gage } \\
\text { height } \\
\text { (ft) }\end{array}$ & $\begin{array}{l}\text { Water } \\
\text { year }\end{array}$ & Date & $\begin{array}{c}\text { Discharge } \\
\left(\mathrm{ft}^{3} / \mathrm{s}\right)\end{array}$ & $\begin{array}{c}\text { Gage } \\
\text { height } \\
\text { (ft) }\end{array}$ & $\begin{array}{l}\text { Water } \\
\text { year }\end{array}$ & Date & $\begin{array}{c}\text { Discharge } \\
\left(\mathrm{ft}^{3} / \mathrm{s}\right)\end{array}$ & $\begin{array}{c}\text { Gage } \\
\text { height } \\
\text { (ft) }\end{array}$ \\
\hline $\begin{array}{l}1951 \\
1952 \\
1953 \\
1954 \\
1955 \\
1956 \\
1957\end{array}$ & $\begin{array}{l}\text { July } 29 \\
\text { Mar. } 03 \\
\text { May } 01 \\
\text { Jan. } 16 \\
\text { Apr. } 15 \\
\text { Mar. } 16 \\
\text { Apr. } 04\end{array}$ & $\begin{array}{r}548 \\
1,900 \\
780 \\
830 \\
585 \\
2,080 \\
1,960\end{array}$ & $\begin{array}{l}7.17 \\
9.47 \\
7.88 \\
8.01 \\
7.30 \\
9.80 \\
9.55\end{array}$ & $\begin{array}{l}1958 \\
1959 \\
1960 \\
1961 \\
1962 \\
1963 \\
1964\end{array}$ & $\begin{array}{l}\text { Feb. } 06 \\
\text { Mar. -- } \\
\text { Apr. } 04 \\
\text { Feb. } 25 \\
\text { Feb. } 22 \\
\text { June } 27 \\
\text { Apr. } 06\end{array}$ & $\begin{array}{r}805 \\
610 \\
1,550 \\
3,640 \\
1,820 \\
2,080 \\
2,400\end{array}$ & $\begin{array}{r}7.97 \\
7.38 \\
9.04 \\
12.37 \\
9.35 \\
9.79 \\
--\end{array}$ & $\begin{array}{l}1965 \\
1966 \\
1967 \\
1968 \\
1969 \\
1970 \\
1971\end{array}$ & $\begin{array}{l}\text { Dec. } 26 \\
\text { Feb. } 13 \\
\text { Aug. } 24 \\
\text { Mar. } 12 \\
\text { Apr. } 18 \\
\text { Mar. } 20 \\
\text { Mar. } 03\end{array}$ & $\begin{array}{l}- \\
- \\
- \\
- \\
- \\
- \\
-\end{array}$ & $\begin{array}{r}8.47 \\
11.10 \\
8.83 \\
9.24 \\
10.14 \\
9.69 \\
11.73\end{array}$ \\
\hline
\end{tabular}

\section{SOUTH RIVER NEAR MCDONOUGH, GEORGIA}

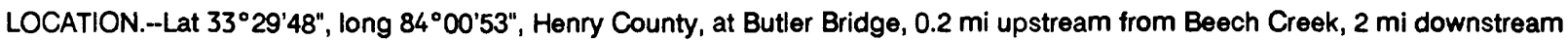
from Big Walnut Creek, 4.5 mi downstream from Cotton River, and 9 mi northeast of McDonough.

DRAINAGE AREA.--456 $\mathrm{mi}^{2}$.

GAGE.--Water-stage recorder prior to Oct. 6, 1960, crest-stage gage from Oct. 6, 1960 to Sept. 30, 1975, water-stage recorder thereafter. Datum of gage is $564.99 \mathrm{ft}$ above sea level (from U.S. Army Corps of Engineers benchmark), supplementary adjustment of 1936.

STAGE-DISCHARGE RELATION.--Defined by current-meter measurement below $22,000 \mathrm{tt}^{3} / \mathrm{s}$, and above on the basis of straightline extension. Bankful stage and discharge, $13 \mathrm{ft}$ and $5,000 \mathrm{ft}^{3} / \mathrm{s}$.

REMARKS.--The flood of January 1946 is thought to be the highest since 1936 based on information at nearby stations.

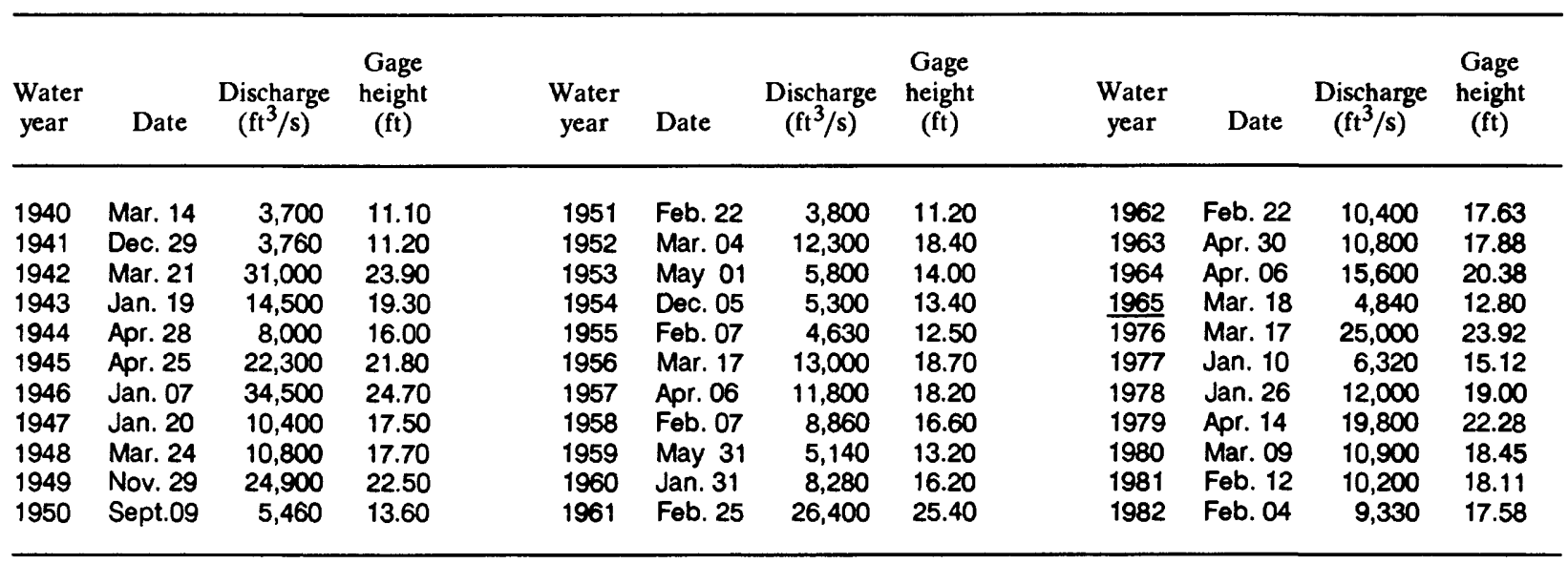




\section{ALTAMAHA RIVER BASIN \\ 02205000 WILDCAT CREEK NEAR LAWRENCEVILLE, GEORGIA}

LOCATION.--Lat $34^{\circ} 00^{\prime} 08^{\prime \prime}$, long $84^{\circ} 00^{\prime} 18^{\prime \prime}$, Gwinnett County, on left bank $75 \mathrm{ft}$ upstream from bridge on Russell Road, $0.7 \mathrm{mi}$ upstream from mouth, 1.1 east of State Highway 20 , and $3.2 \mathrm{mi}$ north of Lawrenceville.

DRAINAGE AREA.--1.59 $\mathrm{mi}^{2}$.

GAGE.--Water-stage recorder. Datum of gage is $967.55 \mathrm{ft}$ above sea level (levels by Metro Engineering).

STAGE-DISCHARGE RELATION.--Defined by current-meter measurement below $90 \mathrm{ft}^{3} / \mathrm{s}$, and extended above on basis of slopearea measurements at $345 \mathrm{ft}^{3} / \mathrm{s}$ and $806 \mathrm{ft}^{3} / \mathrm{s}$. Stage-discharge relation affected by new bridge built in 1974 .

REMARKS.--Flow for recent years may be slightly affected by increasing amounts or urbanization.

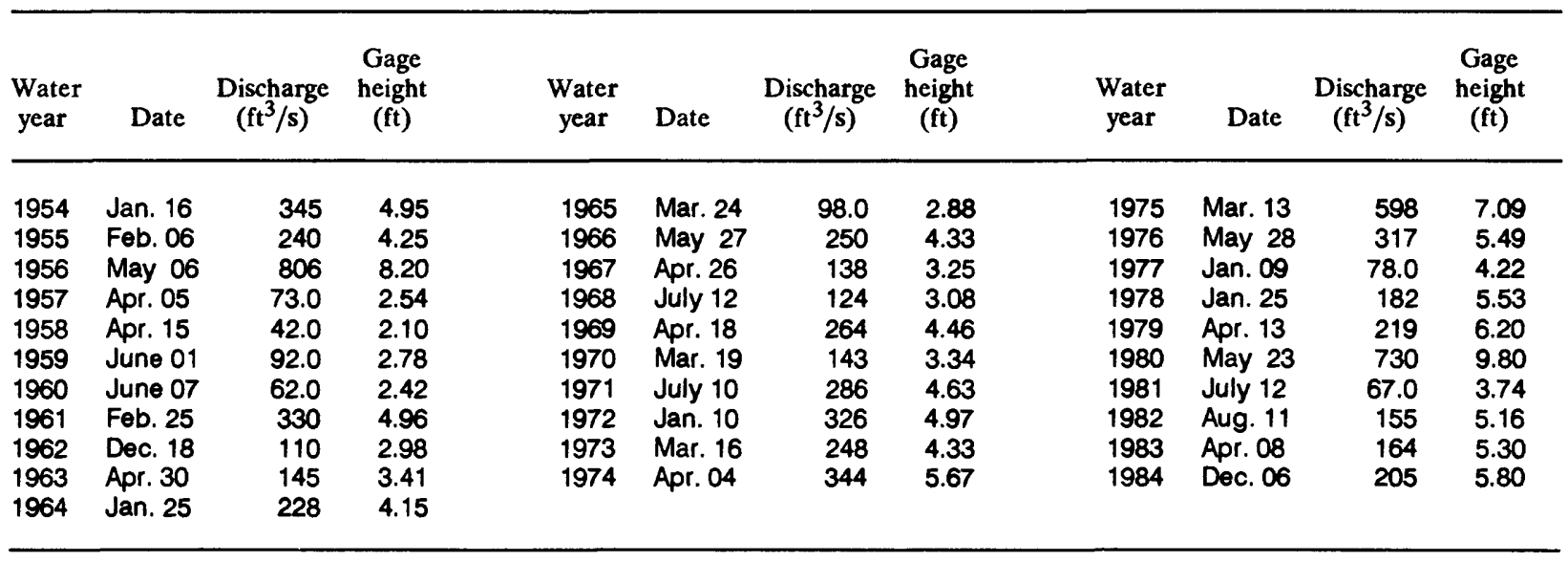

02205500 PEW CREEK NEAR LAWRENCEVLLE, GEORGIA

LOCATION.--Lat $33^{\circ} 56^{\prime} 05^{\prime \prime}$, long $84^{\circ} 01^{\prime} 00^{\prime \prime}$, Gwinnett County, on right bank $20 \mathrm{ft}$ upstream from county highway bridge, $1.0 \mathrm{mi}$ upstream from Redland Creek, and 2.2 mi southwest of Lawrenceville.

DRAINAGE AREA.--2.23 $\mathrm{mi}^{2}$.

GAGE.--Water-stage recorder. Datum of gage is about $930 \mathrm{ft}$ above sea level (by barometer).

STAGE-DISCHARGE RELATION.--Defined by current-meter measurement below $80 \mathrm{ft}^{3} / \mathrm{s}$, and extended above on basis of slopearea measurements at $82,187,341$, and $780 \mathrm{ft}^{3} / \mathrm{s}$.

\begin{tabular}{|c|c|c|c|c|c|c|c|c|c|c|c|}
\hline $\begin{array}{l}\text { Water } \\
\text { year }\end{array}$ & Date & $\begin{array}{c}\text { Discharge } \\
\left(\mathrm{ft}^{3} / \mathrm{s}\right)\end{array}$ & $\begin{array}{c}\text { Gage } \\
\text { height } \\
\text { (ft) }\end{array}$ & $\begin{array}{l}\text { Water } \\
\text { year }\end{array}$ & Date & $\begin{array}{c}\text { Discharge } \\
\left(\mathrm{ft}^{3} / \mathrm{s}\right)\end{array}$ & $\begin{array}{c}\text { Gage } \\
\text { height } \\
\text { (ft) }\end{array}$ & $\begin{array}{l}\text { Water } \\
\text { year }\end{array}$ & Date & $\begin{array}{c}\text { Discharge } \\
\left(\mathrm{ft}^{3} / \mathbf{s}\right)\end{array}$ & $\begin{array}{c}\text { Gage } \\
\text { height } \\
\text { (ft) }\end{array}$ \\
\hline $\begin{array}{l}1954 \\
1955 \\
1956 \\
1957\end{array}$ & $\begin{array}{l}\text { Jan. } 16 \\
\text { Feb. } 06 \\
\text { July } 15 \\
\text { Apr. } 05\end{array}$ & $\begin{array}{l}480 \\
273 \\
615 \\
115\end{array}$ & $\begin{array}{l}5.95 \\
4.30 \\
6.96 \\
2.67\end{array}$ & $\begin{array}{l}1958 \\
1959 \\
1960\end{array}$ & $\begin{array}{l}\text { Apr. } 15 \\
\text { June } 01 \\
\text { Apr. } 04\end{array}$ & $\begin{array}{r}67.0 \\
519 \\
150\end{array}$ & $\begin{array}{l}2.02 \\
6.30 \\
3.44\end{array}$ & $\begin{array}{l}1961 \\
1962 \\
1963\end{array}$ & $\begin{array}{l}\text { Feb. } 25 \\
\text { Dec. } 12 \\
\text { Apr. } 29\end{array}$ & $\begin{array}{l}532 \\
345 \\
438\end{array}$ & $\begin{array}{l}6.35 \\
5.07 \\
5.67\end{array}$ \\
\hline
\end{tabular}


LOCATION.--Lat $33^{\circ} 57^{\prime} 20^{\prime \prime}$, long $84^{\circ} 09^{\prime} 40^{\prime \prime}$, Gwinnett County, on right bank $150 \mathrm{ft}$ upstream from county highway bridge, 1.0 mi upstream from mouth, and $2.8 \mathrm{mi}$ east of Norcross.

DRAINAGE AREA.--0.98 $\mathrm{mi}^{2}$.

GAGE.--Water-stage recorder. Datum of gage is about $890 \mathrm{ft}$ above sea level (from topographic map).

STAGE-DISCHARGE RELATION.--Defined by current-meter measurement below $40 \mathrm{ft}^{3} / \mathrm{s}$, and extended above on basis of slopearea measurements at $440 \mathrm{ft}^{3} / \mathrm{s}$ and $2,320 \mathrm{ft}^{3} / \mathrm{s}$.

REMARKS.--Peak discharge for 1961 increased by dam failure.

\begin{tabular}{|c|c|c|c|c|c|c|c|c|c|c|c|}
\hline $\begin{array}{l}\text { Water } \\
\text { year }\end{array}$ & Date & $\begin{array}{c}\text { Discharge } \\
\left(\mathrm{ft}^{3} / \mathrm{s}\right)\end{array}$ & $\begin{array}{l}\text { Gage } \\
\text { height } \\
\text { (ft) }\end{array}$ & $\begin{array}{l}\text { Water } \\
\text { year }\end{array}$ & Date & $\begin{array}{c}\text { Discharge } \\
\left(\mathrm{ft}^{3} / \mathrm{s}\right)\end{array}$ & $\begin{array}{c}\text { Gage } \\
\text { height } \\
\text { (ft) }\end{array}$ & $\begin{array}{l}\text { Water } \\
\text { year }\end{array}$ & Date & $\begin{array}{c}\text { Discharge } \\
\left(\mathrm{ft}^{3} / \mathrm{s}\right)\end{array}$ & $\begin{array}{c}\text { Gage } \\
\text { height } \\
\text { (ft) }\end{array}$ \\
\hline $\begin{array}{l}1954 \\
1955 \\
1956 \\
1957\end{array}$ & $\begin{array}{l}\text { Jan. } 16 \\
\text { Feb. } 06 \\
\text { May } 06 \\
\text { Apr. } 05\end{array}$ & $\begin{array}{l}442 \\
142 \\
610 \\
142\end{array}$ & $\begin{array}{l}6.37 \\
3.02 \\
7.00 \\
2.98\end{array}$ & $\begin{array}{l}1958 \\
1959 \\
1960 \\
1961\end{array}$ & $\begin{array}{l}\text { Nov. } 25 \\
\text { July } 20 \\
\text { Apr. } 03 \\
\text { Feb. } 21\end{array}$ & $\begin{array}{r}112 \\
59.0 \\
76.0 \\
2,320\end{array}$ & $\begin{array}{r}2.58 \\
3.53 \\
3.78 \\
10.40\end{array}$ & $\begin{array}{l}1962 \\
1963 \\
1973\end{array}$ & $\begin{array}{l}\text { Dec. } 18 \\
\text { Mar. } 05 \\
\text { June } 05\end{array}$ & $\begin{array}{r}74.0 \\
140 \\
470\end{array}$ & $\begin{array}{l}3.73 \\
4.45 \\
6.50 c\end{array}$ \\
\hline
\end{tabular}

\section{YELLOW RIVER NEAR SNELLVILLE, GEORGIA}

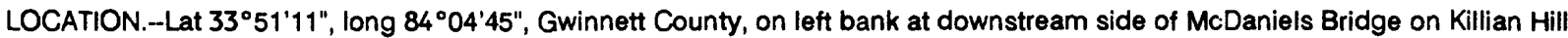
Road, 4 mi downstream from Sweetwater Creek., and $7.5 \mathrm{mi}$ upstream from Stone Mountain Creek, and 3.2 mi west of Snellville.

DRAINAGE AREA.--134 $\mathrm{mi}^{2}$.

GAGE.--Nonrecording prior to Nov. 4, 1952; water-stage recorder Nov. 4, 1952 to Oct. 1, 1971; crest-stage gage from Oct. 1, 1971 to Sept. 30, 1987; water-stage recorder thereafter. Datum of gage is $806.14 \mathrm{ft}$ above sea level (from Georgia Department of Transportation).

STAGE-DISCHARGE RELATION.--Defined by current-meter measurement below $6,500 \mathrm{ft}^{3} / \mathrm{s}$, and above on the basis of contracted opening measurement at $12,600 \mathrm{ft}^{3} / \mathrm{s}$. Bankfull stage and discharge, $13 \mathrm{ft}$ and $14,000 \mathrm{ft}^{3} / \mathrm{s}$.

REMARKS.--Flow for recent years may be slightly affected by increasing amounts of urbanization. Flood of 1948 is thought to be the highest since 1936 based on information at nearby stations. Peak discharge for 1977 is estimated.

\begin{tabular}{|c|c|c|c|c|c|c|c|c|c|c|c|}
\hline $\begin{array}{l}\text { Water } \\
\text { year }\end{array}$ & Date & $\begin{array}{c}\text { Discharge } \\
\left(\mathrm{ft}^{3} / \mathrm{s}\right)\end{array}$ & $\begin{array}{c}\text { Gage } \\
\text { height } \\
\text { (ft) }\end{array}$ & $\begin{array}{l}\text { Water } \\
\text { year }\end{array}$ & Date & $\begin{array}{c}\text { Discharge } \\
\left(\mathrm{ft}^{3} / \mathrm{s}\right)\end{array}$ & $\begin{array}{c}\text { Gage } \\
\text { height } \\
(\mathrm{ft})\end{array}$ & $\begin{array}{l}\text { Water } \\
\text { year }\end{array}$ & Date & $\begin{array}{c}\text { Discharge } \\
\left(\mathrm{ft}^{3} / \mathrm{s}\right)\end{array}$ & $\begin{array}{c}\text { Gage } \\
\text { height } \\
\text { (ft) }\end{array}$ \\
\hline 1943 & Apr. 19 & 4,000 & 13.30 & 1959 & May 31 & 1,400 & 5.70 & 1975 & Mar. 14 & 7,330 & 17.63 \\
\hline 1944 & Mar. 29 & 2,760 & 9.80 & 1960 & Jan. 31 & 2,480 & 9.00 & 1976 & Mar. 17 & 6,450 & 16.72 \\
\hline 1945 & Apr. 25 & 3,000 & 10.50 & 1961 & Feb. 25 & 9,080 & 19.10 & 1977 & Jan. 11 & 1,600 & - \\
\hline 1946 & Mar. 29 & 4,050 & 13.40 & 1962 & Dec. 13 & 3,430 & 11.70 & 1978 & Jan. 26 & 3,310 & 11.27 \\
\hline 1947 & Jan. 20 & 4,370 & 14.10 & 1963 & Apr. 30 & 5,930 & 16.10 & 1979 & Apr. 13 & 6,350 & 16.61 \\
\hline 1948 & Mar. 23 & 2,690 & 9.60 & 1964 & Apr. 07 & 5,640 & 15.70 & 1980 & May 24 & 5,070 & 14.85 \\
\hline 1949 & Nov. 29 & 9,500 & 19.40 & 1965 & Dec. 27 & 1,660 & 6.53 & 1981 & Feb. 11 & 2,140 & 8.27 \\
\hline 1950 & Sept. 08 & 2,030 & 7.65 & 1966 & Feb. 14 & 5,210 & 15.08 & 1982 & Feb. 03 & 3,670 & 12.14 \\
\hline 1951 & Oct. 20 & 1,560 & 6.20 & 1967 & Jan. 09 & 2,840 & 10.02 & 1983 & Apr. 08 & 4,980 & 14.70 \\
\hline 1952 & Dec. 21 & 5,570 & 15.60 & 1968 & Mar. 13 & 2,800 & 9.92 & 1984 & Dec. 06 & 4,420 & 13.65 \\
\hline 1953 & Jan. 10 & 3,180 & 11.00 & 1969 & Apr. 19 & 5,200 & 15.07 & 1985 & July 30 & 3,110 & 10.78 \\
\hline 1954 & Jan. 17 & 4,100 & 13.50 & 1970 & Mar. 20 & 4,170 & 13.34 & 1986 & Feb. - & 1,900 & $-b$ \\
\hline 1955 & Feb. 07 & 3,400 & 11.60 & 1971 & Mar. 03 & 4,240 & 13.28 & 1987 & Mar. 01 & 2,800 & 10.00 \\
\hline 1956 & May 07 & 7,600 & 17.90 & 1972 & Jan. 11 & 5,050 & 14.81 & 1988 & Jan. 20 & 2,660 & 9.47 \\
\hline 1957 & Apr. 05 & 2,970 & 10.40 & 1973 & Mar. 16 & 3,110 & 10.77 & 1989 & July 20 & 3,570 & 11.93 \\
\hline 1958 & Apr. 16 & 1,280 & 5.30 & 1974 & Dec. 31 & 4,370 & 13.54 & 1990 & Mar. 17 & 12,600 & 19.67 \\
\hline
\end{tabular}




\section{ALTAMAHA RIVER BASIN}

\section{GARNER CREEK NEAR SNELLVILLE, GEORGIA}

LOCATION.--Lat $33^{\circ} 51^{\prime} 45^{\prime \prime}$, long $84^{\circ} 05^{\prime} 50^{\prime \prime}$, Gwinnett County, on left bank $100 \mathrm{ft}$ downstream from county highway culvert, 0.9 mi upstream from mouth, and 4.5 mi west of Snellville.

DRAINAGE AREA. $-5.54 \mathrm{mi}^{2}$.

GAGE.--Water-stage recorder. Datum of gage is about $830 \mathrm{ft}$ above sea level (from topographic map).

STAGE-DISCHARGE RELATION.--Defined by current-meter measurement below $72 \mathrm{ft}^{3} / \mathrm{s}$, and extended above on basis of culvert computation at $696 \mathrm{ft}^{3} / \mathrm{s}$ and slope-area measurement at $1,630 \mathrm{ft}^{3} / \mathrm{s}$.

\begin{tabular}{|c|c|c|c|c|c|c|c|c|c|c|c|}
\hline $\begin{array}{l}\text { Water } \\
\text { year }\end{array}$ & Date & $\begin{array}{c}\text { Discharge } \\
\left(\mathrm{ft}^{3} / \mathrm{s}\right)\end{array}$ & $\begin{array}{c}\text { Gage } \\
\text { height } \\
\text { (ft) }\end{array}$ & $\begin{array}{c}\text { Water } \\
\text { year }\end{array}$ & Date & $\begin{array}{c}\text { Discharge } \\
\left(\mathrm{ft}^{3} / \mathrm{s}\right)\end{array}$ & $\begin{array}{c}\text { Gage } \\
\text { height } \\
\text { (ft) }\end{array}$ & $\begin{array}{l}\text { Water } \\
\text { year }\end{array}$ & Date & $\begin{array}{c}\text { Discharge } \\
\left(\mathrm{ft}^{3} / \mathrm{s}\right)\end{array}$ & $\begin{array}{c}\text { Gage } \\
\text { height } \\
(\mathrm{ft})\end{array}$ \\
\hline $\begin{array}{l}1954 \\
1955 \\
1956 \\
1957\end{array}$ & $\begin{array}{l}\text { Jan. } 16 \\
\text { Feb. } 06 \\
\text { Mar. } 16 \\
\text { Apr. } 05\end{array}$ & $\begin{array}{r}94 \\
510 \\
754 \\
390\end{array}$ & $\begin{array}{l}2.98 \\
2.62 \\
3.09 \\
2.35\end{array}$ & $\begin{array}{l}1958 \\
1959 \\
1960 \\
1961\end{array}$ & $\begin{array}{l}\text { Feb. } 27 \\
\text { July } 16 \\
\text { Apr. } 03 \\
\text { Feb. } 25\end{array}$ & $\begin{array}{r}189 \\
232 \\
418 \\
1,630\end{array}$ & $\begin{array}{l}1.74 \\
1.89 \\
2.42 \\
4.30\end{array}$ & $\begin{array}{l}1962 \\
1963 \\
1983\end{array}$ & $\begin{array}{l}\text { Dec. } 18 \\
\text { Apr. } 29 \\
\text { Feb. } 17\end{array}$ & $\begin{array}{r}580 \\
1,530 \\
2,290\end{array}$ & $\begin{array}{l}2.90 \\
4.19 \\
7.620\end{array}$ \\
\hline
\end{tabular}

\section{YELLOW RIVER NEAR COVINGTON, GEORGIA}

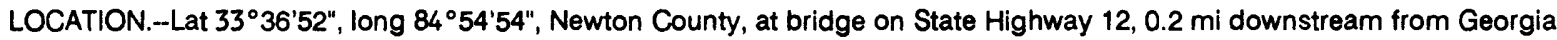
Railroad bridge, $0.5 \mathrm{mi}$ downstream from Gum Creek, and $3.5 \mathrm{mi}$ northwest of Covington.

DRAINAGE AREA.--378 $\mathrm{mi}^{2}$.

GAGE.-Water-stage recorder prior to Sept. 30, 1960; crest-stage gage from Oct. 1, 1960 to Sept. 30, 1965; water-stage recorder

Sept. 19, 1975 to Oct. 27, 1982; crest-stage gage thereafter. Datum of gage is $616.99 \mathrm{ft}$ above sea level (from Georgia

Department of Transportation).

STAGE-DISCHARGE RELATION.--Defined by current-meter measurement below $16,000 \mathrm{ft}^{3} / \mathrm{s}$, and extended above on basis of slope-conveyance study. Bankfull stage and discharge, $9 \mathrm{ft}$ and $2,500 \mathrm{ft}^{3} / \mathrm{s}$.

HISTORICAL DATA.--Flood stage of April 7, 1936, based on information furnished by the Georgia Department of Transportation.

The flood of April 7, 1936 was the highest since 1919, based on information from nearby stations.

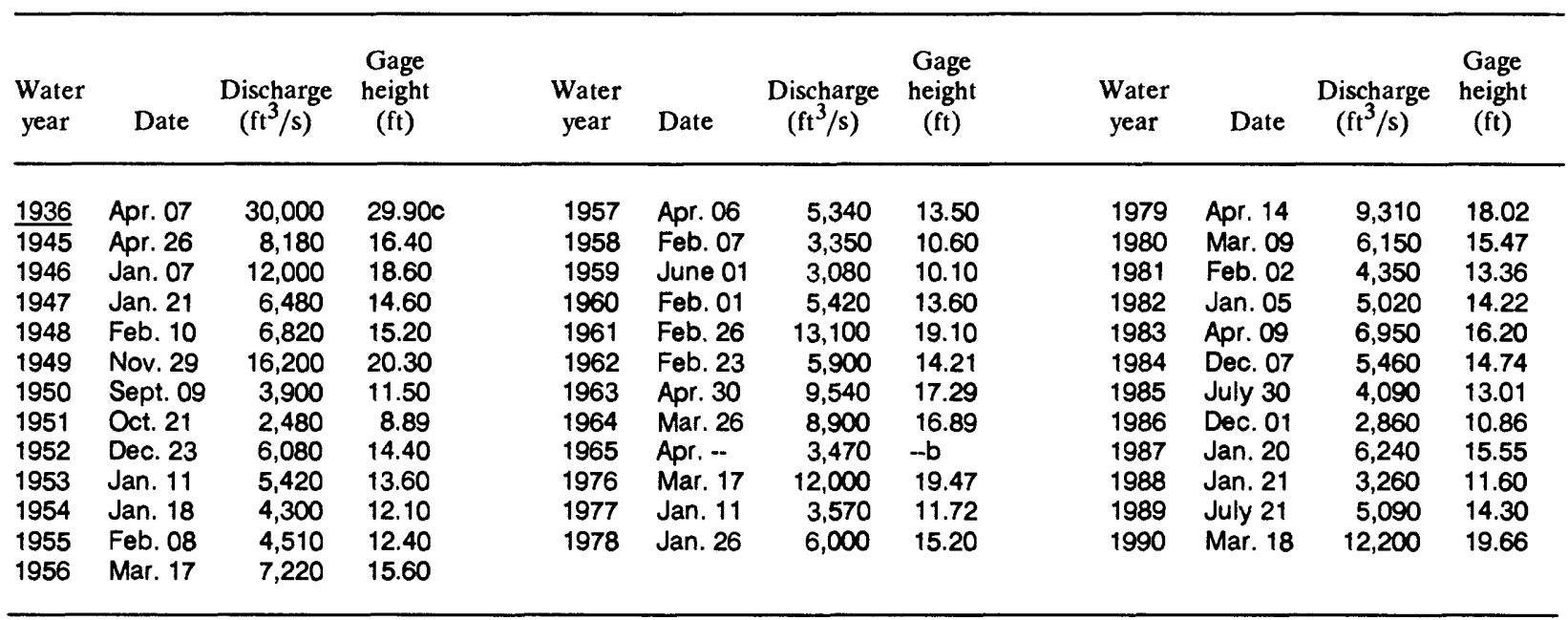




\section{ALTAMAHA RIVER BASIN}

02208050 ALCOVY RIVER NEAR LAWRENCEVILLE, GEORGIA

LOCATION.--Lat 33 $58^{\prime} 40^{\prime \prime}$, long $83^{\circ} 56^{\prime} 23^{\prime \prime}$, Gwinnett County, at U.S. Highway 29,3 mi northeast of Lawrenceville.

DRAINAGE AREA. $-9.97 \mathrm{mi}^{2}$.

GAGE.--Crest-stage gage prior to Nov. 15, 1967; flood-stage recorder Nov. 15, 1967 to Apr. 2, 1968; flood-stage/rainfall recorder thereafter. Datum of gage is about $920 \mathrm{ft}$ above sea level (from topographic map).

STAGE-DISCHARGE RELATION.--Defined by current-meter measurement below $900 \mathrm{ft}^{3} / \mathrm{s}$, and extended above on basis of straight-line extension.

\begin{tabular}{|c|c|c|c|c|c|c|c|c|c|c|c|}
\hline $\begin{array}{l}\text { Water } \\
\text { year }\end{array}$ & Date & $\begin{array}{c}\text { Discharge } \\
\left(\mathbf{f t}^{3} / \mathrm{s}\right)\end{array}$ & $\begin{array}{c}\text { Gage } \\
\text { height } \\
\text { (ft) }\end{array}$ & $\begin{array}{l}\text { Water } \\
\text { year }\end{array}$ & Date & $\begin{array}{c}\text { Discharge } \\
\left(\mathrm{ft}^{3} / \mathrm{s}\right)\end{array}$ & $\begin{array}{c}\text { Gage } \\
\text { height } \\
\text { (ft) }\end{array}$ & $\begin{array}{l}\text { Water } \\
\text { year }\end{array}$ & Date & $\begin{array}{c}\text { Discharge } \\
\left(\mathrm{ft}^{3} / \mathrm{s}\right)\end{array}$ & $\begin{array}{c}\text { Gage } \\
\text { height } \\
\text { (ft) }\end{array}$ \\
\hline $\begin{array}{l}1965 \\
1966 \\
1967 \\
1968\end{array}$ & $\begin{array}{l}\text { Dec. } 25 \\
\text { Mar. } 04 \\
\text { Apr. } 26 \\
\text { Mar. } 12\end{array}$ & $\begin{array}{r}640 \\
893 \\
660 \\
520\end{array}$ & $\begin{array}{l}3.54 \\
4.09 \\
3.40 \\
3.12\end{array}$ & $\begin{array}{l}1969 \\
1970 \\
1971\end{array}$ & $\begin{array}{l}\text { Apr. } 18 \\
\text { Mar. } 20 \\
\text { Mar. } 03\end{array}$ & $\begin{array}{r}1,620 \\
705 \\
734\end{array}$ & $\begin{array}{l}4.92 \\
3.79 \\
3.84\end{array}$ & $\begin{array}{l}1972 \\
1973 \\
1974\end{array}$ & $\begin{array}{l}\text { Jan. } 10 \\
\text { Mar. } 16 \\
\text { Dec. } 31\end{array}$ & $\begin{array}{r}1,010 \\
728 \\
1,080\end{array}$ & $\begin{array}{l}4.26 \\
3.83 \\
4.35\end{array}$ \\
\hline
\end{tabular}

\section{BEAVERDAM CREEK TRIBUTARY AT BOLD SPRINGS, GEORGIA}

LOCATION.--Lat $33^{\circ} 53^{\prime} 59^{\prime \prime}$, long $83^{\circ} 47^{\prime} 36^{\prime \prime}$, Walton County, at culvert on secondary road 917, 0.6 mi east of Bold Springs. DRAINAGE AREA.--1.03 $\mathrm{mi}^{2}$.

GAGE.--Flood-stage/rainfall recorder. Datum of gage is about $830 \mathrm{ft}$ above sea level (from topographic map).

STAGE-DISCHARGE RELATION.--Defined by current-meter measurement below $205 \mathrm{ft}^{3} / \mathrm{s}$, and extended above on basis of culvert computations.

\begin{tabular}{|c|c|c|c|c|c|c|c|c|c|c|c|}
\hline $\begin{array}{l}\text { Water } \\
\text { year }\end{array}$ & Date & $\begin{array}{c}\text { Discharge } \\
\left(\mathrm{ft}^{3} / \mathrm{s}\right)\end{array}$ & $\begin{array}{c}\text { Gage } \\
\text { height } \\
\text { (ft) }\end{array}$ & $\begin{array}{l}\text { Water } \\
\text { year }\end{array}$ & Date & $\begin{array}{c}\text { Discharge } \\
\left(\mathrm{ft}^{3} / \mathrm{s}\right)\end{array}$ & $\begin{array}{c}\text { Gage } \\
\text { height } \\
\text { (ft) }\end{array}$ & $\begin{array}{l}\text { Water } \\
\text { year }\end{array}$ & Date & $\begin{array}{c}\text { Discharge } \\
\left(\mathrm{ft}^{3} / \mathrm{s}\right)\end{array}$ & $\begin{array}{c}\text { Gage } \\
\text { height } \\
\text { (ft) }\end{array}$ \\
\hline $\begin{array}{l}1965 \\
1966 \\
1967 \\
1968\end{array}$ & $\begin{array}{l}\text { Dec. - } \\
\text { Mar. } 04 \\
\text { July } 25 \\
\text { Mar. } 12\end{array}$ & $\begin{array}{r}50.0 \\
291 \\
45 \\
205\end{array}$ & $\begin{array}{l}--b \\
5.11 \\
1.63 \\
4.16\end{array}$ & $\begin{array}{l}1969 \\
1970 \\
1971 \\
1972\end{array}$ & $\begin{array}{l}\text { Jan. } 20 \\
\text { Mar. } 19 \\
\text { Mar. } 03 \\
\text { Jan. } 10\end{array}$ & $\begin{array}{r}295 \\
72 \\
122 \\
124\end{array}$ & $\begin{array}{l}5.15 \\
2.20 \\
3.03 \\
3.05\end{array}$ & $\begin{array}{l}1973 \\
1974 \\
1975\end{array}$ & $\begin{array}{l}\text { Mar. } 16 \\
\text { Apr. } 04 \\
\text { Mar. } 13\end{array}$ & $\begin{array}{l}165 \\
130 \\
152\end{array}$ & $\begin{array}{l}3.64 \\
3.15 \\
3.46\end{array}$ \\
\hline
\end{tabular}

\section{ALCOV RIVER ABOVE COVINGTON, GEORGIA}

LOCATION.--Lat $33^{\circ} 38^{\prime} 24^{\prime \prime}$, long $83^{\circ} 46^{\prime} 45^{\prime \prime}$, Newton County, at bridge on Alcovy Road, $400 \mathrm{ft}$ downstream from city of Covington waterworks intake structure, $200 \mathrm{ft}$ downstream from Strouds Creek, $200 \mathrm{ft}$ upstream from Georgia Railroad bridge, and $6 \mathrm{mi}$ northeast of Covington.

DRAINAGE AREA. $-185 \mathrm{mi}^{2}$, approximately, and includes that of Strouds Creek.

GAGE.-Water-stage recorder. Datum of gage is $646.10 \mathrm{ft}$ above sea level (levels from the Global Positioning System). Prior to

Oct. 1, 1986, at site $400 \mathrm{ft}$ upstream at same datum.

STAGE-DISCHARGE RELATION.-Defined by current-meter measurement below $7,370 \mathrm{ft}^{3} / \mathrm{s}$.

\begin{tabular}{|c|c|c|c|c|c|c|c|c|c|c|c|}
\hline $\begin{array}{l}\text { Water } \\
\text { year }\end{array}$ & Date & $\begin{array}{c}\text { Discharge } \\
\left(\mathrm{ft}^{3} / \mathrm{s}\right)\end{array}$ & $\begin{array}{c}\text { Gage } \\
\text { height } \\
\text { (ft) }\end{array}$ & $\begin{array}{l}\text { Water } \\
\text { year }\end{array}$ & Date & $\begin{array}{c}\text { Discharge } \\
\left(\mathrm{ft}^{3} / \mathrm{s}\right)\end{array}$ & $\begin{array}{c}\text { Gage } \\
\text { height } \\
\text { (ft) }\end{array}$ & $\begin{array}{c}\text { Water } \\
\text { year }\end{array}$ & Date & $\begin{array}{c}\text { Discharge } \\
\left(\mathrm{ft}^{3} / \mathrm{s}\right)\end{array}$ & $\begin{array}{c}\text { Gage } \\
\text { height } \\
\text { (ft) }\end{array}$ \\
\hline $\begin{array}{l}1973 \\
1974 \\
1975 \\
1976 \\
1977 \\
1978\end{array}$ & $\begin{array}{l}\text { Dec. } 16 \\
\text { Jan. } 03 \\
\text { Mar. } 15 \\
\text { Mar. } 16 \\
\text { Jan. } 11 \\
\text { Jan. } 26\end{array}$ & $\begin{array}{l}3,220 \\
2,020 \\
4,140 \\
6,530 \\
1,240 \\
2,970\end{array}$ & $\begin{array}{r}12.05 \\
10.64 \\
12.96 \\
14.79 \\
8.90 \\
11.78\end{array}$ & $\begin{array}{l}1979 \\
1980 \\
1981 \\
1982 \\
1983 \\
1984\end{array}$ & $\begin{array}{l}\text { Apr. } 14 \\
\text { May } 21 \\
\text { Feb. } 02 \\
\text { Feb. } 05 \\
\text { Apr. } 10 \\
\text { Aug. } 01\end{array}$ & $\begin{array}{l}4,280 \\
3,580 \\
1,730 \\
1,940 \\
3,340 \\
3,080\end{array}$ & $\begin{array}{l}12.99 \\
12.09 \\
10.15 \\
10.30 \\
12.04 \\
11.76\end{array}$ & $\begin{array}{l}1985 \\
1986 \\
1987 \\
1988 \\
1989 \\
1990\end{array}$ & $\begin{array}{l}\text { Feb. } 06 \\
\text { Dec. } 01 \\
\text { Jan. } 20 \\
\text { Sept.12 } \\
\text { July } 22 \\
\text { Mar. } 18\end{array}$ & $\begin{array}{l}1,340 \\
1,490 \\
2,570 \\
1,480 \\
1,780 \\
7,620\end{array}$ & $\begin{array}{r}9.20 \\
9.51 \\
10.52 \\
9.25 \\
9.72 \\
14.49\end{array}$ \\
\hline
\end{tabular}




\section{ALTAMAHA RIVER BASIN}

\section{ALCOW RIVER BELOW COVINGTON, GEORGIA}

LOCATION.--Lat $33^{\circ} 30^{\prime} 21^{\prime \prime}$, long $83^{\circ} 49^{\prime} 30^{\prime \prime}$, Newton County, near bridge on county road $600 \mathrm{ft}$ downstream from Henderson Mill, 4 mi downstream from Central of Georgia Railway bridge, and 7 mi southeast of Covington.

DRAINAGE AREA.--244 $\mathrm{mi}^{2}$.

GAGE.--Nonrecording prior to June 27, 1944; Water-stage recorder June 27, 1944, to Jan. 17, 1949; crest-stage gage thereafter.

Prior to June 27, 1944, at site $300 \mathrm{ft}$ upstream at datum about $0.7 \mathrm{ft}$ lower. All stages given adjusted to present datum.

Datum of gage is $600.78 \mathrm{ft}$ above sea level (levels by the U.S. Army Corps of Engineers).

STAGE-DISCHARGE RELATION.--Defined by current-meter measurement below $7,200 \mathrm{ft}^{3} / \mathrm{s}$, and extended above on the basis of slope-conveyance study at $12,400 \mathrm{ft}^{3} / \mathrm{s}$. Bankfull stage and discharge, $10 \mathrm{ft}$ and $2,500 \mathrm{ft}^{3} / \mathrm{s}$.

HISTORICAL DATA.--The peak stage and date of great floods since 1887 are marked on the wall of Henderson Mill, which is $600 \mathrm{ft}$ above gage. These marks have been converted to present site and gage datum and are listed in the tabulation of annual peaks for 1887,1920 , and 1936 .

REMARKS.--Records for 1929-32 from the U.S. Army Corps of Engineers. Peak discharge for 1929-32 and 1950-51 are estimated.

\begin{tabular}{|c|c|c|c|c|c|c|c|c|c|c|c|}
\hline $\begin{array}{l}\text { Water } \\
\text { year }\end{array}$ & Date & $\begin{array}{c}\text { Discharge } \\
\left(\mathrm{ft}^{3} / \mathrm{s}\right)\end{array}$ & $\begin{array}{c}\text { Gage } \\
\text { height } \\
\text { (ft) }\end{array}$ & $\begin{array}{l}\text { Water } \\
\text { year }\end{array}$ & Date & $\begin{array}{c}\text { Discharge } \\
\left(\mathrm{ft}^{3} / \mathrm{s}\right)\end{array}$ & $\begin{array}{c}\text { Gage } \\
\text { height } \\
\text { (ft) }\end{array}$ & $\begin{array}{l}\text { Water } \\
\text { year }\end{array}$ & Date & $\begin{array}{c}\text { Discharge } \\
\left(\mathrm{ft}^{3} / \mathrm{s}\right)\end{array}$ & $\begin{array}{c}\text { Gage } \\
\text { height } \\
\text { (ft) }\end{array}$ \\
\hline $\begin{array}{l}\frac{1887}{1920} \\
1929 \\
1930 \\
1931 \\
\frac{1932}{1936} \\
1945 \\
1946 \\
1947\end{array}$ & $\begin{array}{l}\text { July } 30 \\
\text { Dec. } 10 \\
\text { Mar. } 06 \\
\text { Oct. } 03 \\
\text { May } 08 \\
\text { Feb. } 23 \\
\text { Apr. } 16 \\
\text { Apr. } 26 \\
\text { Jan. } 08 \\
\text { Jan. } 21\end{array}$ & $\begin{array}{r}12,400 \\
9,460 \\
8,410 \\
4,590 \\
1,410 \\
2,080 \\
9,040 \\
4,470 \\
7,520 \\
3,600\end{array}$ & $\begin{array}{l}27.20 c \\
23.00 c \\
- \\
- \\
- \\
- \\
22.40 c \\
14.40 \\
20.20 \\
12.70\end{array}$ & $\begin{array}{l}1948 \\
1949 \\
1950 \\
1951 \\
1952 \\
1953 \\
1954 \\
1955 \\
1956\end{array}$ & $\begin{array}{l}\text { Feb. } 10 \\
\text { Nov. } 29 \\
\text { Sept.09 } \\
\text { Oct. } 21 \\
\text { Mar. -- } \\
\text { Jan. -- } \\
\text { Jan. } 22 \\
\text { June } 00 \\
\text { Mar. -- }\end{array}$ & $\begin{array}{r}3,980 \\
8,270 \\
1,300 \\
800 \\
2,980 \\
2,160 \\
1,440 \\
1,560 \\
2,700\end{array}$ & $\begin{array}{r}13.80 \\
21.30 \\
-- \\
- \\
11.50 \\
9.26 \\
7.19 \\
7.61 \\
10.80\end{array}$ & $\begin{array}{l}1957 \\
1958 \\
1959 \\
1960 \\
1961 \\
1962 \\
1963 \\
1964 \\
1965\end{array}$ & $\begin{array}{l}\text { Apr. - } \\
\text { Feb. } 07 \\
\text { May } 31 \\
\text { Jan. } 30 \\
\text { Feb. } 26 \\
\text { Feb. } 23 \\
\text { June } 28 \\
\text { Apr. } 06 \\
\text { Mar. } 17\end{array}$ & $\begin{array}{l}2,700 \\
1,530 \\
1,700 \\
2,260 \\
5,540 \\
2,780 \\
4,790 \\
5,000 \\
1,350\end{array}$ & $\begin{array}{r}10.80 \\
7.47 \\
8.02 \\
9.56 \\
16.88 \\
10.96 \\
15.51 \\
15.72 \\
6.89\end{array}$ \\
\hline
\end{tabular}

\section{OCMULGEE RIVER NEAR JACKSON, GEORGIA}

LOCATION.--Lat $33^{\circ} 18^{\prime} 27^{\prime \prime}$, long 83 $83^{\circ} 18^{\prime \prime}$, Butts County, on right bank $500 \mathrm{ft}$ upstream from bridge on State Highway $16,0.5 \mathrm{mi}$ upstream from Yellow Water Creek, 1.0 mi downstream from Lloyd Shoals Dam, and 7 mi east of Jackson. DRAINAGE AREA.--1,420 $\mathrm{mi}^{2}$, approximately.

GAGE.--Nonrecording, 1906-12, 1914-15; water-stage recorder, Aug. 3, 1939 to Sept. 30, 1960, Oct. 1, 1975 to Sept. 30,1982 , and March 1987 thereafter. Crest-stage gage Oct. 1, 1960 to Sept. 30, 1965. Datum of gage is $419.29 \mathrm{ft}$ above sea level (from river profile study), supplentary adjustment of 1936.

STAGE-DISCHARGE RELATION.--Defined by current-meter measurements below $46,000 \mathrm{ft}^{3} / \mathrm{s}$, and extended above on basis of flow over Lloyd Shoals Dam at $69,000 \mathrm{ft}^{3} / \mathrm{s}$. Bankfull stage and discharge, $14 \mathrm{ft}$ and $24,000 \mathrm{ft}^{3} / \mathrm{s}$.

REMARKS.-Peak discharges are regulated by storage in Lloyd Shoals Reservoir (maximum flood-control storage, 78,000 acre-ft), which was put in operation in 1910 . Only the smaller peaks are considered to be significantly regulated. Because of the regulation and poor stage-discharge relation, annual peaks for the period 1906-15 are not presented in this report. The flood of 1920 is thought to be the highest since 1887 , based on information at nearby stations.

\begin{tabular}{|c|c|c|c|c|c|c|c|c|c|c|c|}
\hline $\begin{array}{l}\text { Water } \\
\text { year }\end{array}$ & Date & $\begin{array}{c}\text { Discharge } \\
\left(\mathrm{ft}^{3} / \mathrm{s}\right)\end{array}$ & $\begin{array}{c}\text { Gage } \\
\text { height } \\
\text { (ft) }\end{array}$ & $\begin{array}{l}\text { Water } \\
\text { year }\end{array}$ & Date & $\begin{array}{c}\text { Discharge } \\
\left(\mathrm{ft}^{3} / \mathrm{s}\right)\end{array}$ & $\begin{array}{c}\text { Gage } \\
\text { height } \\
\text { (ft) }\end{array}$ & $\begin{array}{l}\text { Water } \\
\text { year }\end{array}$ & Date & $\begin{array}{l}\text { Discharge } \\
\left(\mathrm{ft}^{3} / \mathrm{s}\right)\end{array}$ & $\begin{array}{c}\text { Gage } \\
\text { height } \\
\text { (ft) }\end{array}$ \\
\hline 1912 & Mar. 16 & 45,500 & $20.80 c$ & 1951 & Feb. -- & 3,710 & 5.95 & 1964 & May 03 & 27,000 & 15.06 \\
\hline$\frac{1920}{1940}$ & $\begin{array}{l}\text { Dec. } 11 \\
\text { July } 14\end{array}$ & $\begin{array}{l}69,000 \\
11,900\end{array}$ & $\begin{array}{l}26.80 \mathrm{c} \\
10.00\end{array}$ & $\begin{array}{l}1952 \\
1953\end{array}$ & $\begin{array}{l}\text { Mar. } 04 \\
\text { May } 01\end{array}$ & $\begin{array}{l}27,100 \\
11,500\end{array}$ & $\begin{array}{r}15.10 \\
9.26\end{array}$ & $\frac{1965}{1976}$ & $\begin{array}{l}\text { Mar. } 18 \\
\text { Mar. } 18\end{array}$ & $\begin{array}{l}11,200 \\
41,500\end{array}$ & $\begin{array}{r}9.12 \\
19.61\end{array}$ \\
\hline 1941 & Mar. 27 & 3,300 & 5.87 & 1954 & Dec. 13 & 9,080 & 8.20 & 1977 & Mar. 23 & 11,600 & 9.24 \\
\hline 1942 & Mar. 21 & 45,500 & 20.80 & 1955 & Feb. 09 & 6,250 & 7.09 & 1978 & Jan. 26 & 26,100 & 14.75 \\
\hline 1943 & Jan. 19 & 27,700 & 15.30 & 1956 & Mar. 18 & 19,600 & $\begin{array}{l}12.40 \\
1250\end{array}$ & 1979 & Apr. 15 & 31,900 & 16.67 \\
\hline $\begin{array}{l}1944 \\
1945\end{array}$ & $\begin{array}{l}\text { Mar. } 23 \\
\text { Apr. } 26\end{array}$ & $\begin{array}{l}21,500 \\
30,100\end{array}$ & $\begin{array}{l}13.20 \\
16.10\end{array}$ & $\begin{array}{l}1957 \\
1958\end{array}$ & $\begin{array}{l}\text { Apr. } 05 \\
\text { Feb. } 07\end{array}$ & $\begin{array}{l}19,800 \\
17,200\end{array}$ & $\begin{array}{l}12.50 \\
11.50\end{array}$ & $\begin{array}{l}1980 \\
1981\end{array}$ & Feb. 11 & $\begin{array}{l}20,000 \\
17,200\end{array}$ & $\begin{array}{l}12.71 \\
11.54\end{array}$ \\
\hline 1946 & Jan. 08 & 45,500 & 20.80 & 1959 & June 02 & 28,000 & 15.40 & 1982 & Feb. 04 & 17,900 & 11.77 \\
\hline 1947 & Jan. 21 & $\begin{array}{l}22,900 \\
20,900\end{array}$ & $\begin{array}{l}13.60 \\
12.90\end{array}$ & 1960 & Mar. 30 & $\begin{array}{l}17,500 \\
43,100\end{array}$ & 11.60 & $\begin{array}{l}\overline{1988} \\
1989\end{array}$ & Feb. 05 & 13,100 & $\begin{array}{r}9.85 \\
10.2 n\end{array}$ \\
\hline 1949 & $\begin{array}{l}\text { Neo. } 10 \\
\text { Nov. } 28\end{array}$ & $\begin{array}{l}20,900 \\
56,600\end{array}$ & $\begin{array}{l}12.90 \\
23.90\end{array}$ & $\begin{array}{l}1961 \\
1962\end{array}$ & Feb. 23 & $\begin{array}{l}43,100 \\
21,200\end{array}$ & $\begin{array}{l}20.10 \\
12.95\end{array}$ & 1990 & Mar. 18 & 46,300 & 20.96 \\
\hline 1950 & Sept. 09 & 12,000 & 9.35 & 1963 & Apr. 30 & 22,300 & 13.44 & & & & \\
\hline
\end{tabular}




\section{ALTAMAHA RIVER BASIN}

\section{TOWALIGA RIVER NEAR JACKSON, GEORGIA}

LOCATION.--Lat $33^{\circ} 15^{\prime} 50^{\prime \prime}$ long $84^{\circ} 04^{\prime} 17^{\prime \prime}$, Butts County, at bridge on State Highway 16, 6.5 mi west of Jackson.

DRAINAGE AREA.--105 $\mathrm{mi}^{2}$, approximately.

GAGE.--Water-stage recorder prior to Oct. 1, 1971; crest-stage gage thereafter. Datum of gage is $595.54 \mathrm{ft}$ above sea level (levels from Georgia Department of Transportation).

STAGE-DISCHARGE RELATION.--Defined by current-meter measurements below $7,400 \mathrm{ft}^{3} / \mathrm{s}$, and extended above on basis of straight-line extension. Bankfull stage and discharge, $8 \mathrm{ft}$ and $1,000 \mathrm{ft}^{3} / \mathrm{s}$.

REMARKS.--Flood of 1990 is thought to be the highest since 1919 , based on information from local residents.

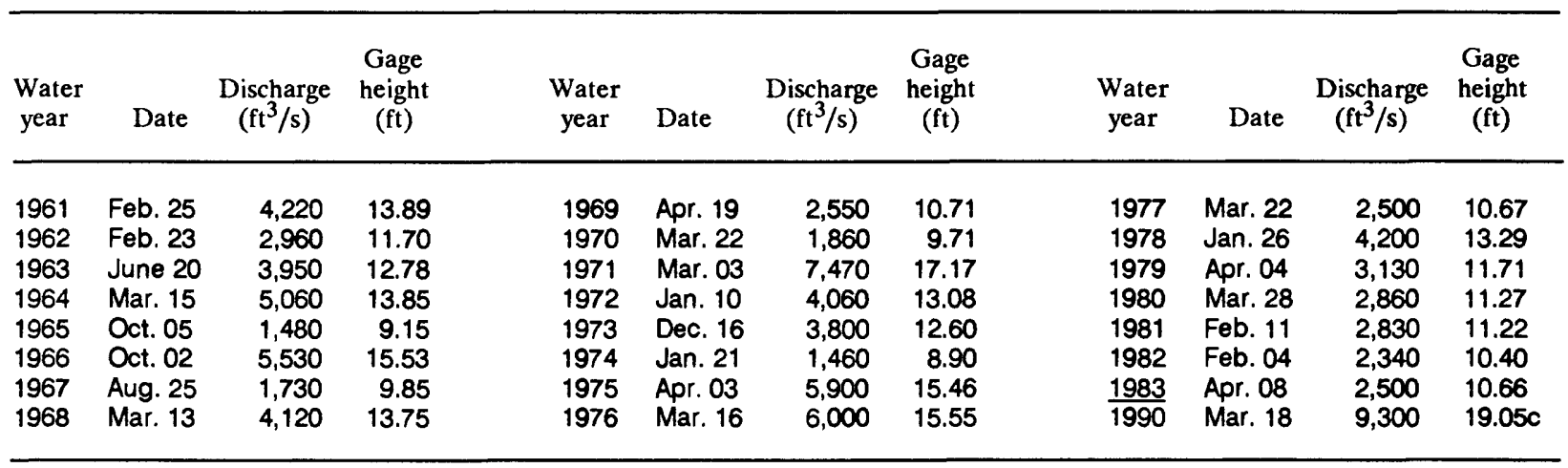

\section{BIG TOWALIGA CREEK NEAR BARNESVILLE, GEORGIA}

LOCATION.--Lat $33^{\circ} 04^{\prime} 20^{\prime \prime}$, long $84^{\circ} 11^{\prime} 04^{\prime \prime}$, Lamar County, at culvert on county road, 6.2 mi upstream from Towaliga River, and 2.1 mi northwest of Barnesville.

DRAINAGE AREA.--2.36 $\mathrm{mi}^{2}$.

GAGE.--Flood-stage/rainfall recorder prior to Feb. 12, 1971; water-stage and rainfall recorders from Feb. 13, 1971 to Sept. 30, 1974, water-stage recorder thereafter. Datum of gage is about $690 \mathrm{ft}$ above sea level (from topographic map).

STAGE-DISCHARGE RELATION.--Defined by current-meter measurements below $200 \mathrm{ft}^{3} / \mathrm{s}$, and extended above on basis of culvert computations.

\begin{tabular}{|c|c|c|c|c|c|c|c|c|c|c|c|}
\hline $\begin{array}{l}\text { Water } \\
\text { year }\end{array}$ & Date & $\begin{array}{c}\text { Discharge } \\
\left(\mathrm{ft}^{3} / \mathrm{s}\right)\end{array}$ & $\begin{array}{c}\text { Gage } \\
\text { height } \\
\text { (ft) }\end{array}$ & $\begin{array}{l}\text { Water } \\
\text { year }\end{array}$ & Date & $\begin{array}{c}\text { Discharge } \\
\left(\mathrm{ft}^{3} / \mathrm{s}\right)\end{array}$ & $\begin{array}{c}\text { Gage } \\
\text { height } \\
\text { (ft) }\end{array}$ & $\begin{array}{l}\text { Water } \\
\text { year }\end{array}$ & Date & $\begin{array}{c}\text { Discharge } \\
\left(\mathrm{ft}^{3} / \mathrm{s}\right)\end{array}$ & $\begin{array}{c}\text { Gage } \\
\text { height } \\
\text { (ft) }\end{array}$ \\
\hline 1969 & Apr. 18 & 183 & 4.64 & 1974 & Apr. 04 & 463 & 6.57 & 1978 & Nov. 05 & 761 & 8.48 \\
\hline 1970 & Mar. 20 & 282 & 5.40 & 1975 & Apr. 03 & 384 & 6.39 & 1979 & Feb. 24 & 273 & 5.65 \\
\hline 1971 & July 30 & 562 & 7.13 & 1976 & Mar. 13 & 195 & 5.06 & 1980 & Mar. 08 & 949 & 9.42 \\
\hline 1972 & June 27 & 218 & 4.93 & 1977 & July 26 & 236 & 5.26 & 1981 & Feb. 11 & 178 & 4.93 \\
\hline 1973 & May 28 & 316 & 5.64 & & & & & & & & \\
\hline
\end{tabular}


LOCATION.-Lat $33^{\circ} 07^{\prime} 17^{\prime \prime}$, long $83^{\circ} 56^{\prime} 36^{\prime \prime}$, Monroe County, at bridge on State Highway 42, 0.2 mi downstream from Rocky Creek, $1.5 \mathrm{mi}$ downstream from Little Towaliga River, and 6 mi north of Forsyth.

DRAINAGE AREA.--315 $\mathrm{mi}^{2}$, approximately.

GAGE.--Water-stage recorder prior to Jan. 1, 1950; crest-stage gage thereafter. Feb. 1, 1929 to Apr. 30, 1932, at site $0.5 \mathrm{mi}$ downstream at different datum.Datum of gage is $409.7 \mathrm{ft}$ above sea level (from U.S. Army Corps of Engineers profile).

STAGE-DISCHARGE RELATION.--Defined by current-meter measurements at former site. Defined by current-meter measurements below $7,000 \mathrm{ft}^{3} / \mathrm{s}$ at present site, and extended above on the basis of records at former site. Bankfull stage and discharge, $13 \mathrm{ft}$ and $5,000 \mathrm{ft}^{3} / \mathrm{s}$.

HISTORICAL DATA.--Flood of March 1929 is highest flood since 1919, based on information from nearby stations. Flood-stage information of Feb. 1966 furnished by the Georgia Department of Transportation.

REMARKS.--Records for 1929-31 are daily peak discharges (from U.S. Army Corps of Engineers). Peak discharges for 1966 and 1990 are estimated.

\begin{tabular}{|c|c|c|c|c|c|c|c|c|c|c|c|}
\hline $\begin{array}{l}\text { Water } \\
\text { year }\end{array}$ & Date & $\begin{array}{c}\text { Discharge } \\
\left(\mathrm{ft}^{3} / \mathrm{s}\right)\end{array}$ & $\begin{array}{c}\text { Gage } \\
\text { height } \\
\text { (ft) }\end{array}$ & $\begin{array}{l}\text { Water } \\
\text { year }\end{array}$ & Date & $\begin{array}{c}\text { Discharge } \\
\left(\mathrm{ft}^{3} / \mathrm{s}\right)\end{array}$ & $\begin{array}{c}\text { Gage } \\
\text { height } \\
\text { (ft) }\end{array}$ & $\begin{array}{l}\text { Water } \\
\text { year }\end{array}$ & Date & $\begin{array}{c}\text { Discharge } \\
\left(\mathrm{ft}^{3} / \mathrm{s}\right)\end{array}$ & $\begin{array}{c}\text { Gage } \\
\text { height } \\
\text { (ft) }\end{array}$ \\
\hline 1929 & Mar. 15 & 15,900 & - & 1951 & Nov. -- & 4,000 & $--b$ & 1960 & Apr. -- & 4,000 & $--b$ \\
\hline 1930 & Oct. 02 & 13,500 & - & 1952 & Mar. -- & 10,900 & 19.28 & 1961 & Feb. 26 & 9,500 & 17.99 \\
\hline 1931 & Nov. 17 & $\underline{3,980}$ & $=$ & 1953 & Apr. 30 & 4,590 & 12.25 & 1962 & Feb. -- & 4,000 & $--b$ \\
\hline$\overline{1945}$ & $\overline{\text { Apr. } 26}$ & $\overline{7,320}$ & $\overline{15} .80$ & 1954 & Feb. -- & 4,000 & $--b$ & 1963 & Mar. 31 & 6,780 & 15.15 \\
\hline 1946 & Jan. 07 & 7,700 & 16.20 & 1955 & Jan. -- & 4,000 & $-b$ & 1964 & Apr. 06 & 8,900 & 17.45 \\
\hline 1947 & Mar. 07 & 7,900 & 16.40 & 1956 & Sept.27 & 5,520 & 13.63 & 1965 & Dec. 26 & 4,410 & 11.88 \\
\hline 1948 & Feb. 10 & 4,110 & 11.40 & 1957 & Dec. 24 & 6,780 & 15.21 & $\underline{1966}$ & Feb. 13 & 15,000 & 22.15 \\
\hline 1949 & Nov. 27 & 13,200 & 20.90 & 1958 & Nov. -- & 4,650 & 12.30 & $\overline{1990}$ & Mar. 18 & 14,000 & $21.63 c$ \\
\hline 1950 & July 00 & 4,000 & $--b$ & 1959 & May 30 & 8,700 & 17.18 & & & & \\
\hline
\end{tabular}

\section{OCMULGEE RIVER AT JULIETTE, GEORGIA}

LOCATION.--Lat $33^{\circ} 05^{\prime} 50^{\prime \prime}$, long $83^{\circ} 47^{\prime} 10^{\prime \prime}$, Jones County, on left bank 0.9 mi downstream from Juliette Mills at Julliette, and 2.5 mi downstream from Towaliga River.

DRAINAGE AREA.--1,960 $\mathrm{mi}^{2}$.

GAGE.--Water-stage recorder from June 1916 to Sept. 1921, July 1974 to May 1988 . Datum of gage is $340.97 \mathrm{ft}$ above sea level (levels by Georgia Department of Transportation).

STAGE-DISCHARGE RELATION.--Defined by current-meter measurements below $44,000 \mathrm{ft}^{3} / \mathrm{s}$, and extended above on the basis of straight-line extension.

HISTORICAL DATA.--Flood stage of 1886 based on information furnished by local residents.

REMARKS.--The smaller peak discharges are regulated by storage in Floyd Shoals Reservoir (maximum flood-control storage, 78,000 acre-ft), which was put into operation in 1910. Flood stage of November 1948 and March 1990 flood from floodmarks.

\begin{tabular}{|c|c|c|c|c|c|c|c|c|c|c|c|}
\hline $\begin{array}{l}\text { Water } \\
\text { year }\end{array}$ & Date & $\begin{array}{c}\text { Discharge } \\
\left(\mathrm{ft}^{3} / \mathrm{s}\right)\end{array}$ & $\begin{array}{c}\text { Gage } \\
\text { height } \\
\text { (ft) }\end{array}$ & $\begin{array}{l}\text { Water } \\
\text { year }\end{array}$ & Date & $\begin{array}{c}\text { Discharge } \\
\left(\mathrm{ft}^{3} / \mathrm{s}\right)\end{array}$ & $\begin{array}{c}\text { Gage } \\
\text { height } \\
\text { (ft) }\end{array}$ & $\begin{array}{l}\text { Water } \\
\text { year }\end{array}$ & Date & $\begin{array}{c}\text { Discharge } \\
\left(\mathrm{ft}^{3} / \mathrm{s}\right)\end{array}$ & $\begin{array}{c}\text { Gage } \\
\text { height } \\
\text { (ft) }\end{array}$ \\
\hline$\underline{1886}$ & May 00 & 73,000 & $32.00 \mathrm{c}$ & 1975 & Apr. 13 & 40,000 & 23.92 & 1983 & Apr. 09 & 28,100 & 19.95 \\
\hline 1916 & July 10 & 49,800 & 26.40 & 1976 & Mar. 18 & 44,600 & 24.89 & 1984 & Aug. 02 & 26,100 & 19.23 \\
\hline 1917 & Mar. 27 & 27,600 & 20.20 & 1977 & Mar. 23 & 15,800 & 14.39 & 1985 & Feb. 07 & 21,000 & 17.02 \\
\hline 1918 & Jan. 30 & 15,300 & 14.20 & 1978 & Jan. 26 & 34,400 & 22.32 & 1986 & Mar. 13 & 7,240 & 9.37 \\
\hline 1919 & Dec. 23 & 28,100 & 20.40 & 1979 & Apr. 16 & 29,900 & 20.97 & 1987 & Mar. 02 & 18,300 & 15.71 \\
\hline 1920 & Dec. 11 & 67,400 & 30.80 & 1980 & Mar. 30 & 24,300 & 18.63 & $\underline{1988}$ & Feb. 05 & 12,900 & 12.79 \\
\hline$\underline{1921}$ & Feb. 11 & 26,000 & 22.80 & 1981 & Feb. 02 & 21,600 & 17.30 & 1990 & Mar. 18 & 58,400 & $28.55 \mathrm{c}$ \\
\hline$\underline{1949}$ & Nov. 29 & 78,000 & $33.10 \mathrm{c}$ & 1982 & Feb. 04 & 21,900 & 17.42 & & & & \\
\hline
\end{tabular}


LOCATION.--Lat $33^{\circ} 05^{\prime} 59^{\prime \prime}$, long $83^{\circ} 43^{\prime} 25^{\prime \prime}$, Jones County, on left bank $100 \mathrm{ft}$ upstream from highway bridge on County Road 1432, 4 mi upstream from Caney Creek, and 5.1 mi east of Juliette.

DRAINAGE AREA.--72.2 $\mathrm{mi}^{2}$.

GAGE.--Water-stage recorder. Datum of gage is $366.52 \mathrm{ft}$ above sea level (levels by Global Positioning System from U.S.

Geological Survey benchmark).

STAGE-DISCHARGE RELATION.--Defined by current-meter measurements below $6,000 \mathrm{ft}^{3} / \mathrm{s}$, and above on the basis of straightline extension. Bankful stage and discharge $14 \mathrm{ft}$ and $2,100 \mathrm{ft}^{3} / \mathrm{s}$.

\begin{tabular}{|c|c|c|c|c|c|c|c|c|c|c|c|}
\hline $\begin{array}{l}\text { Water } \\
\text { year }\end{array}$ & Date & $\begin{array}{c}\text { Discharge } \\
\left(\mathrm{ft}^{3} / \mathrm{s}\right)\end{array}$ & $\begin{array}{c}\text { Gage } \\
\text { height } \\
\text { (ft) }\end{array}$ & $\begin{array}{l}\text { Water } \\
\text { year }\end{array}$ & Date & $\begin{array}{c}\text { Discharge } \\
\left(\mathrm{ft}^{3} / \mathrm{s}\right)\end{array}$ & $\begin{array}{c}\text { Gage } \\
\text { height } \\
\text { (ft) }\end{array}$ & $\begin{array}{l}\text { Water } \\
\text { year }\end{array}$ & Date & $\begin{array}{c}\text { Discharge } \\
\left(\mathrm{ft}^{3} / \mathrm{s}\right)\end{array}$ & $\begin{array}{c}\text { Gage } \\
\text { height } \\
\text { (ft) }\end{array}$ \\
\hline 1965 & Oct. 05 & 5,300 & 19.30 & 1974 & Apr. 05 & 4,730 & 19.66 & 1983 & Apr. 09 & 3,310 & 16.82 \\
\hline 1966 & Jan. 15 & 2,170 & 14.19 & 1975 & Apr. 03 & 5,210 & 20.26 & 1984 & Aug. 02 & 2,020 & 13.68 \\
\hline 1967 & Dec. 29 & 1,900 & 13.35 & 1976 & May 15 & 7,100 & 22.40 & 1985 & Feb. 06 & 3,600 & 17.35 \\
\hline 1968 & Dec. 29 & 1,060 & 9.92 & 1977 & Mar. 22 & 2,580 & 15.93 & 1986 & Mar. 20 & 1,180 & 10.43 \\
\hline 1969 & Apr. 18 & 4,550 & 18.44 & 1978 & Jan. 26 & 3,280 & 17.36 & 1987 & Mar. 01 & 1,320 & 11.10 \\
\hline 1970 & Mar. 22 & 2,680 & 15.77 & 1979 & Feb. 24 & 3,480 & 17.95 & 1988 & Jan. 20 & 804 & 8.42 \\
\hline 1971 & Mar. 02 & 7,700 & 23.00 & 1980 & Mar. 08 & 2,780 & 16.37 & 1989 & Apr. 15 & 1,060 & 9.81 \\
\hline 1972 & Jan. 12 & 1,220 & 11.44 & 1981 & Feb. 11 & 5,550 & 20.21 & 1990 & Mar. 17 & 7,570 & 22.85 \\
\hline 1973 & Apr. 08 & 2,460 & 15.65 & 1982 & Feb. 03 & 2,680 & 15.67 & & & & \\
\hline
\end{tabular}




\section{ALTAMAHA RIVER BASIN}

\section{OCMULGEE RIVER AT MACON, GEORGIA}

LOCATION.--Lat $32^{\circ} 50^{\prime} 19^{\prime \prime}$, long $83^{\circ} 37^{\prime} 14^{\prime \prime}$, Bibb County, at downstream end of center pier of Fifth Street Bridge, 1.5 mi upstream from Walnut Creek, at mile 198.0, and at Macon.

DRAINAGE AREA.--2,240 $\mathrm{mi}^{2}$, approximately.

GAGE.--Nonrecording gage prior to Oct. 1, 1931; water-stage recorder thereafter. At sites within 1.5 mi downstream of present site and at about present datum prior to Oct. 9, 1905, Oct. 9, 1905 to Dec. 31, 1913 nonrecording gage at present site and datum, and for period Jan. 11, 1925 to Apr. 15, 1926. Oct. 9, 1905 to Dec. 31, 1913, nonrecording gage at present site and datum. Water-stage recorder at present site since Oct. 1, 1931. Datum of gage is $269.80 \mathrm{ft}$ above sea level (levels from Georgia Department of Transportation), supplementary adjustment of 1936.

STAGE-DISCHARGE RELATION.--Defined by current-meter measurements below $60,000 \mathrm{ft}^{3} / \mathrm{s}$, and extended above on the basis of slope-conveyance studies. Bankful stage and discharge $18 \mathrm{ft}$ and $12,000 \mathrm{ft}^{3} / \mathrm{s}$.

HISTORICAL DATA.--Flood of 1949 was the highest since 1887, based on information from nearby stations.

REMARKS.--Minor regulation of lower peak discharges from storage in Lloyd Shoals Reservoir (maximum flood-control storage,

78,000 acre-ft), which was put into operation in 1910. Records of 1887, 1893-95, 1900-31 furnished by National Weather

Service. Records of 1893-1909 are maximum daily discharge. Flood peaks for 1887, 1925, and 1926 are present site and datum. Flood peaks for 1887, 1925, and 1926 at present site and datum.

\begin{tabular}{|c|c|c|c|c|c|c|c|c|c|c|c|}
\hline $\begin{array}{l}\text { Water } \\
\text { year }\end{array}$ & Date & $\begin{array}{c}\text { Discharge } \\
\left(\mathrm{ft}^{3} / \mathrm{s}\right)\end{array}$ & $\begin{array}{c}\text { Gage } \\
\text { height } \\
\text { (ft) }\end{array}$ & $\begin{array}{l}\text { Water } \\
\text { year }\end{array}$ & Date & $\begin{array}{c}\text { Discharge } \\
\left(\mathrm{ft}^{3} / \mathrm{s}\right)\end{array}$ & $\begin{array}{c}\text { Gage } \\
\text { height } \\
\text { (ft) }\end{array}$ & $\begin{array}{l}\text { Water } \\
\text { year }\end{array}$ & Date & $\begin{array}{c}\text { Discharge } \\
\left(\mathrm{ft}^{3} / \mathrm{s}\right)\end{array}$ & $\begin{array}{c}\text { Gage } \\
\text { height } \\
\text { (ft) }\end{array}$ \\
\hline 1887 & Aug. -- & 55,000 & $24.00 \mathrm{c}$ & 1925 & Jan. 19 & 72,500 & 26.0 & 1958 & Feb. 08 & 21,600 & 19.50 \\
\hline$\overline{1893}$ & Feb. 17 & 10,200 & 13.40 & 1926 & Mar. 31 & $\underline{28,300}$ & 20.1 & 1959 & June 03 & 27,500 & 20.90 \\
\hline 1894 & Aug. 06 & 11,300 & 14.20 & 1927 & $\overline{\text { Mar. } 12}$ & 7,900 & 13.00 & 1960 & Mar. 31 & 21,600 & 19.50 \\
\hline 1895 & Mar. 17 & 21,000 & $\underline{18.40}$ & 1928 & Aug. 16 & 47,100 & 23.00 & 1961 & Feb. 26 & 48,200 & 24.10 \\
\hline 1896 & $\overline{\text { July } 09}$ & $\overline{53,300}$ & $\overline{20.00}$ & 1929 & Feb. 28 & 73,400 & 26.10 & 1962 & Mar. 12 & 23,700 & 20.03 \\
\hline 1897 & Mar. 14 & 33,800 & 18.00 & 1930 & Oct. 02 & 64,400 & 25.10 & 1963 & Jan. 21 & 38,500 & 22.72 \\
\hline 1898 & Sept.04 & 35,300 & 18.20 & 1931 & Apr. 01 & $\underline{10,700}$ & 14.90 & 1964 & Apr. 08 & 52,600 & 24.73 \\
\hline 1899 & Oct. 05 & 29,000 & $\underline{17.30}$ & 1932 & $\overline{\text { Feb. } 04}$ & $\overline{19,600}$ & 18.10 & 1965 & Dec. 26 & 45,300 & 23.69 \\
\hline 1900 & $\overline{\text { Feb. } 14}$ & 37,700 & 21.70 & 1933 & Feb. 20 & 17,300 & 17.90 & 1966 & Feb. 14 & 40,800 & 23.04 \\
\hline 1901 & Apr. 03 & 22,400 & 18.80 & 1934 & Mar. 06 & 17,000 & 17.30 & 1967 & Aug. 26 & 17,000 & 18.61 \\
\hline 1902 & Mar. 01 & 45,600 & 22.80 & 1935 & Oct. 12 & 24,300 & 18.90 & 1968 & Mar. 14 & 23,200 & 20.46 \\
\hline 1903 & Feb. 09 & 31,600 & 20.70 & 1936 & Apr. 09 & 63,700 & 25.20 & 1969 & Apr. 19 & 33,100 & 22.18 \\
\hline 1904 & Aug. 10 & 12,600 & 15.40 & 1937 & Apr. 30 & 33,300 & 21.00 & 1970 & Mar. 23 & 41,900 & 25.47 \\
\hline 1905 & Feb. 13 & $\underline{15,400}$ & $\underline{16.40}$ & 1938 & Apr. 07 & 31,000 & 20.60 & 1971 & Mar. 04 & 58,600 & 29.45 \\
\hline 1906 & $\overline{\operatorname{Jan} .23}$ & $\overline{27,300}$ & $\overline{19.90}$ & 1939 & Mar. 01 & 33,900 & 21.10 & 1972 & Jan. 13 & 34,000 & 23.60 \\
\hline 1907 & Oct. 04 & 20,300 & 18.20 & 1940 & Feb. 18 & 13,200 & 16.40 & 1973 & Apr. 08 & 25,000 & 21.41 \\
\hline 1908 & Apr. 27 & 29,900 & 20.40 & 1941 & Dec. 28 & 7,300 & 12.70 & 1974 & Apr. 05 & 31,500 & 23.00 \\
\hline 1909 & Mar. 13 & 31,000 & 20.60 & 1942 & Mar. 22 & 73,400 & 26.10 & 1975 & Apr. 04 & 42,600 & 25.64 \\
\hline 1910 & Mar. 01 & 28,800 & 20.20 & 1943 & Mar. 22 & 44,800 & 22.70 & 1976 & Mar. 18 & 42,000 & 25.49 \\
\hline 1911 & Aug. 05 & 8,940 & 12.10 & 1944 & Mar. 20 & 50,200 & 23.40 & 1977 & Mar. 22 & 26,300 & 21.44 \\
\hline 1912 & Mar. 16 & 44,800 & 22.70 & 1945 & Apr. 27 & 40,400 & 22.10 & 1978 & Jan. 27 & 37,000 & 24.30 \\
\hline 1913 & Mar. 16 & 51,000 & 23.50 & 1946 & Jan. 08 & 57,600 & 24.30 & 1979 & Feb. 25 & 33,300 & 23.43 \\
\hline 1914 & Jan. 03 & 4,800 & 8.40 & 1947 & Mar. 09 & 32,600 & 21.80 & 1980 & Mar. 30 & 28,100 & 22.17 \\
\hline 1915 & Jan. 19 & 19,100 & 17.80 & 1948 & Feb. 11 & 24,000 & 20.10 & 1981 & Feb. 11 & 29,300 & 22.47 \\
\hline 1916 & July 11 & 47,800 & 23.10 & 1949 & Nov. 29 & 83,500 & 28.00 & 1982 & Feb. 05 & 24,300 & 21.25 \\
\hline 1917 & Apr. 06 & 25,400 & 19.50 & 1950 & Sept.19 & 9,340 & 15.00 & 1983 & Apr. 10 & 34,100 & 23.63 \\
\hline 1918 & Jan. 31 & 14,300 & 15.90 & 1951 & Apr. 23 & 6,940 & 13.20 & 1984 & Aug. 02 & 28,900 & 22.73 \\
\hline 1919 & Feb. 26 & 31,000 & 20.60 & 1952 & Mar. 05 & 46,800 & 23.90 & 1985 & Feb. 07 & 24,400 & 21.51 \\
\hline 1920 & Dec. 11 & 66,200 & 25.30 & 1953 & May 01 & 38,400 & 22.70 & 1986 & Mar. 20 & 10,400 & 16.41 \\
\hline 1921 & Feb. 11 & 37,000 & 21.60 & 1954 & Dec. 14 & 13,800 & 17.10 & 1987 & Mar. 02 & 19,800 & 20.29 \\
\hline 1922 & Mar. 11 & 48,600 & 23.20 & 1955 & Apr. 14 & 11,800 & 16.30 & 1988 & Feb. 06 & 13,200 & 17.86 \\
\hline 1923 & May 30 & 28,300 & 20.10 & 1956 & Mar. 19 & 19,700 & 19.00 & 1989 & June 23 & 14,900 & 18.60 \\
\hline 1924 & Sept.30 & 21,000 & 18.40 & 1957 & Dec. 25 & 24,400 & 20.20 & 1990 & Mar. 18 & 64,700 & 29.90 \\
\hline
\end{tabular}




\section{ALTAMAHA RIVER BASIN}

\section{WALNUT CREEK NEAR GRAY, GEORGIA}

LOCATION.-Lat $32^{\circ} 58^{\prime} 20^{\prime \prime}$, long $83^{\circ} 37^{\prime} 08^{\prime \prime}$, Jones County, on downstream side of right bank pier of abandoned bridge, $500 \mathrm{ft}$ downstream from bridge on State Highway 18, 1.4 mi upstream from Bonner Creek, and 5.5 mi southeast of Gray. DRAINAGE AREA.--29 $\mathrm{mi}^{2}$, approximately.

GAGE.--Water-stage recorder. Datum of gage is $380.36 \mathrm{ft}$ above sea level (levels by Global Positioning System).

STAGE-DISCHARGE RELATION.--Defined by current-meter measurements below $4,700 \mathrm{ft}^{3} / \mathrm{s}$, and extended above on the basis of contracted-opening measurement at $15,500 \mathrm{t}^{3} / \mathrm{s}$. Bankfull stage and discharge, $8 \mathrm{ft}$ and $2,500 \mathrm{ft}^{3} / \mathrm{s}$.

HISTORICAL DATA.--Flood of December 1964 is the highest since 1948, based on information from nearby stations.

\begin{tabular}{|c|c|c|c|c|c|c|c|c|c|c|c|}
\hline $\begin{array}{l}\text { Water } \\
\text { year }\end{array}$ & Date & $\begin{array}{c}\text { Discharge } \\
\left(\mathrm{ft}^{3} / \mathrm{s}\right)\end{array}$ & $\begin{array}{c}\text { Gage } \\
\text { height } \\
\text { (ft) }\end{array}$ & $\begin{array}{l}\text { Water } \\
\text { year }\end{array}$ & Date & $\begin{array}{c}\text { Discharge } \\
\left(\mathrm{ft}^{3} / \mathrm{s}\right)\end{array}$ & $\begin{array}{c}\text { Gage } \\
\text { height } \\
\text { (ft) }\end{array}$ & $\begin{array}{l}\text { Water } \\
\text { year }\end{array}$ & Date & $\begin{array}{c}\text { Discharge } \\
\left(\mathrm{ft}^{3} / \mathrm{s}\right)\end{array}$ & $\begin{array}{l}\text { Gage } \\
\text { height } \\
\text { (ft) }\end{array}$ \\
\hline 1962 & Feb. 22 & 4,920 & 11.90 & 1972 & Dec. 03 & 1,040 & 4.27 & 1982 & Feb. 03 & 2,050 & 6.82 \\
\hline 1963 & May 28 & 6,600 & 13.80 & 1973 & May 29 & 3,150 & 9.33 & 1983 & Mar. 06 & 4,730 & 11.68 \\
\hline 1964 & Apr. 08 & 5,000 & 12.00 & 1974 & Feb. 15 & 3,490 & 9.90 & 1984 & Mar. 25 & 2,170 & 7.23 \\
\hline 1965 & Dec. 26 & 15,500 & 23.80 & 1975 & Apr. 03 & 4,570 & 11.46 & 1985 & Feb. 05 & 2,410 & 7.91 \\
\hline 1966 & Jan. 15 & 2,260 & 7.47 & 1976 & May 15 & 3,420 & 9.79 & 1986 & Mar. 19 & 1,130 & 4.41 \\
\hline 1967 & Dec. 29 & 1,150 & 4.43 & 1977 & Mar. 22 & 2,950 & 9.05 & 1987 & Mar. 30 & 3,740 & 10.30 \\
\hline 1968 & Jan. 10 & 619 & 3.67 & 1978 & Jan. 25 & 2,960 & 9.02 & 1988 & Jan. 28 & 799 & 3.97 \\
\hline 1969 & Apr. 18 & 1,640 & 5.45 & 1979 & Feb. 24 & 4,040 & 10.69 & 1989 & July 13 & 1,980 & 6.59 \\
\hline 1970 & Mar. 20 & 2,090 & 6.95 & 1980 & Mar. 08 & 7,420 & 15.01 & 1990 & Mar. 17 & 3,070 & 9.21 \\
\hline 1971 & Mar. 02 & 3,940 & 10.56 & 1981 & Feb. 11 & 4,410 & 11.22 & & & & \\
\hline
\end{tabular}

\section{TOBESOFKEE CREEK BELOW FORSYTH, GEORGIA}

LOCATION.--Lat $32^{\circ} 59^{\prime} 37^{\prime \prime}$, long $83^{\circ} 56^{\prime} 41^{\prime \prime}$, Monroe County, at State Highway 42,3 mi southwest of Forsyth.

DRAINAGE AREA.--53.4 $\mathrm{mi}^{2}$.

GAGE.--Crest-stage gage. Datum of gage is $473.5 \mathrm{ft}$ above sea level.

STAGE-DISCHARGE RELATION.--Defined by current-meter measurements below $3,200 \mathrm{ft}^{3} / \mathrm{s}$, and extended above on the basis of contracted-opening measurement at $9,160 \mathrm{ft}^{3} / \mathrm{s}$.

REMARKS.--1972 peak discharge estimated to be $1,400 \mathrm{ft}^{3} / \mathrm{s}$, based on information from nearby stations.

\begin{tabular}{|c|c|c|c|c|c|c|c|c|c|c|c|}
\hline $\begin{array}{l}\text { Water } \\
\text { year }\end{array}$ & Date & $\begin{array}{c}\text { Discharge } \\
\left(\mathrm{ft}^{3} / \mathrm{s}\right)\end{array}$ & $\begin{array}{c}\text { Gage } \\
\text { height } \\
\text { (ft) }\end{array}$ & $\begin{array}{l}\text { Water } \\
\text { year }\end{array}$ & Date & $\begin{array}{c}\text { Discharge } \\
\left(\mathrm{ft}^{3} / \mathrm{s}\right)\end{array}$ & $\begin{array}{l}\text { Gage } \\
\text { height } \\
\text { (ft) }\end{array}$ & $\begin{array}{l}\text { Water } \\
\text { year }\end{array}$ & Date & $\begin{array}{c}\text { Discharge } \\
\left(\mathrm{ft}^{3} / \mathrm{s}\right)\end{array}$ & $\begin{array}{c}\text { Gage } \\
\text { height } \\
\text { (ft) }\end{array}$ \\
\hline 1963 & Jan. 20 & 1,800 & 4.27 & 1972 & June 00 & 1,400 & $--b$ & 1981 & Feb. 11 & 4,320 & 3.35 \\
\hline 1964 & May 02 & 2,300 & 4.85 & 1974 & Apr. 05 & 6,000 & 4.60 & 1982 & Feb. 04 & 2,090 & 1.32 \\
\hline 1965 & Oct. 05 & 3,300 & 5.80 & 1975 & Apr. 03 & 6,500 & 4.90 & 1983 & Apr. 08 & 2,780 & 2.03 \\
\hline 1966 & Feb. 13 & 1,560 & 3.96 & 1976 & May 29 & 5,100 & 3.93 & 1984 & Aug. 02 & 3,440 & 2.62 \\
\hline 1967 & Aug. -- & 1,100 & $--b$ & 1977 & Mar. 22 & 5,200 & 4.00 & 1985 & Feb. 05 & 2,880 & 2.13 \\
\hline 1968 & Mar. 12 & 1,450 & 3.81 & 1978 & Jan. 25 & 4,200 & 3.20 & 1986 & Mar. 19 & 2,360 & 1.61 \\
\hline 1969 & Apr. 18 & 3,050 & 5.62 & 1979 & Feb. 24 & 3,900 & 3.00 & $\underline{1987}$ & Mar. 01 & 850 & -0.46 \\
\hline 1970 & Mar. 19 & 1,230 & 3.44 & 1980 & Mar. 13 & 5,240 & 4.03 & $\overline{1990}$ & Mar. 17 & 7,000 & $5.20 c$ \\
\hline 1971 & July 24 & 9,160 & 10.10 & & & & & & & & \\
\hline
\end{tabular}




\section{ALTAMAHA RIVER BASIN}

\section{LITTLE TOBESOFKEE CREEK NEAR FORSYTH, GEORGIA}

LOCATION.-Lat $32^{\circ} 57^{\prime} 10^{\prime \prime}$, long $84^{\circ} 02^{\prime} 33^{\prime \prime}$, Monroe County, at State Highway $83,8.2$ mi southwest of Forsyth.

DRAINAGE AREA. $-16.8 \mathrm{mi}^{2}$.

GAGE.--Crest-stage gage. Datum of gage is about $580 \mathrm{ft}$ above sea level (from topographic map).

STAGE-DISCHARGE RELATION.--Defined by current-meter measurements below $660 \mathrm{ft}^{3} / \mathrm{s}$, and extended above on the basis of contracted-opening measurement at $3,970 \mathrm{tt}^{3} / \mathrm{s}$.

\begin{tabular}{|c|c|c|c|c|c|c|c|c|c|c|c|}
\hline $\begin{array}{l}\text { Water } \\
\text { year }\end{array}$ & Date & $\begin{array}{c}\text { Discharge } \\
\left(\mathrm{ft}^{3} / \mathrm{s}\right)\end{array}$ & $\begin{array}{c}\text { Gage } \\
\text { height } \\
\text { (ft) }\end{array}$ & $\begin{array}{l}\text { Water } \\
\text { year }\end{array}$ & Date & $\begin{array}{c}\text { Discharge } \\
\left(\mathrm{ft}^{3} / \mathrm{s}\right)\end{array}$ & $\begin{array}{c}\text { Gage } \\
\text { height } \\
\text { (ft) }\end{array}$ & $\begin{array}{l}\text { Water } \\
\text { year }\end{array}$ & Date & $\begin{array}{c}\text { Discharge } \\
\left(\mathrm{ft}^{3} / \mathrm{s}\right)\end{array}$ & $\begin{array}{c}\text { Gage } \\
\text { height } \\
\text { (ft) }\end{array}$ \\
\hline 1951 & Apr. 22 & 380 & 4.96 & 1955 & May 23 & 380 & 4.98 & 1959 & Feb. .- & 352 & 4.80 \\
\hline 1952 & Mar. 03 & 3,060 & 10.11 & 1956 & Mar. 16 & 2,560 & 9.73 & 1960 & Apr. 04 & 729 & 6.93 \\
\hline 1953 & May 01 & 4,040 & 10.67 & 1957 & June 05 & 1,140 & 7.95 & $\underline{1961}$ & Feb. 25 & 3,970 & 10.63 \\
\hline 1954 & Dec. 04 & 338 & 4.66 & 1958 & Nov. 19 & 1,120 & 7.90 & $\overline{1990}$ & Mar. 18 & 180 & $3.59 c$ \\
\hline
\end{tabular}

\section{TOBESOFKEE CREEK ABOVE MACON, GEORGIA}

LOCATION.--Lat $32^{\circ} 52^{\prime} 02^{\prime \prime}$, long $83^{\circ} 50^{\prime} 24^{\prime \prime}$, Bibb County, on left bank $800 \mathrm{ft}$ upstream from bridge on State Highway $74,1.7 \mathrm{mi}$ downstream from Little Tobesofkee Creek, and 8.0 mi west of Macon.

DRAINAGE AREA.--156 $\mathrm{mi}^{2}$.

GAGE.--Water-stage recorder. Datum of gage is $365.2 \mathrm{ft}$ above sea level (from S.J. Gostin Company benchmark).

STAGE-DISCHARGE RELATION.--Defined by current-meter measurements below $7,600 \mathrm{ft}^{3} / \mathrm{s}$, and above on the basis of straightline extension.

\begin{tabular}{|c|c|c|c|c|c|c|c|c|c|c|c|}
\hline $\begin{array}{l}\text { Water } \\
\text { year }\end{array}$ & Date & $\begin{array}{c}\text { Discharge } \\
\left(\mathrm{ft}^{3} / \mathrm{s}\right)\end{array}$ & $\begin{array}{c}\text { Gage } \\
\text { height } \\
\text { (ft) }\end{array}$ & $\begin{array}{l}\text { Water } \\
\text { year }\end{array}$ & Date & $\begin{array}{c}\text { Discharge } \\
\left(\mathrm{ft}^{3} / \mathrm{s}\right)\end{array}$ & $\begin{array}{l}\text { Gage } \\
\text { height } \\
\text { (ft) }\end{array}$ & $\begin{array}{l}\text { Water } \\
\text { year }\end{array}$ & Date & $\begin{array}{c}\text { Discharge } \\
\left(\mathrm{ft}^{3} / \mathrm{s}\right)\end{array}$ & $\begin{array}{c}\text { Gage } \\
\text { height } \\
\text { (ft) }\end{array}$ \\
\hline 1967 & Aug. 25 & 630 & 5.58 & 1972 & June 28 & 2,010 & 8.05 & 1976 & May 29 & 4,900 & 11.39 \\
\hline 1968 & Mar. 13 & 1,710 & 7.59 & 1973 & May 29 & 3,820 & 10.27 & 1977 & Mar. 22 & 6,760 & 12.78 \\
\hline 1969 & Apr. 19 & 6,630 & 12.68 & 1974 & Apr. 05 & 4,890 & 11.28 & $\underline{1978}$ & Jan. 25 & 6,740 & 12.76 \\
\hline 1970 & Mar. 20 & 2,860 & 9.26 & 1975 & Apr. 03 & 6,920 & 12.90 & $\overline{1990}$ & Mar. 18 & 9,620 & $14.78 c$ \\
\hline 1971 & Mar. 02 & 8,580 & 14.09 & & & & & & & & \\
\hline
\end{tabular}




\section{ALTAMAHA RIVER BASIN}

\section{TOBESOFKEE CREEK NEAR MACON, GEORGIA}

LOCATION.--Lat $32^{\circ} 48^{\prime} 32^{\prime \prime}$, long $83^{\circ} 45^{\prime} 30^{\prime \prime}$, Bibb County, on right bank at downstream end of pier of bridge on U.S. Highway 80,8 mi west of Macon, and 14 mi upstream from mouth.

DRAINAGE AREA.--182 $\mathrm{mi}^{2}$.

GAGE.--Water-stage recorder. Datum of gage is $309.98 \mathrm{ft}$ above sea level (from U.S. Coast and Geodetic Survey benchmark), supplementary adjustment of 1936. Prior to Aug. 28, 1942, nonrecording gage at same site and datum.

STAGE-DISCHARGE RELATION.--Defined by current-meter measurements below $6,300 \mathrm{ft}^{3} / \mathrm{s}$, and extended above on basis of straight-line extension. Bankfull stage and discharge, $17 \mathrm{ft}$ and $5,000 \mathrm{ft}^{3} / \mathrm{s}$.

REMARKS.--Minor regulation since November 1967 by Lake Tobsofkee, about 1 mi upstream.

\begin{tabular}{|c|c|c|c|c|c|c|c|c|c|c|c|}
\hline $\begin{array}{l}\text { Water } \\
\text { year }\end{array}$ & Date & $\begin{array}{c}\text { Discharge } \\
\left(\mathrm{ft}^{3} / \mathrm{s}\right)\end{array}$ & $\begin{array}{c}\text { Gage } \\
\text { height } \\
\text { (ft) }\end{array}$ & $\begin{array}{l}\text { Water } \\
\text { year }\end{array}$ & Date & $\begin{array}{c}\text { Discharge } \\
\left(\mathrm{ft}^{3} / \mathrm{s}\right)\end{array}$ & $\begin{array}{c}\text { Gage } \\
\text { height } \\
\text { (ft) }\end{array}$ & $\begin{array}{l}\text { Water } \\
\text { year }\end{array}$ & Date & $\begin{array}{c}\text { Discharge } \\
\left(\mathrm{ft}^{3} / \mathrm{s}\right)\end{array}$ & $\begin{array}{c}\text { Gage } \\
\text { height } \\
\text { (ft) }\end{array}$ \\
\hline 1938 & Apr. 08 & 4,860 & 16.30 & 1956 & Mar. 16 & 1,930 & 10.10 & 1974 & Apr. 05 & 4,700 & 15.42 \\
\hline 1939 & Mar. 01 & 4,260 & 15.00 & 1957 & May 04 & 4,040 & 15.20 & 1975 & Apr. 03 & 5,690 & 17.98 \\
\hline 1940 & Feb. 19 & 2,220 & 10.60 & 1958 & Mar. 07 & 2,520 & 11.80 & 1976 & May 15 & 6,680 & 19.40 \\
\hline 1941 & Dec. 28 & 851 & 5.40 & 1959 & Feb. 04 & 2,230 & 11.00 & 1977 & Mar. 22 & 5,800 & 18.15 \\
\hline 1942 & Dec. 24 & 8,270 & 21.40 & 1960 & Mar. 31 & 2,920 & 12.80 & 1978 & $\operatorname{Jan} .25$ & 7,690 & 20.68 \\
\hline 1943 & Mar. 22 & 5,700 & 18.00 & 1961 & Feb. 25 & 7,390 & 20.30 & 1979 & Feb. 24 & 7,330 & 20.23 \\
\hline 1944 & Mar. 21 & 9,830 & 23.20 & 1962 & Feb. 23 & 5,100 & 16.60 & 1980 & Mar. 09 & 5,480 & 17.69 \\
\hline 1945 & Apr. 25 & 2,090 & 10.20 & 1963 & Jan. 21 & 5,220 & 17.30 & 1981 & Feb. 11 & 5,100 & 17.10 \\
\hline 1946 & Dec. 26 & 3,170 & 13.20 & 1964 & Apr. 09 & 7,230 & 20.10 & 1982 & Feb. 03 & 4,780 & 16.48 \\
\hline 1947 & Mar. 08 & 4,050 & 15.10 & 1965 & Dec. 26 & 9,290 & 22.60 & 1983 & Apr. 09 & 4,690 & 16.30 \\
\hline 1948 & Nov. 12 & 2,450 & 11.60 & 1966 & Jan. 15 & 3,480 & 14.03 & 1984 & Aug. 02 & 4,290 & 15.47 \\
\hline 1949 & Nov. 28 & 7,550 & 20.50 & 1967 & Aug. 25 & 2,140 & 10.75 & 1985 & Feb. 06 & 4,830 & 16.59 \\
\hline 1950 & Mar. 07 & 1,290 & 7.70 & 1968 & Aug. 02 & 1,430 & 8.29 & 1986 & Mar. 20 & 3,430 & 13.42 \\
\hline 1951 & Apr. 23 & 1,380 & 8.13 & 1969 & Apr. 29 & 5,590 & 17.80 & 1987 & May 11 & 5,240 & 17.31 \\
\hline 1952 & Mar. 05 & 5,700 & 18.00 & 1970 & Mar. 20 & 4,530 & 16.10 & 1988 & Apr. 25 & 3,500 & 13.58 \\
\hline 1953 & May 01 & 7,790 & 20.80 & 1971 & Mar. 02 & 7,560 & 20.51 & 1989 & Dec. 31 & 2,240 & 10.16 \\
\hline 1954 & Dec. 06 & 1,580 & 8.90 & 1972 & June 28 & 2,090 & 10.31 & 1990 & Mar. 18 & 7,640 & 20.62 \\
\hline 1955 & Apr. 14 & 2,090 & 11.00 & 1973 & Apr. 07 & 6,210 & 18.73 & & & & \\
\hline
\end{tabular}




\section{ALTAMAHA RIVER BASIN}

\section{ECHECONNEE CREEK NEAR MACON, GEORGIA}

LOCATION.-Lat $32^{\circ} 45^{\prime} 54^{\prime \prime}$, long $83^{\circ} 50^{\prime} 22^{\prime \prime}$, Crawford County, at Marshall Mill Bridge, 18 mi upstream of mouth, and 13 mi southwest of Macon.

DRAINAGE AREA.-147 $\mathrm{mi}^{2}$ (formerly published as $100 \mathrm{mi}^{2}$ ).

GAGE.--Water-stage recorder prior to July 20, 1950; crest-stage gage thereafter. Datum of gage is $332.51 \mathrm{ft}$ above sea level (from U.S. Geological Survey benchmark).

STAGE-DISCHARGE RELATION.--Defined by current-meter measurements below $7,000 \mathrm{ft}^{3} / \mathrm{s}$, and extended above on the basis of straight-line extension. Bankfull stage and discharge, $11 \mathrm{ft}$ and $4,500 \mathrm{ft}^{3} / \mathrm{s}$.

HISTORICAL DATA.--Flood of December 1964 is the highest since 1929, based on information at nearby stations.

\begin{tabular}{|c|c|c|c|c|c|c|c|c|c|c|c|}
\hline $\begin{array}{l}\text { Water } \\
\text { year }\end{array}$ & Date & $\begin{array}{c}\text { Discharge } \\
\left(\mathrm{ft}^{3} / \mathrm{s}\right)\end{array}$ & $\begin{array}{c}\text { Gage } \\
\text { height } \\
\text { (ft) }\end{array}$ & $\begin{array}{l}\text { Water } \\
\text { year }\end{array}$ & Date & $\begin{array}{c}\text { Discharge } \\
\left(\mathrm{ft}^{3} / \mathrm{s}\right)\end{array}$ & $\begin{array}{l}\text { Gage } \\
\text { height } \\
\text { (ft) }\end{array}$ & $\begin{array}{l}\text { Water } \\
\text { year }\end{array}$ & Date & $\begin{array}{c}\text { Discharge } \\
\left(\mathrm{ft}^{3} / \mathrm{s}\right)\end{array}$ & $\begin{array}{c}\text { Gage } \\
\text { height } \\
\text { (ft) }\end{array}$ \\
\hline 1938 & Apr. 07 & 5,720 & 11.60 & 1957 & May 04 & 5,900 & 11.80 & 1969 & Apr. 18 & 4,160 & 10.68 \\
\hline 1939 & Feb. 28 & 4,380 & 10.90 & 1958 & Apr. 06 & 4,060 & 10.60 & 1970 & Mar. 20 & 4,840 & 11.21 \\
\hline 1940 & Feb. 18 & 3,620 & 10.30 & 1959 & Mar. 24 & 2,740 & 8.96 & 1971 & Mar. 02 & 2,590 & 8.73 \\
\hline 1941 & July 12 & 1,710 & 6.95 & 1960 & Mar. 03 & 2,920 & 9.27 & 1972 & Dec. 03 & 1,670 & 6.92 \\
\hline 1942 & Mar. 22 & 8,760 & 12.80 & 1961 & Feb. 25 & 9,840 & 13.40 & 1973 & Apr. 07 & 4,330 & 10.86 \\
\hline 1943 & Mar. 21 & 8,160 & 12.60 & 1962 & Feb. 22 & 8,300 & 12.79 & 1974 & Feb. 15 & 3,120 & 9.57 \\
\hline$\overline{1951}$ & Apr. 04 & 2,010 & 7.58 & 1963 & Jan. 20 & 5,900 & 11.78 & 1975 & Apr. 03 & 4,660 & 11.09 \\
\hline 1952 & Mar. 24 & 6,400 & 12.00 & 1964 & Apr. 06 & 15,000 & 15.04 & 1976 & May 29 & 3,630 & 10.17 \\
\hline 1953 & May 01 & 15,000 & 15.00 & 1965 & Dec. 26 & 18,500 & 15.84 & 1977 & Mar. 22 & 3,500 & 9.97 \\
\hline 1954 & Dec. 05 & 2,010 & 7.61 & 1966 & Feb. 13 & 3,850 & 10.39 & 1978 & Jan. 26 & 7,960 & 12.65 \\
\hline 1955 & Apr. 14 & 2,920 & 9.26 & 1967 & Dec. 29 & 1,760 & 7.11 & $\overline{1990}$ & Mar. 18 & 13,200 & $14.24 c$ \\
\hline 1956 & Sept.26 & 1,860 & 7.34 & 1968 & Mar. -- & 1,100 & $--b$ & & & & \\
\hline
\end{tabular}

02214280 SAVAGE CREEK NEAR BULLARD, GEORGIA

LOCATION.--Lat $32^{\circ} 35^{\prime} 34^{\prime \prime}$ long $83^{\circ} 28^{\prime} 11^{\prime \prime}$, Twiggs County, at bridge on U.S. Highway 23,3 mi southeast of Bullard. DRAINAGE AREA.--33 $\mathrm{mi}^{2}$.

GAGE.--Crest-stage gage. Datum of gage is about $264 \mathrm{ft}$ above sea level (from topographic map).

STAGE-DISCHARGE RELATION.--Defined by current-meter measurements below $920 \mathrm{tt}^{3} / \mathrm{s}$, and extended above on the basis of straight-line extension

\begin{tabular}{|c|c|c|c|c|c|c|c|c|c|c|c|}
\hline $\begin{array}{l}\text { Water } \\
\text { year }\end{array}$ & Date & $\begin{array}{c}\text { Discharge } \\
\left(\mathrm{ft}^{3} / \mathrm{s}\right)\end{array}$ & $\begin{array}{c}\text { Gage } \\
\text { height } \\
\text { (ft) }\end{array}$ & $\begin{array}{l}\text { Water } \\
\text { year }\end{array}$ & Date & $\begin{array}{c}\text { Discharge } \\
\left(\mathrm{ft}^{3} / \mathrm{s}\right)\end{array}$ & $\begin{array}{c}\text { Gage } \\
\text { height } \\
\text { (ft) }\end{array}$ & $\begin{array}{l}\text { Water } \\
\text { year }\end{array}$ & Date & $\begin{array}{c}\text { Discharge } \\
\left(\mathrm{ft}^{3} / \mathrm{s}\right)\end{array}$ & $\begin{array}{c}\text { Gage } \\
\text { height } \\
\text { (ft) }\end{array}$ \\
\hline 1979 & Feb. 24 & 1,370 & 10.47 & 1983 & Feb. 15 & 1,170 & 10.29 & 1987 & Mar. 01 & 486 & 9.31 \\
\hline 1980 & Mar. 13 & 2,700 & 11.49 & 1984 & Mar. 02 & 188 & 8.39 & 1988 & Feb. 20 & 50 & 5.65 \\
\hline 1981 & Apr. 02 & 524 & 9.38 & 1985 & Feb. 06 & 351 & 8.97 & 1989 & June 21 & 175 & 8.28 \\
\hline 1982 & Feb. 04 & 1,250 & 10.36 & 1986 & Feb. 07 & 176 & 8.31 & 1990 & Feb. 10 & 91.0 & 7.58 \\
\hline
\end{tabular}




\section{ALTAMAHA RIVER BASIN}

\section{BIG INDIAN CREEK AT PERRY, GEORGIA}

LOCATION.--Lat $32^{\circ} 27^{\prime} 20^{\prime \prime}$, long $83^{\circ} 44^{\prime} 21^{\prime \prime}$, Houston County, at municipal waterworks at Perry, $300 \mathrm{ft}$ downstream from bridge on U.S. Highway 41, and 1 mi downstream from Bay Creek.

DRAINAGE AREA.--108 $\mathrm{mi}^{2}$.

GAGE.--Water-stage recorder prior to Aug. 1, 1971; crest-stage gage thereafter. Datum of gage is $279.39 \mathrm{ft}$ above sea level, supplementary adjustment of 1936.

STAGE-DISCHARGE RELATION.--Defined by current-meter measurements below $4,600 \mathrm{ft}^{3} / \mathrm{s}$. Bankfull stage and discharge, $4.5 \mathrm{ft}$ and $400 \mathrm{ft}^{3} / \mathrm{s}$.

\begin{tabular}{|c|c|c|c|c|c|c|c|c|c|c|c|}
\hline $\begin{array}{l}\text { Water } \\
\text { year }\end{array}$ & Date & $\begin{array}{c}\text { Discharge } \\
\left(\mathrm{ft}^{3} / \mathrm{s}\right)\end{array}$ & $\begin{array}{c}\text { Gage } \\
\text { height } \\
\text { (ft) }\end{array}$ & $\begin{array}{l}\text { Water } \\
\text { year }\end{array}$ & Date & $\begin{array}{c}\text { Discharge } \\
\left(\mathrm{ft}^{3} / \mathrm{s}\right)\end{array}$ & $\begin{array}{c}\text { Gage } \\
\text { height } \\
\text { (ft) }\end{array}$ & $\begin{array}{c}\text { Water } \\
\text { year }\end{array}$ & Date & $\begin{array}{c}\text { Discharge } \\
\left(\mathrm{ft}^{3} / \mathrm{s}\right)\end{array}$ & $\begin{array}{c}\text { Gage } \\
\text { height } \\
\text { (ft) }\end{array}$ \\
\hline 1944 & Mar. 23 & 3,000 & 8.60 & 1956 & Feb. 07 & 254 & 3.68 & 1968 & Dec. 11 & 208 & 3.58 \\
\hline 1945 & Feb. 21 & 386 & 4.40 & 1957 & May 05 & 840 & 5.97 & 1969 & Aug. 03 & 315 & 4.36 \\
\hline 1946 & Jan. 16 & 1,110 & 6.20 & 1958 & July 20 & 1,040 & 6.48 & 1970 & Mar. 31 & 3,040 & 9.50 \\
\hline 1947 & Apr. 15 & 960 & 5.90 & 1959 & Feb. 05 & 568 & 5.13 & 1971 & Mar. 26 & 840 & 6.00 \\
\hline 1948 & Feb. 10 & 820 & 5.60 & 1960 & Apr. 05 & 1,000 & 6.42 & 1972 & Jan. 14 & 1,510 & 7.28 \\
\hline 1949 & Feb. 11 & 1,110 & 6.20 & 1961 & Apr. 01 & 1,280 & 7.04 & 1973 & Apr. 27 & 2,430 & 8.70 \\
\hline 1950 & June 01 & 268 & 3.70 & 1962 & Jan. 06 & 2,410 & 9.02 & 1974 & June 14 & 591 & 5.35 \\
\hline 1951 & Dec. 30 & 193 & 3.00 & 1963 & Jan. 21 & 625 & 5.35 & 1975 & Apr. 15 & 1,880 & 7.90 \\
\hline 1952 & May 30 & 1,110 & 6.20 & 1964 & Apr. 09 & 2,190 & 8.70 & 1976 & May 15 & 1,850 & 7.82 \\
\hline 1953 & June 27 & 490 & 4.75 & 1965 & Dec. 26 & 1,180 & 7.12 & $\underline{1977}$ & Mar. 23 & 940 & 6.20 \\
\hline 1954 & Dec. 14 & 474 & 4.70 & 1966 & Mar. 04 & 4,820 & 11.52 & 1981 & Apr. 02 & 3,690 & $10.28 \mathrm{c}$ \\
\hline 1955 & Apr. 15 & 1,420 & 7.34 & 1967 & Jan. 02 & 456 & 4.94 & & & & \\
\hline
\end{tabular}

\section{MOSSY CREEK NEAR PERRY, GEORGIA}

LOCATION.--Lat $32^{\circ} 31^{\prime} 15^{\prime \prime}$ long $83^{\circ} 43^{\prime} 23^{\prime \prime}$, Houston-Peach County line, at bridge on U.S. Highway $41,4.5$ mi north of Perry. DRAINAGE AREA.--92.9 $\mathrm{mi}^{2}$.

GAGE.--Crest-stage gage. Datum of gage is about $300 \mathrm{ft}$ above sea level (from topographic map).

STAGE-DISCHARGE RELATION.--Defined by current-meter measurements below $760 \mathrm{ft}^{3} / \mathrm{s}$.

\begin{tabular}{|c|c|c|c|c|c|c|c|c|c|c|c|}
\hline $\begin{array}{l}\text { Water } \\
\text { year }\end{array}$ & Date & $\begin{array}{c}\text { Discharge } \\
\left(\mathrm{ft}^{3} / \mathrm{s}\right)\end{array}$ & $\begin{array}{c}\text { Gage } \\
\text { height } \\
\text { (ft) }\end{array}$ & $\begin{array}{l}\text { Water } \\
\text { year }\end{array}$ & Date & $\begin{array}{c}\text { Discharge } \\
\left(\mathrm{ft}^{3} / \mathrm{s}\right)\end{array}$ & $\begin{array}{l}\text { Gage } \\
\text { height } \\
\text { (ft) }\end{array}$ & $\begin{array}{l}\text { Water } \\
\text { year }\end{array}$ & Date & $\begin{array}{c}\text { Discharge } \\
\left(\mathrm{ft}^{3} / \mathrm{s}\right)\end{array}$ & $\begin{array}{c}\text { Gage } \\
\text { height } \\
\text { (ft) }\end{array}$ \\
\hline 1979 & Mar. 25 & 442 & 7.16 & 1983 & Mar. 07 & -- & 9.35 & 1987 & June 17 & 492 & 7.34 \\
\hline 1980 & Mar. 13 & 756 & 8.19 & 1984 & Aug. 02 & 603 & 7.71 & 1988 & Feb. 20 & 50 & 4.54 \\
\hline 1981 & Apr. 01 & 788 & 8.27 & 1985 & Feb. 06 & 327 & 6.48 & 1989 & Apr. 11 & 150 & 5.33 \\
\hline 1982 & Feb. 04 & 434 & 7.12 & 1986 & Dec. 13 & 242 & 5.93 & 1990 & Mar. 17 & 200 & 5.86 \\
\hline
\end{tabular}




\section{ALTAMAHA RIVER BASIN}

\section{OCMULGEE RIVER AT HAWKINSVILLE, GEORGIA}

LOCATION.--Lat $32^{\circ} 16^{\prime} 50^{\prime \prime}$, long $83^{\circ} 27^{\prime} 40^{\prime \prime}$, Pulaski County, at U.S. Highway 341 , at Hawkinsville, and at mi 135.1.

DRAINAGE AREA.--3,800 $\mathrm{mi}^{2}$, approximately.

GAGE.--Nonrecording from Aug. 13, 1908 to Apr. 1, 1916 at former site $600 \mathrm{ft}$ upstream of present site and at datum $3.25 \mathrm{ft}$ higher; from Apr. 1, 1916 to June 28, 1921 at former site and datum $0.75 \mathrm{ft}$ lower; from June 28, 1921 to Oct. 3, 1959 at former site and present datum; from Oct. 3, 1959 at present site and datum. Datum of gage is $189.56 \mathrm{ft}$ above sea level (from U.S. Geological Survey benchmark), supplementary adjustment of 1936.

STAGE-DISCHARGE RELATION.--Defined by current-meter measurements below $68,000 \mathrm{ft}^{3} / \mathrm{s}$, and extended above on the basis of straight-line extension. Bankfull stage and discharge, $14 \mathrm{ft}$ and $10,000 \mathrm{ft}^{3} / \mathrm{s}$.

HISTORICAL DATA.--Unpublished data (National Weather Service information) indicates that the flood of 1925 was probably the highest since 1841.

REMARKS.--Stage records for 1877, 1909-43, and 1960-90 from National Weather Service. Minor regulation of lower peak discharges from storage in Lloyd Shoals Reservoir (maximum flood-control storage, 78,000 acre-ft) since 1910.

\begin{tabular}{|c|c|c|c|c|c|c|c|c|c|c|c|}
\hline $\begin{array}{l}\text { Water } \\
\text { year }\end{array}$ & Date & $\begin{array}{c}\text { Discharge } \\
\left(\mathrm{ft}^{3} / \mathrm{s}\right)\end{array}$ & $\begin{array}{c}\text { Gage } \\
\text { height } \\
\text { (ft) }\end{array}$ & $\begin{array}{l}\text { Water } \\
\text { year }\end{array}$ & Date & $\begin{array}{c}\text { Discharge } \\
\left(\mathrm{ft}^{3} / \mathrm{s}\right)\end{array}$ & $\begin{array}{c}\text { Gage } \\
\text { height } \\
\text { (ft) }\end{array}$ & $\begin{array}{l}\text { Water } \\
\text { year }\end{array}$ & Date & $\begin{array}{c}\text { Discharge } \\
\left(\mathrm{ft}^{3} / \mathrm{s}\right)\end{array}$ & $\begin{array}{c}\text { Gage } \\
\text { height } \\
(f t)\end{array}$ \\
\hline$\underline{1877}$ & Aug. -- & 70,500 & $34.90 \mathrm{c}$ & 1935 & Oct. 17 & 13,500 & 16.90 & 1962 & Mar. 16 & 25,000 & 23.20 \\
\hline 1909 & Mar. 17 & 35,400 & 26.70 & 1936 & Apr. 12 & 61,000 & 33.00 & 1963 & Jan. 25 & 33,400 & 26.10 \\
\hline 1910 & Mar. 06 & 18,800 & 20.30 & 1937 & May 05 & 25,800 & 23.50 & 1964 & Apr. 12 & 49,200 & 30.30 \\
\hline 1911 & Apr. 19 & 5,920 & 9.20 & 1938 & Apr. 11 & 33,000 & 26.00 & 1965 & Dec. 30 & 19,300 & 20.60 \\
\hline 1912 & Mar. 19 & 44,400 & 29.10 & 1939 & Mar. 04 & 37,900 & 27.40 & 1966 & Mar. 08 & 37,600 & 27.30 \\
\hline 1913 & Mar. 19 & 52,000 & 31.00 & 1940 & Feb. 24 & 13,300 & 16.80 & 1967 & Jan. 05 & 16,500 & 19.00 \\
\hline 1914 & Mar. 03 & 5,850 & 9.10 & 1941 & July 19 & 6,930 & 10.60 & 1968 & Mar. 18 & 18,000 & 19.90 \\
\hline 1915 & Jan. 23 & 20,100 & 21.00 & 1942 & Mar. 25 & 57,000 & 32.10 & 1969 & Apr. 24 & 22,200 & 21.95 \\
\hline 1916 & July 14 & $\underline{40,400}$ & 28.10 & 1943 & Mar. 25 & 41,600 & 28.40 & 1970 & Mar. 26 & 36,500 & 27.00 \\
\hline 1917 & $\overline{\text { Mar. } 09}$ & $\overline{27,000}$ & $\overline{24.00}$ & 1944 & Mar. 26 & 46,800 & 29.70 & 1971 & Mar. 07 & 55,600 & 32.10 \\
\hline 1918 & Feb. 05 & 14,300 & 17.50 & 1945 & May 01 & 28,400 & 23.70 & 1972 & Jan. 16 & 36,500 & 27.00 \\
\hline 1919 & Mar. 01 & 40,000 & 28.00 & 1946 & Jan. 12 & 37,100 & 26.70 & 1973 & Apr. 12 & 26,800 & 23.94 \\
\hline 1920 & Dec. 15 & 45,200 & 29.30 & 1947 & Mar. 12 & 36,500 & 26.50 & 1974 & Feb. 20 & 23,800 & 22.70 \\
\hline 1921 & Feb. 15 & $\underline{30,000}$ & $\underline{25.00}$ & 1948 & Feb. 15 & 28,200 & 24.40 & 1975 & Mar. 19 & 38,600 & 27.59 \\
\hline 1922 & $\overline{\text { Mar. } 14}$ & $\overline{44,000}$ & 29.00 & 1949 & Dec. 02 & 68,000 & 34.40 & 1976 & Mar. 22 & 34,400 & 26.40 \\
\hline 1923 & June 02 & 30,300 & 25.10 & 1950 & Mar. 13 & 9,030 & 13.00 & 1977 & Mar. 25 & 19,900 & 20.91 \\
\hline 1924 & Jan. 24 & 15,200 & 18.10 & 1951 & Apr. 29 & 7,010 & 10.70 & 1978 & Jan. 30 & 37,900 & 27.40 \\
\hline 1925 & Jan. 21 & 79,000 & 36.50 & 1952 & Mar. 09 & 35,100 & 26.60 & 1979 & Mar. 01 & 39,600 & 27.90 \\
\hline 1926 & Apr. 05 & 19,300 & 20.60 & 1953 & May 07 & 32,400 & 25.80 & 1980 & Mar. 16 & 35,100 & 26.60 \\
\hline 1927 & Mar. 16 & 7,580 & 11.40 & 1954 & Dec. 18 & 13,500 & 16.90 & 1983 & Apr. 14 & 30,600 & 25.20 \\
\hline 1928 & Aug. 19 & 42,400 & 28.60 & 1955 & Apr. 20 & 10,900 & 14.80 & 1984 & Aug. 06 & 28,500 & 24.50 \\
\hline 1929 & Mar. 08 & 70,500 & 34.90 & 1956 & Mar. 22 & 17,700 & 19.70 & 1985 & Feb. 11 & 26,800 & 23.90 \\
\hline 1930 & Oct. 06 & 50,000 & 30.50 & 1957 & Apr. 11 & 18,200 & 20.00 & 1986 & Mar. 26 & 11,100 & 14.96 \\
\hline 1931 & Nov. 22 & 12,200 & 15.90 & 1958 & Mar. 12 & 19,000 & 20.40 & 1987 & Mar. 06 & 26,800 & 23.90 \\
\hline 1932 & Jan. 13 & 16,200 & 18.80 & 1959 & June 07 & $\underline{17,400}$ & 19.50 & 1988 & Feb. 11 & 7,110 & 10.83 \\
\hline 1933 & Feb. 25 & 19,900 & 20.90 & 1960 & $\overline{\text { Apr. } 05}$ & $\overline{26,000}$ & 23.60 & 1989 & Apr. 15 & 12,800 & 16.40 \\
\hline 1934 & Mar. 10 & 17,400 & 19.50 & 1961 & Mar. 02 & 48,000 & 30.00 & 1990 & Mar. 22 & 49,600 & 30.40 \\
\hline
\end{tabular}




\section{ALTAMAHA RIVER BASIN}

\section{TUCSAWHATCHEE CREEK NEAR HAWKINSVILLE, GEORGIA}

LOCATION.--Lat $32^{\circ} 14^{\prime} 22^{\prime \prime}$, long $83^{\circ} 30^{\prime} 06^{\prime \prime}$, Pulaski County, on left bank $90 \mathrm{ft}$ upstream from State Highways 27 and $257,0.6 \mathrm{mi}$ upstream from Cedar Creek, $0.6 \mathrm{mi}$ downstream from Long Branch, and $3.5 \mathrm{mi}$ southwest of Hawkinsville. Also known as Big Creek.

DRAINAGE AREA.-163 $\mathrm{mi}^{2}$.

GAGE.--Water-stage recorder. Dec. 6, 1984 to Apr. 1, 1986, crest-stage gage at site $100 \mathrm{ft}$ downstream at a datum $3.0 \mathrm{ft}$ higher.

Datum of gage is $210.49 \mathrm{ft}$ above sea level (levels from Georgia Department of Transportation).

STAGE-DISCHARGE RELATION.--Defined by current-meter measurements below $2,600 \mathrm{ft}^{3} / \mathrm{s}$.

REMARKS.--Gage heights prior to 1986 have been adjusted to present datum.

\begin{tabular}{|c|c|c|c|c|c|c|c|c|c|c|c|}
\hline $\begin{array}{l}\text { Water } \\
\text { year }\end{array}$ & Date & $\begin{array}{c}\text { Discharge } \\
\left(\mathrm{ft}^{3} / \mathrm{s}\right)\end{array}$ & $\begin{array}{c}\text { Gage } \\
\text { height } \\
\text { (ft) }\end{array}$ & $\begin{array}{l}\text { Water } \\
\text { year }\end{array}$ & Date & $\begin{array}{c}\text { Discharge } \\
\left(\mathrm{ft}^{3} / \mathrm{s}\right)\end{array}$ & $\begin{array}{c}\text { Gage } \\
\text { height } \\
\text { (ft) }\end{array}$ & $\begin{array}{l}\text { Water } \\
\text { year }\end{array}$ & Date & $\begin{array}{c}\text { Discharge } \\
\left(\mathrm{ft}^{3} / \mathrm{s}\right)\end{array}$ & $\begin{array}{c}\text { Gage } \\
\text { height } \\
\text { (ft) }\end{array}$ \\
\hline 1984 & May 30 & 2,050 & 11.11 & 1987 & Jan. 20 & 2,760 & 11.94 & 1989 & June 10 & 1,490 & 9.64 \\
\hline 1985 & Feb. 07 & 1,520 & 9.77 & 1988 & Mar. 11 & 358 & 5.49 & 1990 & Jan. 08 & 1,810 & 10.32 \\
\hline 1986 & Dec. 14 & $\underline{820}$ & 7.62 & & & & & & & & \\
\hline
\end{tabular}

\section{OCMULGEE RIVER TRIBUTARY NEAR ABBEVILLE, GEORGIA}

LOCATION.--Lat $32^{\circ} 06^{\prime} 53^{\prime \prime}$, long $83^{\circ} 24^{\prime} 12^{\prime \prime}$, Wilcox County, at culvert on U.S. Highway 129,10 mi northwest of Abbeville. DRAINAGE AREA.--2.92 $\mathrm{mi}^{2}$.

GAGE.--Flood stage/rainfall recorder. Datum of gage is about $201 \mathrm{ft}$ above sea level (from topographic map).

STAGE-DISCHARGE RELATION.--Defined by current-meter measurements below $120 \mathrm{ft}^{3} / \mathrm{s}$, and extended above on the basis of culvert computations.

\begin{tabular}{|c|c|c|c|c|c|c|c|c|c|c|c|}
\hline $\begin{array}{l}\text { Water } \\
\text { year }\end{array}$ & Date & $\begin{array}{c}\text { Discharge } \\
\left(\mathrm{ft}^{3} / \mathrm{s}\right)\end{array}$ & $\begin{array}{c}\text { Gage } \\
\text { height } \\
\text { (ft) }\end{array}$ & $\begin{array}{l}\text { Water } \\
\text { year }\end{array}$ & Date & $\begin{array}{c}\text { Discharge } \\
\left(\mathrm{ft}^{3} / \mathrm{s}\right)\end{array}$ & $\begin{array}{l}\text { Gage } \\
\text { height } \\
\text { (ft) }\end{array}$ & $\begin{array}{l}\text { Water } \\
\text { year }\end{array}$ & Date & $\begin{array}{c}\text { Discharge } \\
\left(\mathrm{ft}^{3} / \mathrm{s}\right)\end{array}$ & $\begin{array}{l}\text { Gage } \\
\text { height } \\
\text { (ft) }\end{array}$ \\
\hline 1965 & Feb. 18 & 116 & 2.68 & 1969 & Aug. 04 & 10.0 & 1.23 & 1973 & Feb. 02 & 81.0 & 2.38 \\
\hline 1966 & Mar. 04 & 156 & 2.97 & 1970 & Mar. 31 & 135 & 2.83 & 1974 & Sept.07 & 37.0 & 1.83 \\
\hline 1967 & Feb. 07 & 63.0 & 2.18 & 1971 & Mar. 03 & 63.0 & 2.19 & 1975 & Apr. 14 & 123 & 3.28 \\
\hline 1968 & Jan. -- & 2.0 & $--b$ & 1972 & Feb. 03 & 59.0 & 2.13 & & & & \\
\hline
\end{tabular}

\section{CEDAR CREEK NEAR PINEVIEW, GEORGIA}

LOCATION.--Lat 32 $05^{\prime} 34^{\prime \prime}$, long $83^{\circ} 30^{\prime} 12^{\prime \prime}$, Wilcox County, at culvert on State Highway 112, 1.5 mi south of Pineview.

DRAINAGE AREA. $-7.80 \mathrm{mi}^{2}$.

GAGE.--Flood stage/rainfall recorder. Datum of gage is about $253 \mathrm{ft}$ above sea level (from topographic map).

STAGE-DISCHARGE RELATION.--Defined by current-meter measurements below $630 \mathrm{ft}^{3} / \mathrm{s}$, and extended above on the basis of culvert computations.

\begin{tabular}{|c|c|c|c|c|c|c|c|c|c|c|c|}
\hline $\begin{array}{l}\text { Water } \\
\text { year }\end{array}$ & Date & $\begin{array}{c}\text { Discharge } \\
\left(\mathrm{ft}^{3} / \mathrm{s}\right)\end{array}$ & $\begin{array}{l}\text { Gage } \\
\text { height } \\
\text { (ft) }\end{array}$ & $\begin{array}{l}\text { Water } \\
\text { year }\end{array}$ & Date & $\begin{array}{c}\text { Discharge } \\
\left(\mathrm{ft}^{3} / \mathrm{s}\right)\end{array}$ & $\begin{array}{l}\text { Gage } \\
\text { height } \\
\text { (ft) }\end{array}$ & $\begin{array}{l}\text { Water } \\
\text { year }\end{array}$ & Date & $\begin{array}{c}\text { Discharge } \\
\left(\mathrm{ft}^{3} / \mathrm{s}\right)\end{array}$ & $\begin{array}{c}\text { Gage } \\
\text { height } \\
\text { (ft) }\end{array}$ \\
\hline 1965 & Feb. 18 & 282 & 3.93 & 1969 & Aug. 04 & 406 & 4.31 & 1973 & Feb. 02 & 766 & 5.06 \\
\hline 1966 & Mar. 03 & 680 & 4.91 & 1970 & Mar. 31 & 305 & 4.01 & 1974 & Apr. 05 & 172 & 3.46 \\
\hline 1967 & Feb. 07 & 190 & 3.55 & 1971 & Mar. 03 & 128 & 3.21 & 1975 & Apr. 14 & 860 & 5.21 \\
\hline 1968 & Jan. -- & 6.0 & $-b$ & 1972 & Jan. 14 & 153 & 3.36 & & & & \\
\hline
\end{tabular}




\section{ALTAMAHA RIVER BASIN}

\section{FOLSOM CREEK TRIBUTARY NEAR ROCHELLE, GEORGIA}

LOCATION.--Lat $32^{\circ} 00^{\prime} 15^{\prime \prime}$, long $83^{\circ} 25^{\prime} 58^{\prime \prime}$, Wilcox County, at culvert on State Highway 233,4 mi north of Rochelle.

DRAINAGE AREA.--1.44 $\mathrm{mi}^{2}$.

GAGE.--Flood stage/rainfall recorder prior to 1975 ; crest-stage gage thereafter. Datum of gage is about $260 \mathrm{ft}$ above sea level (from topographic map).

STAGE-DISCHARGE RELATION.--Defined by current-meter measurements below $46 \mathrm{ft}^{3} / \mathrm{s}$, and extended above on the basis of culvert computations.

\begin{tabular}{|c|c|c|c|c|c|c|c|c|c|c|c|}
\hline $\begin{array}{l}\text { Water } \\
\text { year }\end{array}$ & Date & $\begin{array}{c}\text { Discharge } \\
\left(\mathrm{ft}^{3} / \mathrm{s}\right)\end{array}$ & $\begin{array}{c}\text { Gage } \\
\text { height } \\
\text { (ft) }\end{array}$ & $\begin{array}{l}\text { Water } \\
\text { year }\end{array}$ & Date & $\begin{array}{c}\text { Discharge } \\
\left(\mathrm{ft}^{3} / \mathrm{s}\right)\end{array}$ & $\begin{array}{c}\text { Gage } \\
\text { height } \\
\text { (ft) }\end{array}$ & $\begin{array}{l}\text { Water } \\
\text { year }\end{array}$ & Date & $\begin{array}{c}\text { Discharge } \\
\left(\mathrm{ft}^{3} / \mathrm{s}\right)\end{array}$ & $\begin{array}{c}\text { Gage } \\
\text { height } \\
\text { (ft) }\end{array}$ \\
\hline 1964 & July 21 & 244 & 4.74 & 1973 & Apr. 01 & 89 & 2.66 & 1982 & Feb. 16 & 138 & 3.36 \\
\hline 1965 & July 12 & 80 & 2.51 & 1974 & Apr. 05 & 59 & 2.19 & 1983 & Mar. 06 & 156 & 3.62 \\
\hline 1966 & Feb. 28 & 121 & 3.11 & 1975 & Apr. 14 & 245 & 4.76 & 1984 & Mar. 05 & 121 & 3.11 \\
\hline 1967 & Feb. 07 & 50 & 2.06 & 1976 & May 01 & 52 & 2.08 & 1985 & Aug. 29 & 3 & 0.77 \\
\hline 1968 & Aug. -- & 2.0 & $--b$ & 1977 & Dec. 28 & 153 & 3.56 & 1986 & Dec. 13 & 281 & 5.16 \\
\hline 1969 & Aug. 04 & 39 & 1.89 & 1978 & Apr. 13 & 259 & 4.91 & 1987 & Mar. 01 & 207 & 4.29 \\
\hline 1970 & Aug. 11 & 434 & 7.16 & 1979 & Feb. 24 & 295 & 5.31 & 1988 & Feb. 19 & 19.0 & 1.53 \\
\hline 1971 & Mar. 03 & 246 & 4.77 & 1980 & Mar. 13 & 177 & 3.91 & 1989 & June 21 & 45.0 & 1.98 \\
\hline 1972 & Jan. 05 & 110 & 2.96 & 1981 & Apr. 01 & 18 & 1.55 & 1990 & Jan. 09 & 41.0 & 1.93 \\
\hline
\end{tabular}

02215280 BALL CREEK TRIBUTARY NEAR ROCHELLE, GEORGIA

(formerly published as "Little House Creek Tributary near Rebecca, Georgia")

LOCATION.--Lat $31^{\circ} 49^{\prime} 57^{\prime \prime}$, long $83^{\circ} 22{ }^{\prime} 05^{\prime \prime}$, Ben Hill County, at culvert on State Highway 90, 7.5 mi east of Rebecca.

DRAINAGE AREA.--2.45 $\mathrm{mi}^{2}$.

GAGE.--Crest-stage gage prior to Aug. 20, 1964; flood-stage recorder, Aug. 20, 1964 to Dec. 1, 1967; flood-stage/rainfall recorder,

Dec. 1, 1967 to Aug. 20, 1970; and water-stage/rainfall recorder thereafter. Datum of gage is about $260 \mathrm{ft}$ above sea level (from topographic map).

STAGE-DISCHARGE RELATION.--Defined by current-meter measurements below $100 \mathrm{ft}^{3} / \mathrm{s}$, and extended above on the basis of culvert computations.

REMARKS.--Peak discharges for 1961 and 1964 are estimated.

\begin{tabular}{|c|c|c|c|c|c|c|c|c|c|c|c|}
\hline $\begin{array}{l}\text { Water } \\
\text { year }\end{array}$ & Date & $\begin{array}{c}\text { Discharge } \\
\left(\mathrm{ft}^{3} / \mathrm{s}\right)\end{array}$ & $\begin{array}{c}\text { Gage } \\
\text { height } \\
\text { (ft) }\end{array}$ & $\begin{array}{l}\text { Water } \\
\text { year }\end{array}$ & Date & $\begin{array}{c}\text { Discharge } \\
\left(\mathrm{ft}^{3} / \mathrm{s}\right)\end{array}$ & $\begin{array}{c}\text { Gage } \\
\text { height } \\
\text { (ft) }\end{array}$ & $\begin{array}{l}\text { Water } \\
\text { year }\end{array}$ & Date & $\begin{array}{c}\text { Discharge } \\
\left(\mathrm{ft}^{3} / \mathrm{s}\right)\end{array}$ & $\begin{array}{c}\text { Gage } \\
\text { height } \\
\text { (ft) }\end{array}$ \\
\hline 1960 & Apr. 02 & 775 & 9.50 & 1966 & Mar. 04 & 254 & 4.65 & 1972 & June 25 & 116 & 3.07 \\
\hline 1961 & Apr. 15 & 175 & - & 1967 & Feb. 07 & 150 & 3.49 & 1973 & Apr. 01 & 212 & 4.18 \\
\hline 1962 & Feb. - & 50 & $--b$ & 1968 & Jan. 01 & 16 & 1.20 & 1974 & Sept.17 & 331 & 5.50 \\
\hline 1963 & July 09 & 440 & 6.61 & 1969 & Aug. 22 & 290 & 5.04 & 1975 & Apr. 15 & 334 & 5.53 \\
\hline 1964 & June 25 & 530 & - & 1970 & July 04 & 364 & 5.84 & 1976 & Mar. 15 & 28 & 1.56 \\
\hline 1965 & Feb. 26 & 146 & 3.40 & 1971 & Mar. 26 & 79 & 2.57 & 1977 & Dec. 28 & 244 & 4.53 \\
\hline
\end{tabular}


LOCATION.--Lat $31^{\circ} 55^{\prime} 06^{\prime \prime}$, long $82^{\circ} 40^{\prime} 26^{\prime \prime}$, Telfair-Jeff Davis County line, near left bank on downstream end of pier of bridge on U.S. Highway 341 at Lumber City, $500 \mathrm{ft}$ downstream from Southern Railway bridge, 1 mi upstream from Little Ocmulgee River, and 12 mi upstream from confluence with Oconee River.

DRAINAGE AREA.--5, $180 \mathrm{mi}^{2}$, approximately.

GAGE.-Water-stage recorder. Datum of gage is $87.48 \mathrm{ft}$ above sea level (from U.S. Coast and Geodetic Survey benchmark). Prior to Nov. 8, 1937, nonrecording gage at same site and datum.

STAGE-DISCHARGE RELATION.--Defined by current-meter measurements below $67,000 \mathrm{ft}^{3} / \mathrm{s}$, and extended above on the basis of

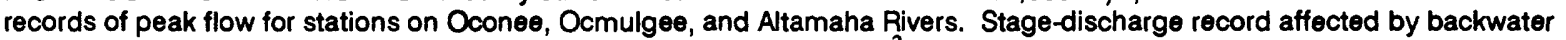
after rises of over $19 \mathrm{ft}$. Bankful stage and discharge, $15 \mathrm{ft}$ and $25,000 \mathrm{ft}^{3} / \mathrm{s}$.

REMARKS.--Stage records for 1909-36 from National Weather Service. Minor regulation of lower peak discharges from storage in Lloyd Shoals Reservoir (maximum flood-control storage, 78,000 acre-ft) since 1910.

HISTORICAL DATA.--Flood of March 1891 was highest known flood by local residents at the time the gage was installed in 1918. Unpublished National Weather Service information indicates that the flood of 1925 was probably the highest since at least 1841.

\begin{tabular}{|c|c|c|c|c|c|c|c|c|c|c|c|}
\hline $\begin{array}{l}\text { Water } \\
\text { year }\end{array}$ & Date & $\begin{array}{c}\text { Discharge } \\
\left(\mathrm{ft}^{3} / \mathrm{s}\right)\end{array}$ & $\begin{array}{c}\text { Gage } \\
\text { height } \\
\text { (ft) }\end{array}$ & $\begin{array}{l}\text { Water } \\
\text { year }\end{array}$ & Date & $\begin{array}{c}\text { Discharge } \\
\left(\mathrm{ft}^{3} / \mathrm{s}\right)\end{array}$ & $\begin{array}{c}\text { Gage } \\
\text { height } \\
\text { (ft) }\end{array}$ & $\begin{array}{l}\text { Water } \\
\text { year }\end{array}$ & Date & $\begin{array}{c}\text { Discharge } \\
\left(\mathrm{ft}^{3} / \mathrm{s}\right)\end{array}$ & $\begin{array}{c}\text { Gage } \\
\text { height } \\
\text { (ft) }\end{array}$ \\
\hline$\underline{1891}$ & Mar. - & 65,200 & $22.00 \mathrm{a}, \mathrm{c}$ & 1936 & Apr. 15 & 69,500 & $22.70 \mathrm{a}$ & 1964 & Apr. 18 & 48,900 & 19.00 \\
\hline$\overline{1909}$ & Mar. 23 & 39,800 & 17.70 & 1937 & May 11 & 20,700 & 14.20 & 1965 & Jan. 06 & 29,200 & 16.00 \\
\hline 1910 & Mar. 12 & 14,200 & 12.10 & 1938 & Apr. 17 & 34,500 & 16.80 & 1966 & Mar. 10 & 51,900 & 19.40 \\
\hline 1911 & Aug. 31 & 36,600 & 17.20 & 1939 & Mar. 09 & 43,800 & 18.30 & 1967 & Jan. 12 & 21,900 & 14.49 \\
\hline 1912 & Mar. 24 & 50,900 & 19.30 & 1940 & Mar. 01 & 12,800 & 11.60 & 1968 & Mar. 26 & 12,800 & 11.68 \\
\hline 1913 & Mar. 22 & 58,300 & $21.10 \mathrm{a}$ & 1941 & July 24 & 8,980 & 9.35 & 1969 & May 02 & 15,900 & 12.77 \\
\hline 1914 & Mar. 09 & 9,960 & 9.80 & 1942 & Mar. 31 & 52,600 & 19.50 & 1970 & Apr. 02 & 39,000 & 18.27 \\
\hline 1915 & Jan. 29 & 18,200 & 13.50 & 1943 & Mar. 30 & 40,500 & 17.80 & 1971 & Mar. 13 & 49,000 & 20.19 \\
\hline 1916 & July 19 & 36,600 & 17.20 & 1944 & Mar. 31 & 60,500 & 20.50 & 1972 & Jan. 23 & 35,000 & 16.95 \\
\hline 1917 & Apr. 06 & 25,100 & 15.20 & 1945 & May 08 & 19,200 & 13.80 & 1973 & Apr. 12 & 26,200 & 15.41 \\
\hline 1918 & Feb. 13 & 12,700 & 11.40 & 1946 & Jan. 19 & 34,000 & 16.80 & 1974 & Feb. 27 & 21,700 & 14.46 \\
\hline 1919 & Mar. 05 & 47,500 & 18.80 & 1947 & Mar. 18 & 32,700 & 16.60 & 1975 & Mar. 25 & 48,200 & 19.50 \\
\hline 1920 & Apr. 07 & 34,000 & 16.80 & 1948 & Apr. 03 & 48,200 & 18.90 & 1976 & Mar. 28 & 28,900 & 15.95 \\
\hline 1921 & Feb. 21 & 24,100 & 15.00 & 1949 & Dec. 08 & 70,000 & $22.70 \mathrm{a}$ & 1977 & Apr. 01 & 23,600 & 14.89 \\
\hline 1922 & Mar. 16 & 45,400 & 18.50 & 1950 & Mar. 19 & 10,200 & 10.00 & 1978 & Feb. 05 & 43,400 & 18.22 \\
\hline 1923 & June 07 & 36,600 & 17.20 & 1951 & Apr. 01 & 11,000 & 10.50 & 1979 & Mar. 06 & 42,500 & 18.09 \\
\hline 1924 & Mar. 08 & 19,900 & 14.00 & 1952 & Mar. 15 & 34,000 & 16.80 & 1980 & Mar. 21 & 42,100 & 18.73 \\
\hline 1925 & Jan. 21 & 98,400 & $26.30 \mathrm{a}$ & 1953 & May 13 & 35,300 & 17.00 & 1981 & Feb. 24 & 17,800 & 13.99 \\
\hline 1926 & Apr. 11 & 17,800 & 13.40 & 1954 & Dec. 26 & 16,600 & 13.00 & 1982 & Feb. 15 & 24,500 & 15.08 \\
\hline 1927 & July 30 & 11,200 & 10.60 & 1955 & Sept.17 & 11,400 & 10.70 & 1983 & Apr. 19 & 30,100 & 16.17 \\
\hline 1928 & Aug. 21 & 56,500 & $20.30 \mathrm{a}$ & 1956 & Mar. 31 & 14,700 & 12.30 & 1984 & Mar. 09 & 22,500 & 14.65 \\
\hline 1929 & Mar. 11 & 75,800 & $23.50 \mathrm{a}$ & 1957 & Apr. 19 & 15,200 & 12.50 & 1985 & Feb. 18 & 20,100 & 14.05 \\
\hline 1930 & Oct. 10 & 54,700 & $20.00 \mathrm{a}$ & 1958 & Mar. 16 & 24,600 & 14.80 & 1986 & Feb. 13 & 14,900 & 12.45 \\
\hline 1931 & Nov. 21 & 11,400 & 10.70 & 1959 & Mar. 17 & 17,200 & 13.20 & 1987 & Mar. 11 & 25,900 & 15.33 \\
\hline 1932 & Jan. 20 & 12,900 & 11.50 & 1960 & Apr. 09 & 39,000 & 18.20 & 1988 & Mar. 12 & 9,880 & 10.16 \\
\hline 1933 & Mar. 03 & 20,300 & 14.10 & 1961 & Mar. 08 & 43,500 & 18.90 & 1989 & Apr. 21 & 12,000 & 11.28 \\
\hline 1934 & Mar. 18 & 18,800 & 13.70 & 1962 & Mar. 07 & 22,300 & 14.60 & 1990 & Mar. 28 & 41,500 & 17.98 \\
\hline 1935 & Mar. 26 & 10,100 & 9.90 & 1963 & Feb. 01 & 26,600 & 15.50 & & & & \\
\hline
\end{tabular}


LOCATION.-Lat $32^{\circ} 07^{\prime} 28^{\prime \prime}$, long $83^{\circ} 03^{\prime} 37^{\prime \prime}$, Dodge County, at bridge on State Highway 165, 1.6 mi north of Chauncey. DRAINAGE AREA.-221 $\mathrm{mi}^{2}$.

GAGE.--Crest-stage gage. Datum of gage is about $182 \mathrm{ft}$ above sea level (from topographic map).

STAGE-DISCHARGE RELATION.--Defined by current-meter measurements below $1,720 \mathrm{ft}^{3} / \mathrm{s}$, and extended above on the basis of straight-line extension.

REMARKS.--This stream is called "Little Ocmulgee River" on county maps.

\begin{tabular}{|c|c|c|c|c|c|c|c|c|c|c|c|}
\hline $\begin{array}{l}\text { Water } \\
\text { year }\end{array}$ & Date & $\begin{array}{c}\text { Discharge } \\
\left(\mathrm{ft}^{3} / \mathrm{s}\right)\end{array}$ & $\begin{array}{c}\text { Gage } \\
\text { height } \\
\text { (ft) }\end{array}$ & $\begin{array}{l}\text { Water } \\
\text { year }\end{array}$ & Date & $\begin{array}{c}\text { Discharge } \\
\left(\mathrm{ft}^{3} / \mathrm{s}\right)\end{array}$ & $\begin{array}{c}\text { Gage } \\
\text { height } \\
\text { (ft) }\end{array}$ & $\begin{array}{l}\text { Water } \\
\text { year }\end{array}$ & Date & $\begin{array}{c}\text { Discharge } \\
\left(\mathrm{ft}^{3} / \mathrm{s}\right)\end{array}$ & $\begin{array}{c}\text { Gage } \\
\text { height } \\
\text { (ft) }\end{array}$ \\
\hline 1984 & Mar. 06 & 1,850 & 7.51 & 1987 & Jan. 20 & 4,740 & 9.33 & 1989 & Apr. 11 & 710 & 6.23 \\
\hline 1985 & Mar. 17 & 1,700 & 7.38 & 1988 & Apr. 17 & 637 & 6.11 & 1990 & Jan. 09 & 1,430 & 7.13 \\
\hline 1986 & Dec. 14 & 1,420 & 7.22 & & & & & & & & \\
\hline
\end{tabular}

\section{LITTLE OCMULGEE RIVER AT TOWNS, GEORGIA}

LOCATION.-Lat $32^{\circ} 00^{\prime} 28^{\prime \prime}$, long $82^{\circ} 45^{\prime} 10^{\prime \prime}$, Telfair County, at State Highway 134 , at Towns.

DRAINAGE AREA. $-351 \mathrm{mi}^{2}$ (formerly published as $329 \mathrm{mi}^{2}$ ).

GAGE.-Nonrecording prior to December 1946; crest-stage gage after March 15, 1949. Datum of gage is $108.06 \mathrm{ft}$ above sea level (levels from Georgia Department of Transportation).

STAGE-DISCHARGE RELATION.--Defined by current-meter measurements below $6,100 \mathrm{tt}^{3} / \mathrm{s}$, and extended above on the basis of slope-conveyance estimates. Bankfull stage and discharge, $10 \mathrm{ft}$ and $1,100 \mathrm{ft}^{3} / \mathrm{s}$.

HISTORICAL DATA.--Flood stages of 1925 and 1948, based on information furnished by local residents. Flood stage of 1929 , based on information furnished by the Georgia Department of Transportation. Flood of Dec. 1949, from floodmark. Flood of 1925 thought to be the highest since 1841 , based on information from nearby stations.

REMARKS.-Peak discharges for 1925 and 1929 are estimated.

\begin{tabular}{|c|c|c|c|c|c|c|c|c|c|c|c|}
\hline $\begin{array}{l}\text { Water } \\
\text { year }\end{array}$ & Date & $\begin{array}{c}\text { Discharge } \\
\left(\mathrm{ft}^{3} / \mathrm{s}\right)\end{array}$ & $\begin{array}{c}\text { Gage } \\
\text { height } \\
\text { (ft) }\end{array}$ & $\begin{array}{c}\text { Water } \\
\text { year }\end{array}$ & Date & $\begin{array}{c}\text { Discharge } \\
\left(\mathrm{ft}^{3} / \mathrm{s}\right)\end{array}$ & $\begin{array}{c}\text { Gage } \\
\text { height } \\
\text { (ft) }\end{array}$ & $\begin{array}{l}\text { Water } \\
\text { year }\end{array}$ & Date & $\begin{array}{c}\text { Discharge } \\
\left(\mathrm{ft}^{3} / \mathrm{s}\right)\end{array}$ & $\begin{array}{c}\text { Gage } \\
\text { height } \\
\text { (ft) }\end{array}$ \\
\hline$\underline{1925}$ & Jan. -- & 15,000 & $20.40 c$ & 1952 & Mar. 15 & 1,460 & 10.90 & 1966 & Mar. 05 & 5,250 & 16.25 \\
\hline 1929 & Mar. -- & 8,500 & $17.30 \mathrm{c}$ & 1953 & Sept.24 & 2,710 & 13.30 & 1967 & Jan. 04 & 1,840 & 11.79 \\
\hline 1938 & Apr. 13 & 2,200 & 12.00 & 1954 & Dec. 26 & 1,540 & 11.10 & 1968 & Apr. -- & 786 & $--b$ \\
\hline 1939 & Mar. 03 & 4,980 & 14.60 & 1955 & Apr. 15 & 1,030 & 9.48 & 1969 & Mar. 18 & 969 & 9.28 \\
\hline 1940 & July 22 & 1,880 & 11.20 & 1956 & Feb. 08 & 1,620 & 11.30 & 1970 & Apr. 01 & 3,350 & 14.17 \\
\hline 1941 & July 22 & 2,150 & 11.90 & 1957 & May 16 & 1,360 & 10.60 & 1971 & Mar. 27 & 3,700 & 14.68 \\
\hline 1942 & Dec. 27 & 7,480 & 16.00 & 1958 & Mar. 14 & 3,400 & 14.00 & 1972 & Feb. 03 & 2,750 & 13.38 \\
\hline 1943 & Jan. 23 & 5,040 & 14.80 & 1959 & Mar. 09 & 2,320 & 12.70 & 1973 & Feb. 02 & 3,260 & 14.07 \\
\hline 1944 & Apr. 19 & 4,750 & 14.60 & 1960 & Apr. 06 & 6,100 & 17.00 & 1974 & Feb. 17 & 1,750 & 11.61 \\
\hline 1945 & Mar. 01 & 1,260 & 9.40 & 1961 & Apr. 15 & 2,710 & 13.30 & 1975 & Apr. 16 & 3,300 & 14.13 \\
\hline$\underline{1946}$ & Jan. 23 & 1,760 & 10.90 & 1962 & Apr. 01 & 1,750 & 11.55 & 1976 & May 16 & 1,290 & 10.41 \\
\hline 1948 & Apr. 04 & 7,080 & 16.00 & 1963 & July 09 & 1,990 & 12.11 & 1977 & Mar. 15 & 2,690 & 13.27 \\
\hline 1949 & Dec. 09 & 2,110 & 11.80 & 1964 & Mar. 05 & 3,680 & 14.60 & $\underline{1978}$ & Jan. 27 & 3,100 & 13.85 \\
\hline$\overline{1951}$ & Mar. 31 & 1,290 & 10.40 & 1965 & Feb. 18 & 4,400 & 15.40 & & & & \\
\hline
\end{tabular}




\section{ALTAMAHA RIVER BASIN}

02216100 ALLIGATOR CREEK NEAR ALAMO, GEORGIA

LOCATION.--Lat 32 $01^{\prime} 35^{\prime \prime}$ long $82^{\circ} 41^{\prime} 44^{\prime \prime}$, Wheeler County, at State Highway 134, 9.5 mi southeast of Alamo.

DRAINAGE AREA.--255 $\mathrm{mi}^{2}$.

GAGE.--Crest-stage gage. Datum of gage is $109.7 \mathrm{ft}$ above sea level (levels from Georgia Department of Transportation).

STAGE-DISCHARGE RELATION.--Defined by current-meter measurements below $4,500 \mathrm{ft}^{3} / \mathrm{s}$, and extended above on the basis of straight-line extension. Bankfull stage and discharge, $10 \mathrm{ft}$ and $1,100 \mathrm{ft}^{3} / \mathrm{s}$.

HISTORICAL DATA.--Flood stage of 1929 based on information furnished by the Georgia Department of Transportation. The flood of 1929 was the highest since 1925 , based on nearby stations.

\begin{tabular}{|c|c|c|c|c|c|c|c|c|c|c|c|}
\hline $\begin{array}{l}\text { Water } \\
\text { year }\end{array}$ & Date & $\begin{array}{c}\text { Discharge } \\
\left(\mathrm{ft}^{3} / \mathrm{s}\right)\end{array}$ & $\begin{array}{c}\text { Gage } \\
\text { height } \\
\text { (ft) }\end{array}$ & $\begin{array}{l}\text { Water } \\
\text { year }\end{array}$ & Date & $\begin{array}{c}\text { Discharge } \\
\left(\mathrm{ft}^{3} / \mathrm{s}\right)\end{array}$ & $\begin{array}{c}\text { Gage } \\
\text { height } \\
\text { (ft) }\end{array}$ & $\begin{array}{l}\text { Water } \\
\text { year }\end{array}$ & Date & $\begin{array}{c}\text { Discharge } \\
\left(\mathrm{ft}^{3} / \mathrm{s}\right)\end{array}$ & $\begin{array}{c}\text { Gage } \\
\text { height } \\
\text { (ft) }\end{array}$ \\
\hline$\underline{1929}$ & Mar. - & 5,000 & $15.40 \mathrm{c}$ & 1956 & Feb. 08 & 1,100 & 9.93 & 1962 & Apr. 01 & 1,280 & 10.61 \\
\hline$\overline{1951}$ & Mar. 31 & 1,260 & 10.50 & 1957 & May 16 & 1,180 & 10.20 & 1963 & July 09 & 2,100 & 12.69 \\
\hline 1952 & Mar. 24 & 1,180 & 10.20 & 1958 & Mar. 10 & 2,300 & 13.00 & 1964 & Feb. 20 & 3,140 & 14.10 \\
\hline 1953 & Sept.30 & 2,230 & 12.90 & 1959 & Mar. 09 & 1,840 & 12.20 & 1965 & Feb. 18 & 3,900 & 14.90 \\
\hline 1954 & Jan. 01 & 1,130 & 9.99 & 1960 & Apr. 06 & 5,500 & 16.20 & $\underline{1966}$ & Mar. 05 & 5,500 & 16.22 \\
\hline 1955 & Sept.15 & 860 & 8.71 & 1961 & Apr. 15 & 1,390 & 11.00 & & & & \\
\hline
\end{tabular}

\section{TURNPIKE CREEK NEAR MCRAE, GEORGIA}

LOCATION.--Lat $31^{\circ} 59^{\prime} 29^{\prime \prime}$, long $82^{\circ} 55^{\prime} 19^{\prime \prime}$, Telfair County, on downstream side of bridge of U.S. Highways 319 and $441,4.8 \mathrm{mi}$ south of McRae.

DRAINAGE AREA.--49.2 $\mathrm{mi}^{2}$.

GAGE.--Water-stage recorder. Datum of gage is $173.17 \mathrm{ft}$ above sea level (levels from Georgia Department of Transportation). STAGE-DISCHARGE RELATION.--Defined by current-meter measurements below $2,200 \mathrm{ft}^{3} / \mathrm{s}$.

\begin{tabular}{|c|c|c|c|c|c|c|c|c|c|c|c|}
\hline $\begin{array}{l}\text { Water } \\
\text { year }\end{array}$ & Date & $\begin{array}{c}\text { Discharge } \\
\left(\mathrm{ft}^{3} / \mathrm{s}\right)\end{array}$ & $\begin{array}{c}\text { Gage } \\
\text { height } \\
\text { (ft) }\end{array}$ & $\begin{array}{l}\text { Water } \\
\text { year }\end{array}$ & Date & $\begin{array}{c}\text { Discharge } \\
\left(\mathrm{ft}^{3} / \mathrm{s}\right)\end{array}$ & $\begin{array}{c}\text { Gage } \\
\text { height } \\
\text { (ft) }\end{array}$ & $\begin{array}{l}\text { Water } \\
\text { year }\end{array}$ & Date & $\begin{array}{c}\text { Discharge } \\
\left(\mathrm{ft}^{3} / \mathrm{s}\right)\end{array}$ & $\begin{array}{c}\text { Gage } \\
\text { height } \\
\text { (ft) }\end{array}$ \\
\hline 1983 & Mar. 07 & 2,170 & 10.51 & 1986 & Nov. 22 & 2,220 & 10.56 & 1989 & July 31 & 359 & 7.38 \\
\hline 1984 & May 04 & 1,640 & 9.92 & 1987 & Mar. 01 & 1,260 & 9.20 & 1990 & Jan. 08 & 1,420 & 9.64 \\
\hline 1985 & Aug. 31 & 294 & 7.11 & 1988 & Apr. 19 & 836 & 8.68 & & & & \\
\hline
\end{tabular}




\section{ALTAMAHA RIVER BASIN}

02216610 TILLMAN MILL CREEK NEAR LUMBER CITY, GEORGIA

(Formerly published as "Ocmulgee River Tributary near Lumber City, Georgia")

LOCATION.--Lat $31^{\circ} 58^{\prime} 53^{\prime \prime}$, long $82^{\circ} 38^{\prime} 32^{\prime \prime}$, Wheeler County, at culvert on State Highway 19, 4.7 mi upstream from mouth, and 4.8 mi northeast of Lumber City.

DRAINAGE AREA.--2.71 $\mathrm{mi}^{2}$.

GAGE.-Prior to Mar. 19, 1969, flood-stage recorder; Mar. 19, 1968 to Sept. 10, 1970, flood-stage/rainfall recorder; waterstage/rainfall recorder thereafter. Prior to Oct. 1, 1974, at datum $2.0 \mathrm{ft}$ lower. Datum of gage is about $170 \mathrm{ft}$ above sea level (from topographic map).

STAGE-DISCHARGE RELATION.--Defined by current-meter measurements below $430 \mathrm{ft}^{3} / \mathrm{s}$, and extended above on the basis of culvert computations.

\begin{tabular}{|c|c|c|c|c|c|c|c|c|c|c|c|}
\hline $\begin{array}{l}\text { Water } \\
\text { year }\end{array}$ & Date & $\begin{array}{c}\text { Discharge } \\
\left(\mathrm{ft}^{3} / \mathrm{s}\right)\end{array}$ & $\begin{array}{c}\text { Gage } \\
\text { height } \\
\text { (ft) }\end{array}$ & $\begin{array}{l}\text { Water } \\
\text { year }\end{array}$ & Date & $\begin{array}{c}\text { Discharge } \\
\left(\mathrm{ft}^{3} / \mathrm{s}\right)\end{array}$ & $\begin{array}{c}\text { Gage } \\
\text { height } \\
\text { (ft) }\end{array}$ & $\begin{array}{l}\text { Water } \\
\text { year }\end{array}$ & Date & $\begin{array}{c}\text { Discharge } \\
\left(\mathrm{ft}^{3} / \mathrm{s}\right)\end{array}$ & $\begin{array}{c}\text { Gage } \\
\text { height } \\
\text { (ft) }\end{array}$ \\
\hline 1966 & May 23 & 1,070 & 9.59 & 1973 & Apr. 07 & 426 & 6.27 & 1980 & Mar. 30 & 93 & 4.09 \\
\hline 1967 & Jan. 02 & 65 & 3.87 & 1974 & Feb. 16 & 77 & $\underline{3.96}$ & 1981 & Apr. 01 & 544 & 6.91 \\
\hline 1968 & July 10 & 56 & 3.79 & 1975 & Apr. 14 & 236 & 5.14 & 1982 & Feb. 12 & 184 & 4.79 \\
\hline 1969 & May 19 & 179 & 4.76 & 1976 & May 16 & 166 & 4.66 & 1983 & Feb. 14 & 131 & 4.45 \\
\hline 1970 & Mar. 21 & 388 & 6.05 & 1977 & Mar. 13 & 491 & 6.63 & 1984 & May 03 & 358 & 5.92 \\
\hline 1971 & Aug. 29 & 960 & 9.05 & 1978 & Jan. 25 & 411 & 6.25 & 1985 & Aug. 28 & 365 & 5.96 \\
\hline 1972 & July 17 & 197 & 4.88 & 1979 & Feb. 23 & 119 & 4.30 & & & & \\
\hline
\end{tabular}

\section{ALLEN CREEK AT TALMO, GEORGIA}

LOCATION.--Lat $34^{\circ} 11^{\prime} 34^{\prime \prime}$, long $83^{\circ} 43^{\prime} 11^{\prime \prime}$, Jackson County, $400 \mathrm{ft}$ upstream from bridge on State Highway 11,5 mi upstream from confluence with Pond Fork, and 0.5 mi north of Talmo, .

DRAINAGE AREA.--17.3 $\mathrm{mi}^{2}$.

GAGE.-Water-stage recorder prior to Oct. 1, 1971; crest-stage gage thereafer. Datum of gage is $784.42 \mathrm{ft}$ above sea level (from U.S. Geological Survey benchmark).

STAGE-DISCHARGE RELATION.--Defined by current-meter measurements below $2,300 \mathrm{ft}^{3} / \mathrm{s}$, and extended above on the basis of contracted-opening measurements at 3,820 and $4,300 \mathrm{ft}^{3} / \mathrm{s}$. Bankfull stage and discharge, $11 \mathrm{ft}$ and $3,000 \mathrm{ft}^{3} / \mathrm{s}$.

REMARKS.--Flood of May 1976 was the highest since 1948, based on information from nearby stations.

\begin{tabular}{|c|c|c|c|c|c|c|c|c|c|c|c|}
\hline $\begin{array}{l}\text { Water } \\
\text { year }\end{array}$ & Date & $\begin{array}{c}\text { Discharge } \\
\left(\mathrm{ft}^{3} / \mathrm{s}\right)\end{array}$ & $\begin{array}{c}\text { Gage } \\
\text { height } \\
\text { (ft) }\end{array}$ & $\begin{array}{l}\text { Water } \\
\text { year }\end{array}$ & Date & $\begin{array}{c}\text { Discharge } \\
\left(\mathrm{ft}^{3} / \mathrm{s}\right)\end{array}$ & $\begin{array}{c}\text { Gage } \\
\text { height } \\
\text { (ft) }\end{array}$ & $\begin{array}{l}\text { Water } \\
\text { year }\end{array}$ & Date & $\begin{array}{c}\text { Discharge } \\
\left(\mathrm{ft}^{3} / \mathrm{s}\right)\end{array}$ & $\begin{array}{c}\text { Gage } \\
\text { height } \\
\text { (ft) }\end{array}$ \\
\hline 1952 & Mar. 10 & 2,330 & 11.50 & 1960 & Feb. 05 & 536 & 4.60 & 1968 & Mar. 12 & 645 & 3.89 \\
\hline 1953 & July 04 & 744 & 6.20 & 1961 & Feb. 21 & 3,820 & 12.60 & 1969 & Aug. 22 & 2,810 & 10.76 \\
\hline 1954 & Jan. 16 & 1,140 & 8.30 & 1962 & Dec. 12 & 1,410 & 9.34 & 1970 & Mar. 19 & 552 & 3.84 \\
\hline 1955 & Feb. 06 & 1,070 & 8.00 & 1963 & Apr. 30 & 1,680 & 10.10 & 1971 & Mar. 03 & 682 & 4.33 \\
\hline 1956 & Mar. 16 & 880 & 7.50 & 1964 & Mar. 26 & 2,270 & 11.42 & 1972 & Jan. 10 & 1,520 & 7.46 \\
\hline 1957 & Apr. 05 & 472 & 4.20 & 1965 & Apr. 25 & 1,340 & 9.11 & 1973 & Mar. 16 & 1,980 & 8.67 \\
\hline 1958 & July 06 & 780 & 6.50 & 1966 & Mar. 04 & 2,760 & 12.03 & $\underline{1974}$ & Dec. 31 & 1,510 & 7.42 \\
\hline 1959 & July 11 & 552 & 4.70 & 1967 & June 04 & 4,300 & 13.30 & 1976 & May 29 & 4,600 & $13.50 \mathrm{c}$ \\
\hline
\end{tabular}




\section{ALTAMAHA RIVER BASIN}

\section{MIDDLE OCONEE RIVER NEAR JEFFERSON, GEORGIA}

LOCATION.--Lat $34^{\circ} 05^{\prime} 46^{\prime \prime}$, long $83^{\circ} 36^{\prime} 23^{\prime \prime}$, Jackson County, at State Highway 11, 2.2 mi southwest of Jefferson. DRAINAGE AREA.--135 $\mathrm{mi}^{2}$ (revised).

GAGE.--Crest-stage gage. Datum of gage is about $660 \mathrm{ft}$ above sea level (from topographic map).

STAGE-DISCHARGE RELATION.--Defined by current-meter measurements below $7,400 \mathrm{ft} / \mathrm{s}$, and extended above on the basis of straight-line extension. Bankfull stage and discharge, $7 \mathrm{ft}$ and $1,500 \mathrm{ft}^{3} / \mathrm{s}$.

REMARKS.--Fiood of May 1976 was the highest since 1948, based on information from nearby stations.

\begin{tabular}{|c|c|c|c|c|c|c|c|c|c|c|c|}
\hline $\begin{array}{l}\text { Water } \\
\text { year }\end{array}$ & Date & $\begin{array}{c}\text { Discharge } \\
\left(\mathrm{ft}^{3} / \mathrm{s}\right)\end{array}$ & $\begin{array}{c}\text { Gage } \\
\text { height } \\
\text { (ft) }\end{array}$ & $\begin{array}{l}\text { Water } \\
\text { year }\end{array}$ & Date & $\begin{array}{c}\text { Discharge } \\
\left(\mathrm{ft}^{3} / \mathrm{s}\right)\end{array}$ & $\begin{array}{c}\text { Gage } \\
\text { height } \\
\text { (ft) }\end{array}$ & $\begin{array}{l}\text { Water } \\
\text { year }\end{array}$ & Date & $\begin{array}{c}\text { Discharge } \\
\left(\mathrm{ft}^{3} / \mathrm{s}\right)\end{array}$ & $\begin{array}{c}\text { Gage } \\
\text { height } \\
\text { (ft) }\end{array}$ \\
\hline 1951 & Oct. 22 & 3,500 & 8.25 & 1957 & Apr. 06 & 3,600 & 8.29 & 1962 & Dec. 13 & 7,000 & 12.00 \\
\hline 1952 & Mar. 24 & 6,640 & 11.80 & 1958 & Apr. 15 & 2,580 & 7.38 & 1963 & June 27 & 7,100 & 12.88 \\
\hline 1953 & Jan. 10 & 3,500 & 8.22 & 1959 & May 30 & 1,360 & 6.93 & 1964 & Apr. 09 & 7,800 & 12.74 \\
\hline 1954 & Jan. 19 & 5,920 & 10.90 & 1960 & Jan. 31 & 2,370 & 7.25 & $\underline{1965}$ & Dec. 25 & 4,260 & 8.94 \\
\hline 1955 & Feb. 07 & 4,930 & 9.70 & 1961 & Feb. 25 & 9,000 & 13.90 & $\overline{1976}$ & May 29 & 11,000 & $15.00 \mathrm{c}$ \\
\hline 1956 & Mar. 16 & 5,280 & 10.10 & & & & & & & & \\
\hline
\end{tabular}

\section{BUFFALO CREEK TRIBUTARY NEAR JEFFERSON, GEORGIA}

LOCATION.--Lat $34^{\circ} 05^{\prime} 00^{\prime \prime}$, long $83^{\circ} 38^{\prime} 01^{\prime \prime}$, Jackson County, at culvert on State Highway 11,4 mi southwest of Jefferson. DRAINAGE AREA.--0.39 $\mathrm{mi}^{2}$.

GAGE.--Fiood-stage recorder. Datum of gage is about $760 \mathrm{ft}$ above sea ievel (from topographic map).

STAGE-DISCHARGE RELATION.--Defined by current-meter measurements beiow $4 \mathrm{tt}^{3} / \mathrm{s}$, and extended above on the basis of culvert computations.

\begin{tabular}{|c|c|c|c|c|c|c|c|c|c|c|c|}
\hline $\begin{array}{l}\text { Water } \\
\text { year }\end{array}$ & Date & $\begin{array}{c}\text { Discharge } \\
\left(\mathrm{ft}^{3} / \mathrm{s}\right)\end{array}$ & $\begin{array}{c}\text { Gage } \\
\text { height } \\
\text { (ft) }\end{array}$ & $\begin{array}{l}\text { Water } \\
\text { year }\end{array}$ & Date & $\begin{array}{c}\text { Discharge } \\
\left(\mathrm{ft}^{3} / \mathrm{s}\right)\end{array}$ & $\begin{array}{c}\text { Gage } \\
\text { height } \\
\text { (ft) }\end{array}$ & $\begin{array}{l}\text { Water } \\
\text { year }\end{array}$ & Date & $\begin{array}{c}\text { Discharge } \\
\left(\mathrm{ft}^{3} / \mathrm{s}\right)\end{array}$ & $\begin{array}{c}\text { Gage } \\
\text { height } \\
\text { (ft) }\end{array}$ \\
\hline 1964 & Mar. 25 & 169 & 4.53 & 1969 & Aug. 22 & 115 & 3.64 & 1973 & May 28 & 136 & 3.99 \\
\hline 1965 & Mar. -- & 38 & $--b$ & 1970 & Mar. 19 & 23 & 1.64 & 1974 & Dec. 31 & 104 & 3.43 \\
\hline 1966 & Mar. 04 & 88 & 3.13 & 1971 & July 06 & 224 & 5.33 & 1975 & Mar. 13 & 94 & 3.24 \\
\hline 1967 & June 04 & 222 & 5.30 & 1972 & Jan. 10 & 80 & 2.97 & 1976 & May 29 & 318 & 6.63 \\
\hline 1968 & Mar. 12 & 84 & 3.04 & & & & & & & & \\
\hline
\end{tabular}




\section{ALTAMAHA RIVER BASIN \\ 02217380 MULBERRY RIVER NEAR WINDER, GEORGIA}

LOCATION.--Lat $34^{\circ} 03^{\prime} 08^{\prime \prime}$, long 83 $33^{\circ} 49^{\prime \prime}$, Barrow-Jackson County line, at bridge on State Highway $11,4.5$ mi northeast of Winder.

DRAINAGE AREA.--142 $\mathrm{mi}^{2}$.

GAGE.--Crest-stage gage. Datum of gage is about $675 \mathrm{ft}$ above sea level (from topographic map).

STAGE-DISCHARGE RELATION.--Defined by current-meter measurements below $4,600 \mathrm{ft}^{3} / \mathrm{s}$, and extended above on the basis of straight-line extension. Bankfull stage and discharge, $11 \mathrm{ft}$ and $2,700 \mathrm{ft}^{3} / \mathrm{s}$.

REMARKS.-Flood stage from 1976 flood from floodmarks.

\begin{tabular}{|c|c|c|c|c|c|c|c|c|c|c|c|}
\hline $\begin{array}{l}\text { Water } \\
\text { year }\end{array}$ & Date & $\begin{array}{c}\text { Discharge } \\
\left(\mathrm{ft}^{3} / \mathrm{s}\right)\end{array}$ & $\begin{array}{c}\text { Gage } \\
\text { height } \\
\text { (ft) }\end{array}$ & $\begin{array}{l}\text { Water } \\
\text { year }\end{array}$ & Date & $\begin{array}{c}\text { Discharge } \\
\left(\mathrm{ft}^{3} / \mathrm{s}\right)\end{array}$ & $\begin{array}{c}\text { Gage } \\
\text { height } \\
\text { (ft) }\end{array}$ & $\begin{array}{l}\text { Water } \\
\text { year }\end{array}$ & Date & $\begin{array}{c}\text { Discharge } \\
\left(\mathrm{ft}^{3} / \mathrm{s}\right)\end{array}$ & $\begin{array}{c}\text { Gage } \\
\text { height } \\
\text { (ft) }\end{array}$ \\
\hline$\underline{1976}$ & May 30 & 4,640 & 12.79 & 1986 & June 00 & 1,200 & $-b$ & 1989 & June 21 & 2,560 & 10.79 \\
\hline 1984 & Dec. 06 & 5,710 & 13.79 & 1987 & Mar. 01 & 3,780 & 12.08 & 1990 & Oct. 01 & 3,980 & 12.58 \\
\hline 1985 & Nov. 27 & 2,700 & 10.78 & 1988 & Jan. 20 & 1,670 & 9.31 & & & & \\
\hline
\end{tabular}

\section{MULBERRY RIVER TRIBUTARY NEAR WINDER, GEORGIA}

LOCATION.--Lat $34^{\circ} 03^{\prime} 53^{\prime \prime}$, long $83^{\circ} 39^{\prime} 45^{\prime \prime}$, Jackson County, at culvert on State Highway 11,6 mi northeast of Winder.

DRAINAGE AREA.--2.68 $\mathrm{mi}^{2}$.

GAGE.--Flood-stage recorder prior to Sept. 30, 1975; crest-stage gage thereafter. Datum of gage is about $740 \mathrm{ft}$ above sea level (from topographic map).

STAGE-DISCHARGE RELATION.--Defined by current-meter measurements below $89 \mathrm{ft}^{3} / \mathrm{s}$, and extended above on the basis of culvert computations.

REMARKS.--Peak discharge for 1980 is an estimate.

\begin{tabular}{|c|c|c|c|c|c|c|c|c|c|c|c|}
\hline $\begin{array}{l}\text { Water } \\
\text { year }\end{array}$ & Date & $\begin{array}{c}\text { Discharge } \\
\left(\mathrm{ft}^{3} / \mathrm{s}\right)\end{array}$ & $\begin{array}{c}\text { Gage } \\
\text { height } \\
\text { (ft) }\end{array}$ & $\begin{array}{l}\text { Water } \\
\text { year }\end{array}$ & Date & $\begin{array}{c}\text { Discharge } \\
\left(\mathrm{ft}^{3} / \mathrm{s}\right)\end{array}$ & $\begin{array}{c}\text { Gage } \\
\text { height } \\
\text { (ft) }\end{array}$ & $\begin{array}{l}\text { Water } \\
\text { year }\end{array}$ & Date & $\begin{array}{c}\text { Discharge } \\
\left(\mathrm{ft}^{3} / \mathrm{s}\right)\end{array}$ & $\begin{array}{c}\text { Gage } \\
\text { height } \\
\text { (ft) }\end{array}$ \\
\hline 1965 & July 14 & 518 & 3.38 & 1974 & Dec. 31 & 352 & 2.77 & 1983 & Feb. 02 & 360 & 2.80 \\
\hline 1966 & Mar. 04 & 556 & 3.52 & 1975 & Mar. 14 & 529 & 3.42 & 1984 & Dec. 06 & 445 & 3.12 \\
\hline 1967 & June 04 & 748 & 4.27 & 1976 & May 29 & 785 & 4.43 & 1985 & Nov. 27 & 221 & 2.24 \\
\hline 1968 & Mar. 12 & 433 & 3.08 & 1977 & May 00 & 278 & $-\mathrm{b}$ & 1986 & Mar. -- & 280 & $--b$ \\
\hline 1969 & Apr. 18 & 656 & 3.90 & 1978 & Jan. 25 & 386 & 2.90 & 1987 & Mar. 01 & 447 & 3.13 \\
\hline 1970 & Mar. 19 & 303 & 2.58 & 1979 & Apr. 13 & 492 & 3.29 & 1988 & Jan. 20 & 269 & 2.44 \\
\hline 1971 & Mar. 03 & 417 & 3.02 & 1980 & Mar. 28 & 400 & 3.32 & 1989 & June 21 & 496 & 3.34 \\
\hline 1972 & Jan. 10 & 407 & 2.98 & 1981 & Mar. -- & 280 & $--b$ & 1990 & Feb. 10 & 1,690 & 7.31 \\
\hline 1973 & Mar. 31 & 300 & 2.57 & 1982 & Jan. 04 & 290 & 2.53 & & & & \\
\hline
\end{tabular}




\section{ALTAMAHA RIVER BASIN}

\section{MULBERRY RIVER TRIBUTARY NO. 2, NEAR JEFFERSON, GEORGIA}

LOCATION.--Lat $34^{\circ} 04^{\prime} 38^{\prime \prime}$, long $83^{\circ} 38^{\prime} 53^{\prime \prime}$, Jackson County, at culvert on State Highway 11,5 mi southwest of Jefferson.

DRAINAGE AREA.--0.72 $\mathrm{mi}^{2}$.

GAGE.--Flood-stage/rainfall recorder. Datum of gage is about $770 \mathrm{ft}$ above sea level (from topographic map).

STAGE-DISCHARGE RELATION.--Defined by current-meter measurements below $165 \mathrm{ft}^{3} / \mathrm{s}$, and extended above on the basis of culvert computations.

\begin{tabular}{|c|c|c|c|c|c|c|c|c|c|c|c|}
\hline $\begin{array}{l}\text { Water } \\
\text { year }\end{array}$ & Date & $\begin{array}{c}\text { Discharge } \\
\left(\mathrm{ft}^{3} / \mathrm{s}\right)\end{array}$ & $\begin{array}{c}\text { Gage } \\
\text { height } \\
\text { (ft) }\end{array}$ & $\begin{array}{l}\text { Water } \\
\text { year }\end{array}$ & Date & $\begin{array}{c}\text { Discharge } \\
.\left(\mathrm{ft}^{3} / \mathrm{s}\right)\end{array}$ & $\begin{array}{c}\text { Gage } \\
\text { height } \\
\text { (ft) }\end{array}$ & $\begin{array}{l}\text { Water } \\
\text { year }\end{array}$ & Date & $\begin{array}{c}\text { Discharge } \\
\left(\mathrm{ft}^{3} / \mathrm{s}\right)\end{array}$ & $\begin{array}{c}\text { Gage } \\
\text { height } \\
\text { (ft) }\end{array}$ \\
\hline 1965 & July 15 & 170 & 2.74 & 1969 & Aug. 22 & 277 & 4.24 & 1973 & May 28 & 158 & 2.44 \\
\hline 1966 & Mar. 04 & 168 & 2.70 & 1970 & Aug. 19 & 62 & 1.39 & $\underline{1974}$ & Dec. 31 & 180 & 3.00 \\
\hline 1967 & June 04 & 385 & 5.45 & 1971 & July 06 & 218 & 3.50 & 1976 & May 29 & 400 & $5.60 \mathrm{c}$ \\
\hline 1968 & Mar. 12 & 229 & 3.64 & 1972 & Jan. 10 & 166 & 2.65 & & & & \\
\hline
\end{tabular}

\section{MIDDLE OCONEE RIVER NEAR ATHENS, GEORGIA}

LOCATION.--Lat $33^{\circ} 56^{\prime} 48^{\prime \prime}$, long $83^{\circ} 25^{\prime} 22^{\prime \prime}$, Clarke County, on left bank 0.5 mi upstream from U.S. Highway 78 and U.S. Highway (Business) 29,5 mi upstream from Barber Creek, and 2 mi west of Athens.

DRAINAGE AREA.--398 $\mathrm{mi}^{2}$.

GAGE.--Water-stage recorder. Datum of gage is $555.56 \mathrm{ft}$ above sea level (from U.S. Coast and Geodetic Survey benchmark), supplementary adjustment of 1936 . Oct. 11, 1901 to Oct. 25, 1902, nonrecording gage at site 1 mi upstream at different datum. Jan. 16, 1929 to Mar. 15, 1932, and Apr. 29, 1937 to Sept. 30, 1940, water-stage recorder at site 4 mi downstream at different datum.

STAGE-DISCHARGE RELATION.--Defined by current-meter measurements below $13,800 \mathrm{ft}^{3} / \mathrm{s}$ at present site. Defined by currentmeter measurements throughout range at former site. Bankfull stage and discharge at present site, $12 \mathrm{ft}$ and $5,200 \mathrm{ft} / \mathrm{s}$. HISTORICAL DATA.--Flood of 1902 is thought to be the highest since that time, based on information from local residents. REMARKS.--Records for 1929-31 from the U.S. Army Corps of Engineers.

\begin{tabular}{|c|c|c|c|c|c|c|c|c|c|c|c|}
\hline $\begin{array}{l}\text { Water } \\
\text { year }\end{array}$ & Date & $\begin{array}{c}\text { Discharge } \\
\left(\mathrm{ft}^{3} / \mathrm{s}\right)\end{array}$ & $\begin{array}{c}\text { Gage } \\
\text { height } \\
\text { (ft) }\end{array}$ & $\begin{array}{l}\text { Water } \\
\text { year }\end{array}$ & Date & $\begin{array}{c}\text { Discharge } \\
\left(\mathrm{ft}^{3} / \mathrm{s}\right)\end{array}$ & $\begin{array}{l}\text { Gage } \\
\text { height } \\
\text { (ft) }\end{array}$ & $\begin{array}{l}\text { Water } \\
\text { year }\end{array}$ & Date & $\begin{array}{c}\text { Discharge } \\
\left(\mathrm{ft}^{3} / \mathrm{s}\right)\end{array}$ & $\begin{array}{c}\text { Gage } \\
\text { height } \\
\text { (ft) }\end{array}$ \\
\hline$\underline{1902}$ & Feb. 28 & $\underline{19,600}$ & $25.50 \mathrm{c}$ & 1954 & Jan. 18 & 7,870 & 14.00 & 1973 & Mar. 18 & 7,490 & 15.10 \\
\hline$\overline{1929}$ & $\overline{\text { Mar. } 05}$ & $\overline{11,800}$ & 23.60 & 1955 & Feb. 08 & 5,600 & 11.00 & 1974 & Jan. 02 & 9,780 & 17.48 \\
\hline$\underline{1930}$ & Oct. 02 & 9,500 & 21.30 & 1956 & Mar. 18 & 6,840 & 12.70 & 1975 & Mar. 14 & 9,580 & 17.28 \\
\hline 1938 & July 26 & 5,160 & 19.60 & 1957 & Apr. 07 & 4,280 & 9.10 & 1976 & May 30 & 12,900 & 20.62 \\
\hline 1939 & Aug. 19 & 8,420 & 23.00 & 1958 & Apr. 17 & 2,560 & 5.40 & 1977 & Mar. 31 & 5,050 & 11.92 \\
\hline 1940 & Aug. 14 & $\underline{5,930}$ & 20.30 & 1959 & May 31 & 6,120 & 11.70 & 1978 & Nov. 07 & 12,500 & 20.10 \\
\hline 1941 & July 06 & 3,000 & 6.80 & 1960 & Jan. 31 & 3,800 & 8.20 & 1979 & Apr. 15 & 12,300 & 19.96 \\
\hline 1942 & Mar. 23 & 8,000 & 13.80 & 1961 & Feb. 26 & 12,200 & 18.20 & 1980 & Mar. 30 & 7,070 & 14.59 \\
\hline 1943 & Apr. 20 & 8,900 & 14.70 & 1962 & Dec. 14 & 8,570 & 14.80 & 1981 & Feb. 12 & 3,520 & 9.25 \\
\hline 1944 & Mar. 31 & 5,680 & 11.10 & 1963 & June 28 & 11,900 & 17.98 & 1982 & Jan. 05 & 8,290 & 16.05 \\
\hline 1945 & Apr. 25 & 4,880 & 10.00 & 1964 & Apr. 08 & 12,600 & 18.54 & 1983 & Apr. 10 & 5,890 & 13.08 \\
\hline 1946 & Jan. 07 & 8,400 & 14.80 & 1965 & Dec. 27 & 5,080 & 11.25 & 1984 & Dec. 07 & 8,300 & 16.06 \\
\hline 1947 & Jan. 21 & 7,800 & 14.00 & 1966 & Mar. 05 & 10,200 & 17.95 & 1985 & Feb. 07 & 3,090 & 8.28 \\
\hline 1948 & Feb. 10 & 5,230 & 10.50 & 1967 & June 06 & 9,550 & 17.25 & 1986 & Nov. 30 & 2,030 & 6.00 \\
\hline 1949 & Nov. 30 & 14,200 & 19.60 & 1968 & Mar. 14 & 5,010 & 11.85 & 1987 & Mar. 02 & 8,080 & 15.81 \\
\hline 1950 & June 01 & 1,500 & 2.98 & 1969 & Jan. 21 & 13,000 & 20.54 & 1988 & Jan. 21 & 3,640 & 9.34 \\
\hline 1951 & Oct. 22 & 3,410 & 7.60 & 1970 & Mar. 21 & 5,330 & 12.33 & 1989 & June 22 & 5,930 & 13.14 \\
\hline 1952 & Dec. 23 & 9,110 & 15.40 & 1971 & Mar. 04 & 7,380 & 14.97 & 1990 & Mar. 18 & 13,700 & 20.84 \\
\hline 1953 & Jan. 11 & 5,520 & 10.90 & 1972 & Jan. 12 & 11,300 & 18.96 & & & & \\
\hline
\end{tabular}




\section{ALTAMAHA RIVER BASIN}

02217505 BROOKLYN CREEK AT ATHENS, GEORGIA

LOCATION.--Lat $33^{\circ} 56^{\prime} 32^{\prime \prime}$, long $83^{\circ} 24^{\prime} 07^{\prime \prime}$, Clarke County, at culvert on Dudley Drive, at Athens.

DRAINAGE AREA. $-1.44 \mathrm{mi}^{2}$.

GAGE.--Flood-stage/rainfall recorder prior to Aug. 21, 1986. Crest-stage gage 1987 to present.

STAGE-DISCHARGE RELATION.--Defined by current-meter measurements below $86 \mathrm{ft} / \mathrm{s}$, and extended above on basis of culvert computations.

REMARKS.--Flow is affected by urbanization. Flood of May 1966 is the highest since 1961, based on information from local residents.

\begin{tabular}{|c|c|c|c|c|c|c|c|c|c|c|c|}
\hline $\begin{array}{l}\text { Water } \\
\text { year }\end{array}$ & Date & $\begin{array}{c}\text { Discharge } \\
\left(\mathrm{ft}^{3} / \mathrm{s}\right)\end{array}$ & $\begin{array}{c}\text { Gage } \\
\text { height } \\
\text { (ft) }\end{array}$ & $\begin{array}{l}\text { Water } \\
\text { year }\end{array}$ & Date & $\begin{array}{c}\text { Discharge } \\
\left(\mathrm{ft}^{3} / \mathrm{s}\right)\end{array}$ & $\begin{array}{c}\text { Gage } \\
\text { height } \\
\text { (ft) }\end{array}$ & $\begin{array}{l}\text { Water } \\
\text { year }\end{array}$ & Date & $\begin{array}{c}\text { Discharge } \\
\left(\mathrm{ft}^{3} / \mathrm{s}\right)\end{array}$ & $\begin{array}{c}\text { Gage } \\
\text { height } \\
\text { (ft) }\end{array}$ \\
\hline 1966 & May 27 & 2,200 & 12.70 & 1982 & Aug. 17 & 431 & 9.22 & 1987 & June 20 & 430 & 9.18 \\
\hline$\underline{1967}$ & June 04 & 606 & 10.20 & 1983 & Sept.02 & 651 & 10.35 & 1988 & Mar. 10 & 419 & 9.01 \\
\hline$\overline{1979}$ & Apr. 13 & 531 & 9.89 & 1984 & July 16 & 548 & 9.97 & 1989 & July 21 & 354 & 8.05 \\
\hline 1980 & May 20 & 723 & 10.59 & 1985 & Oct. 22 & 395 & 8.62 & 1990 & Mar. 17 & 610 & 10.25 \\
\hline 1981 & Sept.04 & 474 & 9.61 & 1986 & Aug. 11 & 401 & 8.71 & & & & \\
\hline
\end{tabular}

\section{BROOKLYN CREEK TRIBUTARY AT ATHENS, GEORGIA}

LOCATION.--Lat $33^{\circ} 56^{\prime} 26^{\prime \prime}$, long $83^{\circ} 23^{\prime} 48^{\prime \prime}$, Clarke County, at culvert on McWhorter Road, at Athens.

DRAINAGE AREA.- $0.19 \mathrm{mi}^{2}$.

GAGE.--Flood-stage/rainfall recorder.

STAGE-DISCHARGE RELATION.--Defined by current-meter measurements below $12 \mathrm{ft}^{3} / \mathrm{s}$, and extended above on basis of culvert computations.

REMARKS.--Flow is affected by urbanization.

\begin{tabular}{|c|c|c|c|c|c|c|c|c|c|c|c|}
\hline $\begin{array}{l}\text { Water } \\
\text { year }\end{array}$ & Date & $\begin{array}{c}\text { Discharge } \\
\left(\mathrm{ft}^{3} / \mathrm{s}\right)\end{array}$ & $\begin{array}{c}\text { Gage } \\
\text { height } \\
\text { (ft) }\end{array}$ & $\begin{array}{l}\text { Water } \\
\text { year }\end{array}$ & Date & $\begin{array}{c}\text { Discharge } \\
\left(\mathrm{ft}^{3} / \mathrm{s}\right)\end{array}$ & $\begin{array}{c}\text { Gage } \\
\text { height } \\
\text { (ft) }\end{array}$ & $\begin{array}{l}\text { Water } \\
\text { year }\end{array}$ & Date & $\begin{array}{c}\text { Discharge } \\
\left(\mathrm{ft}^{3} / \mathrm{s}\right)\end{array}$ & $\begin{array}{c}\text { Gage } \\
\text { height } \\
\text { (ft) }\end{array}$ \\
\hline 1979 & Apr. 13 & 85.0 & 4.11 & 1982 & Aug. 17 & 66.0 & 3.73 & 1985 & July 11 & 32.0 & 3.08 \\
\hline 1980 & May 20 & 94.0 & 4.27 & 1983 & Apr. 08 & 78.0 & 3.98 & 1986 & Aug. 11 & 45.0 & 3.36 \\
\hline 1981 & Apr. 20 & 35.0 & 3.15 & 1984 & July 16 & 89.0 & 4.19 & & & & \\
\hline
\end{tabular}

\section{LITTLE CURRY CREEK NEAR JEFFERSON, GEORGIA}

LOCATION.--Lat $34^{\circ} 08^{\prime} 25^{\prime \prime}$, long $83^{\circ} 32^{\prime} 09^{\prime \prime}$, Jackson County, at culvert on State Highway 15, 2.8 mi northeast of Jefferson. DRAINAGE AREA $-0.87 \mathrm{mi}^{2}$.

GAGE.--Flood-stage/rainfall recorder. Datum of gage is about $770 \mathrm{ft}$ above sea level (from topographic map).

STAGE-DISCHARGE RELATION.--Defined by current-meter measurements below $134 \mathrm{ft}^{3} / \mathrm{s}$, and extended above on basis of culvert computations.

\begin{tabular}{|c|c|c|c|c|c|c|c|c|c|c|c|}
\hline $\begin{array}{l}\text { Water } \\
\text { year }\end{array}$ & Date & $\begin{array}{c}\text { Discharge } \\
\left(\mathrm{ft}^{3} / \mathrm{s}\right)\end{array}$ & $\begin{array}{c}\text { Gage } \\
\text { height } \\
\text { (ft) }\end{array}$ & $\begin{array}{l}\text { Water } \\
\text { year }\end{array}$ & Date & $\begin{array}{c}\text { Discharge } \\
\left(\mathrm{ft}^{3} / \mathbf{s}\right)\end{array}$ & $\begin{array}{c}\text { Gage } \\
\text { height } \\
\text { (ft) }\end{array}$ & $\begin{array}{l}\text { Water } \\
\text { year }\end{array}$ & Date & $\begin{array}{l}\text { Discharge } \\
\left(\mathrm{ft}^{3} / \mathrm{s}\right)\end{array}$ & $\begin{array}{c}\text { Gage } \\
\text { height } \\
\text { (ft) }\end{array}$ \\
\hline 1964 & Mar. 25 & 150 & 3.75 & 1969 & Apr. 18 & 250 & 4.53 & 1973 & Mar. 16 & 299 & 4.82 \\
\hline 1965 & Mar. 24 & 68 & 2.63 & 1970 & Aug. 10 & 194 & 4.14 & 1974 & Dec. 31 & 244 & 4.49 \\
\hline 1966 & May 27 & 365 & 5.15 & 1971 & July 13 & 309 & 4.87 & 1975 & Mar. 13 & 171 & 3.95 \\
\hline 1967 & June 04 & 175 & 3.98 & 1972 & Jan. 10 & 172 & 3.96 & 1976 & May 29 & 558 & 6.03 \\
\hline 1968 & Dec. 11 & 58 & 2.44 & & & & & & & & \\
\hline
\end{tabular}




\section{ALTAMAHA RIVER BASIN}

02217730 TRIBUTARY TO NORTH OCONEE RIVER AT ATHENS, GEORGIA

LOCATION.--Lat $33^{\circ} 58^{\prime} 16^{\prime \prime}$, long $83^{\circ} 23^{\prime} 59^{\prime \prime}$, Clarke County, at culvert on U.S. Highway 29 , at Athens.

DRAINAGE AREA.--0.30 $\mathrm{mi}^{2}$.

GAGE.--Flood-stage/rainfall recorder.

STAGE-DISCHARGE RELATION.--Defined by current-meter measurements below $79 \mathrm{ft}^{3} / \mathrm{s}$, and extended above on basis of culvert computations.

REMARKS.--Flow is affected by urbanization.

\begin{tabular}{|c|c|c|c|c|c|c|c|c|c|c|c|}
\hline $\begin{array}{l}\text { Water } \\
\text { year }\end{array}$ & Date & $\begin{array}{c}\text { Discharge } \\
\left(\mathrm{ft}^{3} / \mathrm{s}\right)\end{array}$ & $\begin{array}{c}\text { Gage } \\
\text { height } \\
\text { (ft) }\end{array}$ & $\begin{array}{l}\text { Water } \\
\text { year }\end{array}$ & Date & $\begin{array}{c}\text { Discharge } \\
\left(\mathrm{ft}^{3} / \mathrm{s}\right)\end{array}$ & $\begin{array}{c}\text { Gage } \\
\text { height } \\
\text { (ft) }\end{array}$ & $\begin{array}{l}\text { Water } \\
\text { year }\end{array}$ & Date & $\begin{array}{c}\text { Discharge } \\
\left(\mathrm{ft}^{3} / \mathrm{s}\right)\end{array}$ & $\begin{array}{c}\text { Gage } \\
\text { height } \\
\text { (ft) }\end{array}$ \\
\hline 1979 & Apr. 13 & 97 & 8.38 & 1982 & Aug. 17 & 123 & 8.82 & 1985 & Nov. 28 & 152 & 9.26 \\
\hline 1980 & May 20 & 192 & 9.93 & 1983 & Apr. 08 & 86 & 8.20 & 1986 & Aug. 11 & 80 & 3.01 \\
\hline 1981 & Sept.04 & 221 & 10.50 & 1984 & July 29 & 162 & 9.44 & & & & \\
\hline
\end{tabular}

\section{NORTH OCONEE RIVER TRIBUTARY AT ATHENS, GEORGIA}

LOCATION.--Lat $33^{\circ} 58^{\prime} 11^{\prime \prime}$, long $83^{\circ} 23^{\prime} 14^{\prime \prime}$, Clarke County, at culvert on Barber Street, at Athens.

DRAINAGE AREA. $-0.35 \mathrm{mi}^{2}$.

GAGE.--Flood-stage/rainfall recorder.

STAGE-DISCHARGE RELATION.--Defined by current-meter measurements below $35 \mathrm{ft}^{3} / \mathrm{s}$, and extended above on basis of culvert computations.

REMARKS.--Flow is affected by urbanization.

\begin{tabular}{|c|c|c|c|c|c|c|c|c|c|c|c|}
\hline $\begin{array}{l}\text { Water } \\
\text { year }\end{array}$ & Date & $\begin{array}{c}\text { Discharge } \\
\left(\mathrm{ft}^{3} / \mathrm{s}\right)\end{array}$ & $\begin{array}{c}\text { Gage } \\
\text { height } \\
\text { (ft) }\end{array}$ & $\begin{array}{l}\text { Water } \\
\text { year }\end{array}$ & Date & $\begin{array}{c}\text { Discharge } \\
\left(\mathrm{ft}^{3} / \mathrm{s}\right)\end{array}$ & $\begin{array}{c}\text { Gage } \\
\text { height } \\
\text { (ft) }\end{array}$ & $\begin{array}{l}\text { Water } \\
\text { year }\end{array}$ & Date & $\begin{array}{c}\text { Discharge } \\
\left(\mathrm{ft}^{3} / \mathrm{s}\right)\end{array}$ & $\begin{array}{c}\text { Gage } \\
\text { heigh } \\
\text { (ft) }\end{array}$ \\
\hline 1979 & Aug. 22 & 287 & 6.83 & 1982 & May 22 & 142 & 4.29 & 1985 & Aug. 07 & 106 & 3.52 \\
\hline 1980 & May 20 & 186 & 5.19 & 1983 & Apr. 08 & 101 & 3.42 & 1986 & Aug. 11 & 80.0 & 3.01 \\
\hline 1981 & Sept.04 & 208 & 5.55 & 1984 & May 02 & 128 & 4.02 & & & & \\
\hline
\end{tabular}


LOCATION.-Lat $33^{\circ} 56^{\prime} 55^{\prime \prime}$, long $83^{\circ} 22^{\prime} 04^{\prime \prime}$, Clarke County, at Cemetery Bridge in Athens, 0.5 mi below bridge on U.S. Highway 78 , and $3 \mathrm{mi}$ downstream from Sandy Creek.

DRAINAGE AREA.--290 $\mathrm{mi}^{2}$ (revised).

GAGE.--Water-stage recorder prior to June 13, 1950; crest-stage gage thereafter. Datum of gage is $577.86 \mathrm{ft}$ above sea level (levels by the Georgia Department of Transportation).

STAGE-DISCHARGE RELATION.--Defined by current-meter measurements below $12,000 \mathrm{ft}^{3} / \mathrm{s}$, and above on the basis of straightline extension. Bankfull stage and discharge, $15 \mathrm{ft}$ and $3,000 \mathrm{ft}^{3} / \mathrm{s}$.

REMARKS.--Records for 1929-31 from U.S. Army Corps of Engineers. Peak discharge for 1931 is maximum daily. Peak discharges for 1950-51, 1955, and 1957-60 are estimated. Peak discharge for 1966 increased by dam failure.

\begin{tabular}{|c|c|c|c|c|c|c|c|c|c|c|c|}
\hline $\begin{array}{l}\text { Water } \\
\text { year }\end{array}$ & Date & $\begin{array}{c}\text { Discharge } \\
\left(\mathrm{ft}^{3} / \mathrm{s}\right)\end{array}$ & $\begin{array}{c}\text { Gage } \\
\text { height } \\
\text { (ft) }\end{array}$ & $\begin{array}{l}\text { Water } \\
\text { year }\end{array}$ & Date & $\begin{array}{c}\text { Discharge } \\
\left(\mathrm{ft}^{3} / \mathrm{s}\right)\end{array}$ & $\begin{array}{c}\text { Gage } \\
\text { height } \\
\text { (ft) }\end{array}$ & $\begin{array}{l}\text { Water } \\
\text { year }\end{array}$ & Date & $\begin{array}{c}\text { Discharge } \\
\left(\mathrm{ft}^{3} / \mathrm{s}\right)\end{array}$ & $\begin{array}{c}\text { Gage } \\
\text { height } \\
\text { (ft) }\end{array}$ \\
\hline 1929 & Mar. 05 & 9,000 & 23.00 & 1953 & Jan. 10 & 3,250 & 12.83 & 1964 & May 04 & 6,580 & 20.64 \\
\hline 1930 & Oct. 02 & 8,600 & 22.50 & 1954 & Jan. 17 & 3,250 & 12.82 & 1965 & Mar. 26 & 3,000 & 14.83 \\
\hline$\underline{1931}$ & Nov. 17 & 1,700 & - & 1955 & Feb. 09 & 2,800 & - & 1966 & May 27 & 15,500 & 27.40 \\
\hline$\overline{1945}$ & Apr. 25 & 4,900 & 16.80 & 1956 & Mar. 18 & 3,100 & 12.44 & 1967 & June 04 & 13,600 & 26.40 \\
\hline 1946 & Jan. 06 & 7,450 & 21.00 & 1957 & Apr. 07 & 2,850 & - & 1968 & Mar. 14 & 3,430 & 15.66 \\
\hline 1947 & Jan. 21 & 4,030 & 14.90 & 1958 & Feb. 06 & 2,550 & -- & 1969 & Sept.20 & 6,820 & 20.90 \\
\hline 1948 & Feb. 10 & 3,390 & 13.20 & 1959 & June 01 & 4,100 & - & 1970 & Mar. 21 & 2,160 & 13.13 \\
\hline 1949 & Nov. 29 & 7,820 & 21.50 & 1960 & Feb. 01 & 3,100 & - & 1971 & Mar. 04 & 5,400 & 17.76 \\
\hline 1950 & Jan. -- & 1,800 & - & 1961 & Feb. 26 & 6,230 & 19.21 & 1972 & Jan. 12 & 5,350 & 17.69 \\
\hline 1951 & Oct. 21 & 2,300 & - & 1962 & Feb. 23 & 3,770 & 14.32 & 1976 & May 29 & 7,470 & 21.00 \\
\hline 1952 & Mar. 10 & 4,600 & 16.25 & 1963 & June 27 & 13,600 & 26.40 & & & & \\
\hline
\end{tabular}

02217905 TANYARD CREEK AT ATHENS, GEORGIA

LOCATION.--Lat $33^{\circ} 57^{\prime} 05^{\prime \prime}$, long $83^{\circ} 22^{\prime} 42^{\prime \prime}$, Clarke County, at culvert on Baxter Street, at Athens.

DRAINAGE AREA.--0.42 $\mathrm{mi}^{2}$.

GAGE.--Flood-stage/rainfall recorder prior to Aug. 21, 1986. Crest-stage gage 1987 to present.

STAGE-DISCHARGE RELATION.--Defined by current-meter measurements below $51 \mathrm{ft}^{3} / \mathrm{s}$, and extended above on basis of culvert computations.

REMARKS.--Flow is affected by urbanization.

\begin{tabular}{|c|c|c|c|c|c|c|c|c|c|c|c|}
\hline $\begin{array}{l}\text { Water } \\
\text { year }\end{array}$ & Date & $\begin{array}{l}\text { Discharge } \\
\left(\mathrm{ft}^{3} / \mathrm{s}\right)\end{array}$ & $\begin{array}{c}\text { Gage } \\
\text { height } \\
\text { (ft) }\end{array}$ & $\begin{array}{l}\text { Water } \\
\text { year }\end{array}$ & Date & $\begin{array}{c}\text { Discharge } \\
\left(\mathrm{ft}^{3} / \mathrm{s}\right)\end{array}$ & $\begin{array}{c}\text { Gage } \\
\text { height } \\
\text { (ft) }\end{array}$ & $\begin{array}{l}\text { Water } \\
\text { year }\end{array}$ & Date & $\begin{array}{c}\text { Discharge } \\
\left(\mathrm{ft}^{3} / \mathrm{s}\right)\end{array}$ & $\begin{array}{c}\text { Gage } \\
\text { height } \\
\text { (ft) }\end{array}$ \\
\hline 1979 & July 19 & 675 & 9.06 & 1983 & Sept.02 & 213 & 6.14 & 1987 & June 20 & 329 & 7.46 \\
\hline 1980 & May 20 & 339 & 7.54 & 1984 & May 02 & 336 & 7.51 & 1988 & Nov. 10 & 359 & 7.76 \\
\hline 1981 & Sept.04 & 515 & 8.74 & 1985 & Aug. 07 & 258 & 6.67 & 1989 & June 21 & 333 & 7.50 \\
\hline 1982 & Sept.01 & 323 & 7.38 & 1986 & Aug. 11 & 289 & 7.06 & 1990 & Feb. 09 & 398 & 8.15 \\
\hline
\end{tabular}




\section{ALTAMAHA RIVER BASIN}

02217990 CEDAR CREEK TRIBUTARY NEAR WHITEHALL, GEORGIA

LOCATION.-Lat $33^{\circ} 55^{\prime} 02^{\prime \prime}$, long $83^{\circ} 20^{\prime} 05^{\prime \prime}$, Clarke County, at culvert on Forest Road near Whitehall.

DRAINAGE AREA.-0.30 $\mathrm{mi}^{2}$.

GAGE.--Flood-stage/rainfall recorder.

STAGE-DISCHARGE RELATION.-Defined by current-meter measurements below $30 \mathrm{ft}^{3} / \mathrm{s}$, and extended above on basis of culvert computations.

REMARKS.--Flow is affected by urbanization.

\begin{tabular}{|c|c|c|c|c|c|c|c|c|c|c|c|}
\hline $\begin{array}{l}\text { Water } \\
\text { year }\end{array}$ & Date & $\begin{array}{c}\text { Discharge } \\
\left(\mathrm{ft}^{3} / \mathrm{s}\right)\end{array}$ & $\begin{array}{c}\text { Gage } \\
\text { height } \\
\text { (ft) }\end{array}$ & $\begin{array}{l}\text { Water } \\
\text { year }\end{array}$ & Date & $\begin{array}{c}\text { Discharge } \\
\left(\mathrm{ft}^{3} / \mathrm{s}\right)\end{array}$ & $\begin{array}{c}\text { Gage } \\
\text { height } \\
\text { (ft) }\end{array}$ & $\begin{array}{l}\text { Water } \\
\text { year }\end{array}$ & Date & $\begin{array}{c}\text { Discharge } \\
\left(\mathrm{ft}^{3} / \mathrm{s}\right)\end{array}$ & $\begin{array}{c}\text { Gage } \\
\text { height } \\
\text { (ft) }\end{array}$ \\
\hline 1979 & July 21 & - & 7.62 & 1981 & Feb. 11 & 42 & 3.03 & 1983 & Apr. 08 & - & 6.86 \\
\hline 1980 & May 20 & - & 7.48 & 1982 & May 22 & 81 & 4.47 & 1984 & July 06 & 135 & 6.74 \\
\hline
\end{tabular}

\section{PORTERS CREEK AT WATKINSVILLE, GEORGIA}

LOCATION.--Lat $33^{\circ} 50^{\prime} 56^{\prime \prime}$, long $83^{\circ} 23^{\prime} 42^{\prime \prime}$, Oconee County, at culvert on State Highway 15, 0.9 mi east of Watkinsville.

DRAINAGE AREA.--1.95 $\mathrm{mi}^{2}$.

GAGE.--Flood-stage/rainfall recorder. Datum of gage is about $680 \mathrm{ft}$ above sea level (from topographic map).

STAGE-DISCHARGE RELATION.--Defined by current-meter measurements below $330 \mathrm{ft}^{3} / \mathrm{s}$, and extended above on basis of culvert computations.

\begin{tabular}{|c|c|c|c|c|c|c|c|c|c|c|c|}
\hline $\begin{array}{l}\text { Water } \\
\text { year }\end{array}$ & Date & $\begin{array}{c}\text { Discharge } \\
\left(\mathrm{ft}^{3} / \mathrm{s}\right)\end{array}$ & $\begin{array}{l}\text { Gage } \\
\text { height } \\
\text { (ft) }\end{array}$ & $\begin{array}{l}\text { Water } \\
\text { year }\end{array}$ & Date & $\begin{array}{c}\text { Discharge } \\
\left(\mathrm{ft}^{3} / \mathrm{s}\right)\end{array}$ & $\begin{array}{l}\text { Gage } \\
\text { height } \\
\text { (ft) }\end{array}$ & $\begin{array}{l}\text { Water } \\
\text { year }\end{array}$ & Date & $\begin{array}{c}\text { Discharge } \\
\left(\mathrm{ft}^{3} / \mathrm{s}\right)\end{array}$ & $\begin{array}{c}\text { Gage } \\
\text { height } \\
\text { (ft) }\end{array}$ \\
\hline 1964 & July 18 & 866 & 6.57 & 1968 & Dec. 02 & 117 & 3.47 & 1972 & Jan. 11 & 196 & 3.79 \\
\hline 1965 & Oct. 05 & 140 & 3.57 & 1969 & Sept.01 & 570 & 5.29 & 1973 & Dec. 15 & 340 & 4.37 \\
\hline 1966 & May 21 & 376 & 4.51 & 1970 & Mar. 20 & 146 & 3.59 & 1974 & Dec. 31 & 206 & 3.83 \\
\hline 1967 & June 04 & 336 & 4.35 & 1971 & Sept.01 & 846 & 6.49 & 1975 & Mar. 13 & 536 & 5.15 \\
\hline
\end{tabular}




\section{ALTAMAHA RIVER BASIN}

\section{OCONEE RIVER NEAR PENFIELD, GEORGIA}

LOCATION.-Lat $33^{\circ} 43^{\prime} 16^{\prime \prime}$, long $83^{\circ} 17^{\prime} 44^{\prime \prime}$, Greene County, on downstream side of bridge on State Highway $15,7.0$ mi upstream from Greenbrier Creek, and 8.0 mi northwest of Penfield.

DRAINAGE AREA. $-940 \mathrm{mi}^{2}$.

GAGE.--Crest-stage gage from Nov. 4, 1969 to July 21, 1977. Water-stage recorder at site $300 \mathrm{ft}$ upstream at same datum from July 21, 1977 to Aug. 1, 1990. Water-stage recorder at present site and datum thereafter. Datum of gage is $433.26 \mathrm{ft}$ above sea level (levels from U.S. Geological Survey benchmark).

STAGE-DISCHARGE RELATION.--Defined by current-meter measurements below $21,200 \mathrm{ft}^{3} / \mathrm{s}$, and extended above on basis of slope-conveyance studies.

REMARKS.--Flood stages for December 1919 and April 1936 furnished by Georgia Department of Transportation.

\begin{tabular}{|c|c|c|c|c|c|c|c|c|c|c|c|}
\hline $\begin{array}{l}\text { Water } \\
\text { year }\end{array}$ & Date & $\begin{array}{c}\text { Discharge } \\
\left(\mathrm{ft}^{3} / \mathrm{s}\right)\end{array}$ & $\begin{array}{c}\text { Gage } \\
\text { height } \\
\text { (ft) }\end{array}$ & $\begin{array}{l}\text { Water } \\
\text { year }\end{array}$ & Date & $\begin{array}{c}\text { Discharge } \\
\left(\mathrm{ft}^{3} / \mathrm{s}\right)\end{array}$ & $\begin{array}{l}\text { Gage } \\
\text { height } \\
\text { (ft) }\end{array}$ & $\begin{array}{l}\text { Water } \\
\text { year }\end{array}$ & Date & $\begin{array}{c}\text { Discharge } \\
\left(\mathrm{ft}^{3} / \mathrm{s}\right)\end{array}$ & $\begin{array}{c}\text { Gage } \\
\text { height } \\
\text { (ft) }\end{array}$ \\
\hline$\underline{1920}$ & Dec. 19 & 37,000 & $26.90 \mathrm{c}$ & 1976 & Mar. 16 & 19,700 & 22.11 & 1984 & Dec. 06 & 14,000 & 19.12 \\
\hline$\underline{1936}$ & Apr. 09 & 36,000 & $26.70 c$ & 1977 & Apr. 02 & 8,440 & 15.70 & 1985 & Feb. 06 & 7,320 & 14.62 \\
\hline$\overline{1970}$ & Mar. 22 & 11,000 & 17.68 & 1978 & Nov. 08 & 19,500 & 22.00 & 1986 & Dec. 01 & 5,150 & 12.70 \\
\hline 1971 & Mar. 03 & 19,100 & 21.78 & 1979 & Apr. 15 & 17,400 & 20.90 & 1987 & Mar. 03 & 13,300 & 18.84 \\
\hline 1972 & Jan. 13 & 16,800 & 20.63 & 1980 & May 21 & 13,300 & 18.78 & 1988 & Feb. 05 & 6,190 & 13.76 \\
\hline 1973 & Dec. 16 & 16,000 & 20.24 & 1981 & Feb. 11 & 8,720 & 15.73 & 1989 & June 23 & 9,780 & 16.58 \\
\hline 1974 & Jan. 03 & 13,200 & 18.87 & 1982 & Jan. 06 & 13,700 & 19.03 & 1990 & Oct. 01 & $\underline{31,700}$ & 25.92 \\
\hline 1975 & Mar. 14 & 18,400 & 21.44 & 1983 & Apr. 09 & 14,000 & 19.24 & & & & \\
\hline
\end{tabular}

\section{TOWN CREEK NEAR GREENSBORO, GEORGIA}

LOCATION.--Lat 33 $38^{\prime} 29^{\prime \prime}$ long $83^{\circ} 13^{\prime} 36^{\prime \prime}$, Greene County, at State Highway 15, 5.7 mi northwest of Greensboro. DRAINAGE AREA. $-11.9 \mathrm{mi}^{2}$.

GAGE.-Crest-stage gage prior to Nov. 16, 1967; flood-stage recorder, Nov. 16, 1967 to Apr. 1, 1968; flood-stage/rainfall recorder from Mar. 1, 1968 to Sept. 30, 1975, crest-stage thereafter. Datum of gage is about $472 \mathrm{ft}$ above sea level (from topographic map).

STAGE-DISCHARGE RELATION.--Defined by current-meter measurements below $1,400 \mathrm{tt}^{3} / \mathrm{s}$, and extended above on basis of straight-line extension.

REMARKS.--Flood stage for 1948 furnished by Georgia Department of Transportation.

\begin{tabular}{|c|c|c|c|c|c|c|c|c|c|c|c|}
\hline $\begin{array}{l}\text { Water } \\
\text { year }\end{array}$ & Date & $\begin{array}{c}\text { Discharge } \\
\left(\mathrm{ft}^{3} / \mathrm{s}\right)\end{array}$ & $\begin{array}{c}\text { Gage } \\
\text { height } \\
\text { (ft) }\end{array}$ & $\begin{array}{l}\text { Water } \\
\text { year }\end{array}$ & Date & $\begin{array}{c}\text { Discharge } \\
\left(\mathrm{ft}^{3} / \mathrm{s}\right)\end{array}$ & $\begin{array}{c}\text { Gage } \\
\text { height } \\
\text { (ft) }\end{array}$ & $\begin{array}{l}\text { Water } \\
\text { year }\end{array}$ & Date & $\begin{array}{c}\text { Discharge } \\
\left(\mathrm{ft}^{3} / \mathrm{s}\right)\end{array}$ & $\begin{array}{c}\text { Gage } \\
\text { height } \\
\text { (ft) }\end{array}$ \\
\hline 1948 & Feb. 09 & 2,500 & 9.60 & 1972 & Jan. 11 & 1,120 & 8.47 & 1980 & June 25 & 580 & 7.40 \\
\hline 1964 & Mar. 15 & 988 & 8.31 & 1973 & Mar. 31 & 442 & 6.71 & 1981 & Feb. 11 & 620 & 7.55 \\
\hline 1965 & Dec. 25 & 1,150 & 8.51 & 1974 & Apr. 04 & 439 & 6.69 & 1982 & Feb. 03 & 336 & 5.93 \\
\hline 1966 & May 27 & 1,600 & 8.90 & 1975 & Mar. 25 & 2,350 & 9.49 & 1983 & Apr. 09 & 1,300 & 8.66 \\
\hline 1967 & Mar. 10 & 361 & 6.14 & 1976 & Mar. 16 & 470 & 6.90 & 1984 & Jan. 11 & 274 & 5.32 \\
\hline 1968 & Jan. 10 & 290 & 5.50 & 1977 & Aug. 03 & 390 & 6.37 & 1985 & Feb. 06 & 405 & 6.47 \\
\hline 1969 & Apr. 18 & 1,310 & 8.67 & 1978 & Jan. 25 & 862 & 8.12 & 1986 & June 00 & 120 & $-b$ \\
\hline 1970 & Mar. 20 & 476 & 6.94 & 1979 & Feb. 24 & 952 & 8.26 & 1987 & Mar. 01 & 242 & 4.92 \\
\hline 1971 & Mar. 03 & 1,630 & 8.92 & & & & & & & & \\
\hline
\end{tabular}




\section{ALTAMAHA RIVER BASIN}

\section{OCONEE RIVER NEAR GREENSBORO, GEORGIA}

LOCATION.--Lat $33^{\circ} 34^{\prime} 52^{\prime \prime}$, long $83^{\circ} 16^{\prime} 22^{\prime \prime}$, Greene County, on right bank $300 \mathrm{ft}$ downstream from bridge on State Highway 12,1 mi downstream from Town Creek, 5 mi upstream from Apalachee River, 5 mi west of Greensboro, and 12 mi downstream from Barnett Shoals Dam.

DRAINAGE AREA.- $-1,090 \mathrm{mi}^{2}$.

GAGE.--Water-stage recorder. Prior to Nov. 8,1938 , nonrecording gage at same site and datum. Datum of gage is $409.82 \mathrm{ft}$ above sea level (from U.S. Geological Survey benchmark map).

STAGE-DISCHARGE RELATION.--Defined by current-meter measurements below $22,000 \mathrm{ft}^{3} / \mathrm{s}$, and extended above on basis of area-velocity studies and computation of flow over Barnett Shoals Dam. Bankfull stage and discharge, $10 \mathrm{ft}$ and $4,000 \mathrm{ft} / \mathrm{s}$. HISTORICAL DATA.--Peak discharge of 1908 thought to be the highest since of 1902, based on records for nearby stations.

REMARKS.--Peak dischrage for 1936 is estimated. Storage in Barnett Shoals Reservoir is insufficient to affect peak discharges.

Records for period 1919-32 from U.S. Army Corps of Engineers. Station has been inundated by Lake Oconee since January 1979

\begin{tabular}{|c|c|c|c|c|c|c|c|c|c|c|c|}
\hline $\begin{array}{l}\text { Water } \\
\text { year }\end{array}$ & Date & $\begin{array}{c}\text { Discharge } \\
\left(\mathrm{ft}^{3} / \mathrm{s}\right)\end{array}$ & $\begin{array}{c}\text { Gage } \\
\text { height } \\
\text { (ft) }\end{array}$ & $\begin{array}{l}\text { Water } \\
\text { year }\end{array}$ & Date & $\begin{array}{c}\text { Discharge } \\
\left(\mathrm{ft}^{3} / \mathrm{s}\right)\end{array}$ & $\begin{array}{c}\text { Gage } \\
\text { height } \\
\text { (ft) }\end{array}$ & $\begin{array}{l}\text { Water } \\
\text { year }\end{array}$ & Date & $\begin{array}{c}\text { Discharge } \\
\left(\mathrm{ft}^{3} / \mathrm{s}\right)\end{array}$ & $\begin{array}{c}\text { Gage } \\
\text { height } \\
\text { (ft) }\end{array}$ \\
\hline 1904 & Aug. 10 & 6,520 & 11.90 & 1928 & Aug. 16 & 14,500 & 20.00 & 1956 & Mar. 19 & 9,290 & 17.00 \\
\hline 1905 & Feb. 14 & 6,960 & 12.50 & 1929 & Mar. 06 & 29,400 & 26.60 & 1957 & Apr. 08 & 7,580 & 15.50 \\
\hline 1906 & Jan. 24 & 13,300 & 18.90 & 1930 & Oct. 03 & 28,800 & 26.40 & 1958 & Feb. 07 & 6,330 & 14.10 \\
\hline 1907 & Feb. 05 & 5,990 & 11.20 & 1931 & Nov. 18 & 6,800 & 12.50 & 1959 & June 02 & 13,300 & 19.70 \\
\hline 1908 & Aug. 26 & 66,800 & 35.40 & $\underline{1932}$ & Jan. 09 & 9,500 & 15.50 & 1960 & Feb. 02 & 8,910 & 16.70 \\
\hline 1909 & Mar. 13 & 12,000 & 18.00 & $\underline{1936}$ & Apr. 09 & 44,000 & -- & 1961 & Feb. 25 & 17,200 & 21.80 \\
\hline 1910 & Mar. 02 & 12,700 & 18.50 & $\overline{1938}$ & July 26 & 15,200 & 20.90 & 1962 & Dec. 15 & 11,900 & 18.79 \\
\hline 1911 & Apr. 10 & 5,690 & 10.80 & 1939 & Aug. 21 & 11,000 & 18.40 & 1963 & June 29 & 22,400 & 24.10 \\
\hline 1912 & Mar. 16 & 31,800 & 27.40 & 1940 & Aug. 14 & 12,200 & 19.00 & 1964 & May 04 & 18,200 & 22.30 \\
\hline 1913 & Mar. 16 & 22,700 & 24.20 & 1941 & July 08 & 5,260 & 12.60 & 1965 & Oct. 06 & 8,100 & 16.00 \\
\hline 1914 & Dec. 31 & 6,180 & 12.00 & 1942 & Mar. 22 & 18,100 & 22.40 & 1966 & May 29 & 20,100 & 22.41 \\
\hline 1915 & Oct. 17 & 14,200 & 19.70 & 1943 & Jan. 20 & 19,200 & 23.00 & 1967 & June 07 & 12,800 & 19.12 \\
\hline 1916 & Dec. 20 & 14,300 & 19.80 & 1944 & Mar. 31 & 10,700 & 18.00 & 1968 & Jan. 13 & 7,840 & 15.44 \\
\hline 1917 & Mar. 07 & 13,800 & 19.30 & 1945 & Apr. 26 & 15,200 & 20.80 & 1969 & Jan. 23 & 17,800 & 21.41 \\
\hline 1918 & Jan. 31 & 8,260 & 14.10 & 1946 & Jan. 08 & 19,800 & 23.30 & 1970 & Mar. 23 & 11,900 & 18.51 \\
\hline 1919 & Dec. 24 & 15,100 & 20.60 & 1947 & Jan. 21 & 15,300 & 20.90 & 1971 & Mar. 04 & 22,000 & 23.63 \\
\hline 1920 & Dec. 11 & 41,100 & 30.00 & 1948 & Feb. 10 & 13,300 & 19.70 & 1972 & Jan. 14 & 14,400 & 20.90 \\
\hline 1921 & Feb. 11 & 15,400 & 20.60 & 1949 & Nov. 29 & 34,100 & 28.10 & 1973 & Apr. 02 & 15,800 & 20.55 \\
\hline 1922 & Feb. 16 & 16,400 & 21.40 & 1950 & Mar. 14 & 3,610 & 9.16 & 1974 & Jan. 04 & 13,200 & 19.32 \\
\hline 1923 & May 30 & 15,400 & 20.90 & 1951 & Oct. 22 & 5,440 & 12.80 & 1975 & Mar. 15 & 19,900 & 22.82 \\
\hline 1924 & Sept.28 & 13,000 & 18.60 & 1952 & Mar. 25 & 13,000 & 19.50 & 1976 & Mar. 17 & 21,400 & 23.46 \\
\hline 1925 & Jan. 19 & 26,100 & 25.50 & 1953 & Jan. 13 & 8,210 & 16.10 & 1977 & Apr. 02 & 7,510 & 14.87 \\
\hline 1926 & July 29 & 9,800 & 15.80 & 1954 & Jan. 20 & 8,910 & 16.70 & 1978 & Nov. 08 & 18,400 & 20.05 \\
\hline 1927 & Dec. 15 & 7,820 & 13.80 & 1955 & Feb. 10 & 7,480 & 15.40 & & & & \\
\hline
\end{tabular}




\section{ALTAMAHA RIVER BASIN}

\section{APALACHEE RIVER NEAR BOSTWICK, GEORGIA}

LOCATION.--Lat $33^{\circ} 47^{\prime} 17^{\prime \prime}$, long $83^{\circ} 28^{\prime} 27^{\prime \prime}$, Morgan County, on left bank 1,000 ft upstream from Price Mill Bridge, 4.0 mi downstream from High Shoals, 4.0 mi upstream from Jacks Creek, and 4.0 mi northeast of Bostwick. DRAINAGE AREA.--176 mi²

GAGE.--Water-stage recorder. Datum of gage is $544.14 \mathrm{ft}$ above sea level (levels by Global Positioning System).

STAGE-DISCHARGE RELATION.--Defined by current-meter measurements below $5,840 \mathrm{ft}^{3} / \mathrm{s}$, and above on the basis of straightline extension. Bankfull stage and discharge, $7 \mathrm{ft}$ and $5,500 \mathrm{ft}^{3} / \mathrm{s}$.

REMARKS.--Peak discharges for January 1946 and November 1948 have been revised.

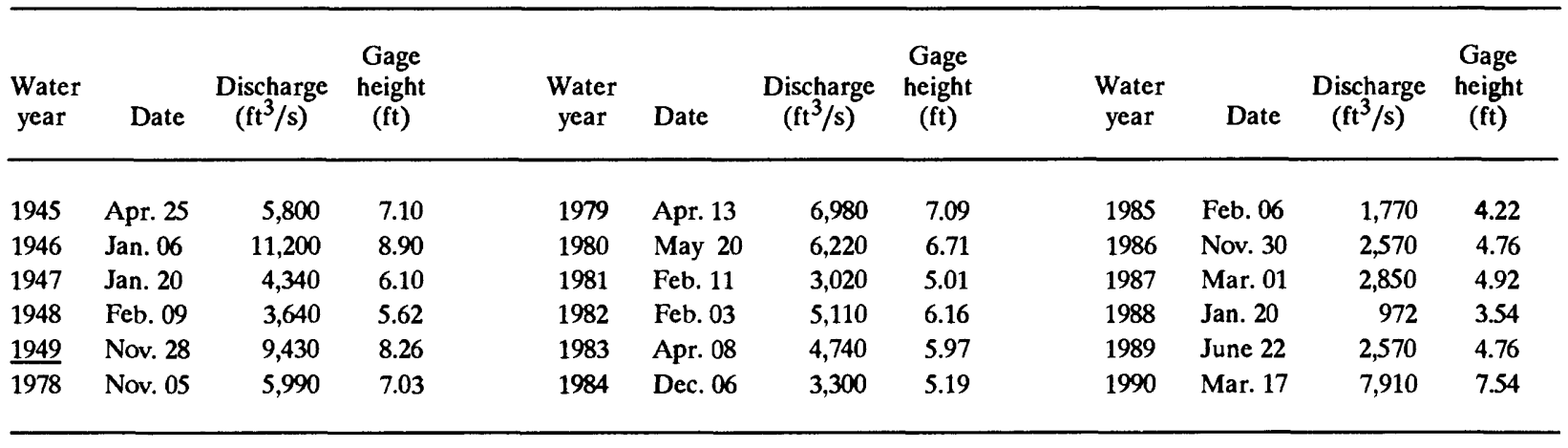

02219300 MILE BRANCH NEAR MADISON, GEORGIA

LOCATION.--Lat $33^{\circ} 36^{\prime} 38^{\prime \prime}$, long $83^{\circ} 28^{\prime} 43^{\prime \prime}$, Morgan County, at culvert on State Highway $83,1.3$ mi north of Madison. DRAINAGE AREA.--0.95 $\mathrm{mi}^{2}$.

GAGE.--Flood-stage/rainfall recorder. Datum of gage is about $548 \mathrm{ft}$ above sea level (from topographic map).

STAGE-DISCHARGE RELATION.--Defined by current-meter measurements below $27.6 \mathrm{ft}^{3} / \mathrm{s}$, and extended above on basis of culvert computations.

REMARKS.--Flow is affected by regulation because of reservoirs upstream.

\begin{tabular}{|c|c|c|c|c|c|c|c|c|c|c|c|}
\hline $\begin{array}{l}\text { Water } \\
\text { year }\end{array}$ & Date & $\begin{array}{c}\text { Discharge } \\
\left(\mathrm{ft}^{3} / \mathrm{s}\right)\end{array}$ & $\begin{array}{c}\text { Gage } \\
\text { height } \\
\text { (ft) }\end{array}$ & $\begin{array}{l}\text { Water } \\
\text { year }\end{array}$ & Date & $\begin{array}{c}\text { Discharge } \\
\left(\mathrm{ft}^{3} / \mathrm{s}\right)\end{array}$ & $\begin{array}{c}\text { Gage } \\
\text { height } \\
\text { (ft) }\end{array}$ & $\begin{array}{l}\text { Water } \\
\text { year }\end{array}$ & Date & $\begin{array}{c}\text { Discharge } \\
\left(\mathrm{ft}^{3} / \mathrm{s}\right)\end{array}$ & $\begin{array}{c}\text { Gage } \\
\text { height } \\
\text { (ft) }\end{array}$ \\
\hline 1964 & Mar. 25 & 318 & 2.81 & 1967 & Mar. 10 & 316 & 2.80 & 1970 & July 23 & 184 & 1.99 \\
\hline 1965 & Oct. 05 & 348 & 2.98 & 1968 & Mar. 12 & 240 & 2.35 & 1971 & Mar. 03 & 493 & 4.02 \\
\hline 1966 & Aug. 24 & 495 & 4.03 & 1969 & Apr. 18 & 441 & 3.73 & 1972 & Jan. 11 & 379 & 3.24 \\
\hline
\end{tabular}


LOCATION.--Lat $33^{\circ} 36^{\prime} 31^{\prime \prime}$, long $83^{\circ} 20^{\prime} 58^{\prime \prime}$, Morgan County, on right bank pier of bridge on State Highway 12, 2 mi downstream from Hard Labor Creek, 3 mi northeast of Buckhead, and 9 mi upstream from mouth.

DRAINAGE AREA.--436 $\mathrm{mi}^{2}$.

GAGE.--Water-stage recorder. Prior to Dec. 31, 1908, nonrecording gage at same site at different datum. May 13, 1937 to Feb. 1, 1939 , nonrecording gage at same site and datum. Datum of gage is $424.07 \mathrm{ft}$ above sea level (from U.S. Coast and Geodetic benchmark).

STAGE-DISCHARGE RELATION.--Defined by current-meter measurements below $18,000 \mathrm{ft}^{3} / \mathrm{s}$, and by velocity area studies to $29,000 \mathrm{ft}^{3} / \mathrm{s}$. Bankfull stage and discharge, $8 \mathrm{tt}$ and $1,800 \mathrm{ft}^{3} / \mathrm{s}$.

REMARKS.--Station inundated by Lake Oconee since January 1979.

\begin{tabular}{|c|c|c|c|c|c|c|c|c|c|c|c|}
\hline $\begin{array}{l}\text { Water } \\
\text { year }\end{array}$ & Date & $\begin{array}{c}\text { Discharge } \\
\left(\mathrm{ft}^{3} / \mathrm{s}\right)\end{array}$ & $\begin{array}{c}\text { Gage } \\
\text { height } \\
\text { (ft) }\end{array}$ & $\begin{array}{l}\text { Water } \\
\text { year }\end{array}$ & Date & $\begin{array}{l}\text { Discharge } \\
\left(\mathrm{ft}^{3} / \mathrm{s}\right)\end{array}$ & $\begin{array}{c}\text { Gage } \\
\text { height } \\
\text { (ft) }\end{array}$ & $\begin{array}{l}\text { Water } \\
\text { year }\end{array}$ & Date & $\begin{array}{c}\text { Discharge } \\
\left(\mathrm{ft}^{3} / \mathrm{s}\right)\end{array}$ & $\begin{array}{c}\text { Gage } \\
\text { height } \\
\text { (ft) }\end{array}$ \\
\hline 1901 & Apr. 03 & 6,250 & 14.00 & 1947 & Jan. 21 & 11,800 & 20.40 & 1963 & June 28 & 12,900 & 20.84 \\
\hline 1902 & Mar. 01 & 23,400 & 25.00 & 1948 & Feb. 10 & 9,790 & 18.70 & 1964 & May 03 & 14,200 & 21.75 \\
\hline 1903 & Feb. 08 & 9,660 & 17.00 & 1949 & Nov. 29 & 23,800 & 26.80 & 1965 & Oct. 06 & 5,860 & 15.21 \\
\hline 1904 & Aug. 10 & 3,090 & 9.90 & 1950 & Mar. 15 & 2,350 & 9.90 & 1966 & May 28 & 13,500 & 21.59 \\
\hline 1905 & Feb. 14 & 4,050 & 11.40 & 1951 & Oct. 21 & 4,480 & 13.60 & 1967 & Mar. 11 & 3,640 & 12.41 \\
\hline 1906 & Jan. 23 & 13,900 & 19.90 & 1952 & Mar. 05 & 11,300 & 19.80 & 1968 & Mar. 14 & 4,330 & 13.40 \\
\hline 1907 & Feb. 06 & 3,700 & 10.90 & 1953 & Jan. 11 & 4,330 & 13.40 & 1969 & Jan. 21 & 9,430 & 18.42 \\
\hline$\underline{1908}$ & Aug. 25 & 28,900 & $\underline{27.50}$ & 1954 & Dec. 14 & 3,630 & 12.40 & 1970 & Mar. 21 & 8,850 & 18.48 \\
\hline 1938 & Apr. 02 & 10,200 & 19.00 & 1955 & Feb. 08 & 3,390 & 12.00 & 1971 & Mar. 04 & 18,300 & 24.07 \\
\hline 1939 & Mar. 01 & 6,600 & 16.10 & 1956 & Sept.26 & 7,780 & 17.10 & 1972 & Jan. 11 & 12,900 & 21.22 \\
\hline 1940 & Feb. 19 & 5,920 & 15.60 & 1957 & Apr. 07 & 5,760 & 15.10 & 1973 & Dec. 16 & 9,310 & 18.76 \\
\hline 1941 & Mar. 25 & 2,080 & 9.20 & 1958 & Feb. 08 & 4,720 & 13.90 & 1974 & Jan. 02 & 4,770 & 14.38 \\
\hline 1942 & Mar. 22 & 17,800 & 23.70 & 1959 & June 02 & 6,650 & 16.00 & 1975 & Mar. 14 & 12,300 & 20.97 \\
\hline 1943 & Jan. 19 & 18,000 & 23.80 & 1960 & Feb. 01 & 6,150 & 15.50 & 1976 & Mar. 17 & 18,200 & 24.10 \\
\hline 1944 & Mar. 30 & 9,270 & 18.30 & 1961 & Feb. 26 & 11,000 & 19.60 & 1977 & Mar. 23 & 3,880 & 12.63 \\
\hline 1945 & Apr. 26 & 13,300 & 21.10 & 1962 & Feb. 23 & 8,420 & 17.63 & 1978 & Jan. 26 & 12,200 & 20.88 \\
\hline 1946 & Jan. 07 & 19,100 & 24.30 & & & & & & & & \\
\hline
\end{tabular}

\section{WHITTEN CREEK NEAR SPARTA, GEORGIA}

LOCATION.--Lat $33^{\circ} 23^{\prime} 12^{\prime \prime}$, long $83^{\circ} 01^{\prime} 34^{\prime \prime}$, Hancock County, on right bank $100 \mathrm{ft}$ upstream from bridge on State Highway 15,5 mi upstream from mouth, and 8.5 mi northwest of Sparta.

DRAINAGE AREA.- $-16.6 \mathrm{mi}^{2}$.

GAGE.--Water-stage recorder. Datum of gage is about $395 \mathrm{ft}$ above sea level (from topographic map). Prior to Aug. 17, 1963, water-stage recorder site $100 \mathrm{ft}$ downstream at same datum.

STAGE-DISCHARGE RELATION.--Defined by current-meter measurements below $2,700 \mathrm{ft}^{3} / \mathrm{s}$, and extended above on straight-line extension. Bankfull stage and discharge, $12 \mathrm{ft}$ and $1,200 \mathrm{ft}^{3} / \mathrm{s}$.

\begin{tabular}{|c|c|c|c|c|c|c|c|c|c|c|c|}
\hline $\begin{array}{l}\text { Water } \\
\text { year }\end{array}$ & Date & $\begin{array}{c}\text { Discharge } \\
\left(\mathrm{ft}^{3} / \mathrm{s}\right)\end{array}$ & $\begin{array}{c}\text { Gage } \\
\text { height } \\
\text { (ft) }\end{array}$ & $\begin{array}{l}\text { Water } \\
\text { year }\end{array}$ & Date & $\begin{array}{c}\text { Discharge } \\
\left(\mathrm{ft}^{3} / \mathrm{s}\right)\end{array}$ & $\begin{array}{l}\text { Gage } \\
\text { height } \\
\text { (ft) }\end{array}$ & $\begin{array}{l}\text { Water } \\
\text { year }\end{array}$ & Date & $\begin{array}{c}\text { Discharge } \\
\left(\mathrm{ft}^{3} / \mathrm{s}\right)\end{array}$ & $\begin{array}{c}\text { Gage } \\
\text { height } \\
\text { (ft) }\end{array}$ \\
\hline 1961 & Feb. 24 & 3,770 & 16.00 & 1970 & Mar. 21 & 1,050 & 11.82 & 1979 & Feb. 24 & 1,440 & 12.46 \\
\hline 1962 & Jan. 06 & 1,110 & 12.93 & 1971 & Mar. 02 & 2,320 & 14.63 & 1980 & Mar. 13 & 945 & 10.98 \\
\hline 1963 & May 29 & $\underline{1,500}$ & 13.70 & 1972 & Jan. 13 & 1,240 & 12.12 & 1981 & Feb. 11 & 2,400 & 14.79 \\
\hline 1964 & May 02 & $\overline{2,310}$ & 14.50 & 1973 & Feb. 02 & 2,060 & 14.07 & 1982 & Dec. 31 & 808 & 10.39 \\
\hline 1965 & Dec. 26 & 2,790 & 15.80 & 1974 & Apr. 05 & 941 & 10.95 & 1983 & Mar. 06 & 1,660 & 13.14 \\
\hline 1966 & Feb. 13 & 1,000 & 11.66 & 1975 & Apr. 03 & 2,030 & 14.01 & 1984 & May 04 & 1,280 & 12.11 \\
\hline 1967 & Mar. 10 & 2,900 & 15.85 & 1976 & May 28 & 1,440 & 12.57 & 1985 & Feb. 05 & 711 & 10.45 \\
\hline 1968 & July 17 & 850 & 11.04 & 1977 & Dec. 12 & 1,080 & 11.45 & 1986 & Mar. 19 & 134 & 5.47 \\
\hline 1969 & Aug. 23 & 645 & 10.13 & 1978 & Jan. 26 & 1,380 & 12.38 & & & & \\
\hline
\end{tabular}


LOCATION.--Lat $33^{\circ} 18^{\prime} 50^{\prime \prime}$, long $83^{\circ} 26^{\prime} 14^{\prime \prime}$, Putnam County, on downstream side of bridge on State Highway $16,0.9$ mi downstream from Glady Creek, and 3.0 mi west of Eatonton.

DRAINAGE AREA.--262 $\mathrm{mi}^{2}$

GAGE.-Water-stage recorder. Datum of gage is $356.03 \mathrm{ft}$ above sea level (levels from Global Positioning System). Feb. 19,1970

to Aug. 1, 1977, crest-stage gage at same site and datum, $7.26 \mathrm{ft}$ higher, and Aug. 2, 1977 to Aug. 25, 1987, water-stage recorder at same site and datum $4.0 \mathrm{fthigher}$. All gage heights have been converted to present datum.

STAGE-DISCHARGE RELATION.--Defined by current-meter measurements below $11,800 \mathrm{ft}^{3} / \mathrm{s}$, and extended above on basis of straight-line extension. Bankfull stage and discharge, $10 \mathrm{ft}$ and $1,500 \mathrm{ft}^{3} / \mathrm{s}$.

REMARKS.--Flood stages for 1948 and 1981 furnished by Georgia Department of Transportation. Peak discharges for 1973 and 1977 are estimated.

\begin{tabular}{|c|c|c|c|c|c|c|c|c|c|c|c|}
\hline $\begin{array}{l}\text { Water } \\
\text { year }\end{array}$ & Date & $\begin{array}{c}\text { Discharge } \\
\left(\mathrm{ft}^{3} / \mathrm{s}\right)\end{array}$ & $\begin{array}{c}\text { Gage } \\
\text { height } \\
\text { (ft) }\end{array}$ & $\begin{array}{l}\text { Water } \\
\text { year }\end{array}$ & Date & $\begin{array}{c}\text { Discharge } \\
\left(\mathrm{ft}^{3} / \mathrm{s}\right)\end{array}$ & $\begin{array}{c}\text { Gage } \\
\text { height } \\
\text { (ft) }\end{array}$ & $\begin{array}{l}\text { Water } \\
\text { year }\end{array}$ & Date & $\begin{array}{c}\text { Discharge } \\
\left(\mathrm{ft}^{3} / \mathrm{s}\right)\end{array}$ & $\begin{array}{c}\text { Gage } \\
\text { height } \\
\text { (ft) }\end{array}$ \\
\hline$\underline{1948}$ & Feb. 09 & 15,000 & 30.80 & 1977 & Aug. - & 3,000 & - & 1984 & Aug. 02 & 4,170 & 17.33 \\
\hline 1961 & Feb. 25 & 8,000 & 23.80 & 1978 & Jan. 26 & 6,830 & 23.03 & 1985 & Feb. 06 & 4,790 & 18.57 \\
\hline$\overline{1971}$ & Mar. 03 & 12,600 & 24.40 & 1979 & Feb. 24 & 9,590 & 25.71 & 1986 & Mar. 20 & 1,350 & 10.09 \\
\hline 1972 & Jan. 11 & 9,740 & 21.94 & 1980 & Mar. 29 & 3,980 & 17.59 & 1987 & Mar. 30 & 3,240 & 15.17 \\
\hline 1973 & Jan. - & 6,500 & - & 1981 & Feb. 11 & 5,600 & 21.03 & 1988 & Feb. 05 & 2,760 & 14.05 \\
\hline 1974 & Apr. 05 & 7,130 & 19.33 & 1982 & Feb. 04 & 5,590 & 21.03 & 1989 & Apr. 15 & 1,920 & 11.81 \\
\hline 1975 & Mar. 14 & 9,020 & 21.22 & 1983 & Apr. 08 & 8,100 & 24.12 & 1990 & Mar. 18 & 12,500 & 28.78 \\
\hline 1976 & Mar. 16 & 10,300 & 22.48 & & & & & & & & \\
\hline
\end{tabular}

\section{MURDER CREEK NEAR MONTICELLO, GEORGIA}

LOCATION.--Lat 33²4'56", long $83^{\circ} 39^{\prime} 43^{\prime \prime}$, Jasper County, $350 \mathrm{ft}$ upstream from bridge on State Highway 229 , and 8 mi north of Monticello.

DRAINAGE AREA.--24 $\mathrm{mi}^{2}$.

GAGE.--Water-stage recorder prior to Oct. 1, 1971; crest-stage gage thereafter. Datum of gage is $498.21 \mathrm{ft}$ above sea level (levels from Georgia Department of Transportation).

STAGE-DISCHARGE RELATION.--Defined by current-meter measurements below $1,500 \mathrm{ft}^{3} / \mathrm{s}$, and extended above on basis of slope-area measurements at 2,510 and $3,050 \mathrm{ft}^{3} / \mathrm{s}$. Bankfull stage and discharge, $8 \mathrm{ft}$ and $2,400 \mathrm{ft}^{3} / \mathrm{s}$.

\begin{tabular}{|c|c|c|c|c|c|c|c|c|c|c|c|}
\hline $\begin{array}{l}\text { Water } \\
\text { year }\end{array}$ & Date & $\begin{array}{c}\text { Discharge } \\
\left(\mathrm{ft}^{3} / \mathrm{s}\right)\end{array}$ & $\begin{array}{c}\text { Gage } \\
\text { height } \\
\text { (ft) }\end{array}$ & $\begin{array}{l}\text { Water } \\
\text { year }\end{array}$ & Date & $\begin{array}{c}\text { Discharge } \\
\left(\mathrm{ft}^{3} / \mathrm{s}\right)\end{array}$ & $\begin{array}{c}\text { Gage } \\
\text { height } \\
\text { (ft) }\end{array}$ & $\begin{array}{l}\text { Water } \\
\text { year }\end{array}$ & Date & $\begin{array}{c}\text { Discharge } \\
\left(\mathrm{ft}^{3} / \mathrm{s}\right)\end{array}$ & $\begin{array}{c}\text { Gage } \\
\text { height } \\
\text { (ft) }\end{array}$ \\
\hline 1952 & Mar. 04 & 1,860 & 6.70 & 1961 & Feb. 25 & 2,060 & 6.95 & 1970 & Mar. 20 & 1,360 & 5.81 \\
\hline 1953 & May 04 & 1,190 & 5.40 & 1962 & Feb. 22 & 1,180 & 5.37 & 1971 & Mar. 03 & 3,240 & 9.64 \\
\hline 1954 & Dec. 06 & 364 & 2.90 & 1963 & June 23 & 3,050 & 9.12 & 1972 & Jan. 10 & 758 & 4.15 \\
\hline 1955 & Sept. 26 & 415 & 3.04 & 1964 & May 03 & 2,050 & 7.30 & 1973 & Apr. 07 & 1,360 & 5.80 \\
\hline 1956 & Sept. 26 & 982 & 4.79 & 1965 & Dec. 26 & 870 & 4.47 & 1974 & Jan. 01 & 1,540 & 6.20 \\
\hline 1957 & Dec. 23 & 1,330 & 5.84 & 1966 & Feb. 13 & 857 & 4.46 & 1975 & Apr. 02 & 2,760 & 8.64 \\
\hline 1958 & Feb. 06 & 846 & 4.68 & 1967 & Dec. 29 & 541 & 3.47 & $\underline{1976}$ & May 15 & 2,320 & 7.84 \\
\hline 1959 & June 02 & 2,510 & 7.64 & 1968 & Mar. 12 & 656 & 3.83 & $\overline{1990}$ & Mar. 17 & 2,550 & $8.51 \mathrm{c}$ \\
\hline 1960 & Mar. 30 & 972 & 4.78 & 1969 & Apr. 18 & 1,970 & 7.14 & & & & \\
\hline
\end{tabular}


LOCATION.--Lat $33^{\circ} 15^{\prime} 08^{\prime \prime}$, long $83^{\circ} 28^{\prime} 53^{\prime \prime}$, Putnam County, on left bank $250 \mathrm{ft}$ upstream from bridge on County Road S-777, 5.8 mi upstream from mouth, and 7.5 mi southwest of Eatonton.

DRAINAGE AREA.--190 $\mathrm{mi}^{2}$.

GAGE.-Water-stage recorder. Datum of gage is 375.09 ft above sea level (levels from Global Positioning System).

STAGE-DISCHARGE RELATION.--Defined by current-meter measurements below $7,690 \mathrm{ft}^{3} / \mathrm{s}$, and extended above on the basis of straight-line extension. Bankfull stage and discharge, $9 \mathrm{ft}$ and $5,500 \mathrm{ft}^{3} / \mathrm{s}$.

REMARKS.--Flood stage of 1961 furnished by the Georgia Department of Transportation.

\begin{tabular}{|c|c|c|c|c|c|c|c|c|c|c|c|}
\hline $\begin{array}{l}\text { Water } \\
\text { year }\end{array}$ & Date & $\begin{array}{c}\text { Discharge } \\
\left(\mathrm{ft}^{3} / \mathrm{s}\right)\end{array}$ & $\begin{array}{l}\text { Gage } \\
\text { height } \\
\text { (ft) }\end{array}$ & $\begin{array}{l}\text { Water } \\
\text { year }\end{array}$ & Date & $\begin{array}{c}\text { Discharge } \\
\left(\mathrm{ft}^{3} / \mathrm{s}\right)\end{array}$ & $\begin{array}{l}\text { Gage } \\
\text { height } \\
\text { (ft) }\end{array}$ & $\begin{array}{l}\text { Water } \\
\text { year }\end{array}$ & Date & $\begin{array}{c}\text { Discharge } \\
\left(\mathrm{ft}^{3} / \mathrm{s}\right)\end{array}$ & $\begin{array}{c}\text { Gage } \\
\text { height } \\
\text { (ft) }\end{array}$ \\
\hline$\underline{1961}$ & Feb. 27 & 6,500 & $9.60 c$ & 1982 & Feb. 04 & 4,910 & 7.68 & 1987 & Mar. 02 & 1,960 & 4.72 \\
\hline$\overline{1978}$ & Jan. 26 & 4,910 & 7.68 & 1983 & Apr. 09 & 6,700 & 9.67 & 1988 & Feb. 06 & 1,480 & 4.24 \\
\hline 1979 & Feb. 24 & 6,270 & 9.19 & 1984 & Aug. 02 & 5,500 & 8.34 & 1989 & Apr. 15 & 1,450 & 4.25 \\
\hline 1980 & Mar. 29 & 3,050 & 5.75 & 1985 & Feb. 06 & 3,910 & 6.62 & 1990 & Mar. 18 & 9,630 & 13.13 \\
\hline 1981 & Feb. 11 & 4,280 & 6.98 & 1986 & Mar. 20 & 1,280 & 4.03 & & & & \\
\hline
\end{tabular}


LOCATION.--Lat $33^{\circ} 04^{\prime} 58^{\prime \prime}$, long $83^{\circ} 12^{\prime} 51^{\prime \prime}$, Baldwin County, at right bank on city of Milledgeville water-works intake structure at Milledgeville, 0.5 mi upstream from bridge on State Highway $24,3.8$ mi downstream from Sinclair Dam of Georgia Power Company, and at mile 139.1 .

DRAINAGE AREA.--2,950 $\mathrm{mi}^{2}$.

GAGE.-Water-stage recorder. Datum of gage is $230.84 \mathrm{ft}$ above sea level (from U.S. Coast and Geodetic Survey benchmark), supplementary adjustment of 1936 . Non-recording prior to Apr. 17, 1937; recording thereafter. Prior to Sept. 30, 1939, at site 0.5 mi downstream; Oct. 1, 1939 to Mar. 8, 1966, water-stage recorder 0.3 mi downstream, all at present datum.

STAGE-DISCHARGE RELATION.--Defined by current-meter measurements below $81,000 \mathrm{ft}^{3} / \mathrm{s}$, and extended above on the basis of logarithmic extension. Data for Fraleys Ferry gage, 7 mi upstream, was used to define changes in stage-discharge relation during period 1909-23 when no discharge measurements were made at Milledgeville. Bankfull stage and discharge, $16 \mathrm{ft}$ and $11,000 \mathrm{ft}^{3} / \mathrm{s}$.

REMARKS.--Stage records for 1906-8, 1910-31 from National Weather Service. Peak discharge regulated by Sinclair Reservoir (maximum flood storage, 214,600 acre-ft) since November 1952 and Lake Oconee (maximum flood storage, 367,000 acre-ft) since Jan. 1979. Only the lower peaks are thought to be significantly affected by regulation.

HISTORICAL DATA.--Flood stage of 1886 from Georgia Department of Transportation. The flood of 1886 is thought to be the highest since that time, based on information from local residents.

\begin{tabular}{|c|c|c|c|c|c|c|c|c|c|c|c|}
\hline $\begin{array}{l}\text { Water } \\
\text { year }\end{array}$ & Date & $\begin{array}{c}\text { Discharge } \\
\left(\mathrm{ft}^{3} / \mathrm{s}\right)\end{array}$ & $\begin{array}{c}\text { Gage } \\
\text { height } \\
\text { (ft) }\end{array}$ & $\begin{array}{l}\text { Water } \\
\text { year }\end{array}$ & Date & $\begin{array}{c}\text { Discharge } \\
\left(\mathrm{ft}^{3} / \mathrm{s}\right)\end{array}$ & $\begin{array}{c}\text { Gage } \\
\text { height } \\
\text { (ft) }\end{array}$ & $\begin{array}{l}\text { Water } \\
\text { year }\end{array}$ & Date & $\begin{array}{c}\text { Discharge } \\
\left(\mathrm{ft}^{3} / \mathrm{s}\right)\end{array}$ & $\begin{array}{c}\text { Gage } \\
\text { height } \\
\text { (ft) }\end{array}$ \\
\hline$\underline{1886}$ & Feb. -- & 140,000 & 46.70 & 1933 & Dec. 31 & 17,000 & 20.00 & 1962 & Mar. 12 & 33,400 & 27.10 \\
\hline 1904 & Aug. 11 & 10,800 & 11.60 & 1934 & Mar. 05 & 34,200 & 26.00 & 1963 & Jan. 21 & 43,500 & 29.90 \\
\hline 1905 & Feb. 13 & 19,500 & 21.00 & 1935 & Mar. 13 & 18,800 & 21.00 & 1964 & May 03 & 57,400 & 33.00 \\
\hline 1906 & Jan. 24 & 31,100 & 25.40 & 1936 & Apr. 10 & 85,400 & 36.80 & 1965 & Dec. 26 & 49,900 & 31.40 \\
\hline 1907 & Feb. 05 & 15,400 & 18.00 & 1937 & Apr. 30 & 48,900 & 29.30 & 1966 & Mar. 04 & $\underline{34,200}$ & 27.34 \\
\hline 1908 & Aug. 27 & 67,800 & 33.20 & 1938 & Apr. 02 & 34,400 & 26.20 & 1967 & June 09 & $\overline{17,100}$ & 20.39 \\
\hline 1909 & Mar. 13 & 36,900 & 26.60 & 1939 & Mar. 01 & $\underline{40,600}$ & 27.60 & 1968 & Jan. 13 & 17,100 & 20.43 \\
\hline 1910 & Mar. 03 & 19,000 & 20.80 & 1940 & Aug. 14 & 27,400 & 24.40 & 1969 & Apr. 19 & 39,500 & 29.00 \\
\hline 1911 & Oct. 08 & 8,710 & 12.00 & 1941 & Mar. 28 & 12,500 & 17.60 & 1970 & Mar. 22 & 59,200 & 34.30 \\
\hline 1912 & Mar. 17 & 70,700 & 33.80 & 1942 & Mar. 22 & 55,600 & 32.60 & 1971 & Mar. 03 & 81,800 & 39.35 \\
\hline 1913 & Mar. 17 & 66,800 & 33.00 & 1943 & Mar. 22 & 43,300 & 29.20 & 1972 & Jan. 14 & 48,600 & 31.64 \\
\hline 1914 & Apr. 15 & 8,840 & 12.10 & 1944 & Mar. 21 & 58,500 & 33.40 & 1973 & Apr. 08 & 41,800 & 29.78 \\
\hline 1915 & Oct. 17 & 32,300 & 25.50 & 1945 & Apr. 27 & 32,600 & 26.00 & 1974 & Apr. 06 & 34,900 & 27.46 \\
\hline 1916 & Mar. 03 & 18,500 & 20.40 & 1946 & Jan. 10 & 33,600 & 26.50 & 1975 & Apr. 03 & 59,000 & 34.46 \\
\hline 1917 & Apr. 06 & 31,900 & 25.40 & 1947 & Mar. 08 & 41,900 & 28.80 & 1976 & Mar. 17 & 46,600 & 30.94 \\
\hline 1918 & Feb. 01 & 14,600 & 17.20 & 1948 & Feb. 13 & 32,100 & 26.70 & 1977 & Mar. 22 & 29,300 & 22.65 \\
\hline 1919 & Feb. 26 & 38,700 & 27.00 & 1949 & Nov. 30 & 80,800 & 37.30 & 1978 & Jan. 26 & 52,100 & 32.53 \\
\hline 1920 & Dec. 12 & 59,100 & 31.40 & 1950 & Oct. 08 & 12,200 & 17.40 & 1979 & Feb. 25 & 59,000 & 34.24 \\
\hline 1921 & Feb. 11 & 39,200 & 27.20 & 1951 & Apr. 23 & 11,200 & 16.70 & 1980 & Mar. 13 & 63,200 & 35.30 \\
\hline 1922 & Mar. 07 & 62,000 & 32.00 & 1952 & Mar. 05 & 56,900 & 32.90 & 1981 & Feb. 11 & 65,900 & 35.98 \\
\hline 1923 & May 06 & 47,600 & 29.00 & 1953 & May 03 & 28,500 & 25.50 & 1982 & Feb. 04 & 35,300 & 27.60 \\
\hline 1924 & Sept. 26 & 59,600 & 31.50 & 1954 & Dec. 14 & 9,420 & 15.40 & 1983 & Apr. 09 & 62,200 & 35.11 \\
\hline 1925 & Jan. 19 & 84,900 & 36.70 & 1955 & Apr. 14 & 8,780 & 14.90 & 1984 & Feb. 27 & 32,000 & 23.71 \\
\hline 1926 & Apr. 01 & 23,300 & 22.80 & 1956 & Mar. 17 & 26,500 & 24.80 & 1985 & Feb. 06 & 56,700 & 33.78 \\
\hline 1927 & Feb. 25 & 15,900 & 18.30 & 1957 & May 30 & 21,900 & 22.90 & 1986 & Mar. 21 & 11,400 & 15.60 \\
\hline 1928 & Aug. 16 & 95,000 & 38.70 & 1958 & Feb. 07 & 32,100 & 26.70 & 1987 & Mar. 01 & 39,700 & 29.02 \\
\hline 1929 & Feb. 28 & 86,500 & 37.00 & 1959 & June 03 & 29,100 & 25.70 & 1988 & Feb. 06 & 26,100 & 21.33 \\
\hline 1930 & Oct. 02 & 85,900 & 36.90 & 1960 & Jan. 31 & 40,000 & 29.00 & 1989 & Apr. 12 & 12,200 & 16.14 \\
\hline 1931 & May 05 & 24,800 & 23.50 & 1961 & Feb. 25 & 122,000 & 42.90 & 1990 & Oct. 02 & 83,100 & 40.18 \\
\hline 1932 & Jan. 09 & 31,100 & 25.20 & & & & & & & & \\
\hline
\end{tabular}




\section{ALTAMAHA RIVER BASIN}

\section{BUFFALO CREEK NEAR LINTON, GEORGIA}

LOCATION.--Lat $33^{\circ} 06^{\prime} 27^{\prime \prime}$, long $82^{\circ} 57^{\prime} 34^{\prime \prime}$, Hancock-Washington County line, at bridge on Hancock County Road 787, 2 mi east of Linton.

DRAINAGE AREA.--92.9 $\mathrm{mi}^{2}$

GAGE.--Crest-stage gage. Datum of gage is about $278 \mathrm{ft}$ above sea level (from topographic map).

STAGE-DISCHARGE RELATION.--Defined by current-meter measurements below $1,800 \mathrm{ft}^{3} / \mathrm{s}$, and extended above on the basis of straight-line extension.

REMARKS.--Flood stage of 1961 furnished by the Georgia Department of Transportation. Peak discharge for 1961 is an estimate.

\begin{tabular}{|c|c|c|c|c|c|c|c|c|c|c|c|}
\hline $\begin{array}{l}\text { Water } \\
\text { year }\end{array}$ & Date & $\begin{array}{c}\text { Discharge } \\
\left(\mathrm{ft}^{3} / \mathrm{s}\right)\end{array}$ & $\begin{array}{c}\text { Gage } \\
\text { height } \\
\text { (ft) }\end{array}$ & $\begin{array}{l}\text { Water } \\
\text { year }\end{array}$ & Date & $\begin{array}{c}\text { Discharge } \\
\left(\mathrm{ft}^{3} / \mathrm{s}\right)\end{array}$ & $\begin{array}{c}\text { Gage } \\
\text { height } \\
\text { (ft) }\end{array}$ & $\begin{array}{l}\text { Water } \\
\text { year }\end{array}$ & Date & $\begin{array}{c}\text { Discharge } \\
\left(\mathrm{ft}^{3} / \mathrm{s}\right)\end{array}$ & $\begin{array}{c}\text { Gage } \\
\text { height } \\
\text { (ft) }\end{array}$ \\
\hline 1961 & Feb. 25 & 5,400 & $20.00 c$ & 1986 & Mar. 20 & 1,330 & 11.49 & 1989 & Apr. 15 & 1,780 & 12.80 \\
\hline 1984 & Feb. 27 & 1,850 & 13.00 & 1987 & Mar. 01 & 2,080 & 13.61 & 1990 & Oct. 01 & 2,210 & 13.92 \\
\hline 1985 & Feb. 06 & 2,550 & 14.75 & 1988 & Apr. 12 & 940 & 10.14 & & & & \\
\hline
\end{tabular}

\section{COMMISSIONER CREEK AT TOOMSBORO, GEORGIA}

LOCATION.--Lat 32 $49^{\prime} 53^{\prime \prime}$, long $83^{\circ} 04^{\prime} 43^{\prime \prime}$, Wilkinson County, at State Highway 112, at Toomsboro.

DRAINAGE AREA.--191 $\mathrm{mi}^{2}$.

GAGE.-Crest-stage gage. Datum of gage is $201.70 \mathrm{ft}$ above sea level (levels from Georgia Department of Transportation).

STAGE-DISCHARGE RELATION.--Defined by current-meter measurements below $5,600 \mathrm{ft}^{3} / \mathrm{s}$, and extended above on the basis of slope-conveyance studies. Bankfull stage and discharge, $15 \mathrm{ft}$ and $600 \mathrm{ft}^{3} / \mathrm{s}$.

HISTORICAL DATA.--The flood stages of 1928 and 1948 was based on information furnished by local residents. The flood of 1928 was the highest in the memory of local residents in 1949, and is thought to be the highest since 1886.

REMARKS.--Peak discharge for 1928 is estimated.

\begin{tabular}{|c|c|c|c|c|c|c|c|c|c|c|c|}
\hline $\begin{array}{l}\text { Water } \\
\text { year }\end{array}$ & Date & $\begin{array}{c}\text { Discharge } \\
\left(\mathrm{ft}^{3} / \mathrm{s}\right)\end{array}$ & $\begin{array}{c}\text { Gage } \\
\text { height } \\
\text { (ft) }\end{array}$ & $\begin{array}{l}\text { Water } \\
\text { year }\end{array}$ & Date & $\begin{array}{c}\text { Discharge } \\
\left(\mathrm{ft}^{3} / \mathrm{s}\right)\end{array}$ & $\begin{array}{c}\text { Gage } \\
\text { height } \\
\text { (ft) }\end{array}$ & $\begin{array}{l}\text { Water } \\
\text { year }\end{array}$ & Date & $\begin{array}{c}\text { Discharge } \\
\left(\mathrm{ft}^{3} / \mathrm{s}\right)\end{array}$ & $\begin{array}{c}\text { Gage } \\
\text { height } \\
\text { (ft) }\end{array}$ \\
\hline$\underline{1928}$ & Feb. -- & 15,000 & $22.50 \mathrm{c}$ & 1958 & Mar. 08 & 1,700 & 16.20 & 1968 & Mar. 13 & 642 & 14.99 \\
\hline 1949 & Nov. -- & 7,510 & 19.50 & 1959 & Mar. - & 1,120 & 15.50 & 1969 & Aug. 05 & 1,360 & 15.75 \\
\hline 1950 & Mar. 07 & 495 & 14.50 & 1960 & Apr. 04 & 2,910 & 17.00 & 1970 & Mar. 21 & 3,000 & 17.24 \\
\hline 1951 & Nov. 20 & 807 & 15.10 & 1961 & Feb. 25 & 6,410 & 19.00 & 1971 & Mar. 04 & 3,530 & 17.39 \\
\hline 1952 & Mar. 06 & 3,710 & 17.50 & 1962 & Feb. 22 & 5,840 & 18.66 & 1972 & Jan. 14 & 2,610 & 16.94 \\
\hline 1953 & Mar. 01 & 4,510 & 18.00 & 1963 & May 00 & 3,550 & 17.40 & 1973 & Apr. 08 & 3,510 & 17.54 \\
\hline 1954 & Jan. 23 & 1,270 & 15.70 & 1964 & Apr. 06 & 8,170 & 19.80 & 1974 & Feb. 17 & 2,790 & 17.06 \\
\hline 1955 & Apr. 15 & 1,190 & 15.60 & 1965 & Dec. 26 & 4,350 & 17.90 & 1975 & Apr. 15 & 3,210 & 17.34 \\
\hline 1956 & Mar. 16 & 1,600 & 16.10 & 1966 & Mar. 04 & 3,930 & 17.64 & $\underline{1976}$ & May 15 & 2,260 & 16.71 \\
\hline 1957 & May 25 & 2,310 & 16.60 & 1967 & Jan. 03 & 1,420 & 15.86 & $\overline{1980}$ & Mar. 14 & 6,920 & $19.09 c$ \\
\hline
\end{tabular}




\section{ALTAMAHA RIVER BASIN}

\section{BIG SANDY CREEK NEAR JEFFERSONVILLE, GEORGIA}

LOCATION.-Lat $32^{\circ} 48^{\prime} 15^{\prime \prime}$, long $83^{\circ} 25^{\prime} 04^{\prime \prime}$, Twiggs County, on downstream side of county highway bridge, 2.9 mi upstream from Myricks Mill, and 9 mi northwest of Jeffersonville.

DRAINAGE AREA.--31 $\mathrm{mi}^{2}$, approximately.

GAGE.--Water-stage recorder. Datum of gage is about $324 \mathrm{ft}$ above sea level (from topographic map).

STAGE-DISCHARGE RELATION.--Defined by current-meter measurements below $1,800 \mathrm{ft}^{3} / \mathrm{s}$. Bankfull stage and discharge, $4 \mathrm{ft}$ and $150 \mathrm{ft}^{3} / \mathrm{s}$.

REMARKS.--The flood of April 1964 is thought to be the highest since 1948, based on information at nearby stations. Peak discharge for 1971 is estimated.

\begin{tabular}{|c|c|c|c|c|c|c|c|c|c|c|c|}
\hline $\begin{array}{l}\text { Water } \\
\text { year }\end{array}$ & Date & $\begin{array}{c}\text { Discharge } \\
\left(\mathrm{ft}^{3} / \mathrm{s}\right)\end{array}$ & $\begin{array}{c}\text { Gage } \\
\text { height } \\
\text { (ft) }\end{array}$ & $\begin{array}{l}\text { Water } \\
\text { year }\end{array}$ & Date & $\begin{array}{c}\text { Discharge } \\
\left(\mathrm{ft}^{3} / \mathrm{s}\right)\end{array}$ & $\begin{array}{c}\text { Gage } \\
\text { height } \\
\text { (ft) }\end{array}$ & $\begin{array}{l}\text { Water } \\
\text { year }\end{array}$ & Date & $\begin{array}{c}\text { Discharge } \\
\left(\mathrm{ft}^{3} / \mathrm{s}\right)\end{array}$ & $\begin{array}{l}\text { Gage } \\
\text { height } \\
\text { (ft) }\end{array}$ \\
\hline 1959 & Feb. 04 & 158 & 3.87 & 1964 & Apr. 08 & 1,890 & 6.69 & 1968 & Dec. 15 & 147 & 3.91 \\
\hline 1960 & Feb. 14 & 532 & 4.78 & 1965 & June 16 & 282 & 4.39 & 1969 & Aug. 04 & 183 & 4.25 \\
\hline 1961 & Apr. 16 & 484 & 4.70 & 1966 & Mar. 04 & 450 & 4.99 & 1970 & Mar. 31 & 505 & 4.97 \\
\hline 1962 & Jan. 06 & 874 & 5.30 & 1967 & Dec. 31 & 104 & 3.63 & 1971 & Dec. 16 & 800 & - \\
\hline 1963 & May 01 & 296 & 4.33 & & & & & & & & \\
\hline
\end{tabular}

\section{BIG SANDY CREEK TRIBUTARY NEAR IRWINTON, GEORGIA}

LOCATION.--Lat $32^{\circ} 48^{\prime} 12^{\prime \prime}$, long $83^{\circ} 13^{\prime} 40^{\prime \prime}$, Wilkinson County, at culvert on White Springs Road, 1.7 mi southwest of Irwinton. DRAINAGE AREA.-0.50 $\mathrm{mi}^{2}$, approximately.

GAGE.--Crest-stage gage. Datum of gage is about $285 \mathrm{ft}$ above sea level (from topographic map).

STAGE-DISCHARGE RELATION.-Defined by current-meter measurements below $6.71 \mathrm{ft} / \mathrm{s}$, and extended above on the basis of culvert computations.

\begin{tabular}{|c|c|c|c|c|c|c|c|c|c|c|c|}
\hline $\begin{array}{l}\text { Water } \\
\text { year }\end{array}$ & Date & $\begin{array}{c}\text { Discharge } \\
\left(\mathrm{ft}^{3} / \mathrm{s}\right)\end{array}$ & $\begin{array}{c}\text { Gage } \\
\text { height } \\
\text { (ft) }\end{array}$ & $\begin{array}{l}\text { Water } \\
\text { year }\end{array}$ & Date & $\begin{array}{c}\text { Discharge } \\
\left(\mathrm{ft}^{3} / \mathrm{s}\right)\end{array}$ & $\begin{array}{c}\text { Gage } \\
\text { height } \\
\text { (ft) }\end{array}$ & $\begin{array}{l}\text { Water } \\
\text { year }\end{array}$ & Date & $\begin{array}{c}\text { Discharge } \\
\left(\mathrm{ft}^{3} / \mathrm{s}\right)\end{array}$ & $\begin{array}{c}\text { Gage } \\
\text { height } \\
\text { (ft) }\end{array}$ \\
\hline 1977 & Mar. 22 & 52.0 & 2.65 & 1982 & Feb. 03 & 36.0 & 2.52 & 1987 & Mar. 08 & 33.0 & 2.43 \\
\hline 1978 & Jan. 25 & 29.0 & 1.90 & 1983 & Feb. 14 & 33.0 & 2.40 & 1988 & Feb. 15 & 8.0 & 1.26 \\
\hline 1979 & Feb. 24 & 36.0 & 2.12 & 1984 & Mar. 06 & 22.0 & 1.80 & 1989 & July 20 & 26.0 & 2.08 \\
\hline 1980 & Mar. 13 & 40.0 & 2.26 & 1985 & Dec. - & 4.0 & $-\mathbf{b}$ & 1990 & Dec. 08 & 18.0 & 1.78 \\
\hline 1981 & Apr. 01 & 5.0 & 0.85 & 1986 & Feb. 11 & 5.0 & 0.78 & & & & \\
\hline
\end{tabular}

\section{BIG SANDY CREEK NEAR IRWINTON, GEORGIA}

LOCATION.--Lat $32^{\circ} 45^{\prime} 59^{\prime \prime}$, long $83^{\circ} 10^{\prime} 05^{\prime \prime}$, Wilkinson County, at bridge on State Highway 29 and U.S. Highway 441,3 mi south of Irwinton. DRAINAGE AREA.--177 $\mathrm{mi}^{2}$.

GAGE.-Crest-stage gage. Datum of gage is about $225 \mathrm{ft}$ above sea level (from topographic map).

STAGE-DISCHARGE RELATION.--Defined by current-meter measurements below $3,910 \mathrm{ft}^{3} / \mathrm{s}$, and extended above on the basis of straight-line extension. Bankfull stage and discharge, $3 \mathrm{ft}$ and $300 \mathrm{ft}^{3} / \mathrm{s}$.

\begin{tabular}{|c|c|c|c|c|c|c|c|c|c|c|c|}
\hline $\begin{array}{l}\text { Water } \\
\text { year }\end{array}$ & Date & $\begin{array}{c}\text { Discharge } \\
\left(\mathrm{ft}^{3} / \mathrm{s}\right)\end{array}$ & $\begin{array}{c}\text { Gage } \\
\text { height } \\
\text { (ft) }\end{array}$ & $\begin{array}{l}\text { Water } \\
\text { year }\end{array}$ & Date & $\begin{array}{c}\text { Discharge } \\
\left(\mathrm{ft}^{3} / \mathrm{s}\right)\end{array}$ & $\begin{array}{c}\text { Gage } \\
\text { height } \\
\text { (ft) }\end{array}$ & $\begin{array}{l}\text { Water } \\
\text { year }\end{array}$ & Date & $\begin{array}{c}\text { Discharge } \\
\left(\mathrm{ft}^{3} / \mathrm{s}\right)\end{array}$ & $\begin{array}{c}\text { Gage } \\
\text { height } \\
\text { (ft) }\end{array}$ \\
\hline 1970 & Mar. 31 & 4,020 & 6.51 & 1976 & May 16 & 1,220 & 4.62 & 1982 & Feb. 04 & 2,840 & 5.46 \\
\hline 1971 & Mar. 04 & 1,620 & 5.06 & 1977 & Mar. 22 & 4,320 & 6.65 & 1983 & Feb. 14 & 3,590 & 5.96 \\
\hline 1972 & Jan. 12 & 1,880 & 5.27 & 1978 & Jan. 26 & 3,380 & 5.82 & 1984 & July 30 & 1,570 & 4.59 \\
\hline 1973 & Feb. 03 & 2,160 & 5.47 & 1979 & Feb. 24 & 3,220 & 5.71 & 1985 & Feb. 07 & 1,080 & 4.18 \\
\hline 1974 & Feb. 08 & 1,730 & 5.15 & 1980 & Mar. 13 & 4,000 & 6.20 & 1986 & Mar. 19 & 380 & 3.10 \\
\hline 1975 & Mar. 20 & 2,450 & 5.67 & 1981 & Apr. 01 & 1,060 & 4.16 & 1987 & Mar. 09 & 2,160 & 5.01 \\
\hline
\end{tabular}




\section{ALTAMAHA RIVER BASIN}

\section{OCONEE RIVER AT DUBLIN, GEORGIA}

LOCATION.--Lat $32^{\circ} 32^{\prime} 40^{\prime \prime}$, long $82^{\circ} 53^{\prime} 41^{\prime \prime}$, Laurens County, near left bank on downstream end of pier of bridge on U.S. Highway 80 at Dublin, and at mile 74.3 .

DRAINAGE AREA.--4,400 $\mathrm{mi}^{2}$

GAGE.-Water-stage recorder. Datum of gage is $149.08 \mathrm{ft}$ above sea level (from U.S. Coast and Geodetic Survey benchmark), supplementary adjustment of 1936. Prior to Apr. 14, 1932, nonrecording gage and Apr. 15, 1932 to June 17, 1934, water-stage recorder at site $420 \mathrm{ft}$ downstream at datum $3.0 \mathrm{ft}$ higher, Oct. 1, 1933 to July 17, 1934 corrected to present datum. July 18, 1934 to Apr. 14, 1936, water-stage recorder, Apr. 15, 1936 to Oct. 12, 1938, nonrecording gage, and Oct. 13, 1938 to Jan. 20 1953, water-stage recorder at site $80 \mathrm{ft}$ upstream at present datum.

STAGE-DISCHARGE RELATION.--Defined by current-meter measurements below $96,000 \mathrm{ft}^{3} / \mathrm{s}$. Bankfull stage and discharge, $20 \mathrm{ft}$ and $20,000 \mathrm{ft}^{3} / \mathrm{s}$

REMARKS.--Stage records for 1894-97 from National Weather Service. Regulation by storage in Sinclair Reservoir (maximum flood-control storage, 214,600 acre-ft) since November 1952 and Lake Oconee (maximum flood-control storage, 367,000 acre-ft) since January 1979 does not materially affect peak discharges.

HISTORICAL DATA.--The flood of 1936 is thought to be the highest since 1886 based on information at nearby stations.

\begin{tabular}{|c|c|c|c|c|c|c|c|c|c|c|c|}
\hline $\begin{array}{l}\text { Water } \\
\text { year }\end{array}$ & Date & $\begin{array}{c}\text { Discharge } \\
\left(\mathrm{ft}^{3} / \mathrm{s}\right)\end{array}$ & $\begin{array}{l}\text { Gage } \\
\text { height } \\
\text { (ft) }\end{array}$ & $\begin{array}{l}\text { Water } \\
\text { year }\end{array}$ & Date & $\begin{array}{c}\text { Discharge } \\
\left(\mathrm{ft}^{3} / \mathrm{s}\right)\end{array}$ & $\begin{array}{c}\text { Gage } \\
\text { height } \\
\text { (ft) }\end{array}$ & $\begin{array}{l}\text { Water } \\
\text { year }\end{array}$ & Date & $\begin{array}{c}\text { Discharge } \\
\left(\mathrm{ft}^{3} / \mathrm{s}\right)\end{array}$ & $\begin{array}{c}\text { Gage } \\
\text { height } \\
\text { (ft) }\end{array}$ \\
\hline 1894 & Feb. 19 & 20,500 & 14.90 & 1927 & July 29 & 14,100 & 11.40 & 1959 & June 08 & 22,600 & 19.50 \\
\hline 1895 & Mar. 19 & 49,700 & 23.40 & 1928 & Aug. 19 & 79,000 & 27.90 & 1960 & Apr. 05 & 32,000 & 22.70 \\
\hline 1896 & Feb. 10 & 25,900 & 17.00 & 1929 & Mar. 07 & 92,300 & 29.30 & 1961 & Feb. 28 & 60,400 & 28.40 \\
\hline 1897 & Mar. 17 & 46,200 & 22.70 & 1930 & Oct. 05 & 76,600 & 27.60 & 1962 & Mar. 15 & 33,500 & 23.10 \\
\hline 1898 & Sept. 05 & 56,200 & 24.60 & 1931 & May 09 & 23,500 & 16.10 & 1963 & July 03 & 31,500 & 23.10 \\
\hline 1899 & Feb. 10 & 45,300 & 22.50 & 1932 & Jan. 12 & 31,200 & 18.80 & 1964 & Apr. 11 & 49,800 & 27.80 \\
\hline 1900 & Feb. 17 & 57,900 & 24.90 & 1933 & Feb. 24 & 20,700 & $\underline{15.00}$ & 1965 & Dec. 30 & 36,600 & 25.17 \\
\hline 1901 & Apr. 06 & 45,800 & 22.60 & 1934 & Mar. 09 & $\underline{23,500}$ & $\overline{19.10}$ & 1966 & Mar. 08 & 41,200 & 26.17 \\
\hline 1902 & Mar. 05 & 63,600 & 25.80 & 1935 & $\overline{\text { Mar. } 19}$ & $\overline{15,100}$ & 14.70 & 1967 & Jan. 05 & 12,100 & 14.34 \\
\hline 1903 & Feb. 12 & 52,800 & 24.00 & 1936 & Apr. 12 & 96,700 & 33.00 & 1968 & Jan. 18 & 13,100 & 15.06 \\
\hline 1904 & Feb. 14 & 11,500 & 9.90 & 1937 & May 04 & 35,200 & 23.20 & 1969 & Apr. 24 & 23,300 & 21.12 \\
\hline 1905 & Feb. 16 & 33,600 & 19.50 & 1938 & Apr. 11 & 38,700 & 24.10 & 1970 & Mar. 25 & 35,000 & 24.84 \\
\hline 1906 & Jan. 28 & 32,600 & 19.20 & 1939 & Mar. 04 & 48,500 & 26.20 & 1971 & Mar. 06 & 70,100 & 30.21 \\
\hline 1907 & Feb. 10 & 18,000 & 13.50 & 1940 & Aug. 19 & 18,800 & 18.00 & 1972 & Jan. 17 & 41,800 & 26.29 \\
\hline 1908 & Aug. 30 & 48,600 & 23.20 & 1941 & Apr. 01 & 10,100 & 12.50 & 1973 & Apr. 11 & 30,800 & 23.72 \\
\hline 1909 & Mar. 16 & 49,200 & 23.30 & 1942 & Mar. 26 & 52,100 & 27.00 & 1974 & Feb. 20 & 26,400 & 21.97 \\
\hline 1910 & Mar. 06 & 20,800 & 15.60 & 1943 & Mar. 25 & 42,800 & 25.20 & 1975 & Mar. 19 & 43,800 & 26.69 \\
\hline 1911 & Apr. 17 & 10,200 & 8.20 & 1944 & Mar. 26 & 61,600 & 28.60 & 1976 & Mar. 21 & 37,000 & 25.28 \\
\hline 1912 & Mar. 20 & 59,800 & 25.20 & 1945 & May 01 & 25,400 & 20.70 & 1977 & Mar. 26 & 27,200 & 22.26 \\
\hline 1913 & Mar. 18 & 68,400 & 26.50 & 1946 & Jan. 13 & 29,500 & 22.00 & 1978 & Jan. 30 & 45,400 & 27.00 \\
\hline 1914 & Mar. 03 & 10,500 & 8.90 & 1947 & Mar. 11 & 42,800 & 25.20 & 1979 & Feb. 28 & 48,500 & 27.56 \\
\hline 1915 & Jan. 23 & 27,900 & 17.70 & 1948 & Feb. 16 & 39,000 & 24.40 & 1980 & Mar. 16 & 49,900 & 27.81 \\
\hline 1916 & July 28 & 24,600 & 16.50 & 1949 & Dec. 03 & 71,200 & 30.10 & 1981 & Feb. 15 & 32,100 & 24.09 \\
\hline 1917 & Mar. 31 & 31,300 & 18.80 & 1950 & Mar. 12 & 10,900 & 13.10 & 1982 & Feb. 08 & 28,400 & 22.78 \\
\hline 1918 & Feb. 06 & 17,300 & 13.30 & 1951 & Apr. 27 & 8,840 & 11.40 & 1983 & Apr. 12 & 45,100 & 26.93 \\
\hline 1919 & Feb. 28 & 47,600 & 23.00 & 1952 & Mar. 09 & $\underline{47,800}$ & 26.20 & 1984 & Dec. 11 & 23,700 & 20.87 \\
\hline 1920 & Dec. 15 & 52,800 & 24.00 & 1953 & $\overline{\text { May } 08}$ & $\overline{33,900}$ & 23.20 & 1985 & Feb. 10 & 31,000 & 23.72 \\
\hline 1921 & Feb. 14 & 37,800 & 20.70 & 1954 & Dec. 18 & 12,100 & 14.10 & 1986 & Mar. 24 & 11,400 & 13.54 \\
\hline 1922 & Mar. 10 & 54,500 & 24.30 & 1955 & Apr. 18 & 11,800 & 13.90 & 1987 & Mar. 05 & 30,700 & 23.60 \\
\hline 1923 & Mar. 23 & 38,900 & 21.00 & 1956 & Mar. 22 & 19,000 & 18.10 & 1988 & Feb. 09 & 10,600 & 13.26 \\
\hline 1924 & Sept. 30 & 49,200 & 23.20 & 1957 & Mar. 31 & 13,000 & 14.60 & 1989 & Apr. 15 & 12,200 & 14.96 \\
\hline 1925 & Jan. 21 & 94,900 & 29.80 & 1958 & Feb. 13 & 19,200 & 18.20 & 1990 & Mar. 21 & 46,200 & 27.14 \\
\hline 1926 & Apr. 05 & 24,300 & 16.40 & & & & & & & & \\
\hline
\end{tabular}




\section{ALTAMAHA RIVER BASIN}

\section{INDIAN BRANCH TRIBUTARY NEAR SCOTT, GEORGIA}

LOCATION.--Lat $32^{\circ} 33^{\prime} 22^{\prime \prime}$, long $82^{\circ} 44^{\prime} 33^{\prime \prime}$, Laurens County, at culvert on U.S. Highway $80,4.8$ mi west of Scott.

DRAINAGE AREA.-2.13 $\mathrm{mi}^{2}$.

GAGE.-Flood-stage/rainfall recorder. Datum of gage is about $220 \mathrm{ft}$ above sea level (from topographic map).

STAGE-DISCHARGE RELATION.--Defined by current-meter measurements below $100 \mathrm{ft}^{3} / \mathrm{s}$, and extended above on basis of culvert computations.

REMARKS.-Peak discharges for 1973-74 are estimated.

\begin{tabular}{|c|c|c|c|c|c|c|c|c|c|c|c|}
\hline $\begin{array}{l}\text { Water } \\
\text { year }\end{array}$ & Date & $\begin{array}{c}\text { Discharge } \\
\left(\mathrm{ft}^{3} / \mathrm{s}\right)\end{array}$ & $\begin{array}{c}\text { Gage } \\
\text { height } \\
\text { (ft) }\end{array}$ & $\begin{array}{l}\text { Water } \\
\text { year }\end{array}$ & Date & $\begin{array}{c}\text { Discharge } \\
\left(\mathrm{ft}^{3} / \mathrm{s}\right)\end{array}$ & $\begin{array}{c}\text { Gage } \\
\text { height } \\
\text { (ft) }\end{array}$ & $\begin{array}{l}\text { Water } \\
\text { year }\end{array}$ & Date & $\begin{array}{c}\text { Discharge } \\
\left(\mathrm{ft}^{3} / \mathrm{s}\right)\end{array}$ & $\begin{array}{c}\text { Gage } \\
\text { height } \\
\text { (ft) }\end{array}$ \\
\hline 1965 & Mar. 23 & 107 & 1.99 & 1969 & Aug. 03 & 166 & 2.39 & 1973 & Feb. 02 & 220 & 2.99 \\
\hline 1966 & Mar. 03 & 198 & 2.59 & 1970 & Mar. 20 & 181 & 2.49 & 1974 & Feb. 08 & 70 & 1.74 \\
\hline 1967 & Jan. 01 & 90 & 1.84 & 1971 & Mar. 26 & 51 & 1.44 & 1975 & Apr. 14 & 136 & 2.19 \\
\hline 1968 & Mar. -- & 49 & $-b$ & 1972 & Dec. 03 & 55 & 1.49 & & & & \\
\hline
\end{tabular}

\section{ROCKY CREEK NEAR DUDLEY, GEORGIA}

LOCATION.-Lat $32^{\circ} 29^{\prime} 38^{\prime \prime}$, long $83^{\circ} 08^{\prime} 49^{\prime \prime}$, Laurens County, on downstream side of highway bridge, 3.2 mi upstream from

Buckhorn Branch, and $5 \mathrm{mi}$ southwest of Dudley.

DRAINAGE AREA.--62.9 $\mathrm{mi}^{2}$.

GAGE.-Water-stage recorder. Datum of gage is about $262 \mathrm{ft}$ above sea level (by barometer).

STAGE-DISCHARGE RELATION.--Defined by current-meter measurements below $3,700 \mathrm{ft}^{3} / \mathrm{s}$, and extended above on basis of contracted-opening measurement at $9,270 \mathrm{ft}^{3} / \mathrm{s}$. Bankfull stage and discharge, $8 \mathrm{ft}$ and $1,500 \mathrm{t}^{3} / \mathrm{s}$.

HISTORICAL DATA.--The flood of 1966 is thought to be the highest since 1948, based on information at nearby stations.

\begin{tabular}{|c|c|c|c|c|c|c|c|c|c|c|c|}
\hline $\begin{array}{l}\text { Water } \\
\text { year }\end{array}$ & Date & $\begin{array}{c}\text { Discharge } \\
\left(\mathrm{ft}^{3} / \mathrm{s}\right)\end{array}$ & $\begin{array}{c}\text { Gage } \\
\text { height } \\
\text { (ft) }\end{array}$ & $\begin{array}{l}\text { Water } \\
\text { year }\end{array}$ & Date & $\begin{array}{c}\text { Discharge } \\
\left(\mathrm{ft}^{3} / \mathrm{s}\right)\end{array}$ & $\begin{array}{l}\text { Gage } \\
\text { height } \\
\text { (ft) }\end{array}$ & $\begin{array}{l}\text { Water } \\
\text { year }\end{array}$ & Date & $\begin{array}{c}\text { Discharge } \\
\left(\mathrm{ft}^{3} / \mathrm{s}\right)\end{array}$ & $\begin{array}{c}\text { Gage } \\
\text { height } \\
\text { (ft) }\end{array}$ \\
\hline 1952 & Mar. 24 & 692 & 5.80 & 1961 & Apr. 16 & 1,080 & 7.10 & 1969 & Aug. 23 & 446 & 4.78 \\
\hline 1953 & May 07 & 2,390 & 9.40 & 1962 & Feb. 20 & 1,350 & 7.80 & 1970 & Mar. 31 & 4,070 & 10.55 \\
\hline 1954 & Dec. 14 & 668 & 5.70 & 1963 & Feb. 12 & 829 & 6.33 & 1971 & Mar. 26 & 948 & 6.67 \\
\hline 1955 & Apr. 15 & 1,350 & 7.80 & 1964 & May 03 & 1,410 & 8.50 & 1972 & Jan. 14 & 2,620 & 9.22 \\
\hline 1956 & Mar. 17 & 474 & 4.80 & 1965 & Feb. 18 & 1,150 & 7.80 & 1973 & Feb. 02 & 1,880 & 8.83 \\
\hline 1957 & Apr. 06 & 1,540 & 8.20 & 1966 & Mar. 03 & 9,270 & 13.49 & 1974 & Feb. 09 & 570 & 5.40 \\
\hline 1958 & Mar. 09 & 1,540 & 8.10 & 1967 & Feb. 07 & 758 & 5.96 & 1975 & July 16 & 4,280 & 10.70 \\
\hline 1959 & Mar. 06 & 2,390 & 9.40 & 1968 & July 11 & 185 & 3.76 & 1976 & May 16 & 1,310 & 7.54 \\
\hline 1960 & Apr. 05 & 2,930 & 10.00 & & & & & & & & \\
\hline
\end{tabular}




\section{ALTAMAHA RIVER BASIN}

\section{TURKEY CREEK NEAR DUBLIN, GEORGIA}

LOCATION.--Lat $32^{\circ} 27^{\prime} 21^{\prime \prime}$, long $82^{\circ} 56^{\prime} 32^{\prime \prime}$, Laurens County, at bridge on U.S. Highways 319 and 441,5 mi south of Dublin. DRAINAGE AREA.--316 $\mathrm{mi}^{2}$.

GAGE.--Crest-stage gage. Datum of gage is about $175 \mathrm{ft}$ above sea level (from topographic map).

STAGE-DISÇHARGE RELATION.--Defined by current-meter measurements below $10,500 \mathrm{ft}^{3} / \mathrm{s}$. Bankfull stage and discharge $10 \mathrm{ft}$ and $900 \mathrm{ft}^{3} / \mathrm{s}$.

\begin{tabular}{|c|c|c|c|c|c|c|c|c|c|c|c|}
\hline $\begin{array}{l}\text { Water } \\
\text { year }\end{array}$ & Date & $\begin{array}{c}\text { Discharge } \\
\left(\mathrm{ft}^{3} / \mathrm{s}\right)\end{array}$ & $\begin{array}{l}\text { Gage } \\
\text { height } \\
\text { (ft) }\end{array}$ & $\begin{array}{l}\text { Water } \\
\text { year }\end{array}$ & Date & $\begin{array}{c}\text { Discharge } \\
\left(\mathrm{ft}^{3} / \mathrm{s}\right)\end{array}$ & $\begin{array}{l}\text { Gage } \\
\text { height } \\
\text { (ft) }\end{array}$ & $\begin{array}{l}\text { Water } \\
\text { year }\end{array}$ & Date & $\begin{array}{c}\text { Discharge } \\
\left(\mathrm{ft}^{3} / \mathrm{s}\right)\end{array}$ & $\begin{array}{c}\text { Gage } \\
\text { height } \\
\text { (ft) }\end{array}$ \\
\hline 1984 & May 29 & $\cdot 2,450$ & 13.00 & 1987 & Jan. 23 & 6,600 & 15.25 & 1989 & Apr. 15 & 1,590 & 11.67 \\
\hline 1985 & Feb. 07 & 2,180 & 12.60 & 1988 & Mar. - & 1,000 & $-b$ & 1990 & Dec. 08 & 2,020 & 12.39 \\
\hline 1986 & Dec. 14 & 2,490 & 13.05 & & & & & & & & \\
\hline
\end{tabular}

\section{MERCER CREEK NEAR SOPERTON, GEORGIA}

LOCATION.--Lat $32^{\circ} 26^{\prime} 38^{\prime \prime}$, long $82^{\circ} 41^{\prime} 30^{\prime \prime}$, Treutlen County, at State Highway $29,7.2$ mi northwest of Soperton.

DRAINAGE AREA.--16.1 $\mathrm{mi}^{2}$.

GAGE.--Flood-stage/rainfall recorder. Datum of gage is about $179 \mathrm{ft}$ above sea level (from topographic map).

STAGE-DISCHARGE RELATION.--Defined by current-meter measurements below $590 \mathrm{ft}^{3} / \mathrm{s}$, and extended above on basis of contracted-opening measurement at $1,210 \mathrm{ft}^{3} / \mathrm{s}$.

\begin{tabular}{|c|c|c|c|c|c|c|c|c|c|c|c|}
\hline $\begin{array}{l}\text { Water } \\
\text { year }\end{array}$ & Date & $\begin{array}{c}\text { Discharge } \\
\left(\mathrm{ft}^{3} / \mathrm{s}\right)\end{array}$ & $\begin{array}{c}\text { Gage } \\
\text { height } \\
\text { (ft) }\end{array}$ & $\begin{array}{l}\text { Water } \\
\text { year }\end{array}$ & Date & $\begin{array}{c}\text { Discharge } \\
\left(\mathrm{ft}^{3} / \mathrm{s}\right)\end{array}$ & $\begin{array}{c}\text { Gage } \\
\text { height } \\
\text { (ft) }\end{array}$ & $\begin{array}{c}\text { Water } \\
\text { year }\end{array}$ & Date & $\begin{array}{c}\text { Discharge } \\
\left(\mathrm{ft}^{3} / \mathrm{s}\right)\end{array}$ & $\begin{array}{c}\text { Gage } \\
\text { height } \\
\text { (ft) }\end{array}$ \\
\hline 1965 & Feb. 17 & 753 & 3.98 & 1969 & May 19 & 480 & 3.20 & 1973 & Feb. 02 & 1,210 & 5.48 \\
\hline 1966 & Mar. 04 & 1,210 & 5.48 & 1970 & Mar. 21 & 669 & 3.74 & 1974 & Feb. 08 & 412 & 3.03 \\
\hline 1967 & Jan. 02 & 829 & 4.23 & 1971 & Mar. 03 & 560 & 3.43 & 1975 & Apr. 14 & 700 & 3.83 \\
\hline 1968 & July 04 & 148 & 2.38 & 1972 & Feb. 02 & 596 & 3.53 & & & & \\
\hline
\end{tabular}

\section{CYPRESS CREEK NEAR TARRYTOWN, GEORGIA}

LOCATION.--Lat $32^{\circ} 16^{\prime} 49^{\prime \prime}$, long $82^{\circ} 35^{\prime} 45^{\prime \prime}$, Montgomery County, at U.S. Highway 221, 3.2 mi southwest of Tarrytown.

DRAINAGE AREA.--6.77 $\mathrm{mi}^{2}$.

GAGE.-Crest-stage gage prior to Mar. 19, 1968; flood-stage/rainfall recorder thereafter. Datum of gage is about $170 \mathrm{ft}$ above sea

level (from topographic map).

STAGE-DISCHARGE RELATION.--Defined by current-meter measurements below $210 \mathrm{tt}^{3} / \mathrm{s}$, and extended above on basis of

contracted-opening measurement at $2,220 \mathrm{ft}^{3} / \mathrm{s}$.

REMARKS.--The flood of 1966 is thought to be the highest since 1948 , based on information at nearby stations.

\begin{tabular}{|c|c|c|c|c|c|c|c|c|c|c|c|}
\hline $\begin{array}{l}\text { Water } \\
\text { year }\end{array}$ & Date & $\begin{array}{c}\text { Discharge } \\
\left(\mathrm{ft}^{3} / \mathrm{s}\right)\end{array}$ & $\begin{array}{c}\text { Gage } \\
\text { height } \\
\text { (ft) }\end{array}$ & $\begin{array}{l}\text { Water } \\
\text { year }\end{array}$ & Date & $\begin{array}{c}\text { Discharge } \\
\left(\mathrm{ft}^{3} / \mathrm{s}\right)\end{array}$ & $\begin{array}{c}\text { Gage } \\
\text { height } \\
\text { (ft) }\end{array}$ & $\begin{array}{l}\text { Water } \\
\text { year }\end{array}$ & Date & $\begin{array}{c}\text { Discharge } \\
\left(\mathrm{ft}^{3} / \mathrm{s}\right)\end{array}$ & $\begin{array}{c}\text { Gage } \\
\text { height } \\
\text { (ft) }\end{array}$ \\
\hline 1965 & Feb. 17 & 295 & 3.66 & 1969 & Mar. 18 & 105 & 2.58 & 1973 & Apr. 01 & 544 & 4.28 \\
\hline 1966 & Mar. 04 & 2,220 & 5.66 & 1970 & Mar. 21 & 245 & 3.47 & 1974 & Feb. 08 & 224 & 3.38 \\
\hline 1967 & Jan. 01 & 295 & 3.66 & 1971 & Mar. 03 & 273 & 3.58 & 1975 & Apr. 14 & 446 & 4.08 \\
\hline 1968 & July 11 & 134 & 2.83 & 1972 & Dec. 20 & 193 & 3.23 & & & & \\
\hline
\end{tabular}




\section{ALTAMAHA RIVER BASIN}

\section{OCONEE RIVER NEAR MOUNT VERNON, GEORGIA}

LOCATION.--Lat $32^{\circ} 11^{\prime} 28^{\prime \prime}$, long $82^{\circ} 38^{\prime} 0^{\prime \prime}$, Montgomery County, at U.S. Highway 280,2 mi west of Mount Vernon, and at mile 28.7.

DRAINAGE AREA.--5,110 $\mathrm{mi}^{2}$.

GAGE.--Water-stage recorder prior to Jan. 5,1956 ; crest-stage gage thereafter. Datum of gage is $103.34 \mathrm{ft}$ above sea level (from U.S. Coast and Geodetic Survey benchmark), supplementary adjustment of 1936.

STAGE-DISCHARGE RELATION.--Defined by current-meter measurements below $62,000 \mathrm{ft}^{3} / \mathrm{s}$, and above on the basis of straightline extension. Bankfull stage and discharge, $14 \mathrm{ft}$ and $14,000 \mathrm{ft}^{3} / \mathrm{s}$.

HISTORICAL DATA.-Flood stage for 1925 and 1936, based on information by Georgia Department of Transportation. The 1936 flood is probably the highest peak since at least 1886 , based on information at nearby stations.

REMARKS.--Stage records for 1956-90 from National Weather Service. Regulation by storage in Sinclair Reservoir (maximum flood-control storage, 214,600 acre-ft) since November 1952 and Lake Oconee (maximum flood-control storage, 367,000 acre-ft) since January 1979, does not materially affect peak discharge. Peak discharge for 1929 is estimated, and is based on records at Oconee River at Dublin.

\begin{tabular}{|c|c|c|c|c|c|c|c|c|c|c|c|}
\hline $\begin{array}{l}\text { Water } \\
\text { year }\end{array}$ & Date & $\begin{array}{c}\text { Discharge } \\
\left(\mathrm{ft}^{3} / \mathrm{s}\right)\end{array}$ & $\begin{array}{l}\text { Gage } \\
\text { height } \\
\text { (ft) }\end{array}$ & $\begin{array}{l}\text { Water } \\
\text { year }\end{array}$ & Date & $\begin{array}{c}\text { Discharge } \\
\left(\mathrm{ft}^{3} / \mathrm{s}\right)\end{array}$ & $\begin{array}{c}\text { Gage } \\
\text { height } \\
\text { (ft) }\end{array}$ & $\begin{array}{l}\text { Water } \\
\text { year }\end{array}$ & Date & $\begin{array}{c}\text { Discharge } \\
\left(\mathrm{ft}^{3} / \mathrm{s}\right)\end{array}$ & $\begin{array}{c}\text { Gage } \\
\text { height } \\
\text { (ft) }\end{array}$ \\
\hline 1925 & Jan. 23 & 94,000 & $25.30 \mathrm{c}$ & 1954 & Dec. 21 & 13,800 & 14.00 & 1972 & Jan. 19 & 45,400 & 20.20 \\
\hline 1929 & Mar. 09 & 92,000 & $-c$ & 1955 & Apr. 21 & 12,000 & 13.30 & 1973 & Apr. 14 & 33,300 & 18.42 \\
\hline 1936 & Apr. 14 & 96,000 & 25.50 & 1956 & Mar. 25 & 20,800 & 16.10 & 1974 & Feb. 24 & 31,300 & 18.10 \\
\hline$\overline{1938}$ & Apr. 13 & 38,500 & 19.00 & 1957 & Apr. 03 & 13,800 & 14.00 & 1975 & Mar. 22 & 46,900 & 20.35 \\
\hline 1939 & Mar. 06 & 48,300 & 20.40 & 1958 & Mar. 13 & 26,000 & 17.20 & 1976 & Mar. 22 & 37,000 & - \\
\hline 1940 & Aug. 21 & 20,000 & 15.90 & 1959 & June 11 & 21,200 & 16.20 & 1977 & Mar. 28 & 29,200 & 17.75 \\
\hline 1941 & July 22 & 10,900 & 12.60 & 1960 & Apr. 07 & 42,800 & 19.80 & 1978 & Feb. 01 & 46,500 & 20.30 \\
\hline 1942 & May 28 & 49,600 & 20.70 & 1961 & Mar. 03 & 58,800 & 21.80 & 1979 & Mar. 02 & 53,000 & - \\
\hline 1943 & Mar. 27 & 38,900 & 19.10 & 1962 & Mar. 18 & 33,900 & 18.50 & 1980 & Mar. 18 & 49,600 & 20.70 \\
\hline 1944 & Mar. 28 & 58,800 & 21.80 & 1963 & July 06 & 31,900 & 18.20 & 1981 & Feb. 18 & 25,000 & - \\
\hline 1945 & May 04 & 24,500 & 16.90 & 1964 & Apr. 14 & 50,400 & 20.80 & 1982 & Feb. 11 & 28,900 & 17.70 \\
\hline 1946 & Jan. 16 & 29,500 & 17.80 & 1965 & Jan. 02 & 40,600 & 19.50 & 1983 & Apr. 13 & 46,000 & - \\
\hline 1947 & Mar. 14 & 41,600 & 19.40 & 1966 & Mar. 07 & 46,500 & 20.30 & 1985 & Feb. 13 & 25,000 & 17.00 \\
\hline 1948 & Feb. 17 & 37,800 & 19.10 & 1967 & Jan. 07 & 15,500 & 14.60 & 1986 & Dec. 06 & 8,600 & 11.50 \\
\hline 1949 & Dec. 05 & 66,300 & 22.60 & 1968 & Jan. 21 & 12,500 & 13.50 & 1987 & Mar. 07 & 31,000 & 18.05 \\
\hline 1950 & Mar. 14 & 11,100 & 12.90 & 1969 & Apr. 27 & 24,000 & 16.85 & 1988 & Apr. 30 & 6,800 & 10.00 \\
\hline 1951 & Apr. 29 & 7,950 & 11.10 & 1970 & Mar. 28 & 38,500 & 19.15 & 1989 & Apr. 16 & 9,500 & 12.05 \\
\hline 1952 & Mar. 11 & 44,300 & 20.00 & 1971 & Mar. 09 & 64,800 & 23.00 & 1990 & Oct. 08 & 42,400 & 19.75 \\
\hline 1953 & May 10 & 35,200 & 18.70 & & & & & & & & \\
\hline
\end{tabular}

02224650 PETERSON CREEK AT GLENWOOD GEORGIA

(Formerly published as "Oconee River Tributary at Glenwood, Georgia"

LOCATION.--Lat $32^{\circ} 10^{\prime} 08^{\prime \prime}$, long $82^{\circ} 40^{\prime} 01^{\prime \prime}$, Wheeler County, at culvert on State Highway 19, at Glenwood.

DRAINAGE AREA. $-5.16 \mathrm{mi}^{2}$.

GAGE.--Flood-stage recorder prior to Nov. 16, 1967; flood-stage/rainfall recorder thereafter. Datum of gage is about $140 \mathrm{ft}$ above sea level (from topographic map).

STAGE-DISCHARGE RELATION.--Defined by current-meter measurements below $308 \mathrm{ft}^{3} / \mathrm{s}$, and extended above on basis of culvert computations.

\begin{tabular}{|c|c|c|c|c|c|c|c|c|c|c|c|}
\hline $\begin{array}{l}\text { Water } \\
\text { year }\end{array}$ & Date & $\begin{array}{c}\text { Discharge } \\
\left(\mathrm{ft}^{3} / \mathrm{s}\right)\end{array}$ & $\begin{array}{c}\text { Gage } \\
\text { height } \\
\text { (ft) }\end{array}$ & $\begin{array}{l}\text { Water } \\
\text { year }\end{array}$ & Date & $\begin{array}{c}\text { Discharge } \\
\left(\mathrm{ft}^{3} / \mathrm{s}\right)\end{array}$ & $\begin{array}{c}\text { Gage } \\
\text { height } \\
\text { (ft) }\end{array}$ & $\begin{array}{l}\text { Water } \\
\text { year }\end{array}$ & Date & $\begin{array}{c}\text { Discharge } \\
\left(\mathrm{ft}^{3} / \mathrm{s}\right)\end{array}$ & $\begin{array}{c}\text { Gage } \\
\text { height } \\
\text { (ft) }\end{array}$ \\
\hline 1965 & Jan. - & 250 & - & 1969 & Sept. 01 & 177 & 4.22 & 1972 & Dec. 20 & 200 & 4.37 \\
\hline 1966 & Feb. 28 & 342 & 5.05 & 1970 & May 29 & 434 & 5.43 & 1973 & Apr. 01 & 215 & 4.47 \\
\hline 1967 & Sept. 02 & 232 & 4.55 & 1971 & Aug. 29 & 338 & 5.07 & 1974 & Feb. 08 & 174 & 4.20 \\
\hline 1968 & July 10 & 146 & 4.03 & & & & & & & & \\
\hline
\end{tabular}




\section{ALTAMAHA RIVER BASIN}

\section{OCONEE RIVER TRIBUTARY NO. 2, NEAR GLENWOOD, GEORGIA}

LOCATION.-Lat $32^{\circ} 03^{\prime} 16^{\prime \prime}$, long $82^{\circ} 39^{\prime} 09^{\prime \prime}$, Wheeler County, at culvert on State Highway 19, 9 mi south of Glenwood.

DRAINAGE AREA. $-1.38 \mathrm{mi}^{2}$ (revised).

GAGE.--Flood-stage/rainfall recorder. Datum of gage is about $165 \mathrm{ft}$ above sea level (from topographic map).

STAGE-DISCHARGE RELATION.--Defined by current-meter measurements below $25 \mathrm{ft}^{3} / \mathrm{s}$, and extended above on basis of culvert computations.

REMARKS.--Peak discharges for 1965-66 are estimated.

\begin{tabular}{|c|c|c|c|c|c|c|c|c|c|c|c|}
\hline $\begin{array}{l}\text { Water } \\
\text { year }\end{array}$ & Date & $\begin{array}{c}\text { Discharge } \\
\left(\mathrm{ft}^{3} / \mathrm{s}\right)\end{array}$ & $\begin{array}{c}\text { Gage } \\
\text { height } \\
\text { (ft) }\end{array}$ & $\begin{array}{l}\text { Water } \\
\text { year }\end{array}$ & Date & $\begin{array}{c}\text { Discharge } \\
\left(\mathrm{ft}^{3} / \mathrm{s}\right)\end{array}$ & $\begin{array}{c}\text { Gage } \\
\text { height } \\
\text { (ft) }\end{array}$ & $\begin{array}{l}\text { Water } \\
\text { year }\end{array}$ & Date & $\begin{array}{c}\text { Discharge } \\
\left(\mathrm{ft}^{3} / \mathrm{s}\right)\end{array}$ & $\begin{array}{c}\text { Gage } \\
\text { height } \\
\text { (ft) }\end{array}$ \\
\hline 1965 & Jan. -- & 80 & -- & 1969 & May 19 & 64 & 2.55 & 1972 & Dec. 20 & 39 & 2.10 \\
\hline 1966 & Feb. - & 150 & -- & 1970 & Mar. 22 & 61 & 2.50 & 1973 & Apr. 07 & 76 & 2.73 \\
\hline 1967 & July 10 & 52 & 2.35 & 1971 & Aug. 29 & 114 & 3.20 & 1974 & July 00 & 198 & 3.90 \\
\hline 1968 & Aug. 01 & 25 & 1.80 & & & & & & & & \\
\hline
\end{tabular}

\section{ALTAMAHA RIVER NEAR BAXLEY, GEORGIA}

LOCATION.--Lat $31^{\circ} 56^{\prime} 20^{\prime \prime}$, long $82^{\circ} 21^{\prime} 13^{\prime \prime}$, Appling-Toombs County line, on right bank $400 \mathrm{ft}$ downstream from bridge on U.S. Highway 1, $2.2 \mathrm{mi}$ upstream from Bay Creek, 8 mi downstream from Bullards Creek, at mile 117.0, and 12 mi north of Baxley. DRAINAGE AREA.--11,600 $\mathrm{mi}^{2}$, approximately.

GAGE.-Water-stage recorder. Datum of gage is $61.51 \mathrm{ft}$ above sea level (levels from Georgia Department of Transportation).

Aug. 13, 1949, to June 30,1951 , nonrecording gage at site $400 \mathrm{ft}$ upstream at same datum.

STAGE-DISCHARGE RELATION.--Defined by current-meter measurements below $96,000 \mathrm{ft}^{3} / \mathrm{s}$, and extended above on basis of slope-conveyance studies. Bankfull stage and discharge, $13 \mathrm{ft}$ and $22,000 \mathrm{ft}^{3} / \mathrm{s}$.

HISTORICAL DATA.--Flood stage of 1925 based on information furnished by the Georgia Department of Transportation. Based on studies at the gaging station downstream on Altamaha River at Doctortown, this is thought to be the highest flood since 1800 . Flood stages of 1928-30, and 1936 furnished by the U.S. Army Corps of Engineers. Flood stages of 1944-48 based on information at Piney Bluff furnished by the National Weather Service. Flood stage of Dec. 1948 from floodmark.

REMARKS.--Minor regulation of lower peak discharge from storage in Lloyd Shoals Reservoir (maximum flood-control storage, 68,000 acre-ft) since 1910; and from Sinclair Reservoir (maximum flood-control storage, 214,600 acre-ft) since 1952; and from Lake Oconee (maximum flood-control storage 367,000 acre-ft) since 1979.

\begin{tabular}{|c|c|c|c|c|c|c|c|c|c|c|c|}
\hline $\begin{array}{l}\text { Water } \\
\text { year }\end{array}$ & Date & $\begin{array}{c}\text { Discharge } \\
\left(\mathrm{ft}^{3} / \mathrm{s}\right)\end{array}$ & $\begin{array}{c}\text { Gage } \\
\text { height } \\
\text { (ft) }\end{array}$ & $\begin{array}{l}\text { Water } \\
\text { year }\end{array}$ & Date & $\begin{array}{c}\text { Discharge } \\
\left(\mathrm{ft}^{3} / \mathrm{s}\right)\end{array}$ & $\begin{array}{c}\text { Gage } \\
\text { height } \\
\text { (ft) }\end{array}$ & $\begin{array}{l}\text { Water } \\
\text { year }\end{array}$ & Date & $\begin{array}{c}\text { Discharge } \\
\left(\mathrm{ft}^{3} / \mathrm{s}\right)\end{array}$ & $\begin{array}{c}\text { Gage } \\
\text { height } \\
\text { (ft) }\end{array}$ \\
\hline$\underline{1925}$ & Jan. 22 & 230,000 & $30.00 \mathrm{c}$ & 1950 & Mar. 21 & 21,400 & 12.90 & 1980 & Mar. 21 & 84,900 & 21.69 \\
\hline$\overline{1928}$ & Aug. 23 & 132,000 & 25.30 & 1951 & Apr. 02 & 21,100 & 12.80 & 1981 & Feb. 22 & 34,700 & 15.98 \\
\hline 1929 & Mar. 11 & 160,000 & 27.40 & 1971 & Mar. 12 & 97,500 & 22.10 & 1982 & Feb. 15 & 49,300 & 18.10 \\
\hline 1930 & Oct. 09 & 130,000 & 25.10 & 1972 & Jan. 23 & 67,800 & 20.18 & 1983 & Apr. 19 & 57,500 & 19.08 \\
\hline 1936 & Apr. 12 & 165,000 & $--c$ & 1973 & Apr. 14 & 53,800 & 18.67 & 1984 & Mar. 09 & 47,600 & 17.87 \\
\hline$\overline{1944}$ & Apr. 01 & 108,000 & 24.50 & 1974 & Feb. 26 & 46,500 & 17.70 & 1985 & Feb. 16 & 42,700 & 17.20 \\
\hline 1945 & May 08 & 35,000 & 16.00 & 1975 & Mar. 26 & 91,300 & 22.22 & 1986 & Feb. 13 & 27,000 & 14.60 \\
\hline 1946 & Jan. 19 & 51,600 & 18.40 & 1976 & Mar. 28 & 53,400 & 18.62 & 1987 & Jan. 28 & 52,600 & 18.50 \\
\hline 1947 & Mar. 18 & 58,000 & 19.20 & 1977 & Apr. 02 & 45,100 & 17.50 & 1988 & Mar. 13 & 17,600 & 11.90 \\
\hline 1948 & Apr. 05 & 69,100 & 20.30 & 1978 & Feb. 05 & 73,000 & 20.65 & 1989 & Apr. 21 & 26,300 & 14.26 \\
\hline 1949 & Dec. 10 & 130,000 & 25.10 & 1979 & Mar. 06 & 76,000 & 20.95 & 1990 & Mar. 28 & 65,500 & 19.35 \\
\hline
\end{tabular}




\section{ALTAMAHA RIVER BASIN}

\section{COBB CREEK NEAR LYONS, GEORGIA}

LOCATION.-Lat $32^{\circ} 02^{\prime} 06^{\prime \prime}$, long $82^{\circ} 22^{\prime} 47^{\prime \prime}$, Toombs County, at State Highway 56, $1.8 \mathrm{mi}$ northeast of Cedar Crossing, and $13 \mathrm{mi}$ northeast of Lyons.

DRAINAGE AREA.-69 $\mathrm{mi}^{2}$, approximately.

GAGE.--Crest-stage gage. Datum of gage is $108.80 \mathrm{ft}$ above sea level (levels from Georgia Department of Transportation).

STAGE-DISCHARGE RELATION.--Defined by current-meter measurements below $1,470 \mathrm{ft}^{3} / \mathrm{s}$, and extended above on the basis of straight-line extension. Bankfull stage and discharge, $4.5 \mathrm{ft}$ and $600 \mathrm{ft}^{3} / \mathrm{s}$.

HISTORICAL DATA.--Flood stage of 1966 is thought to be the highest since 1929, based on information at nearby stations.

\begin{tabular}{|c|c|c|c|c|c|c|c|c|c|c|c|}
\hline $\begin{array}{l}\text { Water } \\
\text { year }\end{array}$ & Date & $\begin{array}{c}\text { Discharge } \\
\left(\mathrm{ft}^{3} / \mathrm{s}\right)\end{array}$ & $\begin{array}{c}\text { Gage } \\
\text { height } \\
\text { (ft) }\end{array}$ & $\begin{array}{l}\text { Water } \\
\text { year }\end{array}$ & Date & $\begin{array}{c}\text { Discharge } \\
\left(\mathrm{ft}^{3} / \mathrm{s}\right)\end{array}$ & $\begin{array}{c}\text { Gage } \\
\text { height } \\
\text { (ft) }\end{array}$ & $\begin{array}{l}\text { Water } \\
\text { year }\end{array}$ & Date & $\begin{array}{c}\text { Discharge } \\
\left(\mathrm{ft}^{3} / \mathrm{s}\right)\end{array}$ & $\begin{array}{c}\text { Gage } \\
\text { height } \\
\text { (ft) }\end{array}$ \\
\hline 1951 & Oct. -- & 1,480 & 6.26 & 1957 & Oct. 21 & 560 & 4.52 & 1962 & Apr. 01 & 425 & 4.12 \\
\hline 1952 & Mar. 24 & 340 & 3.71 & 1958 & Oct. 20 & 745 & 5.04 & 1963 & June 24 & 508 & 4.33 \\
\hline 1953 & Apr. 06 & 455 & 4.20 & 1959 & May 27 & 1,130 & 5.79 & 1964 & Feb. 20 & 1,400 & 6.41 \\
\hline 1954 & Jan. 01 & 320 & 3.65 & 1960 & Dec. 20 & 1,820 & 7.10 & 1965 & Feb. 18 & 1,350 & 6.33 \\
\hline 1955 & Sept. 14 & 1,130 & 5.82 & 1961 & Apr. 16 & 595 & 4.59 & 1966 & Mar. 04 & 3,500 & 9.90 \\
\hline 1956 & Feb. 08 & 1,130 & 5.78 & & & & & & & & \\
\hline
\end{tabular}

\section{OHOOPEE RIVER NEAR WRIGHTSVILLE, GEORGIA}

LOCATION.--Lat $32^{\circ} 42^{\prime} 50^{\prime \prime}$, long $82^{\circ} 45^{\prime} 20^{\prime \prime}$, Johnson County, at U.S. Highway 319, 2.5 mi west of Wrightsville.

DRAINAGE AREA. $-55 \mathrm{mi}^{2}$, approximately.

GAGE.--Crest-stage gage. Datum of gage is $272.12 \mathrm{ft}$ above sea level (levels from Georgia Department of Transportation).

STAGE-DISCHARGE RELATION.--Defined by current-meter measurements below $3,200 \mathrm{ft}^{3} / \mathrm{s}$, and above on the basis of straightline extension. Bankfull stage and discharge, $6 \mathrm{ft}$ and $400 \mathrm{ft}^{3} / \mathrm{s}$.

HISTORICAL DATA.--Flood stage of 1966 is thought to be the highest since 1929, based on information at nearby stations.

\begin{tabular}{|c|c|c|c|c|c|c|c|c|c|c|c|}
\hline $\begin{array}{l}\text { Water } \\
\text { year }\end{array}$ & Date & $\begin{array}{c}\text { Discharge } \\
\left(\mathrm{ft}^{3} / \mathrm{s}\right)\end{array}$ & $\begin{array}{c}\text { Gage } \\
\text { height } \\
\text { (ft) }\end{array}$ & $\begin{array}{l}\text { Water } \\
\text { year }\end{array}$ & Date & $\begin{array}{c}\text { Discharge } \\
\left(\mathrm{ft}^{3} / \mathrm{s}\right)\end{array}$ & $\begin{array}{c}\text { Gage } \\
\text { height } \\
\text { (ft) }\end{array}$ & $\begin{array}{l}\text { Water } \\
\text { year }\end{array}$ & Date & $\begin{array}{c}\text { Discharge } \\
\left(\mathrm{ft}^{3} / \mathrm{s}\right)\end{array}$ & $\begin{array}{c}\text { Gage } \\
\text { height } \\
\text { (ft) }\end{array}$ \\
\hline 1963 & Feb. 12 & 1,020 & 7.64 & 1970 & Mar. 21 & 2,230 & 9.11 & 1977 & Mar. 22 & 2,180 & 9.07 \\
\hline 1964 & Apr. 06 & 1,350 & 8.19 & 1971 & Mar. 02 & 980 & 7.50 & 1978 & Jan. 26 & 1,210 & 7.88 \\
\hline 1965 & Feb. 18 & 1,000 & 7.60 & 1972 & Jan. 14 & 1,270 & 7.98 & 1979 & Jan. 26 & 1,630 & 8.48 \\
\hline 1966 & Mar. 04 & 3,830 & 10.26 & 1973 & Feb. 03 & 1,960 & 8.86 & 1980 & Mar. 13 & 3,540 & 10.09 \\
\hline 1967 & Feb. 08 & 350 & 5.64 & 1974 & Feb. 17 & 704 & 6.86 & 1981 & Feb. 11 & 335 & 5.58 \\
\hline 1968 & Jan. 11 & 386 & 5.79 & 1975 & Feb. 20 & 1,630 & 8.47 & 1982 & Feb. 04 & 900 & 7.34 \\
\hline 1969 & Aug. 23 & 760 & 6.97 & 1976 & Feb. - & 300 & $-b$ & 1983 & Feb. 14 & 1,770 & 8.65 \\
\hline
\end{tabular}


LOCATION.--Lat $32^{\circ} 32^{\prime} 58^{\prime \prime}$, long $82^{\circ} 31^{\prime} 26^{\prime \prime}$, Emanuel County, at U.S. Highway $80,4.8$ mi east of Adrian.

DRAINAGE AREA. $-13.8 \mathrm{mi}^{2}$.

GAGE.-Crest-stage gage prior to Nov. 16, 1967; flood-stage recorder, from Nov. 16, 1967 to Mar. 19, 1968; flood-stage/rainfall recorder thereafter. Datum of gage is about $210 \mathrm{ft}$ above sea level (from topographic map).

STAGE-DISCHARGE RELATION.--Defined by current-meter measurements below $450 \mathrm{ft}^{3} / \mathrm{s}$, and extended above on the basis of straight-line extension. Bankfull stage and discharge, $4 \mathrm{ft}$ and $60 \mathrm{ft}^{3} / \mathrm{s}$.

\begin{tabular}{|c|c|c|c|c|c|c|c|c|c|c|c|}
\hline $\begin{array}{l}\text { Water } \\
\text { year }\end{array}$ & Date & $\begin{array}{c}\text { Discharge } \\
\left(\mathrm{ft}^{3} / \mathrm{s}\right)\end{array}$ & $\begin{array}{c}\text { Gage } \\
\text { height } \\
\text { (ft) }\end{array}$ & $\begin{array}{l}\text { Water } \\
\text { year }\end{array}$ & Date & $\begin{array}{c}\text { Discharge } \\
\left(\mathrm{ft}^{3} / \mathrm{s}\right)\end{array}$ & $\begin{array}{c}\text { Gage } \\
\text { height } \\
\text { (ft) }\end{array}$ & $\begin{array}{l}\text { Water } \\
\text { year }\end{array}$ & Date & $\begin{array}{c}\text { Discharge } \\
\left(\mathrm{ft}^{3} / \mathrm{s}\right)\end{array}$ & $\begin{array}{c}\text { Gage } \\
\text { height } \\
\text { (ft) }\end{array}$ \\
\hline 1965 & Feb. 18 & 703 & 5.49 & 1968 & Mar. - & 44 & $-b$ & 1971 & July 30 & 335 & 4.88 \\
\hline 1966 & Mar. 05 & 375 & 4.96 & 1969 & June 05 & 612 & 5.36 & 1972 & Jan. 14 & 259 & 4.71 \\
\hline 1967 & Jan. 02 & 345 & 4.90 & 1970 & Mar. 21 & 591 & 5.33 & & & & \\
\hline
\end{tabular}

\section{LITTLE OHOOPEE RIVER NEAR WRIGHTSVILLE, GEORGIA}

LOCATION.--Lat $32^{\circ} 47^{\prime} 20^{\prime \prime}$, long $82^{\circ} 33^{\prime} 02^{\prime \prime}$, Johnson County, at U.S. Highway 319 and State Highway 78,10 mi northeast of Wrightsville.

DRAINAGE AREA. $-63 \mathrm{mi}^{2}$, approximately.

GAGE.--Crest-stage gage. Datum of gage is $258.8 \mathrm{ft}$ above sea level (levels by Georgia Department of Transportation).

STAGE-DISCHARGE RELATION.--Defined by current-meter measurements below $2,260 \mathrm{ft}^{3} / \mathrm{s}$, and above on the basis of slopeconveyance studies. Bankfull stage and discharge, $5 \mathrm{ft}$ and $300 \mathrm{ft}^{3} / \mathrm{s}$.

HISTORICAL DATA.--Flood stage of 1925 furnished by the Georgia Department of Transportation. Flood stage of 1980 is thought to be the highest since 1929 , based on information at nearby stations. REMARKS.-Peak discharge for 1925 is estimated.

\begin{tabular}{|c|c|c|c|c|c|c|c|c|c|c|c|}
\hline $\begin{array}{l}\text { Water } \\
\text { year }\end{array}$ & Date & $\begin{array}{c}\text { Discharge } \\
\left(\mathrm{ft}^{3} / \mathrm{s}\right)\end{array}$ & $\begin{array}{c}\text { Gage } \\
\text { height } \\
\text { (ft) }\end{array}$ & $\begin{array}{c}\text { Water } \\
\text { year }\end{array}$ & Date & $\begin{array}{c}\text { Discharge } \\
\left(\mathrm{ft}^{3} / \mathrm{s}\right)\end{array}$ & $\begin{array}{c}\text { Gage } \\
\text { height } \\
\text { (ft) }\end{array}$ & $\begin{array}{l}\text { Water } \\
\text { year }\end{array}$ & Date & $\begin{array}{c}\text { Discharge } \\
\left(\mathrm{ft}^{3} / \mathrm{s}\right)\end{array}$ & $\begin{array}{c}\text { Gage } \\
\text { height } \\
\text { (ft) }\end{array}$ \\
\hline$\underline{1925}$ & Jan. -- & 7,500 & $11.60 \mathrm{c}$ & 1960 & Apr. 05 & 1,890 & 8.44 & 1969 & Aug. 23 & 725 & 6.80 \\
\hline 1951 & June 14 & 216 & 5.27 & 1961 & Apr. 16 & 3,000 & 9.28 & 1970 & Apr. 01 & 2,600 & 8.98 \\
\hline 1952 & Mar. 24 & 876 & 7.06 & 1962 & Mar. 12 & 2,360 & 8.82 & 1971 & Mar. 02 & 750 & 6.85 \\
\hline 1953 & Mar. 01 & 1,140 & 7.50 & 1963 & Feb. 12 & 900 & 7.10 & 1972 & Jan. 14 & 558 & 6.41 \\
\hline 1954 & Jan. 18 & 396 & 5.87 & 1964 & Apr. 06 & 1,140 & 7.50 & 1973 & Feb. 03 & 3,210 & 9.43 \\
\hline 1955 & Apr. 14 & 1,240 & 7.66 & 1965 & Feb. 18 & 1,280 & 7.72 & 1974 & Feb. 17 & 966 & 7.21 \\
\hline 1956 & Feb. 07 & 670 & 6.69 & 1966 & Mar. 04 & 3,880 & 9.80 & 1975 & Apr. 15 & 1,360 & 7.80 \\
\hline 1957 & Apr. 06 & 1,240 & 7.65 & 1967 & July 08 & 606 & 6.54 & $\underline{1976}$ & Mar. 16 & 291 & 5.52 \\
\hline 1958 & Mar. 10 & 775 & 6.89 & 1968 & Jan. 11 & 441 & 6.02 & $\overline{1980}$ & Mar. 13 & 5,240 & $10.48 \mathrm{c}$ \\
\hline 1959 & Mar. 06 & 1,180 & 7.57 & & & & & & & & \\
\hline
\end{tabular}




\section{ALTAMAHA RIVER BASIN}

02225210 HURRICANE BRANCH NEAR WRIGHTSVILLE, GEORGIA

LOCATION.--Lat $32^{\circ} 47^{\prime} 00^{\prime \prime}$, long $82^{\circ} 34^{\prime} 42^{\prime \prime}$, Johnson County, at culvert on U.S. Highway $319,9.6$ mi northeast of Wrightsville. DRAINAGE AREA. $-3.53 \mathrm{mi}^{2}$.

GAGE.--Flood-stage/rainfall recorder. Datum of gage is about $265 \mathrm{ft}$ above sea level (from topographic map).

STAGE-DISCHARGE RELATION.--Defined by current-meter measurements below $270 \mathrm{ft}^{3} / \mathrm{s}$, and extended above on basis of culvert computations.

\begin{tabular}{lccccccccccc}
\hline $\begin{array}{l}\text { Water } \\
\text { year }\end{array}$ & Date & $\begin{array}{c}\text { Discharge } \\
\left(\mathrm{ft}^{3} / \mathrm{s}\right)\end{array}$ & $\begin{array}{c}\text { Gage } \\
\text { height } \\
(\mathrm{ft})\end{array}$ & $\begin{array}{c}\text { Water } \\
\text { year }\end{array}$ & Date & $\begin{array}{c}\text { Discharge } \\
\left(\mathrm{ft}^{3} / \mathrm{s}\right)\end{array}$ & $\begin{array}{c}\text { Gage } \\
\text { height } \\
(\mathrm{ft})\end{array}$ & $\begin{array}{c}\text { Water } \\
\text { year }\end{array}$ & $\begin{array}{c}\text { Gage } \\
\text { Date }\end{array}$ & $\begin{array}{c}\text { Discharge } \\
\left(\mathrm{ft}^{3} / \mathrm{s}\right)\end{array}$ & $\begin{array}{c}\text { height } \\
(\mathrm{ft})\end{array}$ \\
\hline & & & & & & & & & & & \\
1965 & Mar. 24 & 126 & 2.24 & 1969 & Aug. 12 & 210 & 2.65 & 1973 & Feb. 02 & 650 & 4.28 \\
1966 & July 14 & 271 & 2.87 & 1970 & Mar. 31 & 239 & 2.76 & $\underline{1974}$ & Mar. - & 43 & $-\mathrm{b}$ \\
1967 & July 09 & 136 & 2.30 & 1971 & Apr. 24 & 165 & 2.45 & 1980 & Mar. 13 & 600 & $4.10 \mathrm{c}$ \\
1968 & Jan. 10 & 45 & 1.58 & 1972 & Jan. 13 & 222 & 2.70 & & & \\
\hline
\end{tabular}

02225240 CROOKED CREEK NEAR KITE, GEORGIA

(Formerly published as "Little Ohoopee River Tributary near Kite, Georgia"

LOCATION.--Lat $32^{\circ} 40^{\prime} 22^{\prime \prime}$, long $82^{\circ} 26^{\prime} 43^{\prime \prime}$, Emanuel County, at culvert on State Highway 57,5 mi southeast of Kite.

DRAINAGE AREA.--7.22 $\mathrm{mi}^{2}$.

GAGE.--Flood-stage/rainfall recorder. Datum of gage is about $230 \mathrm{ft}$ above sea level (from topographic map).

STAGE-DISCHARGE RELATION.--Defined by current-meter measurements below $400 \mathrm{ft}^{3} / \mathrm{s}$, and extended above on basis of culvert computations.

\begin{tabular}{llcccccccccc}
\hline $\begin{array}{l}\text { Water } \\
\text { year }\end{array}$ & Date & $\begin{array}{c}\text { Discharge } \\
\left(\mathrm{ft}^{3} / \mathrm{s}\right)\end{array}$ & $\begin{array}{c}\text { Gage } \\
\text { height } \\
(\mathrm{ft})\end{array}$ & $\begin{array}{c}\text { Water } \\
\text { year }\end{array}$ & Date & $\begin{array}{c}\text { Discharge } \\
\left(\mathrm{ft}^{3} / \mathrm{s}\right)\end{array}$ & $\begin{array}{c}\text { Gage } \\
\text { height } \\
(\mathrm{ft})\end{array}$ & $\begin{array}{c}\text { Water } \\
\text { year }\end{array}$ & $\begin{array}{c}\text { Gage } \\
\text { Date }\end{array}$ & $\begin{array}{c}\text { Discharge } \\
\left(\mathrm{ft}^{3} / \mathrm{s}\right)\end{array}$ & $\begin{array}{c}\text { height } \\
\left(\mathrm{ft}^{2}\right)\end{array}$ \\
\hline 1965 & Feb. 17 & 231 & 4.43 & 1969 & May 19 & 126 & 3.85 & 1973 & Feb. 02 & 606 & 5.82 \\
1966 & Mar. 05 & 229 & 4.42 & 1970 & Mar. 21 & 251 & 4.55 & $\underline{1974}$ & Apr. 09 & 50.0 & 3.42 \\
1967 & Feb. 07 & 70 & 3.55 & 1971 & May 08 & 110 & 3.75 & 1980 & Mar. 13 & 700 & $6.10 \mathrm{c}$ \\
1968 & Jan. - & 38 & $-\mathrm{b}$ & 1972 & Jan. 14 & 122 & 3.84 & & & & \\
\hline
\end{tabular}

\section{LITTLE OHOOPEE RIVER NEAR SWAINSBORO, GEORGIA}

LOCATION.--Lat $32^{\circ} 33^{\prime} 44^{\prime \prime}$ long $82^{\circ} 28^{\prime} 03^{\prime \prime}$, Emanuel County, on Stage Highway 26 and U.S. Highway 80,9 mi west of Swainsboro. DRAINAGE AREA.--216 $\mathrm{mi}^{2}$.

GAGE.--Crest-stage gage. Prior to Nov. 13,1972 at same site, at datum about $4.6 \mathrm{ft}$ higher. Datum of gage is $184.12 \mathrm{ft}$ above sea level (from U.S. Geological Survey benchmark).

STAGE-DISCHARGE RELATION.--Defined by current-meter measurements below $7,440 \mathrm{ft}^{3} / \mathrm{s}$, and extended above on basis of slope-conveyance studes and straight-line extension.

REMARKS.--The flood stages of 1925 and 1929 were based on information provided by the Georgia Department of Transportation. Peak discharges for 1925 and 1929 are estimates.

\begin{tabular}{|c|c|c|c|c|c|c|c|c|c|c|c|}
\hline $\begin{array}{l}\text { Water } \\
\text { year }\end{array}$ & Date & $\begin{array}{c}\text { Discharge } \\
\left(\mathrm{ft}^{3} / \mathrm{s}\right)\end{array}$ & $\begin{array}{c}\text { Gage } \\
\text { height } \\
\text { (ft) }\end{array}$ & $\begin{array}{l}\text { Water } \\
\text { year }\end{array}$ & Date & $\begin{array}{c}\text { Discharge } \\
\left(\mathrm{ft}^{3} / \mathrm{s}\right)\end{array}$ & $\begin{array}{c}\text { Gage } \\
\text { height } \\
\text { (ft) }\end{array}$ & $\begin{array}{l}\text { Water } \\
\text { year }\end{array}$ & Date & $\begin{array}{c}\text { Discharge } \\
\left(\mathrm{ft}^{3} / \mathrm{s}\right)\end{array}$ & $\begin{array}{c}\text { Gage } \\
\text { height } \\
\text { (ft) }\end{array}$ \\
\hline$\underline{1925}$ & Feb. - & 9,800 & $12.00 \mathrm{c}$ & 1981 & Apr. 02 & 1,350 & 5.74 & 1986 & Dec. 15 & 3,510 & 8.01 \\
\hline$\underline{1929}$ & Mar. - & 13,500 & $14.00 \mathrm{c}$ & 1982 & Jan. 04 & 2,430 & 7.03 & 1987 & Jan. 23 & 3,430 & 7.94 \\
\hline 1970 & Apr. 01 & 3,700 & 8.30 & 1983 & Feb. 15 & 3,540 & 8.03 & 1988 & Mar. - & 2,300 & $-b$ \\
\hline$\underline{1972}$ & Jan. 14 & 3,480 & 8.12 & 1984 & Mar. 06 & 2,000 & $-b$ & 1989 & Feb. - & 2,300 & $-b$ \\
\hline$\overline{1980}$ & Mar. 14 & 6,870 & $\overline{10.42}$ & 1985 & Aug. 31 & 1,300 & $-\mathbf{b}$ & 1990 & Oct. 04 & 2,720 & 7.40 \\
\hline
\end{tabular}


LOCATION.--Lat $32^{\circ} 23^{\prime 2} 9^{\prime \prime}$ long $82^{\circ} 18^{\prime} 49^{\prime \prime}$, Emanuel County, at U.S. Highway 1, 2.5 mi north of Oak Park. DRAINAGE AREA.-620 $\mathrm{mi}^{2}$.

GAGE.-Crest-stage gage. Datum of gage is $140.00 \mathrm{ft}$ above sea level (levels from Georgia Department of Transportation).

STAGE-DISCHARGE RELATION.--Defined by current-meter measurements below $11,000 \mathrm{ft}^{3} / \mathrm{s}$, and extended above on basis of straight-line extension. Bankfull stage and discharge, $8 \mathrm{ft}$ and $2,400 \mathrm{ft}^{3} / \mathrm{s}$.

REMARKS.--Flood stage of 1925 from the Georgia Department of Transportation. Flood stage of 1925 is thought to be the highest since 1886, based on information at nearby stations. Peak discharge of 1925 is estimated.

\begin{tabular}{|c|c|c|c|c|c|c|c|c|c|c|c|}
\hline $\begin{array}{l}\text { Water } \\
\text { year }\end{array}$ & Date & $\begin{array}{c}\text { Discharge } \\
\left(\mathrm{ft}^{3} / \mathrm{s}\right)\end{array}$ & $\begin{array}{c}\text { Gage } \\
\text { height } \\
\text { (ft) }\end{array}$ & $\begin{array}{l}\text { Water } \\
\text { year }\end{array}$ & Date & $\begin{array}{c}\text { Discharge } \\
\left(\mathrm{ft}^{3} / \mathrm{s}\right)\end{array}$ & $\begin{array}{c}\text { Gage } \\
\text { height } \\
\text { (ft) }\end{array}$ & $\begin{array}{l}\text { Water } \\
\text { year }\end{array}$ & Date & $\begin{array}{c}\text { Discharge } \\
\left(\mathrm{ft}^{3} / \mathrm{s}\right)\end{array}$ & $\begin{array}{c}\text { Gage } \\
\text { height } \\
\text { (ft) }\end{array}$ \\
\hline$\underline{1925}$ & Jan. - & 33,000 & $15.70 \mathrm{c}$ & 1956 & Apr. 17 & 2,300 & 7.94 & 1961 & Apr. 17 & 9,900 & 11.60 \\
\hline 1951 & Apr. 01 & 1,970 & 7.48 & 1957 & Apr. 12 & 2,400 & 8.00 & 1962 & Mar. 13 & 8,400 & 11.14 \\
\hline 1952 & Mar. 27 & 4,260 & 9.42 & 1958 & Mar. 10 & 4,990 & 9.80 & 1963 & Jan. 20 & 3,600 & 8.98 \\
\hline 1953 & Sept. 29 & 3,210 & 8.70 & 1959 & Mar. 08 & 4,990 & 9.81 & 1964 & Mar. 04 & 6,150 & 10.34 \\
\hline 1954 & Dec. 15 & 1,540 & 6.87 & 1960 & Apr. 06 & 14,000 & 12.62 & 1965 & Feb. 19 & 10,300 & 11.70 \\
\hline 1955 & Apr. 15 & 3,910 & 9.25 & & & & & & & & \\
\hline
\end{tabular}

\section{OHOOPEE RIVER NEAR ALINE, GEORGIA}

LOCATION.--Lat $32^{\circ} 20^{\prime} 53^{\prime \prime}$, long $82^{\circ} 14^{\prime} 52^{\prime \prime}$, Emanuel-Candler County line, at county road 5 mi west of Aline.

DRAINAGE AREA.--698 $\mathrm{mi}^{2}$.

GAGE.--Crest-stage gage. Datum of gage is $123.60 \mathrm{ft}$ above sea level (levels from Georgia Department of Transportation).

STAGE-DISCHARGE RELATION.--Defined by current-meter measurements below $14,000 \mathrm{ft}^{3} / \mathrm{s}$, and extended above on basis of straight-line extension.

REMARKS.--Flood of March 1980 is thought to be the highest since 1929 , based on information at nearby stations.

\begin{tabular}{|c|c|c|c|c|c|c|c|c|c|c|c|}
\hline $\begin{array}{l}\text { Water } \\
\text { year }\end{array}$ & Date & $\begin{array}{c}\text { Discharge } \\
\left(\mathrm{ft}^{3} / \mathrm{s}\right)\end{array}$ & $\begin{array}{c}\text { Gage } \\
\text { height } \\
\text { (ft) }\end{array}$ & $\begin{array}{l}\text { Water } \\
\text { year }\end{array}$ & Date & $\begin{array}{c}\text { Discharge } \\
\left(\mathrm{ft}^{3} / \mathrm{s}\right)\end{array}$ & $\begin{array}{c}\text { Gage } \\
\text { height } \\
\text { (ft) }\end{array}$ & $\begin{array}{l}\text { Water } \\
\text { year }\end{array}$ & Date & $\begin{array}{c}\text { Discharge } \\
\left(\mathrm{ft}^{3} / \mathrm{s}\right)\end{array}$ & $\begin{array}{c}\text { Gage } \\
\text { height } \\
\text { (ft) }\end{array}$ \\
\hline$\underline{1975}$ & Feb. 21 & 7,850 & $14.86 \mathrm{c}$ & 1982 & Jan. 07 & 4,580 & 13.35 & 1985 & Aug. 31 & 2,700 & 11.88 \\
\hline 1980 & Mar. 16 & 15,200 & 17.25 & 1983 & Mar. 08 & 7,500 & 14.72 & 1986 & Dec. 15 & 9,020 & 15.33 \\
\hline 1981 & Apr. 03 & 2,550 & 11.69 & 1984 & Mar. 06 & 3,900 & 12.90 & 1987 & Mar. 03 & 10,300 & 15.85 \\
\hline
\end{tabular}




\section{ALTAMAHA RIVER BASIN}

\section{BEAVER CREEK NEAR COBBTOWN, GEORGIA}

LOCATION.--Lat $32^{\circ} 16^{\prime} 52^{\prime \prime}$, long $82^{\circ} 11^{\prime} 27^{\prime \prime}$, Tattnall County, at culvert on Stage Highway 152, 3.3 mi west of Cobbtown. DRAINAGE AREA. $-9.58 \mathrm{mi}^{2}$.

GAGE.--Flood-stage/rainfall recorder prior to 1975 , crest-stage gage thereafter. Datum of gage is about $150 \mathrm{ft}$ above sea level (from topographic map).

STAGE-DISCHARGE RELATION.--Defined by current-meter measurements below $470 \mathrm{ft}^{3} / \mathrm{s}$, and extended above on basis of culvert computations.

\begin{tabular}{|c|c|c|c|c|c|c|c|c|c|c|c|}
\hline $\begin{array}{l}\text { Water } \\
\text { year }\end{array}$ & Date & $\begin{array}{c}\text { Discharge } \\
\left(\mathrm{ft}^{3} / \mathrm{s}\right)\end{array}$ & $\begin{array}{c}\text { Gage } \\
\text { height } \\
\text { (ft) }\end{array}$ & $\begin{array}{l}\text { Water } \\
\text { year }\end{array}$ & Date & $\begin{array}{c}\text { Discharge } \\
\left(\mathrm{ft}^{3} / \mathrm{s}\right)\end{array}$ & $\begin{array}{c}\text { Gage } \\
\text { height } \\
\text { (ft) }\end{array}$ & $\begin{array}{l}\text { Water } \\
\text { year }\end{array}$ & Date & $\begin{array}{l}\text { Discharge } \\
\left(\mathrm{ft}^{3} / \mathrm{s}\right)\end{array}$ & $\begin{array}{c}\text { Gage } \\
\text { height } \\
\text { (ft) }\end{array}$ \\
\hline 1965 & Oct. 15 & 305 & 4.76 & 1974 & Feb. 07 & 164 & 4.01 & 1983 & Aug. 01 & 181 & 4.12 \\
\hline 1966 & Mar. 03 & 826 & 6.11 & 1975 & Apr. 14 & 252 & 4.51 & 1984 & May 03 & 488 & 5.35 \\
\hline 1967 & Jan. 02 & 137 & 3.81 & 1976 & June 21 & 286 & 4.67 & 1985 & Sept. 01 & 61 & 2.78 \\
\hline 1968 & Jan. 02 & 36 & 2.14 & 1977 & Oct. 20 & 137 & 3.81 & 1986 & Dec. 13 & 820 & 6.10 \\
\hline 1969 & May 19 & 290 & 4.70 & 1978 & Jan. 25 & 428 & 5.18 & 1987 & Mar. 01 & 292 & 4.71 \\
\hline 1970 & Mar. 22 & 242 & 4.46 & 1979 & Feb. 24 & 164 & 4.01 & 1988 & Mar. 09 & 70 & 2.94 \\
\hline 1971 & Aug. 17 & 137 & 3.81 & 1980 & Mar. 13 & 204 & 4.26 & 1989 & Apr. 15 & 70 & 2.95 \\
\hline 1972 & Mar. 29 & 266 & 4.58 & 1981 & Aug. 08 & 234 & 4.42 & 1990 & Oct. 04 & 376 & 5.02 \\
\hline 1973 & Aug. -- & 526 & 5.46 & 1982 & Feb. 13 & 318 & 4.81 & & & & \\
\hline
\end{tabular}

02225350 REEDY CREEK TRIBUTARY NEAR SOPERTON, GEORGIA

(Formerly published as "Pendleton Creek Tributary No. 2 near Soperton, Georgia")

LOCATION.--Lat $32^{\circ} 25^{\prime} 35^{\prime \prime}$, long $82^{\circ} 29^{\prime} 52^{\prime \prime}$, Treutlen County, at culvert on Stage Highway $86,6.5$ mi northeast of Soperton. DRAINAGE AREA.-1.68 $\mathrm{mi}^{2}$.

GAGE.--Flood-stage recorder prior to Aug. 25, 1965; flood-stage/rainfall recorder from Aug. 25, 1965 to 1975; crest-stage gage thereafter. Datum of gage is about $223 \mathrm{ft}$ above sea level (from topographic map).

STAGE-DISCHARGE RELATION.--Defined by current-meter measurements below $86 \mathrm{tt}^{3} / \mathrm{s}$, and extended above on basis of culvert computations.

\begin{tabular}{|c|c|c|c|c|c|c|c|c|c|c|c|}
\hline $\begin{array}{l}\text { Water } \\
\text { year }\end{array}$ & Date & $\begin{array}{c}\text { Discharge } \\
\left(\mathrm{ft}^{3} / \mathrm{s}\right)\end{array}$ & $\begin{array}{c}\text { Gage } \\
\text { height } \\
\text { (ft) }\end{array}$ & $\begin{array}{l}\text { Water } \\
\text { year }\end{array}$ & Date & $\begin{array}{c}\text { Discharge } \\
\left(\mathrm{ft}^{3} / \mathrm{s}\right)\end{array}$ & $\begin{array}{c}\text { Gage } \\
\text { height } \\
\text { (ft) }\end{array}$ & $\begin{array}{l}\text { Water } \\
\text { year }\end{array}$ & Date & $\begin{array}{l}\text { Discharge } \\
\left(\mathrm{ft}^{3} / \mathrm{s}\right)\end{array}$ & $\begin{array}{l}\text { Gage } \\
\text { height } \\
\text { (ft) }\end{array}$ \\
\hline 1965 & Feb. 17 & 95 & 2.29 & 1973 & June 22 & 290 & 3.47 & 1981 & Aug. 08 & 70 & 2.08 \\
\hline 1966 & Mar. 03 & 208 & 2.99 & 1974 & Feb. 08 & 38 & 1.75 & 1982 & June 05 & 122 & 2.48 \\
\hline 1967 & Jan. 01 & 74 & 2.12 & 1975 & July 15 & 208 & 2.99 & 1983 & Feb. 14 & 108 & 2.27 \\
\hline 1968 & Jan. -- & 29 & $--b$ & 1976 & June 21 & 55 & 1.95 & 1984 & May 03 & 290 & 3.47 \\
\hline 1969 & June 04 & 53 & 1.92 & 1977 & Oct. 20 & 110 & 2.40 & 1985 & July 23 & 132 & 2.54 \\
\hline 1970 & May 28 & 259 & 3.29 & 1978 & Jan. 25 & 222 & 3.07 & 1986 & Dec. 13 & 224 & 3.08 \\
\hline 1971 & Mar. 02 & 174 & 2.79 & 1979 & Feb. 24 & 60 & 3.24 & 1987 & Mar. 01 & 157 & 2.69 \\
\hline 1972 & Feb. 01 & 88.0 & 2.24 & 1980 & Mar. 13 & 119 & 2.46 & 1988 & Mar. - & 13 & $-b$ \\
\hline
\end{tabular}


LOCATION.-Lat $32^{\circ} 04^{\prime} 42^{\prime \prime}$, long $82^{\circ} 10^{\prime} 39^{\prime \prime}$, Tattnall County, on downstream side of pier near center of span of bridge on State Highway 56, 0.5 mi downstream from Brazells Creek, 1.5 mi downstream from Rocky Creek, 3.5 mi west of Reidsville, 6 mi downstream from Pendleton Creok, and 14 mi upstream from mouth.

DRAINAGE AREA, $-1,110 \mathrm{mi}^{2}$, approximately.

GAGE.-Water-stage recorder. Datum of gage is $73.8 \mathrm{ft}$ above sea level (levels by Georgia Department of Transportation), nonrecording gage from June 13, 1903 to Dec. 31, 1907, at same site and different datum. Prior to Feb. 15, 1941, nonrecording gage at same site, and at same datum May 25, 1937, to Feb. 15, 1941.

STAGE-DISCHARGE RELATION.--Defined by current-meter measurements below $16,000 \mathrm{ft}^{3} / \mathrm{s}$, and extended above on basis of slope-conveyance studies. Bankfull stage and discharge, $11 \mathrm{ft}$ and $3,200 \mathrm{ft}^{3} / \mathrm{s}$.

HISTORICAL DATA.--Flood stages of 1925, 1928, and 1929 based on information furnished by the Georgia Department of Transportation. The 1925 flood was the highest since at least 1886 , based on information furnished by local residents.

\begin{tabular}{|c|c|c|c|c|c|c|c|c|c|c|c|}
\hline $\begin{array}{l}\text { Water } \\
\text { year }\end{array}$ & Date & $\begin{array}{c}\text { Discharge } \\
\left(\mathrm{ft}^{3} / \mathrm{s}\right)\end{array}$ & $\begin{array}{c}\text { Gage } \\
\text { height } \\
\text { (ft) }\end{array}$ & $\begin{array}{l}\text { Water } \\
\text { year }\end{array}$ & Date & $\begin{array}{c}\text { Discharge } \\
\left(\mathrm{ft}^{3} / \mathrm{s}\right)\end{array}$ & $\begin{array}{c}\text { Gage } \\
\text { height } \\
\text { (ft) }\end{array}$ & $\begin{array}{l}\text { Water } \\
\text { year }\end{array}$ & Date & $\begin{array}{c}\text { Discharge } \\
\left(\mathrm{ft}^{3} / \mathrm{s}\right)\end{array}$ & $\begin{array}{c}\text { Gage } \\
\text { height } \\
\text { (ft) }\end{array}$ \\
\hline 1904 & Feb. 12 & 4,890 & 12.10 & 1951 & Apr. 02 & 4,240 & 12.40 & 1971 & Mar. 06 & 10,700 & 17.95 \\
\hline 1905 & Feb. 17 & 14,900 & 19.00 & 1952 & Mar. 30 & 5,420 & 13.70 & 1972 & Feb. 05 & 9,070 & 17.01 \\
\hline 1906 & June 20 & 4,120 & 11.00 & 1953 & Mar. 01 & 7,140 & 15.30 & 1973 & Feb. 07 & 11,400 & 18.30 \\
\hline$\underline{1907}$ & July 05 & 4,120 & $\underline{11.00 \mathrm{c}}$ & 1954 & Oct. 01 & 6,350 & 14.60 & 1974 & Feb. 23 & 5,170 & 14.19 \\
\hline$\overline{1925}$ & Jan. -- & 47,000 & $\overline{28.40} \mathrm{c}$ & 1955 & Apr. 20 & 4,160 & 12.60 & 1975 & Feb. 24 & 11,100 & 18.16 \\
\hline$\underline{1928}$ & Aug. -- & 16,300 & $20.60 c$ & 1956 & Feb. 09 & 3,540 & 11.50 & 1976 & Feb. 03 & 2,940 & 11.31 \\
\hline 1930 & Oct. -- & 26,500 & $24.00 \mathrm{c}$ & 1957 & July $\mathbf{3 0}$ & 8,270 & 16.20 & 1977 & Mar. 14 & 6,330 & 15.74 \\
\hline 1938 & Apr. 13 & 6,990 & 15.30 & 1958 & Mar. 12 & 7,610 & 16.10 & 1978 & Jan. 29 & 12,000 & 18.59 \\
\hline 1939 & Mar. 03 & 15,100 & 19.80 & 1959 & Mar. 07 & 6,060 & 15.00 & 1979 & Feb. 28 & 14,600 & 19.83 \\
\hline 1940 & Aug. 16 & 14,900 & 19.70 & 1960 & Apr. 08 & 14,600 & 19.80 & 1980 & Mar. 17 & 18,000 & 20.87 \\
\hline 1941 & July 20 & 7,840 & 15.90 & 1961 & Apr. 19 & 11,000 & 18.10 & 1981 & Apr. 05 & 3,800 & 12.28 \\
\hline 1942 & Dec. 29 & 7,060 & 15.30 & 1962 & Mar. 17 & 8,250 & 16.50 & 1982 & Jan. 09 & 4,800 & 13.40 \\
\hline 1943 & Jan. 24 & 7,450 & 15.60 & 1963 & Jan. 28 & 3,820 & 12.50 & 1983 & Mar. 10 & 9,190 & 17.18 \\
\hline 1944 & Mar. 27 & 12,700 & 18.90 & 1964 & Mar. 06 & 10,300 & 17.70 & 1984 & May 05 & 8,860 & 16.97 \\
\hline 1945 & Feb. 27 & 3,130 & 11.00 & 1965 & Feb. 20 & 14,400 & 19.71 & 1985 & Sept. 01 & 4,170 & 12.84 \\
\hline 1946 & Jan. 23 & 4,950 & 13.20 & 1966 & Mar. 06 & 24,400 & 23.34 & 1986 & Feb. 13 & 7,340 & 15.87 \\
\hline 1947 & Mar. 13 & 7,980 & 16.00 & 1967 & Jan. 07 & 6,560 & 15.40 & 1987 & Jan. 25 & 14,400 & 19.62 \\
\hline 1948 & Apr. 04 & 13,500 & 19.30 & 1968 & Jan. 19 & 1,460 & 7.98 & 1988 & Mar. 13 & 3,480 & 11.91 \\
\hline 1949 & Dec. 04 & 5,870 & 14.20 & 1969 & May 22 & 5,150 & 14.17 & 1989 & Apr. 15 & 5,070 & 13.87 \\
\hline 1950 & Sept. 08 & 1,930 & 8.20 & 1970 & Apr. 04 & 10,400 & 17.78 & 1990 & Jan. 09 & 8,830 & 16.95 \\
\hline
\end{tabular}

\section{BEARDS CREEK NEAR GLENNVILLE, GEORGIA}

LOCATION.--Lat $31^{\circ} 55^{\prime} 26^{\prime \prime}$, long $81^{\circ} 52^{\prime} 58^{\prime \prime}$, Tattnall County, at State Highway 144,3 mi east of Glennville.

DRAINAGE AREA.--74.4 $\mathrm{mi}^{2}$.

GAGE.-Crest-stage gage. Datum of gage is about $90 \mathrm{ft}$ above sea level (from topographic map).

STAGE-DISCHARGE RELATION.--Defined by current-meter measurements below $6,000 \mathrm{ft}^{3} / \mathrm{s}$. Bankfull stage and discharge, $4 \mathrm{ft}$ and $200 \mathrm{ft}^{3} / \mathrm{s}$.

\begin{tabular}{|c|c|c|c|c|c|c|c|c|c|c|c|}
\hline $\begin{array}{l}\text { Water } \\
\text { year }\end{array}$ & Date & $\begin{array}{c}\text { Discharge } \\
\left(\mathrm{ft}^{3} / \mathrm{s}\right)\end{array}$ & $\begin{array}{c}\text { Gage } \\
\text { height } \\
\text { (ft) }\end{array}$ & $\begin{array}{l}\text { Water } \\
\text { year }\end{array}$ & Date & $\begin{array}{c}\text { Discharge } \\
\left(\mathrm{ft}^{3} / \mathbf{s}\right)\end{array}$ & $\begin{array}{c}\text { Gage } \\
\text { height } \\
\text { (ft) }\end{array}$ & $\begin{array}{l}\text { Water } \\
\text { year }\end{array}$ & Date & $\begin{array}{c}\text { Discharge } \\
\left(\mathrm{ft}^{3} / \mathrm{s}\right)\end{array}$ & $\begin{array}{c}\text { Gage } \\
\text { height } \\
\text { (ft) }\end{array}$ \\
\hline 1966 & May 24 & 2,570 & 7.49 & 1974 & Jan. 04 & 1,100 & 5.80 & 1981 & Apr. 03 & 840 & 5.40 \\
\hline 1967 & July 30 & 995 & 5.65 & 1975 & Apr. 16 & 1,620 & 6.47 & 1982 & July 12 & 460 & 4.72 \\
\hline 1968 & June 00 & 120 & $--b$ & 1976 & Aug. 03 & 1,670 & 6.54 & 1983 & Apr. 24 & 876 & 5.46 \\
\hline 1969 & May 20 & 6,700 & 10.73 & 1977 & Nov. 29 & 1,840 & 6.87 & 1984 & Jan. 27 & 1,310 & 6.09 \\
\hline 1970 & May 30 & 1,480 & 6.30 & 1978 & Jan. 26 & 600 & 5.00 & 1985 & Sept. 02 & 535 & 4.87 \\
\hline 1971 & Feb. 12 & 3,500 & 8.33 & 1979 & Sept. 27 & 1,200 & 5.95 & 1986 & Feb. 12 & 2,650 & 7.57 \\
\hline $\begin{array}{l}1972 \\
1973\end{array}$ & $\begin{array}{l}\text { Feb. } 04 \\
\text { Apr. } 01\end{array}$ & $\begin{array}{l}1,140 \\
1,040\end{array}$ & $\begin{array}{l}5.85 \\
5.72\end{array}$ & 1980 & Apr. 05 & 936 & 5.56 & 1987 & Jan. 23 & 1,240 & 6.00 \\
\hline
\end{tabular}




\section{ALTAMAHA RIVER BASIN}

02226000 ALTAMAHA RIVER AT DOCTORTOWN, GEORGIA

LOCATION.--Lat $31^{\circ} 39^{\prime} 16^{\prime \prime}$, long $81^{\circ} 49^{\prime} 41^{\prime \prime}$, Wayne County, on right bank $60 \mathrm{ft}$ downstream from Seaboard Coast Line Railroad bridge at Doctortown, $4.5 \mathrm{mi}$ northeast of Jesup, and at mile 64.5 .

DRAINAGE AREA.--13,600 $\mathrm{mi}^{2}$, approximately.

GAGE.--Water-stage recorder. Datum of gage is $28.48 \mathrm{ft}$ above sea level (from U.S. Coast and Geodetic Survey benchmark), supplementary adjustment of 1936. Prior to Dec. 5, 1934, nonrecording gage at same site and datum, and Sept. 5, 1934 to Sept. 30, 1975, at same site at datum 4.0 ft higher. Peak stages for 1925-75 have been converted to present datum.

STAGE-DISCHARGE RELATION.--Defined by current-meter measurements below $180,000 \mathrm{ft}^{3} / \mathrm{s}$, and extended above on the basis of straight-line extension. Bankfull stage and discharge, $8 \mathrm{ft}$ and $9,200 \mathrm{tt}^{3} / \mathrm{s}$.

HISTORICAL DATA.--Flood of 1925 exceeded any flood described in old newspaper files, historical writings, and similar sources. This flood is believed to be the highest since 1800 .

REMARKS.--Stage records for 1925-31 from National Weather Service. Minor regulation of lower peaks by storage in Lloyd Shoals, Lake Oconee, and Sinclair Reservoirs. (See staion 02225000.)

\begin{tabular}{|c|c|c|c|c|c|c|c|c|c|c|c|}
\hline $\begin{array}{l}\text { Water } \\
\text { year }\end{array}$ & Date & $\begin{array}{c}\text { Discharge } \\
\left(\mathrm{ft}^{3} / \mathrm{s}\right)\end{array}$ & $\begin{array}{c}\text { Gage } \\
\text { height } \\
\text { (ft) }\end{array}$ & $\begin{array}{l}\text { Water } \\
\text { year }\end{array}$ & Date & $\begin{array}{c}\text { Discharge } \\
\left(\mathrm{ft}^{3} / \mathrm{s}\right)\end{array}$ & $\begin{array}{c}\text { Gage } \\
\text { height } \\
\text { (ft) }\end{array}$ & $\begin{array}{l}\text { Water } \\
\text { year }\end{array}$ & Date & $\begin{array}{c}\text { Discharge } \\
\left(\mathrm{ft}^{3} / \mathrm{s}\right)\end{array}$ & $\begin{array}{c}\text { Gage } \\
\text { height } \\
\text { (ft) }\end{array}$ \\
\hline 1925 & Jan. 23 & 300,000 & 18.60 & 1947 & Mar. 21 & 71,000 & 13.00 & 1969 & May 04 & 34,700 & 11.37 \\
\hline 1926 & Feb. 04 & 53,900 & 12.40 & 1948 & Apr. 04 & 92,500 & 14.00 & 1970 & Apr. 06 & 79,000 & 14.04 \\
\hline 1927 & Aug. 02 & 23,000 & 10.60 & 1949 & Dec. 12 & 118,000 & 14.80 & 1971 & Mar. 16 & 96,200 & 14.76 \\
\hline 1928 & Aug. 25 & 126,000 & 15.00 & 1950 & Mar. 22 & 23,400 & 10.30 & 1972 & Jan. 25 & 73,700 & 13.82 \\
\hline 1929 & Mar. 13 & 179,000 & 16.30 & 1951 & Apr. 04 & 29,000 & 10.80 & 1973 & Feb. 14 & 63,600 & 13.38 \\
\hline 1930 & Oct. 13 & 133,000 & 15.20 & 1952 & Mar. 18 & 71,400 & 13.20 & 1974 & Feb. 28 & 48,600 & 12.60 \\
\hline 1931 & May 18 & 32,300 & 11.10 & 1953 & May 16 & 66,700 & 13.00 & 1975 & Mar. 28 & 104,000 & 14.71 \\
\hline 1932 & Jan. 21 & 36,800 & 11.40 & 1954 & Dec. 30 & 39,600 & 11.60 & 1976 & Mar. 31 & 60,800 & 12.90 \\
\hline 1933 & Mar. 04 & 46,400 & 12.10 & 1955 & Apr. 26 & 22,400 & 10.20 & 1977 & Apr. 03 & 55,500 & 12.65 \\
\hline 1934 & Mar. 17 & 46,400 & 12.10 & 1956 & Apr. 01 & 32,700 & 11.10 & 1978 & Feb. 07 & 90,000 & 14.16 \\
\hline 1935 & Sept. 15 & 21,600 & 10.30 & 1957 & Apr. 11 & 31,400 & 11.00 & 1979 & Mar. 08 & 90,200 & 14.17 \\
\hline 1936 & Apr. 18 & 178,000 & 16.00 & 1958 & Mar. 15 & 53,700 & 12.40 & 1980 & Mar. 23 & 99,200 & 14.53 \\
\hline 1937 & May 13 & 47,800 & 12.10 & 1959 & Mar. 16 & 44,300 & 11.90 & 1981 & Feb. 26 & 37,800 & 11.59 \\
\hline 1938 & Apr. 19 & 68,000 & 13.00 & 1960 & Apr. 12 & 89,600 & 13.90 & 1982 & Feb. 17 & 60,600 & 12.89 \\
\hline 1939 & Mar. 11 & 98,000 & 14.20 & 1961 & Mar. 10 & 81,400 & 13.60 & 1983 & Apr. 21 & 69,300 & 13.30 \\
\hline 1940 & Mar. 03 & 35,300 & 11.30 & 1962 & Mar. 10 & 53,700 & 12.40 & 1984 & Mar. 11 & 62,400 & 12.97 \\
\hline 1941 & July 26 & 27,500 & 10.70 & 1963 & Feb. 04 & 53,700 & 12.40 & 1985 & Feb. 19 & 47,000 & 12.18 \\
\hline 1942 & Apr. 03 & 89,500 & 14.00 & 1964 & Apr. 20 & 79,000 & 13.90 & 1986 & Feb. 15 & 41,800 & 11.86 \\
\hline 1943 & Apr. 02 & 71,100 & 13.30 & 1965 & Feb. 23 & 66,000 & 13.30 & 1987 & Jan. 28 & 75,600 & 13.58 \\
\hline 1944 & Apr. 02 & 112,000 & 14.50 & 1966 & Mar. 12 & 110,000 & 14.84 & 1988 & Mar. 16 & 23,700 & 10.36 \\
\hline 1945 & May 10 & 35,200 & 11.30 & 1967 & Jan. 16 & 51,400 & 12.44 & 1989 & Apr. 23 & 31,900 & 11.14 \\
\hline 1946 & Jan. 22 & 71,000 & 13.00 & 1968 & Jan. 26 & 26,000 & 10.61 & 1990 & Mar. 31 & 70,600 & 13.36 \\
\hline
\end{tabular}




\section{ALTAMAHA RIVER BASIN}

02226030 DOCTORS CREEK NEAR LUDOWICI, GEORGIA

LOCATION.--Lat $31^{\circ} 44^{\prime} 07^{\prime \prime}$, long $81^{\circ} 42$ '08", Long County, at Stage Highway 38 , 3 mi northeast of Ludowici.

DRAINAGE AREA.--33 $\mathrm{mi}^{2}$, approximately.

GAGE.--Crest-stage gage. Datum of gage is about $47 \mathrm{ft}$ above sea level (from topographic map).

STAGE-DISCHARGE RELATION.--Defined by current-meter measurements below $640 \mathrm{ft}^{3} / \mathrm{s}$, and extended above on the basis of straight-line extension.

REMARKS.--Peak discharge for 1970 is estimated.

\begin{tabular}{|c|c|c|c|c|c|c|c|c|c|c|c|}
\hline $\begin{array}{l}\text { Water } \\
\text { year }\end{array}$ & Date & $\begin{array}{c}\text { Discharge } \\
\left(\mathrm{ft}^{3} / \mathrm{s}\right)\end{array}$ & $\begin{array}{c}\text { Gage } \\
\text { height } \\
\text { (ft) }\end{array}$ & $\begin{array}{l}\text { Water } \\
\text { year }\end{array}$ & Date & $\begin{array}{c}\text { Discharge } \\
\left(\mathrm{ft}^{3} / \mathrm{s}\right)\end{array}$ & $\begin{array}{c}\text { Gage } \\
\text { height } \\
\text { (ft) }\end{array}$ & $\begin{array}{l}\text { Water } \\
\text { year }\end{array}$ & Date & $\begin{array}{c}\text { Discharge } \\
\left(\mathrm{ft}^{3} / \mathrm{s}\right)\end{array}$ & $\begin{array}{c}\text { Gage } \\
\text { height } \\
\text { (ft) }\end{array}$ \\
\hline 1966 & Mar. 15 & 558 & 7.40 & 1974 & Jan. 04 & 527 & 7.26 & 1981 & Apr. 03 & 189 & 5.55 \\
\hline 1967 & July $\mathbf{3 0}$ & 384 & 6.57 & 1975 & Apr. 16 & 474 & 7.02 & 1982 & Apr. 27 & 203 & 5.63 \\
\hline 1968 & June 07 & 105 & 5.01 & 1976 & May 15 & 664 & 7.83 & 1983 & Mar. 08 & 518 & 7.22 \\
\hline 1969 & Mar. 19 & 223 & 5.74 & 1977 & Nov. 29 & 416 & 6.73 & 1984 & Jan. 27 & 750 & 8.39 \\
\hline 1970 & Mar. 31 & 1,500 & 10.05 & 1978 & Dec. 03 & 394 & 6.62 & 1985 & Sept. 02 & 254 & 5.91 \\
\hline 1971 & July 05 & 227 & 5.76 & 1979 & Sept. 27 & 562 & 7.42 & 1986 & Feb. 12 & 567 & 7.44 \\
\hline 1972 & June 20 & 445 & 6.87 & 1980 & Mar. 13 & 677 & 7.89 & 1987 & Jan. 23 & 689 & 7.93 \\
\hline 1973 & Feb. 02 & 422 & 6.76 & & & & & & & & \\
\hline
\end{tabular}

\section{PENHOLOWAY CREEK NEAR JESUP, GEORGIA}

LOCATION.--Lat $31^{\circ} 34^{\prime} 00^{\prime \prime}$, long $81^{\circ} 50^{\prime} 18^{\prime \prime}$, Wayne County, on downstream side of bridge on U.S. Highway 341,4 mi southeast of Jesup, and about 9.5 mi upstream from mouth.

DRAINAGE AREA.--210 $\mathrm{mi}^{2}$, approximately.

GAGE.-Water-stage recorder. Datum of gage is $19.09 \mathrm{ft}$ above sea level (from U.S. Coast and Geodetic Survey benchmark). Since May 6, 1966, auxiliary water-stage recorder at highway bridge, 2.5 mi downstream.

STAGE-DISCHARGE RELATION.--Defined by current-meter measurements below $3,800 \mathrm{ft}^{3} / \mathrm{s}$. Bankfull stage and discharge, $9 \mathrm{ft}$ and $900 \mathrm{ft}^{3} / \mathrm{s}$.

REMARKS.--Peak discharges for 1974 and 1975 are estimated.

\begin{tabular}{|c|c|c|c|c|c|c|c|c|c|c|c|}
\hline $\begin{array}{l}\text { Water } \\
\text { year }\end{array}$ & Date & $\begin{array}{c}\text { Discharge } \\
\left(\mathrm{ft}^{3} / \mathrm{s}\right)\end{array}$ & $\begin{array}{c}\text { Gage } \\
\text { height } \\
\text { (ft) }\end{array}$ & $\begin{array}{l}\text { Water } \\
\text { year }\end{array}$ & Date & $\begin{array}{c}\text { Discharge } \\
\left(\mathrm{ft}^{3} / \mathrm{s}\right)\end{array}$ & $\begin{array}{c}\text { Gage } \\
\text { height } \\
\text { (ft) }\end{array}$ & $\begin{array}{l}\text { Water } \\
\text { year }\end{array}$ & Date & $\begin{array}{c}\text { Discharge } \\
\left(\mathrm{ft}^{3} / \mathrm{s}\right)\end{array}$ & $\begin{array}{c}\text { Gage } \\
\text { height } \\
\text { (ft) }\end{array}$ \\
\hline 1959 & Mar. 07 & 3,500 & 14.00 & 1970 & Nov. 03 & 1,320 & 11.57 & 1981 & Apr. 03 & 392 & 9.65 \\
\hline 1960 & Apr. 06 & 1,560 & 11.74 & 1971 & Aug. 18 & 2,140 & 12.53 & 1982 & July 20 & 1,400 & 11.68 \\
\hline 1961 & Apr. 17 & 4,300 & 14.80 & 1972 & Feb. 08 & 903 & 11.02 & 1983 & Mar. 19 & 1,960 & 12.35 \\
\hline 1962 & Apr. 03 & 1,520 & 11.72 & 1973 & Apr. 05 & 2,680 & 13.18 & 1984 & Mar. 08 & 3,840 & 14.38 \\
\hline 1963 & June 28 & 2,320 & 12.70 & 1974 & Aug. 17 & 810 & - & 1985 & Sept. 03 & 1,030 & 11.08 \\
\hline 1964 & Sept. 14 & 3,800 & 14.30 & 1975 & May 19 & 1,740 & - & 1986 & Feb. 12 & 2,460 & 12.92 \\
\hline 1965 & Mar. 05 & 2,000 & 12.30 & 1976 & June 22 & 1,240 & 11.48 & 1987 & Jan. 06 & 1,700 & 12.13 \\
\hline 1966 & July 03 & 3,460 & 13.96 & 1977 & Nov. 30 & 2,060 & 12.45 & 1988 & Feb. 22 & 1,500 & 11.74 \\
\hline 1967 & Jan. 06 & 2,030 & 12.41 & 1978 & Dec. 03 & 2,170 & 12.48 & 1989 & Sept. 02 & 1,460 & 11.68 \\
\hline 1968 & June 09 & 2,130 & 12.52 & 1979 & Sept. 30 & 4,420 & 14.96 & 1990 & Oct. 20 & 3,500 & 14.04 \\
\hline 1969 & Aug. 15 & 3,180 & 13.68 & 1980 & Mar. 14 & 3,250 & 13.78 & & & & \\
\hline
\end{tabular}


02226190 LITTLE CREEK NEAR WILLACOOCHEE, GEORGIA

(Formerly published as "Satilla River Tributary near Willacoochee, Georgia"

LOCATION.--Lat $31^{\circ} 27^{\prime 2} 24^{\prime \prime}$ long $83^{\circ} 03^{\prime} 02^{\prime \prime}$, Coffee County, at culvert on State Highway 149, 8.5 mi north of Willacoochee. DRAINAGE AREA.--6.38 $\mathrm{mi}^{2}$.

GAGE.--Flood-stage/rainfall recorder prior to Aug. 21, 1970; water-stage recorder from Aug. 21, 1970 to 1975, crest-stage thereafter. Datum of gage is about $205 \mathrm{ft}$ above sea level (from topographic map).

STAGE-DISCHARGE RELATION.--Defined by current-meter measurements below $580 \mathrm{ft}^{3} / \mathrm{s}$, and extended above on basis of culvert computation.

\begin{tabular}{|c|c|c|c|c|c|c|c|c|c|c|c|}
\hline $\begin{array}{l}\text { Water } \\
\text { year }\end{array}$ & Date & $\begin{array}{c}\text { Discharge } \\
\left(\mathrm{ft}^{3} / \mathrm{s}\right)\end{array}$ & $\begin{array}{c}\text { Gage } \\
\text { height } \\
\text { (ft) }\end{array}$ & $\begin{array}{l}\text { Water } \\
\text { year }\end{array}$ & Date & $\begin{array}{c}\text { Discharge } \\
\left(\mathrm{ft}^{3} / \mathrm{s}\right)\end{array}$ & $\begin{array}{c}\text { Gage } \\
\text { height } \\
\text { (ft) }\end{array}$ & $\begin{array}{c}\text { Water } \\
\text { year }\end{array}$ & Date & $\begin{array}{c}\text { Discharge } \\
\left(\mathrm{ft}^{3} / \mathrm{s}\right)\end{array}$ & $\begin{array}{c}\text { Gage } \\
\text { height } \\
\text { (ft) }\end{array}$ \\
\hline 1965 & Dec. 04 & 595 & 5.13 & 1973 & Apr. 26 & 290 & 3.82 & 1981 & Aug. 10 & 68 & 2.52 \\
\hline 1966 & Mar. 05 & 178 & 3.35 & 1974 & Sept. 08 & 160 & 3.20 & 1982 & Apr. 25 & 190 & 3.33 \\
\hline 1967 & Jan. 01 & 75 & 2.88 & 1975 & Apr. 11 & 472 & 4.61 & 1983 & Mar. 13 & 242 & 3.67 \\
\hline 1968 & Mar. 12 & 48 & 2.63 & 1976 & May 15 & 545 & 4.90 & 1984 & Mar. 06 & 620 & 5.15 \\
\hline 1969 & Aug. 23 & 93 & 3.03 & 1977 & Jan. 05 & 175 & 3.30 & 1985 & Aug. 29 & 170 & 3.27 \\
\hline 1970 & May 29 & 945 & 5.93 & 1978 & Jan. 25 & 130 & 3.00 & 1986 & Feb. 11 & 558 & 4.95 \\
\hline 1971 & Aug. 29 & 377 & 4.21 & 1979 & Feb. 25 & 418 & 4.39 & 1987 & Mar. 01 & 215 & 3.55 \\
\hline 1972 & Feb. 03 & 181 & 3.42 & 1980 & Mar. 13 & 252 & 3.71 & & & & \\
\hline
\end{tabular}

\section{SATILLA RIVER BASIN}

\section{SATILLA RIVER NEAR DOUGLAS, GEORGIA}

LOCATION.--Lat $31^{\circ} 24^{\prime} 49^{\prime \prime}$, long $82^{\circ} 51^{\prime} 02^{\prime \prime}$, Coffee County, at U.S. Highway $441,6.5$ mi south of Douglas.

DRAINAGE AREA.--235 $\mathrm{mi}^{2}$, approximately.

GAGE.--Crest-stage gage. Datum of gage is $150.17 \mathrm{ft}$ above sea level (levels by Georgia Department of Transportation) supplementary adjustment of 1936.

STAGE-DISCHARGE RELATION.--Defined by current-meter measurements below $4,780 \mathrm{ft}^{3} / \mathrm{s}$, and extended above on basis of slope-conveyance studies. Bankfull stage and discharge, $6 \mathrm{ft}$ and $1,200 \mathrm{ft}^{3} / \mathrm{s}$.

REMARKS.--Peak discharge for 1948 is estimated.

HISTORICAL DATA.--Flood stage of 1948 based on information furnished by the Georgia Department of Transportation. The 1948 flood was the highest since 1862 , based on information at nearby stations.

\begin{tabular}{|c|c|c|c|c|c|c|c|c|c|c|c|}
\hline $\begin{array}{l}\text { Water } \\
\text { year }\end{array}$ & Date & $\begin{array}{c}\text { Discharge } \\
\left(\mathrm{ft}^{3} / \mathrm{s}\right)\end{array}$ & $\begin{array}{l}\text { Gage } \\
\text { height } \\
\text { (ft) }\end{array}$ & $\begin{array}{l}\text { Water } \\
\text { year }\end{array}$ & Date & $\begin{array}{c}\text { Discharge } \\
\left(\mathrm{ft}^{3} / \mathrm{s}\right)\end{array}$ & $\begin{array}{l}\text { Gage } \\
\text { height } \\
\text { (ft) }\end{array}$ & $\begin{array}{l}\text { Water } \\
\text { year }\end{array}$ & Date & $\begin{array}{c}\text { Discharge } \\
\left(\mathrm{ft}^{3} / \mathrm{s}\right)\end{array}$ & $\begin{array}{l}\text { Gage } \\
\text { height } \\
\text { (ft) }\end{array}$ \\
\hline 1948 & Apr. -- & 15,500 & $15.40 \mathrm{c}$ & 1960 & Apr. 05 & 6,040 & 10.60 & 1970 & June 01 & 4,300 & 9.50 \\
\hline 1951 & Apr. 01 & 2,220 & 7.21 & 1961 & Apr. 16 & 4,680 & 9.60 & 1971 & Feb. - & 1,200 & $-b$ \\
\hline 1952 & Mar. 06 & 830 & 5.35 & 1962 & Apr. 01 & 1,560 & 6.47 & 1972 & Feb. 03 & 2,120 & 7.09 \\
\hline 1953 & Sept. 29 & 2,490 & 7.46 & 1963 & July 09 & 1,520 & 6.41 & 1973 & Feb. 03 & 2,290 & 7.28 \\
\hline 1954 & Dec. 17 & 495 & $--b$ & 1964 & Mar. 02 & 3,740 & 8.81 & 1974 & Feb. 20 & 940 & 5.54 \\
\hline 1955 & Apr. 16 & 800 & 5.31 & 1965 & Dec. 05 & 6,180 & 10.70 & 1975 & Jan. 20 & 3,560 & 8.62 \\
\hline 1956 & Feb. 08 & 1,100 & 5.81 & 1966 & Mar. 05 & 2,380 & 7.38 & 1976 & May 16 & 1,870 & 6.81 \\
\hline 1957 & Aug. 09 & 1,220 & 5.98 & 1967 & Jan. 04 & 1,530 & 6.41 & $\underline{1984}$ & Mar. 07 & 5,910 & $10.51 \mathrm{c}$ \\
\hline 1958 & Apr. 11 & 2,040 & 6.98 & 1968 & Mar. -- & 1,210 & $--b$ & 1986 & Feb. 12 & 6,040 & $10.60 \mathrm{c}$ \\
\hline 1959 & Mar. 09 & 3,640 & 8.68 & 1969 & Mar. 25 & 1,350 & 6.19 & & & & \\
\hline
\end{tabular}




\section{SATILLA RIVER BASIN}

\section{SATILLA RIVER NEAR PEARSON, GEORGIA}

LOCATION.-Lat $31^{\circ} 20^{\prime} 11^{\prime \prime}$, long $82^{\circ} 46^{\prime} 07^{\prime \prime}$, Atkinson County, at State Highway 64, 6 mi northeast of Pearson.

DRAINAGE AREA.--355 $\mathrm{mi}^{2}$, approximately.

GAGE.--Crest-stage gage. Datum of gage is $123.18 \mathrm{ft}$ above sea level (levels by Georgia Department of Transportation) supplementary adjustment of 1936.

STAGE-DISCHARGE RELATION.--Defined by current-meter measurements below $7,050 \mathrm{tt}^{3} / \mathrm{s}$, and extended above on basis of slope-conveyance studies. Bankfull stage and discharge, $10 \mathrm{ft}$ and $1,200 \mathrm{ft}^{3} / \mathrm{s}$.

HISTORICAL DATA.--Flood stage of 1948 based on information by the Georgia Department of Transportation. The 1948 flood was the highest since 1862, based on information at nearby stations.

REMARKS.--Peak discharge for 1948 and 1962 is estimated.

\begin{tabular}{|c|c|c|c|c|c|c|c|c|c|c|c|}
\hline $\begin{array}{l}\text { Water } \\
\text { year }\end{array}$ & Date & $\begin{array}{c}\text { Discharge } \\
\left(\mathrm{ft}^{3} / \mathrm{s}\right)\end{array}$ & $\begin{array}{c}\text { Gage } \\
\text { height } \\
(\mathrm{ft})\end{array}$ & $\begin{array}{l}\text { Water } \\
\text { year }\end{array}$ & Date & $\begin{array}{c}\text { Discharge } \\
\left(\mathrm{ft}^{3} / \mathrm{s}\right)\end{array}$ & $\begin{array}{c}\text { Gage } \\
\text { height } \\
\text { (ft) }\end{array}$ & $\begin{array}{l}\text { Water } \\
\text { year }\end{array}$ & Date & $\begin{array}{l}\text { Discharge } \\
\left(\mathrm{ft}^{3} / \mathrm{s}\right)\end{array}$ & $\begin{array}{l}\text { Gage } \\
\text { height } \\
\text { (ft) }\end{array}$ \\
\hline$\underline{1948}$ & Apr. 04 & 19,500 & $20.60 c$ & 1958 & Apr. 11 & 1,780 & 11.42 & 1963 & July 09 & 4,380 & 14.23 \\
\hline$\overline{1953}$ & Sept. 29 & 3,240 & 13.61 & 1959 & Mar. 09 & 6,940 & 15.93 & 1964 & Mar. 02 & 7,100 & 15.98 \\
\hline 1954 & Jan. 03 & 1,180 & 9.82 & 1960 & Apr. 05 & 8,200 & 16.63 & $\underline{1965}$ & Dec. 05 & 11,500 & 18.00 \\
\hline 1955 & Apr. 15 & 970 & 9.24 & 1961 & Apr. 16 & 3,740 & 13.71 & $\overline{1984}$ & Mar. 07 & 13,400 & $18.72 c$ \\
\hline 1956 & Feb. 22 & 1,870 & 11.62 & 1962 & Apr. 02 & 2,300 & - & $\overline{1986}$ & Feb. 12 & 8,040 & $16.52 \mathrm{c}$ \\
\hline 1957 & June 10 & 1,780 & 11.43 & & & & & & & & \\
\hline
\end{tabular}

\section{SATILLA RIVER NEAR WAYCROSS, GEORGIA}

LOCATION.-Lat $31^{\circ} 14^{\prime} 17^{\prime \prime}$, long $82^{\circ} 19^{\prime} 29^{\prime \prime}$, Ware-Pierce County line, on downstream side of pier near center span of bridge on State Highway 38, 3 mi northeast of Waycross, and 16 mi upstream from Alabaha River.

DRAINAGE AREA.-1,200 $\mathrm{mi}^{2}$, approximately.

GAGE.-Water-stage recorder. Datum of gage is $66.43 \mathrm{ft}$ above sea level (from U.S. Coast and Geodetic Survey benchmark), supplementary adjustment of 1936. Prior to Nov. 22, 1952, nonrecording gage at site $300 \mathrm{ft}$ downstream at same datum. STAGE-DISCHARGE RELATION.--Defined by current-meter measurements below $23,000 \mathrm{ft}^{3} / \mathrm{s}$, and extended above on basis of slope-conveyance studies. Bankfull stage and discharge, $12 \mathrm{ft}$ and $2,400 \mathrm{tt}^{3} / \mathrm{s}$.

HISTORICAL DATA.--The flood of September 1928 based on information furnished by an employee of the Atlantic Coast Line Railroad Company. This was reported by a local newspaper to be the highest know to the oldest settlers at that time. Based on this information, the flood of 1948 is probably the highest since at least 1862.

\begin{tabular}{|c|c|c|c|c|c|c|c|c|c|c|c|}
\hline $\begin{array}{l}\text { Water } \\
\text { year }\end{array}$ & Date & $\begin{array}{c}\text { Discharge } \\
\left(\mathrm{ft}^{3} / \mathrm{s}\right)\end{array}$ & $\begin{array}{c}\text { Gage } \\
\text { height } \\
\text { (ft) }\end{array}$ & $\begin{array}{l}\text { Water } \\
\text { year }\end{array}$ & Date & $\begin{array}{c}\text { Discharge } \\
\left(\mathrm{ft}^{3} / \mathrm{s}\right)\end{array}$ & $\begin{array}{c}\text { Gage } \\
\text { height } \\
\text { (ft) }\end{array}$ & $\begin{array}{l}\text { Water } \\
\text { year }\end{array}$ & Date & $\begin{array}{c}\text { Discharge } \\
\left(\mathrm{ft}^{3} / \mathrm{s}\right)\end{array}$ & $\begin{array}{c}\text { Gage } \\
\text { height } \\
\text { (ft) }\end{array}$ \\
\hline 1928 & May 00 & 37,000 & $22.20 \mathrm{c}$ & 1955 & Sept. 14 & 2,220 & 11.60 & 1973 & Apr. 07 & 15,300 & 18.75 \\
\hline 1937 & Apr. 11 & 9,240 & 16.20 & 1956 & Feb. 16 & 2,320 & 12.00 & 1974 & Sept. 14 & 7,850 & 16.50 \\
\hline 1938 & July 30 & 4,160 & 14.10 & 1957 & June 17 & 4,300 & 14.20 & 1975 & Apr. 18 & 9,900 & 17.20 \\
\hline 1939 & Mar. 04 & 11,000 & 17.00 & 1958 & Apr. 16 & 9,700 & 16.90 & 1976 & May 29 & 8,340 & 16.68 \\
\hline 1940 & Feb. 23 & 4,300 & 14.20 & 1959 & Mar. 09 & 18,800 & 19.30 & 1977 & Dec. 03 & 9,660 & 17.12 \\
\hline 1941 & Mar. 29 & 1,960 & 10.80 & 1960 & Apr. 08 & 20,600 & 19.70 & 1978 & Jan. 25 & 7,480 & 16.35 \\
\hline 1942 & Jan. 06 & 12,800 & 17.60 & 1961 & Apr. 20 & 17,400 & 19.30 & 1979 & Mar. 01 & 11,000 & 17.56 \\
\hline 1943 & Mar. 12 & 3,120 & 13.00 & 1962 & Apr. 08 & 7,500 & 16.30 & 1980 & Mar. 16 & 16,200 & 19.01 \\
\hline 1944 & Mar. 10 & 13,400 & 18.00 & 1963 & July 02 & 4,200 & 14.50 & 1981 & Apr. 04 & 1,190 & 10.50 \\
\hline 1945 & Oct. 25 & 8,270 & 16.40 & 1964 & Mar. 09 & 16,200 & 19.00 & 1982 & May 02 & 5,520 & 15.51 \\
\hline 1946 & July 31 & 4,820 & 14.60 & 1965 & Dec. 08 & 21,000 & 20.10 & 1983 & Mar. 11 & 14,900 & 18.24 \\
\hline 1947 & Apr. 21 & 8,520 & 16.50 & 1966 & Mar. 09 & 9,840 & 17.18 & 1984 & Mar. 10 & 23,400 & 20.29 \\
\hline 1948 & Apr. 04 & 39,000 & 22.40 & 1967 & Jan. 08 & 8,490 & 16.73 & 1985 & Sept. 06 & 3,670 & 14.33 \\
\hline 1949 & Sept. 04 & 13,800 & 18.10 & 1968 & Mar. 19 & 1,790 & 11.37 & 1986 & Feb. 13 & 21,900 & 20.03 \\
\hline 1950 & July 15 & 3,450 & 13.40 & 1969 & May 26 & 6,150 & 15.82 & 1987 & Jan. 23 & 8,500 & 16.76 \\
\hline 1951 & Apr. 04 & 7,770 & 16.20 & 1970 & Apr. 02 & 6,700 & 16.04 & 1988 & Feb. 24 & 6,950 & 16.15 \\
\hline 1952 & Mar. 04 & $\underline{2,870}$ & 12.70 & 1971 & Aug. 21 & 7,820 & 16.49 & 1989 & Sept. 04 & 1,280 & 10.66 \\
\hline 1953 & Apr. 18 & 4,300 & 14.30 & 1972 & Feb. 10 & 8,700 & 16.80 & 1990 & Feb. 25 & 4,500 & 15.00 \\
\hline 1954 & Oct. 01 & 13,800 & 18.10 & & & & & & & & \\
\hline
\end{tabular}




\section{SATILLA RIVER BASIN}

\section{BIG CREEK NEAR HOBOKEN, GEORGIA}

LOCATION.--Lat $31^{\circ} 10^{\prime} 28^{\prime \prime}$, long 82 11'17", Brantley County, at State Highway 50, 2.5 mi west of Hoboken.

DRAINAGE AREA. $-60 \mathrm{mi}^{2}$, approximately (revised).

GAGE.--Crest-stage gage. Datum of gage is $70.28 \mathrm{ft}$ above sea level (levels from the Georgia Department of Transportation).

STAGE-DISCHARGE RELATION.--Defined by current-meter measurements below $2,570 \mathrm{ft}^{3} / \mathrm{s}$, and extended above on basis of straight-line extension. Bankfull stage and discharge, $6.5 \mathrm{ft}$ and $100 \mathrm{ft}^{3} / \mathrm{s}$.

REMARKS.--Peak discharges for 1973, 1976, 1977, and 1981 are estimated.

\begin{tabular}{|c|c|c|c|c|c|c|c|c|c|c|c|}
\hline $\begin{array}{l}\text { Water } \\
\text { year }\end{array}$ & Date & $\begin{array}{c}\text { Discharge } \\
\left(\mathrm{ft}^{3} / \mathrm{s}\right)\end{array}$ & $\begin{array}{c}\text { Gage } \\
\text { height } \\
\text { (ft) }\end{array}$ & $\begin{array}{l}\text { Water } \\
\text { year }\end{array}$ & Date & $\begin{array}{c}\text { Discharge } \\
\left(\mathrm{ft}^{3} / \mathrm{s}\right)\end{array}$ & $\begin{array}{c}\text { Gage } \\
\text { height } \\
\text { (ft) }\end{array}$ & $\begin{array}{l}\text { Water } \\
\text { year }\end{array}$ & Date & $\begin{array}{c}\text { Discharge } \\
\left(\mathrm{ft}^{3} / \mathrm{s}\right)\end{array}$ & $\begin{array}{c}\text { Gage } \\
\text { height } \\
\text { (ft) }\end{array}$ \\
\hline 1966 & Mar. 05 & 1,650 & 10.49 & 1974 & Sept. 07 & 672 & 8.38 & 1981 & Mar. 05 & 200 & 6.77 \\
\hline 1967 & Jan. 04 & 760 & 8.58 & 1975 & Apr. 11 & 1,060 & 9.17 & 1982 & May 01 & 725 & 8.51 \\
\hline 1968 & July 00 & 300 & $-b$ & 1976 & Mar. 16 & 300 & 7.28 & 1983 & Feb. 16 & 840 & 8.74 \\
\hline 1969 & Aug. 24 & 1,820 & 10.79 & 1977 & Nov. 29 & 2,090 & 11.23 & 1984 & Mar. 07 & 3,130 & 12.96 \\
\hline 1970 & Feb. 05 & 345 & 7.55 & 1978 & Dec. 04 & 560 & 8.10 & 1985 & Aug. 30 & 1,820 & 10.78 \\
\hline 1971 & Aug. 19 & 1,060 & 9.17 & 1979 & June 19 & 1,160 & 9.39 & 1986 & Feb. 11 & 2,650 & 12.16 \\
\hline 1972 & June 20 & 870 & 8.80 & 1980 & Mar. 14 & 720 & 8.50 & 1987 & Jan. 22 & 1,185 & 9.57 \\
\hline 1973 & Apr. 04 & 2,210 & 11.44 & & & & & & & & \\
\hline
\end{tabular}

\section{SATILLA RIVER NEAR HOBOKEN, GEORGIA}

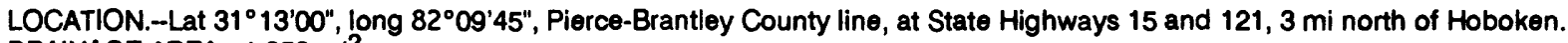
DRAINAGE AREA.-1,350 $\mathrm{mi}^{2}$.

GAGE.--Crest-stage gage. Datum of gage is $52.5 \mathrm{ft}$ above sea level (levels from the U.S. Army Corps of Engineers).

STAGE-DISCHARGE RELATION.--Defined by current-meter measurements below $28,800 \mathrm{ft}^{3} / \mathrm{s}$, and extended above on basis of straight-line extension.

\begin{tabular}{|c|c|c|c|c|c|c|c|c|c|c|c|}
\hline $\begin{array}{l}\text { Water } \\
\text { year }\end{array}$ & Date & $\begin{array}{c}\text { Discharge } \\
\left(\mathrm{ft}^{3} / \mathrm{s}\right)\end{array}$ & $\begin{array}{c}\text { Gage } \\
\text { height } \\
\text { (ft) }\end{array}$ & $\begin{array}{l}\text { Water } \\
\text { year }\end{array}$ & Date & $\begin{array}{c}\text { Discharge } \\
\left(\mathrm{ft}^{3} / \mathrm{s}\right)\end{array}$ & $\begin{array}{c}\text { Gage } \\
\text { height } \\
\text { (ft) }\end{array}$ & $\begin{array}{l}\text { Water } \\
\text { year }\end{array}$ & Date & $\begin{array}{c}\text { Discharge } \\
\left(\mathrm{ft}^{3} / \mathrm{s}\right)\end{array}$ & $\begin{array}{c}\text { Gage } \\
\text { height } \\
\text { (ft) }\end{array}$ \\
\hline 1970 & Apr. 02 & 7,380 & 12.15 & 1973 & Apr. 08 & 16,600 & 14.48 & $\underline{1977}$ & Dec. 03 & 9,860 & 12.99 \\
\hline 1971 & Aug. 21 & 8,360 & 12.52 & 1974 & Sept. 14 & 8,090 & 12.43 & $\overline{1984}$ & Mar. 10 & 22,900 & $15.36 \mathrm{c}$ \\
\hline 1972 & Feb. 11 & 9,170 & 12.79 & 1975 & Apr. 18 & 10,300 & 13.11 & $\overline{1986}$ & Feb. 14 & 25,800 & $15.72 \mathrm{c}$ \\
\hline
\end{tabular}

\section{WHITEHEAD CREEK NEAR DENTON, GEORGIA}

LOCATION.--Lat 31 $44^{\prime} 00^{\prime \prime}$ l long $82^{\circ} 41^{\prime} 26^{\prime \prime}$, Jeff Davis County, on left bank at downstream side of bridge on U.S. Highway 221 and State Highway 135, 5.1 mi upstream from mouth, and 1.0 mi northeast of Denton.

DRAINAGE AREA.-28 $\mathrm{mi}^{2}$, approximately.

GAGE.-Water-stage recorder. Datum of gage is about $208 \mathrm{ft}$ above sea level (from topographic map).

STAGE-DISCHARGE RELATION.--Defined by current-meter measurements below $1,150 \mathrm{ft}^{3} / \mathrm{s}$, and extended above on basis of straight-line extension. Bankfull stage and discharge, $2.5 \mathrm{ft}$ and $60 \mathrm{ft}^{3} / \mathrm{s}$.

REMARKS.--Flood stage of 1953 provided by the Georgia Department of Transportation. The flood of 1953 is at least the highest since 1948, based on information at nearby stations. Peak discharge of 1953 is estimated.

\begin{tabular}{|c|c|c|c|c|c|c|c|c|c|c|c|}
\hline $\begin{array}{l}\text { Water } \\
\text { year }\end{array}$ & Date & $\begin{array}{c}\text { Discharge } \\
\left(\mathrm{ft}^{3} / \mathrm{s}\right)\end{array}$ & $\begin{array}{l}\text { Gage } \\
\text { height } \\
\text { (ft) }\end{array}$ & $\begin{array}{l}\text { Water } \\
\text { year }\end{array}$ & Date & $\begin{array}{c}\text { Discharge } \\
\left(\mathrm{ft}^{3} / \mathrm{s}\right)\end{array}$ & $\begin{array}{c}\text { Gage } \\
\text { height } \\
\text { (ft) }\end{array}$ & $\begin{array}{l}\text { Water } \\
\text { year }\end{array}$ & Date & $\begin{array}{c}\text { Discharge } \\
\left(\mathrm{ft}^{3} / \mathrm{s}\right)\end{array}$ & $\begin{array}{c}\text { Gage } \\
\text { height } \\
\text { (ft) }\end{array}$ \\
\hline 1953 & Sept. 27 & 2,400 & $8.50 \mathrm{c}$ & 1959 & Mar. 06 & 1,160 & 6.24 & 1962 & Apr. 02 & 650 & 5.02 \\
\hline$\overline{1957}$ & June 09 & 116 & 3.20 & 1960 & Apr. 05 & 1,040 & 5.98 & 1963 & June 24 & 730 & 5.45 \\
\hline 1958 & July 04 & 320 & 4.16 & 1961 & Apr. 16 & 890 & 5.62 & & & & \\
\hline
\end{tabular}




\section{SATILLA RIVER BASIN}

02226900 HURRICANE CREEK NEAR HAZELHURST, GEORGIA

LOCATION.--Lat $31^{\circ} 40^{\prime} 58^{\prime \prime}$, long $82^{\circ} 34^{\prime} 15^{\prime \prime}$, Jeff Davis County, at county highway bridge, 4.8 mi downstream from Whitehead Creek and 13 mi south of Hazelhurst.

DRAINAGE AREA.--102 $\mathrm{mi}^{2}$, approximately.

GAGE.--Water-stage recorder. Datum of gage is about $170 \mathrm{ft}$ above sea level (from topographic map).

STAGE-DISCHARGE RELATION.--Defined by current-meter measurements below $3,400 \mathrm{ft} / \mathrm{s}$. Bankfull stage and discharge, $5 \mathrm{ft}$ and $1,000 \mathrm{ft}^{3} / \mathrm{s}$.

\begin{tabular}{|c|c|c|c|c|c|c|c|c|c|c|c|}
\hline $\begin{array}{l}\text { Water } \\
\text { year }\end{array}$ & Date & $\begin{array}{c}\text { Discharge } \\
\left(\mathrm{ft}^{3} / \mathrm{s}\right)\end{array}$ & $\begin{array}{c}\text { Gage } \\
\text { height } \\
\text { (ft) }\end{array}$ & $\begin{array}{l}\text { Water } \\
\text { year }\end{array}$ & Date & $\begin{array}{c}\text { Discharge } \\
\left(\mathrm{ft}^{3} / \mathrm{s}\right)\end{array}$ & $\begin{array}{c}\text { Gage } \\
\text { height } \\
\text { (ft) }\end{array}$ & $\begin{array}{l}\text { Water } \\
\text { year }\end{array}$ & Date & $\begin{array}{c}\text { Discharge } \\
\left(\mathrm{ft}^{3} / \mathrm{s}\right)\end{array}$ & $\begin{array}{c}\text { Gage } \\
\text { height } \\
\text { (ft) }\end{array}$ \\
\hline 1957 & July 21 & 722 & 4.67 & 1960 & Apr. 06 & 3,180 & 7.89 & 1962 & Apr. 03 & 1,700 & 6.57 \\
\hline 1958 & Apr. 18 & 722 & 4.63 & 1961 & Apr. 17 & 2,580 & 7.47 & 1963 & June 25 & 1,330 & 5.92 \\
\hline 1959 & Mar. 07 & 3,580 & 8.15 & & & & & & & & \\
\hline
\end{tabular}

\section{HURRICANE CREEK NEAR ALMA, GEORGIA}

LOCATION.--Lat $31^{\circ} 34^{\prime} 00^{\prime \prime}$, long $82^{\circ} 27^{\prime} 50^{\prime \prime}$, Bacon County, at bridge on State Highway 4 and U.S. Highway 1,11 mi upstream of Ten Mile Creek, and 1.5 mi north of Alma.

DRAINAGE AREA.--139 $\mathrm{mi}^{2}$, approximately (revised).

GAGE.--Water-stage recorder prior to October 1971; crest-stage thereafter. Datum of gage is $136.44 \mathrm{ft}$ above sea level, supplementary adjustment of 1936.

STAGE-DISCHARGE RELATION.--Defined by current-meter measurements below $4,200 \mathrm{ft}^{3} / \mathrm{s}$, and extended above on the basis of straight-line extension. Bankfull stage and discharge, $6 \mathrm{ft}$ and $1,000 \mathrm{ft}^{3} / \mathrm{s}$.

\begin{tabular}{|c|c|c|c|c|c|c|c|c|c|c|c|}
\hline $\begin{array}{l}\text { Water } \\
\text { year }\end{array}$ & Date & $\begin{array}{c}\text { Discharge } \\
\left(\mathrm{ft}^{3} / \mathrm{s}\right)\end{array}$ & $\begin{array}{c}\text { Gage } \\
\text { height } \\
\text { (ft) }\end{array}$ & $\begin{array}{l}\text { Water } \\
\text { year }\end{array}$ & Date & $\begin{array}{c}\text { Discharge } \\
\left(\mathrm{ft}^{3} / \mathrm{s}\right)\end{array}$ & $\begin{array}{c}\text { Gage } \\
\text { height } \\
\text { (ft) }\end{array}$ & $\begin{array}{l}\text { Water } \\
\text { year }\end{array}$ & Date & $\begin{array}{c}\text { Discharge } \\
\left(\mathrm{ft}^{3} / \mathrm{s}\right)\end{array}$ & $\begin{array}{c}\text { Gage } \\
\text { height } \\
\text { (ft) }\end{array}$ \\
\hline 1952 & Dec. 25 & 798 & 5.63 & 1964 & Mar. 03 & 1,570 & 6.79 & 1976 & May 15 & 910 & 5.85 \\
\hline 1953 & Sept. 29 & 4,450 & 9.40 & 1965 & Dec. 05 & 2,780 & 8.10 & 1977 & Oct. 18 & 2,040 & 7.35 \\
\hline 1954 & Oct. 03 & 940 & 5.88 & 1966 & Mar. 07 & 1,700 & 6.99 & 1978 & Jan. 27 & 1,590 & 6.83 \\
\hline 1955 & Apr. 16 & 460 & 4.95 & 1967 & Jan. 05 & 2,290 & 7.62 & 1979 & Feb. 26 & 3,080 & 8.37 \\
\hline 1956 & Feb. 11 & 530 & 5.12 & 1968 & June 09 & 289 & 4.32 & 1980 & Mar. 14 & 1,830 & 7.12 \\
\hline 1957 & July 23 & 582 & 5.24 & 1969 & May 21 & 1,800 & 7.09 & 1981 & Aug. 12 & 988 & 5.98 \\
\hline 1958 & Apr. 15 & 910 & 5.65 & 1970 & Feb. 20 & 1,670 & 6.92 & 1982 & July 27 & 844 & 5.74 \\
\hline 1959 & Mar. 08 & 3,360 & 8.40 & 1971 & Aug. 20 & 1,020 & 6.03 & 1984 & Mar. 08 & 3,260 & 8.52 \\
\hline 1960 & Apr. 06 & 3,120 & 8.40 & 1972 & Feb. 03 & 1,870 & 7.17 & 1985 & Aug. 30 & 1,470 & 6.68 \\
\hline 1961 & Apr. 16 & 2,420 & 7.76 & 1973 & Apr. 04 & 2,040 & 7.35 & 1986 & Feb. 12 & 4,600 & 9.50 \\
\hline 1962 & Apr. 04 & 1,690 & 6.94 & 1974 & Sept. 07 & 1,750 & 7.02 & 1987 & Feb. 22 & 1,130 & 6.20 \\
\hline 1963 & June 27 & 1,410 & 6.60 & 1975 & Apr. 16 & 2,800 & 8.12 & & & & \\
\hline
\end{tabular}


LOCATION.--Lat $31^{\circ} 29^{\prime} 44^{\prime \prime}$, long $82^{\circ} 31^{\prime} 41^{\prime \prime}$, Bacon County, at State Highway 64,5 mi southwest of Alma.

DRAINAGE AREA.-61 $\mathrm{mi}^{2}$, approximately.

GAGE.--Crest-stage gage. Datum of gage is about $155 \mathrm{ft}$ above sea level (from topographic map).

STAGE-DISCHARGE RELATION.-Defined by current-meter measurements below $1,700 \mathrm{ft}^{3} / \mathrm{s}$, and extended above on the basis of slope-conveyance studies. Bankfull stage and discharge, $4.5 \mathrm{ft}$ and $250 \mathrm{ft}^{3} / \mathrm{s}$.

REMARKS.--Peak discharge for 1958 is estimated.

HISTORICAL DATA.--Flood stage of 1948 based on information furnished by local residents, and is thought to be the highest since 1929 , based on information at nearby stations.

\begin{tabular}{|c|c|c|c|c|c|c|c|c|c|c|c|}
\hline $\begin{array}{l}\text { Water } \\
\text { year }\end{array}$ & Date & $\begin{array}{c}\text { Discharge } \\
\left(\mathrm{ft}^{3} / \mathrm{s}\right)\end{array}$ & $\begin{array}{c}\text { Gage } \\
\text { height } \\
\text { (ft) }\end{array}$ & $\begin{array}{l}\text { Water } \\
\text { year }\end{array}$ & Date & $\begin{array}{c}\text { Discharge } \\
\left(\mathrm{ft}^{3} / \mathrm{s}\right)\end{array}$ & $\begin{array}{c}\text { Gage } \\
\text { height } \\
\text { (ft) }\end{array}$ & $\begin{array}{l}\text { Water } \\
\text { year }\end{array}$ & Date & $\begin{array}{c}\text { Discharge } \\
\left(\mathrm{ft}^{3} / \mathrm{s}\right)\end{array}$ & $\begin{array}{c}\text { Gage } \\
\text { height } \\
\text { (ft) }\end{array}$ \\
\hline 1948 & Apr. -- & 5,600 & 10.00 & 1953 & Sept. 27 & 2,100 & 6.96 & 1958 & Apr. 11 & 1,280 & - \\
\hline 1949 & Sept. 01 & 3,000 & 7.93 & 1954 & Mar. 01 & 235 & 4.52 & 1959 & Mar. 08 & 1,650 & 6.48 \\
\hline 1950 & July 17 & 275 & 4.67 & 1955 & Apr. 16 & 93 & 3.75 & 1960 & Apr. 05 & 1,900 & 6.79 \\
\hline 1951 & Mar. 31 & 1,100 & 5.98 & 1956 & Feb. 11 & 105 & 3.83 & 1961 & Apr. 16 & 1,500 & 6.38 \\
\hline 1952 & Feb. 28 & 172 & 4.24 & 1957 & Apr. 09 & 105 & 3.86 & 1962 & Apr. 01 & 800 & 5.66 \\
\hline
\end{tabular}

\section{LITTLE HURRICANE CREEK BELOW ALMA, GEORGIA}

LOCATION.--Lat $31^{\circ} 25^{\prime} 25^{\prime \prime}$, long $82^{\circ} 25^{\prime} 59^{\prime \prime}$, Bacon County, at State Highway $4,8.5$ mi south of Alma.

DRAINAGE AREA.--102 $\mathrm{mi}^{2}$ (revised).

GAGE.--Crest-stage gage. Datum of gage is about $120 \mathrm{ft}$ above sea level (from topographic map).

STAGE-DISCHARGE RELATION.--Defined by current-meter measurements below $2,400 \mathrm{ft}^{3} / \mathrm{s}$, and extended above on the basis of slope-conveyance studies. Bankfull stage and discharge, $5.0 \mathrm{ft}$ and $250 \mathrm{ft}^{3} / \mathrm{s}$.

HISTORICAL DATA.--Flood stage of 1948 based on information furnished by local residents, and is thought to be the highest since 1929 , based on information at nearby stations.

\begin{tabular}{|c|c|c|c|c|c|c|c|c|c|c|c|}
\hline $\begin{array}{l}\text { Water } \\
\text { year }\end{array}$ & Date & $\begin{array}{c}\text { Discharge } \\
\left(\mathrm{ft}^{3} / \mathrm{s}\right)\end{array}$ & $\begin{array}{l}\text { Gage } \\
\text { height } \\
\text { (ft) }\end{array}$ & $\begin{array}{l}\text { Water } \\
\text { year }\end{array}$ & Date & $\begin{array}{c}\text { Discharge } \\
\left(\mathrm{ft}^{3} / \mathrm{s}\right)\end{array}$ & $\begin{array}{c}\text { Gage } \\
\text { height } \\
\text { (ft) }\end{array}$ & $\begin{array}{l}\text { Water } \\
\text { year }\end{array}$ & Date & $\begin{array}{c}\text { Discharge } \\
\left(\mathrm{ft}^{3} / \mathrm{s}\right)\end{array}$ & $\begin{array}{c}\text { Gage } \\
\text { height } \\
\text { (ft) }\end{array}$ \\
\hline 1948 & Apr. -- & 7,500 & 11.00 & 1959 & Mar. 07 & 3,590 & 8.51 & 1970 & Aug. 13 & 1,130 & 6.24 \\
\hline 1949 & Sept. 01 & 3,830 & 8.70 & 1960 & Apr. 06 & 3,170 & 8.17 & 1971 & Aug. 19 & 1,480 & 6.72 \\
\hline 1950 & July 18 & 616 & 5.48 & 1961 & Apr. 15 & 4,620 & 9.28 & 1972 & Feb. 03 & 1,130 & 6.29 \\
\hline 1951 & Mar. 31 & 1,120 & 6.34 & 1962 & Apr. 01 & 1,120 & 6.32 & 1973 & Apr. 04 & 1,470 & 6.70 \\
\hline 1952 & Feb. 28 & 310 & 4.82 & 1963 & July 09 & 630 & 5.54 & 1974 & Sept. 07 & 1,130 & 6.29 \\
\hline 1953 & Sept. 27 & 3,960 & 8.80 & 1964 & Mar. 02 & 3,080 & 8.10 & 1975 & Apr. 16 & 1,230 & 6.41 \\
\hline 1954 & Jan. 01 & 310 & 4.81 & 1965 & Dec. 05 & 4,090 & 8.91 & 1976 & May 15 & 1,270 & 6.46 \\
\hline 1955 & Apr. 18 & 172 & 4.28 & 1966 & Mar. 05 & 1,740 & 6.99 & 1977 & Mar. 08 & 1,320 & 6.53 \\
\hline 1956 & Jan. 24 & 118 & 4.14 & 1967 & Feb. 07 & 2,080 & 7.30 & 1978 & Jan. 27 & 1,210 & 6.39 \\
\hline 1957 & July 23 & 720 & 5.70 & 1968 & Aug. - & 159 & $--b$ & 1984 & Mar. 07 & 4,130 & $8.94 c$ \\
\hline 1958 & Apr. 11 & 1,650 & 6.88 & 1969 & Sept. 19 & 988 & 6.11 & $\overline{1986}$ & Feb. 12 & 4,400 & $9.14 \mathrm{c}$ \\
\hline
\end{tabular}


LOCATION.--Lat $31^{\circ} 21^{\prime} 04^{\prime \prime}$, long $82^{\circ} 14^{\prime} 16^{\prime \prime}$, Pierce County, at State Highways 15 and 121,3 mi north of Blackshear. DRAINAGE AREA.-411 $\mathrm{mi}^{2}$.

GAGE.--Crest-stage gage. Datum of gage is about $72 \mathrm{ft}$ above sea level (from topographic map).

STAGE-DISCHARGE RELATION.--Defined by current-meter measurements below $8,330 \mathrm{ft}^{3} / \mathrm{s}$.

\begin{tabular}{|c|c|c|c|c|c|c|c|c|c|c|c|}
\hline $\begin{array}{l}\text { Water } \\
\text { year }\end{array}$ & Date & $\begin{array}{c}\text { Discharge } \\
\left(\mathrm{ft}^{3} / \mathrm{s}\right)\end{array}$ & $\begin{array}{l}\text { Gage } \\
\text { height } \\
\text { (ft) }\end{array}$ & $\begin{array}{l}\text { Water } \\
\text { year }\end{array}$ & Date & $\begin{array}{c}\text { Discharge } \\
\left(\mathrm{ft}^{3} / \mathrm{s}\right)\end{array}$ & $\begin{array}{c}\text { Gage } \\
\text { height } \\
\text { (ft) }\end{array}$ & $\begin{array}{l}\text { Water } \\
\text { year }\end{array}$ & Date & $\begin{array}{c}\text { Discharge } \\
\left(\mathrm{ft}^{3} / \mathrm{s}\right)\end{array}$ & $\begin{array}{c}\text { Gage } \\
\text { height } \\
\text { (ft) }\end{array}$ \\
\hline 1970 & Mar. 26 & 3,850 & 12.67 & 1976 & May 28 & 3,430 & 12.37 & 1982 & July 17 & 3,330 & 12.30 \\
\hline 1971 & Aug. 20 & 3,270 & 12.26 & 1977 & Jan. 08 & 4,000 & 12.78 & 1983 & Mar. 12 & 4,790 & 13.34 \\
\hline 1972 & Feb. 08 & 4,170 & 12.90 & 1978 & Jan. 27 & 3,270 & 12.26 & 1984 & Mar. 08 & 8,740 & 15.77 \\
\hline 1973 & Apr. 05 & 5,800 & 14.03 & 1979 & May 15 & 4,870 & 13.40 & 1985 & Sept. 03 & 1,930 & 11.18 \\
\hline 1974 & Feb. 11 & 2,810 & 11.92 & 1980 & Mar. 14 & 7,010 & 14.84 & 1986 & Feb. 12 & 8,040 & 15.42 \\
\hline 1975 & Apr. 19 & 4,160 & 12.89 & 1981 & Apr. 04 & 1,330 & 10.62 & 1987 & Feb. 22 & 2,570 & 11.72 \\
\hline
\end{tabular}

\section{BIG SATILLA CREEK NEAR ALMA, GEORGIA}

LOCATION.--Lat $31^{\circ} 39^{\prime} 28^{\prime \prime}$, long $82^{\circ} 25^{\prime} 57^{\prime \prime}$, Bacon County, at State Highway 4, 8.2 mi north of Alma.

DRAINAGE AREA, $-112 \mathrm{mi}^{2}$.

GAGE.-Crest-stage gage. Datum of gage is $138.60 \mathrm{ft}$ above sea level (levels by Georgia Department of Transportation).

STAGE-DISCHARGE RELATION.--Defined by current-meter measurements below $6,400 \mathrm{ft}^{3} / \mathrm{s}$, and extended above on the basis of slope-conveyance studies. Bankfull stage and discharge, $4.5 \mathrm{ft}$ and $1,000 \mathrm{ft}^{3} / \mathrm{s}$.

HISTORICAL DATA.--Flood stage of 1948 based on information furnished by local resident. The 1948 peak is thought to be the highest since 1929 , based on information at nearby stations.

\begin{tabular}{|c|c|c|c|c|c|c|c|c|c|c|c|}
\hline $\begin{array}{l}\text { Water } \\
\text { year }\end{array}$ & Date & $\begin{array}{c}\text { Discharge } \\
\left(\mathrm{ft}^{3} / \mathrm{s}\right)\end{array}$ & $\begin{array}{c}\text { Gage } \\
\text { height } \\
\text { (ft) }\end{array}$ & $\begin{array}{l}\text { Water } \\
\text { year }\end{array}$ & Date & $\begin{array}{c}\text { Discharge } \\
\left(\mathrm{ft}^{3} / \mathrm{s}\right)\end{array}$ & $\begin{array}{c}\text { Gage } \\
\text { height } \\
\text { (ft) }\end{array}$ & $\begin{array}{l}\text { Water } \\
\text { year }\end{array}$ & Date & $\begin{array}{c}\text { Discharge } \\
\left(\mathrm{ft}^{3} / \mathrm{s}\right)\end{array}$ & $\begin{array}{c}\text { Gage } \\
\text { height } \\
\text { (ft) }\end{array}$ \\
\hline 1948 & Apr. - & 14,000 & 13.80 & 1959 & Mar. 08 & 3,850 & 7.84 & 1970 & Mar. 23 & 2,270 & 6.87 \\
\hline 1949 & Aug. - & 2,070 & 5.89 & 1960 & Apr. 06 & 2,960 & 6.88 & 1971 & Aug. 27 & 1,200 & 5.72 \\
\hline 1950 & Mar. 17 & 420 & 3.57 & 1961 & Apr. 16 & 2,780 & 6.67 & 1972 & Feb. 03 & 1,730 & 6.33 \\
\hline 1951 & Mar. 31 & 2,780 & 6.73 & 1962 & Apr. 01 & 650 & 4.64 & 1973 & Apr. 04 & 1,370 & 5.94 \\
\hline 1952 & Sept. 23 & 660 & 3.94 & 1963 & June 26 & 580 & 4.54 & 1974 & Sept. 07 & 2,610 & 7.22 \\
\hline 1953 & Sept. 27 & 7,380 & 10.70 & 1964 & Mar. 02 & 1,260 & 5.40 & 1975 & Apr. 16 & 2,610 & 7.21 \\
\hline 1954 & Dec. 30 & 690 & 4.00 & 1965 & Dec. 05 & 3,100 & 7.40 & 1976 & Jan. 28 & 1,320 & 5.87 \\
\hline 1955 & Apr. 15 & 420 & 3.55 & 1966 & Mar. 05 & 1,920 & 6.52 & 1977 & Oct. 18 & 2,140 & 6.74 \\
\hline 1956 & Jan. 24 & 690 & 4.01 & 1967 & Jan. 04 & 2,510 & 7.11 & $\underline{1978}$ & Jan. 27 & 1,390 & 5.96 \\
\hline 1957 & July 23 & 1,430 & 5.14 & 1968 & Aug. - & 1,000 & $--b$ & $\underline{1984}$ & Mar. 07 & 3,310 & $7.91 \mathrm{c}$ \\
\hline 1958 & Apr. 11 & 1,430 & 5.13 & 1969 & May 20 & 2,690 & 7.29 & $\overline{1986}$ & Feb. 12 & 4,850 & $9.18 \mathrm{c}$ \\
\hline
\end{tabular}




\section{SATILLA RIVER BASIN}

\section{CROOKED CREEK TRIBUTARY NEAR BRISTOL, GEORGIA}

LOCATION.-Lat $31^{\circ} 26^{\prime} 25^{\prime \prime}$, long $82^{\circ} 15^{\prime} 03^{\prime \prime}$, Pierce County, on county road 1903, 2 mi west of Bristol. DRAINAGE AREA.-0.42 $\mathrm{mi}^{2}$.

GAGE.--Crest-stage gage. Datum of gage is about $155 \mathrm{ft}$ above sea level (from topographic map).

STAGE-DISCHARGE RELATION.--Defined by current-meter measurements below $12.9 \mathrm{ft}^{3} / \mathrm{s}$, and extended above on the basis of culvert computations.

\begin{tabular}{|c|c|c|c|c|c|c|c|c|c|c|c|}
\hline $\begin{array}{l}\text { Water } \\
\text { year }\end{array}$ & Date & $\begin{array}{c}\text { Discharge } \\
\left(\mathrm{ft}^{3} / \mathrm{s}\right)\end{array}$ & $\begin{array}{c}\text { Gage } \\
\text { height } \\
\text { (ft) }\end{array}$ & $\begin{array}{l}\text { Water } \\
\text { year }\end{array}$ & Date & $\begin{array}{c}\text { Discharge } \\
\left(\mathrm{ft}^{3} / \mathrm{s}\right)\end{array}$ & $\begin{array}{c}\text { Gage } \\
\text { height } \\
\text { (ft) }\end{array}$ & $\begin{array}{l}\text { Water } \\
\text { year }\end{array}$ & Date & $\begin{array}{c}\text { Discharge } \\
\left(\mathrm{ft}^{3} / \mathrm{s}\right)\end{array}$ & $\begin{array}{c}\text { Gage } \\
\text { height } \\
\text { (ft) }\end{array}$ \\
\hline 1976 & Aug. 03 & 58.0 & 2.50 & 1981 & Apr. 01 & 3.0 & 0.62 & 1986 & Feb. 11 & 58.0 & 2.44 \\
\hline 1977 & Jan. 07 & 25.0 & 1.58 & 1982 & July 15 & 45.0 & 2.13 & 1987 & Feb. 22 & 19.0 & 1.36 \\
\hline 1978 & Mar. 19 & 20.0 & 1.40 & 1983 & Mar. 06 & 22.0 & 1.48 & 1988 & Apr. 19 & 15.0 & 1.22 \\
\hline 1979 & May 07 & 65.0 & 2.55 & 1984 & Mar. 06 & 57.0 & 2.42 & 1989 & Sept. 04 & 29.0 & 1.73 \\
\hline 1980 & Mar. 13 & 29.0 & 1.69 & 1985 & Aug. 29 & 27.0 & 1.64 & 1990 & Feb. 10 & 8.0 & 0.97 \\
\hline
\end{tabular}

\section{LITTLE STATILLA CREEK AT ODUM, GEORGIA}

LOCATION.--Lat $31^{\circ} 40^{\prime} 04^{\prime \prime}$, long $82^{\circ} 02^{\prime} 27^{\prime \prime}$, Wayne County, at State Highway 27, 10 mi northwest of Jesup at Odum. DRAINAGE AREA.- $-49 \mathrm{mr}^{2}$, approximately.

GAGE.--Crest-stage gage. Datum of gage is $121.10 \mathrm{ft}$ above sea level (levels by the Georgia Department of Transportation), supplementary adjustment of 1936.

STAGE-DISCHARGE RELATION.--Defined by current-meter measurements below $1,200 \mathrm{tt}^{3} / \mathrm{s}$, and extended above on the basis of slope-conveyance studies. Bankfull stage and discharge, $4.5 \mathrm{ft}$ and $150 \mathrm{ft}^{3} / \mathrm{s}$.

HISTORICAL DATA.--Flood stage of 1948 based on information furnished by local resident. Flood stage of 1929 provided by the

Georgia Department of Transportation, and is thought to be the highest since 1862, based on information at nearby stations.

\begin{tabular}{|c|c|c|c|c|c|c|c|c|c|c|c|}
\hline $\begin{array}{l}\text { Water } \\
\text { year }\end{array}$ & Date & $\begin{array}{c}\text { Discharge } \\
\left(\mathrm{ft}^{3} / \mathrm{s}\right)\end{array}$ & $\begin{array}{c}\text { Gage } \\
\text { height } \\
\text { (ft) }\end{array}$ & $\begin{array}{l}\text { Water } \\
\text { year }\end{array}$ & Date & $\begin{array}{c}\text { Discharge } \\
\left(\mathrm{ft}^{3} / \mathrm{s}\right)\end{array}$ & $\begin{array}{c}\text { Gage } \\
\text { height } \\
\text { (ft) }\end{array}$ & $\begin{array}{l}\text { Water } \\
\text { year }\end{array}$ & Date & $\begin{array}{c}\text { Discharge } \\
\left(\mathrm{ft}^{3} / \mathrm{s}\right)\end{array}$ & $\begin{array}{c}\text { Gage } \\
\text { height } \\
\text { (ft) }\end{array}$ \\
\hline 1929 & Sept. - & 9,500 & $12.90 \mathrm{c}$ & 1959 & Mar. 06 & 1,350 & 6.46 & 1970 & Mar. 10 & 1,010 & 6.16 \\
\hline$\overline{1949}$ & Nov. - & 3,800 & 9.00 & 1960 & Apr. 05 & 669 & 5.69 & 1971 & Aug. 30 & 1,510 & 6.80 \\
\hline 1950 & Aug. -- & 1,140 & 6.29 & 1961 & Apr. 16 & 1,810 & 7.19 & 1972 & Feb. 03 & 850 & 5.96 \\
\hline 1951 & Apr. 03 & 492 & 5.41 & 1962 & July 19 & 492 & 5.38 & 1973 & Feb. 11 & 1,050 & 6.21 \\
\hline 1952 & May 30 & 155 & 4.51 & 1963 & June 26 & 519 & 5.44 & 1974 & May 14 & 408 & 5.23 \\
\hline 1953 & Sept. 27 & 1,240 & 6.38 & 1964 & Aug. 31 & 1,770 & 7.14 & 1975 & Apr. 16 & 886 & 6.07 \\
\hline 1954 & Dec. 28 & 85 & 4.05 & 1965 & Feb. 18 & 2,190 & 7.59 & 1976 & Jan. 28 & 886 & 6.08 \\
\hline 1955 & Sept. 14 & 96 & 4.17 & 1966 & May 27 & 1,390 & 6.62 & 1977 & Oct. 18 & 2,820 & 8.21 \\
\hline 1956 & May 07 & 90 & 4.09 & 1967 & Jan. 05 & 1,150 & 6.31 & 1978 & Jan. 26 & 750 & 5.82 \\
\hline 1957 & July 31 & 177 & 4.64 & 1968 & June 07 & 338 & 5.07 & $\overline{1984}$ & Mar. 07 & 2,290 & $7.69 c$ \\
\hline 1958 & Apr. 11 & 492 & 5.38 & 1969 & May 20 & 1,250 & 6.41 & & & & \\
\hline
\end{tabular}


LOCATION.--Lat $31^{\circ} 33^{\prime} 48^{\prime \prime}$, long $81^{\circ} 59^{\prime} 11^{\prime \prime}$, Wayne County, at State Highway 99,7 mi southwest of Jesup.

DRAINAGE AREA. $-83 \mathrm{mi}^{2}$, approximately.

GAGE.--Crest-stage gage. Datum of gage is $86.95 \mathrm{ft}$ above sea level (levels by the Georgia Department of Transportation), supplemtary adjustment of 1936.

STAGE-DISCHARGE RELATION.--Defined by current-meter measurements below $3,400 \mathrm{ft}^{3} / \mathrm{s}$, and extended above on the basis of slope-conveyance studies. Bankfull stage and discharge, $6.5 \mathrm{ft}$ and $350 \mathrm{ft}^{3} / \mathrm{s}$.

HISTORICAL DATA.--Flood stage of 1948 based on information furnished by local resident, and is thought to be the highest since 1929 , based on information at nearby stations.

REMARKS.--Peak discharge for 1954 is estimated.

\begin{tabular}{|c|c|c|c|c|c|c|c|c|c|c|c|}
\hline $\begin{array}{l}\text { Water } \\
\text { year }\end{array}$ & Date & $\begin{array}{c}\text { Discharge } \\
\left(\mathrm{ft}^{3} / \mathrm{s}\right)\end{array}$ & $\begin{array}{c}\text { Gage } \\
\text { height } \\
\text { (ft) }\end{array}$ & $\begin{array}{l}\text { Water } \\
\text { year }\end{array}$ & Date & $\begin{array}{c}\text { Discharge } \\
\left(\mathrm{ft}^{3} / \mathrm{s}\right)\end{array}$ & $\begin{array}{c}\text { Gage } \\
\text { height } \\
\text { (ft) }\end{array}$ & $\begin{array}{l}\text { Water } \\
\text { year }\end{array}$ & Date & $\begin{array}{c}\text { Discharge } \\
\left(\mathrm{ft}^{3} / \mathrm{s}\right)\end{array}$ & $\begin{array}{c}\text { Gage } \\
\text { height } \\
\text { (ft) }\end{array}$ \\
\hline 1949 & Nov. - & 5,800 & 11.80 & 1955 & Apr. 16 & 183 & 6.21 & 1961 & Apr. 16 & 1,820 & 8.67 \\
\hline 1950 & Sept. 00 & 3,320 & 9.86 & 1956 & May 07 & 76.0 & 5.78 & 1962 & Apr. 01 & 895 & 7.53 \\
\hline 1951 & Apr. 03 & 392 & 6.72 & 1957 & Aug. 07 & 1,040 & 7.74 & 1963 & June 26 & 620 & 7.09 \\
\hline 1952 & Feb. 28 & 120 & 6.02 & 1958 & June 27 & 740 & 7.29 & 1964 & Mar. 05 & 1,640 & 8.43 \\
\hline 1953 & Sept. 27 & 1,870 & 8.71 & 1959 & Mar. 17 & 1,680 & 8.51 & 1965 & Dec. 07 & 2,070 & 8.90 \\
\hline 1954 & Dec. 28 & 96.0 & - & 1960 & Apr. 05 & 960 & 7.64 & & & & \\
\hline
\end{tabular}

\section{LITTLE SATILLA RIVER NEAR OFFERMAN, GEORGIA}

LOCATION.-Lat $31^{\circ} 27^{\prime} 04^{\prime \prime}$, long $82^{\circ} 03^{\prime} 17^{\prime \prime}$, Pierce County, at right bank pier of steel truss span of Seaboard Coast Line Railroad bridge, 1,500 ft downstream from bridge on State Highway 38, 4 mi northeast of Offerman, and 16 mi upstream from mouth. DRAINAGE AREA.--646 mi².

GAGE.--Water-stage recorder. Datum of gage is $58.01 \mathrm{ft}$ above sea level (levels by the Georgia Department of Transportation), supplemtary adjustment of 1936. Prior to Nov. 8, 1952, water-stage recorder at site 1,500 ft upstream, and Nov. 8, 1952 to

Sept. 30, 1975 at present site and datum $1.0 \mathrm{ft}$ higher.

STAGE-DISCHARGE RELATION.--Defined by current-meter measurements below $16,000 \mathrm{ft}^{3} / \mathrm{s}$, and above on the basis of areavelocity studies. Bankfull stage and discharge, $9 \mathrm{ft}$ and $3,000 \mathrm{ft}^{3} / \mathrm{s}$.

HISTORICAL DATA.--Flood stage of 1948 based on information provided by the Georgia Department of Transportation, and is thought to be the highest since 1929 .

REMARKS.--All gage heights have been adjusted to present datum.

\begin{tabular}{|c|c|c|c|c|c|c|c|c|c|c|c|}
\hline $\begin{array}{l}\text { Water } \\
\text { year }\end{array}$ & Date & $\begin{array}{c}\text { Discharge } \\
\left(\mathrm{ft}^{3} / \mathrm{s}\right)\end{array}$ & $\begin{array}{c}\text { Gage } \\
\text { height } \\
\text { (ft) }\end{array}$ & $\begin{array}{l}\text { Water } \\
\text { year }\end{array}$ & Date & $\begin{array}{l}\text { Discharge } \\
\left(\mathrm{ft}^{3} / \mathrm{s}\right)\end{array}$ & $\begin{array}{c}\text { Gage } \\
\text { height } \\
\text { (ft) }\end{array}$ & $\begin{array}{l}\text { Water } \\
\text { year }\end{array}$ & Date & $\begin{array}{c}\text { Discharge } \\
\left(\mathrm{ft}^{3} / \mathrm{s}\right)\end{array}$ & $\begin{array}{c}\text { Gage } \\
\text { height } \\
\text { (ft) }\end{array}$ \\
\hline 1948 & Apr. -- & 27,000 & $16.40 \mathrm{c}$ & 1964 & Mar. 05 & 11,000 & 13.00 & 1978 & Jan. 22 & 4,010 & 10.50 \\
\hline 1951 & Apr. 03 & 5,100 & 10.50 & 1965 & Dec. 07 & 11,800 & 13.20 & 1979 & May 15 & 13,800 & 13.25 \\
\hline 1952 & June 01 & 1,860 & 8.80 & 1966 & Mar. 06 & 6,770 & 11.67 & 1980 & Mar. 15 & 13,400 & 13.15 \\
\hline 1953 & Sept. 29 & 17,200 & 14.50 & 1967 & Jan. 07 & 4,960 & 10.96 & 1981 & Apr. 07 & 2,340 & 9.66 \\
\hline 1954 & Jan. 02 & 1,610 & 9.20 & 1968 & June 12 & 1,370 & 8.89 & 1982 & July 19 & 3,000 & 10.01 \\
\hline 1955 & Apr. 17 & 1,180 & 8.60 & 1969 & May 24 & 4,370 & 10.68 & 1983 & Mar. 08 & 7,720 & 11.51 \\
\hline 1956 & Feb. 17 & 530 & 7.00 & 1970 & Mar. 26 & 5,550 & 11.22 & 1984 & Jan. 29 & 13,900 & 13.25 \\
\hline 1957 & June 11 & 3,760 & 10.50 & 1971 & Sept. 01 & 4,940 & 10.95 & 1985 & Sept. 04 & 3,150 & 10.09 \\
\hline 1958 & Apr. 17 & 4,620 & 10.80 & 1972 & Feb. 08 & 5,080 & 11.02 & 1986 & Mar. 18 & 1,920 & 9.39 \\
\hline 1959 & Mar. 07 & 8,860 & 12.40 & 1973 & Apr. 05 & 5,950 & 11.37 & 1987 & Jan. 06 & 10,500 & 12.55 \\
\hline 1960 & Apr. 08 & 6,570 & 11.60 & 1974 & Sept. 13 & 3,390 & 10.19 & 1988 & Feb. 24 & 3,690 & 10.35 \\
\hline 1961 & Apr. 18 & 12,600 & 13.40 & 1975 & Apr. 19 & 5,220 & 11.08 & 1989 & Sept. 05 & 3,330 & 10.18 \\
\hline 1962 & Apr. 06 & 4,190 & 10.59 & 1976 & Jan. 31 & 4,680 & 10.83 & 1990 & Jan. 12 & 3,890 & 10.42 \\
\hline 1963 & July 10 & 2,430 & 9.68 & 1977 & Nov. 30 & 5,920 & 11.36 & & & & \\
\hline
\end{tabular}




\section{SATILLA RIVER BASIN}

\section{SATILLA RIVER TRIBUTARY NO. 2, AT ATKINSON, GEORGIA}

LOCATION.--Lat $31^{\circ} 13^{\prime} 35^{\prime \prime}$, long 81 ${ }^{\circ} 50^{\prime} 50^{\prime \prime}$, Brantley County, at culvert on State Route 110, 0.3 mi north of Atkinson. DRAINAGE AREA. - $-0.38 \mathrm{mi}^{2}$.

GAGE.--Crest-stage gage. Datum of gage is $47.74 \mathrm{ft}$ above sea level (from U.S. Geological Survey benchmark).

STAGE-DISCHARGE RELATION.--Defined by current-meter measurements below $46.6 \mathrm{ft}^{3} / \mathrm{s}$, and extended above on the basis of culvert computations.

\begin{tabular}{|c|c|c|c|c|c|c|c|c|c|c|c|}
\hline $\begin{array}{l}\text { Water } \\
\text { year }\end{array}$ & Date & $\begin{array}{c}\text { Discharge } \\
\left(\mathrm{ft}^{3} / \mathrm{s}\right)\end{array}$ & $\begin{array}{c}\text { Gage } \\
\text { height } \\
\text { (ft) }\end{array}$ & $\begin{array}{l}\text { Water } \\
\text { year }\end{array}$ & Date & $\begin{array}{c}\text { Discharge } \\
\left(\mathrm{ft}^{3} / \mathrm{s}\right)\end{array}$ & $\begin{array}{c}\text { Gage } \\
\text { height } \\
\text { (ft) }\end{array}$ & $\begin{array}{l}\text { Water } \\
\text { year }\end{array}$ & Date & $\begin{array}{c}\text { Discharge } \\
\left(\mathrm{ft}^{3} / \mathrm{s}\right)\end{array}$ & $\begin{array}{l}\text { Gage } \\
\text { height } \\
\text { (ft) }\end{array}$ \\
\hline 1977 & Nov. 28 & 46.0 & 1.97 & 1982 & Apr. 25 & 40.0 & 1.85 & 1987 & Feb. 22 & 37.0 & 1.81 \\
\hline 1978 & Aug. 02 & 93.0 & 2.63 & 1983 & July 23 & 70.0 & 2.36 & 1988 & Feb. 19 & 17.0 & 1.25 \\
\hline 1979 & Sept. 25 & 82.0 & 2.50 & 1984 & Mar. 06 & 67.0 & 2.31 & 1989 & Sept. 22 & 9.0 & 0.93 \\
\hline 1980 & Mar. 13 & 16.0 & 1.24 & 1985 & Aug. 08 & 16.0 & 1.24 & 1990 & Feb. 10 & 15.0 & 1.15 \\
\hline 1981 & Aug. 01 & 26.0 & 1.54 & 1986 & Feb. 11 & 55.0 & 2.14 & & & & \\
\hline
\end{tabular}

\section{SATILLA RIVER AT ATKINSON, GEORGIA}

LOCATION.--Lat $31^{\circ} 13^{\prime} 16^{\prime \prime}$, long $81^{\circ} 52^{\prime} 03^{\prime \prime}$, Brantley County, on left bank piling $25 \mathrm{ft}$ upstream from bridge on U.S. Highway 84 , $400 \mathrm{ft}$ downstream from Seaboard Coast Line Railroad bridge, and 1 mi west of Atkinson.

DRAINAGE AREA.--2,790 $\mathrm{mi}^{2}$.

GAGE.--Water-stage recorder. Datum of gage is $14.79 \mathrm{ft}$ above sea level (levels from Seaboard Coast Line Railroad), supplementary adjustment of 1936. Prior to Dec. 6,1933, and Nov. 21, 1961 to Sept. 30, 1964, nonrecording gage at same site and datum.

STAGE-DISCHARGE RELATION.--Defined by current-meter measurements below $68,000 \mathrm{ft}^{3} / \mathrm{s}$, and above on the basis of straightline extension. Bankfull stage and discharge, $13 \mathrm{ft}$ and $5,700 \mathrm{ft}^{3} / \mathrm{s}$.

HISTORICAL DATA.--The flood of September 1929 based on information furnished by local residents, and was the highest known at that time. Atlantic Coast Line Railroad records indicate that the 1929 flood was the highest since the railroad bridge was constructed about 1862.

\begin{tabular}{|c|c|c|c|c|c|c|c|c|c|c|c|}
\hline $\begin{array}{l}\text { Water } \\
\text { year }\end{array}$ & Date & $\begin{array}{c}\text { Discharge } \\
\left(\mathrm{ft}^{3} / \mathrm{s}\right)\end{array}$ & $\begin{array}{l}\text { Gage } \\
\text { height } \\
\text { (ft) }\end{array}$ & $\begin{array}{l}\text { Water } \\
\text { year }\end{array}$ & Date & $\begin{array}{c}\text { Discharge } \\
\left(\mathrm{ft}^{3} / \mathrm{s}\right)\end{array}$ & $\begin{array}{l}\text { Gage } \\
\text { height } \\
\text { (ft) }\end{array}$ & $\begin{array}{l}\text { Water } \\
\text { year }\end{array}$ & Date & $\begin{array}{c}\text { Discharge } \\
\left(\mathrm{ft}^{3} / \mathrm{s}\right)\end{array}$ & $\begin{array}{c}\text { Gage } \\
\text { height } \\
\text { (ft) }\end{array}$ \\
\hline$\underline{1929}$ & Sept. 00 & 110,000 & $27.20 \mathrm{c}$ & 1951 & Oct. 24 & 15,000 & 16.50 & 1971 & Aug. 25 & 13,400 & 16.11 \\
\hline 1931 & Jan. 26 & 5,510 & 13.00 & 1952 & Mar. 11 & 5,360 & 12.90 & 1972 & Feb. 13 & 16,300 & 16.76 \\
\hline 1932 & Aug. 31 & 12,200 & 15.40 & 1953 & Apr. 23 & 6,220 & 13.40 & 1973 & Apr. 10 & 27,100 & 18.68 \\
\hline 1933 & Feb. 18 & 15,200 & 17.00 & 1954 & Oct. 03 & 34,600 & 19.80 & 1974 & Sept. 19 & 11,600 & 15.61 \\
\hline 1934 & June 11 & 11,900 & 15.80 & 1955 & Sept. 21 & 3,900 & 11.80 & 1975 & Apr. 22 & 17,800 & 17.06 \\
\hline 1935 & Sept. 18 & 13,000 & 16.20 & 1956 & Feb. 22 & 3,420 & 11.30 & 1976 & June 02 & 12,300 & 15.81 \\
\hline 1936 & Feb. 17 & 8,770 & 14.50 & 1957 & June 17 & 6,400 & 13.50 & 1977 & Dec. 07 & 17,600 & 17.03 \\
\hline 1937 & Apr. 14 & 13,300 & 16.30 & 1958 & Apr. 20 & 19,000 & 17.30 & 1978 & Jan. 28 & 13,400 & 16.10 \\
\hline 1938 & Aug. 05 & 7,140 & 13.70 & 1959 & Mar. 12 & 29,700 & 19.10 & 1979 & May 18 & 17,500 & 17.00 \\
\hline 1939 & Mar. 07 & 17,000 & 17.50 & 1960 & Apr. 11 & 31,100 & 19.10 & 1980 & Mar. 19 & 31,400 & 19.35 \\
\hline 1940 & Feb. 26 & 7,920 & 14.50 & 1961 & Apr. 23 & 29,700 & 19.10 & 1981 & Apr. 14 & 3,180 & 11.02 \\
\hline 1941 & July 27 & 6,080 & 13.20 & 1962 & Apr. 12 & 14,200 & 16.30 & 1982 & July 21 & 8,570 & 14.52 \\
\hline 1942 & Jan. 09 & 26,600 & 18.80 & 1963 & July 08 & 6,600 & 13.60 & 1983 & Mar. 14 & 20,600 & 17.60 \\
\hline 1943 & Mar. 17 & 5,650 & 13.00 & 1964 & Mar. 08 & 31,800 & 19.40 & 1984 & Mar. 12 & 36,800 & 20.12 \\
\hline 1944 & Mar. 31 & 26,100 & 18.30 & 1965 & Dec. 12 & 30,400 & 19.20 & 1985 & Sept. 09 & 8,270 & 14.39 \\
\hline 1945 & Oct. 30 & 12,200 & 15.60 & 1966 & Mar. 10 & 19,800 & 17.48 & 1986 & Mar. 25 & 7,360 & 13.98 \\
\hline 1946 & Jan. 07 & 8,500 & 14.40 & 1967 & Jan. 15 & 15,900 & 16.68 & 1987 & Jan. 11 & 20,400 & 17.56 \\
\hline 1947 & Apr. 25 & 13,800 & 16.00 & 1968 & Mar. 20 & 2,570 & 10.21 & 1988 & Feb. 29 & 11,700 & 15.63 \\
\hline 1948 & Apr. 06 & 68,100 & 23.90 & 1969 & June 01 & 10,300 & 15.19 & 1989 & Sept. 09 & 5,410 & 12.93 \\
\hline 1949 & Sept. 05 & 33,200 & 19.60 & 1970 & Apr. 03 & 13,800 & 16.21 & 1990 & Mar. 01 & 8,810 & 14.62 \\
\hline 1950 & Sept. 11 & 15,500 & 16.60 & & & & & & & & \\
\hline
\end{tabular}




\section{SATILLA RIVER BASIN}

02228050 BUFFALO CREEK AT HICKOX, GEORGIA

LOCATION.--Lat $31^{\circ} 09^{\prime 2} 21^{\prime \prime}$ long 81 $59^{\prime 2} 29^{\prime \prime}$, Brantley County, on State Highway 23 and U.S. Highway 301, at Hickox. DRAINAGE AREA.-62 $\mathrm{mi}^{2}$.

GAGE.--Crest-stage gage. Datum of gage is $28.4 \mathrm{ft}$ above sea level (levels from the Federal Emergency Management Agency). STAGE-DISCHARGE RELATION.--Defined by current-meter measurements below $1,450 \mathrm{ft}^{3} / \mathrm{s}$, and extended above on the basis of straight-line extension.

\begin{tabular}{|c|c|c|c|c|c|c|c|c|c|c|c|}
\hline $\begin{array}{l}\text { Water } \\
\text { year }\end{array}$ & Date & $\begin{array}{c}\text { Discharge } \\
\left(\mathrm{ft}^{3} / \mathrm{s}\right)\end{array}$ & $\begin{array}{c}\text { Gage } \\
\text { height } \\
\text { (ft) }\end{array}$ & $\begin{array}{l}\text { Water } \\
\text { year }\end{array}$ & Date & $\begin{array}{c}\text { Discharge } \\
\left(\mathrm{ft}^{3} / \mathrm{s}\right)\end{array}$ & $\begin{array}{c}\text { Gage } \\
\text { height } \\
\text { (ft) }\end{array}$ & $\begin{array}{l}\text { Water } \\
\text { year }\end{array}$ & Date & $\begin{array}{c}\text { Discharge } \\
\left(\mathrm{ft}^{3} / \mathrm{s}\right)\end{array}$ & $\begin{array}{c}\text { Gage } \\
\text { height } \\
\text { (ft) }\end{array}$ \\
\hline 1966 & May 24 & 3,350 & 9.85 & 1974 & Sept. 07 & 868 & 6.88 & 1981 & Feb. 18 & 536 & 6.14 \\
\hline 1967 & Jan. 05 & 1,090 & 7.24 & 1975 & Apr. 11 & 916 & 6.96 & 1982 & Apr. 27 & 1,040 & 7.17 \\
\hline 1968 & Aug. - & 700 & $--b$ & 1976 & Feb. -- & 700 & $-b$ & 1983 & Feb. 16 & 790 & 6.74 \\
\hline 1969 & Sept. 22 & 1,830 & 8.26 & 1977 & Nov. 29 & 4,330 & 10.69 & 1984 & Mar. 07 & 2,670 & 9.17 \\
\hline 1970 & Nov. 02 & 3,800 & 10.25 & 1978 & Jan. -- & 700 & $--b$ & 1985 & Aug. 08 & 862 & 6.87 \\
\hline 1971 & Aug. 19 & 958 & 7.03 & 1979 & Sept. 26 & 2,560 & 9.06 & 1986 & Feb. 11 & 2,120 & 8.62 \\
\hline 1972 & Feb. - & 700 & - -b & 1980 & Mar. 14 & 765 & 6.69 & 1987 & Feb. 22 & 1,310 & 7.55 \\
\hline 1973 & Apr. 04 & 3,130 & 9.63 & & & & & & & & \\
\hline
\end{tabular}

\section{SATILLA RIVER TRIBUTARY NO. 3, NEAR WINOKUR, GEORGIA}

LOCATION.--Lat $30^{\circ} 59^{\prime} 59^{\prime \prime}$, long $81^{\circ} 57^{\prime} 30^{\prime \prime}$, Charlton County, at culvert on county road $87,5.3$ mi southeast of Winokur. DRAINAGE AREA.--1.91 $\mathrm{mi}^{2}$.

GAGE.--Crest-stage gage. Datum of gage is about $25 \mathrm{ft}$ above sea level (from topographic map).

STAGE-DISCHARGE RELATION.--Defined by current-meter measurements below $131 \mathrm{ft}^{3} / \mathrm{s}$, and extended above on the basis of culvert computations.

\begin{tabular}{|c|c|c|c|c|c|c|c|c|c|c|c|}
\hline $\begin{array}{l}\text { Water } \\
\text { year }\end{array}$ & Date & $\begin{array}{c}\text { Discharge } \\
\left(\mathrm{ft}^{3} / \mathrm{s}\right)\end{array}$ & $\begin{array}{c}\text { Gage } \\
\text { height } \\
\text { (ft) }\end{array}$ & $\begin{array}{l}\text { Water } \\
\text { year }\end{array}$ & Date & $\begin{array}{c}\text { Discharge } \\
\left(\mathrm{ft}^{3} / \mathrm{s}\right)\end{array}$ & $\begin{array}{c}\text { Gage } \\
\text { height } \\
\text { (ft) }\end{array}$ & $\begin{array}{l}\text { Water } \\
\text { year }\end{array}$ & Date & $\begin{array}{c}\text { Discharge } \\
\left(\mathrm{ft}^{3} / \mathrm{s}\right)\end{array}$ & $\begin{array}{c}\text { Gage } \\
\text { height } \\
\text { (ft) }\end{array}$ \\
\hline 1980 & Mar. 13 & 61 & 6.71 & 1984 & Mar. 27 & 511 & 8.97 & 1987 & Feb. 22 & 380 & 8.52 \\
\hline 1981 & Feb. 12 & 39 & 6.24 & 1985 & Aug. 08 & 70 & 6.85 & 1988 & Feb. 19 & 128 & 7.42 \\
\hline 1982 & Apr. 25 & 86 & 7.08 & 1986 & Dec. 13 & 134 & 7.46 & 1989 & Mar. 23 & 100 & 7.21 \\
\hline 1983 & Mar. 09 & 140 & 7.50 & & & & & & & & \\
\hline
\end{tabular}




\section{SATILLA RIVER BASIN}

\section{NORTH PRONG ST MARYS RIVER AT MONIAC, GEORGIA}

LOCATION.--Lat $30^{\circ} 31^{\prime} 03^{\prime \prime}$, long $82^{\circ} 13^{\prime} 50^{\prime \prime}$, in NW 1/4 sec. 8, T.1 N., R. 21 E; Baker County, Fla; near right bank at upstream side of bridge on State Highways 2 and $94,0.2 \mathrm{mi}$ upstream from Georgia Southern and Florida Railway bridge, $0.4 \mathrm{mi}$ west of Moniac, 1.0 mi downstream from Moccasin Creek, and 122 mi upstream from mouth of St Marys River.

DRAINAGE AREA.-160 $\mathrm{mi}^{2}$, approximately; includes part of watershed in Okeefenokee Swamp, which is indeterminate.

GAGE.--Water-stage recorder. Datum of gage is $89.40 \mathrm{ft}$ above sea level. January 1921 to June 1934, nonrecording gage at site $800 \mathrm{ft}$ downstream at datum $3.22 \mathrm{ft}$ higher.

STAGE-DISCHARGE RELATION.--Defined by current-meter measurements.

REMARKS.--Flood of 1973 is thought to be the highest since 1921. Peak discharges for 1921 and 1965 are estimated.

\begin{tabular}{|c|c|c|c|c|c|c|c|c|c|c|c|}
\hline $\begin{array}{l}\text { Water } \\
\text { year }\end{array}$ & Date & $\begin{array}{c}\text { Discharge } \\
\left(\mathrm{ft}^{3} / \mathrm{s}\right)\end{array}$ & $\begin{array}{c}\text { Gage } \\
\text { height } \\
\text { (ft) }\end{array}$ & $\begin{array}{l}\text { Water } \\
\text { year }\end{array}$ & Date & $\begin{array}{c}\text { Discharge } \\
\left(\mathrm{ft}^{3} / \mathrm{s}\right)\end{array}$ & $\begin{array}{c}\text { Gage } \\
\text { height } \\
\text { (ft) }\end{array}$ & $\begin{array}{l}\text { Water } \\
\text { year }\end{array}$ & Date & $\begin{array}{c}\text { Discharge } \\
\left(\mathrm{ft}^{3} / \mathrm{s}\right)\end{array}$ & $\begin{array}{c}\text { Gage } \\
\text { height } \\
\text { (ft) }\end{array}$ \\
\hline 1921 & July 31 & 2,200 & - & 1958 & Apr. 11 & 1,590 & 13.38 & 1974 & Sept. 09 & 984 & 11.78 \\
\hline 1922 & Sept. 19 & 370 & - & 1959 & Mar. 18 & 2,650 & 14.80 & 1975 & Apr. 15 & 2,180 & 14.46 \\
\hline$\underline{1923}$ & Jan. 08 & 670 & - & 1960 & Mar. 19 & 1,410 & 13.00 & 1976 & Sept. 26 & 1,040 & 11.97 \\
\hline$\overline{1927}$ & July 23 & 1,870 & - & 1961 & Aug. 31 & 668 & 10.76 & 1977 & Aug. 22 & 1,340 & 12.77 \\
\hline 1928 & Sept. 19 & 6,060 & - & 1962 & Apr. 02 & 2,730 & 14.88 & 1978 & Jan. 20 & 1,010 & 11.66 \\
\hline 1929 & Mar. 17 & 1,610 & - & 1963 & Jan. 14 & 729 & 11.18 & 1979 & Sept. 16 & 2,160 & 14.43 \\
\hline$\underline{1930}$ & Oct. 02 & 2,640 & - & 1964 & Sept. 13 & 4,590 & 18.41 & 1980 & Mar. 11 & 1,080 & 11.91 \\
\hline$\overline{1932}$ & Sept. 16 & 1,870 & - & 1965 & Dec. 27 & 1,700 & 14.00 & 1981 & Mar. 06 & 828 & 11.06 \\
\hline 1933 & Feb. 09 & 1,770 & - & 1966 & Aug. 09 & 2,020 & 14.20 & 1982 & Apr. 12 & 894 & 11.63 \\
\hline 1934 & June 18 & $\underline{550}$ & $=$ & 1967 & Aug. 30 & 1,500 & $12.99 \mathrm{a}$ & 1983 & Mar. 18 & 1,800 & 13.51 \\
\hline 1951 & Oct. 22 & 4,050 & 16.20 & 1968 & July 26 & 480 & 10.05 & 1984 & Mar. 29 & 2,750 & 15.43 \\
\hline 1952 & Mar. 14 & 1,330 & 12.36 & 1969 & Mar. 19 & 764 & 11.18 & 1985 & Sept. 02 & 873 & 11.23 \\
\hline 1953 & Sept. 27 & 1,920 & 13.93 & 1970 & Mar. 30 & 4,080 & 17.57 & 1986 & Feb. 11 & 2,300 & 15.00 \\
\hline 1954 & Oct. 01 & 2,140 & 14.27 & 1971 & Aug. 17 & 1,770 & 13.49 & 1987 & Jan. 23 & 1,180 & 12.64 \\
\hline 1955 & Sept. 08 & 443 & 9.79 & 1972 & June 21 & 1,320 & 12.60 & 1988 & Feb. 21 & 2,020 & 14.52 \\
\hline 1956 & May 08 & 312 & 9.05 & 1973 & Apr. 05 & 11,600 & 22.98 & 1989 & Sept. 06 & 251 & 8.68 \\
\hline 1957 & June 11 & 3,110 & 15.26 & & & & & & & & \\
\hline
\end{tabular}

\section{ST MARYS RIVER BASIN}

\section{ST MARYS RIVER NEAR ST. GEORGE, GEORGIA}

LOCATION.--Lat $30^{\circ} 31^{\prime} 28^{\prime \prime}$, long $82^{\circ} 01^{\prime} 07^{\prime \prime}$, in SW 1/4 sec. 4, T.1 N., R. 23 E; Nassau County, Fla; at bridge on State Highway 2

(Georgia State Highway 94), 1.1 mi east of St. George, and 82 mi upstream from mouth.

DRAINAGE AREA. $-890 \mathrm{ml}^{2}$, approximately; includes part of watershed in Okeefenokee Swamp, which is indeterminate.

GAGE.--Crest-stage gage. Datum of gage is mean sea level.

STAGE-DISCHARGE RELATION.--Defined by current-meter measurements.

HISTORICAL DATA.--Flood stage of 1947 furnished by the Forida Department of Transportation, and is thought to be the highest since 1927.

\begin{tabular}{|c|c|c|c|c|c|c|c|c|c|c|c|}
\hline $\begin{array}{l}\text { Water } \\
\text { year }\end{array}$ & Date & $\begin{array}{c}\text { Discharge } \\
\left(\mathrm{ft}^{3} / \mathrm{s}\right)\end{array}$ & $\begin{array}{c}\text { Gage } \\
\text { height } \\
\text { (ft) }\end{array}$ & $\begin{array}{l}\text { Water } \\
\text { year }\end{array}$ & Date & $\begin{array}{c}\text { Discharge } \\
\left(\mathrm{ft}^{3} / \mathrm{s}\right)\end{array}$ & $\begin{array}{c}\text { Gage } \\
\text { height } \\
\text { (ft) }\end{array}$ & $\begin{array}{l}\text { Water } \\
\text { year }\end{array}$ & Date & $\begin{array}{c}\text { Discharge } \\
\left(\mathrm{ft}^{3} / \mathrm{s}\right)\end{array}$ & $\begin{array}{c}\text { Gage } \\
\text { height } \\
\text { (ft) }\end{array}$ \\
\hline 1947 & Sept. 26 & 28,500 & $41.40 \mathrm{c}$ & 1966 & Jan. 27 & 7,270 & 33.93 & 1970 & Apr. 01 & 16,100 & 38.20 \\
\hline$\overline{1954}$ & Oct. 03 & 12,000 & 35.50 & 1967 & Feb. 15 & 6,480 & 33.49 & 1971 & Aug. 21 & 7,630 & 34.13 \\
\hline 1964 & Sept. 15 & 26,700 & 42.43 & 1968 & Sept. 04 & 8,600 & 34.65 & 1972 & June 30 & 5,010 & 32.62 \\
\hline 1965 & Aug. 18 & 5,140 & 32.70 & 1969 & Sept. 00 & 4,200 & 32.08 & 1973 & Apr. 05 & 28,000 & - \\
\hline
\end{tabular}




\section{SUWANNEE RIVER BASIN}

\section{SUWANNEE RIVER AT FARGO, GEORGIA}

LOCATION.-Lat $30^{\circ} 40^{\prime} 50^{\prime \prime}$, long $82^{\circ} 33^{\prime} 38^{\prime \prime}$, Clinch County, on downstream side of right bank pier of bridge on U.S. Highway 441 at Fargo, 4 mi upstream from Suwanoochee Creek, and 12 mi downstram from Mixons Ferry damsite.

DRAINAGE AREA.-1,260 $\mathrm{mi}^{2}$; includes part of watershed in Okefenokee Swamp, which is indeterminate.

GAGE.--Water-stage recorder. Datum of gage is $91.90 \mathrm{ft}$ above sea level (levels from U.S. Coast and Geodetic Survey benchmark). Jan. 27, 1927 to Dec. 31, 1931 and Apr. 20, 1937 to June 10,1938, nonrecording gage at site 1,000 ft upstream at datum $1.00 \mathrm{ft}$ higher. June 11, 1938 to Nov. 26, 1952, nonrecording gage at site 1,000 ft upstream at present datum. Oct. 14, 1960 to Oct. 29, 1970, auxillary water-stage recorder at site about 3 mi upstream and since Nov. 5, 1971, auxiliary water-stage recorder at site about 2 mi upstream. All sites converted to present datum.

STAGE-DISCHARGE RELATION.--Defined by current-meter measurements below $15,000 \mathrm{ft}^{3} / \mathrm{s}$. Stage-discharge relation affected by backwater. Bankfull stage and discharge, $10 \mathrm{ft}$ and $1,800 \mathrm{ft}^{3} / \mathrm{s}$.

\begin{tabular}{|c|c|c|c|c|c|c|c|c|c|c|c|}
\hline $\begin{array}{l}\text { Water } \\
\text { year }\end{array}$ & Date & $\begin{array}{c}\text { Discharge } \\
\left(\mathrm{ft}^{3} / \mathrm{s}\right)\end{array}$ & $\begin{array}{c}\text { Gage } \\
\text { height } \\
\text { (ft) }\end{array}$ & $\begin{array}{l}\text { Water } \\
\text { year }\end{array}$ & Date & $\begin{array}{c}\text { Discharge } \\
\left(\mathrm{ft}^{3} / \mathrm{s}\right)\end{array}$ & $\begin{array}{c}\text { Gage } \\
\text { height } \\
\text { (ft) }\end{array}$ & $\begin{array}{l}\text { Water } \\
\text { year }\end{array}$ & Date & $\begin{array}{l}\text { Discharge } \\
\left(\mathrm{ft}^{3} / \mathrm{s}\right)\end{array}$ & $\begin{array}{c}\text { Gage } \\
\text { height } \\
\text { (ft) }\end{array}$ \\
\hline 1928 & May 02 & 5,210 & 14.40 & 1953 & Sept. 02 & 3,280 & 11.80 & 1972 & Jan. 26 & 5,970 & 14.36 \\
\hline 1929 & Oct. 01 & 13,800 & 19.50 & 1954 & Oct. 05 & 5,640 & 14.60 & 1973 & Apr. 11 & 13,200 & 20.80 \\
\hline 1930 & Oct. 01 & 11,900 & 19.60 & 1955 & Sept. 17 & 1,710 & 10.70 & 1974 & Sept. 19 & 2,480 & 11.20 \\
\hline 1931 & Oct. 03 & 2,460 & 11.40 & 1956 & May 10 & 960 & 7.90 & 1975 & Apr. 21 & 6,650 & 15.10 \\
\hline$\overline{1938}$ & Oct. 08 & 4,410 & 12.70 & 1957 & June 14 & 2,550 & 12.20 & 1976 & June 01 & 3,190 & 12.22 \\
\hline 1939 & Aug. 29 & 2,490 & 11.60 & 1958 & Apr. 24 & 4,400 & 13.20 & 1977 & Dec. 17 & 7,180 & 15.43 \\
\hline 1940 & Feb. 21 & 2,060 & 11.00 & 1959 & Mar. 22 & 8,680 & 17.20 & 1978 & Mar. 17 & 3,200 & 12.12 \\
\hline 1941 & Sept. 23 & 810 & 7.50 & 1960 & Aug. 01 & 4,190 & 12.70 & 1979 & May 15 & 2,450 & 11.22 \\
\hline 1942 & Jan. 11 & 7,960 & 15.90 & 1961 & Apr. 23 & 7,100 & 15.50 & 1980 & Apr. 10 & 3,160 & 12.02 \\
\hline 1943 & Oct. 01 & 495 & 5.60 & 1962 & Apr. 05 & 4,520 & 14.60 & 1981 & Mar. 08 & 1,700 & 10.03 \\
\hline 1944 & Aug. 14 & 4,280 & 12.80 & 1963 & Mar. 05 & 3,830 & 12.40 & 1982 & Apr. 13 & 1,140 & 8.33 \\
\hline 1945 & Aug. 22 & 9,690 & 17.30 & 1964 & Sept. 17 & 9,940 & 18.60 & 1983 & Mar. 22 & 5,200 & 13.84 \\
\hline 1946 & Aug. 08 & 5,920 & 14.20 & 1965 & Mar. 07 & 5,800 & 14.40 & 1984 & Apr. 06 & 10,500 & 18.02 \\
\hline 1947 & Sept. 30 & 6,160 & 14.40 & 1966 & Mar. 16 & 7,240 & 15.45 & 1985 & Sept. 11 & 2,870 & 11.47 \\
\hline 1948 & Oct. 29 & 10,800 & 19.60 & 1967 & Feb. 17 & 3,540 & 12.49 & 1986 & Feb. 20 & 6,310 & 15.25 \\
\hline 1949 & Sept. 10 & 5,900 & 14.30 & 1968 & Sept. 10 & 531 & 5.51 & 1987 & Mar. 03 & 6,050 & 14.73 \\
\hline 1950 & Oct. 01 & 2,660 & 11.30 & 1969 & May 29 & 2,630 & 11.40 & 1988 & Feb. 27 & 4,190 & 13.21 \\
\hline 1951 & Oct. 26 & 3,260 & 11.90 & 1970 & Aug. 18 & 5,870 & 15.42 & 1989 & Nov. 29 & 497 & 5.11 \\
\hline 1952 & Nov. 10 & 4,300 & 12.80 & 1971 & Sept. 05 & 4,840 & 14.55 & 1990 & Feb. 28 & 2,390 & 11.16 \\
\hline
\end{tabular}




\section{SUWANNOOCHEE CREEK AT DU PONT, GEORGIA}

LOCATION.--Lat 3059'09", long 82॰52'50", Clinch County, at U.S. Highway 84, at Du Pont.

DRAINAGE AREA.-143 $\mathrm{mi}^{2}$.

GAGE.--Crest-stage gage. Datum of gage is $169.65 \mathrm{ft}$ above sea level (levels by the Georgia Department of Transportation).

STAGE-DISCHARGE RELATION.--Defined by current-meter measurements below $1,900 \mathrm{ft}^{3} / \mathrm{s}$, and extended above on the basis of straight-line extension. Bankfull stage and discharge, $5.0 \mathrm{ft}$ and $80 \mathrm{ft}^{3} / \mathrm{s}$.

HISTORICAL DATA.--Flood stages of 1930 and 1948 based on information furnished by the Georgia Department of Transportation. REMARKS.--Peak discharge for 1930 is estimated.

\begin{tabular}{|c|c|c|c|c|c|c|c|c|c|c|c|}
\hline $\begin{array}{l}\text { Water } \\
\text { year }\end{array}$ & Date & $\begin{array}{c}\text { Discharge } \\
\left(\mathrm{ft}^{3} / \mathrm{s}\right)\end{array}$ & $\begin{array}{c}\text { Gage } \\
\text { height } \\
\text { (ft) }\end{array}$ & $\begin{array}{l}\text { Water } \\
\text { year }\end{array}$ & Date & $\begin{array}{c}\text { Discharge } \\
\left(\mathrm{ft}^{3} / \mathrm{s}\right)\end{array}$ & $\begin{array}{c}\text { Gage } \\
\text { height } \\
\text { (ft) }\end{array}$ & $\begin{array}{l}\text { Water } \\
\text { year }\end{array}$ & Date & $\begin{array}{l}\text { Discharge } \\
\left(\mathrm{ft}^{3} / \mathrm{s}\right)\end{array}$ & $\begin{array}{c}\text { Gage } \\
\text { height } \\
\text { (ft) }\end{array}$ \\
\hline$\underline{1930}$ & Oct. 01 & 3,400 & $11.20 \mathrm{c}$ & 1960 & Apr. 11 & 1,050 & 7.45 & 1969 & Sept. 26 & 366 & 5.94 \\
\hline 1948 & Apr. -- & 1,150 & $7.70 c$ & 1961 & Apr. 16 & 1,300 & 7.88 & 1970 & Aug. 13 & 1,960 & 9.46 \\
\hline 1952 & Apr. 02 & 195 & 5.60 & 1962 & Apr. 01 & 675 & 6.65 & 1971 & Sept. 05 & 900 & 7.39 \\
\hline 1953 & Sept. 30 & 850 & 7.21 & 1963 & Jan. 21 & 225 & 5.57 & 1972 & Jan. 15 & 1,100 & 7.80 \\
\hline 1954 & Jan. -- & 285 & 5.92 & 1964 & Sept. 15 & 1,100 & 7.52 & 1973 & Apr. 05 & 1,660 & 8.77 \\
\hline 1955 & Sept. 17 & 80.0 & 5.09 & 1965 & Mar. 21 & 1,050 & 7.37 & 1974 & Sept. 09 & 784 & 7.16 \\
\hline 1956 & Aug. 14 & 600 & 6.47 & 1966 & Mar. 14 & 1,140 & 7.58 & 1975 & Apr. 15 & 1,100 & 7.79 \\
\hline 1957 & June 11 & 430 & 6.09 & 1967 & Jan. 05 & 870 & 7.04 & $\underline{1976}$ & May 16 & 696 & $6.94 \mathrm{c}$ \\
\hline 1958 & Apr. 20 & 900 & 7.10 & 1968 & Oct. 10 & 204 & 5.48 & 1986 & Feb. 14 & 1,570 & 8.46 \\
\hline 1959 & Mar. 09 & 1,480 & 8.17 & & & & & & & & \\
\hline
\end{tabular}

\section{SUWANNOOCHEE CREEK NEAR THELMA, GEORGIA}

LOCATION.--Lat 3049'18", long 82 $50^{\prime} 28^{\prime \prime}$, Clinch County, at State Highway 187, 1.2 mi west of Theima.

DRAINAGE AREA.--232 $\mathrm{mi}^{2}$.

GAGE.--Crest-stage gage. Datum of gage is $143.69 \mathrm{ft}$ above sea level (from U.S. Coast and Geodetic Survey benchmark).

STAGE-DISCHARGE RELATION.--Defined by current-meter measurements below $2,700 \mathrm{ft}^{3} / \mathrm{s}$, and above on the basis of straight-

line extension. Bankfull stage and discharge, $5.0 \mathrm{ft}$ and $200 \mathrm{ft}^{3} / \mathrm{s}$.

HISTORICAL DATA.--Flood stages of 1930 based on information furnished by local resident.

REMARKS.--Peak discharges for 1930, 1968, and 1981 are estimated.

\begin{tabular}{|c|c|c|c|c|c|c|c|c|c|c|c|}
\hline $\begin{array}{l}\text { Water } \\
\text { year }\end{array}$ & Date & $\begin{array}{c}\text { Discharge } \\
\left(\mathrm{ft}^{3} / \mathrm{s}\right)\end{array}$ & $\begin{array}{c}\text { Gage } \\
\text { height } \\
\text { (ft) }\end{array}$ & $\begin{array}{l}\text { Water } \\
\text { year }\end{array}$ & Date & $\begin{array}{c}\text { Discharge } \\
\left(\mathrm{ft}^{3} / \mathrm{s}\right)\end{array}$ & $\begin{array}{c}\text { Gage } \\
\text { height } \\
\text { (ft) }\end{array}$ & $\begin{array}{l}\text { Water } \\
\text { year }\end{array}$ & Date & $\begin{array}{c}\text { Discharge } \\
\left(\mathrm{ft}^{3} / \mathrm{s}\right)\end{array}$ & $\begin{array}{c}\text { Gage } \\
\text { height } \\
\text { (ft) }\end{array}$ \\
\hline$\underline{1930}$ & Oct. 02 & 5,000 & $11.80 \mathrm{c}$ & 1971 & Sept. 17 & 970 & 6.80 & 1980 & Mar. 16 & 872 & 6.66 \\
\hline 1963 & Feb. 26 & 400 & 5.82 & 1972 & Jan. 16 & 1,550 & 7.45 & 1981 & Feb. 12 & 500 & - \\
\hline 1964 & May 09 & 1,340 & 7.22 & 1973 & Apr. 06 & 2,860 & 8.44 & 1982 & Aug. 02 & 540 & 6.10 \\
\hline 1965 & Mar. 20 & 1,430 & 7.31 & 1974 & Sept. 10 & 1,610 & 7.51 & 1983 & Feb. 16 & 1,050 & 6.91 \\
\hline 1966 & Mar. 14 & 1,100 & 6.98 & 1975 & Apr. 16 & 2,670 & 8.32 & 1984 & Mar. 10 & 2,020 & 7.87 \\
\hline 1967 & Jan. 05 & 935 & 6.75 & 1976 & May 18 & 872 & 6.66 & 1985 & Aug. 16 & 935 & 6.75 \\
\hline 1968 & Aug. -- & 360 & -- & 1977 & Dec. 01 & 1,410 & 7.31 & 1986 & Feb. 15 & 1,550 & 7.45 \\
\hline 1969 & Sept. 26 & 879 & 6.67 & 1978 & Jan. 28 & 1,710 & 7.61 & 1987 & Apr. 06 & 720 & 6.43 \\
\hline 1970 & Aug. 15 & 2,800 & 8.40 & 1979 & Apr. 27 & 712 & 6.42 & & & & \\
\hline
\end{tabular}




\section{SUWANNEE RIVER BASIN}

02315650 ALAPAHA RIVER TRIBUTARY NO. 2, NEAR PITTS, GEORGIA

LOCATION.--Lat $32^{\circ} 00^{\prime} 20^{\prime \prime}$, long $83^{\circ} 33^{\prime} 27^{\prime \prime}$, Wilcox County, at culvert on State Highway $215,3.5$ mi north of Pitts. DRAINAGE AREA.--0.14 $\mathrm{mi}^{2}$.

GAGE.--Flood-stage/rainfall recorder. Datum of gage is about $400 \mathrm{ft}$ above sea level (from topographic map).

STAGE-DISCHARGE RELATION.--Defined by current-meter measurements below $40 \mathrm{ft}^{3} / \mathrm{s}$, and extended above on basis of culvert computations.

\begin{tabular}{lccccccccccc}
\hline $\begin{array}{l}\text { Water } \\
\text { year }\end{array}$ & Date & $\begin{array}{c}\text { Discharge } \\
\left(\mathrm{ft}^{3} / \mathrm{s}\right)\end{array}$ & $\begin{array}{c}\text { Gage } \\
\text { height } \\
(\mathrm{ft})\end{array}$ & $\begin{array}{c}\text { Water } \\
\text { year }\end{array}$ & Date & $\begin{array}{c}\text { Discharge } \\
\left(\mathrm{ft}^{3} / \mathrm{s}\right)\end{array}$ & $\begin{array}{c}\text { Gage } \\
\text { height } \\
(\mathrm{ft})\end{array}$ & $\begin{array}{c}\text { Water } \\
\text { year }\end{array}$ & $\begin{array}{c}\text { Gage } \\
\text { Date }\end{array}$ & $\begin{array}{c}\text { Discharge } \\
\left(\mathrm{ft}^{3} / \mathrm{s}\right)\end{array}$ & $\begin{array}{c}\text { height } \\
(\mathrm{ft})\end{array}$ \\
\hline & & & & & & & & & & & \\
1965 & June 16 & 31.0 & 1.78 & 1969 & Aug. 04 & 89.0 & 3.24 & 1973 & Feb. 02 & 50.0 & 2.30 \\
1966 & May 19 & 79.0 & 3.03 & 1970 & Mar. 30 & 73.0 & 2.28 & 1974 & Sept. 17 & 57.0 & 2.48 \\
1967 & July 12 & 39.0 & 2.03 & 1971 & Mar. 03 & 36.0 & 1.94 & 1975 & Apr. 14 & 53.0 & 2.38 \\
1968 & Mar. - & 13.0 & - -b & 1972 & June 25 & 40.0 & 2.06 & & & & \\
\hline
\end{tabular}

02315670 ALAPAHA RIVER TRIBUTARY NO. 3, NEAR ROCHELLE, GEORGIA

LOCATION.--Lat $31^{\circ} 56^{\prime} 40^{\prime \prime}$, long $83^{\circ} 30^{\prime} 52^{\prime \prime}$, Wilcox County, at culvert on State Highway 30 and U.S. Highway $280,3.5$ mi west of Rochelle.

DRAINAGE AREA.--3.95 $\mathrm{mi}^{2}$.

GAGE.--Flood-stage/rainfall recorder. Datum of gage is about $340 \mathrm{ft}$ above sea level (from topographic map).

STAGE-DISCHARGE RELATION.--Defined by current-meter measurements below $224 \mathrm{ft}^{3} / \mathrm{s}$.

REMARKS.-Peak discharge for 1973 and 1975 are estimated.

\begin{tabular}{|c|c|c|c|c|c|c|c|c|c|c|c|}
\hline $\begin{array}{l}\text { Water } \\
\text { year }\end{array}$ & Date & $\begin{array}{c}\text { Discharge } \\
\left(\mathrm{ft}^{3} / \mathrm{s}\right)\end{array}$ & $\begin{array}{c}\text { Gage } \\
\text { height } \\
\text { (ft) }\end{array}$ & $\begin{array}{l}\text { Water } \\
\text { year }\end{array}$ & Date & $\begin{array}{c}\text { Discharge } \\
\left(\mathrm{ft}^{3} / \mathrm{s}\right)\end{array}$ & $\begin{array}{c}\text { Gage } \\
\text { height } \\
\text { (ft) }\end{array}$ & $\begin{array}{l}\text { Water } \\
\text { year }\end{array}$ & Date & $\begin{array}{c}\text { Discharge } \\
\left(\mathrm{ft}^{3} / \mathrm{s}\right)\end{array}$ & $\begin{array}{c}\text { Gage } \\
\text { height } \\
\text { (ft) }\end{array}$ \\
\hline 1965 & Feb. 18 & 145 & 3.68 & 1969 & Aug. 04 & 155 & 3.75 & 1972 & Jan. 05 & 127 & 3.54 \\
\hline 1966 & Mar. 05 & 159 & 3.78 & 1970 & Mar. 31 & 230 & 4.15 & 1973 & June 25 & 150 & 3.01 \\
\hline 1967 & Feb. 07 & 116 & 3.46 & 1971 & Mar. 03 & 204 & 4.02 & $\overline{1975}$ & Apr. 14 & 125 & 2.83 \\
\hline 1968 & Mar. - & 18 & $-\mathrm{b}$ & & & & & & & & \\
\hline
\end{tabular}


LOCATION.-Lat $31^{\circ} 48^{\prime} 55^{\prime \prime}$ long $83^{\circ} 28^{\prime} 26^{\prime \prime}$, Ben Hill County, at State Highway 90,1 mi east of Rebecca.

DRAINAGE AREA. $-112 \mathrm{mi}^{2}$.

GAGE.-Crest-stage gage. Datum of gage is $289.93 \mathrm{ft}$ above sea level (levels from the Georgia Department of Transportation).

STAGE-DISCHARGE RELATION.--Defined by current-meter measurements below $3,300 \mathrm{ft}^{3} / \mathrm{s}$. Bankfull stage and discharge, $3 \mathrm{ft}$ and $450 \mathrm{ft}^{3} / \mathrm{s}$.

\begin{tabular}{|c|c|c|c|c|c|c|c|c|c|c|c|}
\hline $\begin{array}{l}\text { Water } \\
\text { year }\end{array}$ & Date & $\begin{array}{c}\text { Discharge } \\
\left(\mathrm{ft}^{3} / \mathrm{s}\right)\end{array}$ & $\begin{array}{l}\text { Gage } \\
\text { height } \\
\text { (ft) }\end{array}$ & $\begin{array}{l}\text { Water } \\
\text { year }\end{array}$ & Date & $\begin{array}{c}\text { Discharge } \\
\left(\mathrm{ft}^{3} / \mathrm{s}\right)\end{array}$ & $\begin{array}{c}\text { Gage } \\
\text { height } \\
\text { (ft) }\end{array}$ & $\begin{array}{l}\text { Water } \\
\text { year }\end{array}$ & Date & $\begin{array}{c}\text { Discharge } \\
\left(\mathrm{ft}^{3} / \mathrm{s}\right)\end{array}$ & $\begin{array}{c}\text { Gage } \\
\text { height } \\
\text { (ft) }\end{array}$ \\
\hline 1951 & Mar. 31 & 700 & 3.77 & 1960 & Apr. 06 & 3,400 & 6.51 & 1969 & Sept. 21 & 2,000 & 5.35 \\
\hline 1952 & May 31 & 1,310 & 4.68 & 1961 & Apr. 16 & 2,000 & 5.34 & 1970 & Apr. 01 & 3,120 & 6.28 \\
\hline 1953 & Sept. 22 & 1,600 & 5.04 & 1962 & Apr. 01 & 835 & 4.07 & 1971 & Mar. 04 & 2,970 & 5.92 \\
\hline 1954 & Jan. 02 & 1,150 & 4.51 & 1963 & July 24 & 975 & 4.24 & 1972 & Jan. 14 & 1,130 & 4.47 \\
\hline 1955 & Aug. 01 & 400 & 3.12 & 1964 & July 18 & 3,260 & 6.44 & 1973 & Feb. 10 & 2,000 & 5.35 \\
\hline 1956 & Feb. 07 & 470 & 3.29 & 1965 & Feb. 18 & 1,650 & 5.05 & 1974 & Feb. 17 & 760 & 3.92 \\
\hline 1957 & Apr. 10 & 1,080 & 4.43 & 1966 & Mar. 05 & 3,210 & 6.36 & 1975 & Apr. 16 & 2,640 & 5.98 \\
\hline 1958 & Apr. 11 & 940 & 4.19 & 1967 & Feb. 09 & 1,200 & 4.56 & 1976 & May 16 & 1,320 & 4.71 \\
\hline 1959 & Mar. 08 & 2,060 & 5.38 & 1968 & Apr. - & 310 & $-b$ & 1977 & Nov. 30 & 2,060 & 5.40 \\
\hline
\end{tabular}

\section{DEEP CREEK NEAR ASHBURN, GEORGIA}

LOCATION.-Lat $31^{\circ} 43^{\prime} 49^{\prime \prime}$ long $83^{\circ} 35^{\prime} 00^{\prime \prime}$, Turner County, at State Highway 112, 4.5 mi east of Ashburn. DRAINAGE AREA. $-137 \mathrm{mi}^{2}$.

GAGE.--Crest-stage gage. Datum of gage is $289.9 \mathrm{ft}$ above sea level (levels by U.S. Geologic Survey).

STAGE-DISCHARGE RELATION.--Defined by current-meter measurements below $4,240 \mathrm{ft}^{3} / \mathrm{s}$, and extended above on the basis of straight-line extention. Bankfull stage and discharge, $9 \mathrm{ft}$ and $700 \mathrm{ft}^{3} / \mathrm{s}$.

\begin{tabular}{|c|c|c|c|c|c|c|c|c|c|c|c|}
\hline $\begin{array}{l}\text { Water } \\
\text { year }\end{array}$ & Date & $\begin{array}{c}\text { Discharge } \\
\left(\mathrm{ft}^{3} / \mathrm{s}\right)\end{array}$ & $\begin{array}{c}\text { Gage } \\
\text { height } \\
\text { (ft) }\end{array}$ & $\begin{array}{l}\text { Water } \\
\text { year }\end{array}$ & Date & $\begin{array}{c}\text { Discharge } \\
\left(\mathrm{ft}^{3} / \mathrm{s}\right)\end{array}$ & $\begin{array}{c}\text { Gage } \\
\text { height } \\
\text { (ft) }\end{array}$ & $\begin{array}{l}\text { Water } \\
\text { year }\end{array}$ & Date & $\begin{array}{c}\text { Discharge } \\
\left(\mathrm{ft}^{3} / \mathrm{s}\right)\end{array}$ & $\begin{array}{c}\text { Gage } \\
\text { height } \\
\text { (ft) }\end{array}$ \\
\hline 1951 & Apr. 01 & 760 & 9.67 & 1960 & Apr. 05 & 3,880 & 13.00 & 1969 & Mar. 26 & 660 & 8.95 \\
\hline 1952 & Mar. 26 & 810 & 9.84 & 1961 & Apr. 16 & 2,940 & 12.30 & 1970 & Apr. 01 & 4,600 & 13.84 \\
\hline 1953 & May 08 & 1,500 & 10.50 & 1962 & Apr. 01 & 725 & 9.08 & 1971 & Mar. 04 & 4,200 & 13.40 \\
\hline 1954 & Jan. 03 & 1,140 & 9.94 & 1963 & June 25 & 1,500 & 10.47 & 1972 & Jan. 14 & 1,320 & 10.20 \\
\hline 1955 & Sept. 08 & 560 & 8.71 & 1964 & Feb. 18 & 4,520 & 13.38 & 1973 & Feb. 10 & 2,130 & 11.35 \\
\hline 1956 & Feb. 08 & 1,080 & 9.82 & 1965 & Feb. 18 & 1,850 & 11.00 & 1974 & Feb. 17 & 1,870 & 11.03 \\
\hline 1957 & May 16 & 1,320 & 10.20 & 1966 & Mar. 05 & 3,450 & 12.69 & 1975 & Apr. 16 & 2,810 & 13.17 \\
\hline 1958 & Apr. 11 & 1,640 & 10.70 & 1967 & Feb. 10 & 1,450 & 10.41 & $\underline{1976}$ & May 16 & 2,400 & 11.69 \\
\hline 1959 & Mar. 06 & 2,740 & 12.10 & 1968 & Apr. -- & 292 & $-b$ & $\overline{1984}$ & Mar. 07 & 2,880 & $12.24 \mathrm{c}$ \\
\hline
\end{tabular}


02315980 JACKS CREEK NEAR OCILLA, GEORGIA

(Formerly published as "Alapaha River Tributary near Ocilla, Georgia")

LOCATION.--Lat $31^{\circ} 33^{\prime} 38^{\prime \prime}$, long $83^{\circ} 21^{\prime} 28^{\prime \prime}$ I Irwin County, at culvert on State Highway 35 and U.S. Highway 319,7 mi west of Ocilla. DRAINAGE AREA.-1.21 $\mathrm{mi}^{2}$.

GAGE.--Flood-stage recorder prior to Mar. 15, 1968; Flood-stage/rainfall recorder thereafter. Datum of gage is about $310 \mathrm{ft}$ above sea level (from topographic map).

STAGE-DISCHARGE RELATION.--Defined by current-meter measurements below $157 \mathrm{ft}^{3} / \mathrm{s}$, and extended above on the basis of culvert computations.

\begin{tabular}{|c|c|c|c|c|c|c|c|c|c|c|c|}
\hline $\begin{array}{l}\text { Water } \\
\text { year }\end{array}$ & Date & $\begin{array}{c}\text { Discharge } \\
\left(\mathrm{ft}^{3} / \mathrm{s}\right)\end{array}$ & $\begin{array}{c}\text { Gage } \\
\text { height } \\
\text { (ft) }\end{array}$ & $\begin{array}{l}\text { Water } \\
\text { year }\end{array}$ & Date & $\begin{array}{c}\text { Discharge } \\
\left(\mathrm{ft}^{3} / \mathrm{s}\right)\end{array}$ & $\begin{array}{c}\text { Gage } \\
\text { height } \\
\text { (ft) }\end{array}$ & $\begin{array}{l}\text { Water } \\
\text { year }\end{array}$ & Date & $\begin{array}{c}\text { Discharge } \\
\left(\mathrm{ft}^{3} / \mathrm{s}\right)\end{array}$ & $\begin{array}{c}\text { Gage } \\
\text { height } \\
\text { (ft) }\end{array}$ \\
\hline 1960 & Apr. 05 & 188 & 3.12 & 1966 & Feb. 28 & 117 & 2.54 & 1972 & Jan. 13 & 75.0 & 2.36 \\
\hline 1961 & Apr. 15 & 307 & 4.05 & 1967 & Sept. 02 & 55 & 1.85 & 1973 & Apr. 01 & 176 & 3.21 \\
\hline 1962 & May 01 & 47 & 1.49 & 1968 & Apr. 27 & 86 & 2.22 & 1974 & Apr. 05 & 96.0 & 2.62 \\
\hline 1963 & June 24 & 117 & 2.54 & 1969 & Sept. 21 & 44 & 1.71 & $\underline{1975}$ & Apr. 14 & 131 & 2.91 \\
\hline 1964 & Feb. 18 & 100 & 1.97 & 1970 & Mar. 21 & 245 & 3.47 & $\overline{1986}$ & Feb. 11 & 640 & $5.81 \mathrm{c}$ \\
\hline 1965 & Mar. 28 & 80.0 & 2.18 & 1971 & Apr. 30 & 57 & 1.88 & & & & \\
\hline
\end{tabular}

\section{ALAPAHA RIVER NEAR ALAPAHA, GEORGIA}

LOCATION.--Lat $31^{\circ} 23^{\prime} 03^{\prime \prime}$, long $83^{\circ} 11^{\prime} 33^{\prime \prime}$, Berrien County, near right bank on downstream side of bridge on State Highway 50,2 mi east of Alapaha, and 6 mi upstream from Willacoochee River.

DRAINAGE AREA.--663 $\mathrm{mi}^{2}$.

GAGE.--Water-stage recorder. Datum of gage is $208.34 \mathrm{ft}$ above sea level. Prior to Sept. 8,1943 , nonrecording gage, and Sept. 8, 1943 to Sept. 30, 1975, water-stage recorder at same site and datum $1.00 \mathrm{ft}$ higher. All gage heights were converted to present datum.

STAGE-DISCHARGE RELATION.--Defined by current-meter measurements below $12,000 \mathrm{ft}^{3} / \mathrm{s}$, and extended above on the basis of straight-line extension. Bankfull stage and discharge, $11 \mathrm{ft}$ and $2,400 \mathrm{ft}^{3} / \mathrm{s}$.

HISTORICAL DATA.--Flood stage of April 1928 based on information furnished by the Georgia Department of Transportation. The 1928 flood is thought to have been the highest since at least 1862 , based on information from nearby stations.

\begin{tabular}{|c|c|c|c|c|c|c|c|c|c|c|c|}
\hline $\begin{array}{l}\text { Water } \\
\text { year }\end{array}$ & Date & $\begin{array}{c}\text { Discharge } \\
\left(\mathrm{ft}^{3} / \mathrm{s}\right)\end{array}$ & $\begin{array}{l}\text { Gage } \\
\text { height } \\
\text { (ft) }\end{array}$ & $\begin{array}{l}\text { Water } \\
\text { year }\end{array}$ & Date & $\begin{array}{c}\text { Discharge } \\
\left(\mathrm{ft}^{3} / \mathrm{s}\right)\end{array}$ & $\begin{array}{c}\text { Gage } \\
\text { height } \\
\text { (ft) }\end{array}$ & $\begin{array}{l}\text { Water } \\
\text { year }\end{array}$ & Date & $\begin{array}{c}\text { Discharge } \\
\left(\mathrm{ft}^{3} / \mathrm{s}\right)\end{array}$ & $\begin{array}{c}\text { Gage } \\
\text { height } \\
\text { (ft) }\end{array}$ \\
\hline 1928 & Apr. 30 & 16,000 & $19.00 \mathrm{c}$ & 1951 & Apr. 03 & 2,220 & 11.80 & 1965 & Feb. 20 & 5,900 & 14.80 \\
\hline$\overline{1938}$ & Apr. 15 & 1,060 & 9.60 & 1952 & Dec. 25 & 2,300 & 11.90 & 1966 & Mar. 08 & 9,380 & 16.39 \\
\hline 1939 & Mar. 03 & 9,220 & 16.30 & 1953 & Apr. 20 & 2,140 & 11.70 & 1967 & Jan. 16 & 4,200 & 13.71 \\
\hline 1940 & Feb. 25 & 2,290 & 11.80 & 1954 & Jan. 01 & 3,160 & 12.70 & 1968 & Mar. 16 & 681 & 8.58 \\
\hline 1941 & Mar. 25 & 1,450 & 10.50 & 1955 & Apr. 17 & 890 & 9.20 & 1969 & Aug. 25 & 2,040 & 11.69 \\
\hline 1942 & Jan. 09 & 4,960 & 13.90 & 1956 & Feb. 22 & 2,400 & 12.00 & 1970 & Apr. 05 & 7,380 & 15.88 \\
\hline 1943 & Mar. 26 & 2,700 & 12.30 & 1957 & Apr. 12 & 2,400 & 12.10 & 1971 & Mar. 09 & 6,160 & 15.20 \\
\hline 1944 & Apr. 23 & 8,620 & 16.00 & 1958 & Apr. 16 & 4,360 & 13.60 & 1972 & Jan. 18 & 3,970 & 13.64 \\
\hline 1945 & July 22 & 2,920 & 12.50 & 1959 & Mar. 10 & 5,620 & 14.40 & 1973 & Apr. 05 & 6,290 & 15.27 \\
\hline 1946 & Jan. 23 & 3,040 & 12.60 & 1960 & Apr. 08 & 8,860 & 16.60 & 1974 & Apr. 08 & 3,850 & 13.44 \\
\hline 1947 & Apr. 21 & 6,160 & 14.70 & 1961 & Apr. 18 & 7,060 & 15.70 & 1975 & Apr. 20 & 6,750 & 15.53 \\
\hline 1948 & Apr. 04 & 12,700 & 17.80 & 1962 & Apr. 06 & 1,920 & 11.50 & $\underline{1976}$ & May 24 & 3,790 & 13.49 \\
\hline 1949 & Dec. 15 & 3,520 & 13.00 & 1963 & June 28 & 2,440 & 12.20 & $\overline{1984}$ & Mar. 11 & 5370 & $14.69 \mathrm{c}$ \\
\hline 1950 & Mar. 22 & 1,130 & 9.90 & 1964 & Mar. 08 & 7,800 & 15.90 & $\overline{1986}$ & Feb. 12 & 8,530 & $16.45 c$ \\
\hline
\end{tabular}


LOCATION.-Lat $31^{\circ} 30^{\prime} 06^{\prime \prime}$, long $83^{\circ} 09^{\prime} 43^{\prime \prime}$, Irwin County, at State Highway 90, 8 mi southeast of Ocilla.

DRAINAGE AREA.--90 $\mathrm{mi}^{2}$, approximately.

GAGE.--Crest-stage gage. Datum of gage is $235.8 \mathrm{ft}$ above sea level (levels from U.S. Geological Survey benchmark).

STAGE-DISCHARGE RELATION.--Defined by current-meter measurements below $2,800 \mathrm{ft}^{3} / \mathrm{s}$, and extended above on the basis of slope-conveyance studies. Bankfull stage and discharge, $6 \mathrm{ft}$ and $500 \mathrm{ft}^{3} / \mathrm{s}$.

HISTORICAL DATA.--Flood stage of 1948 based on information furnished by local resident. The 1948 flood is flood is thought to have been the highest since at least 1928, based on information from nearby stations. Peak discharge for 1948 is an estimate.

\begin{tabular}{|c|c|c|c|c|c|c|c|c|c|c|c|}
\hline $\begin{array}{l}\text { Water } \\
\text { year }\end{array}$ & Date & $\begin{array}{c}\text { Discharge } \\
\left(\mathrm{ft}^{3} / \mathrm{s}\right)\end{array}$ & $\begin{array}{c}\text { Gage } \\
\text { height } \\
\text { (ft) }\end{array}$ & $\begin{array}{l}\text { Water } \\
\text { year }\end{array}$ & Date & $\begin{array}{c}\text { Discharge } \\
\left(\mathrm{ft}^{3} / \mathrm{s}\right)\end{array}$ & $\begin{array}{c}\text { Gage } \\
\text { height } \\
\text { (ft) }\end{array}$ & $\begin{array}{c}\text { Water } \\
\text { year }\end{array}$ & Date & $\begin{array}{c}\text { Discharge } \\
\left(\mathrm{ft}^{3} / \mathrm{s}\right)\end{array}$ & $\begin{array}{c}\text { Gage } \\
\text { height } \\
\text { (ft) }\end{array}$ \\
\hline$\underline{1948}$ & Apr. -- & 7,000 & $11.90 \mathrm{c}$ & 1960 & Apr. 04 & 2,300 & 7.98 & 1970 & Aug. 28 & 3,010 & 8.71 \\
\hline$\overline{1950}$ & Mar. 15 & 295 & 5.46 & 1961 & Apr. 16 & 3,290 & 8.99 & 1971 & Mar. 05 & 1,000 & 6.70 \\
\hline 1951 & Mar. - & 770 & 6.51 & 1962 & Apr. 01 & 830 & 6.28 & 1972 & Feb. 04 & 1,810 & 7.43 \\
\hline 1952 & Mar. 26 & 710 & 6.35 & 1963 & June 24 & 950 & 6.46 & 1973 & Apr. 02 & 2,780 & 8.48 \\
\hline 1953 & Sept. 29 & 910 & 6.45 & 1964 & Mar. 08 & 2,010 & 7.61 & 1974 & Feb. 19 & 966 & 6.47 \\
\hline 1954 & Jan. 01 & 485 & 5.78 & 1965 & Feb. 20 & 1,190 & 6.75 & 1975 & Apr. 16 & 1,760 & 7.39 \\
\hline 1955 & Apr. 19 & 485 & 5.83 & 1966 & Mar. 05 & 2,300 & 7.99 & 1976 & May 16 & 910 & 6.40 \\
\hline 1956 & Feb. 21 & 550 & 5.87 & 1967 & Jan. 04 & 2,260 & 7.79 & $\underline{1977}$ & Mar. 15 & 1,440 & 7.05 \\
\hline 1957 & Apr. 12 & 485 & 5.78 & 1968 & Mar. 12 & 330 & 5.52 & $\underline{1984}$ & Mar. 07 & 1,970 & $7.64 c$ \\
\hline 1958 & Apr. 10 & 760 & 6.20 & 1969 & Sept. 22 & 1,370 & 6.98 & 1986 & Feb. 12 & 3,740 & $9.40 \mathrm{c}$ \\
\hline 1959 & Mar. 07 & 2,270 & 7.83 & & & & & & & & \\
\hline
\end{tabular}

\section{LITTLE BRUSHY CREEK NEAR OCILLA, GEORGIA}

LOCATION.-Lat $31^{\circ} 36^{\prime} 30^{\prime \prime}$, long $83^{\circ} 13^{\prime} 56^{\prime \prime}$, Irwin County, at culvert on secondary road 1533, 1.2 mi northeast of Ocilla.

DRAINAGE AREA.-1.65 $\mathrm{mi}^{2}$.

GAGE.--Flood-stage recorder prior to Nov. 28, 1967; flood-stage/rainfall recorder thereafter. Datum of gage is about $303 \mathrm{ft}$ above sea level (from topographic map).

STAGE-DISCHARGE RELATION.--Defined by current-meter measurements below $139 \mathrm{ft}^{3} / \mathrm{s}$, and extended above on the basis of culvert computations.

\begin{tabular}{lccccccccccc}
\hline $\begin{array}{l}\text { Water } \\
\text { year }\end{array}$ & Date & $\begin{array}{c}\text { Discharge } \\
\left(\mathrm{ft}^{3} / \mathrm{s}\right)\end{array}$ & $\begin{array}{c}\text { Gage } \\
\text { height } \\
(\mathrm{ft})\end{array}$ & $\begin{array}{c}\text { Water } \\
\text { year }\end{array}$ & Date & $\begin{array}{c}\text { Discharge } \\
\left(\mathrm{ft}^{3} / \mathrm{s}\right)\end{array}$ & $\begin{array}{c}\text { Gage } \\
\text { height } \\
(\mathrm{ft})\end{array}$ & $\begin{array}{c}\text { Water } \\
\text { year }\end{array}$ & $\begin{array}{c}\text { Gage } \\
\text { Date }\end{array}$ & $\begin{array}{c}\text { Discharge } \\
\left(\mathrm{ft}^{3} / \mathrm{s}\right)\end{array}$ & $\begin{array}{c}\text { height } \\
(\mathrm{ft})\end{array}$ \\
\hline & & & & & & & & & & & \\
1966 & Feb. 28 & 88.0 & 2.25 & 1970 & Mar. 21 & 122 & 2.57 & 1974 & Apr. 05 & 61 & 1.79 \\
1967 & Aug. 11 & 76.0 & 2.15 & 1971 & Apr. 30 & 43 & 1.59 & $\underline{1975}$ & Apr. 10 & 90 & 2.10 \\
1968 & Dec. 11 & 20.0 & 1.35 & 1972 & Jan. 13 & 63 & 1.89 & 1986 & Feb. 10 & 258 & $3.85 \mathrm{c}$ \\
1969 & Sept. 21 & 33.0 & 1.72 & 1973 & Apr. 01 & 188 & 3.12 & & & \\
\hline
\end{tabular}




\section{SUWANNEE RIVER BASIN}

02316260 ALAPAHA RIVER TRIBUTARY NO. 4, NEAR WILLACOOCHEE, GEORGIA

LOCATION.--Lat $31^{\circ} 16^{\prime} 50^{\prime \prime}$, long $83^{\circ} 03^{\prime} 45^{\prime \prime}$, Berrien County, at culvert on State Highway $135,4.5$ mi south of Willacoochee. DRAINAGE AREA. $-4.16 \mathrm{mi}^{2}$.

GAGE,--Flood-stage/rainfall recorder. Datum of gage is about $217 \mathrm{ft}$ above sea level (from topographic map).

STAGE-DISCHARGE RELATION.--Defined by current-meter measurements below $330 \mathrm{ft}^{3} / \mathrm{s}$, and extended above on the basis of culvert computations.

\begin{tabular}{|c|c|c|c|c|c|c|c|c|c|c|c|}
\hline $\begin{array}{l}\text { Water } \\
\text { year }\end{array}$ & Date & $\begin{array}{c}\text { Discharge } \\
\left(\mathrm{ft}^{3} / \mathrm{s}\right)\end{array}$ & $\begin{array}{c}\text { Gage } \\
\text { height } \\
\text { (ft) }\end{array}$ & $\begin{array}{l}\text { Water } \\
\text { year }\end{array}$ & Date & $\begin{array}{c}\text { Discharge } \\
\left(\mathrm{ft}^{3} / \mathrm{s}\right)\end{array}$ & $\begin{array}{c}\text { Gage } \\
\text { height } \\
\text { (ft) }\end{array}$ & $\begin{array}{l}\text { Water } \\
\text { year }\end{array}$ & Date & $\begin{array}{c}\text { Discharge } \\
\left(\mathrm{ft}^{3} / \mathrm{s}\right)\end{array}$ & $\begin{array}{c}\text { Gage } \\
\text { height } \\
\text { (ft) }\end{array}$ \\
\hline 1965 & Dec. 04 & 1,000 & 8.61 & 1969 & Sept. 21 & 83 & 3.75 & 1973 & Apr. 26 & 223 & 5.02 \\
\hline 1966 & May 26 & 212 & 4.90 & 1970 & Mar. 28 & 147 & 4.40 & 1974 & Sept. 08 & 163 & 4.62 \\
\hline 1967 & Jan. 01 & 135 & 4.30 & 1971 & July 31 & 210 & 4.93 & 1975 & Apr. 10 & 186 & 4.77 \\
\hline 1968 & Sept. 00 & 10 & $--b$ & 1972 & Mar. 03 & 113 & 4.23 & & & & \\
\hline
\end{tabular}

\section{ALAPAHA RIVER AT LAKELAND, GEORGIA}

LOCATION.--Lat $31^{\circ} 02^{\prime} 46^{\prime \prime}$, long $83^{\circ} 02^{\prime} 37^{\prime \prime}$, Lanier County, on State Highway 37,1 mi east of Lakeland.

DRAINAGE AREA.--1,080 $\mathrm{mi}^{2}$.

GAGE.--Crest-stage gage. Datum of gage is $104.88 \mathrm{ft}$ above sea level (levels from the Federal Emergency Management Agency,

Flood Insurance Study).

STAGE-DISCHARGE RELATION.--Defined by current-meter measurements below $16,700 \mathrm{ft}^{3} / \mathrm{s}$, and extended above on the basis of straight-line extension.

REMARKS.--Peak discharges for 1981 and 1985 are estimated.

\begin{tabular}{lccccccccccc}
\hline $\begin{array}{l}\text { Water } \\
\text { year }\end{array}$ & Date & $\begin{array}{c}\text { Discharge } \\
\left(\mathrm{ft}^{3} / \mathrm{s}\right)\end{array}$ & $\begin{array}{c}\text { Gage } \\
\text { height } \\
(\mathrm{ft})\end{array}$ & $\begin{array}{c}\text { Water } \\
\text { year }\end{array}$ & Date & $\begin{array}{c}\text { Discharge } \\
\left(\mathrm{ft}^{3} / \mathrm{s}\right)\end{array}$ & $\begin{array}{c}\text { Gage } \\
\text { height } \\
(\mathrm{ft})\end{array}$ & $\begin{array}{c}\text { Water } \\
\text { year }\end{array}$ & $\begin{array}{c}\text { Gage } \\
\text { Date }\end{array}$ & $\begin{array}{c}\text { Discharge } \\
\left(\mathrm{ft}^{3} / \mathrm{s}\right)\end{array}$ & $\begin{array}{c}\text { height } \\
(\mathrm{ft})\end{array}$ \\
\hline & & & & & & & & & & & \\
1970 & Apr. 08 & 7,140 & 18.47 & 1976 & May 27 & 6,220 & 18.01 & 1982 & Feb. 20 & 4,420 & 16.62 \\
1971 & Mar. 11 & 5,780 & 17.75 & 1977 & Mar. 01 & 6,800 & 18.30 & 1983 & Mar. 17 & 7,080 & 18.44 \\
1972 & Jan. 21 & 5,440 & 17.53 & 1978 & Feb. 07 & 6,660 & 18.23 & 1984 & Mar. 10 & 10,900 & 19.43 \\
1973 & Apr. 08 & 10,300 & 19.33 & 1979 & Mar. 05 & 7,580 & 18.65 & 1985 & Aug. 03 & 1,700 & - \\
1974 & Apr. 09 & 4,900 & 17.08 & 1980 & Mar. 20 & 7,950 & 18.85 & 1986 & Feb. 15 & 20,500 & 20.50 \\
1975 & Apr. 22 & 7,140 & 18.47 & 1981 & Feb. 12 & 1,000 & - & 1987 & Jan. 30 & 8,780 & 19.02 \\
\end{tabular}




\section{SUWANNEE RIVER BASIN}

\section{ALAPAHA RIVER AT STATENVILLE, GEORGIA}

LOCATION.--Lat $30^{\circ} 42^{\prime} 14^{\prime \prime}$, long $83^{\circ} 02^{\prime} 00^{\prime \prime}$, Echols County, at downstream side of left bank pier of bridge on State Highway $94,0.2$ mi west of Statenville.

DRAINAGE AREA. $-1,400 \mathrm{mi}^{2}$, approximately.

GAGE.-Water-stage recorder. Datum of gage is $76.77 \mathrm{ft}$ above sea level (levels by the Georgia Department of Transportation).

Dec. 10,1931, to Nov. 30,1949 , nonrecording gage is site 200 upstream at present datum, and Dec. 1, 1949, to Nov. 22,1952 , nonrcording gage at present site and datum.

STAGE-DISCHARGE RELATION.--Defined by current-meter measurements below $25,000 \mathrm{ft}^{3} / \mathrm{s}$. Bankfull stage and discharge, $24 \mathrm{ft}$ and $6,500 \mathrm{ft}^{3} / \mathrm{s}$.

HISTORICAL DATA.--The flood of April 1948 was the highest since 1862, from information furnished in 1948 by a local resident. Local residents also stated in 1946 that the flood of May 1928 was the highest since 1900 . Flood stage of 1928 based on information furnished by local resident.

REMARKS.--Peak discharges for 1929-31 estimated from records obtained by Mayday, Ga., 11 mi upstream where the drainage area is $1,300 \mathrm{mi}^{2}$.

\begin{tabular}{|c|c|c|c|c|c|c|c|c|c|c|c|}
\hline $\begin{array}{l}\text { Water } \\
\text { year }\end{array}$ & Date & $\begin{array}{c}\text { Discharge } \\
\left(\mathrm{ft}^{3} / \mathrm{s}\right)\end{array}$ & $\begin{array}{c}\text { Gage } \\
\text { height } \\
\text { (ft) }\end{array}$ & $\begin{array}{l}\text { Water } \\
\text { year }\end{array}$ & Date & $\begin{array}{c}\text { Discharge } \\
\left(\mathrm{ft}^{3} / \mathrm{s}\right)\end{array}$ & $\begin{array}{l}\text { Gage } \\
\text { height } \\
\text { (ft) }\end{array}$ & $\begin{array}{l}\text { Water } \\
\text { year }\end{array}$ & Date & $\begin{array}{c}\text { Discharge } \\
\left(\mathrm{ft}^{3} / \mathrm{s}\right)\end{array}$ & $\begin{array}{c}\text { Gage } \\
\text { height } \\
\text { (ft) }\end{array}$ \\
\hline 1928 & May 01 & 18,400 & 28.50 & 1949 & Dec. 10 & $\underline{4,980}$ & 19.50 & 1970 & Apr. 13 & 7,800 & 25.10 \\
\hline 1929 & Mar. 22 & 14,200 & - & 1950 & $\overline{\text { Apr. } 05}$ & $\overline{1,740}$ & 8.70 & 1971 & Mar. 18 & 5,480 & 20.94 \\
\hline 1930 & Oct. 09 & 5,630 & - & 1951 & Apr. 05 & 3,480 & 14.90 & 1972 & Feb. 15 & 6,190 & 22.96 \\
\hline 1931 & May 19 & 3,370 & - & 1952 & Mar. 13 & 3,360 & 14.50 & 1973 & Apr. 11 & 13,500 & 27.42 \\
\hline 1932 & Aug. 30 & 2,740 & 11.60 & 1953 & Sept. 30 & 4,100 & 16.90 & 1974 & Sept. 11 & 4,670 & 18.63 \\
\hline 1933 & Feb. 22 & 6,140 & 21.82 & 1954 & Jan. 09 & 4,010 & 16.60 & 1975 & Apr. 26 & 8,720 & 25.66 \\
\hline 1934 & June 04 & 2,420 & 10.80 & 1955 & Apr. 23 & 1,320 & 7.10 & 1976 & June 02 & 6,440 & 23.60 \\
\hline 1935 & Sept. 06 & 3,440 & 14.60 & 1956 & May 08 & 4,450 & 19.70 & 1977 & Mar. 18 & 7,500 & 24.90 \\
\hline 1936 & Feb. 19 & 4,900 & 18.50 & 1957 & June 14 & 2,940 & 13.10 & 1978 & Feb. 09 & 6,600 & 24.01 \\
\hline 1937 & Apr. 14 & 6,560 & 22.80 & 1958 & Apr. 22 & 7,950 & 25.20 & 1979 & Mar. 09 & 8,540 & 25.57 \\
\hline 1938 & Sept. 30 & 1,130 & 6.40 & 1959 & Màr. 17 & 10,000 & 26.30 & 1980 & Mar. 22 & 9,480 & 26.04 \\
\hline 1939 & Mar. 09 & 10,500 & 26.40 & 1960 & Apr. 11 & 15,000 & 27.80 & 1981 & Apr. 03 & 1,050 & 5.87 \\
\hline 1940 & Feb. 28 & 2,630 & 11.70 & 1961 & Apr. 24 & 12,000 & 27.00 & 1982 & Feb. 23 & 4,460 & 17.83 \\
\hline 1941 & Mar. 21 & 1,910 & 9.40 & 1962 & Apr. 11 & 3,790 & 15.90 & 1983 & Mar. 18 & 9,190 & 25.89 \\
\hline 1942 & Mar. 23 & 6,370 & 22.30 & 1963 & Feb. 26 & 2,380 & 11.10 & 1984 & Mar. 10 & 12,700 & 27.61 \\
\hline 1943 & Apr. 04 & 2,700 & 12.20 & 1964 & Mar. 09 & 10,200 & 26.40 & 1985 & Aug. 03 & 2,010 & 9.49 \\
\hline 1944 & Apr. 27 & 11,100 & 26.80 & 1965 & Mar. 02 & 9,600 & 26.10 & 1986 & Feb. 17 & 18,900 & 28.58 \\
\hline 1945 & Aug. 25 & 6,630 & 22.80 & 1966 & Mar. 14 & 12,300 & 27.10 & 1987 & Feb. 01 & 10,900 & 26.60 \\
\hline 1946 & Jan. 30 & 4,160 & 17.20 & 1967 & Jan. 17 & 6,420 & 23.55 & 1988 & Mar. 07 & 4,770 & 18.79 \\
\hline 1947 & Apr. 28 & 5,990 & 22.40 & 1968 & Mar. 20 & 1,000 & 5.86 & 1989 & July 06 & 1,830 & 8.84 \\
\hline 1948 & Apr. 06 & 27,300 & 29.80 & 1969 & Sept. 03 & 2,690 & 12.20 & 1990 & Jan. 21 & 6,880 & 24.42 \\
\hline
\end{tabular}

\section{LITTLE RIVER NEAR STATENVILLE, GEORGIA}

LOCATION.--Lat $30^{\circ} 42^{\prime} 13^{\prime \prime}$, long $83^{\circ} 07^{\prime} 18^{\prime \prime}$, Echols County, at bridge on State Highway 376, 5.5 mi west of Statenville. DRAINAGE AREA.-199 $\mathrm{mi}^{2}$.

GAGE.--Crest-stage gage. Datum of gage is about $85 \mathrm{ft}$ above sea level (from topographic map).

STAGE-DISCHARGE RELATION.--Defined by current-meter measurements below $8,000 \mathrm{ft}^{3} / \mathrm{s}$, and extended above on the basis of straight-line extension.

\begin{tabular}{|c|c|c|c|c|c|c|c|c|c|c|c|}
\hline $\begin{array}{l}\text { Water } \\
\text { year }\end{array}$ & Date & $\begin{array}{c}\text { Discharge } \\
\left(\mathrm{ft}^{3} / \mathrm{s}\right)\end{array}$ & $\begin{array}{c}\text { Gage } \\
\text { height } \\
\text { (ft) }\end{array}$ & $\begin{array}{c}\text { Water } \\
\text { year }\end{array}$ & Date & $\begin{array}{c}\text { Discharge } \\
\left(\mathrm{ft}^{3} / \mathrm{s}\right)\end{array}$ & $\begin{array}{c}\text { Gage } \\
\text { height } \\
\text { (ft) }\end{array}$ & $\begin{array}{l}\text { Water } \\
\text { year }\end{array}$ & Date & $\begin{array}{c}\text { Discharge } \\
\left(\mathrm{ft}^{3} / \mathrm{s}\right)\end{array}$ & $\begin{array}{c}\text { Gage } \\
\text { height } \\
\text { (ft) }\end{array}$ \\
\hline 1984 & Mar. 28 & 11,000 & 17.36 & 1987 & Jan. 12 & 2,990 & 11.99 & 1989 & June 21 & 472 & 9.64 \\
\hline 1985 & Aug. 03 & 1,260 & 11.07 & 1988 & Mar. 20 & 3,520 & 13.32 & 1990 & Jan. 10 & 870 & 10.45 \\
\hline 1986 & Feb. 12 & 3,250 & 13.21 & & & & & & & & \\
\hline
\end{tabular}


LOCATION.-Lat $31^{\circ} 11^{\prime} 54^{\prime \prime}$ long $83^{\circ} 16^{\prime} 21^{\prime \prime}$, Berrien County, at State Highway 76, 1.5 mi southwest of Nashville.

DRAINAGE AREA.-132 $\mathrm{mi}^{2}$.

GAGE.-Crest-stage gage. Datum of gage is $182.9 \mathrm{ft}$ above sea level (levels from the Georgia Department of Transportation), supplementary adjustment of 1936.

STAGE-DISCHARGE RELATION.--Defined by current-meter measurements below $4,700 \mathrm{tt}^{3} / \mathrm{s}$, and extended above on the basis of slope-conveyance studies. Bankfull stage and discharge, $8 \mathrm{ft}$ and $600 \mathrm{ft}^{3} / \mathrm{s}$.

HISTORICAL DATA.--Flood stage of April 1948 based on information furnished by the Georgia Department of Transportation, and is thought to be the highest since 1928 , based on information at nearby stations.

REMARKS.--Peak discharge for 1948 is estimated.

\begin{tabular}{|c|c|c|c|c|c|c|c|c|c|c|c|}
\hline $\begin{array}{l}\text { Water } \\
\text { year }\end{array}$ & Date & $\begin{array}{c}\text { Discharge } \\
\left(\mathrm{ft}^{3} / \mathrm{s}\right)\end{array}$ & $\begin{array}{c}\text { Gage } \\
\text { height } \\
\text { (ft) }\end{array}$ & $\begin{array}{l}\text { Water } \\
\text { year }\end{array}$ & Date & $\begin{array}{c}\text { Discharge } \\
\left(\mathrm{ft}^{3} / \mathrm{s}\right)\end{array}$ & $\begin{array}{c}\text { Gage } \\
\text { height } \\
\text { (ft) }\end{array}$ & $\begin{array}{l}\text { Water } \\
\text { year }\end{array}$ & Date & $\begin{array}{c}\text { Discharge } \\
\left(\mathrm{ft}^{3} / \mathrm{s}\right)\end{array}$ & $\begin{array}{c}\text { Gage } \\
\text { height } \\
\text { (ft) }\end{array}$ \\
\hline 1948 & Apr. 02 & 8,500 & $14.80 c$ & 1960 & Apr. 05 & 3,460 & 10.82 & 1970 & June 02 & 2,580 & 10.06 \\
\hline$\overline{1951}$ & Apr. 01 & 1,260 & 9.03 & 1961 & Apr. 16 & 3,850 & 11.10 & 1971 & Sept. 01 & 2,030 & 9.66 \\
\hline 1952 & Feb. 18 & 580 & 7.87 & 1962 & Apr. 01 & 1,460 & 9.18 & 1972 & Feb. 07 & 1,960 & 9.61 \\
\hline 1953 & Sept. 30 & 2,500 & 9.98 & 1963 & June 24 & 390 & 7.41 & 1973 & Feb. 10 & 2,160 & 9.75 \\
\hline 1954 & Dec. 27 & 620 & 8.05 & 1964 & Mar. 04 & 3,980 & 11.15 & 1974 & Feb. 20 & 964 & 8.68 \\
\hline 1955 & Apr. 15 & 365 & 7.33 & 1965 & Dec. 05 & 4,830 & 11.86 & 1975 & Apr. 12 & 3,380 & 10.55 \\
\hline 1956 & May 08 & 1,900 & 9.55 & 1966 & Mar. 04 & 1,990 & 9.63 & 1976 & May 25 & 2,230 & 9.80 \\
\hline 1957 & June 11 & 830 & 8.37 & 1967 & Jan. 05 & 2,500 & 10.00 & $\underline{1977}$ & Nov. 30 & 1,740 & 9.44 \\
\hline 1958 & Mar. 14 & 1,780 & 9.53 & 1968 & Mar. 12 & 481 & 7.77 & $\overline{1984}$ & Mar. 07 & 5,500 & $12.36 c$ \\
\hline 1959 & Mar. 08 & 4,350 & 11.51 & 1969 & Aug. 22 & 1,420 & 9.18 & $\overline{1986}$ & Feb. 12 & $5,4,50$ & $12.31 \mathrm{c}$ \\
\hline
\end{tabular}

\section{WITHLACOOCHEE RIVER TRIBUTARY NEAR NASHVILLE, GEORGIA}

LOCATION.-Lat $31^{\circ} 11^{\prime} 54^{\prime \prime}$, long $83^{\circ} 17^{\prime} 17^{\prime \prime}$, Berrien County, at culvert on State Highway 76, 2.2 mi southwest of Nashville.

DRAINAGE AREA.--0.86 $\mathrm{mi}^{2}$.

GAGE.--Crest-stage gage prior to July 8, 1965; flood-stage/rainfall recorder July 8, 1965 to 1975, crest-stage gage thereafter.

Datum of gage is about $200 \mathrm{ft}$ above sea level (from topographic map).

STAGE-DISCHARGE RELATION.--Defined by current-meter measurements below $124 \mathrm{ft}^{3} / \mathrm{s}$, and extended above on the basis of culvert and flow-over-roadway computations.

\begin{tabular}{|c|c|c|c|c|c|c|c|c|c|c|c|}
\hline $\begin{array}{l}\text { Water } \\
\text { year }\end{array}$ & Date & $\begin{array}{c}\text { Discharge } \\
\left(\mathrm{ft}^{3} / \mathrm{s}\right)\end{array}$ & $\begin{array}{c}\text { Gage } \\
\text { height } \\
\text { (ft) }\end{array}$ & $\begin{array}{l}\text { Water } \\
\text { year }\end{array}$ & Date & $\begin{array}{c}\text { Discharge } \\
\left(\mathrm{ft}^{3} / \mathrm{s}\right)\end{array}$ & $\begin{array}{c}\text { Gage } \\
\text { height } \\
\text { (ft) }\end{array}$ & $\begin{array}{l}\text { Water } \\
\text { year }\end{array}$ & Date & $\begin{array}{l}\text { Discharge } \\
\left(\mathrm{ft}^{3} / \mathrm{s}\right)\end{array}$ & $\begin{array}{c}\text { Gage } \\
\text { height } \\
\text { (ft) }\end{array}$ \\
\hline 1960 & Apr. 05 & 65 & 2.74 & 1970 & Aug. 10 & 49 & 2.33 & 1979 & Feb. 24 & 134 & 4.19 \\
\hline 1961 & Apr. 15 & 155 & 4.62 & 1971 & Aug. 29 & 161 & 4.68 & 1980 & Mar. 13 & 66 & 2.75 \\
\hline 1962 & Apr. 01 & 17 & 1.42 & 1972 & Feb. 07 & 38 & 2.06 & 1981 & Feb. 12 & 15 & $-b$ \\
\hline 1963 & Jan. 21 & 17 & 1.42 & 1973 & July 28 & 86 & 3.23 & 1982 & Apr. 25 & 34 & 1.94 \\
\hline 1964 & Mar. 03 & 32 & 1.87 & 1974 & Jan. 01 & 104 & 3.61 & 1983 & Mar. 06 & 138 & 4.27 \\
\hline 1965 & Dec. 04 & 385 & 7.80 & 1975 & Apr. 10 & 174 & 4.92 & 1984 & Mar. 06 & 191 & 5.20 \\
\hline 1966 & Mar. 04 & 74 & 2.95 & 1976 & May 23 & 134 & 4.19 & 1985 & Aug. 28 & 13 & 1.22 \\
\hline 1967 & Oct. 10 & 29 & 1.78 & 1977 & Nov. 29 & 106 & 3.64 & 1986 & Feb. 11 & 210 & 5.59 \\
\hline 1968 & Mar. -- & 15 & $--b$ & 1978 & Jan. 19 & 56 & 2.49 & 1987 & Dec. 11 & 92.0 & 3.34 \\
\hline 1969 & Mar. 18 & 23 & 1.61 & & & & & & & & \\
\hline
\end{tabular}


LOCATION.--Lat $31^{\circ} 17^{\prime} 18^{\prime \prime}$, long $83^{\circ} 20^{\prime} 36^{\prime \prime}$, Berrien County, at culvert on State Highway 125,9 mi northwest of Nashville. DRAINAGE AREA. $-0.95 \mathrm{mi}^{2}$.

GAGE.-Crest-stage gage prior to July 8, 1965; flood-stage/rainfall recorder thereafter. Datum of gage is about $235 \mathrm{ft}$ above sea level (from topographic map).

STAGE-DISCHARGE RELATION.--Defined by current-meter measurements below $204 \mathrm{ft}^{3} / \mathrm{s}$, and extended above on the basis of culvert computations.

\begin{tabular}{|c|c|c|c|c|c|c|c|c|c|c|c|}
\hline $\begin{array}{l}\text { Water } \\
\text { year }\end{array}$ & Date & $\begin{array}{c}\text { Discharge } \\
\left(\mathrm{ft}^{3} / \mathrm{s}\right)\end{array}$ & $\begin{array}{c}\text { Gage } \\
\text { height } \\
\text { (ft) }\end{array}$ & $\begin{array}{l}\text { Water } \\
\text { year }\end{array}$ & Date & $\begin{array}{c}\text { Discharge } \\
\left(\mathrm{ft}^{3} / \mathrm{s}\right)\end{array}$ & $\begin{array}{c}\text { Gage } \\
\text { height } \\
\text { (ft) }\end{array}$ & $\begin{array}{l}\text { Water } \\
\text { year }\end{array}$ & Date & $\begin{array}{c}\text { Discharge } \\
\left(\mathrm{ft}^{3} / \mathrm{s}\right)\end{array}$ & $\begin{array}{c}\text { Gage } \\
\text { height } \\
\text { (ft) }\end{array}$ \\
\hline 1960 & Apr. 05 & 108 & 1.98 & 1966 & Mar. 04 & 88 & 1.76 & 1972 & Jan. 13 & 73 & 1.57 \\
\hline 1961 & Apr. 15 & 116 & 2.07 & 1967 & Jan. 01 & 49 & 1.26 & 1973 & Feb. 10 & 103 & 1.93 \\
\hline 1962 & Apr. 01 & 50 & 1.27 & 1968 & Mar. - & 36 & $-b$ & 1974 & Sept. 08 & 79 & 1.65 \\
\hline 1963 & June 24 & 54 & 1.33 & 1969 & Mar. 18 & 48 & 1.25 & $\underline{1975}$ & Apr. 10 & 173 & 2.65 \\
\hline 1964 & May 02 & 103 & 1.93 & 1970 & Aug. 10 & 158 & 2.50 & $\overline{1984}$ & Mar. 06 & 180 & $2.72 c$ \\
\hline 1965 & Dec. 04 & 250 & 3.32 & 1971 & Apr. 30 & 68 & 1.51 & $\overline{1986}$ & Feb. 11 & 95 & $1.84 c$ \\
\hline
\end{tabular}

\section{NEW RVER NEAR NASHVILLE, GEORGIA}

LOCATION.--Lat $31^{\circ} 10^{\prime} 37^{\prime \prime}$ long 83'19'20", Berrien-Cook County line, at State Highway 76, 5 mi west of Nashville. DRAINAGE AREA. $-146 \mathrm{mi}^{2}$.

GAGE.--Crest-stage gage. Datum of gage is $175.60 \mathrm{ft}$ above sea level (levels from the Georgia Department of Transportation). STAGE-DISCHARGE RELATION.--Defined by current-meter measurements below $6,340 \mathrm{ft}^{3} / \mathrm{s}$.

\begin{tabular}{|c|c|c|c|c|c|c|c|c|c|c|c|}
\hline $\begin{array}{l}\text { Water } \\
\text { year }\end{array}$ & Date & $\begin{array}{c}\text { Discharge } \\
\left(\mathrm{ft}^{3} / \mathrm{s}\right)\end{array}$ & $\begin{array}{c}\text { Gage } \\
\text { height } \\
\text { (ft) }\end{array}$ & $\begin{array}{l}\text { Water } \\
\text { year }\end{array}$ & Date & $\begin{array}{c}\text { Discharge } \\
\left(\mathrm{ft}^{3} / \mathrm{s}\right)\end{array}$ & $\begin{array}{c}\text { Gage } \\
\text { height } \\
\text { (ft) }\end{array}$ & $\begin{array}{l}\text { Water } \\
\text { year }\end{array}$ & Date & $\begin{array}{c}\text { Discharge } \\
\left(\mathrm{ft}^{3} / \mathrm{s}\right)\end{array}$ & $\begin{array}{c}\text { Gage } \\
\text { height } \\
\text { (ft) }\end{array}$ \\
\hline 1970 & Aug. 29 & 2,030 & 9.74 & 1976 & May 26 & 2,850 & 10.59 & 1982 & Feb. 18 & 1,150 & 8.74 \\
\hline 1971 & May 02 & 2,250 & 9.99 & 1977 & Nov. 30 & 2,040 & 9.76 & 1983 & Mar. 15 & 2,930 & 10.67 \\
\hline 1972 & Feb. 07 & 2,210 & 9.94 & 1978 & Mar. 13 & 1,260 & 8.87 & 1984 & Mar. 07 & 6,350 & 12.50 \\
\hline 1973 & Apr. 28 & 2,800 & 10.54 & 1979 & Feb. 24 & 4,350 & 11.77 & 1985 & Aug. 29 & 1,150 & 8.74 \\
\hline 1974 & Apr. 06 & 1,100 & 8.68 & 1980 & Mar. 13 & 3,570 & 11.26 & 1986 & Feb. 12 & 5,880 & 12.38 \\
\hline 1975 & Jan. 13 & 3,800 & 11.43 & 1981 & Apr. -- & 700 & $--b$ & 1987 & Apr. 01 & 2,220 & 9.96 \\
\hline
\end{tabular}


LOCATION.--Lat $30^{\circ} 57^{\prime} 24^{\prime \prime}$, long $83^{\circ} 16^{\prime} 12^{\prime \prime}$, Lowndes County, on downstream side of county bridge on Skipper Bridge Road, 1.9 mi downstream from Cat Creek, and 3.0 mi northwest of Bemiss.

DRAINAGE AREA.--501 $\mathrm{mi}^{2}$, approximately.

GAGE.-Water-stage recorder. Datum of gage is about $130 \mathrm{ft}$ above sea level (from topographic map).

STAGE-DISCHARGE RELATION.-Defined by current-meter measurements below $6,710 \mathrm{ft}^{3} / \mathrm{s}$, and extended above on the basis of rating curve extended above $6,710 \mathrm{ft}^{3} / \mathrm{s}$, and runoff comparison with nearby stations.

HISTORICAL DATA.--The flood of April 1948 was the highest since 1862 , based on information at nearby stations.

REMARKS.--Peak discharges for 1948, 1984, and 1986 estimated from information obtained at Withlacoochee River near Valdosta (02317755).

\begin{tabular}{|c|c|c|c|c|c|c|c|c|c|c|c|}
\hline $\begin{array}{l}\text { Water } \\
\text { year }\end{array}$ & Date & $\begin{array}{c}\text { Discharge } \\
\left(\mathrm{ft}^{3} / \mathrm{s}\right)\end{array}$ & $\begin{array}{c}\text { Gage } \\
\text { height } \\
\text { (ft) }\end{array}$ & $\begin{array}{l}\text { Water } \\
\text { year }\end{array}$ & Date & $\begin{array}{c}\text { Discharge } \\
\left(\mathrm{ft}^{3} / \mathrm{s}\right)\end{array}$ & $\begin{array}{c}\text { Gage } \\
\text { height } \\
\text { (ft) }\end{array}$ & $\begin{array}{l}\text { Water } \\
\text { year }\end{array}$ & Date & $\begin{array}{c}\text { Discharge } \\
\left(\mathrm{ft}^{3} / \mathrm{s}\right)\end{array}$ & $\begin{array}{c}\text { Gage } \\
\text { height } \\
\text { (ft) }\end{array}$ \\
\hline$\underline{1948}$ & Apr. 04 & 37,500 & $--c$ & 1979 & Feb. 26 & 11,500 & 22.24 & $\underline{1982}$ & Feb. 19 & 2,690 & 15.88 \\
\hline$\overline{1977}$ & Dec. 02 & 4,810 & 18.34 & 1980 & Mar. 15 & 7,080 & 19.85 & $\overline{1984}$ & Mar. 08 & 16,000 & $24.28 \mathrm{c}$ \\
\hline 1978 & Mar. 12 & 3,440 & 16.92 & 1981 & Apr. 03 & 1,170 & 11.41 & 1986 & Feb. 12 & 19,500 & $-c$ \\
\hline
\end{tabular}

\section{WITHLACOOCHEE RIVER NEAR VALDOSTA, GEORGIA}

LOCATION.--Lat $30^{\circ} 53^{\prime} 33^{\prime \prime}$, long $83^{\circ} 19^{\prime} 08^{\prime \prime}$, Lowndes County, on downstream side of bridge on U.S. Highway 41 and State Highway 7, 1.1 mi downstream from Cherry Creek, 4.0 mi upstream from Sugar Creek and 5.3 mi north of Valdosta. DRAINAGE AREA.--537 $\mathrm{mi}^{2}$, approximately.

GAGE.-Water-stage recorder. Datum of gage is about $110 \mathrm{ft}$ above sea level (from topographic map).

STAGE-DISCHARGE RELATION.--Defined by current-meter measurements below $6,370 \mathrm{ft}^{3} / \mathrm{s}$, and extended above on the basis of slope-conveyance and profile studies.

HISTORICAL DATA.--Flood stage of 1948 furnished by the Georgia Department of Transportation. The flood of 1948 is thought to be the highest since 1862 , based on information at nearby stations.

\begin{tabular}{|c|c|c|c|c|c|c|c|c|c|c|c|}
\hline $\begin{array}{l}\text { Water } \\
\text { year }\end{array}$ & Date & $\begin{array}{c}\text { Discharge } \\
\left(\mathrm{ft}^{3} / \mathrm{s}\right)\end{array}$ & $\begin{array}{c}\text { Gage } \\
\text { height } \\
\text { (ft) }\end{array}$ & $\begin{array}{l}\text { Water } \\
\text { year }\end{array}$ & Date & $\begin{array}{c}\text { Discharge } \\
\left(\mathrm{ft}^{3} / \mathrm{s}\right)\end{array}$ & $\begin{array}{c}\text { Gage } \\
\text { height } \\
\text { (ft) }\end{array}$ & $\begin{array}{l}\text { Water } \\
\text { year }\end{array}$ & Date & $\begin{array}{c}\text { Discharge } \\
\left(\mathrm{ft}^{3} / \mathrm{s}\right)\end{array}$ & $\begin{array}{c}\text { Gage } \\
\text { height } \\
\text { (ft) }\end{array}$ \\
\hline$\underline{1948}$ & Apr. 04 & 38,000 & $138.90 c$ & $\underline{1980}$ & Mar. 15 & 6,580 & 17.55 & 1989 & July 26 & 1,120 & 11.86 \\
\hline 1977 & Dec. 02 & 5,390 & 16.32 & $\underline{1984}$ & Mar. 08 & 16,000 & 22.11 & 1990 & Jan. 04 & 714 & 10.39 \\
\hline 1978 & Mar. 13 & 3,700 & 15.30 & $\overline{1986}$ & Feb. 12 & 19,500 & 28.00 & & & & \\
\hline
\end{tabular}

\section{LITTLE RVER NEAR ASHBURN, GEORGIA}

LOCATION.--Lat $31^{\circ} 41^{\prime} 33^{\prime \prime}$ long $83^{\circ} 42^{\prime} 16^{\prime \prime}$, Turner County, at culvert on State Highway 32, 3.2 mi west of Ashburn.

DRAINAGE AREA.--8.54 $\mathrm{mi}^{2}$.

GAGE.--Flood-stage/rainfall recorder. Datum of gage is about $350 \mathrm{ft}$ above sea level (from topographic map).

STAGE-DISCHARGE RELATION.--Defined by current-meter measurements below $461 \mathrm{ft}^{3} / \mathrm{s}$, and above on the basis of culvert computations.

\begin{tabular}{|c|c|c|c|c|c|c|c|c|c|c|c|}
\hline $\begin{array}{l}\text { Water } \\
\text { year }\end{array}$ & Date & $\begin{array}{c}\text { Discharge } \\
\left(\mathrm{ft}^{3} / \mathrm{s}\right)\end{array}$ & $\begin{array}{c}\text { Gage } \\
\text { height } \\
\text { (ft) }\end{array}$ & $\begin{array}{l}\text { Water } \\
\text { year }\end{array}$ & Date & $\begin{array}{c}\text { Discharge } \\
\left(\mathrm{ft}^{3} / \mathrm{s}\right)\end{array}$ & $\begin{array}{c}\text { Gage } \\
\text { height } \\
\text { (ft) }\end{array}$ & $\begin{array}{c}\text { Water } \\
\text { year }\end{array}$ & Date & $\begin{array}{c}\text { Discharge } \\
\left(\mathrm{ft}^{3} / \mathrm{s}\right)\end{array}$ & $\begin{array}{c}\text { Gage } \\
\text { height } \\
\text { (ft) }\end{array}$ \\
\hline 1965 & Feb. 17 & 197 & 4.12 & 1969 & May 19 & 456 & 4.51 & 1973 & Apr. 27 & 295 & 4.13 \\
\hline 1966 & Mar. 04 & 517 & 4.87 & 1970 & Mar. 31 & 608 & 4.74 & 1974 & Feb. 07 & 248 & 4.08 \\
\hline 1967 & Jan. 01 & 376 & 4.62 & 1971 & Mar. 03 & 780 & 4.99 & 1975 & Apr. 14 & 787 & 5.01 \\
\hline 1968 & Mar. 12 & 31 & 2.75 & 1972 & Mar. 31 & 190 & 3.95 & & & & \\
\hline
\end{tabular}


LOCATION.--Lat $31^{\circ} 44^{\prime} 20^{\prime \prime}$, long $83^{\circ} 43^{\prime} 30^{\prime \prime}$, Turner County, at culvert on secondary road $1531,3.2$ mi west of Worth. DRAINAGE AREA.--0.98 $\mathrm{mi}^{2}$.

GAGE.--Flood-stage/rainfall recorder prior to July 2, 1965; crest-stage gage July 2, 1965, to June 6, 1967; flood-stage/rainfall recorder thereafter. Datum of gage is about $405 \mathrm{ft}$ above sea level (from topographic map).

STAGE-DISCHARGE RELATION.-Defined by current-meter measurements below $225 \mathrm{ft}^{3} / \mathrm{s}$, and extended above on basis of culvert computations.

\begin{tabular}{|c|c|c|c|c|c|c|c|c|c|c|c|}
\hline $\begin{array}{l}\text { Water } \\
\text { year }\end{array}$ & Date & $\begin{array}{c}\text { Discharge } \\
\left(\mathrm{ft}^{3} / \mathrm{s}\right)\end{array}$ & $\begin{array}{c}\text { Gage } \\
\text { height } \\
\text { (ft) }\end{array}$ & $\begin{array}{l}\text { Water } \\
\text { year }\end{array}$ & Date & $\begin{array}{c}\text { Discharge } \\
\left(\mathrm{ft}^{3} / \mathrm{s}\right)\end{array}$ & $\begin{array}{c}\text { Gage } \\
\text { height } \\
\text { (ft) }\end{array}$ & $\begin{array}{l}\text { Water } \\
\text { year }\end{array}$ & Date & $\begin{array}{c}\text { Discharge } \\
\left(\mathrm{ft}^{3} / \mathrm{s}\right)\end{array}$ & $\begin{array}{c}\text { Gage } \\
\text { height } \\
\text { (ft) }\end{array}$ \\
\hline 1965 & Mar. 20 & 49.0 & 1.56 & 1969 & Aug. 04 & 218 & 3.71 & 1973 & June 28 & 86.0 & 2.46 \\
\hline 1966 & Mar. 04 & 59.0 & 1.72 & 1970 & Mar. 30 & 88 & 2.48 & 1974 & Mar. 29 & 55.0 & 2.01 \\
\hline 1967 & Jan. 10 & 54.0 & 1.65 & 1971 & Mar. 03 & 279 & 4.59 & 1975 & Apr. 10 & 112 & 2.82 \\
\hline 1968 & Mar. - & 30.0 & $-b$ & 1972 & Mar. 30 & 34 & 1.72 & & & & \\
\hline
\end{tabular}

\section{NEWELL BRANCH NEAR ASHBURN, GEORGIA}

LOCATION.-Lat $31^{\circ} 41^{\prime} 50^{\prime \prime}$, long $83^{\circ} 41^{\prime} 56^{\prime \prime}$, Turner County, at culvert on State Highway 32, 2.8 mi west of Ashburn.

DRAINAGE AREA.--6.48 $\mathrm{mi}^{2}$.

GAGE.-Flood-stage recorder prior to July 26, 1967; flood-stage/rainfall recorder after Sept. 13, 1967. Datum of gage is about 350 $f t$ above sea level (from topographic map).

STAGE-DISCHARGE RELATION.--Defined by current-meter measurements below $325 \mathrm{ft}^{3} / \mathrm{s}$, and extended above on basis of culvert computations.

\begin{tabular}{lcccccccccc}
\hline $\begin{array}{l}\text { Water } \\
\text { year }\end{array}$ & Date & $\begin{array}{c}\text { Discharge } \\
\left(\mathrm{ft}^{3} / \mathrm{s}\right)\end{array}$ & $\begin{array}{c}\text { Gage } \\
\text { height } \\
(\mathrm{ft})\end{array}$ & $\begin{array}{c}\text { Water } \\
\text { year }\end{array}$ & Date & $\begin{array}{c}\text { Discharge } \\
\left(\mathrm{ft}^{3} / \mathrm{s}\right)\end{array}$ & $\begin{array}{c}\text { Gage } \\
\text { height } \\
(\mathrm{ft})\end{array}$ & $\begin{array}{c}\text { Water } \\
\text { year }\end{array}$ & $\begin{array}{c}\text { Gage } \\
\text { Date } \\
\text { Deight } \\
(\mathrm{ft})\end{array}$ \\
\hline & & & & & & & & & & \\
$\left(\mathrm{ft}^{3} / \mathrm{s}\right)$
\end{tabular}




\section{SUWANNEE RIVER BASIN}

\section{DANIELS CREEK NEAR ASHBURN, GEORGIA}

LOCATION.--Lat $31^{\circ} 40^{\prime} 40^{\prime \prime}$ long $83^{\circ} 45^{\prime} 06^{\prime \prime}$, Turner County, at culvert on State Highway 32, 5.7 mi west of Ashburn. DRAINAGE AREA.-1.11 $\mathrm{mi}^{2}$.

GAGE.--Flood-stage recorder prior to 1975; crest-stage gage thereafter. Datum of gage is about $385 \mathrm{ft}$ above sea level (from topographic map).

STAGE-DISCHARGE RELATION.--Defined by current-meter measurements below $96 \mathrm{tt}^{3} / \mathrm{s}$, and extended above on basis of culvert computations.

\begin{tabular}{|c|c|c|c|c|c|c|c|c|c|c|c|}
\hline $\begin{array}{l}\text { Water } \\
\text { year }\end{array}$ & Date & $\begin{array}{c}\text { Discharge } \\
\left(\mathrm{ft}^{3} / \mathrm{s}\right)\end{array}$ & $\begin{array}{c}\text { Gage } \\
\text { height } \\
\text { (ft) }\end{array}$ & $\begin{array}{l}\text { Water } \\
\text { year }\end{array}$ & Date & $\begin{array}{c}\text { Discharge } \\
\left(\mathrm{ft}^{3} / \mathrm{s}\right)\end{array}$ & $\begin{array}{c}\text { Gage } \\
\text { height } \\
\text { (ft) }\end{array}$ & $\begin{array}{l}\text { Water } \\
\text { year }\end{array}$ & Date & $\begin{array}{c}\text { Discharge } \\
\left(\mathrm{ft}^{3} / \mathrm{s}\right)\end{array}$ & $\begin{array}{c}\text { Gage } \\
\text { height } \\
\text { (ft) }\end{array}$ \\
\hline 1965 & Mar. 20 & 75 & 1.93 & 1973 & Apr. 26 & 103 & 2.24 & 1981 & Sept. 05 & 11 & 1.12 \\
\hline 1966 & Mar. 04 & 151 & 2.75 & 1974 & Feb. 07 & 57 & 1.73 & 1982 & Apr. 26 & 131 & 2.55 \\
\hline 1967 & Jan. 01 & 159 & 2.84 & 1975 & Apr. 14 & 111 & 2.33 & 1983 & Mar. 06 & 231 & 3.60 \\
\hline 1968 & Mar. 11 & 11 & 1.11 & 1976 & May 15 & 96 & 2.17 & 1984 & Mar. 06 & 143 & 2.67 \\
\hline 1969 & Aug. 02 & 72 & 1.90 & 1977 & Jan. 04 & 45 & 1.60 & 1985 & Feb. 06 & 23 & 1.30 \\
\hline 1970 & June 04 & 127 & 2.51 & 1978 & Jan. 25 & 148 & 2.72 & 1986 & Nov. 21 & 59 & 1.76 \\
\hline 1971 & July 02 & 72 & 1.90 & 1979 & Feb. 24 & 184 & 3.12 & 1987 & Feb. 28 & 132 & 2.56 \\
\hline 1972 & June 25 & 46 & 1.61 & 1980 & Mar. 13 & 117 & 2.40 & & & & \\
\hline
\end{tabular}

\section{LIME SINK CREEK NEAR SYCAMORE, GEORGIA}

LOCATION.--Lat $31^{\circ} 36^{\prime} 20^{\prime \prime}$, long $83^{\circ} 40^{\prime} 31^{\prime \prime}$, Turner County, at culvert on secondary road $1181,4.5$ mi southwest of Sycamore. DRAINAGE AREA, $-0.68 \mathrm{mi}^{2}$.

GAGE.--Flood-stage/rainfall recorder prior to 1975; crest-stage gage thereafter. Datum of gage is about $355 \mathrm{ft}$ above sea level (from topographic map).

STAGE-DISCHARGE RELATION.--Defined by current-meter measurements below $87 \mathrm{tt}^{3} / \mathrm{s}$, and extended above on basis of culvert computations.

REMARKS.--Peak discharge for 1984 is estimated.

\begin{tabular}{|c|c|c|c|c|c|c|c|c|c|c|c|}
\hline $\begin{array}{l}\text { Water } \\
\text { year }\end{array}$ & Date & $\begin{array}{c}\text { Discharge } \\
\left(\mathrm{ft}^{3} / \mathrm{s}\right)\end{array}$ & $\begin{array}{c}\text { Gage } \\
\text { height } \\
\text { (ft) }\end{array}$ & $\begin{array}{l}\text { Water } \\
\text { year }\end{array}$ & Date & $\begin{array}{c}\text { Discharge } \\
\left(\mathrm{ft}^{3} / \mathrm{s}\right)\end{array}$ & $\begin{array}{c}\text { Gage } \\
\text { height } \\
\text { (ft) }\end{array}$ & $\begin{array}{l}\text { Water } \\
\text { year }\end{array}$ & Date & $\begin{array}{l}\text { Discharge } \\
\left(\mathrm{ft}^{3} / \mathrm{s}\right)\end{array}$ & $\begin{array}{c}\text { Gage } \\
\text { height } \\
\text { (ft) }\end{array}$ \\
\hline 1965 & Dec. 25 & 102 & 3.48 & 1972 & Jan. 13 & 27 & 1.82 & 1979 & Feb. 24 & 161 & 4.58 \\
\hline 1966 & Mar. 04 & 144 & 4.29 & 1973 & Apr. 07 & 145 & 4.30 & 1980 & Apr. 05 & 126 & 3.97 \\
\hline 1967 & Jan. 01 & 62 & 2.69 & 1974 & Apr. 04 & 98 & 3.40 & 1981 & Mar. 13 & -- & 10.0 \\
\hline 1968 & Mar. 11 & 18 & 1.55 & 1975 & Apr. 14 & 103 & 3.50 & 1982 & Apr. 26 & 252 & 6.08 \\
\hline 1969 & Aug. 23 & 29 & 1.87 & 1976 & July 20 & 81 & 3.06 & 1983 & Mar. 06 & 244 & 5.97 \\
\hline 1970 & May 28 & 119 & 3.82 & 1977 & Nov. 30 & 85 & 3.14 & 1984 & Mar. 06 & 75 & 3.38 \\
\hline 1971 & July 04 & 86 & 3.15 & 1978 & Jan. 25 & 48 & 2.35 & & & & \\
\hline
\end{tabular}




\section{SUWANNEE RIVER BASIN}

\section{MILL CREEK NEAR TIFTON, GEORGIA}

LOCATION.--Lat $31^{\circ} 29^{\prime} 36^{\prime \prime}$, long $83^{\circ} 34^{\prime} 04^{\prime \prime}$, Tift County, at culvert on county road, 3 mi northwest of Tifton.

DRAINAGE AREA. $-6.21 \mathrm{mi}^{2}$.

GAGE.--Flood-stage recorder prior to June 29, 1965; June 29, 1965, to Aug. 22, 1968, crest-stage gage; flood-stage/rainfall recorder thereafter. Datum of gage is about $275 \mathrm{ft}$ above sea level (from topographic map).

STAGE-DISCHARGE RELATION.--Defined by current-meter measurements below $450 \mathrm{ft}^{3} / \mathrm{s}$, and extended above on basis of culvert computations.

\begin{tabular}{|c|c|c|c|c|c|c|c|c|c|c|c|}
\hline $\begin{array}{l}\text { Water } \\
\text { year }\end{array}$ & Date & $\begin{array}{c}\text { Discharge } \\
\left(\mathrm{ft}^{3} / \mathrm{s}\right)\end{array}$ & $\begin{array}{c}\text { Gage } \\
\text { height } \\
\text { (ft) }\end{array}$ & $\begin{array}{l}\text { Water } \\
\text { year }\end{array}$ & Date & $\begin{array}{c}\text { Discharge } \\
\left(\mathrm{ft}^{3} / \mathrm{s}\right)\end{array}$ & $\begin{array}{l}\text { Gage } \\
\text { height } \\
\text { (ft) }\end{array}$ & $\begin{array}{l}\text { Water } \\
\text { year }\end{array}$ & Date & $\begin{array}{c}\text { Discharge } \\
\left(\mathrm{ft}^{3} / \mathrm{s}\right)\end{array}$ & $\begin{array}{c}\text { Gage } \\
\text { height } \\
\text { (ft) }\end{array}$ \\
\hline 1965 & Mar. 02 & 232 & 5.04 & 1970 & Mar. 21 & 796 & 6.22 & 1974 & Apr. 05 & 398 & 5.52 \\
\hline 1966 & Feb. 28 & 712 & 6.12 & 1971 & Apr. 30 & 153 & 4.67 & $\underline{1975}$ & Apr. 14 & 458 & 5.65 \\
\hline 1967 & Feb. 07 & 144 & 4.62 & 1972 & Feb. 03 & 206 & 4.94 & $\overline{1984}$ & Mar. 06 & 525 & $5.79 c$ \\
\hline 1968 & July 10 & 55 & 3.78 & 1973 & Feb. 02 & 836 & 6.27 & $\overline{1986}$ & Feb. 11 & 1,400 & $11.06 c$ \\
\hline 1969 & Mar. 18 & 229 & 5.03 & & & & & & & & \\
\hline
\end{tabular}

\section{LITTLE RIVER NEAR TIFTON, GEORGIA}

LOCATION.--Lat $31^{\circ} 26^{\prime} 21^{\prime \prime}$, long $83^{\circ} 33^{\prime} 38^{\prime \prime}$, Tift County, at U.S. Highway 82,3 mi west of Tifton.

DRAINAGE AREA.-145 $\mathrm{mi}^{2}$, approximately.

GAGE.--Crest-stage gage. Datum of gage is $251.5 \mathrm{ft}$ above sea level (levels from U.S. Geological Survey).

STAGE-DISCHARGE RELATION.--Defined by current-meter measurements below $3,580 \mathrm{ft}^{3} / \mathrm{s}$. Bankfull stage and discharge, $7 \mathrm{ft}$ and $900 \mathrm{ft}^{3} / \mathrm{s}$.

\begin{tabular}{|c|c|c|c|c|c|c|c|c|c|c|c|}
\hline $\begin{array}{l}\text { Water } \\
\text { year }\end{array}$ & Date & $\begin{array}{c}\text { Discharge } \\
\left(\mathrm{ft}^{3} / \mathrm{s}\right)\end{array}$ & $\begin{array}{c}\text { Gage } \\
\text { height } \\
\text { (ft) }\end{array}$ & $\begin{array}{l}\text { Water } \\
\text { year }\end{array}$ & Date & $\begin{array}{l}\text { Discharge } \\
\left(\mathrm{ft}^{3} / \mathrm{s}\right)\end{array}$ & $\begin{array}{c}\text { Gage } \\
\text { height } \\
\text { (ft) }\end{array}$ & $\begin{array}{l}\text { Water } \\
\text { year }\end{array}$ & Date & $\begin{array}{c}\text { Discharge } \\
\left(\mathrm{ft}^{3} / \mathrm{s}\right)\end{array}$ & $\begin{array}{c}\text { Gage } \\
\text { height } \\
\text { (ft) }\end{array}$ \\
\hline 1951 & Mar. 30 & 950 & 7.43 & 1959 & Mar. 08 & 2,930 & 9.05 & 1967 & Jan. 04 & 2,600 & 8.34 \\
\hline 1952 & Feb. 28 & 640 & 7.05 & 1960 & Apr. 05 & 3,470 & 9.78 & 1968 & Apr. -- & 700 & $-b$ \\
\hline 1953 & Sept. 30 & 1,030 & 7.52 & 1961 & Apr. 16 & 3,630 & 9.89 & 1969 & Mar. -- & 700 & $-b$ \\
\hline 1954 & Dec. 27 & 870 & 7.30 & 1962 & Apr. 01 & 740 & 6.96 & 1970 & Aug. 27 & 2,200 & 8.24 \\
\hline 1955 & Apr. 14 & 460 & 6.73 & 1963 & June 24 & 1,800 & 7.81 & 1971 & Sept. 02 & 970 & 7.19 \\
\hline 1956 & Mar. 17 & 790 & 7.23 & 1964 & Mar. 05 & 2,950 & 8.62 & 1972 & Jan. 14 & 1,590 & 7.71 \\
\hline 1957 & Apr. 09 & 1,080 & 7.32 & 1965 & Feb. 17 & 1,790 & 8.20 & 1973 & Apr. 04 & 3,500 & 9.10 \\
\hline 1958 & Apr. 11 & 1,670 & 8.07 & 1966 & Mar. 06 & 3,600 & 9.18 & & & & \\
\hline
\end{tabular}




\section{SUWANNEE RIVER BASIN}

02317810 ARNOLD CREEK TRIBUTARY NEAR TIFTON, GEORGIA

(Formerly published as "Little River Tributary No. 2 near Tifton, Georgia")

LOCATION.--Lat $31^{\circ} 25^{\prime} 30^{\prime \prime}$, long $83^{\circ} 34^{\prime} 23^{\prime \prime}$, Tift County, at culvert on secondary road 546, 4 mi southwest of Tifton.

DRAINAGE AREA. $-0.47 \mathrm{mi}^{2}$.

GAGE.--Flood-stage recorder prior to April 17, 1967; flood-stage/rainfall recorder from April 17, 1967 to 1975, crest-stage gage thereafter.. Datum of gage is about $310 \mathrm{ft}$ above sea level (from topographic map).

STAGE-DISCHARGE RELATION.--Defined by current-meter measurements below $25 \mathrm{ft}^{3} / \mathrm{s}$, and extended above on basis of culvert computations.

\begin{tabular}{|c|c|c|c|c|c|c|c|c|c|c|c|}
\hline $\begin{array}{l}\text { Water } \\
\text { year }\end{array}$ & Date & $\begin{array}{c}\text { Discharge } \\
\left(\mathrm{ft}^{3} / \mathrm{s}\right)\end{array}$ & $\begin{array}{l}\text { Gage } \\
\text { height } \\
\text { (ft) }\end{array}$ & $\begin{array}{l}\text { Water } \\
\text { year }\end{array}$ & Date & $\begin{array}{c}\text { Discharge } \\
\left(\mathrm{ft}^{3} / \mathrm{s}\right)\end{array}$ & $\begin{array}{c}\text { Gage } \\
\text { height } \\
\text { (ft) }\end{array}$ & $\begin{array}{l}\text { Water } \\
\text { year }\end{array}$ & Date & $\begin{array}{c}\text { Discharge } \\
\left(\mathrm{ft}^{3} / \mathrm{s}\right)\end{array}$ & $\begin{array}{c}\text { Gage } \\
\text { height } \\
\text { (ft) }\end{array}$ \\
\hline 1965 & Mar. 28 & 64 & 2.46 & 1974 & Apr. 05 & 42 & 1.90 & 1983 & Mar. 06 & 55 & 2.22 \\
\hline 1966 & Feb. 28 & 55 & 2.23 & 1975 & Apr. 10 & 48 & 23.0 & 1984 & Mar. 06 & 147 & 4.22 \\
\hline 1967 & Jan. 02 & 19 & 1.23 & 1976 & May 24 & 28 & 1.55 & 1985 & Aug. 29 & 4.0 & 0.48 \\
\hline 1968 & Dec. -- & 16 & $-b$ & 1977 & Jan. 04 & 10 & 0.82 & 1986 & Feb. 11 & 160 & 4.46 \\
\hline 1969 & July 22 & 25 & 1.43 & 1978 & May 26 & 86 & 2.99 & 1987 & Mar. 01 & 61 & 2.37 \\
\hline 1970 & Mar. 21 & 78 & 2.80 & 1979 & Feb. 24 & 76 & 2.75 & 1988 & Mar. 04 & 67 & 2.53 \\
\hline 1971 & Apr. 30 & 78 & 2.79 & 1980 & Apr. 05 & 140 & 4.07 & 1989 & Apr. 15 & 16 & 1.10 \\
\hline 1972 & Jan. 13 & 66 & 2.51 & 1981 & Jan. -- & 5 & $-\mathrm{b}$ & 1990 & Jan. 09 & 49 & 2.09 \\
\hline 1973 & Feb. 02 & 35 & 1.72 & 1982 & Apr. 26 & 66 & 2.49 & & & & \\
\hline
\end{tabular}

\section{ARNOLD CREEK NEAR TIFTON, GEORGIA}

LOCATION.--Lat $31^{\circ} 24^{\prime} 44^{\prime \prime}$, long $83^{\circ} 35^{\prime} 26^{\prime \prime}$, Tift County, at culvert on county road S-546, 2.3 mi west of Tifton.

DRAINAGE AREA. $-4.80 \mathrm{mi}^{2}$.

GAGE.-Crest-stage gage. Datum of gage is about $290 \mathrm{ft}$ above sea level (from topographic map).

STAGE-DISCHARGE RELATION.--Defined by current-meter measurements below $151 \mathrm{ft}^{3} / \mathrm{s}$, and extended above on basis of culvert computations.

\begin{tabular}{|c|c|c|c|c|c|c|c|c|c|c|c|}
\hline $\begin{array}{l}\text { Water } \\
\text { year }\end{array}$ & Date & $\begin{array}{c}\text { Discharge } \\
\left(\mathrm{ft}^{3} / \mathrm{s}\right)\end{array}$ & $\begin{array}{c}\text { Gage } \\
\text { height } \\
\text { (ft) }\end{array}$ & $\begin{array}{c}\text { Water } \\
\text { year }\end{array}$ & Date & $\begin{array}{c}\text { Discharge } \\
\left(\mathrm{ft}^{3} / \mathrm{s}\right)\end{array}$ & $\begin{array}{c}\text { Gage } \\
\text { height } \\
\text { (ft) }\end{array}$ & $\begin{array}{l}\text { Water } \\
\text { year }\end{array}$ & Date & $\begin{array}{c}\text { Discharge } \\
\left(\mathrm{ft}^{3} / \mathrm{s}\right)\end{array}$ & $\begin{array}{c}\text { Gage } \\
\text { height } \\
\text { (ft) }\end{array}$ \\
\hline 1965 & Mar. 28 & 191 & 3.79 & 1968 & Aug. 25 & 31 & 2.78 & 1971 & Apr. 30 & 292 & 4.08 \\
\hline 1966 & Feb. 28 & 260 & 4.00 & 1969 & July 28 & 164 & 3.69 & 1972 & Dec. 20 & 97 & 3.39 \\
\hline 1967 & Jan. 01 & 137 & 3.58 & 1970 & Mar. 26 & 450 & 4.43 & 1973 & Feb. 02 & 345 & 4.21 \\
\hline
\end{tabular}


LOCATION.--Lat $31^{\circ} 15^{\prime} 15^{\prime \prime}$, long $83^{\circ} 30^{\prime} 32^{\prime \prime}$, Cook County, at county road S-548, 2.5 mi west of Lenox.

DRAINAGE AREA.--208 $\mathrm{mi}^{2}$, approximately.

GAGE.--Water-stage recorder. Datum of gage is $196.68 \mathrm{ft}$ above sea level (levels by the Georgia Department of Transportation). STAGE-DISCHARGE RELATION.--Defined by current-meter measurements below 4,500 $\mathrm{tt}^{3} / \mathrm{s}$, and extended above on basis of straight-line extension. Bankfull stage and discharge, $10 \mathrm{ft}$ and $800 \mathrm{ft}^{3} / \mathrm{s}$.

HISTORICAL DATA.-The flood of 1973 is thought to be the highest since 1961 , based on information at nearby stations.

\begin{tabular}{|c|c|c|c|c|c|c|c|c|c|c|c|}
\hline $\begin{array}{l}\text { Water } \\
\text { year }\end{array}$ & Date & $\begin{array}{c}\text { Discharge } \\
\left(\mathrm{ft}^{3} / \mathrm{s}\right)\end{array}$ & $\begin{array}{c}\text { Gage } \\
\text { height } \\
\text { (ft) }\end{array}$ & $\begin{array}{l}\text { Water } \\
\text { year }\end{array}$ & Date & $\begin{array}{c}\text { Discharge } \\
\left(\mathrm{ft}^{3} / \mathrm{s}\right)\end{array}$ & $\begin{array}{l}\text { Gage } \\
\text { height } \\
\text { (ft) }\end{array}$ & $\begin{array}{l}\text { Water } \\
\text { year }\end{array}$ & Date & $\begin{array}{c}\text { Discharge } \\
\left(\mathrm{ft}^{3} / \mathrm{s}\right)\end{array}$ & $\begin{array}{c}\text { Gage } \\
\text { height } \\
\text { (ft) }\end{array}$ \\
\hline 1968 & Mar. 17 & 376 & 8.37 & 1973 & Apr. 06 & 4,550 & 14.05 & 1977 & Mar. 08 & 2,330 & 12.32 \\
\hline 1969 & Mar. 20 & 956 & 10.94 & 1974 & Apr. 06 & 2,490 & 12.42 & $\underline{1978}$ & Jan. 29 & 2,680 & 12.55 \\
\hline 1970 & Apr. 03 & 2,450 & 12.39 & 1975 & Apr. 11 & 3,300 & 12.97 & $\underline{1984}$ & Mar. 07 & 5,600 & $14.84 \mathrm{c}$ \\
\hline 1971 & July 07 & 1,960 & 12.02 & 1976 & May 17 & 2,600 & 12.50 & $\overline{1986}$ & Feb. 11 & 7,700 & $15.71 \mathrm{c}$ \\
\hline 1972 & Jan. 14 & 2,410 & 12.38 & & & & & & & & \\
\hline
\end{tabular}

\section{WARRIOR CREEK NEAR SYLVESTER, GEORGIA}

LOCATION.--Lat $31^{\circ} 33^{\prime} 10^{\prime \prime}$ long $83^{\circ} 48^{\prime} 53^{\prime \prime}$, Worth County, at State Highway $112,1.8$ mi northeast of Sylvester.

DRAINAGE AREA.--8.24 $\mathrm{mi}^{2}$.

GAGE.-Crest-stage prior to Mar. 14, 1968; flood-stage/rainfall recorder thereafter. Datum of gage is about $355 \mathrm{ft}$ above sea level (from topographic map).

STAGE-DISCHARGE RELATION.--Defined by current-meter measurements below $800 \mathrm{ft}^{3} / \mathrm{s}$, and extended above on basis of straight-line extension.

HISTORICAL DATA.--Peak of 1966 is thought to be the highest since 1961, based on information at nearby stations.

\begin{tabular}{|c|c|c|c|c|c|c|c|c|c|c|c|}
\hline $\begin{array}{l}\text { Water } \\
\text { year }\end{array}$ & Date & $\begin{array}{c}\text { Discharge } \\
\left(\mathrm{ft}^{3} / \mathrm{s}\right)\end{array}$ & $\begin{array}{c}\text { Gage } \\
\text { height } \\
\text { (ft) }\end{array}$ & $\begin{array}{l}\text { Water } \\
\text { year }\end{array}$ & Date & $\begin{array}{c}\text { Discharge } \\
\left(\mathrm{ft}^{3} / \mathrm{s}\right)\end{array}$ & $\begin{array}{c}\text { Gage } \\
\text { height } \\
\text { (ft) }\end{array}$ & $\begin{array}{c}\text { Water } \\
\text { year }\end{array}$ & Date & $\begin{array}{c}\text { Discharge } \\
\left(\mathrm{ft}^{3} / \mathrm{s}\right)\end{array}$ & $\begin{array}{c}\text { Gage } \\
\text { height } \\
\text { (ft) }\end{array}$ \\
\hline 1965 & Dec. 25 & 388 & 6.03 & 1969 & Mar. 18 & 179 & 42 & 1973 & Apr. 03 & 243 & 4.47 \\
\hline 1966 & Mar. 04 & 1,160 & 6.83 & 1970 & May 30 & 364 & 5.90 & 1974 & Apr. 04 & 234 & 4.39 \\
\hline 1967 & Jan. 02 & 240 & 4.44 & 1971 & Apr. 30 & 237 & 4.42 & $\underline{1975}$ & Apr. 10 & 705 & 6.47 \\
\hline 1968 & Mar. 11 & 240 & 4.44 & 1972 & June 25 & 162 & 3.92 & $\overline{1984}$ & Mar. 06 & 380 & $6.00 \mathrm{c}$ \\
\hline
\end{tabular}

\section{WARRIOR CREEK TRIBUTARY NEAR SYLVESTER, GEORGIA}

LOCATION.--Lat $31^{\circ} 32^{\prime} 54^{\prime \prime}$, long $83^{\circ} 49^{\prime} 11^{\prime \prime}$, Worth County, at culvert on State Highway 112, 1.2 mi northeast of Sylvester. DRAINAGE AREA. $-1.64 \mathrm{mi}^{2}$.

GAGE.--Flood-stage/rainfall recorder. Datum of gage is about $360 \mathrm{ft}$ above sea level (from topographic map).

STAGE-DISCHARGE RELATION.--Defined by current-meter measurements below $120 \mathrm{ft}^{3} / \mathrm{s}$, and extended above on basis of culvert computations.

\begin{tabular}{|c|c|c|c|c|c|c|c|c|c|c|c|}
\hline $\begin{array}{l}\text { Water } \\
\text { year }\end{array}$ & Date & $\begin{array}{c}\text { Discharge } \\
\left(\mathrm{ft}^{3} / \mathrm{s}\right)\end{array}$ & $\begin{array}{l}\text { Gage } \\
\text { height } \\
\text { (ft) }\end{array}$ & $\begin{array}{l}\text { Water } \\
\text { year }\end{array}$ & Date & $\begin{array}{c}\text { Discharge } \\
\left(\mathrm{ft}^{3} / \mathrm{s}\right)\end{array}$ & $\begin{array}{l}\text { Gage } \\
\text { height } \\
\text { (ft) }\end{array}$ & $\begin{array}{l}\text { Water } \\
\text { year }\end{array}$ & Date & $\begin{array}{c}\text { Discharge } \\
\left(\mathrm{ft}^{3} / \mathrm{s}\right)\end{array}$ & $\begin{array}{c}\text { Gage } \\
\text { height } \\
\text { (ft) }\end{array}$ \\
\hline 1965 & Dec. 25 & 264 & 3.35 & 1969 & Sept. 21 & 86 & 2.15 & 1973 & Apr. 07 & 217 & 3.07 \\
\hline 1966 & Mar. 04 & 255 & 3.30 & 1970 & Aug. 26 & 252 & 3.28 & 1974 & Sept. 06 & 166 & 2.75 \\
\hline 1967 & Feb. 07 & 119 & 2.40 & 1971 & Apr. 30 & 110 & 2.33 & 1975 & Apr. 10 & 321 & 3.67 \\
\hline 1968 & Mar. 11 & 128 & 2.47 & 1972 & Jan. 30 & 100 & 2.25 & & & & \\
\hline
\end{tabular}


LOCATION.--Lat $31^{\circ} 21^{\prime} 45^{\prime \prime}$ long $83^{\circ} 46^{\prime} 11^{\prime \prime}$, Worth County, at county road, 10.8 mi south of Sumner.

DRAINAGE AREA.--109 $\mathrm{mi}^{2}$, approximately.

GAGE.--Crest-stage gage. Datum of gage is $256.6 \mathrm{ft}$ above sea level (levels from U.S. Geological Survey).

STAGE-DISCHARGE RELATION.--Defined by current-meter measurements below $3,700 \mathrm{tt}^{3} / \mathrm{s}$, and extended above on the basis of straight-line extension. Bankfull stage and discharge, $11 \mathrm{ft}$ and $800 \mathrm{tt}^{3} / \mathrm{s}$.

\begin{tabular}{|c|c|c|c|c|c|c|c|c|c|c|c|}
\hline $\begin{array}{l}\text { Water } \\
\text { year }\end{array}$ & Date & $\begin{array}{c}\text { Discharge } \\
\left(\mathrm{ft}^{3} / \mathrm{s}\right)\end{array}$ & $\begin{array}{c}\text { Gage } \\
\text { height } \\
\text { (ft) }\end{array}$ & $\begin{array}{l}\text { Water } \\
\text { year }\end{array}$ & Date & $\begin{array}{c}\text { Discharge } \\
\left(\mathrm{ft}^{3} / \mathrm{s}\right)\end{array}$ & $\begin{array}{c}\text { Gage } \\
\text { height } \\
\text { (ft) }\end{array}$ & $\begin{array}{l}\text { Water } \\
\text { year }\end{array}$ & Date & $\begin{array}{c}\text { Discharge } \\
\left(\mathrm{ft}^{3} / \mathrm{s}\right)\end{array}$ & $\begin{array}{c}\text { Gage } \\
\text { height } \\
\text { (ft) }\end{array}$ \\
\hline 1966 & Mar. 05 & 3,020 & 13.51 & 1974 & Apr. 06 & 2,360 & 13.01 & 1981 & Feb. 18 & 100 & 7.69 \\
\hline 1967 & Jan. 04 & 1,710 & 12.34 & 1975 & Apr. 11 & 4,010 & 14.22 & 1982 & Apr. 28 & 1,020 & 11.50 \\
\hline 1968 & Mar. 12 & 805 & 11.09 & 1976 & May 25 & 1,620 & 12.25 & 1983 & Feb. 15 & 2,320 & 12.97 \\
\hline 1969 & Mar. 19 & 1,380 & 11.98 & 1977 & Mar. 09 & 1,770 & 12.41 & 1984 & Mar. 06 & 3,720 & 14.01 \\
\hline 1970 & Aug. 10 & 4,320 & 14.36 & 1978 & Jan. 29 & 2,590 & 13.20 & 1985 & Feb. 07 & 845 & 11.17 \\
\hline 1971 & Mar. 27 & 3,640 & 13.90 & 1979 & Feb. 27 & 2,510 & 13.13 & 1986 & Feb. 11 & 4,440 & 14.42 \\
\hline 1972 & Jan. 14 & 2,520 & 13.14 & 1980 & Apr. 07 & 2,780 & 13.34 & 1987 & Dec. 11 & 2,460 & 13.09 \\
\hline 1973 & Apr. 27 & 3,390 & 13.78 & & & & & & & & \\
\hline
\end{tabular}

\section{LITTLE CREEK NEAR SYLVESTER, GEORGIA}

LOCATION.--Lat $31^{\circ} 36^{\prime} 48^{\prime \prime}$, long $83^{\circ} 45^{\prime} 29^{\prime \prime}$, Worth County, at culvert on State Highway $112,7.5$ mi northwest of Sylvester. DRAINAGE AREA.-0.39 $\mathrm{mi}^{2}$.

GAGE.--Flood-stage recorder prior to Mar. 14, 1968; flood-stage/rainfall recorder thereafter. Datum of gage is about $410 \mathrm{ft}$ above sea level (from topographic map).

STAGE-DISCHARGE RELATION.--Defined by current-meter measurements below $87 \mathrm{tt}^{3} / \mathrm{s}$, and extended above on basis of culvert computations.

\begin{tabular}{|c|c|c|c|c|c|c|c|c|c|c|c|}
\hline $\begin{array}{l}\text { Water } \\
\text { year }\end{array}$ & Date & $\begin{array}{c}\text { Discharge } \\
\left(\mathrm{ft}^{3} / \mathrm{s}\right)\end{array}$ & $\begin{array}{c}\text { Gage } \\
\text { height } \\
\text { (ft) }\end{array}$ & $\begin{array}{l}\text { Water } \\
\text { year }\end{array}$ & Date & $\begin{array}{c}\text { Discharge } \\
\left(\mathrm{ft}^{3} / \mathrm{s}\right)\end{array}$ & $\begin{array}{c}\text { Gage } \\
\text { height } \\
\text { (ft) }\end{array}$ & $\begin{array}{l}\text { Water } \\
\text { year }\end{array}$ & Date & $\begin{array}{c}\text { Discharge } \\
\left(\mathrm{ft}^{3} / \mathrm{s}\right)\end{array}$ & $\begin{array}{c}\text { Gage } \\
\text { height } \\
\text { (ft) }\end{array}$ \\
\hline 1965 & Dec. 25 & 39 & 2.10 & 1969 & May 18 & 43 & 2.02 & 1973 & Apr. 07 & 86 & 2.34 \\
\hline 1966 & Mar. 04 & 137 & 3.04 & 1970 & June 04 & 88 & 2.36 & 1974 & Apr. 04 & 43 & 2.02 \\
\hline 1967 & Aug. 20 & 82 & 2.30 & 1971 & July 02 & 81 & 2.29 & 1975 & Apr. 10 & 133 & 2.99 \\
\hline 1968 & Mar. -- & 6.0 & $--b$ & 1972 & June 25 & 14 & 1.59 & & & & \\
\hline
\end{tabular}


LOCATION.--Lat $31^{\circ} 28^{\prime} 22^{\prime \prime}$, long $83^{\circ} 39^{\prime} 47^{\prime \prime}$, Tift County, at U.S. Highway 82,1 mi west of Ty Ty.

DRAINAGE AREA, $-47 \mathrm{mi}^{2}$, approximately.

GAGE.--Crest-stage gage. Datum of gage is $289.26 \mathrm{ft}$ above sea level (levels by the Georgia Department of Transportation).

STAGE-DISCHARGE RELATION.--Defined by current-meter measurements below $1,840 \mathrm{ft}^{3} / \mathrm{s}$, and extended above on the basis of slope-conveyance studies. Bankfull stage and discharge, $4.5 \mathrm{ft}$ and $250 \mathrm{ft}^{3} / \mathrm{s}$.

HISTORICAL DATA.--Flood stage of April 1948 based on information furnished by the Georgia Department of Transportation, and is thought to be the highest since 1928 on the basis of information at nearby stations.

REMARKS.--Peak discharge for 1948 is estimated.

\begin{tabular}{|c|c|c|c|c|c|c|c|c|c|c|c|}
\hline $\begin{array}{l}\text { Water } \\
\text { year }\end{array}$ & Date & $\begin{array}{c}\text { Discharge } \\
\left(\mathrm{ft}^{3} / \mathrm{s}\right)\end{array}$ & $\begin{array}{c}\text { Gage } \\
\text { height } \\
\text { (ft) }\end{array}$ & $\begin{array}{l}\text { Water } \\
\text { year }\end{array}$ & Date & $\begin{array}{c}\text { Discharge } \\
\left(\mathrm{ft}^{3} / \mathrm{s}\right)\end{array}$ & $\begin{array}{l}\text { Gage } \\
\text { height } \\
\text { (ft) }\end{array}$ & $\begin{array}{l}\text { Water } \\
\text { year }\end{array}$ & Date & $\begin{array}{c}\text { Discharge } \\
\left(\mathrm{ft}^{3} / \mathrm{s}\right)\end{array}$ & $\begin{array}{l}\text { Gage } \\
\text { height } \\
\text { (ft) }\end{array}$ \\
\hline$\underline{1948}$ & Apr. -- & 3,500 & $9.30 c$ & 1961 & Apr. 16 & 1,880 & 7.32 & 1971 & Mar. 27 & 645 & 5.61 \\
\hline$\overline{1951}$ & Mar. 30 & 405 & 5.05 & 1962 & Apr. 01 & 360 & 4.84 & 1972 & Jan. 14 & 824 & 5.94 \\
\hline 1952 & Dec. 22 & 690 & 5.68 & 1963 & June 24 & 770 & 5.87 & 1973 & Apr. 27 & 1,880 & 7.30 \\
\hline 1953 & Sept. 30 & 640 & 5.57 & 1964 & Feb. 18 & 1,040 & 6.25 & 1974 & Apr. 05 & 1,490 & 6.77 \\
\hline 1954 & Dec. 31 & 260 & 4.50 & 1965 & Dec. 27 & 1,160 & 6.39 & 1975 & Apr. 11 & 1,290 & 6.56 \\
\hline 1955 & May 25 & 345 & 4.80 & 1966 & Mar. 06 & 1,500 & 6.87 & 1976 & May 15 & 746 & 5.81 \\
\hline 1956 & Feb. 17 & 475 & 5.17 & 1967 & Jan. 04 & 538 & 5.37 & 1977 & Mar. 08 & 1,080 & 6.31 \\
\hline 1957 & Apr. 09 & 740 & 5.84 & 1968 & Mar. 12 & 218 & 4.33 & $\underline{1978}$ & Jan. 27 & 1,620 & 7.01 \\
\hline 1958 & Apr. 11 & 930 & 6.13 & 1969 & Mar. 19 & 351 & 4.82 & $\overline{1984}$ & Mar. 07 & 1,660 & $7.06 c$ \\
\hline 1959 & Mar. 08 & 1,330 & 6.62 & 1970 & Aug. 28 & 778 & 5.85 & $\overline{1986}$ & Feb. 11 & 1,520 & $6.90 c$ \\
\hline 1960 & Apr. 05 & 1,670 & 6.97 & & & & & & & & \\
\hline
\end{tabular}

\section{LITTLE CREEK NEAR OMEGA, GEORGIA}

LOCATION.--Lat $31^{\circ} 23^{\prime} 35^{\prime \prime}$, long $83^{\circ} 38^{\prime} 00^{\prime \prime}$, Tift County, at secondary road 546, 4.2 mi north of Omega.

DRAINAGE AREA. $-4.22 \mathrm{mi}^{2}$.

GAGE.-Crest-stage gage prior to June 6, 1967; flood-stage/rainfall recorder thereafter. Datum of gage is about $270 \mathrm{ft}$ above sea

level (from topographic map).

STAGE-DISCHARGE RELATION.--Defined by current-meter measurements below $420 \mathrm{ft}^{3} / \mathrm{s}$, and extended above on the basis of straight-line extension.

\begin{tabular}{|c|c|c|c|c|c|c|c|c|c|c|c|}
\hline $\begin{array}{l}\text { Water } \\
\text { year }\end{array}$ & Date & $\begin{array}{c}\text { Discharge } \\
\left(\mathrm{ft}^{3} / \mathrm{s}\right)\end{array}$ & $\begin{array}{c}\text { Gage } \\
\text { height } \\
\text { (ft) }\end{array}$ & $\begin{array}{l}\text { Water } \\
\text { year }\end{array}$ & Date & $\begin{array}{c}\text { Discharge } \\
\left(\mathrm{ft}^{3} / \mathrm{s}\right)\end{array}$ & $\begin{array}{c}\text { Gage } \\
\text { height } \\
\text { (ft) }\end{array}$ & $\begin{array}{l}\text { Water } \\
\text { year }\end{array}$ & Date & $\begin{array}{c}\text { Discharge } \\
\left(\mathrm{ft}^{3} / \mathrm{s}\right)\end{array}$ & $\begin{array}{c}\text { Gage } \\
\text { height } \\
\text { (ft) }\end{array}$ \\
\hline 1965 & Mar. 28 & 524 & 4.66 & 1970 & Mar. 21 & 725 & 5.09 & 1974 & Apr. 05 & 333 & 4.16 \\
\hline 1966 & Feb. 28 & 380 & 4.30 & 1971 & Apr. 30 & 660 & 4.96 & $\underline{1975}$ & Apr. 10 & 195 & 3.65 \\
\hline 1967 & Jan. 03 & 150 & 3.48 & 1972 & Jan. 13 & 564 & 4.76 & $\underline{1984}$ & Mar. 06 & 600 & $4.84 c$ \\
\hline 1968 & July 11 & 71 & 3.16 & 1973 & Feb. 02 & 440 & 4.45 & $\overline{1986}$ & Feb. 11 & 820 & $5.28 \mathrm{c}$ \\
\hline 1969 & Mar. 24 & 184 & 3.97 & & & & & & & & \\
\hline
\end{tabular}




\section{SUWANNEE RIVER BASIN}

\section{TY TY CREEK TRIBUTARY AT CROSLAND, GEORGIA}

LOCATION.--Lat $31^{\circ} 19^{\prime} 17^{\prime \prime}$, long $83^{\circ} 37^{\prime} 24^{\prime \prime}$, Colquitt County, at culvert on U.S. Highway 319 and State Highway 35, at Crosland. DRAINAGE AREA.--2.07 $\mathrm{mi}^{2}$.

GAGE.--Crest-stage gage prior to July 7,1965 ; flood-stage/rainfall recorder thereafter. Datum of gage is about $240 \mathrm{ft}$ above sea level (from topographic map).

STAGE-DISCHARGE RELATION.--Defined by current-meter measurements below $362 \mathrm{ft}^{3} / \mathrm{s}$, and extended above on the basis of culvert computations.

\begin{tabular}{|c|c|c|c|c|c|c|c|c|c|c|c|}
\hline $\begin{array}{l}\text { Water } \\
\text { year }\end{array}$ & Date & $\begin{array}{c}\text { Discharge } \\
\left(\mathrm{ft}^{3} / \mathrm{s}\right)\end{array}$ & $\begin{array}{c}\text { Gage } \\
\text { height } \\
\text { (ft) }\end{array}$ & $\begin{array}{l}\text { Water } \\
\text { year }\end{array}$ & Date & $\begin{array}{c}\text { Discharge } \\
\left(\mathrm{ft}^{3} / \mathrm{s}\right)\end{array}$ & $\begin{array}{c}\text { Gage } \\
\text { height } \\
\text { (ft) }\end{array}$ & $\begin{array}{l}\text { Water } \\
\text { year }\end{array}$ & Date & $\begin{array}{c}\text { Discharge } \\
\left(\mathrm{ft}^{3} / \mathrm{s}\right)\end{array}$ & $\begin{array}{l}\text { Gage } \\
\text { height } \\
\text { (ft) }\end{array}$ \\
\hline 1960 & Apr. 05 & $\dot{2}_{42}$ & 3.76 & 1966 & May 17 & 294 & 4.23 & 1972 & Feb. 03 & 198 & 3.27 \\
\hline 1961 & Apr. 15 & 400 & 5.12 & 1967 & Jan. 01 & 90 & 1.99 & 1973 & Apr. 03 & 203 & 3.32 \\
\hline 1962 & Apr. 01 & 85 & 1.90 & 1968 & Mar. 10 & 120 & 2.38 & 1974 & Apr. 05 & 235 & 3.67 \\
\hline 1963 & Feb. 12 & 81 & 1.83 & 1969 & Mar. 18 & 87 & 1.94 & $\overline{1984}$ & Mar. 06 & 484 & $5.85 \mathrm{c}$ \\
\hline 1964 & Apr. 07 & 210 & 3.40 & 1970 & Aug. 10 & 238 & 3.70 & 1986 & Feb. 10 & 398 & $5.14 c$ \\
\hline 1965 & Dec. 04 & 273 & 4.05 & 1971 & May 12 & 247 & 3.79 & & & & \\
\hline
\end{tabular}

\section{LITTLE RIVER NEAR SPARKS, GEORGIA}

LOCATION.--Lat $31^{\circ} 11^{\prime} 34^{\prime \prime}$ long $83^{\circ} 31^{\prime} 22^{\prime \prime}$, Cook County, at bridge by on county highway, 5.5 mi west of Sparks.

DRAINAGE AREA.--555 $\mathrm{mi}^{2}$.

GAGE.--Crest-stage gage. Datum of gage is $185.01 \mathrm{ft}$ above sea level (levels by the Georgia Department of Transportation.)

STAGE-DISCHARGE RELATION.--Defined by current-meter measurements below $17,200 \mathrm{ft}^{3} / \mathrm{s}$, and extended above on the basis of records for station on Little River near Adel. Bankfull stage and discharge, $10 \mathrm{ft}$ and 2,500 $\mathrm{ft}^{3} / \mathrm{s}$.

HISTORICAL DATA.--Based on records for nearby station, the April 1948 flood is thought to be the highest since 1862 . Peak discharges for the 1928 and 1948 are estimated, based on station downstream on Little River near Adel (02318000).

\begin{tabular}{|c|c|c|c|c|c|c|c|c|c|c|c|}
\hline $\begin{array}{l}\text { Water } \\
\text { year }\end{array}$ & Date & $\begin{array}{c}\text { Discharge } \\
\left(\mathrm{ft}^{3} / \mathrm{s}\right)\end{array}$ & $\begin{array}{l}\text { Gage } \\
\text { height } \\
\text { (ft) }\end{array}$ & $\begin{array}{l}\text { Water } \\
\text { year }\end{array}$ & Date & $\begin{array}{c}\text { Discharge } \\
\left(\mathrm{ft}^{3} / \mathrm{s}\right)\end{array}$ & $\begin{array}{c}\text { Gage } \\
\text { height } \\
\text { (ft) }\end{array}$ & $\begin{array}{l}\text { Water } \\
\text { year }\end{array}$ & Date & $\begin{array}{c}\text { Discharge } \\
\left(\mathrm{ft}^{3} / \mathrm{s}\right)\end{array}$ & $\begin{array}{c}\text { Gage } \\
\text { height } \\
\text { (ft) }\end{array}$ \\
\hline 1928 & Aug. 17 & 25,000 & $-c$ & 1967 & Jan. 05 & 4,220 & 11.24 & 1975 & Apr. 12 & 10,200 & 12.83 \\
\hline 1948 & Apr. 02 & 28,000 & $-c$ & 1968 & Mar. 18 & 900 & $-b$ & 1976 & May 25 & 6,320 & 11.83 \\
\hline 1961 & Apr. 17 & 12,000 & 13.20 & 1969 & Mar. 21 & 2,890 & 10.37 & 1977 & Mar. 10 & 5,400 & 11.60 \\
\hline 1962 & Apr. 02 & 2,890 & 10.39 & 1970 & June 02 & 6,280 & 11.82 & 1978 & Jan. 29 & 7,400 & 12.08 \\
\hline 1963 & June 27 & 5,440 & 11.61 & 1971 & May 02 & 6,280 & 11.82 & $\underline{1979}$ & Feb. 27 & 10,900 & 12.98 \\
\hline 1964 & May 04 & 6,520 & 11.88 & 1972 & Feb. 07 & 6,160 & 11.79 & $\underline{1984}$ & Mar. 07 & 17,400 & $14.21 \mathrm{c}$ \\
\hline 1965 & Mar. 30 & 6,680 & 11.92 & 1973 & Apr. 06 & 12,800 & 12.83 & $\overline{1986}$ & Feb. 12 & 24,900 & $15.49 \mathrm{c}$ \\
\hline 1966 & Mar. 09 & 6,680 & 11.92 & 1974 & Feb. 09 & 6,160 & $11.79^{\circ}$ & & & & \\
\hline
\end{tabular}




\section{SUWANNEE RIVER BASIN \\ 02318000 LITTLE RIVER NEAR ADEL, GEORGIA}

LOCATION.--Lat $31^{\circ} 09^{\prime} 18^{\prime \prime}$, long $83^{\circ} 32^{\prime} 38^{\prime \prime}$, Cook County, on right bank $500 \mathrm{ft}$ downstream from bridge on State Highway $37,0.5$ mi downstream from Georgia \& Florida Railroad bridge, 5.5 mi upstream from Bear Creek, 6 mi downstream from Warrior Creek, and $7 \mathrm{mi}$ west of Adel.

DRAINAGE AREA. $-577 \mathrm{mi}^{2}$.

GAGE.-Water-stage recorder. Datum of gage is $171.08 \mathrm{ft}$ above sea level, supplementary adjustment of 1936.

STAGE-DISCHARGE RELATION.--Defined by current-meter measurements below $23,800 \mathrm{ft}^{3} / \mathrm{s}$, and extended above on the basis of velocity-area studies. Bankfull stage and discharge, $16 \mathrm{ft}$ and $4,200 \mathrm{ft}^{3} / \mathrm{s}$.

HISTORICAL DATA.-Flood stage of August 1928 based on information furnished by the Georgia Department of Transportation. The August 1928 flood was, at that time, said to be the highest known to local residents since at least 1862.

REMARKS.--Minor regulation since 1961 from small dam about 0.3 mi upstream. Peak discharges for $1974-79$ are estimated, based on station upstream on Little River near Sparks (02317980).

\begin{tabular}{|c|c|c|c|c|c|c|c|c|c|c|c|}
\hline $\begin{array}{l}\text { Water } \\
\text { year }\end{array}$ & Date & $\begin{array}{c}\text { Discharge } \\
\left(\mathrm{ft}^{3} / \mathrm{s}\right)\end{array}$ & $\begin{array}{c}\text { Gage } \\
\text { height } \\
\text { (ft) }\end{array}$ & $\begin{array}{l}\text { Water } \\
\text { year }\end{array}$ & Date & $\begin{array}{c}\text { Discharge } \\
\left(\mathrm{ft}^{3} / \mathrm{s}\right)\end{array}$ & $\begin{array}{c}\text { Gage } \\
\text { height } \\
\text { (ft) }\end{array}$ & $\begin{array}{l}\text { Water } \\
\text { year }\end{array}$ & Date & $\begin{array}{c}\text { Discharge } \\
\left(\mathrm{ft}^{3} / \mathrm{s}\right)\end{array}$ & $\begin{array}{l}\text { Gage } \\
\text { height } \\
\text { (ft) }\end{array}$ \\
\hline 1928 & Aug. 17 & 26,000 & $20.50 c$ & 1954 & Jan. 02 & 2,750 & 14.40 & 1968 & Mar. 18 & 923 & 9.63 \\
\hline 1941 & Mar. 24 & 1,520 & 11.50 & 1955 & Apr. 18 & 1,550 & 11.60 & 1969 & Mar. 22 & 2,900 & 14.86 \\
\hline 1942 & Jan. 06 & 5,900 & 16.70 & 1956 & May 08 & 4,360 & 15.80 & 1970 & June 03 & 5,680 & 16.87 \\
\hline 1943 & May 26 & 3,950 & 15.60 & 1957 & Apr. 11 & 2,240 & 13.60 & 1971 & May 03 & 5,850 & 16.95 \\
\hline 1944 & Mar. 08 & 15,000 & 18.70 & 1958 & Apr. 13 & 5,070 & 16.50 & 1973 & Apr. 06 & 13,500 & 18.71 \\
\hline 1945 & July 22 & 3,670 & 15.30 & 1959 & Mar. 08 & 9,600 & 17.60 & 1974 & Feb. 09 & 6,250 & - \\
\hline 1946 & May 24 & 2,920 & 14.60 & 1960 & Apr. 05 & 12,500 & 18.30 & 1975 & Apr. 12 & 11,000 & - \\
\hline 1947 & Mar. 10 & 7,580 & 17.10 & 1961 & Apr. 17 & 13,500 & 19.00 & 1976 & May 25 & 6,450 & - \\
\hline 1948 & Apr. 02 & 30,800 & 21.00 & 1962 & Apr. 04 & 3,440 & 15.22 & 1977 & Mar. 10 & 5,500 & - \\
\hline 1949 & Dec. 12 & 4,520 & 15.90 & 1963 & Mar. 16 & 3,920 & 15.60 & 1978 & Jan. 29 & 7,500 & - \\
\hline 1950 & July 15 & 2,750 & 14.40 & 1964 & May 04 & 6,950 & 17.25 & 1979 & Feb. 27 & 11,500 & - \\
\hline 1951 & Apr. 02 & 3,320 & 15.00 & 1965 & Mar. 30 & 6,350 & 17.11 & $\underline{1984}$ & Mar. 08 & 18,900 & $19.73 \mathrm{c}$ \\
\hline 1952 & Dec. 25 & 4,360 & 15.80 & 1966 & Mar. 08 & 7,500 & 17.43 & 1986 & Feb. 12 & 24,000 & $21.00 \mathrm{c}$ \\
\hline 1953 & Sept. 30 & 3,210 & 14.90 & 1967 & Jan. 06 & 5,080 & 16.59 & & & & \\
\hline
\end{tabular}

\section{BULL CREEK NEAR NORMAN PARK, GEORGIA}

LOCATION.--Lat $31^{\circ} 13^{\prime} 13^{\prime \prime}$, long $83^{\circ} 37^{\prime} 20^{\prime \prime}$, Colquitt County, at culvert on secondary road 548, 5 mi southeast of Norman Park. DRAINAGE AREA.-1.36 $\mathrm{mi}^{2}$.

GAGE.--Crest-stage gage prior to July 8, 1965; flood-stage recorder July 8, 1965 to November 3, 1967; flood-stage/rainfall recorder thereafter. Datum of gage is about $275 \mathrm{ft}$ above sea level (from topographic map).

STAGE-DISCHARGE RELATION.--Defined by current-meter measurements below $277 \mathrm{ft}^{3} / \mathrm{s}$, and extended above on the basis of culvert computations.

\begin{tabular}{|c|c|c|c|c|c|c|c|c|c|c|c|}
\hline $\begin{array}{l}\text { Water } \\
\text { year }\end{array}$ & Date & $\begin{array}{c}\text { Discharge } \\
\left(\mathrm{ft}^{3} / \mathrm{s}\right)\end{array}$ & $\begin{array}{c}\text { Gage } \\
\text { height } \\
\text { (ft) }\end{array}$ & $\begin{array}{l}\text { Water } \\
\text { year }\end{array}$ & Date & $\begin{array}{c}\text { Discharge } \\
\left(\mathrm{ft}^{3} / \mathrm{s}\right)\end{array}$ & $\begin{array}{c}\text { Gage } \\
\text { height } \\
\text { (ft) }\end{array}$ & $\begin{array}{l}\text { Water } \\
\text { year }\end{array}$ & Date & $\begin{array}{c}\text { Discharge } \\
\left(\mathrm{ft}^{3} / \mathrm{s}\right)\end{array}$ & $\begin{array}{c}\text { Gage } \\
\text { height } \\
\text { (ft) }\end{array}$ \\
\hline 1965 & June 15 & 236 & 3.40 & 1969 & Mar. 18 & 71 & 2.13 & 1973 & July 18 & 276 & 3.85 \\
\hline 1966 & Feb. 28 & 94 & 2.33 & 1970 & Mar. 28 & 88 & 2.28 & 1974 & Feb. 08 & 96 & 2.35 \\
\hline 1967 & Jan. 03 & 55 & 1.97 & 1971 & July 12 & 536 & 5.88 & 1975 & Apr. 10 & 232 & 3.37 \\
\hline 1968 & Aug. 19 & 17 & 1.46 & 1972 & Feb. 03 & 215 & 3.25 & & & & \\
\hline
\end{tabular}




\section{BULL CREEK TRIBUTARY NEAR ELLENTON, GEORGIA}

LOCATION.--Lat $31^{\circ} 09^{\prime} 19^{\prime \prime}$, long $83^{\circ} 37^{\prime} 06^{\prime \prime}$, Colquitt County, at culvert on State Highway 37,3 mi west of Ellenton.

DRAINAGE AREA. $-0.27 \mathrm{mi}^{2}$.

GAGE.--Crest-stage gage prior to July 8, 1965; flood-stage recorder thereafter. Datum of gage is about $230 \mathrm{ft}$ above sea level (from topographic map).

STAGE-DISCHARGE RELATION.--Defined by current-meter measurements below $90 \mathrm{ft}^{3} / \mathrm{s}$, and extended above on the basis of culvert computations.

\begin{tabular}{|c|c|c|c|c|c|c|c|c|c|c|c|}
\hline $\begin{array}{l}\text { Water } \\
\text { year }\end{array}$ & Date & $\begin{array}{c}\text { Discharge } \\
\left(\mathrm{ft}^{3} / \mathrm{s}\right)\end{array}$ & $\begin{array}{c}\text { Gage } \\
\text { height } \\
\text { (ft) }\end{array}$ & $\begin{array}{l}\text { Water } \\
\text { year }\end{array}$ & Date & $\begin{array}{c}\text { Discharge } \\
\left(\mathrm{ft}^{3} / \mathrm{s}\right)\end{array}$ & $\begin{array}{l}\text { Gage } \\
\text { height } \\
\text { (ft) }\end{array}$ & $\begin{array}{l}\text { Water } \\
\text { year }\end{array}$ & Date & $\begin{array}{c}\text { Discharge } \\
\left(\mathrm{ft}^{3} / \mathrm{s}\right)\end{array}$ & $\begin{array}{c}\text { Gage } \\
\text { height } \\
\text { (ft) }\end{array}$ \\
\hline 1960 & Apr. 05 & 97 & 3.76 & 1966 & May 17 & 130 & 4.63 & 1972 & Jan. 13 & 130 & 4.65 \\
\hline 1961 & Apr. 15 & 181 & 5.63 & 1967 & Jan. 14 & 27 & 1.80 & 1973 & Apr. 04 & 98 & 3.79 \\
\hline 1962 & Apr. 01 & 18 & 1.40 & 1968 & Aug. 27 & 22 & 1.61 & 1974 & June 09 & 94 & 3.70 \\
\hline 1963 & Jan. 21 & 47 & 2.43 & 1969 & May 19 & 49 & 2.52 & $\underline{1975}$ & Apr. 10 & 140 & 4.95 \\
\hline 1964 & Mar. 26 & 74 & 3.17 & 1970 & Aug. 11 & 58 & 2.77 & $\overline{1984}$ & Mar. 06 & 106 & $3.94 \mathrm{c}$ \\
\hline 1965 & Dec. 04 & 123 & 4.51 & 1971 & Mar. 26 & 138 & 4.85 & & & & \\
\hline
\end{tabular}

02318500 WITHLACOOCHEE RIVER NEAR QUITMAN, GEORGIA

LOCATION.--Lat $30^{\circ} 47^{\prime 2} 22^{\prime \prime}$ long $83^{\circ} 27^{\prime} 06^{\prime \prime}$, Brooks-Lowndes County line, at abandoned bridge on old U.S. Highway $84,500 \mathrm{ft}$ upstream from Tiger Creek, $800 \mathrm{ft}$ downstream from Atlantic Coast Line Railroad bridge, 4 mi upstream from Piscola Creek, 6 mi east of Quitman, and 9 mi downstream from Little River.

DRAINAGE AREA. $-1,480 \mathrm{mi}^{2}$.

GAGE.--Nonrecording gage at same site and datum $5.0 \mathrm{ft}$ lower prior to October 1932 (published as "at Blue Springs"), June 9 , 1937 to May 31, 1948, nonrecording gage at same site and datum, May 19, 1949 to March 1, 1954, crest-stage gage at same site and datum, Sept. 29, 1988 to May 4, 1989, water-stage recorder at site 2,000 ft upstream at same datum, and May 5, 1989 to present, water-stage recorder at same site and datum. All gage heights converted to present datum. Datum of gage is $84.30 \mathrm{ft}$ above sea level, supplemtary adjustment of 1936.

STAGE-DISCHARGE RELATION.--Defined by current-meter measurements below $48,300 \mathrm{ft}^{3} / \mathrm{s}$. Bankfull stage and discharge, $19 \mathrm{ft}$ and $7,800 \mathrm{ft}^{3} / \mathrm{s}$.

HISTORICAL DATA.--The August 1928 flood was reported at that time to be the highest known to the older residents of the area, dating back to 1862.

REMARKS.--Annual flood stages obtained from graphs based on twice-daily gage readings prior to May 31, 1948.

\begin{tabular}{|c|c|c|c|c|c|c|c|c|c|c|c|}
\hline $\begin{array}{l}\text { Water } \\
\text { year }\end{array}$ & Date & $\begin{array}{c}\text { Discharge } \\
\left(\mathrm{ft}^{3} / \mathrm{s}\right)\end{array}$ & $\begin{array}{c}\text { Gage } \\
\text { height } \\
\text { (ft) }\end{array}$ & $\begin{array}{l}\text { Water } \\
\text { year }\end{array}$ & Date & $\begin{array}{c}\text { Discharge } \\
\left(\mathrm{ft}^{3} / \mathrm{s}\right)\end{array}$ & $\begin{array}{c}\text { Gage } \\
\text { height } \\
\text { (ft) }\end{array}$ & $\begin{array}{l}\text { Water } \\
\text { year }\end{array}$ & Date & $\begin{array}{c}\text { Discharge } \\
\left(\mathrm{ft}^{3} / \mathrm{s}\right)\end{array}$ & $\begin{array}{l}\text { Gage } \\
\text { height } \\
\text { (ft) }\end{array}$ \\
\hline 1928 & Aug. 19 & 49,000 & 31.30 & 1942 & Jan. 09 & 11,600 & 22.00 & 1953 & May 20 & 6,010 & 17.10 \\
\hline 1929 & Mar. 20 & 18,000 & 24.80 & 1943 & Mar. 11 & 3,730 & 12.50 & $\underline{1954}$ & Oct. 01 & 6,700 & 18.00 \\
\hline 1930 & Oct. 07 & 12,200 & 21.90 & 1944 & Mar. 11 & 18,500 & 25.50 & $\overline{1964}$ & May 05 & 15,000 & $24.97 \mathrm{c}$ \\
\hline 1931 & Aug. 21 & 2,760 & $9.60 \mathrm{c}$ & 1945 & July 27 & 10,600 & 21.40 & $\underline{1979}$ & Mar. 01 & 17,000 & $25.83 \mathrm{c}$ \\
\hline$\overline{1938}$ & Nov. 21 & 1,380 & 6.10 & 1946 & Mar. 21 & 6,860 & 18.20 & 1984 & Mar. 09 & 30,500 & $29.52 c$ \\
\hline 1939 & Mar. 05 & 12,800 & 22.60 & 1947 & Apr. 22 & 9,960 & 21.00 & $\overline{1986}$ & Feb. 13 & 39,000 & $30.79 c$ \\
\hline 1940 & Feb. 25 & 3,450 & 11.00 & 1948 & Apr. 04 & 52,000 & 31.70 & $\overline{1989}$ & July 27 & 4,460 & 14.30 \\
\hline 1941 & Mar. 29 & 2,320 & 8.30 & $\underline{1949}$ & Apr. 19 & 5,660 & 16.60 & 1990 & $\overline{\text { Jan. } 15}$ & $\overline{8,420}$ & 20.33 \\
\hline
\end{tabular}


LOCATION.--Lat $31^{\circ} 02^{\prime} 48^{\prime \prime}$ long $83^{\circ} 37^{\prime} 02^{\prime \prime}$, Colquitt County, on county road, 1 mi south of Berlin.

DRAINAGE AREA,--101 $\mathrm{mi}^{2}$.

GAGE.--Crest-stage gage. Datum of gage is about $170 \mathrm{ft}$ above sea level (from topographic map).

STAGE-DISCHARGE RELATION.--Defined by current-meter measurements below $5,800 \mathrm{ft}^{3} / \mathrm{s}$, and extended above on the basis of straight-line extension. Bankfull stage and discharge, $9 \mathrm{ft}$ and $900 \mathrm{ft}^{3} / \mathrm{s}$.

HISTORICAL DATA.--The April 1961 flood stage based on information furnished by local resident. The flood of 1965 is thought to be the highest since 1948, based on information at nearby stations.

\begin{tabular}{|c|c|c|c|c|c|c|c|c|c|c|c|}
\hline $\begin{array}{l}\text { Water } \\
\text { year }\end{array}$ & Date & $\begin{array}{c}\text { Discharge } \\
\left(\mathrm{ft}^{3} / \mathrm{s}\right)\end{array}$ & $\begin{array}{l}\text { Gage } \\
\text { height } \\
\text { (ft) }\end{array}$ & $\begin{array}{l}\text { Water } \\
\text { year }\end{array}$ & Date & $\begin{array}{c}\text { Discharge } \\
\left(\mathrm{ft}^{3} / \mathrm{s}\right)\end{array}$ & $\begin{array}{c}\text { Gage } \\
\text { height } \\
\text { (ft) }\end{array}$ & $\begin{array}{l}\text { Water } \\
\text { year }\end{array}$ & Date & $\begin{array}{c}\text { Discharge } \\
\left(\mathrm{ft}^{3} / \mathrm{s}\right)\end{array}$ & $\begin{array}{l}\text { Gage } \\
\text { height } \\
\text { (ft) }\end{array}$ \\
\hline 1961 & Apr. 16 & 7,200 & $13.20 c$ & 1970 & Aug. 28 & 1,440 & 9.18 & 1978 & May 06 & 1,550 & 9.83 \\
\hline$\overline{1963}$ & Dec. 26 & 2,150 & 10.43 & 1971 & May 02 & 2,730 & 10.94 & 1979 & Feb. 07 & 2,640 & 10.87 \\
\hline 1964 & May 02 & 2,620 & 10.85 & 1972 & Jan. 14 & 2,430 & 10.69 & 1980 & Mar. 13 & 2,310 & 10.59 \\
\hline 1965 & Dec. 05 & 7,500 & 13.32 & 1973 & Apr. 26 & 4,190 & 11.86 & 1981 & Apr. 03 & 860 & 8.85 \\
\hline 1966 & Mar. 04 & 2,100 & 10.40 & 1974 & Apr. 06 & 1,160 & 9.33 & 1982 & Feb. 05 & 1,030 & 9.13 \\
\hline 1967 & Jan. 04 & 1,410 & 9.66 & 1975 & Apr. 11 & 5,040 & 12.29 & 1983 & Mar. 07 & 3,120 & 11.20 \\
\hline 1968 & Mar. 12 & 308 & 6.82 & 1976 & May 24 & 5,210 & 12.37 & 1984 & Mar. 06 & 7,890 & 13.43 \\
\hline 1969 & Mar. 19 & 1,050 & 9.17 & 1977 & Mar. 08 & 1,550 & 9.83 & 1986 & Feb. 11 & 6,720 & $13.04 \mathrm{c}$ \\
\hline
\end{tabular}

\section{OKAPILCO CREEK NEAR QUITMAN, GEORGIA}

LOCATION.--Lat 30 $49^{\prime} 32^{\prime \prime}$, long 83³3'45", Brooks County, at downstream side of bridge on State Highway $33,3.0$ mi north of Quitman.

DRAINAGE AREA.--269 $\mathrm{mi}^{2}$.

GAGE.--Water-stage recorder. Datum of gage is about $110 \mathrm{ft}$ above sea level (from topographic map).

STAGE-DISCHARGE RELATION.--Defined by current-meter measurements below $11,200 \mathrm{ft}^{3} / \mathrm{s}$, and extended above on the basis of straight-line extension.

REMARKS.--Flood stage of Feburary 1986 from floodmarks.

\begin{tabular}{|c|c|c|c|c|c|c|c|c|c|c|c|}
\hline $\begin{array}{l}\text { Water } \\
\text { year }\end{array}$ & Date & $\begin{array}{c}\text { Discharge } \\
\left(\mathrm{ft}^{3} / \mathrm{s}\right)\end{array}$ & $\begin{array}{c}\text { Gage } \\
\text { height } \\
\text { (ft) }\end{array}$ & $\begin{array}{l}\text { Water } \\
\text { year }\end{array}$ & Date & $\begin{array}{c}\text { Discharge } \\
\left(\mathrm{ft}^{3} / \mathrm{s}\right)\end{array}$ & $\begin{array}{c}\text { Gage } \\
\text { height } \\
\text { (ft) }\end{array}$ & $\begin{array}{l}\text { Water } \\
\text { year }\end{array}$ & Date & $\begin{array}{c}\text { Discharge } \\
\left(\mathrm{ft}^{3} / \mathrm{s}\right)\end{array}$ & $\begin{array}{c}\text { Gage } \\
\text { height } \\
\text { (ft) }\end{array}$ \\
\hline 1980 & Mar. 15 & 4,100 & 13.45 & 1984 & Mar. 07 & 11,800 & 16.68 & 1988 & Feb. 22 & 5,480 & 14.20 \\
\hline 1981 & Apr. 03 & 840 & 10.54 & 1985 & Sept. 01 & 2,310 & 12.37 & 1989 & July 25 & 2,280 & 12.34 \\
\hline 1982 & Feb. 07 & 1,380 & 11.47 & 1986 & Feb. 12 & 18,500 & 18.75 & 1990 & Feb. 22 & 1,510 & 11.62 \\
\hline 1983 & Mar. 09 & 6,500 & 14.38 & 1987 & Feb. 24 & 2,550 & 12.55 & & & & \\
\hline
\end{tabular}




\section{SUWANNEE RIVER BASIN}

02318725 OKAPILCO CREEK AT QUITMAN, GEORGIA

(formerly published as "Okapilco Creek near Quitman")

LOCATION.--Lat 30 $47^{\prime} 10^{\prime \prime}$, long $83^{\circ} 31^{\prime} 33^{\prime \prime}$, Brooks County, at U.S. Highways 84 and 221 and State Highway $38,1.8$ mi east of Quitman.

DRAINAGE AREA.--278 $\mathrm{mi}^{2}$.

GAGE.--Crest-stage gage. Prior to Sept. 18, 1973 at same site at different datum. Datum of gage is about $94 \mathrm{ft}$ above sea level (from topographic map).

STAGE-DISCHARGE RELATION.--Defined by current-meter measurements below $6,700 \mathrm{ft}^{3} / \mathrm{s}$, and extended above on the basis of information obtained at Okapilco Creek at State Highway 33 near Quitman (02318700).

REMARKS.--Peak discharges are estimated for 1982 and 1985.

\begin{tabular}{|c|c|c|c|c|c|c|c|c|c|c|c|}
\hline $\begin{array}{l}\text { Water } \\
\text { year }\end{array}$ & Date & $\begin{array}{c}\text { Discharge } \\
\left(\mathrm{ft}^{3} / \mathrm{s}\right)\end{array}$ & $\begin{array}{c}\text { Gage } \\
\text { height } \\
\text { (ft) }\end{array}$ & $\begin{array}{l}\text { Water } \\
\text { year }\end{array}$ & Date & $\begin{array}{c}\text { Discharge } \\
\left(\mathrm{ft}^{3} / \mathrm{s}\right)\end{array}$ & $\begin{array}{c}\text { Gage } \\
\text { height } \\
\text { (ft) }\end{array}$ & $\begin{array}{l}\text { Water } \\
\text { year }\end{array}$ & Date & $\begin{array}{l}\text { Discharge } \\
\left(\mathrm{ft}^{3} / \mathrm{s}\right)\end{array}$ & $\begin{array}{c}\text { Gage } \\
\text { height } \\
\text { (ft) }\end{array}$ \\
\hline 1970 & May 30 & 1,440 & 10.80 & 1979 & Feb. 28 & 4,900 & 13.45 & 1983 & Mar. 09 & 5,240 & 13.62 \\
\hline 1971 & May 03 & 2,600 & 12.00 & 1980 & Mar. 15 & 3,590 & 12.66 & 1984 & Mar. 08 & 12,000 & 16.16 \\
\hline 1972 & Jan. 14 & 2,900 & 12.20 & 1981 & Apr. 05 & 792 & 9.73 & 1985 & Sept. 01 & 2,350 & - \\
\hline 1973 & Apr. 26 & 6,200 & $\underline{14.10}$ & 1982 & Feb. 08 & 1,400 & - & 1986 & Feb. 12 & 19,000 & 18.36 \\
\hline$\overline{1978}$ & Mar. 12 & 2,030 & $\overline{11.43}$ & & & & & & & & \\
\hline
\end{tabular}

\section{AUCILLA RIVER NEAR BOSTON, GEORGIA}

LOCATION.--Lat $30^{\circ} 46^{\prime} 44^{\prime \prime}$, long $83^{\circ} 48^{\prime} 12^{\prime \prime}$, Thomas County, at bridge on State Highway $133,1.2$ mi south of Boston.

DRAINAGE AREA.--81 $\mathrm{mi}^{2}$, approximately.

GAGE.--Crest-stage gage. Datum of gage is $97.08 \mathrm{ft}$ above sea level (levels from the Georgia Department of Transportation). STAGE-DISCHARGE RELATION.--Defined by current-meter measurements below $3,700 \mathrm{ft}^{3} / \mathrm{s}$, and extended above on the basis of straight-line extension. Bankfull stage and discharge, $5.5 \mathrm{ft}$ and $500 \mathrm{ft}^{3} / \mathrm{s}$.

REMARKS.--Flood stage of April 1948 based on information furnished by the Georgia Department of Transportation.

\begin{tabular}{|c|c|c|c|c|c|c|c|c|c|c|c|}
\hline $\begin{array}{l}\text { Water } \\
\text { year }\end{array}$ & Date & $\begin{array}{c}\text { Discharge } \\
\left(\mathrm{ft}^{3} / \mathrm{s}\right)\end{array}$ & $\begin{array}{c}\text { Gage } \\
\text { height } \\
\text { (ft) }\end{array}$ & $\begin{array}{l}\text { Water } \\
\text { year }\end{array}$ & Date & $\begin{array}{c}\text { Discharge } \\
\left(\mathrm{ft}^{3} / \mathrm{s}\right)\end{array}$ & $\begin{array}{c}\text { Gage } \\
\text { height } \\
\text { (ft) }\end{array}$ & $\begin{array}{l}\text { Water } \\
\text { year }\end{array}$ & Date & $\begin{array}{c}\text { Discharge } \\
\left(\mathrm{ft}^{3} / \mathrm{s}\right)\end{array}$ & $\begin{array}{c}\text { Gage } \\
\text { height } \\
\text { (ft) }\end{array}$ \\
\hline 1948 & Apr. 04 & 5,800 & $9.90 \mathrm{c}$ & 1970 & Mar. 24 & 1,280 & 6.58 & 1978 & Jan. 27 & 626 & 5.71 \\
\hline 1962 & Apr. 01 & 1,020 & 6.44 & 1971 & Feb. 09 & 196 & 4.79 & 1979 & May 11 & 1,340 & 6.64 \\
\hline 1963 & Jan. 22 & 334 & 5.26 & 1972 & Jan. 04 & 1,560 & 6.83 & 1980 & Mar. 14 & 1,300 & 6.60 \\
\hline 1964 & May 03 & 3,940 & 8.96 & 1973 & Apr. 04 & 3,040 & 7.83 & 1981 & Apr. 05 & 262 & 4.98 \\
\hline 1965 & Dec. 05 & 6,840 & 10.57 & 1974 & Apr. 06 & 260 & 4.95 & 1982 & Feb. 08 & 435 & 5.37 \\
\hline 1966 & Mar. 04 & 1,840 & 7.07 & 1975 & Apr. 12 & 3,220 & 7.95 & 1983 & Mar. 08 & 2,500 & 7.56 \\
\hline 1967 & July 04 & 864 & 6.08 & 1976 & May 24 & 3,720 & 8.26 & 1984 & Mar. 07 & 4,020 & 8.56 \\
\hline 1968 & Apr. -- & 50 & $-b$ & 1977 & Nov. 30 & 1,700 & 6.95 & 1986 & Feb. 11 & 4,450 & 8.83 \\
\hline 1969 & Mar. 19 & 264 & 4.96 & & & & & & & & \\
\hline
\end{tabular}


LOCATION.--Lat $31^{\circ} 10^{\prime} 58^{\prime \prime}$, long $83^{\circ} 48^{\prime} 32^{\prime \prime}$, Colquitt County, at State Highway 37, at Moultrie.

DRAINAGE AREA.-96 $\mathrm{mi}^{2}$, approximately.

GAGE.--Crest-stage gage. Datum of gage is $246.04 \mathrm{ft}$ above sea level (levels from the Georgia Department of Transportation).

STAGE-DISCHARGE RELATION.--Defined by current-meter measurements below $3,850 \mathrm{ft}^{3} / \mathrm{s}$, and extended above on the basis of records for nearby stations and slope-conveyance studies. Bankfull stage and discharge, $7.5 \mathrm{ft}$ and $1,000 \mathrm{t}^{3} / \mathrm{s}$.

HISTORICAL DATA.-Flood stage of 1948 from floodmarks. The flood of April 1948 is thought to be the highest based on information furnished by local residents. The 1948 flood was probably the highest since 1862 , based on other stations in this area.

\begin{tabular}{|c|c|c|c|c|c|c|c|c|c|c|c|}
\hline $\begin{array}{l}\text { Water } \\
\text { year }\end{array}$ & Date & $\begin{array}{c}\text { Discharge } \\
\left(\mathrm{ft}^{3} / \mathrm{s}\right)\end{array}$ & $\begin{array}{c}\text { Gage } \\
\text { height } \\
\text { (ft) }\end{array}$ & $\begin{array}{l}\text { Water } \\
\text { year }\end{array}$ & Date & $\begin{array}{c}\text { Discharge } \\
\left(\mathrm{ft}^{3} / \mathrm{s}\right)\end{array}$ & $\begin{array}{c}\text { Gage } \\
\text { height } \\
\text { (ft) }\end{array}$ & $\begin{array}{l}\text { Water } \\
\text { year }\end{array}$ & Date & $\begin{array}{c}\text { Discharge } \\
\left(\mathrm{ft}^{3} / \mathrm{s}\right)\end{array}$ & $\begin{array}{c}\text { Gage } \\
\text { height } \\
\text { (ft) }\end{array}$ \\
\hline 1948 & Apr. -- & 11,000 & $15.50 \mathrm{c}$ & 1960 & Apr. 05 & 1,550 & 8.17 & 1970 & Aug. 12 & 2,160 & 8.38 \\
\hline$\overline{1951}$ & Mar. 30 & 760 & 6.92 & 1961 & Apr. 16 & 3,250 & 9.50 & 1971 & Mar. 26 & 2,200 & 8.42 \\
\hline 1952 & Dec. 29 & 1,190 & 7.71 & 1962 & Apr. 01 & 680 & 6.72 & 1972 & Feb. 04 & 1,220 & 7.35 \\
\hline 1953 & Apr. 13 & 760 & 6.94 & 1963 & Jan. 22 & 1,030 & 7.45 & 1973 & Apr. 26 & 3,100 & 9.16 \\
\hline 1954 & Dec. - & 520 & 6.27 & 1964 & Mar. 05 & 1,180 & 7.72 & 1974 & Feb. 08 & 1,830 & 8.05 \\
\hline 1955 & Apr. 15 & 680 & 6.72 & 1965 & Dec. 05 & 1,650 & 8.24 & 1975 & Apr. 11 & 3,250 & 9.16 \\
\hline 1956 & May 06 & 900 & 7.23 & 1966 & Mar. 04 & 1,300 & 7.87 & 1976 & May 17 & 1,370 & 7.54 \\
\hline 1957 & Sept. 30 & 850 & 7.12 & 1967 & Jan. 04 & 885 & 7.17 & $\underline{1977}$ & Nov. 30 & 800 & 6.73 \\
\hline 1958 & Apr. 10 & 950 & 7.33 & 1968 & May 00 & 273 & $-b$ & $\underline{1984}$ & Mar. 07 & 4,000 & $10.14 c$ \\
\hline 1959 & Mar. 07 & 2,800 & 9.19 & 1969 & Sept. 22 & 1,320 & 7.48 & $\overline{1986}$ & Feb. 12 & 5,000 & $11.14 c$ \\
\hline
\end{tabular}

\section{OCHLOCKONEE RIVER TRIBUTARY NEAR COOLIDGE, GEORGIA}

LOCATION.--Lat $31^{\circ} 01^{\prime} 33^{\prime \prime}$, long $83^{\circ} 57^{\prime} 32^{\prime \prime}$, Thomas County, at culvert on State Highway 202, 5.5 mi west of Coolidge.

DRAINAGE AREA.--1.81 $\mathrm{mi}^{2}$.

GAGE.--Flood-stage/rainfall recorder prior to April 30, 1975; crest-stage gage thereafter. Datum of gage is about $200 \mathrm{ft}$ above sea level (from topographic map).

STAGE-DISCHARGE RELATION.--Defined by current-meter measurements below $113 \mathrm{ft}^{3} / \mathrm{s}$, and extended above on the basis of culvert computation.

\begin{tabular}{|c|c|c|c|c|c|c|c|c|c|c|c|}
\hline $\begin{array}{l}\text { Water } \\
\text { year }\end{array}$ & Date & $\begin{array}{c}\text { Discharge } \\
\left(\mathrm{ft}^{3} / \mathrm{s}\right)\end{array}$ & $\begin{array}{c}\text { Gage } \\
\text { height } \\
\text { (ft) }\end{array}$ & $\begin{array}{l}\text { Water } \\
\text { year }\end{array}$ & Date & $\begin{array}{c}\text { Discharge } \\
\left(\mathrm{ft}^{3} / \mathrm{s}\right)\end{array}$ & $\begin{array}{c}\text { Gage } \\
\text { height } \\
\text { (ft) }\end{array}$ & $\begin{array}{l}\text { Water } \\
\text { year }\end{array}$ & Date & $\begin{array}{c}\text { Discharge } \\
\left(\mathrm{ft}^{3} / \mathrm{s}\right)\end{array}$ & $\begin{array}{c}\text { Gage } \\
\text { height } \\
\text { (ft) }\end{array}$ \\
\hline 1965 & Dec. 04 & 789 & 6.14 & 1974 & Apr. 05 & 83 & 1.49 & 1983 & Mar. 06 & 215 & 2.50 \\
\hline 1966 & Mar. 04 & 143 & 2.00 & 1975 & Apr. 10 & 186 & 2.31 & 1984 & Jan. 24 & 534 & 4.35 \\
\hline 1967 & July 10 & 270 & 2.86 & 1976 & May 16 & 276 & 2.90 & 1985 & Aug. 29 & 377 & 3.50 \\
\hline 1968 & July 11 & 36 & 0.99 & 1977 & Mar. 08 & 80 & 1.46 & 1986 & Feb. 11 & 694 & 5.26 \\
\hline 1969 & Mar. 18 & 65 & 1.31 & 1978 & May 30 & 125 & 1.86 & 1987 & Mar. 01 & 140 & 2.02 \\
\hline 1970 & Mar. 28 & 63 & 1.29 & 1979 & July 13 & 214 & 2.49 & 1988 & Mar. 05 & 235 & 2.63 \\
\hline 1971 & Mar. 26 & 268 & 2.85 & 1980 & Apr. 05 & 328 & 3.22 & 1989 & July 20 & 210 & 2.52 \\
\hline 1972 & Dec. 20 & 451 & 3.91 & 1981 & Apr. 03 & 124 & 1.85 & 1990 & Jan. 01 & 100 & 1.70 \\
\hline 1973 & May 26 & 393 & 3.59 & 1982 & Feb. 03 & 162 & 2.14 & & & & \\
\hline
\end{tabular}




\section{OCHLOCKONEE RIVER NEAR COOLIDGE, GEORGIA}

LOCATION.--Lat $31^{\circ} 00^{\prime} 08^{\prime \prime}$, long $83^{\circ} 56^{\prime} 21^{\prime \prime}$, Thomas County, at State Highway 188, 4 mi west of Coolidge.

DRAINAGE AREA.--260 $\mathrm{mi}^{2}$.

GAGE.--Crest-stage gage. Datum of gage is $166.86 \mathrm{ft}$ above sea level (levels from the Georgia Department of Transportation). STAGE-DISCHARGE RELATION.--Defined by current-meter measurements below $12,600 \mathrm{ft}^{3} / \mathrm{s}$. Bankfull stage and discharge, $11 \mathrm{ft}$ and $1,800 \mathrm{ft}^{3} / \mathrm{s}$.

\begin{tabular}{|c|c|c|c|c|c|c|c|c|c|c|c|}
\hline $\begin{array}{l}\text { Water } \\
\text { year }\end{array}$ & Date & $\begin{array}{c}\text { Discharge } \\
\left(\mathrm{ft}^{3} / \mathrm{s}\right)\end{array}$ & $\begin{array}{c}\text { Gage } \\
\text { height } \\
\text { (ft) }\end{array}$ & $\begin{array}{l}\text { Water } \\
\text { year }\end{array}$ & Date & $\begin{array}{c}\text { Discharge } \\
\left(\mathrm{ft}^{3} / \mathrm{s}\right)\end{array}$ & $\begin{array}{c}\text { Gage } \\
\text { height } \\
\text { (ft) }\end{array}$ & $\begin{array}{l}\text { Water } \\
\text { year }\end{array}$ & Date & $\begin{array}{c}\text { Discharge } \\
\left(\mathrm{ft}^{3} / \mathrm{s}\right)\end{array}$ & $\begin{array}{c}\text { Gage } \\
\text { height } \\
\text { (ft) }\end{array}$ \\
\hline 1981 & Apr. 06 & 1,040 & 9.23 & 1985 & Aug. 30 & 4,280 & 13.99 & 1988 & Feb. 24 & 5,740 & 14.72 \\
\hline 1982 & Apr. 28 & 2,080 & 12.32 & 1986 & Feb. 11 & 10,800 & 16.67 & 1989 & July 20 & 2,380 & 12.36 \\
\hline 1983 & Feb. 15 & 3,740 & 13.73 & 1987 & Dec. 12 & 2,670 & 13.18 & 1990 & Jan. 09 & 3,250 & 13.19 \\
\hline 1984 & Mar. 07 & 13,100 & 17.28 & & & & & & & & \\
\hline
\end{tabular}

\section{SALLYS BRANCH TRIBUTARY NEAR SALE CITY, GEORGIA}

LOCATION.--Lat 31 ${ }^{\circ} 14^{\prime} 46^{\prime \prime}$, long $84^{\circ} 01^{\prime} 40^{\prime \prime}$, Mitchell County, at culvert on State Highway 93, 1.2 mi south of Sale City. DRAINAGE AREA.--3.70 $\mathrm{mi}^{2}$.

GAGE.--Flood-stage recorder prior to Nov. 3, 1967; flood-stage/rainfall recorder thereafter. Datum of gage is about $295 \mathrm{ft}$ above sea level (from topographic map).

STAGE-DISCHARGE RELATION.--Defined by current-meter measurements below $227 \mathrm{ft}^{3} / \mathrm{s}$, and extended above on the basis of culvert computations.

\begin{tabular}{|c|c|c|c|c|c|c|c|c|c|c|c|}
\hline $\begin{array}{l}\text { Water } \\
\text { year }\end{array}$ & Date & $\begin{array}{c}\text { Discharge } \\
\left(\mathrm{ft}^{3} / \mathrm{s}\right)\end{array}$ & $\begin{array}{c}\text { Gage } \\
\text { height } \\
\text { (ft) }\end{array}$ & $\begin{array}{l}\text { Water } \\
\text { year }\end{array}$ & Date & $\begin{array}{c}\text { Discharge } \\
\left(\mathrm{ft}^{3} / \mathrm{s}\right)\end{array}$ & $\begin{array}{c}\text { Gage } \\
\text { height } \\
\text { (ft) }\end{array}$ & $\begin{array}{l}\text { Water } \\
\text { year }\end{array}$ & Date & $\begin{array}{l}\text { Discharge } \\
\left(\mathrm{ft}^{3} / \mathrm{s}\right)\end{array}$ & $\begin{array}{c}\text { Gage } \\
\text { height } \\
\text { (ft) }\end{array}$ \\
\hline 1966 & Feb. 28 & 290 & 4.53 & 1970 & Mar. 22 & 110 & 3.58 & 1974 & Feb. 07 & 376 & 5.18 \\
\hline 1967 & June 23 & 724 & 5.83 & 1971 & Mar. 26 & 360 & 5.15 & $\underline{1975}$ & Apr. 10 & 460 & 5.35 \\
\hline 1968 & June 22 & 191 & 3.94 & 1972 & June 25 & 800 & 5.92 & 1984 & Mar. 06 & 1,200 & $6.64 c$ \\
\hline 1969 & Mar. 18 & 152 & 3.68 & 1973 & Apr. 26 & 764 & 5.88 & & & & \\
\hline
\end{tabular}




\section{OCHLOCKONEE RIVER BASIN}

\section{LITTLE OCHLOCKONEE RIVER NEAR MOULTRIE, GEORGIA}

LOCATION.--Lat $31^{\circ} 07^{\prime} 02^{\prime \prime}$, long $83^{\circ} 58^{\prime} 42^{\prime \prime}$, Colquitt County, at State Highway 111,10 mi west of Moultrie.

DRAINAGE AREA.--44.8 $\mathrm{mi}^{2}$.

GAGE.--Crest-stage gage. Datum of gage is $218.65 \mathrm{ft}$ above sea level (levels by the Georgia Department of Transportation).

STAGE-DISCHARGE RELATION.--Defined by current-meter measurements below $4,570 \mathrm{ft}^{3} / \mathrm{s}$, and extended above on the basis of straight-line extension.

\begin{tabular}{|c|c|c|c|c|c|c|c|c|c|c|c|}
\hline $\begin{array}{l}\text { Water } \\
\text { year }\end{array}$ & Date & $\begin{array}{c}\text { Discharge } \\
\left(\mathrm{ft}^{3} / \mathrm{s}\right)\end{array}$ & $\begin{array}{c}\text { Gage } \\
\text { height } \\
\text { (ft) }\end{array}$ & $\begin{array}{l}\text { Water } \\
\text { year }\end{array}$ & Date & $\begin{array}{c}\text { Discharge } \\
\left(\mathrm{ft}^{3} / \mathrm{s}\right)\end{array}$ & $\begin{array}{c}\text { Gage } \\
\text { height } \\
\text { (ft) }\end{array}$ & $\begin{array}{l}\text { Water } \\
\text { year }\end{array}$ & Date & $\begin{array}{c}\text { Discharge } \\
\left(\mathrm{ft}^{3} / \mathrm{s}\right)\end{array}$ & $\begin{array}{c}\text { Gage } \\
\text { height } \\
\text { (ft) }\end{array}$ \\
\hline 1981 & Apr. 04 & 418 & 6.06 & 1985 & July 06 & 1,360 & 7.58 & 1988 & Mar. 05 & 2,280 & 8.41 \\
\hline 1982 & Apr. 26 & 1,110 & 7.29 & 1986 & Feb. 11 & 5,860 & 10.22 & 1989 & July 20 & 1,030 & 7.19 \\
\hline 1983 & Feb. 14 & 1,560 & 7.78 & 1987 & Mar. 01 & 1,180 & 7.38 & 1990 & Jan. 08 & 1,050 & 7.21 \\
\hline 1984 & Mar. 06 & 5,020 & 9.91 & & & & & & & & \\
\hline
\end{tabular}

\section{OCHLOCKONEE RIVER NEAR THOMASVILLE, GEORGIA}

LOCATION.--Lat $30^{\circ} 52^{\prime} 32^{\prime \prime}$, long $84^{\circ} 02^{\prime} 44^{\prime \prime}$, Thomas County, on downstream side of bridge on U.S. Highway 84,2 mi upstream from Seaboard Coast Line Railroad bridge, 4 mi upstream from Barnetts Creek, 5 mi northwest of Thomasville, and $6 \mathrm{mi}$ downstream from Little Ochlockonee River.

DRAINAGE AREA.--550 $\mathrm{mi}^{2}$, approximately.

GAGE.--Nonrecording prior to Jan. 7, 1947; water-stage recorder Jan. 7, 1947, to June 30, 1971; crest-stage gage thereafter. Datum of gage is $133.6 \mathrm{ft}$ above sea level (from U.S. Coast and Geodetic Survey benchmark), supplementary adjustment of 1936.

STAGE-DISCHARGE RELATION.--Defined by current-meter measurements below $24,300 \mathrm{ft}^{3} / \mathrm{s}$, and extended above on the basis of slope-conveyance studies. Bankfull stage and discharge, $9 \mathrm{ft}$ and $1,200 \mathrm{ft}^{3} / \mathrm{s}$.

HISTORICAL DATA.--Flood of April 1948 was reported to be the highest based on information furnished by local residents. The 1948 flood was the highest since 1862 , based on other stations in this area.

REMARKS.--Peak discharges for 1949 and 1973 are estimated.

\begin{tabular}{|c|c|c|c|c|c|c|c|c|c|c|c|}
\hline $\begin{array}{l}\text { Water } \\
\text { year }\end{array}$ & Date & $\begin{array}{c}\text { Discharge } \\
\left(\mathrm{ft}^{3} / \mathrm{s}\right)\end{array}$ & $\begin{array}{c}\text { Gage } \\
\text { height } \\
\text { (ft) }\end{array}$ & $\begin{array}{l}\text { Water } \\
\text { year }\end{array}$ & Date & $\begin{array}{c}\text { Discharge } \\
\left(\mathrm{ft}^{3} / \mathrm{s}\right)\end{array}$ & $\begin{array}{c}\text { Gage } \\
\text { height } \\
\text { (ft) }\end{array}$ & $\begin{array}{l}\text { Water } \\
\text { year }\end{array}$ & Date & $\begin{array}{c}\text { Discharge } \\
\left(\mathrm{ft}^{3} / \mathrm{s}\right)\end{array}$ & $\begin{array}{c}\text { Gage } \\
\text { height } \\
\text { (ft) }\end{array}$ \\
\hline 1937 & Sept. 21 & 9,090 & 17.60 & 1951 & Apr. 02 & 2,660 & 13.20 & 1965 & Dec. 05 & 19,000 & 20.40 \\
\hline 1938 & Nov. 15 & 1,430 & 9.30 & 1952 & Mar. 27 & 3,080 & 13.80 & 1966 & Mar. 06 & 6,620 & 16.01 \\
\hline 1939 & Mar. 03 & 3,240 & 14.00 & 1953 & Apr. 14 & 5,140 & 15.60 & 1967 & Jan. 05 & 5,030 & 15.02 \\
\hline 1940 & Feb. 21 & 1,820 & 10.70 & 1954 & Dec. 09 & 3,520 & 14.30 & 1968 & Mar. 16 & 1,350 & 10.17 \\
\hline 1941 & Mar. 10 & 1,730 & 10.40 & 1955 & Apr. 18 & 1,810 & 11.20 & 1969 & Mar. 22 & 3,590 & 13.84 \\
\hline 1942 & Jan. 05 & 9,900 & 17.80 & 1956 & May 09 & 4,280 & 15.00 & 1970 & Mar. 25 & 4,390 & 14.53 \\
\hline 1943 & Mar. 09 & 4,040 & 14.80 & 1957 & June 11 & 3,820 & 14.60 & 1971 & Mar. 28 & 8,750 & 17.10 \\
\hline 1944 & Mar. 08 & 9,900 & 17.80 & 1958 & Apr. 11 & 8,650 & 17.40 & 1972 & Jan. 14 & 6,960 & 16.20 \\
\hline 1945 & July 12 & 4,680 & 15.30 & 1959 & Mar. 07 & 13,900 & 19.30 & 1973 & May 31 & 16,000 & -- \\
\hline 1946 & May 22 & 5,480 & 15.80 & 1960 & Apr. 04 & 10,000 & 18.00 & 1975 & Apr. 12 & 20,100 & 20.70 \\
\hline 1947 & Apr. 17 & 7,920 & 17.00 & 1961 & Apr. 17 & 19,200 & 20.80 & $\underline{1984}$ & Mar. 08 & 24,000 & $22.80 \mathrm{c}$ \\
\hline 1948 & Apr. 02 & 66,000 & 29.10 & 1962 & Apr. 03 & 4,980 & 15.50 & $\overline{1986}$ & Feb. 12 & 22,500 & $21.99 \mathrm{c}$ \\
\hline 1949 & Apr. 14 & 3,700 & -- & 1963 & Jan. 23 & 5,140 & 15.60 & $\overline{1990}$ & Jan. 11 & 6,430 & $15.90 \mathrm{c}$ \\
\hline 1950 & Mar. 17 & 2,090 & 11.90 & 1964 & May 03 & 14,800 & 18.80 & & & & \\
\hline
\end{tabular}


LOCATION.-Lat $31^{\circ} 01^{\prime} 32^{\prime \prime}$, long $84^{\circ} 08^{\prime} 14^{\prime \prime}$, Grady County, at State Highway 111, 4.2 mi southwest of Meigs.

DRAINAGE AREA.--15 $\mathrm{mi}^{2}$.

GAGE.--Crest-stage gage prior to Mar. 14, 1968; flood-stage/rainfall recorder from Mar. 14, 1968 to 1975; crest-stage gage thereafter. Datum of gage is about $230 \mathrm{ft}$ above sea level (from topographic map).

STAGE-DISCHARGE RELATION.--Defined by current-meter measurements below $1,160 \mathrm{ft}^{3} / \mathrm{s}$, and extended above on the basis of contracted-opening measurement at $3,620 \mathrm{ft}^{3} / \mathrm{s}$.

HISTORICAL DATA.--Flood of December 1964 was the highest since 1948, based on records at nearby stations.

\begin{tabular}{|c|c|c|c|c|c|c|c|c|c|c|c|}
\hline $\begin{array}{l}\text { Water } \\
\text { year }\end{array}$ & Date & $\begin{array}{c}\text { Discharge } \\
\left(\mathrm{ft}^{3} / \mathrm{s}\right)\end{array}$ & $\begin{array}{c}\text { Gage } \\
\text { height } \\
\text { (ft) }\end{array}$ & $\begin{array}{l}\text { Water } \\
\text { year }\end{array}$ & Date & $\begin{array}{c}\text { Discharge } \\
\left(\mathrm{ft}^{3} / \mathrm{s}\right)\end{array}$ & $\begin{array}{c}\text { Gage } \\
\text { height } \\
\text { (ft) }\end{array}$ & $\begin{array}{l}\text { Water } \\
\text { year }\end{array}$ & Date & $\begin{array}{c}\text { Discharge } \\
\left(\mathrm{ft}^{3} / \mathrm{s}\right)\end{array}$ & $\begin{array}{c}\text { Gage } \\
\text { height } \\
\text { (ft) }\end{array}$ \\
\hline 1965 & Dec. 04 & 3,620 & 7.38 & 1972 & Dec. 20 & 3,290 & 7.18 & 1981 & Feb. 11 & 375 & 4.09 \\
\hline 1966 & Mar. 01 & 508 & 4.40 & 1973 & May 27 & 1,040 & 5.25 & 1982 & Apr. 26 & 262 & 3.79 \\
\hline 1967 & July 26 & 286 & 3.86 & 1974 & Feb. 08 & 504 & 4.39 & 1983 & Feb. 14 & 1,130 & 5.36 \\
\hline 1968 & Feb. - & 94 & $-\mathbf{b}$ & $\underline{1975}$ & Apr. 10 & 1,590 & 5.87 & 1984 & Mar. 06 & 3,980 & 7.59 \\
\hline 1969 & Sept. 22 & 170 & 3.47 & 1978 & May 08 & 1,530 & 5.80 & 1985 & Aug. 29 & 1,160 & 5.39 \\
\hline 1970 & Mar. 28 & 743 & 4.82 & 1979 & Aug. 31 & 1,550 & 5.82 & 1986 & Feb. 11 & 2,270 & 6.48 \\
\hline 1971 & Apr. 30 & 1,330 & 5.58 & 1980 & Apr. 05 & 718 & 4.78 & 1987 & June 24 & 530 & 4.44 \\
\hline
\end{tabular}

\section{BARNETTS CREEK NEAR THOMASVILLE, GEORGIA}

LOCATION.--Lat $30^{\circ} 54^{\prime} 18^{\prime \prime}$, long $84^{\circ} 04^{\prime} 34^{\prime \prime}$, Grady County, at county road, 7.5 mi northwest of Thomasville.

DRAINAGE AREA.--104 $\mathrm{mi}^{2}$.

GAGE.--Crest-stage gage. Datum of gage is $152.0 \mathrm{ft}$ above sea level (leveis from the U.S. Geological Survey benchmark).

STAGE-DISCHARGE RELATION.--Defined by current-meter measurements below $13,300 \mathrm{ft}^{3} / \mathrm{s}$, and extended above on the basis of straight-line extension. Bankfull stage and discharge, $11 \mathrm{ft}$ and $1,000 \mathrm{ft}^{3} / \mathrm{s}$.

HISTORICAL DATA.--Flood of December 1964 was the highest since 1948, based on records at nearby stations.

\begin{tabular}{|c|c|c|c|c|c|c|c|c|c|c|c|}
\hline $\begin{array}{l}\text { Water } \\
\text { year }\end{array}$ & Date & $\begin{array}{c}\text { Discharge } \\
\left(\mathrm{ft}^{3} / \mathrm{s}\right)\end{array}$ & $\begin{array}{c}\text { Gage } \\
\text { height } \\
\text { (ft) }\end{array}$ & $\begin{array}{l}\text { Water } \\
\text { year }\end{array}$ & Date & $\begin{array}{c}\text { Discharge } \\
\left(\mathrm{ft}^{3} / \mathrm{s}\right)\end{array}$ & $\begin{array}{l}\text { Gage } \\
\text { height } \\
\text { (ft) }\end{array}$ & $\begin{array}{l}\text { Water } \\
\text { year }\end{array}$ & Date & $\begin{array}{c}\text { Discharge } \\
\left(\mathrm{ft}^{3} / \mathrm{s}\right)\end{array}$ & $\begin{array}{c}\text { Gage } \\
\text { height } \\
\text { (ft) }\end{array}$ \\
\hline 1951 & Mar. 30 & 1,150 & 11.30 & 1961 & Apr. 16 & 8,460 & 16.60 & 1971 & May 01 & 2,800 & 13.51 \\
\hline 1952 & Sept. 22 & 1,050 & 11.10 & 1962 & Apr. 01 & 3,580 & 14.08 & 1972 & Dec. 21 & 5,800 & 14.80 \\
\hline 1953 & Apr. 07 & 1,940 & 12.70 & 1963 & Jan. 21 & 2,360 & 13.11 & 1973 & Apr. 26 & 7,600 & 15.91 \\
\hline 1954 & Dec. 27 & 1,940 & 12.70 & 1964 & May 03 & 14,100 & 19.04 & 1974 & Feb. 08 & 3,600 & 13.29 \\
\hline 1955 & Apr. - & 850 & 10.50 & 1965 & Dec. 05 & 17,700 & 20.40 & 1975 & Apr. 11 & 8,560 & 16.28 \\
\hline 1956 & May 09 & 1,100 & 11.20 & 1966 & Mar. 04 & 1,410 & 11.82 & 1976 & May 26 & 1,840 & 11.99 \\
\hline 1957 & June 27 & 2,200 & 13.00 & 1967 & July 04 & 4,500 & 14.61 & $\underline{1977}$ & Mar. 10 & 1,490 & 11.60 \\
\hline 1958 & Apr. 10 & 3,800 & 14.40 & 1968 & Mar. -- & 300 & $-b$ & $\underline{1984}$ & Mar. 07 & 15,200 & $19.46 \mathrm{c}$ \\
\hline 1959 & Mar. 06 & 8,880 & 16.80 & 1969 & Sept. 22 & 680 & 10.36 & $\overline{1986}$ & Feb. 12 & 8,060 & $16.38 \mathrm{c}$ \\
\hline 1960 & Apr. 04 & 5,000 & 15.00 & 1970 & Mar. 23 & 1,520 & 12.03 & & & & \\
\hline
\end{tabular}


LOCATION.--Lat $30^{\circ} 47^{\prime} 30^{\prime \prime}$, long $84^{\circ} 09^{\prime} 16^{\prime \prime}$, Grady County, at State Highway 93,5 mi south of Cairo.

DRAINAGE AREA. $-747 \mathrm{mi}^{2}$.

GAGE.--Crest-stage gage. Datum of gage is $108.53 \mathrm{ft}$ above sea level (levels by the Georgia Department of Transportation).

STAGE-DISCHARGE RELATION.-Defined by current-meter measurements below $22,300 \mathrm{ft}^{3} / \mathrm{s}$, and extended above on the basis of straight-line extension.

\begin{tabular}{|c|c|c|c|c|c|c|c|c|c|c|c|}
\hline $\begin{array}{l}\text { Water } \\
\text { year }\end{array}$ & Date & $\begin{array}{c}\text { Discharge } \\
\left(\mathrm{ft}^{3} / \mathrm{s}\right)\end{array}$ & $\begin{array}{c}\text { Gage } \\
\text { height } \\
\text { (ft) }\end{array}$ & $\begin{array}{l}\text { Water } \\
\text { year }\end{array}$ & Date & $\begin{array}{c}\text { Discharge } \\
\left(\mathrm{ft}^{3} / \mathrm{s}\right)\end{array}$ & $\begin{array}{c}\text { Gage } \\
\text { height } \\
\text { (ft) }\end{array}$ & $\begin{array}{l}\text { Water } \\
\text { year }\end{array}$ & Date & $\begin{array}{c}\text { Discharge } \\
\left(\mathrm{ft}^{3} / \mathbf{s}\right)\end{array}$ & $\begin{array}{c}\text { Gage } \\
\text { height } \\
\text { (ft) }\end{array}$ \\
\hline 1970 & Apr. 02 & 4,710 & 20.82 & 1976 & May 27 & 8,710 & 22.84 & 1982 & Feb. 15 & 4,080 & 20.33 \\
\hline 1971 & Mar. 29 & 9,190 & 23.01 & 1977 & Mar. 12 & 7,730 & 22.48 & 1983 & Feb. 19 & 7,830 & 22.52 \\
\hline 1972 & Feb. 07 & 5,980 & 21.68 & 1978 & May 09 & 5,820 & 21.59 & 1984 & Mar. 08 & 33,000 & 29.31 \\
\hline 1973 & June 01 & 17,500 & 25.80 & 1979 & Feb. 28 & 8,680 & 22.83 & 1985 & Aug. 31 & 8,740 & 22.85 \\
\hline 1974 & Feb. 09 & 7,880 & 22.54 & 1980 & Mar. 16 & 9,160 & 23.00 & 1986 & Feb. 13 & 37,400 & 30.07 \\
\hline 1975 & Apr. 12 & 23,400 & 27.32 & 1981 & Apr. 07 & 2,700 & 18.63 & 1987 & Mar. 09 & 5,580 & 21.44 \\
\hline
\end{tabular}

\section{POPPLE BRANCH NEAR WHIGHAM, GEORGIA}

LOCATION.--Lat $30^{\circ} 55^{\prime} 36^{\prime \prime}$, long $84^{\circ} 20^{\prime} 18^{\prime \prime}$, Grady County, at culvert on State Highway $179,3.2$ mi north of Whigham. DRAINAGE AREA.-171 $\mathrm{mi}^{2}$.

GAGE.-Crest-stage gage. Datum of gage is about $245 \mathrm{ft}$ above sea level (from topographic map).

STAGE-DISCHARGE RELATION.-Defined on the basis of culvert computations.

\begin{tabular}{|c|c|c|c|c|c|c|c|c|c|c|c|}
\hline $\begin{array}{l}\text { Water } \\
\text { year }\end{array}$ & Date & $\begin{array}{c}\text { Discharge } \\
\left(\mathrm{ft}^{3} / \mathrm{s}\right)\end{array}$ & $\begin{array}{c}\text { Gage } \\
\text { height } \\
\text { (ft) }\end{array}$ & $\begin{array}{l}\text { Water } \\
\text { year }\end{array}$ & Date & $\begin{array}{c}\text { Discharge } \\
\left(\mathrm{ft}^{3} / \mathrm{s}\right)\end{array}$ & $\begin{array}{c}\text { Gage } \\
\text { height } \\
\text { (ft) }\end{array}$ & $\begin{array}{l}\text { Water } \\
\text { year }\end{array}$ & Date & $\begin{array}{c}\text { Discharge } \\
\left(\mathrm{ft}^{3} / \mathrm{s}\right)\end{array}$ & $\begin{array}{c}\text { Gage } \\
\text { height } \\
\text { (ft) }\end{array}$ \\
\hline 1977 & July 30 & 133 & 2.64 & 1982 & Mar. 26 & 253 & 3.97 & 1987 & Aug. 15 & 127 & 2.56 \\
\hline 1978 & Aug. 22 & 112 & 2.37 & 1983 & June 25 & 180 & 3.22 & 1988 & Mar. 04 & 169 & 3.08 \\
\hline 1979 & May 24 & 128 & 2.57 & 1984 & Mar. 06 & 444 & 5.65 & 1989 & June 20 & 146 & 2.82 \\
\hline 1980 & Apr. 05 & 191 & 3.35 & 1985 & Nov. 04 & 452 & 5.72 & 1990 & Mar. 17 & 83 & 2.02 \\
\hline 1981 & Apr. 03 & 128 & 2.58 & 1986 & Feb. 11 & 609 & 6.92 & & & & \\
\hline
\end{tabular}




\section{OCHLOCKONEE RIVER BASIN}

\section{WOLF CREEK NEAR WHIGHAM, GEORGIA}

LOCATION.-Lat $30^{\circ} 53^{\prime} 36^{\prime \prime}$, long $84^{\circ} 17^{\prime} 26^{\prime \prime}$, Grady County, at U.S. Highway $84,2.2$ mi northeast of Whigham.

DRAINAGE AREA.-19 $\mathrm{mi}^{2}$, approximately.

GAGE.--Crest-stage gage. Datum of gage is about $180 \mathrm{ft}$ above sea level (from topographic map).

STAGE-DISCHARGE RELATION.--Defined by current-meter measurements below $1,700 \mathrm{ft}^{3} / \mathrm{s}$, and extended above on the basis of correlation of discharges with nearby station. Undefined change in stage-discharge relation between 1958 and 1965.

HISTORICAL DATA.--Flood stage of April 1948 based on information furnished by local resident. Flood of April 1948 was highest since 1862 , based on records at nearby stations.

REMARKS.--Peak discharges for 1959-60, 1962, 1964-65, 1969, and 1972-74 are estimated.

\begin{tabular}{|c|c|c|c|c|c|c|c|c|c|c|c|}
\hline $\begin{array}{l}\text { Water } \\
\text { year }\end{array}$ & Date & $\begin{array}{c}\text { Discharge } \\
\left(\mathrm{ft}^{3} / \mathrm{s}\right)\end{array}$ & $\begin{array}{c}\text { Gage } \\
\text { height } \\
\text { (ft) }\end{array}$ & $\begin{array}{l}\text { Water } \\
\text { year }\end{array}$ & Date & $\begin{array}{c}\text { Discharge } \\
\left(\mathrm{ft}^{3} / \mathrm{s}\right)\end{array}$ & $\begin{array}{c}\text { Gage } \\
\text { height } \\
\text { (ft) }\end{array}$ & $\begin{array}{l}\text { Water } \\
\text { year }\end{array}$ & Date & $\begin{array}{c}\text { Discharge } \\
\left(\mathrm{ft}^{3} / \mathrm{s}\right)\end{array}$ & $\begin{array}{c}\text { Gage } \\
\text { height } \\
\text { (ft) }\end{array}$ \\
\hline 1948 & Apr. -- & 11,000 & $15.00 \mathrm{c}$ & 1960 & Sept. 26 & 1,800 & 7.47 & 1969 & Sept. 21 & 1,500 & 7.56 \\
\hline 1951 & Mar. 19 & 1,000 & 7.21 & 1961 & Apr. 16 & 1,110 & 6.79 & 1970 & Feb. 03 & 1,100 & 7.03 \\
\hline 1952 & Nov. 15 & 640 & 6.72 & 1962 & Apr. 01 & 2,200 & 8.25 & 1971 & Mar. 26 & 353 & 6.01 \\
\hline 1953 & Apr. 06 & 920 & 7.11 & 1963 & Jan. 21 & 994 & 6.71 & 1972 & Dec. 21 & 900 & 6.85 \\
\hline 1954 & Dec. 06 & 840 & 7.04 & 1964 & May 02 & 3,200 & 9.32 & 1973 & Apr. 26 & 2,400 & 8.59 \\
\hline 1955 & Sept. 09 & 920 & 7.07 & 1965 & Dec. 04 & 4,300 & 10.07 & 1974 & June 10 & 1,400 & 7.49 \\
\hline 1956 & May 07 & 410 & 6.29 & 1966 & Mar. 04 & 1,260 & 6.90 & 1975 & Jan. 13 & 2,300 & 8.43 \\
\hline 1957 & Sept. 29 & 240 & 5.85 & 1967 & June 05 & 740 & 6.53 & 1976 & May 26 & 1,100 & 7.04 \\
\hline 1958 & Apr. 15 & 1,650 & 7.90 & 1968 & Sept. 00 & 100 & $--b$ & 1977 & Nov. 30 & 800 & 6.74 \\
\hline 1959 & Mar. 06 & 2,100 & 8.23 & & & & & & & & \\
\hline
\end{tabular}

\section{TIRED CREEK NEAR CAIRO, GEORGIA}

LOCATION.--Lat $30^{\circ} 51^{\prime} 54^{\prime \prime}$, long $84^{\circ} 15^{\prime} 46^{\prime \prime}$, Grady County, $140 \mathrm{ft}$ upstream from highway bridge, and 3 mi west of Cairo.

DRAINAGE AREA.-60 $\mathrm{mi}^{2}$, approximately.

GAGE.--Water-stage recorder prior to June 30, 1971; crest-stage gage thereafter. Datum of gage is $159.0 \mathrm{ft}$ above sea level, supplementary adjustment of 1936.

STAGE-DISCHARGE RELATION.--Defined by current-meter measurements below $10,200 \mathrm{ft}^{3} / \mathrm{s}$, and extended above on the basis of contracted-opening measurement at $18,200 \mathrm{tt}^{3} / \mathrm{s}$ and slope-area measurement at $28,100 \mathrm{ft}^{3} / \mathrm{s}$. Bankfull stage and discharge, 6.0 $\mathrm{ft}$ and $500 \mathrm{ft}^{3} / \mathrm{s}$.

HISTORICAL DATA.--Flood of 1948 was reported to be the highest in memory of residents of the area. The 1948 flood was the highest since 1862 , based on records at nearby stations.

\begin{tabular}{|c|c|c|c|c|c|c|c|c|c|c|c|}
\hline $\begin{array}{l}\text { Water } \\
\text { year }\end{array}$ & Date & $\begin{array}{c}\text { Discharge } \\
\left(\mathrm{ft}^{3} / \mathrm{s}\right)\end{array}$ & $\begin{array}{c}\text { Gage } \\
\text { height } \\
\text { (ft) }\end{array}$ & $\begin{array}{l}\text { Water } \\
\text { year }\end{array}$ & Date & $\begin{array}{c}\text { Discharge } \\
\left(\mathrm{ft}^{3} / \mathrm{s}\right)\end{array}$ & $\begin{array}{c}\text { Gage } \\
\text { height } \\
\text { (ft) }\end{array}$ & $\begin{array}{l}\text { Water } \\
\text { year }\end{array}$ & Date & $\begin{array}{c}\text { Discharge } \\
\left(\mathrm{ft}^{3} / \mathrm{s}\right)\end{array}$ & $\begin{array}{l}\text { Gage } \\
\text { height } \\
\text { (ft) }\end{array}$ \\
\hline 1944 & Mar. 07 & 4,640 & 9.20 & 1957 & Sept. 30 & 662 & 6.23 & 1970 & Aug. 11 & 2,800 & 8.22 \\
\hline 1945 & Apr. 23 & 3,100 & 8.30 & 1958 & Apr. 15 & 2,820 & 8.05 & 1971 & Mar. 27 & 1,220 & 7.10 \\
\hline 1946 & Mar. 17 & 7,310 & 10.50 & 1959 & Mar. 06 & 5,010 & 9.40 & 1972 & June 23 & 2,130 & 7.80 \\
\hline 1947 & Apr. 16 & 2,940 & 8.20 & 1960 & Apr. 02 & 4,010 & 8.83 & 1973 & Apr. 26 & 6,400 & 10.09 \\
\hline 1948 & Apr. 01 & 28,100 & 16.30 & 1961 & Apr. 13 & 1,620 & 7.28 & 1974 & June 10 & 2,060 & 7.75 \\
\hline 1949 & Apr. 12 & 1,850 & 7.38 & 1962 & Mar. 31 & 5,390 & 9.60 & 1975 & Jan. 13 & 5,830 & 9.82 \\
\hline 1950 & July 07 & 1,730 & 7.30 & 1963 & Jan. 21 & 2,280 & 7.80 & 1976 & May 26 & 1,920 & 7.66 \\
\hline 1951 & Mar. 19 & 1,670 & 7.27 & 1964 & May 02 & 12,400 & 13.00 & 1977 & Mar. 10 & 1,650 & 7.46 \\
\hline 1952 & Nov. 16 & 928 & 6.57 & 1965 & Dec. 04 & 18,200 & 14.60 & 1978 & Mar. 10 & 1,840 & 7.60 \\
\hline 1953 & Apr. 07 & 1,940 & 7.53 & 1966 & Mar. 05 & 1,560 & 7.39 & $\underline{1979}$ & Feb. 26 & 8,400 & 11.00 \\
\hline 1954 & Dec. 07 & 1,370 & 7.08 & 1967 & Jan. 03 & 982 & 6.84 & $\overline{1984}$ & Mar. 06 & 12,000 & $12.82 \mathrm{c}$ \\
\hline 1955 & Sept. 02 & 836 & 6.47 & 1968 & May 30 & 122 & 4.16 & $\overline{1986}$ & Feb. 11 & 10,900 & $12.02 c$ \\
\hline 1956 & July 16 & 630 & 6.30 & 1969 & Sept. 21 & 2,940 & 8.30 & & & & \\
\hline
\end{tabular}




\section{APALACHICOLA RIVER BASIN \\ 02330450 CHATTAHOOCHEE RIVER AT HELEN, GEORGIA}

LOCATION.--Lat $34^{\circ} 42^{\prime} 03^{\prime \prime}$, long $83^{\circ} 43^{\prime} 44^{\prime \prime}$, White County, on downstream side of bridge on State Highways 17 and $75,1.1 \mathrm{mi}$ downstream from Smith Creek, at Helen, and at mile 421.6.

DRAINAGE AREA.--44.7 $\mathrm{mi}^{2}$.

GAGE.-Water-stage recorder. Datum of gage is 1,404.04 ft above sea level (from U.S. Army Corps of Engineers benchmark).

STAGE-DISCHARGE RELATION.--Defined by current-meter measurements below $2,820 \mathrm{tt}^{3} / \mathrm{s}$, and extended above on the basis of straight-line extension.

HISTORICAL DATA.--Peak discharges of August 1967 estimated from floodmarks and contracted-opening computation discharge of $11,000 \mathrm{ft}^{3} / \mathrm{s}$ at highway bridge, $2 \mathrm{mi}$ downstream at a drainage area of $48.2 \mathrm{mi}^{2}$.

\begin{tabular}{lccccccccccc}
\hline $\begin{array}{l}\text { Water } \\
\text { year }\end{array}$ & Date & $\begin{array}{c}\text { Discharge } \\
\left(\mathrm{ft}^{3} / \mathrm{s}\right)\end{array}$ & $\begin{array}{c}\text { Gage } \\
\text { height } \\
(\mathrm{ft})\end{array}$ & $\begin{array}{c}\text { Water } \\
\text { year }\end{array}$ & Date & $\begin{array}{c}\text { Discharge } \\
\left(\mathrm{ft}^{3} / \mathrm{s}\right)\end{array}$ & $\begin{array}{c}\text { Gage } \\
\text { height } \\
(\mathrm{ft})\end{array}$ & $\begin{array}{c}\text { Water } \\
\text { year }\end{array}$ & $\begin{array}{c}\text { Gage } \\
\text { Date }\end{array}$ & $\begin{array}{c}\text { Discharge } \\
\left(\mathrm{ft}^{3} / \mathrm{s}\right)\end{array}$ & $\begin{array}{c}\text { height } \\
(\mathrm{ft})\end{array}$ \\
\hline & & & & & & & & & & \\
1967 & Aug. 23 & 10,500 & $-\mathrm{c}$ & 1984 & Mar. 20 & 1,410 & 3.69 & 1988 & Jan. 20 & 1,420 & 3.71 \\
1981 & May 27 & 1,280 & 3.50 & 1985 & Aug. 17 & 755 & 2.51 & 1989 & June 20 & 1,170 & 3.29 \\
1982 & Feb. 03 & 1,750 & 4.19 & 1986 & Feb. 28 & 1,520 & 3.87 & 1990 & Mar. 17 & 3,850 & 5.94 \\
1983 & Feb. 02 & 3,260 & 5.54 & 1987 & Feb. 28 & 1,520 & 3.87 & & & & \\
\hline
\end{tabular}

\section{CHATTAHOOCHEE RIVER NEAR LEAF, GEORGIA}

LOCATION.--Lat $34^{\circ} 34^{\prime} 37^{\prime \prime}$, long $83^{\circ} 38^{\prime} 09^{\prime \prime}$, Habersham County, $700 \mathrm{ft}$ upstream from bridge on State Highway $115,1.5 \mathrm{mi}$ east of Leaf, and $7.5 \mathrm{mi}$ southwest of Cleveland, and at mile 405.6.

DRAINAGE AREA.--150 $\mathrm{mi}^{2}$.

GAGE.--Water-stage recorder prior to June 30, 1971; crest-stage gage thereafter. Datum of gage is $1,219.47 \mathrm{ft}$ above sea level, (from U.S. Geological Survey benchmark), supplementary adjustment of 1936.

STAGE-DISCHARGE RELATION.--Defined by current-meter measurements below $11,000 \mathrm{ft}^{3} / \mathrm{s}$, and extended above on the basis of slope-area measurement at $22,500 \mathrm{ft}^{3} / \mathrm{s}$. Bankfull stage and discharge, $10.0 \mathrm{ft}$ and $8,400 \mathrm{ft}^{3} / \mathrm{s}$.

\begin{tabular}{|c|c|c|c|c|c|c|c|c|c|c|c|}
\hline $\begin{array}{l}\text { Water } \\
\text { year }\end{array}$ & Date & $\begin{array}{c}\text { Discharge } \\
\left(\mathrm{ft}^{3} / \mathrm{s}\right)\end{array}$ & $\begin{array}{c}\text { Gage } \\
\text { height } \\
\text { (ft) }\end{array}$ & $\begin{array}{l}\text { Water } \\
\text { year }\end{array}$ & Date & $\begin{array}{c}\text { Discharge } \\
\left(\mathrm{ft}^{3} / \mathrm{s}\right)\end{array}$ & $\begin{array}{c}\text { Gage } \\
\text { height } \\
\text { (ft) }\end{array}$ & $\begin{array}{l}\text { Water } \\
\text { year }\end{array}$ & Date & $\begin{array}{c}\text { Discharge } \\
\left(\mathrm{ft}^{3} / \mathrm{s}\right)\end{array}$ & $\begin{array}{c}\text { Gage } \\
\text { height } \\
\text { (ft) }\end{array}$ \\
\hline 1940 & Aug. 13 & 11,200 & 11.80 & 1957 & Apr. 05 & 5,460 & 7.80 & 1974 & Dec. 31 & 5,780 & 8.06 \\
\hline 1941 & July 05 & 2,680 & 5.28 & 1958 & Nov. 19 & 4,740 & 7.20 & 1975 & Mar. 15 & 6,220 & 8.40 \\
\hline 1942 & Feb. 16 & 9,450 & 10.70 & 1959 & May 31 & 5,700 & 8.00 & 1976 & May 15 & 9,220 & 10.55 \\
\hline 1943 & Dec. 29 & 5,830 & 8.06 & 1960 & Mar. 30 & 4,500 & 7.00 & 1977 & Mar. 30 & 8,780 & 10.26 \\
\hline 1944 & Mar. 19 & 7,560 & 9.40 & 1961 & Feb. 25 & 7,700 & 9.50 & 1978 & Jan. 25 & 7,290 & 9.21 \\
\hline 1945 & Sept. 14 & 2,680 & 5.30 & 1962 & Dec. 12 & 11,600 & 12.05 & 1979 & Mar. 04 & 7,930 & 9.66 \\
\hline 1946 & Jan. 07 & 14,100 & 13.60 & 1963 & Mar. 12 & 16,200 & 14.80 & 1980 & Mar. 21 & 6,940 & 8.95 \\
\hline 1947 & Jan. 20 & 8,120 & 9.80 & 1964 & Jan. 25 & 8,550 & 10.13 & 1981 & May 27 & 3,130 & 5.75 \\
\hline 1948 & Aug. 04 & 6,350 & 8.50 & 1965 & Oct. 04 & 9,900 & 11.01 & 1982 & Feb. 03 & 7,310 & 9.22 \\
\hline 1949 & June 16 & 12,100 & 12.40 & 1966 & Feb. 13 & 12,400 & 12.56 & 1983 & Feb. 02 & 6,920 & 8.94 \\
\hline 1950 & Mar. 13 & 5,700 & 8.00 & 1967 & Aug. 23 & 17,500 & 15.44 & 1984 & May 08 & 5,730 & 8.02 \\
\hline 1951 & Mar. 29 & 3,620 & 6.20 & 1968 & Mar. 12 & 7,640 & 9.46 & 1985 & Feb. 02 & 1,980 & 4.55 \\
\hline 1952 & Mar. 11 & 13,800 & 13.40 & 1969 & Feb. 03 & 6,820 & 8.86 & 1986 & Nov. 30 & 2,050 & 4.62 \\
\hline 1953 & July 22 & 8,120 & 9.80 & 1970 & June 03 & 2,250 & 4.84 & 1987 & Nov. 26 & 5,600 & 7.93 \\
\hline 1954 & Jan. 16 & 10,200 & 11.20 & 1971 & Jan. 04 & 3,150 & 5.74 & 1988 & Jan. 20 & 5,300 & 7.68 \\
\hline 1955 & Feb. 06 & 9,300 & 10.60 & 1972 & May 14 & 6,670 & 8.75 & 1989 & Feb. 28 & 2,180 & 4.77 \\
\hline 1956 & Apr. 16 & 6,480 & 8.60 & 1973 & May 28 & 22,500 & 17.50 & 1990 & Mar. 17 & 8,920 & 10.36 \\
\hline
\end{tabular}




\section{APALACHICOLA RIVER BASIN \\ 02331500 SOQUE RIVER NEAR DEMOREST, GEORGIA}

LOCATION.--Lat $34^{\circ} 34^{\prime} 23^{\prime \prime}$, long $83^{\circ} 35^{\prime} 27^{\prime \prime}$, Habersham County, $300 \mathrm{ft}$ upstream from bridge on State Highway $105,2.5 \mathrm{mi}$ west of Demorest, $3 \mathrm{mi}$ downstręam from Habersham Mill Dam, and $3 \mathrm{mi}$ upstream from mouth.

DRAINAGE AREA.--156 $\mathrm{mi}^{2}$.

GAGE.--Nonrecording gage prior to May 30, 1929; water-stage recorder, May 30, 1929, to Dec. 5, 1931, and Mar. 27, 1940 to Dec. 31, 1951; crest-stage gage thereafter. Datum of gage is $1,152.16 \mathrm{ft}$ above sea level, (from U.S. Coast and Geodetic Survey benchmark), supplementary adjustment of 1936.

STAGE-DISCHARGE RELATION.--Defined by current-meter measurements below $12,000 \mathrm{ft}^{3} / \mathrm{s}$, and extended above on the basis of slope-area measurement at $21,000 \mathrm{ft}^{3} / \mathrm{s}$. Bankfull stage and discharge, $10 \mathrm{ft}$ and $9,200 \mathrm{ft}^{3} / \mathrm{s}$.

HISTORICL DATA.--Flood of June 1949 was the highest in the memory of residents of the area.

REMARKS.--Peak discharge for 1960 is estimated. Peak stage of July 1938 and June 1949 from floodmarks.

\begin{tabular}{|c|c|c|c|c|c|c|c|c|c|c|c|}
\hline $\begin{array}{l}\text { Water } \\
\text { year }\end{array}$ & Date & $\begin{array}{c}\text { Discharge } \\
\left(\mathrm{ft}^{3} / \mathrm{s}\right)\end{array}$ & $\begin{array}{c}\text { Gage } \\
\text { height } \\
\text { (ft) }\end{array}$ & $\begin{array}{l}\text { Water } \\
\text { year }\end{array}$ & Date & $\begin{array}{c}\text { Discharge } \\
\left(\mathrm{ft}^{3} / \mathrm{s}\right)\end{array}$ & $\begin{array}{c}\text { Gage } \\
\text { height } \\
\text { (ft) }\end{array}$ & $\begin{array}{l}\text { Water } \\
\text { year }\end{array}$ & Date & $\begin{array}{c}\text { Discharge } \\
\left(\mathrm{ft}^{3} / \mathrm{s}\right)\end{array}$ & $\begin{array}{l}\text { Gage } \\
\text { height } \\
\text { (ft) }\end{array}$ \\
\hline 1905 & June $\mathbf{3 0}$ & 11,000 & 18.90 & 1943 & Apr. 19 & 4,010 & 9.40 & 1955 & Feb. 06 & 6,520 & 13.10 \\
\hline 1906 & Aug. 18 & 9,500 & 17.00 & 1944 & Mar. 19 & 5,820 & 12.10 & 1956 & Apr. 14 & 3,940 & 9.30 \\
\hline 1907 & Oct. 03 & 3,150 & 8.00 & 1945 & Sept. 16 & 2,650 & 7.10 & 1957 & Apr. 04 & 3,940 & 9.30 \\
\hline$\underline{1908}$ & Apr. 25 & 5,610 & 11.80 & 1946 & Jan. 07 & 13,500 & 21.80 & 1958 & July 08 & 3,390 & 8.40 \\
\hline$\overline{1929}$ & Sept. 26 & 8,020 & 15.10 & 1947 & Jan. 20 & 6,310 & 12.80 & 1959 & May 31 & 4,080 & 9.50 \\
\hline 1930 & Mar. 07 & 2,880 & 7.50 & 1948 & July 12 & 5,190 & 11.20 & 1960 & Mar. -- & 3,200 & - \\
\hline 1931 & Nov. 16 & 1,630 & 5.30 & 1949 & June 16 & 21,000 & 28.50 & 1961 & Feb. 25 & 5,820 & 12.10 \\
\hline$\underline{1932}$ & Dec. 14 & 5,310 & 10.70 & 1950 & June 08 & 3,150 & 8.00 & 1962 & Dec. 12 & 8,320 & 15.54 \\
\hline 1938 & July 21 & 14,400 & $22.80 \mathrm{c}$ & 1951 & Oct. 20 & 3,040 & 7.90 & 1963 & Mar. 13 & 12,200 & 20.27 \\
\hline$\overline{1940}$ & Aug. 13 & 11,900 & 20.00 & 1952 & Mar. 11 & 6,600 & 13.20 & 1964 & Mar. 26 & 6,900 & 13.57 \\
\hline 1941 & July 07 & 3,450 & 8.50 & 1953 & July 22 & 6,450 & 13.00 & $\underline{1965}$ & Oct. 05 & 4,400 & 10.02 \\
\hline 1942 & Feb. 16 & 6,820 & 13.50 & 1954 & Jan. 16 & 7,120 & 14.00 & $\overline{1973}$ & May 28 & 11,900 & $19.95 \mathrm{c}$ \\
\hline
\end{tabular}

\section{CHATTAHOOCHEE RIVER NEAR CORNELIA, GEORGIA}

LOCATION.--Lat $34^{\circ} 32^{\prime} 27^{\prime \prime}$, long $83^{\circ} 37^{\prime} 14^{\prime \prime}$, White County, on downstream side of Duncan Bridge, 1 mi downstream from Soque River, 6 mi northwest of Cornelia, and at mile 401.4 DRAINAGE AREA. $-315 \mathrm{mi}^{2}$

GAGE.--Water-stage recorder. Datum of gage is $1,128.53 \mathrm{ft}$ above sea level, (levels by U.S. Army Corps of Engineeers).

STAGE-DISCHARGE RELATION.--Defined by current-meter measurements below $17,000 \mathrm{ft}^{3} / \mathrm{s}$, and extended above on the basis of contracted-opening measurement at $26,400 \mathrm{ft}^{3} / \mathrm{s}$. Bankfull stage and discharge, $16 \mathrm{ft}$ and $17,500 \mathrm{ft}^{3} / \mathrm{s}$.

\begin{tabular}{|c|c|c|c|c|c|c|c|c|c|c|c|}
\hline $\begin{array}{l}\text { Water } \\
\text { year }\end{array}$ & Date & $\begin{array}{c}\text { Discharge } \\
\left(\mathrm{ft}^{3} / \mathrm{s}\right)\end{array}$ & $\begin{array}{c}\text { Gage } \\
\text { height } \\
\text { (ft) }\end{array}$ & $\begin{array}{l}\text { Water } \\
\text { year }\end{array}$ & Date & $\begin{array}{c}\text { Discharge } \\
\left(\mathrm{ft}^{3} / \mathrm{s}\right)\end{array}$ & $\begin{array}{c}\text { Gage } \\
\text { height } \\
\text { (ft) }\end{array}$ & $\begin{array}{l}\text { Water } \\
\text { year }\end{array}$ & Date & $\begin{array}{c}\text { Discharge } \\
\left(\mathrm{ft}^{3} / \mathrm{s}\right)\end{array}$ & $\begin{array}{c}\text { Gage } \\
\text { height } \\
\text { (ft) }\end{array}$ \\
\hline 1958 & Nov. 19 & 8,000 & 8.64 & 1969 & Feb. 03 & 10,300 & 10.72 & 1980 & Mar. 17 & 14,500 & 12.11 \\
\hline 1959 & May 31 & 9,840 & 10.12 & 1970 & Nov. 02 & 3,380 & 4.40 & 1981 & May 27 & 4,400 & 4.92 \\
\hline 1960 & Feb. 05 & 6,200 & 7.00 & 1971 & July 31 & 6,400 & 7.33 & 1982 & Feb. 03 & 14,500 & 12.12 \\
\hline 1961 & Feb. 25 & 12,900 & 12.87 & 1972 & May 14 & 10,500 & 10.90 & 1983 & Feb. 02 & 13,300 & 11.33 \\
\hline 1962 & Dec. 12 & 17,800 & 16.20 & 1973 & May 28 & 25,800 & 20.30 & 1984 & Dec. 04 & 10,100 & 9.26 \\
\hline 1963 & Mar. 12 & 26,400 & 20.55 & 1974 & Dec. 31 & 9,840 & 10.37 & 1985 & Feb. 02 & 4,120 & 4.70 \\
\hline 1964 & Jan. 25 & 14,500 & 14.00 & 1975 & Mar. 14 & 10,900 & 10.85 & 1986 & Nov. 30 & 3,240 & 3.95 \\
\hline 1965 & Oct. 04 & 11,500 & 11.75 & 1976 & May 29 & 21,100 & 17.95 & 1987 & Nov. 26 & 12,700 & 10.99 \\
\hline 1966 & Mar. 04 & 17,700 & 16.10 & 1977 & Mar. 30 & 19,300 & 15.36 & 1988 & Jan. 20 & 9,270 & 8.68 \\
\hline 1967 & Aug. 23 & 22,000 & 18.83 & 1978 & Jan. 25 & 14,400 & 12.04 & 1989 & June 20 & 9,360 & 8.74 \\
\hline 1968 & Mar. 12 & 10,700 & 11.12 & 1979 & Apr. 13 & 17,600 & 14.19 & 1990 & Mar. 17 & 18,900 & 15.07 \\
\hline
\end{tabular}




\section{CHATTAHOOCHEE RIVER NEAR GAINESVILLE, GEORGIA}

LOCATION.-Lat $34^{\circ} 19^{\prime} 17^{\prime \prime}$, long $83^{\circ} 52^{\prime} 46^{\prime \prime}$, Hall County, on right bank 1,100 ft upstream from State Highway $53,0.5$ mi upstream from Eddie Creek, 3.5 mi downstream from Little River, 4 mi northwest of Gainesville, and 6 mi upstream from Chestatee River, and at mile 368.8 .

DRAINAGE AREA. $-559 \mathrm{mi}^{2}$

GAGE.-Water-stage recorder. Datum of gage is $974.98 \mathrm{ft}$ above sea level, supplementary adjustment of 1936.

STAGE-DISCHARGE RELATION.-Defined by current-meter measurements below $40,000 \mathrm{ft}^{3} / \mathrm{s}$ have been obtained, but stagedischarge relation is not well defined due to changes in the channel and rate of change of stage effect.

HISTORICAL DATA. - The flood of January 1946 was the highest since 1880 , based on information furnished by local resident. REMARKS.--Site is inundated by Lake Sidney Laner after January 1956.

\begin{tabular}{|c|c|c|c|c|c|c|c|c|c|c|c|}
\hline $\begin{array}{l}\text { Water } \\
\text { year }\end{array}$ & Date & $\begin{array}{c}\text { Discharge } \\
\left(\mathrm{ft}^{3} / \mathrm{s}\right)\end{array}$ & $\begin{array}{c}\text { Gage } \\
\text { height } \\
\text { (ft) }\end{array}$ & $\begin{array}{l}\text { Water } \\
\text { year }\end{array}$ & Date & $\begin{array}{c}\text { Discharge } \\
\left(\mathrm{ft}^{3} / \mathrm{s}\right)\end{array}$ & $\begin{array}{c}\text { Gage } \\
\text { height } \\
\text { (ft) }\end{array}$ & $\begin{array}{l}\text { Water } \\
\text { year }\end{array}$ & Date & $\begin{array}{c}\text { Discharge } \\
\left(\mathrm{ft}^{3} / \mathrm{s}\right)\end{array}$ & $\begin{array}{c}\text { Gage } \\
\text { height } \\
\text { (ft) }\end{array}$ \\
\hline 1938 & July 22 & 38,000 & 18.10 & 1944 & Mar. 20 & 21,200 & 15.60 & 1950 & Mar. 14 & 9,600 & 11.00 \\
\hline 1939 & Aug. 18 & 13,500 & 12.50 & 1945 & Sept. 17 & 8,910 & 9.20 & 1951 & Oct. 20 & 7,850 & 9.50 \\
\hline 1940 & Aug. 14 & 30,500 & 18.70 & 1946 & Jan. 07 & 45,800 & 26.20 & 1952 & Mar. 11 & 25,000 & 20.50 \\
\hline 1941 & July 15 & 9,150 & 9.50 & 1947 & Jan. 20 & 20,100 & 17.90 & 1953 & July 23 & 12,200 & 12.90 \\
\hline 1942 & Feb. 17 & 23,300 & 16.40 & 1948 & Aug. 04 & 17,800 & 16.60 & 1954 & Jan. 17 & 21,400 & 18.80 \\
\hline 1943 & Dec. 30 & 13,000 & 12.00 & 1949 & June 17 & 24,600 & 20.30 & 1955 & Feb. 07 & 21,400 & 18.60 \\
\hline
\end{tabular}

\section{CHESTATEE RIVER NEAR DAHLONEGA, GEORGIA}

LOCATION.--Lat $34^{\circ} 31^{\prime} 41^{\prime \prime}$, long $83^{\circ} 56^{\prime} 23^{\prime \prime}$, Lumpkin County, on left bank $250 \mathrm{ft}$ upstream from Bearden Bridge on State Highway 52, 2 mi downstream from Ballplay Creek, 2.5 mi east of Dahlonega, and 3.5 mi upstream from Yahoola Creek. DRAINAGE AREA. $-153 \mathrm{mi}^{2}$.

GAGE.-Water-stage recorder. Datum of gage is $1,128.6 \mathrm{ft}$ above sea level (levels by the U.S. Army Corps of Engineers).

STAGE-DISCHARGE RELATION.--Defined by current-meter measurements below $2,000 \mathrm{ft}^{3} / \mathrm{s}$ for period $1929-32$. Defined by current-meter measurements below $18,000 \mathrm{ft}^{3} / \mathrm{s}$ thereafter, and extended above on the basis of straight-line extension. The construction of new bridge and fill $250 \mathrm{ft}$ below gage in 1938 caused considerable change in the stage-discharge relation at the gage. Bankfull stage and discharge, $15 \mathrm{ft}$ and $9,500 \mathrm{ft}^{3} / \mathrm{s}$.

HISTORICAL DATA.-The flood of 1967 was the highest since 1907, based on information furnished by local resident.

REMARKS.--Failure of Gorge Dam upstream increased the flood peak of 1907 , based on information furnished by local resident.

\begin{tabular}{|c|c|c|c|c|c|c|c|c|c|c|c|}
\hline $\begin{array}{l}\text { Water } \\
\text { year }\end{array}$ & Date & $\begin{array}{c}\text { Discharge } \\
\left(\mathrm{ft}^{3} / \mathrm{s}\right)\end{array}$ & $\begin{array}{c}\text { Gage } \\
\text { height } \\
\text { (ft) }\end{array}$ & $\begin{array}{l}\text { Water } \\
\text { year }\end{array}$ & Date & $\begin{array}{c}\text { Discharge } \\
\left(\mathrm{ft}^{3} / \mathrm{s}\right)\end{array}$ & $\begin{array}{c}\text { Gage } \\
\text { height } \\
\text { (ft) }\end{array}$ & $\begin{array}{l}\text { Water } \\
\text { year }\end{array}$ & Date & $\begin{array}{c}\text { Discharge } \\
\left(\mathrm{ft}^{3} / \mathrm{s}\right)\end{array}$ & $\begin{array}{c}\text { Gage } \\
\text { height } \\
\text { (ft) }\end{array}$ \\
\hline$\underline{1907}$ & Aug. 12 & 22,000 & $25.00 \mathrm{c}$ & 1954 & Jan. 16 & 10,200 & 17.60 & 1973 & May 28 & 20,300 & 23.60 \\
\hline 1929 & Sept. 25 & 7,300 & 12.60 & 1955 & Feb. 06 & 8,330 & 15.70 & 1974 & Dec. 31 & 4,940 & 9.93 \\
\hline 1930 & Mar. 07 & 5,450 & 10.30 & 1956 & Apr. 16 & 4,840 & 10.90 & 1975 & Mar. 14 & 5,110 & 10.14 \\
\hline 1931 & Nov. 16 & 2,650 & 6.60 & 1957 & Apr. 05 & 5,320 & 11.70 & 1976 & May 15 & 11,500 & 16.56 \\
\hline 1932 & Dec. 14 & 9,000 & 14.60 & 1958 & Dec. 20 & 2,920 & 7.50 & 1977 & Mar. 30 & 11,700 & 16.88 \\
\hline 1940 & Aug. 13 & 9,950 & 17.40 & 1959 & Jan. 22 & 4,300 & 10.00 & 1978 & Jan. 26 & 7,280 & 12.38 \\
\hline 1941 & July 14 & 3,320 & 9.90 & 1960 & Mar. 30 & 3,360 & 8.30 & 1979 & Apr. 13 & 8,440 & 13.69 \\
\hline 1942 & Feb. 17 & 10,500 & 17.90 & 1961 & Feb. 25 & 8,600 & 16.00 & 1980 & Mar. 17 & 9,210 & 14.41 \\
\hline 1943 & Dec. 29 & 4,510 & 11.60 & 1962 & Dec. 12 & 12,500 & 19.73 & 1981 & May 27 & 4,230 & 8.60 \\
\hline 1944 & Mar. 19 & 6,770 & 14.30 & 1963 & Mar. 12 & 21,700 & 24.53 & 1982 & Feb. 03 & 9,100 & 14.31 \\
\hline 1945 & Sept. 16 & 2,980 & 9.10 & 1964 & Jan. 25 & 9,330 & 14.70 & 1983 & Dec. 05 & 5,460 & 10.20 \\
\hline 1946 & Jan. 07 & 15,300 & 22.10 & 1965 & Oct. 04 & 8,000 & 13.34 & 1984 & May 08 & 5,740 & 10.54 \\
\hline 1947 & Jan. 20 & 8,150 & 15.60 & 1966 & Feb. 13 & 15,800 & 20.34 & 1985 & Feb. 02 & 2,280 & 5.65 \\
\hline 1948 & Aug. 04 & 8,150 & 15.60 & 1967 & Aug. 23 & 22,700 & 25.17 & 1986 & Nov. 30 & 2,110 & 5.36 \\
\hline 1949 & Jan. 05 & 9,450 & 16.90 & 1968 & Mar. 12 & 10,500 & 15.79 & 1987 & Feb. 28 & 5,430 & 10.16 \\
\hline 1950 & Mar. 13 & 4,370 & 11.10 & 1969 & Aug. 22 & 10,100 & 15.51 & 1988 & Jan. 20 & 5,320 & 10.03 \\
\hline 1951 & Mar. 29 & 2,400 & 7.40 & 1970 & Dec. 31 & 1,960 & 5.52 & 1989 & June 20 & 4,160 & 8.51 \\
\hline 1952 & Mar. 11 & 13,800 & 20.80 & 1971 & Jan. 05 & 2,680 & 6.72 & 1990 & Mar. 17 & 11,600 & 16.76 \\
\hline 1953 & July 22 & 3,860 & 10.30 & 1972 & Dec. 07 & 4,580 & 9.52 & & & & \\
\hline
\end{tabular}




\section{APALACHICOLA RIVER BASIN}

\section{CHATTAHOOCHEE RIVER AT BUFORD DAM NEAR BUFORD, GEORGIA}

LOCATION.--Lat $34^{\circ} 09^{\prime} 25^{\prime \prime}$, long $84^{\circ} 04^{\prime} 44^{\prime \prime}$, Gwinnett-Forsyth County line, on right bank 1,200 ft downstream from Buford Dam, 4 mi northwest of Buford, and at mile 348.1 .

DRAINAGE AREA.-1,040 $\mathrm{mi}^{2}$, approximately.

GAGE.-Water-stage recorder. Datum of gage is $912.04 \mathrm{ft}$ above sea level (levels by the U.S. Army Corps of Engineers).

STAGE-DISCHARGE RELATION.--Defined by current-meter measurements below $10,300 \mathrm{ft}^{3} / \mathrm{s}$ and extended above on the basis of straight-line extension.

REMARKS.--Peak discharges regulated by Lake Sidney Lanier (maximum flood-control storage, 637,000 acre-ft) since January 1956.

\begin{tabular}{|c|c|c|c|c|c|c|c|c|c|c|c|}
\hline $\begin{array}{l}\text { Water } \\
\text { year }\end{array}$ & Date & $\begin{array}{c}\text { Discharge } \\
\left(\mathrm{ft}^{3} / \mathrm{s}\right)\end{array}$ & $\begin{array}{l}\text { Gage } \\
\text { height } \\
\text { (ft) }\end{array}$ & $\begin{array}{l}\text { Water } \\
\text { year }\end{array}$ & Date & $\begin{array}{c}\text { Discharge } \\
\left(\mathrm{ft}^{3} / \mathrm{s}\right)\end{array}$ & $\begin{array}{c}\text { Gage } \\
\text { height } \\
\text { (ft) }\end{array}$ & $\begin{array}{l}\text { Water } \\
\text { year }\end{array}$ & Date & $\begin{array}{c}\text { Discharge } \\
\left(\mathrm{ft}^{3} / \mathrm{s}\right)\end{array}$ & $\begin{array}{c}\text { Gage } \\
\text { height } \\
\text { (ft) }\end{array}$ \\
\hline 1972 & Oct. 22 & 9,670 & 7.88 & 1979 & Nov. 02 & 11,000 & 7.41 & 1985 & Sept. 24 & 9,290 & 6.06 \\
\hline 1973 & Oct. 10 & 9,620 & 7.76 & 1980 & May 23 & 10,800 & 6.92 & 1986 & July 28 & 10,000 & 6.00 \\
\hline 1974 & Oct. 25 & 8,760 & 7.05 & 1981 & Sept. 29 & 9,510 & 6.13 & 1987 & Sept. 25 & 11,100 & 5.91 \\
\hline 1975 & Sept. 04 & 9,970 & 7.30 & 1982 & Nov. 24 & 10,400 & 6.78 & 1988 & Oct. 29 & 11,200 & 5.95 \\
\hline 1976 & June 29 & 9,970 & 7.30 & 1983 & Feb. 16 & 9,330 & 6.08 & 1989 & Jan. 18 & 11,000 & 5.89 \\
\hline 1977 & July 21 & 9,760 & 7.13 & 1984 & Nov. 02 & 9,290 & 6.06 & 1990 & Sept. 05 & 10,300 & 5.55 \\
\hline 1978 & Feb. 08 & 10,400 & 7.02 & & & & & & & & \\
\hline
\end{tabular}

\section{CHATTAHOOCHEE RIVER NEAR BUFORD, GEORGIA}

LOCATION.--Lat $34^{\circ} 07^{\prime} 34^{\prime \prime}$, long $84^{\circ} 05^{\prime} 37^{\prime \prime}$, Gwinnett County, at bridge on State Highway $20,0.8$ mi upstream from Dave Creek, 3.2 mi downstream from Buford Dam, 4 mi downstream from Bald Ridge Creek, 5 mi west of Buford, and at mile 345.8 . DRAINAGE AREA.-1,060 $\mathrm{mi}^{2}$

GAGE.--Water-stage recorder. Datum of gage is $905.20 \mathrm{ft}$ above sea level (levels by the U.S. Army Corps of Engineers), supplementary adjustment of 1936. Jan. 28,1942 to Dec. 3, 1944, nonrecording gage and Dec. 4, 1944 to Dec. 31, 1947, waterstage recorder at site 1,000 ft downstream at same datum.

STAGE-DISCHARGE RELATION.--Defined by current-meter measurements below $28,000 \mathrm{ft}^{3} / \mathrm{s}$ for period $1942-55$. Defined by current-meter measurements below $11,000 \mathrm{ft}^{3} / \mathrm{s}$ for period $1956-71$.

HISTORICAL DATA.--The flood of Janaury 1946 was the highest since 1880, based on information at nearby stations.

REMARKS.--Peak discharges regulated by Lake Sidney Lanier (maximum flood-control storage, 637,000 acre-ft) since January 1956.

\begin{tabular}{|c|c|c|c|c|c|c|c|c|c|c|c|}
\hline $\begin{array}{l}\text { Water } \\
\text { year }\end{array}$ & Date & $\begin{array}{c}\text { Discharge } \\
\left(\mathrm{ft}^{3} / \mathrm{s}\right)\end{array}$ & $\begin{array}{c}\text { Gage } \\
\text { height } \\
\text { (ft) }\end{array}$ & $\begin{array}{l}\text { Water } \\
\text { year }\end{array}$ & Date & $\begin{array}{c}\text { Discharge } \\
\left(\mathrm{ft}^{3} / \mathrm{s}\right)\end{array}$ & $\begin{array}{c}\text { Gage } \\
\text { height } \\
\text { (ft) }\end{array}$ & $\begin{array}{l}\text { Water } \\
\text { year }\end{array}$ & Date & $\begin{array}{c}\text { Discharge } \\
\left(\mathrm{ft}^{3} / \mathrm{s}\right)\end{array}$ & $\begin{array}{c}\text { Gage } \\
\text { height } \\
\text { (ft) }\end{array}$ \\
\hline 1942 & Feb. 18 & 21,400 & 23.00 & 1953 & Jan. 10 & 16,200 & 19.90 & 1963 & Nov. 21 & 11,400 & 15.20 \\
\hline 1943 & Dec. 30 & 19,100 & 21.90 & 1954 & Jan. 17 & 28,900 & 25.90 & 1964 & Apr. 06 & 10,600 & 14.54 \\
\hline 1944 & Mar. 29 & 19,900 & 22.30 & 1955 & Feb. 08 & 17,500 & 20.60 & 1965 & Oct. 16 & 9,990 & 13.99 \\
\hline 1945 & Sept. 17 & 10,400 & 15.40 & 1956 & Apr. 17 & 5,400 & 10.30 & 1966 & Sept. 08 & 8,580 & 12.82 \\
\hline 1946 & Jan. 08 & 55,000 & 32.60 & 1957 & Apr. 05 & 6,760 & 11.70 & 1967 & Aug. 14 & 9,540 & 12.40 \\
\hline 1947 & Jan. 21 & $\underline{29,800}$ & 25.40 & 1958 & Feb. 13 & 11,100 & 15.70 & 1968 & Sept. 26 & 10,100 & 12.64 \\
\hline 1948 & $\overline{\text { Aug. } 05}$ & $\overline{22,900}$ & 22.90 & 1959 & July 16 & 9,300 & 14.00 & 1969 & Oct. 02 & 9,980 & 12.27 \\
\hline 1949 & Jan. 06 & 28,200 & 25.60 & 1960 & June 10 & 9,100 & 13.80 & 1970 & Sept. 22 & 9,640 & 12.03 \\
\hline 1950 & Mar. 14 & 13,700 & 18.20 & 1961 & Aug. 11 & 9,760 & 13.80 & 1971 & Aug. 13 & 8,890 & 11.89 \\
\hline 1951 & Oct. 21 & 10,800 & 15.80 & 1962 & Apr. 16 & 10,100 & 14.10 & 1972 & Oct. 22 & 9,670 & 13.59 \\
\hline 1952 & Mar. 12 & 34,100 & 27.70 & & & & & & & & \\
\hline
\end{tabular}




\section{APALACHICOLA RIVER BASIN}

\section{SUWANEE CREEK NEAR SUWANEE, GEORGIA}

LOCATION.--Lat $34^{\circ} 01^{\prime} 56^{\prime \prime}$, long $84^{\circ} 05^{\prime} 22^{\prime \prime}$, Gwinnett County, on upstream side of right bank pier of bridge on State Highway 13, $0.2 \mathrm{mi}$ upstream from Bennett Creek, $2.4 \mathrm{mi}$ southwest of Suwanee, and $3.1 \mathrm{mi}$ upstream from mouth.

DRAINAGE AREA.--46.8 $\mathrm{mi}^{2}$.

GAGE.-Water-stage recorder. Datum of gage is $909.71 \mathrm{ft}$ above sea level (from U.S. Coast and Geodetic Survey benchmark).

STAGE-DISCHARGE RELATION.--Defined by current-meter measurements below $3,760 \mathrm{ft}^{3} / \mathrm{s}$, and extended above on the basis of straight-line extension.

\begin{tabular}{|c|c|c|c|c|c|c|c|c|c|c|c|}
\hline $\begin{array}{l}\text { Water } \\
\text { year }\end{array}$ & Date & $\begin{array}{c}\text { Discharge } \\
\left(\mathrm{ft}^{3} / \mathrm{s}\right)\end{array}$ & $\begin{array}{c}\text { Gage } \\
\text { height } \\
\text { (ft) }\end{array}$ & $\begin{array}{l}\text { Water } \\
\text { year }\end{array}$ & Date & $\begin{array}{c}\text { Discharge } \\
\left(\mathrm{ft}^{3} / \mathrm{s}\right)\end{array}$ & $\begin{array}{c}\text { Gage } \\
\text { height } \\
\text { (ft) }\end{array}$ & $\begin{array}{l}\text { Water } \\
\text { year }\end{array}$ & Date & $\begin{array}{c}\text { Discharge } \\
\left(\mathrm{ft}^{3} / \mathrm{s}\right)\end{array}$ & $\begin{array}{c}\text { Gage } \\
\text { height } \\
\text { (ft) }\end{array}$ \\
\hline 1985 & July $\mathbf{3 0}$ & 1,440 & 9.39 & 1987 & Nov. 26 & 2,150 & 10.41 & 1989 & June 21 & 1,220 & 9.01 \\
\hline 1986 & Dec. 13 & 386 & 5.97 & 1988 & Jan. 20 & 948 & 8.45 & 1990 & Mar. 17 & 3,760 & 11.42 \\
\hline
\end{tabular}




\section{CHATTAHOOCHEE RIVER NEAR NORCROSS, GEORGIA}

LOCATION.--Lat $33^{\circ} 59^{\prime} 50^{\prime \prime}$, long $84^{\circ} 12^{\prime} 07^{\prime \prime}$, Gwinnett-Fulton County line, on downstream side of right bank pier of bridge on State Highway 141, $1.5 \mathrm{mi}$ upstream from John Creek, $4.5 \mathrm{mi}$ north of Norcross, $6.5 \mathrm{mi}$ downstream from Suwanee Creek, $18 \mathrm{mi}$ downstream from Buford Dam, and at mile 330.8 .

DRAINAGE AREA.--1,170 $\mathrm{mi}^{2}$, approximately.

GAGE.--Water-stage recorder. Datum of gage is $\mathbf{8 7 8 . 1 4} \mathrm{ft}$ above sea level (levels by the U.S. Army Corps of Engineers). Prior to July 13,1955 , nonrecording gage at site $500 \mathrm{ft}$ downstream at same datum. July 14, 1955, to Mar. 11, 1957, nonrecording gage at present site and datum.

STAGE-DISCHARGE RELATION.--Defined by current-meter measurements below $36,000 \mathrm{ft}^{3} / \mathrm{s}$, and extended above on the basis of flow over Morgan Falls Dam at $56,000 \mathrm{ft}^{3} / \mathrm{s}$. Bankfull stage and discharge, $11 \mathrm{ft}$ and $10,000 \mathrm{ft}^{3} / \mathrm{s}$.

HISTORICAL DATA.--Flood of January 1946 was the highest since 1880, based on information from local residents. Flood of 1886 , based on information from local residents.

REMARKS.--Peak discharges regulated by Lake Sidney Lanier (maximum flood-control storage, 637,000 acre-ft) since January 1956. Peak discharges for 1907 is maximum daily.

\begin{tabular}{|c|c|c|c|c|c|c|c|c|c|c|c|}
\hline $\begin{array}{l}\text { Water } \\
\text { year }\end{array}$ & Date & $\begin{array}{c}\text { Discharge } \\
\left(\mathrm{ft}^{3} / \mathrm{s}\right)\end{array}$ & $\begin{array}{c}\text { Gage } \\
\text { height } \\
\text { (ft) }\end{array}$ & $\begin{array}{l}\text { Water } \\
\text { year }\end{array}$ & Date & $\begin{array}{c}\text { Discharge } \\
\left(\mathrm{ft}^{3} / \mathrm{s}\right)\end{array}$ & $\begin{array}{c}\text { Gage } \\
\text { height } \\
\text { (ft) }\end{array}$ & $\begin{array}{l}\text { Water } \\
\text { year }\end{array}$ & Date & $\begin{array}{c}\text { Discharge } \\
\left(\mathrm{ft}^{3} / \mathrm{s}\right)\end{array}$ & $\begin{array}{c}\text { Gage } \\
\text { height } \\
\text { (ft) }\end{array}$ \\
\hline 1886 & Apr. -- & 40,000 & $23.40 \mathrm{C}$ & 1932 & Dec. 16 & 19,500 & 14.70 & 1962 & Apr. 12 & 9,500 & 11.00 \\
\hline$\overline{1903}$ & Mar. 24 & 32,500 & 20.60 & 1933 & Dec. 29 & 32,100 & 20.00 & 1963 & Nov. 22 & 11,000 & 12.05 \\
\hline 1904 & Aug. 09 & 14,300 & 11.20 & 1934 & Mar. 05 & 31,800 & 19.90 & 1964 & Apr. 05 & 13,200 & 13.10 \\
\hline 1905 & Jan. 13 & 16,100 & 12.20 & 1935 & Oct. 07 & 17,200 & 13.60 & 1965 & Apr. 02 & 9,760 & 10.84 \\
\hline 1906 & Jan. 04 & 24,300 & 16.40 & 1936 & Apr. 07 & 38,400 & 22.20 & 1966 & Apr. 28 & 9,500 & 10.67 \\
\hline 1907 & Oct. 03 & 13,900 & 11.00 & 1937 & Jan. 04 & 27,200 & 18.10 & 1967 & June 06 & 8,800 & 10.20 \\
\hline 1908 & Apr. 26 & 20,400 & 14.30 & 1938 & July 23 & 17,800 & 13.90 & 1968 & Jan. 10 & 10,500 & 11.30 \\
\hline 1909 & Mar. 14 & 22,000 & 16.00 & 1939 & Aug. 19 & 14,800 & 12.40 & 1969 & Sept. 23 & 8,530 & 10.02 \\
\hline 1910 & May 09 & 12,400 & 10.70 & 1940 & Aug. 15 & 22,500 & 18.00 & 1970 & Dec. 02 & 8,650 & 10.10 \\
\hline 1911 & Apr. 06 & 14,000 & 12.20 & 1941 & July 06 & 9,340 & 10.70 & 1971 & Oct. 14 & 9,300 & 10.53 \\
\hline 1912 & Mar. 16 & 30,500 & 19.30 & 1942 & Feb. 18 & 20,600 & 17.30 & 1972 & Jan. 10 & 9,430 & 10.62 \\
\hline 1913 & Mar. 15 & 16,000 & 13.40 & 1943 & Dec. 31 & 15,500 & 14.80 & 1973 & Mar. 16 & 12,200 & 12.47 \\
\hline 1914 & Apr. 15 & 11,300 & 10.50 & 1944 & Mar. 30 & 22,500 & 18.00 & 1974 & Apr. 05 & 9,260 & 10.30 \\
\hline 1915 & Dec. 05 & 18,400 & 14.80 & 1945 & Apr. 26 & 9,460 & 10.80 & 1975 & May 07 & 11,200 & 11.48 \\
\hline 1916 & Dec. 30 & 36,200 & 21.40 & 1946 & Jan. 08 & 55,000 & 27.70 & 1976 & May 28 & 11,100 & 11.49 \\
\hline 1917 & Mar. 25 & 24,200 & 16.90 & 1947 & Jan. 21 & 28,900 & 20.10 & 1977 & Mar. 30 & 10,500 & 11.09 \\
\hline 1918 & Jan. 29 & 10,800 & 10.40 & 1948 & Aug. 06 & 16,600 & 15.40 & 1978 & Feb. 09 & 10,400 & 11.03 \\
\hline 1919 & Dec. 23 & 35,900 & 21.30 & 1949 & Jan. 07 & 29,200 & 20.20 & 1979 & Apr. 13 & 10,600 & 11.66 \\
\hline 1920 & Dec. 10 & 54,700 & 27.10 & 1950 & Mar. 14 & 11,000 & 12.00 & 1980 & May 23 & 10,500 & 11.59 \\
\hline 1921 & Feb. 10 & 33,300 & 20.40 & 1951 & Oct. 21 & 10,500 & 11.60 & 1981 & Sept. 28 & 8,500 & 9.92 \\
\hline 1922 & Mar. 11 & 14,000 & 12.40 & 1952 & Mar. 12 & 35,000 & 22.00 & 1982 & Sept. 13 & 8,280 & 9.73 \\
\hline 1923 & Dec. 18 & 18,600 & 14.60 & 1953 & Jan. 11 & 15,800 & 15.00 & 1983 & Apr. 06 & 9,440 & 10.71 \\
\hline 1924 & Apr. 19 & 11,400 & 10.50 & 1954 & Jan. 17 & 28,600 & 20.00 & 1984 & May 02 & 10,000 & 11.19 \\
\hline 1925 & Jan. 19 & 16,800 & 13.40 & 1955 & Feb. 09 & $\underline{17,300}$ & 15.80 & 1985 & Sept. 23 & 9,260 & 10.56 \\
\hline 1926 & Jan. 19 & 19,700 & 14.80 & 1956 & $\overline{\text { Apr. } 19}$ & 5,120 & 6.90 & 1986 & July 31 & 9,380 & 10.66 \\
\hline 1927 & Feb. 14 & 11,400 & 10.50 & 1957 & Apr. 05 & 8,580 & 10.10 & 1987 & July 17 & 8,820 & 10.19 \\
\hline 1928 & Aug. 17 & 15,600 & 12.80 & 1958 & Feb. 13 & 8,970 & 10.00 & 1988 & Oct. 02 & 8,210 & 9.69 \\
\hline 1929 & Sept. 27 & 31,100 & 19.60 & 1959 & June 20 & 7,890 & 9.60 & 1989 & Aug. 01 & 9,010 & 10.35 \\
\hline 1930 & Mar. 08 & 16,000 & 13.00 & 1960 & Apr. 06 & 8710 & 10.20 & 1990 & Mar. 17 & 11,000 & 11.99 \\
\hline 1931 & Nov. 17 & 10,600 & 9.70 & 1961 & Fè่. 21 & 8,950 & $10 . \Omega_{\delta}$ & & & & \\
\hline
\end{tabular}




\section{APALACHICOLA RIVER BASIN}

\section{CHATTAHOOCHEE RIVER ABOVE ROSWELL, GEORGIA}

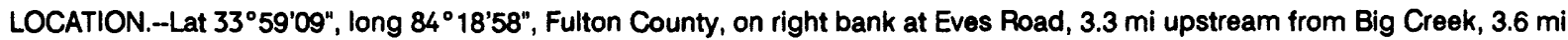
southeast of Roswell, and at mile 320.6 .

DRAINAGE AREA.--1,220 $\mathrm{mi}^{2}$, approximately.

GAGE.-Water-stage recorder. Datum of gage is $858.01 \mathrm{ft}$ above sea level (levels by the U.S. Army Corps of Engineers).

STAGE-DISCHARGE RELATION.--Defined by current-meter measurements below $9,980 \mathrm{ft}^{3} / \mathrm{s}$, and extended above on the basis of straight-line extension.

REMARKS.--Peak discharges regulated by Lake Sidney Lanier (maximum flood-control storage, 637,000 acre-ft) since January 1956.

\begin{tabular}{|c|c|c|c|c|c|c|c|c|c|c|c|}
\hline $\begin{array}{l}\text { Water } \\
\text { year }\end{array}$ & Date & $\begin{array}{c}\text { Discharge } \\
\left(\mathrm{ft}^{3} / \mathrm{s}\right)\end{array}$ & $\begin{array}{c}\text { Gage } \\
\text { height } \\
\text { (ft) }\end{array}$ & $\begin{array}{l}\text { Water } \\
\text { year }\end{array}$ & Date & $\begin{array}{c}\text { Discharge } \\
\left(\mathrm{ft}^{3} / \mathrm{s}\right)\end{array}$ & $\begin{array}{c}\text { Gage } \\
\text { height } \\
\text { (ft) }\end{array}$ & $\begin{array}{l}\text { Water } \\
\text { year }\end{array}$ & Date & $\begin{array}{c}\text { Discharge } \\
\left(\mathrm{ft}^{3} / \mathrm{s}\right)\end{array}$ & $\begin{array}{c}\text { Gage } \\
\text { height } \\
\text { (ft) }\end{array}$ \\
\hline 1977 & Mar. 30 & 11,800 & 8.88 & 1982 & Feb. 03 & 10,600 & 8.64 & 1987 & Sept. 08 & 8,640 & 7.74 \\
\hline 1978 & Jan. 25 & 10,800 & 8.45 & 1983 & Apr. 08 & 9,700 & 8.29 & 1988 & Oct. 02 & 7,340 & 7.16 \\
\hline 1979 & Apr. 13 & 13,800 & 9.75 & 1984 & Dec. 06 & 11,500 & 8.98 & 1989 & Aug. 02 & 8,810 & 7.81 \\
\hline 1980 & May 24 & 10,600 & 8.63 & 1985 & Sept. 24 & 8,750 & 7.88 & 1990 & Mar. 17 & 14,500 & 9.89 \\
\hline 1981 & Sept. 29 & 8,020 & 7.57 & 1986 & Aug. 01 & 8,480 & 7.67 & & & & \\
\hline
\end{tabular}

\section{CHATTAHOOCHEE RIVER NEAR ROSWELL, GEORGIA}

LOCATION.--Lat $34^{\circ} 00^{\prime} 20^{\prime \prime}$, long $84^{\circ} 19^{\prime} 53^{\prime \prime}$, Fulton County, on right bank $1.5 \mathrm{mi}$ upstream from Big Creek and bridge on U.S.

Highway 19, 2 mi southeast of Roswell, and at mile 318.8.

DRAINAGE AREA.-1,230 $\mathrm{mi}^{2}$, approximately.

GAGE.-Water-stage recorder. Datum of gage is $849.50 \mathrm{ft}$ above sea level (levels by the U.S. Army Corps of Engineers).

STAGE-DISCHARGE RELATION.--Defined by current-meter measurements below $30,000 \mathrm{ft}^{3} / \mathrm{s}$, and extended above on the basis of flow over Morgan Falls Dam at $56,000 \mathrm{ft}^{3} / \mathrm{s}$. Bankfull stage and discharge, $13 \mathrm{ft}$ and $15,000 \mathrm{ft}^{3} / \mathrm{s}$.

HISTORICAL DATA.--Flood of January 1946 was the highest since 1880 , based on information at nearby stations.

REMARKS.-Peak discharges regulated by Lake Sidney Lanier (maximum flood-control storage, 637,000 acre-ft) since January 1956.

\begin{tabular}{|c|c|c|c|c|c|c|c|c|c|c|c|}
\hline $\begin{array}{l}\text { Water } \\
\text { year }\end{array}$ & Date & $\begin{array}{c}\text { Discharge } \\
\left(\mathrm{ft}^{3} / \mathrm{s}\right)\end{array}$ & $\begin{array}{c}\text { Gage } \\
\text { height } \\
\text { (ft) }\end{array}$ & $\begin{array}{l}\text { Water } \\
\text { year }\end{array}$ & Date & $\begin{array}{c}\text { Discharge } \\
\left(\mathrm{ft}^{3} / \mathrm{s}\right)\end{array}$ & $\begin{array}{c}\text { Gage } \\
\text { height } \\
\text { (ft) }\end{array}$ & $\begin{array}{l}\text { Water } \\
\text { year }\end{array}$ & Date & $\begin{array}{c}\text { Discharge } \\
\left(\mathrm{ft}^{3} / \mathrm{s}\right)\end{array}$ & $\begin{array}{c}\text { Gage } \\
\text { height } \\
\text { (ft) }\end{array}$ \\
\hline 1942 & Feb. 18 & 19,800 & 15.10 & 1949 & Jan. 07 & 28,800 & 17.90 & 1955 & Feb. 09 & 18,000 & 14.20 \\
\hline 1943 & Dec. 31 & 17,000 & 18.00 & 1950 & Mar. 15 & 13,000 & 12.00 & 1956 & Mar. 16 & 6,940 & 8.30 \\
\hline 1944 & Mar. 30 & 22,200 & 15.90 & 1951 & Oct. 21 & 10,900 & 10.80 & 1957 & Apr. 05 & 11,400 & 11.10 \\
\hline 1945 & Apr. 26 & 10,400 & 10.60 & 1952 & Mar. 13 & 33,700 & 19.20 & 1958 & Feb. 13 & 7,670 & $8.8 ?$ \\
\hline 1946 & Jan. 08 & 56,000 & 23.40 & 1953 & Jan. 11 & 17,400 & 14.00 & 1959 & June 18 & 8,200 & 8.00 \\
\hline 1947 & Jan. 22 & 28,400 & 17.80 & 1954 & Jan. 18 & 28,100 & 17.70 & 15050 & Afe. 06 & 8,520 & 8.20 \\
\hline $19: 8$ & Aug. 06 & 18,800 & 14.40 & & & & & & & & \\
\hline
\end{tabular}




\section{APALACHICOLA RIVER BASIN \\ 02335700 BIG CREEK NEAR ALPHARETTA, GEORGIA}

LOCATION.--Lat $34^{\circ} 03^{\prime} 02^{\prime \prime}$, long $84^{\circ} 16^{\prime} 10^{\prime \prime}$, Fulton County, on left bank at downstream side of Kimball Bridge Road, $2.6 \mathrm{mi}$ southeast of Alpharetta, and 9.4 mi upstream from mouth.

DRAINAGE AREA.-72 $\mathrm{mi}^{2}$, approximately.

GAGE.-Water-stage recorder. Datum of gage is $960.80 \mathrm{ft}$ above sea level (levels by the U.S. Soil Conservation Service).

STAGE-DISCHARGE RELATION.--Defined by current-meter measurements below $6,100 \mathrm{ft}^{3} / \mathrm{s}$. Bankfull stage and discharge, $7 \mathrm{ft}$ and $650 \mathrm{tt}^{3} / \mathrm{s}$.

\begin{tabular}{|c|c|c|c|c|c|c|c|c|c|c|c|}
\hline $\begin{array}{l}\text { Water } \\
\text { year }\end{array}$ & Date & $\begin{array}{c}\text { Discharge } \\
\left(\mathrm{ft}^{3} / \mathrm{s}\right)\end{array}$ & $\begin{array}{c}\text { Gage } \\
\text { height } \\
\text { (ft) }\end{array}$ & $\begin{array}{l}\text { Water } \\
\text { year }\end{array}$ & Date & $\begin{array}{c}\text { Discharge } \\
\left(\mathrm{ft}^{3} / \mathrm{s}\right)\end{array}$ & $\begin{array}{c}\text { Gage } \\
\text { height } \\
\text { (ft) }\end{array}$ & $\begin{array}{l}\text { Water } \\
\text { year }\end{array}$ & Date & $\begin{array}{c}\text { Discharge } \\
\left(\mathrm{ft}^{3} / \mathrm{s}\right)\end{array}$ & $\begin{array}{c}\text { Gage } \\
\text { height } \\
\text { (ft) }\end{array}$ \\
\hline 1961 & Feb. 21 & 5,800 & 12.54 & 1971 & Mar. 04 & 820 & 7.89 & 1981 & Feb. 19 & 823 & 7.87 \\
\hline 1962 & Dec. 13 & 4,700 & 11.97 & 1972 & Jan. 11 & 2,430 & 10.78 & 1982 & Feb. 03 & 6,100 & 13.05 \\
\hline 1963 & Apr. 30 & 2,860 & 10.77 & 1973 & Mar. 17 & 1,740 & 9.82 & 1983 & Apr. 09 & 1,150 & 9.08 \\
\hline 1964 & Mar. 26 & 4,140 & 11.82 & 1974 & Jan. 01 & 2,510 & 10.81 & 1984 & Dec. 06 & 4,880 & 12.30 \\
\hline 1965 & Jan. 23 & 684 & 7.17 & 1975 & Mar. 14 & 1,940 & 10.14 & 1985 & Feb. 02 & 817 & 7.61 \\
\hline 1966 & Mar. 05 & 3,240 & 11.26 & 1976 & Mar. 31 & 2,620 & 10.80 & 1986 & Sept. 04 & 379 & 5.22 \\
\hline 1967 & Aug. 25 & 1,280 & 9.22 & 1977 & Mar. 30 & 5,080 & 12.20 & 1987 & Mar. 01 & 2,410 & 10.49 \\
\hline 1968 & Jan. 11 & 1,580 & 9.73 & 1978 & Nov. 06 & 1,890 & 10.15 & 1988 & Sept. 13 & 2,080 & 10.10 \\
\hline 1969 & Aug. 23 & 1,740 & 9.92 & 1979 & Apr. 14 & 4,220 & 11.65 & 1989 & June 23 & 652 & 6.72 \\
\hline 1970 & Mar. 21 & 879 & 8.03 & 1980 & Mar. 09 & 2,640 & 10.62 & 1990 & Mar. 17 & 5,820 & 12.81 \\
\hline
\end{tabular}

02335870 SOPE CREEK NEAR MARIETTA, GEORGIA

LOCATION.--Lat 33 $57^{\prime} 14^{\prime \prime}$, long $84^{\circ} 26^{\prime} 36^{\prime \prime}$, Cobb County, on downstream side of bridge on Lower Roswell road, $0.3 \mathrm{mi}$ downstream from Bishop Creek, and 2.6 mi upstream from mouth.

DRAINAGE AREA.-29.2 $\mathrm{mi}^{2}$.

GAGE.--Water-stage recorder. Datum of gage is $881.37 \mathrm{ft}$ above sea level (levels by the U.S. Army Corps of Engineers).

STAGE-DISCHARGE RELATION.--Defined by current-meter measurements below $3,910 \mathrm{ft}^{3} / \mathrm{s}$, and extended above on the basis of straight-line extension.

REMARKS.--Flood stage of March 1977 and February 1982 from flood marks, and the peak dischrges for these floods are unknown. Peak flows are affected by urbanization to an unknown degree.

\begin{tabular}{|c|c|c|c|c|c|c|c|c|c|c|c|}
\hline $\begin{array}{l}\text { Water } \\
\text { year }\end{array}$ & Date & $\begin{array}{c}\text { Discharge } \\
\left(\mathrm{ft}^{3} / \mathrm{s}\right)\end{array}$ & $\begin{array}{c}\text { Gage } \\
\text { height } \\
\text { (ft) }\end{array}$ & $\begin{array}{l}\text { Water } \\
\text { year }\end{array}$ & Date & $\begin{array}{c}\text { Discharge } \\
\left(\mathrm{ft}^{3} / \mathrm{s}\right)\end{array}$ & $\begin{array}{c}\text { Gage } \\
\text { height } \\
\text { (ft) }\end{array}$ & $\begin{array}{l}\text { Water } \\
\text { year }\end{array}$ & Date & $\begin{array}{c}\text { Discharge } \\
\left(\mathrm{ft}^{3} / \mathrm{s}\right)\end{array}$ & $\begin{array}{c}\text { Gage } \\
\text { height } \\
\text { (ft) }\end{array}$ \\
\hline$\underline{1977}$ & Mar. 30 & - & $21.10 c$ & 1986 & May 28 & 1,370 & 9.48 & 1989 & Sept. 30 & 6,630 & 16.22 \\
\hline$\underline{1982}$ & Feb. 04 & - & $20.00 c$ & 1987 & Oct. 25 & 3,270 & 12.01 & 1990 & Mar. 16 & 5,730 & 15.27 \\
\hline 1985 & Aug. 17 & 2,140 & 10.61 & 1988 & Jan. 20 & 1,820 & 10.21 & & & & \\
\hline
\end{tabular}


LOCATION.--Lat $33^{\circ} 51^{\prime} 33^{\prime \prime}$, long $84^{\circ} 27^{\prime} 16^{\prime \prime}$, Fulton County, on left bank $20 \mathrm{ft}$ upstream from Paces Ferry Bridge at Atlanta, 1 mi downstream from Rottenwood Creek, 2.5 mi upstream from Peachtree Creek, and at mile 303.0.

DRAINAGE AREA.--1,450 $\mathrm{mi}^{2}$, approximately.

GAGE.--Water-stage recorder. Datum of gage is $750.10 \mathrm{ft}$ above sea level (from city of Atlanta benchmark), supplementary adjustment of 1936. Aug. 3, 1928 to Dec. 31, 1931, water-stage recorder, and Nov. 15, 1936, to Mar. 8, 1937, nonrecording gage at same site and datum. Since June 1967, auxiliary water-stage recorder at bridge on U.S. Highway 41, 0.8 mi upstream. Prior to October 1951 published as "near Vinings".

STAGE-DISCHARGE RELATION.--Defined by current-meter measurements below $51,000 \mathrm{ft}^{3} / \mathrm{s}$, and extended above on the basis of straight-line extension. Stage-discharge relation is affected by return of overbank storage and backwater from Peachtree Creek. Bankfull stage and discharge, $15 \mathrm{ft}$ and about $14,000 \mathrm{ft}^{3} / \mathrm{s}$.

HISTORICAL DATA.--Flood of December 1919 was highest since 1880 , based on records for nearby gaging stations. Flood stage for peak of December 1919 obtained from floodmark at city of Atlanta sewage disposal plant, 4 mi downstream, and stage relation between the two sites.

REMARKS.--Peak discharges regulated by Lake Sidney Lanier (maximum flood-control storage, 637,00 acre-ft) since January 1956.

\begin{tabular}{|c|c|c|c|c|c|c|c|c|c|c|c|}
\hline $\begin{array}{l}\text { Water } \\
\text { year }\end{array}$ & Date & $\begin{array}{c}\text { Discharge } \\
\left(\mathrm{ft}^{3} / \mathrm{s}\right)\end{array}$ & $\begin{array}{c}\text { Gage } \\
\text { height } \\
\text { (ft) }\end{array}$ & $\begin{array}{l}\text { Water } \\
\text { year }\end{array}$ & Date & $\begin{array}{c}\text { Discharge } \\
\left(\mathrm{ft}^{3} / \mathrm{s}\right)\end{array}$ & $\begin{array}{c}\text { Gage } \\
\text { height } \\
\text { (ft) }\end{array}$ & $\begin{array}{l}\text { Water } \\
\text { year }\end{array}$ & Date & $\begin{array}{c}\text { Discharge } \\
\left(\mathrm{ft}^{3} / \mathrm{s}\right)\end{array}$ & $\begin{array}{c}\text { Gage } \\
\text { height } \\
\text { (ft) }\end{array}$ \\
\hline$\underline{1920}$ & Dec. 10 & 64,000 & $29.00 \mathrm{c}$ & 1952 & Mar. 13 & 34,400 & 21.70 & 1972 & Jan. 11 & 17,500 & 17.74 \\
\hline 1929 & Sept. 28 & 28,700 & 18.80 & 1953 & Jan. 11 & 18,000 & 14.30 & 1973 & Mar. 17 & 16,800 & 16.43 \\
\hline 1930 & Mar. 09 & 16,800 & 12.00 & 1954 & Jan. 18 & 27,400 & 19.30 & 1974 & Jan. 01 & 14,100 & 15.51 \\
\hline 1931 & Nov. 17 & 8,900 & 7.50 & 1955 & Feb. 09 & 18,000 & 14.30 & 1975 & Mar. 13 & 18,300 & 17.36 \\
\hline 1932 & Dec. 16 & 18,900 & 13.20 & 1956 & Mar. 16 & 15,100 & 12.10 & 1976 & Mar. 16 & 19,200 & 18.17 \\
\hline$\overline{1937}$ & Jan. 04 & 25,300 & 18.10 & 1957 & Apr. 05 & 20,100 & 15.80 & 1977 & Mar. 30 & 28,900 & 20.57 \\
\hline 1938 & July 24 & 18,300 & 14.10 & 1958 & Feb. 14 & 7,540 & 7.20 & 1978 & Jan. 26 & 15,200 & 15.84 \\
\hline 1939 & Aug. 19 & 14,100 & 11.50 & 1959 & May 31 & 8,260 & 7.70 & 1979 & Apr. 13 & 26,700 & 22.29 \\
\hline 1940 & Aug. 15 & 24,200 & 17.50 & 1960 & Mar. 30 & 12,400 & 10.20 & 1980 & Mar. 28 & 15,000 & 15.03 \\
\hline 1941 & July 07 & 11,500 & 9.90 & 1961 & Feb. 25 & 24,900 & 18.30 & 1981 & Feb. 10 & 8,460 & $9.53 \mathrm{a}$ \\
\hline 1942 & Feb. 19 & 22,100 & 16.30 & 1962 & Dec. 12 & 19,200 & 15.20 & 1982 & Feb. 03 & 24,100 & 20.66 \\
\hline 1943 & Dec. 31 & 19,200 & 14.60 & 1963 & Apr. 30 & 17,000 & 18.19 & 1983 & Apr. 08 & 15,400 & 15.82 \\
\hline 1944 & Mar. 31 & 23,400 & 17.60 & 1964 & Apr. 06 & 26,000 & 19.38 & 1984 & Dec. 06 & 18,100 & 16.99 \\
\hline 1945 & Feb. 23 & 10,200 & 8.90 & 1965 & Mar. 26 & 10,700 & 9.41 & 1985 & Aug. 17 & 9,910 & 10.91 \\
\hline 1946 & Jan. 09 & 59,000 & 28.00 & 1966 & Mar. 04 & 24,800 & 18.24 & 1986 & Aug. 01 & 6,870 & 7.33 \\
\hline 1947 & Jan. 22 & 29,800 & 20.20 & 1967 & Aug. 24 & 11,900 & 10.20 & 1987 & Jan. 19 & 17,300 & 13.72 \\
\hline 1948 & Aug. 06 & 18,200 & 14.50 & 1968 & Jan. 11 & 11,000 & 11.90 & 1988 & Feb. 04 & 9,920 & 9.48 \\
\hline 1949 & Nov. 28 & 34,400 & 21.70 & 1969 & Apr. 19 & 11,000 & 15.06 & 1989 & July 17 & 12,500 & 11.82 \\
\hline 1950 & Mar. 15 & 13,900 & 11.20 & 1970 & Mar. 20 & 8,400 & 13.28 & 1990 & Mar. 17 & 25,100 & 23.03 \\
\hline 1951 & Oct. 21 & 11,400 & 9.50 & 1971 & Mar. 03 & 13,700 & 11.28 & & & & \\
\hline
\end{tabular}




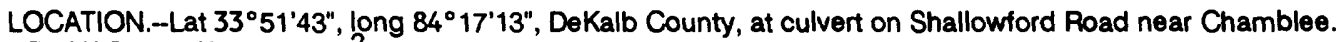

DRAINAGE AREA.-19.10 $\mathrm{mi}^{2}$.

GAGE.--Flood-stage/rainfall recorder, Sept. 6, 1973 to Oct. 20,1980; crest-stage gage 1982 to 1988 . Datum of gage is $854.30 \mathrm{ft}$ above sea level (levels from the U.S. Army Corps of Engineers benchmark).

STAGE-DISCHARGE RELATION.--Defined by current-meter measurements below $2,360 \mathrm{ft}^{3} / \mathrm{s}$, and extended above on basis of culvert computations.

HISTORICAL DATA.--The flood of March 1975 is thought to be the highest since 1948, based on information at nearby stations. REMARKS.--Peak stages prior to September 1973 are from floodmarks. Peak discharges for 1986-88 undetermined because of debris in culvert. Flow is affected by urbanization.

\begin{tabular}{|c|c|c|c|c|c|c|c|c|c|c|c|}
\hline $\begin{array}{l}\text { Water } \\
\text { year }\end{array}$ & Date & $\begin{array}{c}\text { Discharge } \\
\left(\mathrm{ft}^{3} / \mathrm{s}\right)\end{array}$ & $\begin{array}{c}\text { Gage } \\
\text { height } \\
\text { (ft) }\end{array}$ & $\begin{array}{l}\text { Water } \\
\text { year }\end{array}$ & Date & $\begin{array}{c}\text { Discharge } \\
\left(\mathrm{ft}^{3} / \mathrm{s}\right)\end{array}$ & $\begin{array}{c}\text { Gage } \\
\text { height } \\
\text { (ft) }\end{array}$ & $\begin{array}{l}\text { Water } \\
\text { year }\end{array}$ & Date & $\begin{array}{c}\text { Discharge } \\
\left(\mathrm{ft}^{3} / \mathrm{s}\right)\end{array}$ & $\begin{array}{c}\text { Gage } \\
\text { height } \\
\text { (ft) }\end{array}$ \\
\hline$\underline{1961}$ & Feb. 25 & 2,120 & $11.30 \mathrm{c}$ & 1975 & Mar. 13 & 3,050 & 15.27 & 1983 & Apr. 08 & 2,400 & 12.21 \\
\hline 1963 & Apr. 30 & 2,120 & 11.30 & 1976 & Mar. 16 & 2,510 & 12.56 & 1984 & July 14 & 2,140 & 11.35 \\
\hline 1964 & Apr. 06 & 1,780 & 10.50 & 1977 & Jan. 09 & 1,110 & 8.20 & 1985 & July 17 & 2,330 & 11.98 \\
\hline 1966 & Feb. 13 & 1,560 & 9.70 & 1978 & Jan. 25 & 1,760 & 10.37 & 1986 & Mar. 13 & - & 11.76 \\
\hline$\underline{1967}$ & July 08 & 1,200 & 7.30 & 1979 & Apr. 13 & 2,190 & 11.49 & 1987 & Jan. 18 & - & 12.18 \\
\hline 1969 & Apr. 18 & 2,250 & $11.70 \mathrm{c}$ & 1980 & May 23 & 2,570 & 12.86 & 1988 & Jan. 20 & - & 11.13 \\
\hline$\overline{1973}$ & June 05 & 2,540 & 12.70 & 1981 & Feb. 11 & 978 & 7.76 & 1990 & Mar. 17 & 2,180 & $11.48 c$ \\
\hline 1974 & Aug. 07 & 2,300 & 11.85 & 1982 & Feb. 03 & 2,160 & 11.40 & & & & \\
\hline
\end{tabular}

\section{NORTH FORK PEACTHREE CREEK TRIBUTARY NEAR CHAMBLEE, GEORGIA}

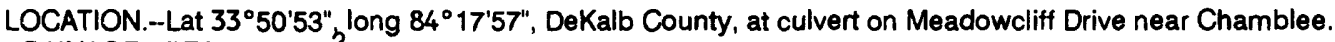

DRAINAGE AREA.--0.32 $\mathrm{mi}^{2}$.

GAGE.--Flood-stage/rainfall recorder prior to Oct. 3, 1980. Crest-stage gage 1981 to present.

STAGE-DISCHARGE RELATION.--Defined by current-meter measurements below $25.0 \mathrm{tt}^{3} / \mathrm{s}$, and extended above on basis of culvert computations.

REMARKS.--Flow is affected by urbanization.

\begin{tabular}{|c|c|c|c|c|c|c|c|c|c|c|c|}
\hline $\begin{array}{l}\text { Water } \\
\text { year }\end{array}$ & Date & $\begin{array}{c}\text { Discharge } \\
\left(\mathrm{ft}^{3} / \mathrm{s}\right)\end{array}$ & $\begin{array}{c}\text { Gage } \\
\text { height } \\
\text { (ft) }\end{array}$ & $\begin{array}{l}\text { Water } \\
\text { year }\end{array}$ & Date & $\begin{array}{c}\text { Discharge } \\
\left(\mathrm{ft}^{3} / \mathrm{s}\right)\end{array}$ & $\begin{array}{c}\text { Gage } \\
\text { height } \\
\text { (ft) }\end{array}$ & $\begin{array}{l}\text { Water } \\
\text { year }\end{array}$ & Date & $\begin{array}{c}\text { Discharge } \\
\left(\mathrm{ft}^{3} / \mathrm{s}\right)\end{array}$ & $\begin{array}{c}\text { Gage } \\
\text { height } \\
\text { (ft) }\end{array}$ \\
\hline 1973 & June 05 & 179 & 7.75 & 1979 & Aug. 31 & 197 & 8.37 & 1985 & July 28 & 142 & 6.44 \\
\hline 1974 & Aug. 07 & 89 & 4.77 & 1980 & May 23 & 343 & 11.13 & 1986 & Oct. 01 & 53 & 3.75 \\
\hline 1975 & July 20 & 216 & 9.09 & 1981 & Mar. 30 & 39 & 3.30 & 1987 & Jan. 18 & 128 & 5.98 \\
\hline 1976 & May 28 & 148 & 6.66 & 1982 & June 22 & 110 & 5.41 & 1988 & Jan. 20 & 57 & 3.86 \\
\hline 1977 & Jan. 09 & 29 & 2.98 & 1983 & Apr. 08 & 110 & 5.41 & 1989 & June 20 & 83 & 4.62 \\
\hline 1978 & Jan. 25 & 114 & 5.53 & 1984 & May 03 & 233 & 9.83 & 1990 & Oct. 01 & 150 & 6.75 \\
\hline
\end{tabular}




\section{APALACHICOLA RIVER BASIN}

\section{NORTH FORK PEACTHREE CREEK TRIBUTARY NEAR ATLANTA, GEORGIA}

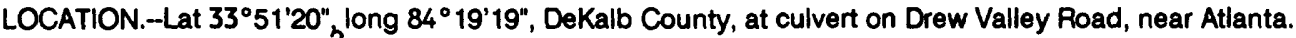

DRAINAGE AREA.--21.9 $\mathrm{mi}^{2}$.

GAGE.--Flood-stage/rainfall recorder prior to July 14, 1978. Crest-stage gage 1980 to present.

STAGE-DISCHARGE RELATION.--Defined by current-meter measurements below $45.0 \mathrm{ft}^{3} / \mathrm{s}$, and extended above on basis of culvert computations.

REMARKS.--Flow is affected by urbanization. Peak discharge for 1988 undetermined owing to debris in culvert.

\begin{tabular}{lccccccccccc}
\hline $\begin{array}{l}\text { Water } \\
\text { year }\end{array}$ & Date & $\begin{array}{c}\text { Discharge } \\
\left(\mathrm{ft}^{3} / \mathrm{s}\right)\end{array}$ & $\begin{array}{c}\text { Gage } \\
\text { height } \\
(\mathrm{ft})\end{array}$ & $\begin{array}{c}\text { Water } \\
\text { year }\end{array}$ & Date & $\begin{array}{c}\text { Discharge } \\
\left(\mathrm{ft}^{3} / \mathrm{s}\right)\end{array}$ & $\begin{array}{c}\text { Gage } \\
\text { height } \\
(\mathrm{ft})\end{array}$ & $\begin{array}{c}\text { Water } \\
\text { year }\end{array}$ & $\begin{array}{c}\text { Gage } \\
\text { Date }\end{array}$ & $\begin{array}{c}\text { Discharge } \\
\left(\mathrm{ft}^{3} / \mathrm{s}\right)\end{array}$ & $\begin{array}{c}\text { height } \\
(\mathrm{ft})\end{array}$ \\
\hline & & & & & & & & & & & \\
1973 & June 05 & 647 & 5.80 & 1980 & May 23 & 509 & 5.21 & 1986 & Mar. 13 & 875 & 6.85 \\
1974 & Aug. 07 & 931 & 7.13 & 1981 & Sept. 01 & 616 & 5.67 & 1987 & Jan. 18 & 518 & 5.25 \\
1975 & Mar. 13 & 1,110 & 8.16 & 1982 & June 22 & 790 & 6.43 & 1988 & Feb. 02 & 4.77 & - \\
1976 & Mar. 16 & 702 & 6.03 & 1983 & Mar. 05 & 955 & 7.25 & 1989 & July 03 & 748 & 6.24 \\
1977 & July 01 & 334 & 4.34 & 1984 & May 03 & 861 & 6.78 & 1990 & Feb. 09 & 1,030 & 7.65 \\
1978 & Jan. 25 & 652 & 5.82 & 1985 & July 28 & 547 & 5.38 & & & & \\
\hline
\end{tabular}

\section{SOUTH FORK PEACHTREE CREEK AT CLARKSTON, GEORGIA}

LOCATION.-Lat $33^{\circ} 48^{\prime} 51^{\prime \prime}$, long $84^{\circ} 14^{\prime} 38^{\prime \prime}$, DeKalb County, at culvert on Montreal Road at Clarkston. DRAINAGE AREA. $-5.29 \mathrm{mi}^{2}$.

GAGE.-Crest-state gage. Datum of gage is $940.59 \mathrm{ft}$ above sea level (levels by the U.S. Army Corps of Engineers).

STAGE-DISCHARGE RELATION.--Defined by current-meter measurements below $2.0 \mathrm{ft}^{3} / \mathrm{s}$, and extended above on the basis of culvert computations.

REMARKS.--Flow is affected by urbanization. Peak discharges for $1964-65$ are estimated.

\begin{tabular}{|c|c|c|c|c|c|c|c|c|c|c|c|}
\hline $\begin{array}{l}\text { Water } \\
\text { year }\end{array}$ & Date & $\begin{array}{c}\text { Discharge } \\
\left(\mathrm{ft}^{3} / \mathrm{s}\right)\end{array}$ & $\begin{array}{c}\text { Gage } \\
\text { height } \\
\text { (ft) }\end{array}$ & $\begin{array}{l}\text { Water } \\
\text { year }\end{array}$ & Date & $\begin{array}{c}\text { Discharge } \\
\left(\mathrm{ft}^{3} / \mathrm{s}\right)\end{array}$ & $\begin{array}{c}\text { Gage } \\
\text { height } \\
\text { (ft) }\end{array}$ & $\begin{array}{l}\text { Water } \\
\text { year }\end{array}$ & Date & $\begin{array}{c}\text { Discharge } \\
\left(\mathrm{ft}^{3} / \mathrm{s}\right)\end{array}$ & $\begin{array}{c}\text { Gage } \\
\text { height } \\
\text { (ft) }\end{array}$ \\
\hline$\underline{1961}$ & Feb. 25 & 1,450 & $9.90 c$ & $\underline{1967}$ & June 03 & 1,010 & 8.30 & 1976 & Mar. 16 & 1,420 & 9.08 \\
\hline 1963 & Apr. 30 & 1,100 & 8.64 & $\underline{1969}$ & Apr. 18 & 1,470 & $9.40 c$ & 1977 & Mar. 21 & 502 & 4.91 \\
\hline 1964 & Apr. 06 & 1,110 & 8.63 & $\overline{1973}$ & June 05 & 1,770 & 10.69 & 1978 & May 08 & 818 & 6.43 \\
\hline 1965 & Jan. 23 & 480 & - & 1974 & Dec. 31 & 847 & 6.51 & 1990 & Mar. 17 & 1,250 & $8.33 c$ \\
\hline 1966 & Feb. 13 & 1,320 & 9.50 & 1975 & Mar. 13 & 1,580 & 9.88 & & & & \\
\hline
\end{tabular}




\section{SOUTH FORK PEACHTREE CREEK NEAR DECATUR, GEORGIA}

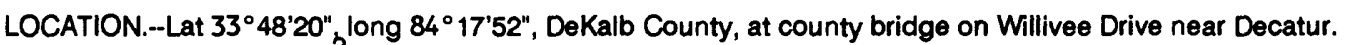

DRAINAGE AREA $-11.0 \mathrm{mi}^{2}$.

GAGE.--Crest-state gage. Datum of gage is $884.85 \mathrm{ft}$ above sea level (levels by the U.S. Army Corps of Engineers).

STAGE-DISCHARGE RELATION.--Defined by current-meter measurements below $1,090 \mathrm{ft}^{3} / \mathrm{s}$, and based above on the basis of straight-line extension.

REMARKS.--Flow is affected by urbanization. Peak discharges for 1962 and 1973 are estimated.

\begin{tabular}{|c|c|c|c|c|c|c|c|c|c|c|c|}
\hline $\begin{array}{l}\text { Water } \\
\text { year }\end{array}$ & Date & $\begin{array}{c}\text { Discharge } \\
\left(\mathrm{ft}^{3} / \mathrm{s}\right)\end{array}$ & $\begin{array}{c}\text { Gage } \\
\text { height } \\
\text { (ft) }\end{array}$ & $\begin{array}{l}\text { Water } \\
\text { year }\end{array}$ & Date & $\begin{array}{c}\text { Discharge } \\
\left(\mathrm{ft}^{3} / \mathrm{s}\right)\end{array}$ & $\begin{array}{l}\text { Gage } \\
\text { height } \\
\text { (ft) }\end{array}$ & $\begin{array}{l}\text { Water } \\
\text { year }\end{array}$ & Date & $\begin{array}{c}\text { Discharge } \\
\left(\mathrm{ft}^{3} / \mathrm{s}\right)\end{array}$ & $\begin{array}{c}\text { Gage } \\
\text { height } \\
\text { (ft) }\end{array}$ \\
\hline 1961 & Feb. 25 & 1,620 & 11.90 & $\underline{1967}$ & June 03 & 780 & 8.95 & 1976 & Mar. 16 & 1,630 & 11.95 \\
\hline 1962 & Dec. 18 & 1,000 & - & $\overline{1969}$ & Apr. 18 & 1,630 & $11.95 \mathrm{c}$ & 1977 & Mar. 21 & 616 & 8.53 \\
\hline 1963 & Apr. 30 & 1,930 & 12.68 & $\overline{1973}$ & June 05 & 2,200 & - & 1978 & May 08 & 708 & 8.89 \\
\hline 1964 & Mar. 25 & 1,060 & 10.70 & 1974 & Dec. 31 & 965 & 10.06 & $\underline{1979}$ & Apr. 13 & 1,170 & 10.80 \\
\hline 1965 & Jan. 23 & 560 & 7.65 & 1975 & Mar. 13 & 1,320 & 11.33 & $\overline{1990}$ & Mar. 17 & 1,450 & $11.54 \mathrm{c}$ \\
\hline 1966 & Feb. 13 & 1,230 & 10.95 & & & & & & & & \\
\hline
\end{tabular}

\section{SOUTH FORK PEACHTREE CREEK TRIBUTARY NEAR ATLANTA, GEORGIA}

LOCATION.--Lat $33^{\circ} 47^{\prime} 11^{\prime \prime}$, long 84 $20^{\prime} 29^{\prime \prime}$, DeKalb County, at culvert on East Rock Springs Road, near Atlanta.

DRAINAGE AREA.--0.92 $\mathrm{mi}^{2}$.

GAGE.--Flood-stage/rainfall recorder prior to Oct. 3, 1980. Crest-state gage 1981 to present.

STAGE-DISCHARGE RELATION.--Defined by current-meter measurements below $85 \mathrm{ft}^{3} / \mathrm{s}$, and based above on the basis of culvert computations.

REMARKS.--Flow is affected by urbanization.

\begin{tabular}{|c|c|c|c|c|c|c|c|c|c|c|c|}
\hline $\begin{array}{l}\text { Water } \\
\text { year }\end{array}$ & Date & $\begin{array}{c}\text { Discharge } \\
\left(\mathrm{ft}^{3} / \mathrm{s}\right)\end{array}$ & $\begin{array}{c}\text { Gage } \\
\text { height } \\
\text { (ft) }\end{array}$ & $\begin{array}{l}\text { Water } \\
\text { year }\end{array}$ & Date & $\begin{array}{c}\text { Discharge } \\
\left(\mathrm{ft}^{3} / \mathrm{s}\right)\end{array}$ & $\begin{array}{l}\text { Gage } \\
\text { height } \\
\text { (ft) }\end{array}$ & $\begin{array}{l}\text { Water } \\
\text { year }\end{array}$ & Date & $\begin{array}{c}\text { Discharge } \\
\left(\mathrm{ft}^{3} / \mathrm{s}\right)\end{array}$ & $\begin{array}{l}\text { Gage } \\
\text { height } \\
\text { (ft) }\end{array}$ \\
\hline 1974 & Aug. 07 & 588 & 4.54 & 1980 & May 23 & 592 & 4.56 & 1986 & June 10 & 566 & 4.50 \\
\hline 1975 & July 23 & 1,140 & 6.44 & 1981 & July 06 & 360 & 3.10 & 1987 & June 15 & 641 & 4.50 \\
\hline 1976 & Mar. 16 & 486 & 3.88 & 1982 & Sept. 02 & 471 & 3.90 & 1988 & June 15 & 611 & 4.73 \\
\hline 1977 & Aug. 26 & 416 & 3.34 & 1983 & Mar. 05 & 829 & 5.66 & 1989 & June 20 & 541 & 4.37 \\
\hline 1978 & May 08 & 753 & 5.21 & 1984 & July 14 & 790 & 5.51 & 1990 & Mar. 17 & 579 & 4.57 \\
\hline 1979 & Apr. 13 & 552 & 4.35 & 1985 & Oct. 22 & 554 & 4.44 & & & & \\
\hline
\end{tabular}


LOCATION.--Lat 3348'20", long $84^{\circ} 21^{\prime} 02^{\prime \prime}$, Fulton County, at bridge on Lenox Road in Atlanta, 0.9 mi upstream from Seaboard Coast Line Railroad, and 2.3 mi upstream from confluence with North Fork Peachtree Creek.

DRAINAGE AREA.--29.6 $\mathrm{mi}^{2}$.

GAGE.-Crest-state gage. Datum of gage is $809.25 \mathrm{ft}$ above sea level (levels by the U.S. Army Corps of Engineers), supplementary adjustment of 1936.

STAGE-DISCHARGE RELATION.--Defined by current-meter measurements below $2,620 \mathrm{tt}^{3} / \mathrm{s}$, and above on the basis of straightline extension.

HISTORICAL DATA.--The flood of 1976 is thought to be the highest since 1948, based on information at nearby stations.

REMARKS.--Flood peaks are affected by increasing urbanization.

\begin{tabular}{|c|c|c|c|c|c|c|c|c|c|c|c|}
\hline $\begin{array}{l}\text { Water } \\
\text { year }\end{array}$ & Date & $\begin{array}{c}\text { Discharge } \\
\left(\mathrm{ft}^{3} / \mathrm{s}\right)\end{array}$ & $\begin{array}{c}\text { Gage } \\
\text { height } \\
\text { (ft) }\end{array}$ & $\begin{array}{l}\text { Water } \\
\text { year }\end{array}$ & Date & $\begin{array}{c}\text { Discharge } \\
\left(\mathrm{ft}^{3} / \mathrm{s}\right)\end{array}$ & $\begin{array}{c}\text { Gage } \\
\text { height } \\
\text { (ft) }\end{array}$ & $\begin{array}{l}\text { Water } \\
\text { year }\end{array}$ & Date & $\begin{array}{c}\text { Discharge } \\
\left(\mathrm{ft}^{3} / \mathrm{s}\right)\end{array}$ & $\begin{array}{c}\text { Gage } \\
\text { height } \\
\text { (ft) }\end{array}$ \\
\hline$\underline{1961}$ & Feb. 25 & 2,480 & $11.30 \mathrm{c}$ & 1967 & Aug. 23 & 1,900 & 10.20 & $\underline{1973}$ & June 06 & 3,300 & $12.60 \mathrm{c}$ \\
\hline 1963 & Apr. 30 & 3,020 & 12.20 & 1968 & Mar. 12 & 2,240 & 10.88 & $\underline{1975}$ & Mar. 13 & 3,240 & $12.50 \mathrm{c}$ \\
\hline 1964 & Mar. 25 & 2,660 & 11.60 & 1969 & Apr. 18 & 4,700 & 14.50 & 1976 & Mar. 16 & 5,000 & 14.71 \\
\hline 1965 & Jan. 23 & 1,400 & 9.03 & 1970 & Mar. 19 & 3,740 & 13.40 & $\underline{1983}$ & Mar. 06 & 3,360 & $12.70 c$ \\
\hline 1966 & Feb. 13 & 2,480 & 11.30 & 1971 & Mar. 03 & 2,050 & 10.60 & $\overline{1990}$ & Mar. 17 & 3,000 & $11.96 \mathrm{c}$ \\
\hline
\end{tabular}

\section{PEACHTREE CREEK AT ATLANTA, GEORGIA}

LOCATION.--Lat $33^{\circ} 49^{\prime} 10^{\prime \prime}$, long $84^{\circ} 24^{\prime} 28^{\prime \prime}$, Fulton County, on downstream side of bridge on Northside Drive at Atlanta, $0.4 \mathrm{mi}$ downstream from Tanyard Branch, and 4 mi upstream from mouth.

DRAINAGE AREA. $-86.8 \mathrm{mi}^{2}$.

GAGE.--Water-stage recorder. Datum of gage is $763.96 \mathrm{ft}$ above sea level (from city of Atlanta benchmark). Prior to May 27,1963 , water-stage recorder at site $1,000 \mathrm{ft}$ downstream at same datum.

STAGE-DISCHARGE RELATION.--Defined by current-meter measurements below $9,200 \mathrm{ft}^{3} / \mathrm{s}$. Bankfull stage and discharge, $15 \mathrm{ft}$ and $4,500 \mathrm{ft}^{3} / \mathrm{s}$.

REMARKS.--Flood peaks are affected by increasing urbanization.

\begin{tabular}{|c|c|c|c|c|c|c|c|c|c|c|c|}
\hline $\begin{array}{l}\text { Water } \\
\text { year }\end{array}$ & Date & $\begin{array}{c}\text { Discharge } \\
\left(\mathrm{ft}^{3} / \mathrm{s}\right)\end{array}$ & $\begin{array}{c}\text { Gage } \\
\text { height } \\
\text { (ft) }\end{array}$ & $\begin{array}{l}\text { Water } \\
\text { year }\end{array}$ & Date & $\begin{array}{c}\text { Discharge } \\
\left(\mathrm{ft}^{3} / \mathrm{s}\right)\end{array}$ & $\begin{array}{c}\text { Gage } \\
\text { height } \\
\text { (ft) }\end{array}$ & $\begin{array}{l}\text { Water } \\
\text { year }\end{array}$ & Date & $\begin{array}{c}\text { Discharge } \\
\left(\mathrm{ft}^{3} / \mathrm{s}\right)\end{array}$ & $\begin{array}{c}\text { Gage } \\
\text { height } \\
\text { (ft) }\end{array}$ \\
\hline$\underline{1949}$ & Nov. 28 & 6,880 & $18.70 c$ & 1967 & July 29 & 5,340 & 16.48 & 1979 & Apr. 13 & 8,070 & 19.08 \\
\hline 1956 & Mar. 16 & 6,300 & 18.36 & 1968 & Mar. 12 & 3,840 & 13.48 & 1980 & May 23 & 6,360 & 16.95 \\
\hline 1957 & Apr. 05 & 5,670 & 16.76 & 1969 & Apr. 18 & 6,840 & 17.91 & 1981 & Feb. 11 & 4,300 & 13.88 \\
\hline 1958 & Feb. 06 & 3,450 & 12.48 & 1970 & Mar. 19 & 6,950 & 18.31 & 1982 & Feb. 03 & 6,520 & 17.16 \\
\hline 1959 & May 30 & 4,300 & 14.20 & 1971 & July 30 & 5,500 & 16.24 & 1983 & Apr. 08 & 7,120 & 17.97 \\
\hline 1960 & Apr. 03 & 3,230 & 12.00 & 1972 & Jan. 10 & 5,470 & 16.24 & 1984 & May 02 & 6,420 & 17.04 \\
\hline 1961 & Feb. 25 & 5,860 & 17.10 & 1973 & Feb. 01 & 5,930 & 16.90 & 1985 & Aug. 17 & 5,810 & 16.20 \\
\hline 1962 & Feb. 22 & 4,650 & 14.90 & 1974 & Dec. 31 & 5,960 & 16.88 & 1986 & Oct. 01 & 3,920 & 13.27 \\
\hline 1963 & Apr. 30 & 6,880 & 18.70 & 1975 & Mar. 13 & 8,350 & 19.41 & 1987 & Jan. 18 & 8,110 & 19.22 \\
\hline 1964 & Apr. 06 & 5,760 & 17.30 & 1976 & Mar. 16 & 8,660 & 20.30 & 1988 & Apr. 11 & 5,300 & 15.45 \\
\hline 1965 & Jan. 23 & 3,800 & 13.40 & 1977 & Mar. 21 & 4,030 & 13.89 & 1989 & Sept.30 & 8,310 & 19.47 \\
\hline 1966 & Feb. 13 & 4,830 & 15.46 & 1978 & Jan. 25 & 5,460 & 16.23 & 1990 & Mar. 17 & 9,650 & 21.06 \\
\hline
\end{tabular}




\section{APALACHICOLA RIVER BASIN}

\section{NANCY CREEK AT RICKENBACKER WAY AT ATLANTA, GEORGIA}

LOCATION.-Lat $33^{\circ} 52^{\prime} 09^{\prime \prime}$ long $84^{\circ} 22^{\prime} 44^{\prime \prime}$, Fulton County, at bridge on Rickenbacker Drive at Atlanta.

DRAINAGE AREA.--26.6 $\mathrm{mi}^{2}$.

GAGE.-Flood-hydrograph recorder. Datum of gage is $810.16 \mathrm{ft}$ above sea level (levels by the U.S. Army Corps of Engineers benchmark).

STAGE-DISCHARGE RELATION.--Defined by current-meter measurements below 2,900 $\mathrm{tt}^{3} / \mathrm{s}$, and extended above on basis of straight-line extension.

REMARKS.--Flood peaks are affected by increasing urbanization. Peak discharges for 1961 and 1975 are estimated.

\begin{tabular}{|c|c|c|c|c|c|c|c|c|c|c|c|}
\hline $\begin{array}{l}\text { Water } \\
\text { year }\end{array}$ & Date & $\begin{array}{c}\text { Discharge } \\
\left(\mathrm{ft}^{3} / \mathrm{s}\right)\end{array}$ & $\begin{array}{c}\text { Gage } \\
\text { height } \\
\text { (ft) }\end{array}$ & $\begin{array}{l}\text { Water } \\
\text { year }\end{array}$ & Date & $\begin{array}{c}\text { Discharge } \\
\left(\mathrm{ft}^{3} / \mathrm{s}\right)\end{array}$ & $\begin{array}{l}\text { Gage } \\
\text { height } \\
\text { (ft) }\end{array}$ & $\begin{array}{l}\text { Water } \\
\text { year }\end{array}$ & Date & $\begin{array}{c}\text { Discharge } \\
\left(\mathrm{ft}^{3} / \mathrm{s}\right)\end{array}$ & $\begin{array}{c}\text { Gage } \\
\text { height } \\
\text { (ft) }\end{array}$ \\
\hline$\underline{1961}$ & Feb. 25 & 2,400 & $-c$ & 1967 & June 03 & 1,550 & 9.45 & $\underline{1975}$ & Mar. 13 & 3,700 & - \\
\hline$\overline{1963}$ & Apr. 30 & 2,790 & 12.55 & $\underline{1969}$ & Apr. 18 & 2,600 & $12.05 \mathrm{c}$ & 1982 & Feb. 03 & 3,150 & $13.15 \mathrm{c}$ \\
\hline$\underline{1964}$ & Apr. 06 & 2,900 & 12.85 & $\underline{1973}$ & June 05 & 4,500 & $14.84 \mathrm{c}$ & 1990 & Mar. 17 & 3,200 & $12.93 c$ \\
\hline 1966 & Feb. 13 & 1,650 & 9.75 & 1974 & Dec. 31 & 3,100 & 13.05 & & & & \\
\hline
\end{tabular}

\section{NANCY CREEK AT RANDALL MILL ROAD AT ATLANTA, GEORGIA}

LOCATION.--Lat $33^{\circ} 51^{\prime} 35^{\prime \prime}$, long $84^{\circ} 25^{\prime} 28^{\prime \prime}$, Fulton County, on left bank downstream end of bridge on Randall Mill Road, 3.3 mi above mouth at Atlanta.

DRAINAGE AREA.--34.8 $\mathrm{mi}^{2}$.

GAGE.--Water-stage recorder. Datum of gage is $778.03 \mathrm{ft}$ above sea level (from the U.S. Army Corps of Engineers benchmark).

STAGE-DISCHARGE RELATION.--Defined by current-meter measurements below $2,660 \mathrm{ft}^{3} / \mathrm{s}$, and extended above on basis of straight-line extension.

REMARKS.--Flood peaks are affected by increasing urbanization. Peak discharges for 1966 and 1967 are estimated.

\begin{tabular}{|c|c|c|c|c|c|c|c|c|c|c|c|}
\hline $\begin{array}{l}\text { Water } \\
\text { year }\end{array}$ & Date & $\begin{array}{c}\text { Discharge } \\
\left(\mathrm{ft}^{3} / \mathrm{s}\right)\end{array}$ & $\begin{array}{c}\text { Gage } \\
\text { height } \\
\text { (ft) }\end{array}$ & $\begin{array}{l}\text { Water } \\
\text { year }\end{array}$ & Date & $\begin{array}{c}\text { Discharge } \\
\left(\mathrm{ft}^{3} / \mathrm{s}\right)\end{array}$ & $\begin{array}{c}\text { Gage } \\
\text { height } \\
\text { (ft) }\end{array}$ & $\begin{array}{l}\text { Water } \\
\text { year }\end{array}$ & Date & $\begin{array}{c}\text { Discharge } \\
\left(\mathrm{ft}^{3} / \mathrm{s}\right)\end{array}$ & $\begin{array}{c}\text { Gage } \\
\text { height } \\
\text { (ft) }\end{array}$ \\
\hline 1961 & Feb. $\approx$ & 2,320 & $12.25 \mathrm{c}$ & 1967 & June 03 & 1,600 & - & 1975 & Mar. 13 & 3,500 & 14.15 \\
\hline$\overline{1963}$ & Apr. 30 & 2,700 & 13.15 & $\underline{1969}$ & Apr. 18 & 2,150 & $11.25 \mathrm{c}$ & $\underline{1982}$ & Feb. 03 & 2,950 & $13.55 \mathrm{c}$ \\
\hline 1964 & Apr. 06 & 2,800 & 13.35 & 1973 & June 05 & 2,650 & 12.83 & $\underline{1983}$ & Mar. 06 & 1,200 & $8.80 \mathrm{c}$ \\
\hline 1966 & Feb. 13 & 1,700 & - & 1974 & Dec. 31 & 2,650 & 12.85 & 1990 & Mar. 17 & 3,600 & $14.77 \mathrm{c}$ \\
\hline
\end{tabular}




\section{APALACHICOLA RIVER BASIN}

\section{CHATTAHOOCHEE RIVER AT STATE HIGHWAY 280 NEAR ATLANTA, GEORGIA}

LOCATION.--Lat $33^{\circ} 49^{\prime} 01^{\prime \prime}$, long $84^{\circ} 28^{\prime} 48^{\prime \prime}$, Fulton-Cobb County line, at bridge on State Highway $280,0.6$ mi upstream from Southern Railway bridge, 1.7 mi downstream from Peachtree Creek near Atlanta, and at mile 298.8.

DRAINAGE AREA. $-1,600 \mathrm{mi}^{2}$, approximately.

GAGE.-Water-stage recorder. Prior to March 1981, crest-stage gage at same site and datum. Datum of gage is $736.35 \mathrm{ft}$ above sea level (levels by the U.S. Army Corps of Engineers).

STAGE-DISCHARGE RELATION.-Defined by current-meter measurements below $29,300 \mathrm{ft}^{3} / \mathrm{s}$, and extended above on basis of straight-line extension.

REMARKS.-Peak discharges regulated by Lake Sidney Lanier (maximum flood-control stage 637,000 acre-ft) since January 1956.

\begin{tabular}{|c|c|c|c|c|c|c|c|c|c|c|c|}
\hline $\begin{array}{l}\text { Water } \\
\text { year }\end{array}$ & Date & $\begin{array}{c}\text { Discharge } \\
\left(\mathrm{ft}^{3} / \mathrm{s}\right)\end{array}$ & $\begin{array}{c}\text { Gage } \\
\text { height } \\
\text { (ft) }\end{array}$ & $\begin{array}{l}\text { Water } \\
\text { year }\end{array}$ & Date & $\begin{array}{c}\text { Discharge } \\
\left(\mathrm{ft}^{3} / \mathrm{s}\right)\end{array}$ & $\begin{array}{c}\text { Gage } \\
\text { height } \\
\text { (ft) }\end{array}$ & $\begin{array}{l}\text { Water } \\
\text { year }\end{array}$ & Date & $\begin{array}{c}\text { Discharge } \\
\left(\mathrm{ft}^{3} / \mathrm{s}\right)\end{array}$ & $\begin{array}{c}\text { Gage } \\
\text { height } \\
\text { (ft) }\end{array}$ \\
\hline 1973 & Mar. 17 & 22,000 & 24.46 & 1979 & Apr. 13 & 32,000 & 30.71 & 1986 & Oct. 01 & 10,200 & 14.89 \\
\hline 1974 & Jan. 01 & 22,000 & 24.45 & $\overline{1982}$ & Feb. 03 & 28,300 & 28.91 & 1987 & Jan. 19 & 20,800 & 23.47 \\
\hline 1975 & Mar. 13 & 25,400 & 26.42 & 1983 & Apr. 08 & 22,500 & 24.66 & 1988 & Jan. 20 & 13,900 & 18.26 \\
\hline 1976 & Mar. 16 & 26,800 & 27.41 & 1984 & Dec. 06 & 22,400 & 24.74 & 1989 & July 17 & 14,900 & 19.09 \\
\hline 1977 & Mar. 30 & 25,700 & 26.77 & 1985 & Aug. 17 & 15,000 & 19.17 & 1990 & Mar. 17 & 33,300 & 31.51 \\
\hline
\end{tabular}

02336500 CHATTAHOOCHEE RIVER AT OAKDALE, GEORGIA

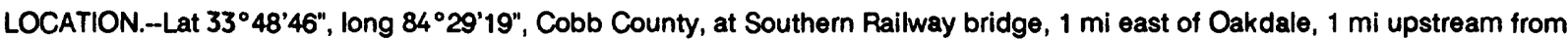
Proctor Creek, 2 mi downstream from Peachtree Creek, 8 mi northwest of Atlanta, and at mile 298.1. DRAINAGE AREA. $-1,600 \mathrm{mi}^{2}$, approximately.

GAGE.--Nonrecording gage, July 1, 1898, to May 31, 1899, at site $1 \mathrm{mi}$ downstream at datum $1 \mathrm{ft}$ lower. Datum of gage is $739.97 \mathrm{ft}$ above sea level (levels by the U.S. Army Corps of Engineers), supplementary adjustment of 1936.

STAGE-DISCHARGE RELATION.--Defined by current-meter measurements below $24,000 \mathrm{ft}^{3} / \mathrm{s}$.

HISTORICAL DATA.--Flood of Jan. 8, 1946, reached a stage of 29.4 at Southern Railway bridge, from information furnished by employee of Southern Railway Co. This was probably the highest flood since December 1919, based on nearby gaging-station records.

REMARKS.--Peak discharges regulated by Lake Sidney Lanier (maximum flood-control stage 637,000 acre-ft) since January 1956.

\begin{tabular}{|c|c|c|c|c|c|c|c|c|c|c|c|}
\hline $\begin{array}{l}\text { Water } \\
\text { year }\end{array}$ & Date & $\begin{array}{c}\text { Discharge } \\
\left(\mathrm{ft}^{3} / \mathrm{s}\right)\end{array}$ & $\begin{array}{c}\text { Gage } \\
\text { height } \\
\text { (ft) }\end{array}$ & $\begin{array}{l}\text { Water } \\
\text { year }\end{array}$ & Date & $\begin{array}{c}\text { Discharge } \\
\left(\mathrm{ft}^{3} / \mathrm{s}\right)\end{array}$ & $\begin{array}{c}\text { Gage } \\
\text { height } \\
\text { (ft) }\end{array}$ & $\begin{array}{l}\text { Water } \\
\text { year }\end{array}$ & Date & $\begin{array}{c}\text { Discharge } \\
\left(\mathrm{ft}^{3} / \mathrm{s}\right)\end{array}$ & $\begin{array}{c}\text { Gage } \\
\text { height } \\
\text { (ft) }\end{array}$ \\
\hline 1896 & July 10 & 24,600 & 18.40 & 1900 & Feb. 14 & 28,600 & 20.70 & 1903 & Feb. 18 & 43,900 & 25.60 \\
\hline 1897 & Apr. 06 & 21,900 & $\underline{17.00}$ & 1901 & Mar. 27 & 36,600 & 23.50 & $\underline{1946}$ & Jan. 08 & 59,000 & $29.40 \mathrm{c}$ \\
\hline 1898 & Sept. 03 & $\overline{45,000}$ & 27.80 & 1902 & Dec. 30 & 48,800 & 27.00 & $\overline{1961}$ & Feb. 25 & 34,000 & $23.00 c$ \\
\hline 1899 & Mar. 17 & $\underline{29,400}$ & 24.20 & & & & & & & & \\
\hline
\end{tabular}


LOCATION.--Lat $33^{\circ} 50^{\prime} 28^{\prime \prime}$, long $84^{\circ} 31^{\prime} 58^{\prime \prime}$, Cobb County, at bridge on Cooper Lake Road near Mableton, 5.2 mi above mouth. DRAINAGE AREA.--20.6 $\mathrm{mi}^{2}$.

GAGE.--Crest-stage gage. Datum of gage is $789.79 \mathrm{ft}$ above sea level (levels by the U.S. Army Corps of Engineers).

STAGE-DISCHARGE RELATION.-Defined by current-meter measurements below $1,200 \mathrm{ft}^{3} / \mathrm{s}$, and extended above on the basis of straight-line extension.

REMARKS.--Flow is affected by urbanization.

\begin{tabular}{|c|c|c|c|c|c|c|c|c|c|c|c|}
\hline $\begin{array}{l}\text { Water } \\
\text { year }\end{array}$ & Date & $\begin{array}{c}\text { Discharge } \\
\left(\mathrm{ft}^{3} / \mathrm{s}\right)\end{array}$ & $\begin{array}{c}\text { Gage } \\
\text { height } \\
\text { (ft) }\end{array}$ & $\begin{array}{l}\text { Water } \\
\text { year }\end{array}$ & Date & $\begin{array}{c}\text { Discharge } \\
\left(\mathrm{ft}^{3} / \mathrm{s}\right)\end{array}$ & $\begin{array}{c}\text { Gage } \\
\text { height } \\
\text { (ft) }\end{array}$ & $\begin{array}{l}\text { Water } \\
\text { year }\end{array}$ & Date & $\begin{array}{c}\text { Discharge } \\
\left(\mathrm{ft}^{3} / \mathrm{s}\right)\end{array}$ & $\begin{array}{c}\text { Gage } \\
\text { height } \\
\text { (ft) }\end{array}$ \\
\hline$\underline{1961}$ & Feb. 25 & 3,000 & $18.20 \mathrm{c}$ & 1967 & Aug. 23 & 1,850 & 14.30 & 1977 & Mar. 30 & 3,750 & $21.30 c$ \\
\hline 1963 & Apr. 30 & 3,350 & $19.10 \mathrm{c}$ & 1968 & Mar. 18 & 2,150 & 15.30 & 1982 & Feb. 03 & 3,600 & $20.80 \mathrm{c}$ \\
\hline 1966 & Mar. 04 & 2,900 & 17.80 & 1969 & Apr. 18 & 2,050 & 15.00 & & & & \\
\hline
\end{tabular}

\section{SOUTH UTOY CREEK TRIBUTARY AT EAST POINT, GEORGIA}

LOCATION.--Lat $33^{\circ} 41^{\prime} 25^{\prime \prime}$, long $84^{\circ} 28^{\prime} 05^{\prime \prime}$, Fulton County, at culvert on Headland Drive at East Point.

DRAINAGE AREA. $-0.79 \mathrm{mi}^{2}$.

GAGE.--Water-stage recorder prior to Sept. 30, 1969; flood-stage/rainfall recorder Feb. 17, 1973 to July 14, 1978; crest-stage gage thereafter. Datum of gage is $869.70 \mathrm{ft}$ above sea level (levels by the U.S. Army Corps of Engineers).

STAGE-DISCHARGE RELATION.-Defined by current-meter mesurements below $73 \mathrm{ft}^{3} / \mathrm{s}$, and above based on culvert computations.

REMARKS.--Flood peaks affected by increasing urbanization.

\begin{tabular}{|c|c|c|c|c|c|c|c|c|c|c|c|}
\hline $\begin{array}{l}\text { Water } \\
\text { year }\end{array}$ & Date & $\begin{array}{l}\text { Discharge } \\
\left(\mathrm{ft}^{3} / \mathrm{s}\right)\end{array}$ & $\begin{array}{c}\text { Gage } \\
\text { height } \\
\text { (ft) }\end{array}$ & $\begin{array}{l}\text { Water } \\
\text { year }\end{array}$ & Date & $\begin{array}{c}\text { Discharge } \\
\left(\mathrm{ft}^{3} / \mathrm{s}\right)\end{array}$ & $\begin{array}{c}\text { Gage } \\
\text { height } \\
\text { (ft) }\end{array}$ & $\begin{array}{l}\text { Water } \\
\text { year }\end{array}$ & Date & $\begin{array}{l}\text { Discharge } \\
\left(\mathrm{ft}^{3} / \mathrm{s}\right)\end{array}$ & $\begin{array}{c}\text { Gage } \\
\text { height } \\
\text { (ft) }\end{array}$ \\
\hline 1964 & Aug. 04 & 307 & 4.60 & 1973 & Feb. 01 & 283 & 4.36 & 1983 & Mar. 05 & 294 & 4.49 \\
\hline 1965 & Dec. 26 & 277 & 4.30 & 1974 & Aug. 01 & 320 & 4.73 & 1984 & May 03 & 275 & 4.30 \\
\hline 1966 & Feb. 13 & 212 & 3.65 & 1975 & May 17 & 408 & 5.77 & 1985 & July 28 & 230 & 3.83 \\
\hline 1967 & Aug. 22 & 447 & 5.83 & 1976 & May 28 & 298 & 4.50 & 1986 & July 23 & 220 & 3.72 \\
\hline 1968 & Dec. 19 & 413 & 5.55 & 1977 & June 22 & 184 & 3.24 & 1987 & Feb. 28 & 250 & 4.05 \\
\hline 1969 & Apr. 18 & 371 & 5.20 & $\underline{1978}$ & Nov. 05 & 369 & 5.21 & 1988 & Jan. 20 & 358 & 5.13 \\
\hline 1970 & Mar. 19 & 237 & 3.90 & $\overline{1980}$ & May 23 & 390 & 5.50 & 1989 & Apr. -- & 140 & $--b$ \\
\hline 1971 & Aug. 02 & 533 & 7.88 & 1981 & Sept. 01 & 285 & 4.37 & 1990 & Oct. 01 & 313 & 4.68 \\
\hline 1972 & Jan. 10 & 297 & 4.50 & 1982 & Dec. 31 & 258 & 4.13 & & & & \\
\hline
\end{tabular}


LOCATION.-Lat $33^{\circ} 46^{\prime} 22^{\prime \prime}$, long $84^{\circ} 36^{\prime} 53^{\prime \prime}$, Douglas County, on right bank $100 \mathrm{ft}$ upstream from bridge on Interstate Highway 20 , $400 \mathrm{ft}$ upstream from Blair Bridge, $3 \mathrm{mi}$ southeast of Austell, and $5.5 \mathrm{mi}$ upstream from mouth.

DRAINAGE AREA.-246 $\mathrm{mi}^{2}$.

GAGE.--Water-stage recorder. Datum of gage is $857.01 \mathrm{ft}$ above sea level (levels by the U.S. Army Corps of Engineers). May 6, 1904, to Dec. 31,1905 , and Nov. 3 to Dec. 27 1913, nonrecording gage at site 2.5 mi upstream at different datum. Mar. 24 to Nov. 29, 1937, nonrecording gage at present site and datum.

STAGE-DISCHARGE RELATION.--Defined by current-meter measurements below $6,500 \mathrm{ft}^{3} / \mathrm{s}$, and extended above on the basis of contracted-opeining measurement at $10,100 \mathrm{ft}^{3} / \mathrm{s}$ prior to 1965 . For period $1966-90$, defined by current-meter measurements below $10,700 \mathrm{ft}^{3} / \mathrm{s}$. There was a considerable change in higher portion of stage-discharge relation during 1965 from constuction of Interstate Highway 20 bridge, $100 \mathrm{ft}$ downstream from gage. Bankfull stage and discharge, $10 \mathrm{ft}$ and $3,500 \mathrm{ft}^{3} / \mathrm{s}$.

REMARKS.--Flood stage of July 1916 based on information furnished by local resident.

\begin{tabular}{|c|c|c|c|c|c|c|c|c|c|c|c|}
\hline $\begin{array}{l}\text { Water } \\
\text { year }\end{array}$ & Date & $\begin{array}{c}\text { Discharge } \\
\left(\mathrm{ft}^{3} / \mathrm{s}\right)\end{array}$ & $\begin{array}{l}\text { Gage } \\
\text { height } \\
\text { (ft) }\end{array}$ & $\begin{array}{l}\text { Water } \\
\text { year }\end{array}$ & Date & $\begin{array}{c}\text { Discharge } \\
\left(\mathrm{ft}^{3} / \mathrm{s}\right)\end{array}$ & $\begin{array}{c}\text { Gage } \\
\text { height } \\
\text { (ft) }\end{array}$ & $\begin{array}{l}\text { Water } \\
\text { year }\end{array}$ & Date & $\begin{array}{c}\text { Discharge } \\
\left(\mathrm{ft}^{3} / \mathrm{s}\right)\end{array}$ & $\begin{array}{c}\text { Gage } \\
\text { height } \\
\text { (ft) }\end{array}$ \\
\hline 1904 & Aug. 09 & 5,910 & 16.50 & 1953 & Jan. 10 & 3,130 & 9.60 & 1972 & Jan. 12 & 6,700 & 15.63 \\
\hline 1905 & July 12 & 6,260 & 17.30 & 1954 & Jan. 17 & 3,490 & 10.40 & 1973 & Mar. 18 & 3,940 & 11.19 \\
\hline$\underline{1916}$ & $\overline{\text { July } 08}$ & $\overline{12,600}$ & $\overline{20.00} c$ & 1955 & Feb. 08 & 2,680 & 8.50 & 1974 & Jan. 02 & 4,250 & 11.90 \\
\hline 1937 & May 01 & 5,360 & 14.00 & 1956 & Mar. 16 & 3,540 & 10.50 & 1975 & Mar. 15 & 8,240 & 18.73 \\
\hline 1938 & Apr. 09 & 6,640 & 16.20 & 1957 & Apr. 06 & 4,910 & 13.20 & 1976 & Mar. 17 & 6,280 & 15.46 \\
\hline 1939 & Mar. 01 & 2,580 & 8.60 & 1958 & Feb. 07 & 1,910 & 6.50 & 1977 & Mar. 31 & 7,590 & 17.65 \\
\hline 1940 & July 10 & 3,540 & 10.70 & 1959 & June 02 & 3,900 & 11.70 & 1978 & Nov. 07 & 5,480 & 14.14 \\
\hline 1941 & July 17 & 1,630 & 6.00 & 1960 & Feb. 01 & 2,720 & 9.30 & 1979 & Apr. 14 & 7,490 & 17.48 \\
\hline 1942 & Mar. 22 & 4,460 & 12.70 & 1961 & Feb. 26 & 10,100 & 18.20 & 1980 & Mar. 09 & 3,210 & 9.93 \\
\hline 1943 & Mar. 22 & 5,190 & 13.70 & 1962 & Dec. 19 & 4,980 & 13.70 & 1981 & May 28 & 3,900 & 10.91 \\
\hline 1944 & Mar. 30 & 3,390 & 10.40 & 1963 & May 01 & 4,350 & 12.80 & 1982 & Feb. 04 & 10,700 & 19.90 \\
\hline 1945 & Apr. 25 & 2,130 & 7.40 & 1964 & Apr. 08 & 6,270 & 14.70 & 1983 & Apr. 09 & 3,530 & 10.16 \\
\hline 1946 & Jan. 08 & 6,000 & 15.10 & 1965 & Dec. 28 & 4,160 & 12.10 & 1984 & Dec. 07 & 4,490 & 12.08 \\
\hline 1947 & Jan. 21 & 6,110 & 15.30 & 1966 & Mar. 05 & 5,420 & 13.90 & 1985 & May 02 & 2,420 & 7.65 \\
\hline 1948 & Feb. 10 & 3,440 & 10.30 & 1967 & Aug. 26 & 4,330 & 12.13 & 1986 & Dec. 13 & 1,200 & 4.58 \\
\hline 1949 & Nov. 29 & 10,400 & 18.40 & 1968 & Jan. 11 & 2,490 & 8.43 & 1987 & Jan. 20 & 4,020 & 11.17 \\
\hline 1950 & Sept.09 & 2,020 & 6.80 & 1969 & Apr. 18 & 2,760 & 8.55 & 1988 & Jan. 20 & 1,980 & 6.60 \\
\hline 1951 & Apr. 23 & 1,950 & 6.60 & 1970 & Mar. 21 & 5,540 & 13.54 & 1989 & July 07 & 3,150 & 9.34 \\
\hline 1952 & Dec. 22 & 4,970 & 13.30 & 1971 & Mar. 04 & 3,580 & 10.55 & 1990 & Mar. 18 & 9,950 & 19.30 \\
\hline
\end{tabular}

\section{CAMP CREEK AT COLLEGE PARK, GEORGIA}

LOCATION.--Lat $33^{\circ} 39^{\prime} 39^{\prime \prime}$, long $84^{\circ} 27^{\prime} 44^{\prime \prime}$, Fulton County, at culvert on Park Terrace at College Park. DRAINAGE AREA. $-0.88 \mathrm{mi}^{2}$.

GAGE.--Flood-stage/rainfall recorder. Datum of gage is $888.00 \mathrm{ft}$ above sea level (levels by the U.S. Army Corps of Engineers). STAGE-DISCHARGE RELATION.--Defined by current-meter measurements below $32 \mathrm{tt}^{3} / \mathrm{s}$, and extended above on the basis of culvert computations.

REMARKS.--Flow is affected by urbanization. Peak discharges for 1966 and 1967 are estimated.

\begin{tabular}{|c|c|c|c|c|c|c|c|c|c|c|c|}
\hline $\begin{array}{l}\text { Water } \\
\text { year }\end{array}$ & Date & $\begin{array}{c}\text { Discharge } \\
\left(\mathrm{ft}^{3} / \mathrm{s}\right)\end{array}$ & $\begin{array}{c}\text { Gage } \\
\text { height } \\
\text { (ft) }\end{array}$ & $\begin{array}{l}\text { Water } \\
\text { year }\end{array}$ & Date & $\begin{array}{c}\text { Discharge } \\
\left(\mathrm{ft}^{3} / \mathrm{s}\right)\end{array}$ & $\begin{array}{c}\text { Gage } \\
\text { height } \\
\text { (ft) }\end{array}$ & $\begin{array}{c}\text { Water } \\
\text { year }\end{array}$ & Date & $\begin{array}{c}\text { Discharge } \\
\left(\mathrm{ft}^{3} / \mathrm{s}\right)\end{array}$ & $\begin{array}{c}\text { Gage } \\
\text { heigh } \\
\text { (ft) }\end{array}$ \\
\hline$\underline{1963}$ & Apr. 30 & 390 & 6.22 & 1974 & Jan. 23 & 394 & 6.27 & 1977 & June 22 & 271 & 5.01 \\
\hline 1966 & Feb. 13 & 360 & - & 1975 & Ján. 10 & 340 & 5.70 & 1978 & Nov. 05 & 461 & 7.01 \\
\hline$\underline{1967}$ & Mar. 10 & 550 & - & 1976 & May 28 & 378 & 6.09 & & & & \\
\hline
\end{tabular}




\section{APALACHICOLA RIVER BASIN}

\section{NORTH FORK CAMP CREK AT ATLANTA, GEORGIA}

LOCATION.--Lat $33^{\circ} 39^{\prime} 40^{\prime \prime}$, long $84^{\circ} 30^{\prime} 40^{\prime \prime}$, Fulton County, at bridge on Redwine Road, at Atlanta.

DRAINAGE AREA. $-5.25 \mathrm{mi}^{2}$.

GAGE.-Water-stage recorder prior to Sept. 30, 1969; crest-stage gage thereafter. Datum of gage is $812.00 \mathrm{ft}$ above sea level (from U.S. Coast and Geodetic Survey benchmark).

STAGE-DISCHARGE RELATION.--Defined by current-meter measurements below $800 \mathrm{ft}^{3} / \mathrm{s}$, and extended above on the basis of straight-line extension.

REMARKS.-Flood peaks may be affected by increasing amount of urbanization. Peak discharge for 1973 is estimated.

\begin{tabular}{|c|c|c|c|c|c|c|c|c|c|c|c|}
\hline $\begin{array}{l}\text { Water } \\
\text { year }\end{array}$ & Date & $\begin{array}{l}\text { Discharge } \\
\left(\mathrm{ft}^{3} / \mathrm{s}\right)\end{array}$ & $\begin{array}{c}\text { Gage } \\
\text { height } \\
\text { (ft) }\end{array}$ & $\begin{array}{l}\text { Water } \\
\text { year }\end{array}$ & Date & $\begin{array}{c}\text { Discharge } \\
\left(\mathrm{ft}^{3} / \mathrm{s}\right)\end{array}$ & $\begin{array}{c}\text { Gage } \\
\text { height } \\
\text { (ft) }\end{array}$ & $\begin{array}{l}\text { Water } \\
\text { year }\end{array}$ & Date & $\begin{array}{l}\text { Discharge } \\
\left(\mathrm{ft}^{3} / \mathrm{s}\right)\end{array}$ & $\begin{array}{c}\text { Gage } \\
\text { height } \\
\text { (ft) }\end{array}$ \\
\hline 1963 & Apr. 30 & 660 & 6.80 & 1968 & Dec. 19 & 923 & 8.35 & 1973 & Feb. 01 & 1,250 & - \\
\hline 1964 & Apr. 06 & 774 & 7.50 & 1969 & Apr. 18 & 1,250 & 10.15 & 1974 & Aug. 01 & 1,230 & 10.82 \\
\hline 1965 & Oct. 16 & 536 & 5.96 & 1970 & Mar. 20 & 1,070 & 9.80 & 1975 & Jan. 10 & 960 & 9.10 \\
\hline 1966 & Feb. 13 & 830 & 7.80 & 1971 & Aug. 02 & 980 & 9.10 & 1976 & Mar. 16 & 1,140 & 10.23 \\
\hline 1967 & Aug. 22 & 1,270 & 10.26 & 1972 & Jan. 10 & 926 & 8.90 & 1977 & July 01 & 603 & 6.18 \\
\hline
\end{tabular}

\section{CHATTAHOOCHEE RIVER NEAR FAIRBURN, GEORGIA}

LOCATION.-Lat $33^{\circ} 39^{\prime} 24^{\prime \prime}$, long $84^{\circ} 40^{\prime} 25^{\prime \prime}$, Fulton County, at downstream end of pier of bridge on State Highways 74 and $92,1.4$ mi downstream from Deep Creek, 8.5 mi northwest of Fairburn, and at mile 281.8.

DRAINAGE AREA.--2,060 $\mathrm{mi}^{2}$.

GAGE.-Water-stage recorder. Datum of gage is $719.07 \mathrm{ft}$ above sea level (levels by the Georgia Department of Transportaiton). STAGE-DISCHARGE RELATION.--Defined by current-meter measurements below $37,000 \mathrm{ft}^{3} / \mathrm{s}$, and above on the basis of slopeconveyance study at $75,000 \mathrm{ft}^{3} / \mathrm{s}$. Bankfull stage and discharge, $18 \mathrm{ft}$ and $19,000 \mathrm{ft}^{3} / \mathrm{s}$.

HISTORICAL DATA.-Flood stage of December 1919 based on information provided by the Georgia Department of Transportation; and is the highest since 1886, based on information at nearby stations.

REMARKS.--Peak discharges regulated by Lake Sideny Lanier (maximum flood-control capacity, 637,000 acre-ft) since January 1956.

\begin{tabular}{|c|c|c|c|c|c|c|c|c|c|c|c|}
\hline $\begin{array}{l}\text { Water } \\
\text { year }\end{array}$ & Date & $\begin{array}{c}\text { Discharge } \\
\left(\mathrm{ft}^{3} / \mathrm{s}\right)\end{array}$ & $\begin{array}{c}\text { Gage } \\
\text { height } \\
\text { (ft) }\end{array}$ & $\begin{array}{l}\text { Water } \\
\text { year }\end{array}$ & Date & $\begin{array}{c}\text { Discharge } \\
\left(\mathrm{ft}^{3} / \mathrm{s}\right)\end{array}$ & $\begin{array}{c}\text { Gage } \\
\text { height } \\
\text { (ft) }\end{array}$ & $\begin{array}{l}\text { Water } \\
\text { year }\end{array}$ & Date & $\begin{array}{c}\text { Discharge } \\
\left(\mathrm{ft}^{3} / \mathrm{s}\right)\end{array}$ & $\begin{array}{c}\text { Gage } \\
\text { height } \\
\text { (ft) }\end{array}$ \\
\hline$\underline{1920}$ & Dec. 10 & 75,000 & $31.60 c$ & 1974 & Jan. 01 & 24,500 & 20.26 & 1983 & Apr. 09 & 22,300 & 19.88 \\
\hline 1966 & Feb. 14 & 22,000 & 19.98 & 1975 & Mar. 14 & 31,800 & 23.27 & 1984 & Dec. 07 & 19,900 & 18.51 \\
\hline 1967 & Aug. 24 & 19,300 & 18.17 & 1976 & Mar. 16 & 34,300 & 24.09 & 1985 & Feb. 06 & 13,600 & 13.88 \\
\hline 1968 & Jan. 11 & 16,400 & 16.30 & 1977 & Mar. 31 & 27,100 & 21.70 & 1986 & Oct. 01 & 11,100 & 11.42 \\
\hline 1969 & Apr. 18 & 22,600 & 20.40 & 1978 & Jan. 26 & 23,600 & 20.42 & 1987 & Mar. 01 & 15,800 & 15.88 \\
\hline 1970 & Mar. 20 & 24,600 & 21.74 & 1979 & Apr. 14 & 37,500 & 25.18 & 1988 & Jan. 20 & 13,900 & 14.20 \\
\hline 1971 & Mar. 03 & 20,500 & 19.01 & 1980 & Mar. 08 & 22,000 & 19.73 & 1989 & June 21 & 14,200 & 14.52 \\
\hline 1972 & Jan. 11 & 32,700 & 23.56 & 1981 & Feb. 11 & 16,500 & 16.34 & 1990 & Mar. 17 & 39,200 & 25.74 \\
\hline 1973 & Mar. 17 & 22,200 & 19.12 & 1982 & Feb. 04 & 32,300 & 23.44 & & & & \\
\hline
\end{tabular}


LOCATION.--Lat $33^{\circ} 39^{\prime} 36^{\prime \prime}$, long $84^{\circ} 51^{\prime} 41^{\prime \prime}$, Douglas County, at county road, 2.2 mi north of Fairplay, and 9.1 mi southwest of Douglasville.

DRAINAGE AREA $-43 \mathrm{mi}^{2}$, approximately.

GAGE.--Crest-stage gage. Datum of gage is $904.8 \mathrm{ft}$ above sea level (levels from the U.S. Geological Survey benchmark).

STAGE-DISCHARGE RELATION.--Defined by current-meter measurements below $4,730 \mathrm{tt}^{3} / \mathrm{s}$, and above on the basis of contractedopening measurement at $9,910 \mathrm{ft}^{3} / \mathrm{s}$. Bankfull stage and discharge, $11 \mathrm{ft}$ and $3,200 \mathrm{ft}^{3} / \mathrm{s}$.

REMARKS.--Peak discharge for 1972 is estimated.

\begin{tabular}{|c|c|c|c|c|c|c|c|c|c|c|c|}
\hline $\begin{array}{l}\text { Water } \\
\text { year }\end{array}$ & Date & $\begin{array}{c}\text { Discharge } \\
\left(\mathrm{ft}^{3} / \mathrm{s}\right)\end{array}$ & $\begin{array}{c}\text { Gage } \\
\text { height } \\
\text { (ft) }\end{array}$ & $\begin{array}{c}\text { Water } \\
\text { year }\end{array}$ & Date & $\begin{array}{c}\text { Discharge } \\
\left(\mathrm{ft}^{3} / \mathrm{s}\right)\end{array}$ & $\begin{array}{c}\text { Gage } \\
\text { height } \\
\text { (ft) }\end{array}$ & $\begin{array}{l}\text { Water } \\
\text { year }\end{array}$ & Date & $\begin{array}{c}\text { Discharge } \\
\left(\mathrm{ft}^{3} / \mathrm{s}\right)\end{array}$ & $\begin{array}{c}\text { Gage } \\
\text { height } \\
\text { (ft) }\end{array}$ \\
\hline 1951 & Mar. 08 & 1,080 & 5.52 & 1961 & Feb. 25 & 9,910 & 16.15 & 1971 & Mar. 03 & 2,600 & 10.23 \\
\hline 1952 & Dec. 21 & 4,610 & 12.81 & 1962 & Dec. 12 & 3,420 & 11.39 & 1972 & Jan. 10 & 4,500 & - \\
\hline 1953 & Jan. 09 & 1,270 & 6.80 & 1963 & Mar. 13 & 3,430 & 11.40 & 1973 & May 28 & 2,460 & 10.32 \\
\hline 1954 & Jan. 16 & 695 & 3.59 & 1964 & Apr. 06 & 3,720 & 11.77 & 1974 & Dec. 31 & 5,040 & 13.20 \\
\hline 1955 & Feb. 06 & 1,090 & 5.57 & 1965 & Dec. 26 & 4,600 & 12.80 & 1975 & Mar. 14 & 6,070 & 13.98 \\
\hline 1956 & Mar. 16 & 6,680 & 14.36 & 1966 & Feb. 13 & 3,590 & 11.61 & 1976 & Mar. 16 & 6,030 & 13.95 \\
\hline 1957 & Apr. 05 & 4,080 & 12.23 & 1967 & Aug. 25 & 3,690 & 11.74 & $\underline{1977}$ & Mar. 30 & 3,450 & 11.43 \\
\hline 1958 & Feb. 06 & 1,780 & 8.70 & 1968 & Apr. 05 & 1,190 & 6.32 & $\underline{1982}$ & Feb. 03 & 9,310 & $15.84 \mathrm{c}$ \\
\hline 1959 & May 31 & 5,990 & 13.92 & 1969 & Apr. 18 & 1,940 & 9.11 & $\overline{1990}$ & Mar. 16 & 7,220 & $14.68 \mathrm{c}$ \\
\hline 1960 & Apr. 03 & 1,650 & 8.32 & 1970 & Mar. 19 & 8,000 & 15.12 & & & & \\
\hline
\end{tabular}

02337448 HURRICANE CREEK TRIBUTARY NEAR FAIRPLAY, GEORGIA

LOCATION.--Lat $33^{\circ} 35^{\prime} 03^{\prime \prime}$, long $84^{\circ} 50^{\prime} 54^{\prime \prime}$, Douglas County, at culvert on State Highway 5, 0.9 mi north of Douglas-Carroll County line, $8 \mathrm{mi}$ east of Fairplay.

DRAINAGE AREA.--0.33 $\mathrm{mi}^{2}$.

GAGE.--Crest-stage gage. Datum of gage is about $930 \mathrm{ft}$ above sea level (from topographic map).

STAGE-DISCHARGE RELATION.--Defined by current-meter measurements below $4.9 \mathrm{tt}^{3} / \mathrm{s}$, and extended above on the basis of culvert computations.

\begin{tabular}{|c|c|c|c|c|c|c|c|c|c|c|c|}
\hline $\begin{array}{l}\text { Water } \\
\text { year }\end{array}$ & Date & $\begin{array}{c}\text { Discharge } \\
\left(\mathrm{ft}^{3} / \mathrm{s}\right)\end{array}$ & $\begin{array}{c}\text { Gage } \\
\text { height } \\
\text { (ft) }\end{array}$ & $\begin{array}{l}\text { Water } \\
\text { year }\end{array}$ & Date & $\begin{array}{c}\text { Discharge } \\
\left(\mathrm{ft}^{3} / \mathrm{s}\right)\end{array}$ & $\begin{array}{c}\text { Gage } \\
\text { height } \\
\text { (ft) }\end{array}$ & $\begin{array}{l}\text { Water } \\
\text { year }\end{array}$ & Date & $\begin{array}{c}\text { Discharge } \\
\left(\mathrm{ft}^{3} / \mathrm{s}\right)\end{array}$ & $\begin{array}{c}\text { Gage } \\
\text { height } \\
\text { (ft) }\end{array}$ \\
\hline 1977 & Mar. 30 & 153 & 7.06 & 1982 & Feb. 03 & 87.0 & 5.74 & 1987 & June 25 & 127 & 6.57 \\
\hline 1978 & Nov. 05 & 292 & 9.46 & 1983 & Apr. 08 & 55.0 & 4.99 & 1988 & Jan. 20 & 29.0 & 4.24 \\
\hline 1979 & Apr. 13 & 170 & 7.39 & 1984 & Dec. 06 & 44.0 & 4.72 & 1989 & June 20 & 45.0 & 4.72 \\
\hline 1980 & June 24 & 91.0 & 5.82 & 1985 & - & 5.0 & $-b$ & 1990 & Mar. 16 & 229 & 8.37 \\
\hline 1981 & May 27 & 42.0 & 4.68 & 1986 & - & 5.0 & $-b$ & & & & \\
\hline
\end{tabular}


LOCATION.--Lat $33^{\circ} 31^{\prime} 46^{\prime \prime}$, long $84^{\circ} 55^{\prime} 42^{\prime \prime}$, Carroll County, at downstream end of left bank pier of former highway bridge at Banning Mills, 1.6 mi north of State Highway 16, 3 mi northwest of Whitesburg, 4 mi downstream from Little Snake Creek, and 7 mi upstream from mouth,

DRAINAGE AREA.--35.5 $\mathrm{mi}^{2}$, approximately.

GAGE.--Water-stage recorder. Datum of gage is 832.75 above sea level (levels by Global Positioning system).

STAGE-DISCHARGE RELATION.--Defined by current-meter measurements below $5,900 \mathrm{tt}^{3} / \mathrm{s}$, and extended above on the basis of straight-line extension.

REMARKS.--Peak discharge for 1979 is estimated.

\begin{tabular}{|c|c|c|c|c|c|c|c|c|c|c|c|}
\hline $\begin{array}{l}\text { Water } \\
\text { year }\end{array}$ & Date & $\begin{array}{c}\text { Discharge } \\
\left(\mathrm{ft}^{3} / \mathrm{s}\right)\end{array}$ & $\begin{array}{c}\text { Gage } \\
\text { height } \\
\text { (ft) }\end{array}$ & $\begin{array}{l}\text { Water } \\
\text { year }\end{array}$ & Date & $\begin{array}{c}\text { Discharge } \\
\left(\mathrm{ft}^{3} / \mathrm{s}\right)\end{array}$ & $\begin{array}{c}\text { Gage } \\
\text { height } \\
\text { (ft) }\end{array}$ & $\begin{array}{l}\text { Water } \\
\text { year }\end{array}$ & Date & $\begin{array}{c}\text { Discharge } \\
\left(\mathrm{ft}^{3} / \mathrm{s}\right)\end{array}$ & $\begin{array}{c}\text { Gage } \\
\text { height } \\
\text { (ft) }\end{array}$ \\
\hline 1955 & Feb. 06 & 1,200 & 5.82 & 1967 & Nov. 10 & 3,790 & 9.98 & 1979 & Apr. 13 & 3,500 & - \\
\hline 1956 & Mar. 16 & 6,110 & 12.80 & 1968 & May 15 & 2,360 & 7.85 & 1980 & Apr. 13 & 2,310 & 8.10 \\
\hline 1957 & Apr. 05 & 3,520 & 9.60 & 1969 & Apr. 18 & 4,040 & 10.35 & 1981 & May 26 & 2,190 & 7.86 \\
\hline 1958 & Feb. 06 & 2,390 & 7.90 & 1970 & Mar. 19 & 3,610 & 9.73 & 1982 & Feb. 03 & 6,680 & 13.40 \\
\hline 1959 & May 31 & 3,170 & 9.10 & 1971 & Mar. 03 & 2,680 & 8.75 & 1983 & Apr. 08 & 3,250 & 9.41 \\
\hline 1960 & Apr. 03 & 2,390 & 7.90 & 1972 & May 13 & 3,070 & 9.33 & 1984 & July 31 & 3,270 & 9.44 \\
\hline 1961 & Feb. 25 & 7,690 & 14.40 & 1973 & May 28 & 2,890 & 9.11 & 1985 & Feb. 05 & 970 & 5.14 \\
\hline 1962 & Dec. 12 & 2,900 & 8.66 & 1974 & Dec. 31 & 6,420 & 13.12 & 1986 & Mar. 13 & 199 & 3.13 \\
\hline 1963 & Apr. 30 & 4,630 & 11.10 & 1975 & Mar. 13 & 4,020 & 10.54 & 1987 & Jan. 18 & 2,950 & 8.99 \\
\hline 1964 & Jan. 25 & 3,450 & 9.48 & 1976 & Jan. 26 & 4,360 & 10.88 & 1988 & Jan. 20 & 1,850 & 7.19 \\
\hline 1965 & Jan. 23 & 2,610 & 8.24 & 1977 & Mar. 30 & 3,320 & 9.57 & 1989 & June 16 & 1,590 & 6.58 \\
\hline 1966 & Feb. 13 & 3,600 & 9.72 & 1978 & Jan. 25 & 4,110 & 10.60 & 1990 & Mar. 16 & 5,220 & 12.37 \\
\hline
\end{tabular}




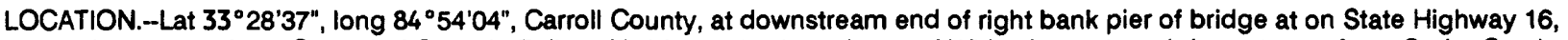
$0.5 \mathrm{mi}$ upstream from Central of Georgia Railroad bridge, $1.2 \mathrm{mi}$ southeast of Whitesburg, $1.5 \mathrm{mi}$ downstream from Cedar Creek, $2.0 \mathrm{mi}$ downstream from Snake Creek, and at mile 259.8 .

DRAINAGE AREA.--2,430 $\mathrm{mi}^{2}$, approximately.

GAGE.--Water-stage recorder. Datum of gage is 682.06 above sea level (levels by the Georgia Department of Transportation), supplementary adjustment of 1936 . Prior to May 1,1949 , nonrecording gage at site 1.0 mi upstream at datum $2.00 \mathrm{ft}$ higher. May 1, 1949, to June 30, 1954, nonrecording gage at present site at datum $2.00 \mathrm{ft}$ higher.

STAGE-DISCHARGE RELATION.--Defined by current-meter measurements below $42,500 \mathrm{ft}^{3} / \mathrm{s}$. Bankfull stage and discharge, $18 \mathrm{ft}$ and $27,000 \mathrm{ft}^{3} / \mathrm{s}$. Peak discharge for 1946 flood based on rating curve extension and velocity-area and channel capacity studies. HISTORICAL DATA.--Flood of January 1946 was probably the highest since at least 1919 , based on records for gaging station downstream at West Point.

REMARKS.--Peak discharges regulated by Lake Sidney Lanier (maximum flood-control capacity, 637,000 acre-ft) since January 1956.

\begin{tabular}{|c|c|c|c|c|c|c|c|c|c|c|c|}
\hline $\begin{array}{l}\text { Water } \\
\text { year }\end{array}$ & Date & $\begin{array}{c}\text { Discharge } \\
\left(\mathrm{ft}^{3} / \mathrm{s}\right)\end{array}$ & $\begin{array}{c}\text { Gage } \\
\text { height } \\
\text { (ft) }\end{array}$ & $\begin{array}{l}\text { Water } \\
\text { year }\end{array}$ & Date & $\begin{array}{c}\text { Discharge } \\
\left(\mathrm{ft}^{3} / \mathrm{s}\right)\end{array}$ & $\begin{array}{c}\text { Gage } \\
\text { height } \\
\text { (ft) }\end{array}$ & $\begin{array}{l}\text { Water } \\
\text { year }\end{array}$ & Date & $\begin{array}{c}\text { Discharge } \\
\left(\mathrm{ft}^{3} / \mathrm{s}\right)\end{array}$ & $\begin{array}{c}\text { Gage } \\
\text { height } \\
\text { (ft) }\end{array}$ \\
\hline 1938 & Apr. 08 & 25,000 & 16.40 & 1953 & Jan. 10 & 21,200 & 15.40 & 1977 & Mar. 31 & 31,100 & 19.56 \\
\hline 1939 & Feb. 28 & 23,300 & 15.70 & $\underline{1954}$ & Jan. 19 & 26,300 & 17.80 & 1978 & Nov. 05 & 37,600 & 21.87 \\
\hline 1940 & Aug. 16 & 20,800 & 14.50 & 1965 & Jan. 24 & 23,600 & 16.70 & 1979 & Apr. 14 & 42,600 & 23.79 \\
\hline 1941 & Aug. 17 & 13,800 & 11.00 & 1966 & Feb. 14 & 28,500 & 18.85 & 1980 & Mar. 09 & 26,400 & 17.69 \\
\hline 1942 & Mar. 21 & 33,900 & 19.60 & 1967 & Aug. 25 & 24,100 & 17.58 & 1981 & Feb. 11 & 23,500 & 16.61 \\
\hline 1943 & Mar. 21 & 30,000 & 18.20 & 1968 & Apr. 05 & 19,800 & 14.80 & 1982 & Feb. 04 & 36,900 & 21.89 \\
\hline 1944 & Apr. 01 & 26,900 & 17.60 & 1969 & Apr. 19 & 28,300 & 18.79 & 1983 & Apr. 09 & 29,400 & 18.89 \\
\hline 1945 & Apr. 25 & 22,900 & 15.70 & 1970 & Mar. 20 & 33,200 & 20.89 & 1984 & Dec. 07 & 23,000 & 16.46 \\
\hline 1946 & Jan. 10 & 59,000 & 25.10 & 1971 & Mar. 03 & 28,200 & 18.73 & 1985 & Feb. 06 & 18,100 & 14.30 \\
\hline 1947 & Jan. 23 & 33,500 & 20.20 & 1972 & Jan. 12 & 37,500 & 21.84 & 1986 & Nov. 02 & 12,600 & 11.44 \\
\hline 1948 & Feb. 09 & 25,800 & 17.20 & 1973 & Feb. 01 & 26,400 & 17.24 & 1987 & Jan. 19 & 28,400 & 18.65 \\
\hline$\underline{1949}$ & Nov. 29 & 46,000 & $\underline{25.00}$ & 1974 & Jan. 01 & 29,200 & 18.82 & 1988 & Jan. 20 & 18,200 & 14.35 \\
\hline$\overline{1950}$ & Mar. 16 & $\overline{15,000}$ & $\overline{12.20}$ & 1975 & Mar. 14 & 36,400 & 21.48 & 1989 & June 22 & 19,500 & 14.92 \\
\hline 1951 & Mar. 30 & 12,800 & 11.00 & 1976 & Mar. 16 & 43,700 & 23.90 & 1990 & Mar. 18 & 48,700 & 25.90 \\
\hline 1952 & Mar. 14 & 32,400 & 20.50 & & & & & & & & \\
\hline
\end{tabular}

\section{CHATTAHOOCHEE RIVER AT FRANKLIN, GEORGIA}

LOCATION.--Lat 33 $16^{\prime} 45^{\prime \prime}$, long $85^{\circ} 06^{\prime} 00^{\prime \prime}$, Heard County, at bridge on U.S. Highway $27,0.2$ mi southwest of Franklin, 1.5 mi downstream from Centralhatchee Creek, 2 mi upstream from Hillabahatchee Creek, at at mile 235.5.

DRAINAGE AREA.--2,680 $\mathrm{mi}^{2}$, approximately.

GAGE.--Nonrecording. Prior to Oct. 31, 1931, at site $250 \mathrm{ft}$ downstream, Mar. 1, 1937, to Sept. 30, 1939, at site $500 \mathrm{ft}$ downstream. All gages at about same datum. Datum of gage is $623.86 \mathrm{ft}$ above sea level (levels by the U.S. Army Corps of Engineers).

STAGE-DISCHARGE RELATION.--Defined by current-meter measurements below $36,000 \mathrm{ft}^{3} / \mathrm{s}$, and extended above on basis of peak flow at stations of Chattahoochee River near Norcross and at West Point.

HISTORICAL DATA.--Flood of December 1919 was probably the highest since 1886, based on records for gaging station downstream at West Point.

REMARKS.--Peak discharges regulated by Lake Sidney Lanier (maximum flood-control capacity, 637,000 acre-ft) since January 1956. Station in backwater from West Point Dam after October 1974. Peak discharges for 1920 and 1961 floods are estimated.

\begin{tabular}{|c|c|c|c|c|c|c|c|c|c|c|c|}
\hline $\begin{array}{l}\text { Water } \\
\text { year }\end{array}$ & Date & $\begin{array}{c}\text { Discharge } \\
\left(\mathrm{ft}^{3} / \mathrm{s}\right)\end{array}$ & $\begin{array}{c}\text { Gage } \\
\text { height } \\
\text { (ft) }\end{array}$ & $\begin{array}{l}\text { Water } \\
\text { year }\end{array}$ & Date & $\begin{array}{c}\text { Discharge } \\
\left(\mathrm{ft}^{3} / \mathrm{s}\right)\end{array}$ & $\begin{array}{c}\text { Gage } \\
\text { height } \\
\text { (ft) }\end{array}$ & $\begin{array}{l}\text { Water } \\
\text { year }\end{array}$ & Date & $\begin{array}{c}\text { Discharge } \\
\left(\mathrm{ft}^{3} / \mathrm{s}\right)\end{array}$ & $\begin{array}{c}\text { Gage } \\
\text { height } \\
\text { (ft) }\end{array}$ \\
\hline$\underline{1920}$ & Dec. - & 105,000 & $28.40 c$ & 1938 & Apr. 08 & 34,100 & 18.80 & 1958 & Feb. 07 & 23,300 & 15.20 \\
\hline$\overline{1929}$ & Mar. 15 & 54,000 & 22.70 & $\underline{1939}$ & Feb. 28 & 28,300 & 17.00 & $\underline{1959}$ & June 01 & 26,200 & 16.60 \\
\hline 1930 & Nov. 15 & 24,500 & 14.70 & $\underline{1949}$ & Nov. 24 & 48,000 & $26.60 \mathrm{c}$ & $\overline{1961}$ & Feb. 26 & 50,000 & $26.70 c$ \\
\hline$\underline{1931}$ & Nov. 16 & $\underline{21,600}$ & 13.50 & & & & & & & & \\
\hline
\end{tabular}


LOCATION.-Lat $33^{\circ} 14^{\prime} 07^{\prime \prime}$, long $84^{\circ} 59^{\prime} 16^{\prime \prime}$, Heard County, at bridge on State Highway 100, 1.7 mi downstream of Caney Creek, $2.5 \mathrm{mi}$ west of Corinth and $8.1 \mathrm{mi}$ upstream of Chattahoochee River.

DRAINAGE AREA.--127 $\mathrm{mi}^{2}$.

GAGE.--Water-stage recorder. Datum of gage is $634.68 \mathrm{ft}$ above sea level (from U.S. Geological Survey benchmark). STAGE-DISCHARGE RELATION.--Defined by current-meter measurements below $9,400 \mathrm{ft}^{3} / \mathrm{s}$.

\begin{tabular}{|c|c|c|c|c|c|c|c|c|c|c|c|}
\hline $\begin{array}{l}\text { Water } \\
\text { year }\end{array}$ & Date & $\begin{array}{c}\text { Discharge } \\
\left(\mathrm{ft}^{3} / \mathrm{s}\right)\end{array}$ & $\begin{array}{c}\text { Gage } \\
\text { height } \\
\text { (ft) }\end{array}$ & $\begin{array}{c}\text { Water } \\
\text { year }\end{array}$ & Date & $\begin{array}{c}\text { Discharge } \\
\left(\mathrm{ft}^{3} / \mathrm{s}\right)\end{array}$ & $\begin{array}{c}\text { Gage } \\
\text { height } \\
\text { (ft) }\end{array}$ & $\begin{array}{c}\text { Water } \\
\text { year }\end{array}$ & Date & $\begin{array}{c}\text { Discharge } \\
\left(\mathrm{ft}^{3} / \mathrm{s}\right)\end{array}$ & $\begin{array}{c}\text { Gage } \\
\text { height } \\
\text { (ft) }\end{array}$ \\
\hline 1979 & Apr. 14 & 7,450 & 13.92 & 1983 & Apr. 09 & 4,330 & 11.86 & 1987 & Mar. 01 & 1,730 & 9.37 \\
\hline 1980 & June 20 & 4,230 & 11.38 & 1984 & Dec. 04 & 2,430 & 10.21 & 1988 & Feb. 05 & 1,930 & 9.63 \\
\hline 1981 & Feb. 11 & 5,150 & 12.70 & 1985 & Feb. 06 & 2,340 & 10.11 & 1989 & June 21 & 2,200 & 9.94 \\
\hline 1982 & Feb. 04 & 3,660 & 11.58 & 1986 & Nov. 02 & 1,010 & 8.23 & 1990 & Mar. 17 & 10,000 & 17.17 \\
\hline
\end{tabular}

\section{YELLOWJACKET CREEK AT HOGANSVILLE, GEORGIA}

LOCATION.--Lat $33^{\circ} 10^{\prime} 59^{\prime \prime}$, long $84^{\circ} 54^{\prime} 56^{\prime \prime}$, Troup County, on right downstream end of bridge on State Highway 100 at Hogansville city limits. DRAINAGE AREA. $-42.5 \mathrm{mi}^{2}$.

GAGE.--Crest-stage gage. Datum of gage is $666.50 \mathrm{ft}$ above sea level (from U.S. Corps of Engineers benchmark).

STAGE-DISCHARGE RELATION.--Defined by current-meter measurements below $1,570 \mathrm{ft}^{3} / \mathrm{s}$, and extended above on basis of rating curve extension. Bankfull stage and discharge $13 \mathrm{ft}$, and $2,500 \mathrm{ft}^{3} / \mathrm{s}$.

HISTORICAL DATA.--Flood of February 1961 was probably the highest 1919, based on records at nearby stations. Flood stage of February 1961 based on information provided by local resident.

REMARKS.--Peak discharge of February 1961 is estimated.

\begin{tabular}{|c|c|c|c|c|c|c|c|c|c|c|c|}
\hline $\begin{array}{l}\text { Water } \\
\text { year }\end{array}$ & Date & $\begin{array}{c}\text { Discharge } \\
\left(\mathrm{ft}^{3} / \mathrm{s}\right)\end{array}$ & $\begin{array}{c}\text { Gage } \\
\text { height } \\
\text { (ft) }\end{array}$ & $\begin{array}{l}\text { Water } \\
\text { year }\end{array}$ & Date & $\begin{array}{c}\text { Discharge } \\
\left(\mathrm{ft}^{3} / \mathrm{s}\right)\end{array}$ & $\begin{array}{c}\text { Gage } \\
\text { height } \\
\text { (ft) }\end{array}$ & $\begin{array}{l}\text { Water } \\
\text { year }\end{array}$ & Date & $\begin{array}{c}\text { Discharge } \\
\left(\mathrm{ft}^{3} / \mathrm{s}\right)\end{array}$ & $\begin{array}{c}\text { Gage } \\
\text { height } \\
\text { (ft) }\end{array}$ \\
\hline$\underline{1961}$ & Feb. 25 & 8,400 & $24.50 \mathrm{c}$ & 1970 & July 05 & 1,190 & 9.48 & 1973 & Feb. 02 & 1,960 & 11.77 \\
\hline 1967 & May 00 & 850 & $-\mathrm{b}$ & 1971 & Mar. 03 & 2,780 & 13.47 & $\underline{1974}$ & Mar. -- & 850 & $-\mathbf{b}$ \\
\hline 1968 & Mar. 12 & 1,580 & 10.75 & 1972 & Jan. 10 & 2,970 & 13.78 & 1990 & Mar. 17 & 2,100 & $12.20 \mathrm{c}$ \\
\hline 1969 & Apr. 18 & 640 & 7.30 & & & & & & & & \\
\hline
\end{tabular}




\section{APALACHICOLA RIVER BASIN}

\section{YELLOWJACKET CREEK BELOW HOGANSVILLE, GEORGIA}

LOCATION.--Lat 33 $03^{\prime 22} "$, long $84^{\circ} 58^{\prime} 31^{\prime \prime}$, Troup County, on bridge on Hammet Road, 0.7 mi downstream from Flat Creek, and 5.8 mi southwest of Hogansville. DRAINAGE AREA.--91.0 $\mathrm{mi}^{2}$

GAGE.-Water-stage recorder. Datum of gage is $640.93 \mathrm{ft}$ above sea level (from U.S. Geological Survey benchmark). STAGE-DISCHARGE RELATION.-Defined by current-meter measurements below $1,720 \mathrm{ft}^{3} / \mathrm{s}$, and extended above on basis of straight-line extension.

\begin{tabular}{lccccccccccc}
\hline $\begin{array}{l}\text { Water } \\
\text { year }\end{array}$ & Date & $\begin{array}{c}\text { Discharge } \\
\left(\mathrm{ft}^{3} / \mathrm{s}\right)\end{array}$ & $\begin{array}{c}\text { Gage } \\
\text { height } \\
(\mathrm{ft})\end{array}$ & $\begin{array}{c}\text { Water } \\
\text { year }\end{array}$ & Date & $\begin{array}{c}\text { Discharge } \\
\left(\mathrm{ft}^{3} / \mathrm{s}\right)\end{array}$ & $\begin{array}{c}\text { Gage } \\
\text { height } \\
(\mathrm{ft})\end{array}$ & $\begin{array}{c}\text { Water } \\
\text { year }\end{array}$ & $\begin{array}{c}\text { Gage } \\
\text { Date }\end{array}$ & $\begin{array}{c}\text { Discharge } \\
\left(\mathrm{ft}^{3} / \mathrm{s}\right)\end{array}$ & $\begin{array}{c}\text { height } \\
(\mathrm{ft})\end{array}$ \\
\hline & & & & & & & & & & \\
1979 & Apr. 05 & 2,070 & 8.31 & 1982 & Apr. 21 & 3,990 & 10.71 & 1984 & Dec. 04 & 2,630 & 9.40 \\
1980 & Mar. 09 & 1,930 & 8.28 & 1983 & Apr. 09 & 2,070 & 8.61 & 1985 & July 29 & 1,790 & 8.29 \\
1981 & Feb. 11 & 2,710 & 9.60 & & & & & & & & \\
\hline
\end{tabular}

\section{YELLOWJACKET CREEK NEAR LAGRANGE, GEORGIA}

LOCATION.-Lat $33^{\circ} 05^{\prime} 27^{\prime \prime}$, long $85^{\circ} 03^{\prime} 40^{\prime \prime}$, Troup County, at bridge on State Highway 219, 1.2 mi downstream from Beach Creek, 2 mi upstream from Jackson Creek, and 4.2 mi northwest of LaGrange. DRAINAGE AREA.--182 $\mathrm{mi}^{2}$.

GAGE.-Water-stage recorder. Datum of gage is about $601 \mathrm{ft}$ above sea level (by barometer).

STAGE-DISCHARGE RELATION.--Defined by current-meter measurements below $12,800 \mathrm{ft}^{3} / \mathrm{s}$, and extended above on basis of straight-line extension. Bankfull stage and discharge, $8 \mathrm{ft}$ and $1,600 \mathrm{ft}^{3} / \mathrm{s}$.

REMARKS.--Station inundated by West Point Reservoir in 1974.

\begin{tabular}{|c|c|c|c|c|c|c|c|c|c|c|c|}
\hline $\begin{array}{l}\text { Water } \\
\text { year }\end{array}$ & Date & $\begin{array}{c}\text { Discharge } \\
\left(\mathrm{ft}^{3} / \mathrm{s}\right)\end{array}$ & $\begin{array}{c}\text { Gage } \\
\text { height } \\
\text { (ft) }\end{array}$ & $\begin{array}{c}\text { Water } \\
\text { year }\end{array}$ & Date & $\begin{array}{c}\text { Discharge } \\
\left(\mathrm{ft}^{3} / \mathrm{s}\right)\end{array}$ & $\begin{array}{c}\text { Gage } \\
\text { height } \\
\text { (ft) }\end{array}$ & $\begin{array}{l}\text { Water } \\
\text { year }\end{array}$ & Date & $\begin{array}{c}\text { Discharge } \\
\left(\mathrm{ft}^{3} / \mathrm{s}\right)\end{array}$ & $\begin{array}{c}\text { Gage } \\
\text { height } \\
\text { (ft) }\end{array}$ \\
\hline 1951 & Apr. 24 & 880 & 6.60 & 1958 & Feb. 08 & 4,900 & 12.00 & 1965 & Dec. 26 & 3,900 & 10.53 \\
\hline 1952 & Mar. 05 & 4,200 & 11.28 & 1959 & Mar. 06 & 960 & 7.25 & 1966 & Feb. 14 & 6,400 & 13.10 \\
\hline 1953 & May 02 & 2,760 & 9.70 & 1960 & Apr. 05 & 3,000 & 10.00 & 1967 & May 23 & 2,010 & 8.47 \\
\hline 1954 & Dec. 05 & 2,760 & 9.70 & 1961 & Feb. 25 & 21,600 & 22.50 & 1968 & Mar. 13 & 5,350 & 12.54 \\
\hline 1955 & Apr. 15 & 1,726 & 8.63 & 1962 & Dec. 13 & 4,300 & 11.91 & 1969 & Apr. 19 & 3,030 & 10.13 \\
\hline 1956 & Mar. 17 & 4,300 & 11.35 & 1963 & Jan. 21 & 2,290 & 9.38 & 1970 & Mar. 21 & 4,290 & 10.39 \\
\hline 1957 & Apr. 06 & 6,110 & 13.36 & 1964 & Apr. 28 & 7,580 & $13.80 \mathrm{a}$ & $19:-1$ & Mar. 03 & 14,500 & 17.45 \\
\hline
\end{tabular}




\section{CHATTAHOOCHEE RIVER AT WEST POINT, GEORGIA}

LOCATION.-Lat 32 $53^{\prime} 10^{\prime \prime}$, long $85^{\circ} 10^{\prime} 56^{\prime \prime}$, Troup County, on right bank just downstream from Oseligee Creek at West Point, 1 mi upstream from bridge on U.S. Highway 29 , and at mile 198.9.

DRAINAGE AREA.--3,550 $\mathrm{mi}^{2}$, approxiamtely.

GAGE.-Water-stage recorder. Datum of gage is $551.67 \mathrm{ft}$ above sea level (from U.S. Coast and Geodetic Survey benchmark). Prior to Oct. 20,1912, nonrecording gage at site $0.8 \mathrm{mi}$ downstream at datum $2.83 \mathrm{ft}$ lower. Oct. 20, 1912, to Jan. 25, 1925, nonrecording gage at site $500 \mathrm{ft}$ upstream at present datum.

STAGE-DISCHARGE RELATION.--Defined by current-meter measurements below $85,000 \mathrm{ft}^{3} / \mathrm{s}$, and extended above on basis of computation of peak flow over Langdale Dam. Bankfull stage and discharge, $19 \mathrm{ft}$ and $48,000 \mathrm{ft}^{3} / \mathrm{s}$.

HISTORICAL DATA.--Well documented records of major floods at Columbus, Ga., indicate that the 1886 flood on the

Chattahoochee River was, at that time, the highest since at least 1827 . The stage of the 1886 flood from floodmarks from the National Weather Service.

REMARKS.--Peak discharge since January 1956 may be slightly affected by storage in Lake Sidney Lanier (maximum flood-control storage, 637,000 acre-ft). Peak discharges affected by West Point Lake (flood-control capacity, 221,000 acre-ft) beginning October 1974. Peak discharges for 1897-1905 are maximum daily discharges. Peak gage height for 1920 flood at present site.

\begin{tabular}{|c|c|c|c|c|c|c|c|c|c|c|c|}
\hline $\begin{array}{l}\text { Water } \\
\text { year }\end{array}$ & Date & $\begin{array}{c}\text { Discharge } \\
\left(\mathrm{ft}^{3} / \mathrm{s}\right)\end{array}$ & $\begin{array}{c}\text { Gage } \\
\text { height } \\
\text { (ft) }\end{array}$ & $\begin{array}{l}\text { Water } \\
\text { year }\end{array}$ & Date & $\begin{array}{c}\text { Discharge } \\
\left(\mathrm{ft}^{3} / \mathrm{s}\right)\end{array}$ & $\begin{array}{c}\text { Gage } \\
\text { height } \\
\text { (ft) }\end{array}$ & $\begin{array}{l}\text { Water } \\
\text { year }\end{array}$ & Date & $\begin{array}{c}\text { Discharge } \\
\left(\mathrm{ft}^{3} / \mathrm{s}\right)\end{array}$ & $\begin{array}{c}\text { Gage } \\
\text { height } \\
\text { (ft) }\end{array}$ \\
\hline 1886 & Apr. -- & 92,800 & $25.60 \mathrm{c}$ & 1928 & Apr. 23 & 30,500 & 14.30 & 1960 & Apr. 04 & 28,800 & 15.10 \\
\hline 1897 & Mar. 14 & 38,500 & 14.10 & 1929 & Mar. 15 & 87,600 & 25.40 & 1961 & Feb. 26 & 94,400 & 24.90 \\
\hline 1898 & Sept.06 & 57,400 & 18.20 & 1930 & Nov. 16 & 28,200 & 13.60 & 1962 & Dec. 13 & 47,200 & 19.79 \\
\hline 1899 & Feb. 28 & 43,600 & 15.20 & 1931 & Nov. 17 & 30,900 & 14.40 & 1963 & Nov. 22 & 35,100 & 16.77 \\
\hline 1900 & Feb. 14 & 63,300 & 19.50 & 1932 & Feb. 22 & 29,200 & 14.20 & 1964 & Apr. 07 & 55,300 & 19.98 \\
\hline 1901 & May 23 & 52,800 & 17.20 & 1933 & Dec. 30 & 58,600 & 21.70 & 1965 & Jan. 24 & 38,600 & 17.85 \\
\hline 1902 & Dec. 30 & 88,600 & 25.00 & 1934 & Mar. 05 & 34,700 & 16.50 & 1966 & Feb. 14 & 40,900 & 18.23 \\
\hline 1903 & Feb. 09 & 66,100 & 20.10 & 1935 & Oct. 12 & 30,200 & 15.20 & 1967 & Aug. 26 & 29,400 & 14.59 \\
\hline 1904 & Aug. 09 & 29,300 & 12.60 & 1936 & Apr. 08 & 75,400 & 22.90 & 1968 & Apr. 06 & 30,300 & 15.37 \\
\hline 1905 & Jan. 13 & 29,300 & 12.60 & 1937 & Jan. 06 & 49,900 & 18.40 & 1969 & Apr. 19 & 43,600 & 17.91 \\
\hline 1906 & Mar. 20 & 51,800 & 18.90 & 1938 & Apr. 09 & 63,900 & 20.20 & 1970 & Mar. 22 & 47,200 & 18.63 \\
\hline 1907 & Mar. 03 & 30,500 & 12.50 & 1939 & Mar. 01 & 45,500 & 17.60 & 1971 & Mar. 03 & 57,900 & 21.29 \\
\hline 1908 & Apr. 26 & 40,800 & 16.00 & 1940 & July 10 & 28,600 & 14.10 & 1972 & Jan. 12 & 57,400 & 20.90 \\
\hline 1909 & Mar. 13 & 51,500 & 19.00 & 1941 & July 17 & 13,800 & 9.10 & 1973 & Feb. 03 & 37,400 & 16.81 \\
\hline 1910 & May 25 & 23,100 & 11.30 & 1942 & Mar. 22 & 64,200 & 20.20 & 1974 & Jan. 03 & 28,600 & 14.46 \\
\hline 1911 & Apr. 10 & 20,700 & 10.50 & 1943 & Mar. 22 & 64,200 & 20.20 & 1975 & Apr. 03 & 46,900 & 18.88 \\
\hline 1912 & Mar. 16 & $\underline{73,400}$ & $\underline{22.90}$ & 1944 & Apr. 27 & 46,200 & 17.70 & 1976 & Mar. 19 & 34,600 & 16.15 \\
\hline 1913 & Mar. 15 & 46,900 & 18.60 & 1945 & Apr. 25 & 65,700 & 20.40 & 1977 & Apr. 04 & 26,300 & 13.76 \\
\hline 1914 & Apr. 17 & 18,500 & 9.60 & 1946 & Jan. 12 & 59,700 & 19.60 & 1978 & Nov. 07 & 23,900 & 12.97 \\
\hline 1915 & Dec. 06 & 25,000 & 12.10 & 1947 & Jan. 21 & 47,200 & 19.60 & 1979 & Apr. 16 & 41,800 & 17.37 \\
\hline 1916 & July 10 & 64,500 & 22.10 & 1948 & July 12 & 32,800 & 16.20 & 1980 & Mar. 08 & 25,500 & 12.83 \\
\hline 1917 & Mar. 28 & 51,400 & 19.60 & 1949 & Nov. 29 & 61,900 & 22.40 & 1981 & Feb. 11 & 19,300 & 10.13 \\
\hline 1918 & Jan. 12 & 34,800 & 16.30 & 1950 & Mar. 16 & 16,000 & 10.40 & 1982 & Feb. 03 & 28,600 & 13.87 \\
\hline 1919 & Dec. 23 & 63,700 & 21.00 & 1951 & Apr. 23 & 16,800 & 10.70 & 1983 & Apr. 10 & 24,600 & 12.59 \\
\hline 1920 & Dec. 10 & 134,000 & 29.25 & 1952 & Mar. 05 & 43,200 & 18.70 & 1984 & Dec. 08 & 25,100 & 12.75 \\
\hline 1921 & Feb. 10 & 53,000 & 19.30 & 1953 & Jan. 10 & 26,100 & 14.20 & 1985 & Jan. 17 & 18,900 & 10.30 \\
\hline 1922 & Mar. 11 & 54,800 & 19.60 & 1954 & Jan. 20 & 25,800 & 14.10 & 1986 & Nov. 24 & 17,800 & 9.94 \\
\hline 1923 & Feb. 14 & 39,400 & 16.70 & 1955 & Feb. 08 & 24,000 & 13.50 & 1987 & Jan. 19 & 17,300 & 9.75 \\
\hline 1924 & Apr. 19 & 25,400 & 12.60 & 1956 & Mar. 17 & 40,900 & 18.20 & 1988 & Feb. 18 & 17,500 & 9.82 \\
\hline 1925 & Jan. 19 & $\underline{90,300}$ & 24.60 & 1957 & Apr. 06 & 46,800 & 19.50 & 1989 & June 21 & 29,000 & 13.56 \\
\hline 1926 & Apr. 01 & 28,500 & 13.70 & 1958 & Feb. 07 & 34,000 & 16.50 & 1990 & Mar. 19 & ${ }^{* *} 800$ & 18.30 \\
\hline 1927 & Feb. 14 & 24,100 & 12.20 & 1959 & June 02 & 27,000 & 14.50 & & & & \\
\hline
\end{tabular}


02340250 FLAT SHOAL CREEK NEAR WEST POINT, GEORGIA

LOCATION.--Lat $32^{\circ} 53^{\prime} 53^{\prime \prime}$, long $85^{\circ} 04^{\prime} 41^{\prime \prime}$, Troup County, on bridge on State Highway 18, about 5 mi east of I-85, near West Point. DRAINAGE AREA.-204 $\mathrm{mi}^{2}$.

GAGE.--Crest-stage gage. Datum of gage is about $566 \mathrm{ft}$ above sea level (from topographic map).

STAGE-DISCHARGE RELATION.--Defined by current-meter measurements below $7,490 \mathrm{ft}^{3} / \mathrm{s}$, and extended above on basis of straight-line extension.

\begin{tabular}{|c|c|c|c|c|c|c|c|c|c|c|c|}
\hline $\begin{array}{l}\text { Water } \\
\text { year }\end{array}$ & Date & $\begin{array}{c}\text { Discharge } \\
\left(\mathrm{ft}^{3} / \mathrm{s}\right)\end{array}$ & $\begin{array}{c}\text { Gage } \\
\text { height } \\
\text { (ft) }\end{array}$ & $\begin{array}{l}\text { Water } \\
\text { year }\end{array}$ & Date & $\begin{array}{c}\text { Discharge } \\
\left(\mathrm{ft}^{3} / \mathrm{s}\right)\end{array}$ & $\begin{array}{c}\text { Gage } \\
\text { height } \\
\text { (ft) }\end{array}$ & $\begin{array}{l}\text { Water } \\
\text { year }\end{array}$ & Date & $\begin{array}{c}\text { Discharge } \\
\left(\mathrm{ft}^{3} / \mathrm{s}\right)\end{array}$ & $\begin{array}{c}\text { Gage } \\
\text { height } \\
\text { (ft) }\end{array}$ \\
\hline 1984 & Dec. 04 & 1,970 & 10.42 & 1987 & Nov. 17 & 2,920 & 12.92 & 1989 & Apr. 06 & 2,100 & 10.83 \\
\hline 1985 & Feb. 06 & 3,780 & 14.90 & 1988 & Feb. - & 1,400 & $-b$ & 1990 & Mar. 17 & 7,670 & 22.16 \\
\hline 1986 & Sept. - & 1,400 & $-b$ & & & & & & & & \\
\hline
\end{tabular}

\section{BIG BRANCH NEAR WEST POINT, GEORGIA}

LOCATION.--Lat $32^{\circ} 52^{\prime} 10^{\prime \prime}$, long $85^{\circ} 05^{\prime} 57^{\prime \prime}$, Troup County, at culvert on State Highway $18,4.8$ mi west of West Point. DRAINAGE AREA, $--4.30 \mathrm{mi}^{2}$.

GAGE.--Crest-stage gage. Datum of gage is about $605 \mathrm{ft}$ above sea level (from topographic map).

STAGE-DISCHARGE RELATION.--Defined on basis of culvert computation.

\begin{tabular}{|c|c|c|c|c|c|c|c|c|c|c|c|}
\hline $\begin{array}{l}\text { Water } \\
\text { year }\end{array}$ & Date & $\begin{array}{c}\text { Discharge } \\
\left(\mathrm{ft}^{3} / \mathrm{s}\right)\end{array}$ & $\begin{array}{c}\text { Gage } \\
\text { height } \\
\text { (ft) }\end{array}$ & $\begin{array}{l}\text { Water } \\
\text { year }\end{array}$ & Date & $\begin{array}{c}\text { Discharge } \\
\left(\mathrm{ft}^{3} / \mathrm{s}\right)\end{array}$ & $\begin{array}{c}\text { Gage } \\
\text { height } \\
\text { (ft) }\end{array}$ & $\begin{array}{l}\text { Water } \\
\text { year }\end{array}$ & Date & $\begin{array}{c}\text { Discharge } \\
\left(\mathrm{ft}^{3} / \mathrm{s}\right)\end{array}$ & $\begin{array}{c}\text { Gage } \\
\text { height } \\
\text { (ft) }\end{array}$ \\
\hline 1960 & Mar. 30 & 514 & 6.58 & 1963 & Jan. 21 & 130 & 3.80 & $\underline{1965}$ & Jan. 19 & 270 & 4.73 \\
\hline 1961 & Feb. 25 & 1,340 & 10.85 & 1964 & Apr. 27 & 1,560 & 11.75 & 1990 & Mar. 16 & 410 & $5.96 c$ \\
\hline 1962 & Apr. 12 & 480 & 6.45 & & & & & & & & \\
\hline
\end{tabular}




\section{MOUNTAIN OAK CREEK NEAR HAMILTON, GEORGIA}

LOCATION.--Lat $32^{\circ} 44^{\prime 2} 8^{\prime \prime}$, long $85^{\circ} 04^{\prime} 08^{\prime \prime}$, Harris County, on right bank $300 \mathrm{ft}$ upstream from bridge on State Highway $103,5 \mathrm{mi}$ upstream from mouth, and 11 mi west of Hamilton.

DRAINAGE AREA. $-61.7 \mathrm{mi}^{2}$.

GAGE.-Water-stage recorder. Datum of gage is about $550 \mathrm{ft}$ above sea level (by barometer). Dec. 22, 1943, to Sept. 8, 1950, nonrecording gage, and Sept. 9, 1950, to June 12, 1964, water-stage recorder at site $300 \mathrm{ft}$ downstream at datum $3.00 \mathrm{ft}$ lower. Datum Oct. 1, 1958, to June 12, 1964, adjusted to present datum.

STAGE-DISCHARGE RELATION.--Defined by current-meter measurements below $7,000 \mathrm{ft}^{3} / \mathrm{s}$, and extended above on basis of slope-conveyance studies at $12,000 \mathrm{ft}^{3} / \mathrm{s}$. Bankfull stage and discharge, $4 \mathrm{ft}$ and $1,700 \mathrm{ft}^{3} / \mathrm{s}$.

HISTORICAL DATA.--The flood of 1948 is thought to be the highest since 1919, based on information at nearby stations.

\begin{tabular}{|c|c|c|c|c|c|c|c|c|c|c|c|}
\hline $\begin{array}{l}\text { Water } \\
\text { year }\end{array}$ & Date & $\begin{array}{c}\text { Discharge } \\
\left(\mathrm{ft}^{3} / \mathrm{s}\right)\end{array}$ & $\begin{array}{c}\text { Gage } \\
\text { height } \\
\text { (ft) }\end{array}$ & $\begin{array}{l}\text { Water } \\
\text { year }\end{array}$ & Date & $\begin{array}{c}\text { Discharge } \\
\left(\mathrm{ft}^{3} / \mathrm{s}\right)\end{array}$ & $\begin{array}{c}\text { Gage } \\
\text { height } \\
\text { (ft) }\end{array}$ & $\begin{array}{l}\text { Water } \\
\text { year }\end{array}$ & Date & $\begin{array}{c}\text { Discharge } \\
\left(\mathrm{ft}^{3} / \mathrm{s}\right)\end{array}$ & $\begin{array}{c}\text { Gage } \\
\text { height } \\
\text { (ft) }\end{array}$ \\
\hline 1944 & Apr. 27 & 4,380 & 7.50 & 1955 & Apr. 14 & 630 & 3.50 & 1965 & Oct. 05 & 1,380 & 3.63 \\
\hline 1945 & May 13 & 1,810 & 5.20 & 1956 & Mar. 16 & 955 & 4.03 & 1966 & Feb. 13 & 3,690 & 5.37 \\
\hline 1946 & Jan. 07 & 4,120 & 7.30 & 1957 & Apr. 05 & 2,580 & 6.10 & 1967 & Sept.04 & 1,130 & 3.40 \\
\hline 1947 & Apr. 02 & 2,180 & 5.60 & 1958 & Nov. 19 & 1,100 & $\underline{4.72}$ & 1968 & Mar. 12 & 1,560 & 3.81 \\
\hline 1948 & July 11 & 11,800 & 16.60 & 1959 & Feb. 04 & 515 & $\overline{2.55}$ & 1969 & Apr. 19 & 1,360 & 3.66 \\
\hline 1949 & Nov. 27 & 7,490 & 12.10 & 1960 & Apr. 04 & 1,840 & 4.18 & 1970 & Mar. 22 & 2,530 & 4.59 \\
\hline 1950 & Mar. 28 & 780 & 3.82 & 1961 & Feb. 25 & 5,200 & 6.80 & 1971 & Mar. 03 & 4,710 & 5.95 \\
\hline 1951 & Apr. 23 & 462 & 3.14 & 1962 & Apr. 13 & 1,520 & 3.85 & 1972 & Feb. 07 & 806 & 3.02 \\
\hline 1952 & Mar. 25 & 1,220 & 4.40 & 1963 & Jan. 21 & 1,260 & 3.55 & $\underline{1973}$ & Dec. 16 & 2,030 & 4.21 \\
\hline 1953 & May 01 & 899 & 3.97 & 1964 & Apr. 08 & 2,960 & 4.92 & $\overline{1990}$ & Mar. 17 & 4,750 & $6.06 c$ \\
\hline 1954 & Dec. 05 & 2,340 & 5.80 & & & & & & & & \\
\hline
\end{tabular}

\section{MULBERRY CREEK NEAR MULBERRY GROVE, GEORGIA}

LOCATION.--Lat $32^{\circ} 42^{\prime} 11^{\prime \prime}$, long $84^{\circ} 57^{\prime} 29^{\prime \prime}$, Harris County, at bridge on Hamilton-Mulberry Grove Road, near Mulberry Grove. DRAINAGE AREA.--190 $\mathrm{mi}^{2}$.

GAGE.-Crest-stage gage. Datum of gage is about $490 \mathrm{ft}$ above sea level (from topographic map).

STAGE-DISCHARGE RELATION.-Defined by current-meter measurements below $20,000 \mathrm{ft}^{3} / \mathrm{s}$, and extended above on basis of straight-line extension.

\begin{tabular}{|c|c|c|c|c|c|c|c|c|c|c|c|}
\hline $\begin{array}{l}\text { Water } \\
\text { year }\end{array}$ & Date & $\begin{array}{c}\text { Discharge } \\
\left(\mathrm{ft}^{3} / \mathrm{s}\right)\end{array}$ & $\begin{array}{c}\text { Gage } \\
\text { height } \\
\text { (ft) }\end{array}$ & $\begin{array}{l}\text { Water } \\
\text { year }\end{array}$ & Date & $\begin{array}{c}\text { Discharge } \\
\left(\mathrm{ft}^{3} / \mathrm{s}\right)\end{array}$ & $\begin{array}{c}\text { Gage } \\
\text { height } \\
\text { (ft) }\end{array}$ & $\begin{array}{l}\text { Water } \\
\text { year }\end{array}$ & Date & $\begin{array}{c}\text { Discharge } \\
\left(\mathrm{ft}^{3} / \mathrm{s}\right)\end{array}$ & $\begin{array}{c}\text { Gage } \\
\text { height } \\
\text { (ft) }\end{array}$ \\
\hline 1984 & Dec. 04 & 2,000 & 11.29 & 1987 & Feb. 28 & 3,830 & 16.31 & 1989 & June 21 & 5,510 & 19.27 \\
\hline 1985 & Feb. 06 & 5,210 & 18.81 & 1988 & Jan. 20 & 1,800 & 10.61 & 1990 & Mar. 17 & 21,000 & 27.74 \\
\hline 1986 & Mar. 19 & 3,810 & 16.28 & & & & & & & & \\
\hline
\end{tabular}


LOCATION.--Lat $32^{\circ} 27^{\prime} 45^{\prime \prime}$, long $84^{\circ} 59^{\prime} 52^{\prime \prime}$, Muscogee County, on downstream side of center pier of Central of Georgia Railway bridge at Columbus, 0.5 mi downstream from Eagle and Phenix Dam, 1.2 mi downstream from City Mills Dam, $2.6 \mathrm{mi}$ downstream from North Highlands Dam, 3.3 mi downstream from Oliver Dam, 17.5 mi downstream from Bartletts Ferry Dam, and at mile 159.9.

DRAINAGE AREA.--4,670 $\mathrm{mi}^{2}$, approximately.

GAGE.-Water-stage recorder. Datum of gage is about $183.14 \mathrm{ft}$ above sea level (levels from U.S. Geological Survey benchmark), supplementary adjustment of 1936. Dec. 1-31, 1912, nonrecording gage at site $800 \mathrm{ft}$ upstream at same datum, and Aug. 23, 1929 to Sept. 30, 1975, recording gage at present site at datum $2.0 \mathrm{ft}$ higher. Oct. 1, 1963, to Sept. 30, 1966, water-stage recorder at Walter F. George Reservoir, and since Oct. 1, 1966, water-stage recorder at Alabama State Docks used as auxiliary gage for this station. Al gage readings have been adjusted to present datum.

STAGE-DISCHARGE RELATION.--Defined by current-meter measurements below $140,000 \mathrm{ft}^{3} / \mathrm{s}$, and extended above by computation of flow over North Highlands Dam. Laboratory rating to $198,000 \mathrm{ft}^{3} / \mathrm{s}$ obtained from North Highlands Dam. Stagedischarge relation affected by backwater.

HISTORICAL DATA.--The record of major floods prior to the establishment of the gage station in August 1929 is well established through records of the National Weather Service, marks on river-front factories, and old issues of the Columbus Enquirer dating back to 1827. The flood of March 1841 was said at that time to be the highest since the town was established in 1827.

REMARKS.--Peak discharge slightly regulated by Lake Sidney Lanier (maximum flood-control capacity, 637,000 acre-ft) since January 1956; West Point Lake (maximum flood-control capacity, 221,000 acre-ft) since October 1974; and Bartletts Ferry Reservoir (Lake Harding) (maximum flood-control capacity, 57,000 acre-ft) since 1926. Peak discharges for 1964, 1968, and 1973-74 are estimated.

\begin{tabular}{|c|c|c|c|c|c|c|c|c|c|c|c|}
\hline $\begin{array}{l}\text { Water } \\
\text { year }\end{array}$ & Date & $\begin{array}{c}\text { Discharge } \\
\left(\mathrm{ft}^{3} / \mathrm{s}\right)\end{array}$ & $\begin{array}{c}\text { Gage } \\
\text { height } \\
\text { (ft) }\end{array}$ & $\begin{array}{l}\text { Water } \\
\text { year }\end{array}$ & Date & $\begin{array}{c}\text { Discharge } \\
\left(\mathrm{ft}^{3} / \mathrm{s}\right)\end{array}$ & $\begin{array}{c}\text { Gage } \\
\text { height } \\
\text { (ft) }\end{array}$ & $\begin{array}{l}\text { Water } \\
\text { year }\end{array}$ & Date & $\begin{array}{c}\text { Discharge } \\
\left(\mathrm{ft}^{3} / \mathrm{s}\right)\end{array}$ & $\begin{array}{c}\text { Gage } \\
\text { height } \\
\text { (ft) }\end{array}$ \\
\hline 1841 & Mar. 11 & 113,000 & $45.00 \mathrm{c}$ & 1946 & Jañ. 07 & 62,600 & 33.50 & 1969 & Apr. 19 & 66,800 & $29.69 a$ \\
\hline$\overline{1886}$ & Apr. 01 & 154,000 & $50.50 c$ & 1947 & Jan. 21 & 54,100 & 30.90 & 1970 & Mar. 22 & 87,200 & $34.44 a$ \\
\hline$\overline{1913}$ & Mar. 15 & 107,000 & $44.00 c$ & 1948 & July 11 & 81,900 & $38.60 \mathrm{a}$ & 1971 & Mar. 03 & 110,000 & $40.50 \mathrm{a}$ \\
\hline$\underline{1916}$ & July $\mathbf{0 0}$ & 106,000 & $43.90 c$ & 1949 & Nov. 28 & 104,000 & $44.40 \mathrm{a}$ & 1972 & Jan. 12 & 70,800 & $30.70 a$ \\
\hline$\overline{1920}$ & Dec. 12 & 172,000 & $52.60 \mathrm{c}$ & 1950 & Mar. 17 & 16,200 & 14.30 & 1973 & Dec. 22 & 54,700 & $26.67 \mathrm{a}$ \\
\hline$\overline{1925}$ & Jan. 19 & 133,000 & $48.00 \mathrm{a}$ & 1951 & Apr. 23 & 24,100 & 18.00 & 1974 & Feb. 16 & 38,300 & $21.13 a$ \\
\hline$\overline{1929}$ & Mar. 15 & 198,000 & 55.20 & 1952 & Mar. 05 & 57,800 & 32.20 & 1975 & Apr. 03 & 89,900 & $33.98 \mathrm{a}$ \\
\hline 1930 & Oct. 01 & 42,000 & 26.10 & 1953 & May 02 & 44,400 & 27.10 & 1976 & Mar. 31 & 52,200 & $24.54 a$ \\
\hline 1931 & Nov. 17 & 46,000 & 28.63 & 1954 & Dec. 04 & 39,800 & 25.20 & 1977 & Mar. 31 & 57,900 & $26.07 a$ \\
\hline 1932 & Feb. 22 & 36,000 & 24.30 & 1955 & Apr. 15 & 30,300 & 21.00 & 1978 & Jan. 26 & 75,000 & $31.60 \mathrm{a}$ \\
\hline 1933 & Dec. 30 & 58,800 & 33.12 & 1956 & Mar. 17 & 51,700 & 30.00 & 1979 & Apr. 14 & 72,900 & 30.91 \\
\hline 1934 & Mar. 05 & 49,200 & 29.62 & 1957 & Apr. 06 & 74,600 & $36.00 \mathrm{a}$ & 1980 & Mar. 09 & 60,400 & $27.37 a$ \\
\hline 1935 & Mar. 06 & 36,100 & 24.26 & 1958 & Feb. 07 & 41,500 & 25.90 & 1981 & Apr. 01 & 73,700 & 30.71 \\
\hline 1936 & Apr. 09 & 84,700 & 40.24 & 1959 & June 02 & 35,500 & $25.90 \mathrm{a}$ & 1982 & Feb. 04 & 54,000 & 26.23 \\
\hline 1937 & Jan. 06 & 55,000 & 32.50 & 1960 & Apr. 05 & 59,100 & $31.90 \mathrm{a}$ & 1983 & Apr. 09 & 56,700 & 26.94 \\
\hline 1938 & Apr. 09 & 81,700 & 39.60 & 1961 & Feb. 26 & 145,000 & $49.80 \mathrm{a}$ & 1984 & Dec. 04 & 40,500 & 20.57 \\
\hline 1939 & Mar. 30 & 59,000 & $32.15 \mathrm{a}$ & 1962 & Dec. 14 & 57,300 & 32.02 & 1985 & Feb. 07 & 44,700 & 21.15 \\
\hline 1940 & July 10 & 40,900 & $25.50 \mathrm{a}$ & 1963 & Jan. 21 & 40,900 & 25.68 & 1986 & Mar. 19 & 17,400 & $13.21 \mathrm{a}$ \\
\hline 1941 & July 15 & 16,700 & $12.80 \mathrm{a}$ & 1964 & Apr. 08 & 140,000 & $45.85 \mathrm{a}$ & 1987 & Mar. 01 & 38,700 & 20.52 \\
\hline 1942 & Mar. 22 & 82,500 & $38.90 \mathrm{a}$ & 1965 & Jan. 25 & 55,300 & $26.78 \mathrm{a}$ & 1988 & Jan. 22 & 24,500 & 14.52 \\
\hline 1943 & Mar. 22 & 102,000 & 43.00 & 1966 & Feb. 14 & 77,800 & $32.40 \mathrm{a}$ & 1989 & June 22 & 45,000 & 21.24 \\
\hline 1944 & Mar. 23 & 72,400 & 36.10 & 1967 & Nov. 12 & 37,100 & $21.60 \mathrm{a}$ & 1990 & Mar. 17 & 98,800 & $41.14 a$ \\
\hline 1945 & Apr. 26 & 68,800 & 35.20 & 1968 & Mar. 13 & 46,000 & $25.91 \mathrm{a}$ & & & & \\
\hline
\end{tabular}




\section{APALACHICOLA RIVER BASIN}

\section{FLAT ROCK CREEK AT COLUMBUS, GEORGIA}

LOCATION.--Lat $32^{\circ} 32^{\prime} 57^{\prime \prime}$, long $84^{\circ} 53^{\prime} 07^{\prime \prime}$, Muscogee County, at bridge on Warm Springs Road at Columbus.

DRAINAGE AREA $--6.54 \mathrm{mi}^{2}$.

GAGE.--Flood-stage, rainfall recorder.

STAGE-DISCHARGE RELATION.--Defined by current-meter measurements below $190 \mathrm{ft}^{3} / \mathrm{s}$, and extended above on basis of culvert computations.

REMARKS.--Flow is affected by urbanization.

\begin{tabular}{|c|c|c|c|c|c|c|c|c|c|c|c|}
\hline $\begin{array}{l}\text { Water } \\
\text { year }\end{array}$ & Date & $\begin{array}{c}\text { Discharge } \\
\left(\mathrm{ft}^{3} / \mathrm{s}\right)\end{array}$ & $\begin{array}{c}\text { Gage } \\
\text { height } \\
\text { (ft) }\end{array}$ & $\begin{array}{l}\text { Water } \\
\text { year }\end{array}$ & Date & $\begin{array}{c}\text { Discharge } \\
\left(\mathrm{ft}^{3} / \mathrm{s}\right)\end{array}$ & $\begin{array}{c}\text { Gage } \\
\text { height } \\
\text { (ft) }\end{array}$ & $\begin{array}{l}\text { Water } \\
\text { year }\end{array}$ & Date & $\begin{array}{l}\text { Discharge } \\
\left(\mathrm{ft}^{3} / \mathrm{s}\right)\end{array}$ & $\begin{array}{c}\text { Gage } \\
\text { height } \\
\text { (ft) }\end{array}$ \\
\hline 1977 & Aug. 03 & 1,910 & 7.21 & 1980 & Apr. 13 & 620 & 5.80 & 1983 & Mar. 05 & 1,020 & 6.29 \\
\hline 1978 & Jan. 25 & 700 & 5.90 & 1981 & Apr. 01 & 2,320 & 7.62 & 1984 & Dec. 11 & 215 & 5.15 \\
\hline 1979 & Apr. 13 & 692 & 5.89 & 1982 & Feb. 02 & 812 & 6.04 & 1985 & Feb. 05 & 294 & 5.29 \\
\hline
\end{tabular}

\section{MILL BRANCH AT COLUMBUS, GEORGIA}

LOCATION.--Lat $32^{\circ} 28^{\prime} 19^{\prime \prime}$, long $84^{\circ} 53^{\prime} 58^{\prime \prime}$, Muscogee County, at culvert on Chalbena Road at Columbus.

DRAINAGE AREA. $-1.58 \mathrm{mi}^{2}$.

GAGE.--Flood-stage, rainfall recorder prior to Oct. 17, 1985. Crest-stage gage 1986 to present.

STAGE-DISCHARGE RELATION.--Defined by current-meter measurements below $101 \mathrm{ft}^{3} / \mathrm{s}$, and extended above on basis of culvert computations.

REMARKS.-Flow is affected by urbanization.

\begin{tabular}{|c|c|c|c|c|c|c|c|c|c|c|c|}
\hline $\begin{array}{l}\text { Water } \\
\text { year }\end{array}$ & Date & $\begin{array}{c}\text { Discharge } \\
\left(\mathrm{ft}^{3} / \mathrm{s}\right)\end{array}$ & $\begin{array}{c}\text { Gage } \\
\text { height } \\
\text { (ft) }\end{array}$ & $\begin{array}{l}\text { Water } \\
\text { year }\end{array}$ & Date & $\begin{array}{c}\text { Discharge } \\
\left(\mathrm{ft}^{3} / \mathrm{s}\right)\end{array}$ & $\begin{array}{c}\text { Gage } \\
\text { height } \\
\text { (ft) }\end{array}$ & $\begin{array}{l}\text { Water } \\
\text { year }\end{array}$ & Date & $\begin{array}{c}\text { Discharge } \\
\left(\mathrm{ft}^{3} / \mathrm{s}\right)\end{array}$ & $\begin{array}{c}\text { Gage } \\
\text { height } \\
\text { (ft) }\end{array}$ \\
\hline 1977 & July 28 & 569 & 5.31 & 1982 & Apr. 26 & 607 & 5.51 & 1987 & Feb. 28 & 326 & 4.14. \\
\hline 1978 & June 03 & 686 & 5.93 & 1983 & Mar. 05 & 559 & 5.26 & 1988 & Jan. 20 & 255 & 3.64 \\
\hline 1979 & Apr. 04 & 639 & 5.68 & 1984 & Aug. 12 & 388 & 4.30 & 1989 & Aug. 26 & 547 & 5.51 \\
\hline 1980 & Jan. 18 & 465 & 4.75 & 1985 & May 08 & 514 & 5.02 & 1990 & Mar. 16 & 1,390 & 10.59 \\
\hline 1981 & Apr. 01 & 734 & 6.18 & 1986 & Mar. 19 & 593 & 5.78 & & & & \\
\hline
\end{tabular}

\section{BULL CREEK TRIBUTARY AT COLUMBUS, GEORGIA}

LOCATION.--Lat 32 $28^{\prime} 38^{\prime \prime}$, long 84 '55'36", Muscogee County, at culvert on Woodland Drive at Columbus. DRAINAGE AREA.--0.26 $\mathrm{mi}^{2}$.

GAGE.--Flood-stage, rainfall recorder prior to Oct. 17, 1985. Crest-stage gage 1986 to present.

STAGE-DISCHARGE RELATION.--Defined by current-meter measurements below $25 \mathrm{ft}^{3} / \mathrm{s}$, and extended above on basis of culvert computations.

REMARKS.-Flow is affected by urbanization.

\begin{tabular}{|c|c|c|c|c|c|c|c|c|c|c|c|}
\hline $\begin{array}{l}\text { Water } \\
\text { year }\end{array}$ & Date & $\begin{array}{c}\text { Discharge } \\
\left(\mathrm{ft}^{3} / \mathrm{s}\right)\end{array}$ & $\begin{array}{c}\text { Gage } \\
\text { height } \\
\text { (ft) }\end{array}$ & $\begin{array}{l}\text { Water } \\
\text { year }\end{array}$ & Date & $\begin{array}{c}\text { Discharge } \\
\left(\mathrm{ft}^{3} / \mathrm{s}\right)\end{array}$ & $\begin{array}{c}\text { Gage } \\
\text { height } \\
\text { (ft) }\end{array}$ & $\begin{array}{l}\text { Water } \\
\text { year }\end{array}$ & Date & $\begin{array}{c}\text { Discharge } \\
\left(\mathrm{ft}^{3} / \mathrm{s}\right)\end{array}$ & $\begin{array}{c}\text { Gage } \\
\text { height } \\
\text { (ft) }\end{array}$ \\
\hline 1977 & Aug. 03 & 134 & 5.29 & 1982 & July 13 & 52.0 & 3.48 & 1987 & June 14 & 55.0 & 3.74 \\
\hline 1978 & June 03 & 82.0 & 4.47 & 1983 & Mar. 05 & 67.0 & 3.95 & 1988 & Jan. 20 & 43.0 & 3.27 \\
\hline 1979 & May 19 & 119 & 5.16 & 1984 & Aug. 12 & 49.0 & 3.36 & 1989 & July 03 & 65.0 & 4.08 \\
\hline 1980 & Apr. 13 & 88.0 & 4.65 & 1985 & May 10 & 38.0 & 3.00 & 1990 & Mar. 16 & 244 & 5.79 \\
\hline 1981 & Apr. 01 & 96.0 & 4.84 & 1986 & Aug. 12 & 78.0 & 4.51 & & & & \\
\hline
\end{tabular}




\section{APALACHICOLA RIVER BASIN}

\section{LINDSEY CREEK TRIBUTARY AT COLUMBUS, GEORGIA}

LOCATION.--Lat $32^{\circ} 31^{\prime} 33^{\prime \prime}$, long $84^{\circ} 56^{\prime} 21^{\prime \prime}$, Muscogee County, at culvert on Canberra Avenue at Columbus.

DRAINAGE AREA.-1.42 $\mathrm{mi}^{2}$

GAGE.--Flood-stage, rainfall recorder prior to Oct. 18, 1985. Crest-stage gage 1986 to present.

STAGE-DISCHARGE RELATION.--Defined by current-meter measurements below $55 \mathrm{ft}^{3} / \mathrm{s}$, and extended above on basis of culvert computations.

REMARKS.--Flow is affected by urbanization. Peak discharge for 1977 undetermined, owing to debris in culvert.

\begin{tabular}{|c|c|c|c|c|c|c|c|c|c|c|c|}
\hline $\begin{array}{l}\text { Water } \\
\text { year }\end{array}$ & Date & $\begin{array}{c}\text { Discharge } \\
\left(\mathrm{ft}^{3} / \mathrm{s}\right)\end{array}$ & $\begin{array}{c}\text { Gage } \\
\text { height } \\
\text { (ft) }\end{array}$ & $\begin{array}{l}\text { Water } \\
\text { year }\end{array}$ & Date & $\begin{array}{c}\text { Discharge } \\
\left(\mathrm{ft}^{3} / \mathrm{s}\right)\end{array}$ & $\begin{array}{c}\text { Gage } \\
\text { height } \\
\text { (ft) }\end{array}$ & $\begin{array}{l}\text { Water } \\
\text { year }\end{array}$ & Date & $\begin{array}{c}\text { Discharge } \\
\left(\mathrm{ft}^{3} / \mathrm{s}\right)\end{array}$ & $\begin{array}{c}\text { Gage } \\
\text { height } \\
\text { (ft) }\end{array}$ \\
\hline 1977 & Aug. 03 & -- & 9.13 & 1982 & May 19 & 379 & 5.37 & 1987 & June 14 & 496 & 6.93 \\
\hline 1978 & Aug. 09 & 337 & 4.95 & 1983 & July 15 & 345 & 4.89 & 1988 & July 21 & 462 & 6.27 \\
\hline 1979 & Apr. 13 & 448 & 6.26 & 1984 & Dec. 11 & 241 & 3.90 & 1989 & July 03 & 437 & 5.91 \\
\hline 1980 & Aug. 14 & 525 & 7.00 & 1985 & Apr. 05 & 143 & 3.00 & 1990 & Mar. 16 & 466 & 6.34 \\
\hline 1981 & Apr. 01 & 669 & 7.73 & 1986 & Mar. 19 & 312 & 4.60 & & & & \\
\hline
\end{tabular}

\section{JUNIPER CREEK NEAR GENEVA, GEORGIA}

LOCATION.--Lat $32^{\circ} 31^{\prime} 41^{\prime \prime}$, long $84^{\circ} 34^{\prime} 14^{\prime \prime}$, Talbot County, at State Highway $41,1.8$ mi south of Geneva.

DRAINAGE AREA. $-47.4 \mathrm{mi}^{2}$.

GAGE.--Crest-stage gage. Datum of gage is about $373 \mathrm{ft}$ above sea level (from topographic map).

STAGE-DISCHARGE RELATION.--Defined by current-meter measurements below $1,700 \mathrm{ft}^{3} / \mathrm{s}$, and extended above on basis of straight-line extension. Bankfull stage and discharge, $6 \mathrm{ft}$ and $400 \mathrm{tt}^{3} / \mathrm{s}$.

\begin{tabular}{|c|c|c|c|c|c|c|c|c|c|c|c|}
\hline $\begin{array}{l}\text { Water } \\
\text { year }\end{array}$ & Date & $\begin{array}{c}\text { Discharge } \\
\left(\mathrm{ft}^{3} / \mathrm{s}\right)\end{array}$ & $\begin{array}{c}\text { Gage } \\
\text { height } \\
\text { (ft) }\end{array}$ & $\begin{array}{l}\text { Water } \\
\text { year }\end{array}$ & Date & $\begin{array}{c}\text { Discharge } \\
\left(\mathrm{ft}^{3} / \mathrm{s}\right)\end{array}$ & $\begin{array}{c}\text { Gage } \\
\text { height } \\
\text { (ft) }\end{array}$ & $\begin{array}{l}\text { Water } \\
\text { year }\end{array}$ & Date & $\begin{array}{c}\text { Discharge } \\
\left(\mathrm{ft}^{3} / \mathrm{s}\right)\end{array}$ & $\begin{array}{c}\text { Gage } \\
\text { height } \\
\text { (ft) }\end{array}$ \\
\hline 1963 & Dec. 27 & 640 & 6.83 & 1973 & Apr. 07 & 845 & 7.25 & 1982 & Apr. 05 & 720 & 7.00 \\
\hline 1964 & Apr. 13 & 1,360 & 8.23 & 1974 & Apr. 05 & 708 & 6.97 & 1983 & Mar. 07 & 484 & 6.41 \\
\hline 1965 & Dec. 27 & 870 & 7.30 & 1975 & Apr. 15 & 1,510 & 8.45 & 1984 & Mar. 06 & 636 & 6.79 \\
\hline 1966 & Mar. 03 & 2,010 & 9.19 & 1976 & Mar. 14 & 552 & 6.58 & 1985 & Feb. 07 & 395 & 6.15 \\
\hline 1967 & May 23 & 504 & 6.46 & 1977 & Apr. 01 & 660 & 6.85 & 1986 & Mar. 14 & 440 & 6.30 \\
\hline 1968 & Mar. 12 & 338 & 5.93 & 1978 & Jan. 27 & 1,370 & 8.22 & 1987 & Nov. 17 & 745 & 7.05 \\
\hline 1969 & May 20 & 616 & 6.74 & 1979 & Feb. 27 & 1,180 & 7.90 & 1988 & Jan. 17 & 316 & 5.83 \\
\hline 1970 & Mar. 20 & 712 & 6.98 & 1980 & Mar. 13 & 716 & 6.99 & 1989 & Apr. 06 & 434 & 6.28 \\
\hline 1971 & Mar. 25 & 780 & 7.12 & 1981 & Apr. 01 & 1,800 & 8.89 & 1990 & Mar. 17 & 4,300 & 11.78 \\
\hline 1972 & Feb. 07 & 422 & 6.24 & & & & & & & & \\
\hline
\end{tabular}




\section{APALACHICOLA RIVER BASIN}

02341723 PINE KNOT CREEK NEAR JUNIPER, GEORGIA

LOCATION.--Lat $32^{\circ} 26^{\prime} 14^{\prime \prime}$, long $84^{\circ} 39^{\prime} 25^{\prime \prime}$, Marion County, at bridge on State Highway 355,8 mi south of Juniper.

DRAINAGE AREA.-33.1 $\mathrm{mi}^{2}$.

GAGE.-Crest-stage gage. Datum of gage is about $330 \mathrm{ft}$ above sea level (from topographic map).

STAGE-DISCHARGE RELATION.--Defined by current-meter measurements below $970 \mathrm{ft}^{3} / \mathrm{s}$, and extended above on basis of straight-line extension.

\begin{tabular}{lcccccccccc}
\hline $\begin{array}{l}\text { Water } \\
\text { year }\end{array}$ & Date & $\begin{array}{c}\text { Discharge } \\
\left(\mathrm{ft}^{3} / \mathrm{s}\right)\end{array}$ & $\begin{array}{c}\text { Gage } \\
\text { height } \\
(\mathrm{ft})\end{array}$ & $\begin{array}{c}\text { Water } \\
\text { year }\end{array}$ & Date & $\begin{array}{c}\text { Discharge } \\
\left(\mathrm{ft}^{3} / \mathrm{s}\right)\end{array}$ & $\begin{array}{c}\text { Gage } \\
\text { height } \\
(\mathrm{ft})\end{array}$ & $\begin{array}{c}\text { Water } \\
\text { year }\end{array}$ & $\begin{array}{c}\text { Gage } \\
\text { Date }\end{array}$ & $\begin{array}{c}\text { Discharge } \\
\left(\mathrm{ft}^{3} / \mathrm{s}\right)\end{array}$ \\
\hline \\
1979 & Feb. 24 & 336 & 5.64 & 1983 & Mar. 06 & 378 & 5.89 & 1987 & Mar. 01 & 180 \\
$(\mathrm{ft})$
\end{tabular}

\section{UPATOI CREEK NEAR COLUMBUS, GEORGIA}

LOCATION.-Lat $32^{\circ} 24^{\prime} 48^{\prime \prime}$, long $84^{\circ} 49^{\prime} 12^{\prime \prime}$, Muscogee-Chattahoochee County-line, at downstream side of pier near left end of bridge on Red Arrow road at Fort Benning, 2 mi downstream from Randall Creek, 2 mi upstream from Ochillee Creek, 8 mi southeast of Columbus, and $12 \mathrm{mi}$ upstream from mouth.

DRAINAGE AREA.--342 $\mathrm{mi}^{2}$.

GAGE.--Water-stage recorder. Datum of gage is about $230 \mathrm{ft}$ above sea level (from topographic map).

STAGE-DISCHARGE RELATION.--Defined by current-meter measurements below $36,000 \mathrm{ft}^{3} / \mathrm{s}$, and extended above on basis of rating-curve extension, and flow-over-road measurement.

REMARKS.--Peak stage from March 1990 from floodmarks.

\begin{tabular}{|c|c|c|c|c|c|c|c|c|c|c|c|}
\hline $\begin{array}{l}\text { Water } \\
\text { year }\end{array}$ & Date & $\begin{array}{c}\text { Discharge } \\
\left(\mathrm{ft}^{3} / \mathrm{s}\right)\end{array}$ & $\begin{array}{c}\text { Gage } \\
\text { height } \\
\text { (ft) }\end{array}$ & $\begin{array}{l}\text { Water } \\
\text { year }\end{array}$ & Date & $\begin{array}{c}\text { Discharge } \\
\left(\mathrm{ft}^{3} / \mathrm{s}\right)\end{array}$ & $\begin{array}{c}\text { Gage } \\
\text { height } \\
\text { (ft) }\end{array}$ & $\begin{array}{l}\text { Water } \\
\text { year }\end{array}$ & Date & $\begin{array}{c}\text { Discharge } \\
\left(\mathrm{ft}^{3} / \mathrm{s}\right)\end{array}$ & $\begin{array}{c}\text { Gage } \\
\text { height } \\
\text { (ft) }\end{array}$ \\
\hline 1969 & Apr. 18 & 8,850 & 14.32 & 1977 & Aug. 03 & 6,440 & 12.44 & 1984 & Mar. 06 & 3,650 & 10.07 \\
\hline 1970 & Mar. 21 & 6,800 & 12.75 & 1978 & Jan. 25 & 7,350 & 13.85 & 1985 & Feb. 06 & 4,180 & 10.75 \\
\hline 1971 & Mar. 03 & 8,940 & 14.74 & 1979 & Feb. 24 & 7,770 & 14.52 & 1986 & Mar. 19 & 6,850 & 13.59 \\
\hline 1972 & June 27 & 4,310 & 10.31 & 1980 & Mar. 30 & 5,630 & 12.37 & 1987 & Mar. 01 & 5,740 & 12.52 \\
\hline 1973 & Apr. 07 & 7,570 & 13.56 & 1981 & Apr. 01 & 17,300 & 21.06 & 1988 & Jan. 20 & 3,330 & 9.77 \\
\hline 1974 & Apr. 04 & 6,070 & 12.07 & 1982 & Feb. 03 & 6,730 & 13.51 & 1989 & Mar. 06 & 3,830 & 10.39 \\
\hline 1975 & Apr. 15 & 10,200 & 15.76 & 1983 & Dec. 11 & 4,700 & 11.33 & 1990 & Mar. 17 & 46,300 & 32.12 \\
\hline 1976 & June 04 & 3,990 & 9.98 & & & & & & & & \\
\hline
\end{tabular}




\section{APALACHICOLA RIVER BASIN}

02341900 OCHILLEE CREEK NEAR CUSSETA, GEORGIA

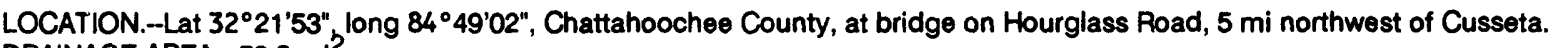
DRAINAGE AREA.--53.3 $\mathrm{mi}^{2}$.

GAGE.--Crest-stage gage. Datum of gage is $281.53 \mathrm{ft}$ above sea level (levels by the Georgia Department of Transportation).

STAGE-DISCHARGE RELATION.-Defined by current-meter measurements below $2,160 \mathrm{ft}^{3} / \mathrm{s}$, and extended above on basis of slope-conveyance studies. Bankfull stage and discharge, $11 \mathrm{ft}$ and $1,400 \mathrm{ft}^{3} / \mathrm{s}$.

REMARKS.--Peak stage from March 1990 from floodmarks.

\begin{tabular}{|c|c|c|c|c|c|c|c|c|c|c|c|}
\hline $\begin{array}{l}\text { Water } \\
\text { year }\end{array}$ & Date & $\begin{array}{c}\text { Discharge } \\
\left(\mathrm{ft}^{3} / \mathrm{s}\right)\end{array}$ & $\begin{array}{c}\text { Gage } \\
\text { height } \\
\text { (ft) }\end{array}$ & $\begin{array}{l}\text { Water } \\
\text { year }\end{array}$ & Date & $\begin{array}{c}\text { Discharge } \\
\left(\mathrm{ft}^{3} / \mathrm{s}\right)\end{array}$ & $\begin{array}{c}\text { Gage } \\
\text { height } \\
\text { (ft) }\end{array}$ & $\begin{array}{l}\text { Water } \\
\text { year }\end{array}$ & Date & $\begin{array}{c}\text { Discharge } \\
\left(\mathrm{ft}^{3} / \mathrm{s}\right)\end{array}$ & $\begin{array}{c}\text { Gage } \\
\text { height } \\
\text { (ft) }\end{array}$ \\
\hline 1979 & Feb. 25 & 1,590 & 11.29 & 1983 & Mar. 06 & 1,200 & 10.31 & 1987 & Feb. 28 & 545 & 6.97 \\
\hline 1980 & Mar. 15 & 1,890 & 11.63 & 1984 & Dec. 12 & 585 & 7.22 & 1988 & Feb. 04 & 300 & 3.73 \\
\hline 1981 & Apr. 01 & 2,180 & 11.88 & 1985 & May 08 & 330 & 5.51 & 1989 & Apr. 06 & 531 & 6.72 \\
\hline 1982 & Feb. 03 & 796 & 8.33 & 1986 & Mar. 19 & 612 & 7.39 & 1990 & Mar. 17 & 11,000 & 16.00 \\
\hline
\end{tabular}

\section{PATAULA CREEK NEAR LUMPKIN, GEORGIA}

LOCATION.--Lat $31^{\circ} 56^{\prime} 03^{\prime \prime}$, long $84^{\circ} 48^{\prime} 12^{\prime \prime}$, Stewart County, at bridge on U.S. Highway 27,8 mi south of Lumpkin.

DRAINAGE AREA.-70 $\mathrm{mi}^{2}$, approximately.

GAGE.--Crest-stage gage prior to June 21, 1958, and after Oct. 1, 1972. Water-stage recorder, June 21, 1958, to Sept. $30,1972$. Datum of gage is $285.5 \mathrm{ft}$ above sea level (levels by the U.S. Geological Survey) (revised).

STAGE-DISCHARGE RELATION.--Defined by current-meter measurements below $1,200 \mathrm{ft}^{3} / \mathrm{s}$, and extended above on basis of contracted-opening measurements at 8,320 and $9,400 \mathrm{ft}^{3} / \mathrm{s}$. Bankfull stage and discharge, $4.0 \mathrm{ft}$ and $350 \mathrm{ft}^{3} / \mathrm{s}$.

\begin{tabular}{|c|c|c|c|c|c|c|c|c|c|c|c|}
\hline $\begin{array}{l}\text { Water } \\
\text { year }\end{array}$ & Date & $\begin{array}{c}\text { Discharge } \\
\left(\mathrm{ft}^{3} / \mathrm{s}\right)\end{array}$ & $\begin{array}{c}\text { Gage } \\
\text { height } \\
\text { (ft) }\end{array}$ & $\begin{array}{l}\text { Water } \\
\text { year }\end{array}$ & Date & $\begin{array}{c}\text { Discharge } \\
\left(\mathrm{ft}^{3} / \mathrm{s}\right)\end{array}$ & $\begin{array}{c}\text { Gage } \\
\text { height } \\
\text { (ft) }\end{array}$ & $\begin{array}{l}\text { Water } \\
\text { year }\end{array}$ & Date & $\begin{array}{c}\text { Discharge } \\
\left(\mathrm{ft}^{3} / \mathrm{s}\right)\end{array}$ & $\begin{array}{c}\text { Gage } \\
\text { height } \\
\text { (ft) }\end{array}$ \\
\hline 1950 & Sept.01 & 1,390 & 5.50 & 1960 & Feb. 11 & 1,940 & 5.90 & 1970 & Mar. 30 & 8,320 & 9.19 \\
\hline 1951 & Apr. 01 & 270 & 3.29 & 1961 & Apr. 01 & 2,220 & 6.12 & 1971 & Mar. 26 & 1,760 & 5.87 \\
\hline 1952 & Feb. 15 & 675 & 4.62 & 1962 & Jan. 06 & 1,320 & 5.45 & 1972 & Jan. 14 & 962 & 5.08 \\
\hline 1953 & May 03 & 3,380 & 6.99 & 1963 & July 09 & 700 & 4.80 & 1973 & Apr. 26 & 1,700 & 5.82 \\
\hline 1954 & Dec. 05 & 800 & 4.87 & 1964 & Jan. 09 & 1,010 & 5.10 & 1974 & Apr. 06 & 1,960 & 6.04 \\
\hline 1955 & Apr. 14 & 582 & 4.37 & 1965 & Dec. 25 & 3,020 & 6.75 & 1975 & Feb. 17 & 9,390 & 9.36 \\
\hline 1956 & Sept.25 & 1,560 & 5.65 & 1966 & Feb. 13 & 2,530 & 6.42 & 1976 & Aug. 08 & 1,170 & 5.31 \\
\hline 1957 & Apr. 07 & 1,120 & 5.26 & 1967 & Jan. 01 & 3,070 & 6.78 & 1977 & Nov. 30 & 1,810 & 5.92 \\
\hline 1958 & June 20 & 502 & 4.50 & 1968 & Dec. 11 & 257 & 3.71 & $\underline{1978}$ & Jan. 26 & 3,900 & 7.26 \\
\hline 1959 & Feb. 04 & 1,050 & 5.20 & 1969 & Mar. 24 & 692 & 4.72 & $\overline{1990}$ & Mar. 18 & 7,200 & $8.76 c$ \\
\hline
\end{tabular}




\section{APALACHICOLA RIVER BASIN}

02343219 BLUFF SPRINGS BRANCH NEAR LUMPKIN, GEORGIA

LOCATION.--Lat $32^{\circ} 01^{\prime} 53^{\prime \prime}$, long $84^{\circ} 53^{\prime} 18^{\prime \prime}$, Stewart County, at culvert on State Highway $27,5.8$ mi southwest of Lumpkin. DRAINAGE AREA.--2.98 $\mathrm{mi}^{2}$.

GAGE.--Crest-stage gage. Datum of gage is about $390 \mathrm{ft}$ above sea level (from topographic map).

STAGE-DISCHARGE RELATION.-Defined by culvert computations.

\begin{tabular}{|c|c|c|c|c|c|c|c|c|c|c|c|}
\hline $\begin{array}{l}\text { Water } \\
\text { year }\end{array}$ & Date & $\begin{array}{c}\text { Discharge } \\
\left(\mathrm{ft}^{3} / \mathrm{s}\right)\end{array}$ & $\begin{array}{c}\text { Gage } \\
\text { height } \\
\text { (ft) }\end{array}$ & $\begin{array}{l}\text { Water } \\
\text { year }\end{array}$ & Date & $\begin{array}{c}\text { Discharge } \\
\left(\mathrm{ft}^{3} / \mathrm{s}\right)\end{array}$ & $\begin{array}{c}\text { Gage } \\
\text { height } \\
\text { (ft) }\end{array}$ & $\begin{array}{l}\text { Water } \\
\text { year }\end{array}$ & Date & $\begin{array}{c}\text { Discharge } \\
\left(\mathrm{ft}^{3} / \mathrm{s}\right)\end{array}$ & $\begin{array}{c}\text { Gage } \\
\text { height } \\
\text { (ft) }\end{array}$ \\
\hline 1977 & Aug. 15 & 193 & 2.51 & 1982 & Feb. 23 & 121 & 1.97 & 1987 & Nov. 30 & 101 & 1.77 \\
\hline 1978 & July 31 & 489 & 4.27 & 1983 & Mar. 06 & 241 & 2.82 & 1988 & Apr. - & 75 & $-b$ \\
\hline 1979 & Feb. 24 & 161 & 2.28 & 1984 & Dec. 11 & 90 & 1.66 & 1989 & July 20 & 93 & 1.68 \\
\hline 1980 & Mar. 30 & 121 & 1.97 & 1985 & Aug. 29 & 170 & 2.34 & 1990 & Mar. 17 & 568 & 4.70 \\
\hline 1981 & Feb. 10 & 147 & 2.18 & 1986 & Dec. 13 & 88 & 1.64 & & & & \\
\hline
\end{tabular}

\section{PATAULA CREEK NEAR GEORGETOWN, GEORGIA}

LOCATION.--Lat $31^{\circ} 49^{\prime} 06^{\prime \prime}$, long $84^{\circ} 57^{\prime 2} 27^{\prime \prime}$, Quitman County, at bridge on U.S. Highway 82 (State Highway 50), about 11 mi east of Georgetown.

DRAINAGE AREA.--295 $\mathrm{mi}^{2}$.

GAGE.--Crest-stage gage. Datum of gage is $209.64 \mathrm{ft}$ above sea level (levels by the Georgia Department of Transportation).

STAGE-DISCHARGE RELATION.--Defined by current-meter measurements below $7,500 \mathrm{t}^{3} / \mathrm{s}$, and extended above on basis of contracted-opening measurements at $19,000 \mathrm{ft}^{3} / \mathrm{s}$, and extended above on the basis of straight-line extension. Bankfull stage and discharge, $5.0 \mathrm{ft}$ and $3,500 \mathrm{ft}^{3} / \mathrm{s}$.

REMARKS.--The flood stage of the 1949 flood is based on information provided by the Georgia Department of Transportation.

\begin{tabular}{|c|c|c|c|c|c|c|c|c|c|c|c|}
\hline $\begin{array}{l}\text { Water } \\
\text { year }\end{array}$ & Date & $\begin{array}{c}\text { Discharge } \\
\left(\mathrm{ft}^{3} / \mathrm{s}\right)\end{array}$ & $\begin{array}{l}\text { Gage } \\
\text { height } \\
\text { (ft) }\end{array}$ & $\begin{array}{l}\text { Water } \\
\text { year }\end{array}$ & Date & $\begin{array}{c}\text { Discharge } \\
\left(\mathrm{ft}^{3} / \mathrm{s}\right)\end{array}$ & $\begin{array}{c}\text { Gage } \\
\text { height } \\
\text { (ft) }\end{array}$ & $\begin{array}{l}\text { Water } \\
\text { year }\end{array}$ & Date & $\begin{array}{c}\text { Discharge } \\
\left(\mathrm{ft}^{3} / \mathrm{s}\right)\end{array}$ & $\begin{array}{c}\text { Gage } \\
\text { height } \\
\text { (ft) }\end{array}$ \\
\hline$\underline{1949}$ & Nov. 27 & 42,000 & $11.80 \mathrm{c}$ & 1960 & Apr. 03 & 4,140 & 5.15 & 1970 & Mar. 31 & 19,000 & 9.40 \\
\hline$\overline{1951}$ & Dec. 29 & 1,730 & 4.38 & 1961 & Apr. 12 & 4,600 & 5.40 & 1971 & Mar. 27 & 2,850 & 5.03 \\
\hline 1952 & Feb. -- & 1,620 & 4.29 & 1962 & Jan. 07 & 2,450 & 4.40 & 1972 & Jan. 14 & 1,860 & 4.52 \\
\hline 1953 & May 03 & 11,000 & 8.02 & 1963 & Jan. 22 & 2,450 & 4.45 & 1973 & Apr. 26 & 4,900 & 6.38 \\
\hline 1954 & Dec. 08 & 2,080 & 4.73 & 1964 & Jan. 10 & 2,650 & 4.47 & 1974 & Apr. 06 & 3,000 & 5.33 \\
\hline 1955 & Feb. 07 & 3,730 & 5.80 & 1965 & Dec. 27 & 5,460 & 5.76 & 1975 & Feb. 17 & 19,400 & 9.69 \\
\hline 1956 & Sept.25 & 3,400 & 5.63 & 1966 & Feb. 12 & 4,460 & 5.34 & 1976 & May 15 & 1,990 & 4.53 \\
\hline 1957 & Apr. 07 & 2,950 & 5.27 & 1967 & Jan. 02 & 6,410 & 6.07 & 1977 & Dec. 02 & 3,500 & 5.60 \\
\hline 1958 & Feb. 28 & 1,320 & 4.00 & 1968 & Nov. 02 & 700 & $2.47 \mathrm{~b}$ & 1978 & Jan. 28 & 8,000 & 7.19 \\
\hline 1959 & Feb. 06 & 2,650 & 4.54 & 1969 & May 19 & 2,410 & 4.94 & $\overline{1990}$ & Mar. 18 & 7,540 & $7.43 c$ \\
\hline
\end{tabular}




\section{APALACHICOLA RIVER BASIN}

\section{TEMPLE CREEK NEAR BLAKELY, GEORGIA}

LOCATION.--Lat $31^{\circ} 26^{\prime} 35^{\prime \prime}$, long $84^{\circ} 59^{\prime} 00^{\prime \prime}$, Early County, at culvert on State Highway $39,5.2$ mi north of Blakely. DRAINAGE AREA.--2.78 $\mathrm{mi}^{2}$.

GAGE.--Water-stage recorder. Datum of gage is about $290 \mathrm{ft}$ above sea level (from topographic map).

STAGE-DISCHARGE RELATION.--Defined by current-meter measurements below $62.0 \mathrm{ft}^{3} / \mathrm{s}$, and extended above on the basis of culvert computations.

\begin{tabular}{|c|c|c|c|c|c|c|c|c|c|c|c|}
\hline $\begin{array}{l}\text { Water } \\
\text { year }\end{array}$ & Date & $\begin{array}{c}\text { Discharge } \\
\left(\mathrm{ft}^{3} / \mathrm{s}\right)\end{array}$ & $\begin{array}{c}\text { Gage } \\
\text { height } \\
\text { (ft) }\end{array}$ & $\begin{array}{l}\text { Water } \\
\text { year }\end{array}$ & Date & $\begin{array}{c}\text { Discharge } \\
\left(\mathrm{ft}^{3} / \mathrm{s}\right)\end{array}$ & $\begin{array}{l}\text { Gage } \\
\text { height } \\
\text { (ft) }\end{array}$ & $\begin{array}{l}\text { Water } \\
\text { year }\end{array}$ & Date & $\begin{array}{c}\text { Discharge } \\
\left(\mathrm{ft}^{3} / \mathrm{s}\right)\end{array}$ & $\begin{array}{c}\text { Gage } \\
\text { height } \\
\text { (ft) }\end{array}$ \\
\hline 1978 & Jan. 26 & 110 & 2.03 & 1983 & Mar. 06 & 66.0 & 2.05 & 1987 & Mar. 01 & 22.0 & 1.30 \\
\hline 1979 & Feb. 25 & 60.0 & 1.79 & 1984 & Dec. 06 & 41.0 & 1.72 & 1988 & Apr. 17 & 34.0 & 1.58 \\
\hline 1980 & Apr. 05 & 80.0 & 1.81 & 1985 & Feb. 06 & 17.0 & 1.16 & 1989 & July 20 & 26.0 & 1.41 \\
\hline 1981 & Apr. 05 & 15.0 & $--b$ & 1986 & Feb. -- & 15.0 & $-\mathbf{b}$ & 1990 & Jan. 07 & 23.0 & 1.33 \\
\hline 1982 & July 24 & 82.0 & 2.27 & & & & & & & & \\
\hline
\end{tabular}

\section{CHATTAHOOCHEE RIVER AT COLUMBIA, ALABAMA}

LOCATION.--Lat $31^{\circ} 17^{\prime} 11^{\prime \prime}$, long $85^{\circ} 05^{\prime} 45^{\prime \prime}$, in T. 4 N., R. 29 E., Houston County, Ala., on downstream side of bridge on State Highway 52, 0.2 mi downstream from Central of Georgia Railway bridge, 0.5 mi upstream from Omussee Creek, 0.5 mi east of Columbia, and at mile 48.9 .

DRAINAGE AREA.-8,040 $\mathrm{mi}^{2}$, approximately.

GAGE.--Water-stage recorder. Datum of gage is $72.23 \mathrm{ft}$ above sea level (levels by the U.S. Army Corps of Engineers).

STAGE-DISCHARGE RELATION.--Defined by current-meter measurements below $115,000 \mathrm{ft}^{3} / \mathrm{s}$, and extended above on basis of slope-conveyance study at $203,000 \mathrm{ft}^{3} / \mathrm{s}$. Bankfull stage and discharge, $45 \mathrm{ft}$ and $93,000 \mathrm{ft}^{3} / \mathrm{s}$.

HISTORICAL DATA.-Flood of March 1929 thought to be the highest since 1827, based on information from local residents and for station upstream on Chattahoochee River at Columbus.

REMARKS.--Peak discharges are slightly regulated by Lake Sidney Lanier, West Point Lake, Bartletts Ferry Reservoir (Lake Harding) (For flood-control storage capacities, see station 02341500), and Walter F. George Lake (maximum flood-control capacity, 244,400 acre-ft) since 1963.

\begin{tabular}{|c|c|c|c|c|c|c|c|c|c|c|c|}
\hline $\begin{array}{l}\text { Water } \\
\text { year }\end{array}$ & Date & $\begin{array}{c}\text { Discharge } \\
\left(\mathrm{ft}^{3} / \mathrm{s}\right)\end{array}$ & $\begin{array}{c}\text { Gage } \\
\text { height } \\
\text { (ft) }\end{array}$ & $\begin{array}{l}\text { Water } \\
\text { year }\end{array}$ & Date & $\begin{array}{c}\text { Discharge } \\
\left(\mathrm{ft}^{3} / \mathrm{s}\right)\end{array}$ & $\begin{array}{c}\text { Gage } \\
\text { height } \\
\text { (ft) }\end{array}$ & $\begin{array}{l}\text { Water } \\
\text { year }\end{array}$ & Date & $\begin{array}{c}\text { Discharge } \\
\left(\mathrm{ft}^{3} / \mathrm{s}\right)\end{array}$ & $\begin{array}{c}\text { Gage } \\
\text { height } \\
\text { (ft) }\end{array}$ \\
\hline 1929 & Mar. 18 & 203,000 & 56.00 & 1940 & Feb. 19 & 51,200 & 32.60 & 1951 & Apr. 24 & 28,800 & 22.50 \\
\hline 1930 & Oct. 02 & 105,000 & 45.60 & 1941 & Mar. 09 & 18,400 & 16.00 & 1952 & Mar. 26 & 71,100 & 40.70 \\
\hline 1931 & Nov. 18 & 69,300 & 38.90 & 1942 & Mar. 24 & 81,300 & 42.30 & 1953 & May 04 & 92,000 & 45.80 \\
\hline 1932 & Feb. 24 & 42,100 & 28.20 & 1943 & Mar. 24 & 119,000 & 49.50 & 1954 & Dec. 07 & 57,300 & 36.10 \\
\hline 1933 & Mar. 22 & 63,800 & 37.20 & 1944 & Mar. 25 & 97,000 & 45.80 & 1955 & Apr. 16 & 39,500 & 28.00 \\
\hline 1934 & Mar. 06 & 63,200 & 36.00 & 1945 & Apr. 28 & 59,600 & 35.60 & 1956 & Mar. 19 & 51,200 & 33.70 \\
\hline 1935 & Mar. 08 & 49,100 & 30.60 & 1946 & Mar. 30 & 72,600 & 39.80 & 1957 & Apr. 08 & 74,000 & 41.50 \\
\hline 1936 & Apr. 12 & 102,000 & 46.60 & 1947 & Mar. 09 & 59,900 & 35.70 & 1958 & Mar. 10 & 74,900 & 39.40 \\
\hline 1937 & Mar. 22 & 57,200 & 34.80 & 1948 & July 14 & 81,200 & 43.30 & 1959 & June 04 & 51,700 & 31.70 \\
\hline 1938 & Apr. 11 & 91,500 & 44.70 & 1949 & Dec. 01 & 111,000 & 49.30 & 1960 & Apr. 05 & 84,800 & 44.20 \\
\hline 1939 & Mar. 03 & 77,600 & 41.30 & 1950 & Mar. 07 & 28,300 & 22.20 & 1961 & Mar. 01 & 110,000 & 47.90 \\
\hline
\end{tabular}




\section{APALACHICOLA RIVER BASIN}

\section{CHATTAHOOCHEE RIVER NEAR COLUMBIA, ALABAMA}

LOCATION.--Lat 31 $11^{\prime} 33^{\prime \prime}$, long $85^{\circ} 06^{\prime} 37^{\prime \prime}$, Early County, Ga.,-Houston County, Ala., at left end of George W. Andrews Lock and Dam, 1.3 mi downstream from Omusee Creek, 2.3 mi south of Columbia, Ala., and at mile 46.5.

DRAINAGE AREA. $-8,210 \mathrm{mi}^{2}$, approximately.

GAGE.-Gate-opening and water-stage recorders. Datum of gage is $00.00 \mathrm{ft}$ above sea level (levels by the U.S. Army Corps of Engineers).

STAGE-DISCHARGE RELATION.--Below a stage of 110.ft, the discharge is defined by flow through gate openings, flow over the fixed spillway and flow through the lock. When the structure becomes submerged at a stage of $110 \mathrm{ft}$, the discharge is defined by current-meter measurements.

REMARKS.--Peak discharges are slightly regulated by Lake Sidney Lanier, West Point Lake, Bartletts Ferry Reservoir (Lake Harding), and Walter F. George Lake (For flood-control storage capacities, see station 02343500); and George W. Andrews Reservoir. The flood peak of March 1990 from floodmarks.

\begin{tabular}{|c|c|c|c|c|c|c|c|c|c|c|c|}
\hline $\begin{array}{l}\text { Water } \\
\text { year }\end{array}$ & Date & $\begin{array}{c}\text { Discharge } \\
\left(\mathrm{ft}^{3} / \mathrm{s}\right)\end{array}$ & $\begin{array}{c}\text { Gage } \\
\text { height } \\
\text { (ft) }\end{array}$ & $\begin{array}{l}\text { Water } \\
\text { year }\end{array}$ & Date & $\begin{array}{c}\text { Discharge } \\
\left(\mathrm{ft}^{3} / \mathrm{s}\right)\end{array}$ & $\begin{array}{c}\text { Gage } \\
\text { height } \\
\text { (ft) }\end{array}$ & $\begin{array}{l}\text { Water } \\
\text { year }\end{array}$ & Date & $\begin{array}{c}\text { Discharge } \\
\left(\mathrm{ft}^{3} / \mathrm{s}\right)\end{array}$ & $\begin{array}{c}\text { Gage } \\
\text { height } \\
\text { (ft) }\end{array}$ \\
\hline 1975 & Apr. 05 & 58,000 & 104.70 & 1981 & Apr. 03 & 72,600 & 106.16 & 1986 & Mar. 15 & 60,400 & $104.60 \mathrm{a}$ \\
\hline 1976 & Apr. 01 & 45,700 & 103.12 & 1982 & Feb. 04 & 71,100 & 105.77 & 1987 & Mar. 02 & 57,900 & $103.32 \mathrm{a}$ \\
\hline 1977 & Nov. 29 & 43,600 & 103.00 & 1983 & Feb. 04 & 64,400 & $104.01 \mathrm{a}$ & 1988 & Jan. 20 & 30,800 & $103.29 a$ \\
\hline 1978 & Jan. 27 & 131,000 & 118.12 & 1984 & Dec. 12 & 51,900 & $103.39 \mathrm{a}$ & 1989 & Apr. 10 & 40,900 & $103.21 \mathrm{a}$ \\
\hline 1979 & Feb. 25 & 77,800 & 106.74 & 1985 & Feb. 06 & 35,200 & $103.47 \mathrm{a}$ & 1990 & Mar. 19 & 195,000 & 123.29 \\
\hline 1980 & Mar. 31 & 78,600 & 107.58 & & & & & & & & \\
\hline
\end{tabular}




\section{APALACHICOLA RIVER BASIN}

\section{CHATTAHOOCHEE RIVER AT ALAGA, ALABAMA}

LOCATION.-Lat $31^{\circ} 06^{\prime} 54^{\prime \prime}$, long $85^{\circ} 02^{\prime} 43^{\prime \prime}$, Early County, Ga., on downstream side of bridge on U.S. Highway $84,0.5 \mathrm{mi}$ downstream from Seaboad Coast Line Railroad bridge, $0.5 \mathrm{mi}$ south of Alaga, Ala., and at mile 34.4. DRAINAGE AREA. $-8,340 \mathrm{mi}^{2}$, approximately.

GAGE.-Water-stage recorder. Nonrecording gage prior to Jan. 17, 1960. Datum of gage is $62.72 \mathrm{ft}$ above sea level (levels by the

U.S. Army Corps of Engineers). Prior to October 1936, at site $0.5 \mathrm{mi}$ upstream at datum $2.45 \mathrm{ft}$ higher. Jan. 17, 1960, to Aug. 25, 1962, nonrecording gage, and since Aug. 26, 1962, auxiliary water-stage recorder at bridge 10.8 mi downstream.

STAGE-DISCHARGE RELATION.--Defined at present site by current-meter measurements below $115,000 \mathrm{ft}^{3} / \mathrm{s}$. Defined at former site by four discharge measurements made during period 1908-11, stage relation between sites, and discharge records for station on Chattahoochee River at Columbia. Bankfull stage and discharge, $32 \mathrm{ft}$ and $60,000 \mathrm{ft}^{3} / \mathrm{s}$.

REMARKS.--Gage-height record for 1905-36 furnished by the National Weather Service. Peak discharges for 1937, 1938, and 194560 estimated, based on station on Chattahoochee River at Columbia, Ala. Peak discharges are slightly regulated by Lake Sidney Lanier, West Point Lake, Bartletts Ferry Reservoir (Lake Harding), and Walter F. George Lake (For flood-control storage capacities, seo station 02343500).

HISTORICAL DATA.--Flood of March 1929 is thought to be the highest since 1827, based on information on the Chattahoochee River at Columbus, Ga.

\begin{tabular}{|c|c|c|c|c|c|c|c|c|c|c|c|}
\hline $\begin{array}{l}\text { Water } \\
\text { year }\end{array}$ & Date & $\begin{array}{c}\text { Discharge } \\
\left(\mathrm{ft}^{3} / \mathrm{s}\right)\end{array}$ & $\begin{array}{c}\text { Gage } \\
\text { height } \\
\text { (ft) }\end{array}$ & $\begin{array}{l}\text { Water } \\
\text { year }\end{array}$ & Date & $\begin{array}{c}\text { Discharge } \\
\left(\mathrm{ft}^{3} / \mathrm{s}\right)\end{array}$ & $\begin{array}{c}\text { Gage } \\
\text { height } \\
\text { (ft) }\end{array}$ & $\begin{array}{l}\text { Water } \\
\text { year }\end{array}$ & Date & $\begin{array}{c}\text { Discharge } \\
\left(\mathrm{ft}^{3} / \mathrm{s}\right)\end{array}$ & $\begin{array}{c}\text { Gage } \\
\text { height } \\
\text { (ft) }\end{array}$ \\
\hline 1905 & Feb. 14 & 67,100 & 34.00 & 1928 & Apr. 24 & 104,000 & 39.60 & 1950 & Mar. 07 & 28,300 & - \\
\hline 1906 & Mar. 23 & 51,400 & 29.70 & 1929 & Mar. 18 & 207,000 & 46.00 & 1951 & Apr. 24 & 28,800 & - \\
\hline 1907 & Oct. 21 & 44,300 & 26.80 & 1930 & Oct. 03 & 105,000 & 39.10 & 1952 & Mar. 26 & 71,100 & - \\
\hline 1908 & Apr. 30 & 92,000 & 38.20 & 1931 & Nov. 19 & 74,600 & 34.90 & 1953 & May 04 & 92,000 & - \\
\hline 1909 & Mar. 16 & 73,500 & 35.30 & 1932 & Feb. 24 & 44,300 & 25.40 & 1954 & Dec. 07 & 57,300 & - \\
\hline 1910 & Apr. 19 & 46,100 & 27.60 & 1933 & Mar. 22 & 68,500 & 33.20 & 1955 & Apr. 16 & 39,500 & - \\
\hline 1911 & Jan. 06 & 27,900 & 18.50 & 1934 & Mar. 07 & 64,500 & 33.50 & 1956 & Mar. 19 & 51,200 & - \\
\hline 1912 & Apr. 23 & 97,600 & 38.90 & 1935 & Mar. 09 & 50,100 & 28.60 & 1957 & Dec. 26 & 55,000 & - \\
\hline 1913 & Mar. 18 & 110,000 & 40.20 & 1936 & Apr. 12 & $\underline{104,000}$ & $\underline{40.50}$ & 1958 & Mar. 10 & 74,900 & - \\
\hline 1914 & Apr. 17 & 21,400 & 14.80 & 1937 & Mar. 22 & 57,200 & - & 1959 & June 04 & 51,700 & - \\
\hline 1915 & July 05 & 43,700 & 26.50 & 1938 & Apr. 11 & 91,500 & - & 1960 & Apr. 05 & 84,800 & - \\
\hline 1916 & July 09 & 162,000 & 44.00 & 1939 & Mar. 03 & 74,500 & 37.30 & 1961 & Mar. 01 & 104,000 & 40.81 \\
\hline 1917 & Mar. 07 & 82,900 & 36.90 & 1940 & Feb. 19 & 48,400 & 30.40 & 1962 & Apr. 15 & 66,700 & 32.96 \\
\hline 1918 & Oct. 01 & 44,800 & 27.00 & 1941 & Mar. 09 & 18,000 & 14.50 & 1963 & Jan. 22 & 55,600 & 30.87 \\
\hline 1919 & Dec. 25 & 116,000 & 40.80 & 1942 & Mar. 25 & 80,300 & 38.30 & 1964 & Apr. 10 & 110,000 & 41.18 \\
\hline 1920 & Dec. 14 & 115,000 & 40.70 & 1943 & Mar. 24 & 112,000 & 42.20 & 1965 & Apr. 10 & 76,200 & 35.80 \\
\hline 1921 & Feb. 13 & 58,300 & 31.90 & 1944 & Apr. 30 & 92,800 & 40.10 & 1966 & Mar. 05 & 102,000 & 40.35 \\
\hline 1922 & Mar. 10 & 87,800 & 37.60 & 1945 & Apr. 28 & 59,600 & - & 1967 & Jan. 03 & 66,900 & 34.20 \\
\hline 1923 & Mar. 20 & 70,000 & 34.60 & 1946 & Mar. 30 & 72,600 & - & 1968 & Mar. 14 & 64,800 & 33.77 \\
\hline 1924 & Jan. 26 & 44,800 & 27.00 & 1947 & Mar. 09 & 59,900 & - & 1969 & Apr. 20 & 68,600 & 34.70 \\
\hline 1925 & Jan. 21 & 173,000 & 44.50 & 1948 & July 14 & 81,200 & - & 1970 & Mar. 24 & 74,300 & 36.05 \\
\hline 1926 & Apr. 02 & 67,100 & 34.00 & 1949 & Dec. 01 & 110,000 & - & 1971 & Mar. 06 & 97,900 & 39.99 \\
\hline 1927 & Feb. 17 & 28,300 & 18.70 & & & & & & & & \\
\hline
\end{tabular}


LOCATION.--Lat $33^{\circ} 31^{\prime} 00^{\prime \prime}$, long $84^{\circ} 25^{\prime} 39^{\prime \prime}$, Fayette County, at downstream side of bridge on State Highway $85,3.5 \mathrm{mi}$ uptream mouth, and 5.2 mi north of Fayetteville.

DRAINAGE AREA.--17.2 $\mathrm{mi}^{2}$.

GAGE.--Water-stage recorder. Datum of gage is about $800 \mathrm{ft}$ above sea level (from topographic map).

STAGE-DISCHARGE RELATION.--Defined by current-meter measurements below $2,000 \mathrm{ft} / \mathrm{s}$, and above on the basis of straightline extension.

HISTORICAL DATA.--The flood of February 1961 is thought to be the highest since 1948, based on information at nearby stations.

\begin{tabular}{|c|c|c|c|c|c|c|c|c|c|c|c|}
\hline $\begin{array}{l}\text { Water } \\
\text { year }\end{array}$ & Date & $\begin{array}{l}\text { Discharge } \\
\left(\mathrm{ft}^{3} / \mathrm{s}\right)\end{array}$ & $\begin{array}{c}\text { Gage } \\
\text { height } \\
\text { (ft) }\end{array}$ & $\begin{array}{l}\text { Water } \\
\text { year }\end{array}$ & Date & $\begin{array}{c}\text { Discharge } \\
\left(\mathrm{ft}^{3} / \mathrm{s}\right)\end{array}$ & $\begin{array}{l}\text { Gage } \\
\text { height } \\
\text { (ft) }\end{array}$ & $\begin{array}{l}\text { Water } \\
\text { year }\end{array}$ & Date & $\begin{array}{c}\text { Discharge } \\
\left(\mathrm{ft}^{3} / \mathrm{s}\right)\end{array}$ & $\begin{array}{c}\text { Gage } \\
\text { height } \\
\text { (ft) }\end{array}$ \\
\hline 1961 & Feb. 25 & 2,800 & 9.90 & 1966 & Feb. 13 & 1,390 & 8.81 & 1970 & Mar. 20 & 1,240 & 9.25 \\
\hline 1962 & Feb. 22 & 684 & 7.48 & 1967 & Aug. 24 & 868 & 7.92 & 1971 & Mar. 03 & 1,100 & 9.04 \\
\hline 1963 & Nov. 21 & 680 & 7.55 & 1968 & Mar. 12 & 1,100 & 8.99 & 1972 & Jan. 10 & 1,160 & 9.00 \\
\hline 1964 & Apr. 27 & 1,480 & 8.96 & 1969 & Apr. 18 & 1,020 & 8.90 & 1973 & May. 28 & 1,800 & 9.98 \\
\hline 1965 & Jan. 23 & 600 & 7.34 & & & & & & & & \\
\hline
\end{tabular}

\section{FLINT RIVER NEAR LOVEJOY, GEORGIA}

LOCATION.--Lat $33^{\circ} 24^{\prime} 56^{\prime \prime}$, long 84 $4^{\circ} 23^{\prime} 05^{\prime \prime}$, Clayton County, at downstream side of bridge on Hampton Road, 0.7 mi upstream from Shoal Creek, $4.4 \mathrm{mi}$ southwest of Lovejoy, and at mile 325.7. DRAINAGE AREA. $-130 \mathrm{mi}^{2}$

GAGE.--Water-stage recorder. Datum of gage is $758.75 \mathrm{ft}$ above sea level (levels by Clayton County). STAGE-DISCHARGE RELATION.--Defined by current-meter measurements below $6,610 \mathrm{ft}^{3} / \mathrm{s}$, and above on the basis of ratingcurve extension and flow-over-the-road computations.

\begin{tabular}{|c|c|c|c|c|c|c|c|c|c|c|c|}
\hline $\begin{array}{l}\text { Water } \\
\text { year }\end{array}$ & Date & $\begin{array}{c}\text { Discharge } \\
\left(\mathrm{ft}^{3} / \mathrm{s}\right)\end{array}$ & $\begin{array}{c}\text { Gage } \\
\text { height } \\
\text { (ft) }\end{array}$ & $\begin{array}{l}\text { Water } \\
\text { year }\end{array}$ & Date & $\begin{array}{c}\text { Discharge } \\
\left(\mathrm{ft}^{3} / \mathrm{s}\right)\end{array}$ & $\begin{array}{c}\text { Gage } \\
\text { height } \\
\text { (ft) }\end{array}$ & $\begin{array}{l}\text { Water } \\
\text { year }\end{array}$ & Date & $\begin{array}{c}\text { Discharge } \\
\left(\mathrm{ft}^{3} / \mathrm{s}\right)\end{array}$ & $\begin{array}{c}\text { Gage } \\
\text { height } \\
\text { (ft) }\end{array}$ \\
\hline 1986 & Dec. 01 & 1,890 & 11.08 & 1988 & Feb. 05 & 2,520 & 12.25 & 1990 & Mar. 17 & 8,090 & 17.76 \\
\hline 1987 & Oct. 15 & 4,690 & 15.16 & 1989 & June 21 & 3,140 & 12.86 & & & & \\
\hline
\end{tabular}


LOCATION.--Lat $33^{\circ} 14^{\prime} 39^{\prime \prime}$, long $84^{\circ} 25^{\prime} 45^{\prime \prime}$, Spalding County, at downstream side of pier of bridge on State Highway 16, 1.5 mi downstream from Shoal Creek, 5.5 mi upstream from Line Creek, 10 mi west of Griffin, and at mile 304.4.

DRAINAGE AREA.--272 $\mathrm{mi}^{2}$.

GAGE.--Water-stage recorder. Datum of gage is $711.44 \mathrm{ft}$ above sea level (levels by the U.S. Army Corps of Engineers). Prior to Aug. 25, 1938, nonrecording gage at present site at datum 3.00 ft higher. Aug. 25, 1938, to May 5, 1941, nonrecording gage, May 6, 1941, to Aug. 20,1959, water-stage recorder, and Aug. 21, 1959, to Sept. 13, 1960, nonrecording gage, all at present site and datum.

STAGE-DISCHARGE RELATION.--Defined by current-meter measurements below $12,600 \mathrm{ft}^{3} / \mathrm{s}$, and above on the basis of straightline extension. Bankfull stage and discharge, $10 \mathrm{ft}$ and $1,500 \mathrm{ft}^{3} / \mathrm{s}$.

HISTORICAL DATA.--Flood stage for 1929 based on floodmark furnished by local resident, and is thought to be the highest since 1919 , on the basis of information at nearby stations.

\begin{tabular}{|c|c|c|c|c|c|c|c|c|c|c|c|}
\hline $\begin{array}{l}\text { Water } \\
\text { year }\end{array}$ & Date & $\begin{array}{c}\text { Discharge } \\
\left(\mathrm{ft}^{3} / \mathrm{s}\right)\end{array}$ & $\begin{array}{c}\text { Gage } \\
\text { height } \\
\text { (ft) }\end{array}$ & $\begin{array}{l}\text { Water } \\
\text { year }\end{array}$ & Date & $\begin{array}{c}\text { Discharge } \\
\left(\mathrm{ft}^{3} / \mathrm{s}\right)\end{array}$ & $\begin{array}{c}\text { Gage } \\
\text { height } \\
\text { (ft) }\end{array}$ & $\begin{array}{l}\text { Water } \\
\text { year }\end{array}$ & Date & $\begin{array}{c}\text { Discharge } \\
\left(\mathrm{ft}^{3} / \mathrm{s}\right)\end{array}$ & $\begin{array}{c}\text { Gage } \\
\text { height } \\
\text { (ft) }\end{array}$ \\
\hline$\underline{1929}$ & Mar. 14 & 15,300 & $17.90 \mathrm{c}$ & 1955 & Apr. 14 & 2,370 & 10.66 & 1973 & Dec. 15 & 5,540 & 13.21 \\
\hline 1937 & May. 01 & 2,980 & 11.40 & 1956 & Mar. 18 & 4,590 & 12.66 & 1974 & Jan. 03 & 3,110 & 11.51 \\
\hline 1938 & Apr. 03 & 5,200 & 13.00 & 1957 & Apr. 05 & 5,330 & 13.20 & 1975 & Apr. 03 & 7,470 & 14.30 \\
\hline 1939 & Feb. 28 & 3,650 & 12.00 & 1958 & Feb. 07 & 4,730 & 12.80 & 1976 & Mar. 17 & 9,240 & 15.02 \\
\hline 1940 & July 12 & 2,080 & 10.60 & 1959 & June 02 & 5,180 & 13.10 & 1977 & Mar. 31 & 3,390 & 12.06 \\
\hline 1941 & Mar. 28 & 1,040 & 9.00 & 1960 & Apr. 04 & 4,730 & 12.80 & 1978 & Nov. 06 & 5,420 & 13.21 \\
\hline 1942 & Mar. 22 & 13,000 & 17.00 & 1961 & Feb. 26 & 11,100 & 16.18 & 1979 & Apr. 15 & 6,380 & 13.87 \\
\hline 1943 & Jan. 19 & 6,310 & 13.80 & 1962 & Feb. 23 & 3,900 & 12.39 & 1980 & Mar. 30 & 4,620 & 12.75 \\
\hline 1944 & Mar. 23 & 4,170 & 12.40 & 1963 & June 20 & 4,850 & 12.88 & 1981 & Feb. 13 & 5,320 & 12.82 \\
\hline 1945 & Apr. 25 & 7,750 & 14.60 & 1964 & Apr. 28 & 5,810 & 13.46 & 1982 & Feb. 05 & 4,430 & 12.74 \\
\hline 1946 & Jan. 07 & 9,350 & 15.40 & 1965 & Dec. 27 & 2,880 & 11.37 & 1983 & Mar. 07 & 4,530 & 12.80 \\
\hline 1947 & Mar. 08 & 5,490 & 13.30 & 1966 & Feb. 13 & 7,520 & 14.48 & 1984 & Dec. 06 & 3,000 & 11.82 \\
\hline 1948 & May. 31 & 4,170 & 12.40 & 1967 & Aug. 26 & 3,880 & 12.34 & 1985 & Feb. 06 & 3,280 & 12.07 \\
\hline 1949 & Nov. 27 & 13,200 & 18.00 & 1968 & Mar. 14 & 4,550 & 12.82 & 1986 & Dec. 02 & 2,080 & 10.87 \\
\hline 1950 & Feb. 11 & 875 & 8.97 & 1969 & Apr. 20 & 4,170 & 12.50 & 1987 & Mar. 01 & 4,120 & 12.52 \\
\hline 1951 & Apr. 23 & 920 & 8.78 & 1970 & Mar. 22 & 6,820 & 14.12 & 1988 & Feb. 06 & 3,000 & 11.82 \\
\hline 1952 & Mar. 04 & 6,480 & 13.90 & 1971 & Mar. 03 & 12,300 & 16.70 & 1989 & June 22 & 3,390 & 12.16 \\
\hline 1953 & May. 01 & 2,860 & 11.55 & 1972 & Jan. 11 & 7,850 & 14.46 & 1990 & Mar. 17 & 11,500 & 16.20 \\
\hline 1954 & Dec. 07 & 2,640 & 11.14 & & & & & & & & \\
\hline
\end{tabular}

\section{LINE CREEK NEAR SENOIA, GEORGIA}

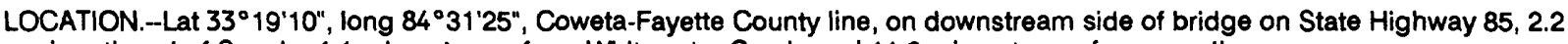
mi northeast of Senoia, $4.1 \mathrm{mi}$ upstream from Whitewater Creek, and $11.2 \mathrm{mi}$ upstream from mouth. DRAINAGE AREA.-101 $\mathrm{mi}^{2}$, approximately.

GAGE.--Water-stage recorder. Datum of gage is $729.27 \mathrm{ft}$ above sea level (levels by Global Positioning System).

STAGE-DISCHARGE RELATION.--Defined by current-meter measurements below $6,500 \mathrm{tt}^{3} / \mathrm{s}$, and above on the basis of straightline extension. Bankfull stage and discharge, $8 \mathrm{ft}$ and $760 \mathrm{ft}^{3} / \mathrm{s}$.

\begin{tabular}{|c|c|c|c|c|c|c|c|c|c|c|c|}
\hline $\begin{array}{l}\text { Water } \\
\text { year }\end{array}$ & Date & $\begin{array}{c}\text { Discharge } \\
\left(\mathrm{ft}^{3} / \mathrm{s}\right)\end{array}$ & $\begin{array}{c}\text { Gage } \\
\text { height } \\
\text { (ft) }\end{array}$ & $\begin{array}{l}\text { Water } \\
\text { year }\end{array}$ & Date & $\begin{array}{c}\text { Discharge } \\
\left(\mathrm{ft}^{3} / \mathrm{s}\right)\end{array}$ & $\begin{array}{c}\text { Gage } \\
\text { height } \\
\text { (ft) }\end{array}$ & $\begin{array}{l}\text { Water } \\
\text { year }\end{array}$ & Date & $\begin{array}{c}\text { Discharge } \\
\left(\mathrm{ft}^{3} / \mathrm{s}\right)\end{array}$ & $\begin{array}{c}\text { Gage } \\
\text { height } \\
\text { (ft) }\end{array}$ \\
\hline 1965 & Jan. 24 & 1,660 & 10.40 & 1974 & Jan. 01 & 1,410 & 9.39 & 1983 & Apr. 09 & 2,240 & 10.61 \\
\hline 1966 & Feb. 14 & 4,380 & 12.27 & 1975 & Apr. 03 & 2,050 & 9.99 & 1984 & Dec. 04 & 1,850 & 9.93 \\
\hline 1967 & Oct. 24 & 2,540 & 10.76 & 1976 & Mar. 16 & 6,260 & 13.38 & 1985 & Feb. 06 & 1,950 & 10.07 \\
\hline 1968 & Mar. 13 & 3,160 & 11.33 & 1977 & Mar. 31 & 3,020 & 11.28 & 1986 & Dec. 01 & 660 & 7.40 \\
\hline 1969 & Apr. 19 & 3,200 & 11.36 & 1978 & Nov. 05 & 9,580 & 14.88 & 1987 & Mar. 01 & 1,590 & 9.52 \\
\hline 1970 & Mar. 20 & 4,180 & 12.03 & 1979 & Apr. 14 & 4,910 & 12.65 & 1988 & Feb. 05 & 2,030 & 10.18 \\
\hline 1971 & Mar. 03 & 4,950 & 12.63 & 1980 & Mar. 29 & 2,450 & 10.65 & 1989 & Apr. 06 & 1,560 & 9.47 \\
\hline 1972 & Jan. 11 & 4,700 & 12.47 & 1981 & Feb. 11 & 3,360 & 11.89 & 1990 & Mar. 17 & 7,290 & 13.84 \\
\hline 1973 & Feb. 02 & 3,630 & 11.69 & 1982 & Feb. 04 & 2,900 & 11.23 & & & & \\
\hline
\end{tabular}


LOCATION.--Lat $32^{\circ} 59^{\prime} 21^{\prime \prime}$, long $84^{\circ} 31^{\prime} 45^{\prime \prime}$, Pike County, on downstream side of bridge on State Highway 18, $500 \mathrm{ft}$ downstream from Southern Railway bridge, $0.5 \mathrm{mi}$ downstream from Poppys Creek, $1.8 \mathrm{mi}$ upstream from Elkins Creek, 2 mi southwest of Molena, and at mile 278.1.

DRAINAGE AREA.-990 $\mathrm{mi}^{2}$, approximately.

GAGE.-Nonrecording prior to December 1945; water-stage recorder thereafter. Datum of gage is $646.78 \mathrm{ft}$ above sea level (levels by U.S. Army Corps of Engineers).

STAGE-DISCHARGE RELATION.-Defined by current-meter measurements below $30,000 \mathrm{ft}^{3} / \mathrm{s}$, and above on the basis of straightline extension. Bankfull stage and discharge, $14 \mathrm{ft}$ and $9,000 \mathrm{ft}^{3} / \mathrm{s}$.

HISTORICAL DATA.--The peak discharge for 1929 is thought to be the highest since 1897, based on information at Flint River at Montezuma (02349500).

REMARKS.--Records for 1900-27 estimated from gaging station on Flint River at Woodbury (drainage area, 1,090 $\mathrm{mi}^{2}$, approximately). The peak stage for the 1929 flood furnished by the Georgia Department of Transportation. Records for $1939-43$ furnished by the U.S. Army Corps of Engineers.

\begin{tabular}{|c|c|c|c|c|c|c|c|c|c|c|c|}
\hline $\begin{array}{l}\text { Water } \\
\text { year }\end{array}$ & Date & $\begin{array}{c}\text { Discharge } \\
\left(\mathrm{ft}^{3} / \mathrm{s}\right)\end{array}$ & $\begin{array}{c}\text { Gage } \\
\text { height } \\
\text { (ft) }\end{array}$ & $\begin{array}{l}\text { Water } \\
\text { year }\end{array}$ & Date & $\begin{array}{c}\text { Discharge } \\
\left(\mathrm{ft}^{3} / \mathrm{s}\right)\end{array}$ & $\begin{array}{c}\text { Gage } \\
\text { height } \\
\text { (ft) }\end{array}$ & $\begin{array}{l}\text { Water } \\
\text { year }\end{array}$ & Date & $\begin{array}{c}\text { Discharge } \\
\left(\mathrm{ft}^{3} / \mathrm{s}\right)\end{array}$ & $\begin{array}{c}\text { Gage } \\
\text { height } \\
\text { (ft) }\end{array}$ \\
\hline 1900 & June 24 & 15,800 & - & 1914 & Apr. 15 & 6,770 & - & $\underline{1929}$ & Mar. 15 & 42,000 & $29.80 \mathrm{c}$ \\
\hline 1901 & May. 23 & 18,200 & - & 1915 & Dec. 05 & 10,700 & - & 1939 & Mar. 31 & 16,400 & 18.90 \\
\hline 1902 & Feb. 28 & 30,200 & - & 1916 & July 10 & 26,100 & - & 1940 & July 11 & 7,680 & 12.60 \\
\hline 1903 & Feb. 08 & 25,800 & - & 1917 & Mar. 05 & 18,100 & - & 1941 & Mar. 28 & 2,300 & 8.00 \\
\hline 1904 & Aug. 08 & 15,000 & - & 1918 & Jan. 31 & 8,320 & - & 1942 & Mar. 23 & 24,500 & 23.30 \\
\hline 1905 & Feb. 14 & 9,100 & - & 1919 & Dec. 24 & 19,100 & - & $\underline{1943}$ & Jan. 20 & 17,100 & 19.30 \\
\hline 1906 & Mar. 21 & 12,800 & - & 1920 & Dec. 11 & 38,400 & - & 1946 & Jan. 08 & 21,800 & 21.70 \\
\hline 1907 & Feb. 07 & 6,520 & - & 1921 & Feb. 11 & 17,800 & - & 1947 & Mar. 08 & 16,200 & 18.80 \\
\hline 1908 & Apr. 27 & 16,200 & - & 1922 & Mar. 11 & 23,900 & - & 1948 & July 11 & 28,400 & 24.70 \\
\hline 1909 & Mar. 13 & 19,200 & - & 1923 & Mar. 13 & 17,800 & - & 1949 & Nov. 27 & 31,100 & 25.90 \\
\hline 1910 & Mar. 01 & 8,450 & - & 1924 & Jan. 17 & 7,530 & - & 1950 & Mar. 06 & 4,140 & 9.67 \\
\hline 1911 & Aug. 03 & 5,820 & - & 1925 & Jan. 19 & 37,200 & - & 1951 & Apr. 23 & 3,780 & 9.28 \\
\hline 1912 & Mar. 16 & 26,300 & - & 1926 & Apr. 01 & 12,600 & - & 1952 & Mar. 05 & 17,400 & 19.50 \\
\hline 1913 & Mar. 15 & 35,300 & - & $\underline{1927}$ & Mar. 11 & 6,400 & - & 1953 & May 01 & 10,700 & 14.90 \\
\hline
\end{tabular}

\section{FLINT RIVER NEAR WOODBURY, GEORGIA}

LOCATION.--Lat $32^{\circ} 57^{\prime} 59^{\prime \prime}$, long $84^{\circ} 31^{\prime} 58^{\prime \prime}$, Meriwether County, on downstream side of Macon and Birmingham Railroad bridge (abandoned), $0.2 \mathrm{mi}$ downstream from Elkins Creek, $0.3 \mathrm{mi}$ upstream from Cane Creek, $3 \mathrm{mi}$ east of Woodbury, and at mile 276.1.

DRAINAGE AREA.-1,090 $\mathrm{mi}^{2}$, approximately (revised).

GAGE.-Nonrecording. Prior to May 24, 1918, at site $300 \mathrm{ft}$ upstream. Datum of gage is $649 \mathrm{ft}$ above sea level (from the U.S. Army Corps of Engineers low-water profile).

STAGE-DISCHARGE RELATION.--Defined by current-meter measurements below $20,000 \mathrm{tt}^{3} / \mathrm{s}$, and extended above on the basis of straight-line extension. Bankfull stage and discharge, $9 \mathrm{ft}$ and $16,000 \mathrm{ft}^{3} / \mathrm{s}$.

REMARKS.--Stage records for 1921-27 furnished by the National Weather Service. All peak discharges are maximum daily.

\begin{tabular}{|c|c|c|c|c|c|c|c|c|c|c|c|}
\hline $\begin{array}{l}\text { Water } \\
\text { year }\end{array}$ & Date & $\begin{array}{c}\text { Discharge } \\
\left(\mathrm{ft}^{3} / \mathrm{s}\right)\end{array}$ & $\begin{array}{l}\text { Gage } \\
\text { height } \\
\text { (ft) }\end{array}$ & $\begin{array}{l}\text { Water } \\
\text { year }\end{array}$ & Date & $\begin{array}{c}\text { Discharge } \\
\left(\mathrm{ft}^{3} / \mathrm{s}\right)\end{array}$ & $\begin{array}{c}\text { Gage } \\
\text { height } \\
\text { (ft) }\end{array}$ & $\begin{array}{l}\text { Water } \\
\text { year }\end{array}$ & Date & $\begin{array}{c}\text { Discharge } \\
\left(\mathrm{ft}^{3} / \mathrm{s}\right)\end{array}$ & $\begin{array}{c}\text { Gage } \\
\text { height } \\
\text { (ft) }\end{array}$ \\
\hline 1900 & June 24 & 15,800 & 9.00 & 1910 & Mar. 01 & 8,450 & 6.00 & 1919 & Dec. 24 & 19,100 & 10.50 \\
\hline 1901 & May. 23 & 18,200 & 10.00 & 1911 & Aug. 03 & 5,820 & 4.60 & 1920 & Dec. 11 & 38,400 & 17.10 \\
\hline 1902 & Feb. 28 & 30,200 & 14.00 & 1912 & Mar. 16 & 26,300 & 13.00 & 1921 & Feb. 11 & 17,800 & 10.00 \\
\hline 1903 & Feb. 08 & 25,800 & 13.00 & 1913 & Mar. 15 & 36,300 & 16.20 & 1922 & Mar. 11 & 23,900 & 12.20 \\
\hline 1904 & Aug. 08 & 15,000 & 8.70 & 1914 & Apr. 15 & 6,770 & 5.30 & 1923 & Mar. 13 & 17,800 & 10.00 \\
\hline 1905 & Feb. 14 & 9,100 & 6.30 & 1915 & Dec. 05 & 10,700 & 7.20 & 1924 & Jan. 17 & 7,530 & 5.60 \\
\hline 1906 & Mar. 21 & 12,800 & 7.80 & 1916 & July 10 & 26,100 & 13.00 & 1925 & Jan. 19 & 37,200 & 16.70 \\
\hline 1907 & Feb. 07 & 6,520 & 5.00 & 1917 & Mar. 05 & 18,100 & 10.10 & 1926 & Apr. 01 & 12,600 & 7.90 \\
\hline 1908 & Apr. 27 & 16,200 & 9.20 & 1918 & Jan. 31 & $\underline{8,320}$ & 6.00 & 1927 & Mar. 11 & 6,400 & 5.00 \\
\hline 1909 & Mar. 13 & 19,200 & 10.40 & & & & & & & & \\
\hline
\end{tabular}




\section{APALACHICOLA RIVER BASIN \\ 02346180 FLINT RIVER NEAR THOMASTON, GEORGIA}

LOCATION.--Lat $32^{\circ} 50^{\prime} 20^{\prime \prime}$, long $84^{\circ} 25^{\prime} 27^{\prime \prime}$, Upson-Talbot County line, at downstream end of left bank pier of bridge on State Highway 36, 2.5 mi upstream from Lazar Creek, and 7.8 mi west of Thomaston.

DRAINAGE AREA.-1,220 $\mathrm{mi}^{2}$, approximately.

GAGE.--Crest-stage gage prior to 1967, at site $100 \mathrm{ft}$ downstream and at datum $11.40 \mathrm{ft}$ lower. Water-stage recorder thereafter.

Datum of gage is $490.00 \mathrm{ft}$ above sea level (levels from the U.S. Army Corps of Engineers). All gage readings have been adjusted to present datum.

STAGE-DISCHARGE RELATION.-Defined by current-meter measurements below $29,200 \mathrm{t}^{3} / \mathrm{s}$, and extended above on the basis of straight-line extension. Bankfull stage and discharge, $12 \mathrm{ft}$ and $9,000 \mathrm{ft}^{3} / \mathrm{s}$.

HISTORICAL DATA.--Peak discharge for 1949 thought to be the highest since 1929 , based on information at nearby stations. The peak stage for the 1949 flood provided by local residents.

REMARKS.--Records for 1967-74 furnished by the U.S. Army Corps of Engineers.

\begin{tabular}{|c|c|c|c|c|c|c|c|c|c|c|c|}
\hline $\begin{array}{l}\text { Water } \\
\text { year }\end{array}$ & Date & $\begin{array}{c}\text { Discharge } \\
\left(\mathrm{ft}^{3} / \mathrm{s}\right)\end{array}$ & $\begin{array}{c}\text { Gage } \\
\text { height } \\
\text { (ft) }\end{array}$ & $\begin{array}{l}\text { Water } \\
\text { year }\end{array}$ & Date & $\begin{array}{c}\text { Discharge } \\
\left(\mathrm{ft}^{3} / \mathrm{s}\right)\end{array}$ & $\begin{array}{c}\text { Gage } \\
\text { height } \\
\text { (ft) }\end{array}$ & $\begin{array}{l}\text { Water } \\
\text { year }\end{array}$ & Date & $\begin{array}{c}\text { Discharge } \\
\left(\mathrm{ft}^{3} / \mathrm{s}\right)\end{array}$ & $\begin{array}{c}\text { Gage } \\
\text { height } \\
\text { (ft) }\end{array}$ \\
\hline 1949 & Nov. 28 & 39,000 & 19.30 & 1971 & Mar. 03 & 34,400 & 18.40 & 1981 & Feb. 12 & 17,500 & 14.63 \\
\hline 1950 & Mar. 06 & 5,000 & 10.40 & 1972 & Jan. 13 & 20,500 & 15.27 & 1982 & Apr. 21 & 16,200 & 14.31 \\
\hline 1952 & Mar. 05 & 25,500 & 16.50 & 1973 & Apr. 08 & 14,200 & 13.58 & 1983 & Apr. 09 & 21,600 & 15.66 \\
\hline 1953 & May. 01 & 16,400 & 14.40 & 1974 & Feb. 16 & 17,400 & 14.49 & 1984 & Dec. 05 & 11,800 & 13.10 \\
\hline 1954 & Dec. 07 & 15,900 & 14.25 & 1975 & Apr. 04 & 24,900 & 16.35 & 1985 & Feb. 07 & 13,200 & 13.49 \\
\hline 1955 & Apr. 14 & 9,900 & 12.40 & 1976 & Mar. 18 & 22,200 & 15.99 & 1986 & Dec. 01 & 6,940 & 11.46 \\
\hline 1956 & Mar. 16 & 16,000 & 14.30 & 1977 & Apr. 01 & 15,000 & 13.74 & 1987 & Mar. 01 & 11,500 & 13.01 \\
\hline 1967 & Aug. 27 & 9,700 & 12.20 & 1978 & Jan. 26 & 19,200 & 15.28 & 1988 & Feb. 07 & 7,110 & 11.41 \\
\hline 1968 & Mar. 12 & 17,700 & 14.57 & 1979 & Feb. 25 & 15,400 & 14.19 & 1989 & Apr. 06 & 8,190 & 11.75 \\
\hline 1969 & Apr. 19 & 15,200 & 13.87 & 1980 & Mar. 09 & 21,900 & 15.92 & 1990 & Mar. 17 & 29,200 & 17.35 \\
\hline 1970 & Mar. 22 & 22,700 & 15.82 & & & & & & & & \\
\hline
\end{tabular}

\section{SCOTT CREEK NEAR TALBOTTON, GEORGIA}

LOCATION.--Lat 32 $39^{\prime} 48^{\prime \prime}$, long $84^{\circ} 36^{\prime} 06^{\prime \prime}$, Talbot County, at culvert on county road 76, 4.2 mi west of Talbotton.

DRAINAGE AREA.--3.36 $\mathrm{mi}^{2}$.

GAGE.-Flood-stage, rainfall recorder prior to Sept. 30, 1975. Crest-stage gage thereafter. Datum of gage is about $600 \mathrm{ft}$ above sea level (from topographic map).

STAGE-DISCHARGE RELATION.--Defined by current-meter measurements below $322 \mathrm{ft}^{3} / \mathrm{s}$, and extended above on the basis of culvert computations.

\begin{tabular}{|c|c|c|c|c|c|c|c|c|c|c|c|}
\hline $\begin{array}{l}\text { Water } \\
\text { year }\end{array}$ & Date & $\begin{array}{c}\text { Discharge } \\
\left(\mathrm{ft}^{3} / \mathrm{s}\right)\end{array}$ & $\begin{array}{c}\text { Gage } \\
\text { height } \\
\text { (ft) }\end{array}$ & $\begin{array}{l}\text { Water } \\
\text { year }\end{array}$ & Date & $\begin{array}{c}\text { Discharge } \\
\left(\mathrm{ft}^{3} / \mathrm{s}\right)\end{array}$ & $\begin{array}{c}\text { Gage } \\
\text { height } \\
\text { (ft) }\end{array}$ & $\begin{array}{l}\text { Water } \\
\text { year }\end{array}$ & Date & $\begin{array}{l}\text { Discharge } \\
\left(\mathrm{ft}^{3} / \mathrm{s}\right)\end{array}$ & $\begin{array}{c}\text { Gage } \\
\text { height } \\
\text { (ft) }\end{array}$ \\
\hline 1969 & Apr. 18 & 1,870 & 7.99 & 1976 & Mar. 16 & 548 & 5.94 & 1983 & Dec. 06 & 488 & 5.67 \\
\hline 1970 & Mar. 20 & 1,450 & 7.59 & 1977 & Mar. 22 & 667 & 6.38 & 1984 & Dec. 12 & 234 & 3.98 \\
\hline 1971 & Mar. 03 & 1,320 & 7.44 & 1978 & Jan. 25 & 868 & 6.89 & 1985 & Feb. 06 & 478 & 5.62 \\
\hline 1972 & Mar. 16 & 285 & 4.04 & 1979 & Apr. 04 & 652 & 6.33 & 1986 & Mar. 13 & 1,340 & 7.49 \\
\hline 1973 & Apr. 07 & 742 & 6.61 & 1980 & Mar. 08 & 838 & 6.83 & $\underline{1987}$ & Feb. 28 & 327 & 4.79 \\
\hline 1974 & Apr. 04 & 566 & 5.93 & 1981 & Apr. 01 & 1,960 & 8.07 & $\overline{1990}$ & Mar. 16 & 1,880 & $8.01 \mathrm{c}$ \\
\hline 1975 & Feb. 17 & 847 & 6.94 & 1982 & Feb. 03 & 538 & 5.90 & & & & \\
\hline
\end{tabular}




\section{APALACHICOLA RIVER BASIN}

\section{LAZAR CREEK NEAR TALBOTTON, GEORGIA}

LOCATION.--Lat $32^{\circ} 44^{\prime} 33^{\prime \prime}$, long $84^{\circ} 33^{\prime} 20^{\prime \prime}$, Talbot County, at bridge on State Highway 41,5 mi north of Talbotton. DRAINAGE AREA.--81.3 $\mathrm{mi}^{2}$.

GAGE.--Crest-stage gage. Datum of gage is about $499 \mathrm{ft}$ above sea level (from topographic map).

STAGE-DISCHARGE RELATION.--Defined by current-meter measurements below $1,530 \mathrm{ft}^{3} / \mathrm{s}$, and extended above on the basis of contracted-opening determination at $36,100 \mathrm{ft}^{3} / \mathrm{s}$.

\begin{tabular}{|c|c|c|c|c|c|c|c|c|c|c|c|}
\hline $\begin{array}{l}\text { Water } \\
\text { year }\end{array}$ & Date & $\begin{array}{c}\text { Discharge } \\
\left(\mathrm{ft}^{3} / \mathrm{s}\right)\end{array}$ & $\begin{array}{l}\text { Gage } \\
\text { height } \\
\text { (ft) }\end{array}$ & $\begin{array}{l}\text { Water } \\
\text { year }\end{array}$ & Date & $\begin{array}{c}\text { Discharge } \\
\left(\mathrm{ft}^{3} / \mathrm{s}\right)\end{array}$ & $\begin{array}{c}\text { Gage } \\
\text { height } \\
\text { (ft) }\end{array}$ & $\begin{array}{l}\text { Water } \\
\text { year }\end{array}$ & Date & $\begin{array}{c}\text { Discharge } \\
\left(\mathrm{ft}^{3} / \mathrm{s}\right)\end{array}$ & $\begin{array}{c}\text { Gage } \\
\text { height } \\
\text { (ft) }\end{array}$ \\
\hline 1981 & Apr. 01 & 3,330 & $14.42 \mathrm{c}$ & 1986 & Mar. 13 & 3,750 & 15.50 & 1989 & June 21 & 3,090 & 13.78 \\
\hline$\overline{1984}$ & Dec. 12 & 2,770 & 12.90 & 1987 & Mar. 01 & 2,430 & 11.96 & 1990 & Mar. 17 & 36,100 & 24.10 \\
\hline 1985 & Feb. 06 & 3,540 & 14.96 & 1988 & Apr. -- & 1,570 & $-b$ & & & & \\
\hline
\end{tabular}

\section{KIMBROUGH CREEK NEAR TALBOTTON, GEORGIA}

LOCATION.--Lat $32^{\circ} 41^{\prime} 19^{\prime \prime}$, long $84^{\circ} 30^{\prime} 48^{\prime \prime}$, Talbot County, at culvert on U.S. Highway 80 and State Highway $22,1.8$ mi northeast of Talbotton.

DRAINAGE AREA.--6.62 $\mathrm{mi}^{2}$

GAGE.--Flood-stage, rainfall recorder prior to June 26, 1970; water-stage, rainfall recorder from June 26, 1970 to Sept. 30,1975 , crest-stage gage thereafter. Datum of gage is $561.59 \mathrm{ft}$ above sea level (from U.S. Geological Survey benchmark).

STAGE-DISCHARGE RELATION.--Defined by current-meter measurements below $460 \mathrm{ft}^{3} / \mathrm{s}$, and extended above on the basis of culvert computations.

\begin{tabular}{|c|c|c|c|c|c|c|c|c|c|c|c|}
\hline $\begin{array}{l}\text { Water } \\
\text { year }\end{array}$ & Date & $\begin{array}{c}\text { Discharge } \\
\left(\mathrm{ft}^{3} / \mathrm{s}\right)\end{array}$ & $\begin{array}{c}\text { Gage } \\
\text { height } \\
\text { (ft) }\end{array}$ & $\begin{array}{l}\text { Water } \\
\text { year }\end{array}$ & Date & $\begin{array}{c}\text { Discharge } \\
\left(\mathrm{ft}^{3} / \mathrm{s}\right)\end{array}$ & $\begin{array}{c}\text { Gage } \\
\text { height } \\
\text { (ft) }\end{array}$ & $\begin{array}{l}\text { Water } \\
\text { year }\end{array}$ & Date & $\begin{array}{c}\text { Discharge } \\
\left(\mathrm{ft}^{3} / \mathrm{s}\right)\end{array}$ & $\begin{array}{c}\text { Gage } \\
\text { height } \\
\text { (ft) }\end{array}$ \\
\hline 1969 & Apr. 18 & 1,800 & 6.31 & 1976 & Jan. 28 & 314 & 2.28 & 1983 & Dec. 06 & 670 & 3.67 \\
\hline 1970 & Mar. 19 & 1,320 & 5.19 & 1977 & Aug. 03 & 708 & 3.58 & 1984 & Feb. 14 & 850 & 4.16 \\
\hline 1971 & Mar. 25 & 841 & 3.96 & 1978 & Jan. 25 & 1,120 & 4.70 & 1985 & Feb. 06 & 650 & 3.95 \\
\hline 1972 & Jan. 13 & 279 & 2.14 & 1979 & Feb. 24 & 953 & 4.28 & 1986 & Mar. 13 & 1,250 & 5.54 \\
\hline 1973 & Apr. 07 & 925 & 4.20 & 1980 & Mar. 08 & 1,300 & 5.41 & 1987 & Mar. 01 & 477 & 2.88 \\
\hline 1974 & Apr. 04 & 642 & 3.39 & 1981 & Apr. 01 & 2,000 & 6.66 & 1990 & Mar. 16 & 3,050 & 8.55 \\
\hline 1975 & Feb. 17 & 1,170 & 4.83 & 1982 & Feb. 03 & 900 & 4.35 & & & & \\
\hline
\end{tabular}




\section{APALACHICOLA RIVER BASIN}

02346217 COLEOATCHEE CREEK NEAR MANCHESTER, GEORGIA

(formerly published as "Celeoth Creek near Manchester, Georgia)

LOCATION.--Lat 32 $49^{\prime} 20^{\prime \prime}$, long $84^{\circ} 36^{\prime} 16^{\prime \prime}$, Talbot County, at culvert on county road 39, 1.2 mi south of Manchester (revised). DRAINAGE AREA.-2.82 $\mathrm{mi}^{2}$.

GAGE.--Flood-stage, rainfall recorder prior to Sept. 30,1975 , crest-stage gage thereafter. Datum of gage is about $779 \mathrm{ft}$ above sea level (from topographic map).

STAGE-DISCHARGE RELATION.--Defined by current-meter measurements below $86 \mathrm{ft}^{3} / \mathrm{s}$, and extended above on the basis of culvert computations.

REMARKS.--Record unavailable Oct. 7, 1986 to Oct. 1, 1987, owing to vandalism.

\begin{tabular}{|c|c|c|c|c|c|c|c|c|c|c|c|}
\hline $\begin{array}{l}\text { Water } \\
\text { year }\end{array}$ & Date & $\begin{array}{c}\text { Discharge } \\
\left(\mathrm{ft}^{3} / \mathrm{s}\right)\end{array}$ & $\begin{array}{l}\text { Gage } \\
\text { height } \\
\text { (ft) }\end{array}$ & $\begin{array}{l}\text { Water } \\
\text { year }\end{array}$ & Date & $\begin{array}{c}\text { Discharge } \\
\left(\mathrm{ft}^{3} / \mathrm{s}\right)\end{array}$ & $\begin{array}{c}\text { Gage } \\
\text { height } \\
\text { (ft) }\end{array}$ & $\begin{array}{l}\text { Water } \\
\text { year }\end{array}$ & Date & $\begin{array}{c}\text { Discharge } \\
\left(\mathrm{ft}^{3} / \mathrm{s}\right)\end{array}$ & $\begin{array}{c}\text { Gage } \\
\text { height } \\
\text { (ft) }\end{array}$ \\
\hline 1969 & Mar. 03 & 375 & 2.53 & 1976 & Sept.30 & 702 & 3.75 & 1983 & Apr. 08 & 640 & 3.50 \\
\hline 1970 & Mar. 20 & 96 & 1.40 & 1977 & Aug. 03 & 531 & 3.09 & 1984 & Dec. 12 & 78 & 1.28 \\
\hline 1971 & Aug. 21 & 1,020 & 4.93 & 1978 & Jan. 25 & 433 & 2.74 & 1985 & Feb. 06 & 146 & 1.68 \\
\hline 1972 & Jan. -- & - & $8.0 \mathrm{~b}$ & 1979 & Feb. 24 & 122 & 1.55 & 1986 & June 10 & 170 & 1.80 \\
\hline 1973 & Mar. 31 & 322 & 2.34 & 1980 & Mar. 08 & 705 & 3.76 & $\overline{1988}$ & Mar. - & - & $8.00 \mathrm{~b}$ \\
\hline 1974 & Feb. 14 & 227 & 2.00 & 1981 & Feb. 11 & 266 & 2.14 & 1989 & Mar. - & - & $8.00 \mathrm{~b}$ \\
\hline 1975 & Apr. 02 & 509 & 3.01 & 1982 & Feb. 03 & 238 & 2.04 & 1990 & Mar. 16 & 1,750 & 8.31 \\
\hline
\end{tabular}

\section{POTATO CREEK NEAR THOMASTON, GEORGIA}

LOCATION.--Lat $32^{\circ} 54^{\prime} 15^{\prime \prime}$, long $84^{\circ} 21^{\prime} 45^{\prime \prime}$, Upson County, on right bank $300 \mathrm{ft}$ downstream from State Highway 74, $600 \mathrm{ft}$ downstream from Basin Creek, 1,000 ft downstream from Central of Georgia Railway bridge, 1 mi downstream from Ten Mile Creek, and $2.5 \mathrm{mi}$ northwest of Thomaston.

DRAINAGE AREA.--186 $\mathrm{mi}^{2}$.

GAGE.--Water-stage recorder. Datum of gage is $605.07 \mathrm{ft}$ above sea level (from city of Thomaston benchmark). Prior to July 23 , 1938 , nonrecording gage at highway bridge $300 \mathrm{ft}$ upstream at same datum.

STAGE-DISCHARGE RELATION.--Defined by current-meter measurements below $5,000 \mathrm{ft}^{3} / \mathrm{s}$, and extended above on the basis of straight-line extension. Bankfull stage and discharge, $6 \mathrm{ft}$ and $3,000 \mathrm{ft}^{3} / \mathrm{s}$.

\begin{tabular}{|c|c|c|c|c|c|c|c|c|c|c|c|}
\hline $\begin{array}{l}\text { Water } \\
\text { year }\end{array}$ & Date & $\begin{array}{c}\text { Discharge } \\
\left(\mathrm{ft}^{3} / \mathrm{s}\right)\end{array}$ & $\begin{array}{c}\text { Gage } \\
\text { height } \\
\text { (ft) }\end{array}$ & $\begin{array}{l}\text { Water } \\
\text { year }\end{array}$ & Date & $\begin{array}{c}\text { Discharge } \\
\left(\mathrm{ft}^{3} / \mathrm{s}\right)\end{array}$ & $\begin{array}{l}\text { Gage } \\
\text { height } \\
\text { (ft) }\end{array}$ & $\begin{array}{l}\text { Water } \\
\text { year }\end{array}$ & Date & $\begin{array}{c}\text { Discharge } \\
\left(\mathrm{ft}^{3} / \mathrm{s}\right)\end{array}$ & $\begin{array}{l}\text { Gage } \\
\text { height } \\
\text { (ft) }\end{array}$ \\
\hline 1938 & Apr. 08 & $\underline{4,640}$ & 6.85 & 1951 & Apr. 24 & 997 & 4.51 & 1963 & Jan. 20 & 3,400 & 6.18 \\
\hline 1939 & Feb. 28 & 4,000 & 6.47 & 1952 & Mar. 05 & 5,810 & 7.30 & 1964 & Apr. 08 & 6,400 & 7.39 \\
\hline 1940 & Jan. 14 & 1,750 & 5.19 & 1953 & Apr. 30 & 4,240 & 6.65 & 1965 & Dec. 27 & 2,120 & 5.44 \\
\hline 1941 & July 13 & 1,450 & 4.97 & 1954 & Dec. 06 & 2,300 & 5.59 & 1966 & Feb. 13 & 6,780 & 7.54 \\
\hline 1942 & Mar. 22 & 6,030 & 7.46 & 1955 & Apr. 15 & 1,580 & 4.95 & 1967 & Sept.09 & 6,000 & 7.27 \\
\hline 1943 & Mar. 22 & 4,740 & 6.90 & 1956 & Feb. 28 & 2,590 & 5.72 & 1968 & Mar. 12 & 4,780 & 6.79 \\
\hline 1944 & Mar. 20 & 6,380 & 7.63 & 1957 & Apr. 06 & 3,670 & 6.35 & 1969 & Apr. 20 & 2,920 & 5.88 \\
\hline 1945 & Apr. 26 & 3,140 & 6.03 & 1958 & Nov. 19 & 5,260 & 7.16 & 1970 & Mar. 22 & 5,160 & 6.94 \\
\hline 1946 & Jan. 08 & 3,580 & 6.32 & 1959 & June 02 & 5,480 & 7.25 & 1971 & Mar. 03 & 10,600 & 8.81 \\
\hline 1947 & Mar. 08 & 4,640 & 6.85 & 1960 & Mar. 30 & 2,980 & 5.95 & 1972 & June 29 & 1,820 & 5.14 \\
\hline 1948 & Feb. 09 & 2,400 & 5.62 & 1961 & Feb. 25 & 8,450 & 8.50 & $\underline{1973}$ & Mar. 16 & 2,370 & 5.55 \\
\hline 1949 & Nov. 27 & 9,240 & 8.80 & 1962 & Mar. 12 & 3,760 & 6.40 & $\overline{1990}$ & Mar. 18 & 12,300 & $9.19 \mathrm{c}$ \\
\hline 1950 & Mar. 07 & 1,500 & 4.89 & & & & & & & & \\
\hline
\end{tabular}




\section{APALACHICOLA RIVER BASIN}

\section{FLINT RIVER NEAR CULLODEN, GEORGIA}

LOCATION.-Lat $32^{\circ} 43^{\prime} 17^{\prime \prime}$, long $84^{\circ} 13^{\prime} 57^{\prime \prime}$, Taylor-Upson County line, on left bank underneath bridge on U.S. Highway 19,4 mi upstream from Auchumpkee Creek, 5 mi downstream from Swift Creek, 13 mi southwest of Culloden, and at mile 238.4. DRAINAGE AREA.-1,850 $\mathrm{mi}^{2}$, approximately.

GAGE.-Water-stage recorder. Datum of gage is $334.54 \mathrm{ft}$ above sea level (levels from U.S. Coast and Geodetic benchmark), supplementary adjustment of 1936. July 1,1911 , to Oct. 11,1918 , nonrecording gage and Oct. 12, 1918, to May 31 , 1923, waterstage recorder, at site 2.5 mi downstream at different datum. July 21, 1928, to Dec. 31, 1931, and Mar. 18, 1937, to May 3, 1939, nonrecording gage at present site and datum.

STAGE-DISCHARGE RELATION.--Defined by current-meter measurements below $85,600 \mathrm{ft}^{3} / \mathrm{s}$, and extended above on the basis of straight-line extension. Bankfull stage and discharge, $18 \mathrm{ft}$ and $18,000 \mathrm{ft}^{3} / \mathrm{s}$.

HISTORICAL DATA.--The flood of 1929 is thought to be the highest since 1897 based on records at Flint River at Montezuma (02395000).

\begin{tabular}{|c|c|c|c|c|c|c|c|c|c|c|c|}
\hline $\begin{array}{l}\text { Water } \\
\text { year }\end{array}$ & Date & $\begin{array}{c}\text { Discharge } \\
\left(\mathrm{ft}^{3} / \mathrm{s}\right)\end{array}$ & $\begin{array}{c}\text { Gage } \\
\text { height } \\
\text { (ft) }\end{array}$ & $\begin{array}{l}\text { Water } \\
\text { year }\end{array}$ & Date & $\begin{array}{c}\text { Discharge } \\
\left(\mathrm{ft}^{3} / \mathrm{s}\right)\end{array}$ & $\begin{array}{c}\text { Gage } \\
\text { height } \\
\text { (ft) }\end{array}$ & $\begin{array}{l}\text { Water } \\
\text { year }\end{array}$ & Date & $\begin{array}{c}\text { Discharge } \\
\left(\mathrm{ft}^{3} / \mathrm{s}\right)\end{array}$ & $\begin{array}{c}\text { Gage } \\
\text { height } \\
\text { (ft) }\end{array}$ \\
\hline 1913 & Mar. 16 & 59,000 & 30.50 & 1946 & Jan. 08 & 27,000 & 23.40 & 1969 & Apr. 18 & 27,200 & 22.88 \\
\hline 1914 & Apr. 15 & 7,290 & 7.30 & 1947 & Mar. 08 & 28,400 & 24.10 & 1970 & Mar. 22 & 30,900 & 24.53 \\
\hline 1915 & Jan. 18 & 13,900 & 12.00 & 1948 & July 12 & 27,800 & 23.80 & 1971 & Mar. 03 & 64,600 & 34.39 \\
\hline 1916 & July 09 & 69,200 & 33.30 & 1949 & Nov. 28 & 54,900 & 34.70 & 1972 & Jan. 14 & 24,200 & 21.42 \\
\hline 1917 & Mar. 05 & 30,200 & 20.70 & 1950 & Mar. 05 & 11,000 & 13.80 & 1973 & Apr. 08 & 22,900 & 20.72 \\
\hline 1918 & Jan. 31 & 11,000 & 10.10 & 1951 & Apr. 23 & 8,940 & 12.00 & 1974 & Feb. 16 & 23,200 & 20.88 \\
\hline 1919 & Feb. 25 & 45,500 & 26.50 & 1952 & Mar. 04 & 37,700 & 28.20 & 1975 & Apr. 04 & 35,500 & 26.18 \\
\hline 1920 & Dec. 11 & 49,100 & 27.60 & 1953 & May 01 & 35,800 & 27.60 & 1976 & Mar. 18 & 23,100 & 20.86 \\
\hline 1921 & Feb. 11 & 27,200 & 19.30 & 1954 & Dec. 06 & 18,300 & 18.80 & 1977 & Mar. 22 & 21,700 & 20.09 \\
\hline 1922 & Mar. 11 & 47,800 & 27.20 & 1955 & Apr. 14 & 11,400 & 14.10 & 1978 & Jan. 26 & 38,800 & 27.25 \\
\hline 1923 & Mar. 19 & 29,100 & 20.20 & 1956 & Mar. 17 & 16,000 & 17.40 & 1979 & Feb. 24 & 31,100 & 24.62 \\
\hline$\overline{1929}$ & $\overline{\text { Mar. } 15}$ & $\overline{92,000}$ & $\overline{38.40}$ & 1957 & Apr. 06 & 26,000 & 22.90 & 1980 & Mar. 09 & 33,800 & 25.65 \\
\hline 1930 & Oct. 02 & 38,900 & 25.20 & 1958 & Nov. 19 & 21,100 & 20.40 & 1981 & Feb. 11 & 36,000 & 26.33 \\
\hline 1931 & Nov. 17 & 18,700 & 17.90 & 1959 & June 02 & 34,400 & 26.80 & 1982 & Feb. 03 & 22,300 & 20.41 \\
\hline$\overline{1937}$ & Mar. 20 & 22,200 & 19.10 & 1960 & Mar. 30 & 22,200 & 21.00 & 1983 & Apr. 10 & 31,000 & 24.60 \\
\hline 1938 & Apr. 09 & 37,500 & 26.60 & 1961 & Feb. 25 & 58,200 & 32.80 & 1984 & Dec. 05 & 14,300 & 15.54 \\
\hline 1939 & Mar. 01 & 29,200 & 23.50 & 1962 & Feb. 22 & 25,100 & 22.43 & 1985 & Feb. 06 & 24,400 & 21.51 \\
\hline 1940 & Feb. 19 & 12,300 & 15.00 & 1963 & Jan. 21 & 26,700 & 23.08 & 1986 & Mar. 19 & 16,500 & 17.02 \\
\hline 1941 & Dec. 28 & 4,940 & 8.40 & 1964 & Apr. 08 & 64,400 & 34.36 & 1987 & Mar. 01 & 21,700 & 20.09 \\
\hline 1942 & Mar. 22 & 37,200 & 27.80 & 1965 & Dec. 25 & 39,400 & 27.47 & 1988 & Jan. 20 & 11,300 & 13.32 \\
\hline 1943 & Jan. 19 & 36,000 & 29.60 & 1966 & Feb. 14 & 42,400 & 28.45 & 1989 & July 04 & 12,900 & 14.53 \\
\hline 1944 & Mar. 20 & 49,800 & 31.30 & 1967 & Dec. 29 & 12,700 & 14.21 & 1990 & Mar. 17 & 80,000 & 38.00 \\
\hline 1945 & Apr. 27 & 23,800 & 21.80 & 1968 & Mar. 13 & 33,600 & 25.52 & & & & \\
\hline
\end{tabular}




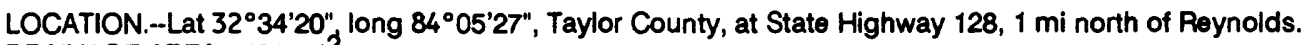

DRAINAGE AREA. $-139 \mathrm{mi}^{2}$.

GAGE.-Crest-stage gage. Datum of gage is about $313 \mathrm{ft}$ above sea level (from topographic map).

STAGE-DISCHARGE RELATION.--Defined by current-meter measurements below $3,320 \mathrm{ft}^{3} / \mathrm{s}$. Bankfull stage and discharge, $7 \mathrm{ft}$ and $750 \mathrm{tt}^{3} / \mathrm{s}$.

\begin{tabular}{|c|c|c|c|c|c|c|c|c|c|c|c|}
\hline $\begin{array}{l}\text { Water } \\
\text { year }\end{array}$ & Date & $\begin{array}{c}\text { Discharge } \\
\left(\mathrm{ft}^{3} / \mathrm{s}\right)\end{array}$ & $\begin{array}{c}\text { Gage } \\
\text { height } \\
\text { (ft) }\end{array}$ & $\begin{array}{l}\text { Water } \\
\text { year }\end{array}$ & Date & $\begin{array}{c}\text { Discharge } \\
\left(\mathrm{ft}^{3} / \mathrm{s}\right)\end{array}$ & $\begin{array}{c}\text { Gage } \\
\text { height } \\
\text { (ft) }\end{array}$ & $\begin{array}{l}\text { Water } \\
\text { year }\end{array}$ & Date & $\begin{array}{c}\text { Discharge } \\
\left(\mathrm{ft}^{3} / \mathrm{s}\right)\end{array}$ & $\begin{array}{c}\text { Gage } \\
\text { height } \\
\text { (ft) }\end{array}$ \\
\hline 1963 & Jan. 21 & 1,590 & 7.87 & 1971 & Mar. 03 & 2,100 & 7.94 & 1978 & Jan. 26 & 2,000 & 7.87 \\
\hline 1964 & Apr. 09 & 3,320 & 9.09 & 1972 & Jan. 14 & 648 & 6.37 & 1979 & June 01 & 2,800 & 8.37 \\
\hline 1965 & Dec. 26 & 1,590 & 7.87 & 1973 & Apr. 07 & 1,270 & 7.27 & 1980 & Mar. 14 & 1,170 & 7.16 \\
\hline 1966 & Mar. 04 & 3,200 & 8.55 & 1974 & Apr. 05 & 984 & 6.93 & 1981 & Apr. 02 & 2,800 & 8.37 \\
\hline 1967 & Feb. 07 & 920 & 6.85 & 1975 & Feb. 18 & 1,610 & 7.59 & 1982 & Jan. 01 & 2,840 & 8.39 \\
\hline 1968 & Dec. 29 & 377 & 5.59 & 1976 & July 01 & 1,400 & 7.40 & 1983 & Mar. 08 & 984 & 6.93 \\
\hline 1969 & Apr. 19 & 760 & 6.58 & 1977 & Apr. 01 & 850 & 6.75 & 1984 & Mar. 07 & 888 & 6.81 \\
\hline 1970 & Mar. 30 & 1,620 & 7.56 & & & & & & & & \\
\hline
\end{tabular}

\section{WHITEWATER CREEK NEAR BUTLER, GEORGIA}

LOCATION.--Lat $32^{\circ} 30^{\prime} 14^{\prime \prime}$, long $84^{\circ} 20^{\prime} 03^{\prime \prime}$, Taylor County, at bridge on State Highway 137, 6.5 mi southwest of Butler. DRAINAGE AREA, $-17.3 \mathrm{mi}^{2}$.

GAGE.--Crest-stage gage. Datum of gage is about $403 \mathrm{ft}$ above sea level (from topographic map).

STAGE-DISCHARGE RELATION.--Defined by current-meter measurements below $243 \mathrm{ft}^{3} / \mathrm{s}$, and extended above on the basis of straight-line extension.

\begin{tabular}{|c|c|c|c|c|c|c|c|c|c|c|c|}
\hline $\begin{array}{l}\text { Water } \\
\text { year }\end{array}$ & Date & $\begin{array}{c}\text { Discharge } \\
\left(\mathrm{ft}^{3} / \mathrm{s}\right)\end{array}$ & $\begin{array}{c}\text { Gage } \\
\text { height } \\
\text { (ft) }\end{array}$ & $\begin{array}{l}\text { Water } \\
\text { year }\end{array}$ & Date & $\begin{array}{c}\text { Discharge } \\
\left(\mathrm{ft}^{3} / \mathrm{s}\right)\end{array}$ & $\begin{array}{c}\text { Gage } \\
\text { height } \\
\text { (ft) }\end{array}$ & $\begin{array}{l}\text { Water } \\
\text { year }\end{array}$ & Date & $\begin{array}{c}\text { Discharge } \\
\left(\mathrm{ft}^{3} / \mathrm{s}\right)\end{array}$ & $\begin{array}{c}\text { Gage } \\
\text { height } \\
\text { (ft) }\end{array}$ \\
\hline 1979 & Feb. 24 & 111 & 7.02 & 1983 & Mar. 06 & 138 & 7.46 & 1987 & Nov. 30 & 122 & 7.21 \\
\hline 1980 & Mar. 13 & 141 & 7.51 & 1984 & Mar. 06 & 106 & 6.94 & 1988 & Jan. 19 & 64 & 5.97 \\
\hline 1981 & Apr. 01 & 248 & 8.74 & 1985 & May. 08 & $7,4.0$ & 6.25 & 1989 & July 20 & 60 & 5.86 \\
\hline 1982 & Apr. 06 & 141 & 7.51 & 1986 & Dec. 13 & $9,3.0$ & 6.68 & 1990 & Mar. 17 & 244 & 8.72 \\
\hline
\end{tabular}




\section{APALACHICOLA RIVER BASIN}

02349000 WHITEWATER CREEK BELOW RAMBULETTE CREEK, NEAR BUTLER, GEORGIA

LOCATION.--Lat $32^{\circ} 28^{\prime} 00^{\prime \prime}$, long $84^{\circ} 15^{\prime} 58^{\prime \prime}$, Taylor County, on left bank $500 \mathrm{ft}$ downstream from bridge on U.S. Highway 19 , at mouth of Rambulette Creek, and $6.5 \mathrm{mi}$ south of Butler.

DRAINAGE AREA.--93.4 $\mathrm{mi}^{2}$. At former site, $80 \mathrm{mi}^{2}$.

GAGE.--Nonrecording prior to Oct. 10, 1951 at different datum of former site, $500 \mathrm{ft}$ upstream; water-stage recorder, Oct. 10,1951 to Sept. 30, 1971; crest-stage gage thereafter. Datum of gage is $365.85 \mathrm{ft}$ above sea level (levels from U.S. Coast and Geodetic benchmark), supplementary adjustment of 1936.

STAGE-DISCHARGE RELATION.--Defined by current-meter measurements below $1,300 \mathrm{ft}^{3} / \mathrm{s}$, and extended above on the basis of straight-line extension. Peak discharge at former site adjusted to present site on basis of high-water discharge measurements made since 1952. Bankfull stage and discharge, $3 \mathrm{ft}$ and $300 \mathrm{ft}^{3} / \mathrm{s}$.

\begin{tabular}{|c|c|c|c|c|c|c|c|c|c|c|c|}
\hline $\begin{array}{l}\text { Water } \\
\text { year }\end{array}$ & Date & $\begin{array}{c}\text { Discharge } \\
\left(\mathrm{ft}^{3} / \mathrm{s}\right)\end{array}$ & $\begin{array}{c}\text { Gage } \\
\text { height } \\
\text { (ft) }\end{array}$ & $\begin{array}{l}\text { Water } \\
\text { year }\end{array}$ & Date & $\begin{array}{c}\text { Discharge } \\
\left(\mathrm{ft}^{3} / \mathrm{s}\right)\end{array}$ & $\begin{array}{c}\text { Gage } \\
\text { height } \\
\text { (ft) }\end{array}$ & $\begin{array}{l}\text { Water } \\
\text { year }\end{array}$ & Date & $\begin{array}{c}\text { Discharge } \\
\left(\mathrm{ft}^{3} / \mathrm{s}\right)\end{array}$ & $\begin{array}{c}\text { Gage } \\
\text { height } \\
\text { (ft) }\end{array}$ \\
\hline 1944 & Mar. 23 & 1,400 & 6.50 & 1956 & Sept.26 & 440 & 3.82 & 1968 & Nov. 02 & 268 & 2.73 \\
\hline 1945 & Feb. 21 & 350 & 3.80 & 1957 & May. 04 & 2,160 & 7.01 & 1969 & May. 19 & 245 & 2.52 \\
\hline 1946 & Dec. 25 & 460 & 4.30 & 1958 & Mar. 08 & 668 & 4.55 & 1970 & Mar. 31 & 328 & 3.19 \\
\hline 1947 & May. 21 & 400 & 4.00 & 1959 & June 02 & 580 & 4.32 & 1971 & Dec. 17 & 403 & 3.64 \\
\hline 1948 & July 10 & 545 & 4.60 & 1960 & Mar. 30 & 615 & 4.38 & 1972 & June 29 & 368 & 3.45 \\
\hline 1949 & Nov. 29 & 610 & 4.80 & 1961 & Feb. 20 & 452 & 3.84 & 1973 & Dec. 06 & 588 & 4.39 \\
\hline 1950 & June 29 & 325 & 3.50 & 1962 & Mar. 12 & 478 & 3.94 & 1974 & Apr. 05 & 316 & 3.11 \\
\hline$\underline{1951}$ & Dec. 30 & $\underline{300}$ & $\underline{3.30}$ & 1963 & Jan. 21 & 668 & 4.54 & 1975 & Apr. 15 & 884 & 5.24 \\
\hline$\overline{1952}$ & Mar. 24 & 503 & 4.06 & 1964 & Apr. 09 & 895 & 5.08 & 1976 & June 04 & 898 & 5.27 \\
\hline 1953 & May. 01 & 1,120 & 5.54 & 1965 & Oct. 05 & 765 & 4.80 & $\underline{1977}$ & Apr. 01 & 485 & 3.98 \\
\hline 1954 & Dec. 04 & 632 & 4.43 & 1966 & Mar. 04 & 1,230 & 5.87 & 1981 & Apr. 01 & 846 & $5.14 \mathrm{c}$ \\
\hline 1955 & Apr. 14 & 452 & 3.87 & 1967 & June 05 & 399 & 3.62 & & & & \\
\hline
\end{tabular}

\section{CEDAR CREEK NEAR RUPERT, GEORGIA}

LOCATION.--Lat $32^{\circ} 23^{\prime} 21^{\prime \prime}$, long $8^{\circ} 17^{\prime} 49^{\prime \prime}$, Taylor County, at bridge on State Highway 19,3 mi south of Rupert.

DRAINAGE AREA. $-41.1 \mathrm{mi}^{2}$.

GAGE.--Crest-stage gage. Datum of gage is about $390 \mathrm{ft}$ above sea level (from topographic map).

STAGE-DISCHARGE RELATION.--Defined by current-meter measurements below $418 \mathrm{tt}^{3} / \mathrm{s}$, and extended above on the basis of straight-line extension.

\begin{tabular}{|c|c|c|c|c|c|c|c|c|c|c|c|}
\hline $\begin{array}{l}\text { Water } \\
\text { year }\end{array}$ & Date & $\begin{array}{c}\text { Discharge } \\
\left(\mathrm{ft}^{3} / \mathrm{s}\right)\end{array}$ & $\begin{array}{l}\text { Gage } \\
\text { height } \\
\text { (ft) }\end{array}$ & $\begin{array}{l}\text { Water } \\
\text { year }\end{array}$ & Date & $\begin{array}{c}\text { Discharge } \\
\left(\mathrm{ft}^{3} / \mathrm{s}\right)\end{array}$ & $\begin{array}{c}\text { Gage } \\
\text { height } \\
\text { (ft) }\end{array}$ & $\begin{array}{l}\text { Water } \\
\text { year }\end{array}$ & Date & $\begin{array}{c}\text { Discharge } \\
\left(\mathrm{ft}^{3} / \mathrm{s}\right)\end{array}$ & $\begin{array}{c}\text { Gage } \\
\text { height } \\
\text { (ft) }\end{array}$ \\
\hline 1979 & Feb. 24 & 580 & 4.72 & 1983 & Mar. 06 & 464 & 4.27 & 1987 & Nov. 30 & 209 & 2.86 \\
\hline 1980 & Mar. 13 & 290 & 3.40 & 1984 & Feb. 12 & 194 & 2.76 & 1988 & Jan. 20 & 116 & 2.30 \\
\hline 1981 & Apr. 01 & 432 & 4.11 & 1985 & May. 08 & 210 & 2.87 & 1989 & Apr. 06 & 117 & 2.31 \\
\hline 1982 & Feb. 04 & 290 & 3.40 & 1986 & Nov. 22 & 140 & 2.39 & 1990 & Oct. 01 & 496 & 4.40 \\
\hline
\end{tabular}


LOCATION.--Lat $32^{\circ} 20^{\prime} 49^{\prime \prime}$, long $84^{\circ} 22^{\prime} 26^{\prime \prime}$, Schley County, at culvert on State Highway $240,4.3$ mi west of Tazewell. DRAINAGE AREA.--0.4 $\mathrm{mi}^{2}$, approximately.

GAGE.--Crest-stage gage. Datum of gage is about $495 \mathrm{ft}$ above sea level (from topographic map).

STAGE-DISCHARGE RELATION.--Defined by culvert computations.

\begin{tabular}{|c|c|c|c|c|c|c|c|c|c|c|c|}
\hline $\begin{array}{l}\text { Water } \\
\text { year }\end{array}$ & Date & $\begin{array}{c}\text { Discharge } \\
\left(\mathrm{ft}^{3} / \mathrm{s}\right)\end{array}$ & $\begin{array}{c}\text { Gage } \\
\text { height } \\
\text { (ft) }\end{array}$ & $\begin{array}{l}\text { Water } \\
\text { year }\end{array}$ & Date & $\begin{array}{c}\text { Discharge } \\
\left(\mathrm{ft}^{3} / \mathrm{s}\right)\end{array}$ & $\begin{array}{c}\text { Gage } \\
\text { height } \\
\text { (ft) }\end{array}$ & $\begin{array}{l}\text { Water } \\
\text { year }\end{array}$ & Date & $\begin{array}{c}\text { Discharge } \\
\left(\mathrm{ft}^{3} / \mathrm{s}\right)\end{array}$ & $\begin{array}{c}\text { Gage } \\
\text { height } \\
\text { (ft) }\end{array}$ \\
\hline 1977 & Aug. 19 & 28.0 & 2.28 & 1982 & July 09 & 27.0 & 2.23 & 1987 & Nov. 30 & 44 & 2.80 \\
\hline 1978 & Aug. 12 & 53.0 & 3.09 & 1983 & Mar. 06 & 84.0 & 3.90 & 1988 & Feb. 04 & 25 & 2.12 \\
\hline 1979 & Mar. 25 & 78.0 & 3.75 & 1984 & Feb. 12 & 22.0 & 2.05 & 1989 & June 20 & 24 & 2.22 \\
\hline 1980 & Mar. 13 & 15.0 & 1.70 & 1985 & Aug. 29 & 44.0 & 2.80 & 1990 & Oct. 01 & 103 & 4.37 \\
\hline 1981 & Apr. 01 & 56.0 & 3.20 & 1986 & Aug. 12 & 29.0 & 2.31 & & & & \\
\hline
\end{tabular}

\section{BUCK CREEK NEAR ELLAVILLE, GEORGIA}

LOCATION.--Lat $32^{\circ} 18^{\prime} 35^{\prime \prime}$, long $84^{\circ} 17^{\prime} 36^{\prime \prime}$, Schley County, at bridge on U.S. Highway 19,5 mi north of Ellaville.

DRAINAGE AREA.--146 $\mathrm{mi}^{2}$, approximately.

GAGE.--Crest-stage gage. Datum of gage is about $350 \mathrm{ft}$ above sea level (from topographic map).

STAGE-DISCHARGE RELATION.--Defined by current-meter measurements below $3,200 \mathrm{ft}^{3} / \mathrm{s}$, and extended above on the basis of straight-line extension.

\begin{tabular}{|c|c|c|c|c|c|c|c|c|c|c|c|}
\hline $\begin{array}{l}\text { Water } \\
\text { year }\end{array}$ & Date & $\begin{array}{c}\text { Discharge } \\
\left(\mathrm{ft}^{3} / \mathrm{s}\right)\end{array}$ & $\begin{array}{c}\text { Gage } \\
\text { height } \\
\text { (ft) }\end{array}$ & $\begin{array}{l}\text { Water } \\
\text { year }\end{array}$ & Date & $\begin{array}{c}\text { Discharge } \\
\left(\mathrm{ft}^{3} / \mathrm{s}\right)\end{array}$ & $\begin{array}{c}\text { Gage } \\
\text { height } \\
\text { (ft) }\end{array}$ & $\begin{array}{l}\text { Water } \\
\text { year }\end{array}$ & Date & $\begin{array}{c}\text { Discharge } \\
\left(\mathrm{ft}^{3} / \mathrm{s}\right)\end{array}$ & $\begin{array}{c}\text { Gage } \\
\text { height } \\
\text { (ft) }\end{array}$ \\
\hline 1979 & Feb. 25 & 1,490 & 7.83 & 1983 & Mar. 06 & 2,050 & 8.52 & 1987 & Mar. 01 & 565 & 6.53 \\
\hline 1980 & Apr. 14 & 1,300 & 7.59 & 1984 & Mar. 06 & 635 & 6.67 & 1988 & Apr. 17 & 146 & 4.13 \\
\hline 1981 & Apr. 02 & 1,900 & 8.34 & 1985 & Feb. 07 & 640 & 6.68 & 1989 & July 20 & 197 & 4.64 \\
\hline 1982 & Feb. 06 & 1,280 & 7.57 & 1986 & Nov. 22 & 316 & 5.47 & 1990 & Mar. 17 & 3,730 & 9.67 \\
\hline
\end{tabular}


LOCATION.--Lat 32 $17^{\prime} 53^{\prime \prime}$, long $84^{\circ} 02^{\prime} 38^{\prime \prime}$, Macon County, near left bank on downstream end of pier of bridge on State Highways 26 and 49, 1,000 ft upstream from Central of Georgia Railway bridge, 1,400 ft upstream from Seaboard Coast Line Railroad bridge, just upstream from Buck Creek, 1 mi west of Montezuma, and at mile 180.6.

DRAINAGE AREA.-2,900 $\mathrm{mi}^{2}$, approximately. At site used prior to October $1925,2,640 \mathrm{mi}^{2}$, approximately includes that of Buck Creek.

GAGE.--Nonrecording prior to Dec. 13, 1941; water-stage recorder thereafter. Prior to October 1925, at site 1.5 mi upstream at same datum. From Dec. 13, 1941 to Oct. 25, 1955, at site $500 \mathrm{ft}$ downstream at same datum. Datum of gage is $255.83 \mathrm{ft}$ above sea level (from U.S. Coast and Geodetic benchmark).

STAGE-DISCHARGE RELATION.--Defined by current-meter measurements below $65,000 \mathrm{tt}^{3} / \mathrm{s}$, and extended above on the basis of straight-line extension. Bankfull stage and discharge, $15 \mathrm{ft}$ and $15,000 \mathrm{ft}^{3} / \mathrm{s}$.

HISTORICAL DATA.-Flood peak of 1897 probably highest since then, based on record at nearby gaging stations. REMARKS.-Stage records for 1897 and 1905-29 furnished by the National Weather Service.

\begin{tabular}{|c|c|c|c|c|c|c|c|c|c|c|c|}
\hline $\begin{array}{l}\text { Water } \\
\text { year }\end{array}$ & Date & $\begin{array}{c}\text { Discharge } \\
\left(\mathrm{ft}^{3} / \mathrm{s}\right)\end{array}$ & $\begin{array}{c}\text { Gage } \\
\text { height } \\
\text { (ft) }\end{array}$ & $\begin{array}{l}\text { Water } \\
\text { year }\end{array}$ & Date & $\begin{array}{c}\text { Discharge } \\
\left(\mathrm{ft}^{3} / \mathrm{s}\right)\end{array}$ & $\begin{array}{c}\text { Gage } \\
\text { height } \\
\text { (ft) }\end{array}$ & $\begin{array}{l}\text { Water } \\
\text { year }\end{array}$ & Date & $\begin{array}{l}\text { Discharge } \\
\left(\mathrm{ft}^{3} / \mathrm{s}\right)\end{array}$ & $\begin{array}{c}\text { Gage } \\
\text { height } \\
\text { (ft) }\end{array}$ \\
\hline$\underline{1897}$ & Mar. 02 & 97,000 & $26.00 c$ & 1933 & Feb. 23 & 19,000 & 16.68 & 1962 & Mar. 15 & 26,000 & 18.70 \\
\hline 1905 & Feb. 15 & 24,500 & 17.30 & 1934 & June 08 & 22,100 & 17.70 & 1963 & $\operatorname{Jan} .23$ & 30,900 & 19.70 \\
\hline 1906 & Jan. 26 & 15,800 & 15.00 & 1935 & Mar. 17 & 12,400 & 13.90 & 1964 & Apr. 10 & 67,100 & 25.00 \\
\hline 1907 & Feb. 08 & 11,000 & 13.00 & 1936 & Apr. 12 & 54,600 & 22.85 & 1965 & Dec. 29 & 36,900 & 20.80 \\
\hline 1908 & Apr. 29 & 66,000 & 23.20 & 1937 & Mar. 23 & 20,900 & 17.34 & 1966 & Feb. 16 & 42,000 & 21.65 \\
\hline 1909 & Mar. 16 & 31,800 & 18.70 & 1938 & Apr. 11 & 42,300 & 21.00 & 1967 & Jan. 04 & 14,300 & 14.76 \\
\hline 1910 & Mar. 04 & 18,400 & 15.80 & 1939 & Mar. 03 & 34,800 & 19.75 & 1968 & Mar. 16 & 25,500 & 18.57 \\
\hline 1911 & Aug. 06 & 6,080 & 9.30 & 1940 & Feb. 22 & 16,000 & 15.50 & 1969 & Apr. 22 & 21,800 & 17.61 \\
\hline 1912 & Mar. 18 & 43,700 & 20.60 & 1941 & Mar. 11 & 6,280 & 9.30 & 1970 & Mar. 24 & 34,200 & 20.35 \\
\hline 1913 & Mar. 18 & 57,400 & 22.30 & 1942 & Mar. 25 & 40,800 & 21.30 & 1971 & Mar. 06 & 58,200 & 24.73 \\
\hline 1914 & Apr. 18 & 5,500 & 9.00 & 1943 & Mar. 24 & 48,900 & 22.50 & 1972 & Jan. 16 & 25,900 & 18.68 \\
\hline 1915 & Jan. 21 & 15,800 & 15.00 & 1944 & Mar. 25 & 48,200 & 22.40 & 1973 & Apr. 11 & 23,800 & 18.16 \\
\hline 1916 & July 12 & 54,500 & 22.00 & 1945 & Apr. 30 & 23,900 & 18.10 & 1974 & Feb. 19 & 20,800 & 17.25 \\
\hline 1917 & Mar. 07 & 29,100 & 18.20 & 1946 & Jan. 11 & 27,000 & 18.80 & 1975 & Apr. 06 & 32,700 & 20.06 \\
\hline 1918 & Feb. 04 & 11,600 & 13.30 & 1947 & Mar. 11 & 29,000 & 19.20 & 1976 & Mar. 21 & 22,800 & 17.90 \\
\hline 1919 & Feb. 28 & 45,100 & 20.80 & 1948 & Feb. 13 & 20,900 & 17.30 & 1977 & Mar. 25 & 21,200 & 17.39 \\
\hline 1920 & Dec. 13 & 56,400 & 22.20 & 1949 & Nov. 30 & 68,900 & 25.20 & 1978 & Jan. 29 & 38,500 & 21.56 \\
\hline 1921 & Feb. 14 & 28,000 & 18.00 & 1950 & Mar. 10 & 12,300 & 13.80 & 1979 & Feb. 27 & 36,400 & 20.72 \\
\hline 1922 & Mar. 10 & 48,100 & 21.20 & 1951 & Apr. 27 & 8,700 & 11.60 & 1980 & Mar. 12 & 29,300 & 19.38 \\
\hline 1923 & Mar. 22 & 28,600 & 18.10 & 1952 & Mar. 07 & 36,300 & 20.70 & 1981 & Feb. 14 & 36,000 & 19.94 \\
\hline 1924 & Jan. 28 & 16,400 & 15.20 & 1953 & May 04 & 34,500 & 20.40 & 1982 & Feb. 07 & 24,600 & 17.63 \\
\hline 1925 & Jan. 20 & $\underline{85,000}$ & 25.00 & 1954 & Dec. 09 & 21,200 & 17.40 & 1983 & Apr. 12 & 32,800 & 19.36 \\
\hline 1926 & Apr. 03 & 22,800 & 17.90 & 1955 & Apr. 18 & 13,500 & 14.40 & 1984 & Dec. 09 & 14,900 & 14.44 \\
\hline 1927 & Mar. 15 & 7,890 & 10.90 & 1956 & Mar. 21 & 17,500 & 16.10 & 1985 & Feb. 09 & 23,900 & 17.69 \\
\hline 1928 & Apr. 26 & 39,900 & 21.30 & 1957 & Apr. 09 & 26,000 & 18.70 & 1986 & Mar. 23 & 14,200 & 14.13 \\
\hline 1929 & Mar. 17 & 92,300 & 27.40 & 1958 & Mar. 11 & 21,800 & 17.60 & 1987 & Mar. 04 & 25,000 & 17.76 \\
\hline 1930 & Oct. 04 & 33,900 & 20.30 & 1959 & June 05 & 28,900 & 19.30 & 1988 & Jan. 25 & 9,400 & 11.53 \\
\hline 1931 & Nov. 20 & 23,100 & 17.80 & 1960 & Apr. 07 & 25,200 & 18.50 & 1989 & Apr. 13 & 14,100 & 14.11 \\
\hline 1932 & Jan. 11 & 12,600 & 14.10 & 1961 & Feb. 28 & 58,800 & 24.00 & 1990 & Mar. 20 & 64,900 & 26.05 \\
\hline
\end{tabular}


LOCATION.--Lat $32^{\circ} 21^{\prime} 18^{\prime \prime}$, long $83^{\circ} 56^{\prime} 12^{\prime \prime}$, Macon County, at culvert on State Highway 224, 8.7 mi northeast of Montezuma. DRAINAGE AREA.- $0.72 \mathrm{mi}^{2}$, approximately.

GAGE.-Crest-stage gage. Datum of gage is about $315 \mathrm{ft}$ above sea level (from topographic map).

STAGE-DISCHARGE RELATION.-Defined by culvert computations.

\begin{tabular}{|c|c|c|c|c|c|c|c|c|c|c|c|}
\hline $\begin{array}{l}\text { Water } \\
\text { year }\end{array}$ & Date & $\begin{array}{c}\text { Discharge } \\
\left(\mathrm{ft}^{3} / \mathrm{s}\right)\end{array}$ & $\begin{array}{c}\text { Gage } \\
\text { height } \\
\text { (ft) }\end{array}$ & $\begin{array}{l}\text { Water } \\
\text { year }\end{array}$ & Date & $\begin{array}{c}\text { Discharge } \\
\left(\mathrm{ft}^{3} / \mathrm{s}\right)\end{array}$ & $\begin{array}{c}\text { Gage } \\
\text { height } \\
\text { (ft) }\end{array}$ & $\begin{array}{l}\text { Water } \\
\text { year }\end{array}$ & Date & $\begin{array}{c}\text { Discharge } \\
\left(\mathrm{ft}^{3} / \mathrm{s}\right)\end{array}$ & $\begin{array}{c}\text { Gage } \\
\text { height } \\
\text { (ft) }\end{array}$ \\
\hline 1977 & Aug. 05 & 146 & 5.60 & 1982 & Apr. 06 & 18 & 1.58 & 1987 & June 17 & 32 & 2.21 \\
\hline 1978 & Jan. 26 & 55 & 2.98 & 1983 & Mar. 06 & 82 & 3.86 & 1988 & Apr. 16 & 115 & 4.88 \\
\hline 1979 & June 08 & 158 & 5.89 & 1984 & Aug. 19 & 144 & 5.55 & 1989 & July 20 & 35 & 2.38 \\
\hline 1980 & Apr. 14 & 83 & 3.90 & 1985 & May 08 & 85 & 3.97 & 1990 & July 21 & 167 & 6.17 \\
\hline 1981 & Apr. 01 & 83 & 3.90 & 1986 & Aug. 20 & 144 & 5.54 & & & & \\
\hline
\end{tabular}

\section{TURKEY CREEK AT BYROMVILLE, GEORGIA}

LOCATION.--Lat $32^{\circ} 11^{\prime} 44^{\prime \prime}$, long $83^{\circ} 54^{\prime} 03^{\prime \prime}$, Dooly County, on downstream side of bridge on State Highway $90,0.5$ mi southwest of Byromville, and 11 mi upstream from mouth.

DRAINAGE AREA.--45 $\mathrm{mi}^{2}$, approximately.

GAGE.-Water-stage recorder. Prior to June 19, 1958, crest-stage gage at site $50 \mathrm{ft}$ upstream at same datum. Datum of gage is about $286 \mathrm{ft}$ above sea level (from topographic map).

STAGE-DISCHARGE RELATION.--Defined by current-meter measurements below $4,600 \mathrm{ft}^{3} / \mathrm{s}$, and extended above on the basis of straight-line extension. Bankfull stage and discharge, $10 \mathrm{ft}$ and $550 \mathrm{ft}^{3} / \mathrm{s}$.

\begin{tabular}{|c|c|c|c|c|c|c|c|c|c|c|c|}
\hline $\begin{array}{l}\text { Water } \\
\text { year }\end{array}$ & Date & $\begin{array}{c}\text { Discharge } \\
\left(\mathrm{ft}^{3} / \mathrm{s}\right)\end{array}$ & $\begin{array}{c}\text { Gage } \\
\text { height } \\
\text { (ft) }\end{array}$ & $\begin{array}{l}\text { Water } \\
\text { year }\end{array}$ & Date & $\begin{array}{c}\text { Discharge } \\
\left(\mathrm{ft}^{3} / \mathrm{s}\right)\end{array}$ & $\begin{array}{c}\text { Gage } \\
\text { height } \\
\text { (ft) }\end{array}$ & $\begin{array}{l}\text { Water } \\
\text { year }\end{array}$ & Date & $\begin{array}{c}\text { Discharge } \\
\left(\mathrm{ft}^{3} / \mathrm{s}\right)\end{array}$ & $\begin{array}{c}\text { Gage } \\
\text { height } \\
\text { (ft) }\end{array}$ \\
\hline 1951 & Mar. 20 & 150 & $--b$ & 1965 & Dec. 26 & 2,020 & 11.41 & 1978 & Jan. 25 & 2,260 & 12.13 \\
\hline 1952 & Mar. 12 & 474 & 9.79 & 1966 & Mar. 04 & 3,220 & 12.26 & 1979 & Feb. 24 & 2,040 & 11.94 \\
\hline 1953 & May 03 & 560 & 10.03 & 1967 & Jan. 02 & 428 & 9.74 & 1980 & Mar. 13 & 938 & 10.68 \\
\hline 1954 & Dec. 14 & 610 & 10.12 & 1968 & Jan. 11 & $5,8.0$ & 7.40 & 1981 & Apr. 01 & $.4,820$ & 13.82 \\
\hline 1955 & Apr. 12 & 150 & 8.65 & 1969 & May 27 & 1,100 & 10.78 & 1982 & Feb. 17 & 748 & 10.49 \\
\hline 1956 & Mar. 20 & 184 & 8.83 & 1970 & Mar. 31 & 3,940 & 13.30 & 1983 & Feb. 14 & 1,690 & 11.65 \\
\hline 1957 & May 00 & 447 & 9.73 & 1971 & Mar. 03 & 1,210 & 11.06 & 1984 & Aug. 01 & 936 & 10.69 \\
\hline 1958 & Mar. 11 & $\underline{1,680}$ & 11.20 & 1972 & Jan. 13 & 2,760 & 12.54 & 1985 & Feb. 06 & 1,300 & 11.21 \\
\hline 1959 & Mar. 06 & 751 & 10.33 & 1973 & Feb. 02 & 1,300 & 11.17 & 1986 & Dec. 13 & 222 & 8.70 \\
\hline 1960 & Apr. 05 & 2,140 & 11.49 & 1974 & Apr. 05 & 500 & 9.80 & 1987 & Jan. 22 & 1,010 & 10.67 \\
\hline 1961 & Apr. 13 & 624 & 10.14 & 1975 & Mar. 19 & 1,240 & 11.10 & 1988 & Mar. 04 & $6,3.0$ & 7.13 \\
\hline 1962 & Jan. 07 & 556 & 10.02 & 1976 & May 15 & 2,520 & 12.35 & 1989 & July 04 & 717 & 10.25 \\
\hline 1963 & July 10 & 1,970 & 11.38 & 1977 & Mar. 22 & 1,280 & 10.85 & 1990 & Jan. 08 & 540 & 9.80 \\
\hline 1964 & Feb. 18 & 1,150 & 10.80 & & & & & & & & \\
\hline
\end{tabular}




\section{APALACHICOLA RIVER BASIN}

\section{FLINT RIVER NEAR VIENNA, GEORGIA}

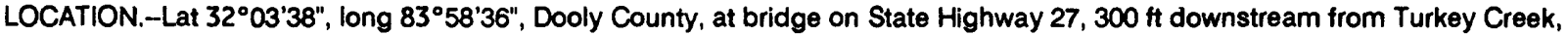
12 mi west of Vienna, and at mile 261.9.

DRAINAGE AREA.-3,390 $\mathrm{mi}^{2}$, approximately.

GAGE.--Nonrecording. Datum of gage is $220.28 \mathrm{ft}$ above sea level (levels by the Georgia Department of Transportation).

STAGE-DISCHARGE RELATION.--Defined by current-meter measurements below $53,000 \mathrm{ft}^{3} / \mathrm{s}$, and extended above on the basis of straight-line extension. Bankfull stage and discharge, $16 \mathrm{ft}$ and $12,500 \mathrm{ft}^{3} / \mathrm{s}$.

HISTORICAL DATA.-Peak of 1925 was the highest since 1897, based on records for gaging station upstream on Flint River at Montezuma (02349500).

REMARKS.--Flood stages of 1925 and 1949 from floodmarks.

\begin{tabular}{lccccccccccc}
\hline $\begin{array}{l}\text { Water } \\
\text { year }\end{array}$ & Date & $\begin{array}{c}\text { Discharge } \\
\left(\mathrm{ft}^{3} / \mathrm{s}\right)\end{array}$ & $\begin{array}{c}\text { Gage } \\
\text { height } \\
(\mathrm{ft})\end{array}$ & $\begin{array}{c}\text { Water } \\
\text { year }\end{array}$ & Date & $\begin{array}{c}\text { Discharge } \\
\left(\mathrm{ft}^{3} / \mathrm{s}\right)\end{array}$ & $\begin{array}{c}\text { Gage } \\
\text { height } \\
(\mathrm{ft})\end{array}$ & $\begin{array}{c}\text { Water } \\
\text { year }\end{array}$ & $\begin{array}{c}\text { Gage } \\
\text { Date }\end{array}$ & $\begin{array}{c}\text { Discharge } \\
\left(\mathrm{ft}^{3} / \mathrm{s}\right)\end{array}$ & $\begin{array}{c}\text { height } \\
(\mathrm{ft})\end{array}$ \\
\hline 1925 & Jan. 20 & 89,000 & $31.20 \mathrm{c}$ & 1928 & Apr. 26 & 45,500 & 24.40 & $\underline{1930}$ & Oct. 06 & 36,500 & 23.00 \\
1927 & Mar. 16 & 8,490 & 13.30 & 1929 & Mar. 18 & 85,500 & 30.60 & 1949 & Dec. 02 & 63,000 & $26.00 \mathrm{c}$ \\
\hline
\end{tabular}

\section{FLINT RIVER AT OAKFIELD, GEORGIA}

LOCATION.-Lat $31^{\circ} 46^{\prime} 07^{\prime \prime}$, long $83^{\circ} 59^{\prime} 24^{\prime \prime}$, Worth County, on downstream side of center pier of Albany and Northern Railroad bridge, 1 mi southwest of Oakfield, 1 mi upstream from Jones Creek, 9.7 mi downstream from Crisp County Dam, and at mile 125.0 .

DRAINAGE AREA.- $-3,860 \mathrm{mi}^{2}$, approximately.

GAGE.--Water-stage recorder, October 1929 to December 1958. From May 1987 at site 4.2 mi downstream at unknowm datum. Datum of gage is $193.29 \mathrm{ft}$ above sea level (levels from U.S. Geological Survey benchmark), supplementary adjustment of 1936.

STAGE-DISCHARGE RELATION.-Defined by current-meter measurements below $56,100 \mathrm{ft}^{3} / \mathrm{s}$, and extended above on the basis of straight-line extension. Bankfull stage and discharge, $18 \mathrm{ft}$ and $23,000 \mathrm{ft}^{3} / \mathrm{s}$.

HISTORICAL DATA.--Flood stage of 1925 determined from high-water mark furnished by local resident. The Jan. 20,1925 peak is the highest since 1897, based on records for gaging station upstream on Flint River at Montezuma (02349500).

REMARKS.--Regulation by storage in Lake Blackshear does not matrially afect peak discharges. Peak discharges for 1930 and 1934 are estimated. Peak discharges at both sites are considered equivalent.

\begin{tabular}{|c|c|c|c|c|c|c|c|c|c|c|c|}
\hline $\begin{array}{l}\text { Water } \\
\text { year }\end{array}$ & Date & $\begin{array}{c}\text { Discharge } \\
\left(\mathrm{ft}^{3} / \mathrm{s}\right)\end{array}$ & $\begin{array}{c}\text { Gage } \\
\text { height } \\
\text { (ft) }\end{array}$ & $\begin{array}{l}\text { Water } \\
\text { year }\end{array}$ & Date & $\begin{array}{c}\text { Discharge } \\
\left(\mathrm{ft}^{3} / \mathrm{s}\right)\end{array}$ & $\begin{array}{c}\text { Gage } \\
\text { height } \\
\text { (ft) }\end{array}$ & $\begin{array}{l}\text { Water } \\
\text { year }\end{array}$ & Date & $\begin{array}{c}\text { Discharge } \\
\left(\mathfrak{f t}^{3} / \mathrm{s}\right)\end{array}$ & $\begin{array}{c}\text { Gage } \\
\text { height } \\
\text { (ft) }\end{array}$ \\
\hline 1925 & Jan. 20 & 90,000 & $35.10 \mathrm{c}$ & 1940 & Feb. 24 & 24,300 & 18.90 & 1951 & Apr. 28 & 13,700 & 12.20 \\
\hline$\overline{1929}$ & Mar. 18 & 85,000 & 34.00 & 1941 & Mar. 23 & 6,010 & 6.70 & 1952 & Mar. 30 & 28,400 & 20.90 \\
\hline 1930 & Oct. 06 & 26,000 & -- & 1942 & Mar. 27 & 41,400 & 25.40 & 1953 & May 07 & 32,100 & 22.50 \\
\hline 1931 & Nov. 23 & 20,200 & 16.33 & 1943 & Mar. 26 & 44,800 & 27.00 & 1954 & Dec. 12 & 21,700 & 17.20 \\
\hline 1932 & Jan. 14 & 13,200 & 11.80 & 1944 & Mar. 25 & 48,800 & 27.70 & 1955 & Apr. 19 & 13,200 & 11.90 \\
\hline 1933 & Feb. 27 & 21,600 & 17.30 & 1945 & May 02 & 21,700 & 17.20 & 1956 & Mar. 23 & 17,400 & 14.60 \\
\hline 1934 & Mar. 12 & 16,000 & - & 1946 & Jan. 14 & 25,600 & 19.40 & 1957 & Apr. 12 & 22,200 & 17.50 \\
\hline 1935 & Mar. 20 & 11,800 & 11.00 & 1947 & Mar. 14 & 27,100 & 20.20 & $\underline{1958}$ & Mar. 13 & 24,200 & 18.60 \\
\hline 1936 & Apr. 15 & 46,800 & 27.20 & 1948 & Apr. 02 & 27,600 & 20.50 & $\overline{1988}$ & Jan. 25 & $\underline{12.100}$ & $\underline{11.07}$ \\
\hline 1937 & Jan. 11 & 18,700 & 15.50 & 1949 & Dec. 03 & 60,500 & 30.10 & 1989 & Apr. 14 & 15,700 & $\overline{13.12}$ \\
\hline 1938 & Apr. 13 & 37,200 & 24.40 & 1950 & Mar. 11 & 12,400 & 11.30 & 1990 & Mar. 23 & 50,200 & 27.37 \\
\hline 1939 & Mar. 05 & 33,200 & 22.90 & & & & & & & & \\
\hline
\end{tabular}




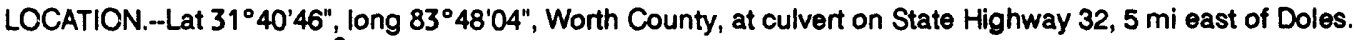
DRAINAGE AREA.--3.77 $\mathrm{mi}^{2}$.

GAGE.--Flood-stage, rainfall recorder. Datum of gage is about $217 \mathrm{ft}$ above sea level (from topographic map). STAGE-DISCHARGE RELATION.--Defined by current-meter measurements below $320 \mathrm{ft}^{3} / \mathrm{s}$, and extended above on the basis of culvert computations.

\begin{tabular}{|c|c|c|c|c|c|c|c|c|c|c|c|}
\hline $\begin{array}{l}\text { Water } \\
\text { year }\end{array}$ & Date & $\begin{array}{c}\text { Discharge } \\
\left(\mathbf{f t}^{3} / \mathbf{s}\right)\end{array}$ & $\begin{array}{c}\text { Gage } \\
\text { height } \\
\text { (ft) }\end{array}$ & $\begin{array}{c}\text { Water } \\
\text { year }\end{array}$ & Date & $\begin{array}{c}\text { Discharge } \\
\left(\mathrm{ft}^{3} / \mathrm{s}\right)\end{array}$ & $\begin{array}{c}\text { Gage } \\
\text { height } \\
\text { (ft) }\end{array}$ & $\begin{array}{l}\text { Water } \\
\text { year }\end{array}$ & Date & $\begin{array}{c}\text { Discharge } \\
\left(\mathrm{ft}^{3} / \mathrm{s}\right)\end{array}$ & $\begin{array}{c}\text { Gage } \\
\text { height } \\
\text { (ft) }\end{array}$ \\
\hline 1965 & Mar. 20 & 302 & 3.75 & 1969 & Aug. 02 & 330 & 3.93 & 1973 & Apr. 26 & 242 & 3.49 \\
\hline 1966 & Mar. 04 & 402 & 4.43 & 1970 & June 04 & 304 & 3.76 & 1974 & Feb. 07 & 248 & 3.51 \\
\hline 1967 & Jan. 01 & 652 & 5.99 & 1971 & Mar. 03 & 194 & 3.34 & 1975 & Feb. 18 & 348 & 4.06 \\
\hline 1968 & Mar. 11 & 47 & 2.46 & 1972 & Dec. 20 & 190 & 3.33 & & & & \\
\hline
\end{tabular}

\section{KINCHAFOONEE CREEK AT PRESTON, GEORGIA}

LOCATION.--Lat 32 $03^{\prime} 09^{\prime \prime}$, long $84^{\circ} 32^{\prime} 54^{\prime \prime}$, Webster County, near right bank on downstream side of bridge on State Highway 41,1 mi southwest of Preston, and 1 mi upstream from Harrel Mill Creek.

DRAINAGE AREA.--197 $\mathrm{mi}^{2}$.

GAGE.--Water-stage recorder. Datum of gage is $337.7 \mathrm{ft}$ above sea level (levels from the Georgia Department of Transportation). STAGE-DISCHARGE RELATION.-Defined by current-meter measurements below $13,900 \mathrm{ft}^{3} / \mathrm{s}$, and extended above on the basis of slope-conveyance studies. Bankfull stage and discharge, $6 \mathrm{ft}$ and $1,000 \mathrm{ft}^{3} / \mathrm{s}$.

HISTORICAL DATA.--Flood stages of January 1943 and April 1948 based on information furnished by the Georgia Department of Transportation). The flood of January 1943 was the highest since about 1900 , based on information furnished by local residents. REMARKS.--Peak discharge for 1949 is estimated. Peak discharge for 1967 is maximum daily.

\begin{tabular}{|c|c|c|c|c|c|c|c|c|c|c|c|}
\hline $\begin{array}{l}\text { Water } \\
\text { year }\end{array}$ & Date & $\begin{array}{c}\text { Discharge } \\
\left(\mathrm{ft}^{3} / \mathrm{s}\right)\end{array}$ & $\begin{array}{c}\text { Gage } \\
\text { height } \\
\text { (ft) }\end{array}$ & $\begin{array}{l}\text { Water } \\
\text { year }\end{array}$ & Date & $\begin{array}{c}\text { Discharge } \\
\left(\mathrm{ft}^{3} / \mathrm{s}\right)\end{array}$ & $\begin{array}{c}\text { Gage } \\
\text { height } \\
\text { (ft) }\end{array}$ & $\begin{array}{l}\text { Water } \\
\text { year }\end{array}$ & Date & $\begin{array}{c}\text { Discharge } \\
\left(\mathrm{ft}^{3} / \mathrm{s}\right)\end{array}$ & $\begin{array}{c}\text { Gage } \\
\text { height } \\
\text { (ft) }\end{array}$ \\
\hline$\underline{1943}$ & Jan. 19 & 11,000 & $11.40 \mathrm{c}$ & 1959 & Feb. 05 & 1,900 & 6.98 & 1971 & Mar. 27 & 3,210 & 7.43 \\
\hline$\overline{1948}$ & July 12 & 7,800 & 10.00 & 1960 & Mar. 31 & 1,840 & 6.96 & 1972 & Jan. 14 & 3,040 & 7.57 \\
\hline 1949 & July 16 & 3,100 & - & 1961 & Apr. 01 & 4,700 & 8.41 & 1973 & Dec. 07 & 5,060 & 8.63 \\
\hline 1950 & Mar. 30 & 750 & 5.75 & 1962 & Apr. 02 & 1,520 & 6.62 & 1974 & Apr. 06 & 1,600 & 6.66 \\
\hline 1951 & Mar. 19 & 1,120 & 6.30 & 1963 & Jan. 22 & 1,780 & 6.88 & 1975 & Feb. 18 & 4,940 & 8.57 \\
\hline 1952 & Mar. 24 & 2,610 & 7.44 & 1964 & Apr. 09 & 2,520 & 7.26 & 1976 & Jan. 28 & 1,900 & 6.92 \\
\hline 1953 & May 04 & 5,400 & 8.80 & 1965 & Dec. 26 & 4,040 & 7.77 & 1977 & Nov. 30 & 1,920 & 6.93 \\
\hline 1954 & Dec. 07 & 2,980 & 7.65 & 1966 & Mar. 04 & 4,970 & 8.09 & $\underline{1978}$ & Jan. 26 & 7,200 & 9.70 \\
\hline 1955 & Apr. 15 & 2,120 & 7.15 & 1967 & Jan. 02 & 1,800 & & $\overline{1987}$ & Mar. 01 & 1,380 & 6.45 \\
\hline 1956 & Sept. 26 & 1,520 & 6.70 & 1968 & Mar. 14 & 521 & 5.24 & 1988 & Jan. 21 & 750 & 5.67 \\
\hline 1957 & May 05 & 4,320 & 8.23 & 1969 & May 20 & 1,050 & 6.05 & 1989 & Apr. 11 & 1,190 & 6.25 \\
\hline 1958 & Mar. 09 & 1,900 & 7.00 & 1970 & Mar. 30 & 5,720 & 8.96 & 1990 & Mar. 17 & 14,500 & 12.16 \\
\hline
\end{tabular}




\section{APALACHICOLA RIVER BASIN}

\section{CHOCTAHATCHEE CREEK TRIBUTARY NEAR PLAINS, GEORGIA}

LOCATION.--Lat $32^{\circ} 02^{\prime} 02^{\prime \prime}$, long $84^{\circ} 25^{\prime} 54^{\prime \prime}$, Sumter County, at culvert on U.S. Highway $280,2.4$ mi west of Plains. DRAINAGE AREA. $-0.32 \mathrm{mi}^{2}$.

GAGE.-Crest-stage gage. Datum of gage is about $440 \mathrm{ft}$ above sea level (from topographic map).

STAGE-DISCHARGE RELATION.--Defined by culvert computations.

\begin{tabular}{|c|c|c|c|c|c|c|c|c|c|c|c|}
\hline $\begin{array}{l}\text { Water } \\
\text { year }\end{array}$ & Date & $\begin{array}{c}\text { Discharge } \\
\left(\mathrm{ft}^{3} / \mathrm{s}\right)\end{array}$ & $\begin{array}{c}\text { Gage } \\
\text { height } \\
\text { (ft) }\end{array}$ & $\begin{array}{l}\text { Water } \\
\text { year }\end{array}$ & Date & $\begin{array}{c}\text { Discharge } \\
\left(\mathrm{ft}^{3} / \mathrm{s}\right)\end{array}$ & $\begin{array}{c}\text { Gage } \\
\text { height } \\
\text { (ft) }\end{array}$ & $\begin{array}{l}\text { Water } \\
\text { year }\end{array}$ & Date & $\begin{array}{c}\text { Discharge } \\
\left(\mathrm{ft}^{3} / \mathrm{s}\right)\end{array}$ & $\begin{array}{c}\text { Gage } \\
\text { height } \\
\text { (ft) }\end{array}$ \\
\hline 1977 & Mar. 21 & 48,0 & 1.83 & 1983 & Mar. 06 & 82.0 & 2.69 & 1987 & June 17 & 8.0 & 1.01 \\
\hline 1978 & Apr. 12 & 62.0 & 2.10 & 1984 & July 29 & 20.0 & 1.42 & 1988 & Sept.05 & 22.0 & 1.47 \\
\hline 1979 & Feb. 25 & 72.0 & 2.31 & 1985 & Feb. 06 & 92.0 & 2.75 & 1989 & July 20 & 6.0 & 1.06 \\
\hline 1981 & Aug. 09 & 72.0 & 2.49 & 1986 & Nov. 22 & 30.0 & 1.57 & 1990 & July 21 & 8.0 & 1.17 \\
\hline 1982 & July 14 & 73.0 & 2.42 & & & & & & & & \\
\hline
\end{tabular}

\section{KINCHAFOONEE CREEK NEAR DAWSON, GEORGIA}

LOCATION.--Lat $31^{\circ} 45^{\prime} 52^{\prime \prime}$, long $84^{\circ} 15^{\prime} 12^{\prime \prime}$, Lee County, at Anson Farm Road, on downstream side of left pier, and 12 mi east of Dawson.

DRAINAGE AREA. $-527 \mathrm{mi}^{2}$.

GAGE.--Crest-stage gage prior to Sept. 30, 1984 at site 1,500 ft upstream at same datum. Water-stage recorder thereafter. Datum of gage is $211.74 \mathrm{ft}$ above sea level (levels by the Georgia Department of Transportation).

STAGE-DISCHARGE RELATION.--Defined by current-meter measurements below $5,900 \mathrm{ft}^{3} / \mathrm{s}$, and extended above on the basis of slope-conveyance studies, prior to 1984 . Thereafter, defined by current-meter measurements below $11,200 \mathrm{ft}^{3} / \mathrm{s}$. Bankfull stage and discharge, $15 \mathrm{ft}$ and $3,600 \mathrm{ft}^{3} / \mathrm{s}$.

HISTORICAL DATA.--Flood stage of January 1943 based on information furnished by local residents. The January 1943 flood was the highest since 1900 , based on information from local residents.

\begin{tabular}{|c|c|c|c|c|c|c|c|c|c|c|c|c|}
\hline $\begin{array}{l}\text { Water } \\
\text { year }\end{array}$ & Date & $\begin{array}{c}\text { Discharge } \\
\left(\mathrm{ft}^{3} / \mathrm{s}\right)\end{array}$ & $\begin{array}{c}\text { Gage } \\
\text { height } \\
\text { (ft) }\end{array}$ & $\begin{array}{l}\text { Water } \\
\text { year }\end{array}$ & Date & $\begin{array}{c}\text { Discharge } \\
\left(\mathrm{ft}^{3} / \mathrm{s}\right)\end{array}$ & $\begin{array}{c}\text { Gage } \\
\text { height } \\
\text { (ft) }\end{array}$ & & $\begin{array}{l}\text { Water } \\
\text { year }\end{array}$ & Date & $\begin{array}{c}\text { Discharge } \\
\left(\mathrm{ft}^{3} / \mathrm{s}\right)\end{array}$ & $\begin{array}{c}\text { Gage } \\
\text { height } \\
\text { (ft) }\end{array}$ \\
\hline$\underline{1943}$ & Jan. 20 & 15,000 & $23.00 \mathrm{c}$ & 1957 & May 14 & 3,210 & 14.30 & & $\underline{1966}$ & Mar. 05 & 9,000 & 20.46 \\
\hline 1949 & June 11 & 5,880 & 17.80 & 1958 & Mar. 11 & 3,210 & 14.30 & & $\underline{1973}$ & Dec. 07 & $\underline{8,300}$ & $20.03 c$ \\
\hline 1950 & Apr. 01 & 1,860 & 11.00 & 1959 & Feb. 05 & 3,060 & 14.00 & & 1985 & May 13 & 1,830 & 10.21 \\
\hline 1951 & Apr. 20 & 1,070 & 9.03 & 1960 & Apr. 06 & 7,800 & 19.40 & & 1986 & Dec. 14 & 1,870 & 10.32 \\
\hline 1952 & Mar. 28 & 2,760 & 13.40 & 1961 & Apr. 13 & 5,760 & 17.70 & - & 1987 & Jan. 23 & 2,550 & 11.96 \\
\hline 1953 & May 06 & 5,880 & 17.80 & 1962 & Jan. 09 & 4,180 & 15.94 & & 1988 & Feb. 21 & 1,280 & 8.62 \\
\hline 1954 & Dec. 09 & 3,600 & 15.00 & 1963 & Jan. 22 & 2,560 & 12.96 & & 1989 & July 07 & 1,610 & 9.61 \\
\hline 1955 & Apr. 17 & 2,100 & 11.80 & 1964 & Sept.15 & 4,600 & 16.51 & & 1990 & Mar. 20 & 11,300 & 20.44 \\
\hline 1956 & Sept.26 & 2,240 & 12.20 & 1965 & Dec. 27 & 6,360 & 18.17 & & & & & \\
\hline
\end{tabular}


LOCATION.--Lat $32^{\circ} 04^{\prime} 59^{\prime \prime}$, long $84^{\circ} 15^{\prime} 29^{\prime \prime}$, Sumter County, at State Highway 30,1 mi west of Americus. DRAINAGE AREA. $-140 \mathrm{mi}^{2}$.

GAGE.-Crest-stage gage. Datum of gage is $321.09 \mathrm{ft}$ above sea level (from U.S. Geological Survey benchmark).

STAGE-DISCHARGE RELATION.--Defined by current-meter measurements below $3,660 \mathrm{ft}^{3} / \mathrm{s}$, and above on the basis of straightline extension. Bankfull stage and discharge, $6 \mathrm{ft}$ and $600 \mathrm{ft}^{3} / \mathrm{s}$.

\begin{tabular}{|c|c|c|c|c|c|c|c|c|c|c|c|}
\hline $\begin{array}{l}\text { Water } \\
\text { year }\end{array}$ & Date & $\begin{array}{c}\text { Discharge } \\
\left(\mathrm{ft}^{3} / \mathrm{s}\right)\end{array}$ & $\begin{array}{c}\text { Gage } \\
\text { height } \\
\text { (ft) }\end{array}$ & $\begin{array}{l}\text { Water } \\
\text { year }\end{array}$ & Date & $\begin{array}{c}\text { Discharge } \\
\left(\mathrm{ft}^{3} / \mathrm{s}\right)\end{array}$ & $\begin{array}{c}\text { Gage } \\
\text { height } \\
\text { (ft) }\end{array}$ & $\begin{array}{l}\text { Water } \\
\text { year }\end{array}$ & Date & $\begin{array}{c}\text { Discharge } \\
\left(\mathrm{ft}^{3} / \mathrm{s}\right)\end{array}$ & $\begin{array}{c}\text { Gage } \\
\text { height } \\
\text { (ft) }\end{array}$ \\
\hline 1963 & Jan. 22 & 870 & 6.48 & 1970 & Mar. 31 & 6,320 & 11.51 & 1977 & Mar. 10 & 1,390 & 7.38 \\
\hline 1964 & Jan. 10 & 1,140 & 6.99 & 1971 & Mar. 26 & 1,060 & 6.86 & 1978 & Jan. 27 & 3,510 & 9.51 \\
\hline 1965 & Oct. 25 & 2,170 & 8.26 & 1972 & Jan. 14 & 1,340 & 7.31 & 1979 & Feb. 25 & 2,050 & 8.18 \\
\hline 1966 & Mar. 04 & 3,820 & 9.77 & 1973 & Apr. 27 & 2,650 & 8.77 & 1980 & Mar. 14 & 1,340 & 7.31 \\
\hline 1967 & Jan. 04 & 1,050 & 6.85 & 1974 & Apr. 06 & 925 & 6.61 & 1981 & Feb. 11 & 2,950 & 9.04 \\
\hline 1968 & May 00 & 480 & $-b$ & 1975 & Feb. 20 & 3,090 & 9.16 & 1982 & Feb. 16 & 1,240 & 7.17 \\
\hline 1969 & Dec. -- & 480 & $-b$ & 1976 & May 16 & 1,070 & 6.89 & 1983 & Mar. 06 & 3,390 & 9.41 \\
\hline
\end{tabular}

\section{MUCKALEE CREEK NEAR SMITHVILLE, GEORGIA}

LOCATION.-Lat $31^{\circ} 53^{\prime} 43^{\prime \prime}$, long $84^{\circ} 11^{\prime} 52^{\prime \prime}$, Lee County, at State Highway 118,3 mi east of Smithville.

DRAINAGE AREA.--265 $\mathrm{mi}^{2}$.

GAGE.--Crest-stage gage. Datum of gage is $257.83 \mathrm{ft}$ above sea level (levels by the Georgia Department of Transportation).

STAGE-DISCHARGE RELATION.--Defined by current-meter measurements below $5,200 \mathrm{ft}^{3} / \mathrm{s}$, and extended above on the basis of slope-conveyance studies. Bankfull stage and discharge, $6 \mathrm{ft}$ and $1,200 \mathrm{ft}^{3} / \mathrm{s}$.

HISTORICAL DATA.-Flood stage of March 1929 based on information furnished by local resident. Flood stage of April 1948 based on information furnished by the Georgia Department of Transportation.

REMARKS.--Peak discharge for 1929, 1948, and 1951 are estimated.

\begin{tabular}{|c|c|c|c|c|c|c|c|c|c|c|c|}
\hline $\begin{array}{l}\text { Water } \\
\text { year }\end{array}$ & Date & $\begin{array}{c}\text { Discharge } \\
\left(\mathrm{ft}^{3} / \mathrm{s}\right)\end{array}$ & $\begin{array}{c}\text { Gage } \\
\text { height } \\
\text { (ft) }\end{array}$ & $\begin{array}{l}\text { Water } \\
\text { year }\end{array}$ & Date & $\begin{array}{c}\text { Discharge } \\
\left(\mathrm{ft}^{3} / \mathrm{s}\right)\end{array}$ & $\begin{array}{l}\text { Gage } \\
\text { height } \\
\text { (ft) }\end{array}$ & $\begin{array}{l}\text { Water } \\
\text { year }\end{array}$ & Date & $\begin{array}{c}\text { Discharge } \\
\left(\mathrm{ft}^{3} / \mathrm{s}\right)\end{array}$ & $\begin{array}{c}\text { Gage } \\
\text { height } \\
\text { (ft) }\end{array}$ \\
\hline 1929 & Mar. 16 & 9,000 & $11.00 \mathrm{c}$ & 1955 & Apr. 15 & 1,850 & 6.79 & 1961 & Apr. 13 & 3,220 & 7.95 \\
\hline 1948 & July 12 & 15,000 & $14.00 \mathrm{c}$ & 1956 & Feb. 07 & 720 & 5.34 & 1962 & Jan. 08 & 3,220 & 8.02 \\
\hline 1951 & Mar. 19 & 1,040 & - & 1957 & Apr. 07 & 1,100 & 6.00 & 1963 & Feb. 12 & 1,520 & 6.52 \\
\hline 1952 & Nov. 16 & 2,100 & 6.98 & 1958 & Feb. 28 & 1,850 & 6.84 & 1964 & Jan. 12 & 2,680 & 7.59 \\
\hline 1953 & Sept.28 & 2,100 & 7.01 & 1959 & Feb. 05 & 1,740 & 6.68 & 1965 & Dec. 27 & 4,600 & 8.79 \\
\hline 1954 & Dec. 15 & 1,850 & 6.76 & 1960 & Apr. 04 & 5,400 & 9.21 & 1966 & Mar. 04 & 5,860 & 9.43 \\
\hline
\end{tabular}




\section{APALACHICOLA RIVER BASIN}

\section{MUCKALOOCHEE CREEK AT SMITHVILLE, GEORGIA}

LOCATION.--Lat $31^{\circ} 54^{\prime} 19^{\prime \prime}$, long $84^{\circ} 14^{\prime} 44^{\prime \prime}$, Lee County, at State Highway 118, at Smithville.

DRAINAGE AREA.--47 $\mathrm{mi}^{2}$.

GAGE.--Crest-stage gage. Datum of gage is $277.98 \mathrm{ft}$ above sea level (from U.S. Geological Survey benchmark).

STAGE-DISCHARGE RELATION.--Defined by current-meter measurements below $1,860 \mathrm{ft}^{3} / \mathrm{s}$, and extended above on the basis of slope-conveyance studies. Bankfull stage and discharge, $4 \mathrm{ft}$ and $500 \mathrm{ft}^{3} / \mathrm{s}$.

HISTORICAL DATA.--Flood peaks of January 1943 and April 1948 based on information furnished by the Georgia Department of Transportation. Flood of January 1943 is probably highest since 1900 , based on information furnished by local residents.

\begin{tabular}{|c|c|c|c|c|c|c|c|c|c|c|c|}
\hline $\begin{array}{l}\text { Water } \\
\text { year }\end{array}$ & Date & $\begin{array}{c}\text { Discharge } \\
\left(\mathrm{ft}^{3} / \mathrm{s}\right)\end{array}$ & $\begin{array}{c}\text { Gage } \\
\text { height } \\
\text { (ft) }\end{array}$ & $\begin{array}{l}\text { Water } \\
\text { year }\end{array}$ & Date & $\begin{array}{c}\text { Discharge } \\
\left(\mathrm{ft}^{3} / \mathrm{s}\right)\end{array}$ & $\begin{array}{c}\text { Gage } \\
\text { height } \\
\text { (ft) }\end{array}$ & $\begin{array}{l}\text { Water } \\
\text { year }\end{array}$ & Date & $\begin{array}{l}\text { Discharge } \\
\left(\mathrm{ft}^{3} / \mathrm{s}\right)\end{array}$ & $\begin{array}{c}\text { Gage } \\
\text { height } \\
\text { (ft) }\end{array}$ \\
\hline$\underline{1943}$ & Jan. 19 & 6,000 & $10.80 c$ & 1959 & Feb. 05 & 395 & 3.59 & 1969 & Sept.23 & 161 & 2.57 \\
\hline$\overline{1948}$ & Apr. 01 & 1,260 & 5.20 & 1960 & Apr. 04 & 1,760 & 5.86 & 1970 & Mar. 31 & 2,040 & 6.25 \\
\hline 1950 & July 08 & 395 & 3.61 & 1961 & Apr. 12 & 820 & 4.52 & 1971 & Mar. 26 & 700 & 4.30 \\
\hline 1952 & Feb. 17 & 305 & 3.32 & 1962 & Jan. 08 & 1,060 & 4.88 & 1972 & Jan. 14 & 655 & 4.21 \\
\hline 1953 & May 04 & 860 & 4.64 & 1963 & Feb. 12 & 550 & 4.05 & 1973 & Apr. 27 & 784 & 4.44 \\
\hline 1954 & Dec. 14 & 510 & 3.94 & 1964 & Jan. 12 & 940 & 4.71 & 1974 & Apr. 06 & 514 & 3.91 \\
\hline 1955 & Apr. 15 & 280 & 3.15 & 1965 & Dec. 27 & 1,920 & 6.09 & 1975 & Feb. 20 & 1,370 & 5.36 \\
\hline 1956 & May 06 & 162 & 2.60 & 1966 & Mar. 04 & 2,560 & 6.87 & 1976 & Apr. - & 118 & $-\mathrm{b}$ \\
\hline 1957 & Apr. 06 & 360 & 3.54 & 1967 & Jan. 04 & 904 & 4.64 & 1977 & Nov. 30 & 796 & 4.46 \\
\hline 1958 & Feb. 27 & 510 & 3.92 & 1968 & Feb. -- & 118 & $-\mathrm{b}$ & 1978 & Jan. 27 & 1,570 & 5.64 \\
\hline
\end{tabular}

\section{MUCKALEE CREEK AT STATE HIGHWAY 195 NEAR LEESBURG, GEORGIA}

LOCATION.--Lat $31^{\circ} 46^{\prime} 34^{\prime \prime}$, long $84^{\circ} 08^{\prime} 22^{\prime \prime}$, Lee County, at bridge on State Highway 195, $75 \mathrm{ft}$ downstream from White Oak Branch, 3.3 mi downstream from Muckaloochee Creek, and 4.0 mi northeast of Leesburg.

DRAINAGE AREA.--362 $\mathrm{mi}^{2}$.

GAGE.-Water-stage recorder. Datum of gage is about $220 \mathrm{ft}$ above sea level (from topographic map).

STAGE-DISCHARGE RELATION.--Defined by current-meter measurements below $3,820 \mathrm{ft}^{3} / \mathrm{s}$, and extended above on the basis of straight-line extension.

HISTORICAL DATA.--Flood peak of April 1948 based on information furnished by Georgia Department of Transportation, and the datum is sea level.

REMARKS.--Peak discharge for 1948 is estimated, and based on records at station 0231900 (Muckalee Creek at State Highway 32 near Leesburg).

\begin{tabular}{|c|c|c|c|c|c|c|c|c|c|c|c|}
\hline $\begin{array}{l}\text { Water } \\
\text { year }\end{array}$ & Date & $\begin{array}{c}\text { Discharge } \\
\left(\mathrm{ft}^{3} / \mathrm{s}\right)\end{array}$ & $\begin{array}{c}\text { Gage } \\
\text { height } \\
\text { (ft) }\end{array}$ & $\begin{array}{l}\text { Water } \\
\text { year }\end{array}$ & Date & $\begin{array}{c}\text { Discharge } \\
\left(\mathrm{ft}^{3} / \mathrm{s}\right)\end{array}$ & $\begin{array}{c}\text { Gage } \\
\text { height } \\
\text { (ft) }\end{array}$ & $\begin{array}{l}\text { Water } \\
\text { year }\end{array}$ & Date & $\begin{array}{c}\text { Discharge } \\
\left(\mathrm{ft}^{3} / \mathrm{s}\right)\end{array}$ & $\begin{array}{c}\text { Gage } \\
\text { height } \\
\text { (ft) }\end{array}$ \\
\hline 1948 & Apr. 03 & 15,000 & 234.66 & 1983 & Mar. 08 & 4,810 & 13.20 & 1987 & Jan. 24 & 2,620 & 11.75 \\
\hline$\overline{1980}$ & Mar. 31 & 3,100 & 12.12 & 1984 & May 04 & 4,160 & 12.83 & 1988 & Apr. 27 & 1,040 & 9.77 \\
\hline 1981 & Feb. 14 & 4,420 & 12.98 & 1985 & Feb. 07 & 6,290 & 13.91 & 1989 & July 07 & 1,710 & 10.90 \\
\hline 1982 & Jan. 06 & 3,080 & 12.10 & 1986 & Dec. 15 & 1,430 & 10.54 & 1990 & Jan. 08 & 2,840 & 11.92 \\
\hline
\end{tabular}




\section{MUCKALEE CREEK NEAR LEESBURG, GEORGIA}

LOCATION.--Lat $31^{\circ} 43^{\prime} 55^{\prime \prime}$ long $84^{\circ} 07^{\prime} 30^{\prime \prime}$, Lee County, at State Highway $32,2.8$ mi east of Leesburg.

DRAINAGE AREA.--405 $\mathrm{mi}^{2}$.

GAGE.--Crest-stage gage. Datum of gage is $206.88 \mathrm{ft}$ above sea level (levels by the Georgia Department of Transportation).

STAGE-DISCHARGE RELATION.--Defined by current-meter measurements below $4,800 \mathrm{ft}^{3} / \mathrm{s}$, and extended above on the basis of slope-conveyance studies, and comparison with other stations. Bankfull stage and discharge, $11 \mathrm{ft}$ and $2,200 \mathrm{ft}^{3} / \mathrm{s}$.

HISTORICAL DATA.--Flood peak of April 1948 based on information furnished by local residents, and is thought to be the highest since 1943.

\begin{tabular}{|c|c|c|c|c|c|c|c|c|c|c|c|}
\hline $\begin{array}{l}\text { Water } \\
\text { year }\end{array}$ & Date & $\begin{array}{l}\text { Discharge } \\
\left(\mathrm{ft}^{3} / \mathrm{s}\right)\end{array}$ & $\begin{array}{c}\text { Gage } \\
\text { height } \\
\text { (ft) }\end{array}$ & $\begin{array}{l}\text { Water } \\
\text { year }\end{array}$ & Date & $\begin{array}{c}\text { Discharge } \\
\left(\mathrm{ft}^{3} / \mathrm{s}\right)\end{array}$ & $\begin{array}{c}\text { Gage } \\
\text { height } \\
\text { (ft) }\end{array}$ & $\begin{array}{l}\text { Water } \\
\text { year }\end{array}$ & Date & $\begin{array}{l}\text { Discharge } \\
\left(\mathrm{ft}^{3} / \mathrm{s}\right)\end{array}$ & $\begin{array}{c}\text { Gage } \\
\text { height } \\
\text { (ft) }\end{array}$ \\
\hline$\underline{1948}$ & Apr. 03 & 16,000 & $19.70 \mathrm{c}$ & 1956 & Mar. 22 & 1,040 & 7.91 & 1961 & Apr. 13 & 3,300 & 12.52 \\
\hline 1951 & Mar. 30 & 1,020 & 7.78 & 1957 & Apr. 10 & 1,650 & 10.00 & 1962 & Jan. 09 & 3,140 & 12.28 \\
\hline 1952 & Feb. 17 & 1,860 & 10.50 & 1958 & Mar. 02 & 2,450 & 11.70 & 1963 & Feb. 13 & 2,080 & 10.80 \\
\hline 1953 & May 08 & 2,000 & 10.80 & 1959 & Feb. 05 & 2,300 & 11.40 & 1964 & Jan. 12 & 3,800 & 12.97 \\
\hline 1954 & Dec. 16 & 2,350 & 11.50 & 1960 & Apr. 06 & 6,400 & 14.77 & 1965 & Dec. 27 & 6,200 & 14.52 \\
\hline 1955 & Apr. 16 & 1,690 & 10.10 & & & & & & & & \\
\hline
\end{tabular}


LOCATION.--Lat $31^{\circ} 35^{\prime} 39^{\prime \prime}$, long $84^{\circ} 08^{\prime} 39^{\prime \prime}$, Dougherty County, on right bank at downstream side of Georgia Northern Railway bridge in Albany, and at mile 103.4.

DRAINAGE AREA.--5,310 $\mathrm{mi}^{2}$, approximately.

GAGE.--Prior to Jan. 1, 1902, nonrecording gage at site 1 mi downstream at datum $1.3 \mathrm{ft}$ lower. Jan. 1, 1902 to Sept. 3, 1929, nonrecording gage at site $1 \mathrm{mi}$ downstream at datum $2.0 \mathrm{ft}$ lower. Water-stage recorder thereafter. Datum of gage is $150.03 \mathrm{ft}$ above sea level (from the U.S. Coast and Geodetic Survey benchmark).

STAGE-DISCHARGE RELATION.--Defined by current-meter measurements below $57,000 \mathrm{tt}^{3} / \mathrm{s}$ at former site. Defined by currentmeter measurements below $75,000 \mathrm{ft}^{3} / \mathrm{s}$ at present site and above, on the basis of rating-curve extension. Bankfull stage and discharge, $23 \mathrm{ft}$ and $33,000 \mathrm{ft}^{3} / \mathrm{s}$.

REMARKS.-Peak stages for periods $1893-1901$ and 1922-29 furnished by the National Weather Service. Capacity of powerplant reservoirs upstream is insufficient to materially affect peak discharge. Peak stage of 1925 flood from floodmark at present site and datum.

\begin{tabular}{|c|c|c|c|c|c|c|c|c|c|c|c|}
\hline $\begin{array}{l}\text { Water } \\
\text { year }\end{array}$ & Date & $\begin{array}{c}\text { Discharge } \\
\left(\mathrm{ft}^{3} / \mathrm{s}\right)\end{array}$ & $\begin{array}{l}\text { Gage } \\
\text { height } \\
\text { (ft) }\end{array}$ & $\begin{array}{l}\text { Water } \\
\text { year }\end{array}$ & Date & $\begin{array}{c}\text { Discharge } \\
\left(\mathrm{ft}^{3} / \mathrm{s}\right)\end{array}$ & $\begin{array}{l}\text { Gage } \\
\text { height } \\
\text { (ft) }\end{array}$ & $\begin{array}{l}\text { Water } \\
\text { year }\end{array}$ & Date & $\begin{array}{c}\text { Discharge } \\
\left(\mathrm{ft}^{3} / \mathrm{s}\right)\end{array}$ & $\begin{array}{c}\text { Gage } \\
\text { height } \\
\text { (ft) }\end{array}$ \\
\hline 1893 & Aug. 21 & 18,900 & 14.10 & 1926 & Apr. 07 & 26,600 & 19.40 & 1959 & June 08 & 27,400 & 20.50 \\
\hline 1894 & Feb. 20 & 25,600 & 18.70 & 1927 & Mar. 17 & 13,000 & 9.80 & 1960 & Apr. 07 & 57,000 & 30.80 \\
\hline 1895 & Mar. 20 & 40,500 & 25.80 & 1928 & Apr. 24 & 58,100 & 29.40 & 1961 & Mar. 03 & 48,000 & 29.00 \\
\hline 1896 & Feb. 13 & 22,700 & 16.80 & 1929 & Mar. 20 & $\underline{78,800}$ & 34.40 & 1962 & Mar. 17 & 29,700 & 21.80 \\
\hline 1897 & Mar. 25 & 72,800 & 32.40 & 1930 & Oct. 04 & 37,100 & 25.10 & 1963 & Jan. 26 & 29,300 & 21.60 \\
\hline 1898 & Sept.02 & 24,500 & 18.00 & 1931 & Nov. 21 & 25,000 & 19.20 & 1964 & Apr. 14 & 58,600 & 31.12 \\
\hline 1899 & Feb. 15 & 32,600 & 22.60 & 1932 & Jan. 14 & 16,400 & 13.50 & 1965 & Dec. 31 & 37,200 & 25.58 \\
\hline 1900 & Feb. 18 & 55,900 & 29.80 & 1933 & Feb. 27 & 23,800 & 18.58 & 1966 & Mar. 07 & 77,000 & 34.72 \\
\hline 1901 & $\underline{\text { Sept.22 }}$ & 41,000 & 26.00 & 1934 & Mar. 12 & 21,700 & 17.30 & 1967 & Jan. 04 & 27,700 & 20.70 \\
\hline 1902 & $\overline{\text { Mar. } 07}$ & $\overline{33,300}$ & $\overline{22.90}$ & 1935 & Mar. 19 & 14,700 & 11.70 & 1968 & Mar. 17 & 25,100 & 19.10 \\
\hline 1903 & Feb. 17 & 38,400 & 25.00 & 1936 & Apr. 15 & 52,300 & 29.00 & 1969 & Apr. 24 & 21,500 & 16.66 \\
\hline 1904 & Feb. 13 & 27,400 & 19.20 & 1937 & Mar. 27 & 20,600 & 16.00 & 1970 & Apr. 02 & 54,800 & 30.69 \\
\hline 1905 & Feb. 17 & 39,200 & 25.30 & 1938 & Apr. 14 & 39,800 & 25.80 & 1971 & Mar. 09 & 56,000 & 31.01 \\
\hline 1906 & Jan. 27 & 25,100 & 18.10 & 1939 & Mar. 05 & 39,200 & 25.60 & 1972 & Jan. 16 & 31,300 & 22.62 \\
\hline 1907 & Feb. 11 & 14,600 & 11.10 & 1940 & Feb. 19 & 26,300 & 19.90 & 1973 & Feb. 04 & 35,400 & 24.68 \\
\hline 1908 & May 03 & 47,800 & 28.00 & 1941 & Mar. 24 & 8,890 & 8.00 & 1974 & Apr. 07 & 25,000 & 18.77 \\
\hline 1909 & Mar. 20 & 32,500 & 22.40 & 1942 & Mar. 27 & 43,200 & 26.70 & 1975 & Mar. 21 & 56,300 & 30.32 \\
\hline 1910 & Apr. 24 & 17,000 & 12.70 & 1943 & Jan. 22 & 64,800 & 31.60 & 1976 & May 17 & 25,100 & 18.75 \\
\hline 1911 & Jan. 10 & 10,400 & 7.80 & 1944 & Mar. 26 & 62,800 & 31.20 & 1977 & Mar. 08 & 28,700 & 20.60 \\
\hline 1912 & Apr. 24 & 57,300 & 30.10 & 1945 & May 02 & 24,200 & 18.50 & 1978 & Jan. 29 & 44,500 & 27.18 \\
\hline 1913 & Mar. 21 & 58,300 & 30.30 & 1946 & Jan. 14 & 28,600 & 21.20 & 1979 & Feb. 26 & 41,800 & 26.13 \\
\hline 1914 & Mar. 03 & 11,900 & 9.00 & 1947 & Mar. 14 & 33,200 & 23.40 & 1980 & Mar. 15 & 39,500 & 25.19 \\
\hline 1915 & Jan. 25 & 22,800 & 16.60 & 1948 & Apr. 02 & 45,800 & 27.50 & 1981 & Feb. 17 & 29,900 & 21.21 \\
\hline 1916 & July 15 & 45,500 & 27.40 & 1949 & Dec. 04 & 64,300 & 31.50 & 1982 & Feb. 08 & 25,300 & 18.87 \\
\hline 1917 & Mar. 11 & 28,900 & 20.80 & 1950 & Mar. 12 & 14,500 & 11.50 & 1983 & Apr. 14 & 32,100 & 22.27 \\
\hline 1918 & Feb. 09 & 17,100 & 12.30 & 1951 & Apr. 28 & 16,000 & 12.70 & 1984 & Mar. 07 & 26,600 & 19.57 \\
\hline 1919 & Mar. 03 & 47,200 & 27.80 & 1952 & Mar. 30 & 32,200 & 23.00 & 1985 & Feb. 08 & 30,500 & 21.52 \\
\hline 1920 & Apr. 05 & 41,600 & 26.20 & 1953 & May 08 & 41,400 & 26.30 & 1986 & Mar. 24 & 17,300 & 13.06 \\
\hline 1921 & Feb. 18 & 23,400 & 17.30 & 1954 & Dec. 12 & 26,800 & 20.20 & 1987 & Mar. 06 & 27,000 & 19.78 \\
\hline 1922 & Mar. 16 & 43,300 & 26.80 & 1955 & Apr. 19 & 17,200 & 13.40 & 1988 & Jan. 26 & 14,800 & 11.25 \\
\hline 1923 & Mar. 25 & 33,000 & 22.80 & 1956 & Mar. 23 & 19,600 & 15.20 & 1989 & July 07 & 19,500 & 14.67 \\
\hline 1924 & Apr. 19 & 19,400 & 14.40 & 1957 & Apr. 12 & 25,500 & 19.40 & 1990 & Mar. 23 & 58,700 & 30.92 \\
\hline 1925 & Jan. 21 & 92,000 & 37.80 & 1958 & Mar. 14 & 30,300 & 22.10 & & & & \\
\hline
\end{tabular}




\section{APALACHICOLA RIVER BASIN}

\section{FLINT RIVER AT NEWTON, GEORGIA}

LOCATION.--Lat $31^{\circ} 18^{\prime} 34^{\prime \prime}$, long $84^{\circ} 20^{\prime} 06^{\prime \prime}$, Baker County, on downstream side of pier of bridge on State Highway 37 at Newton, 1 mi downstream from Coolewahee Creek, and at mile 69.5.

DRAINAGE AREA.--5,740 $\mathrm{mi}^{2}$, approximately.

GAGE.--Water-stage recorder. Datum of gage is $110.20 \mathrm{ft}$ above sea level (levels by the U.S. Army Corps of Engineers), supplementary adjustment of 1936. Prior to Nov. 12, 1956, nonrecording gage at same site and datum.

STAGE-DISCHARGE RELATION.--Defined by current-meter measurements below $66,000 \mathrm{ft}^{3} / \mathrm{s}$, and extended above on the basis of slope-conveyance studies. Bankfull stage and discharge, $24 \mathrm{ft}$ and $35,000 \mathrm{ft}^{3} / \mathrm{s}$.

HISTORICAL DATA.--Peak stage of January 1925 from floodmarks. The January 1925 flood was the highest since at least 1893 , based on gaging station upstream on Flint River at Albany.

REMARKS.--Peak stages for 1948-49 and 1956 are estimated, based on gaging station upstream on Flint River at Albany.

\begin{tabular}{|c|c|c|c|c|c|c|c|c|c|c|c|}
\hline $\begin{array}{l}\text { Water } \\
\text { year }\end{array}$ & Date & $\begin{array}{c}\text { Discharge } \\
\left(\mathrm{ft}^{3} / \mathrm{s}\right)\end{array}$ & $\begin{array}{c}\text { Gage } \\
\text { height } \\
\text { (ft) }\end{array}$ & $\begin{array}{l}\text { Water } \\
\text { year }\end{array}$ & Date & $\begin{array}{c}\text { Discharge } \\
\left(\mathrm{ft}^{3} / \mathrm{s}\right)\end{array}$ & $\begin{array}{c}\text { Gage } \\
\text { height } \\
\text { (ft) }\end{array}$ & $\begin{array}{l}\text { Water } \\
\text { year }\end{array}$ & Date & $\begin{array}{c}\text { Discharge } \\
\left(\mathrm{ft}^{3} / \mathrm{s}\right)\end{array}$ & $\begin{array}{c}\text { Gage } \\
\text { height } \\
\text { (ft) }\end{array}$ \\
\hline$\underline{1925}$ & Jan. 21 & 94,000 & $41.30 c$ & 1955 & Apr. 20 & 15,600 & 14.50 & 1973 & Feb. 05 & 30,800 & 22.50 \\
\hline$\overline{1938}$ & Apr. 15 & 40,000 & 25.60 & 1956 & Mar. 24 & 19,000 & - & 1974 & Apr. 08 & 22,200 & 18.15 \\
\hline 1939 & Mar. 07 & 40,200 & 25.70 & 1957 & Apr. 13 & 24,200 & 19.20 & 1975 & Mar. 22 & 47,700 & 28.91 \\
\hline 1940 & Feb. 22 & 25,400 & 19.20 & 1958 & Mar. 15 & 30,100 & 22.20 & 1976 & May 18 & 21,300 & 17.70 \\
\hline 1941 & Mar. 24 & 8,940 & 10.40 & 1959 & June 09 & 24,400 & 19.30 & 1977 & Mar. 10 & 26,000 & 20.13 \\
\hline 1942 & Mar. 30 & 43,000 & 26.80 & 1960 & Apr. 08 & 52,400 & 30.90 & 1978 & Feb. 02 & 41,000 & 26.62 \\
\hline 1943 & Mar. 27 & 51,100 & 29.60 & 1961 & Mar. 04 & 45,700 & 27.70 & 1979 & Mar. 03 & 37,400 & 25.25 \\
\hline 1944 & Mar. 28 & 59,600 & 31.70 & 1962 & Mar. 19 & 26,500 & 20.40 & 1980 & Mar. 16 & 35,100 & 24.33 \\
\hline 1945 & May 03 & 23,400 & 18.20 & 1963 & Jan. 28 & 26,700 & 20.50 & 1981 & Feb. 18 & 25,500 & 19.87 \\
\hline 1946 & Jan. 16 & 29,200 & 21.00 & 1964 & Apr. 15 & 53,400 & 30.20 & 1982 & Feb. 10 & 22,600 & 18.36 \\
\hline 1947 & Mar. 15 & 32,600 & 22.50 & 1965 & Jan. 02 & 37,900 & 25.10 & 1983 & Apr. 16 & 30,700 & 21.90 \\
\hline 1948 & Apr. 03 & 45,000 & - & 1966 & Mar. 09 & 66,600 & 34.90 & 1984 & Mar. 08 & 27,500 & 20.38 \\
\hline 1949 & Dec. 05 & 64,000 & - & 1967 & Jan. 06 & 26,000 & 20.16 & 1985 & Feb. 10 & 25,900 & 19.61 \\
\hline 1950 & Mar. 13 & 13,200 & 13.20 & 1968 & Mar. 19 & 22,200 & 18.15 & 1986 & Feb. 12 & 15,800 & 14.29 \\
\hline 1951 & Apr. 29 & 14,600 & 14.00 & 1969 & Apr. 26 & 18,600 & 16.20 & 1987 & Mar. 07 & 26,100 & 19.73 \\
\hline 1952 & Mar. 31 & 30,400 & 22.33 & 1970 & Apr. 04 & 47,300 & 28.76 & 1988 & Jan. 26 & 12,900 & 12.54 \\
\hline 1953 & May 10 & 40,000 & 25.68 & 1971 & Mar. 11 & 52,000 & 30.34 & 1989 & Apr. 15 & 17,400 & 15.18 \\
\hline 1954 & Dec. 12 & 25,200 & 19.72 & 1972 & Jan. 20 & 30,600 & 22.45 & 1990 & Mar. 25 & 47,700 & 28.81 \\
\hline
\end{tabular}

02353100 ICHAWAYNOCHAWAY CREEK NEAR GRAVES, GEORGIA

Formerly published as "Ichawaynochaway Creek near Dawson, Georgia"

LOCATION.--Lat $31^{\circ} 46^{\prime} 16^{\prime \prime}$, long $84^{\circ} 33^{\prime} 44^{\prime \prime}$, Terrell County, at State Highway 50 and U.S. Highway $82,5.0$ mi west of Graves. DRAINAGE AREA.--118 $\mathrm{mi}^{2}$.

GAGE.--Crest-stage gage. Datum of gage is $272.70 \mathrm{ft}$ above sea level (levels by the U.S. Geological Survey).

STAGE-DISCHARGE RELATION.--Defined by current-meter measurements below $2,230 \mathrm{ft}^{3} / \mathrm{s}$, and extended above on the basis of straight-line extension. Bankfull stage and discharge, $8 \mathrm{ft}$ and $1,400 \mathrm{ft}^{3} / \mathrm{s}$.

\begin{tabular}{|c|c|c|c|c|c|c|c|c|c|c|c|}
\hline $\begin{array}{l}\text { Water } \\
\text { year }\end{array}$ & Date & $\begin{array}{c}\text { Discharge } \\
\left(\mathrm{ft}^{3} / \mathrm{s}\right)\end{array}$ & $\begin{array}{c}\text { Gage } \\
\text { height } \\
\text { (ft) }\end{array}$ & $\begin{array}{l}\text { Water } \\
\text { year }\end{array}$ & Date & $\begin{array}{c}\text { Discharge } \\
\left(\mathrm{ft}^{3} / \mathrm{s}\right)\end{array}$ & $\begin{array}{c}\text { Gage } \\
\text { height } \\
\text { (ft) }\end{array}$ & $\begin{array}{l}\text { Water } \\
\text { year }\end{array}$ & Date & $\begin{array}{c}\text { Discharge } \\
\left(\mathrm{ft}^{3} / \mathrm{s}\right)\end{array}$ & $\begin{array}{c}\text { Gage } \\
\text { height } \\
\text { (ft) }\end{array}$ \\
\hline 1963 & Feb. 12 & 1,280 & 7.88 & 1971 & Mar. 26 & 1,300 & 7.93 & 1978 & Jan. 27 & 3,460 & 9.74 \\
\hline 1964 & Jan. 10 & 1,700 & 8.40 & 1972 & Dec. 20 & 1,070 & 7.60 & 1979 & Feb. 26 & 2,120 & 8.79 \\
\hline 1965 & Jan. 27 & 2,790 & 9.34 & 1973 & Apr. 27 & 2,110 & 8.78 & 1980 & Mar. 31 & 972 & 7.46 \\
\hline 1966 & Mar. 04 & 3,420 & 9.71 & 1974 & Apr. 05 & 1,730 & 8.43 & 1981 & Feb. 11 & 2,120 & 8.79 \\
\hline 1967 & Jan. 04 & 1,670 & 8.37 & 1975 & Feb. 19 & 2,690 & 9.23 & 1982 & Jan. 05 & 1,420 & 8.07 \\
\hline 1968 & Dec. 10 & 505 & 6.57 & 1976 & May 16 & 1,500 & 8.17 & $\underline{1983}$ & Mar. 06 & 2,960 & 9.41 \\
\hline 1969 & Mar. 19 & 816 & 7.21 & 1977 & Nov. 30 & 1,720 & 8.42 & $\overline{1990}$ & Mar. 20 & 1,080 & $7.62 c$ \\
\hline 1970 & Mar. 31 & 3,960 & 10.05 & & & & & & & & \\
\hline
\end{tabular}




\section{APALACHICOLA RIVER BASIN}

\section{LITTLE ICHAWAYNOCHAWAY CREEK NEAR SHELLMAN, GEORGIA}

(Formerly published as "Nochaway Creek near Shellman, Georgia")

LOCATION.--Lat $31^{\circ} 46^{\prime} 45^{\prime \prime}$, long $84^{\circ} 36^{\prime} 13^{\prime \prime}$, Randolph County, at State Highway 41, 1.5 mi north of Shellman.

DRAINAGE AREA. $-52 \mathrm{mi}^{2}$, approximately.

GAGE.--Crest-stage gage. Datum of gage is $288.26 \mathrm{ft}$ above sea level (levels by the U.S. Geological Survey).

STAGE-DISCHARGE RELATION.--Defined by current-meter measurements below $560 \mathrm{tt}^{3} / \mathrm{s}$, and extended above on the basis of slope-conveyance studies. Stage-discharge relation unstable.

\begin{tabular}{|c|c|c|c|c|c|c|c|c|c|c|c|}
\hline $\begin{array}{l}\text { Water } \\
\text { year }\end{array}$ & Date & $\begin{array}{c}\text { Discharge } \\
\left(\mathrm{ft}^{3} / \mathrm{s}\right)\end{array}$ & $\begin{array}{c}\text { Gage } \\
\text { height } \\
\text { (ft) }\end{array}$ & $\begin{array}{l}\text { Water } \\
\text { year }\end{array}$ & Date & $\begin{array}{c}\text { Discharge } \\
\left(\mathrm{ft}^{3} / \mathrm{s}\right)\end{array}$ & $\begin{array}{l}\text { Gage } \\
\text { height } \\
\text { (ft) }\end{array}$ & $\begin{array}{l}\text { Water } \\
\text { year }\end{array}$ & Date & $\begin{array}{c}\text { Discharge } \\
\left(\mathrm{ft}^{3} / \mathrm{s}\right)\end{array}$ & $\begin{array}{c}\text { Gage } \\
\text { height } \\
\text { (ft) }\end{array}$ \\
\hline 1951 & Apr. 01 & 544 & 4.04 & 1955 & Apr. - & 282 & 3.30 & 1959 & May 21 & 870 & 4.84 \\
\hline 1952 & Feb. 15 & 502 & 4.32 & 1956 & Sept.00 & 300 & 3.40 & 1960 & Apr. 03 & 930 & 4.96 \\
\hline 1953 & May 03 & 2,130 & 6.91 & 1957 & Apr. 06 & 450 & 4.02 & 1961 & Apr. 12 & 320 & 3.52 \\
\hline 1954 & Dec. 08 & 449 & 4.17 & 1958 & Feb. 27 & 450 & 4.02 & 1962 & Jan. 07 & 1,880 & 6.60 \\
\hline
\end{tabular}

\section{PACHITLA CREEK NEAR EDISON, GEORGIA}

LOCATION.--Lat $31^{\circ} 33^{\prime} 17^{\prime \prime}$, long $84^{\circ} 40^{\prime} 43^{\prime \prime}$, Calhoun County, at bridge on State Highway $37,3.6$ mi east of Edison, and 8.5 mi upstream from mouth.

DRAINAGE AREA. $-188 \mathrm{mi}^{2}$.

GAGE.--Crest-stage gage from Mar. 17, 1949 to Mar. 16, 1955 at same site and datum. Crest-stage gage from Mar. 17, 1955 to June 9, 1959 at site $200 \mathrm{ft}$ downstream at same datum; water-stage recorder June 9, 1959 to Sept. 30, 1971 at same site and datum; crest-stage gage, Oct. 1, 1971 to March 1988; water-stage recorder thereafter at same site and datum. Datum of gage is $212.64 \mathrm{ft}$ above sea level (levels by the Georgia Department of Transportation) (revised).

STAGE-DISCHARGE RELATION.--Defined by current-meter measurements below $3,400 \mathrm{ft}^{3} / \mathrm{s}$, and extended above on the basis of slope-conveyance studies. Bankfull stage and discharge, $6 \mathrm{ft}$ and $800 \mathrm{ft}^{3} / \mathrm{s}$.

HISTORICAL DATA.--Flood peaks of 1916, 1928, and 1948 were provided by the Georgia Department of Transportation. The flood of 1916 is thought to be the highest since 1900 , based on information at nearby stations.

\begin{tabular}{|c|c|c|c|c|c|c|c|c|c|c|c|}
\hline $\begin{array}{l}\text { Water } \\
\text { year }\end{array}$ & Date & $\begin{array}{c}\text { Discharge } \\
\left(\mathrm{ft}^{3} / \mathrm{s}\right)\end{array}$ & $\begin{array}{c}\text { Gage } \\
\text { height } \\
\text { (ft) }\end{array}$ & $\begin{array}{l}\text { Water } \\
\text { year }\end{array}$ & Date & $\begin{array}{c}\text { Discharge } \\
\left(\mathrm{ft}^{3} / \mathrm{s}\right)\end{array}$ & $\begin{array}{c}\text { Gage } \\
\text { height } \\
\text { (ft) }\end{array}$ & $\begin{array}{l}\text { Water } \\
\text { year }\end{array}$ & Date & $\begin{array}{c}\text { Discharge } \\
\left(\mathrm{ft}^{3} / \mathrm{s}\right)\end{array}$ & $\begin{array}{c}\text { Gage } \\
\text { height } \\
\text { (ft) }\end{array}$ \\
\hline$\underline{1916}$ & July 10 & 11,800 & $11.88 \mathrm{c}$ & 1959 & Mar. 07 & $\underline{2,280}$ & 7.19 & 1971 & Jan. 05 & 3,800 & 8.14 \\
\hline 1928 & Sept.29 & 7,000 & $9.83 c$ & 1960 & Apr. 05 & 5,580 & 9.19 & 1972 & Jan. 05 & 3,680 & 8.05 \\
\hline$\underline{1948}$ & July 12 & 5,200 & $8.93 c$ & 1961 & Apr. 01 & 5,140 & 8.97 & 1973 & Dec. 09 & 3,700 & 8.10 \\
\hline$\overline{1950}$ & Sept.01 & 2,700 & 7.37 & 1962 & Jan. 07 & 7,880 & 10.34 & 1974 & Jan. 03 & 5,010 & 8.88 \\
\hline 1951 & Apr. 01 & 1,130 & 6.30 & 1963 & Feb. 12 & 2,380 & 7.24 & 1975 & Apr. 11 & 2,540 & 7.51 \\
\hline 1952 & Feb. 14 & 1,650 & 6.74 & 1964 & Jan. 09 & 3,800 & 8.12 & 1976 & Jan. 26 & 778 & 5.94 \\
\hline 1953 & Sept.30 & 1,510 & 6.63 & 1965 & Dec. 26 & 5,190 & 8.99 & 1977 & Nov. 30 & 3,950 & 8.20 \\
\hline 1954 & Dec. 27 & 2,060 & 7.02 & 1966 & Mar. 05 & 4,700 & 8.50 & $\underline{1978}$ & Jan. 26 & 6,820 & 9.81 \\
\hline 1955 & Apr. 17 & $\underline{1,110}$ & 6.28 & 1967 & Jan. 02 & 2,420 & 7.44 & $\underline{1981}$ & Jan. 07 & 3,940 & $8.19 \mathrm{c}$ \\
\hline 1956 & Feb. 18 & 2,040 & 7.01 & 1968 & Dec. 12 & 995 & 6.25 & 1989 & July 16 & 2,040 & $7.18 \mathrm{c}$ \\
\hline 1957 & Apr. 07 & 2,500 & 7.27 & 1969 & May 19 & 1,640 & 6.87 & 1990 & Oct. 02 & 2,330 & $7.38 \mathrm{c}$ \\
\hline 1958 & Mar. 09 & 1,760 & 6.82 & 1970 & Mar. 31 & 5,100 & 8.94 & & & & \\
\hline
\end{tabular}




\section{APALACHICOLA RIVER BASIN}

\section{ICHAWAYNOCHAWAY CREEK AT MILFORD, GEORGIA}

LOCATION.-Lat $31^{\circ} 22^{\prime} 58^{\prime \prime}$, long $84^{\circ} 32^{\prime} 52^{\prime \prime}$, Baker County, on downstream end of left bank pier of bridge on State Highway 216 at Milford, 2.2 mi upstream from Alligator Creek, and 5.5 mi upstream from Chickasawhatchee Creek.

DRAINAGE AREA.-620 $\mathrm{mi}^{2}$, approximately.

GAGE.--Water-stage recorder. Datum of gage is $150.3 \mathrm{ft}$ above sea level (levels by the Georgia Department of Transportation).

Aug. 29, 1905, to Dec. 31, 1907, nonrecording gage at several sites within $450 \mathrm{ft}$ of present site at various datums. Oct. 1 , 1939, to Nov. 10, 1941, nonrecording gage at site $100 \mathrm{ft}$ downstream at present datum.

STAGE-DISCHARGE RELATION.--Defined by current-meter measurements below $14,000 \mathrm{ft}^{3} / \mathrm{s}$, and extended above on the basis of straight-line extension. Bankfull stage and discharge, $7 \mathrm{ft}$ and $3,400 \mathrm{ft}^{3} / \mathrm{s}$.

HISTORICAL DATA.--Peak stages of July 1916 and January 1925 based on information furnished by local residents at present site and datum. The July 1916 peak is thought to be the highest since 1900, based on information from local residents and nearby gaging station.

REMARKS.--Peak discharge for 1947 is estimated. The peak stage for the 1925 flood at present site and datum.

\begin{tabular}{|c|c|c|c|c|c|c|c|c|c|c|c|}
\hline $\begin{array}{l}\text { Water } \\
\text { year }\end{array}$ & Date & $\begin{array}{c}\text { Discharge } \\
\left(\mathrm{ft}^{3} / \mathrm{s}\right)\end{array}$ & $\begin{array}{c}\text { Gage } \\
\text { height } \\
\text { (ft) }\end{array}$ & $\begin{array}{c}\text { Water } \\
\text { year }\end{array}$ & Date & $\begin{array}{c}\text { Discharge } \\
\left(\mathrm{ft}^{3} / \mathrm{s}\right)\end{array}$ & $\begin{array}{c}\text { Gage } \\
\text { height } \\
\text { (ft) }\end{array}$ & $\begin{array}{c}\text { Water } \\
\text { year }\end{array}$ & Date & $\begin{array}{c}\text { Discharge } \\
\left(\mathrm{ft}^{3} / \mathrm{s}\right)\end{array}$ & $\begin{array}{c}\text { Gage } \\
\text { height } \\
\text { (ft) }\end{array}$ \\
\hline 1906 & June 14 & 8,780 & $\underline{12.80}$ & 1955 & Apr. 17 & 1,540 & 3.40 & 1973 & Feb. 03 & 8,560 & 12.42 \\
\hline 1907 & Sept. 30 & 7,400 & $\underline{13.80}$ & 1956 & Feb. 18 & 3,020 & 6.40 & 1974 & Feb. 09 & 5,850 & 9.67 \\
\hline$\overline{1925}$ & Jan. 21 & 13,800 & $16.20 c$ & 1958 & Apr. 12 & 4,090 & 8.00 & 1976 & May 17 & 3,830 & 7.23 \\
\hline 1940 & Feb. 20 & 9,000 & 12.80 & 1959 & Mar. 08 & 4,250 & 8.20 & 1977 & Nov. 30 & 7,890 & 11.79 \\
\hline 1941 & Nov. 17 & $\underline{1,940}$ & 4.16 & 1960 & Apr. 06 & 9,960 & 13.80 & 1978 & Jan. 27 & 11,900 & 15.08 \\
\hline 1942 & $\overline{\text { Mar. } 23}$ & $\overline{4,010}$ & 7.87 & 1961 & Apr. 17 & 7,900 & 12.00 & 1979 & Feb. 26 & 8,010 & 11.91 \\
\hline 1943 & Jan. 21 & 10,100 & 13.90 & 1962 & Jan. 09 & 6,400 & 10.60 & 1980 & Mar. 14 & 7,890 & 11.79 \\
\hline 1944 & Apr. 17 & 9,000 & 13.00 & 1963 & Feb. 14 & 3,450 & 7.10 & 1981 & Feb. 15 & 3,260 & 6.36 \\
\hline 1945 & Sept.17 & 1,940 & 4.23 & 1964 & Mar. 05 & 7,570 & 11.70 & 1982 & Feb. 05 & 7,370 & 11.27 \\
\hline 1947 & Mar. 10 & 8,200 & - & 1966 & Mar. 06 & 9,480 & 13.23 & 1984 & May 05 & 10,300 & 13.90 \\
\hline 1948 & July 12 & 8,230 & 12.30 & 1967 & Jan. 04 & 5,590 & 9.38 & 1985 & Feb. 08 & 7,010 & 10.91 \\
\hline 1949 & Dec. 09 & 7,680 & 11.80 & 1968 & Mar. 14 & 1,370 & 3.01 & 1986 & Dec. 17 & 2,360 & 4.81 \\
\hline 1950 & Sept.03 & 2,360 & 4.76 & 1969 & Mar. 27 & 2,340 & 4.78 & 1987 & Jan. 24 & 3,310 & 6.46 \\
\hline 1951 & Apr. 02 & 1,770 & 3.70 & 1970 & Apr. 02 & 9,210 & 13.01 & 1988 & Mar. 07 & 2,630 & 5.30 \\
\hline 1952 & Feb. 19 & 2,510 & 5.40 & 1971 & Feb. 23 & 4,320 & 7.84 & 1989 & July 18 & 3,030 & 6.04 \\
\hline 1953 & May 08 & 3,800 & 7.60 & 1972 & Dec. 23 & 5,640 & 9.43 & 1990 & Jan. 09 & 5,000 & 8.70 \\
\hline 1954 & Dec. 16 & 4,010 & 7.90 & & & & & & & & \\
\hline
\end{tabular}




\section{APALACHICOLA RIVER BASIN}

\section{CHICKASAWHATCHEE CREEK AT ELMODEL, GEORGIA}

LOCATION.--Lat $31^{\circ} 21^{\prime} 09^{\prime \prime}$, long $84^{\circ} 29^{\prime} 10^{\prime \prime}$, Baker County, at bridge on State Highway 37 at Elmodel, and 2 mi upstream from mouth.

DRAINAGE AREA.-320 $\mathrm{mi}^{2}$, approximately.

GAGE.--Nonrecording prior to Oct. 30, 1941; recording Oct. 30, 1941 to Dec. 31, 1949; crest-stage gage after Sept. 25, 1951.

Datum of gage is $137.7 \mathrm{ft}$ above sea level (levels by the Georgia Department of Transportation).

STAGE-DISCHARGE RELATION.--Defined by current-meter measurements below $3,630 \mathrm{ft}^{3} / \mathrm{s}$. Bankfull stage and discharge, $6 \mathrm{ft}$ and $900 \mathrm{ft}^{3} / \mathrm{s}$.

REMARKS.--Peak discharge for 1955 based on gaging station on Ichawaynochaway Creek at Milford and near Newton.

\begin{tabular}{|c|c|c|c|c|c|c|c|c|c|c|c|}
\hline $\begin{array}{l}\text { Water } \\
\text { year }\end{array}$ & Date & $\begin{array}{c}\text { Discharge } \\
\left(\mathrm{ft}^{3} / \mathrm{s}\right)\end{array}$ & $\begin{array}{c}\text { Gage } \\
\text { height } \\
\text { (ft) }\end{array}$ & $\begin{array}{c}\text { Water } \\
\text { year }\end{array}$ & Date & $\begin{array}{c}\text { Discharge } \\
\left(\mathrm{ft}^{3} / \mathrm{s}\right)\end{array}$ & $\begin{array}{c}\text { Gage } \\
\text { height } \\
\text { (ft) }\end{array}$ & $\begin{array}{l}\text { Water } \\
\text { year }\end{array}$ & Date & $\begin{array}{c}\text { Discharge } \\
\left(\mathrm{ft}^{3} / \mathrm{s}\right)\end{array}$ & $\begin{array}{c}\text { Gage } \\
\text { height } \\
\text { (ft) }\end{array}$ \\
\hline 1940 & Feb. 21 & 3,180 & 11.50 & 1955 & Apr. 17 & 670 & - & 1972 & Apr. 01 & 2,120 & 8.84 \\
\hline 1941 & Mar. 26 & 608 & 4.88 & 1956 & Apr. 02 & 1,170 & 6.23 & 1973 & Feb. 03 & 3,250 & 10.93 \\
\hline 1942 & Jan. 08 & 1,920 & 9.10 & 1957 & Apr. 08 & 1,260 & 6.53 & 1974 & Feb. 09 & 2,360 & 9.32 \\
\hline 1943 & Jan. 21 & 1,460 & 8.00 & 1958 & Apr. 10 & 2,480 & 9.56 & 1975 & Apr. 16 & 3,760 & 11.66 \\
\hline 1944 & Apr. 20 & 3,240 & 11.60 & 1959 & Mar. 07 & 2,160 & 8.91 & 1976 & May 17 & 2,660 & 9.92 \\
\hline 1945 & Sept.20 & 724 & 5.32 & 1960 & Apr. 06 & 3,860 & 11.80 & 1977 & Nov. 30 & 2,370 & 9.34 \\
\hline 1946 & May 24 & 2,340 & 10.00 & 1961 & Apr. 17 & 3,120 & 10.70 & 1978 & Jan. 27 & 4,300 & 12.38 \\
\hline 1947 & Mar. 12 & 2,450 & 10.20 & 1962 & Apr. 01 & 1,240 & 6.46 & 1979 & Mar. 09 & 2,760 & 10.43 \\
\hline 1948 & Mar. 10 & 3,630 & 11.90 & 1963 & Feb. 14 & 1,280 & 6.59 & 1980 & Mar. 17 & 3,210 & 10.85 \\
\hline 1949 & Dec. 11 & 2,700 & 10.60 & 1964 & Mar. 05 & 3,570 & 11.38 & 1981 & Feb. 12 & 1,830 & 8.21 \\
\hline 1952 & Feb. 19 & 1,320 & 6.75 & 1965 & Dec. 05 & 2,450 & 9.50 & 1982 & Mar. 07 & 1,930 & 8.45 \\
\hline 1953 & May 08 & 1,390 & 6.98 & 1970 & Apr. 02 & 3,830 & 11.76 & 1983 & Feb. 15 & 2,750 & 10.08 \\
\hline 1954 & Dec. 30 & 2,140 & 8.87 & 1971 & Mar. 10 & 2,220 & 9.04 & & & & \\
\hline
\end{tabular}

\section{ICHAWAYNOCHAWAY CREEK NEAR NEWTON, GEORGIA}

LOCATION.--Lat $31^{\circ} 16^{\prime} 00^{\prime \prime}$, long $84^{\circ} 29^{\prime} 00^{\prime \prime}$, Baker County, $300 \mathrm{ft}$ upstream from bridge on State Highway $200,4.5$ mi downstream from Chickasawhatchee Creek, and 9 mi southwest of Newton.

DRAINAGE AREA.--1,020 $\mathrm{mi}^{2}$, approximately.

GAGE.--Nonrecording prior to Nov. 24, 1941; water-stage recorder thereafter. Prior to Sept. 21, 1939, at site 5 mi downstream at different datum. Datum of gage is $113.8 \mathrm{ft}$ above sea level (levels by the Georgia Department of Transportation), supplementary adjustment of 1936.

STAGE-DISCHARGE RELATION.--Defined by current-meter measurements below $10,000 \mathrm{ft}^{3} / \mathrm{s}$, and extended above on the basis of slope-conveyance studies. Bankfull stage and discharge, $7 \mathrm{ft}$ and $3,500 \mathrm{ft}^{3} / \mathrm{s}$.

HISTORICAL DATA.--Peak stages for July 1916 and January 1925 based on information furnished by local resident, and are at present site and datum. The July 1916 peak is thought to be the highest since 1900 , based on nearby gaging stations.

\begin{tabular}{|c|c|c|c|c|c|c|c|c|c|c|c|}
\hline $\begin{array}{l}\text { Water } \\
\text { year }\end{array}$ & Date & $\begin{array}{c}\text { Discharge } \\
\left(\mathrm{ft}^{3} / \mathrm{s}\right)\end{array}$ & $\begin{array}{c}\text { Gage } \\
\text { height } \\
\text { (ft) }\end{array}$ & $\begin{array}{l}\text { Water } \\
\text { year }\end{array}$ & Date & $\begin{array}{c}\text { Discharge } \\
\left(\mathrm{ft}^{3} / \mathrm{s}\right)\end{array}$ & $\begin{array}{c}\text { Gage } \\
\text { height } \\
\text { (ft) }\end{array}$ & $\begin{array}{l}\text { Water } \\
\text { year }\end{array}$ & Date & $\begin{array}{c}\text { Discharge } \\
\left(\mathrm{ft}^{3} / \mathrm{s}\right)\end{array}$ & $\begin{array}{c}\text { Gage } \\
\text { height } \\
\text { (ft) }\end{array}$ \\
\hline$\underline{1916}$ & July 14 & 28,000 & $35.00 \mathrm{c}$ & 1940 & Feb. 20 & 10,200 & 18.10 & 1944 & Apr. 18 & 10,300 & 18.30 \\
\hline$\underline{1925}$ & Jan. 23 & 21,000 & $30.00 c$ & 1941 & Mar. 12 & 2,080 & 4.40 & 1945 & May 17 & 2,350 & 4.86 \\
\hline 1938 & Nov. 15 & 2,450 & 6.20 & 1942 & Mar. 23 & 5,380 & 10.70 & 1946 & Apr. 01 & 7,100 & 13.70 \\
\hline 1939 & Mar. 03 & $\underline{8,800}$ & $\underline{17.40}$ & 1943 & Jan. 22 & 9,650 & 17.40 & 1947 & Mar. 10 & 9,720 & 17.50 \\
\hline
\end{tabular}




\section{APALACHICOLA RIVER BASIN}

\section{FLINT RIVER AT BAINBRIDGE, GEORGIA}

LOCATION.-Lat 3054'41", long 84 '34'48", Decatur County, on downstream side of right major pier of Decatur County Memorial Bridge on U.S. Highway 27 at Bainbridge, 0.2 mi downstream from Seaboard Coast Line Railroad bridge, and 29.2 mi upstream from Jim Woodruff Dam, and at mile 29.0.

DRAINAGE AREA.--7,570 $\mathrm{mi}^{2}$, approximately.

GAGE.--Nonrecording prior to Jan. 16, 1929; water-stage recorder thereafter. Prior to Jan. 24, 1925, at datum $0.3 \mathrm{ft}$ higher. Jan. 15, 1957 to Sept. 30, 1971, auxiliary water-stage recorder at site $6.4 \mathrm{mi}$ upstream. Datum of gage is $58.06 \mathrm{ft}$ above sea level (from the U.S. Coast and Geodetic Survey benchmark).

STAGE-DISCHARGE RELATION.--Defined for period after 1928 by current-meter measurements below $70,000 \mathrm{Ht}^{3} / \mathrm{s}$, and extended above on the basis of slope-conveyance studies. Prior to 1928, stage-discharge relation defined by seven current-meter measurements made during 1908-12, stage relation with gage on Fint River at Albany, and present stage-discharge relation. The change in stage-discharge relation of about $3 \mathrm{ft}$, from 1908 to 1928, is due either to a gradual shift in the channel or unknown change in datum. Stage-discharge relation affected by backwater from Jim Woodruff Reservoir since 1955. Bankfull stage and discharge, $18 \mathrm{ft}$ and $20,000 \mathrm{ft}^{3} / \mathrm{s}$.

HISTORICAL DATA.-Peak of January 1925 is highest since 1893, based on information from the National Weather Service.

REMARKS.--Peak stages for 1897, 1905-07, 1914-28, and 1972-74 are from the National Weather Service. Peak stage of the 1897 flood is from floodmark. Peak discharges for 1977 and 1982 are estimated.

\begin{tabular}{|c|c|c|c|c|c|c|c|c|c|c|c|}
\hline $\begin{array}{l}\text { Water } \\
\text { year }\end{array}$ & Date & $\begin{array}{c}\text { Discharge } \\
\left(\mathrm{ft}^{3} / \mathrm{s}\right)\end{array}$ & $\begin{array}{c}\text { Gage } \\
\text { height } \\
\text { (ft) }\end{array}$ & $\begin{array}{c}\text { Water } \\
\text { year }\end{array}$ & Date & $\begin{array}{c}\text { Discharge } \\
\left(\mathrm{ft}^{3} / \mathrm{s}\right)\end{array}$ & $\begin{array}{c}\text { Gage } \\
\text { height } \\
\text { (ft) }\end{array}$ & $\begin{array}{l}\text { Water } \\
\text { year }\end{array}$ & Date & $\begin{array}{c}\text { Discharge } \\
\left(\mathrm{ft}^{3} / \mathrm{s}\right)\end{array}$ & $\begin{array}{c}\text { Gage } \\
\text { height } \\
\text { (ft) }\end{array}$ \\
\hline$\underline{1897}$ & Mar. 26 & 83,000 & $34.30 \mathrm{c}$ & 1933 & Mar. 01 & 25,900 & 20.80 & 1962 & Apr. 19 & 27,700 & 23.50 \\
\hline$\overline{1905}$ & Feb. 19 & 41,500 & 24.80 & 1934 & Mar. 13 & 20,900 & 18.40 & 1963 & Jan. 29 & 27,600 & 23.30 \\
\hline 1906 & Jan. 27 & 30,300 & 20.40 & 1935 & Mar. 15 & 14,200 & 14.50 & 1964 & Apr. 16 & 46,800 & 28.05 \\
\hline 1907 & Apr. 29 & 14,600 & 12.30 & 1936 & Apr. 17 & 51,700 & 30.90 & 1965 & Jan. 02 & 37,600 & 26.15 \\
\hline 1908 & May 06 & 47,600 & 26.80 & 1937 & Apr. 10 & 25,000 & 21.80 & 1966 & Mar. 09 & 68,500 & 31.22 \\
\hline 1909 & Mar. 26 & 33,600 & 21.80 & 1938 & Apr. 16 & 36,200 & 26.40 & 1967 & Jan. 07 & 28,400 & 24.10 \\
\hline 1910 & Mar. 11 & 17,900 & 14.30 & 1939 & Mar. 07 & 40,700 & 27.70 & 1968 & Mar. 19 & 21,000 & 22.10 \\
\hline 1911 & Jan. 11 & 9,060 & 8.40 & 1940 & Feb. 22 & 30,000 & 24.00 & 1969 & Apr. 26 & 17,700 & 21.57 \\
\hline 1912 & Apr. 26 & 72,800 & 33.20 & 1941 & Mar. 26 & 11,000 & 12.00 & 1970 & Apr. 04 & 48,600 & 28.12 \\
\hline 1913 & Mar. 23 & 63,500 & 31.10 & 1942 & Mar. 31 & 40,700 & 27.90 & 1971 & Mar. 12 & 46,400 & 27.65 \\
\hline 1914 & Mar. 06 & 14,200 & 12.40 & 1943 & Mar. 28 & 50,100 & 30.50 & 1972 & Jan. 19 & 29,600 & 24.33 \\
\hline 1915 & Jan. 26 & 23,700 & 17.90 & 1944 & Mar. 29 & 58,800 & 32.60 & 1973 & Feb. 08 & 38,100 & 26.07 \\
\hline 1916 & July 13 & 51,000 & 28.40 & 1945 & May 03 & 21,900 & 19.80 & 1974 & Feb. 22 & 27,500 & 23.59 \\
\hline 1917 & Mar. 13 & 29,200 & 20.60 & 1946 & Apr. 02 & 29,800 & 23.90 & 1975 & Mar. 24 & 47,800 & 28.11 \\
\hline 1918 & Feb. 10 & 14,300 & 13.10 & 1947 & Mar. 16 & 32,400 & 25.00 & 1976 & May 19 & 24,600 & 22.79 \\
\hline 1919 & Mar. 05 & 52,400 & 29.20 & 1948 & Apr. 05 & 61,500 & 33.20 & 1977 & Mar. 11 & 30,000 & - \\
\hline 1920 & Mar. 08 & 46,000 & 27.40 & 1949 & Dec. 07 & 51,700 & 30.90 & 1978 & $\operatorname{Jan} .31$ & 45,000 & 27.00 \\
\hline 1921 & Feb. 19 & 19,000 & 16.20 & 1950 & Mar. 13 & 13,500 & 14.30 & 1979 & Mar. 01 & 40,600 & 26.15 \\
\hline 1922 & Mar. 18 & 41,800 & 26.30 & 1951 & Apr. 29 & 12,800 & 13.80 & 1980 & Apr. 06 & 39,800 & 25.99 \\
\hline 1923 & Mar. 27 & 31,400 & 22.40 & 1952 & Apr. 01 & 31,000 & 24.00 & 1981 & Feb. 19 & 23,800 & 22.79 \\
\hline 1924 & Apr. 20 & 22,100 & $\underline{18.20}$ & 1953 & May 11 & 37,900 & 27.00 & 1982 & Feb. 10 & 22,800 & - \\
\hline 1925 & Jan. 24 & 101,000 & $\overline{40.90}$ & 1954 & Dec. 14 & 24,500 & 21.30 & 1983 & Feb. 18 & 32,900 & 24.63 \\
\hline 1926 & Apr. 08 & 31,200 & 23.00 & 1955 & Apr. 21 & 16,300 & 16.30 & 1984 & Mar. 09 & 33,500 & 24.77 \\
\hline 1927 & Mar. 16 & 11,200 & 12.30 & 1956 & Mar. 24 & 18,400 & 17.70 & 1985 & Feb. 10 & 28,000 & 23.64 \\
\hline 1928 & Apr. 27 & 59,400 & 32.50 & 1957 & Apr. 14 & 26,100 & 23.26 & 1986 & Feb. 12 & 17,200 & 21.47 \\
\hline 1929 & Mar. 21 & 83,200 & 37.70 & 1958 & Mar. 15 & 34,400 & 25.40 & 1987 & Jan. 25 & 27,300 & 23.54 \\
\hline 1930 & Oct. 09 & 35,500 & 25.00 & 1959 & Mar. 10 & 26,800 & 23.42 & 1988 & Mar. 10 & 12,500 & 20.72 \\
\hline 1931 & Nov. 22 & 28,500 & 22.00 & 1960 & Apr. 09 & 59,600 & 30.15 & 1989 & Apr. 16 & 16,300 & 21.35 \\
\hline 1932 & Jan. 15 & 16,500 & 16.00 & 1961 & Mar. 06 & 44,100 & 26.72 & 1990 & Mar. 25 & 43,900 & 26.80 \\
\hline
\end{tabular}




\section{APALACHICOLA RIVER BASIN \\ 02356100 SPRING CREEK NEAR ARLINGTON, GEORGIA}

LOCATION.--Lat $31^{\circ} 24^{\prime} 47^{\prime \prime}$, long $84^{\circ} 46^{\prime} 33^{\prime \prime}$, Early County, at State Highway 62, $3.5 \mathrm{mi}$ southwest of Arlington.

DRAINAGE AREA.--49 $\mathrm{mi}^{2}$, approximately.

GAGE.--Crest-stage gage. Datum of gage is about $195 \mathrm{ft}$ above sea level (from topographic map).

STAGE-DISCHARGE RELATION.--Defined by current-meter measurements below $2,440 \mathrm{ft}^{3} / \mathrm{s}$, and extended above on the basis of straight-line extension. Bankfull stage and discharge, $7 \mathrm{ft}$ and $700 \mathrm{ft}^{3} / \mathrm{s}$.

\begin{tabular}{|c|c|c|c|c|c|c|c|c|c|c|c|}
\hline $\begin{array}{l}\text { Water } \\
\text { year }\end{array}$ & Date & $\begin{array}{c}\text { Discharge } \\
\left(\mathrm{ft}^{3} / \mathrm{s}\right)\end{array}$ & $\begin{array}{c}\text { Gage } \\
\text { height } \\
\text { (ft) }\end{array}$ & $\begin{array}{l}\text { Water } \\
\text { year }\end{array}$ & Date & $\begin{array}{c}\text { Discharge } \\
\left(\mathrm{ft}^{3} / \mathrm{s}\right)\end{array}$ & $\begin{array}{c}\text { Gage } \\
\text { height } \\
\text { (ft) }\end{array}$ & $\begin{array}{l}\text { Water } \\
\text { year }\end{array}$ & Date & $\begin{array}{c}\text { Discharge } \\
\left(\mathrm{ft}^{3} / \mathrm{s}\right)\end{array}$ & $\begin{array}{c}\text { Gage } \\
\text { height } \\
\text { (ft) }\end{array}$ \\
\hline 1951 & Apr. 01 & 560 & 6.85 & 1960 & Apr. 05 & 3,120 & 8.47 & 1972 & Feb. 08 & 304 & 6.49 \\
\hline 1952 & Feb. 17 & 592 & 6.89 & 1961 & Apr. 16 & 2,650 & 8.25 & 1973 & Jan. 23 & 1,050 & 7.31 \\
\hline 1953 & Mar. 15 & 512 & 6.79 & 1962 & Jan. 07 & 872 & 7.16 & 1975 & Apr. 11 & 3,750 & 8.40 \\
\hline 1954 & Jan. 03 & 860 & 7.15 & 1963 & Feb. 12 & 1,620 & 7.71 & 1976 & Mar. 15 & 720 & 7.02 \\
\hline 1955 & Apr. 19 & 214 & 6.31 & 1964 & Feb. 18 & 2,650 & 8.24 & 1977 & Nov. 30 & 1,750 & 7.80 \\
\hline 1956 & Feb. 06 & 472 & 6.74 & $\underline{1965}$ & Dec. 27 & 1,450 & 7.59 & 1978 & Jan. 26 & 4,880 & 9.15 \\
\hline 1957 & Apr. - & 1,170 & 7.41 & $\overline{1970}$ & Apr. 02 & 1,640 & 7.73 & 1979 & Feb. 27 & 1,850 & 7.85 \\
\hline 1958 & Apr. 14 & 1,340 & 7.53 & 1971 & Jan. 05 & 1,230 & 7.45 & & & & \\
\hline$\underline{1980}$ & Mar. 15 & 3,720 & 8.69 & & & & & & & & \\
\hline$\overline{1959}$ & Mar. 08 & 1,790 & 7.82 & & & & & & & & \\
\hline
\end{tabular}

02356640 SPRING CREEK AT COLQUITT, GEORGIA

LOCATION.--Lat 31 $10^{\prime} 14^{\prime \prime}$ long $84^{\circ} 44^{\prime} 34^{\prime \prime}$, Miller County, at bridge on U.S. Highway 27,1 mi north of Colquitt. DRAINAGE AREA.--281 $\mathrm{mi}^{2}$.

GAGE.--Crest-stage gage. Datum of gage is about $281 \mathrm{ft}$ above sea level (from topographic map).

STAGE-DISCHARGE RELATION.--Defined by current-meter measurements below $5,060 \mathrm{ft}^{3} / \mathrm{s}$, and extended above on the basis of straight-line extension.

\begin{tabular}{|c|c|c|c|c|c|c|c|c|c|c|c|}
\hline $\begin{array}{l}\text { Water } \\
\text { year }\end{array}$ & Date & $\begin{array}{c}\text { Discharge } \\
\left(\mathrm{ft}^{3} / \mathrm{s}\right)\end{array}$ & $\begin{array}{c}\text { Gage } \\
\text { height } \\
\text { (ft) }\end{array}$ & $\begin{array}{l}\text { Water } \\
\text { year }\end{array}$ & Date & $\begin{array}{c}\text { Discharge } \\
\left(\mathrm{ft}^{3} / \mathrm{s}\right)\end{array}$ & $\begin{array}{c}\text { Gage } \\
\text { height } \\
\text { (ft) }\end{array}$ & $\begin{array}{l}\text { Water } \\
\text { year }\end{array}$ & Date & $\begin{array}{c}\text { Discharge } \\
\left(\mathrm{ft}^{3} / \mathrm{s}\right)\end{array}$ & $\begin{array}{c}\text { Gage } \\
\text { height } \\
\text { (ft) }\end{array}$ \\
\hline 1981 & Apr. 06 & 660 & 6.18 & 1985 & Feb. 10 & 1,320 & 7.17 & 1988 & Feb. 22 & 2,560 & 8.55 \\
\hline 1982 & Feb. 06 & 6,240 & 11.23 & 1986 & Feb. 12 & 2,740 & 8.53 & 1989 & June 20 & 2,540 & 8.54 \\
\hline 1983 & Feb. 16 & 4,120 & 9.55 & 1987 & Apr. 01 & 2,810 & 8.59 & 1990 & Feb. 10 & 3,430 & 9.27 \\
\hline 1984 & Dec. 07 & 3,810 & 9.34 & & & & & & & & \\
\hline
\end{tabular}


LOCATION.--Lat $31^{\circ} 02^{\prime} 23^{\prime \prime}$, long $84^{\circ} 44^{\prime} 18^{\prime \prime}$, Decatur County, on right bank $25 \mathrm{ft}$ below county highway bridge, 1.5 mi downstream from Aycock Creek, 1.5 mi upstream from Dry Creek, and 5.5 mi northeast of Iron City.

DRAINAGE AREA.--485 $\mathrm{mi}^{2}$, approximately.

GAGE.--Nonrecording prior to Oct. 18, 1952; water-stage recorder, Oct. 18, 1952, to Apr. 30, 1971; crest-stage gage 1972 to Dec. 1978; water-stage recorder thereafter. Prior to Oct. 18, 1952, at site $125 \mathrm{ft}$ upstream. Datum of gage is $85.7 \mathrm{ft}$ above sea level (from U.S. Coast and Geodetic benchmark).

STAGE-DISCHARGE RELATION.--Defined by current-meter measurements below $13,000 \mathrm{ft}^{3} / \mathrm{s}$, and extended above on the basis of straight-line extension. Bankfull stage and discharge, $11 \mathrm{ft}$ and $1,700 \mathrm{ft}^{3} / \mathrm{s}$.

\begin{tabular}{|c|c|c|c|c|c|c|c|c|c|c|c|}
\hline $\begin{array}{l}\text { Water } \\
\text { year }\end{array}$ & Date & $\begin{array}{c}\text { Discharge } \\
\left(\mathrm{ft}^{3} / \mathrm{s}\right)\end{array}$ & $\begin{array}{c}\text { Gage } \\
\text { height } \\
\text { (ft) }\end{array}$ & $\begin{array}{l}\text { Water } \\
\text { year }\end{array}$ & Date & $\begin{array}{c}\text { Discharge } \\
\left(\mathrm{ft}^{3} / \mathrm{s}\right)\end{array}$ & $\begin{array}{c}\text { Gage } \\
\text { height } \\
\text { (ft) }\end{array}$ & $\begin{array}{l}\text { Water } \\
\text { year }\end{array}$ & Date & $\begin{array}{c}\text { Discharge } \\
\left(\mathrm{ft}^{3} / \mathrm{s}\right)\end{array}$ & $\begin{array}{c}\text { Gage } \\
\text { height } \\
\text { (ft) }\end{array}$ \\
\hline 1938 & Nov. 16 & 3,160 & 13.40 & 1955 & Aug. 01 & 632 & 7.00 & 1971 & Mar. 28 & 6,160 & 16.59 \\
\hline 1939 & Mar. 02 & 5,300 & 16.00 & 1956 & Mar. 18 & 1,390 & 10.20 & 1972 & Jan. 14 & 2,420 & 12.62 \\
\hline 1940 & Feb. 20 & 7,080 & 17.30 & 1957 & Apr. 10 & 2,060 & 11.90 & 1973 & Feb. 03 & 11,000 & 18.28 \\
\hline 1941 & Mar. 27 & 812 & 7.74 & 1958 & Oct. 03 & 4,250 & 15.10 & 1974 & Feb. 16 & 7,470 & 17.36 \\
\hline 1942 & Mar. 24 & 3,780 & 14.40 & 1959 & Mar. 09 & 4,940 & 15.70 & 1975 & Apr. 12 & 17,700 & 19.43 \\
\hline 1943 & Mar. 10 & 2,810 & 13.00 & 1960 & Apr. 06 & 8,260 & 17.80 & 1976 & May 27 & 4,940 & 15.09 \\
\hline 1944 & Mar. 09 & 7,240 & 17.40 & 1961 & Apr. 18 & 7,900 & 17.60 & 1977 & Mar. 09 & 4,740 & 14.96 \\
\hline 1945 & Apr. 30 & 1,840 & 11.00 & 1962 & Feb. 23 & 2,510 & 12.80 & $\underline{1978}$ & Jan. 28 & 13,400 & 18.35 \\
\hline 1946 & Mar. 30 & 5,900 & 16.50 & 1963 & Feb. 15 & 2,860 & 13.40 & 1983 & Feb. 16 & 7,840 & 16.27 \\
\hline 1947 & Mar. 10 & 7,900 & 17.60 & 1964 & Mar. 06 & 7,360 & 17.30 & 1984 & Mar. 08 & 6,860 & 16.16 \\
\hline 1948 & Apr. 02 & 12,600 & 19.90 & 1965 & Dec. 28 & 7,860 & 17.58 & 1985 & Mar. 07 & 1,200 & 9.34 \\
\hline 1949 & Dec. 10 & 8,080 & 17.70 & 1966 & Mar. 03 & 5,910 & 16.42 & 1986 & Feb. 12 & 5,860 & 15.87 \\
\hline 1950 & Apr. 02 & 1,120 & 9.30 & 1967 & Feb. 10 & 2,970 & 13.58 & 1987 & Jan. 25 & 3,660 & 13.96 \\
\hline 1951 & Apr. 05 & 563 & 6.60 & 1968 & Mar. 17 & 585 & 6.73 & 1988 & Mar. 02 & 4,540 & 14.28 \\
\hline 1952 & Feb. 19 & $\underline{2,310}$ & 12.40 & 1969 & Mar. 28 & 1,580 & 10.69 & 1989 & June 20 & 3,650 & 13.95 \\
\hline 1953 & May 10 & 1,460 & 10.60 & 1970 & Apr. 03 & 4,900 & 15.67 & 1990 & Jan. 10 & 5,840 & 15.64 \\
\hline 1954 & Dec. 27 & 2,460 & 12.70 & & & & & & & & \\
\hline
\end{tabular}




\section{CARTECAY RIVER NEAR ELLWAY, GEORGIA}

LOCATION.--Lat $34^{\circ} 40^{\prime} 53^{\prime \prime}$, long $84^{\circ} 27^{\prime} 20^{\prime \prime}$, Gilmer County, on right bank adjacent to State Highway $52,0.8$ mi downstream from Owltown Creek, 2 mi southeast of Ellijay, and 2 mi upstream from confluence with Ellijay River.

DRAINAGE AREA.-134 $\mathrm{mi}^{2}$ (revised).

GAGE.-Water-stage recorder, Dec. 19, 1938 to Sept. 30, 1977; crest-stage gage thereafter. Datum of gage is $1,255.39 \mathrm{ft}$ above sea level (levels by the U.S. Army Corps of Engineers). Prior to Dec. 19, 1938, nonrecording gage at same site and datum.

STAGE-DISCHARGE RELATION.--Defined by current-meter measurements below $3,900 \mathrm{ft}^{3} / \mathrm{s}$, and extended above on the basis of slope-area measurement to $20,000 \mathrm{ft}^{3} / \mathrm{s}$. Bankfull stage and discharge, $6 \mathrm{ft}$ and $3,700 \mathrm{ft}^{3} / \mathrm{s}$.

HISTORICAL DATA.-Peak of 1938 is the highest since 1886 , based on nearby gaging stations.

\begin{tabular}{|c|c|c|c|c|c|c|c|c|c|c|c|}
\hline $\begin{array}{l}\text { Water } \\
\text { year }\end{array}$ & Date & $\begin{array}{c}\text { Discharge } \\
\left(\mathrm{ft}^{3} / \mathrm{s}\right)\end{array}$ & $\begin{array}{c}\text { Gage } \\
\text { height } \\
\text { (ft) }\end{array}$ & $\begin{array}{l}\text { Water } \\
\text { year }\end{array}$ & Date & $\begin{array}{c}\text { Discharge } \\
\left(\mathrm{ft}^{3} / \mathrm{s}\right)\end{array}$ & $\begin{array}{c}\text { Gage } \\
\text { height } \\
\text { (ft) }\end{array}$ & $\begin{array}{l}\text { Water } \\
\text { year }\end{array}$ & Date & $\begin{array}{c}\text { Discharge } \\
\left(\mathrm{ft}^{3} / \mathrm{s}\right)\end{array}$ & $\begin{array}{c}\text { Gage } \\
\text { height } \\
\text { (ft) }\end{array}$ \\
\hline 1938 & Apr. 08 & 20,000 & 13.00 & 1955 & Mar. 22 & 4,860 & 6.80 & 1971 & Jan. 24 & 1,980 & 4.45 \\
\hline 1939 & Feb. 15 & 2,280 & 4.77 & 1956 & Apr. 15 & 3,880 & 6.10 & 1972 & Jan. 10 & 2,790 & 5.22 \\
\hline 1940 & Aug. 13 & 1,980 & 4.43 & 1957 & Apr. 04 & 5,940 & 7.53 & 1973 & May 28 & 9,100 & 9.22 \\
\hline 1941 & July 05 & 1,700 & 4.14 & 1958 & Dec. 20 & 2,280 & 4.76 & 1974 & Apr. 13 & 4,720 & 6.70 \\
\hline 1942 & Feb. 17 & 3,360 & 5.73 & 1959 & Jan. 21 & 1,780 & 4.27 & 1975 & Jan. 25 & 2,740 & 5.10 \\
\hline 1943 & Dec. 29 & 3,620 & 5.88 & 1960 & Mar. 03 & 1,140 & 3.55 & 1976 & May 15 & 4,640 & 6.49 \\
\hline 1944 & Feb. 27 & 3,120 & 5.50 & 1961 & Feb. 25 & 5,300 & 7.12 & 1977 & Mar. 30 & 9,190 & 9.15 \\
\hline 1945 & Feb. 17 & 1,150 & 3.50 & 1962 & Dec. 12 & 7,760 & 8.53 & 1978 & Nov. 05 & 3,620 & 5.90 \\
\hline 1946 & Feb. 10 & 6,960 & 8.10 & 1963 & Apr. 30 & 6,440 & 7.76 & 1979 & Mar. 04 & 10,400 & 9.75 \\
\hline 1947 & Jan. 20 & 5,940 & 7.46 & 1964 & Mar. 26 & 6,160 & 7.57 & 1980 & Mar. 21 & 5,300 & 7.10 \\
\hline 1948 & Feb. 12 & 3,240 & 5.56 & 1965 & Oct. 04 & 5,420 & 7.05 & 1981 & Feb. 10 & 1,860 & 4.32 \\
\hline 1949 & Nov. 28 & 4,860 & 6.77 & 1966 & Mar. 04 & 5,010 & 6.76 & 1982 & Feb. 03 & 7,920 & 8.61 \\
\hline 1950 & Mar. 13 & 6,260 & 7.74 & 1967 & Aug. 23 & 4,090 & 6.25 & 1983 & Feb. 02 & 2,770 & 5.20 \\
\hline 1951 & Mar. 29 & 12,000 & 10.40 & 1968 & Apr. 05 & 2,230 & 4.70 & 1985 & Feb. 01 & 1,860 & 4.32 \\
\hline 1952 & Mar. 11 & 4,860 & 6.80 & 1969 & Feb. 02 & 3,240 & 5.60 & $\underline{1986}$ & Aug. 20 & 1,060 & 3.42 \\
\hline 1953 & Feb. 21 & 2,940 & 5.33 & 1970 & June 04 & 2,730 & 5.16 & 1990 & Feb. 16 & 7,500 & $8.33 c$ \\
\hline 1954 & Jan. 16 & 10,000 & 9.60 & & & & & & & & \\
\hline
\end{tabular}

\section{ELLIJAY RIVER AT ELLIJAY, GEORGIA}

LOCATION.--Lat $34^{\circ} 41^{\prime} 06^{\prime \prime}$, long $84^{\circ} 28^{\prime} 40^{\prime \prime}$, Gilmer County, on left bank at downstream side of bridge on State Highway 5 at Ellijay, and 1 mi upstream from confluence with Cartecay River.

DRAINAGE AREA.--87.7 $\mathrm{mi}^{2}$, approximately (revised).

GAGE.--Nonrecording gage prior to June 30, 1921, and Feb. 26 to July 8, 1953. Prior to Feb. 26, 1953, at site 1,000 ft downstream at datum $1.44 \mathrm{ft}$ lower. Water-stage recorder, July 8, 1953, to Sept. 30, 1969; crest-stage gage thereafter. Auxilliary water recorder at site $1.0 \mathrm{mi}$ downstream at State Highway 52, from Aug. 19, 1965 to Sept. 30, 1969. Datum of gage is $1,242.32 \mathrm{ft}$ above sea level (from U.S. Coast and Geodetic benchmark), supplementary adjustment of 1936.

STAGE-DISCHARGE RELATION.-Defined by current-meter measurements below $5,500 \mathrm{ft}^{3} / \mathrm{s}$, and extended above on the basis of contracted-opening mesurement at $15,300 \mathrm{tt}^{3} / \mathrm{s}$. Bankfull stage and discharge, $14 \mathrm{ft}$ and $5,000 \mathrm{ft}^{3} / \mathrm{s}$.

REMARKS.--Peak stages of the 1938 and 1951 floods from floodmarks.

\begin{tabular}{|c|c|c|c|c|c|c|c|c|c|c|c|}
\hline $\begin{array}{l}\text { Water } \\
\text { year }\end{array}$ & Date & $\begin{array}{c}\text { Discharge } \\
\left(\mathrm{ft}^{3} / \mathrm{s}\right)\end{array}$ & $\begin{array}{c}\text { Gage } \\
\text { height } \\
\text { (ft) }\end{array}$ & $\begin{array}{l}\text { Water } \\
\text { year }\end{array}$ & Date & $\begin{array}{c}\text { Discharge } \\
\left(\mathrm{ft}^{3} / \mathrm{s}\right)\end{array}$ & $\begin{array}{c}\text { Gage } \\
\text { height } \\
\text { (ft) }\end{array}$ & $\begin{array}{l}\text { Water } \\
\text { year }\end{array}$ & Date & $\begin{array}{c}\text { Discharge } \\
\left(\mathrm{ft}^{3} / \mathrm{s}\right)\end{array}$ & $\begin{array}{c}\text { Gage } \\
\text { height } \\
\text { (ft) }\end{array}$ \\
\hline 1919 & Mar. 05 & 1,660 & 6.60 & 1958 & Nov. 18 & 2,780 & 10.40 & 1966 & Mar. 04 & 4,880 & 13.83 \\
\hline 1920 & Apr. 02 & 4,970 & 14.10 & 1959 & May 31 & 1,570 & 7.60 & 1967 & Aug. 23 & 7,180 & 15.34 \\
\hline 1921 & Feb. 10 & 4,170 & 12.50 & 1960 & Mar. 03 & 2,640 & 10.10 & 1968 & Dec. 22 & 2,500 & 9.78 \\
\hline$\underline{1938}$ & Apr. 08 & 8,000 & $17.22 \mathrm{c}$ & 1961 & Feb. 25 & 4,090 & 12.70 & 1969 & Feb. 02 & 2,750 & 10.33 \\
\hline$\overline{1951}$ & Mar. 29 & $\underline{6,400}$ & $\underline{16.73 \mathrm{c}}$ & 1962 & Dec. 12 & 4,790 & 13.70 & 1970 & June 04 & 1,840 & 8.27 \\
\hline 1954 & Jan. 16 & $\overline{7,940}$ & $\overline{16.30}$ & 1963 & Mar. 06 & 7,500 & 15.50 & 1971 & Aug. 09 & 1,280 & 6.88 \\
\hline 1955 & Feb. 06 & 3,720 & 12.90 & 1964 & Mar. 26 & 5,460 & 14.40 & $\underline{1972}$ & Jan. 10 & 1,740 & 8.02 \\
\hline 1956 & Apr. 16 & 4,580 & 13.40 & 1965 & Oct. 04 & 15,300 & 17.90 & $\overline{1990}$ & Feb. 16 & 12,000 & $17.22 \mathrm{c}$ \\
\hline 1957 & Feb. 01 & 5,860 & 14.80 & & & & & & & & \\
\hline
\end{tabular}


LOCATION.--Lat $34^{\circ} 40^{\prime} 18^{\prime \prime}$, long $84^{\circ} 30^{\prime} 31^{\prime \prime}$, Gilmer County, on right bank 0.5 mi downstream from State Highway 5,2 mi southwest of Ellijay, and 2.2 mi downstream from confluence of Cartecay and Ellijay Rivers.

DRAINAGE AREA. --236 $\mathrm{mi}^{2}$ (revised).

GAGE.-Water-stage recorder. Datum of gage is 1,216.04 ft above sea level (from U.S. Coast and Geodetic Survey benchmark).

Prior to June 10,1940, nonrecording gage at site 0.5 mi upstream at datum $8.04 \mathrm{ft}$ higher.

STAGE-DISCHARGE RELATION.-Defined by current-meter measurements below $13,000 \mathrm{ft}^{3} / \mathrm{s}$, and extended above on the basis of contracted-opening mesurement at $17,000 \mathrm{ft}^{3} / \mathrm{s}$. Bankfull stage and discharge, $9 \mathrm{ft}$ and $7,000 \mathrm{ft}^{3} / \mathrm{s}$.

HISTORICAL DATA.--Peak of March 1951 is highest since 1938, based on data at nearby stations. Peak stage of 1951 based on floodmark.

\begin{tabular}{|c|c|c|c|c|c|c|c|c|c|c|c|}
\hline $\begin{array}{l}\text { Water } \\
\text { year }\end{array}$ & Date & $\begin{array}{c}\text { Discharge } \\
\left(\mathrm{ft}^{3} / \mathrm{s}\right)\end{array}$ & $\begin{array}{c}\text { Gage } \\
\text { height } \\
\text { (ft) }\end{array}$ & $\begin{array}{l}\text { Water } \\
\text { year }\end{array}$ & Date & $\begin{array}{c}\text { Discharge } \\
\left(\mathrm{ft}^{3} / \mathrm{s}\right)\end{array}$ & $\begin{array}{c}\text { Gage } \\
\text { height } \\
\text { (ft) }\end{array}$ & $\begin{array}{l}\text { Water } \\
\text { year }\end{array}$ & Date & $\begin{array}{c}\text { Discharge } \\
\left(\mathrm{ft}^{3} / \mathrm{s}\right)\end{array}$ & $\begin{array}{c}\text { Gage } \\
\text { height } \\
\text { (ft) }\end{array}$ \\
\hline 1939 & Feb. 15 & $\underline{4,570}$ & $\underline{7.20}$ & 1965 & Oct. 04 & 17,000 & 17.63 & 1978 & Nov. 05 & 4,400 & 6.05 \\
\hline 1940 & Aug. 13 & 2,500 & 4.70 & 1966 & Mar. 04 & 9,210 & 11.46 & 1979 & Mar. 04 & 12,600 & 14.16 \\
\hline 1941 & July 05 & 2,040 & 4.17 & 1967 & Aug. 23 & 9,470 & 11.70 & 1980 & Mar. 21 & 8,090 & 9.64 \\
\hline 1942 & Feb. 17 & 5,790 & 8.16 & 1968 & Dec. 22 & 4,110 & 6.45 & 1981 & Feb. 11 & 2,800 & 4.58 \\
\hline 1943 & Dec. 29 & 7,470 & 9.78 & 1969 & Feb. 02 & 5,810 & 8.22 & 1982 & Jan. 03 & 9,330 & 11.30 \\
\hline 1944 & Feb. 27 & 6,090 & 8.48 & 1970 & June 04 & 3,610 & 5.94 & 1983 & Feb. 02 & 3,730 & 5.47 \\
\hline 1945 & Feb. 13 & 3,500 & 5.83 & 1971 & Jan. 24 & 3,100 & 5.35 & 1984 & Mar. 20 & 7,330 & 9.31 \\
\hline 1946 & Feb. 10 & 13,000 & 14.30 & 1972 & Jan. 10 & 4,410 & 6.76 & 1985 & Feb. 01 & 2,920 & 4.52 \\
\hline 1947 & Jan. 20 & 13,000 & 14.30 & 1973 & May 28 & 13,400 & 14.95 & 1986 & Feb. 18 & 1,490 & 3.27 \\
\hline 1948 & Feb. 12 & 6,490 & 8.94 & 1974 & Dec. 31 & 7,090 & 9.50 & 1987 & Feb. 28 & 4,710 & 6.59 \\
\hline 1949 & Nov. 28 & 11,400 & 13.10 & 1975 & Jan. 25 & 4,060 & 6.35 & 1988 & Jan. 20 & 3,160 & 4.82 \\
\hline 1951 & Mar. 29 & 22,000 & $20.70 c$ & 1976 & May 15 & 6,500 & 8.86 & 1989 & Sept.30 & 5,970 & 7.87 \\
\hline 1964 & Mar. 26 & 10,900 & 12.72 & 1977 & Mar. 30 & 11,000 & 12.71 & 1990 & Feb. 16 & 15,200 & 16.74 \\
\hline
\end{tabular}

\section{MOUNTAINTOWN CREEK TRIBUTARY NEAR ELLIJAY, GEORGIA}

LOCATION.--Lat $34^{\circ} 42^{\prime} 04^{\prime \prime}$, long $84^{\circ} 31^{\prime} 54^{\prime \prime}$, Gilmer County, at culvert on State Highway 282,3 mi west of Ellijay.

DRAINAGE AREA.--2.41 $\mathrm{mi}^{2}$.

GAGE.-Flood-stage/rainfall recorder. Datum of gage is about $1,310 \mathrm{ft}$ above sea level (from topographic map).

STAGE-DISCHARGE RELATION.--Defined by current-meter measurements below $92 \mathrm{ft}^{3} / \mathrm{s}$, and extended above on the basis of culvert computations.

REMARKS.--Peak dischartge for the flood of 1979 is estimated.

\begin{tabular}{|c|c|c|c|c|c|c|c|c|c|c|c|}
\hline $\begin{array}{l}\text { Water } \\
\text { year }\end{array}$ & Date & $\begin{array}{c}\text { Eischarge } \\
\left(\mathrm{ft}^{3} / \mathrm{s}\right)\end{array}$ & $\begin{array}{c}\text { Gage } \\
\text { height } \\
\text { (ft) }\end{array}$ & $\begin{array}{l}\text { Water } \\
\text { year }\end{array}$ & Date & $\begin{array}{c}\text { Discharge } \\
\left(\mathrm{ft}^{3} / \mathrm{s}\right)\end{array}$ & $\begin{array}{c}\text { Gage } \\
\text { height } \\
\text { (ft) }\end{array}$ & $\begin{array}{l}\text { Water } \\
\text { year }\end{array}$ & Date & $\begin{array}{c}\text { Discharge } \\
\left(\mathrm{ft}^{3} / \mathrm{s}\right)\end{array}$ & $\begin{array}{c}\text { Gage } \\
\text { height } \\
\text { (ft) }\end{array}$ \\
\hline 1965 & Oct. 04 & 635 & 6.30 & 1970 & June 04 & 125 & 3.11 & 1974 & Mar. 29 & 237 & 4.02 \\
\hline 1966 & Mar. 03 & 290 & 4.40 & 1971 & July 06 & 170 & 3.51 & 1977 & Mar. 29 & 400 & 5.05 \\
\hline 1967 & Sept.28 & 235 & 4.01 & 1972 & Aug. 01 & 256 & 4.16 & 1979 & Mar. 04 & 500 & - \\
\hline 1968 & July 26 & 165 & 3.47 & 1973 & May 27 & 822 & 7.20 & 1990 & Feb. 16 & 485 & $5.53 \mathrm{c}$ \\
\hline 1969 & Aug. 23 & 98 & 2.86 & & & & & & & & \\
\hline
\end{tabular}




\section{MOBILE RIVER BASIN}

\section{FIR CREEK NEAR ELLIJAY, GEORGIA}

LOCATION.--Lat $34^{\circ} 41^{\prime} 06^{\prime \prime}$, long $84^{\circ} 37^{\prime} 23^{\prime \prime}$, Gilmer County, at culvert on U.S. Highway 76 and State Highway 282,8 mi west of Ellijay.

DRAINAGE AREA. $-1.35 \mathrm{mi}^{2}$.

GAGE.--Flood-stage/rainfall recorder prior to Oct. 1, 1974; crest-stage gage thereafter. Datum of gage is $1,370.30 \mathrm{ft}$ above sea

level (from U.S. Coast and Geodetic Survey benchmark).

STAGE-DISCHARGE RELATION.--Defined by current-meter measurements below $46 \mathrm{ft}^{3} / \mathrm{s}$, and extended above on the basis of culvert computations.

\begin{tabular}{|c|c|c|c|c|c|c|c|c|c|c|c|}
\hline $\begin{array}{l}\text { Water } \\
\text { year }\end{array}$ & Date & $\begin{array}{c}\text { Discharge } \\
\left(\mathrm{ft}^{3} / \mathrm{s}\right)\end{array}$ & $\begin{array}{c}\text { Gage } \\
\text { height } \\
\text { (ft) }\end{array}$ & $\begin{array}{l}\text { Water } \\
\text { year }\end{array}$ & Date & $\begin{array}{c}\text { Discharge } \\
\left(\mathrm{ft}^{3} / \mathrm{s}\right)\end{array}$ & $\begin{array}{c}\text { Gage } \\
\text { height } \\
\text { (ft) }\end{array}$ & $\begin{array}{l}\text { Water } \\
\text { year }\end{array}$ & Date & $\begin{array}{c}\text { Discharge } \\
\left(\mathrm{ft}^{3} / \mathrm{s}\right)\end{array}$ & $\begin{array}{c}\text { Gage } \\
\text { height } \\
\text { (ft) }\end{array}$ \\
\hline 1966 & Mar. 04 & 280 & 4.80 & 1974 & Dec. 31 & 108 & 2.79 & 1982 & Jan. 03 & 127 & 3.03 \\
\hline 1967 & May 12 & 74 & 2.28 & 1975 & Feb. 04 & 82 & 2.40 & 1983 & Nov. 30 & 84.0 & 2.44 \\
\hline 1968 & Dec. 22 & 68 & 2.18 & 1976 & May 15 & 75 & 2.29 & 1984 & Dec. 27 & 59.0 & 2.05 \\
\hline 1969 & Feb. 02 & 68 & 2.18 & 1977 & Mar. 29 & 201 & 3.95 & 1985 & July 05 & 96.0 & 2.61 \\
\hline 1970 & June 04 & 199 & 3.93 & 1978 & Aug. 04 & 69 & 2.20 & 1986 & Jan. -- & 38.0 & $-b$ \\
\hline 1971 & Feb. 26 & 38 & 1.66 & 1979 & Mar. 04 & 263 & 4.63 & $\underline{1987}$ & Feb. 28 & 80.0 & 2.38 \\
\hline 1972 & May 13 & 59 & 2.04 & 1980 & Mar. 08 & 98 & 2.65 & 1990 & Feb. 16 & 320 & $5.20 c$ \\
\hline 1973 & May 27 & 156 & 3.39 & 1981 & Aug. -- & 38 & $-\mathrm{b}$ & & & & \\
\hline
\end{tabular}

\section{FAUSETT CREEK NEAR TALKING ROCK, GEORGIA}

LOCATION.--Lat $34^{\circ} 34^{\prime} 17^{\prime \prime}$, long $84^{\circ} 27^{\prime} 55^{\prime \prime}$, Gilmer County, on right bank $25 \mathrm{ft}$ upstream, at culvert on secondary road $1011,4.5 \mathrm{mi}$ northeast of Talking Rock.

DRAINAGE AREA.--9.99 $\mathrm{mi}^{2}$.

GAGE.--Flood-stage/rainfall recorder prior to Oct. 1, 1974; water-stage recorder thereafter. Datum of gage is $1,311.74 \mathrm{ft}$ above sea level (Global Positioning System from U.S. Geological Survey benchmark).

STAGE-DISCHARGE RELATION.--Defined by current-meter measurements below $155 \mathrm{ft}^{3} / \mathrm{s}$, and extended above on the basis of culvert computations.

HISTORICAL DATA.--Flood of 1973 is highest since 1951, based on information at nearby stations.

REMARKS.--Peak stage for the flood of 1973 based on floodmarks.

\begin{tabular}{|c|c|c|c|c|c|c|c|c|c|c|c|}
\hline $\begin{array}{l}\text { Water } \\
\text { year }\end{array}$ & Date & $\begin{array}{c}\text { Discharge } \\
\left(\mathrm{ft}^{3} / \mathrm{s}\right)\end{array}$ & $\begin{array}{c}\text { Gage } \\
\text { height } \\
\text { (ft) }\end{array}$ & $\begin{array}{l}\text { Water } \\
\text { year }\end{array}$ & Date & $\begin{array}{c}\text { Discharge } \\
\left(\mathrm{ft}^{3} / \mathrm{s}\right)\end{array}$ & $\begin{array}{c}\text { Gage } \\
\text { height } \\
\text { (ft) }\end{array}$ & $\begin{array}{l}\text { Water } \\
\text { year }\end{array}$ & Date & $\begin{array}{c}\text { Discharge } \\
\left(\mathrm{ft}^{3} / \mathrm{s}\right)\end{array}$ & $\begin{array}{c}\text { Gage } \\
\text { height } \\
(\mathrm{ft})\end{array}$ \\
\hline 1966 & Mar. 04 & 1,130 & 7.80 & 1975 & Jan. 25 & 462 & 4.62 & 1983 & Aug. 01 & 754 & 6.13 \\
\hline 1967 & May. 12 & 296 & 3.57 & 1976 & May. 15 & 1,220 & 8.17 & 1984 & Mar. 20 & 1,740 & 10.15 \\
\hline 1968 & Apr. 05 & 363 & 4.02 & 1977 & Mar. 29 & 1,740 & 10.14 & 1985 & Feb. 01 & 248 & 3.32 \\
\hline 1969 & Feb. 02 & 610 & 5.42 & 1978 & Nov. 04 & 614 & 5.44 & 1986 & Aug. 20 & 600 & 7.52 \\
\hline 1970 & June 04 & 397 & 4.22 & 1979 & Mar. 04 & 2,630 & 13.70 & 1987 & Feb. 28 & 428 & 4.41 \\
\hline 1971 & July 30 & 261 & 3.34 & 1980 & Mar. 21 & 1,220 & 8.16 & 1988 & Jan. 20 & 333 & 3.84 \\
\hline 1972 & Jan. 14 & 493 & 4.78 & 1981 & June 03 & 260 & 3.29 & 1989 & Sept.30 & 564 & 5.18 \\
\hline 1973 & May. 27 & 3,160 & 16.96 & 1982 & Jan. 03 & 1,670 & 9.89 & 1990 & Feb. 16 & 1,770 & 10.27 \\
\hline 1974 & Apr. 13 & 1,490 & 9.25 & & & & & & & & \\
\hline
\end{tabular}


LOCATION.--Lat $34^{\circ} 36^{\prime} 29^{\prime \prime}$, long $84^{\circ} 31^{\prime} 42^{\prime \prime}$, Gilmer County, at culvert at State Highway 5, 6.5 mi south of Ellijay. DRAINAGE AREA. $-1.27 \mathrm{mi}^{2}$.

GAGE.-Flood-stage/rainfall recorder. Datum of gage is about 1,210 ft above sea level (from topographic map).

STAGE-DISCHARGE RELATION.--Defined by current-meter measurements below $10 \mathrm{ft}^{3} / \mathrm{s}$, and extended above on the basis of culvert computations.

\begin{tabular}{|c|c|c|c|c|c|c|c|c|c|c|c|}
\hline $\begin{array}{l}\text { Water } \\
\text { year }\end{array}$ & Date & $\begin{array}{c}\text { Discharge } \\
\left(\mathrm{ft}^{3} / \mathrm{s}\right)\end{array}$ & $\begin{array}{c}\text { Gage } \\
\text { height } \\
\text { (ft) }\end{array}$ & $\begin{array}{l}\text { Water } \\
\text { year }\end{array}$ & Date & $\begin{array}{c}\text { Discharge } \\
\left(\mathrm{ft}^{3} / \mathrm{s}\right)\end{array}$ & $\begin{array}{c}\text { Gage } \\
\text { height } \\
\text { (ft) }\end{array}$ & $\begin{array}{l}\text { Water } \\
\text { year }\end{array}$ & Date & $\begin{array}{c}\text { Discharge } \\
\left(\mathrm{ft}^{3} / \mathrm{s}\right)\end{array}$ & $\begin{array}{c}\text { Gage } \\
\text { height } \\
\text { (ft) }\end{array}$ \\
\hline 1966 & Apr. 28 & 815 & 5.62 & 1968 & Dec. 22 & 47.0 & 1.71 & 1970 & Apr. 01 & 30.0 & 1.48 \\
\hline 1967 & Aug. 24 & 43 & 1.66 & 1969 & Feb. 02 & 20.0 & 1.31 & 1971 & Feb. 22 & 23.0 & 1.36 \\
\hline
\end{tabular}

\section{BALL CREEK NEAR TALKING ROCK, GEORGIA}

LOCATION.-Lat $34^{\circ} 31^{\prime} 52^{\prime \prime}$, long $84^{\circ} 34^{\prime} 11^{\prime \prime}$, Pickens County, at culvert at State Highway 156, 3.8 mi west of Talking Rock. DRAINAGE AREA,--3.5 $\mathrm{mi}^{2}$.

GAGE.--Flood-stage/rainfall recorder. Datum of gage is about 1,005 $\mathrm{ft}$ above sea level (from topographic map).

STAGE-DISCHARGE RELATION.--Defined by current-meter measurements below $437 \mathrm{ft}^{3} / \mathrm{s}$, and extended above on the basis of culvert computations.

\begin{tabular}{|c|c|c|c|c|c|c|c|c|c|c|c|}
\hline $\begin{array}{l}\text { Water } \\
\text { year }\end{array}$ & Date & $\begin{array}{c}\text { Discharge } \\
\left(\mathrm{ft}^{3} / \mathrm{s}\right)\end{array}$ & $\begin{array}{c}\text { Gage } \\
\text { height } \\
\text { (ft) }\end{array}$ & $\begin{array}{l}\text { Water } \\
\text { year }\end{array}$ & Date & $\begin{array}{c}\text { Discharge } \\
\left(\mathrm{ft}^{3} / \mathrm{s}\right)\end{array}$ & $\begin{array}{c}\text { Gage } \\
\text { height } \\
\text { (ft) }\end{array}$ & $\begin{array}{l}\text { Water } \\
\text { year }\end{array}$ & Date & $\begin{array}{c}\text { Discharge } \\
\left(\mathrm{ft}^{3} / \mathrm{s}\right)\end{array}$ & $\begin{array}{c}\text { Gage } \\
\text { height } \\
\text { (ft) }\end{array}$ \\
\hline 1965 & Oct. 04 & 444 & 3.64 & 1969 & May. 19 & 480 & 4.00 & 1973 & May. 27 & 1,240 & 6.69 \\
\hline 1966 & Apr. 29 & 865 & 5.65 & 1970 & Mar. 21 & 37 & 2.63 & 1974 & Dec. 31 & 526 & 4.37 \\
\hline 1967 & Oct. 18 & 125 & 2.99 & 1971 & Sept.01 & 454 & 3.74 & 1977 & Mar. 29 & 1,110 & 6.60 \\
\hline 1968 & July 12 & 266 & 3.21 & 1972 & Jan. 04 & 379 & 3.39 & $\overline{1990}$ & Feb. 16 & 1,000 & $6.24 c$ \\
\hline
\end{tabular}

\section{SCARECORN CREEK ABOVE HINTON, GEORGIA}

LOCATION.--Lat $34^{\circ} 27^{\prime} 11^{\prime \prime}$, long $84^{\circ} 33^{\prime} 28^{\prime \prime}$, Pickens County, on right bank, $300 \mathrm{ft}$ downstream from bridge on county road $150,2.4$ mi southeast of Hinton, and 8.0 mi upstream from mouth.

DRAINAGE AREA.--6.4 $\mathrm{mi}^{2}$.

GAGE.--Water-stage recorder. Datum of gage is $1,107.59 \mathrm{ft}$ above sea level (levels by Global Positioning System from U.S.

Geological Survey benchmark).

STAGE-DISCHARGE RELATION.--Defined by current-meter measurements below $150 \mathrm{ft}^{3} / \mathrm{s}$, and extended above on the basis of straight-line extension.

REMARKS.--Peak flow is regulated upstream by Soil Conservation Service flood-retention reservoir since 1961.

\begin{tabular}{|c|c|c|c|c|c|c|c|c|c|c|c|}
\hline $\begin{array}{l}\text { Water } \\
\text { year }\end{array}$ & Date & $\begin{array}{c}\text { Discharge } \\
\left(\mathrm{ft}^{3} / \mathrm{s}\right)\end{array}$ & $\begin{array}{c}\text { Gage } \\
\text { height } \\
\text { (ft) }\end{array}$ & $\begin{array}{l}\text { Water } \\
\text { year }\end{array}$ & Date & $\begin{array}{c}\text { Discharge } \\
\left(\mathrm{ft}^{3} / \mathrm{s}\right)\end{array}$ & $\begin{array}{c}\text { Gage } \\
\text { height } \\
\text { (ft) }\end{array}$ & $\begin{array}{l}\text { Water } \\
\text { year }\end{array}$ & Date & $\begin{array}{c}\text { Discharge } \\
\left(\mathrm{ft}^{3} / \mathrm{s}\right)\end{array}$ & $\begin{array}{c}\text { Gage } \\
\text { height } \\
\text { (ft) }\end{array}$ \\
\hline 1986 & Sept. 03 & 241 & 2.83 & 1988 & Jan. 20 & 192 & 2.61 & 1990 & Feb. 16 & 333 & 3.28 \\
\hline 1987 & Feb. 28 & 234 & 2.80 & 1989 & Sept. 30 & 173 & 2.52 & & & & \\
\hline
\end{tabular}


LOCATION.--Lat $34^{\circ} 28^{\prime} 04^{\prime \prime}$, long $84^{\circ} 35^{\prime} 30^{\prime \prime}$, Pickens County, on left bank $100 \mathrm{ft}$ upstream from bridge on State Highway $53,0.2$ mi west of Hinton, 1 mi upstream from Deans Mill, and 5 mi upstream from mouth.

DRAINAGE AREA.--21.3 $\mathrm{mi}^{2}$ (revised).

GAGE.-Water-stage recorder. Datum of gage is $1,051.30 \mathrm{ft}$ above sea level (levels by Global Positioning System from U.S.

Geological Survey benchmark).

STAGE-DISCHARGE RELATION.--Defined by current-meter measurements below $1,030 \mathrm{ft}^{3} / \mathrm{s}$, and extended above on the basis of flow over dam computation at $1,900 \mathrm{tt}^{3} / \mathrm{s}$ prior to 1974 . Defined by current-meter measurements below $1,150 \mathrm{ft}^{3} / \mathrm{s}$, and extended above on the basis of slope-area computation at $2,300 \mathrm{ft}^{3} / \mathrm{s}$ thereafter.

HISTORICAL DATA.-Flood of 1942 was highest since 1938, based on information from local resident.

REMARKS.-Peak discharge for 1961-64, 1966, and 1973, are estimated. Peak regulated by Soil Conservation Service floodretention reservoir since 1961 .

\begin{tabular}{|c|c|c|c|c|c|c|c|c|c|c|c|}
\hline $\begin{array}{l}\text { Water } \\
\text { year }\end{array}$ & Date & $\begin{array}{c}\text { Discharge } \\
\left(\mathrm{ft}^{3} / \mathrm{s}\right)\end{array}$ & $\begin{array}{c}\text { Gage } \\
\text { height } \\
\text { (ft) }\end{array}$ & $\begin{array}{l}\text { Water } \\
\text { year }\end{array}$ & Date & $\begin{array}{c}\text { Discharge } \\
\left(\mathrm{ft}^{3} / \mathrm{s}\right)\end{array}$ & $\begin{array}{c}\text { Gage } \\
\text { height } \\
\text { (ft) }\end{array}$ & $\begin{array}{l}\text { Water } \\
\text { year }\end{array}$ & Date & $\begin{array}{c}\text { Discharge } \\
\left(\mathrm{ft}^{3} / \mathrm{s}\right)\end{array}$ & $\begin{array}{l}\text { Gage } \\
\text { height } \\
\text { (ft) }\end{array}$ \\
\hline 1940 & June 08 & 1,350 & 7.30 & 1966 & Apr. 22 & 1,640 & 8.45 & $\underline{1974}$ & Nov. 28 & 1,030 & 5.90 \\
\hline 1941 & Aug. 13 & 1,470 & 7.78 & 1967 & Aug. 24 & 614 & 3.79 & $\underline{1979}$ & Mar. 04 & 2,000 & $9.85 \mathrm{c}$ \\
\hline$\underline{1942}$ & Feb. 16 & 2,500 & 11.20 & 1968 & Dec. 19 & 878 & 5.22 & 1986 & Sept.03 & 1,530 & 5.59 \\
\hline$\overline{1961}$ & Feb. 25 & 1,800 & 9.08 & 1969 & Feb. 02 & 866 & 5.12 & 1987 & Feb. 28 & 1,520 & 5.56 \\
\hline 1962 & Dec. 12 & 1,800 & 9.08 & 1970 & Mar. 19 & 574 & 3.57 & 1988 & Jan. 30 & 1,370 & 5.17 \\
\hline 1963 & Mar. 05 & 1,130 & 6.36 & 1971 & Jan. 04 & 818 & 4.94 & 1989 & Mar. 04 & 1,530 & 5.59 \\
\hline 1964 & Mar. 25 & 1,670 & 8.60 & 1972 & Jan. 10 & 833 & 5.00 & 1990 & Feb. 16 & 2,300 & 7.92 \\
\hline 1965 & May 21 & 666 & 4.11 & 1973 & May 27 & 1,900 & 9.52 & & & & \\
\hline
\end{tabular}

\section{TALKING ROCK CREEK NEAR HINTON, GEORGIA}

LOCATION.--Lat $34^{\circ} 31^{\prime} 22^{\prime \prime}$, long $84^{\circ} 36^{\prime} 40^{\prime \prime}$, Pickens County, on left bank $300 \mathrm{ft}$ downstream from Scarecorn Creek, and $3.3 \mathrm{mi}$ northwest of Hinton.

DRAINAGE AREA.--119 $\mathrm{mi}^{2}$.

GAGE.--Water-stage recorder. Datum of gage is $893.69 \mathrm{ft}$ above sea level (levels by Global Positioning System from U.S.

Geological Survey benchmark).

STAGE-DISCHARGE RELATION.--Defined by current-meter measurements below $6,100 \mathrm{ft}^{3} / \mathrm{s}$, and extended above on the basis of slope-area computations.

HISTORICAL DATA.--The flood of 1973 is thought to be the highest since 1951, based on information at nearby stations.

\begin{tabular}{|c|c|c|c|c|c|c|c|c|c|c|c|}
\hline $\begin{array}{l}\text { Water } \\
\text { year }\end{array}$ & Date & $\begin{array}{c}\text { Discharge } \\
\left(\mathrm{ft}^{3} / \mathrm{s}\right)\end{array}$ & $\begin{array}{c}\text { Gage } \\
\text { height } \\
\text { (ft) }\end{array}$ & $\begin{array}{l}\text { Water } \\
\text { year }\end{array}$ & Date & $\begin{array}{c}\text { Discharge } \\
\left(\mathrm{ft}^{3} / \mathrm{s}\right)\end{array}$ & $\begin{array}{c}\text { Gage } \\
\text { height } \\
\text { (ft) }\end{array}$ & $\begin{array}{l}\text { Water } \\
\text { year }\end{array}$ & Date & $\begin{array}{c}\text { Discharge } \\
\left(\mathrm{ft}^{3} / \mathrm{s}\right)\end{array}$ & $\begin{array}{c}\text { Gage } \\
\text { height } \\
\text { (ft) }\end{array}$ \\
\hline 1973 & May. 28 & 18,400 & 15.45 & 1979 & Mar. 04 & 14,100 & 14.18 & 1985 & Feb. 01 & 2,370 & 5.68 \\
\hline 1974 & Apr. 13 & 4,850 & 8.45 & 1980 & Mar. 21 & 7,090 & 10.16 & 1986 & Aug. 21 & 1,620 & 4.60 \\
\hline 1975 & July 02 & 3,550 & 7.26 & 1981 & June 04 & 2,500 & 5.87 & 1987 & Feb. 28 & 3,680 & 7.26 \\
\hline 1976 & May. 15 & 4,600 & 8.25 & 1982 & Jan. 03 & 11,800 & 13.04 & 1988 & Jan. 20 & 2,530 & 5.90 \\
\hline 1977 & Apr. 04 & 10,300 & 12.35 & 1983 & Feb. 02 & 3,170 & 6.71 & 1989 & Sept.30 & 4,980 & 8.59 \\
\hline 1978 & Nov. 05 & 4,060 & 7.66 & 1984 & Mar. 20 & 3,570 & 7.14 & 1990 & Feb. 16 & 11,200 & 12.02 \\
\hline
\end{tabular}




\section{MOBILE RIVER BASIN}

\section{TALKING ROCK CREEK NEAR CARTERS, GEORGIA}

LOCATION.--Lat $34^{\circ} 35^{\prime} 20^{\prime \prime}$, long $84^{\circ} 40^{\prime} 05^{\prime \prime}$, Murray County, near center of channel on downstream side of pier of bridge on State Highway 156, 2.1 mi upstream from mouth, and 2.2 mi southeast of Carters.

DRAINAGE AREA. $-142 \mathrm{mi}^{2}$.

GAGE.-Water-stage recorder. Datum of gage is $667.67 \mathrm{ft}$ above sea level (levels by the U.S. Army Corps of Engineers). Waterstage recorder for station on Coosawattee River at Carters used as auxilliary gage for this station.

STAGE-DISCHARGE RELATION.--Defined by current-meter measurements below $8,700 \mathrm{ft}^{3} / \mathrm{s}$, and above on the basis of straightline extension. State-discharge relation affected by backwater from Coosawattee River. Bankfull stage and discharge, $16 \mathrm{ft}$ and $6,500 \mathrm{ft}^{3} / \mathrm{s}$.

REMARKS.-Peak stages furnished by the U.S. Army Corps of Engineers.

\begin{tabular}{|c|c|c|c|c|c|c|c|c|c|c|c|}
\hline $\begin{array}{l}\text { Water } \\
\text { year }\end{array}$ & Date & $\begin{array}{c}\text { Discharge } \\
\left(\mathrm{ft}^{3} / \mathrm{s}\right)\end{array}$ & $\begin{array}{c}\text { Gage } \\
\text { height } \\
\text { (ft) }\end{array}$ & $\begin{array}{l}\text { Water } \\
\text { year }\end{array}$ & Date & $\begin{array}{c}\text { Discharge } \\
\left(\mathrm{ft}^{3} / \mathrm{s}\right)\end{array}$ & $\begin{array}{c}\text { Gage } \\
\text { height } \\
\text { (ft) }\end{array}$ & $\begin{array}{l}\text { Water } \\
\text { year }\end{array}$ & Date & $\begin{array}{c}\text { Discharge } \\
\left(\mathrm{ft}^{3} / \mathrm{s}\right)\end{array}$ & $\begin{array}{l}\text { Gage } \\
\text { height } \\
\text { (ft) }\end{array}$ \\
\hline 1964 & Mar. 26 & 11,600 & 17.98 & 1967 & Aug. 24 & 3,200 & 10.07 & 1970 & Mar. 19 & 2,080 & 7.35 \\
\hline 1965 & Oct. 04 & 3,300 & 14.60 & 1968 & Jan. 10 & 4,200 & 12.40 & 1971 & Jan. 24 & 2,830 & 10.20 \\
\hline 1966 & Mar. 04 & 12,700 & 18.23 & 1969 & Feb. 02 & 4,980 & 15.17 & & & & \\
\hline
\end{tabular}

\section{COOSAWATTEE RIVER AT CARTERS, GEORGIA}

LOCATION.--Lat $34^{\circ} 36^{\prime} 13^{\prime \prime}$, long $84^{\circ} 41^{\prime} 44^{\prime \prime}$, Murray County, on downstream side of center bank pier of bridge on old U.S. Highway 411 at Carters, $200 \mathrm{ft}$ upstream from Louisville \& Nashville Railroad bridge, and $0.6 \mathrm{mi}$ downstream from Talking Rock Creek, and $0.4 \mathrm{mi}$ downstream from Carters re-regulation dam.

DRAINAGE AREA. $-521 \mathrm{mi}^{2}$ (revised).

GAGE.-Water-stage recorder. Prior to September 1923, nonrecording gage at site $0.2 \mathrm{mi}$ upstream at datum $2.00 \mathrm{ft}$ higher. Datum of gage is $650.67 \mathrm{ft}$ above sea level (levels by the U.S. Army Corps of Engineers), supplementary adjustment of 1936 (revised). All gage heights have been converted to same datum.

STAGE-DISCHARGE RELATION.--Defined by current-meter measurements below $26,000 \mathrm{ft}^{3} / \mathrm{s}$, and above on the basis of straightline extension. Bankfull stage and discharge, $22 \mathrm{ft}$ and $11,000 \mathrm{ft}^{3} / \mathrm{s}$.

HISTORICAL DATA.-Peak stages of April 1938, March 1950, and March 1951 obtained from levels to floodmarks. The March 1951 flood is thought to be the highest since 1886, based on gaging-station records at Conasauga River at Tilton.

REMARKS.--Peak discharges are regulated by Carters Lake (maximum flood-control storage, 230,000 acre-ft) and Carters reregulation dam (maximum flood-control storage, 17,300 acre-ft) since November 1974. Records furnished by the U.S. Army Corps of Engineers, from 1962-78.

\begin{tabular}{|c|c|c|c|c|c|c|c|c|c|c|c|}
\hline $\begin{array}{l}\text { Water } \\
\text { year }\end{array}$ & Date & $\begin{array}{c}\text { Discharge } \\
\left(\mathrm{ft}^{3} / \mathrm{s}\right)\end{array}$ & $\begin{array}{c}\text { Gage } \\
\text { height } \\
\text { (ft) }\end{array}$ & $\begin{array}{l}\text { Water } \\
\text { year }\end{array}$ & Date & $\begin{array}{c}\text { Discharge } \\
\left(\mathrm{ft}^{3} / \mathrm{s}\right)\end{array}$ & $\begin{array}{c}\text { Gage } \\
\text { height } \\
\text { (ft) }\end{array}$ & $\begin{array}{l}\text { Water } \\
\text { year }\end{array}$ & Date & $\begin{array}{c}\text { Discharge } \\
\left(\mathrm{ft}^{3} / \mathrm{s}\right)\end{array}$ & $\begin{array}{c}\text { Gage } \\
\text { height } \\
\text { (ft) }\end{array}$ \\
\hline 1897 & Mar. 12 & 13,700 & 23.20 & $\underline{1923}$ & Dec. 17 & $\underline{15,200}$ & 24.50 & 1976 & July 07 & 5,750 & 13.65 \\
\hline 1898 & Apr. 05 & 7,600 & 15.50 & $\underline{1938}$ & Apr. 08 & 46,000 & $33.30 \mathrm{c}$ & 1977 & Apr. 18 & 6,370 & 14.80 \\
\hline 1899 & Oct. 05 & 16,000 & 25.00 & $\underline{1950}$ & Mar. 13 & 23,500 & $27.94 \mathrm{c}$ & 1978 & Jan. 30 & 5,100 & 12.50 \\
\hline 1900 & Feb. 13 & 13,000 & 22.50 & $\underline{1951}$ & Mar. 30 & 57,000 & $36.00 \mathrm{c}$ & 1979 & Mar. 12 & 5,110 & 13.21 \\
\hline 1901 & May. 21 & 12,000 & 21.50 & $\overline{1962}$ & Dec. 12 & 25,200 & 28.40 & 1980 & Mar. 28 & 5,080 & 13.14 \\
\hline 1902 & Feb. 28 & 16,000 & 25.00 & 1963 & Mar. 06 & 22,600 & 27.80 & 1981 & Jan. 06 & 3,490 & 10.25 \\
\hline 1903 & Feb. 28 & 14,000 & 23.50 & 1964 & Mar. 26 & 25,800 & 28.10 & 1982 & Feb. 02 & 5,760 & 14.47 \\
\hline 1904 & Mar. 23 & 2,620 & 7.20 & 1965 & Oct. 05 & 24,100 & 27.50 & 1983 & Dec. 10 & 5,780 & 14.45 \\
\hline 1905 & Jan. 12 & 8,200 & 16.50 & 1966 & Mar. 04 & 20,900 & 26.46 & 1984 & May. 14 & 5,320 & 13.58 \\
\hline 1906 & Mar. 15 & 11,300 & 20.80 & 1967 & Aug. 24 & 9,220 & 20.48 & 1985 & Apr. 25 & 3,230 & 9.78 \\
\hline 1907 & Nov. 19 & 28,500 & 30.60 & 1968 & Dec. 22 & 10,100 & 21.63 & 1986 & Dec. 03 & 1,770 & 6.86 \\
\hline 1908 & Feb. 15 & 7,900 & 16.00 & 1969 & Feb. 02 & 13,800 & 23.73 & 1987 & Mar. 05 & 4,120 & 11.40 \\
\hline 1919 & Dec. 22 & 11,500 & 21.00 & 1970 & June 05 & 6,910 & 16.75 & 1988 & Apr. 14 & 1,730 & 6.78 \\
\hline 1920 & Apr. 02 & 19,000 & 26.50 & 1971 & Jan. 24 & 8,030 & 18.62 & 1989 & Mar. 11 & 4,940 & 12.89 \\
\hline 1921 & Dec. 14 & 25,800 & 29.50 & 1972 & Jan. 04 & 10,100 & 21.59 & 1990 & Feb. 16 & 8,370 & 18.94 \\
\hline 1922 & Jan. 21 & 23,200 & 28.50 & 1975 & Jan. 25 & 4,240 & 11.65 & & & & \\
\hline
\end{tabular}




\section{MOBILE RIVER BASIN}

\section{SUGAR CREEK NEAR CHATSWORTH, GEORGIA}

LOCATION.--Lat $34^{\circ} 40^{\prime} 26^{\prime \prime}$, long $84^{\circ} 42^{\prime} 40^{\prime \prime}$, Murray County, at culvert on Old U.S. Highway $411,7.5$ mi southeast of Chatsworth. DRAINAGE AREA $--7.30 \mathrm{mi}^{2}$.

GAGE.--Flood-stage/rainfall recorder. Datum of gage is about $710 \mathrm{ft}$ above sea level (from topographic map).

STAGE-DISCHARGE RELATION.--Defined by current-meter measurements below $548 \mathrm{ft}^{3} / \mathrm{s}$, and above on the basis of culvert computations.

\begin{tabular}{|c|c|c|c|c|c|c|c|c|c|c|c|}
\hline $\begin{array}{l}\text { Water } \\
\text { year }\end{array}$ & Date & $\begin{array}{c}\text { Discharge } \\
\left(\mathrm{ft}^{3} / \mathrm{s}\right)\end{array}$ & $\begin{array}{l}\text { Gage } \\
\text { height } \\
\text { (ft) }\end{array}$ & $\begin{array}{l}\text { Water } \\
\text { year }\end{array}$ & Date & $\begin{array}{c}\text { Discharge } \\
\left(\mathrm{ft}^{3} / \mathrm{s}\right)\end{array}$ & $\begin{array}{c}\text { Gage } \\
\text { height } \\
\text { (ft) }\end{array}$ & $\begin{array}{l}\text { Water } \\
\text { year }\end{array}$ & Date & $\begin{array}{c}\text { Discharge } \\
\left(\mathrm{ft}^{3} / \mathrm{s}\right)\end{array}$ & $\begin{array}{c}\text { Gage } \\
\text { height } \\
\text { (ft) }\end{array}$ \\
\hline 1965 & Mar. 26 & 630 & 3.53 & 1969 & Feb. 02 & 486 & 2.70 & 1973 & May. 27 & 949 & 6.20 \\
\hline 1966 & Mar. 04 & 995 & 7.00 & 1970 & Apr. 01 & 585 & 3.20 & $\underline{1974}$ & Dec. 31 & 899 & 5.60 \\
\hline 1967 & May. 12 & 391 & 2.33 & 1971 & Feb. 26 & 252 & 1.80 & $\underline{1977}$ & Apr. 04 & 1,040 & $7.78 \mathrm{c}$ \\
\hline 1968 & Dec. 22 & 665 & 3.70 & 1972 & Jan. 04 & 462 & 2.60 & $\overline{1990}$ & Feb. 16 & 1,100 & $8.63 c$ \\
\hline
\end{tabular}

\section{DRY CREEK AT OAKMAN, GEORGIA}

LOCATION.--Lat $34^{\circ} 33^{\prime} 13^{\prime \prime}$, long $84^{\circ} 42^{\prime} 27^{\prime \prime}$, Gordon County, at culvert on U.S. Highway $411,0.8$ mi south of Oakman. DRAINAGE AREA.--3.06 $\mathrm{mi}^{2}$

GAGE.-Flood-stage/rainfall recorder prior to Aug. 11, 1970; water-stage/rainfall recorder thereafter. Datum of gage is about $715 \mathrm{ft}$ above sea level (from topographic map).

STAGE-DISCHARGE RELATION.--Defined by current-meter measurements below $40 \mathrm{ft}^{3} / \mathrm{s}$, and above on the basis of culvert computations.

HISTORICAL DATA.--Flood of 1977 is thought to be the highest since 1951, based on information at nearby stations.

\begin{tabular}{|c|c|c|c|c|c|c|c|c|c|c|c|}
\hline $\begin{array}{l}\text { Water } \\
\text { year }\end{array}$ & Date & $\begin{array}{c}\text { Discharge } \\
\left(\mathrm{ft}^{3} / \mathrm{s}\right)\end{array}$ & $\begin{array}{c}\text { Gage } \\
\text { height } \\
\text { (ft) }\end{array}$ & $\begin{array}{l}\text { Water } \\
\text { year }\end{array}$ & Date & $\begin{array}{c}\text { Discharge } \\
\left(\mathrm{ft}^{3} / \mathrm{s}\right)\end{array}$ & $\begin{array}{c}\text { Gage } \\
\text { height } \\
\text { (ft) }\end{array}$ & $\begin{array}{l}\text { Water } \\
\text { year }\end{array}$ & Date & $\begin{array}{c}\text { Discharge } \\
\left(\mathrm{ft}^{3} / \mathrm{s}\right)\end{array}$ & $\begin{array}{c}\text { Gage } \\
\text { height } \\
\text { (ft) }\end{array}$ \\
\hline 1965 & June 07 & 443 & 2.97 & 1970 & Apr. 01 & 142 & 1.74 & $\underline{1974}$ & Dec. 31 & 467 & 3.07 \\
\hline 1966 & Mar. 04 & 754 & 4.47 & 1971 & Feb. 22 & 426 & 2.90 & $\underline{1977}$ & Apr. 04 & 1,410 & $8.45 \mathrm{c}$ \\
\hline 1967 & May 12 & 278 & 2.29 & 1972 & Jan. 10 & 252 & 2.19 & $\underline{1979}$ & Mar. 04 & 900 & $5.20 \mathrm{c}$ \\
\hline 1968 & Dec. 22 & 328 & 2.49 & 1973 & May 27 & 721 & 4.22 & $\overline{1990}$ & Feb. 16 & 1,020 & 5.73 \\
\hline 1969 & Feb. 02 & 290 & 2.34 & & & & & & & & \\
\hline
\end{tabular}

\section{PINE LOG CREEK AT RYDAL, GEORGIA}

LOCATION.--Lat $34^{\circ} 22^{\prime} 02^{\prime \prime}$ long $84^{\circ} 42^{\prime} 45^{\prime \prime}$, Bartow County, at U.S. Highway 411 (State Highway 61 ), 2 mi north of Rydal. DRAINAGE AREA.- $-12.8 \mathrm{mi}^{2}$.

GAGE.--Crest-stage gage prior to Aug. 2, 1967; flood-stage recorder Aug. 2 to Dec. 18, 1967; flood-stage/rainfall recorder thereafter. Datum of gage is about $769 \mathrm{ft}$ above sea level (from topographic map).

STAGE-DISCHARGE RELATION.--Defined by current-meter measurements below $800 \mathrm{ft}^{3} / \mathrm{s}$, and above on the basis of straight-line extension.

HISTORICAL DATA.--Flood of 1964 is thought to be the highest since 1951, based on information at nearby stations.

REMARKS.--The peak discharge for the flood of 1964 is estimated.

\begin{tabular}{|c|c|c|c|c|c|c|c|c|c|c|c|}
\hline $\begin{array}{l}\text { Water } \\
\text { year }\end{array}$ & Date & $\begin{array}{c}\text { Discharge } \\
\left(\mathrm{ft}^{3} / \mathrm{s}\right)\end{array}$ & $\begin{array}{c}\text { Gage } \\
\text { height } \\
\text { (ft) }\end{array}$ & $\begin{array}{c}\text { Water } \\
\text { year }\end{array}$ & Date & $\begin{array}{c}\text { Discharge } \\
\left(\mathrm{ft}^{3} / \mathrm{s}\right)\end{array}$ & $\begin{array}{c}\text { Gage } \\
\text { height } \\
\text { (ft) }\end{array}$ & $\begin{array}{l}\text { Water } \\
\text { year }\end{array}$ & Date & $\begin{array}{c}\text { Discharge } \\
\left(\mathrm{ft}^{3} / \mathrm{s}\right)\end{array}$ & $\begin{array}{c}\text { Gage } \\
\text { height } \\
\text { (ft) }\end{array}$ \\
\hline 1964 & Mar. 23 & 3,800 & 10.00 & 1969 & Feb. 02 & 376 & 3.52 & 1973 & Dec. 15 & 1,100 & 5.76 \\
\hline 1965 & Mar. 26 & 1,030 & 5.57 & 1970 & Mar. 19 & 436 & 3.72 & 1974 & Mar. 29 & 811 & 4.91 \\
\hline 1966 & Mar. 04 & 613 & 4.29 & 1971 & Feb. 22 & 448 & 3.76 & $\underline{1977}$ & Apr. 04 & 1,510 & $6.85 c$ \\
\hline 1967 & Aug. 24 & 348 & 3.42 & 1972 & Mar. 21 & 715 & 4.61 & 1990 & Feb. 16 & 1,510 & $6.85 \mathrm{c}$ \\
\hline 1968 & Jan. 10 & 348 & 3.42 & & & & & & & & \\
\hline
\end{tabular}




\section{MOBILE RIVER BASIN}

\section{ROCK CREEK NEAR FAIRMOUNT, GEORGIA}

LOCATION.--Lat $34^{\circ} 21^{\prime} 32^{\prime \prime}$, long $84^{\circ} 46^{\prime} 46^{\prime \prime}$, Bartow County, on right upstream wingwall of culvert on State Highway $140,2.8 \mathrm{mi}$ upstream from mouth and $7 \mathrm{mi}$ southwest of Fairmount.

DRAINAGE AREA.--6.17 $\mathrm{mi}^{2}$ (revised).

GAGE.-Water-stage recorder prior to May 2, 1968; water-stage/rainfall recorder thereafter. Datum of gage is $758.96 \mathrm{ft}$ above sea level (from U.S. Geological Survey benchmark).

STAGE-DISCHARGE RELATION.--Defined by current-meter measurements below $350 \mathrm{ft}^{3} / \mathrm{s}$, and above on the basis of culvert computations. Stage-discharge relation had considerable change after 1972 owing to culvert installation near gage.

\begin{tabular}{|c|c|c|c|c|c|c|c|c|c|c|c|}
\hline $\begin{array}{l}\text { Water } \\
\text { year }\end{array}$ & Date & $\begin{array}{c}\text { Discharge } \\
\left(\mathrm{ft}^{3} / \mathrm{s}\right)\end{array}$ & $\begin{array}{c}\text { Gage } \\
\text { height } \\
\text { (ft) }\end{array}$ & $\begin{array}{l}\text { Water } \\
\text { year }\end{array}$ & Date & $\begin{array}{c}\text { Discharge } \\
\left(\mathrm{ft}^{3} / \mathrm{s}\right)\end{array}$ & $\begin{array}{c}\text { Gage } \\
\text { height } \\
\text { (ft) }\end{array}$ & $\begin{array}{l}\text { Water } \\
\text { year }\end{array}$ & Date & $\begin{array}{c}\text { Discharge } \\
\left(\mathrm{ft}^{3} / \mathrm{s}\right)\end{array}$ & $\begin{array}{c}\text { Gage } \\
\text { height } \\
\text { (ft) }\end{array}$ \\
\hline 1952 & Mar. 22 & 735 & 4.01 & 1961 & Feb. 25 & 735 & 4.01 & 1970 & Mar. 20 & 257 & 2.92 \\
\hline 1953 & Sept. 25 & 313 & 3.04 & 1962 & Dec. 12 & 855 & 4.25 & 1971 & Feb. 22 & 282 & 2.93 \\
\hline 1954 & Jan. 16 & 820 & 4.18 & 1963 & Apr. 29 & 580 & 3.70 & 1972 & Mar. 22 & 401 & 3.48 \\
\hline 1955 & Mar. 22 & 745 & 4.03 & 1964 & Mar. 25 & 971 & $4.33 a$ & 1973 & May. 27 & 860 & 6.00 \\
\hline 1956 & Apr. 16 & 249 & 2.82 & 1965 & Mar. 24 & 310 & 3.14 & $\underline{1974}$ & Apr. 04 & 263 & 3.84 \\
\hline 1957 & Apr. 05 & 454 & 3.43 & 1966 & Mar. 04 & 461 & 3.67 & $\overline{1977}$ & Apr. 04 & 1,400 & $8.25 \mathrm{c}$ \\
\hline 1958 & Sept. 21 & 175 & 2.50 & 1967 & May 22 & 222 & 2.76 & $\underline{1979}$ & Mar. 04 & 1,150 & $7.29 c$ \\
\hline 1959 & May. 20 & 155 & 2.39 & 1968 & Jan. 10 & 254 & 2.91 & $\overline{1990}$ & Feb. 16 & 700 & $5.38 \mathrm{c}$ \\
\hline 1960 & Apr. 03 & 132 & 2.25 & 1969 & Feb. 02 & 362 & 3.34 & & & & \\
\hline
\end{tabular}

\section{REBUD CREEK NEAR RANGER, GEORGIA}

LOCATION.--Lat $34^{\circ} 31^{\prime} 57^{\prime \prime}$, long $84^{\circ} 43^{\prime} 39^{\prime \prime}$, Gordon County, at culvert on State Highway 156, 3.5 mi northwest of Ranger. DRAINAGE AREA.-1.97 $\mathrm{mi}^{2}$.

GAGE.--Flood-stage/rainfall recorder. Datum of gage is about $700 \mathrm{ft}$ above sea level (from topographic map).

STAGE-DISCHARGE RELATION.--Defined by current-meter measurements below $458 \mathrm{ft}^{3} / \mathrm{s}$, and above on the basis of culvert computations.

HISTORICAL DATA.-Flood of 1977 is thought to be the highest since 1951, based on information at nearby stations.

\begin{tabular}{|c|c|c|c|c|c|c|c|c|c|c|c|}
\hline $\begin{array}{l}\text { Water } \\
\text { year }\end{array}$ & Date & $\begin{array}{c}\text { Discharge } \\
\left(\mathrm{ft}^{3} / \mathrm{s}\right)\end{array}$ & $\begin{array}{c}\text { Gage } \\
\text { height } \\
\text { (ft) }\end{array}$ & $\begin{array}{l}\text { Water } \\
\text { year }\end{array}$ & Date & $\begin{array}{c}\text { Discharge } \\
\left(\mathrm{ft}^{3} / \mathrm{s}\right)\end{array}$ & $\begin{array}{c}\text { Gage } \\
\text { height } \\
\text { (ft) }\end{array}$ & $\begin{array}{l}\text { Water } \\
\text { year }\end{array}$ & Date & $\begin{array}{c}\text { Discharge } \\
\left(\mathrm{ft}^{3} / \mathrm{s}\right)\end{array}$ & $\begin{array}{c}\text { Gage } \\
\text { height } \\
\text { (ft) }\end{array}$ \\
\hline 1964 & Mar. 23 & 294 & 3.45 & 1969 & Feb. 02 & 214 & 3.12 & 1973 & May. 27 & 678 & 4.62 \\
\hline 1965 & Mar. 26 & 411 & 3.90 & 1970 & Mar. 19 & 112 & 2.62 & $\underline{1974}$ & Dec. 31 & 375 & 3.77 \\
\hline 1966 & Mar. 04 & 710 & 4.70 & 1971 & Feb. 22 & 290 & 3.44 & 1977 & Apr. 04 & 1,210 & $6.20 c$ \\
\hline 1967 & May. 12 & 328 & 3.59 & 1972 & Mar. 21 & 132 & 2.72 & 1990 & Feb. 16 & 370 & $3.74 \mathrm{c}$ \\
\hline 1968 & Dec. 22 & 335 & 3.62 & & & & & & & & \\
\hline
\end{tabular}




\section{REBUD CREEK TRIBUTARY NEAR RANGER, GEORGIA}

LOCATION.-Lat $34^{\circ} 32^{\prime} 29^{\prime \prime}$, long $84^{\circ} 44^{\prime} 10^{\prime \prime}$, Gordon County, at culvert on State Highway 156, 3.2 mi northwest of Ranger. DRAINAGE AREA.-0.56 $\mathrm{mi}^{2}$.

GAGE.-Flood-stage recorder. Datum of gage is about $710 \mathrm{ft}$ above sea level (from topographic map).

STAGE-DISCHARGE RELATION.--Defined by current-meter measurements below $204 \mathrm{ft}^{3} / \mathrm{s}$, and above on the basis of culvert computations.

\begin{tabular}{|c|c|c|c|c|c|c|c|c|c|c|c|}
\hline $\begin{array}{l}\text { Water } \\
\text { year }\end{array}$ & Date & $\begin{array}{c}\text { Discharge } \\
\left(\mathrm{ft}^{3} / \mathrm{s}\right)\end{array}$ & $\begin{array}{c}\text { Gage } \\
\text { height } \\
\text { (ft) }\end{array}$ & $\begin{array}{l}\text { Water } \\
\text { year }\end{array}$ & Date & $\begin{array}{c}\text { Discharge } \\
\left(\mathrm{ft}^{3} / \mathrm{s}\right)\end{array}$ & $\begin{array}{c}\text { Gage } \\
\text { height } \\
\text { (ft) }\end{array}$ & $\begin{array}{l}\text { Water } \\
\text { year }\end{array}$ & Date & $\begin{array}{c}\text { Discharge } \\
\left(\mathrm{ft}^{3} / \mathrm{s}\right)\end{array}$ & $\begin{array}{c}\text { Gage } \\
\text { height } \\
\text { (ft) }\end{array}$ \\
\hline 1965 & Mar. 26 & 170 & 3.41 & 1969 & Feb. 02 & 72.0 & 2.21 & 1972 & Mar. 21 & 63.0 & 2.09 \\
\hline 1966 & Apr. 28 & 264 & 4.35 & 1970 & Mar. 19 & 68.0 & 2.16 & $\underline{1973}$ & May. 27 & 410 & 5.64 \\
\hline 1967 & May. 12 & 58.0 & 2.01 & 1971 & Feb. 22 & 53.0 & 1.94 & 1990 & Feb. 16 & 165 & $3.37 \mathrm{c}$ \\
\hline 1968 & Dec. 22 & 72.0 & 2.21 & & & & & & & & \\
\hline
\end{tabular}

02383500 COOSAWATTEE RIVER NEAR PINE CHAPEL, GEORGIA

(Formerly published as "Coosawattee River at Pine Chapel, Georgia")

LOCATION.--Lat $34^{\circ} 33^{\prime} 51^{\prime \prime}$, long 84 $44^{\circ}$ '59", Gordon County, on right bank at downstream side of Owens Bridge on Owens Gin Road, 1.4 mi downstream from Sallacoa Creek, 8.7 mi upstream from confluence with Conasauga River, and 2.4 mi east of Pine Chapel (revised).

DRAINAGE AREA.--831 $\mathrm{mi}^{2}$, at site downstream $847 \mathrm{mi}^{2}$ (revised).

GAGE.--Water-stage recorder. Datum of gage is $616.16 \mathrm{ft}$ above sea level (levels by the U.S. Army Corps of Engineers). Since October 1, 1976, auxiliary water-stage recorder at highway bridge 2.2 mi downstream. Prior to Feb. 23, 1940, nonrecording gage at current auxiliary gage site and datum. Feb. 23,1940, to April 8, 1975, water-station recorder at current auxiliary gage site and same datum. Feb. 23, 1940, to April 8, 1975 auxiliary water-stage recorder at current gage site. April 9, 1975, to Sept. 30, 1976, water-stage recorder on Oostanaula River at Resaca used as auxiliary age, owing to bridge construction.

STAGE-DISCHARGE RELATION.--Defined by current-meter measurements below $29,000 \mathrm{ft}^{3} / \mathrm{s}$, and extended above on the basis of straight-line extension. Stage-discharge relation is affected by backwater from Conasauga River, and the fall between gages is used as a factor in computing discharge. Bankfull stage and discharge, $23 \mathrm{ft}$ and about $15,000 \mathrm{ft}^{3} / \mathrm{s}$.

REMARKS.--Peak discharges are regulated by Carters Lake (maximum flood-control storage, 230,000 acre-ft) and Carters reregulation dam (maximum flood-control storage 17,300 acre-ft) since November 1974. Discharge given for 1975 is estimated.

\begin{tabular}{|c|c|c|c|c|c|c|c|c|c|c|c|}
\hline $\begin{array}{l}\text { Water } \\
\text { year }\end{array}$ & Date & $\begin{array}{c}\text { Discharge } \\
\left(\mathrm{ft}^{3} / \mathrm{s}\right)\end{array}$ & $\begin{array}{c}\text { Gage } \\
\text { height } \\
\text { (ft) }\end{array}$ & $\begin{array}{l}\text { Water } \\
\text { year }\end{array}$ & Date & $\begin{array}{c}\text { Discharge } \\
\left(\mathrm{ft}^{3} / \mathrm{s}\right)\end{array}$ & $\begin{array}{c}\text { Gage } \\
\text { height } \\
\text { (ft) }\end{array}$ & $\begin{array}{l}\text { Water } \\
\text { year }\end{array}$ & Date & $\begin{array}{c}\text { Discharge } \\
\left(\mathrm{ft}^{3} / \mathrm{s}\right)\end{array}$ & $\begin{array}{l}\text { Gage } \\
\text { height } \\
\text { (ft) }\end{array}$ \\
\hline 1938 & Apr. 08 & 34,000 & 30.00 & 1956 & Apr. 17 & 10,800 & 25.30 & 1974 & Jan. 01 & 11,200 & $26.10 a$ \\
\hline 1939 & Feb. 16 & 9,680 & 20.70 & 1957 & Apr. 06 & 24,600 & 31.00 & 1975 & Mar. 14 & 7,910 & - \\
\hline 1940 & July 13 & 6,560 & $13.90 \mathrm{a}$ & 1958 & Nov. 19 & 7,980 & 22.00 & 1976 & Apr. 01 & 14,700 & $27.08 \mathrm{a}$ \\
\hline 1941 & July 16 & 5,290 & 12.80 & 1959 & Feb. 14 & 7,100 & 19.30 & 1977 & Mar. 30 & 17,200 & $27.93 a$ \\
\hline 1942 & Feb. 18 & 13,500 & 27.10 & 1960 & Mar. 04 & 9,840 & 23.90 & 1978 & Jan. 26 & 9,770 & 23.33 \\
\hline 1943 & Dec. 30 & 23,300 & 30.70 & 1961 & Feb. 26 & 18,200 & 29.00 & 1979 & Mar. 04 & 24,900 & 30.07 \\
\hline 1944 & Mar. 30 & 15,900 & 28.50 & 1962 & Dec. 13 & 28,200 & 31.70 & 1980 & Mar. 09 & 11,800 & 26.03 \\
\hline 1945 & Feb. 14 & 9,750 & 23.00 & 1963 & Mar. 07 & 21,600 & 30.10 & 1981 & Mar. 31 & 6,180 & 17.48 \\
\hline 1946 & Feb. 11 & 32,000 & 32.70 & 1964 & Mar. 26 & 32,000 & $31.90 \mathrm{a}$ & 1982 & Jan. 04 & 19,800 & 28.77 \\
\hline 1947 & Jan. 21 & 19,400 & 31.80 & 1965 & Mar. 27 & 10,600 & 25.70 & 1983 & Apr. 10 & 8,190 & 22.63 \\
\hline 1948 & Feb. 13 & 11,300 & 26.50 & 1966 & Mar. 05 & 18,400 & 29.00 & 1984 & Dec. 04 & 8,250 & 22.39 \\
\hline 1949 & Nov. 29 & 26,700 & 31.60 & 1967 & Aug. 25 & 8,820 & 22.80 & 1985 & Feb. 02 & 5,430 & 16.68 \\
\hline 1950 & Mar. 14 & 26,200 & 31.40 & 1968 & Jan. 11 & 11,500 & $26.80 \mathrm{a}$ & 1986 & Feb. 18 & 2,880 & 10.61 \\
\hline 1951 & Mar. 30 & 40,200 & 34.20 & 1969 & Feb. 03 & 15,000 & $27.70 a$ & 1987 & Mar. 01 & 8,720 & 23.44 \\
\hline 1952 & Mar. 12 & 12,300 & 27.10 & 1970 & Mar. 21 & 8,680 & 21.40 & 1988 & Jan. 21 & 4,290 & 14.43 \\
\hline 1953 & Jan. 10 & 9,310 & 23.00 & 1971 & Jan. 25 & 9,360 & $23.30 \mathrm{a}$ & 1989 & Mar. 06 & 8,990 & 23.94 \\
\hline 1954 & Jan. 17 & 35,200 & 33.30 & 1972 & Jan. 12 & 10,900 & 26.20 & 1990 & Feb. 17 & 20,600 & 29.55 \\
\hline 1955 & Feb. 08 & 13,800 & 27.80 & 1973 & May 29 & 23,200 & 29.74 & & & & \\
\hline
\end{tabular}


LOCATION.--Lat $35^{\circ} 00^{\prime} 34^{\prime \prime}$, long $84^{\circ} 44^{\prime} 02^{\prime \prime}$, Polk County, Tenn., at U.S. Highway 411, 1.5 mi north of Tennga.

DRAINAGE AREA. $-108 \mathrm{mi}^{2}$.

GAGE.--Nonrecording prior to Sept. 30, 1943; water-stage recorder Sept. 30, 1943, to Dec. 31, 1947; crest-stage gage after Aug. 24,

1950. Prior to Jan. 1, 1932, at datum $1.08 \mathrm{ft}$ lower. Datum of gage is $755.78 \mathrm{ft}$ above sea level (levels by the U.S. Army Corps of

Engineers), supplementary adjustment of 1936. Al gage heights have been converted to the same datum.

STAGE-DISCHARGE RELATION.--Defined by current-meter measurements below $14,000 \mathrm{ft}^{3} / \mathrm{s}$, and above on the basis of straight

line extension. Bankfull stage and discharge, $14 \mathrm{ft}$ and about $5,000 \mathrm{ft}^{3} / \mathrm{s}$.

REMARKS.--Stage records for 1938 and 1940-43 furnished by the U.S. Army Corps of Engineers.

\begin{tabular}{|c|c|c|c|c|c|c|c|c|c|c|c|}
\hline $\begin{array}{l}\text { Water } \\
\text { year }\end{array}$ & Date & $\begin{array}{c}\text { Discharge } \\
\left(\mathrm{ft}^{3} / \mathrm{s}\right)\end{array}$ & $\begin{array}{c}\text { Gage } \\
\text { height } \\
\text { (ft) }\end{array}$ & $\begin{array}{l}\text { Water } \\
\text { year }\end{array}$ & Date & $\begin{array}{c}\text { Discharge } \\
\left(\mathrm{ft}^{3} / \mathrm{s}\right)\end{array}$ & $\begin{array}{c}\text { Gage } \\
\text { height } \\
\text { (ft) }\end{array}$ & $\begin{array}{l}\text { Water } \\
\text { year }\end{array}$ & Date & $\begin{array}{c}\text { Discharge } \\
\left(\mathrm{ft}^{3} / \mathrm{s}\right)\end{array}$ & $\begin{array}{c}\text { Gage } \\
\text { height } \\
\text { (ft) }\end{array}$ \\
\hline 1930 & Nov. 15 & 4,940 & 13.30 & 1953 & Feb. 27 & 10,300 & 15.58 & 1966 & Feb. 14 & 8,940 & 15.12 \\
\hline 1931 & Apr. 04 & 4,380 & 12.90 & 1954 & Jan. 16 & 12,300 & 16.33 & 1967 & July 08 & 10,400 & 15.66 \\
\hline 1938 & Apr. 08 & 8,360 & 14.90 & 1955 & Feb. 06 & 6,520 & 14.13 & 1968 & Dec. 22 & 7,880 & 14.70 \\
\hline 1940 & Feb. 06 & 1,880 & 9.50 & 1956 & Apr. 16 & 10,300 & 15.64 & 1969 & Feb. 03 & 8,600 & 15.01 \\
\hline 1941 & July 07 & 1,400 & 8.60 & 1957 & Feb. 01 & 14,400 & 17.01 & 1970 & Dec. 30 & 5,120 & 13.44 \\
\hline 1942 & Feb. 16 & 7,400 & 14.50 & 1958 & Apr. 28 & 19,400 & 18.20 & 1971 & July 07 & 8,310 & 14.88 \\
\hline 1943 & Dec. 29 & 7,640 & 14.60 & 1959 & Jan. 22 & 12,600 & 16.42 & 1972 & Jan. - & 2,500 & $-b$ \\
\hline 1944 & Mar. 29 & 9,720 & 15.40 & 1960 & Nov. 29 & 9,160 & 15.19 & 1973 & Mar. 16 & 11,100 & 15.39 \\
\hline 1945 & Feb. 17 & 8,120 & 14.80 & 1961 & June 22 & 12,000 & 16.16 & 1974 & Dec. 26 & 8,020 & 14.76 \\
\hline 1946 & Feb. 10 & 14,100 & 16.90 & 1962 & Dec. 12 & 13,200 & 16.63 & 1975 & Mar. 30 & 12,700 & 16.42 \\
\hline 1947 & Jan. 20 & 12,900 & 16.50 & 1963 & Mar. 12 & 13,800 & 16.75 & $\underline{1976}$ & July 05 & 6,100 & 13.90 \\
\hline$\overline{1951}$ & Mar. 28 & 16,400 & 17.54 & 1964 & Apr. 08 & 12,300 & 16.26 & $\overline{1990}$ & Feb. 16 & 11,100 & $15.88 \mathrm{c}$ \\
\hline 1952 & Mar. 10 & 11,400 & 16.02 & 1965 & Mar. 26 & 14,100 & 16.91 & & & & \\
\hline
\end{tabular}

\section{CONASAUGA RIVER NEAR ETON, GEORGIA}

LOCATION.-Lat $35^{\circ} 49^{\prime} 40^{\prime \prime}$ long $84^{\circ} 51^{\prime} 03^{\prime \prime}$, Murray County, at State Highway 286, 5 mi west of Eton.

DRAINAGE AREA.-252 $\mathrm{mi}^{2}$ (revised).

GAGE.-Water-stage recorder. Crest-stage gage prior to Sept. 30, 1981 at site $75 \mathrm{ft}$ downstream and at datum $3.00 \mathrm{ft}$ higher.

Datum of gage is $672.64 \mathrm{ft}$ above sea level (levels by the Georgia Department of Transportation).

STAGE-DISCHARGE RELATION.--Defined by current-meter measurements below $29,500 \mathrm{ft}^{3} / \mathrm{s}$. Bankfull stage and discharge, $10 \mathrm{ft}$ and about $5,000 \mathrm{ft}^{3} / \mathrm{s}$.

HISTORICAL DATA.-Flood of 1990 is thought to be the highest since 1951, based on information at nearby stations.

REMARKS.-All gage heights have been converted to the present datum.

\begin{tabular}{|c|c|c|c|c|c|c|c|c|c|c|c|}
\hline $\begin{array}{l}\text { Water } \\
\text { year }\end{array}$ & Date & $\begin{array}{c}\text { Discharge } \\
\left(\mathrm{ft}^{3} / \mathrm{s}\right)\end{array}$ & $\begin{array}{c}\text { Gage } \\
\text { height } \\
\text { (ft) }\end{array}$ & $\begin{array}{l}\text { Water } \\
\text { year }\end{array}$ & Date & $\begin{array}{c}\text { Discharge } \\
\left(\mathrm{ft}^{3} / \mathrm{s}\right)\end{array}$ & $\begin{array}{c}\text { Gage } \\
\text { height } \\
\text { (ft) }\end{array}$ & $\begin{array}{l}\text { Water } \\
\text { year }\end{array}$ & Date & $\begin{array}{c}\text { Discharge } \\
\left(\mathrm{ft}^{3} / \mathrm{s}\right)\end{array}$ & $\begin{array}{c}\text { Gage } \\
\text { height } \\
\text { (ft) }\end{array}$ \\
\hline 1954 & Jan. 16 & 14,700 & 16.75 & 1969 & Feb. 03 & 11,600 & 15.40 & 1980 & Mar. 22 & 18,200 & 17.04 \\
\hline 1955 & Feb. 06 & 6,500 & 14.03 & 1970 & Apr. 01 & 3,500 & 11.80 & 1981 & Feb. 11 & 3,680 & 12.10 \\
\hline 1956 & May 28 & 8,100 & 14.77 & 1971 & Feb. 05 & 4,850 & 13.01 & 1982 & Jan. 04 & 11,200 & 14.91 \\
\hline 1957 & Feb. 01 & 18,000 & 17.52 & 1972 & Jan. 05 & 4,000 & 12.30 & 1983 & Dec. 02 & 9,910 & 14.48 \\
\hline 1958 & Apr. 28 & 14,300 & 16.70 & 1973 & Mar. 17 & 25,200 & 18.59 & 1984 & May 04 & 8,880 & 14.09 \\
\hline 1963 & Mar. 13 & 13,600 & 15.77 & 1974 & Dec. 31 & 6,310 & 13.66 & 1985 & Feb. 02 & 8,510 & 13.94 \\
\hline 1964 & Mar. 15 & 15,100 & 16.04 & 1975 & Mar. 30 & 13,900 & 15.97 & 1986 & Feb. 19 & 3,030 & 10.21 \\
\hline 1965 & Mar. 26 & 15,800 & 16.46 & 1976 & July 05 & 4,920 & 12.99 & 1987 & Jan. 20 & 6,850 & 13.19 \\
\hline 1966 & Feb. 14 & 7,570 & 14.29 & 1977 & Apr. 04 & 10,300 & 15.08 & 1988 & Jan. 21 & 4,940 & 12.10 \\
\hline 1967 & Aug. 28 & 4,840 & 13.00 & 1978 & Jan. 26 & 5,170 & 13.12 & 1989 & Mar. 01 & 7,140 & 13.33 \\
\hline 1968 & Dec. 22 & 9,720 & 14.93 & 1979 & Mar. 04 & 11,200 & 15.29 & 1990 & Feb. 16 & 33,200 & 20.50 \\
\hline
\end{tabular}




\section{MOBILE RIVER BASIN}

\section{MILL CREEK NEAR CRANDALL, GEORGIA}

LOCATION.--Lat $34^{\circ} 52^{\prime} 19^{\prime \prime}$, long $84^{\circ} 43^{\prime} 17^{\prime \prime}$, Murray County, on right bank $100 \mathrm{ft}$ south of Forest Service Road $630,1.3$ mi upstream from Cohan Creek, 1.4 mi northeast of Crandall.

DRAINAGE AREA.--8.27 $\mathrm{mi}^{2}$.

GAGE.--Water-stage recorder. Datum of gage is $888.98 \mathrm{ft}$ above sea level (from U.S. Geological Survey benchmark).

STAGE-DISCHARGE RELATION.--Defined by current-meter measurements below $420 \mathrm{ft}^{3} / \mathrm{s}$, and extended above on the basis of slope-area computations. Bankfull stage and discharge, $4 \mathrm{ft}$ and $300 \mathrm{ft} / \mathrm{s}$.

\begin{tabular}{|c|c|c|c|c|c|c|c|c|c|c|c|}
\hline $\begin{array}{l}\text { Water } \\
\text { year }\end{array}$ & Date & $\begin{array}{c}\text { Discharge } \\
\left(\mathrm{ft}^{3} / \mathrm{s}\right)\end{array}$ & $\begin{array}{c}\text { Gage } \\
\text { height } \\
\text { (ft) }\end{array}$ & $\begin{array}{l}\text { Water } \\
\text { year }\end{array}$ & Date & $\begin{array}{c}\text { Discharge } \\
\left(\mathrm{ft}^{3} / \mathrm{s}\right)\end{array}$ & $\begin{array}{c}\text { Gage } \\
\text { height } \\
\text { (ft) }\end{array}$ & $\begin{array}{l}\text { Water } \\
\text { year }\end{array}$ & Date & $\begin{array}{c}\text { Discharge } \\
\left(\mathrm{ft}^{3} / \mathrm{s}\right)\end{array}$ & $\begin{array}{c}\text { Gage } \\
\text { height } \\
\text { (ft) }\end{array}$ \\
\hline 1985 & Feb. 01 & 272 & 3.39 & 1987 & Feb. 28 & 305 & 3.60 & 1989 & Sept.30 & 894 & 4.95 \\
\hline 1986 & Feb. 18 & 179 & 3.05 & 1988 & Jan. 20 & 363 & 3.81 & 1990 & Feb. 16 & 2,240 & 6.96 \\
\hline
\end{tabular}

02384600 PINHOOK CREEK NEAR ETON, GEORGIA

(Formerly published as "Mill Creek Tributary near Eton, Georgia")

LOCATION.--Lat 34 $44^{\prime} 38^{\prime \prime}$ long $84^{\circ} 48^{\prime} 58^{\prime \prime}$, Murray County, at culvert on State Highway 286, 3 mi west of Eton. DRAINAGE AREA. $-4.28 \mathrm{mi}^{2}$.

GAGE.-Flood-stage/rainfall recorder prior to Dec. 27, 1974; crest-stage gage thereafter. Datum of gage is $706.72 \mathrm{ft}$ above sea level (levels by Global Positioning System).

STAGE-DISCHARGE RELATION.-Defined by current-meter measurements below $226 \mathrm{ft}^{3} / \mathrm{s}$, and extended above on the basis of culvert computations.

\begin{tabular}{|c|c|c|c|c|c|c|c|c|c|c|c|}
\hline $\begin{array}{l}\text { Water } \\
\text { year }\end{array}$ & Date & $\begin{array}{c}\text { Discharge } \\
\left(\mathrm{ft}^{3} / \mathrm{s}\right)\end{array}$ & $\begin{array}{c}\text { Gage } \\
\text { height } \\
\text { (ft) }\end{array}$ & $\begin{array}{l}\text { Water } \\
\text { year }\end{array}$ & Date & $\begin{array}{c}\text { Discharge } \\
\left(\mathrm{ft}^{3} / \mathrm{s}\right)\end{array}$ & $\begin{array}{c}\text { Gage } \\
\text { height } \\
\text { (ft) }\end{array}$ & $\begin{array}{l}\text { Water } \\
\text { year }\end{array}$ & Date & $\begin{array}{c}\text { Discharge } \\
\left(\mathrm{ft}^{3} / \mathrm{s}\right)\end{array}$ & $\begin{array}{c}\text { Gage } \\
\text { height } \\
\text { (ft) }\end{array}$ \\
\hline 1964 & Mar. 25 & 367 & 5.42 & 1973 & Mar. 16 & 665 & 6.57 & 1982 & Jan. 03 & 376 & 5.47 \\
\hline 1965 & Mar. 26 & 442 & 5.77 & 1974 & Apr. 04 & 410 & 5.63 & 1983 & Nov. 30 & 392 & 5.55 \\
\hline 1966 & Mar. 04 & 412 & 5.64 & 1975 & Mar. 29 & 480 & 5.93 & 1984 & May 02 & 662 & 6.56 \\
\hline 1967 & Aug. 22 & 960 & 7.30 & 1976 & July 04 & 426 & 5.70 & 1985 & Oct. 23 & 313 & 5.13 \\
\hline 1968 & Dec. 18 & 474 & 5.91 & 1977 & Apr. 04 & 428 & 5.71 & 1986 & Mar. 12 & 164 & 3.74 \\
\hline 1969 & Feb. 02 & 242 & 4.64 & 1978 & Nov. 05 & 380 & 5.49 & 1987 & Nov. 25 & 126 & 3.21 \\
\hline 1970 & Apr. 02 & 227 & 4.51 & 1979 & July 25 & 940 & 7.25 & 1988 & Jan. 20 & 273 & 4.88 \\
\hline 1971 & Feb. 05 & 263 & 4.80 & 1980 & Apr. 14 & 374 & 5.46 & 1989 & Feb. 21 & 254 & 4.73 \\
\hline 1972 & May 13 & 228 & 4.52 & 1981 & Feb. 11 & 169 & 3.84 & 1990 & Feb. 16 & 768 & 6.86 \\
\hline
\end{tabular}


LOCATION.-Lat 34 $53^{\prime} 43^{\prime \prime}$, long $84^{\circ} 55^{\prime} 15^{\prime \prime}$, Whitfield County, 350 ft downstream from Praters Mill, 2 mi upstream from Spring Creek, and 3 mi east of Varnell.

DRAINAGE AREA. $-86.7 \mathrm{mi}^{2}$.

GAGE.-Water-stage recorder prior to Jan. 1, 1943; crest-stage gage after Aug. 24, 1950. Datum of gage is $704.92 \mathrm{ft}$ above sea level (from U.S. Geological Survey benchmark).

STAGE-DISCHARGE RELATION.--Defined by current-meter measurements below $2,700 \mathrm{ft}^{3} / \mathrm{s}$, and above by adjustment of currentmeter measurements made at a bridge $6 \mathrm{mi}$ downstream, and slope-conveyance studies. Bankfull stage and discharge, $10 \mathrm{ft}$ and $1,400 \mathrm{ft}^{3} / \mathrm{s}$.

HISTORICAL DATA.-Peak stage for 1919 or 1920 based on information furnished by local resident. Discharges for 1919 and 1951 are estimated.

\begin{tabular}{|c|c|c|c|c|c|c|c|c|c|c|c|}
\hline $\begin{array}{l}\text { Water } \\
\text { year }\end{array}$ & Date & $\begin{array}{c}\text { Discharge } \\
\left(\mathrm{ft}^{3} / \mathrm{s}\right)\end{array}$ & $\begin{array}{c}\text { Gage } \\
\text { height } \\
\text { (ft) }\end{array}$ & $\begin{array}{l}\text { Water } \\
\text { year }\end{array}$ & Date & $\begin{array}{c}\text { Discharge } \\
\left(\mathrm{ft}^{3} / \mathrm{s}\right)\end{array}$ & $\begin{array}{c}\text { Gage } \\
\text { height } \\
\text { (ft) }\end{array}$ & $\begin{array}{l}\text { Water } \\
\text { year }\end{array}$ & Date & $\begin{array}{c}\text { Discharge } \\
\left(\mathrm{ft}^{3} / \mathrm{s}\right)\end{array}$ & $\begin{array}{c}\text { Gage } \\
\text { height } \\
\text { (ft) }\end{array}$ \\
\hline 1919 & Mar. -- & 12,500 & $16.80 \mathrm{c}$ & 1952 & Mar. 11 & 3,380 & 12.00 & 1958 & Nov. -- & 3,380 & 12.00 \\
\hline 1940 & Feb. 18 & 2,300 & 11.30 & 1953 & Feb. 21 & 2,680 & 11.50 & 1959 & Apr. 19 & 2,180 & 11.00 \\
\hline 1941 & July 08 & 1,040 & 9.40 & 1954 & Jan. 22 & 5,340 & 12.90 & 1960 & Mar. 03 & 3,660 & 12.16 \\
\hline 1942 & Feb. 17 & 1,350 & 10.00 & 1955 & Mar. 23 & 2,680 & 11.50 & 1961 & May 23 & 3,960 & 12.32 \\
\hline 1943 & Dec. 29 & 6,600 & 13.80 & 1956 & Apr. 17 & 2,930 & 11.70 & 1962 & Dec. 12 & 6,470 & 13.26 \\
\hline 1951 & Mar. 29 & 10,000 & 15.70 & 1957 & Feb. 02 & 5,080 & 12.80 & & & & \\
\hline
\end{tabular}

\section{ROCK CREEK NEAR CHATSWORTH, GEORGIA}

LOCATION.--Lat $34^{\circ} 46^{\prime} 33^{\prime \prime}$, long $84^{\circ} 44^{\prime} 33^{\prime \prime}$, Murray County, at culvert on secondary road 2321, 1.5 mi northeast of Chatsworth.

DRAINAGE AREA.--3.46 $\mathrm{mi}^{2}$.

GAGE.--Flood-stage/rainfall recorder. Datum of gage is about $812 \mathrm{ft}$ above sea level (from topographic map).

STAGE-DISCHARGE RELATION.--Defined by current-meter measurements below $220 \mathrm{ft}^{3} / \mathrm{s}$, and extended above on basis of culvert computations.

REMARKS.--The flood of 1990 is thought to be the highest since 1951, based on information at nearby stations.

\begin{tabular}{|c|c|c|c|c|c|c|c|c|c|c|c|}
\hline $\begin{array}{l}\text { Water } \\
\text { year }\end{array}$ & Date & $\begin{array}{c}\text { Discharge } \\
\left(\mathrm{ft}^{3} / \mathrm{s}\right)\end{array}$ & $\begin{array}{l}\text { Gage } \\
\text { height } \\
\text { (ft) }\end{array}$ & $\begin{array}{l}\text { Water } \\
\text { year }\end{array}$ & Date & $\begin{array}{c}\text { Discharge } \\
\left(\mathrm{ft}^{3} / \mathrm{s}\right)\end{array}$ & $\begin{array}{c}\text { Gage } \\
\text { height } \\
\text { (ft) }\end{array}$ & $\begin{array}{l}\text { Water } \\
\text { year }\end{array}$ & Date & $\begin{array}{c}\text { Discharge } \\
\left(\mathrm{ft}^{3} / \mathrm{s}\right)\end{array}$ & $\begin{array}{c}\text { Gage } \\
\text { height } \\
\text { (ft) }\end{array}$ \\
\hline 1965 & Mar. 26 & 403 & 3.76 & 1969 & Feb. 02 & 206 & 2.94 & 1973 & May 27 & 397 & 3.74 \\
\hline 1966 & Mar. 04 & 387 & 3.70 & 1970 & Dec. 30 & 243 & 3.10 & 1974 & Apr. 04 & 434 & 3.88 \\
\hline 1967 & May 12 & 241 & 3.09 & 1971 & Oct. 29 & 182 & 2.83 & $\underline{1979}$ & Mar. 04 & 750 & 5.63 \\
\hline 1968 & Dec. 22 & 252 & 3.14 & 1972 & Jan. 10 & 173 & 2.79 & 1990 & Feb. 16 & 2,300 & $9.42 \mathrm{c}$ \\
\hline
\end{tabular}




\section{MOBILE RIVER BASIN}

02385800 HOLLY CREEK NEAR CHATSWORTH, GEORGIA

LOCATION.--Lat $34^{\circ} 43^{\prime} 00^{\prime \prime}$, long $84^{\circ} 46^{\prime} 12^{\prime \prime}$, Murray County, on right bank $100 \mathrm{ft}$ upstream from bridge on county road $48,3 \mathrm{mi}$ upstream from Rock Creek, and 3.3 mi south of Chatsworth.

DRAINAGE AREA.-64.0 $\mathrm{mi}^{2}$ (revised).

GAGE.-Water-stage recorder. Datum of gage is $689.25 \mathrm{ft}$ above sea level (levels by Global Positioning System).

STAGE-DISCHARGE RELATION.-Defined by current-meter measurements below $10,200 \mathrm{tt}^{3} / \mathrm{s}$, and extended above on basis of contracted-opening mesurement at $20,600 \mathrm{ft}^{3} / \mathrm{s}$. Bankfull stage and discharge, $9 \mathrm{ft}$ and $1,900 \mathrm{ft}^{3} / \mathrm{s}$.

REMARKS.--The flood of 1990 is thought to be the highest since 1951, based on information at nearby stations.

\begin{tabular}{|c|c|c|c|c|c|c|c|c|c|c|c|}
\hline $\begin{array}{l}\text { Water } \\
\text { year }\end{array}$ & Date & $\begin{array}{c}\text { Discharge } \\
\left(\mathrm{ft}^{3} / \mathrm{s}\right)\end{array}$ & $\begin{array}{c}\text { Gage } \\
\text { height } \\
\text { (ft) }\end{array}$ & $\begin{array}{l}\text { Water } \\
\text { year }\end{array}$ & Date & $\begin{array}{c}\text { Discharge } \\
\left(\mathrm{ft}^{3} / \mathrm{s}\right)\end{array}$ & $\begin{array}{c}\text { Gage } \\
\text { height } \\
\text { (ft) }\end{array}$ & $\begin{array}{l}\text { Water } \\
\text { year }\end{array}$ & Date & $\begin{array}{c}\text { Discharge } \\
\left(\mathrm{ft}^{3} / \mathrm{s}\right)\end{array}$ & $\begin{array}{c}\text { Gage } \\
\text { height } \\
\text { (ft) }\end{array}$ \\
\hline 1961 & Feb. 23 & 3,480 & 10.24 & 1971 & July 31 & 1,510 & 8.74 & 1981 & Feb. 11 & 1,560 & 8.62 \\
\hline 1962 & Dec. 12 & 4,920 & 11.09 & 1972 & Jan. 05 & 1,410 & 8.65 & 1982 & Jan. 04 & 4,430 & 10.53 \\
\hline 1963 & Mar. 12 & 4,810 & 11.03 & 1973 & May 28 & 4,170 & 10.43 & 1983 & Dec. 01 & 3,380 & 9.82 \\
\hline 1964 & Mar. 15 & 6,040 & 11.37 & 1974 & Dec. 31 & 4,700 & 10.70 & 1984 & Dec. 28 & 2,600 & 9.33 \\
\hline 1965 & Mar. 26 & 4,700 & 10.70 & 1975 & Mar. 30 & 3,350 & 10.08 & 1985 & Feb. 01 & 1,560 & 8.55 \\
\hline 1966 & Feb. 13 & 3,840 & 10.06 & 1976 & July 05 & 2,520 & 9.25 & 1986 & Feb. 18 & 1,170 & 8.19 \\
\hline 1967 & Aug. 27 & 2,430 & 9.42 & 1977 & Apr. 05 & 5,500 & 11.00 & 1987 & Jan. 19 & 2,370 & 9.14 \\
\hline 1968 & Dec. 22 & 2,700 & 9.58 & 1978 & Jan. 09 & 3,780 & 10.11 & 1988 & Jan. 20 & 1,910 & 8.81 \\
\hline 1969 & Feb. 02 & 2,850 & 9.71 & 1979 & Mar. 04 & 9,110 & 12.54 & 1989 & June 20 & 4,260 & 10.40 \\
\hline 1970 & Dec. 31 & 2,030 & 9.10 & 1980 & Apr. 14 & 4,210 & 10.18 & 1990 & Feb. 16 & 20,600 & 14.87 \\
\hline
\end{tabular}


LOCATION.-Lat $34^{\circ} 40^{\prime} 00^{\prime \prime}$, long $84^{\circ} 55^{\prime} 42^{\prime \prime}$, Murray County, on left bank $250 \mathrm{ft}$ downstream from Tilton Road bridge, $0.2 \mathrm{mi}$ downstream from Swamp Creek, 0.5 mi northeast of Tilton, and $12 \mathrm{mi}$ upstream from confluence with Coosawattee River. DRAINAGE AREA.-687 $\mathrm{mi}^{2}$ (revised).

GAGE.-Water-stage recorder. Datum of gage is $622.28 \mathrm{ft}$ above sea level (levels by the U.S. Army Corps of Engineers), supplementary adjustment of 1936. Prior to Aug. 24, 1940, nonrecording gage at site $150 \mathrm{ft}$ upstream at same datum. Waterstage recorder on Oostanaula River at Resaca used as auxiliary gage from 1961 to 1979. Since 1979, auxiliary water-stage recorder at Sloan bridge, $3.2 \mathrm{mi}$ downstream.

STAGE-DISCHARGE RELATION.-Defined by current-meter measurements below $33,100 \mathrm{ft}^{3} / \mathrm{s}$. Stage-discharge relation is affected by backwater, and the fall between this gage and auxiliary gage is used as a factor in computing discharge. Bankfull stage and discharge, $19 \mathrm{ft}$ and $8,600 \mathrm{ft}^{3} / \mathrm{s}$.

HISTORICAL DATA.--Peak stage for April 1886 based on inforamtion furnished by local resident, and is highest since 1834, based on information at gaging station at Oostanaula River at Resaca.

\begin{tabular}{|c|c|c|c|c|c|c|c|c|c|c|c|}
\hline $\begin{array}{l}\text { Water } \\
\text { year }\end{array}$ & Date & $\begin{array}{c}\text { Discharge } \\
\left(\mathrm{ft}^{3} / \mathrm{s}\right)\end{array}$ & $\begin{array}{c}\text { Gage } \\
\text { height } \\
\text { (ft) }\end{array}$ & $\begin{array}{l}\text { Water } \\
\text { year }\end{array}$ & Date & $\begin{array}{c}\text { Discharge } \\
\left(\mathrm{ft}^{3} / \mathrm{s}\right)\end{array}$ & $\begin{array}{c}\text { Gage } \\
\text { height } \\
\text { (ft) }\end{array}$ & $\begin{array}{l}\text { Water } \\
\text { year }\end{array}$ & Date & $\begin{array}{c}\text { Discharge } \\
\left(\mathrm{ft}^{3} / \mathrm{s}\right)\end{array}$ & $\begin{array}{c}\text { Gage } \\
\text { height } \\
\text { (ft) }\end{array}$ \\
\hline 1886 & Apr. 01 & 40,000 & $34.00 \mathrm{c}$ & 1955 & Feb. 09 & 8,970 & 19.90 & 1973 & Mar. 18 & 26,300 & 28.13 \\
\hline 1938 & Apr. 10 & 20,300 & 25.40 & 1956 & Feb. 06 & 11,600 & 21.30 & 1974 & Nov. 30 & 10,500 & 20.54 \\
\hline 1939 & Feb. 17 & 11,300 & 21.10 & 1957 & Feb. 03 & 25,000 & 27.30 & 1975 & Apr. 01 & 16,800 & 24.60 \\
\hline 1940 & Mar. 16 & $\underline{5,880}$ & 15.20 & 1958 & Nov. 20 & 17,500 & 24.20 & 1976 & July 07 & 10,400 & 20.49 \\
\hline 1941 & July 08 & 4,700 & 13.10 & 1959 & Apr. 22 & 9,530 & 19.80 & 1977 & Apr. 06 & 19,700 & 24.34 \\
\hline 1942 & Feb. 19 & 8,090 & 18.40 & 1960 & Mar. 05 & 12,100 & 21.60 & 1978 & Nov. 09 & 10,700 & $19.40 \mathrm{a}$ \\
\hline 1943 & Dec. 31 & 20,700 & 25.60 & 1961 & Feb. 25 & 16,500 & 24.30 & 1979 & Mar. 06 & 18,900 & 24.73 \\
\hline 1944 & Mar. 30 & 17,900 & 24.40 & 1962 & Dec. 20 & 20,700 & 26.10 & 1980 & Mar. 23 & 23,500 & 26.73 \\
\hline 1945 & Feb. 20 & 10,700 & 20.70 & 1963 & Mar. 15 & 16,600 & 23.82 & 1981 & Feb. 13 & 6,300 & 15.70 \\
\hline 1946 & Feb. 12 & 22,400 & 26.30 & 1964 & Mar. 17 & 21,100 & 25.74 & 1982 & Jan. 06 & 18,700 & 24.53 \\
\hline 1947 & Jan. 21 & 26,000 & 27.70 & 1965 & Mar. 28 & 19,500 & 25.10 & 1983 & Dec. 04 & 13,500 & 21.72 \\
\hline 1948 & Nov. 30 & 20,800 & 27.30 & 1966 & Mar. 06 & 12,100 & 21.62 & 1984 & May 06 & 13,600 & 21.78 \\
\hline 1949 & Nov. 30 & 22,500 & 27.30 & 1967 & July 10 & 9,530 & 19.83 & 1985 & Feb. 04 & 9,870 & 19.60 \\
\hline 1950 & Mar. 15 & 19,300 & 26.10 & 1968 & Dec. 24 & 13,400 & 22.80 & 1986 & Mar. 15 & 5,040 & 12.41 \\
\hline 1951 & Mar. 30 & 29,000 & 30.20 & 1969 & Feb. 04 & 18,200 & 24.50 & 1987 & Mar. 02 & 11,500 & 20.50 \\
\hline 1952 & Mar. 13 & 11,000 & 21.30 & 1970 & Apr. 04 & 8,330 & 18.58 & 1988 & Jan. 22 & 7,820 & 16.67 \\
\hline 1953 & Feb. 24 & 10,800 & 20.80 & 1971 & Feb. 08 & 8,820 & 19.17 & 1989 & Mar. 02 & 11,100 & 20.09 \\
\hline 1954 & Jan. 18 & 19,100 & 24.90 & 1972 & Jan. 07 & 8,070 & $19.05 \mathrm{a}$ & 1990 & Feb. 17 & 36,800 & 29.89 \\
\hline
\end{tabular}

\section{POLECAT CREEK NEAR SPRING PLACE, GEORGIA}

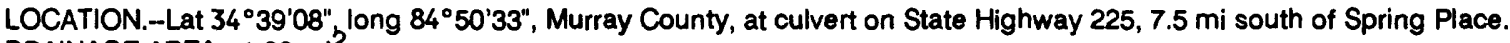
DRAINAGE AREA. $-1.22 \mathrm{mi}^{2}$.

GAGE.--Flood-stage/rainfall recorder. Datum of gage is $679.19 \mathrm{ft}$ above sea level (levels by Global Positioning System). STAGE-DISCHARGE RELATION.--Defined by current-meter measurements below $236 \mathrm{ft}^{3} / \mathrm{s}$, and extended above on the basis of culvert computation.

\begin{tabular}{lccccccccccc}
\hline $\begin{array}{l}\text { Water } \\
\text { year }\end{array}$ & Date & $\begin{array}{c}\text { Discharge } \\
\left(\mathrm{ft}^{3} / \mathrm{s}\right)\end{array}$ & $\begin{array}{c}\text { Gage } \\
\text { height } \\
(\mathrm{ft})\end{array}$ & $\begin{array}{c}\text { Water } \\
\text { year }\end{array}$ & Date & $\begin{array}{c}\text { Discharge } \\
\left(\mathrm{ft}^{3} / \mathrm{s}\right)\end{array}$ & $\begin{array}{c}\text { Gage } \\
\text { height } \\
(\mathrm{ft})\end{array}$ & $\begin{array}{c}\text { Water } \\
\text { year }\end{array}$ & $\begin{array}{c}\text { Gage } \\
\text { Date }\end{array}$ & $\begin{array}{c}\text { Discharge } \\
\left(\mathrm{ft}^{3} / \mathrm{s}\right)\end{array}$ & $\begin{array}{c}\text { height } \\
(\mathrm{ft})\end{array}$ \\
\hline & & & & & & & & & & \\
1964 & Mar. 23 & 390 & 4.93 & 1969 & Feb. 02 & 205 & 3.80 & 1974 & Dec. 31 & 272 & 4.51 \\
1965 & Mar. 26 & 228 & 3.89 & 1970 & Apr. 01 & 219 & 4.23 & 1977 & Apr. 04 & 508 & 5.75 \\
1966 & Mar. 04 & 828 & 7.75 & 1971 & Feb. 26 & 176 & 3.99 & $\underline{1979}$ & Mar. 04 & 703 & 7.02 \\
1967 & Feb. 20 & 212 & 3.83 & 1972 & Jan. 04 & 149 & 3.84 & 1990 & Feb. 16 & 475 & $5.54 c$ \\
1968 & Dec. 22 & 298 & 4.30 & 1973 & Dec. 15 & 324 & 4.77 & & & & \\
\hline
\end{tabular}


MOBILE RIVER BASIN

02387200 BEAMER CREEK NEAR SPRING PLACE, GEORGIA

LOCATION.--Lat $34^{\circ} 38^{\prime} 03^{\prime \prime}$, long $84^{\circ} 51^{\prime} 52^{\prime \prime}$, Murray County, at culvert on State Highway $225,8.8$ mi south of Spring Place. DRAINAGE AREA. $-1.29 \mathrm{mi}^{2}$.

GAGE.--Flood-stage recorder prior to May 1, 1968; flood-stage/rainfall recorder thereafter. Datum of gage is about $665 \mathrm{ft}$ above sea level (from topographic map).

STAGE-DISCHARGE RELATION.--Defined by current-meter measurements below $396 \mathrm{ft}^{3} / \mathrm{s}$, and extended above on the basis of culvert computation.

\begin{tabular}{|c|c|c|c|c|c|c|c|c|c|c|c|}
\hline $\begin{array}{l}\text { Water } \\
\text { year }\end{array}$ & Date & $\begin{array}{c}\text { Discharge } \\
\left(\mathrm{ft}^{3} / \mathrm{s}\right)\end{array}$ & $\begin{array}{c}\text { Gage } \\
\text { height } \\
\text { (ft) }\end{array}$ & $\begin{array}{l}\text { Water } \\
\text { year }\end{array}$ & Date & $\begin{array}{c}\text { Discharge } \\
\left(\mathrm{ft}^{3} / \mathrm{s}\right)\end{array}$ & $\begin{array}{c}\text { Gage } \\
\text { height } \\
\text { (ft) }\end{array}$ & $\begin{array}{l}\text { Water } \\
\text { year }\end{array}$ & Date & $\begin{array}{c}\text { Discharge } \\
\left(\mathrm{ft}^{3} / \mathrm{s}\right)\end{array}$ & $\begin{array}{l}\text { Gage } \\
\text { height } \\
\text { (ft) }\end{array}$ \\
\hline 1964 & Mar. 23 & 389 & 3.70 & 1969 & Feb. 02 & 245 & 2.92 & 1973 & Dec. 15 & 444 & 4.02 \\
\hline 1965 & Mar. 26 & 231 & 2.87 & 1970 & Apr. 01 & 329 & 3.45 & $\underline{1974}$ & Dec. 31 & 322 & 3.42 \\
\hline 1966 & Mar. 04 & 879 & 6.20 & 1971 & Feb. 26 & 245 & 3.07 & $\overline{1977}$ & Apr. 04 & 512 & $4.40 \mathrm{c}$ \\
\hline 1967 & Feb. 20 & 282 & 3.07 & 1972 & Jan. 04 & 174 & 2.72 & $\overline{1979}$ & Mar. 04 & 670 & $5.20 \mathrm{c}$ \\
\hline 1968 & Dec. 22 & 401 & 3.77 & & & & & & & & \\
\hline
\end{tabular}

\section{DEAD MANS BRANCH NEAR RESACA, GEORGIA}

LOCATION.--Lat $34^{\circ} 35^{\prime} 44^{\prime \prime}$, long $84^{\circ} 52^{\prime} 11^{\prime \prime}$, Gordon County, at culvert on State Highway 225, 4.2 mi east of Resaca. DRAINAGE AREA.--0.17 $\mathrm{mi}^{2}$.

GAGE.--Flood-stage/rainfall recorder prior to Dec. 27, 1974; crest-stage gage thereafter. Datum of gage is about $670 \mathrm{ft}$ above sea level (from topographic map).

STAGE-DISCHARGE RELATION.--Defined by current-meter measurements below $20 \mathrm{tt}^{3} / \mathrm{s}$, and extended above on the basis of culvert computation.

REMARKS.--Peak discharge for 1985 is estimated.

\begin{tabular}{|c|c|c|c|c|c|c|c|c|c|c|c|}
\hline $\begin{array}{l}\text { Water } \\
\text { year }\end{array}$ & Date & $\begin{array}{c}\text { Discharge } \\
\left(\mathrm{ft}^{3} / \mathrm{s}\right)\end{array}$ & $\begin{array}{c}\text { Gage } \\
\text { height } \\
\text { (ft) }\end{array}$ & $\begin{array}{l}\text { Water } \\
\text { year }\end{array}$ & Date & $\begin{array}{c}\text { Discharge } \\
\left(\mathrm{ft}^{3} / \mathrm{s}\right)\end{array}$ & $\begin{array}{c}\text { Gage } \\
\text { height } \\
\text { (ft) }\end{array}$ & $\begin{array}{l}\text { Water } \\
\text { year }\end{array}$ & Date & $\begin{array}{c}\text { Discharge } \\
\left(\mathrm{ft}^{3} / \mathrm{s}\right)\end{array}$ & $\begin{array}{c}\text { Gage } \\
\text { height } \\
\text { (ft) }\end{array}$ \\
\hline 1965 & Mar. 26 & 64 & 3.44 & 1973 & May 27 & 91 & 4.22 & 1981 & Mar. 30 & 36 & 2.44 \\
\hline 1966 & Mar. 03 & 184 & 6.50 & 1974 & Dec. 31 & 67 & 3.52 & 1982 & Jan. 03 & 49 & 2.94 \\
\hline 1967 & Feb. 20 & 36 & 2.47 & 1975 & Jan. 25 & 114 & 4.82 & 1983 & Apr. 06 & 80 & 3.90 \\
\hline 1968 & Dec. 22 & 87 & 4.12 & 1976 & May 15 & 139 & 5.45 & 1984 & Dec. 03 & 123 & 5.06 \\
\hline 1969 & Mar. 18 & 28 & 2.12 & 1977 & Apr. 04 & 172 & 6.25 & 1985 & Jan. 31 & 100 & 4.92 \\
\hline 1970 & Dec. 30 & 56 & 3.17 & 1978 & May 08 & 121 & 5.00 & 1986 & July 01 & 130 & 5.23 \\
\hline 1971 & Apr. 23 & 34 & 2.37 & 1979 & Mar. 04 & 149 & 5.69 & $\underline{1987}$ & Feb. 28 & 131 & 5.24 \\
\hline 1972 & Jan. 04 & 36 & 2.47 & 1980 & Apr. 13 & 73 & 3.70 & 1990 & Feb. 16 & 105 & $4.65 c$ \\
\hline
\end{tabular}


LOCATION.--Lat $34^{\circ} 34^{\prime} 42^{\prime \prime}$, long $84^{\circ} 56^{\prime} 29^{\prime \prime}$, Gordon County, on downstream side of pier of bridge on U.S. Highway 41 at Resaca, $200 \mathrm{ft}$ downstream from Nashville, Chattanooga \& St. Louis Railway bridge, 0.8 mi upstream from Camp Creek, and $3.5 \mathrm{mi}$ downstream from confluence of Conasauga and Coosawattee Rivers.

DRAINAGE AREA. $-1,600 \mathrm{mi}^{2}$, approximately (revised).

GAGE.-Water-stage recorder. Datum of gage is $604.14 \mathrm{ft}$ above sea level (levels by the U.S. Army Corps of Engineers). Prior to Mar. 23, 1919, nonrecording gage at site $200 \mathrm{ft}$ upstream at same datum. March 23, 1919, to Oct. 23, 1928, nonrecording gage at site $400 \mathrm{ft}$ downstream at same datum. Oct. 24, 1928, to Sept. 11, 1938, nonrecording gage at present site and datum. From Oct. 28, 1948, to May 31, 1979, auxiliary nonrecording gage at bridge on State Highway 143, 7.1 mi downstream. Since June 1, 1979, auxiliary water-stage recorder at Calhoun water-works intake, $6.5 \mathrm{mi}$ downstream.

STAGE-DISCHARGE RELATION.--Defined by current-meter measurements below $44,000 \mathrm{ft}^{3} / \mathrm{s}$, and extended above on the basis of straight-line extension. Stage-discharge relation is affected by backwater, and the fall between the base and auxiliary gages is used as a factor in computing discharge. Bankfull stage and discharge, $24 \mathrm{ft}$ and $20,000 \mathrm{ft}^{3} / \mathrm{s}$.

HISTORICAL DATA.--Peak stage of April 1886 based on information furnished by the National Weather Service. The April 1886 flood on the Oostanaula River was the highest that has occurred since the city of Rome was founded in 1834, based on information given in "A History of Rome and Floyd County," Georgia Department of Archives.

REMARKS.-The peak discharges are slightly regulated by Carters Dam (maximum flood-control storage, 230,000 acre-ft) and Carters re-regulation dam (maximum flood-control storage, 17,300 acre-ft) since November 1974. Peak stage of 1990 flood from floodmarks.

\begin{tabular}{|c|c|c|c|c|c|c|c|c|c|c|c|}
\hline $\begin{array}{l}\text { Water } \\
\text { year }\end{array}$ & Date & $\begin{array}{c}\text { Discharge } \\
\left(\mathrm{ft}^{3} / \mathrm{s}\right)\end{array}$ & $\begin{array}{c}\text { Gage } \\
\text { height } \\
\text { (ft) }\end{array}$ & $\begin{array}{l}\text { Water } \\
\text { year }\end{array}$ & Date & $\begin{array}{c}\text { Discharge } \\
\left(\mathrm{ft}^{3} / \mathrm{s}\right)\end{array}$ & $\begin{array}{c}\text { Gage } \\
\text { height } \\
\text { (ft) }\end{array}$ & $\begin{array}{l}\text { Water } \\
\text { year }\end{array}$ & Date & $\begin{array}{c}\text { Discharge } \\
\left(\mathrm{ft}^{3} / \mathrm{s}\right)\end{array}$ & $\begin{array}{c}\text { Gage } \\
\text { height } \\
\text { (ft) }\end{array}$ \\
\hline 1886 & Apr. 01 & 68,600 & $36.30 \mathrm{a}$ & 1925 & Jan. 20 & 16,600 & 21.20 & 1958 & Nov. 21 & 20,000 & 24.10 \\
\hline$\overline{1892}$ & Apr. 07 & 39,900 & $31.70 \mathrm{a}$ & 1926 & Jan. 19 & 12,400 & 17.30 & 1959 & Apr. 20 & 12,100 & 17.00 \\
\hline 1893 & Feb. 17 & 16,200 & 21.00 & 1927 & Dec. 29 & 20,000 & $24.80 \mathrm{a}$ & 1960 & Mar. 05 & 17,000 & 21.50 \\
\hline 1894 & Feb. 05 & 6,870 & 10.30 & 1928 & Mar. 31 & $\underline{16,100}$ & 20.80 & 1961 & Feb. 27 & 31,700 & 29.20 \\
\hline 1895 & Jan. 11 & 21,800 & $26.20 \mathrm{a}$ & 1929 & Mar. 25 & $\overline{17,300}$ & $22.00 \mathrm{a}$ & 1962 & Dec. 14 & 32,400 & 29.40 \\
\hline 1896 & Feb. 07 & 12,200 & 16.70 & 1930 & Nov. 17 & 26,700 & $28.20 \mathrm{a}$ & 1963 & May 02 & 25,700 & 27.20 \\
\hline 1897 & Mar. 15 & 21,500 & $26.00 \mathrm{a}$ & 1931 & Apr. 05 & 13,400 & 18.20 & 1964 & Mar. 17 & 32,000 & $30.10 \mathrm{a}$ \\
\hline 1898 & Sept.04 & 16,500 & $21.30 \mathrm{a}$ & 1932 & Dec. 16 & 18,400 & $23.20 \mathrm{a}$ & 1965 & Mar. 29 & 25,000 & $27.10 \mathrm{a}$ \\
\hline 1899 & Mar. 17 & 28,300 & $28.70 \mathrm{a}$ & 1933 & Dec. 29 & 36,500 & $30.90 \mathrm{a}$ & 1966 & Mar. 06 & 25,200 & 27.00 \\
\hline 1900 & Feb. 14 & 18,800 & $23.60 \mathrm{a}$ & 1934 & Mar. 06 & 25,300 & 27.30 & 1967 & Aug. 26 & 14,200 & 19.00 \\
\hline 1901 & Jan. 13 & 22,700 & $26.70 \mathrm{a}$ & 1935 & Mar. 13 & 15,300 & 20.10 & 1968 & Dec. 25 & 23,300 & 26.09 \\
\hline 1902 & Dec. 31 & 22,300 & $26.50 \mathrm{a}$ & 1936 & Apr. 03 & 35,300 & $30.60 \mathrm{a}$ & 1969 & Feb. 05 & 26,800 & 27.63 \\
\hline 1903 & Mar. 02 & 23,800 & $27.10 \mathrm{a}$ & 1937 & Jan. 05 & 23,500 & 26.50 & 1970 & Mar. 22 & 13,700 & 18.37 \\
\hline 1904 & Mar. 24 & 8,340 & 12.50 & 1938 & Apr. 09 & 37,700 & $31.20 \mathrm{a}$ & 1971 & Jan. 26 & 16,100 & $21.02 \mathrm{a}$ \\
\hline 1905 & Feb. 22 & 17,300 & $22.00 \mathrm{a}$ & 1939 & Feb. 17 & 17,000 & 21.70 & 1972 & Jan. 13 & 18,100 & 23.07 \\
\hline 1906 & Mar. 16 & 16,900 & $21.70 \mathrm{a}$ & 1940 & Mar. 14 & 10,700 & 15.60 & 1973 & Mar. 19 & 29,000 & $28.40 \mathrm{a}$ \\
\hline 1907 & Nov. 20 & 31,700 & $29.70 \mathrm{a}$ & 1941 & July 08 & 9,150 & 14.00 & 1974 & Jan. 03 & 18,900 & $23.80 \mathrm{a}$ \\
\hline 1908 & Feb. 16 & 15,100 & 20.00 & 1942 & Feb. 19 & 18,000 & 22.60 & 1975 & Apr. 02 & 18,800 & 23.12 \\
\hline 1909 & Mar. 14 & 39,900 & $31.70 \mathrm{a}$ & 1943 & Dec. 29 & 33,000 & 29.80 & 1976 & Apr. 02 & 18,500 & $23.58 \mathrm{a}$ \\
\hline 1910 & May 21 & 15,100 & 20.00 & 1944 & Mar. 31 & 28,300 & 28.40 & 1977 & Apr. 06 & 29,000 & 28.40 \\
\hline 1911 & Apr. 09 & 16,900 & $21.60 \mathrm{a}$ & 1945 & Feb. 15 & 14,700 & 19.60 & 1978 & Jan. 27 & 16,000 & 21.00 \\
\hline 1912 & Mar. 31 & 20,000 & $24.80 \mathrm{a}$ & 1946 & Feb. 11 & 42,200 & $32.20 \mathrm{a}$ & 1979 & Mar. 06 & 26,200 & $28.00 \mathrm{a}$ \\
\hline 1913 & Mar. 16 & 20,900 & $25.60 \mathrm{a}$ & 1947 & Jan. 21 & 47,000 & $33.20 \mathrm{a}$ & 1980 & Mar. 24 & 27,900 & 28.58 \\
\hline 1914 & Apr. 15 & 10,800 & 15.50 & 1948 & Feb. 15 & 26,800 & $28.40 \mathrm{a}$ & 1981 & Mar. 31 & 11,400 & 16.34 \\
\hline 1915 & Feb. 02 & 16,900 & $21.70 \mathrm{a}$ & 1949 & Nov. 30 & 36,300 & $31.10 \mathrm{a}$ & 1982 & Jan. 06 & 25,300 & 27.65 \\
\hline 1916 & July 12 & 23,300 & $27.00 \mathrm{a}$ & 1950 & Mar. 15 & 31,900 & 30.10 & 1983 & Apr. 10 & 16,200 & 21.74 \\
\hline 1917 & Mar. 06 & 33,500 & $30.20 \mathrm{a}$ & 1951 & Mar. 31 & 54,800 & $34.50 \mathrm{a}$ & 1984 & May 07 & 15,900 & 20.96 \\
\hline 1918 & Jan. 31 & 18,400 & $23.20 \mathrm{a}$ & 1952 & Mar. 25 & 20,100 & 24.20 & 1985 & Feb. 02 & 12,700 & 17.76 \\
\hline 1919 & Dec. 24 & 16,900 & $21.60 \mathrm{a}$ & 1953 & Feb. 23 & 15,600 & 20.30 & 1986 & Feb. 18 & 7,390 & 12.30 \\
\hline 1920 & Apr. 04 & 39,900 & $31.70 \mathrm{a}$ & 1954 & Jan. 18 & 30,700 & 30.20 & 1987 & Mar. 02 & 17,600 & 22.79 \\
\hline 1921 & Feb. 11 & 44,400 & $32.70 \mathrm{a}$ & 1955 & Feb. 09 & 19,100 & 23.40 & 1988 & Jan. 21 & 11,400 & 16.43 \\
\hline 1922 & Jan. 22 & 40,800 & $31.90 \mathrm{a}$ & 1956 & Apr. 28 & 18,200 & 22.60 & 1989 & Mar. 07 & 17,000 & 22.87 \\
\hline 1923 & Dec. 18 & 15,500 & 20.30 & 1957 & Feb. 04 & 32,800 & 30.80 & 1990 & Feb. 18 & 45,500 & 32.59 \\
\hline 1924 & Apr. 20 & 20,000 & $24.80 \mathrm{a}$ & & & & & & & & \\
\hline
\end{tabular}




\section{MOBILE RIVER BASIN \\ 02387560 OOTHKALOOGA CREEK TRIBUTARY AT ADAIRSVILLE, GEORGIA}

LOCATION.--Lat $34^{\circ} 21^{\prime} 34^{\prime \prime}$ long $84^{\circ} 55^{\prime} 20^{\prime \prime}$, Bartow County, at culvert on U.S. Highway 41, 1 mi south of Adairsville.

DRAINAGE AREA.-3.56 $\mathrm{mi}^{2}$.

GAGE.--Flood-stage/rainfall recorder. Datum of gage is about $700 \mathrm{ft}$ above sea level (from topographic map).

STAGE-DISCHARGE RELATION.--Defined by current-meter measurements below $245 \mathrm{ft}^{3} / \mathrm{s}$, and extended above on the basis of culvert computations.

\begin{tabular}{|c|c|c|c|c|c|c|c|c|c|c|c|}
\hline $\begin{array}{l}\text { Water } \\
\text { year }\end{array}$ & Date & $\begin{array}{c}\text { Discharge } \\
\left(\mathrm{ft}^{3} / \mathrm{s}\right)\end{array}$ & $\begin{array}{c}\text { Gage } \\
\text { height } \\
\text { (ft) }\end{array}$ & $\begin{array}{l}\text { Water } \\
\text { year }\end{array}$ & Date & $\begin{array}{c}\text { Discharge } \\
\left(\mathrm{ft}^{3} / \mathrm{s}\right)\end{array}$ & $\begin{array}{c}\text { Gage } \\
\text { height } \\
\text { (ft) }\end{array}$ & $\begin{array}{l}\text { Water } \\
\text { year }\end{array}$ & Date & $\begin{array}{c}\text { Discharge } \\
\left(\mathrm{ft}^{3} / \mathrm{s}\right)\end{array}$ & $\begin{array}{c}\text { Gage } \\
\text { height } \\
\text { (ft) }\end{array}$ \\
\hline 1965 & Mar. 24 & 243 & 3.63 & 1969 & Aug. 03 & 305 & 4.00 & 1973 & May 27 & 350 & 4.25 \\
\hline 1966 & Mar. 04 & 465 & 4.70 & 1970 & Apr. 26 & 251 & 3.63 & $\underline{1974}$ & Apr. 04 & 474 & 4.73 \\
\hline 1967 & Aug. 26 & 408 & 4.49 & 1971 & Apr. 23 & 311 & 4.04 & $\underline{1977}$ & Apr. 04 & 1,520 & $6.89 c$ \\
\hline 1968 & Mar. 12 & 205 & 3.19 & 1972 & Jan. 04 & 266 & 3.74 & 1979 & Mar. 04 & 1,850 & $7.80 c$ \\
\hline
\end{tabular}

\section{OOTHKALOOGA CREEK AT ADAIRSVILLE, GEORGIA}

LOCATION.--Lat $34^{\circ} 22^{\prime} 40^{\prime \prime}$ long $84^{\circ} 56^{\prime} 34^{\prime \prime}$, Bartow County, at State Highway $140,0.8$ mi west of Adairsville.

DRAINAGE AREA.--21.7 $\mathrm{mi}^{2}$ (revised).

GAGE.--Crest-stage gage prior to June 30, 1967; flood-stage/rainfall recorder thereafter. Datum of gage is about $675 \mathrm{ft}$ above sea level (from topographic map).

STAGE-DISCHARGE RELATION.--Defined by current-meter measurements below $900 \mathrm{ft}^{3} / \mathrm{s}$, and extended above on the basis of straight-line extension.

\begin{tabular}{|c|c|c|c|c|c|c|c|c|c|c|c|}
\hline $\begin{array}{l}\text { Water } \\
\text { year }\end{array}$ & Date & $\begin{array}{c}\text { Discharge } \\
\left(\mathrm{ft}^{3} / \mathrm{s}\right)\end{array}$ & $\begin{array}{c}\text { Gage } \\
\text { height } \\
\text { (ft) }\end{array}$ & $\begin{array}{l}\text { Water } \\
\text { year }\end{array}$ & Date & $\begin{array}{c}\text { Discharge } \\
\left(\mathrm{ft}^{3} / \mathrm{s}\right)\end{array}$ & $\begin{array}{c}\text { Gage } \\
\text { height } \\
\text { (ft) }\end{array}$ & $\begin{array}{l}\text { Water } \\
\text { year }\end{array}$ & Date & $\begin{array}{c}\text { Discharge } \\
\left(\mathrm{ft}^{3} / \mathrm{s}\right)\end{array}$ & $\begin{array}{c}\text { Gage } \\
\text { height } \\
\text { (ft) }\end{array}$ \\
\hline 1964 & Mar. 23 & 1,650 & 7.60 & 1968 & Mar. 12 & 775 & 6.27 & 1972 & Jan. 04 & 782 & 6.25 \\
\hline 1965 & Mar. 26 & 820 & 6.31 & 1969 & Feb. 02 & 968 & 6.56 & 1973 & May 27 & 884 & 6.42 \\
\hline 1966 & Mar. 04 & 2,000 & 8.05 & 1970 & Mar. 19 & 854 & 6.37 & 1974 & Apr. 04 & 1,500 & 7.37 \\
\hline 1967 & Aug. 26 & 1,200 & 6.92 & 1971 & Mar. 25 & 854 & 6.37 & & & & \\
\hline
\end{tabular}

\section{ROCKY CREEK AT CURRYVLLE, GEORGIA}

LOCATION.--Lat $34^{\circ} 26^{\prime} 44^{\prime \prime}$, long $85^{\circ} 05^{\prime} 12^{\prime \prime}$, Gordon County, at culvert on State Highway 156, 0.4 mi west of Curryville. DRAINAGE AREA, $-9.41 \mathrm{mi}^{2}$.

GAGE.--Flood-stage/rainfall recorder. Datum of gage is about $612 \mathrm{ft}$ above sea level (from topographic map).

STAGE-DISCHARGE RELATION.--Defined by current-meter measurements below $523 \mathrm{ft}^{3} / \mathrm{s}$, and extended above on the basis of culvert computations.

\begin{tabular}{|c|c|c|c|c|c|c|c|c|c|c|c|}
\hline $\begin{array}{l}\text { Water } \\
\text { year }\end{array}$ & Date & $\begin{array}{c}\text { Discharge } \\
\left(\mathrm{ft}^{3} / \mathrm{s}\right)\end{array}$ & $\begin{array}{c}\text { Gage } \\
\text { height } \\
\text { (ft) }\end{array}$ & $\begin{array}{l}\text { Water } \\
\text { year }\end{array}$ & Date & $\begin{array}{c}\text { Discharge } \\
\left(\mathrm{ft}^{3} / \mathrm{s}\right)\end{array}$ & $\begin{array}{c}\text { Gage } \\
\text { height } \\
\text { (ft) }\end{array}$ & $\begin{array}{l}\text { Water } \\
\text { year }\end{array}$ & Date & $\begin{array}{c}\text { Discharge } \\
\left(\mathrm{ft}^{3} / \mathrm{s}\right)\end{array}$ & $\begin{array}{c}\text { Gage } \\
\text { height } \\
\text { (ft) }\end{array}$ \\
\hline 1965 & Oct. 04 & 805 & 4.05 & 1969 & Feb. 02 & 910 & 4.26 & 1973 & May 27 & 1,060 & 4.56 \\
\hline 1966 & Mar. 04 & 1,660 & 5.70 & 1970 & Apr. 26 & 712 & 3.86 & $\underline{1974}$ & Apr. 04 & 1,110 & 4.66 \\
\hline 1967 & July 10 & 910 & 4.26 & 1971 & Jan. 24 & 405 & 3.06 & $\overline{1977}$ & Apr. 04 & 3,970 & $9.00 \mathrm{c}$ \\
\hline 1968 & Dec. 22 & 644 & 3.71 & 1972 & Jan. 04 & 690 & 3.81 & $\overline{1979}$ & Mar. 04 & 2,200 & $6.54 c$ \\
\hline
\end{tabular}


LOCATION.--Lat $34^{\circ} 40^{\prime} 10^{\prime \prime}$, long $85^{\circ} 05^{\prime} 40^{\prime \prime}$, Walker County, at culvert on State Highway 143, 1.2 mi east of Villanow. DRAINAGE AREA.-3.82 $\mathrm{mi}^{2}$.

GAGE.-Flood-stage/rainfall recorder. Datum of gage is about $875 \mathrm{ft}$ above sea level (from topographic map).

STAGE-DISCHARGE RELATION.--Defined by current-meter measurements below $155 \mathrm{ft}^{3} / \mathrm{s}$, and extended above on the basis of culvert computations. Stage-discharge relation unstable in 1972 owing to construction near culvert.

REMARKS.-Peak discharge for 1972 is estimated.

\begin{tabular}{|c|c|c|c|c|c|c|c|c|c|c|c|}
\hline $\begin{array}{l}\text { Water } \\
\text { year }\end{array}$ & Date & $\begin{array}{c}\text { Discharge } \\
\left(\mathrm{ft}^{3} / \mathrm{s}\right)\end{array}$ & $\begin{array}{c}\text { Gage } \\
\text { height } \\
\text { (ft) }\end{array}$ & $\begin{array}{l}\text { Water } \\
\text { year }\end{array}$ & Date & $\begin{array}{c}\text { Discharge } \\
\left(\mathrm{ft}^{3} / \mathrm{s}\right)\end{array}$ & $\begin{array}{c}\text { Gage } \\
\text { height } \\
\text { (ft) }\end{array}$ & $\begin{array}{l}\text { Water } \\
\text { year }\end{array}$ & Date & $\begin{array}{c}\text { Discharge } \\
\left(\mathrm{ft}^{3} / \mathrm{s}\right)\end{array}$ & $\begin{array}{c}\text { Gage } \\
\text { height } \\
\text { (ft) }\end{array}$ \\
\hline 1965 & Mar. 26 & 306 & 4.31 & 1969 & Feb. 02 & 297 & 4.26 & 1973 & Mar. 16 & 853 & 6.64 \\
\hline 1966 & Mar. 04 & 1,020 & 7.25 & 1970 & Apr. 02 & 244 & 3.96 & $\underline{1974}$ & Apr. 04 & 1,490 & 8.26 \\
\hline 1967 & July 06 & 1,130 & 7.61 & 1971 & Feb. 04 & 362 & 4.61 & $\overline{1977}$ & Apr. 04 & 2,100 & $9.90 \mathrm{c}$ \\
\hline 1968 & Dec. 18 & 270 & 4.11 & 1972 & May 13 & 260 & 4.06 & & & & \\
\hline
\end{tabular}

\section{WEST ARMUCHEE CREEK NEAR SUBLIGNA, GEORGIA}

LOCATION.--Lat $34^{\circ} 34^{\prime} 04^{\prime \prime}$, long $85^{\circ} 09^{\prime} 16^{\prime \prime}$, Chattooga County, on left bank 500 ft downstream from bridge on county road, 1 mi upstream from Ruff Creek, and 2 mi east of Subligna.

DRAINAGE AREA,-36.4 $\mathrm{mi}^{2}$ (revised).

GAGE.-Water-stage recorder. Datum of gage is about $710 \mathrm{ft}$ above sea level (from topographic map).

STAGE-DISCHARGE RELATION.--Defined by current-meter measurements below $2,600 \mathrm{ft}^{3} / \mathrm{s}$, and extended above on the basis of contracted-opening mesurement at $9,760 \mathrm{ft}^{3} / \mathrm{s}$, and extension based on straight-line extension. Bankfull stage and discharge, 7 $\mathrm{ft}$ and $1,500 \mathrm{ft}^{3} / \mathrm{s}$.

REMARKS.-Peak stage of March 1951 and 1990 obtained from levels to floodmarks.

\begin{tabular}{|c|c|c|c|c|c|c|c|c|c|c|c|}
\hline $\begin{array}{l}\text { Water } \\
\text { year }\end{array}$ & Date & $\begin{array}{c}\text { Discharge } \\
\left(\mathrm{ft}^{3} / \mathrm{s}\right)\end{array}$ & $\begin{array}{c}\text { Gage } \\
\text { height } \\
(\mathrm{ft})\end{array}$ & $\begin{array}{l}\text { Water } \\
\text { year }\end{array}$ & Date & $\begin{array}{c}\text { Discharge } \\
\left(\mathrm{ft}^{3} / \mathrm{s}\right)\end{array}$ & $\begin{array}{c}\text { Gage } \\
\text { height } \\
\text { (ft) }\end{array}$ & $\begin{array}{l}\text { Water } \\
\text { year }\end{array}$ & Date & $\begin{array}{c}\text { Discharge } \\
\left(\mathrm{ft}^{3} / \mathrm{s}\right)\end{array}$ & $\begin{array}{c}\text { Gage } \\
\text { height } \\
\text { (ft) }\end{array}$ \\
\hline$\underline{1951}$ & Mar. 29 & 12,400 & $12.10 \mathrm{c}$ & 1968 & Dec. 19 & 2,740 & 8.15 & 1976 & July 05 & 1,770 & 7.20 \\
\hline$\overline{1961}$ & Feb. 23 & 3,250 & 8.51 & 1969 & Feb. 02 & 2,470 & 7.86 & 1977 & Mar. 12 & 5,780 & 10.03 \\
\hline 1962 & Dec. 18 & 3,780 & 8.83 & 1970 & Dec. 30 & 1,500 & 6.88 & 1978 & Nov. 05 & 2,610 & 8.25 \\
\hline 1963 & Oct. 03 & 4,750 & 9.50 & 1971 & Feb. 05 & 2,140 & 7.60 & 1979 & Mar. 04 & 6,860 & 10.52 \\
\hline 1964 & Mar. 14 & 4,000 & 8.98 & 1972 & June 20 & 2,760 & 8.28 & 1980 & Mar. 21 & 3,710 & 9.07 \\
\hline 1965 & Mar. 26 & 2,660 & 8.09 & 1973 & Mar. 16 & 5,190 & 9.52 & $\underline{1981}$ & Feb. 10 & 2,640 & 8.28 \\
\hline 1966 & Mar. 04 & 9,760 & 11.33 & 1974 & Apr. 04 & 7,570 & 10.62 & $\overline{1990}$ & Feb. 06 & 22,000 & $14.01 \mathrm{c}$ \\
\hline 1967 & Feb. 20 & 1,540 & 6.88 & 1975 & Sept.23 & 6,750 & 10.22 & & & & \\
\hline
\end{tabular}




\section{MOBILE RIVER BASIN}

\section{STOREY MILL CREEK NEAR SUMMERVILLE, GEORGIA}

LOCATION.--Lat $34^{\circ} 25^{\prime} 39^{\prime \prime}$ long $85^{\circ} 16^{\prime} 03^{\prime \prime}$, Chattooga County, at culvert on county road 7, 6 mi southeast of Summerville. DRAINAGE AREA. $-6.02 \mathrm{mi}^{2}$

GAGE.--Flood-stage/rainfall recorder prior to Feb. 27, 1975; crest-stage gage thereafter.

STAGE-DISCHARGE RELATION.--Defined by current-meter measurements below $550 \mathrm{ft}^{3} / \mathrm{s}$, and extended above on the basis of culvert computations.

REMARKS.--Peak stage of 1990 flood based on floodmarks.

\begin{tabular}{|c|c|c|c|c|c|c|c|c|c|c|c|}
\hline $\begin{array}{l}\text { Water } \\
\text { year }\end{array}$ & Date & $\begin{array}{c}\text { Discharge } \\
\left(\mathrm{ft}^{3} / \mathrm{s}\right)\end{array}$ & $\begin{array}{c}\text { Gage } \\
\text { height } \\
\text { (ft) }\end{array}$ & $\begin{array}{l}\text { Water } \\
\text { year }\end{array}$ & Date & $\begin{array}{c}\text { Discharge } \\
\left(\mathrm{ft}^{3} / \mathrm{s}\right)\end{array}$ & $\begin{array}{c}\text { Gage } \\
\text { height } \\
\text { (ft) }\end{array}$ & $\begin{array}{l}\text { Water } \\
\text { year }\end{array}$ & Date & $\begin{array}{c}\text { Discharge } \\
\left(\mathrm{ft}^{3} / \mathrm{s}\right)\end{array}$ & $\begin{array}{c}\text { Gage } \\
\text { height } \\
\text { (ft) }\end{array}$ \\
\hline 1966 & Mar. 04 & 1,090 & 7.55 & 1974 & Apr. 04 & 720 & 6.27 & 1982 & Jan. 03 & 1,330 & 8.32 \\
\hline 1967 & Feb. 20 & 370 & 4.75 & 1975 & Jan. 25 & 1,030 & 7.38 & 1983 & Nov. 28 & 648 & 5.99 \\
\hline 1968 & Jan. 10 & 508 & 5.40 & 1976 & Nov. 05 & 1,450 & 8.66 & 1984 & Apr. 04 & 1,430 & 8.63 \\
\hline 1969 & Feb. 02 & 588 & 5.74 & 1977 & Apr. 04 & 1,550 & 8.96 & 1985 & Mar. - & 230 & $-b$ \\
\hline 1970 & Apr. 25 & 490 & 5.32 & 1978 & Nov. 05 & 609 & 5.83 & 1986 & Mar. 12 & 200 & 3.73 \\
\hline 1971 & Feb. 05 & 583 & 5.72 & 1979 & Mar. 04 & 1,730 & 9.58 & $\underline{1987}$ & Nov. 25 & 578 & 5.70 \\
\hline 1972 & Jan. 04 & 517 & 5.44 & 1980 & Mar. 17 & 864 & 6.80 & 1990 & Feb. 16 & 1,980 & $10.41 \mathrm{c}$ \\
\hline 1973 & May 20 & 1,320 & 8.27 & 1981 & Mar. 30 & 508 & 5.40 & & & & \\
\hline
\end{tabular}

\section{HEATH CREEK NEAR ROME, GEORGIA}

LOCATION.-Lat $34^{\circ} 21^{\prime} 57^{\prime \prime}$, long $85^{\circ} 16^{\prime} 17^{\prime \prime}$, Floyd County, on upstream left wingwall of bridge on Antioch Church road, $4 \mathrm{mi}$ upstream from Little Armuchee Creek, and $9.5 \mathrm{mi}$ northwest of Rome.

DRAINAGE AREA. $-14.7 \mathrm{mi}^{2}$ (revised).

GAGE.-Water-stage recorder. Datum of gage is $643.15 \mathrm{ft}$ above sea level (levels from Georgia Power benchmark).

STAGE-DISCHARGE RELATION.--Defined by current-meter measurements below $650 \mathrm{ft}^{3} / \mathrm{s}$, and above on the basis of straight-line extension.

REMARKS.--Peaks regulated by flood-retention pond upstream since early 1980 's. Station inundated by reservoir, September 1990.

\begin{tabular}{|c|c|c|c|c|c|c|c|c|c|c|c|}
\hline $\begin{array}{l}\text { Water } \\
\text { year }\end{array}$ & Date & $\begin{array}{c}\text { Discharge } \\
\left(\mathrm{ft}^{3} / \mathrm{s}\right)\end{array}$ & $\begin{array}{c}\text { Gage } \\
\text { height } \\
\text { (ft) }\end{array}$ & $\begin{array}{l}\text { Water } \\
\text { year }\end{array}$ & Date & $\begin{array}{c}\text { Discharge } \\
\left(\mathrm{ft}^{3} / \mathrm{s}\right)\end{array}$ & $\begin{array}{c}\text { Gage } \\
\text { height } \\
\text { (ft) }\end{array}$ & $\begin{array}{l}\text { Water } \\
\text { year }\end{array}$ & Date & $\begin{array}{c}\text { Discharge } \\
\left(\mathrm{ft}^{3} / \mathrm{s}\right)\end{array}$ & $\begin{array}{c}\text { Gage } \\
\text { height } \\
\text { (ft) }\end{array}$ \\
\hline 1969 & Feb. 02 & 450 & 7.08 & 1977 & Apr. 04 & 1,590 & 9.82 & 1984 & May 08 & 714 & 6.97 \\
\hline 1970 & Apr. 27 & 807 & 7.42 & 1978 & Nov. 05 & 1,150 & 8.50 & 1985 & Feb. 01 & 357 & 4.91 \\
\hline 1971 & Feb. 26 & 622 & 6.97 & 1979 & Mar. 04 & 1,660 & 10.03 & 1986 & Feb. 18 & 217 & 3.76 \\
\hline 1972 & Jan. 10 & 525 & 6.42 & 1980 & Mar. 08 & 1,060 & 8.20 & 1987 & Feb. 28 & 488 & 5.79 \\
\hline 1973 & May 28 & 869 & 7.53 & 1981 & Feb. 10 & 426 & 5.85 & 1988 & Jan. 20 & 571 & 6.26 \\
\hline 1974 & Apr. 04 & 1,140 & 8.48 & 1982 & Jan. 03 & 847 & 7.49 & 1989 & Feb. 28 & 533 & 6.07 \\
\hline 1975 & Sept.23 & 1,320 & 9.05 & 1983 & Nov. 28 & 700 & 6.90 & 1990 & Oct. 01 & 947 & 7.83 \\
\hline 1976 & Mar. 30 & 616 & 6.53 & & & & & & & & \\
\hline
\end{tabular}


LOCATION.-Lat $34^{\circ} 21^{\prime} 18^{\prime \prime}$, long $85^{\circ} 15^{\prime} 50^{\prime \prime}$, Floyd County, on right bank 0.6 mi downstream from bridge on Antioch Road, $3.4 \mathrm{mi}$ upstream from Little Armuchee Creek, 5.2 mi west of Armuchee. DRAINAGE AREA. $-16.6 \mathrm{mi}^{2}$.

GAGE.--Water-stage recorder. Datum of gage is $637.00 \mathrm{ft}$ above sea level (levels from Georgia Power benchmark).

STAGE-DISCHARGE RELATION.--Defined by current-meter measurements below $590 \mathrm{ft}^{3} / \mathrm{s}$, and above on the basis of straight-line extension. Bankfull stage and discharge, $7 \mathrm{ft}$ and $700 \mathrm{ft}^{3} / \mathrm{s}$.

REMARKS.--Peaks regulated by flood-retention pond upstream since early 1980 's.

\begin{tabular}{|c|c|c|c|c|c|c|c|c|c|c|c|}
\hline $\begin{array}{l}\text { Water } \\
\text { year }\end{array}$ & Date & $\begin{array}{c}\text { Discharge } \\
\left(\mathrm{ft}^{3} / \mathrm{s}\right)\end{array}$ & $\begin{array}{c}\text { Gage } \\
\text { height } \\
\text { (ft) }\end{array}$ & $\begin{array}{l}\text { Water } \\
\text { year }\end{array}$ & Date & $\begin{array}{c}\text { Discharge } \\
\left(\mathrm{ft}^{3} / \mathrm{s}\right)\end{array}$ & $\begin{array}{l}\text { Gage } \\
\text { height } \\
\text { (ft) }\end{array}$ & $\begin{array}{c}\text { Water } \\
\text { year }\end{array}$ & Date & $\begin{array}{c}\text { Discharge } \\
\left(\mathrm{ft}^{3} / \mathrm{s}\right)\end{array}$ & $\begin{array}{c}\text { Gage } \\
\text { height } \\
\text { (ft) }\end{array}$ \\
\hline 1982 & Jan. 03 & 980 & 8.26 & 1985 & Feb. 01 & 358 & 4.98 & 1988 & Jan. 20 & 630 & 6.76 \\
\hline 1983 & Nov. 28 & 864 & 7.55 & 1986 & Feb. 18 & 239 & 4.06 & 1989 & Feb. 28 & 589 & 6.44 \\
\hline 1984 & May 08 & 900 & 8.10 & 1987 & Feb. 28 & 555 & 6.24 & 1990 & Feb. 16 & 944 & 8.32 \\
\hline
\end{tabular}

\section{DOZIER CREEK NEAR SHANNON, GEORGIA}

LOCATION.--Lat $34^{\circ} 18^{\prime} 53^{\prime \prime}$, long $8^{\circ} 5^{\circ} 5^{\prime} 47^{\prime \prime}$, Floyd County, at culvert on State Highway 53, 2 mi southwest of Shannon. DRAINAGE AREA. $-3.00 \mathrm{mi}^{2}$.

GAGE.-Flood-stage/rainfall recorder. Datum of gage is about $610 \mathrm{ft}$ above sea level (from topographic map).

STAGE-DISCHARGE RELATION.--Defined by current-meter measurements below $105 \mathrm{ft}^{3} / \mathrm{s}$, and extended above on the basis of culvert computations.

\begin{tabular}{|c|c|c|c|c|c|c|c|c|c|c|c|}
\hline $\begin{array}{l}\text { Water } \\
\text { year }\end{array}$ & Date & $\begin{array}{c}\text { Discharge } \\
\left(\mathrm{ft}^{3} / \mathrm{s}\right)\end{array}$ & $\begin{array}{c}\text { Gage } \\
\text { height } \\
\text { (ft) }\end{array}$ & $\begin{array}{l}\text { Water } \\
\text { year }\end{array}$ & Date & $\begin{array}{c}\text { Discharge } \\
\left(\mathrm{ft}^{3} / \mathrm{s}\right)\end{array}$ & $\begin{array}{c}\text { Gage } \\
\text { height } \\
\text { (ft) }\end{array}$ & $\begin{array}{l}\text { Water } \\
\text { year }\end{array}$ & Date & $\begin{array}{c}\text { Discharge } \\
\left(\mathrm{ft}^{3} / \mathrm{s}\right)\end{array}$ & $\begin{array}{l}\text { Gage } \\
\text { height } \\
\text { (ft) }\end{array}$ \\
\hline 1965 & Mar. 23 & 356 & 3.37 & 1969 & Feb. 02 & 271 & 2.96 & 1973 & May 27 & 686 & 4.53 \\
\hline 1966 & Mar. 04 & 930 & 5.10 & 1970 & Mar. 19 & 136 & 2.06 & $\underline{1974}$ & Apr. 04 & 502 & 3.96 \\
\hline 1967 & Aug. 25 & 475 & 3.86 & 1971 & Mar. 25 & 213 & 2.64 & $\underline{1977}$ & Apr. 04 & 1,330 & $6.26 \mathrm{c}$ \\
\hline 1968 & Dec. 22 & 332 & 3.26 & 1972 & Jan. 04 & 307 & 3.14 & 1979 & Mar. 04 & 1,160 & $5.80 \mathrm{c}$ \\
\hline
\end{tabular}




\section{MOBILE RIVER BASIN}

\section{OOSTANAULA RIVER NEAR ROME, GEORGIA}

LOCATION.-Lat $34^{\circ} 18^{\prime} 02^{\prime \prime}$, long $85^{\circ} 08^{\prime} 30^{\prime \prime}$, Floyd County, on left bank 1.2 mi upstream from Dry Creek, 4.5 mi north of Rome, 4.5 mi upstream from confluence with Etowah River, and 6.5 mi downstream from Armuchee Creek.

DRAINAGE AREA.--2,120 $\mathrm{mi}^{2}$, approximately.

GAGE.-Water-stage recorder. Datum of gage is $561.70 \mathrm{ft}$ above sea level (levels from U.S. Coast and Geodetic benchmark). Oct. 1, 1939, to Dec. 7, 1950, water-stage recorder at site 3.2 mi downstream at same datum at Southern Railway bridge. Records at Fifth Avenue Bridge since 1890 are contained in reports of the U.S. Weather Bureau. Since Oct. 1, 1939, auxiliary water-stage recorder at Fifth Avenue Bridge, 4.2 mi downstream. Nonrecording gage at site of auxiliary gage used as base gage for records published as "Coosa River at Rome," Jan. 1, 1897, to Dec. 31, 1903.

STAGE-DISCHARGE RELATION.--Defined by current-meter measurements below $40,500 \mathrm{ft}^{3} / \mathrm{s}$, and above on the basis of straightline extension. Stage-discharge relation is affected by backwater from Etowah River and fall between the base and auxiliary gages is used as a factor in computing discharge. Bankfull stage and discharge, $19 \mathrm{ft}$ and $15,000 \mathrm{ft}^{3} / \mathrm{s}$.

HISTORICAL DATA.-Peak stage for April 1886 at auxiliary gage site based on information from the National Weather Service. The flood of April 1886 was the highest flood that has occurred since the city of Rome was founded in 1834, based on information given in "A History of Rome and Floyd County," Georgia Department of Archives.

REMARKS.--Peak discharge for April 1886 flood estimated from records on gaging station upstream on Oostanaula River at Resaca. Peak stage for April 1886 flood at site of auxiliary gage, based on information from the National Weather Service. Data collected before the installation of two gages has not been reproduced because the discharge is indeterminate where the fall is unknown. Peak discharges regulated by Carters Dam and Carters re-regulation dam since November 1974 (see station 02387500).

\begin{tabular}{|c|c|c|c|c|c|c|c|c|c|c|c|}
\hline $\begin{array}{l}\text { Water } \\
\text { year }\end{array}$ & Date & $\begin{array}{c}\text { Discharge } \\
\left(\mathrm{ft}^{3} / \mathrm{s}\right)\end{array}$ & $\begin{array}{c}\text { Gage } \\
\text { height } \\
\text { (ft) }\end{array}$ & $\begin{array}{l}\text { Water } \\
\text { year }\end{array}$ & Date & $\begin{array}{c}\text { Discharge } \\
\left(\mathrm{ft}^{3} / \mathrm{s}\right)\end{array}$ & $\begin{array}{c}\text { Gage } \\
\text { height } \\
\text { (ft) }\end{array}$ & $\begin{array}{l}\text { Water } \\
\text { year }\end{array}$ & Date & $\begin{array}{c}\text { Discharge } \\
\left(\mathrm{ft}^{3} / \mathrm{s}\right)\end{array}$ & $\begin{array}{c}\text { Gage } \\
\text { height } \\
\text { (ft) }\end{array}$ \\
\hline$\underline{1886}$ & Apr. -- & 70,000 & $40.3 c$ & 1957 & Feb. 06 & 32,500 & 31.90 & 1974 & Apr. 06 & 22,600 & $29.66 a$ \\
\hline 1940 & Mar. 15 & 15,000 & 17.7 & 1958 & Nov. 20 & 21,300 & $24.40 \mathrm{a}$ & 1975 & Mar. 31 & 21,400 & $26.57 \mathrm{a}$ \\
\hline 1941 & July 08 & 12,800 & 15.5 & 1959 & Apr. 21 & 15,100 & 19.60 & 1976 & Apr. 02 & 23,100 & $29.53 \mathrm{a}$ \\
\hline 1942 & Mar. 24 & 19,700 & 24.4 & 1960 & Mar. 05 & 18,600 & 22.40 & 1977 & Apr. 05 & 37,300 & 35.22 \\
\hline 1943 & Jan. 02 & 29,900 & 27.0 & 1961 & Feb. 24 & 32,700 & $32.06 \mathrm{a}$ & 1978 & Nov. 07 & 21,600 & $26.78 \mathrm{a}$ \\
\hline 1944 & Apr. 01 & 29,100 & 27.0 & 1962 & Dec. 19 & 33,700 & 32.56 & 1979 & Mar. 07 & 31,400 & $35.47 \mathrm{a}$ \\
\hline 1945 & Feb. 15 & 19,400 & 20.2 & 1963 & May 01 & 27,000 & 30.36 & 1980 & Mar. 25 & 28,100 & $31.90 \mathrm{a}$ \\
\hline 1946 & Feb. 13 & 45,500 & 33.1 & 1964 & Mar. 28 & 30,200 & $33.28 \mathrm{a}$ & 1981 & Feb. 11 & 15,500 & 21.22 \\
\hline 1947 & Jan. 23 & 47,000 & 34.1 & 1965 & Mar. 31 & 26,300 & 27.55 & 1982 & Jan. 05 & 33,600 & 33.03 \\
\hline 1948 & Feb. 18 & 28,200 & 25.3 & 1966 & Mar. 05 & 27,500 & 30.49 & 1983 & Dec. 02 & 22,500 & $27.05 a$ \\
\hline 1949 & Dec. 02 & 37,300 & 31.6 & 1967 & July 11 & 19,000 & $25.79 \mathrm{a}$ & 1984 & May 09 & 26,000 & 27.95 \\
\hline 1950 & Mar. 17 & 30,500 & 25.5 & 1968 & Dec. 23 & 24,300 & $28.64 a$ & 1985 & Feb. 02 & 16,900 & $22.63 \mathrm{a}$ \\
\hline 1951 & Apr. 02 & 43,600 & 35.4 & 1969 & Feb. 07 & 23,200 & 25.91 & 1986 & Feb. 19 & 10,300 & 15.85 \\
\hline 1952 & Mar. 12 & 23,900 & $27.8 \mathrm{a}$ & 1970 & Mar. 22 & 18,500 & 25.06 & 1987 & Mar. 02 & 22,900 & $28.32 \mathrm{a}$ \\
\hline 1953 & Feb. 22 & 18,800 & 22.5 & 1971 & Jan. 26 & 18,800 & $23.46 \mathrm{a}$ & 1988 & Jan. 21 & 19,300 & 23.97 \\
\hline 1954 & Jan. 23 & 28,900 & $30.1 \mathrm{a}$ & 1972 & Jan. 14 & 21,000 & 27.04 & 1989 & Mar. 07 & 24,300 & 27.96 \\
\hline 1955 & Feb. 07 & 23,800 & 26.2 & 1973 & Mar. 22 & 24,100 & $26.97 \mathrm{a}$ & 1990 & Feb. 20 & 42,600 & 35.70 \\
\hline 1956 & Apr. 17 & 20,600 & 23.9 & & & & & & & & \\
\hline
\end{tabular}




\section{MOBILE RIVER BASIN}

\section{ETOWAH RIVER NEAR DAHLONEGA, GEORGIA}

LOCATION.--Lat $34^{\circ} 30^{\prime} 56^{\prime \prime}$, long $84^{\circ} 03^{\prime} 40^{\prime \prime}$, Lumpkin County, at bridge on State Highway 9, 4.5 mi west of Dahlonega. DRAINAGE AREA.-69.7 $\mathrm{mi}^{2}$ (revised).

GAGE.--Crest-stage gage. Datum of gage is $1,270.80 \mathrm{ft}$ above sea level (levels by the Georgia Department of Transportation).

STAGE-DISCHARGE RELATION.--Defined by current-meter measurements below $4,300 \mathrm{ft}^{3} / \mathrm{s}$, and above on the basis of contracted-opening measurement at $6,750 \mathrm{ft}^{3} / \mathrm{s}$, and extended above on the basis of straight-line extension. Bankfull stage and discharge, $11 \mathrm{ft}$ and $2,500 \mathrm{ft}^{3} / \mathrm{s}$.

REMARKS.--Peak discharges for 1958 and 1960 are estimated.

\begin{tabular}{|c|c|c|c|c|c|c|c|c|c|c|c|}
\hline $\begin{array}{l}\text { Water } \\
\text { year }\end{array}$ & Date & $\begin{array}{c}\text { Discharge } \\
\left(\mathrm{ft}^{3} / \mathrm{s}\right)\end{array}$ & $\begin{array}{l}\text { Gage } \\
\text { height } \\
\text { (ft) }\end{array}$ & $\begin{array}{l}\text { Water } \\
\text { year }\end{array}$ & Date & $\begin{array}{c}\text { Discharge } \\
\left(\mathrm{ft}^{3} / \mathrm{s}\right)\end{array}$ & $\begin{array}{c}\text { Gage } \\
\text { height } \\
\text { (ft) }\end{array}$ & $\begin{array}{l}\text { Water } \\
\text { year }\end{array}$ & Date & $\begin{array}{c}\text { Discharge } \\
\left(\mathrm{ft}^{3} / \mathrm{s}\right)\end{array}$ & $\begin{array}{c}\text { Gage } \\
\text { height } \\
\text { (ft) }\end{array}$ \\
\hline 1950 & Mar. 15 & 2,580 & 11.27 & 1960 & Feb. 10 & 1,600 & - & 1970 & Apr. - & 1,350 & $-b$ \\
\hline 1951 & Mar. 30 & 1,620 & 9.11 & 1961 & Feb. 25 & 6,750 & 13.40 & 1971 & Mar. -- & 1,350 & $--b$ \\
\hline 1952 & Mar. 10 & 4,400 & 12.57 & 1962 & Dec. 12 & 8,680 & 13.93 & 1972 & May 14 & 2,120 & 10.39 \\
\hline 1953 & Feb. -- & 1,840 & 9.69 & 1963 & Apr. 30 & 3,700 & 12.18 & 1973 & May 28 & 5,340 & 12.98 \\
\hline 1954 & Jan. 16 & 4,800 & 12.81 & 1964 & May 03 & 4,200 & 12.52 & 1974 & Dec. 05 & 2,440 & 11.06 \\
\hline 1955 & Feb. 06 & 4,200 & 12.47 & 1965 & Oct. 04 & 1,960 & 9.95 & 1975 & Mar. 14 & 1,510 & 8.71 \\
\hline 1956 & Apr. 16 & 2,410 & 11.05 & 1966 & Feb. 13 & 4,520 & 12.66 & 1976 & Mar. 16 & 1,860 & 9.74 \\
\hline 1957 & Apr. 05 & 2,410 & 10.96 & 1967 & Aug. 23 & 9,680 & 14.22 & $\underline{1977}$ & Mar. 30 & 3,970 & 12.38 \\
\hline 1958 & Jan. 21 & 1,250 & - & 1968 & Mar. 12 & 1,730 & 9.41 & $\overline{1982}$ & Feb. 03 & 2,450 & $11.14 c$ \\
\hline 1959 & Jan. 28 & 2,210 & 10.54 & 1969 & Aug. 22 & 1,480 & 8.71 & & & & \\
\hline
\end{tabular}

\section{ETOWAH RIVER NEAR DAWSONVILLE, GEORGIA}

LOCATION.--Lat $34^{\circ} 22^{\prime} 57^{\prime \prime}$, long $84^{\circ} 03^{\prime} 21^{\prime \prime}$, Dawson County, on left bank 0.4 mi upstream from Palmer Creek, 0.5 mi upstream from bridge on State Highway 53, 1.2 mi downstream from Russell Creek, 4 mi southeast of Dawsonville, and 7.5 mi upstream from Shoal Creek.

DRAINAGE AREA.-107 $\mathrm{mi}^{2}$ (revised).

GAGE.-Water-stage recorder. Datum of gage is $1,049.80 \mathrm{ft}$ above sea level (levels by the Georgia Department of Transportation). STAGE-DISCHARGE RELATION.--Defined by current-meter measurements below $5,200 \mathrm{ft}^{3} / \mathrm{s}$, and above on the basis of straightline extension. There was a change in the stage-discharge relation after August 1965 from channel clearing. Bankfull stage and discharge, $11 \mathrm{tt}$ and $4,500 \mathrm{tt}^{3} / \mathrm{s}$.

\begin{tabular}{|c|c|c|c|c|c|c|c|c|c|c|c|}
\hline $\begin{array}{l}\text { Water } \\
\text { year }\end{array}$ & Date & $\begin{array}{c}\text { Discharge } \\
\left(\mathrm{ft}^{3} / \mathrm{s}\right)\end{array}$ & $\begin{array}{c}\text { Gage } \\
\text { height } \\
\text { (ft) }\end{array}$ & $\begin{array}{c}\text { Water } \\
\text { year }\end{array}$ & Date & $\begin{array}{c}\text { Discharge } \\
\left(\mathrm{ft}^{3} / \mathrm{s}\right)\end{array}$ & $\begin{array}{c}\text { Gage } \\
\text { height } \\
\text { (ft) }\end{array}$ & $\begin{array}{l}\text { Water } \\
\text { year }\end{array}$ & Date & $\begin{array}{c}\text { Discharge } \\
\left(\mathrm{ft}^{3} / \mathrm{s}\right)\end{array}$ & $\begin{array}{c}\text { Gage } \\
\text { height } \\
\text { (ft) }\end{array}$ \\
\hline 1940 & Aug. 13 & 1,840 & 7.70 & 1954 & Jan. 16 & 4,150 & 14.60 & 1967 & Aug. 24 & 6,140 & 13.70 \\
\hline 1941 & July 05 & 2,200 & 9.20 & 1955 & Feb. 07 & 4,010 & 14.30 & 1968 & Mar. 12 & 4,470 & 11.04 \\
\hline 1942 & Feb. 17 & 4,100 & 14.50 & 1956 & Apr. 16 & 2,520 & 10.30 & 1969 & Aug. 22 & 3,500 & 10.70 \\
\hline 1943 & Dec. 29 & 2,430 & 10.00 & 1957 & Apr. 05 & 3,000 & 11.80 & 1970 & Dec. 31 & 1,490 & 5.09 \\
\hline 1944 & Mar. 20 & 2,640 & 10.70 & 1958 & Dec. 20 & 1,630 & 7.10 & 1971 & July 22 & 1,790 & 5.86 \\
\hline 1945 & Sept.16 & 1,820 & 7.80 & 1959 & Jan. 22 & 2,290 & 9.50 & 1972 & May 14 & 3,500 & 9.37 \\
\hline 1946 & Jan. 07 & 4,780 & 15.80 & 1960 & Sept.28 & 1,980 & 8.40 & 1973 & May 28 & 4,770 & 11.53 \\
\hline 1947 & Jan. 20 & 3,660 & 13.50 & 1961 & Feb. 25 & 4,150 & 14.60 & 1974 & Apr. 04 & 3,420 & 9.22 \\
\hline 1948 & Aug. 04 & 4,050 & 14.40 & 1962 & Dec. 12 & 5,010 & 16.18 & 1975 & Mar. 14 & 3,710 & 9.75 \\
\hline 1949 & Jan. 06 & 3,870 & 14.00 & 1963 & Mar. 12 & 4,810 & 15.62 & 1976 & Mar. 31 & 4,130 & 11.27 \\
\hline 1950 & Mar. 13 & 2,760 & 11.10 & 1964 & Mar. 26 & 4,150 & 14.28 & 1979 & Apr. 13 & 4,400 & 11.84 \\
\hline 1951 & Mar. 29 & 2,120 & 8.90 & 1965 & Oct. 05 & 2,670 & 10.56 & $\underline{1980}$ & Mar. 21 & 4,800 & 12.47 \\
\hline 1952 & Mar. 11 & 4,100 & 14.50 & 1966 & Mar. 04 & 6,140 & 13.70 & $\overline{1982}$ & Feb. 03 & 5,750 & $13.15 \mathrm{c}$ \\
\hline 1953 & Jan. 10 & 2,120 & 8.90 & & & & & & & & \\
\hline
\end{tabular}




\section{MOBILE RIVER BASIN}

\section{SHOAL CREEK NEAR DAWSONVILLE, GEORGIA}

LOCATION.--Lat $34^{\circ} 25^{\prime} 13^{\prime \prime}$, long $84^{\circ} 08^{\prime} 47^{\prime \prime}$, Dawson County, on left bank at bridge on State Highway 53,650 ft upstream from Flat Creek, 1 mi west of Dawsonville, and 6.5 mi upstream from mouth. DRAINAGE AREA.--21.7 $\mathrm{mi}^{2}$ (revised).

GAGE.-Water-stage recorder. Datum of gage is about 1,150 tt above sea level (from topographic map).

STAGE-DISCHARGE RELATION.--Defined by current-meter measurements below $2,100 \mathrm{ft}^{3} / \mathrm{s}$, and above on the basis of contracted-opening measurement at $6,160 \mathrm{ft}^{3} / \mathrm{s}$. Bankfull stage and discharge, $6 \mathrm{ft}$ and $1,700 \mathrm{ft}^{3} / \mathrm{s}$.

\begin{tabular}{|c|c|c|c|c|c|c|c|c|c|c|c|}
\hline $\begin{array}{l}\text { Water } \\
\text { year }\end{array}$ & Date & $\begin{array}{c}\text { Discharge } \\
\left(\mathrm{ft}^{3} / \mathrm{s}\right)\end{array}$ & $\begin{array}{c}\text { Gage } \\
\text { height } \\
\text { (ft) }\end{array}$ & $\begin{array}{l}\text { Water } \\
\text { year }\end{array}$ & Date & $\begin{array}{c}\text { Discharge } \\
\left(\mathrm{ft}^{3} / \mathrm{s}\right)\end{array}$ & $\begin{array}{c}\text { Gage } \\
\text { height } \\
\text { (ft) }\end{array}$ & $\begin{array}{l}\text { Water } \\
\text { year }\end{array}$ & Date & $\begin{array}{c}\text { Discharge } \\
\left(\mathrm{ft}^{3} / \mathrm{s}\right)\end{array}$ & $\begin{array}{c}\text { Gage } \\
\text { height } \\
\text { (ft) }\end{array}$ \\
\hline 1959 & Jan. 21 & 1,540 & 5.78 & 1965 & Mar. 24 & 1,140 & 4.85 & 1971 & Feb. 05 & 636 & 3.47 \\
\hline 1960 & Sept.28 & 1,450 & 5.62 & 1966 & Mar. 04 & 4,390 & 10.42 & 1972 & Jan. 04 & 1,830 & 6.44 \\
\hline 1961 & Feb. 25 & 2,380 & 7.60 & 1967 & Aug. 24 & 2,180 & 7.21 & 1973 & Dec. 15 & 2,670 & 8.08 \\
\hline 1962 & Dec. 12 & 2,280 & 7.40 & 1968 & Mar. 12 & 1,960 & 6.73 & $\underline{1974}$ & Apr. 04 & 2,490 & 7.84 \\
\hline 1963 & Mar. 12 & 6,160 & 11.85 & 1969 & Aug. 22 & 2,030 & 6.88 & $\underline{1977}$ & Mar. 30 & 2,700 & $7.95 \mathrm{c}$ \\
\hline 1964 & Apr. 08 & 4,000 & 10.01 & 1970 & Mar. 19 & 427 & 2.86 & $\overline{1982}$ & Feb. 03 & 3,460 & $8.30 \mathrm{c}$ \\
\hline
\end{tabular}

\section{AMICALOLA CREEK NEAR DAWSONVILLE, GEORGIA}

LOCATION.--Lat $34^{\circ} 25^{\prime} 32^{\prime \prime}$, long $84^{\circ} 12^{\prime} 43^{\prime \prime}$, Dawson County, on left bank under bridge at State Highway 53,5 mi upstream from mouth, and 5.5 mi west of Dawsonville.

DRAINAGE AREA.--89 $\mathrm{mi}^{2}$ (revised).

GAGE.--Water-stage recorder. Datum of gage is $1,203.87 \mathrm{ft}$ above sea level (levels from U.S. Coast and Geodetic Survey benchmark).

STAGE-DISCHARGE RELATION.--Defined by current-meter measurements below $4,400 \mathrm{ft}^{3} / \mathrm{s}$, and above on the basis of slope-area measurement at $5,400 \mathrm{ft}^{3} / \mathrm{s}$, and straight-line extension.

\begin{tabular}{|c|c|c|c|c|c|c|c|c|c|c|c|}
\hline $\begin{array}{l}\text { Water } \\
\text { year }\end{array}$ & Date & $\begin{array}{c}\text { Discharge } \\
\left(\mathrm{ft}^{3} / \mathrm{s}\right)\end{array}$ & $\begin{array}{c}\text { Gage } \\
\text { height } \\
\text { (ft) }\end{array}$ & $\begin{array}{l}\text { Water } \\
\text { year }\end{array}$ & Date & $\begin{array}{c}\text { Discharge } \\
\left(\mathrm{ft}^{3} / \mathrm{s}\right)\end{array}$ & $\begin{array}{c}\text { Gage } \\
\text { height } \\
\text { (ft) }\end{array}$ & $\begin{array}{l}\text { Water } \\
\text { year }\end{array}$ & Date & $\begin{array}{c}\text { Discharge } \\
\left(\mathrm{ft}^{3} / \mathrm{s}\right)\end{array}$ & $\begin{array}{c}\text { Gage } \\
\text { height } \\
\text { (ft) }\end{array}$ \\
\hline 1940 & Aug. 13 & 2,500 & 3.48 & 1945 & Feb. 13 & 1,130 & 2.20 & 1950 & Mar. 13 & 3,460 & 4.34 \\
\hline 1941 & July 05 & 5,200 & 5.64 & 1946 & Feb. 10 & 5,050 & 5.50 & 1951 & Mar. 29 & 2,380 & 3.40 \\
\hline 1942 & Feb. 17 & 7,450 & 7.00 & 1947 & Jan. 20 & 4,770 & 5.30 & $\underline{1952}$ & Mar. 11 & 5,960 & 6.10 \\
\hline 1943 & Dec. 29 & 2,680 & 3.65 & 1948 & Aug. 04 & 5,650 & 5.86 & $\overline{1982}$ & Feb. 03 & 5,960 & $6.10 c$ \\
\hline 1944 & Mar. 19 & 3,460 & 4.30 & 1949 & Nov. 28 & 5,500 & 5.84 & & & & \\
\hline
\end{tabular}




\section{MOBILE RIVER BASIN}

\section{ETOWAH RIVER NEAR BALL GROUND, GEORGIA}

LOCATION.--Lat $34^{\circ} 19^{\prime} 05^{\prime \prime}$, long $84^{\circ} 20^{\prime} 35^{\prime \prime}$, Cherokee County, on upstream side of county highway bridge, 0.2 mi downstream from Long Swamp Creek, and $3 \mathrm{mi}$ southeast of Ball Ground.

DRAINAGE AREA.--466 $\mathrm{mi}^{2}$

GAGE.-Nonrecording gage. Prior to Aug. 19, 1908, at site $75 \mathrm{ft}$ downstream. Datum of gage is about $910 \mathrm{ft}$ above sea level (from topographic map).

STAGE-DISCHARGE RELATION.--Defined by current-meter measurements below $6,500 \mathrm{ft}^{3} / \mathrm{s}$, and above on the basis of straightline extension.

REMARKS.--Peak discharges for 1911-13 are maximum daily.

\begin{tabular}{lccccccccccc}
\hline $\begin{array}{l}\text { Water } \\
\text { year }\end{array}$ & Date & $\begin{array}{c}\text { Discharge } \\
\left(\mathrm{ft}^{3} / \mathrm{s}\right)\end{array}$ & $\begin{array}{c}\text { Gage } \\
\text { height } \\
(\mathrm{ft})\end{array}$ & $\begin{array}{c}\text { Water } \\
\text { year }\end{array}$ & Date & $\begin{array}{c}\text { Discharge } \\
\left(\mathrm{ft}^{3} / \mathrm{s}\right)\end{array}$ & $\begin{array}{c}\text { Gage } \\
\text { height } \\
(\mathrm{ft})\end{array}$ & $\begin{array}{c}\text { Water } \\
\text { year }\end{array}$ & $\begin{array}{c}\text { Gage } \\
\text { Date }\end{array}$ & $\begin{array}{c}\text { Discharge } \\
\left(\mathrm{ft}^{3} / \mathrm{s}\right)\end{array}$ & $\begin{array}{c}\text { height } \\
(\mathrm{ft})\end{array}$ \\
\hline & & & & & & & & & & & \\
1908 & Mar. 24 & $\underline{10,800}$ & 15.00 & 1912 & Mar. 15 & 14,300 & 18.40 & 1919 & Dec. 22 & 22,200 & 25.50 \\
1909 & Mar. 14 & 14,000 & 18.00 & 1913 & Mar. 15 & 9,180 & 13.60 & 1920 & Dec. 10 & 17,600 & 21.30 \\
1910 & May 21 & 6,500 & 10.00 & 1914 & Apr. 11 & 7,390 & 11.80 & 1921 & Feb. 09 & 11,800 & 16.00 \\
1911 & Apr. 05 & 7,980 & 12.40 & $\underline{1915}$ & Dec. 26 & 8,780 & 13.20 & & & & \\
\hline
\end{tabular}




\section{MOBILE RIVER BASIN}

\section{ETOWAH RIVER AT CANTON, GEORGIA}

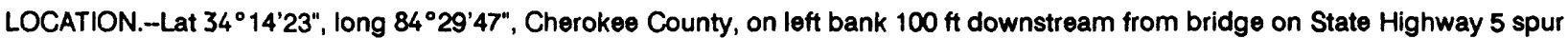
and 140 at Canton, 0.8 mi upstream from Canton Creek, and 1.8 mi downstream from Hickory Log Creek.

DRAINAGE AREA.--613 $\mathrm{mi}^{2}$ (revised).

GAGE.-Water-stage recorder. Datum of gage is $844.55 \mathrm{ft}$ above sea level (levels from the U.S. Coast and Geodetic Survey benchmark), supplementary adjustment of 1936. March 1892 to December 1905, nonrecording gage at site $100 \mathrm{ft}$ upstream at datum $2.0 \mathrm{ft}$ higher. Mar. 16, 1937, to Jan. 17, 1939, nonrecording gage at site $100 \mathrm{ft}$ upstream at present datum. Water-stage recorder at Allatoona Reservoir is used as an auxiliary gage for this station. All gage readings have been converted to present datum.

STAGE-DISCHARGE RELATION.--Defined by current-meter measurements below $25,000 \mathrm{ft}^{3} / \mathrm{s}$, and above on the basis of slope conveyance study at $32,300 \mathrm{ft}^{3} / \mathrm{s}$. Bankfull stage and discharge, $15 \mathrm{ft}$ and $8,000 \mathrm{ft}^{3} / \mathrm{s}$.

REMARKS.--Peak stages for 1892-95, and 1906-36 furnished by the National Weather Service. Peak discharge for 1934 is estimated. Peak discharge for the 1946 flood has been revised.

\begin{tabular}{|c|c|c|c|c|c|c|c|c|c|c|c|}
\hline $\begin{array}{l}\text { Water } \\
\text { year }\end{array}$ & Date & $\begin{array}{c}\text { Discharge } \\
\left(\mathrm{ft}^{3} / \mathrm{s}\right)\end{array}$ & $\begin{array}{c}\text { Gage } \\
\text { height } \\
\text { (ft) }\end{array}$ & $\begin{array}{l}\text { Water } \\
\text { year }\end{array}$ & Date & $\begin{array}{c}\text { Discharge } \\
\left(\mathrm{ft}^{3} / \mathrm{s}\right)\end{array}$ & $\begin{array}{c}\text { Gage } \\
\text { height } \\
\text { (ft) }\end{array}$ & $\begin{array}{l}\text { Water } \\
\text { year }\end{array}$ & Date & $\begin{array}{c}\text { Discharge } \\
\left(\mathrm{ft}^{3} / \mathrm{s}\right)\end{array}$ & $\begin{array}{c}\text { Gage } \\
\text { height } \\
\text { (ft) }\end{array}$ \\
\hline 1892 & Jan. -- & 36,700 & 25.00 & 1925 & Jan. 19 & 8,740 & 16.10 & 1958 & Dec. 21 & 5,440 & 11.70 \\
\hline 1893 & Feb. 16 & 9,380 & 14.60 & 1926 & Jan. 18 & 6,530 & 12.80 & 1959 & Feb. 14 & 7,230 & 14.30 \\
\hline 1894 & Sept.18 & 4,360 & 7.30 & 1927 & Feb. 14 & 9,460 & 16.50 & 1960 & Apr. 04 & 6,320 & 13.00 \\
\hline 1895 & Jan. 10 & 12,400 & 17.50 & 1928 & May 24 & 10,700 & 17.60 & 1961 & Feb. 26 & 19,300 & 23.20 \\
\hline 1896 & Jan. 24 & 5,300 & 7.80 & 1929 & Mar. 05 & 13,600 & 19.50 & 1962 & Dec. 13 & 20,900 & 23.80 \\
\hline 1897 & Apr. 05 & 10,100 & 13.60 & 1930 & Mar. 07 & 15,300 & 20.20 & 1963 & Apr. 30 & 22,600 & 24.38 \\
\hline 1898 & Sept.02 & 10,900 & 14.60 & 1931 & Nov. 17 & 5,200 & 9.90 & 1964 & Mar. 26 & 25,000 & $24.70 \mathrm{a}$ \\
\hline 1899 & Mar. 16 & 20,800 & 22.20 & 1932 & Mar. 31 & 10,400 & 17.30 & 1965 & Mar. 25 & 8,740 & 16.04 \\
\hline 1900 & Feb. 12 & 12,300 & 16.20 & 1933 & Dec. 12 & 28,200 & 25.20 & 1966 & Mar. 04 & 19,000 & 22.67 \\
\hline 1901 & May 21 & 19,600 & 21.60 & 1934 & Mar. -- & 9,600 & & 1967 & Aug. 25 & 15,900 & 21.32 \\
\hline 1902 & Dec. 29 & 20,800 & 22.20 & 1935 & Mar. 13 & 6,530 & 11.90 & 1968 & Jan. 11 & 11,000 & 18.24 \\
\hline 1903 & Feb. 17 & 20,400 & 22.00 & 1936 & Feb. 05 & 22,700 & 23.20 & 1969 & Aug. 23 & 11,900 & 18.91 \\
\hline 1904 & Aug. 08 & 9,620 & 13.00 & 1937 & Jan. 03 & 15,300 & 20.50 & 1970 & Mar. 20 & 6,590 & 13.24 \\
\hline 1905 & Jan. 13 & 8,870 & 12.10 & 1938 & Apr. 08 & 19,700 & 22.40 & 1971 & July 24 & 5,790 & 12.13 \\
\hline 1906 & Dec. 03 & 12,900 & 18.30 & 1939 & Feb. 28 & 6,360 & 12.80 & 1972 & Jan. 11 & 14,200 & 20.41 \\
\hline 1907 & $\overline{\text { Mar. } 02}$ & 6,950 & 11.90 & 1940 & Aug. 13 & 8,900 & 16.00 & 1973 & Dec. 16 & 11,200 & 18.56 \\
\hline 1908 & Apr. 25 & 10,600 & 16.60 & 1941 & July 05 & 8,820 & 15.90 & 1974 & Apr. 05 & 12,300 & 19.20 \\
\hline 1909 & Mar. 14 & 14,900 & 19.50 & 1942 & Feb. 17 & 13,300 & 21.20 & 1975 & Mar. 14 & 11,900 & 19.04 \\
\hline 1910 & May 21 & 6,880 & 12.00 & 1943 & Dec. 30 & 10,100 & 18.40 & 1976 & Mar. 31 & 19,000 & 22.76 \\
\hline 1911 & Apr. 05 & 11,100 & 17.20 & 1944 & Mar. 20 & 10,600 & 19.00 & 1977 & Mar. 31 & 18,500 & 23.56 \\
\hline 1912 & Mar. 15 & 18,400 & 21.20 & 1945 & Apr. 25 & 5,180 & 11.80 & 1978 & Nov. 06 & 17,200 & 21.96 \\
\hline 1913 & Mar. 27 & 8,350 & 14.20 & 1946 & Jan. 07 & 32,300 & 26.70 & 1979 & Apr. 14 & 21,600 & 23.57 \\
\hline 1914 & Apr. 15 & 7,440 & 13.00 & 1947 & Jan. 21 & 14,500 & 21.20 & 1980 & Mar. 09 & 14,900 & 20.17 \\
\hline 1915 & Dec. 04 & 9,300 & 15.50 & 1948 & Aug. 05 & 8,500 & 16.10 & 1981 & Feb. 11 & 5,500 & 10.95 \\
\hline 1916 & July 10 & 36,100 & 25.90 & 1949 & Nov. 29 & 17,200 & 22.40 & 1982 & Feb. 03 & 24,100 & 24.45 \\
\hline 1917 & Mar. 24 & 14,300 & 19.60 & 1950 & Mar. 14 & 8,500 & 16.10 & 1983 & Apr. 09 & 8,970 & 15.34 \\
\hline 1918 & Jan. 29 & 6,320 & 11.60 & 1951 & Mar. 30 & 7,790 & 15.10 & 1984 & Dec. 07 & 12,800 & 18.05 \\
\hline 1919 & Dec. 22 & 29,500 & 25.20 & 1952 & Mar. 23 & 19,500 & 23.30 & 1985 & Feb. 01 & 5,030 & 9.48 \\
\hline 1920 & Dec. 10 & 36,100 & 26.30 & 1953 & Jan. 10 & 8,140 & 15.60 & 1986 & Nov. 30 & 3,090 & 6.32 \\
\hline 1921 & Feb. 09 & 21,500 & 23.20 & 1954 & Jan. 17 & 15,500 & 21.70 & 1987 & Mar. 01 & 12,200 & 18.43 \\
\hline 1922 & Jan. 22 & 10,200 & 17.60 & 1955 & Feb. 07 & 12,600 & 20.10 & 1988 & Jan. 20 & 9,340 & 15.71 \\
\hline 1923 & Dec. 18 & 11,700 & 19.00 & 1956 & Apr. 16 & 7,300 & 14.40 & 1989 & June 21 & 9,080 & 15.46 \\
\hline 1924 & Apr. 19 & 4,960 & 10.90 & 1957 & Apr. 05 & 15,500 & 21.70 & 1990 & Mar. 17 & 27,100 & 25.33 \\
\hline
\end{tabular}


LOCATION.--Lat $34^{\circ} 07^{\prime} 09^{\prime \prime}$, long $84^{\circ} 23^{\prime} 18^{\prime \prime}$, Fulton County, on upstream side of bridge on State Highway 140, 1 mi downstream from Cooper Sandy Creek, and 7 mi north of Roswell.

DRAINAGE AREA. $-60 \mathrm{mi}^{2}$ (revised).

GAGE.--Water-stage recorder. Datum of gage is $894.8 \mathrm{ft}$ above sea level (levels by the Georgia Department of Transportation). Prior to July 25,1949 , nonrecording gage, and July 25,1949 , to Sept. 30,1965 , water-stage recorder at site $500 \mathrm{ft}$ upstream at datum $3.0 \mathrm{ft}$ higher.

STAGE-DISCHARGE RELATION.--Defined by current-meter measurements below $2,600 \mathrm{ft}^{3} / \mathrm{s}$, and above on the basis of straightline extension. Bankfull stage and discharge, $7 \mathrm{ft}$ and $1,150 \mathrm{ft}^{3} / \mathrm{s}$.

HISTORICAL DATA.--Peak stage of January 1946, based on information from local resident, was the highest known flood since 1890.

REMARKS.--Regulation by several flood-detention reservoirs since 1960 probably does not materially affect the peak discharges. Peak discharge for 1965 is estimated.

\begin{tabular}{|c|c|c|c|c|c|c|c|c|c|c|c|}
\hline $\begin{array}{l}\text { Water } \\
\text { year }\end{array}$ & Date & $\begin{array}{c}\text { Discharge } \\
\left(\mathrm{ft}^{3} / \mathrm{s}\right)\end{array}$ & $\begin{array}{c}\text { Gage } \\
\text { height } \\
\text { (ft) }\end{array}$ & $\begin{array}{l}\text { Water } \\
\text { year }\end{array}$ & Date & $\begin{array}{c}\text { Discharge } \\
\left(\mathrm{ft}^{3} / \mathrm{s}\right)\end{array}$ & $\begin{array}{c}\text { Gage } \\
\text { height } \\
\text { (ft) }\end{array}$ & $\begin{array}{l}\text { Water } \\
\text { year }\end{array}$ & Date & $\begin{array}{c}\text { Discharge } \\
\left(\mathrm{ft}^{3} / \mathrm{s}\right)\end{array}$ & $\begin{array}{l}\text { Gage } \\
\text { height } \\
\text { (ft) }\end{array}$ \\
\hline$\underline{1946}$ & Jan. - & 5,000 & $18.00 c$ & 1958 & Feb. 26 & 700 & 5.40 & 1969 & Jan. 20 & 1,280 & 7.67 \\
\hline 1948 & July 15 & 1,560 & 8.88 & 1959 & May 31 & 926 & 6.40 & 1970 & Mar. 20 & 1,290 & 7.72 \\
\hline 1949 & Nov. 28 & $\underline{3,200}$ & 14.00 & 1960 & Jan. 31 & 950 & 6.50 & 1971 & Mar. 26 & 755 & 5.95 \\
\hline 1950 & $\overline{\text { Sept.07 }}$ & $\overline{600}$ & 4.88 & 1961 & Feb. 23 & 4,040 & 15.60 & 1972 & Jan. 10 & 1,840 & 9.16 \\
\hline 1951 & Mar. 08 & 998 & 6.68 & 1962 & Dec. 12 & 2,600 & 12.00 & 1973 & Mar. 17 & 2,180 & 9.95 \\
\hline 1952 & Mar. 11 & 2,180 & 11.10 & 1963 & Mar. 13 & 1,810 & 9.80 & 1974 & Jan. 01 & 2,320 & 10.24 \\
\hline 1953 & Jan. 09 & 974 & 6.60 & 1964 & Mar. 26 & 2,840 & 12.65 & 1975 & Mar. 14 & 1,910 & 9.27 \\
\hline 1954 & Jan. 16 & 2,030 & 10.60 & 1965 & Dec. 26 & $\underline{650}$ & $\underline{6.85}$ & $\underline{1976}$ & Mar. 16 & 1,870 & 10.49 \\
\hline 1955 & Feb. 07 & 1,830 & 9.90 & 1966 & $\overline{\text { Mar. } 04}$ & $2, \overline{820}$ & $\overline{11.49}$ & $\underline{1982}$ & Feb. 03 & 4,600 & $14.78 \mathrm{c}$ \\
\hline 1956 & Mar. 16 & 1,500 & 8.70 & 1967 & June 04 & 1,280 & 7.65 & $\overline{1984}$ & Dec. 06 & 4,800 & $14.94 \mathrm{c}$ \\
\hline 1957 & Apr. 05 & 2,760 & 12.90 & 1968 & Mar. 12 & 1,470 & 8.47 & & & & \\
\hline
\end{tabular}




\section{MOBILE RIVER BASIN}

\section{ETOWAH RIVER ABOVE CARTERSVILLE, GEORGIA}

LOCATION.-Lat $34^{\circ} 09^{\prime} 47^{\prime \prime}$, long $84^{\circ} 44^{\prime} 28^{\prime \prime}$, Bartow County, on right bank 0.8 mi downstream from Alatoona Dam, 2 mi upstream from Nashville, Chattanooga \& St. Louis Railway bridge, and 3 mi east of Cartersville.

DRAINAGE AREA.--1,120 $\mathrm{mi}^{2}$ (revised).

GAGE.-Water-stage recorder. Datum of gage is $686.92 \mathrm{ft}$ above sea level (levels by the U.S. Army Corps of Engineers). Prior to Dec. 19, 1938, nonrecording gage at same site and datum.

STAGE-DISCHARGE RELATION.--Defined by current-meter measurements below $26,000 \mathrm{ft}^{3} / \mathrm{s}$, and above on the basis of siopearea study to $40,400 \mathrm{ft}^{3} / \mathrm{s}$. Bankfull stage and discharge, $10 \mathrm{ft}$ and $12,000 \mathrm{ft}^{3} / \mathrm{s}$.

HISTORICAL DATA.--Peak stage of December 1919, based on information from local resident, was the highest known flood since at least 1916.

REMARKS.--Peak discharges since December 1949 are regulated by storage in Allatoona Lake (maximum flood-control storage, 587,200 acre-ft).

\begin{tabular}{|c|c|c|c|c|c|c|c|c|c|c|c|}
\hline $\begin{array}{l}\text { Water } \\
\text { year }\end{array}$ & Date & $\begin{array}{c}\text { Discharge } \\
\left(\mathrm{ft}^{3} / \mathrm{s}\right)\end{array}$ & $\begin{array}{c}\text { Gage } \\
\text { height } \\
\text { (ft) }\end{array}$ & $\begin{array}{l}\text { Water } \\
\text { year }\end{array}$ & Date & $\begin{array}{c}\text { Discharge } \\
\left(\mathrm{ft}^{3} / \mathrm{s}\right)\end{array}$ & $\begin{array}{c}\text { Gage } \\
\text { height } \\
\text { (ft) }\end{array}$ & $\begin{array}{l}\text { Water } \\
\text { year }\end{array}$ & Date & $\begin{array}{c}\text { Discharge } \\
\left(\mathrm{ft}^{3} / \mathrm{s}\right)\end{array}$ & $\begin{array}{c}\text { Gage } \\
\text { height } \\
\text { (ft) }\end{array}$ \\
\hline$\underline{1920}$ & Dec. 11 & 40,000 & $20.00 \mathrm{c}$ & 1955 & Jan. 10 & 8,100 & 7.05 & 1973 & June 01 & 8,930 & 7.02 \\
\hline 1938 & Apr. 09 & 27,500 & 16.50 & 1956 & May 14 & 8,190 & 7.29 & 1974 & Apr. 04 & 9,280 & 7.25 \\
\hline 1939 & Feb. 28 & 11,600 & 9.23 & 1957 & Apr. 12 & 9,840 & 8.50 & 1975 & Jan. 17 & 8,870 & 6.98 \\
\hline 1940 & Aug. 14 & 13,800 & 10.50 & 1958 & June 05 & 8,520 & 7.38 & 1976 & Dec. 17 & 9,020 & 7.08 \\
\hline 1941 & July 06 & 12,400 & 9.88 & 1959 & June 10 & 8,610 & 7.46 & 1977 & Nov. 29 & 9,600 & 7.50 \\
\hline 1942 & Mar. 21 & 18,200 & 13.40 & 1960 & Jan. 15 & 8,480 & 7.28 & 1978 & Feb. 03 & 9,290 & 7.28 \\
\hline 1943 & Dec. 29 & 18,400 & 13.50 & 1961 & Mar. 15 & 9,720 & 8.32 & 1979 & Feb. 02 & 9,470 & 7.41 \\
\hline 1944 & Mar. 29 & 16,600 & 13.10 & 1962 & Jan. 07 & 10,200 & 8.75 & 1980 & Mar. 03 & 9,170 & 7.48 \\
\hline 1945 & Apr. 25 & 9,300 & 8.50 & 1963 & Mar. 28 & 10,300 & 8.82 & 1981 & Sept.28 & 8,950 & 7.28 \\
\hline 1946 & Jan. 08 & 40,400 & 20.80 & 1964 & Mar. 22 & 22,600 & 15.00 & 1982 & Feb. 02 & 9,060 & 7.43 \\
\hline 1947 & Jan. 20 & 21,900 & 15.30 & 1965 & Oct. 15 & 9,130 & 7.50 & 1983 & Jan. 19 & 9,040 & 7.38 \\
\hline 1948 & Feb. 09 & 13,500 & 12.70 & 1966 & Feb. 28 & 9,370 & 7.67 & 1984 & Dec. 02 & 8,980 & 7.33 \\
\hline 1949 & Nov. 29 & 26,500 & 16.90 & 1967 & July 11 & 9,280 & 7.61 & 1985 & Feb. 04 & 9,170 & 7.48 \\
\hline 1950 & Mar. 13 & 9,280 & 8.65 & 1968 & Jan. 18 & 9,340 & 7.65 & 1986 & Nov. 29 & 9,130 & 7.45 \\
\hline 1951 & Jan. 10 & 8,570 & 8.02 & 1969 & Feb. 21 & 8,510 & 7.06 & 1987 & Jan. 21 & 8,910 & 7.28 \\
\hline 1952 & Mar. 27 & 10,300 & 9.10 & 1970 & Jan. 09 & 8,560 & 7.21 & 1988 & Nov. 06 & 8,840 & 7.22 \\
\hline 1953 & Dec. 31 & 8,740 & 7.63 & 1971 & Nov. 23 & 8,940 & 7.30 & 1989 & Jan. 02 & 8,710 & 7.12 \\
\hline 1954 & Jan. 29 & 8,420 & 7.27 & 1972 & Jan. 10 & 9,230 & 7.52 & 1990 & Mar. 29 & 10,200 & 8.18 \\
\hline
\end{tabular}

02394400 PUMPKINVINE CREEK BELOW DALLAS, GEORGIA

LOCATION.--Lat $33^{\circ} 54^{\prime} 59^{\prime \prime}$, long $84^{\circ} 52^{\prime} 41^{\prime \prime}$, Paulding County, at State Highway 6, 2.2 mi west of Dallas.

DRAINAGE AREA.--42.8 $\mathrm{mi}^{2}$ (revised).

GAGE.--Crest-stage gage. Datum of gage is about $860 \mathrm{ft}$ above sea level (from topographic map).

STAGE-DISCHARGE RELATION.--Defined by current-meter measurements below $6,000 \mathrm{ft}^{3} / \mathrm{s}$. Bankfull stage and discharge, $13 \mathrm{ft}$ and $1,600 \mathrm{ft}^{3} / \mathrm{s}$.

\begin{tabular}{|c|c|c|c|c|c|c|c|c|c|c|c|}
\hline $\begin{array}{l}\text { Water } \\
\text { year }\end{array}$ & Date & $\begin{array}{c}\text { Discharge } \\
\left(\mathrm{ft}^{3} / \mathrm{s}\right)\end{array}$ & $\begin{array}{c}\text { Gage } \\
\text { height } \\
\text { (ft) }\end{array}$ & $\begin{array}{c}\text { Water } \\
\text { year }\end{array}$ & Date & $\begin{array}{c}\text { Discharge } \\
\left(\mathrm{ft}^{3} / \mathrm{s}\right)\end{array}$ & $\begin{array}{c}\text { Gage } \\
\text { height } \\
\text { (ft) }\end{array}$ & $\begin{array}{l}\text { Water } \\
\text { year }\end{array}$ & Date & $\begin{array}{c}\text { Discharge } \\
\left(\mathrm{ft}^{3} / \mathrm{s}\right)\end{array}$ & $\begin{array}{c}\text { Gage } \\
\text { height } \\
\text { (ft) }\end{array}$ \\
\hline 1951 & Mar. 29 & 800 & 10.36 & 1961 & Feb. 23 & 6,800 & 20.28 & 1971 & Apr. 24 & 1,960 & 13.83 \\
\hline 1952 & Mar. 24 & 2,720 & 15.25 & 1962 & Dec. 19 & 2,150 & 14.19 & 1972 & May 14 & 2,610 & 15.02 \\
\hline 1953 & Jan. 10 & 2,300 & 14.48 & 1963 & Mar. 13 & 4,910 & 18.19 & 1973 & Mar. 16 & 2,400 & 14.67 \\
\hline 1954 & Jan. 16 & 2,970 & 15.64 & 1964 & Jan. 25 & 3,040 & 15.73 & 1974 & Dec. 31 & 2,610 & 15.01 \\
\hline 1955 & Feb. 06 & 2,360 & 14.57 & 1965 & Feb. 12 & 1,160 & 11.69 & 1975 & Mar. 14 & 2,820 & 15.36 \\
\hline 1956 & Mar. 16 & 1,500 & 12.69 & 1966 & Mar. 04 & 5,740 & 19.20 & 1976 & Jan. 26 & 2,860 & 14.64 \\
\hline 1957 & Apr. 05 & 2,840 & 15.45 & 1967 & Apr. 26 & 1,060 & 11.37 & 1977 & Mar. 30 & 4,800 & 17.33 \\
\hline 1958 & Feb. 27 & 840 & 10.61 & 1968 & Apr. 05 & 1,100 & 11.49 & $\underline{1982}$ & Feb. 03 & 5,200 & $18.30 \mathrm{c}$ \\
\hline 1959 & July 01 & 1,800 & 13.48 & 1969 & Jan. -- & 515 & $--b$ & $\underline{1984}$ & Dec. 06 & 5,900 & $19.30 c$ \\
\hline 1960 & Jan. 30 & 1,640 & 13.12 & 1970 & Mar. 20 & 2,480 & 14.80 & $\overline{1990}$ & Oct. 01 & 4,100 & $17.05 \mathrm{c}$ \\
\hline
\end{tabular}




\section{MOBILE RIVER BASIN}

\section{ETOWAH RIVER NEAR CARTERSVILLE, GEORGIA}

LOCATION.--Lat $34^{\circ} 08^{\prime} 34^{\prime \prime}$, long 84 $54^{\prime} 20^{\prime \prime}$, Bartow County, on downstream side of bridge pier on State Highway $61,3 \mathrm{mi}$ southwest of Cartersville, $9.6 \mathrm{mi}$ downstream from Allatoona Dam, and at mile 38.2.

DRAINAGE AREA.--1,345 $\mathrm{mi}^{2}$.

GAGE.--Water-stage recorder. Datum of gage is $650.81 \mathrm{ft}$ above sea level (levels from the U.S. Coast and Geodetic Survey benchmark).

STAGE-DISCHARGE RELATION.--Defined by current-meter measurements below $15,700 \mathrm{ft}^{3} / \mathrm{s}$.

REMARKS.--Records furnished by the U.S. Army Corps of Engineers. Peak discharges since December 1949 are regulated by storage in Allatoona Lake (maximum flood-control storage 587,200 acre-ft).

\begin{tabular}{|c|c|c|c|c|c|c|c|c|c|c|c|}
\hline $\begin{array}{l}\text { Water } \\
\text { year }\end{array}$ & Date & $\begin{array}{c}\text { Discharge } \\
\left(\mathrm{ft}^{3} / \mathrm{s}\right)\end{array}$ & $\begin{array}{l}\text { Gage } \\
\text { height } \\
\text { (ft) }\end{array}$ & $\begin{array}{l}\text { Water } \\
\text { year }\end{array}$ & Date & $\begin{array}{c}\text { Discharge } \\
\left(\mathrm{ft}^{3} / \mathrm{s}\right)\end{array}$ & $\begin{array}{c}\text { Gage } \\
\text { height } \\
\text { (ft) }\end{array}$ & $\begin{array}{l}\text { Water } \\
\text { year }\end{array}$ & Date & $\begin{array}{c}\text { Discharge } \\
\left(\mathrm{ft}^{3} / \mathrm{s}\right)\end{array}$ & $\begin{array}{c}\text { Gage } \\
\text { height } \\
\text { (ft) }\end{array}$ \\
\hline$\underline{1886}$ & Apr. - & 55,000 & $37.00 \mathrm{c}$ & 1955 & Apr. 14 & 8,300 & 14.08 & 1973 & Mar. 16 & 11,400 & 16.55 \\
\hline 1920 & Dec. 19 & 41,000 & $31.00 \mathrm{c}$ & 1956 & May 02 & 8,350 & 13.99 & 1974 & Apr. 04 & 12,900 & 17.70 \\
\hline 1938 & Apr. 08 & 35,000 & 29.90 & 1957 & Apr. 12 & 10,600 & 15.55 & 1975 & Feb. 04 & 10,300 & 15.65 \\
\hline 1939 & Mar. 01 & 14,700 & 19.20 & 1958 & Feb. 07 & 9,750 & 15.15 & 1976 & Mar. 31 & 10,600 & 15.92 \\
\hline 1940 & Aug. 14 & 15,400 & 19.80 & 1959 & June 01 & 8,960 & 14.60 & 1977 & Mar. 29 & 14,000 & 18.40 \\
\hline 1941 & July 02 & 13,100 & 18.00 & 1960 & Feb. 01 & 9,350 & 14.90 & 1978 & Jan. 26 & 10,800 & 16.05 \\
\hline 1942 & Mar. 22 & 22,000 & 24.50 & 1961 & Feb. 21 & 16,200 & 18.00 & 1979 & Mar. 04 & 17,300 & 20.70 \\
\hline 1943 & Dec. 30 & 22,500 & 24.80 & 1962 & Jan. 02 & 10,400 & 15.80 & 1980 & Apr. 14 & 14,800 & 18.85 \\
\hline 1944 & Mar. 30 & 18,000 & 22.60 & 1963 & Mar. 22 & 10,100 & 15.70 & 1981 & May 28 & 16,400 & 19.70 \\
\hline 1946 & Jan. 08 & 39,000 & 30.40 & 1964 & Apr. 10 & 15,800 & 20.10 & 1982 & Feb. 03 & 17,600 & 20.76 \\
\hline 1947 & Jan. 27 & 25,000 & 25.80 & 1965 & Apr. 05 & 9,010 & 14.80 & 1983 & Dec. 05 & 10,900 & 16.16 \\
\hline 1948 & Aug. 03 & 14,400 & 19.00 & 1966 & Apr. 27 & 10,600 & 16.10 & 1984 & Dec. 06 & 16,000 & 19.50 \\
\hline 1949 & Nov. 29 & 36,000 & 30.00 & 1967 & Aug. 24 & 12,400 & 17.45 & 1985 & Feb. 07 & 9,250 & 14.70 \\
\hline 1950 & Mar. 14 & 11,300 & 17.74 & 1968 & Dec. 11 & 9,590 & 15.30 & 1986 & Dec. 04 & 8,700 & 14.54 \\
\hline 1951 & Apr. 19 & 8,400 & 14.80 & 1969 & Apr. 18 & 9,230 & 15.00 & 1987 & Jan. 26 & 9,400 & 15.17 \\
\hline 1952 & Mar. 22 & 14,700 & 19.35 & 1970 & June 04 & 9,580 & 15.00 & 1988 & Jan. 21 & 8,600 & 14.41 \\
\hline 1953 & May 07 & 11,100 & 16.85 & 1971 & Feb. 26 & 9,840 & 15.24 & 1989 & June 20 & 9,000 & 14.83 \\
\hline 1954 & Jan. 29 & 8,560 & 14.30 & 1972 & Jan. 10 & 12,200 & 17.24 & 1990 & Mar. 17 & 13,000 & 17.96 \\
\hline
\end{tabular}

\section{EUHARLEE CREEK AT ROCKMART, GEORGIA}

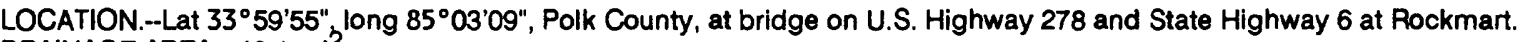
DRAINAGE AREA. $-42.1 \mathrm{mi}^{2}$.

GAGE.--Water-stage recorder. Datum of gage is $732.98 \mathrm{ft}$ above sea level (levels by the Georgia Department of Transportation). STAGE-DISCHARGE RELATION.--Defined by current-meter measurements below $3,060 \mathrm{ft}^{3} / \mathrm{s}$, and extended above on the basis of contracted opening at $5,920 \mathrm{ft}^{3} / \mathrm{s}$. Bankfull stage and discharge, $9 \mathrm{ft}$ and $2,100 \mathrm{ft}^{3} / \mathrm{s}$.

HISTORICAL DATA.--Flood of 1979 is thought to be the highest since 1886, based on information at nearby stations.

REMARKS.--Flood stages for 1961, and 1974 provided by Georgia Department of Transportation. Flood stage for 1979 from floodmarks.

\begin{tabular}{|c|c|c|c|c|c|c|c|c|c|c|c|}
\hline $\begin{array}{l}\text { Water } \\
\text { year }\end{array}$ & Date & $\begin{array}{c}\text { Discharge } \\
\left(\mathrm{ft}^{3} / \mathrm{s}\right)\end{array}$ & $\begin{array}{c}\text { Gage } \\
\text { height } \\
\text { (ft) }\end{array}$ & $\begin{array}{l}\text { Water } \\
\text { year }\end{array}$ & Date & $\begin{array}{c}\text { Discharge } \\
\left(\mathrm{ft}^{3} / \mathrm{s}\right)\end{array}$ & $\begin{array}{c}\text { Gage } \\
\text { height } \\
\text { (ft) }\end{array}$ & $\begin{array}{l}\text { Water } \\
\text { year }\end{array}$ & Date & $\begin{array}{c}\text { Discharge } \\
\left(\mathrm{ft}^{3} / \mathrm{s}\right)\end{array}$ & $\begin{array}{c}\text { Gage } \\
\text { height } \\
\text { (ft) }\end{array}$ \\
\hline 1961 & Feb. 21 & 5,920 & $14.20 c$ & 1985 & May 03 & 1,860 & 8.55 & 1988 & Jan. 20 & 1,770 & 8.37 \\
\hline$\underline{1974}$ & Apr. 04 & 5,500 & $13.80 \mathrm{c}$ & 1986 & Aug. 09 & 636 & 4.76 & 1989 & July 20 & 1,840 & 8.50 \\
\hline$\underline{1979}$ & Mar. 04 & 7,000 & $15.00 c$ & 1987 & Feb. 28 & 1,380 & 7.48 & 1990 & Mar. 16 & 3,090 & 10.43 \\
\hline 1984 & Dec. 06 & 1,760 & 8.33 & & & & & & & & \\
\hline
\end{tabular}




\section{MOBILE RIVER BASIN}

\section{HILLS CREEK NEAR TAYLORSVILLE, GEORGIA}

LOCATION.--Lat $34^{\circ} 04^{\prime 2} 27^{\prime \prime}$, long $84^{\circ} 57^{\prime} 02^{\prime \prime}$, Polk County, on left bank on downstream side of highway bridge on county road, 2 mi southeast of Taylorsville, and 2 mi upstream from mouth. DRAINAGE AREA.--25 $\mathrm{mi}^{2}$ (revised).

GAGE.--Water-stage recorder. Datum of gage is about $690 \mathrm{ft}$ above sea level (from topographic map).

STAGE-DISCHARGE RELATION.--Defined by current-meter measurements below $1,670 \mathrm{ft}^{3} / \mathrm{s}$, and extended above on the basis of slope-area determination at $7,500 \mathrm{ft}^{3} / \mathrm{s}$. Bankfull stage and discharge, $6 \mathrm{ft}$ and $400 \mathrm{ft}^{3} / \mathrm{s}$.

\begin{tabular}{|c|c|c|c|c|c|c|c|c|c|c|c|}
\hline $\begin{array}{l}\text { Water } \\
\text { year }\end{array}$ & Date & $\begin{array}{c}\text { Discharge } \\
\left(\mathrm{ft}^{3} / \mathrm{s}\right)\end{array}$ & $\begin{array}{c}\text { Gage } \\
\text { height } \\
\text { (ft) }\end{array}$ & $\begin{array}{l}\text { Water } \\
\text { year }\end{array}$ & Date & $\begin{array}{c}\text { Discharge } \\
\left(\mathrm{ft}^{3} / \mathrm{s}\right)\end{array}$ & $\begin{array}{c}\text { Gage } \\
\text { height } \\
\text { (ft) }\end{array}$ & $\begin{array}{l}\text { Water } \\
\text { year }\end{array}$ & Date & $\begin{array}{c}\text { Discharge } \\
\left(\mathrm{ft}^{3} / \mathrm{s}\right)\end{array}$ & $\begin{array}{c}\text { Gage } \\
\text { height } \\
\text { (ft) }\end{array}$ \\
\hline 1960 & Jan. 31 & 24 & 7.98 & 1967 & Apr. 26 & 1,050 & 8.71 & 1973 & Mar. 16 & 1,460 & 9.21 \\
\hline 1961 & Feb. 21 & 3,000 & 10.40 & 1968 & Apr. 05 & 697 & 7.99 & 1974 & Apr. 04 & 3,460 & 10.64 \\
\hline 1962 & Dec. 12 & 2,500 & 10.10 & 1969 & Jan. 20 & 423 & 6.69 & 1977 & Mar. 30 & 2,710 & 10.14 \\
\hline 1963 & Mar. 12 & 3,900 & 10.80 & 1970 & Mar. 20 & 1,820 & 9.57 & $\underline{1979}$ & Mar. 04 & 7,500 & 11.18 \\
\hline 1964 & Mar. 26 & 1,450 & 9.20 & 1971 & Apr. 23 & 1,130 & 8.88 & $\underline{1982}$ & Feb. 03 & 3,650 & $10.70 \mathrm{c}$ \\
\hline 1965 & Apr. 12 & 805 & 8.23 & 1972 & Jan. 04 & 1,510 & 9.26 & 1990 & Mar. 16 & 1,510 & $9.46 c$ \\
\hline 1966 & Mar. 04 & 1,110 & 8.81 & & & & & & & & \\
\hline
\end{tabular}

\section{ETOWAH RIVER NEAR KINGSTON, GEORGIA}

LOCATION.--Lat $34^{\circ} 12^{\prime} 24^{\prime \prime}$, long $84^{\circ} 58^{\prime} 44^{\prime \prime}$, Bartow County, on downstream side of center pier of bridge on U.S. Highway 411,1 mi upstream from Two Run Creek, 1.5 mi upstream from Connesena Creek, and 2.5 mi southwest of Kingston. DRAINAGE AREA.-1,630 $\mathrm{mi}^{2}$, approximately.

GAGE.--Water-stage recorder. Datum of gage is $609.97 \mathrm{ft}$ above sea level (level from Dixie Construction Company benchmark). Prior to Aug. 11, 1928, nonrecording gage, Aug. 11, 1928, to Dec. 28, 1931, water-stage recorder, Nov. 16, 1936, to June 15, 1937, nonrecording gage and June 16, 1937, to June 27, 1960, water-stage recorder, all $500 \mathrm{ft}$ upstream at same datum.

STAGE-DISCHARGE RELATION.--Defined by current-meter measurements below $41,000 \mathrm{ft}^{3} / \mathrm{s}$, and above on the basis of straightline extension. Bankfull stage and discharge, $14 \mathrm{ft}$ and $14,500 \mathrm{ft}^{3} / \mathrm{s}$.

HISTORICAL DATA.-Peak stage for December 1919 based on inforamtion from local resident. The December 1919 flood was the highest since 1916, based on records downstream on Etowah River at Rome.

REMARKS.-Peak discharges since December 1949 are regulated by storage in Alatoona Reservoir (maximum flood-control storage, 587,200 acre-ft). Records furnished by the U.S. Army Corps of Engineers from 1950 to 1976.

\begin{tabular}{|c|c|c|c|c|c|c|c|c|c|c|c|}
\hline $\begin{array}{l}\text { Water } \\
\text { year }\end{array}$ & Date & $\begin{array}{c}\text { Discharge } \\
\left(\mathrm{ft}^{3} / \mathrm{s}\right)\end{array}$ & $\begin{array}{c}\text { Gage } \\
\text { height } \\
\text { (ft) }\end{array}$ & $\begin{array}{l}\text { Water } \\
\text { year }\end{array}$ & Date & $\begin{array}{c}\text { Discharge } \\
\left(\mathrm{ft}^{3} / \mathrm{s}\right)\end{array}$ & $\begin{array}{c}\text { Gage } \\
\text { height } \\
\text { (ft) }\end{array}$ & $\begin{array}{l}\text { Water } \\
\text { year }\end{array}$ & Date & $\begin{array}{c}\text { Discharge } \\
\left(\mathrm{ft}^{3} / \mathrm{s}\right)\end{array}$ & $\begin{array}{c}\text { Gage } \\
\text { height } \\
\text { (ft) }\end{array}$ \\
\hline$\underline{1920}$ & Dec. 11 & 52,000 & $31.00 \mathrm{c}$ & 1953 & May 08 & 12,800 & 12.10 & 1972 & Jan. 10 & 16,100 & 15.04 \\
\hline 1929 & May 02 & 29,700 & 21.42 & 1954 & Jan. 16 & 13,600 & 12.68 & 1973 & Mar. 16 & 16,200 & 15.14 \\
\hline 1930 & Mar. 07 & 29,900 & 21.50 & 1955 & Apr. 05 & 9,520 & 10.60 & 1974 & Apr. 05 & 20,100 & 17.56 \\
\hline$\underline{1931}$ & Nov. 16 & 12,600 & 12.30 & 1956 & Mar. 16 & 11,400 & 11.71 & 1975 & Feb. 05 & 13,300 & 13.30 \\
\hline 1937 & Jan. 03 & 31,800 & 22.40 & 1957 & Apr. 05 & 18,000 & 15.15 & 1976 & Mar. 17 & 19,800 & 17.35 \\
\hline 1938 & Apr. 09 & 42,700 & 27.70 & 1958 & Nov. 19 & 11,400 & 11.70 & 1977 & Mar. 30 & 30,000 & 21.53 \\
\hline 1939 & Feb. 28 & 17,600 & 15.50 & 1959 & June 01 & 9,730 & 11.10 & 1978 & May 09 & 13,000 & 13.11 \\
\hline 1940 & Aug. 14 & 14,500 & 13.80 & 1960 & Feb. 01 & $\underline{9,330}$ & 10.80 & 1979 & Mar. 04 & 27,700 & 22.30 \\
\hline 1941 & July 07 & 12,600 & 12.70 & 1961 & Feb. 21 & 25,200 & 18.52 & 1980 & Apr. 14 & 20,300 & 17.70 \\
\hline 1942 & Mar. 22 & 28,000 & 20.90 & 1962 & Dec. 12 & 19,300 & 15.80 & 1981 & May 28 & 14,300 & 14.32 \\
\hline 1943 & Dec. 29 & 29,800 & 21.80 & 1963 & Mar. 13 & 16,600 & 15.00 & 1982 & Feb. 03 & 28,000 & 21.97 \\
\hline 1944 & Mar. 30 & 23,100 & 18.40 & 1964 & Mar. 26 & 22,900 & 19.40 & 1983 & Jan. 20 & 13,200 & 13.47 \\
\hline 1945 & Apr. 25 & 11,700 & 12.20 & 1965 & Oct. 16 & 12,000 & 12.55 & 1984 & Dec. 06 & 17,000 & 15.80 \\
\hline 1946 & Jan. 09 & 39,000 & 26.10 & 1966 & Apr. 28 & 13,300 & 13.40 & 1985 & Feb. 06 & 11,500 & 12.36 \\
\hline 1947 & Jan. 21 & 29,900 & 22.10 & 1967 & Aug. 25 & 15,000 & 14.37 & 1986 & Nov. 19 & 8,110 & 10.08 \\
\hline 1948 & Feb. 09 & 20,300 & 17.30 & 1968 & Jan. 10 & 14,300 & 13.92 & 1987 & Feb. 28 & 10,700 & 11.84 \\
\hline 1949 & Nov. 30 & 38,600 & 25.90 & 1969 & Apr. 19 & 10,500 & 11.55 & 1988 & Jan. 20 & 8,810 & 10.56 \\
\hline 1950 & Sept.08 & 16,300 & 15.20 & 1970 & Mar. 21 & 11,700 & 12.30 & 1989 & June 20 & 10,500 & 11.69 \\
\hline 1951 & Mar. 29 & 12,000 & 11.70 & 1971 & Mar. 25 & 11,700 & 12.05 & 1990 & Mar. 17 & 26,600 & 21.26 \\
\hline 1952 & Mar. 23 & 24,700 & $18.6,0$ & & & & & & & & \\
\hline
\end{tabular}




\section{TWO RUN CREEK NEAR KINGSTON, GEORGIA}

LOCATION.-Lat $34^{\circ} 14^{\prime} 34^{\prime \prime}$, long $84^{\circ} 53^{\prime} 23^{\prime \prime}$, Bartow County, on right bank $200 \mathrm{ft}$ upstream from bridge on State Highway $293,1.9$ mi upstream from Limekiln Branch, and 3 mi east of Kingston.

DRAINAGE AREA.--33.1 $\mathrm{mi}^{2}$.

GAGE.--Water-stage recorder. Datum of gage is $723.1 \mathrm{ft}$ above sea level (level by Global Positioning System).

STAGE-DISCHARGE RELATION.--Defined by current-meter measurements below $1,430 \mathrm{ft}^{3} / \mathrm{s}$, and extended above on the basis of straight-line extension.

\begin{tabular}{|c|c|c|c|c|c|c|c|c|c|c|c|}
\hline $\begin{array}{l}\text { Water } \\
\text { year }\end{array}$ & Date & $\begin{array}{c}\text { Discharge } \\
\left(\mathrm{ft}^{3} / \mathrm{s}\right)\end{array}$ & $\begin{array}{c}\text { Gage } \\
\text { height } \\
\text { (ft) }\end{array}$ & $\begin{array}{l}\text { Water } \\
\text { year }\end{array}$ & Date & $\begin{array}{c}\text { Discharge } \\
\left(\mathrm{ft}^{3} / \mathrm{s}\right)\end{array}$ & $\begin{array}{c}\text { Gage } \\
\text { height } \\
\text { (ft) }\end{array}$ & $\begin{array}{l}\text { Water } \\
\text { year }\end{array}$ & Date & $\begin{array}{c}\text { Discharge } \\
\left(\mathrm{ft}^{3} / \mathrm{s}\right)\end{array}$ & $\begin{array}{c}\text { Gage } \\
\text { height } \\
\text { (ft) }\end{array}$ \\
\hline 1981 & Mar. 30 & 531 & 5.04 & 1985 & Feb. 01 & 394 & 3.82 & 1988 & Jan. 20 & 692 & 5.15 \\
\hline 1982 & Feb. 03 & 3,180 & 7.91 & 1986 & Oct. 01 & 118 & 1.89 & 1989 & Mar. 05 & 2,170 & 7.10 \\
\hline 1983 & May 19 & 1,140 & 5.99 & 1987 & Feb. 28 & 1,330 & 6.23 & 1990 & Mar. 16 & 2,940 & 7.74 \\
\hline 1984 & Dec. 04 & 1,370 & 6.27 & & & & & & & & \\
\hline
\end{tabular}

\section{DIKES CREEK NEAR ROME, GEORGIA}

LOCATION.--Lat $34^{\circ} 15^{\prime} 30^{\prime \prime}$, long $85^{\circ} 05^{\prime} 01^{\prime \prime}$, Floyd County, 0.5 mi upstream from bridge on U.S. Highway $411,1.5$ mi upstream from mouth, and 5 mi east of Rome.

DRAINAGE AREA.--14.9 $\mathrm{mi}^{2}$ (revised).

GAGE.--Water-stage recorder. Datum of gage is about $620 \mathrm{ft}$ above sea level (from topographic map).

STAGE-DISCHARGE RELATION.--Defined by current-meter measurements below $700 \mathrm{ft}^{3} / \mathrm{s}$, and extended above on the basis of straight-line extension.

\begin{tabular}{|c|c|c|c|c|c|c|c|c|c|c|c|}
\hline $\begin{array}{l}\text { Water } \\
\text { year }\end{array}$ & Date & $\begin{array}{c}\text { Discharge } \\
\left(\mathrm{ft}^{3} / \mathrm{s}\right)\end{array}$ & $\begin{array}{l}\text { Gage } \\
\text { height } \\
\text { (ft) }\end{array}$ & $\begin{array}{l}\text { Water } \\
\text { year }\end{array}$ & Date & $\begin{array}{c}\text { Discharge } \\
\left(\mathrm{ft}^{3} / \mathrm{s}\right)\end{array}$ & $\begin{array}{l}\text { Gage } \\
\text { height } \\
\text { (ft) }\end{array}$ & $\begin{array}{l}\text { Water } \\
\text { year }\end{array}$ & Date & $\begin{array}{c}\text { Discharge } \\
\left(\mathrm{ft}^{3} / \mathrm{s}\right)\end{array}$ & $\begin{array}{c}\text { Gage } \\
\text { height } \\
\text { (ft) }\end{array}$ \\
\hline 1939 & Feb. 28 & 259 & 2.54 & 1941 & July 07 & 70.0 & 1.38 & 1943 & Dec. 29 & 873 & 4.60 \\
\hline 1940 & Mar. 14 & 141 & 1.87 & 1942 & Feb. 16 & 1,010 & 5.10 & & & & \\
\hline
\end{tabular}

\section{ETOWAH RIVER TRIBUTARY AT ROME, GEORGIA}

LOCATION.--Lat $34^{\circ} 16^{\prime} 02^{\prime \prime}$, long $85^{\circ} 08^{\prime} 18^{\prime \prime}$, Floyd County, at culvert on Atteiram Road at Rome.

DRAINAGE AREA.--0.37 $\mathrm{mi}^{2}$

GAGE.--Flood-stage/rainfall recorder prior to Aug. 13, 1986. Crest-stage 1987 to present.

STAGE-DISCHARGE RELATION.--Defined by current-meter measurements below $45 \mathrm{tt}^{3} / \mathrm{s}$, and extended above on the basis of culvert computations.

REMARKS.--Flow is affected by urbanization.

\begin{tabular}{lccccccccccc}
\hline $\begin{array}{l}\text { Water } \\
\text { year }\end{array}$ & Date & $\begin{array}{c}\text { Discharge } \\
\left(\mathrm{ft}^{3} / \mathrm{s}\right)\end{array}$ & $\begin{array}{c}\text { Gage } \\
\text { height } \\
(\mathrm{ft})\end{array}$ & $\begin{array}{c}\text { Water } \\
\text { year }\end{array}$ & Date & $\begin{array}{c}\text { Discharge } \\
\left(\mathrm{ft}^{3} / \mathrm{s}\right)\end{array}$ & $\begin{array}{c}\text { Gage } \\
\text { height } \\
(\mathrm{ft})\end{array}$ & $\begin{array}{c}\text { Water } \\
\text { year }\end{array}$ & $\begin{array}{c}\text { Gage } \\
\text { Date }\end{array}$ & $\begin{array}{c}\text { Discharge } \\
\left(\mathrm{ft}^{3} / \mathrm{s}\right)\end{array}$ & $\begin{array}{c}\text { height } \\
(\mathrm{ft})\end{array}$ \\
\hline & & & & & & & & & & & \\
1979 & Apr. 13 & 190 & 7.20 & 1983 & Nov. 28 & 104 & 5.00 & 1987 & Aug. 05 & 29.0 & 2.61 \\
1980 & July 24 & 116 & 5.46 & 1984 & July 17 & 125 & 5.82 & 1988 & Jan. 19 & 77.0 & 4.10 \\
1981 & May 31 & 73.0 & 3.96 & 1985 & May 12 & 94.0 & 4.67 & 1989 & Feb. 28 & 175 & 7.34 \\
1982 & Mar. 17 & 135 & 6.16 & 1986 & Mar. 13 & 193 & 7.46 & 1990 & Feb. 16 & 185 & 7.41 \\
\hline
\end{tabular}




\section{MOBILE RIVER BASIN}

\section{ETOWAH RIVER AT ROME, GEORGIA}

LOCATION.--Lat $34^{\circ} 15^{\prime} 26^{\prime \prime}$, long $85^{\circ} 09^{\prime} 30^{\prime \prime}$, Floyd County, on downstream side of center pier of Southern Railway bridge in Rome, 2 mi upstream from confluence with Oostanaula River.

DRAINAGE AREA.--1,820 $\mathrm{mi}^{2}$ (revised).

GAGE.-Water-stage recorder. Datum of gage is $561.70 \mathrm{ft}$ above sea level (level from U.S. Coast and Geodetic Survey benchmark). Since May 15, 1939, auxiliary water-stage recorder at Second Avenue Bridge, 1 mi downstream.

STAGE-DISCHARGE RELATION.--Defined by current-meter measurements below $46,500 \mathrm{ft}^{3} / \mathrm{s}$. Stage-discharge relation is affected by backwater from Oostanaula River and fall between the base and auxiliary gages is used as a factor in computing discharge. Bankfull stage and discharge, $25 \mathrm{ft}$ and about $15,000 \mathrm{ft}^{3} / \mathrm{s}$.

HISTORICAL DATA.--Peak stage for April 1938 based on information furnished by the U.S. Army Corps of Engineers. Flood of December 1919 was maximum known flood since 1916, based on information from local residents; discharge estimated from data at upstream gaging stations.

REMARKS.--Peak discharges since December 1949 are regulated by storage in Alatoona Reservoir (maximum flood-control storage, 587,200 acre-ft). Peak discharges for 1920 and 1939 are estimated.

\begin{tabular}{|c|c|c|c|c|c|c|c|c|c|c|c|}
\hline $\begin{array}{l}\text { Water } \\
\text { year }\end{array}$ & Date & $\begin{array}{c}\text { Discharge } \\
\left(\mathrm{ft}^{3} / \mathrm{s}\right)\end{array}$ & $\begin{array}{c}\text { Gage } \\
\text { height } \\
\text { (ft) }\end{array}$ & $\begin{array}{l}\text { Water } \\
\text { year }\end{array}$ & Date & $\begin{array}{c}\text { Discharge } \\
\left(\mathrm{ft}^{3} / \mathrm{s}\right)\end{array}$ & $\begin{array}{c}\text { Gage } \\
\text { height } \\
\text { (ft) }\end{array}$ & $\begin{array}{l}\text { Water } \\
\text { year }\end{array}$ & Date & $\begin{array}{c}\text { Discharge } \\
\left(\mathrm{ft}^{3} / \mathrm{s}\right)\end{array}$ & $\begin{array}{c}\text { Gage } \\
\text { height } \\
\text { (ft) }\end{array}$ \\
\hline$\underline{1920}$ & Dec. 11 & 55,000 & $-c$ & 1955 & Feb. 07 & 9,430 & $21.30 \mathrm{a}$ & 1973 & Mar. 17 & 18,100 & $25.22 \mathrm{a}$ \\
\hline 1938 & Apr. 09 & 46,500 & 37.50 & 1956 & Mar. 17 & 11,400 & $20.50 \mathrm{a}$ & 1974 & Apr. 05 & 21,700 & 29.02 \\
\hline 1939 & Mar. 01 & 18,000 & -- & 1957 & Apr. 05 & 19,300 & $27.90 \mathrm{a}$ & 1975 & Mar. 16 & 15,800 & $24.50 \mathrm{a}$ \\
\hline 1940 & Aug. 14 & 14,400 & $18.40 \mathrm{a}$ & 1958 & Nov. 19 & 10,500 & $20.81 a$ & 1976 & Mar. 31 & 24,200 & $30.20 \mathrm{a}$ \\
\hline 1941 & July 07 & 13,200 & $19.30 \mathrm{a}$ & 1959 & June 01 & 8,580 & $16.10 \mathrm{a}$ & 1977 & Mar. 30 & 30,700 & $32.99 \mathrm{a}$ \\
\hline 1942 & Mar. 22 & 27,000 & $29.10 \mathrm{a}$ & 1960 & Feb. 01 & 8,620 & $17.30 \mathrm{a}$ & 1978 & Jan. 26 & 15,600 & 24.88 \\
\hline 1943 & Dec. 30 & 29,000 & $32.10 \mathrm{a}$ & 1961 & Feb. 22 & 23,700 & $30.10 \mathrm{a}$ & 1979 & Mar. 04 & 36,000 & $36.13 a$ \\
\hline 1944 & Mar. 30 & 25,200 & $30.70 a$ & 1962 & Dec. 12 & 20,700 & $28.16 \mathrm{a}$ & 1980 & Apr. 14 & 26,400 & $30.21 \mathrm{a}$ \\
\hline 1945 & Apr. 26 & 12,000 & $17.80 \mathrm{a}$ & 1963 & Apr. 30 & 18,500 & $27.60 \mathrm{a}$ & 1981 & May 28 & 13,100 & 18.53 \\
\hline 1946 & Jan. 09 & 36,900 & $36.20 \mathrm{a}$ & 1964 & Mar. 26 & 29,500 & $33.25 \mathrm{a}$ & 1982 & Feb. 04 & 30,100 & 32.81 \\
\hline 1947 & Jan. 21 & 28,900 & $36.70 a$ & 1965 & Apr. 05 & 12,500 & $22.97 \mathrm{a}$ & 1983 & Apr. 09 & 15,700 & 25.04 \\
\hline 1948 & Feb. 10 & 22,200 & $28.20 \mathrm{a}$ & 1966 & Mar. 04 & 18,000 & $27.58 \mathrm{a}$ & 1984 & Dec. 07 & 19,100 & 26.45 \\
\hline 1949 & Nov. 30 & 35,700 & $37.40 \mathrm{a}$ & 1967 & Aug. 27 & 16,700 & $25.31 \mathrm{a}$ & 1985 & Feb. 06 & 12,200 & 21.25 \\
\hline 1950 & Mar. 14 & 16,600 & $27.60 \mathrm{a}$ & 1968 & Jan. 10 & 16,500 & $26.58 \mathrm{a}$ & 1986 & Dec. 05 & 8,420 & 13.96 \\
\hline 1951 & Mar. 29 & 14,800 & $28.30 \mathrm{a}$ & 1969 & Apr. 19 & 10,700 & $21.07 \mathrm{a}$ & 1987 & Mar. 01 & 17,000 & 26.24 \\
\hline 1952 & Mar. 23 & 23,000 & $28.60 \mathrm{a}$ & 1970 & Mar. 20 & 13,200 & $22.94 \mathrm{a}$ & 1988 & Jan. 20 & 9,410 & 20.49 \\
\hline 1953 & May 08 & 11,700 & 19.80 & 1971 & Mar. 26 & 11,600 & $21.29 a$ & 1989 & Mar. 06 & 14,900 & 25.96 \\
\hline 1954 & Jan. 16 & 15,000 & $25.40 \mathrm{a}$ & 1972 & Jan. 11 & 17,700 & $26.40 \mathrm{a}$ & 1990 & Mar. 17 & 33,800 & 36.77 \\
\hline
\end{tabular}

\section{SILVER CREEK TRIBUTARY NO. 1, NEAR ROME, GEORGIA}

LOCATION.--Lat $34^{\circ} 10^{\prime} 24^{\prime \prime}$, long $85^{\circ} 09^{\prime} 21^{\prime \prime}$, Floyd County, at culvert on Silver Creek Road, near Rome.

DRAINAGE AREA.--0.62 $\mathrm{mi}^{2}$.

GAGE.--Flood-stage/rainfall recorder.

STAGE-DISCHARGE RELATION.--Defined by current-meter measurements below $74 \mathrm{ft}^{3} / \mathrm{s}$, and extended above on the basis of culvert computations.

REMARKS.--Flow is affected by urbanization.

\begin{tabular}{|c|c|c|c|c|c|c|c|c|c|c|c|}
\hline $\begin{array}{l}\text { Water } \\
\text { year }\end{array}$ & Date & $\begin{array}{c}\text { Discharge } \\
\left(\mathrm{ft}^{3} / \mathrm{s}\right)\end{array}$ & $\begin{array}{c}\text { Gage } \\
\text { height } \\
\text { (ft) }\end{array}$ & $\begin{array}{l}\text { Water } \\
\text { year }\end{array}$ & Date & $\begin{array}{c}\text { Discharge } \\
\left(\mathrm{ft}^{3} / \mathrm{s}\right)\end{array}$ & $\begin{array}{c}\text { Gage } \\
\text { height } \\
\text { (ft) }\end{array}$ & $\begin{array}{l}\text { Water } \\
\text { year }\end{array}$ & Date & $\begin{array}{c}\text { Discharge } \\
\left(\mathrm{ft}^{3} / \mathrm{s}\right)\end{array}$ & $\begin{array}{c}\text { Gage } \\
\text { height } \\
\text { (ft) }\end{array}$ \\
\hline 1979 & Mar. 03 & 314 & 6.94 & 1982 & Apr. 25 & 113 & 3.80 & 1985 & July 21 & 73.0 & 3.10 \\
\hline 1980 & Mar. 20 & 199 & 5.24 & 1983 & Feb. 01 & 44.0 & 2.51 & 1986 & Aug. 19 & 54.0 & 2.72 \\
\hline 1981 & Sept.01 & 145 & 4.34 & 1984 & July 31 & 131 & 4.10 & & & & \\
\hline
\end{tabular}




\section{MOBILE RIVER BASIN}

02396510 SILVER CREEK TRIBUTARY NO. 2, AT LINDALE ROAD NEAR ROME, GEORGIA

LOCATION.--Lat $34^{\circ} 12^{\prime} 56^{\prime \prime}$, long 85'10'09", Floyd County, at culvert on Lindale Road, near Rome.

DRAINAGE AREA.$-0.04 \mathrm{mi}^{2}$.

GAGE.--Flood-stage/rainfall recorder prior to Sept. 4, 1986. Crest-stage gage 1987 to present.

STAGE-DISCHARGE RELATION.--Defined by current-meter measurements below $10 \mathrm{tt}^{3} / \mathrm{s}$, and extended above on the basis of culvert computations.

REMARKS.--Flow is affected by urbanization.

\begin{tabular}{lccccccccccc}
\hline $\begin{array}{l}\text { Water } \\
\text { year }\end{array}$ & Date & $\begin{array}{c}\text { Discharge } \\
\left(\mathrm{ft}^{3} / \mathrm{s}\right)\end{array}$ & $\begin{array}{c}\text { Gage } \\
\text { height } \\
(\mathrm{ft})\end{array}$ & $\begin{array}{c}\text { Water } \\
\text { year }\end{array}$ & Date & $\begin{array}{c}\text { Discharge } \\
\left(\mathrm{ft}^{3} / \mathrm{s}\right)\end{array}$ & $\begin{array}{c}\text { Gage } \\
\text { height } \\
(\mathrm{ft})\end{array}$ & $\begin{array}{c}\text { Water } \\
\text { year }\end{array}$ & $\begin{array}{c}\text { Gage } \\
\text { Date }\end{array}$ & $\begin{array}{c}\text { Discharge } \\
\left(\mathrm{ft}^{3} / \mathrm{s}\right)\end{array}$ & $\begin{array}{c}\text { height } \\
(\mathrm{ft})\end{array}$ \\
\hline & & & & & & & & & & & \\
1979 & Sept.28 & 35.0 & 3.39 & 1983 & May 19 & 19.0 & 2.74 & 1987 & Mar. 01 & 13.0 & 2.18 \\
1980 & Mar. 20 & 12.0 & 2.40 & 1984 & Apr. 28 & 35.0 & 3.41 & 1988 & Aug. 20 & 6.0 & 1.82 \\
1981 & Aug. 30 & 15.0 & 2.56 & 1985 & July 24 & 17.0 & 2.65 & 1989 & Feb. 28 & 44.0 & 3.48 \\
1982 & July 15 & 14.0 & 2.55 & 1986 & Aug. 08 & 13.0 & 2.46 & 1990 & Feb. 16 & 41.0 & 3.36 \\
\hline
\end{tabular}

\section{SILVER CREEK TRIBUTARY NO. 2, AT U.S. HIGHWAYS 27 AND 411 NEAR ROME, GEORGIA}

LOCATION.--Lat 34 ${ }^{\circ} 13^{\prime} 08^{\prime \prime}$, long $85^{\circ} 10^{\prime} 27^{\prime \prime}$, Floyd County, at culvert on U.S. Highways 27 and 411 at junction with Old Lindale

Road, near Rome.

DRAINAGE AREA.--0.19 $\mathrm{mi}^{2}$.

GAGE.--Flood-stage/rainfall recorder.

STAGE-DISCHARGE RELATION.--Defined by current-meter measurements below $49 \mathrm{ft}^{3} / \mathrm{s}$, and extended above on the basis of culvert computations.

REMARKS.--Flow is affected by urbanization.

\begin{tabular}{|c|c|c|c|c|c|c|c|c|c|c|c|}
\hline $\begin{array}{l}\text { Water } \\
\text { year }\end{array}$ & Date & $\begin{array}{c}\text { Discharge } \\
\left(\mathrm{ft}^{3} / \mathrm{s}\right)\end{array}$ & $\begin{array}{c}\text { Gage } \\
\text { height } \\
\text { (ft) }\end{array}$ & $\begin{array}{l}\text { Water } \\
\text { year }\end{array}$ & Date & $\begin{array}{c}\text { Discharge } \\
\left(\mathrm{ft}^{3} / \mathrm{s}\right)\end{array}$ & $\begin{array}{c}\text { Gage } \\
\text { height } \\
\text { (ft) }\end{array}$ & $\begin{array}{l}\text { Water } \\
\text { year }\end{array}$ & Date & $\begin{array}{c}\text { Discharge } \\
\left(\mathrm{ft}^{3} / \mathrm{s}\right)\end{array}$ & $\begin{array}{c}\text { Gage } \\
\text { height } \\
\text { (ft) }\end{array}$ \\
\hline 1979 & Apr. 13 & 108 & 4.27 & 1982 & Feb. 02 & 37.0 & 3.44 & 1985 & July 24 & 5.9 & 2.21 \\
\hline 1980 & Mar. 17 & 74 & 3.90 & 1983 & June 19 & 32.0 & 3.38 & 1986 & Mar. 13 & 4.0 & 2.02 \\
\hline 1981 & Aug. 30 & 72 & 3.87 & 1984 & July 31 & 78.0 & 3.95 & & & & \\
\hline
\end{tabular}

\section{SILVER CREEK TRIBUTARY NO. 3, AT ROME, GEORGIA}

LOCATION.--Lat $34^{\circ} 13^{\prime} 26^{\prime \prime}$, long $85^{\circ} 09^{\prime} 14^{\prime \prime}$, Floyd County, at culvert on U.S. Highway $27,0.4$ mile north of U.S. Highway 411 interchange, at Rome.

DRAINAGE AREA.--0.19 $\mathrm{mi}^{2}$.

GAGE.--Flood-stage/rainfall recorder prior to Aug. 13, 1986. Crest-stage gage 1987 to present.

STAGE-DISCHARGE RELATION.--Defined by current-meter measurements below $47 \mathrm{ft}^{3} / \mathrm{s}$, and extended above on the basis of culvert computations.

REMARKS.--Flow is affected by urbanization.

\begin{tabular}{|c|c|c|c|c|c|c|c|c|c|c|c|}
\hline $\begin{array}{l}\text { Water } \\
\text { year }\end{array}$ & Date & $\begin{array}{c}\text { Discharge } \\
\left(\mathrm{ft}^{3} / \mathrm{s}\right)\end{array}$ & $\begin{array}{c}\text { Gage } \\
\text { height } \\
\text { (ft) }\end{array}$ & $\begin{array}{c}\text { Water } \\
\text { year }\end{array}$ & Date & $\begin{array}{c}\text { Discharge } \\
\left(\mathrm{ft}^{3} / \mathrm{s}\right)\end{array}$ & $\begin{array}{l}\text { Gage } \\
\text { height } \\
\text { (ft) }\end{array}$ & $\begin{array}{l}\text { Water } \\
\text { year }\end{array}$ & Date & $\begin{array}{c}\text { Discharge } \\
\left(\mathrm{ft}^{3} / \mathrm{s}\right)\end{array}$ & $\begin{array}{l}\text { Gage } \\
\text { height } \\
\text { (ft) }\end{array}$ \\
\hline 1979 & Sept.28 & 181 & 5.06 & 1983 & Apr. 08 & 144 & 4.79 & 1987 & Oct. 13 & 133 & 4.89 \\
\hline 1980 & May 22 & 123 & 4.62 & 1984 & July 28 & 156 & 4.97 & 1988 & Jan. 19 & 113 & 4.69 \\
\hline 1981 & Aug. 30 & 115 & 4.55 & 1985 & Aug. 17 & 110 & 4.51 & 1989 & Feb. 28 & 181 & 5.35 \\
\hline 1982 & July 15 & 189 & 5.11 & 1986 & Aug. 27 & 185 & 5.39 & 1990 & Feb. 16 & 162 & 5.17 \\
\hline
\end{tabular}




\section{MOBILE RIVER BASIN}

\section{HORSELEG CREEK AT ROME, GEORGIA}

LOCATION.--Lat $34^{\circ} 16^{\prime} 03^{\prime \prime}$, long $85^{\circ} 13^{\prime} 29^{\prime \prime}$, Floyd County, at culvert on Castlewood Drive, at Rome.

DRAINAGE AREA. $-1.31 \mathrm{mi}^{2}$.

GAGE.--Flood-stage/rainfall recorder.

STAGE-DISCHARGE RELATION.--Defined by current-meter measurements below $158 \mathrm{ft}^{3} / \mathrm{s}$, and extended above on the basis of culvert computations.

REMARKS.--Flow is affected by urbanization.

\begin{tabular}{|c|c|c|c|c|c|c|c|c|c|c|c|}
\hline $\begin{array}{l}\text { Water } \\
\text { year }\end{array}$ & Date & $\begin{array}{c}\text { Discharge } \\
\left(\mathrm{ft}^{3} / \mathrm{s}\right)\end{array}$ & $\begin{array}{c}\text { Gage } \\
\text { height } \\
\text { (ft) }\end{array}$ & $\begin{array}{l}\text { Water } \\
\text { year }\end{array}$ & Date & $\begin{array}{c}\text { Discharge } \\
\left(\mathrm{ft}^{3} / \mathrm{s}\right)\end{array}$ & $\begin{array}{c}\text { Gage } \\
\text { height } \\
\text { (ft) }\end{array}$ & $\begin{array}{l}\text { Water } \\
\text { year }\end{array}$ & Date & $\begin{array}{c}\text { Discharge } \\
\left(\mathrm{ft}^{3} / \mathrm{s}\right)\end{array}$ & $\begin{array}{c}\text { Gage } \\
\text { height } \\
\text { (ft) }\end{array}$ \\
\hline 1979 & Mar. 04 & 562 & 7.63 & 1982 & Jan. 03 & 399 & 6.47 & 1985 & Aug. 25 & 284 & 4.67 \\
\hline 1980 & Mar. 07 & 296 & 4.85 & 1983 & Aug. 31 & 310 & 5.08 & 1986 & Mar. 19 & 264 & 4.42 \\
\hline 1981 & Aug. 30 & 414 & 6.62 & 1984 & July 31 & 453 & 7.01 & & & & \\
\hline
\end{tabular}




\section{MOBILE RIVER BASIN}

\section{COOSA RIVER NEAR ROME, GEORGIA}

LOCATION.-Lat $34^{\circ} 12^{\prime} 01^{\prime \prime}$, long $85^{\circ} 15^{\prime} 24^{\prime \prime}$, Floyd County, on left bank attached to shoreward side of lock wall of Mayo Bar lock near upstream end, $1.5 \mathrm{mi}$ upstream from Webb Creek, $6 \mathrm{mi}$ southwest of Rome, $7.5 \mathrm{mi}$ downstream from confluence of Dostanaula and Etowah Rivers, and at mile 278.6.

DRAINAGE AREA.--4,040 $\mathrm{mi}^{2}$, approximately.

GAGE.-Water-stage recorder. Datum of gage is $553.05 \mathrm{ft}$ abaove sea level (levels by the U.S. Army Corps of Engineers).

Nonrecording gage prior to June 21, 1928; water-stage recorder June 21, 1928, to Feb. 28, 1932; nonrecording gage Mar. 1, 1932, to Mar. 9, 1937; water-stage recorder Mar. 10, 1937, to Dec. 31, 1958; at site $200 \mathrm{ft}$ downstream at same datum. Creststage gage December 1958 to Oct. 1, 1962, and water-stage recorder thereafter at present site. Water-stage recorder on the Oostanaula River at Fifth Avenue in Rome used as auxiliary gage since 1963.

STAGE-DISCHARGE RELATION.-Defined by current-meter measurements below $63,000 \mathrm{ft}^{3} / \mathrm{s}$, and extended above on the basis of peak flow at gaging station on Coosa River at Gadsden, Ala. Stage-discharge relation is affected by backwater at higher stages and fall between the base and auxillary gages, and is used as a factor in computing discharge. Bankfull stage and discharge, 30 $\mathrm{ft}$ and $39,000 \mathrm{ft}^{3} / \mathrm{s}$.

HISTORICAL DATA. -The April 1886 flood on the Coosa River was the highest that has occurred since the city of Rome was founded in 1834, based on information given in, "A History of Rome and Floyd County," Georgia Department of Archives. REMARKS.--Peak stage of 1886 flood $40.3 \mathrm{ft}$ at site and datum at Rome is equivalent to about $43 \mathrm{ft}$ at present site.Peak stages for 1914-27 and 1933-36 furnished by the U.S. Army Corps of Engineers. Peak discharges since December 1949 are slightly affected by storage in Allatoona Reservoir (maximum flood-control storage, 587,200 acre-ft) and since November 1924 by storage in Carters Lake and re-regulation dam (maximum flood-control storage, 230,600 acre-ft). Peak discharge for 1916 is estimated.

\begin{tabular}{|c|c|c|c|c|c|c|c|c|c|c|c|}
\hline $\begin{array}{l}\text { Water } \\
\text { year }\end{array}$ & Date & $\begin{array}{c}\text { Discharge } \\
\left(\mathrm{ft}^{3} / \mathrm{s}\right)\end{array}$ & $\begin{array}{c}\text { Gage } \\
\text { height } \\
\text { (ft) }\end{array}$ & $\begin{array}{l}\text { Water } \\
\text { year }\end{array}$ & Date & $\begin{array}{c}\text { Discharge } \\
\left(\mathrm{ft}^{3} / \mathrm{s}\right)\end{array}$ & $\begin{array}{c}\text { Gage } \\
\text { height } \\
\text { (ft) }\end{array}$ & $\begin{array}{l}\text { Water } \\
\text { year }\end{array}$ & Date & $\begin{array}{c}\text { Discharge } \\
\left(\mathrm{ft}^{3} / \mathrm{s}\right)\end{array}$ & $\begin{array}{c}\text { Gage } \\
\text { height } \\
\text { (ft) }\end{array}$ \\
\hline$\underline{1886}$ & Apr. 01 & 100,000 & $43.00 \mathrm{c}$ & 1939 & Mar. 01 & 34,000 & 26.50 & 1965 & Mar. 31 & 30,300 & 25.02 \\
\hline 1914 & Apr. 16 & 25,900 & 22.00 & 1940 & Mar. 14 & 25,500 & 20.40 & 1966 & Mar. 05 & 35,300 & 28.31 \\
\hline 1915 & Feb. 02 & 29,900 & 25.10 & 1941 & July 06 & 25,000 & 19.80 & 1967 & Aug. 26 & 30,900 & 25.06 \\
\hline 1916 & July 12 & 65,500 & - & 1942 & Mar. 22 & 39,600 & 29.50 & 1968 & Jan. 17 & 33,800 & 27.10 \\
\hline 1917 & Mar. 06 & 51,000 & 34.00 & 1943 & Dec. 31 & 48,800 & 33.20 & 1969 & Feb. 09 & 28,000 & 23.55 \\
\hline 1918 & Jan. 31 & 31,400 & 26.20 & 1944 & Mar. 31 & 45,700 & 32.40 & 1970 & Mar. 22 & 29,500 & 24.55 \\
\hline 1919 & Dec. 24 & 44,000 & 32.00 & 1945 & Feb. 14 & 27,100 & 22.90 & 1971 & Mar. 04 & 27,000 & 22.91 \\
\hline 1920 & Dec. 12 & 62,000 & 36.40 & 1946 & Feb. 12 & 69,500 & 36.80 & 1972 & Jan. 12 & 32,300 & 26.69 \\
\hline 1921 & Feb. 12 & 59,500 & 35.90 & 1947 & Jan. 22 & 71,000 & 37.05 & 1973 & Mar. 18 & 31,200 & 25.85 \\
\hline 1922 & Jan. 24 & 50,600 & 33.90 & 1948 & Feb. 15 & 41,000 & 31.00 & 1974 & Apr. 05 & 37,000 & 28.89 \\
\hline 1923 & Dec. 19 & 37,800 & 29.70 & 1949 & Nov. 30 & 69,000 & 36.70 & 1975 & Mar. 15 & 31,200 & 25.86 \\
\hline 1924 & Apr. 20 & 31,900 & 26.60 & 1950 & Mar. 15 & 37,500 & 29.60 & 1976 & Apr. 01 & 37,700 & 29.64 \\
\hline 1925 & Jan. 20 & $44 ; 300$ & 32.10 & 1951 & Mar. 30 & 49,400 & 33.60 & 1977 & Apr. 06 & 55,700 & 33.79 \\
\hline 1926 & Jan. 19 & 28,500 & 24.00 & 1952 & Mar. 24 & 35,600 & 28.80 & 1978 & Jan. 27 & 31,500 & 26.05 \\
\hline 1927 & Dec. 30 & 31,900 & 26.60 & 1953 & Jan. 10 & 25,300 & 21.50 & 1979 & Mar. 05 & 60,500 & 35.00 \\
\hline 1928 & Dec. 17 & 23,700 & 20.20 & 1954 & Jan. 23 & 37,200 & 29.50 & 1980 & Mar. 22 & 44,400 & 30.97 \\
\hline 1929 & Mar. 16 & 43,000 & 30.70 & 1955 & Feb. 08 & 29,400 & 24.70 & 1981 & Feb. 12 & 22,000 & 20.29 \\
\hline 1930 & Mar. 09 & 44,200 & 30.94 & 1956 & Apr. 17 & 25,500 & 21.70 & 1982 & Feb. 04 & 46,500 & 31.57 \\
\hline 1931 & Nov. 17 & 30,000 & 24.90 & 1957 & Apr. 06 & 36,200 & 29.10 & 1983 & Apr. 09 & 32,400 & 26.80 \\
\hline 1932 & Feb. 04 & 33,700 & 27.80 & 1958 & Nov. 20 & $\underline{27,100}$ & 22.90 & 1984 & Dec. 07 & 33,000 & 26.99 \\
\hline 1933 & Dec. 30 & 70,500 & 37.00 & 1959 & Apr. 21 & 18,600 & 16.10 & 1985 & Feb. 06 & 26,000 & 22.55 \\
\hline 1934 & Mar. 06 & 42,800 & 31.60 & 1960 & Mar. 05 & 23,300 & 19.80 & 1986 & Feb. 19 & 11,300 & 15.60 \\
\hline 1935 & Mar. 14 & 27,800 & 23.50 & 1961 & Feb. 26 & 39,000 & 30.20 & 1987 & Mar. 01 & 33,600 & 27.45 \\
\hline 1936 & Apr. 08 & 70,000 & 36.90 & 1962 & Dec. 19 & 37,000 & 29.43 & 1988 & Jan. 21 & 25,600 & 22.32 \\
\hline 1937 & Jan. 04 & 60,500 & 34.90 & 1963 & May 01 & 34,600 & 28.33 & 1989 & Mar. 06 & 33,900 & 27.46 \\
\hline 1938 & Apr. 10 & 66,600 & 36.20 & 1964 & Mar. 27 & 49,500 & 31.98 & 1990 & Mar. 18 & 65,500 & 35.97 \\
\hline
\end{tabular}




\section{MOBILE RIVER BASIN}

\section{CEDAR CREEK AT CEDARTOWN, GEORGIA}

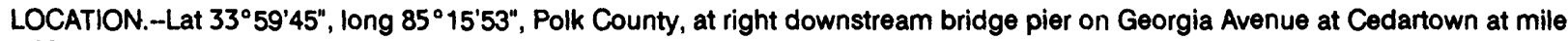
29.9.

DRAINAGE AREA.--66.9 $\mathrm{mi}^{2}$.

GAGE.-Water-stage recorder. Datum of gage is $758.88 \mathrm{ft}$ above sea level (levels by the Georgia Department of Transportation). July 1948 to Dec. 1959, water-stage recorder at same site and datum.

STAGE-DISCHARGE RELATION.--Defined by current-meter measurements below $6,700 \mathrm{ft}^{3} / \mathrm{s}$, and extended above on the basis of contracted opening and flow over the road computations.

HISTORICAL DATA.--The flood of 1979 is thought to be the highest since 1886, based on information from local residents.

REMARKS.--Records furnished by the U.S. Army Corps of Engineers from 1948 to 1958. Peak stages for 1974, 1975, and 1979 based on floodmarks.

\begin{tabular}{|c|c|c|c|c|c|c|c|c|c|c|c|}
\hline $\begin{array}{l}\text { Water } \\
\text { year }\end{array}$ & Date & $\begin{array}{c}\text { Discharge } \\
\left(\mathrm{ft}^{3} / \mathrm{s}\right)\end{array}$ & $\begin{array}{c}\text { Gage } \\
\text { height } \\
\text { (ft) }\end{array}$ & $\begin{array}{l}\text { Water } \\
\text { year }\end{array}$ & Date & $\begin{array}{c}\text { Discharge } \\
\left(\mathrm{ft}^{3} / \mathrm{s}\right)\end{array}$ & $\begin{array}{c}\text { Gage } \\
\text { height } \\
\text { (ft) }\end{array}$ & $\begin{array}{l}\text { Water } \\
\text { year }\end{array}$ & Date & $\begin{array}{c}\text { Discharge } \\
\left(\mathrm{ft}^{3} / \mathrm{s}\right)\end{array}$ & $\begin{array}{c}\text { Gage } \\
\text { height } \\
\text { (ft) }\end{array}$ \\
\hline 1949 & Nov. 28 & 11,000 & 18.80 & 1957 & Apr. 05 & 5,700 & 15.90 & 1984 & July 31 & 2,700 & 12.89 \\
\hline 1950 & Mar. 13 & 3,240 & 12.80 & 1958 & Nov. 17 & 2,700 & 11.60 & 1985 & Feb. 01 & 1,460 & 9.43 \\
\hline 1951 & Mar. 29 & 8,800 & 17.20 & $\overline{1974}$ & Apr. 04 & 12,700 & $19.55 \mathrm{c}$ & 1986 & Mar. 13 & 477 & 5.66 \\
\hline 1952 & Mar. 23 & 6,600 & 16.20 & $\overline{1975}$ & Sept.23 & 10,500 & $18.60 \mathrm{c}$ & 1987 & Feb. 28 & 3,230 & 13.88 \\
\hline 1953 & Jan. 19 & 2,850 & 12.00 & $\overline{1979}$ & Mar. 04 & 16,500 & $21.10 c$ & 1988 & Jan. 20 & 1,990 & 11.11 \\
\hline 1954 & Jan. 16 & 8,600 & 16.70 & 1980 & Mar. 20 & 7,800 & 17.50 & 1989 & Mar. 06 & 4,280 & 15.94 \\
\hline 1955 & Feb. 06 & 2,800 & 11.90 & $\overline{1982}$ & Feb. 03 & 5,080 & 16.43 & 1990 & Mar. 16 & 7,910 & 18.36 \\
\hline 1956 & Feb. 06 & 2,000 & 10.00 & 1983 & Apr. 08 & 2,610 & 13.01 & & & & \\
\hline
\end{tabular}

\section{CEDAR CREEK NEAR CEDARTOWN, GEORGIA}

LOCATION.--Lat $34^{\circ} 03^{\prime} 38^{\prime \prime}$, long $85^{\circ} 18^{\prime} 41^{\prime \prime}$, Polk County, on left bank $700 \mathrm{ft}$ downstream from bridge on State Highway $161,4.5 \mathrm{mi}$ upstream from Lake Creek, and 4.5 mi northwest of Cedartown.

DRAINAGE AREA.--115 $\mathrm{mi}^{2}$ (revised).

GAGE.--Water-stage recorder prior to Sept. 30, 1973; crest-stage gage thereafter. Datum of gage is $724.72 \mathrm{ft}$ above sea level (levels by the Georgia Department of Transportation).

STAGE-DISCHARGE RELATION.--Defined by current-meter measurements below $10,700 \mathrm{ft}^{3} / \mathrm{s}$, and abaove on the basis of straightline extension. Bankfull stage and discharge, $8 \mathrm{ft}$ and $3,000 \mathrm{ft}^{3} / \mathrm{s}$.

HISTORICAL DATA.--The flood of 1979 is thought to be the highest since 1886, based on information from local residents. REMARKS.--Peak stage of 1977 and 1979 based on floodmarks.

\begin{tabular}{|c|c|c|c|c|c|c|c|c|c|c|c|}
\hline $\begin{array}{l}\text { Water } \\
\text { year }\end{array}$ & Date & $\begin{array}{c}\text { Discharge } \\
\left(\mathrm{ft}^{3} / \mathrm{s}\right)\end{array}$ & $\begin{array}{c}\text { Gage } \\
\text { height } \\
\text { (ft) }\end{array}$ & $\begin{array}{l}\text { Water } \\
\text { year }\end{array}$ & Date & $\begin{array}{c}\text { Discharge } \\
\left(\mathrm{ft}^{3} / \mathrm{s}\right)\end{array}$ & $\begin{array}{c}\text { Gage } \\
\text { height } \\
\text { (ft) }\end{array}$ & $\begin{array}{l}\text { Water } \\
\text { year }\end{array}$ & Date & $\begin{array}{c}\text { Discharge } \\
\left(\mathrm{ft}^{3} / \mathrm{s}\right)\end{array}$ & $\begin{array}{c}\text { Gage } \\
\text { height } \\
\text { (ft) }\end{array}$ \\
\hline 1943 & Apr. 19 & 4,240 & 10.30 & 1955 & Feb. 07 & 4,170 & 9.90 & 1966 & Apr. 29 & 7,280 & 14.43 \\
\hline 1944 & Mar. 07 & 4,370 & 10.50 & 1956 & Mar. 16 & 3,340 & 8.80 & 1967 & Apr. 27 & 3,360 & 8.58 \\
\hline 1945 & Mar. 04 & 2,830 & 7.90 & 1957 & Apr. 05 & 6,500 & 13.50 & 1968 & Mar. 12 & 3,770 & $9.88 \mathrm{a}$ \\
\hline 1946 & Feb. 10 & 9,700 & 15.80 & 1958 & July 20 & 2,920 & 8.20 & 1969 & Apr. 15 & 2,220 & 6.98 \\
\hline 1947 & Jan. 20 & 7,060 & 14.20 & 1959 & May 31 & 4,170 & 9.90 & 1970 & Mar. 20 & 6,920 & 14.08 \\
\hline 1948 & Feb. 09 & 3,200 & 8.65 & 1960 & Jan. 31 & 1,720 & 6.60 & 1971 & Apr. 24 & 4,370 & 10.70 \\
\hline 1949 & Nov. 28 & 10,800 & 16.40 & 1961 & Feb. 21 & 8,400 & 16.20 & 1972 & Jan. 05 & 5,100 & 11.70 \\
\hline 1950 & Mar. 13 & 4,680 & 10.50 & 1962 & July 07 & 8,300 & 16.10 & 1973 & Mar. 17 & 5,700 & 11.76 \\
\hline 1951 & Mar. 29 & 7,300 & 14.54 & 1963 & Mar. 13 & 6,840 & 14.20 & $\underline{1974}$ & Apr. 06 & 10,800 & 16.40 \\
\hline 1952 & Mar. 23 & 6,420 & 13.40 & 1964 & Mar. 26 & 5,360 & 11.40 & 1977 & Mar. 30 & 9,970 & $15.98 \mathrm{c}$ \\
\hline 1953 & Jan. 09 & 3,200 & 8.60 & 1965 & June 08 & 2,560 & 6.92 & $\overline{1979}$ & Mar. 05 & 17,000 & $19.40 c$ \\
\hline 1954 & Jan. 16 & 6,180 & 13.10 & & & & & & & & \\
\hline
\end{tabular}


LOCATION.--Lat $34^{\circ} 42^{\prime} 17^{\prime \prime}$, long $85^{\circ} 19^{\prime} 40^{\prime \prime}$, Walker County, at culvert on county road, 2.5 mi west of Lafayette. DRAINAGE AREA. $-6.34 \mathrm{mi}^{2}$.

GAGE.--Flood-stage/rainfall recorder. Datum of gage is about $790 \mathrm{Ht}$ above sea level (from topographic map). STAGE-DISCHARGE RELATION.--Defined by current-meter measurements below $410 \mathrm{ft}^{3} / \mathrm{s}$, and extended above on basis of culvert computations.

\begin{tabular}{|c|c|c|c|c|c|c|c|c|c|c|c|}
\hline $\begin{array}{l}\text { Water } \\
\text { year }\end{array}$ & Date & $\begin{array}{c}\text { Discharge } \\
\left(\mathrm{ft}^{3} / \mathrm{s}\right)\end{array}$ & $\begin{array}{c}\text { Gage } \\
\text { height } \\
\text { (ft) }\end{array}$ & $\begin{array}{l}\text { Water } \\
\text { year }\end{array}$ & Date & $\begin{array}{c}\text { Discharge } \\
\left(\mathrm{ft}^{3} / \mathrm{s}\right)\end{array}$ & $\begin{array}{c}\text { Gage } \\
\text { height } \\
\text { (ft) }\end{array}$ & $\begin{array}{l}\text { Water } \\
\text { year }\end{array}$ & Date & $\begin{array}{c}\text { Discharge } \\
\left(\mathrm{ft}^{3} / \mathrm{s}\right)\end{array}$ & $\begin{array}{c}\text { Gage } \\
\text { height } \\
\text { (ft) }\end{array}$ \\
\hline 1965 & Mar. 26 & 812 & 6.93 & 1969 & Sept.05 & 885 & 7.22 & 1973 & Mar. 16 & 1,880 & 10.45 \\
\hline 1966 & Mar. 04 & 1,030 & 7.85 & 1970 & Dec. 30 & 557 & 5.76 & $\underline{1974}$ & Dec. 05 & 679 & 6.37 \\
\hline 1967 & Nov. 10 & 505 & 5.50 & 1971 & Feb. 05 & 633 & 6.14 & $\underline{1977}$ & Mar. 30 & 868 & $7.15 \mathrm{c}$ \\
\hline 1968 & Dec. 18 & 553 & 5.74 & 1972 & May 13 & 1,200 & 8.40 & 1990 & Feb. 16 & 2,040 & $10.86 c$ \\
\hline
\end{tabular}

\section{HARRISBURG CREEK NEAR HAWKINS, GEORGIA}

LOCATION.--Lat $34^{\circ} 36^{\prime} 02^{\prime \prime}$, long $85^{\circ} 23^{\prime} 21^{\prime \prime}$, Walker County, at bridge on county road no. $91,0.7$ mi west of Hawkins. DRAINAGE AREA. $-13.3 \mathrm{mi}^{2}$.

GAGE.--Water-stage recorder prior to Sept. 30, 1982, crest-stage gage thereafter. Datum of gage is about $730 \mathrm{ft}$ above sea level (from topographic map). Bankfull stage and discharge, $9 \mathrm{ft}$ and $2,100 \mathrm{ft}^{3} / \mathrm{s}$.

STAGE-DISCHARGE RELATION.--Defined by current-meter measurements below $470 \mathrm{ft}^{3} / \mathrm{s}$, and extended above on basis of slopearea computations.

\begin{tabular}{|c|c|c|c|c|c|c|c|c|c|c|c|}
\hline $\begin{array}{l}\text { Water } \\
\text { year }\end{array}$ & Date & $\begin{array}{c}\text { Discharge } \\
\left(\mathrm{ft}^{3} / \mathrm{s}\right)\end{array}$ & $\begin{array}{c}\text { Gage } \\
\text { height } \\
\text { (ft) }\end{array}$ & $\begin{array}{l}\text { Water } \\
\text { year }\end{array}$ & Date & $\begin{array}{c}\text { Discharge } \\
\left(\mathrm{ft}^{3} / \mathrm{s}\right)\end{array}$ & $\begin{array}{c}\text { Gage } \\
\text { height } \\
\text { (ft) }\end{array}$ & $\begin{array}{l}\text { Water } \\
\text { year }\end{array}$ & Date & $\begin{array}{c}\text { Discharge } \\
\left(\mathrm{ft}^{3} / \mathrm{s}\right)\end{array}$ & $\begin{array}{c}\text { Gage } \\
\text { height } \\
\text { (ft) }\end{array}$ \\
\hline 1980 & Mar. 21 & 1,740 & 8.89 & 1984 & July 31 & 1,110 & 7.85 & 1988 & Jan. 20 & 4,260 & 11.20 \\
\hline 1981 & Mar. 30 & 612 & 6.78 & 1985 & Jan. 31 & 1,110 & 7.85 & 1989 & Feb. 28 & 825 & 7.30 \\
\hline 1982 & Jan. 03 & 1,640 & 8.74 & 1986 & Feb. 18 & $6,6.0$ & 4.41 & 1990 & Feb. 16 & 5,530 & 12.00 \\
\hline 1983 & Nov. 30 & 3,570 & 10.74 & 1987 & Nov. 25 & 2,000 & 9.12 & & & & \\
\hline
\end{tabular}




\section{MOBILE RIVER BASIN}

\section{CHATTOOGA RIVER AT SUMMERVILLE, GEORGIA}

LOCATION.--Lat $34^{\circ} 28^{\prime} 03^{\prime \prime}$, long $85^{\circ} 20^{\prime} 19^{\prime \prime}$, Chattooga County, on left bank $600 \mathrm{ft}$ downstream from bridge on U.S. Highway 27,1 mi southeast of Summerville, and 4 mi upstream from Raccoon Creek. DRAINAGE AREA.-192 $\mathrm{mi}^{2}$ (revised).

GAGE.-Water-stage recorder. Datum of gage is $613.47 \mathrm{ft}$ above sea level (levels by the Georgia Department of Transportation). Prior to Nov. 12, 1937, nonrecording gage at same site and datum.

STAGE-DISCHARGE RELATION.--Defined by current-meter measurements below $24,300 \mathrm{ft}^{3} / \mathrm{s}$, and extended above on basis of straight-line extension. Bankfull stage and discharge, $13 \mathrm{ft}$ and $3,600 \mathrm{ft}^{3} / \mathrm{s}$.

REMARKS.--Peak stage of 1990 from floodmarks.

\begin{tabular}{|c|c|c|c|c|c|c|c|c|c|c|c|}
\hline $\begin{array}{l}\text { Water } \\
\text { year }\end{array}$ & Date & $\begin{array}{c}\text { Discharge } \\
\left(\mathrm{ft}^{3} / \mathrm{s}\right)\end{array}$ & $\begin{array}{c}\text { Gage } \\
\text { height } \\
\text { (ft) }\end{array}$ & $\begin{array}{l}\text { Water } \\
\text { year }\end{array}$ & Date & $\begin{array}{c}\text { Discharge } \\
\left(\mathrm{ft}^{3} / \mathrm{s}\right)\end{array}$ & $\begin{array}{c}\text { Gage } \\
\text { height } \\
\text { (ft) }\end{array}$ & $\begin{array}{l}\text { Water } \\
\text { year }\end{array}$ & Date & $\begin{array}{c}\text { Discharge } \\
\left(\mathrm{ft}^{3} / \mathrm{s}\right)\end{array}$ & $\begin{array}{c}\text { Gage } \\
\text { height } \\
\text { (ft) }\end{array}$ \\
\hline 1938 & Apr. 08 & 12,100 & 17.70 & 1956 & Feb. 17 & 6,500 & 15.60 & 1974 & Nov. 28 & 7,320 & 15.71 \\
\hline 1939 & Feb. 28 & 10,200 & 16.90 & 1957 & Feb. 01 & 7,540 & 16.10 & 1975 & Mar. 14 & 6,980 & 15.54 \\
\hline 1940 & Mar. 14 & 3,240 & 12.20 & 1958 & Nov. 18 & 13,900 & 18.40 & 1976 & July 05 & 6,300 & 15.20 \\
\hline 1941 & July 16 & 2,660 & 11.40 & 1959 & Jan. 22 & 3,290 & 13.00 & 1977 & Mar. 31 & 12,500 & 17.66 \\
\hline 1942 & Feb. 17 & 5,040 & 14.80 & 1960 & Mar. 03 & 3,190 & 12.80 & 1978 & Nov. 06 & 8,400 & 16.20 \\
\hline 1943 & Dec. 29 & 12,600 & 17.90 & 1961 & Feb. 23 & 8,220 & 16.40 & 1979 & Mar. 04 & 20,000 & 19.43 \\
\hline 1944 & Mar. 29 & 7,330 & 16.20 & 1962 & Dec. 18 & 9,460 & 16.90 & 1980 & Mar. 21 & 10,300 & 16.91 \\
\hline 1945 & Feb. 13 & 7,110 & 16.10 & 1963 & Apr. $\mathbf{3 0}$ & 11,700 & 17.40 & 1981 & Mar. 30 & 3,940 & 13.35 \\
\hline 1946 & Jan. 08 & 16,600 & 18.80 & 1964 & Mar. 15 & 11,700 & 17.40 & 1982 & Jan. 04 & 17,000 & 18.82 \\
\hline 1947 & Jan. 20 & 10,400 & 17.30 & 1965 & Mar. 27 & 9,070 & 16.47 & 1983 & Dec. 02 & 13,200 & 17.90 \\
\hline 1948 & Feb. 13 & 9,200 & 16.80 & 1966 & Mar. 04 & 20,400 & 19.50 & 1984 & May 03 & 7,500 & 15.67 \\
\hline 1949 & Nov. 28 & 22,700 & 20.60 & 1967 & Feb. 21 & 3,790 & 13.29 & 1985 & Feb. 02 & 5,060 & 14.14 \\
\hline 1950 & Sept.08 & 9,720 & 17.00 & 1968 & Dec. 19 & 7,440 & 15.77 & 1986 & Feb. 19 & 2,350 & 10.38 \\
\hline 1951 & Mar. 29 & 24,500 & 21.00 & 1969 & Feb. 03 & 7,220 & 15.66 & 1987 & Nov. 26 & 5,450 & 14.68 \\
\hline 1952 & Mar. 11 & 16,000 & 19.00 & 1970 & Dec. 31 & 4,730 & 14.57 & 1988 & Jan. 20 & 10,200 & 16.88 \\
\hline 1953 & Feb. 21 & 8,220 & 16.40 & 1971 & Feb. 05 & 5,230 & 14.64 & 1989 & July 04 & 6,730 & 15.39 \\
\hline 1954 & Jan. 16 & 10,300 & 17.20 & 1972 & May 14 & 11,700 & 17.48 & 1990 & Feb. 16 & 30,100 & 22.63 \\
\hline 1955 & Feb. 07 & 6,310 & 15.50 & 1973 & Mar. 17 & 18,600 & 19.15 & & & & \\
\hline
\end{tabular}

\section{MCCLENDON CREEK TRIBUTARY NEAR DALLAS, GEORGIA}

LOCATION.-Lat $33^{\circ} 50^{\prime} 58^{\prime \prime}$, long $84^{\circ} 51^{\prime} 20^{\prime \prime}$, Paulding County, at culvert on Georgia Highway 120, 9.3 mi southwest of Dallas. DRAINAGE AREA. $-0.88 \mathrm{mi}^{2}$.

GAGE.--Crest-stage gage. Datum of gage is about 1,200 ft above sea level (from topographic map).

STAGE-DISCHARGE RELATION.--Defined by current-meter measurements below $17.3 \mathrm{tt}^{3} / \mathrm{s}$, and extended above on basis of culvert computations.

\begin{tabular}{|c|c|c|c|c|c|c|c|c|c|c|c|}
\hline $\begin{array}{l}\text { Water } \\
\text { year }\end{array}$ & Date & $\begin{array}{c}\text { Discharge } \\
\left(\mathrm{ft}^{3} / \mathrm{s}\right)\end{array}$ & $\begin{array}{c}\text { Gage } \\
\text { height } \\
\text { (ft) }\end{array}$ & $\begin{array}{l}\text { Water } \\
\text { year }\end{array}$ & Date & $\begin{array}{c}\text { Discharge } \\
\left(\mathrm{ft}^{3} / \mathrm{s}\right)\end{array}$ & $\begin{array}{c}\text { Gage } \\
\text { height } \\
\text { (ft) }\end{array}$ & $\begin{array}{l}\text { Water } \\
\text { year }\end{array}$ & Date & $\begin{array}{c}\text { Discharge } \\
\left(\mathrm{ft}^{3} / \mathrm{s}\right)\end{array}$ & $\begin{array}{c}\text { Gage } \\
\text { height } \\
\text { (ft) }\end{array}$ \\
\hline 1977 & Mar. 30 & 302 & 4.27 & 1982 & Feb. 03 & 299 & 4.21 & 1987 & Feb. - & 22 & $-b$ \\
\hline 1978 & Nov. 05 & 416 & 5.27 & 1983 & Feb. 02 & 260 & 3.85 & 1988 & Jan. 20 & 189 & 3.18 \\
\hline 1979 & Mar. 04 & 295 & 4.20 & 1984 & Dec. 06 & 480 & 5.70 & 1989 & June 21 & 164 & 2.92 \\
\hline 1980 & Apr. 13 & 240 & 3.65 & 1985 & Feb. 01 & 154 & 2.79 & 1990 & Oct. 01 & 392 & 5.01 \\
\hline 1981 & May 27 & 860 & 8.23 & 1986 & Jan. - & 22 & $-b$ & & & & \\
\hline
\end{tabular}




\section{MOBILE RIVER BASIN}

\section{LITTLE RIVER NEAR BUCHANAN, GEORGIA}

LOCATION.-Lat $33^{\circ} 47^{\prime} 51^{\prime \prime}$, long $8^{\circ} 07^{\prime} 03^{\prime \prime}$, Haralson County, on right bank $150 \mathrm{ft}$ upstream from county highway bridge, $4.5 \mathrm{mi}$ east of Buchanan, and $7 \mathrm{mi}$ upstream from mouth.

DRAINAGE AREA.--20.2 $\mathrm{mi}^{2}$ (revised).

GAGE.-Water-stage recorder. Datum of gage is about $1,110 \mathrm{ft}$ above sea level (from topographic map).

STAGE-DISCHARGE RELATION.--Defined by current-meter measurements below $2,300 \mathrm{ft}^{3} / \mathrm{s}$, and extended above on basis of slope-area measurement at $3,710 \mathrm{ft}^{3} / \mathrm{s}$. Bankfull stage and discharge, $8 \mathrm{ft}$ and $1,500 \mathrm{ft}^{3} / \mathrm{s}$.

\begin{tabular}{|c|c|c|c|c|c|c|c|c|c|c|c|}
\hline $\begin{array}{l}\text { Water } \\
\text { year }\end{array}$ & Date & $\begin{array}{c}\text { Discharge } \\
\left(\mathrm{ft}^{3} / \mathrm{s}\right)\end{array}$ & $\begin{array}{c}\text { Gage } \\
\text { height } \\
\text { (ft) }\end{array}$ & $\begin{array}{l}\text { Water } \\
\text { year }\end{array}$ & Date & $\begin{array}{c}\text { Discharge } \\
\left(\mathrm{ft}^{3} / \mathrm{s}\right)\end{array}$ & $\begin{array}{c}\text { Gage } \\
\text { height } \\
\text { (ft) }\end{array}$ & $\begin{array}{l}\text { Water } \\
\text { year }\end{array}$ & Date & $\begin{array}{c}\text { Discharge } \\
\left(\mathrm{ft}^{3} / \mathrm{s}\right)\end{array}$ & $\begin{array}{c}\text { Gage } \\
\text { height } \\
\text { (ft) }\end{array}$ \\
\hline 1960 & Apr. 03 & 780 & 6.05 & 1969 & Jan. 20 & 518 & 3.68 & 1978 & Nov. 05 & 1,450 & 8.00 \\
\hline 1961 & Feb. 21 & 3,710 & 12.47 & 1970 & Mar. 20 & 3,080 & 11.69 & 1979 & Mar. 03 & 3,010 & 11.00 \\
\hline 1962 & Feb. 22 & 1,450 & 8.50 & 1971 & Mar. 03 & 1,080 & 6.15 & 1980 & May 23 & 916 & 4.73 \\
\hline 1963 & Mar. 12 & 2,700 & 11.50 & 1972 & May 14 & 1,290 & 7.18 & 1981 & May 26 & 1,050 & 5.38 \\
\hline 1964 & Jan. 25 & 3,480 & 12.20 & 1973 & Mar. 16 & 2,180 & 10.16 & 1982 & Feb. 03 & 1,870 & 8.56 \\
\hline 1965 & Apr. 05 & 1,140 & 6.69 & 1974 & Dec. 31 & 1,840 & 9.30 & 1983 & May 19 & 1,400 & 7.01 \\
\hline 1966 & Mar. 04 & 3,820 & 12.58 & 1975 & Mar. 13 & 981 & 5.70 & 1984 & Dec. 06 & 2,640 & 10.19 \\
\hline 1967 & Aug. 24 & 1,840 & 9.25 & 1976 & Mar. 16 & 1,420 & 7.83 & $\underline{1985}$ & Jan. 31 & 552 & 3.13 \\
\hline 1968 & Apr. 05 & 1,030 & 5.90 & 1977 & Mar. 29 & 3,190 & 11.91 & $\overline{1990}$ & Mar. 16 & 1,400 & $6.81 \mathrm{c}$ \\
\hline
\end{tabular}

\section{TALLAPOOSA RIVER AT TALLAPOOSA, GEORGIA}

LOCATION.-Lat 33 $46^{\prime} 27^{\prime \prime}$ long $85^{\circ} 18^{\prime} 00^{\prime \prime}$, Haralson County, at State Highway 100, 2 mi north of Tallapoosa.

DRAINAGE AREA,--236 $\mathrm{mi}^{2}$ (revised).

GAGE.-Crest-stage gage. Datum of gage is $935.06 \mathrm{ft}$ above sea level (levels by the Georgia Department of Transportation), supplementary adjustment of 1936.

STAGE-DISCHARGE RELATION.--Defined by current-meter measurements below $8,700 \mathrm{ft}^{3} / \mathrm{s}$, and extended above on basis of slope-area measurement and contracted-opening measurement at 20,000 and $29,500 \mathrm{ft}^{3} / \mathrm{s}$, respectively. Bankfull stage and discharge, $19 \mathrm{ft}$ and $6,000 \mathrm{ft}^{3} / \mathrm{s}$.

HISTORICAL DATA.--Peak stage for November 1948 obtained from floodmarks. The 1977 flood is thought to be the highest since 1919 , based on nearby gaging stations. Peak stage for February 1936 based on information from local resident.

\begin{tabular}{|c|c|c|c|c|c|c|c|c|c|c|c|}
\hline $\begin{array}{l}\text { Water } \\
\text { year }\end{array}$ & Date & $\begin{array}{c}\text { Discharge } \\
\left(\mathrm{ft}^{3} / \mathrm{s}\right)\end{array}$ & $\begin{array}{c}\text { Gage } \\
\text { height } \\
\text { (ft) }\end{array}$ & $\begin{array}{l}\text { Water } \\
\text { year }\end{array}$ & Date & $\begin{array}{c}\text { Discharge } \\
\left(\mathrm{ft}^{3} / \mathrm{s}\right)\end{array}$ & $\begin{array}{c}\text { Gage } \\
\text { height } \\
\text { (ft) }\end{array}$ & $\begin{array}{l}\text { Water } \\
\text { year }\end{array}$ & Date & $\begin{array}{c}\text { Discharge } \\
\left(\mathrm{ft}^{3} / \mathrm{s}\right)\end{array}$ & $\begin{array}{c}\text { Gage } \\
\text { height } \\
\text { (ft) }\end{array}$ \\
\hline$\underline{1936}$ & Feb. 02 & 10,400 & $24.10 c$ & 1960 & Apr. 03 & 2,340 & 10.36 & 1970 & Mar. 20 & 10,600 & 23.30 \\
\hline 1949 & Nov. 29 & 20,000 & $27.40 c$ & 1961 & Feb. 21 & 11,500 & 24.70 & 1971 & June 23 & 5,040 & 17.19 \\
\hline$\overline{1951}$ & Mar. -- & 3,080 & 12.50 & 1962 & Feb. 23 & 6,740 & 20.38 & 1972 & Jan. 10 & 7,100 & 20.10 \\
\hline 1952 & Mar. 23 & 8,120 & 22.37 & 1963 & Mar. 13 & 6,980 & 20.76 & 1973 & Mar. 16 & 6,010 & 19.12 \\
\hline 1953 & Jan. 10 & 5,660 & 18.10 & 1964 & Apr. 06 & 6,380 & 19.75 & 1974 & Dec. 31 & 7,820 & 22.02 \\
\hline 1954 & Jan. 16 & 6,440 & 19.93 & 1965 & Mar. 27 & 3,080 & 12.53 & 1975 & Mar. 14 & 5,490 & 18.08 \\
\hline 1955 & Feb. 23 & 3,390 & 13.43 & 1966 & Mar. 03 & 5,800 & 18.60 & 1976 & Mar. 16 & 8,010 & 22.27 \\
\hline 1956 & Mar. 16 & 7,560 & 21.66 & 1967 & Aug. 24 & 9,700 & 23.72 & $\underline{1977}$ & Mar. 31 & 29,500 & 29.30 \\
\hline 1957 & Apr. 05 & 6,860 & 20.60 & 1968 & May 16 & 4,530 & 16.16 & $\underline{1982}$ & Feb. 04 & 13,000 & $25.59 \mathrm{c}$ \\
\hline 1958 & Apr. -- & 2,860 & 11.93 & 1969 & May 19 & 3,080 & 12.54 & $\overline{1990}$ & Mar. 17 & 8,200 & $22.72 c$ \\
\hline 1959 & May 31 & 5,300 & 17.50 & & & & & & & & \\
\hline
\end{tabular}




\section{MOBILE RIVER BASIN}

\section{MANN CREEK TRIBUTARY NEAR TALLAPOOSA, GEORGIA}

LOCATION.--Lat $33^{\circ} 51^{\prime} 16^{\prime \prime}$, long $85^{\circ} 17^{\prime} 28^{\prime \prime}$, Haralson County, at culvert on State Highway 100, 8.5 mi north of Tallapoosa.

DRAINAGE AREA. $-0.12 \mathrm{mi}^{2}$.

GAGE.--Crest-stage gage. Datum of gage is about $1,120 \mathrm{ft}$ above sea level (from topographic map).

STAGE-DISCHARGE RELATION.--Defined by culvert computations.

\begin{tabular}{|c|c|c|c|c|c|c|c|c|c|c|c|}
\hline $\begin{array}{l}\text { Water } \\
\text { year }\end{array}$ & Date & $\begin{array}{c}\text { Discharge } \\
\left(\mathrm{ft}^{3} / \mathrm{s}\right)\end{array}$ & $\begin{array}{l}\text { Gage } \\
\text { height } \\
\text { (ft) }\end{array}$ & $\begin{array}{l}\text { Water } \\
\text { year }\end{array}$ & Date & $\begin{array}{c}\text { Discharge } \\
\left(\mathrm{ft}^{3} / \mathrm{s}\right)\end{array}$ & $\begin{array}{c}\text { Gage } \\
\text { height } \\
\text { (ft) }\end{array}$ & $\begin{array}{l}\text { Water } \\
\text { year }\end{array}$ & Date & $\begin{array}{c}\text { Discharge } \\
\left(\mathrm{ft}^{3} / \mathrm{s}\right)\end{array}$ & $\begin{array}{l}\text { Gage } \\
\text { height } \\
\text { (ft) }\end{array}$ \\
\hline 1977 & Apr. 03 & 101 & 5.33 & 1982 & Feb. 03 & 36.0 & 3.04 & 1987 & Feb. 28 & 31.0 & 2.83 \\
\hline 1978 & May 08 & 56 & 3.85 & 1983 & Apr. 08 & 41.0 & 3.25 & 1988 & Jan. 20 & 40.0 & 3.21 \\
\hline 1979 & Apr. 13 & 107 & 5.51 & 1984 & Apr. 20 & 38.0 & 3.10 & 1989 & Mar. 06 & 52.0 & 3.74 \\
\hline 1980 & Mar. 13 & 87 & 4.89 & 1985 & Dec. 03 & 41.0 & 3.27 & 1990 & Oct. 01 & 47.0 & 3.52 \\
\hline 1981 & Mar. 30 & 14 & 2.00 & 1986 & Apr. -- & 12.0 & $-\mathrm{b}$ & & & & \\
\hline
\end{tabular}

\section{LITTLE TALLAPOOSA RIVER AT CARROLLTON, GEORGIA}

LOCATION.--Lat $33^{\circ} 35^{\prime} 50^{\prime \prime}$, long $85^{\circ} 04^{\prime} 49^{\prime \prime}$, Carroll County, on left bank at city water-pumping plant, $200 \mathrm{ft}$ downstream from bridge on U.S. Highway 27 at Carrollton, 1 mi upstream from Central of Georgia Railway bridge, and 3.5 mi upstream from Buck Creek.

DRAINAGE AREA.--95.1 $\mathrm{mi}^{2}$ (revised).

GAGE.--Nonrecording gage. Datum of gage is $971.25 \mathrm{ft}$ above sea level (from the U.S. Coast and Geodetic Survey benchmark), supplementary adjustment of 1936.

STAGE-DISCHARGE RELATION.--Defined by current-meter measurements below $5,200 \mathrm{ft}^{3} / \mathrm{s}$, and above on basis of straight-line extension. Bankfull stage and discharge, $11 \mathrm{ft}$ and $1,800 \mathrm{ft}^{3} / \mathrm{s}$.

REMARKS.--Peak stage for February 1936 obtained from floodmarks.

\begin{tabular}{|c|c|c|c|c|c|c|c|c|c|c|c|}
\hline $\begin{array}{l}\text { Water } \\
\text { year }\end{array}$ & Date & $\begin{array}{c}\text { Discharge } \\
\left(\mathrm{ft}^{3} / \mathrm{s}\right)\end{array}$ & $\begin{array}{c}\text { Gage } \\
\text { height } \\
\text { (ft) }\end{array}$ & $\begin{array}{l}\text { Water } \\
\text { year }\end{array}$ & Date & $\begin{array}{c}\text { Discharge } \\
\left(\mathrm{ft}^{3} / \mathrm{s}\right)\end{array}$ & $\begin{array}{c}\text { Gage } \\
\text { height } \\
\text { (ft) }\end{array}$ & $\begin{array}{l}\text { Water } \\
\text { year }\end{array}$ & Date & $\begin{array}{c}\text { Discharge } \\
\left(\mathrm{ft}^{3} / \mathrm{s}\right)\end{array}$ & $\begin{array}{c}\text { Gage } \\
\text { height } \\
\text { (ft) }\end{array}$ \\
\hline$\underline{1936}$ & Feb. 01 & 5,450 & $18.20 c$ & 1947 & Jan. 20 & 4,080 & 15.90 & 1957 & Apr. 05 & 3,330 & 14.00 \\
\hline$\overline{1938}$ & Apr. 08 & 5,370 & 16.70 & 1948 & Feb. 09 & 1,930 & 11.20 & 1958 & Feb. 07 & 1,980 & 11.30 \\
\hline 1939 & Aug. 18 & 1,680 & 10.60 & 1949 & Nov. 29 & 6,010 & 19.30 & 1959 & June 01 & 3,130 & 13.60 \\
\hline 1940 & July 09 & 3,030 & 13.10 & 1950 & Sept.08 & 1,670 & 10.70 & 1960 & Jan. 31 & 2,330 & 12.00 \\
\hline 1941 & July 12 & 1,060 & 9.28 & 1951 & Mar. 30 & 980 & 9.30 & 1961 & Feb. 25 & 3,580 & 14.50 \\
\hline 1942 & Mar. 22 & 2,670 & 13.10 & 1952 & Dec. 21 & 3,980 & 15.30 & 1962 & Dec. 19 & 3,030 & 13.40 \\
\hline 1943 & Mar. 21 & 3,220 & 14.10 & 1953 & Jan. 09 & 2,830 & 13.00 & 1963 & Apr. 30 & 2,030 & 11.40 \\
\hline 1944 & Apr. 12 & 2,520 & 12.80 & 1954 & Jan. 17 & 1,620 & 10.60 & 1964 & Apr. 07 & 2,430 & 12.20 \\
\hline 1945 & July 14 & 3,380 & 14.70 & 1955 & Feb. 08 & 1,510 & 10.50 & 1965 & Dec. 26 & 1,780 & 10.90 \\
\hline 1946 & Jan. 07 & 3,220 & 14.40 & 1956 & Mar. 16 & 3,630 & 14.60 & & & & \\
\hline
\end{tabular}




\section{LITTLE TALLAPOOSA RIVER NEAR BOWDON, GEORGIA}

LOCATION.--Lat 33 $33^{\prime} 46^{\prime \prime}$ long $85^{\circ} 14^{\prime} 03^{\prime \prime}$, Carroll County, at State Highway 5, 2.2 mi southeast of Bowdon.

DRAINAGE AREA.--220 $\mathrm{mi}^{2}$ (revised).

GAGE.--Crest-stage gage. Prior to December 10,1954, at site $200 \mathrm{ft}$ downstream at same datum. Datum of gage is $914.79 \mathrm{ft}$ above sea level (from U.S. Geological Survey benchmark).

STAGE-DISCHARGE RELATION.--Defined by current-meter measurements below $7,160 \mathrm{tt}^{3} / \mathrm{s}$, and above on basis of straight-line extension. Bankfull stage and discharge, $14 \mathrm{ft}$ and $3,000 \mathrm{ft}^{3} / \mathrm{s}$.

HISTORICAL DATA.--Peak of November 1948 is thought to be the highest since 1936, based on information at nearby stations.

\begin{tabular}{|c|c|c|c|c|c|c|c|c|c|c|c|}
\hline $\begin{array}{l}\text { Water } \\
\text { year }\end{array}$ & Date & $\begin{array}{c}\text { Discharge } \\
\left(\mathrm{ft}^{3} / \mathrm{s}\right)\end{array}$ & $\begin{array}{c}\text { Gage } \\
\text { height } \\
\text { (ft) }\end{array}$ & $\begin{array}{l}\text { Water } \\
\text { year }\end{array}$ & Date & $\begin{array}{c}\text { Discharge } \\
\left(\mathrm{ft}^{3} / \mathrm{s}\right)\end{array}$ & $\begin{array}{c}\text { Gage } \\
\text { height } \\
\text { (ft) }\end{array}$ & $\begin{array}{l}\text { Water } \\
\text { year }\end{array}$ & Date & $\begin{array}{c}\text { Discharge } \\
\left(\mathrm{ft}^{3} / \mathrm{s}\right)\end{array}$ & $\begin{array}{c}\text { Gage } \\
\text { height } \\
\text { (ft) }\end{array}$ \\
\hline 1949 & Nov. 29 & 9,500 & 22.50 & 1960 & Jan. 31 & 3,160 & 13.90 & 1970 & Mar. 20 & 6,280 & 19.10 \\
\hline 1950 & Sept.09 & 1,440 & 8.88 & 1961 & Feb. 26 & 5,260 & 17.80 & 1971 & Mar. 30 & 4,740 & 17.05 \\
\hline 1951 & June 05 & 1,870 & 10.30 & 1962 & Dec. 20 & 4,580 & 16.84 & 1972 & Jan. 10 & 5,900 & 18.62 \\
\hline 1952 & Dec. 22 & 4,520 & 16.70 & 1963 & Apr. 30 & 5,400 & 18.00 & 1973 & Mar. 16 & 3,190 & 14.18 \\
\hline 1953 & Jan. 10 & 3,280 & 14.20 & 1964 & Apr. 06 & 4,100 & 16.04 & 1974 & Dec. 31 & 5,320 & 17.89 \\
\hline 1954 & $\underline{\text { Jan. } 16}$ & $\underline{1,200}$ & 8.08 & 1965 & Dec. 26 & 2,260 & 11.86 & 1975 & Mar. 14 & 6,100 & 18.88 \\
\hline 1955 & Mar. -- & 1,680 & 9.72 & 1966 & Feb. 13 & 3,020 & 13.81 & 1976 & Mar. 16 & 7,000 & 20.00 \\
\hline 1956 & Mar. 16 & 5,800 & 18.50 & 1967 & Nov. 10 & 2,940 & 13.60 & $\underline{1977}$ & Mar. 31 & 4,510 & 16.68 \\
\hline 1957 & Apr. 05 & 4,580 & 16.80 & 1968 & May 16 & 5,560 & 18.20 & $\underline{1982}$ & Feb. 04 & 7,300 & $20.00 \mathrm{c}$ \\
\hline 1958 & July 20 & 2,800 & 13.00 & 1969 & May 09 & 3,950 & 15.72 & 1990 & Mar. 17 & 7,400 & $20.30 \mathrm{c}$ \\
\hline 1959 & May 31 & 4,000 & 15.80 & & & & & & & & \\
\hline
\end{tabular}

\section{TENNESSEE RIVER BASIN}

\section{BRIER CREEK NEAR HIAWASSEE, GEORGIA}

LOCATION.--Lat $34^{\circ} 50^{\prime} 05^{\prime \prime}$, long $83^{\circ} 42^{\prime} 34^{\prime \prime}$, Towns County, on left bank 0.3 mi upstream from Corbin Creek, 8.2 mi southeast of Hiawassee.

DRAINAGE AREA.--1.67 $\mathrm{mi}^{2}$ (revised).

GAGE.--Water-stage recorder. Datum of gage is $2,141.43 \mathrm{ft}$ above sea level (levels by Global Positioning System).

STAGE-DISCHARGE RELATION.--Defined by current-meter measurements below $40 \mathrm{ft}^{3} / \mathrm{s}$, and above on basis of slope-area measurement at $413 \mathrm{ft}^{3} / \mathrm{s}$.

\begin{tabular}{|c|c|c|c|c|c|c|c|c|c|c|c|}
\hline $\begin{array}{l}\text { Water } \\
\text { year }\end{array}$ & Date & $\begin{array}{c}\text { Discharge } \\
\left(\mathrm{ft}^{3} / \mathrm{s}\right)\end{array}$ & $\begin{array}{c}\text { Gage } \\
\text { height } \\
\text { (ft) }\end{array}$ & $\begin{array}{l}\text { Water } \\
\text { year }\end{array}$ & Date & $\begin{array}{c}\text { Discharge } \\
\left(\mathrm{ft}^{3} / \mathrm{s}\right)\end{array}$ & $\begin{array}{c}\text { Gage } \\
\text { height } \\
\text { (ft) }\end{array}$ & $\begin{array}{l}\text { Water } \\
\text { year }\end{array}$ & Date & $\begin{array}{c}\text { Discharge } \\
\left(\mathrm{ft}^{3} / \mathrm{s}\right)\end{array}$ & $\begin{array}{c}\text { Gage } \\
\text { height } \\
\text { (ft) }\end{array}$ \\
\hline 1984 & June 21 & 64.0 & 2.72 & 1987 & Nov. 26 & 185 & 3.19 & 1989 & June 20 & 72.0 & 2.77 \\
\hline 1985 & Aug. 17 & 35.0 & 2.40 & 1988 & Jan. 20 & 86.0 & 2.84 & 1990 & Mar. 17 & 414 & 3.64 \\
\hline 1986 & Nov. 01 & 75.0 & 2.77 & & & & & & & & \\
\hline
\end{tabular}


LOCATION.--Lat $34^{\circ} 54^{\prime} 17^{\prime \prime}$, long $83^{\circ} 43^{\prime} 01^{\prime \prime}$, Towns County, on left bank 0.1 mi downstream from Cynth Creek, 0.5 mi southeast of Presley, 1.4 mi upstream from Hightower Creek, and at mile 133.9.

DRAINAGE AREA.--45.5 $\mathrm{mi}^{2}$.

GAGE.--Water-stage recorder. Datum of gage is $1,932.69 \mathrm{ft}$ above sea level (levels from the Tennessee Valley Authority), supplementary adjustment of 1936.

STAGE-DISCHARGE RELATION.--Defined by current-meter measurements below $4,160 \mathrm{ft}^{3} / \mathrm{s}$, and above on basis of slope-area and contracted-opening measurements at 3,660 and $5,700 \mathrm{ft}^{3} / \mathrm{s}$, respectively. Bankfull stage and discharge, $7 \mathrm{ft}$ and $1,800 \mathrm{ft} / 3$. REMARKS.--Peaks after 1983 furnished by the Tennessee Valley Authority.

\begin{tabular}{|c|c|c|c|c|c|c|c|c|c|c|c|}
\hline $\begin{array}{l}\text { Water } \\
\text { year }\end{array}$ & Date & $\begin{array}{c}\text { Discharge } \\
\left(\mathrm{ft}^{3} / \mathrm{s}\right)\end{array}$ & $\begin{array}{c}\text { Gage } \\
\text { height } \\
\text { (ft) }\end{array}$ & $\begin{array}{l}\text { Water } \\
\text { year }\end{array}$ & Date & $\begin{array}{c}\text { Discharge } \\
\left(\mathrm{ft}^{3} / \mathrm{s}\right)\end{array}$ & $\begin{array}{c}\text { Gage } \\
\text { height } \\
\text { (ft) }\end{array}$ & $\begin{array}{l}\text { Water } \\
\text { year }\end{array}$ & Date & $\begin{array}{c}\text { Discharge } \\
\left(\mathrm{ft}^{3} / \mathrm{s}\right)\end{array}$ & $\begin{array}{c}\text { Gage } \\
\text { height } \\
\text { (ft) }\end{array}$ \\
\hline 1942 & Feb. 16 & 1,330 & 6.85 & 1959 & May 31 & 3,020 & 10.82 & 1975 & Mar. 13 & 1,560 & 6.42 \\
\hline 1943 & Dec. 29 & 2,600 & 10.17 & 1960 & Apr. 03 & 978 & 5.36 & 1976 & May 15 & 3,360 & 10.91 \\
\hline 1944 & Mar. 29 & 1,170 & 6.30 & 1961 & Feb. 25 & 3,970 & 12.41 & 1977 & Mar. 12 & 2,890 & 9.97 \\
\hline 1945 & Sept. 14 & 750 & 5.42 & 1962 & Dec. 12 & 2,700 & 10.23 & 1978 & Nov. 06 & 2,620 & 8.27 \\
\hline 1946 & Feb. 10 & 2,040 & 9.70 & 1963 & Mar. 12 & 2,110 & 8.84 & 1979 & Mar. 04 & 4,620 & 11.52 \\
\hline 1947 & Jan. 20 & 1,510 & 7.85 & 1964 & Mar. 26 & 1,540 & 7.19 & 1980 & Mar. 21 & 1,800 & 6.69 \\
\hline 1948 & Feb. 14 & 1,020 & 6.22 & 1965 & Oct. 04 & 4,110 & 12.63 & 1981 & May 27 & 1,190 & 5.35 \\
\hline 1949 & June 16 & 3,660 & 12.80 & 1966 & Feb. 13 & 4,620 & 13.38 & 1982 & Feb. 03 & 1,620 & 6.40 \\
\hline 1950 & Mar. 13 & 2,540 & 10.44 & 1967 & Aug. 23 & 3,760 & 12.10 & 1983 & Feb. 02 & 3,990 & 10.55 \\
\hline 1951 & Dec. 07 & 1,310 & 7.10 & 1968 & Mar. 12 & 2,380 & 9.53 & 1984 & Mar. 20 & 1,320 & 5.68 \\
\hline 1952 & Mar. 11 & 5,700 & 15.24 & 1969 & Jan. 20 & 1,480 & 5.94 & 1985 & Feb. 01 & 420 & 3.20 \\
\hline 1953 & Feb. 21 & 2,720 & 10.74 & 1970 & Dec. 30 & 1,630 & 6.36 & 1986 & Nov. 01 & 864 & 4.47 \\
\hline 1954 & Jan. 16 & 1,960 & 9.00 & 1971 & July $\mathbf{3 0}$ & 1,090 & 4.69 & 1987 & Nov. 26 & 1,550 & 6.09 \\
\hline 1955 & Feb. 06 & 1,220 & 6.78 & 1972 & Dec. 07 & 1,650 & 6.42 & 1988 & Jan. 20 & 886 & 4.53 \\
\hline 1956 & Apr. 15 & 1,900 & 8.82 & 1973 & May 28 & 5,080 & 13.96 & 1989 & June 20 & 1,010 & 4.86 \\
\hline 1957 & Apr. 05 & 2,040 & 8.64 & 1974 & Dec. 26 & 2,390 & 8.72 & 1990 & Feb. 16 & 2,100 & 9.78 \\
\hline 1958 & Dec. 20 & 1,310 & 6.47 & & & & & & & & \\
\hline
\end{tabular}




\section{NOTTELY RIVER NEAR BLAIRSVILLE, GEORGIA}

LOCATION.--Lat $34^{\circ} 50^{\prime} 28^{\prime \prime}$, long $83^{\circ} 56^{\prime} 10^{\prime \prime}$, Union County, on left bank $250 \mathrm{ft}$ upstream from county road bridge, 0.1 mi downstream from Arkaqua Creek, 0.2 mi upstream from Akins Creek, 2.7 mi southeast of Blairsville, and at mile 44.3. DRAINAGE AREA. $--74.8 \mathrm{mi}^{2}$.

GAGE.--Water-stage recorder. Datum of gage is $1,812.47 \mathrm{ft}$ above sea level (levels from the Tennessee Valley Authority), supplementary adjustment of 1936.

STAGE-DISCHARGE RELATION.--Defined by current-meter measurements below $3,400 \mathrm{tt}^{3} / \mathrm{s}$, and above on basis of contractedopening measurements at $4,950,8,500$, and $12,900 \mathrm{ft}^{3} / \mathrm{s}$. Bankfull stage and discharge, $11 \mathrm{ft}$ and $3,900 \mathrm{ft}^{3} / \mathrm{s}$. HISTORICAL DATA.--Peak of August 1967 was the highest since 1907, based on nearby gaging stations. REMARKS.--Peaks after 1983 furnished by the Tennessee Valley Authority.

\begin{tabular}{|c|c|c|c|c|c|c|c|c|c|c|c|}
\hline $\begin{array}{l}\text { Water } \\
\text { year }\end{array}$ & Date & $\begin{array}{c}\text { Discharge } \\
\left(\mathrm{ft}^{3} / \mathrm{s}\right)\end{array}$ & $\begin{array}{c}\text { Gage } \\
\text { height } \\
\text { (ft) }\end{array}$ & $\begin{array}{l}\text { Water } \\
\text { year }\end{array}$ & Date & $\begin{array}{c}\text { Discharge } \\
\left(\mathrm{ft}^{3} / \mathrm{s}\right)\end{array}$ & $\begin{array}{l}\text { Gage } \\
\text { height } \\
\text { (ft) }\end{array}$ & $\begin{array}{l}\text { Water } \\
\text { year }\end{array}$ & Date & $\begin{array}{c}\text { Discharge } \\
\left(\mathrm{ft}^{3} / \mathrm{s}\right)\end{array}$ & $\begin{array}{c}\text { Gage } \\
\text { height } \\
\text { (ft) }\end{array}$ \\
\hline 1943 & Dec. 29 & 2,860 & 8.85 & 1959 & Jan. 21 & 3,850 & 10.66 & 1975 & Mar. 13 & 2,200 & 7.18 \\
\hline 1944 & Mar. 29 & 1,840 & 6.10 & 1960 & Feb. 10 & 2,120 & 7.15 & 1976 & May 15 & 6,080 & 14.26 \\
\hline 1945 & Sept.16 & 1,040 & 4.82 & 1961 & Feb. 25 & 4,950 & 13.29 & 1977 & Mar. 30 & 5,260 & 12.93 \\
\hline 1946 & Feb. 10 & 4,160 & 11.18 & 1962 & Dec. 12 & 4,300 & 12.05 & 1978 & Jan. 25 & 3,300 & 9.00 \\
\hline 1947 & Jan. 20 & 3,100 & 9.17 & 1963 & Apr. 30 & 3,300 & 9.88 & 1979 & Mar. 04 & 6,770 & 15.13 \\
\hline 1948 & Feb. 12 & 1,980 & 6.88 & 1964 & Mar. 26 & 3,100 & 9.43 & 1980 & Mar. 21 & 3,740 & 9.89 \\
\hline 1949 & Jan. 05 & 2,900 & 8.86 & 1965 & Oct. 04 & 7,950 & 16.28 & 1981 & May 27 & 3,210 & 8.82 \\
\hline 1950 & Mar. 13 & 4,320 & 11.43 & 1966 & Feb. 13 & 5,640 & 14.22 & 1982 & Feb. 03 & 3,500 & 9.40 \\
\hline 1951 & Mar. 29 & 2,140 & 7.27 & 1967 & Aug. 23 & 12,900 & 21.04 & 1983 & Feb. 02 & 4,460 & 11.33 \\
\hline 1952 & Mar. 11 & 8,500 & 16.78 & 1968 & Mar. 12 & 3,060 & 9.10 & 1984 & Mar. 20 & 2,120 & 6.65 \\
\hline 1953 & Feb. 21 & 3,460 & 10.00 & 1969 & June 15 & 3,890 & 10.97 & 1985 & Feb. 01 & 1,020 & 4.60 \\
\hline 1954 & Jan. 16 & 4,080 & 11.05 & 1970 & Dec. 30 & 2,940 & 8.83 & 1986 & Mar. 13 & 1,230 & 4.95 \\
\hline 1955 & May 22 & 4,430 & 11.59 & 1971 & July 31 & 2,860 & 8.64 & 1987 & Nov. 26 & 2,300 & 6.92 \\
\hline 1956 & Apr. 15 & 4,530 & 11.75 & 1972 & Dec. 07 & 2,180 & 7.14 & 1988 & Jan. 20 & 2,100 & 6.63 \\
\hline 1957 & Apr. 05 & 3,630 & 10.30 & 1973 & May 28 & 7,230 & 16.04 & 1989 & June 20 & 1,940 & 6.30 \\
\hline 1958 & Dec. 20 & 2,310 & 7.66 & 1974 & Dec. 05 & 3,780 & 10.71 & 1990 & Feb. 16 & 4,600 & 11.84 \\
\hline
\end{tabular}

\section{NOTTELY RIVER NEAR IMLOG, GEORGIA}

LOCATION.-Lat $34^{\circ} 57^{\prime} 55^{\prime \prime}$, long $84^{\circ} 05^{\prime} 25^{\prime \prime}$, Union County, on right bank 1,600 ft downstream from Rhodes Branch, $0.6 \mathrm{mi}$ downstream from Nottely Dam, $0.6 \mathrm{mi}$ upstream from Dooley Creek, $1.8 \mathrm{mi}$ northwest of $\mathrm{kylog}$, and at mile 20.4 . DRAINAGE AREA.--215 $\mathrm{mi}^{2}$.

GAGE.--Water-stage recorder. Datum of gage is 1,599.21 ft above sea level (levels from the Tennessee Valley Authority), supplementary adjustment of 1936.

STAGE-DISCHARGE RELATION.--Defined by current-meter measurements below $2,000 \mathrm{ft}^{3} / \mathrm{s}$, and extended above on the basis of flow over dam computation at 5,240 and $8,110 \mathrm{ft}^{3} / \mathrm{s}$. Bankfull stage and discharge, $10 \mathrm{ft}$ and $6,400 \mathrm{ft}^{3} / \mathrm{s}$.

REMARKS.-Peaks discharges are regulated by Nottely Lake (maximum flood-control storage, 162,000 acre-ft) since January 1942.

\begin{tabular}{|c|c|c|c|c|c|c|c|c|c|c|c|}
\hline $\begin{array}{l}\text { Water } \\
\text { year }\end{array}$ & Date & $\begin{array}{c}\text { Discharge } \\
\left(\mathrm{ft}^{3} / \mathrm{s}\right)\end{array}$ & $\begin{array}{c}\text { Gage } \\
\text { height } \\
\text { (ft) }\end{array}$ & $\begin{array}{l}\text { Water } \\
\text { year }\end{array}$ & Date & $\begin{array}{c}\text { Discharge } \\
\left(\mathrm{ft}^{3} / \mathrm{s}\right)\end{array}$ & $\begin{array}{c}\text { Gage } \\
\text { height } \\
\text { (ft) }\end{array}$ & $\begin{array}{l}\text { Water } \\
\text { year }\end{array}$ & Date & $\begin{array}{c}\text { Discharge } \\
\left(\mathrm{ft}^{3} / \mathrm{s}\right)\end{array}$ & $\begin{array}{c}\text { Gage } \\
\text { heigh } \\
\text { (ft) }\end{array}$ \\
\hline 1942 & Sept.28 & 2,420 & 5.79 & 1954 & May 05 & 2,290 & 5.58 & 1965 & July 24 & 1,960 & 5.11 \\
\hline 1943 & Oct. 01 & 2,270 & 5.56 & 1955 & May 23 & 3,130 & 6.54 & 1966 & Dec. 21 & 1,840 & 4.94 \\
\hline 1944 & May 25 & 2,830 & 6.34 & 1956 & Aug. 14 & 1,800 & 4.91 & 1967 & Oct. 13 & 1,820 & 4.95 \\
\hline 1945 & Sept.25 & 2,370 & 5.56 & 1957 & Mar. 29 & 2,070 & 5.28 & 1968 & Dec. 17 & 1,960 & 5.12 \\
\hline 1946 & Feb. 11 & 2,580 & 5.86 & 1958 & Jan. 03 & 1,990 & 5.20 & 1969 & Jan. 09 & 2,490 & 5.79 \\
\hline 1947 & Apr. 18 & 1,810 & 4.98 & 1959 & Mar. 25 & 1,830 & 5.00 & 1970 & July 30 & 2,000 & 5.18 \\
\hline 1948 & June 03 & 2,490 & 5.82 & 1960 & Feb. 04 & 1,870 & 5.05 & 1971 & Mar. 24 & 1,820 & 4.95 \\
\hline 1949 & Sept.12 & 2,600 & 5.95 & 1961 & Sept.27 & 1,840 & 4.94 & 1972 & Jan. 12 & 1,990 & 5.16 \\
\hline 1950 & Feb. 14 & 2,490 & 5.82 & 1962 & Dec. 24 & 1,960 & 5.11 & 1973 & May 28 & 8,110 & 11.63 \\
\hline 1951 & Jan. 08 & 2,290 & 5.58 & 1963 & Feb. 22 & 1,850 & 4.96 & 1974 & Nov. 17 & 2,000 & 5.17 \\
\hline 1952 & May 12 & 1,530 & 4.57 & 1964 & May 03 & 3,240 & 6.63 & 1975 & Feb. 25 & 1,960 & 5.13 \\
\hline 1953 & Aug. 19 & 1,800 & 4.95 & & & & & & & & \\
\hline
\end{tabular}


LOCATION.--Lat $34^{\circ} 47^{\prime} 24^{\prime \prime}$, long $84^{\circ} 14^{\prime} 24^{\prime \prime}$, Fannin County, on right bank 1.4 mi upstream from Shallowford Bridge, $1.8 \mathrm{mi}$ upstream from Stanley Creek, 2.5 mi northwest of Dial, and at mile 69.1.

DRAINAGE AREA.--177 $\mathrm{mi}^{2}$.

GAGE.--Water-stage recorder. Datum of gage is 1,782.08 ft above sea level (levels from the Tennessee Valley Authority), supplementary adjustment of 1936 . Prior to Oct. 1, 1927, water-stage recorder; and Oct. 1, 1927 to Nov. 16, 1928, nonrecording gage at same site and datum.

STAGE-DISCHARGE RELATION.--Defined by current-meter measurements below $5,660 \mathrm{tt}^{3} / \mathrm{s}$, and extended above on the basis of slope-area and contracted-opening mesurements at 10,800 and $14,700 \mathrm{tt}^{3} / \mathrm{s}$, respectively. Bankfull stage and discharge, $8 \mathrm{ft}$ and $6,000 \mathrm{ft}^{3} / \mathrm{s}$.

HISTORICAL DATA.--Peak stage of 1907 was highest since 1840, based on information from the Tennessee Valley Authority.

REMARKS.--Peaks discharges listed for 1913-15 and 1917-19 are maximum daily.

\begin{tabular}{|c|c|c|c|c|c|c|c|c|c|c|c|}
\hline $\begin{array}{l}\text { Water } \\
\text { year }\end{array}$ & Date & $\begin{array}{c}\text { Discharge } \\
\left(\mathrm{ft}^{3} / \mathrm{s}\right)\end{array}$ & $\begin{array}{c}\text { Gage } \\
\text { height } \\
\text { (ft) }\end{array}$ & $\begin{array}{l}\text { Water } \\
\text { year }\end{array}$ & Date & $\begin{array}{c}\text { Discharge } \\
\left(\mathrm{ft}^{3} / \mathrm{s}\right)\end{array}$ & $\begin{array}{c}\text { Gage } \\
\text { height } \\
\text { (ft) }\end{array}$ & $\begin{array}{l}\text { Water } \\
\text { year }\end{array}$ & Date & $\begin{array}{c}\text { Discharge } \\
\left(\mathrm{ft}^{3} / \mathrm{s}\right)\end{array}$ & $\begin{array}{c}\text { Gage } \\
\text { height } \\
\text { (ft) }\end{array}$ \\
\hline 1907 & Nov. - & 28,000 & $18.50 \mathrm{c}$ & 1939 & Feb. 03 & 3,240 & 5.60 & 1965 & Oct. 04 & 10,100 & 10.78 \\
\hline$\overline{1913}$ & Mar. 14 & 5,140 & 6.60 & 1940 & Aug. 13 & 2,940 & 5.34 & 1966 & Feb. 13 & 6,830 & 8.63 \\
\hline 1914 & Apr. 14 & 1,260 & 3.05 & 1941 & July 05 & 4,330 & 6.59 & 1967 & Aug. 23 & 14,700 & 13.73 \\
\hline 1915 & Dec. 25 & 2,680 & 4.60 & 1942 & Feb. 17 & 3,880 & 6.22 & 1968 & Mar. 12 & 2,590 & 5.10 \\
\hline 1916 & July 08 & 9,200 & 10.00 & 1943 & Dec. 29 & 4,810 & 6.97 & 1969 & Feb. 02 & 3,720 & 6.22 \\
\hline 1917 & Mar. 04 & 4,700 & 6.47 & 1944 & Feb. 27 & 3,040 & 5.43 & 1970 & Dec. 31 & 3,230 & 5.76 \\
\hline 1918 & Jan. 28 & 1,880 & 3.85 & 1945 & Sept.16 & 1,610 & 3.80 & 1971 & July 31 & 2,440 & 4.93 \\
\hline 1919 & Dec. 22 & 6,080 & 7.60 & 1946 & Feb. 10 & 7,490 & 9.13 & 1972 & Dec. 07 & 3,290 & 5.82 \\
\hline 1920 & Apr. 02 & 5,560 & 7.20 & 1947 & Jan. 20 & 6,160 & 8.08 & 1973 & May 28 & 8,720 & 9.95 \\
\hline 1921 & Feb. 10 & 8,220 & 9.25 & 1948 & Feb. 12 & 4,020 & 6.33 & 1974 & Dec. 31 & 4,760 & 7.07 \\
\hline 1922 & Jan. 21 & 6,600 & 8.00 & 1949 & Aug. 17 & 6,230 & 8.13 & 1975 & Mar. 14 & 3,110 & 5.54 \\
\hline 1923 & Dec. 17 & 3,160 & 5.50 & 1950 & Mar. 13 & 6,380 & 8.25 & 1976 & May 15 & 7,100 & 8.82 \\
\hline 1924 & Mar. 05 & 3,660 & 6.00 & 1951 & Mar. 29 & 7,410 & 9.04 & 1977 & Mar. 30 & 8,400 & 9.73 \\
\hline 1925 & Dec. 31 & 2,450 & 4.45 & 1952 & Mar. 11 & 10,800 & 11.20 & 1978 & Jan. 26 & 3,970 & 6.42 \\
\hline 1926 & Jan. 18 & 2,400 & 4.42 & 1953 & Feb. 21 & 4,850 & 7.03 & 1979 & Mar. 04 & 10,400 & 11.19 \\
\hline 1927 & Dec. 28 & 3,060 & 5.40 & 1954 & Jan. 16 & 7,840 & 9.35 & 1980 & Mar. 21 & 5,960 & 8.05 \\
\hline 1928 & Mar. 30 & 1,980 & 4.05 & 1955 & Mar. 22 & 5,170 & 7.30 & 1981 & May 27 & 2,980 & 5.38 \\
\hline 1929 & Sept. 25 & 4,810 & 7.03 & 1956 & Apr. 16 & 4,650 & 6.87 & 1982 & Feb. 03 & 5,630 & 7.73 \\
\hline 1930 & Nov. 15 & 3,260 & 5.60 & 1957 & Apr. 05 & 5,490 & 7.56 & 1983 & Feb. 02 & 4,560 & 6.93 \\
\hline 1931 & Apr. 04 & 2,400 & 4.57 & 1958 & Dec. 20 & 3,190 & 5.55 & 1984 & May 08 & 4,050 & 6.46 \\
\hline 1932 & Dec. 14 & 6,060 & 8.05 & 1959 & Jan. 21 & 3,530 & 5.88 & 1985 & Feb. 01 & 2,260 & 4.56 \\
\hline 1933 & Dec. 28 & 6,190 & 8.10 & 1960 & July 27 & 3,100 & 5.46 & 1986 & Mar. 13 & 1,230 & 3.30 \\
\hline 1934 & Mar. 03 & 4,810 & 7.05 & 1961 & Feb. 25 & 7,360 & 9.00 & 1987 & Nov. 26 & 3,770 & 6.20 \\
\hline 1935 & Mar. 12 & 1,900 & 4.05 & 1962 & Dec. 12 & 7,270 & 8.94 & 1988 & Jan. 20 & 4,080 & 6.49 \\
\hline 1936 & Apr. 02 & 8,140 & 9.60 & 1963 & Apr. 30 & 5,810 & 7.88 & 1989 & June 20 & 5,800 & 7.96 \\
\hline 1937 & Jan. 03 & 3,340 & 5.66 & 1964 & Mar. 26 & 6,370 & 8.30 & 1990 & Feb. 16 & 8,790 & 10.13 \\
\hline 1938 & Apr. 08 & 6,450 & 8.28 & & & & & & & & \\
\hline
\end{tabular}




\section{TENNESSEE RIVER BASIN}

\section{TOCCOA RIVER NEAR BLUE RIDGE, GEORGIA}

LOCATION.-Lat $34^{\circ} 53^{\prime} 14^{\prime \prime}$, long $84^{\circ} 17^{\prime} 07^{\prime \prime}$, Fannin County, on left bank 0.4 mi downstream from Blue Ridge Dam of Tennessee Valley Authority, 2.2 mi west of Morganton, 2.5 mi northeast of Blue Ridge, and at mile 52.5 .

DRAINAGE AREA.--233 $\mathrm{mi}^{2}$.

GAGE.-Water-stage recorder. Datum of gage is 1,538.77 $\mathrm{ft}$ above sea level (levels from the Tennessee Valley Authority).

Nonrecording gage at site $1.1 \mathrm{mi}$ upstream prior to 1914 and at site $150 \mathrm{ft}$ downstream from previous gage, 1914 to April 17, 1926, at datum $5.60 \mathrm{ft}$ higher; at site $800 \mathrm{ft}$ upstream from present gage at datum $0.44 \mathrm{ft}$ higher April 18, 1926, to April 1, 1931. STAGE-DISCHARGE RELATION.--Defined by current-meter measurements below $5,000 \mathrm{ft}^{3} / \mathrm{s}$, and extended above on the basis of flow over dam computation at $10,300 \mathrm{t}^{3} / \mathrm{s}$. Bankfull stage and discharge, $10 \mathrm{ft}$ and $5,800 \mathrm{ft}^{3} / \mathrm{s}$.

HISTORICAL DATA.--Peak of 1907 was highest since 1840, based on information from the Tennessee Valley Authority. REMARKS.--Peaks discharges are regulated by storage in Blue Ridge Lake (maximum flood-control storage, 184,000 acre-ft) since Dec. 6, 1930. Discharge listed for 1901-02, 1915, 1918-20 are maximum daily. Peak discharge for 1907 is estimated.

\begin{tabular}{|c|c|c|c|c|c|c|c|c|c|c|c|}
\hline $\begin{array}{l}\text { Water } \\
\text { year }\end{array}$ & Date & $\begin{array}{c}\text { Discharge } \\
\left(\mathrm{ft}^{3} / \mathrm{s}\right)\end{array}$ & $\begin{array}{c}\text { Gage } \\
\text { height } \\
\text { (ft) }\end{array}$ & $\begin{array}{l}\text { Water } \\
\text { year }\end{array}$ & Date & $\begin{array}{c}\text { Discharge } \\
\left(\mathrm{ft}^{3} / \mathrm{s}\right)\end{array}$ & $\begin{array}{c}\text { Gage } \\
\text { height } \\
\text { (ft) }\end{array}$ & $\begin{array}{l}\text { Water } \\
\text { year }\end{array}$ & Date & $\begin{array}{c}\text { Discharge } \\
\left(\mathrm{ft}^{3} / \mathrm{s}\right)\end{array}$ & $\begin{array}{c}\text { Gage } \\
\text { height } \\
\text { (ft) }\end{array}$ \\
\hline 1901 & Aug. 22 & 15,500 & 14.00 & 1933 & Dec. 28 & 3,400 & 7.40 & 1954 & June 04 & 1,900 & 5.14 \\
\hline 1902 & Dec. 14 & 12,300 & 12.00 & 1934 & June 26 & 1,810 & 5.14 & 1955 & July 20 & 1,870 & 5.10 \\
\hline$\underline{1907}$ & Nov. 18 & 34,000 & $-c$ & 1935 & Oct. 22 & 1,600 & 4.72 & 1956 & June 25 & 1,970 & 5.25 \\
\hline$\overline{1914}$ & Apr. 14 & $\underline{2,330}$ & $\underline{5.40}$ & 1936 & Apr. 06 & 3,900 & 8.04 & 1957 & Apr. 24 & 2,010 & 5.32 \\
\hline 1915 & Dec. 04 & 2,990 & $\overline{6.22}$ & 1937 & Apr. 29 & 2,100 & 5.50 & 1958 & May 12 & 1,900 & 5.14 \\
\hline 1916 & July 09 & 13,900 & 13.00 & 1938 & July 23 & 4,880 & 9.31 & 1959 & Oct. 03 & 1,730 & 4.89 \\
\hline 1917 & Mar. 04 & 9,410 & 10.20 & 1939 & Mar. 04 & 1,700 & 5.04 & 1960 & May 26 & 1,900 & 5.14 \\
\hline 1918 & Jan. 28 & 2,220 & 5.30 & 1940 & Sept.26 & 1,820 & 5.16 & 1961 & Apr. 18 & 2,170 & 5.56 \\
\hline 1919 & Dec. 22 & 6,370 & 8.30 & 1941 & Oct. 12 & 1,760 & 5.09 & 1962 & Apr. 11 & 2,220 & 5.64 \\
\hline 1920 & Apr. 02 & 12,100 & 11.90 & 1942 & Sept.01 & 1,940 & 5.40 & 1963 & July 20 & 2,030 & 5.35 \\
\hline 1921 & Feb. 10 & 11,800 & 11.70 & 1943 & Jan. 18 & 2,140 & 5.69 & 1964 & Mar. 26 & 3,740 & 7.77 \\
\hline 1922 & Jan. 21 & 9,730 & 10.40 & 1944 & May 25 & 2,020 & 5.37 & 1965 & Oct. 12 & 2,780 & 6.55 \\
\hline 1923 & Dec. 17 & 6,850 & 8.60 & 1945 & Oct. 02 & 1,800 & 5.07 & 1966 & May 28 & 2,000 & 5.42 \\
\hline 1924 & Mar. 05 & 6,370 & 8.30 & 1946 & Feb. 12 & 5,160 & 9.41 & 1967 & Aug. 27 & 3,610 & 7.61 \\
\hline 1925 & Dec. 31 & 1,930 & 5.00 & 1947 & June 17 & 1,840 & 5.12 & 1968 & Dec. 18 & 1,960 & 5.36 \\
\hline 1926 & Jan. 18 & $\underline{3,070}$ & $\underline{6.20}$ & 1948 & Apr. 20 & 1,830 & 5.04 & 1969 & June 27 & 1,810 & 5.14 \\
\hline 1927 & Dec. 28 & 4,570 & 8.46 & 1949 & Sept.06 & 2,030 & 5.35 & 1970 & May 24 & 1,810 & 5.12 \\
\hline 1928 & Mar. 30 & 4,380 & 8.81 & 1950 & Mar. 13 & 8,140 & 11.40 & 1971 & Aug. 02 & 1,960 & 5.35 \\
\hline 1929 & May 07 & 5,060 & 9.71 & 1951 & June 13 & 2,030 & 5.34 & 1972 & Apr. 11 & 1,970 & 5.37 \\
\hline 1930 & Nov. 15 & $\underline{3,330}$ & $\underline{7.40}$ & 1952 & Mar. 23 & 4,520 & 8.65 & 1973 & May 28 & 10,300 & 13.61 \\
\hline 1931 & June 18 & 2,080 & 5.40 & 1953 & May 25 & 1,970 & 5.29 & 1974 & Apr. 04 & 1,970 & 5.37 \\
\hline 1932 & July 05 & 2,600 & 6.30 & & & & & & & & \\
\hline
\end{tabular}




\section{TENNESSEE RIVER BASIN}

\section{OCOEE RIVER AT COPPER HILL, TENNESSEE}

LOCATION.--Lat 34 $59^{\prime} 29^{\prime \prime}$, long $84^{\circ} 22^{\prime} 36^{\prime \prime}$, Polk County, on right bank 0.2 mi upstream from Fightingtown Creek, and 4 mi downstream from Copper Hill, Tenn.

DRAINAGE AREA.--352 $\mathrm{mi}^{2}$

GAGE.--Nonrecording gage prior to Oct. 31, 1942; recording thereafter. At site 0.4 mi upstream at datum $0.72 \mathrm{ft}$ higher Mar. 21 , 1903, to Dec. 31, 1913. At site one-eighth mi downstream at datum $0.58 \mathrm{ft}$ lower Nov. 12, 1914, to Aug. 27, 1925. Datum of gage is $1,445.28 \mathrm{ft}$ above sea level.

STAGE-DISCHARGE RELATION.--Defined by current-meter measurements below $8,000 \mathrm{ft}^{3} / \mathrm{s}$. The peak discharge for the 1990 flood is based on backwater studies.

HISTORICAL DATA.--Flood of Nov. 19, 1906, is highest since about 1840 , based on reports by the Tennessee Valley Authority.

REMARKS.--Peaks discharges are regulated by storage in Blue Ridge Lake (maximum flood-control storage, 184,000 acre-ft) since Dec. 6, 1930. Peak discharge for 1886, 1898-99, 1936, and 1938 furnished by the Tennessee Valley Authority; adjusted to the present site and datum. Peak discharges for 1904-05 and 1912-14 are maximum daily. Peak discharges for 1907 and 1909 are estimated. Peak discharge for 1990 furnished by the Tennessee Valley Authority.

\begin{tabular}{|c|c|c|c|c|c|c|c|c|c|c|c|}
\hline $\begin{array}{l}\text { Water } \\
\text { year }\end{array}$ & Date & $\begin{array}{c}\text { Discharge } \\
\left(\mathrm{ft}^{3} / \mathrm{s}\right)\end{array}$ & $\begin{array}{c}\text { Gage } \\
\text { height } \\
\text { (ft) }\end{array}$ & $\begin{array}{l}\text { Water } \\
\text { year }\end{array}$ & Date & $\begin{array}{c}\text { Discharge } \\
\left(\mathrm{ft}^{3} / \mathrm{s}\right)\end{array}$ & $\begin{array}{l}\text { Gage } \\
\text { height } \\
\text { (ft) }\end{array}$ & $\begin{array}{l}\text { Water } \\
\text { year }\end{array}$ & Date & $\begin{array}{c}\text { Discharge } \\
\left(\mathrm{ft}^{3} / \mathrm{s}\right)\end{array}$ & $\begin{array}{c}\text { Gage } \\
\text { height } \\
\text { (ft) }\end{array}$ \\
\hline$\underline{1886}$ & Mar. -- & 18,000 & $12.00 \mathrm{c}$ & 1924 & Mar. 05 & - & 5.80 & 1955 & Feb. 06 & 4,900 & 5.61 \\
\hline 1898 & Sept.00 & 30,000 & $16.00 c$ & $\underline{1925}$ & Dec. 08 & $=$ & $\underline{4.20}$ & 1956 & Apr. 16 & 6,080 & 6.19 \\
\hline 1899 & Mar. 19 & 10,000 & $9.00 c$ & 1928 & Mar. 30 & $8,50 \overline{0}$ & $\overline{8.00 c}$ & 1957 & Feb. 01 & 5,480 & 6.29 \\
\hline$\overline{1904}$ & Mar. 23 & 2,330 & 3.60 & $\overline{1936}$ & Feb. 04 & 9,000 & $8.50 c$ & 1958 & Apr. 29 & 6,350 & 6.49 \\
\hline 1905 & Jan. 12 & 5,710 & 6.40 & 1938 & Mar. 23 & 10,000 & $9.00 c$ & 1959 & Aug. 19 & 3,260 & 4.63 \\
\hline 1906 & Jan. 23 & 6,580 & 6.90 & $\overline{1943}$ & Jan. 18 & 4,570 & 5.54 & 1960 & July 10 & 3,460 & 4.73 \\
\hline 1907 & Nov. 19 & 35,000 & 18.50 & 1944 & Mar. 29 & 2,720 & 4.46 & 1961 & Feb. 25 & 4,260 & 5.35 \\
\hline 1908 & Feb. 15 & 6,950 & 7.10 & 1945 & Feb. 17 & 2,580 & 4.20 & 1962 & Dec. 18 & 5,380 & 6.16 \\
\hline 1909 & Mar. 13 & 15,000 & 12.50 & 1946 & Feb. 10 & 12,100 & 9.00 & 1963 & Mar. 12 & 7,880 & 7.44 \\
\hline 1910 & May 21 & 3,510 & 4.80 & 1947 & Jan. 20 & 6,620 & 7.03 & 1964 & Mar. 26 & 6,250 & 6.64 \\
\hline$\overline{1912}$ & Mar. 29 & 8,100 & 7.70 & 1948 & Feb. 12 & 2,810 & 4.40 & 1965 & Oct. 04 & 11,900 & 9.42 \\
\hline$\underline{1913}$ & Mar. 14 & $\underline{8,700}$ & $\underline{8.00}$ & 1949 & Nov. 28 & 7,200 & 7.23 & 1966 & Mar. 04 & 4,120 & 5.06 \\
\hline$\overline{1916}$ & July 10 & $\overline{12,500}$ & $\overline{10.00}$ & 1950 & Mar. 13 & 10,800 & 7.94 & 1967 & Aug. 27 & 5,000 & 5.50 \\
\hline 1917 & Mar. 04 & 11,500 & 9.50 & 1951 & Mar. 29 & 10,500 & 9.83 & 1968 & Dec. 18 & 4,620 & 5.31 \\
\hline$\overline{1920}$ & Apr. 02 & 15,500 & 11.10 & 1952 & Mar. 23 & 6,120 & 6.05 & 1969 & Feb. 02 & 4,380 & 5.19 \\
\hline 1921 & Dec. 14 & - & 6.58 & 1953 & July 22 & 2,420 & 3.97 & $\underline{1970}$ & June 05 & 4,400 & 5.20 \\
\hline 1922 & Jan. 21 & - & 7.90 & 1954 & Jan. 16 & 6,100 & 6.36 & $\overline{1990}$ & Feb. 16 & 33,500 & $17.75 \mathrm{c}$ \\
\hline 1923 & Dec. 17 & - & 6.00 & & & & & & & & \\
\hline
\end{tabular}




\section{TENNESSEE RIVER BASIN}

\section{FIGHTINGTOWN CREEK AT MCCAYSVILLE, GEORGIA}

LOCATION.-Lat $34^{\circ} 58^{\prime} 53^{\prime \prime}$, long $84^{\circ} 23^{\prime} 12^{\prime \prime}$, Fannin County, on right bank 0.2 mi upstream from highway bridge, 0.9 mi upstream from mouth, and 0.9 mi west of McCaysville.

DRAINAGE AREA.-70.9 $\mathrm{mi}^{2}$.

GAGE.--Water-stage recorder. Datum of gage is $1,449.75 \mathrm{ft}$ above sea level (levels from the Tennessee Valley Authority), supplementary adjustment of 1936.

STAGE-DISCHARGE RELATION.--Defined by current-meter measurements below $5,400 \mathrm{tt}^{3} / \mathrm{s}$, and extended above on the basis of slope-area measurement at $12,200 \mathrm{ft}^{3} / \mathrm{s}$. Bankfull stage and discharge, $9 \mathrm{ft}$ and $3,200 \mathrm{ft}^{3} / \mathrm{s}$.

\begin{tabular}{|c|c|c|c|c|c|c|c|c|c|c|c|}
\hline $\begin{array}{l}\text { Water } \\
\text { year }\end{array}$ & Date & $\begin{array}{c}\text { Discharge } \\
\left(\mathrm{ft}^{3} / \mathrm{s}\right)\end{array}$ & $\begin{array}{c}\text { Gage } \\
\text { height } \\
\text { (ft) }\end{array}$ & $\begin{array}{l}\text { Water } \\
\text { year }\end{array}$ & Date & $\begin{array}{c}\text { Discharge } \\
\left(\mathrm{ft}^{3} / \mathrm{s}\right)\end{array}$ & $\begin{array}{c}\text { Gage } \\
\text { height } \\
\text { (ft) }\end{array}$ & $\begin{array}{l}\text { Water } \\
\text { year }\end{array}$ & Date & $\begin{array}{c}\text { Discharge } \\
\left(\mathrm{ft}^{3} / \mathrm{s}\right)\end{array}$ & $\begin{array}{l}\text { Gage } \\
\text { height } \\
\text { (ft) }\end{array}$ \\
\hline 1943 & Dec. 29 & 1,590 & 6.24 & 1954 & Jan. 16 & 3,380 & 9.25 & 1965 & Oct. 04 & 3,490 & 9.42 \\
\hline 1944 & Mar. 29 & 1,890 & 7.04 & 1955 & Feb. 05 & 2,600 & 8.12 & 1966 & Feb. 13 & 1,950 & 6.48 \\
\hline 1945 & Feb. 13 & 1,630 & 6.28 & 1956 & Apr. 16 & 3,150 & 8.93 & 1967 & July 07 & 1,500 & 5.48 \\
\hline 1946 & Feb. 10 & 5,180 & 11.25 & 1957 & Feb. 01 & 3,800 & 9.85 & 1968 & Nov. 01 & 1,770 & 6.08 \\
\hline 1947 & Jan. 20 & 5,280 & 11.32 & 1958 & Apr. 28 & 2,690 & 8.27 & 1969 & Feb. 02 & 2,340 & 7.36 \\
\hline 1948 & Feb. 12 & 1,690 & 6.28 & 1959 & Jan. 21 & 1,520 & 5.72 & 1970 & Dec. 31 & 2,320 & 7.31 \\
\hline 1949 & Nov. 28 & 5,140 & 11.17 & 1960 & Nov. 28 & 1,330 & 5.18 & 1971 & July $\mathbf{3 0}$ & 1,380 & 5.22 \\
\hline 1950 & Oct. 30 & 2,900 & 8.56 & 1961 & June 21 & 2,260 & 7.17 & 1972 & May 14 & 1,810 & 6.16 \\
\hline 1951 & Mar. 29 & 5,420 & 11.92 & 1962 & Dec. 12 & 3,000 & 8.68 & $\underline{1973}$ & May 28 & 1,680 & 5.90 \\
\hline 1952 & Mar. 11 & 2,380 & 7.75 & 1963 & Mar. 12 & 4,090 & 10.26 & $\overline{1990}$ & Feb. 16 & 12,200 & $17.30 \mathrm{c}$ \\
\hline 1953 & Feb. 21 & 1,940 & 6.86 & 1964 & Mar. 15 & 2,580 & 7.90 & & & & \\
\hline
\end{tabular}

\section{SUGAR CREEK NEAR RINGGOLD, GEORGIA}

LOCATION.--Lat $34^{\circ} 58^{\prime} 14^{\prime \prime}$ long $85^{\circ} 01^{\prime 2} 29^{\prime \prime}$, Catoosa Coūnty, at culvert on Kieth Road, 6 mi northeast of Ringgold. DRAINAGE AREA.-4.44 $\mathrm{mi}^{2}$.

GAGE.--Flood-stage/rainfall recorder. Datum of gage is about $840 \mathrm{ft}$ above sea level (from topographic map).

STAGE-DISCHARGE RELATION.--Defined by current-meter measurements below $626 \mathrm{ft}^{3} / \mathrm{s}$, and extended above on basis of culvert and flow over the road computations to $2,620 \mathrm{ft}^{3} / \mathrm{s}$.

HISTORICAL DATA.--Peak of March 1973 is thought to be the highest since 1951, based on records at nearby stations.

REMARKS.--Flood stage for 1990 from floodmarks.

\begin{tabular}{lccccccccccc}
\hline $\begin{array}{l}\text { Water } \\
\text { year }\end{array}$ & Date & $\begin{array}{c}\text { Discharge } \\
\left(\mathrm{ft}^{3} / \mathrm{s}\right)\end{array}$ & $\begin{array}{c}\text { Gage } \\
\text { height } \\
(\mathrm{ft})\end{array}$ & $\begin{array}{c}\text { Water } \\
\text { year }\end{array}$ & Date & $\begin{array}{c}\text { Discharge } \\
\left(\mathrm{ft}^{3} / \mathrm{s}\right)\end{array}$ & $\begin{array}{c}\text { Gage } \\
\text { height } \\
(\mathrm{ft})\end{array}$ & $\begin{array}{c}\text { Water } \\
\text { year }\end{array}$ & $\begin{array}{c}\text { Gage } \\
\text { Date }\end{array}$ & $\begin{array}{c}\text { Discharge } \\
\left(\mathrm{ft}^{3} / \mathrm{s}\right)\end{array}$ & $\begin{array}{c}\text { height } \\
(\mathrm{ft})\end{array}$ \\
\hline & & & & & & & & & & & \\
1966 & Mar. 04 & 410 & 4.42 & 1970 & Apr. 02 & 593 & 5.10 & 1973 & Mar. 16 & 2,620 & 7.77 \\
1967 & July 07 & 305 & 3.89 & 1971 & Feb. 05 & 523 & 4.86 & $\underline{1974}$ & Dec. 31 & 520 & 4.85 \\
1968 & Dec. 18 & 674 & 5.36 & 1972 & May 13 & 578 & 5.05 & 1990 & Feb. 16 & 605 & $5.14 c$ \\
1969 & Feb. 02 & 484 & 4.72 & & & & & & & & \\
\hline
\end{tabular}




\section{LITTLE CHICKAMAUGA CREEK NEAR RINGOLD, GEORGIA}

LOCATION.-Lat $34^{\circ} 50^{\prime} 32^{\prime \prime}$, long $85^{\circ} 08^{\prime} 28^{\prime \prime}$, Catoosa County, at State Highway 151, 5.2 mi south of Ringgold.

DRAINAGE AREA. $-35.5 \mathrm{mi}^{2}$.

GAGE.--Crest-stage gage prior to Dec. 14, 1967; flood-stage recorder thereafter. Datum of gage is about $775 \mathrm{ft}$ above sea level (from topographic map).

STAGE-DISCHARGE RELATION.--Defined by current-meter measurements below $7,000 \mathrm{ft}^{3} / \mathrm{s}$. Bankfull stage and discharge, $7 \mathrm{ft}$ and $1,300 \mathrm{ft}^{3} / \mathrm{s}$.

HISTORICAL DATA.--Peak of March 1973 is thought to be the highest since 1867, based on records from the Tennessee Valley

Authority for this area.

\begin{tabular}{|c|c|c|c|c|c|c|c|c|c|c|c|}
\hline $\begin{array}{l}\text { Water } \\
\text { year }\end{array}$ & Date & $\begin{array}{c}\text { Discharge } \\
\left(\mathrm{ft}^{3} / \mathrm{s}\right)\end{array}$ & $\begin{array}{c}\text { Gage } \\
\text { height } \\
\text { (ft) }\end{array}$ & $\begin{array}{c}\text { Water } \\
\text { year }\end{array}$ & Date & $\begin{array}{c}\text { Discharge } \\
\left(\mathrm{ft}^{3} / \mathrm{s}\right)\end{array}$ & $\begin{array}{l}\text { Gage } \\
\text { height } \\
\text { (ft) }\end{array}$ & $\begin{array}{l}\text { Water } \\
\text { year }\end{array}$ & Date & $\begin{array}{c}\text { Discharge } \\
\left(\mathrm{ft}^{3} / \mathrm{s}\right)\end{array}$ & $\begin{array}{c}\text { Gage } \\
\text { height } \\
\text { (ft) }\end{array}$ \\
\hline 1964 & Mar. 23 & 4,200 & 9.09 & 1968 & Dec. 18 & 1,630 & 7.46 & 1972 & May 14 & 1,550 & 7.41 \\
\hline 1965 & Mar. 26 & 2,940 & 8.40 & 1969 & Feb. 02 & 1,800 & 7.56 & 1973 & Mar. 16 & 7,120 & 10.19 \\
\hline 1966 & Mar. 04 & 3,120 & 8.52 & 1970 & Apr. 02 & 800 & 6.65 & 1974 & Nov. 28 & 3,180 & 8.56 \\
\hline 1967 & July 07 & 1,300 & 7.24 & 1971 & Feb. 05 & 725 & 6.51 & 1975 & Mar. 14 & 978 & 6.91 \\
\hline
\end{tabular}

\section{LITTLE CHICKAMAUGA CREEK TRIBUTARY NEAR RINGOLD, GEORGIA}

LOCATION.--Lat $34^{\circ} 51^{\prime} 36^{\prime \prime}$, long $85^{\circ} 08^{\prime} 40^{\prime \prime}$. Catoosa County, at culvert on State Highway 151, 4.2 mi south of Ringgold. DRAINAGE AREA.-3.6 $\mathrm{mi}^{2}$.

GAGE.--Flood-stage/rainfall recorder. Datum of gage is about $790 \mathrm{ft}$ above sea level (from topographic map).

STAGE-DISCHARGE RELATION.--Defined by current-meter measurements below $590 \mathrm{ft}^{3} / \mathrm{s}$, and extended above on basis of culvert computations.

HISTORICAL DATA.-Peak of March 1973 is thought to be the highest since 1951, based on records at nearby stations.

REMARKS.--Flood stage of 1990 based on floodmarks.

\begin{tabular}{|c|c|c|c|c|c|c|c|c|c|c|c|}
\hline $\begin{array}{l}\text { Water } \\
\text { year }\end{array}$ & Date & $\begin{array}{c}\text { Discharge } \\
\left(\mathrm{ft}^{3} / \mathrm{s}\right)\end{array}$ & $\begin{array}{l}\text { Gage } \\
\text { height } \\
\text { (ft) }\end{array}$ & $\begin{array}{l}\text { Water } \\
\text { year }\end{array}$ & Date & $\begin{array}{c}\text { Discharge } \\
\left(\mathrm{ft}^{3} / \mathrm{s}\right)\end{array}$ & $\begin{array}{l}\text { Gage } \\
\text { height } \\
\text { (ft) }\end{array}$ & $\begin{array}{l}\text { Water } \\
\text { year }\end{array}$ & Date & $\begin{array}{c}\text { Discharge } \\
\left(\mathrm{ft}^{3} / \mathrm{s}\right)\end{array}$ & $\begin{array}{c}\text { Gage } \\
\text { height } \\
\text { (ft) }\end{array}$ \\
\hline 1965 & Mar. 26 & 487 & 3.82 & 1969 & Feb. 02 & 353 & 3.41 & 1973 & Mar. 16 & 1,970 & 9.13 \\
\hline 1966 & Mar. 03 & 195 & 2.88 & 1970 & Apr. 02 & 242 & 3.04 & $\underline{1974}$ & Dec. 31 & 293 & 3.21 \\
\hline 1967 & July 06 & 221 & 2.97 & 1971 & June 29 & 592 & 4.12 & $\overline{1990}$ & Feb. 16 & 886 & $4.96 \mathrm{c}$ \\
\hline 1968 & Dec. 22 & 281 & 3.17 & 1972 & May 13 & 398 & 3.56 & & & & \\
\hline
\end{tabular}


LOCATION.--Lat $34^{\circ} 55^{\prime} 07^{\prime \prime}$, long $85^{\circ} 07^{\prime} 32^{\prime \prime}$, Catoosa County, at State Highway 3 , at Ringgold.

DRAINAGE AREA.--169 $\mathrm{mi}^{2}$.

GAGE.--Crest-stage gage. Datum of gage is $739.50 \mathrm{ft}$ above sea level (levels by the Georgia Department of Transportation).

STAGE-DISCHARGE RELATION.--Defined by current-meter measurements below $10,500 \mathrm{ft}^{3} / \mathrm{s}$, and extended above on basis of contracted-opening measurement at $33,400 \mathrm{ft}^{3} / \mathrm{s}$. Bankfull stage and discharge, $16 \mathrm{ft}$ and $8,000 \mathrm{ft}^{3} / \mathrm{s}$.

HISTORICAL DATA.--Peak of March 1973 is thought to be the highest since 1867, based on records furnished by the Tennessee Valley Authority.

REMARKS.--Flood stage of 1990 based on floodmarks.

\begin{tabular}{|c|c|c|c|c|c|c|c|c|c|c|c|}
\hline $\begin{array}{l}\text { Water } \\
\text { year }\end{array}$ & Date & $\begin{array}{c}\text { Discharge } \\
\left(\mathrm{ft}^{3} / \mathrm{s}\right)\end{array}$ & $\begin{array}{c}\text { Gage } \\
\text { height } \\
\text { (ft) }\end{array}$ & $\begin{array}{l}\text { Water } \\
\text { year }\end{array}$ & Date & $\begin{array}{c}\text { Discharge } \\
\left(\mathrm{ft}^{3} / \mathrm{s}\right)\end{array}$ & $\begin{array}{c}\text { Gage } \\
\text { height } \\
\text { (ft) }\end{array}$ & $\begin{array}{l}\text { Water } \\
\text { year }\end{array}$ & Date & $\begin{array}{c}\text { Discharge } \\
\left(\mathrm{ft}^{3} / \mathrm{s}\right)\end{array}$ & $\begin{array}{l}\text { Gage } \\
\text { height } \\
\text { (ft) }\end{array}$ \\
\hline 1949 & Nov. 29 & 18,300 & 24.50 & 1956 & Feb. 03 & 3,680 & 10.80 & 1962 & Dec. 18 & 11,200 & 19.20 \\
\hline 1950 & Sept.07 & 13,000 & 20.70 & 1957 & Feb. 01 & 8,400 & 16.40 & 1963 & Mar. 06 & 9,000 & 17.00 \\
\hline 1951 & Mar. 29 & 19,400 & 25.30 & 1958 & Nov. 18 & 8,000 & 16.00 & 1964 & Mar. 15 & 10,900 & 18.93 \\
\hline 1952 & Mar. 10 & 10,500 & 18.50 & 1959 & Apr. 19 & 5,680 & 13.60 & 1965 & Mar. 26 & 10,800 & 18.83 \\
\hline 1953 & Feb. 24 & 6,000 & 14.00 & 1960 & Mar. 03 & 6,600 & 14.60 & $\underline{1973}$ & Mar. 17 & 33,400 & 27.39 \\
\hline 1954 & Jan. 16 & 10,000 & 18.00 & 1961 & Feb. 22 & 9,200 & 17.20 & $\overline{1990}$ & Feb. 16 & 19,500 & $22.80 \mathrm{c}$ \\
\hline 1955 & May 16 & 5,060 & 12.80 & & & & & & & & \\
\hline
\end{tabular}

\section{WEST CHICKAMAUGA CREEK NEAR KENSINGTON, GEORGIA}

LOCATION.--Lat $34^{\circ} 48^{\prime} 10^{\prime \prime}$, long $85^{\circ} 20^{\prime} 52^{\prime \prime}$, Walker County, at State Highway $143,2.5$ mi northeast of Kensington. DRAINAGE AREA.--73 $\mathrm{mi}^{2}$.

GAGE.--Crest-stage gage. Datum of gage is about $760 \mathrm{ft}$ above sea level (from topographic map).

STAGE-DISCHARGE RELATION.--Defined by current-meter measurements below $9,420 \mathrm{t}^{3} / \mathrm{s}$, and extended above on basis of straight-line extension. Bankfull stage and disccharge, $15 \mathrm{ft}$ and $5,000 \mathrm{ft}^{3} / \mathrm{s}$.

REMARKS.-Flood stage of 1990 based on floodmarks.

\begin{tabular}{|c|c|c|c|c|c|c|c|c|c|c|c|}
\hline $\begin{array}{l}\text { Water } \\
\text { year }\end{array}$ & Date & $\begin{array}{c}\text { Discharge } \\
\left(\mathrm{ft}^{3} / \mathrm{s}\right)\end{array}$ & $\begin{array}{c}\text { Gage } \\
\text { height } \\
\text { (ft) }\end{array}$ & $\begin{array}{l}\text { Water } \\
\text { year }\end{array}$ & Date & $\begin{array}{c}\text { Discharge } \\
\left(\mathrm{ft}^{3} / \mathrm{s}\right)\end{array}$ & $\begin{array}{c}\text { Gage } \\
\text { height } \\
\text { (ft) }\end{array}$ & $\begin{array}{c}\text { Water } \\
\text { year }\end{array}$ & Date & $\begin{array}{c}\text { Discharge } \\
\left(\mathrm{ft}^{3} / \mathrm{s}\right)\end{array}$ & $\begin{array}{c}\text { Gage } \\
\text { height } \\
\text { (ft) }\end{array}$ \\
\hline 1950 & Sept.07 & 6,480 & 15.70 & 1960 & Mar. 03 & 2,150 & 11.50 & 1969 & Feb. 02 & 4,570 & 14.52 \\
\hline 1951 & Mar. 29 & 12,000 & 18.50 & 1961 & Feb. 23 & 4,220 & 14.20 & 1970 & Dec. 31 & 2,150 & 11.52 \\
\hline 1952 & Mar. 11 & 8,070 & 16.60 & 1962 & Dec. 12 & 7,600 & 16.40 & 1971 & Feb. 05 & 2,370 & 12.32 \\
\hline 1953 & Feb. 21 & 3,260 & 13.20 & 1963 & Apr. 30 & 8,200 & 16.70 & 1972 & May 14 & 3,630 & 13.93 \\
\hline 1954 & Jan. 16 & 5,990 & 15.40 & 1964 & Mar. 15 & 8,180 & 16.69 & 1973 & Mar. 16 & 9,900 & 17.50 \\
\hline 1955 & Feb. 06 & 3,260 & 13.20 & 1965 & Mar. 26 & 7,540 & 16.37 & 1974 & Nov. 28 & 2,970 & 13.18 \\
\hline 1956 & Feb. 20 & 2,300 & 11.80 & 1966 & Mar. 03 & 4,380 & 14.69 & 1975 & Mar. 14 & 3,520 & 13.82 \\
\hline 1957 & Feb. 26 & 4,450 & 14.40 & 1967 & May 12 & 2,150 & 11.50 & $\underline{1976}$ & May 15 & 2,080 & 11.83 \\
\hline 1958 & Nov. 18 & 4,220 & 14.20 & 1968 & Dec. 22 & 2,350 & 11.78 & $\overline{1990}$ & Feb. 16 & 14,000 & $19.34 \mathrm{c}$ \\
\hline 1959 & Apr. 20 & 2,710 & 12.50 & & & & & & & & \\
\hline
\end{tabular}




\section{SOUTH CHICKAMAUGA CREEK NEAR CHICKAMAUGA, TENNESSEE}

LOCATION.--Lat $35^{\circ} 00^{\prime} 51^{\prime \prime}$, long $85^{\circ} 12^{\prime} 35^{\prime \prime}$, Hamilton County, Tenn., on left bank 0.1 mi upstream from bridge on U.S. Highway 11 , $1.5 \mathrm{mi}$ south of Chickamauga, $6.0 \mathrm{mi}$ east of the city hall in Chattanooga, and at mile 12.2.

DRAINAGE AREA.--428 $\mathrm{mi}^{2}$.

GAGE.--Water-stage recorder. Datum of gage is $644.12 \mathrm{ft}$ above sea level. Prior to Oct. 7, 1930, nonrecording gage and Oct. 7 , 1930 to Oct. 29, 1980, water-stage recorder at site 1,000 ft upstream at datum $7.0 \mathrm{ft}$ higher.

STAGE-DISCHARGE RELATION.--Defined by current-meter measurements. Stage-discharge relation affected by backwater from Tennessee River at high river stages.

\begin{tabular}{|c|c|c|c|c|c|c|c|c|c|c|c|}
\hline $\begin{array}{l}\text { Water } \\
\text { year }\end{array}$ & Date & $\begin{array}{c}\text { Discharge } \\
\left(\mathrm{ft}^{3} / \mathrm{s}\right)\end{array}$ & $\begin{array}{c}\text { Gage } \\
\text { height } \\
\text { (ft) }\end{array}$ & $\begin{array}{l}\text { Water } \\
\text { year }\end{array}$ & Date & $\begin{array}{c}\text { Discharge } \\
\left(\mathrm{ft}^{3} / \mathrm{s}\right)\end{array}$ & $\begin{array}{l}\text { Gage } \\
\text { height } \\
\text { (ft) }\end{array}$ & $\begin{array}{l}\text { Water } \\
\text { year }\end{array}$ & Date & $\begin{array}{c}\text { Discharge } \\
\left(\mathrm{ft}^{3} / \mathrm{s}\right)\end{array}$ & $\begin{array}{c}\text { Gage } \\
\text { height } \\
\text { (ft) }\end{array}$ \\
\hline 1929 & Mar. 15 & 15,400 & 15.95 & 1949 & Nov. 29 & 24,900 & 19.83 & 1969 & Feb. 03 & 18,500 & 17.64 \\
\hline 1930 & Nov. 15 & 15,100 & 15.90 & 1950 & Sept.08 & 18,600 & 17.61 & 1970 & Apr. 03 & 6,330 & 12.71 \\
\hline 1931 & Nov. 17 & 4,810 & 11.25 & 1951 & Mar. 30 & 27,600 & 20.73 & 1971 & Feb. 06 & 6,670 & 12.95 \\
\hline 1932 & Jan. 30 & 12,100 & 14.80 & 1952 & Mar. 12 & 15,800 & 16.59 & 1972 & May 15 & 8,190 & 13.77 \\
\hline 1933 & Dec. 29 & 13,500 & 15.43 & 1953 & Feb. 22 & 10,800 & 14.60 & 1973 & Mar. 17 & 30,000 & $21.70 \mathrm{a}$ \\
\hline 1934 & Mar. 04 & 13,500 & 15.95 & 1954 & Jan. 17 & 14,900 & 16.24 & 1974 & Nov. 29 & 12,000 & 15.51 \\
\hline 1935 & Mar. 13 & 11,000 & 14.90 & 1955 & Feb. 07 & 9,050 & 14.20 & 1975 & Sept. 24 & 13,200 & 15.59 \\
\hline 1936 & Feb. 05 & 20,000 & 18.47 & 1956 & Feb. 04 & 9,290 & 14.31 & 1976 & July 05 & 6,620 & 12.42 \\
\hline 1937 & Jan. 03 & 11,200 & 15.30 & 1957 & Feb. 02 & 14,200 & 16.68 & 1977 & Apr. 06 & 11,400 & 15.06 \\
\hline 1938 & Apr. 09 & 18,400 & 17.36 & 1958 & Nov. 19 & 13,600 & 15.90 & $\underline{1978}$ & Nov. 07 & $\underline{11,000}$ & $\underline{14.85}$ \\
\hline 1939 & Mar. 01 & 11,800 & 15.14 & 1959 & Apr. 20 & 6,980 & 13.02 & 1981 & Feb. 11 & 5,030 & 14.73 \\
\hline 1940 & Feb. 19 & 6,200 & 12.18 & 1960 & Mar. 03 & 13,400 & 15.42 & 1982 & Jan. 05 & 13,600 & 21.03 \\
\hline 1941 & Dec. 29 & 4,720 & 11.00 & 1961 & Feb. 23 & 17,400 & 17.27 & 1983 & Dec. 02 & 12,200 & 20.23 \\
\hline 1942 & Mar. 22 & 5,400 & 11.48 & 1962 & Dec. 19 & 18,500 & 18.70 & 1984 & Dec. 04 & 10,600 & 19.23 \\
\hline 1943 & Dec. 29 & 21,400 & 18.65 & 1963 & May 01 & 13,800 & 15.95 & 1985 & Feb. 02 & 10,200 & 18.96 \\
\hline 1944 & Mar. 30 & 12,300 & 15.58 & 1964 & Mar. 16 & 17,600 & 17.32 & 1986 & Feb. 18 & 5,750 & 15.16 \\
\hline 1945 & Feb. 14 & 11,600 & 14.87 & 1965 & Mar. 27 & 16,400 & 16.88 & 1987 & Jan. 20 & 12,500 & 20.38 \\
\hline 1946 & Feb. 11 & 18,400 & $17.65 \mathrm{a}$ & 1966 & Mar. 05 & 10,300 & 14.70 & 1988 & Jan. 21 & 10,100 & 18.86 \\
\hline 1947 & Jan. 21 & 18,100 & 18.35 & 1967 & July 08 & 9,940 & 14.57 & 1989 & July 05 & 10,100 & 19.24 \\
\hline 1948 & Feb. 13 & 20,300 & 19.19 & 1968 & Dec. 23 & 8,430 & 13.89 & 1990 & Feb. 17 & 27,300 & 28.72 \\
\hline
\end{tabular}

\section{CHATTANOOGA CREEK NEAR FLINTSTONE, GEORGIA}

LOCATION.-Lat $34^{\circ} 58^{\prime} 20^{\prime \prime}$, long $85^{\circ} 19^{\prime} 40^{\prime \prime}$, Walker County, on right bank $0.8 \mathrm{mi}$ south of Georgia-Tennessee State line, $2.3 \mathrm{mi}$ northeast of Flintstone, and at mile 10.3 .

DRAINAGE AREA.--50.6 $\mathrm{mi}^{2}$.

GAGE.--Water-stage recorder. Datum of gage is $649.18 \mathrm{ft}$ above sea level.

STAGE-DISCHARGE RELATION.--Defined by current-meter measurements.

\begin{tabular}{|c|c|c|c|c|c|c|c|c|c|c|c|}
\hline $\begin{array}{l}\text { Water } \\
\text { year }\end{array}$ & Date & $\begin{array}{c}\text { Discharge } \\
\left(\mathrm{ft}^{3} / \mathrm{s}\right)\end{array}$ & $\begin{array}{c}\text { Gage } \\
\text { height } \\
\text { (ft) }\end{array}$ & $\begin{array}{l}\text { Water } \\
\text { year }\end{array}$ & Date & $\begin{array}{c}\text { Discharge } \\
\left(\mathrm{ft}^{3} / \mathrm{s}\right)\end{array}$ & $\begin{array}{c}\text { Gage } \\
\text { height } \\
\text { (ft) }\end{array}$ & $\begin{array}{l}\text { Water } \\
\text { year }\end{array}$ & Date & $\begin{array}{c}\text { Discharge } \\
\left(\mathrm{ft}^{3} / \mathrm{s}\right)\end{array}$ & $\begin{array}{c}\text { Gage } \\
\text { height } \\
\text { (ft) }\end{array}$ \\
\hline 1951 & Mar. 29 & 6,140 & 12.90 & 1959 & Jan. 22 & 2,300 & 9.68 & 1967 & May 13 & 1,900 & 9.83 \\
\hline 1952 & Mar. 11 & 3,610 & 10.72 & 1960 & Mar. 03 & 1,680 & 9.00 & 1968 & Dec. 18 & 1,620 & 9.43 \\
\hline 1953 & Feb. 21 & 2,360 & 9.36 & 1961 & Mar. 08 & 4,310 & 12.04 & 1969 & Feb. 02 & 4,560 & 12.33 \\
\hline 1954 & Jan. 16 & 2,820 & 9.90 & 1962 & Feb. 23 & 6,140 & 13.48 & 1970 & Dec. 31 & 1,760 & 9.63 \\
\hline 1955 & Feb. 06 & 2,850 & 10.44 & 1963 & Mar. 12 & 4,130 & 12.09 & 1971 & Feb. 26 & 1,680 & 9.52 \\
\hline 1956 & Feb. 02 & 2,130 & 9.56 & 1964 & Apr. 07 & 5,060 & 12.72 & 1972 & May 14 & 1,920 & 9.86 \\
\hline 1957 & Feb. 01 & 2,600 & 10.43 & 1965 & Mar. 26 & 4,300 & 12.12 & 1973 & Mar. 16 & 6,300 & 13.59 \\
\hline 1958 & Apr. 29 & 2,590 & 10.04 & 1966 & Feb. 13 & 1,390 & 9.00 & 1974 & Nov. 28 & 3,950 & 11.85 \\
\hline
\end{tabular}


LOCATION.--Lat $34^{\circ} 53^{\prime} 51^{\prime \prime}$, long $85^{\circ} 27^{\prime} 47^{\prime \prime}$, Dade County, at bridge on county road, 0.4 mi downstream of Squirrel Town Creek, 2.2 mi southeast of New England and at mile 16.3.

DRAINAGE AREA.-149 $\mathrm{mi}^{2}$.

GAGE.-Water-stage recorder. Datum of gage is $663.80 \mathrm{ft}$ above sea level (levels from the Tennessee Valley Authority). Aug. 30 , 1979 to Oct. 4, 1988 at site $200 \mathrm{ft}$ downstream at same datum.

STAGE-DISCHARGE RELATION.--Defined by current-meter measurements below $10,200 \mathrm{ft}^{3} / \mathrm{s}$, and extended above to $20,000 \mathrm{ft}^{3} / \mathrm{s}$ on the basis of indirect measurements. Bankfull stage and discharge, $11 \mathrm{ft}$ and $1,800 \mathrm{ft}^{3} / \mathrm{s}$.

HISTORICAL DATA.--The flood of 1982 is thought to be the highest since 1973, based on information at nearby stations.

\begin{tabular}{|c|c|c|c|c|c|c|c|c|c|c|c|}
\hline $\begin{array}{l}\text { Water } \\
\text { year }\end{array}$ & Date & $\begin{array}{c}\text { Discharge } \\
\left(\mathrm{ft}^{3} / \mathrm{s}\right)\end{array}$ & $\begin{array}{c}\text { Gage } \\
\text { height } \\
\text { (ft) }\end{array}$ & $\begin{array}{l}\text { Water } \\
\text { year }\end{array}$ & Date & $\begin{array}{c}\text { Discharge } \\
\left(\mathrm{ft}^{3} / \mathrm{s}\right)\end{array}$ & $\begin{array}{c}\text { Gage } \\
\text { height } \\
\text { (ft) }\end{array}$ & $\begin{array}{l}\text { Water } \\
\text { year }\end{array}$ & Date & $\begin{array}{c}\text { Discharge } \\
\left(\mathrm{ft}^{3} / \mathrm{s}\right)\end{array}$ & $\begin{array}{c}\text { Gage } \\
\text { height } \\
\text { (ft) }\end{array}$ \\
\hline 1980 & Mar. 21 & 14,900 & 18.21 & 1984 & May 03 & 6,710 & 15.46 & 1988 & Jan. 20 & 3,930 & 13.67 \\
\hline 1981 & Feb. 11 & 2,940 & 12.84 & 1985 & Feb. 01 & 3,580 & 13.40 & 1989 & Feb. 28 & 5,720 & 14.80 \\
\hline 1982 & Aug. 17 & 20,000 & 20.73 & 1986 & Feb. 18 & 3,870 & 13.62 & 1990 & Feb. 16 & 14,300 & 18.76 \\
\hline 1983 & Dec. 01 & 9,800 & 16.92 & 1987 & Jan. 19 & 6,350 & 15.26 & & & & \\
\hline
\end{tabular}

